PNNL-18894

Prepared for the U.S. Department of Energy

Under Contract DE-AC05-76RL01830

\title{
Pretreatment Engineering Platform Phase 1 Final Test Report
}

DE Kurath ${ }^{(a)}$

BD Hanson ${ }^{(a)}$

MJ Minette ${ }^{(a)}$

DL Baldwin ${ }^{(a)}$

BM Rapko ${ }^{(a)}$

LA Mahoney ${ }^{(a)}$

PP Schonewill ${ }^{(a)}$

RC Daniel ${ }^{(a)}$
PW Eslinger ${ }^{(a)}$

JL Huckaby ${ }^{(a)}$

JM Billing ${ }^{(a)}$

PS Sundar ${ }^{(b)}$

GJ Josephson ${ }^{(a)}$

JJ Toth ${ }^{(a)}$

ST Yokuda ${ }^{(a)}$

EBK Baer ${ }^{(a)}$
SM Barnes ${ }^{(b)}$

EC Golovich ${ }^{(a)}$

SD Rassat ${ }^{(a)}$

CF Brown ${ }^{(a)}$

JGH Geeting (a)

GJ Sevigny ${ }^{(a)}$

AJ Casella ${ }^{(a)}$

JR Bontha ${ }^{(a)}$
RL Aaberg (a)

PM Aker ${ }^{(a)}$

CE Guzman-Leong ${ }^{(a)}$

ML Kimura ${ }^{(a)}$

SK Sundaram ${ }^{(a)}$

RP Pires ${ }^{(a)}$

BE Wells ${ }^{(a)}$

OP Bredt ${ }^{(a)}$

(a) Pacific Northwest National Laboratory

(b) URS Washington Division

December 2009

Pacific Northwest NATIONAL LABORATORY

Proudly Operated by Battelle Since 1965 


\section{Pretreatment Engineering Platform Phase 1 Final Test Report}

$\begin{array}{llll}\text { DE Kurath }^{(a)} & \text { PW Eslinger }^{(a)} & \text { SM Barnes }^{(\text {b) }} & \text { RL Aaberg }^{(a)} \\ \text { BD Hanson }^{(a)} & \text { JL Huckaby }^{(a)} & \text { EC Golovich }^{(a)} & \text { PM Aker }^{(a)} \\ \text { MJ Minette }^{(a)} & \text { JM Billing }^{(a)} & \text { SD Rassat }^{(a)} & \text { CE Guzman-Leong }^{(a)} \\ \text { DL Baldwin }^{(a)} & \text { PS Sundar }^{(b)} & \text { CF Brown }^{(a)} & \text { ML Kimura }^{(a)} \\ \text { BM Rapko }^{(a)} & \text { GJ Josephson }^{(a)} & \text { JGH Geeting }^{(a)} & \text { SK Sundaram }^{(a)} \\ \text { LA Mahoney }^{(a)} & \text { JJ Toth }^{(a)} & \text { GJ Sevigny }^{(a)} & \text { RP Pires }^{(a)} \\ \text { PP Schonewill }^{(a)} & \text { ST Yokuda }^{(a)} & \text { AJ Casella }^{(a)} & \text { BE Wells }^{(a)} \\ \text { RC Daniel }^{(a)} & \text { EBK Baer }^{(a)} & \text { JR Bontha }^{(a)} & \text { OP Bredt }^{(a)}\end{array}$

(a) Pacific Northwest National Laboratory

(b) URS Washington Division

December 2009

Test Specification: 24590-PTF-TSP-RT-07-001 Rev 2

Work Authorization: WA\# 2007-024

Test Plan: TP-RPP-WTP-506, Rev 0.4; TP-WTP-PEP-044, Rev 0.2

Test Exceptions: 24590-PTF-TEF-RT-08-00002

24590-PTF-TEF-RT-09-00001

24590-WTP-TEF-RT-09-00001 Rev 1

24590-WTP-TEF-RT-09-00002 Rev 0

24590-WTP-TEF-RT-09-00003

R\&T focus area: Pretreatment

Test Scoping Statement(s): NA

Prepared for

the U.S. Department of Energy

under Contract DE-AC05-76RL01830

Pacific Northwest National Laboratory

Richland, Washington 99352 


\section{COMPLETENESS OF TESTING}

This report describes the results of work and testing specified by Test Specification 24590-PTF-TSP-RT-07-001 Rev 2 "Pretreatment Engineering Platform (PEP) Testing (Phase 1)" and Test Plans TP-RPP-WTP-506 Rev 0.4 "Pretreatment Engineering Platform (PEP) Testing (Phase 1) and TP-WTP-PEP-044 Rev 0.2" Test Plan for the PEP Parallel Laboratory Testing." The work and any associated testing followed the quality assurance requirements outlined in the Test Specification/Plan. The descriptions provided in this test report are an accurate account of both the conduct of the work and the data collected. Test Plan results are reported. Also reported are any unusual or anomalous occurrences that are different from expected results. The test results and this report have been reviewed and verified.

\section{Approved:}

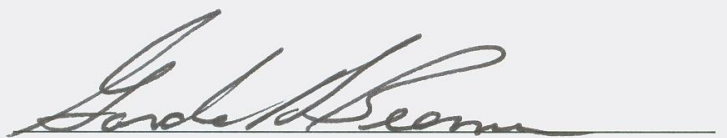

Gordon H. Beeman, Manager

WTP R\&T Support Project

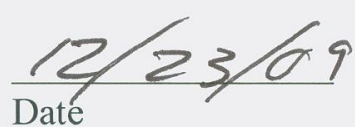




\section{Contents}

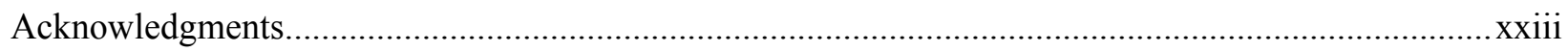

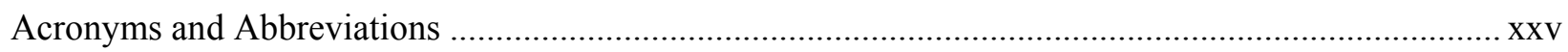

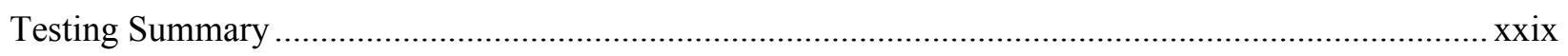

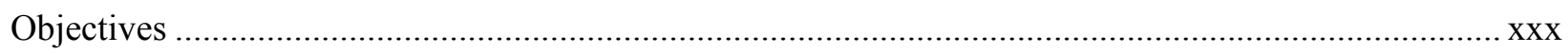

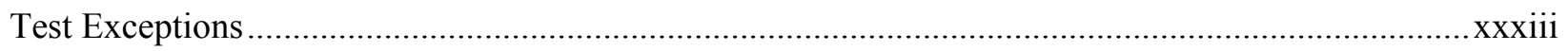

Results and Performance Against Success Criteria .....................................................................xxuvii

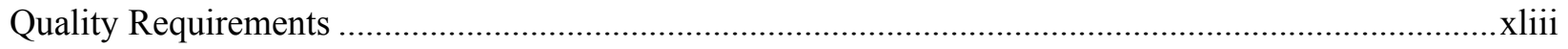

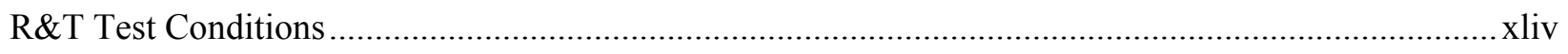

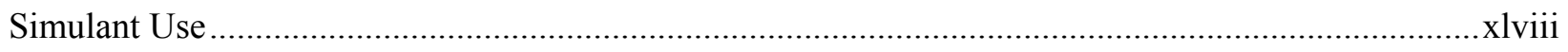

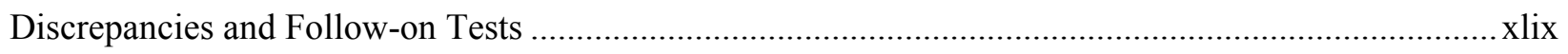

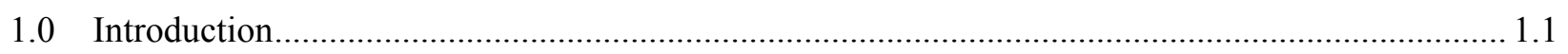

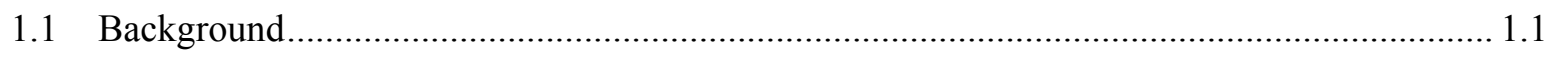

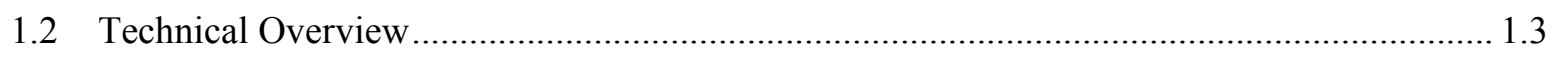

1.2.1 Ultrafiltration and Leaching Process Description..................................................... 1.3

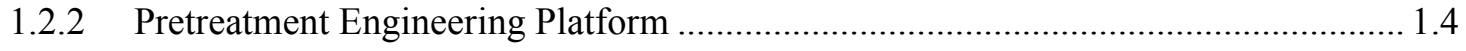

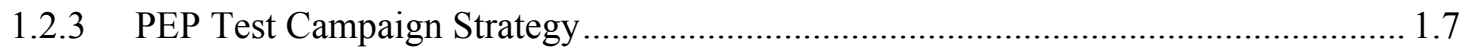

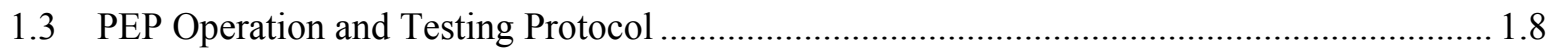

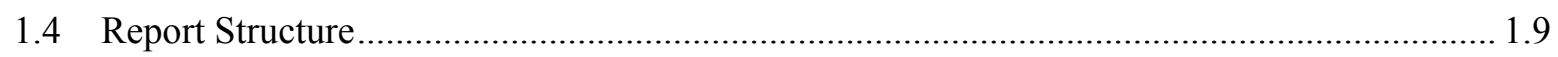

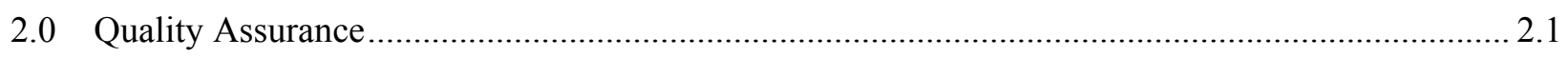

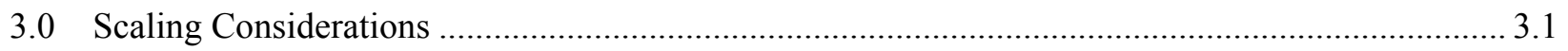

3.1 Bases for Scaling of Individual Process Steps ................................................................ 3.1

3.1.1 Initial and Post-Caustic-Leach Solids Concentration ............................................. 3.2

3.1.2 Slurry Transfers and In-Line Additions of Caustic, Permanganate, and

3.1.3 Heat-Up, Caustic-Leach, and Cool-Down ................................................................. 3.3

3.1.4 Post-Caustic-Leach and Post-Oxidative-Leach Slurry Washing ................................ 3.3

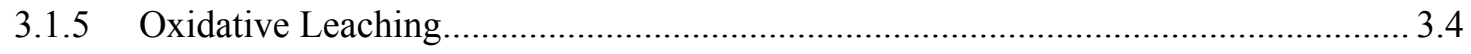

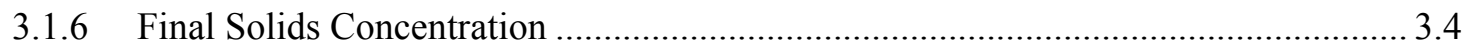

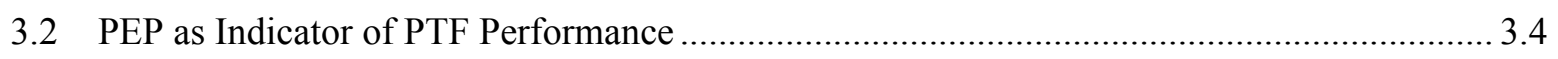

3.2.1 Caustic Leaching in Tank T01A/B (Functional Test and Integrated Test A)............ 3.5

3.2.2 Caustic Leaching in Tank T02A (Functional Test and Integrated Tests B and D)..... 3.6

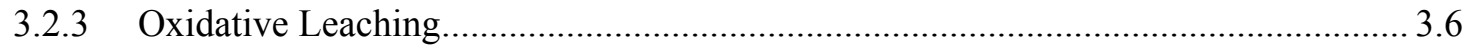

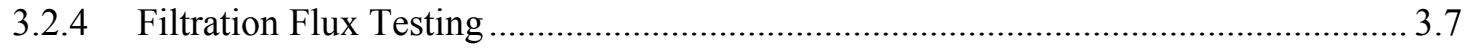

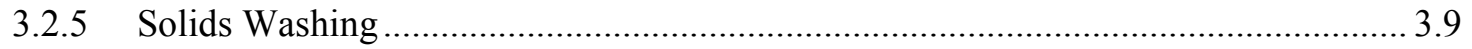




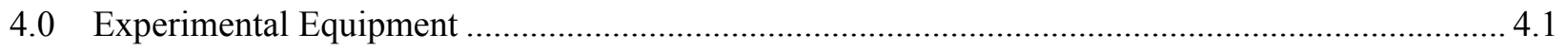

4.1 Pretreatment Engineering Platform (PEP) ................................................................. 4.1

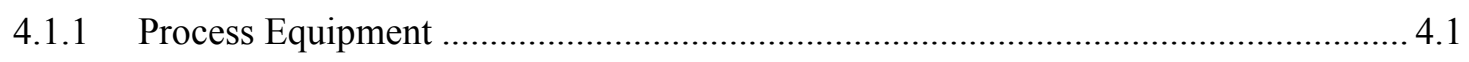

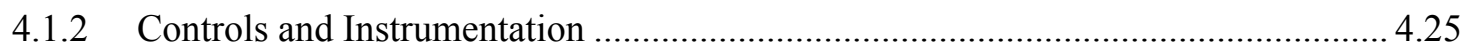

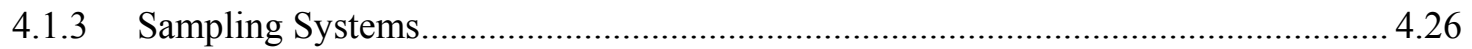

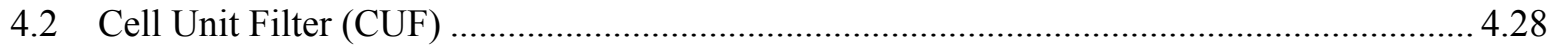

4.3 Laboratory-Scale Leaching Apparatus ........................................................................... 4.31

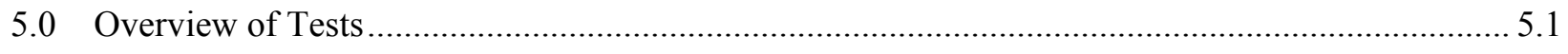

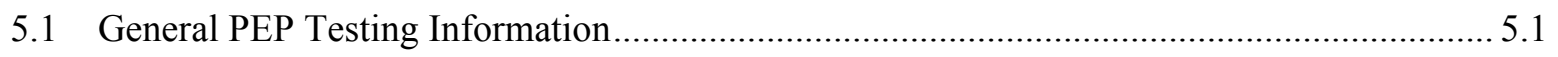

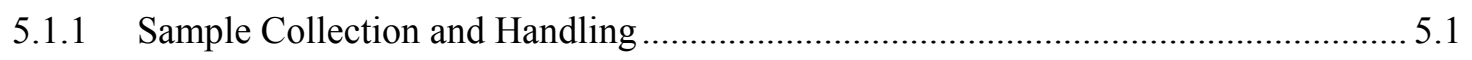

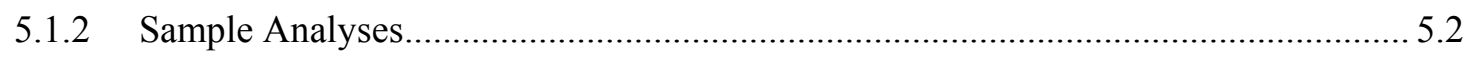

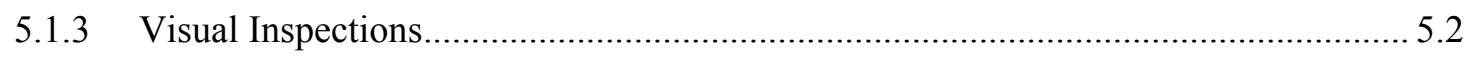

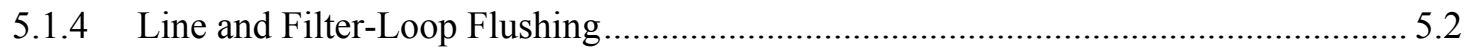

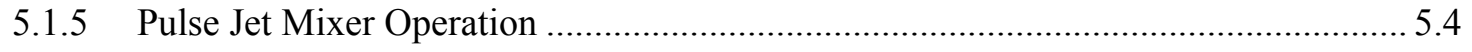

5.1.6 Air Sparge Mixers and Steam Ring Air Purge ...................................................... 5.5

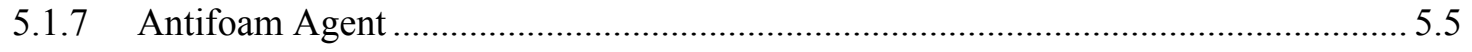

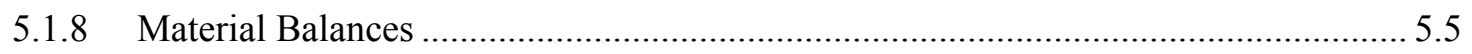

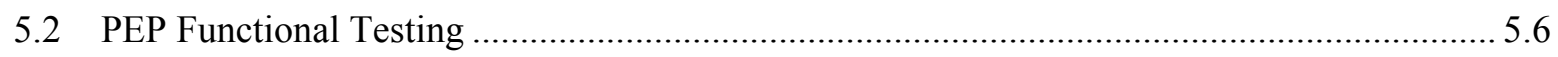

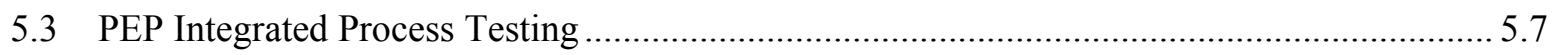

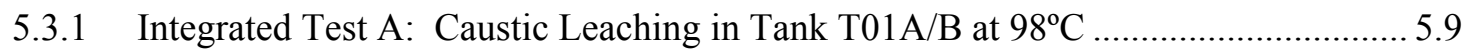

5.3.2 Integrated Test B: Caustic Leaching in Tank T02A at $98^{\circ} \mathrm{C}$................................ 5.12

5.3.3 Integrated Test D: Caustic Leaching in Tank T02A at $85^{\circ} \mathrm{C}$............................... 5.13

5.4 Supporting and Parallel Laboratory Testing ............................................................... 5.15

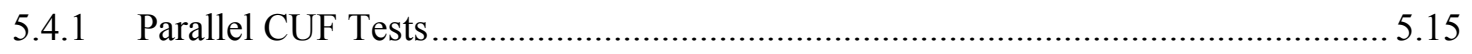

5.4.2 Parallel Caustic and Oxidative Leaching Tests .................................................. 5.16

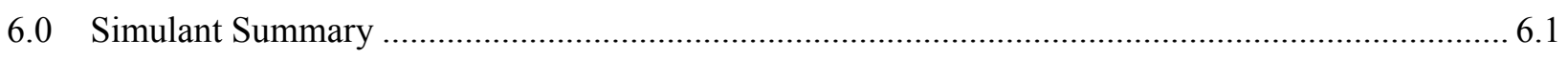

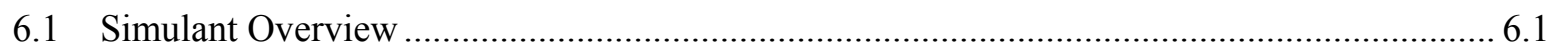

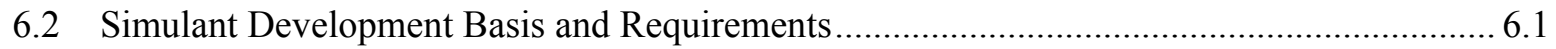

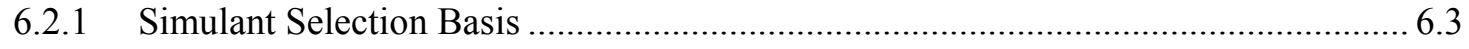

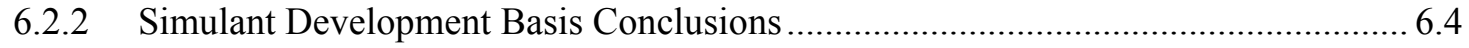

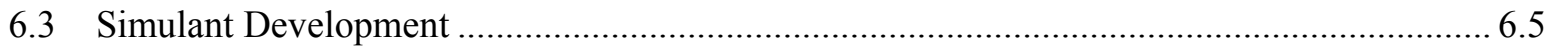

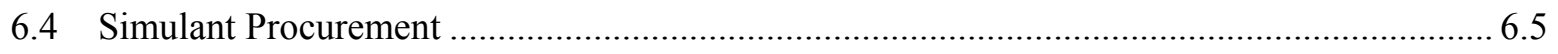

6.5 Simulant Compositions for Integrated Testing ............................................................... 6.6

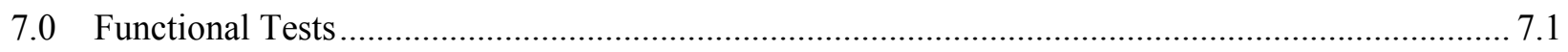

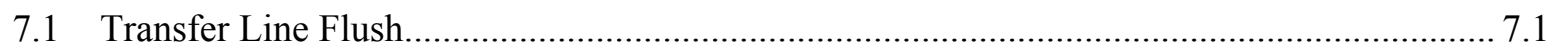

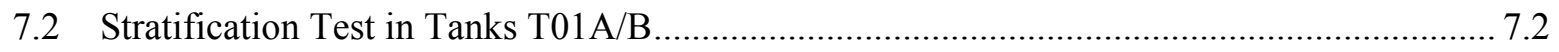


7.3 Evaluation of In-Line and In-Tank Sampling Precision and Variability .............................. 7.6

7.4 Evaluation of Mixing of $\mathrm{NaOH}$ After In-Line Addition...................................................... 7.7

7.5 Stratification of Solids During Caustic Leaching (Tanks T01A and T02A) ......................... 7.8

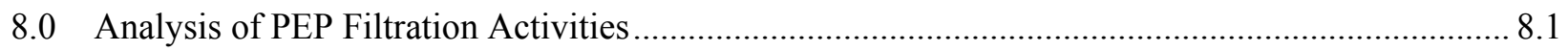

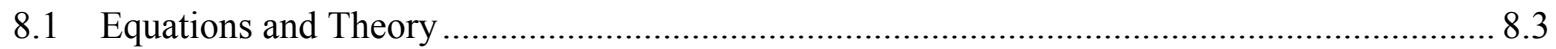

8.1.1 Analysis of Solids Dewatering/Concentration Operations ........................................ 8.4

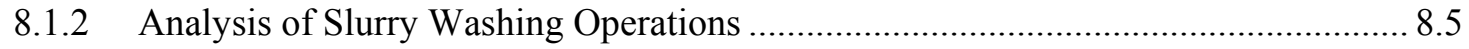

8.1.3 Evaluation of Backpulsing Effectiveness …........................................................... 8.5

8.2 Filter Scaling Tests - Low- and High-Solids................................................................... 8.6

8.2.1 Summary of Low-Solids Scaling Test Results ..................................................... 8.6

8.2.2 Summary of High-Solids Scaling Test Results.................................................... 8.12

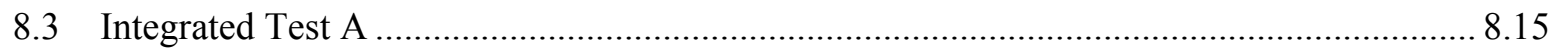

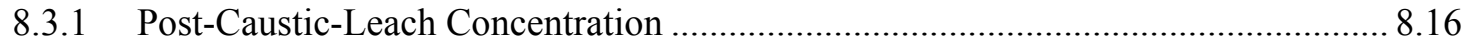

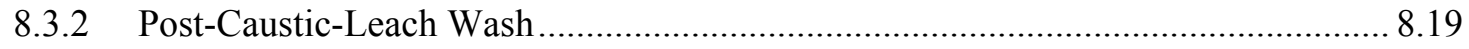

8.3.3 Post-Chromium Slurry Addition Concentration and Wash ..................................... 8.22

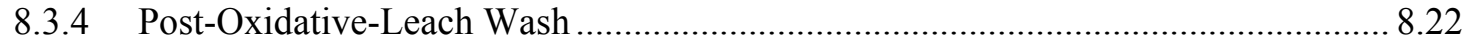

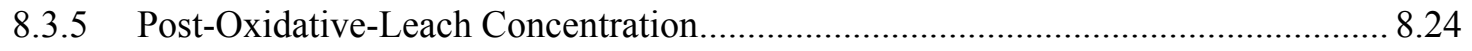

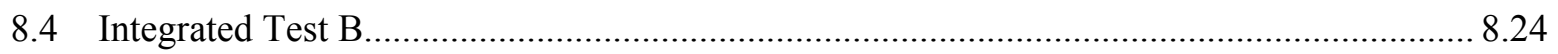

8.4.1 Pre-Caustic-Leach Solids Concentration Batch \#1 .............................................. 8.25

8.4.2 Pre-Caustic-Leach Concentration Batch \#2 .............................................................. 8.2

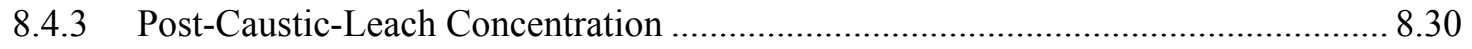

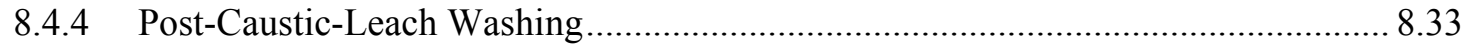

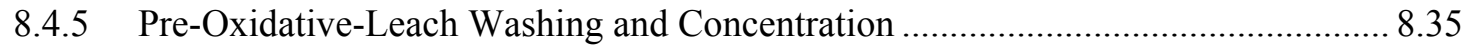

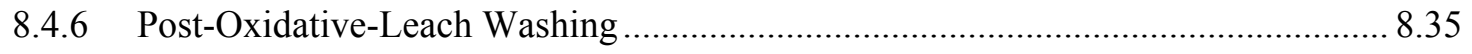

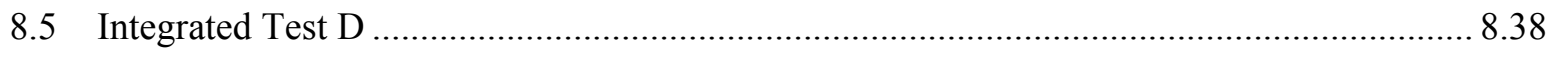

8.5.1 Pre-Caustic-Leach Concentration Batch \#1 ........................................................ 8.38

8.5.2 Pre-Caustic-Leach Concentration Batch \#2 …...................................................... 8.40

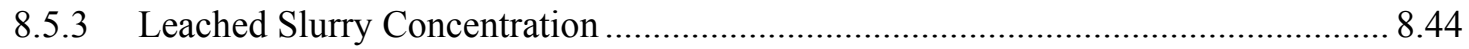

8.5.4 Post-Caustic-Leach Slurry Washing ...................................................................... 8.46

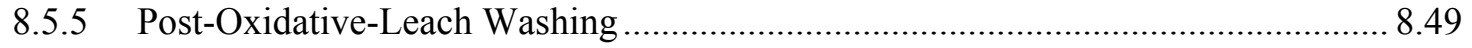

8.5.6 Post-Oxidative Wash Concentration.................................................................. 8.51

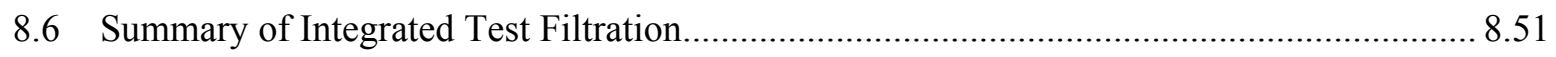

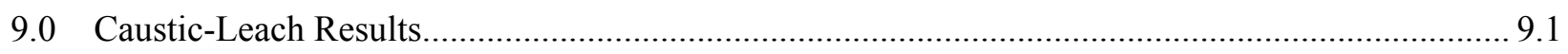

9.1 Overview of Caustic-Leach Data Analysis Approach ....................................................... 9.3

9.1.1 Approach for Condensate Accumulation Analyses ............................................... 9.3

9.1.2 Approach for Reagent Addition Analyses ............................................................... 9.6 
9.1.3 Approach for Caustic-Leach Analysis ................................................................ 9.6

9.1.4 Approach for Excess Caustic Analysis.................................................................... 9.10

9.2 PEP Caustic Reagent Addition and Batch Components ................................................... 9.10

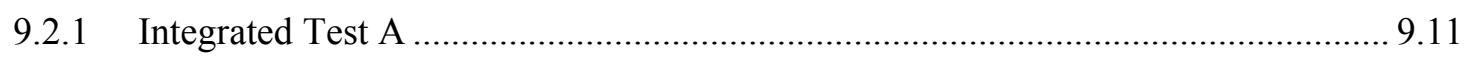

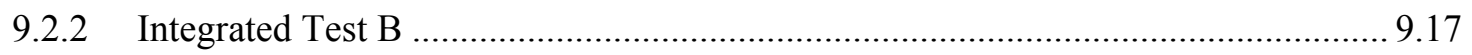

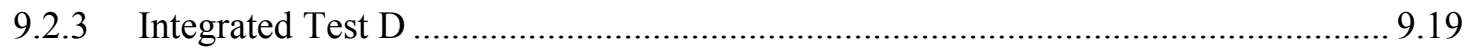

9.3 PEP Caustic-Leach Process Description............................................................................. 9.22

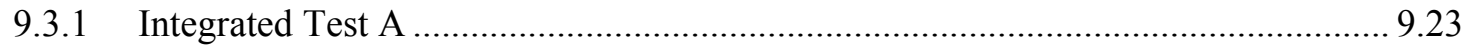

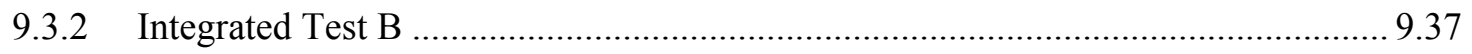

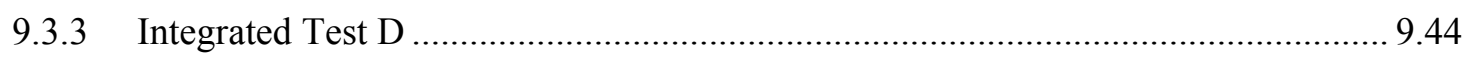

9.4 Laboratory-Scale Leach Process Description and Conditions ............................................ 9.51

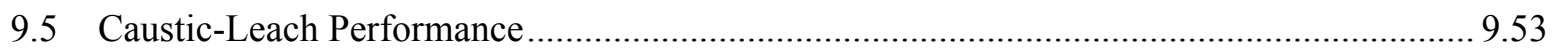

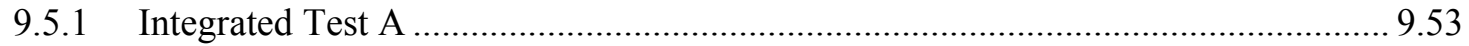

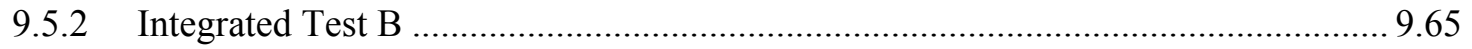

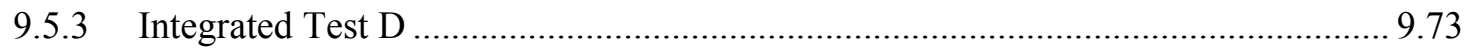

9.6 Results Based on Samples from Multiple Locations ...................................................... 9.86

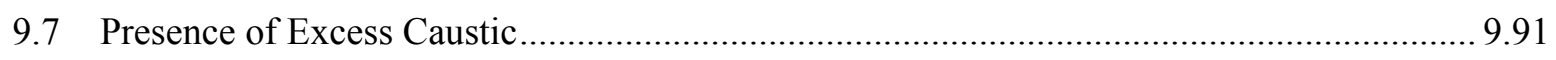

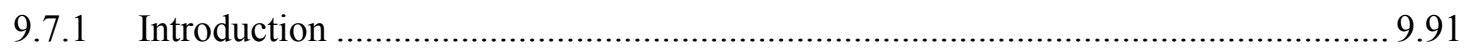

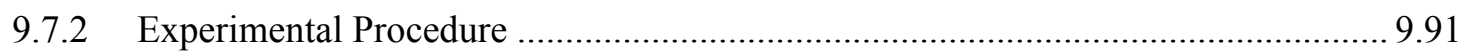

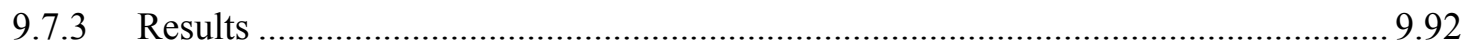

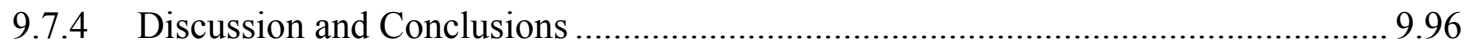

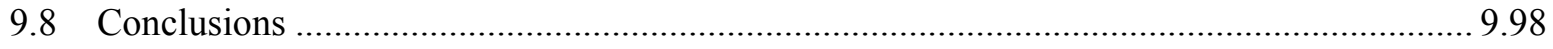

9.8.1 Temperature Control and Condensate Accumulation........................................... 9.98

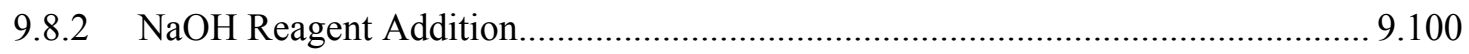

9.8.3 Caustic-Leach Performance ................................................................................. 9.101

9.8.4 Presence of Excess Caustic.............................................................................. 9.103

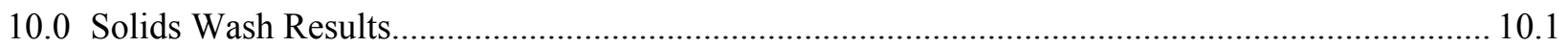

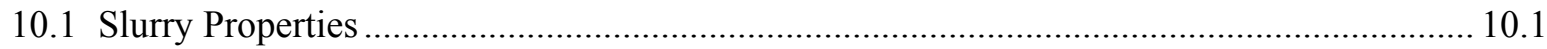

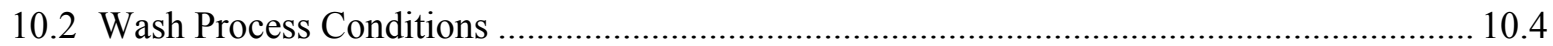

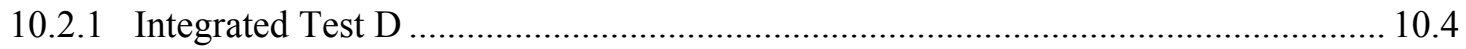

10.2.2 Post-Caustic-Leach Wash for Integrated Tests A, B, and D ................................. 10.5

10.2.3 Post-Oxidative-Leach Wash for Integrated Tests A, B, and D........................... 10.10

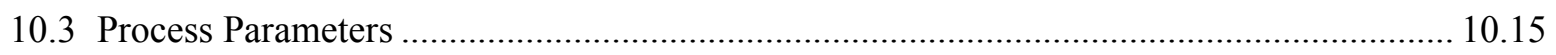

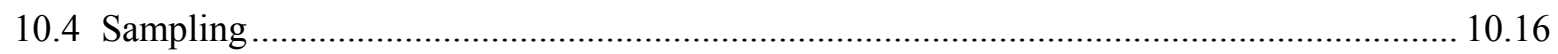

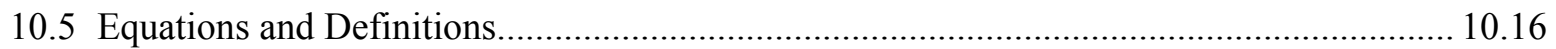

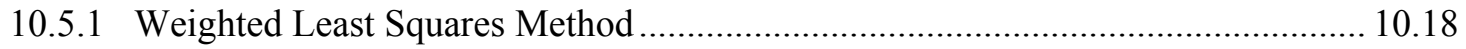


10.5.2 Incremental Method

10.6 Results 10.20

10.6.1 Standard Analytical Method Results 10.20

10.6.2 Raman Method Results 10.32

10.6.3 Additional Comparison of Raman with Other Methods 10.38

10.6.4 Comparison of Measured to Calculated Oxalate Concentration. 10.39

10.6.5 Uncertainty Evaluation for Solids Washing 10.42

10.7 Discussion. 10.42

10.8 Solids Washing Conclusions 10.46

11.0 Oxidative Leaching of Chromium 11.1

11.1 Introduction 11.1

11.2 Experimental Approach 11.1

11.2.1 PEP Oxidative-Leach 11.1

11.2.2 Laboratory-Scale Oxidative-Leach 11.2

11.3 Results 11.3

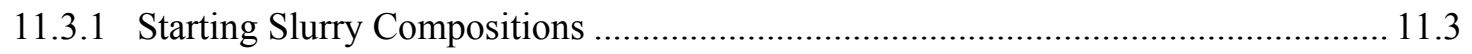

11.3.2 PEP Experimental Process Conditions ............................................................. 11.4

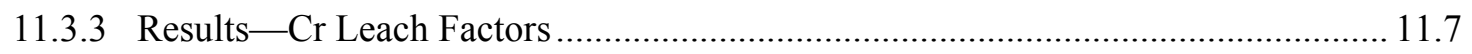

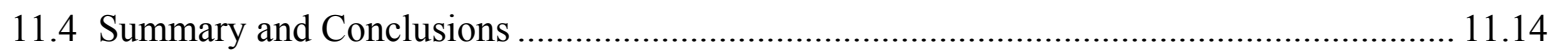

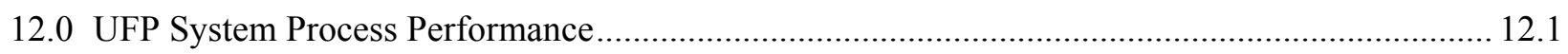

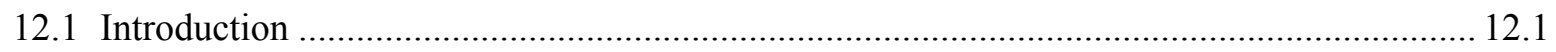

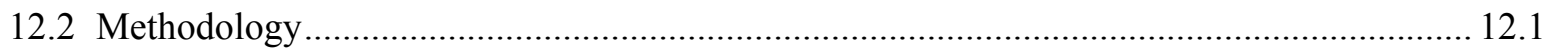

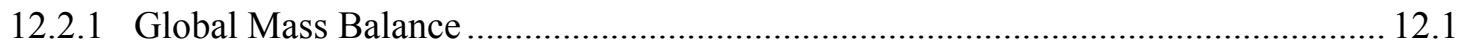

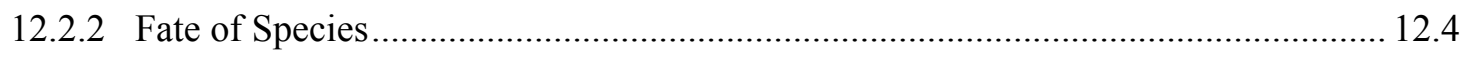

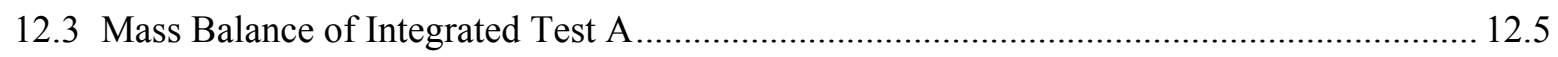

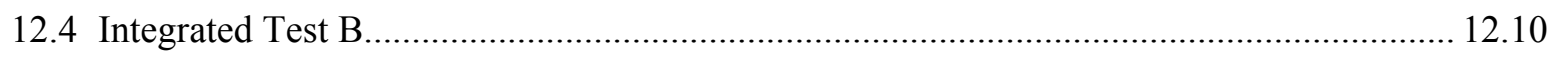

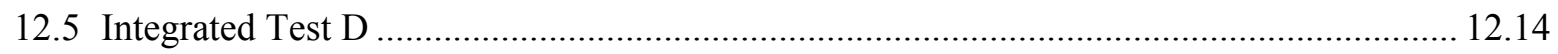

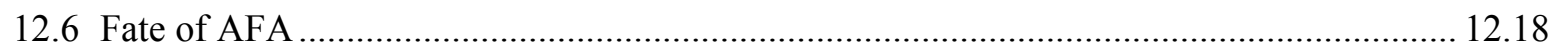

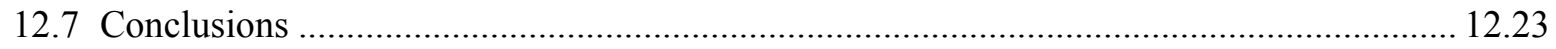

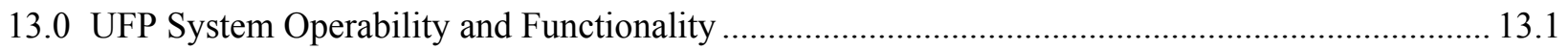

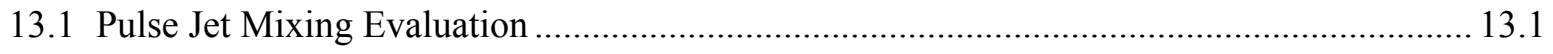

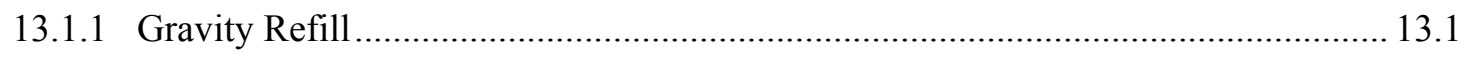

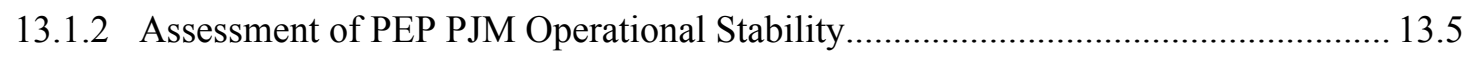

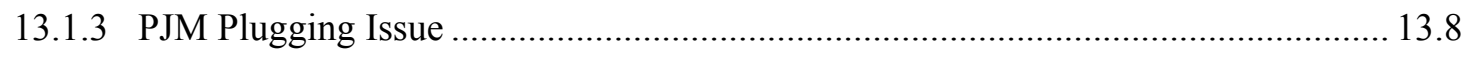

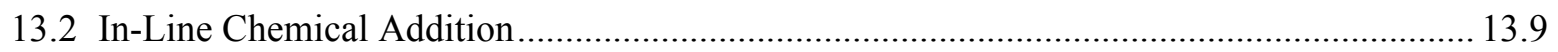

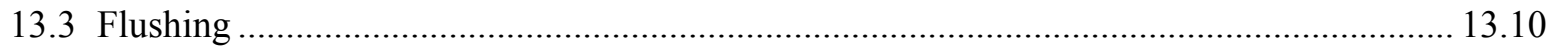




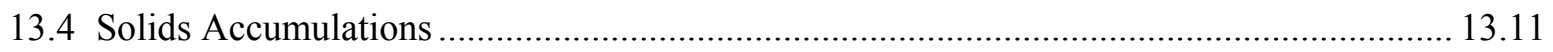

13.5 Ultrafilter Assembly Cleaning Events and Final Filter Inspection ................................... 13.16

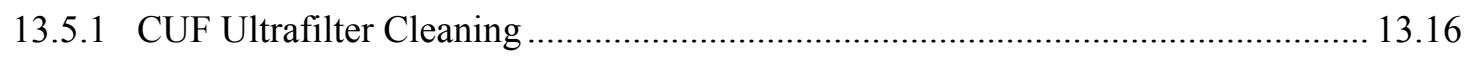

13.5.2 Prototypic Filter Cleaning with Nitric Acid ...................................................... 13.17

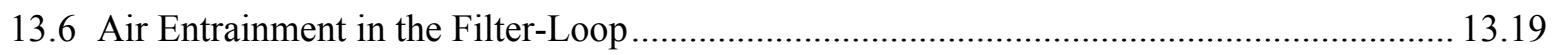

13.6.1 Integrated Test A Data Observations and Estimate of Air Entrainment in the Filter-Loop.

13.6.2 Integrated Test B Data Observations and Estimate of Air Entrainment in the Filter-Loop.

13.6.3 Integrated Test D Data Observations and Estimate of Air Entrainment in the Filter-Loop.

13.6.4 Pump Operations Without Air Entrainment ...................................................... 13.30

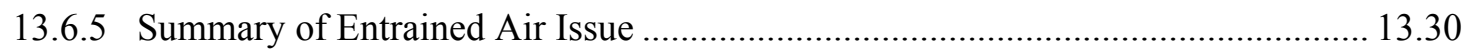

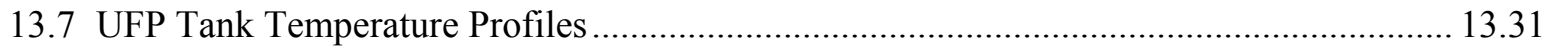

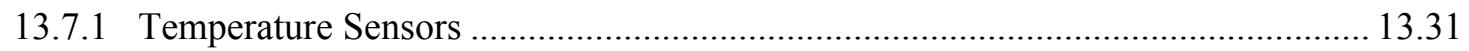

13.7.2 Data Analysis for Vessel Temperature Profiles.................................................. 13.34

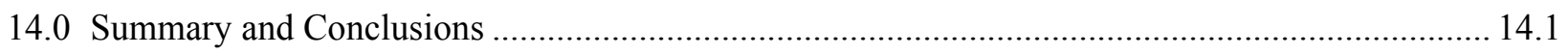

14.1 Demonstration of Process Operability, Controls, and Flowsheets .................................... 14.1

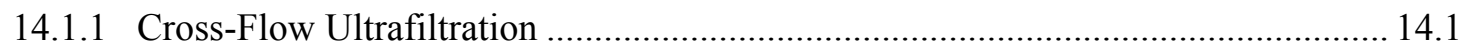

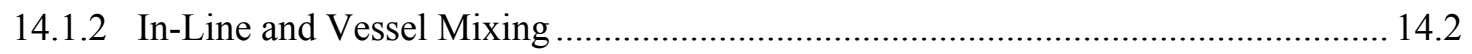

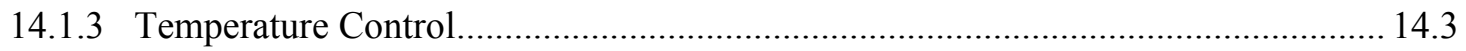

14.1.4 Make-Up and Wash-Water Batch Control ............................................................ 14.4

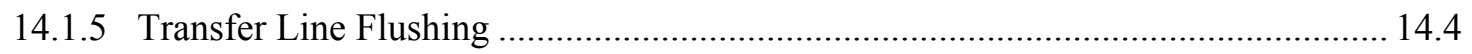

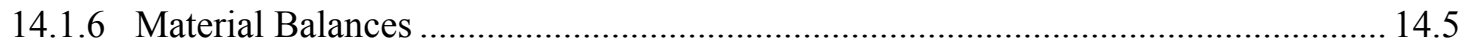

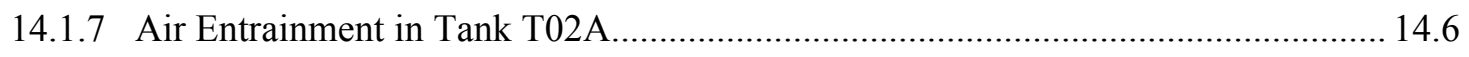

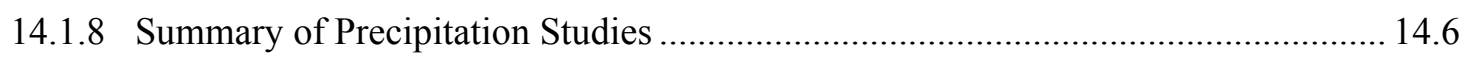

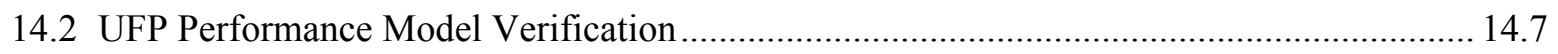

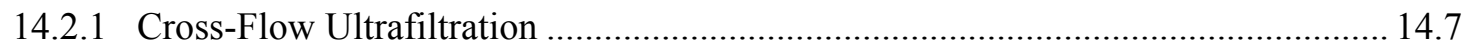

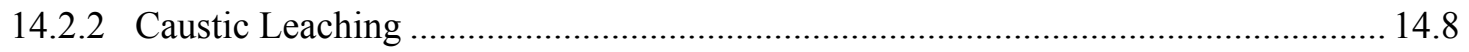

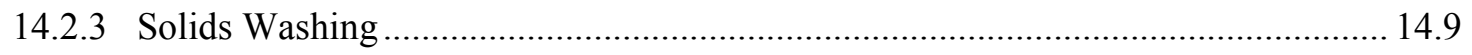

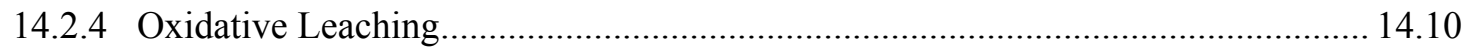

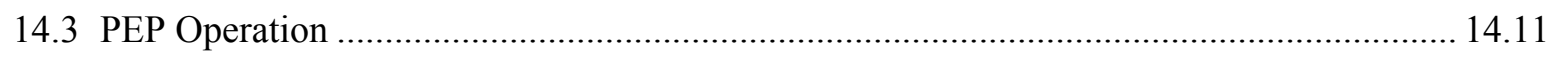

14.3.1 In-Line and In-Tank Sampling Variability .................................................... 14.11

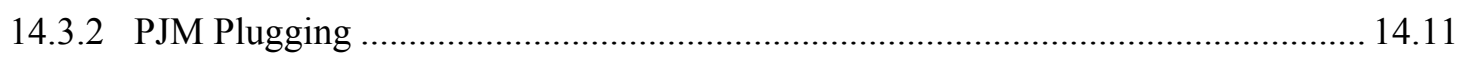

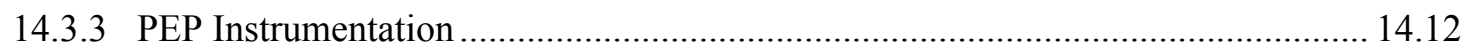

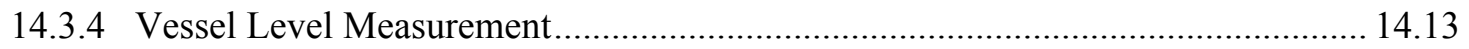

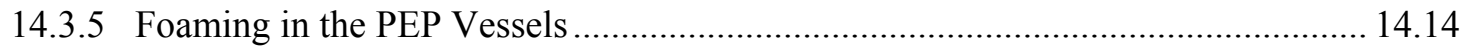




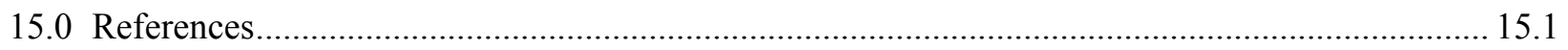

Appendix A Data Used in Caustic-Leach Factor and Boehmite Dissolution Rate Constants ................ A.1

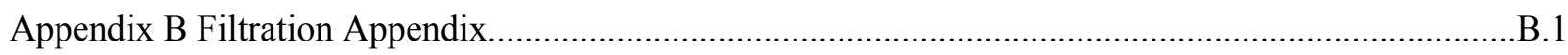

B.1 Analysis of Solids Dewatering/Concentration Operations …...............................................1

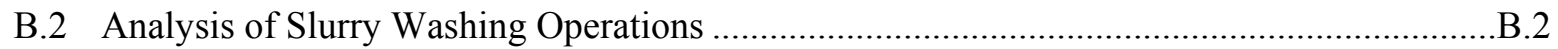

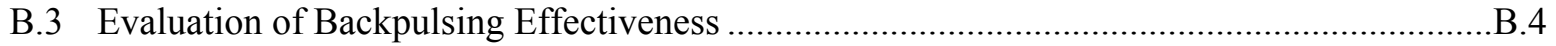

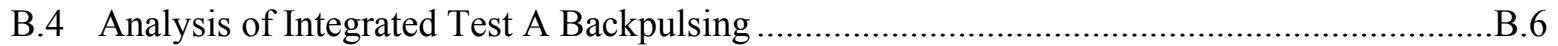

B.5 Analysis of Integrated Test B Backpulsing .....................................................................

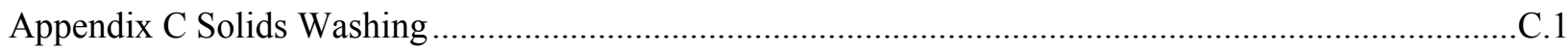

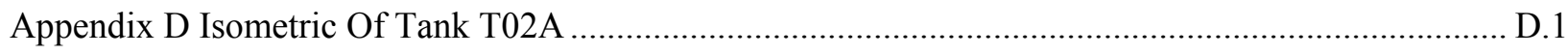

Appendix E Analytical Techniques, Sample Handling and Naming .................................................... 1

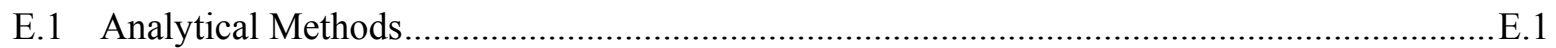

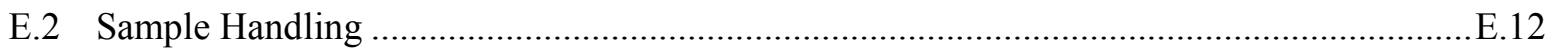

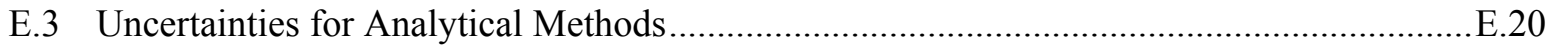




\section{Figures}

Figure 1.1. A Simplified Process Flow Diagram for the WTP Ultrafiltration and Leaching Process ...... 1.4

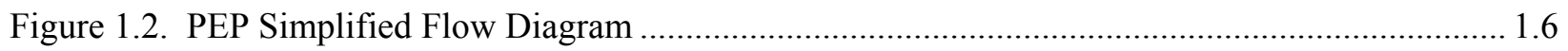

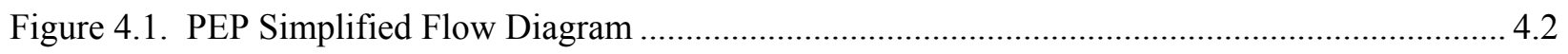

Figure 4.2. A Majority of the PEP Skids Were Moved into PDL-W and Assembled into the

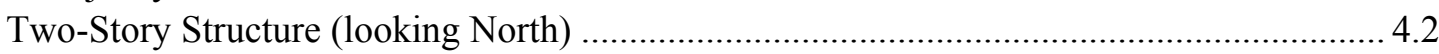

Figure 4.3. Vessels FRP-VSL-T01, HLP-VSL-T22, and FEP-VSL-T01 at Ground Level

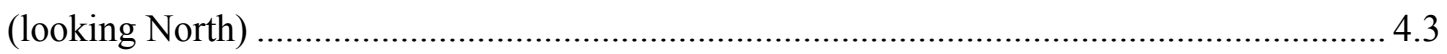

Figure 4.4. The PEP as Viewed Through the North Rollup Door on PDL-W ...................................... 4.3

Figure 4.5. Looking South on the Second Floor of the PEP.............................................................. 4.4

Figure 4.6. PEP Rendering (viewed from the Southwest - not to scale) ............................................... 4.5

Figure 4.7. Plan View Illustration (not to scale and for information only) of Tank T01A/B ................. 4.8

Figure 4.8. The Delivered PJM Before Installation into Tank T01A/B............................................. 4.9

Figure 4.9. Cross-Sectional Illustration (not to scale and for information only) of TankT01A/B......... 4.10

Figure 4.10. Isometric Illustration (not to scale and for information only) of TankT01A/B ................ 4.11

Figure 4.11. Tank T01A Plan View Showing Resistance Temperature Detector (RTD)

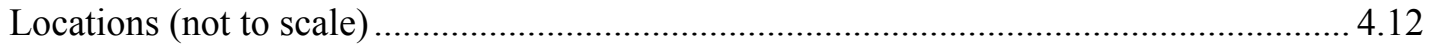

Figure 4.12. Tank T01A Elevation View Showing RTD Locations (not to scale) .............................. 4.13

Figure 4.13. Schematic of Tank T02A Loop and Filtration.............................................................. 4.15

Figure 4.14. Cross-Sectional Illustration (not to scale and for information only) of Tank T02A ......... 4.16

Figure 4.15. Plan View Illustration (not to scale and for information only) of Tank T02A .................. 4.17

Figure 4.16. Delivered PJMs Before Installation into Tank T02A …................................................... 4.17

Figure 4.17. Isometric of Tank T02A Without the Lower Spargers (not to scale) .............................. 4.18

Figure 4.18. Isometric Detail of the Bottom of Tank T02A (not to sacle)........................................... 4.19

Figure 4.19. Tank T02A Plan View Showing RTD Locations (not to scale) ..................................... 4.20

Figure 4.20. Tank T02A Elevation View Showing RTD Locations (not to scale) ............................... 4.21

Figure 4.21. PEP Filter Bundle Assembly with Key Geometric Parameters Listed............................. 4.22

Figure 4.22. PEP Filter Element Arrangement (axial and side views), ............................................. 4.23

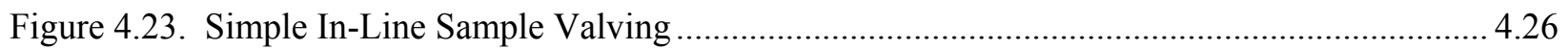

Figure 4.24. In-Tank Sampling for Tank T02A Showing the Three Radial Positions at Three Heights and Sampling Flow Loop ................................................................... 4.27

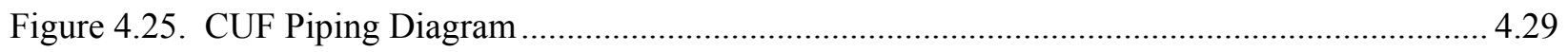

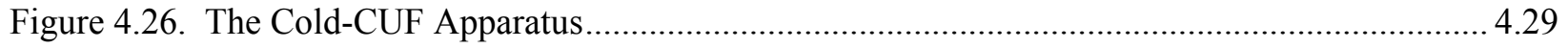

Figure 4.27. CUF Filter Assembly Sketch (not to scale) .................................................................. 4.30

Figure 4.28. The Cell Unit Filter Assembly ...................................................................................... 4.31 
Figure 4.29. Schematic Drawing of the Caustic Leaching Test Setup......

Figure 4.30. Simulant Leaching Vessel

Figure 5.1. Caustic- and Oxidative-Leach and Ultrafilter Operations .................................................. 5.8

Figure 7.1. Simulant Line Flush Analytical Data ........................................................................... 7.2

Figure 7.2. Tank T01A Wt\% UDS Analysis for All Stratification Samplings

Figure 7.3. Tank T01A Stratification-Wt\% UDS Analyses Showing Sample Means with 95\% Confidence (2 std. dev.) Limits.

Figure 7.4. Tank T01B Stratification-Wt\% UDS Analysis for All Stratification Samplings from the Second Test

Figure 7.5. Tank T01B Stratification-Wt\% UDS Analyses Showing Sample Means with 95\% Confidence (2 std. dev.) Limits from the Second Test .................................................... 7.5

Figure 7.6. Sampling Comparison for In-Line Loop Sampling vs. Tank T02A In-Tank Sampling ........ 7.6

Figure 8.1. A Comparison of PEP Total (area-averaged) Flux to CUF Flux as Measured in Low-Solids Scaling Test \#2

Figure 8.2. Individual Permeate Flux for PEP Filters (corrected for variation in TMP and temperature) During Low-Solids Scaling Test \#1

Figure 8.3. Typical Filter Flux Behavior as a Function of Solids Concentration .

Figure 8.4. Summary of PEP and CUF Dewatering Curves for the High-Solids Filter Tests Performed at the End of Integrated Test B Operations

Figure 8.5. Comparison of Measured to Calculated UDS During Integrated Test A Post-Caustic-Leach Concentration.

Figure 8.6. Filter \#1 Flux (corrected for TMP and temperature variations) for Integrated Test A Post-Caustic-Leach Concentration as a Function of Time.

Figure 8.7. Corrected Filter \#1 Flux for Integrated Test A Post-Caustic-Leach Concentration as a Function of Slurry UDS

Figure 8.8. Comparison of Measured to Calculated DS During Integrated Test A Leached Slurry Washing

Figure 8.9. Total Filter Flux (corrected for TMP and temperature variations) for Integrated Test A Leached Slurry Washing as a Function of Time

Figure 8.10. Individual Filter Flux (corrected for TMP and temperature variations) for Integrated Test A Leached Slurry Washing as a Function of Time (showing oscillation on all 5 filter bundles)

Figure 8.11. Total Filter Flux (corrected for TMP and temperature variations) for Integrated Test A Leached Slurry Washing as a Function of Supernate DS Concentration.

Figure 8.12. Comparison of Measured to Calculated DS During Integrated Test A Post-Oxidative-Leached Slurry Washing.

Figure 8.13. Total Filter Flux (corrected for TMP and temperature variations) for Integrated A Post-Oxidative-Leach Washing as a Function of Time

Figure 8.14. Total Filter Flux (corrected for TMP and temperature variations) for Integrated A Post-Oxidative-Leach Washing as a Function of Supernate DS Concentration 8.24 
Figure 8.15. Measured and Estimated (by mass balance) Slurry UDS Concentration for Pre-Caustic-Leach Concentration Batch \#1, Integrated Test B

Figure 8.16. Corrected Total Filter Flux for Pre-Caustic-Leach Solids Concentration, Integrated Test B, Caustic-Leach Batch \#1

Figure 8.17. Filter Flux as a Function of wt\% UDS for Pre-Caustic-Leach Solids Concentration, Integrated Test B, Caustic-Leach Batch \#1

Figure 8.18. Measured and Estimated (by mass balance) Slurry UDS Concentration for Pre-Caustic-Leach Solids Concentration, Integrated Test B, Caustic-Leach Batch \#2 ..... 8.28

Figure 8.19. Corrected Total Filter Flux for Pre-Caustic-Leach Solids Concentration, Integrated Test B, Caustic-Leach Batch \#2.

Figure 8.20. Dewatering Curve for Pre-Caustic-Leach Solids Concentration, Integrated Test B, Caustic-Leach Batch \#2

Figure 8.21. Comparison of Flux as a Function of UDS Concentration for Batch \#1 and Batch \#2 Pre-Caustic-Leach Solids Concentration, Integrated Test B.

Figure 8.22. Measured and Estimated (by mass balance) Slurry UDS Concentration for Post-Caustic-Leach Concentration, Integrated Test B

Figure 8.23. Corrected Filter Flux for Filter 1 During Post-Caustic-Leach Concentration, Integrated Test B.

Figure 8.24. Corrected Filter Flux for Filter 1 During Post-Caustic-Leach Concentration as a Function of the Slurry UDS Concentration, Integrated Test B.

Figure 8.25. Measured and Estimated (by mass balance) Supernate Dissolved Solids Concentration for Post-Caustic-Leach Washing, Integrated Test B.

Figure 8.26. Total Corrected Filter Flux for Post-Caustic-Leach Washing, Integrated Test B 8.34

Figure 8.27. Total Corrected Filter Flux as a Function of Supernate DS Concentration for Post-Caustic-Leach Washing, Integrated Test B

Figure 8.28. Measured and Estimated (by mass balance) Supernate Dissolved Solids Concentration for Post-Oxidative-Leach Washing, Integrated Test B

Figure 8.29. Corrected Total Filter Flux for Post-Oxidative-Leach Washing, Integrated Test B

Figure 8.30. Corrected Total Filter Flux as a Function of Supernate DS Concentration for Post-Oxidative-Leach Washing, Integrated Test B....

Figure 8.31. Comparison of Measured to Calculated UDS During Integrated Test D Batch \#1 Pre-Caustic-Leach Concentration

Figure 8.32. Filter \#1 Flux (corrected for TMP and temperature variations) for Integrated Test D Batch \#1 Pre-Caustic-Leach Concentration as a Function of Time

Figure 8.33. Corrected Filter \#1 Flux for Integrated Test D Batch \#1 Pre-Caustic-Leach Concentration as a Function of Slurry UDS

Figure 8.34. Comparison of Measured to Calculated UDS During Integrated Test D Batch \#2 Pre-Caustic-Leach Concentration

Figure 8.35. Total Filter Flux (corrected for TMP and temperature variations) for Integrated Test D Batch \#2 Pre-Caustic-Leach Concentration as a Function of Time. 
Figure 8.36. Corrected Total Filter Flux for Integrated Test D Batch \#2 Pre-Caustic-Leach

Concentration as a Function of Slurry UDS

Figure 8.37. Total Filter Flux (corrected for TMP and temperature variations) Comparison of Integrated Test D Batch \#1 to Batch \#2 Pre-Caustic-Leach Concentration as a Function of Slurry UDS

Figure 8.38. Comparison of Measured to Calculated UDS During Integrated Test D Post-Caustic-Leach Concentration.

Figure 8.39. Total Filter Flux (corrected for TMP and temperature variations) for Integrated Test D Post-Caustic-Leach Concentration as a Function of Time.

Figure 8.40. Corrected Total Filter Flux for Integrated Test D Post-Caustic-Leach Concentration as a Function of Slurry UDS

Figure 8.41. Comparison of Measured to Calculated DS During Integrated Test D Leached Slurry Washing

Figure 8.42. Total Filter Flux (corrected for TMP and temperature variations) for Integrated Test D Leached Slurry Washing as a Function of Time

Figure 8.43. Total Filter Flux (corrected for TMP and temperature variations) for Integrated Test D Leached Slurry Washing as a Function of Supernate DS Concentration.

Figure 8.44. Comparison of Measured to Calculated DS During Integrated Test D Oxidative Leaching and Washing... 8.50

Figure 8.45. Total Filter Flux (corrected for TMP and temperature variations) for Integrated Test D Oxidative Leaching and Washing as a Function of Time

Figure 8.46. Total Filter Flux (corrected for TMP and temperature variations) for Integrated Test D Oxidative Leaching and Washing as a Function of Supernate DS Concentration..... 8.51

Figure 9.1. Temperature Measured at the Prototypic Sensor in PEP Vessel Tank T01A During Integrated Test A, Batch 1

Figure 9.2. Temperature Measured at the Prototypic Sensor in PEP Vessel Tank T01B During Integrated Test A, Batch 2

Figure 9.3. Temperature Measured at the Prototypic Sensor in PEP Vessel Tank T01A During Integrated Test A, Batch 3

Figure 9.4. Temperature Measured at the Prototypic Sensor in PEP Vessel Tank T01B During Integrated Test A, Batch 4

Figure 9.5. Temperature Measured at the Prototypic Sensor in PEP Vessel Tank T01A During Integrated Test A, Batch 5

Figure 9.6. Temperature Measured at the Prototypic Sensor in PEP Vessel Tank T01B During Integrated Test A, Batch 6

Figure 9.7. Slurry Component Volume Changes ( $\Delta$ volume) in Tank T01A Associated with Direct Steam Injection and IW Addition During the Heat-Up and Caustic-Leach Periods of Integrated Test A, Batch 1

Figure 9.8. Slurry Component Volume Changes ( $\Delta$ volume) in Tank T01B Associated with Direct Steam Injection and IW Addition During the Heat-Up and Caustic-Leach Periods of Integrated Test A, Batch 2 
Figure 9.9. Slurry Component Volume Changes ( $\Delta$ volume) in Tank T01A Associated with Direct Steam Injection and IW Addition During the Heat-Up and Caustic-Leach Periods of Integrated Test A, Batch 3

Figure 9.10. Slurry Component Volume Changes ( $\Delta$ volume) in Tank T01B Associated with Direct Steam Injection and IW Addition During the Heat-Up and Caustic-Leach Periods of Integrated Test A, Batch 4

Figure 9.11. Slurry Component Volume Changes ( $\Delta$ volume) in Tank T01A Associated with Direct Steam Injection and IW Addition During the Heat-Up and Caustic-Leach Periods of Integrated Test A, Batch 5

Figure 9.12. Slurry Component Volume Changes ( $\Delta$ volume) in Tank T01B Associated with Direct Steam Injection and IW Addition During the Heat-Up and Caustic-Leach Periods of Integrated Test A, Batch 6

Figure 9.13. Temperature Measured at the "Prototypic" Sensor in PEP Vessel Tank T02A During Integrated Test B, Batch 1 .

Figure 9.14. Temperature Measured at the "Prototypic" Sensor in PEP Vessel Tank T02A During Integrated Test B, Batch 2 .

Figure 9.15. Slurry Component Volume Changes ( $\Delta$ volume) in Tank T02A Associated with Direct Steam Injection During the Heat-Up and Caustic-Leach Periods of Integrated Test B, Batch 1

Figure 9.16. Slurry Component Volume Changes ( $\Delta$ volume) in Tank T02A Associated with Direct Steam Injection During the Heat-Up and Caustic-Leach Periods of Integrated Test B, Batch 2

Figure 9.17. Temperature Measured at the "Prototypic" Sensor in PEP Vessel Tank T02A During Integrated Test $\mathrm{D}$, Batch 1

Figure 9.18. Temperature Measured at the "Prototypic" Sensor in PEP Vessel Tank T02A During Integrated Test $\mathrm{D}$, Batch 2

Figure 9.19. Slurry Component Volume Changes ( $\Delta$ volume) in Tank T02A Associated with Direct Steam Injection During the Heat-Up and Caustic-Leach Periods of Integrated Test D, Batch 1

Figure 9.20. Slurry Component Volume Changes ( $\Delta$ volume) in Tank T02A Associated with Direct Steam Injection During the Heat-Up and Caustic-Leach Periods of Integrated Test D,

Batch 2

Figure 9.21. Dilution Factors with 95\% Confidence Intervals During Batch 1 of PEP Integrated Test A (caustic leaching in Tank T01A).

Figure 9.22. Dilution Factors with 95\% Confidence Intervals During Batch 2 of PEP Integrated Test A (caustic leaching in Tank T01B) 9.55

Figure 9.23. Dilution Factors with 95\% Confidence Intervals During Batch 3 of PEP Integrated Test A (caustic leaching in Tank T01A)..... 9.55

Figure 9.24. Dilution Factors with 95\% Confidence Intervals During Batch 4 of PEP Integrated Test A (caustic leaching in Tank T01B) 9.56

Figure 9.25. Dilution Factors with 95\% Confidence Intervals During Batch 5 of PEP Integrated Test A (caustic leaching in Tank T01A).... 9.56 
Figure 9.26. Dilution Factors with 95\% Confidence Intervals During Batch 6 of PEP Integrated Test A (caustic leaching in Tank T01B)

Figure 9.27. Dilution Factors with 95\% Confidence Intervals During Batch 1 of PEP Integrated Test B (caustic leaching in Tank T02A, $98^{\circ} \mathrm{C}$ ) 9.66

Figure 9.28. Dilution Factors with 95\% Confidence Intervals During Batch 2 of PEP Integrated Test B (caustic leaching in Tank T02A) .

Figure 9.29. Dilution Factors with 95\% Confidence Intervals for Laboratory-Scale Tests Paralleling Integrated Test $\mathrm{D}$ (caustic leaching in Tank T02A at $85^{\circ} \mathrm{C}$ ).

Figure 9.30. Dilution Factors with 95\% Confidence Intervals for Batch 1 of PEP Integrated Test D (caustic leaching in Tank $\mathrm{T} 02 \mathrm{~A}$ at $85^{\circ} \mathrm{C}$ ).

Figure 9.31. Dilution Factors with 95\% Confidence Intervals for Batch 2 of PEP Integrated Test D

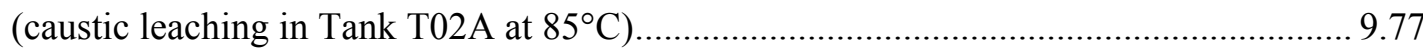

Figure 9.32. FTIR Spectrum for Unprocessed Integrated Test D Simulant. 9.81

Figure 9.33. FTIR Spectrum for Water-Washed Solids from 0-hr and 24-hr Slurry from Integrated Test D, Batch 2 .

Figure 9.34. Increase in Dissolved Aluminum (change from initial) as a Function of Time After 14-g Gibbsite Was Added to Integrated Test A Permeate Samples.

Figure 9.35. Increase in Dissolved Aluminum (change from initial) as a Function of Time After 14-g Gibbsite Was Added to Integrated Test B Permeate Samples.

Figure 9.36. Increase in Dissolved Aluminum (change from initial) as a Function of Time After 14-g Gibbsite was Added to Integrated Test D Permeate Samples.

Figure 9.37. Plot of the Final Dissolved Aluminum Concentrations as a Function of the Initial Total Hydroxide Present in the Permeate Samples.

Figure 10.1. Bulk Densities Measured During the Post-Caustic-Leach Wash of the Three Integrated Tests 10.6

Figure 10.2. Supernate Densities Measured During the Post-Caustic-Leach Wash of the Three Integrated Tests

Figure 10.3. Undissolved Solids Measured During the Post-Caustic-Leach Wash of the Three Integrated Tests

Figure 10.4. Temperature Measured in Tank T02A During the Post-Caustic-Leach Wash of Integrated Tests A, B, and D.

Figure 10.5. Laser Level Measured in Tank T02A During the Post-Caustic-Leach Wash of Integrated Tests A, B, and D.

Figure 10.6. Flow Rates in the Filter-Loop During the Post-Caustic-Leach Wash of Integrated Tests A, B, and D.

Figure 10.7. Total Normalized Filter Flux Measured During the Post-Caustic-Leach Wash of Integrated Tests A, B, and D.

Figure 10.8. Bulk Densities Measured During the Post-Oxidative-Leach Wash of the Three Integrated Tests $\mathrm{A}, \mathrm{B}$, and $\mathrm{D}$. 
Figure 10.9. Supernate Densities Measured During the Post-Oxidative-Leach Wash of the Three Integrated Tests A, B, and D.

Figure 10.10. Undissolved Solids Measured During the Post-Oxidative-Leach Wash of the Three Integrated Tests A, B, and D.

Figure 10.11. Temperature Measured in Tank T02A During the Post-Oxidative-Leach Wash of Integrated Tests $\mathrm{A}, \mathrm{B}$, and $\mathrm{D}$.

Figure 10.12. Laser Level Measured in Tank T02A During the Post-Oxidative-Leach Wash of Integrated Tests A, B, and D.

Figure 10.13. Flow Rates in the Filter-Loop During the Post-Oxidative-Leach Wash of Integrated Tests A, B, and D.

Figure 10.14. Total Normalized Filter Flux Measured During the Post-Oxidative-Leach Wash of Integrated Tests A, B, and D.

Figure 10.15. Concentration Ratio $(\mathrm{Cn} / \mathrm{Co})$ for Nitrate During the Post-Caustic-Leach Wash.

Figure 10.16. Concentration Ratio $(\mathrm{Cn} / \mathrm{Co})$ for Nitrite During the Post-Caustic-Leach Wash.

Figure 10.17. Concentration Ratio (Cn/Co) for Sulfate During the Post-Caustic-Leach Wash.

Figure 10.18. Concentration Ratio $(\mathrm{Cn} / \mathrm{Co})$ for Aluminum During the Post-Caustic-Leach Wash. .... 10.24

Figure 10.19. Concentration Ratio (Cn/Co) for Free Hydroxide During the Post-Caustic-Leach Wash

Figure 10.20. As-Measured Concentration Curves Overlaid, for Integrated Test A

Post-Caustic-Leach Wash, to Allow Visual Comparison of Major Analytes of Interest.

Figure 10.21. As-Measured Concentration Curves Overlaid, for Integrated Test B Post-Caustic-Leach Wash, to Allow Visual Comparison of Major Analytes of Interest.

Figure 10.22. As-Measured Concentration Curves Overlaid, for Integrated Test D Post-Caustic-Leach Wash, to Allow Visual Comparison of Major Analytes of Interest.

Figure 10.23. Concentration Ratio $(\mathrm{Cn} / \mathrm{Co})$ for Chromium During the Post-Oxidative-Leach Wash.. 10.27

Figure 10.24. Concentration Ratio $(\mathrm{Cn} / \mathrm{Co})$ for Nitrate During the Post-Oxidative-Leach Wash.

Figure 10.25. Concentration Ratio $(\mathrm{Cn} / \mathrm{Co})$ for Sodium During the Post-Oxidative-Leach Wash....... 10.28

Figure 10.26. Concentration Ratio $(\mathrm{Cn} / \mathrm{Co})$ for Oxalate During the Post-Oxidative-Leach Wash....... 10.29

Figure 10.27. Concentration Ratio ( $\mathrm{Cn} / \mathrm{Co}$ ) for TDS During the Post-Oxidative-Leach Wash

Figure 10.28. As-Measured Concentration Curves Overlaid, for Integrated Test A Post-Oxidative-Leach Wash, to Allow Visual Comparison of Major Analytes of Interest.

Figure 10.29. As-Measured Concentration Curves Overlaid, for Integrated Test B Post-Oxidative-Leach Wash, to Allow Visual Comparison of Major Analytes of Interest. 
Figure 10.30. As-Measured Concentration Curves Overlaid, for Integrated Test D Post-Oxidative-Leach Wash, to Allow Visual Comparison of Major Analytes of Interest.

Figure 10.31. Concentration of Nitrate During Integrated Test A Post-Caustic-Leach Wash as Measured by Two Analytical Methods

Figure 10.32. Concentration of Nitrite During Integrated Test A Post-Caustic-Leach Wash as Measured by Two Analytical Methods.

Figure 10.33. Concentration of Sulfate During Integrated Test A Post-Caustic-Leach Wash as Measured by Two Analytical Methods.

Figure 10.34. Concentration of Free Hydroxide During Integrated Test A Post-Caustic-Leach Wash as Measured by Two Analytical Methods

Figure 10.35. Concentration of Aluminum/Aluminate During Integrated Test A

Post-Caustic-Leach Wash as Measured by Two Analytical Methods.

Figure 10.36. Concentration of Chromium/Chromate During Integrated Test A

Post-Oxidative-Leach Wash as Measured by Two Analytical Methods. 10.36

Figure 10.37. Concentration of Phosphate During Integrated Test A Post-Oxidative-Leach Wash as Measured by Two Analytical Methods

Figure 10.38. Raman Data for Carbonate Compared to Ideal Wash Efficiency Prediction for the Post-Caustic-Leach Wash of Integrated Test A 10.38

Figure 10.39. Comparison of Measured to Calculated Oxalate Concentration for Integrated Test A Post-Caustic-Leach Wash.

Figure 10.40. Comparison of Measured to Calculated Oxalate Concentration for Integrated Test B Post-Caustic-Leach Wash.

Figure 10.41. Comparison of Measured to Calculated Oxalate Concentration for Integrated Test D Post-Caustic-Leach Wash.

Figure 11.1. Dissolution of Cr During Integrated Test D Caustic Leaching as Determined by Method 1 .

Figure 11.2. Cr Concentrations in the Supernate for Integrated Tests A, B and D and Bench-Scale Test $\mathrm{D}$ as a Function of Time (hours).

Figure 11.3. Cr Leach Factors During Oxidative Leaching as a Function of Time (hours) for the PEP and Laboratory-Scale Tests A and B as Calculated by Method 2

Figure 12.1. Schematic Used for Mass Balance in the Integrated Tests.

Figure 12.2. Mass Balance Envelope Used in the Calculations Presented in this Section

Figure 13.1. Tank T01A/B Gravity Refill.

Figure 13.2. Tank T02A Gravity Refill 13.2

Figure 13.3. UFP-VSL-T0001A/B Full-Scale PJM Gravity Refill.

Figure 13.4. UFP-VSL-T0002A Full-Scale PJM Gravity Refill 13.4

Figure 13.5. The Tank Bottom and Steam Ring in Tank T01A After IW Cleaning.....

Figure 13.6. The Steam Ring and Bracket in Tank T01A After IW Cleaning.

Figure 13.7. Tank T02A After the Prototypic Nitric Acid Cleaning 
Figure 13.8. Tank T02A After the Prototypic Nitric Acid Cleaning

Figure 13.9. Tank T02A Before the Prototypic Nitric Acid Cleaning

Figure 13.10. Tank T02A After the Prototypic Nitric Acid Cleaning

Figure 13.11. Inspections of Filter T01A Inlet

Figure 13.12. Inspections of 8-ft Spare Ultrafilter.

Figure 13.13. Filter-Loop Flow Rates for Integrated Test A

Figure 13.14. Entrained Gas Present in Filter-Loop During Integrated Test A.

Figure 13.15. Filter-Loop Flow Rates During Integrated Test B.

Figure 13.16. Entrained Gas Present in Filter-Loop During Integrated Test B

Figure 13.17. Filter-Loop Flow Rates During Integrated Test D

Figure 13.18. Entrained Gas Present in Filter-Loop During Integrated Test D

Figure 13.19. Illustration of Tank T02A RTD Locations.

Figure 13.20. Tank T01A Temperature Near the Tank Wall at Various Locations

Figure 13.21. Tank T02A Temperature Near the Tank Wall at Various Locations

Figure 13.22. Tank T01A Average, Maximum, and Standard Deviation of the Tank T01A Sensors During Three Caustic-Leach Steam Addition Cycles for Integrated Test A, Batch 1

Figure 13.23. Tank T02A Average, Maximum, and Standard Deviation of All Tank T02A Sensors During Three Caustic-Leach Steam Addition Cycles for Integrated Test B, Batch 2

Figure 13.24. Effect of PJM Operation on Tank Temperature in Tank T01A 13.38

Figure 13.25. Effect of PJM Operation on Tank Temperature in Tank T02A 13.39 


\section{Tables}

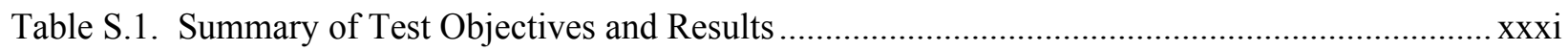

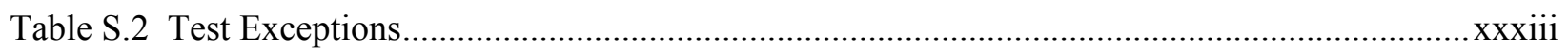

Table S.3 Deviations from Test Specification ................................................................................ xxxvi

Table S.4 Results and Performance Against Success Criteria ........................................................xxxviii

Table S.5 R\&T Test Conditions........................................................................................................ xliv

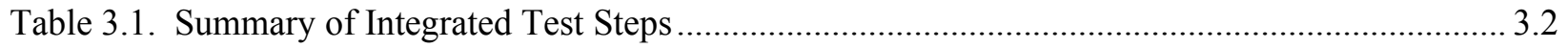

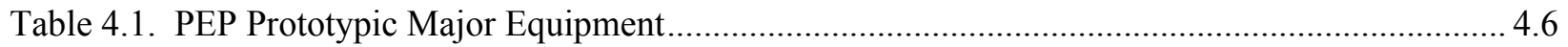

Table 4.2. Functionally Prototypic Major PEP Equipment and Systems............................................ 4.7

Table 4.3. Nonprototypic Major PEP Equipment ........................................................................... 4.7

Table 4.4. Specifications of the Five PEP Cross-Flow Filtration Bundles ........................................... 4.24

Table 4.5. Permeate Metering and Pulse-Pot Configurations for PEP................................................ 4.26

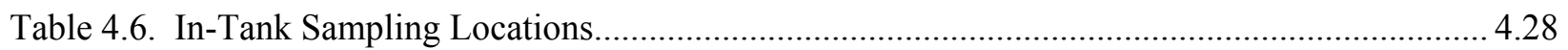

Table 5.1. Estimated Quantitative Limits for Solids and Supernatants in Sample Loop Testing, PEP Operation, and Simulant Acceptance Samples ....................................................... 5.3

Table 5.2. Tank T02A Air Sparge Mixer Operation ................................................................................. 5.5

Table 6.1. Simulant Feed Composition for Integrated Tests A and B ................................................. 6.8

Table 6.2. Simulant Feed Composition for Integrated Test D .............................................................. 6.9

Table 7.1. Variance Apportionment Between Analytical Measurements and All Other Sources of Variability (slurry variations, sample collection and handling) ............................................ 7.7

Table 7.2. Free $\mathrm{OH}$ (molarity) in Tank T01A After In-Line NaOH Addition........................................ 7.8

Table 7.3. Free Hydroxide (molarity) in Tank T02A After In-Line NaOH Addition............................. 7.8

Table 7.4. Sampling Data (wt\% UDS and slurry density) Used to Test for Stratification of

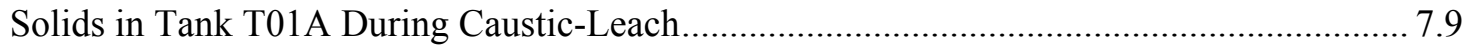

Table 7.5. Mean Values of Sampling Data (wt\% UDS and slurry density) Grouped by Elevation or Radial Distance Used to Test for Stratification of Solids in Tank T01A During Caustic-Leach ....

Table 7.6. Sampling Data (wt\% UDS and slurry density) Used to Test for Stratification of Solids in T02A During Caustic-Leach.

Table 7.7. Mean Values of Sampling Data (wt $\%$ UDS and slurry density) Grouped by Elevation or Radial Distance Used to Test for Stratification of Solids in Tank T02A During Caustic-Leach

Table 8.1. Success Criteria Addressed in Executive Summary in the Section "Results and Performance Against Success Criteria" ........................................................................ 8.2

Table 8.2. Results for Low-Solids Scaling Tests ............................................................................ 8.7

Table 8.3. Results for High-Solids Scaling Test ........................................................................... 8.14 
Table 8.4. Integrated Test A Filtration Times (at target TMP and AV) ........................................... 8.53

Table 8.5. Integrated Test B Filtration Times (at target TMP and AV)........................................... 8.55

Table 8.6. Integrated Test D Filtration Times (at target TMP and AV) .......................................... 8.57

Table 8.7. Average Filter Flux for Integrated Test Filtration Operations ........................................... 8.58

Table 9.1. Roadmap to Discussions of Relevant Test Requirements................................................... 9.2

Table 9.2. Caustic-Leach Reagent Additions for Tank T01A Batches in Integrated Test A.................9.13

Table 9.3. Caustic-Leach Reagent Additions for Tank T01B Batches in Integrated Test A ................ 9.14

Table 9.4. Caustic-Leach Batch Component Masses for Tank T01A Batches in Integrated Test A ...... 9.16

Table 9.5. Caustic-Leach Batch Component Masses for Tank T01B Batches in Integrated Test A ...... 9.17

Table 9.6. Caustic-Leach Reagent Additions for Tank T02A Batches in Integrated Test B ................ 9.18

Table 9.7. Caustic-Leach Batch Component Masses for Tank T02A Batches in Integrated Test B ...... 9.19

Table 9.8. Caustic-Leach Reagent Additions for Tank T02A Batches in Integrated Test D ................. 9.20

Table 9.9. Caustic-Leach Batch Component Masses for Tank T02A Batches in Integrated Test D ...... 9.22

Table 9.10. Dilution of Liquid Phase During Integrated Test A Caustic-Leach Batches in

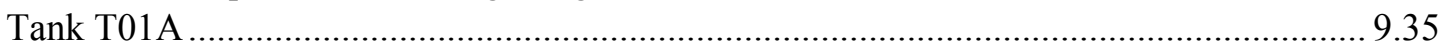

Table 9.11. Dilution of Liquid Phase During Integrated Test A Caustic-Leach Batches in Tank T01B 9.36

Table 9.12. Dilution of Liquid Phase During Integrated Test B Caustic-Leach Batches in Tank T02A

Table 9.13. Dilution of Liquid Phase During Integrated Test D Caustic-Leach Batches in

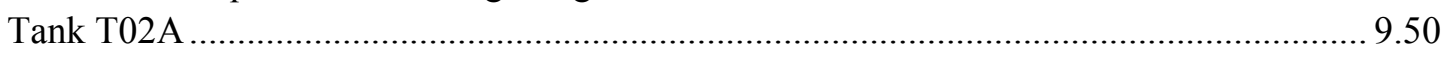

Table 9.14. Experimental Parameters for Laboratory-Scale Versions of Integrated Test A................. 9.52

Table 9.15. Experimental Parameters for Laboratory-Scale Versions of Integrated Test B.................. 9.52

Table 9.16. Experimental Parameters for Laboratory-Scale Versions of Integrated Test D................. 9.53

Table 9.17. Integrated Test A Initial Conditions for Kinetic Rate Constant Fit ................................... 9.61

Table 9.18. Integrated Test A Boehmite Leach Factors Using Liquid Tracers .................................... 9.62

Table 9.19. Integrated Test A Boehmite Leach Factors Using Solid Tracers...................................... 9.63

Table 9.20. Scale-Up Factors and Related Leach Information for PEP Integrated Test A and

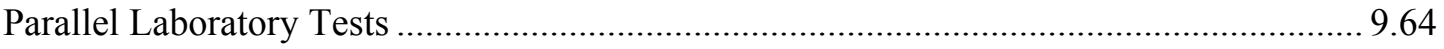

Table 9.21. PEP Integrated Test B Total Aluminum Leach Factors Using Liquid Tracers................... 9.68

Table 9.22. Integrated Test B Initial Conditions for Kinetic Rate Constant Fit .................................. 9.69

Table 9.23. Integrated Test B Boehmite Leach Factors Using Liquid Tracers.................................... 9.70

Table 9.24. Integrated Test B Boehmite Leach Factors Using Solid Tracers ..................................... 9.71

Table 9.25. Scale-Up Factors and Related Leach Information for PEP Integrated Test B and

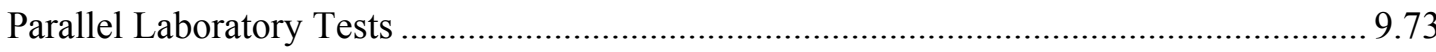

Table 9.26. Integrated Test D Total Aluminum Leach Factors Using Liquid Tracers ......................... 9.79

Table 9.27. Integrated Test D Total Aluminum Leach Factors Using Solid Tracers ........................... 9.80 
Table 9.28. Slurry Al Concentration in the Initial Diluted Slurry in Laboratory-Scale Tests for

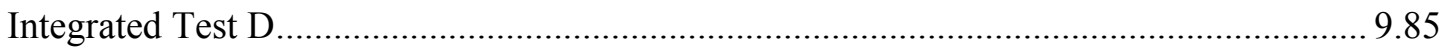

Table 9.29. Integrated Test D Initial Conditions for Kinetic Rate Constant Fit ................................. 9.85

Table 9.30. Scale-Up Factors and Related Leach Information for PEP Integrated Test D and

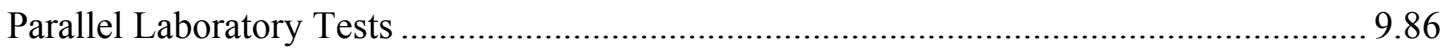

Table 9.31. Aluminum Concentrations at Multiple CD Ports, Integrated Test A Batch 1................... 9.89

Table 9.32. Aluminum Concentrations at Multiple CD Ports, Integrated Test B Batch 2 ................... 9.89

Table 9.33. Aluminum Concentrations at Multiple CD Ports, Integrated Test D Batch 2................... 9.90

Table 9.34. Comparison of Single-Port and Multi-Port Kinetic Results and Scale-Up Factors ............ 9.90

Table 9.35. Composition of Initial Permeate Samples........................................................................... 9.92

Table 9.36. Source Data for Figure 9.34; Aluminum Dissolution for Integrated Test A Samples ......... 9.95

Table 9.37. Source Data for Figure 9.35, Aluminum Dissolution for Integrated Test B Samples ......... 9.96

Table 9.38. Source Data for Figure 9.36, Aluminum Dissolution for Integrated Test D Samples ......... 9.96

Table 9.39. Final Dissolved Al Concentration Increase Resulting from Gibbsite Addition.................. 9.97

Table 9.40. Summary of Condensate Mass Fractions ...................................................................... 9.100

Table 9.41. Scale-Up Factors and Kinetic Rate Constants for PEP and Parallel Laboratory-Scale

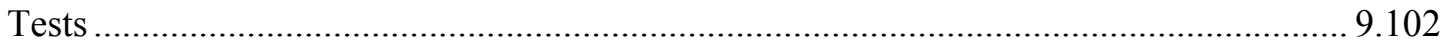

Table 9.42. Final Dissolved Al Concentration Increase Resulting from Gibbsite Addition................ 9.104

Table 10.1. Initial Slurry Composition for Post-Caustic-Leach Wash for Integrated

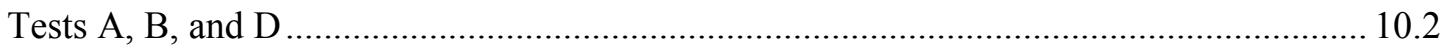

Table 10.2. Initial Slurry Composition for Post-Oxidative-Leach Wash for Integrated

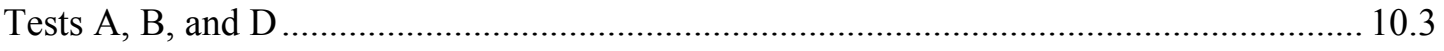

Table 10.3. Wash Volume Parameters for Integrated Tests A, B, D ................................................ 10.5

Table 10.4. Summary of Weff Results (Weighted Least Squares Method) for All Analytes, for Integrated Tests A, B, and D

Table 10.5. Comparison of the Weighted Least Squares Wash Efficiency Calculated Using Concentrations from Standard Analytical Technique and Raman Data

Table 10.6. Comparison of Phosphate Concentration Data by Three Methods

Table 11.1. Initial Oxidative-Leach Slurry Composition for Integrated Tests A, B, and D

Table 11.2. Mn:Cr Experimental Ratio.

Table 11.3. Final Cr Oxidative-Leach Factors for the PEP (6-hr contact time) and Laboratory-Scale Tests A, B, and D (8-hr contact time) as Calculated by Methods 1 and 2 (95\% confidence values in parenthesis)

Table 11.4. Cumulative Leach Factors for Cr in Tests A, B, and D as Calculated by Methods 1 and 2 ( $95 \%$ confidence range in parenthesis)

Table 11.5. Comparison of Leach Factors Determined from Mass Balance Calculations (Section 12, Table 12.12) and Oxidative-Leach Calculations (current section, Table 11.4).

Table 11.6. Mass Summary of Cr for Oxidative Leaching in Integrated Tests A, B, and D 11.13 
Table 12.1. Global Mass Balance for Integrated Test A ................................................................ 12.6

Table 12.2. Fate of Species During Integrated Test A ................................................................... 12.8

Table 12.3. Global Mass Balance for Integrated Test B ................................................................. 12.11

Table 12.4. Fate of Species During Integrated Test B ............................................................... 12.13

Table 12.5. Global Mass Balance for Integrated Test D............................................................... 12.15

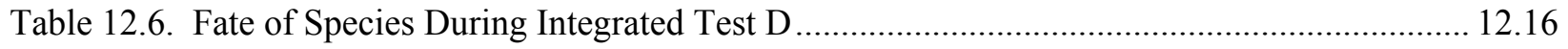

Table 12.7. AFA Inventory During Integrated Test A ..................................................................... 12.20

Table 12.8. AFA Inventory During Integrated Test B .............................................................. 12.21

Table 12.9. AFA Inventory During Integrated Test D ............................................................. 12.22

Table 12.10. Q2-3183A Concentration in Process Slurry During the Integrated Tests...................... 12.23

Table 12.11. Distribution of Aluminum and Sodium at Important Process Points............................ 12.26

Table 12.12. Percent Removed of Each Species During Integrated Tests A, B, and D..................... 12.26

Table 13.1. "Excess" Times for Tanks T01A/B and T02A with Gravity Refill.................................. 13.3

Table 13.2. Excess Times for WTP Vessels UFP-VSL-00001 and UFP-VSL-00002 with

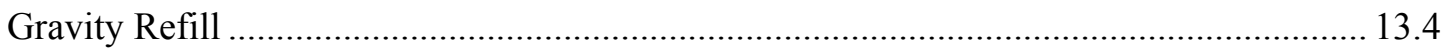

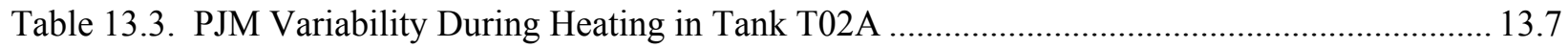

Table 13.4. PJM Variability During Cool-Down in Tank T02A ….................................................... 13.7

Table 13.5. PJM Variation During Level Change in Tank T01A ...................................................... 13.8

Table 13.6. Cesium Concentration Data as Measured by ICP-MS from Tracer Tests Performed During Integrated Tests A and B........................................................... 13.10

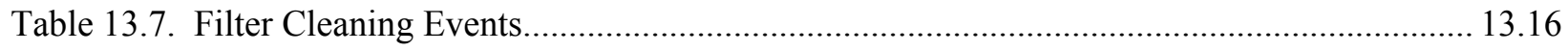

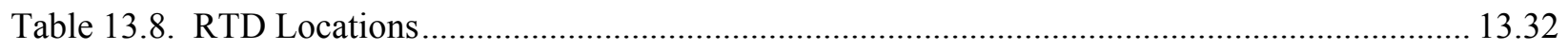

Table 14.1. Percent of Species Removed in the Liquid Phase During Integrated Tests A, B, and D.... 14.5

Table 14.2. Median Scale-Up Factors and Kinetic Rate Constants for PEP and Laboratory-Scale Tests $(95 \%$ confidence intervals in parentheses) ......................................................... 14.8

Table 14.3. Final Dissolved Al Concentration Increase Resulting from Gibbsite Addition.................. 14.9 


\section{Acknowledgments}

The authors would like to thank all of the individuals who contributed to the success of the Pretreatment Engineering Platform (PEP) testing. This success is due to the dedication and commitment of all involved in a remarkable team effort. Since there were more than 500 staff involved in some capacity, it is not possible to acknowledge all contributions. Unless otherwise noted, staff are from Pacific Northwest National Laboratory (PNNL).

First, the authors would like to acknowledge the leadership and contributions of the staff from the Hanford Tank Waste Treatment and Immobilization Plant (WTP) and the Office of River Protection (ORP). This includes Steve Barnes (PEP Test Program Manager), John Truax (PEP Project Manager), Rob Burk (PEP Technical Support Manager), and Rob Gilbert (DOE ORP Technical Lead for PEP). The following WTP/ORP staff were members of the PEP testing crew and worked many long shifts over the course of six months: Ricky Bang (DOE ORP), James Lynch (DOE ORP), and from WTP Scott Lehrman, Jeff Markillie, Bryan Crume, Chris Chapman, Brad Stiver, Gary Harvey, Benn Dunn, Kevin Groves, and Chris Dreyer.

The authors would also like to acknowledge the PNNL Program management of Gordon Beeman and Wes Lawrence (PEP Installation Manager) as well as the Project Office support provided by Chrissy Charron, Andrea Boehler, and Mona Champion.

Timely completion of the testing would not have been possible without the dedicated support from Francis Buck (PDL-W Building Manager) and his skilled crew of craft support.

The testing could not have proceeded without the Phase I simulant. The efforts of Randy Scheele (task leader simulant procurement), Garrett Brown, Reid Peterson, Renee Russell, PS Sundar (WTP), Beric Wells, Harry Smith, and NOAH Technologies Corporation (San Antonio TX; vendor for PEP simulants) are all greatly appreciated.

Analyzing the thousands of samples taken during the PEP testing was a critical part of the testing. Support in this effort was provided by the sample handling team consisting of Ofelia Bredt (task manager; sample handling and analysis), Carolyn Burns, Jesse Loveland, Ellen Baer, Elsa Cordova, Autumn Edmondson, Rebecca Elmore, Eric Mast, Kevin D. Miller, Carmen Rodriguez, Brian Riley, Dennese Smith, Jolen Soelberg, and Angie Woodstock. Crucial analytical support was provided by Southwest Research Institute (San Antonio, Texas) and the Analytical Support Operations at PNNL's Radiochemical Processing Laboratory (Karl Pool, Manager).

Laboratory support testing for the determination of scale-up factors was provided by Reid Peterson (task manager), Renee Russell, Justin Billing, Amanda Casella, and Don Rinehart.

The authors would like to thank Wayne Cosby for valuable editorial support, Dave MacPherson and Kirsten Meier for Quality Assurance support throughout and the project, and Bill Kuhn as well as Gregg Lumetta, Reid Peterson, and Don Bachand for their careful and thorough technical reviews and discussions. We appreciate and highly value their abilities to work flexibly and to put in the extra effort to support the M12 Data Analysis and Reporting Team to produce a well thought-out and critically reviewed report summarizing all aspects of the project. 
The authors would also like to extend a very special recognition to the outstanding data analysis work provided by Rosanne Aaberg, Pam Aker, John Bower, Carolyn Burns, Marcia Kimura, Reid Peterson, Steve Shoemaker, Dennese Smith, and Jake Tucker. This team did an outstanding job of compiling and organizing the critical information from the over 28 billion data points collected during the PEP testing. Their efforts were fundamental to the analysis of the information in this report, and their works are presented in the tables and figures throughout.

In addition to the authors, this summary report was supported by many dedicated staff involved in data acquisition, data processing, data quality confirmation, technical reviews, and data analysis. These people are especially recognized for putting in extra effort to support the Pretreatment Engineering Platform Project.

$\begin{array}{lll}\text { JM Alzheimer } & \text { MS Fountain } & \text { RD Scheele } \\ \text { C Arimescu } & \text { RE Hohimer } & \text { RW Shimskey } \\ \text { DD Bachand } & \text { TS Hausmann } & \text { LA Snow } \\ \text { AW Baumann } & \text { NK Karri } & \text { SF Snyder } \\ \text { GH Beeman } & \text { WL Kuhn } & \text { JJ Soelberg } \\ \text { DL Blanchard Jr } & \text { WE Lawrence } & \text { YF Su } \\ \text { SA Bryan } & \text { D Neiner } & \text { WB Taylor } \\ \text { KJ Cantrell } & \text { KE Parker } & \text { JJ Thompson } \\ \text { AJ Casella } & \text { DM Pfund } & \text { JM Tingey } \\ \text { AM Casella } & \text { DE Rinehart } & \text { MW Urie } \\ \text { J Chun } & \text { PJ Robinson } & \text { JK Young } \\ \text { JM Cuta } & \text { RL Russell } & \\ \text { PE Dresel } & \text { JH Sachs } & \end{array}$

These individuals, the PEP-assigned Bechtel National Inc. and WTP staff, and the rest of the operations and sampling crew are especially recognized for supporting the PEP Project by working unpredictable, long, and off-hour shifts for the better part of a year. The tests and reports could not have progressed this far without their extraordinary effort. 


\section{Acronyms and Abbreviations}

AES atomic emission spectroscopy

AFA

$\mathrm{Al}$

APEL

ASME

ASO

AV

$\mathrm{BNI}$

BS

CD

CFR

$\mathrm{CrOOH}$

$\mathrm{CsBr}$

CUF

DAS

DB

DIW

DL

DOE

DS

DSC

DT

EFRT

EQL

FE

FEP

FT

FRP

FTIR

GPC

HASQARD

$\mathrm{H} / \mathrm{D}$

HDI

antifoam agent (DOW Corning DOW Q2-3183A)

aluminum

Applied Process Engineering Laboratory

American Society of Mechanical Engineers

Analytical Support Operations

axial velocity

Bechtel National Inc.

blank spike

Coriolis densitometer

Code of Federal Regulations

chromium oxyhydroxide

cesium bromide

Cells Unit Filter

data acquisition system

Drexelbrook (capacitance probe)

deionized water

Detection Limit

U.S. Department of Energy

dissolved solids

differential scanning calorimeter

density transmitter

External Flowsheet Review Team

Estimated Quantification Limit

flow element

Feed Evaporation Process

flow transmitter

Feed Receipt Process

Fourier Transform Infrared (spectroscopy)

gel permeation chromatography

Hanford Analytical Services Quality Assurance Requirements Document (vessel slurry height)/(vessel diameter)

How Do I...? (a system for managing the delivery of laboratory-level policies, requirements and procedures) 


\begin{tabular}{|c|c|}
\hline hp & horse power \\
\hline HLW & High-Level Waste \\
\hline HMI & human machine interface \\
\hline HX & heat exchanger \\
\hline $\mathrm{IC}$ & ion chromatography \\
\hline ICP & inductively coupled plasma \\
\hline ICP-AES & inductively coupled plasma-atomic emission spectroscopy \\
\hline ICP-MS & inductively coupled plasma-mass spectrometry \\
\hline IRP & Issue Response Plan \\
\hline IW & inhibited water (0.01 molar $\mathrm{NaOH})$ \\
\hline JTG & Joint Test Group \\
\hline LAW & Low-Activity Waste \\
\hline LCS & laboratory control sample \\
\hline LT & level transmitter \\
\hline LTE & lead test engineer \\
\hline $\mathrm{m}$ & meter or molal \\
\hline M\&TE & measuring and testing equipment \\
\hline MS & matrix spike \\
\hline $\mathrm{NaMnO}_{4}$ & sodium permanganate \\
\hline $\mathrm{NaOH}$ & sodium hydroxide, caustic \\
\hline NCR & nonconformance report \\
\hline NQA & nuclear quality assurance \\
\hline ODE & ordinary differential equation \\
\hline OES & optical emission spectroscopy \\
\hline $\mathrm{OH}$ & free hydroxide \\
\hline ORP & Office of River Protection \\
\hline PB & preparation blank \\
\hline PCLW & Post-caustic-leach wash \\
\hline PDL-W & Process Development Laboratory-West \\
\hline PDMS & polydimethylsiloxane \\
\hline PDT & Pacific Daylight Time \\
\hline PEP & Pretreatment Engineering Platform \\
\hline PJM & pulse jet mixer \\
\hline PLC & programmable logic controller \\
\hline PLM & polarized light microscopy \\
\hline PMP & polymethylpentene (or pump) \\
\hline PNNL & Pacific Northwest National Laboratory \\
\hline
\end{tabular}




\begin{tabular}{|c|c|}
\hline POLW & Post-oxidative-leach wash \\
\hline PPG & polypropylene glycol \\
\hline PST & Pacific Standard Time \\
\hline PT & pressure transmitter \\
\hline PTF & Pretreatment Facility \\
\hline PSD & particle-size distribution \\
\hline QA & quality assurance \\
\hline QAM & Quality Assurance Manual \\
\hline QAP & Quality Assurance Plan \\
\hline QARD & Quality Assurance Requirements and Descriptions \\
\hline QC & quality control \\
\hline $\mathrm{R} \& \mathrm{~T}$ & Research and Technology \\
\hline RL & Reporting Limit \\
\hline RPL & Radiochemical Processing Laboratory \\
\hline RPP & River Protection Project \\
\hline RSD & Relative Standard Deviation \\
\hline RTD & resistance temperature detector \\
\hline SEM & scanning electron microscopy \\
\hline SST & stainless steel \\
\hline SwRI & Southwest Research Institute \\
\hline TDS & total dissolved solids \\
\hline THF & tetrahydrofuran \\
\hline TI & Test Instruction \\
\hline TIC & total inorganic carbon \\
\hline TMP & transmembrane pressure \\
\hline TOC & total organic carbon \\
\hline $\mathrm{TP}$ & Test Plan \\
\hline TT & temperature transmitter \\
\hline UDS & undissolved solids \\
\hline UFP & ultrafiltration process \\
\hline WLS & weighted least squares \\
\hline WTP & Hanford Tank Waste Treatment and Immobilization Plant \\
\hline $\mathrm{Wt} \%$ & weight percent \\
\hline $\mathrm{XRD}$ & X-ray diffraction \\
\hline
\end{tabular}





\section{Testing Summary}

In 2005, the U.S. Department of Energy (DOE) Office of River Protection (ORP) and the Hanford Tank Waste Treatment and Immobilization Plant (WTP) prime contractor Bechtel National Inc. commissioned an External Flowsheet Review Team (EFRT) to critically review the WTP flowsheets. One of the major issues identified by the EFRT was that the pretreatment leaching and filtration processes had not been demonstrated at a meaningful scale. Testing had been limited to laboratory scale (bench scale). Testing at the engineering scale was considered necessary to confirm the process design and provide improved projections of system capacity.

A multi-part issue response plan was prepared to address this issue. The most prominent part of the issue response plan was engineering-scale testing of the leaching and filtration system in the Pretreatment Engineering Platform (PEP). The PEP is a $1 / 4.5$-scale facility designed, constructed, and operated to test the integrated leaching and ultrafiltration processes being deployed in the WTP. ${ }^{(a)}$ The PEP replicates the WTP leaching processes using prototypic equipment and control strategies. The PEP also includes nonprototypic ancillary equipment to support the systems used to leach and filter slurries. The testing approach used a nonradioactive aqueous slurry simulant to demonstrate the unit operations of caustic and oxidative leaching, ultrafiltration solids concentration, and solids washing.

Two process flowsheets are currently being evaluated for the ultrafiltration process (UFP) and leaching operations. The baseline flowsheet has caustic leaching conducted in the UFP-1 ultrafiltration feed preparation vessels (i.e., vessels UFP-VSL-T01A and B in the PEP; vessels UFP-VSL-00001A and $\mathrm{B}$ [UFP-1] in the WTP Pretreatment Facility [PTF]). The alternative scenario has caustic leaching performed in the UFP-2 ultrafiltration feed vessels (i.e., vessel UFP-VSL-T02 $\mathrm{A}^{(\mathrm{b})}$ in the PEP and vessels UFP-VSL-00002A and B [UFP-2] in the WTP PTF).

With both flowsheets, 19-M sodium hydroxide solution ( $\mathrm{NaOH}$, caustic) is added to the waste slurry to leach solid aluminum compounds (e.g., gibbsite, boehmite). Caustic addition is followed by a heating step that uses direct injection of steam to accelerate the leaching process. Following the caustic-leach, the vessel contents are cooled using vessel cooling jackets and/or external heat exchangers. The main difference between the two scenarios is that for leaching in UFP-1, the $19-\mathrm{M} \mathrm{NaOH}$ is added to unconcentrated waste slurry (3- to 8-wt\% solids), while for leaching in UFP-2, the slurry is concentrated to nominally $20-\mathrm{wt} \%$ solids using cross-flow ultrafiltration before adding caustic. After cooling, the leached slurry is concentrated and washed with an aqueous solution of $0.01-\mathrm{M} \mathrm{NaOH}$ (referred to as inhibited water) to remove soluble salts. If the resulting waste solids remain high in chromium, sodium permanganate reagent is added, and the slurry is circulated to oxidize and dissolve the chromium solids. Following the oxidative leaching of chromium-containing solids, the slurry is washed to remove the dissolved chromium and concentrated.

(a) The scale of $1 / 4.5$ was chosen because this scale enables the ultrafiltration loop to be configured to meet two important criteria: 1) using one filter bundle, the ratio of solids in the feed tank to filter surface area will be the same as in the plant, and 2) using five filter bundles, the type and extent of mixing in the feed vessel will be approximately prototypic during the solids washing processes.

(b) In this report, the PEP UFP vessels are generally denoted as Tank T01A/B and Tank T02A. In some cases, alternative designations are used to maintain continuity with previous documentation (e.g., Test Specification/Plan). 
The PEP testing program was conducted under Test Plan TP-RPP-WTP-506 ${ }^{(\mathrm{a})}$ using a waste simulant

that was developed in response to Task 5 from the M12 EFRT issue response plan. ${ }^{(b)}$ The testing included the following tests with simulated Hanford tank waste:

- Shakedown/Functional testing: tested process operations (e.g., slurry transfers, steam heating of the vessels and the accumulation of condensate, filter backpulsing and flushing), process controls (e.g., transmembrane pressure [TMP] and axial flow velocity in the filter-loop), and certain test functions (e.g., in-line slurry sampling accuracy and precision).

- Integrated Test A: demonstrated integrated processing when caustic leaching $\left(98^{\circ} \mathrm{C}\right)$ is performed in UFP-VSL-00001A/B with the Cr simulant component added after the post-caustic-leach washing step.

- Integrated Test B: demonstrated integrated processing when the caustic leaching $\left(98^{\circ} \mathrm{C}\right)$ is performed in UFP-VSL-00002A with the Cr simulant component added after the post-caustic-leach washing step.

- Integrated Test D: demonstrated integrated processing when the caustic leaching is performed at a lower temperature $\left(85^{\circ} \mathrm{C}\right)$ in UFP-VSL-00002A and with the $\mathrm{Cr}$ simulant component added to the initial batch of simulant.

Integrated Test $\mathrm{C}$ was deleted from the scope of the testing (ICN-TP-RPP-WTP-506_R0.2). ${ }^{(\mathrm{c})}$

This report summarizes the critical information gained during the Shakedown and Functional Testing, Integrated Test A, Integrated Test B, and Integrated Test D. Laboratory-scale filtration and caustic and oxidative leaching tests are also summarized. The objectives, success criteria, and research and technology (R\&T) conditions defined in the Test Plan are discussed in the tables in this summary. A summary of the PEP Testing program conclusions is provided in Section 14.

\section{Objectives}

Table S.1 summarizes the objectives and results of this testing along with a discussion of how the objectives were met.

(a) Josephson GB, OP Bredt, JK Young, and DE Kurath. 2009. Test Plan for Pretreatment Engineering Platform (PEP) Testing (Phase I). TP-RPP-WTP-506, Rev 0.4, Pacific Northwest National Laboratory, Richland, Washington.

(b) Barnes SM and R Voke. 2006. "Issue Response Plan for Implementation of External Flowsheet Review Team (EFRT) Recommendations - M12: Undemonstrated Leaching Process.” 24590-WTP-PL-ENG-06-0024 Rev 0, Bechtel National Inc, Richland, Washington.

(c) Josephson GB, OP Bredt, JK Young, and DE Kurath. 2009. Test Plan for Pretreatment Engineering Platform (PEP) Testing (Phase I). TP-RPP-WTP-506, Rev 0.2, Pacific Northwest National Laboratory, Richland, Washington. 
Table S.1. Summary of Test Objectives and Results

\begin{tabular}{|c|c|c|}
\hline Test Objective & $\begin{array}{l}\text { Objective } \\
\text { Met? }\end{array}$ & Discussion \\
\hline $\begin{array}{l}\text { Caustic-leach process: Compare } \\
\text { engineering- and } \\
\text { laboratory-scale results to } \\
\text { determine impact of scale-up. }\end{array}$ & $\mathrm{Y}$ & $\begin{array}{l}\text { The caustic-leach results for the PEP and the laboratory-scale results } \\
\text { are compared, and scale-up factors have been calculated for the } \\
\text { kinetic rate constant as discussed by Mahoney et al. (2009) in } \\
\text { Section } 4.3 \text { and Section } 9.5 \text { of this report. Uncertainties were } \\
\text { calculated using a Monte Carlo approach. The uncertainties in the } \\
\text { scale-up factors were found to be strongly sensitive to the } \\
\text { uncertainties in the concentrations used to calculate them. } \\
\text { For caustic leaching conducted at a temperature of } 98^{\circ} \mathrm{C} \text { in } \\
\text { Tank T01A (Integrated Test A), the median estimate of the scale-up } \\
\text { factor was } 0.88 \text { with a } 95 \% \text { confidence interval that ranged from } 0.47 \\
\text { to } 1.56 \text {. } \\
\text { For caustic leaching in Tank T02A conducted at a temperature of } \\
98^{\circ} \mathrm{C} \text { (Integrated Test B), the median estimate of the scale-up factor } \\
\text { was } 1.38 \text { with a } 95 \% \text { confidence interval that ranged from } 0.80 \text { to } \\
2.41 . \\
\text { For caustic leaching in Tank T02A conducted at a temperature of } \\
85^{\circ} \mathrm{C} \text { (Integrated Test D), the median estimate of the scale-up factor } \\
\text { was } 1.10 \text { with a } 95 \% \text { confidence interval that ranged from } 0.64 \text { to } \\
2.02 \text {. } \\
\text { The rate constants from the six PEP and laboratory-scale tests were } \\
\text { not statistically distinguishable from each other at a } 95 \% \text { confidence } \\
\text { level. It is possible that the scale-up factor is unity or greater for } \\
\text { caustic leaching in both Tank T01A and T02A. The probability of } \\
\text { this hypothesis is about } 21 \% \text { for Test A/Test A-1, } 43 \% \text { for Test } \\
\text { A/Test A-2, } 93 \% \text { for Test B/Test B- } 1,77 \% \text { for Test B/Test B-2, } 73 \% \\
\text { for Test D/Test D1, and } 53 \% \text { for Test D/Test D-2. }\end{array}$ \\
\hline $\begin{array}{l}\text { Oxidative leach process: } \\
\text { Compare engineering- and } \\
\text { laboratory-scale results to } \\
\text { determine impact of scale-up. }\end{array}$ & $\mathrm{Y}$ & $\begin{array}{l}\text { Chromium concentrations and leach factors obtained during the PEP } \\
\text { and laboratory-scale testing are compared in Rapko et al. (2009) for } \\
\text { Integrated Tests A and B and are also discussed in Section } 11 \text { of this } \\
\text { report along with the results of Integrated Test D. The cumulative } \\
\text { leach factors were found to be approximately } 0.9 \text { and the } \\
\text { recommended scale-up factor is } 1 .\end{array}$ \\
\hline $\begin{array}{l}\text { Cross-flow ultrafiltration: } \\
\text { Monitor cross-flow filter } \\
\text { performance at engineering- and } \\
\text { laboratory-scale to determine } \\
\text { scale-up. }\end{array}$ & $\bar{Y}$ & $\begin{array}{l}\text { Tests were conducted at the laboratory and engineering scales with a } \\
\text { Hanford tank waste simulant at low- and high-solids concentrations. } \\
\text { The test conditions, results, and scale-up factor analyses are reported } \\
\text { in Section } 5 \text { of Daniel et al. (2009b). For the low-solids } \\
\text { concentrations, the current scaling tests indicate that a scale-up factor } \\
\text { of } 1.0 \text { provides a conservative estimate of scaled filter flux (where } \\
\text { the scale-up factor was defined as the ratio of engineering-scale filter } \\
\text { flux to laboratory-scale filter flux). For the high-solids } \\
\text { concentrations, scale-up factors are ratios of parameters that } \\
\text { characterize the dewatering behavior of the simulant slurry and were } \\
\text { determined to be 1.0. }\end{array}$ \\
\hline
\end{tabular}


Table S.1. Summary of Test Objectives and Results

\begin{tabular}{|c|c|c|}
\hline Test Objective & $\begin{array}{c}\text { Objective } \\
\text { Met? }\end{array}$ & Discussion \\
\hline $\begin{array}{l}\text { Slurry wash process: Determine } \\
\text { the post-caustic-leach wash and } \\
\text { post-oxidative-leach wash } \\
\text { efficiencies. }\end{array}$ & $\mathrm{Y}$ & $\begin{array}{l}\text { The wash efficiency is explicitly defined in Section 10.6; for fully } \\
\text { soluble components, it is the ratio of the material removed to the } \\
\text { amount of material expected to be removed in an ideal washing } \\
\text { system. } \\
\text { The overall wash efficiency for the post-caustic-leach wash was } \\
\text { determined to be } 1.00 \pm 0.01 \text {. The overall wash efficiency for the } \\
\text { post-oxidative-leach wash was determined to be } 0.98 \pm 0.01 \text {. These } \\
\text { wash efficiencies were based on the weighted least squares fit of the } \\
\text { full data set for each applicable analyte and are an average of several } \\
\text { analytes traced during the washing steps in Integrated Tests A, B, } \\
\text { and D. Incremental wash efficiencies as a function of wash step for } \\
\text { Integrated Tests A and B were also provided in Sections } 5.1 \text { and } 5.2 \\
\text { of Baldwin et al. (2009) to provide an indication of the variability } \\
\text { during the washing process. }\end{array}$ \\
\hline $\begin{array}{l}\text { Process integration: Evaluate } \\
\text { the chemical addition, filter } \\
\text { operation cycle performance, } \\
\text { and pressure pot operations. } \\
\text { Also perform mass balances for } \\
\text { aluminum, chromium, } \\
\text { manganese, sodium, hydroxide, } \\
\text { oxalate, phosphate, sulfate, and } \\
\text { water and monitor permeates for } \\
\text { post-filtration precipitation. }\end{array}$ & $\mathrm{Y}$ & $\begin{array}{l}\text { The addition of } \mathrm{NaOH} \text { during caustic leaching was evaluated and is } \\
\text { discussed in Sections } 7.4 \text { and } 9.2 \text {. } \\
\text { The addition of inhibited water (IW) during the solids washing steps } \\
\text { is addressed in Section } 10 \text {. } \\
\text { The addition of sodium permanganate for oxidative leaching is } \\
\text { addressed in Section } 11 \text {. } \\
\text { An overall assessment of in-line chemical addition is presented in } \\
\text { Section } 13.2 \text {. } \\
\text { The filter and pulse-pot operations are addressed in Section } 8 \text {. } \\
\text { Mass balances for the specified components are presented in } \\
\text { Section } 12 \text {. }\end{array}$ \\
\hline $\begin{array}{l}\text { Monitor the performance of the } \\
\text { recirculation system pumps, } \\
\text { filters, and heat exchanger to } \\
\text { support Engineering fabrication } \\
\text { decisions for these components. }\end{array}$ & $\mathrm{Y}$ & $\begin{array}{l}\text { The data required to meet this objective were provided on compact } \\
\text { disks transmitted in the following reference: Letter from } \\
\text { GH Beeman to H Hazen, "Subcontract No. } \\
\text { 24590-QL-HC9-WA49-00001, Project No. } 53569 \text { (WA-024) } \\
\text { Engineering Ties Data Transmittal: The Electronic File Enclosed } \\
\text { With This letter Has Been Reviewed For Technical Accuracy Per the } \\
\text { QA Program," WTP/RPP-MOA-PNNL-00392, dated 4/10/09. }\end{array}$ \\
\hline
\end{tabular}




\section{Test Exceptions}

A summary description of the Test Exceptions applied to these tests is shown in Table S.2.

Table S.2. Test Exceptions

\begin{tabular}{|c|c|}
\hline Test Exceptions & Description of Test Exceptions \\
\hline $\begin{array}{l}\text { 1) } 24590 \text {-PTF-TEF-RT-08- } \\
\text { 00002, incorporated into ICN-1 } \\
\text { to Test Plan TP-RPP-WTP-506. }\end{array}$ & $\begin{array}{l}\text { This Test Exception: } \\
\text { 1. Added a stage during the filter conditioning section of the } \\
\text { Shakedown/Functional Test where the simulant slurry is concentrated from } \\
\text { approximately } 5 \text {-wt } \% \text { solids to } 20 \text {-wt } \% \text { solids in one operation. This is in } \\
\text { addition to the previously specified low-solids filter and high-solids filter } \\
\text { testing. } \\
\text { 2. Documented the Joint Test Group (JTG) decision regarding the number of } \\
\text { replicate samples to be collected at various processing times. } \\
\text { 3. Revised the terminology specifying the Coriolis densitometer (CD) sample } \\
\text { locations, which were changed to be consistent with PEP operating } \\
\text { procedures. Renamed the "center" array to "inner." } \\
\text { 4. The sampling specified in the low-solids filtration test over-specifies the } \\
\text { sample collection timing required. The technical requirement is to get } 30 \\
\text { unique samples. The sampling schedule specified is not required to achieve } \\
\text { this test objective. }\end{array}$ \\
\hline $\begin{array}{l}\text { 2) } 24590-P T F-T E F-R T-09- \\
00001 \text { incorporated into ICN-2 } \\
\text { and ICN-3 to Test Plan } \\
\text { TP-RPP-WTP-506. }\end{array}$ & $\begin{array}{l}\text { This Test Exception: } \\
\text { 1. In several steps, the sampling location was changed from the filer-loop } \\
\text { in-line location to a middle-low CD sample loop location in the Tank T02A } \\
\text { vessel. This change impacted sampling in the Shakedown/Functional and all } \\
\text { Integrated tests (ref CCN 187749). } \\
\text { 2. Added a step to the Shakedown/Functional Test (Step A.1.31) to add sodium } \\
\text { permanganate to UFP-VSL-T02A to assess a possible foaming issue (ref } \\
\text { CCN 187749). } \\
\text { 3. Changed the location of the second sample for laboratory-scale Cells Unit } \\
\text { Filter (CUF) testing from the in-line filter-loop to the middle-low CD port in } \\
\text { the UFP-VSL-T02A (Step A.1.10; Functional Test) (ref CCN 187749). } \\
\text { 4. Collected samples for the laboratory-scale laboratory leaching test before } \\
\text { and after caustic addition in UFP-VSL-T01A (A.1.20; Functional Test) and } \\
\text { UFP-VSL-T02A (Step A.1.15; Functional Test), and in the Integrated Test } \\
\text { steps (B.1.2; Integrated Test A, B.2.6; Integrated Tests B/D) (ref CCN } \\
\text { 192734). } \\
\text { 5. Deleted reconfiguration of the filter-loop to bypass UFP-VSL-T02A and } \\
\text { circulate flush water with UFP-PMP-T02A and/or UFP-PMP-43A to allow a } \\
\text { representative in-line sample to be collected. This step (Step A.1.17; } \\
\text { Functional Test) could not be done under the operating restrictions in place } \\
\text { on the operation of the filter-loop (ref CCN 192734). } \\
\text { 6. Eliminated Step A.1.25 (filter-loop bypass test with tracer) from the } \\
\text { Shakedown/Functional Test. This test was conducted after the completion of } \\
\text { Integrated Test B (ref CCN 187753). } \\
\text { 7. Modified Step A.1.29 (Functional Test) to eliminate the removal of solids } \\
\text { from UFP-VSL-T02A before the high-solids filter test. This step was not } \\
\text { needed as the amount of solids is less than anticipated (ref CCN 187752). }\end{array}$ \\
\hline
\end{tabular}


Table S.2. Test Exceptions

\begin{tabular}{|c|c|}
\hline Test Exceptions & Description of Test Exceptions \\
\hline 2) Cont'd & 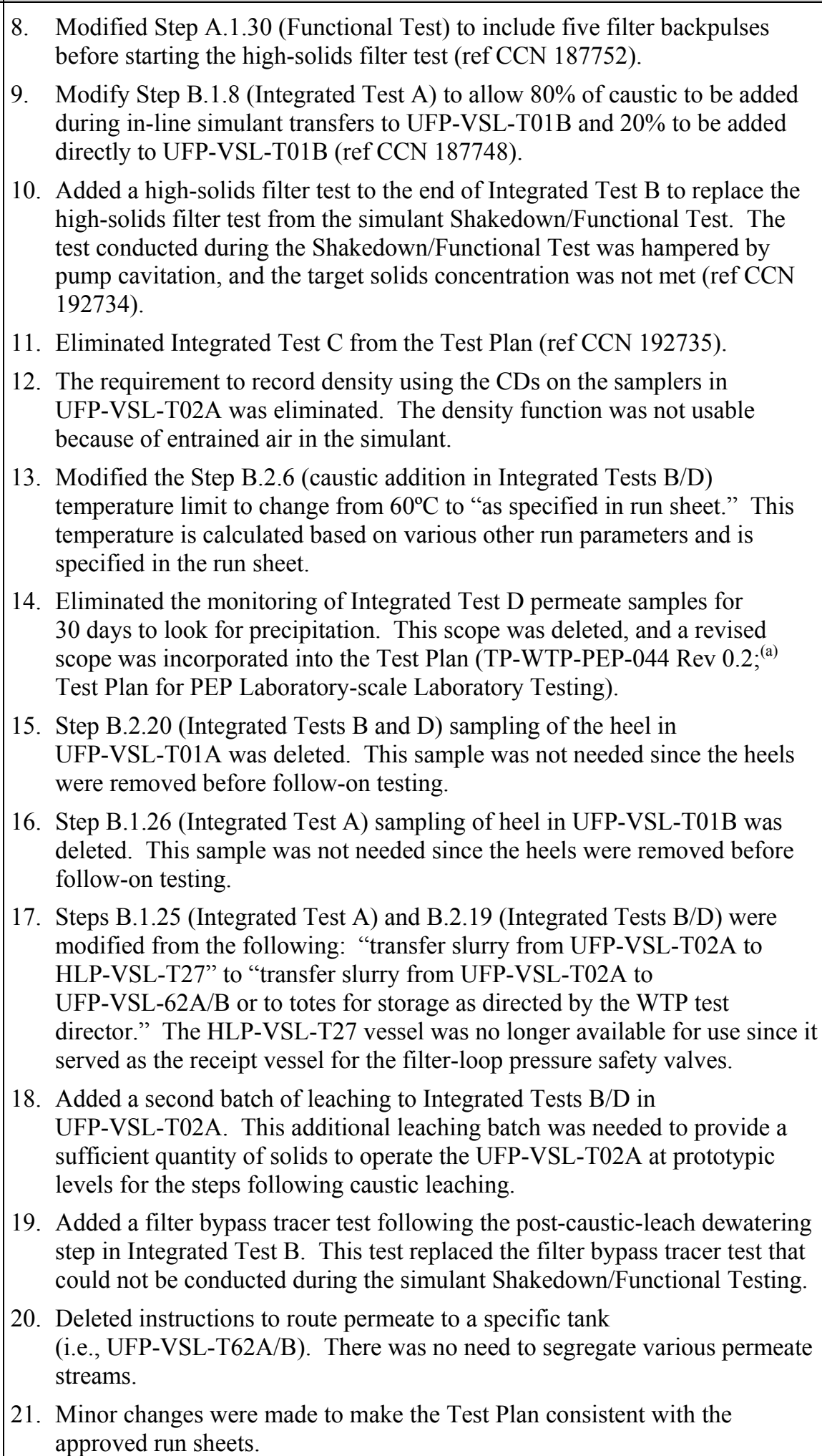 \\
\hline
\end{tabular}


Table S.2. Test Exceptions

\begin{tabular}{|c|c|}
\hline Test Exceptions & Description of Test Exceptions \\
\hline $\begin{array}{l}\text { 3) } 24590 \text {-WTP-TEF-RT-09- } \\
00003 \text { incorporated into ICN-1 } \\
\text { to Test Plan TP-WTP-PEP-044. }\end{array}$ & $\begin{array}{l}\text { This Test Exception specified activities to be performed with permeate samples } \\
\text { obtained from Integrated Test D. The Integrated Test D permeate samples were } \\
\text { originally stored in a temperature-controlled environment and then moved to a } \\
\text { location with a reduced temperature where precipitation was likely to occur. The } \\
\text { Test Exception requested that the approximate size distribution of the solids be } \\
\text { measured in several (three or four) selected PEP samples from Integrated Test D } \\
\text { using polarized light microscopy (PLM). Size-calibrated photographs should be } \\
\text { provided along with the analysis. If possible, record the mineral identification of } \\
\text { the solids phase(s) along with the particle-size distribution (PSD). Samples will } \\
\text { be selected by WTP personnel in consultation with the subcontractor and will be } \\
\text { based in part on observing which samples contain the most solids or appear to } \\
\text { contain different types of solids. Repeat the size-distribution analysis } \\
\text { approximately 1-week after the initial measurements to determine whether there } \\
\text { was a significant change in crystal size, habit, or composition. } \\
\text { Perform each size-distribution analysis by measuring the diameter (or length and } \\
\text { width for elongated crystals) of approximately } 100 \text { individual particles in each } \\
\text { sample. The size may be measured either on the microscope slide, using a } \\
\text { calibrated ocular scale, or on the size-calibrated photographs. The program } \\
\text { recognizes the limitations of the statistical significance of a size-distribution } \\
\text { measurement based on such a small population. This Test Exception did not } \\
\text { affect any of the existing Test Plan objectives. }\end{array}$ \\
\hline $\begin{array}{l}\text { 4) } 24590-P T F-T E F-R T-09- \\
\text { 00002 Rev 0, incorporated into } \\
\text { ICN4 to Test Plan } \\
\text { TP-RPP-WTP-506. }\end{array}$ & $\begin{array}{l}\text { This Test Exception: } \\
\text { 1. Requests a report summarizing the lessons learned during scale-up, } \\
\text { manufacture, and transport of the PEP simulant. } \\
\text { 2. Specifies the sampling and analysis scope to be performed to complete the } \\
\text { prototypic nitric acid PEP filter cleaning process. } \\
\text { 3. Deletes the Engineering Ties report scope. } \\
\text { 4. Specifies additional experimental and analytical work required to estimate } \\
\text { the amount of excess caustic in caustic-leachate samples and } \\
\text { post-caustic-leach wash solutions containing } \approx 3.5-\mathrm{M} \mathrm{Na} \text {. }\end{array}$ \\
\hline
\end{tabular}

(a) Russell RL. 2008. "Test Plan for the PEP Parallel Laboratory Testing." TP-WTP-PEP-044, Rev 0.2, Pacific Northwest National Laboratory, Richland, Washington. 
Table S.2. Test Exceptions

\begin{tabular}{|c|c|}
\hline Test Exceptions & Description of Test Exceptions \\
\hline $\begin{array}{l}\text { 5) } 24590-W T P-T E F-R T-09- \\
00001 \text { Rev } 1 \text { incorporated into } \\
\text { ICN-2 to Test Plan } \\
\text { TP-WTP-PEP-044. }\end{array}$ & $\begin{array}{l}\text { This Test Exception specifies additional work to be conducted with caustic-leach } \\
\text { solutions and post-caustic-leach washing permeate samples obtained from PEP } \\
\text { Integrated Tests A, B, and D. It contains the following tasks: } \\
\text { 1. Determination of precipitate mineralogy, precipitate phase compositions, and } \\
\text { solution saturation composition. } \\
\text { 2. Determination of rate of approach to saturation concentrations. } \\
\text { 3. Identification and characterization of precipitates formed in } \\
\text { post-caustic-leach filtrate. } \\
\text { 4. Determination of the dilution required to redissolve the precipitate. } \\
\text { 5. Determination of supersaturation in post-caustic-leach filtrates from } \\
\text { Integrated Test B in the PEP. } \\
\text { 6. Determine the effects of blending during the post-caustic-leach dewatering } \\
\text { and wash cycle. }\end{array}$ \\
\hline
\end{tabular}

As documented in the PEP Test Plan, the deviations from the Test Specification are provided in Table S.3.

Table S.3. Deviations from Test Specification

\begin{tabular}{|c|c|}
\hline Test Specification Reference & Exception Taken \\
\hline $\begin{array}{l}\text { Section 6.4.4 "Analytical measurements will be } \\
\text { made in conformance to the Guidelines for } \\
\text { Performing Chemical Physical, and Rheological } \\
\text { Properties Measurements }{ }^{(\text {a) }} \text { as applicable." }\end{array}$ & $\begin{array}{l}\text { Three method exceptions are required under this Test Plan: } \\
\text { 1. Caustic-leach and oxidative-leach samples taken during this } \\
\text { testing must be separated more quickly than the standard } \\
\text { method using syringes. This testing will use a modified } \\
\text { method with a shorter centrifuge time and will apply higher } \\
\text { g forces (e.g., } 4000 \text {-g vs. 1000-g). } \\
\text { Impact on results: If the standard methods were used, the } \\
\text { longer time could very well lead to greater precipitation and } \\
\text { inaccurate results. Laboratory testing will be conducted } \\
\text { with simulants to confirm that this method of sample } \\
\text { handling is adequate. } \\
\text { 2. The densities of samples smaller than } 10 \text {-mL can only be } \\
\text { established within } 2 \text { significant figures of accuracy. Density } \\
\text { measurements for this Test Plan require greater accuracy. } \\
\text { Therefore, a more accurate method employing a pycnometer } \\
\text { will be used. } \\
\text { Impact on results: The change to a pycnometer will } \\
\text { generate more precise results than the standard method. The } \\
\text { main impact is expected to be on analysis time. The } \\
\text { pycnometer method will be slower. } \\
\text { 3. The process for determining the wt } \% \text { UDS content of the }\end{array}$ \\
\hline
\end{tabular}

(a) Smith GL and K Prindiville. 2002. Guidelines for Performing Chemical, Physical, and Rheological Properties Measurements. 24590-WTP-GPG-RTD-001, Rev 0, Bechtel National, Inc., Richland, Washington. 


\begin{tabular}{|l|l||}
\hline & $\begin{array}{l}\text { slurries will in some cases be determined with the use of a } \\
\text { moisture analyzer. In addition, the method of drying } \\
\text { samples will be modified to allow the use of glass fiber }\end{array}$ \\
& $\begin{array}{l}\text { filters to aid in drying the samples. } \\
\text { Impact on results: Both modifications are intended to } \\
\text { decrease the time required to obtain results. }\end{array}$ \\
\hline
\end{tabular}

\section{Results and Performance Against Success Criteria}

The PEP system tests were designed to generate the data necessary to:

- Provide engineering-scale system performance data. This information is used to support the WTP projections of the waste processing campaign produced by computer process models.

- Confirm the operability and functionality of UFP system components.

The success criteria for achieving these objectives are discussed in Table S.4. 
Table S.4. Results and Performance Against Success Criteria

\begin{tabular}{|c|c|}
\hline Success Criteria & How Testing Did or Did Not Meet Success Criteria \\
\hline \multicolumn{2}{|l|}{ UFP System Process Performance } \\
\hline $\begin{array}{l}\text { Measure the aluminum leaching } \\
\text { performance of the PEP and } \\
\text { laboratory systems as a function of } \\
\text { time under WTP UFP-1 and UFP-2 } \\
\text { projected leaching conditions at } \\
\text { bounding high and low process } \\
\text { temperatures (nominally } 100^{\circ} \mathrm{C} \text { and } \\
80^{\circ} \mathrm{C} \text { ). }\end{array}$ & $\begin{array}{l}\text { As discussed in Section 9, the aluminum leaching performance was measured } \\
\text { at } 98^{\circ} \mathrm{C} \text { for } 16 \text { hours in Integrated Tests A and B and at } 85^{\circ} \mathrm{C} \text { for } 24 \text { hours in } \\
\text { Integrated Test D. }\end{array}$ \\
\hline $\begin{array}{l}\text { Compare aluminum leach } \\
\text { performance in UFP-1 where all of } \\
\text { the } \mathrm{NaOH} \text { is added in-line to the } \\
\text { case where a fraction of the total } \\
\mathrm{NaOH} \text { is added directly to the tank. }\end{array}$ & $\begin{array}{l}\text { This comparison is presented in Section } 9.5 \text { and is based on the results of six } \\
\text { caustic leaching batches conducted during Integrated Test A. For Batches } 1 \text {, } \\
3 \text {, and } 5,100 \% \text { of the caustic was added in-line during the transfer of } \\
\text { simulant into Tanks T01A/B. For Batches } 2,4 \text {, and } 6,80 \% \text { of the caustic } \\
\text { was added in-line during the transfer of simulant into the vessels, and the } \\
\text { remaining } 20 \% \text { was added to the top of the vessel after the transfer was } \\
\text { complete. Based on a comparison of the rate constants between Batches } 1 \\
\text { and } 3 \text { and } 2,4 \text {, and } 6 \text {, the two methods of caustic addition produce results } \\
\text { that are statistically the same. Batch } 5 \text { was not included in the analysis } \\
\text { because of a high-temperature spike at the beginning of the } \\
\text { constant-temperature leach. }\end{array}$ \\
\hline $\begin{array}{l}\text { Measure chromium leaching } \\
\text { performance in the PEP and } \\
\text { laboratory systems as a function of } \\
\text { time at the WTP-projected } \\
\text { conditions in UFP-2 for both the } \\
\text { UFP-1 and UFP-2 aluminum } \\
\text { leaching flowsheets. }\end{array}$ & $\begin{array}{l}\text { Chromium leaching performance in the PEP and laboratory systems as a } \\
\text { function of time at the WTP projected conditions is provided in Rapko et al. } \\
\text { (2009) for Integrated Test A (UFP-1 caustic leaching) and B (UFP-2 caustic } \\
\text { leaching). Results for these tests as well as the results for Integrated Test D } \\
\text { are summarized and discussed in Section } 11 \text { of this report. }\end{array}$ \\
\hline $\begin{array}{l}\text { Evaluate the process control } \\
\text { strategy for specification of } \\
\text { required reagent additions, } \\
\text { including } \mathrm{NaOH}, \mathrm{NaMnO}_{4} \text {, and } \\
\text { wash solutions provided in the PEP } \\
\text { Phase } 1 \text { Testing Process } \\
\text { Description. }\end{array}$ & $\begin{array}{l}\text { The process control strategy for the specification of } \mathrm{NaOH} \text { is discussed in } \\
\text { Section } 9 \text {. Based on the amount of gibbsite that was dissolved in post-test } \\
\text { permeate solutions, the process control strategy for the specification of the } \\
\mathrm{NaOH} \text { was a qualified success. } \\
\text { The process control strategy for the specification of the wash solutions is } \\
\text { discussed in Section } 10 \text {. The strategy for specifying the wash solutions was } \\
\text { successful. } \\
\text { The process control strategy for the specification of the } \mathrm{NaMnO}_{4} \text { is discussed } \\
\text { in Section } 11 \text {. The strategy of performing laboratory-scale tests to predict the } \\
\text { permanganate requirement was not successful. This was due to large } \\
\text { differences between the preliminary laboratory-scale test and the PEP results; } \\
\text { much more Cr was leached in the PEP than was leached in the } \\
\text { laboratory-scale test. }\end{array}$ \\
\hline
\end{tabular}


Table S.4. Results and Performance Against Success Criteria

\begin{tabular}{|c|c|c|c|}
\hline Success Criteria & \multicolumn{3}{|c|}{ How Testing Did or Did Not Meet Success Criteria } \\
\hline $\begin{array}{l}\text { Measure the filter system } \\
\text { performance at the nominal flow } \\
\text { velocity and TMPs for the solids } \\
\text { concentration and washing stages } \\
\text { for the UFP-1 and UFP-2 aluminum } \\
\text { leaching flowsheets. }\end{array}$ & \multicolumn{3}{|c|}{$\begin{array}{l}\text { The filter system performance at the nominal flow velocity and TMPs for the } \\
\text { solids concentration and the washing steps is discussed in Sections } 8 \text { and } 10 \text {, } \\
\text { respectively. Maintaining the nominal flow velocity was difficult when the } \\
\text { slurry level in Tank T02A dropped below the slurry return nozzle, and } \\
\text { entrained air entered into the pump intake. The entrained air reduced the } \\
\text { pump performance, and achieving the target flow rate in the filter-loop was } \\
\text { not possible. This generally appeared to have some effect on the filtration } \\
\text { performance. A low permeate rate during the Integrated Test D } \\
\text { post-oxidative-leach wash was attributed to filter fouling and low axial } \\
\text { velocity. Detailed accounts of ultrafiltration system behavior are given in the } \\
\text { run reports (Josephson et al. 2009, Guzman-Leong et al. 2009, Geeting et al. } \\
2009 \text {, Sevigny et al. 2009). }\end{array}$} \\
\hline $\begin{array}{l}\text { Evaluate the control strategy for } \\
\text { make-up additions from } \\
\text { UFP-VSL-00001A/B to } \\
\text { UFP-VSL-00002A/B during initial } \\
\text { dewatering process. }\end{array}$ & \multicolumn{3}{|c|}{$\begin{array}{l}\text { The control strategy for the make-up additions during the initial dewatering } \\
\text { process is discussed in Section } 8 \text { of this report. The control strategy involved } \\
\text { monitoring the level in Tank T02A and adding additional material when the } \\
\text { vessel level dropped to a pre-determined set point. This approach was found } \\
\text { to work well as long as good level measurements were available. }\end{array}$} \\
\hline \multirow{5}{*}{$\begin{array}{l}\text { Measure the wash-water volumes } \\
\text { required to remove or reduce the } \\
\text { free hydroxide following the } \\
\text { aluminum leaching stage and } \\
\text { dissolved chromium after the } \\
\text { oxidative leaching process to the } \\
\text { specified concentrations. }\end{array}$} & Test & $\begin{array}{c}\text { Number of IW } \\
\text { Batches Required } \\
\text { to Reach 0.25-M } \\
\text { Hydroxide } \\
\end{array}$ & $\begin{array}{l}\text { IW Volume Required } \\
\text { to Reach 0.25-M } \\
\text { Hydroxide } \\
\end{array}$ \\
\hline & $\begin{array}{c}\text { Integrated Test A: } \\
\text { Caustic leaching in Tank } \\
\text { T01A/B }\end{array}$ & 64 & $\begin{array}{c}718 \text { gal } \\
\text { (slurry vol. } 269 \text { gal) }\end{array}$ \\
\hline & $\begin{array}{c}\text { Integrated Test B: } \\
\text { Caustic leaching in Tank } \\
\text { T02A } \\
\end{array}$ & 39 & $\begin{array}{c}436 \text { gal } \\
\text { (slurry vol. } 154 \text { gal) }\end{array}$ \\
\hline & $\begin{array}{c}\text { Integrated Test D: } \\
\text { Caustic leaching in Tank } \\
\text { T02A }\end{array}$ & 43 & $\begin{array}{c}493 \text { gal } \\
\text { (slurry vol. } 157 \text { gal) }\end{array}$ \\
\hline & \multicolumn{3}{|c|}{$\begin{array}{l}\text { The volume of wash-water required to reduce the dissolved chromium } \\
\text { concentration was determined to be accurately predicted by the WTP } \\
\text { washing model. }\end{array}$} \\
\hline $\begin{array}{l}\text { Perform mass balances for selected } \\
\text { constituents, including aluminum, } \\
\text { chromium, manganese, sodium, } \\
\text { hydroxide, oxalate, phosphate, } \\
\text { sulfate, and water to evaluate } \\
\text { leaching and washing process } \\
\text { performance. }\end{array}$ & \multicolumn{3}{|c|}{$\begin{array}{l}\text { Chromium mass balances for Integrated Tests A, B, and D are provided in } \\
\text { Section 11. A discussion of the mass balances for all of the selected } \\
\text { constituents is presented in Section } 12 \text {. }\end{array}$} \\
\hline $\begin{array}{l}\text { Measure solids distribution under } \\
\text { scaled mixing conditions before and } \\
\text { after caustic leaching evolutions. }\end{array}$ & \multicolumn{3}{|c|}{$\begin{array}{l}\text { Solids distributions under scaled mixing conditions before and after caustic } \\
\text { leaching evolutions are discussed in Section 7.5. }\end{array}$} \\
\hline
\end{tabular}


Table S.4. Results and Performance Against Success Criteria

\begin{tabular}{|c|c|}
\hline Success Criteria & How Testing Did or Did Not Meet Success Criteria \\
\hline $\begin{array}{l}\text { Measure the rheology of the slurry } \\
\text { simulant and shear strength of the } \\
\text { settled solids before and after each } \\
\text { leaching and washing unit operation } \\
\text { and following final concentration. }\end{array}$ & $\begin{array}{l}\text { The rheology of the slurry simulant and shear strength of the settled solids } \\
\text { was measured before and after each leaching and washing unit operation and } \\
\text { following the final concentration. These results are presented in the run } \\
\text { reports for each Integrated Test (Josephson et al. 2009, Guzman-Leong et al. } \\
\text { 2009, Geeting et al. 2009, and Sevigny et al. 2009). }\end{array}$ \\
\hline \multirow{2}{*}{$\begin{array}{l}\text { Estimate the quantity of excess } \\
\text { hydroxide added in the process that } \\
\text { may not be needed to keep } \\
\text { aluminate in solution following } \\
\text { filtration. }\end{array}$} & $\begin{array}{l}\text { Direct measurement of excess caustic could not be made for reasons } \\
\text { discussed in Section } 9 \text {. This success criterion was addressed indirectly by } \\
\text { measuring the amount of additional aluminum that could be dissolved in PEP } \\
\text { leachate and washate samples at } 25^{\circ} \mathrm{C} \text {. }\end{array}$ \\
\hline & $\begin{array}{l}\text { For each PEP Integrated Test, one sample of post-caustic-leach permeate and } \\
\text { one of post-caustic-leach wash permeate were used in excess caustic } \\
\text { testing-a total of six cases. In five of the six cases, the final aluminum } \\
\text { concentration was greater than the initial concentration by } 10 \% \text { or more. The } \\
\text { exception was the wash permeate from Integrated Test B: no statistically } \\
\text { significant amount of gibbsite dissolved, indicating that there was no } \\
\text { significant excess caustic present at this point in the process. }\end{array}$ \\
\hline $\begin{array}{l}\text { Collect and retain permeate samples } \\
\text { for extended precipitation studies } \\
\text { (including permeate/simulated } \\
\text { supernatant blended cases) from } \\
\text { each concentration cycle. }\end{array}$ & $\begin{array}{l}\text { Samples were collected and retained for extended precipitation studies. The } \\
\text { results of the precipitation studies are discussed in Russell et al. (2009d) and } \\
\text { Russell et al. (2009e). Precipitates were found in many of the wash solutions } \\
\text { and were identified primarily as sodium oxalate and sodium phosphate. No } \\
\text { aluminum-bearing solids were found. }\end{array}$ \\
\hline \multicolumn{2}{|c|}{ UFP System Operability and Functionality } \\
\hline $\begin{array}{l}\text { Verify that the dual, in-series pump } \\
\text { configuration is controllable and } \\
\text { maintains the required slurry } \\
\text { velocity and pressures for ultrafilter } \\
\text { operation. }\end{array}$ & $\begin{array}{l}\text { The data required to meet this success criterion were provided on compact } \\
\text { disks transmitted in the following reference: Letter from GH Beeman to } \\
\text { H Hazen, "Subcontract No. 24590-QL-HC9-WA49-00001, Project No. } \\
53569 \text { (WA-024) Engineering Ties Data Transmittal: The Electronic File } \\
\text { Enclosed With This letter Has Been Reviewed For Technical Accuracy Per } \\
\text { the Quality Assurance (QA) Program," WTP/RPP-MOA-PNNL-00392, } \\
\text { dated 4/10/09. }\end{array}$ \\
\hline $\begin{array}{l}\text { Measure the operating } \\
\text { characteristics for the cooling heat } \\
\text { exchanger for the UFP-VSL- } 00002 \\
\text { filter recirculation loop } \\
\text { (temperature changes as a function } \\
\text { of flow to determine how to achieve } \\
\text { the desired performance in the PTF } \\
\text { analog). }\end{array}$ & $\begin{array}{l}\text { The data required to meet this success criterion were provided on compact } \\
\text { disks transmitted in the following reference: Letter from GH Beeman to } \\
\text { H Hazen, "Subcontract No. 24590-QL-HC9-WA49-00001, Project No. } \\
53569 \text { (WA-024) Engineering Ties Data Transmittal: The Electronic File } \\
\text { Enclosed With This letter Has Been Reviewed For Technical Accuracy Per } \\
\text { the QA Program," WTP/RPP-MOA-PNNL-00392, dated 4/10/09. }\end{array}$ \\
\hline
\end{tabular}


Table S.4. Results and Performance Against Success Criteria

\begin{tabular}{|c|c|}
\hline Success Criteria & How Testing Did or Did Not Meet Success Criteria \\
\hline $\begin{array}{l}\text { Confirm whether the WTP process } \\
\text { control strategies for ultrafilter } \\
\text { system filling, operating, } \\
\text { backpulsing, draining, flushing, and } \\
\text { cleaning are adequate for stable } \\
\text { operation. Provide to WTP data to } \\
\text { determine whether backpulsing is a } \\
\text { required and effective means of } \\
\text { restoring the filter permeate rates to } \\
\text { make certain that production } \\
\text { throughput is maintained and to } \\
\text { determine whether operation of the } \\
\text { backpulse system induces any } \\
\text { process or equipment operations } \\
\text { issues. }\end{array}$ & $\begin{array}{l}\text { As indicated in the run reports (Josephson et al. 2009, Guzman-Leong et al. } \\
\text { 2009, Geeting et al. 2009, Sevigny et al. 2009), the system used to control the } \\
\text { filtration and backpulse operations worked well. The TMP was generally } \\
\text { controlled to the target of } 40 \text { psid even with fluctuations in the filter-loop } \\
\text { flow caused by air entrainment in the filter-loop pumps. At low levels in } \\
\text { Tank T02A, air entrainment into the filter-loop pumps reduced the pump } \\
\text { efficiency to the point that the target axial flow velocity of } 15 \text {-ft/s was not } \\
\text { maintained. The control strategy for batch make-up additions was } \\
\text { implemented with no apparent issues as long as good level measurements } \\
\text { were available. } \\
\text { Filter cleaning is discussed in Section 13.5. The filter cleaning protocol was } \\
\text { successfully conducted after Integrated testing was completed and followed } \\
\text { the procedure specified by WTP. } \\
\text { Data on backpulsing are provided and discussed in Section } 8 \text {. Operating the } \\
\text { backpulse system did not induce any process or equipment operations issues. } \\
\text { An initial evaluation of the backpulse data indicates that backpulsing was } \\
\text { beneficial and increased the permeate production. }\end{array}$ \\
\hline $\begin{array}{l}\text { Use only the process information } \\
\text { and data available to the WTP PTF } \\
\text { operating staff during WTP } \\
\text { operations (e.g., caustic and } \\
\text { permanganate addition volumes, } \\
\text { permeate mass balances for solids } \\
\text { concentration) to operate the PEP. }\end{array}$ & $\begin{array}{l}\text { This success criterion was met by developing a run sheet of all the operating } \\
\text { parameters (e.g., transfer volumes, reagent addition volumes, control levels, } \\
\text { etc.) based on prototypic characterization data before the start of each test. } \\
\text { Changes to the run sheet made during the test itself were based only on data } \\
\text { that would be available to the plant, and were not, for example, based on } \\
\text { information from nonprototypic samples. }\end{array}$ \\
\hline $\begin{array}{l}\text { Confirm whether the elevated } \\
\text { temperature pulse jet mixer (PJM) } \\
\text { operating strategy is adequate for } \\
\text { stable PEP and WTP operation. }\end{array}$ & $\begin{array}{l}\text { The strategy for operating PJMs at elevated temperatures was successfully } \\
\text { demonstrated by PEP testing and is discussed in Section } 13.1 \text {. The Bernoulli } \\
\text { equation was used to estimate the refill and cycle times for the PTF PJMs in } \\
\text { UFP-VSL-00001 and UFP-VSL-00002 and the estimates show that gravity } \\
\text { refill should also be successful in the full-scale plant. Use of the standard } \\
\text { vacuum refill is not feasible because of the increased vapor pressure of the } \\
\text { liquid, which leads to excessive evaporation. }\end{array}$ \\
\hline $\begin{array}{l}\text { Measure the heat-up rate and } \\
\text { controllability of the PEP } \\
\text { UFP-VSL-00001 and } \\
\text { UFP-VSL-00002 vessels and the } \\
\text { cooling performance for UFP } \\
\text { vessels. }\end{array}$ & $\begin{array}{l}\text { The heat-up rate and controllability of the PEP UFP-VSL-00001 and } \\
\text { UFP-VSL- } 00002 \text { vessels and the cooling performance for UFP vessels is } \\
\text { presented and discussed in Section } 9 \text {. In general, the caustic leaching } \\
\text { temperatures were controlled within the specified } \pm 2^{\circ} \mathrm{C} \text { tolerance. Any } \\
\text { deviations were due to equipment or operational problems specific to PEP. } \\
\text { Heat-up and cool-down control of the PEP vessels was adequate to conduct } \\
\text { the PEP tests. After adding caustic, heating to the caustic-leach temperature } \\
\text { was conducted using the PEP control system to match a projected } \\
\text { temperature profile. Matching the cooling curves was performed manually. } \\
\text { It should be noted that the heat-transfer characteristics do not readily scale to } \\
\text { the full-size equipment because similarity could not be maintained. While } \\
\text { the PEP heat losses and thermal variability are not strictly prototypic, they } \\
\text { are reasonably representative and probably a good indication of the WTP } \\
\text { performance. }\end{array}$ \\
\hline
\end{tabular}


Table S.4. Results and Performance Against Success Criteria

\begin{tabular}{|c|c|}
\hline Success Criteria & How Testing Did or Did Not Meet Success Criteria \\
\hline $\begin{array}{l}\text { Measure the performance of the } \\
\text { in-line addition of process } \\
\text { chemicals into the simulated wastes } \\
\text { and determine the extent of } \\
\text { blending in the process vessels. }\end{array}$ & $\begin{array}{l}\text { The performance of the in-line addition of process chemicals into the } \\
\text { simulated wastes and the extent of blending is summarized in Section 13.2. } \\
\text { In-line addition of the process chemicals appears to be a successful method } \\
\text { of addition. }\end{array}$ \\
\hline $\begin{array}{l}\text { Monitor ultrafilter performance (to } \\
\text { include visual inspection of the } \\
\text { filter tubes, tube sheets, and heads } \\
\text { from an ultrafilter for any evidence } \\
\text { of flow mal-distribution and/or } \\
\text { solids buildup at least once during } \\
\text { Phase 1). }\end{array}$ & $\begin{array}{l}\text { The ultrafilters were inspected after the completion of testing, and no } \\
\text { evidence of flow mal-distribution and/or solids buildup was observed. The } \\
\text { final filter inspection is discussed in Section 13.5. }\end{array}$ \\
\hline $\begin{array}{l}\text { Measure, record, and control } \\
\text { ultrafiltration temperature, TMP, } \\
\text { and slurry flow during filter-loop } \\
\text { operations. }\end{array}$ & $\begin{array}{l}\text { Results to meet this success criterion are provided in Daniel et al. (2009b) for } \\
\text { the low- and high-solids filter tests. } \\
\text { Results to meet this success criterion for other process steps are discussed in } \\
\text { the run reports for each of the Integrated tests (Josephson et al. 2009, } \\
\text { Guzman-Leong et al. 2009, Geeting et al. 2009, and Sevigny et al. 2009). } \\
\text { Some results are also presented in Section } 8 \text {. }\end{array}$ \\
\hline $\begin{array}{l}\text { Record any solids accumulations } \\
\text { observed during any operating stage } \\
\text { or maintenance evolution. }\end{array}$ & $\begin{array}{l}\text { A discussion of solids accumulation is presented in Section 13.4. During } \\
\text { maintenance and final cleanout of the PEP system, solids were mainly found } \\
\text { to accumulate in piping that was below and out of the main flow and that was } \\
\text { not flushed during testing. It should be noted that the PEP design and/or } \\
\text { operation of the low points and clean outs was not prototypic of the PTF. } \\
\text { Solids buildup did not impact operation of the PEP. }\end{array}$ \\
\hline $\begin{array}{l}\text { Monitor the permeate production } \\
\text { rate of each ultrafilter assembly in } \\
\text { operation. }\end{array}$ & $\begin{array}{l}\text { The data to meet this success criterion for the low- and high-solids filter tests } \\
\text { are reported in Daniel et al. (2009b), Section } 5 \text {. The data for the remaining } \\
\text { filtration steps are presented in Section } 8 \text {. } \\
\text { Details of the permeate production rates for each ultrafilter assembly may be } \\
\text { found in the run reports for each of the Integrated tests (Josephson et al. } \\
2009 \text {, Guzman-Leong et al. } 2009 \text {, Geeting et al. 2009, and Sevigny et al. } \\
\text { 2009). }\end{array}$ \\
\hline $\begin{array}{l}\text { Record the operating time of each } \\
\text { ultrafilter assembly. }\end{array}$ & $\begin{array}{l}\text { The operating time of each ultrafilter assembly was recorded and reported in } \\
\text { the run reports for each of the Integrated tests (Josephson et al. 2009, } \\
\text { Guzman-Leong et al. 2009, Geeting et al. 2009, and Sevigny et al. 2009). } \\
\text { The operating times are summarized in Section } 8 \text {. }\end{array}$ \\
\hline $\begin{array}{l}\text { Record each ultrafilter assembly } \\
\text { cleaning event (backpulse, flush, } \\
\text { chemical cleaning, etc.). }\end{array}$ & $\begin{array}{l}\text { The ultrafilter cleaning events are summarized in Section 13.5. Details of the } \\
\text { filter cleaning events may be found in the PEP run reports (Josephson et al. } \\
\text { 2009, Guzman-Leong et al. 2009, Geeting et al. 2009, and Sevigny et al. } \\
\text { 2009). }\end{array}$ \\
\hline $\begin{array}{l}\text { Evaluate the pulse-pot operation } \\
\text { and backpulse operation strategies } \\
\text { contained in PEP Phase } 1 \text { Testing } \\
\text { Process Description. }\end{array}$ & $\begin{array}{l}\text { The pulse-pot operation and backpulse operation strategies are discussed in } \\
\text { Section } 8 \text {. }\end{array}$ \\
\hline
\end{tabular}


Table S.4. Results and Performance Against Success Criteria

\begin{tabular}{|l|l||}
\hline \multicolumn{1}{|c|}{ Success Criteria } & \multicolumn{1}{|c|}{ How Testing Did or Did Not Meet Success Criteria } \\
\hline $\begin{array}{l}\text { Evaluate permeate and permeate } \\
\text { blends for precipitation of solids, } \\
\text { particularly aluminum and oxalate } \\
\text { solids. }\end{array}$ & $\begin{array}{l}\text { Results to meet this success criterion are discussed in Russell et al. (2009d) } \\
\text { and Russell et al. (2009e). Precipitates were found in many of the wash } \\
\text { solutions and were identified primarily as sodium oxalate and sodium } \\
\text { phosphate. No aluminum-bearing solids were found. }\end{array}$ \\
\hline
\end{tabular}

\section{Quality Requirements}

The Pacific Northwest National Laboratory (PNNL) quality assurance (QA) program is based upon the requirements as defined in DOE Order 414.1C, Quality Assurance and 10 CFR 830, Energy/Nuclear Safety Management, Subpart A-Quality Assurance Requirements (a.k.a. the Quality Rule). PNNL has chosen to implement the following consensus standards in a graded approach:

- ASME NQA-1-2000, Quality Assurance Requirements for Nuclear Facility Applications, Part 1, Requirements for Quality Assurance Programs for Nuclear Facilities.

- ASME NQA-1-2000, Part II, Subpart 2.7, Quality Assurance Requirements for Computer Software for Nuclear Facility Applications.

- $\quad$ ASME NQA-1-2000, Part IV, Subpart 4.2, Graded Approach Application of Quality Assurance Requirements for Research and Development.

The procedures necessary to implement the requirements are documented in PNNL's "How Do I...?" (HDI) system. ${ }^{\text {(a) }}$

PNNL implements the RPP-WTP quality requirements by performing work in accordance with the River Protection Project-Waste Treatment Plant Support Program (RPP-WTP) Quality Assurance Plan (RPP-WTP-QA-001, QAP). Work was performed to the quality requirements of NQA-1-1989 Part I, Basic and Supplementary Requirements, NQA-2a-1990, Part 2.7, and DOE/RW-0333P, Rev 13, Quality Assurance Requirements and Descriptions (QARD) as applicable. These quality requirements are implemented through the River Protection Project-Waste Treatment Plant Support Program (RPP-WTP) Quality Assurance Manual (RPP-WTP-QA-003, QAM). The requirements of DOE/RW-0333P Rev 13, Quality Assurance Requirements and Descriptions (QARD) and 10 CFR 830 Subpart A were not required for this work.

RPP-WTP addresses internal verification and validation activities by conducting an Independent Technical Review of the final data report in accordance with RPP-WTP's procedure QA-RPP-WTP-604. This review procedure is part of PNNL's RPP-WTP Quality Assurance Manual (RPP-WTP-QA-003). Following this procedure, a technical review would verify that the reported results are traceable, that inferences and conclusions are soundly based, and the reported work satisfies the objectives.

Key analytes in the laboratory control sample (LCS) and PEP control sample were plotted over time to look for anomalies. The PEP control sample is a project-provided material generated from material very similar to the initial simulant feed. In general, the plots constructed to date associated with the

(a) PNNL's system for managing the delivery of laboratory-level policies, requirements, and procedures. 
inductively coupled plasma (ICP) and ion chromatography (IC) analysis of solutions shows recovery within limits of $80 \%$ to $120 \%$.

Limited data reported for the upper and lower sparger air flowmeters in UFP-VSL-T02A (FT-1901 and FT-1977, respectively) are impacted by NCR 38767.1. The flowmeter vendor, Micro-Motion, identifies a minimum flow rate $(0.090-\mathrm{kg} / \mathrm{min})$ where the Coriolis flow uncertainty increases above $0.5 \%$. For the lowest flow rate reported $(0.012-\mathrm{kg} / \mathrm{min}$ on FT-1977), the estimated uncertainty is $\sim 4 \%$. Since these instruments are used primarily to indicate the approximate air flow rates, higher uncertainty in these data is not considered significant.

\section{R\&T Test Conditions}

The WTP Research and Technology (R\&T) test conditions as defined in the Test Specification are summarized in Table S.5.

Table S.5. R\&T Test Conditions

\begin{tabular}{|c|c|}
\hline List R\&T Test Conditions & Were Test Conditions Followed? \\
\hline \multicolumn{2}{|c|}{ General Requirements } \\
\hline $\begin{array}{l}\text { Perform mass balances for selected constituents, } \\
\text { including aluminum, chromium, manganese, } \\
\text { sodium, hydroxide, oxalate, phosphate, sulfate, and } \\
\text { water to evaluate leaching and washing process } \\
\text { performance. }\end{array}$ & $\begin{array}{l}\text { Yes. The chromium mass balance is discussed in Rapko et al. } \\
\text { (2009) for Integrated Tests A (T01 A/B caustic leaching) and } \\
\text { B (T02A caustic leaching). A discussion of the mass balances } \\
\text { for all of the selected constituents is presented in Section } 12 \text {. }\end{array}$ \\
\hline $\begin{array}{l}\text { Evaluate ultrafilter performance (to include visual } \\
\text { inspection of the filter tubes, tube sheets, and } \\
\text { heads from an ultrafilter for any evidence of flow } \\
\text { mal-distribution and/or solids buildup or evidence } \\
\text { of potential failure). }\end{array}$ & $\begin{array}{l}\text { Yes. The ultrafilters were inspected during testing } \\
\text { maintenance outages and after testing was completed, and no } \\
\text { evidence of flow mal-distribution and/or solids buildup was } \\
\text { observed. The final filter inspection is discussed in Section } \\
\text { 13.5. }\end{array}$ \\
\hline $\begin{array}{l}\text { Assess the blending achieved during in-line } \\
\text { additions of leaching and washing solutions. }\end{array}$ & $\begin{array}{l}\text { Yes. In-line addition of leaching and washing solutions is } \\
\text { addressed in Section } 13.2 \text { of this report. In-line addition of } \\
\text { the process chemicals appears to be a successful method of } \\
\text { addition. }\end{array}$ \\
\hline $\begin{array}{l}\text { Record any solids accumulations observed during } \\
\text { any operating stage or maintenance evolution } \\
\text { (e.g., photography and PSD). }\end{array}$ & $\begin{array}{l}\text { Yes. A discussion of solids accumulation is presented in } \\
\text { Section 13.4. During maintenance and final cleanout of the } \\
\text { PEP system, solids were mainly found to accumulate in piping } \\
\text { that was below and out of the main flow that was not cleaned } \\
\text { or routinely flushed during testing. It should be noted that the } \\
\text { PEP design and/or operation of the low points and clean outs } \\
\text { was not prototypic of the PTF. The solids build-up did not } \\
\text { impact operation of the PEP test system during the period of } \\
\text { testing. }\end{array}$ \\
\hline \multicolumn{2}{|l|}{ Leaching Operations } \\
\hline $\begin{array}{l}\text { Maintain caustic leaching temperature at the } \\
\text { required set point and record steam usage to } \\
\text { remain in the temperature range. }\end{array}$ & $\begin{array}{l}\text { Yes. As discussed in Section } 9 \text {, this R\&T test condition was } \\
\text { met. In general, the caustic leaching temperatures were } \\
\text { controlled within the specified } \pm 2^{\circ} \mathrm{C} \text { tolerance. Any } \\
\text { deviations were due to equipment or operational problems } \\
\text { specific to PEP. }\end{array}$ \\
\hline
\end{tabular}


Table S.5. R\&T Test Conditions

\begin{tabular}{|c|c|}
\hline List R\&T Test Conditions & "Were Test Conditions Followed? \\
\hline $\begin{array}{l}\text { Maintain oxidative leaching temperature at the } \\
\text { required set point. }\end{array}$ & $\begin{array}{l}\text { Yes. As discussed in Section 11, the average temperature } \\
\text { during oxidative leaching in the PEP was maintained at the } \\
\text { required set point, although the temperature deviated during } \\
\text { the first hour because of heat generated by the addition of the } \\
\text { permanganate (heat of reaction and dilution). The } \\
\text { temperature during oxidative leaching in the laboratory-scale } \\
\text { tests for Integrated Tests A and B exceeded } 25^{\circ} \mathrm{C} \text { and ranged } \\
\text { from } 26^{\circ} \mathrm{C} \text { (end of test) to } 31.5^{\circ} \mathrm{C} \text { (beginning), but an } \\
\text { acceptable range was not provided. The initial temperature } \\
\text { increase is due to heat generated by the addition of the } \\
\text { permanganate. A cooling capability at the laboratory-scale } \\
\text { was not available. The temperature set point for oxidative } \\
\text { leaching was maintained during Integrated Test D. }\end{array}$ \\
\hline $\begin{array}{l}\text { Obtain periodic samples during the leaching } \\
\text { operations to monitor the amount of aluminum or } \\
\text { chromium that has dissolved and concentrations of } \\
\text { the reactants and products in the liquid fraction in } \\
\text { the vessel. }\end{array}$ & $\begin{array}{l}\text { Yes. This R\&T condition is discussed in Mahoney et al. } \\
\text { (2009) and Section } 9 \text { of this report for caustic leaching. It is } \\
\text { discussed in Rapko et al. (2009) and Section } 11 \text { in this report } \\
\text { for oxidative leaching. Details of the sampling and analytical } \\
\text { results are provided in the run reports (Josephson et al. 2009, } \\
\text { Guzman-Leong et al. 2009, Geeting et al. 2009, and Sevigny } \\
\text { et al. 2009). }\end{array}$ \\
\hline $\begin{array}{l}\text { Provide data to demonstrate the WTP process } \\
\text { control strategy for the caustic and permanganate } \\
\text { addition. }\end{array}$ & $\begin{array}{l}\text { Yes. These data are provided in the run reports (Josephson et } \\
\text { al. 2009, Guzman-Leong et al. 2009, Geeting et al. 2009, and } \\
\text { Sevigny et al. 2009) and are discussed in Section } 9 \text { for caustic } \\
\text { leaching, Section } 10 \text { for solids washing, and Section } 11 \text { for } \\
\text { oxidative leaching. }\end{array}$ \\
\hline $\begin{array}{l}\text { Measure the rheology of the slurry simulant and } \\
\text { shear strength of the settled solids before and } \\
\text { following each leaching unit operation. }\end{array}$ & $\begin{array}{l}\text { Yes. The rheology of the slurry simulant and the shear } \\
\text { strength of the settled solids were measured before and after } \\
\text { each leaching and washing unit operation and following the } \\
\text { final concentration. These results are presented in the run } \\
\text { reports for each Integrated test (Josephson et al. } 2009 \text {, } \\
\text { Guzman-Leong et al. 2009, Geeting et al. 2009, and Sevigny } \\
\text { et al. 2009). }\end{array}$ \\
\hline \multicolumn{2}{|l|}{ Concentration Operations } \\
\hline $\begin{array}{l}\text { Monitor the permeate production rate of each } \\
\text { ultrafilter assembly in operation. }\end{array}$ & $\begin{array}{l}\text { Yes. This R\&T test condition is discussed in Daniel et al. } \\
\text { (2009b). See the run reports for the individual tests } \\
\text { (Josephson et al. 2009, Guzman-Leong et al. 2009, Geeting et } \\
\text { al. 2009, and Sevigny et al. 2009) and Section } 8 \text { of this report. }\end{array}$ \\
\hline Record operating time of each ultrafilter assembly. & $\begin{array}{l}\text { Yes. The operating time of each ultrafilter assembly was } \\
\text { recorded and reported in the run reports for each of the tests } \\
\text { (Josephson et al. 2009, Guzman-Leong et al. 2009, Geeting et } \\
\text { al. 2009, and Sevigny et al. 2009). Operating times are } \\
\text { summarized in Section } 8 \text { of this report. }\end{array}$ \\
\hline $\begin{array}{l}\text { Record each ultrafilter assembly "cleaning" event } \\
\text { (backpulse, flush, chemical cleaning, etc.). }\end{array}$ & $\begin{array}{l}\text { Yes. The ultrafilter cleaning events were recorded and are } \\
\text { discussed in Section 13.5. Details of the filter cleaning events } \\
\text { may be found in the PEP run reports (Josephson et al. 2009, } \\
\text { Guzman-Leong et al. 2009, Geeting et al. 2009, and Sevigny } \\
\text { et al. 2009). }\end{array}$ \\
\hline
\end{tabular}


Table S.5. R\&T Test Conditions

\begin{tabular}{|c|c|}
\hline List R\&T Test Conditions & Were Test Conditions Followed? \\
\hline $\begin{array}{l}\text { Confirm pulse-pot operation and backpulse } \\
\text { operation strategies. }\end{array}$ & $\begin{array}{l}\text { Yes. The pulse-pot operation and backpulse operation } \\
\text { strategies were confirmed and are discussed in Section } 8 \text {. }\end{array}$ \\
\hline $\begin{array}{l}\text { Control ultrafiltration temperature, TMP, and } \\
\text { slurry flow as specified in test-specific run sheets. }\end{array}$ & $\begin{array}{l}\text { Yes, except when air entrainment limited the slurry flow rate. } \\
\text { This R\&T test condition is discussed in Daniel et al. (2009b) } \\
\text { for the low- and high-solids filter tests, and the remaining } \\
\text { tests are discussed in the run reports (Josephson et al. } 2009 \text {, } \\
\text { Guzman-Leong et al. } 2009 \text {, Geeting et al. 2009, and Sevigny } \\
\text { et al. 2009) and Section } 8 \text { of this report. }\end{array}$ \\
\hline $\begin{array}{l}\text { Collect and retain permeate samples for extended } \\
\text { precipitation studies (including permeate/simulated } \\
\text { supernatant blended cases) from each } \\
\text { concentration cycle. }\end{array}$ & $\begin{array}{l}\text { Yes. Samples were collected and retained for extended } \\
\text { precipitation studies. The results of the precipitation studies } \\
\text { are discussed in Russell et al. ( } 2009 \mathrm{~d}) \text { and Russell et al. } \\
(2009 \mathrm{e}) \text {. Precipitates were found in many of the wash } \\
\text { solutions and were identified primarily as sodium oxalate and } \\
\text { sodium phosphate. No aluminum-bearing solids were found. }\end{array}$ \\
\hline $\begin{array}{l}\text { Demonstrate the WTP ultrafiltration system } \\
\text { control scheme in normal operating modes (e.g., } \\
\text { fill and startup, operation, backpulsing, flush and } \\
\text { drain, cleaning and return to service). }\end{array}$ & $\begin{array}{l}\text { Yes. This R\&T test condition is discussed in Section } 8 \text { and } \\
\text { the PEP run reports (Josephson et al. 2009, Guzman-Leong } \\
\text { et al. 2009, Geeting et al. 2009, and Sevigny et al. 2009). All } \\
\text { process ultrafiltration steps were successfully demonstrated, } \\
\text { including initial solids concentration (Integrated Tests B and } \\
\text { D only), post-caustic-leach solids reconcentration, } \\
\text { post-caustic-leach wash, post-oxidative-leach wash and final } \\
\text { solids concentration. Specific filter operations were also } \\
\text { successfully demonstrated, including flow and TMP control } \\
\text { with two pumps in-series, filter backpulsing, and chemical } \\
\text { filter cleaning. Because the PEP was not designed to perform } \\
\text { filter-loop backflushing at the high prototypic flow rate, this } \\
\text { particular operation was not demonstrated. }\end{array}$ \\
\hline \multicolumn{2}{|l|}{ Washing Operations } \\
\hline $\begin{array}{l}\text { Wash slurries using a washing protocol to be } \\
\text { specified in test-specific run sheets. }\end{array}$ & $\begin{array}{l}\text { Yes. The slurries were washed per the protocols specified in } \\
\text { the approved run sheets. Some of the process conditions } \\
\text { specified in the run sheet were not met during the washing: } \\
\text { Integrated Test A: The filter-loop flow rate target of } \\
109 \pm 10 \text { GPM was not achieved for the post-caustic-leach and } \\
\text { post-oxidative-leach washing. The actual flow rate is not } \\
\text { known because of a failure of the filter-loop flowmeter and air } \\
\text { entrainment. The target temperature of } 25 \pm 2{ }^{\circ} \mathrm{C} \text { was not } \\
\text { achieved for the first seven washes of the post-caustic-leach } \\
\text { wash because of extreme pump behavior that added excess } \\
\text { heat to the system. The air flows to the spargers and the } \\
\text { steam ring were reduced in an effort to manage air } \\
\text { entrainment in the slurry. } \\
\text { Integrated Test B: The filter-loop flow rate target of } \\
109 \pm 10 \text { GPM was not achieved for the post-caustic- and } \\
\text { post-oxidative-leach washes. The pumps were operated at the } \\
\text { maximum achievable flow rate, which was lower than the } \\
\text { minimum target of } 99 \text { GPM. Air flows to the spargers and the } \\
\text { steam ring were off during the washing steps to minimize air }\end{array}$ \\
\hline
\end{tabular}


Table S.5. R\&T Test Conditions

\begin{tabular}{|l|l||}
\hline List R\&T Test Conditions & Were Test Conditions Followed? \\
\hline & $\begin{array}{l}\text { entrainment in the slurry. } \\
\text { Integrated Test D: The filter-loop flow started out lower than } \\
\text { the target of } 109 \pm 10 \text { GPM (90 to 100 GPM) for the first } \\
\text { several wash batches and was then generally within the target } \\
\text { range until wash Batch 38. At this point, the flow rate was } \\
\text { preemptively reduced to avoid air entrainment issues. Air } \\
\text { flow to the spargers and the steam ring was off during the } \\
\text { washing steps to minimize air entrainment in the slurry. }\end{array}$ \\
\hline $\begin{array}{l}\text { Sample permeate immediately before each wash } \\
\text { solution addition to monitor washing } \\
\text { performance/efficiency. }\end{array}$ & $\begin{array}{l}\text { No. Slurry samples were obtained every third wash batch, } \\
\text { and the supernatant liquid was analyzed. This was the best } \\
\text { available means of monitoring the permeate concentrations as } \\
\text { a function of the quantity of wash-water added. Details of the } \\
\text { sampling protocol may be found in each of the run reports } \\
\text { (Josephson et al. 2009, Guzman-Leong et al. 2009, Geeting et } \\
\text { al. 2009, and Sevigny et al. 2009). }\end{array}$ \\
\hline Measure rheology of the washed solids. & $\begin{array}{l}\text { Yes. The rheology of the washed solids was measured and is } \\
\text { reported in each of the run reports (Josephson et al. 2009, } \\
\text { Guzman-Leong et al. 2009, Geeting et al. 2009, and Sevigny } \\
\text { et al. 2009). }\end{array}$ \\
\hline
\end{tabular}




\section{Simulant Use}

PEP process testing was performed with a nonradioactive aqueous slurry of simulant waste chemicals and solids. The simulant composition and make-up recipe were provided by WTP as documented in Simulant Recommendation for Phase 1 Testing in the Pretreatment Engineering Platform. ${ }^{\text {(a) }}$ Aqueous chemical concentrations were within the ranges expected for waste feeds to the PTF. The hydroxide concentration was marginally one standard deviation lower than the average concentration expected in the feeds to the plant. The oxalate and phosphate components were at the lower end of the expected ranges, but the oxalate component was at the solubility limit, and the phosphate component was at or near the solubility limit. The solids components and blend were selected to obtain targeted solids mass loss (aluminum and chromium leaching and oxalate washing) and treatment time. The simulant was not selected to represent any particular Hanford tank waste type.

The simulant was blended from the components listed below. The basis for selecting the individual components and the comparison to actual waste behavior are provided where applicable in the indicated references.

- Boehmite (for Al) (Russell et al. 2009a)

- Gibbsite (for Al) (Russell et al. 2009b)

- Chromium oxyhydroxide (CrOOH) slurry (Rapko et al. 2007)

- Sodium oxalate

- Filtration simulant (Russell et al. 2009c)

- Supernate.

A separate chromium solids slurry simulant was prepared and added to the PEP process after post-caustic-leach washing (a nonprototypic addition) during the Shakedown/Functional Tests and Integrated Tests A and B. This approach was taken because laboratory-scale tests had shown that the high-temperature caustic leaching step dissolved significant amounts of the $\mathrm{CrOOH}$ solids (Russell et al. 2009a). In Integrated Test D, the chromium solids component of the simulant was added during the simulant make-up process to demonstrate the PTF permanganate addition strategy. Simulant was procured from NOAH Technologies Corporation (San Antonio, TX). Samples of each simulant batch were characterized to make certain that the requirements for chemical and physical properties were met. Batches of the simulant were procured as follows:

- A 15-gallon trial batch of the blended simulant for laboratory testing to demonstrate the efficacy of the simulant fabrication procedure.

- A 250-gallon scale-up batch of the blended simulant to demonstrate scale-up of the simulant fabrication procedure to an intermediate scale.

(a) Sundar PS. 2008. Simulant Recommendation for Phase I Testing in the Pretreatment Engineering Platform. 24590-PTF-RPT-RT-08-006, Rev. 0, CCN 176990, Bechtel National, Inc., Richland, Washington. 
- Batches 0, 1, and 2, each nominally 3500 gallons, of blended simulant for the Shakedown/Functional Tests and Integrated Tests A and B. These batches did not contain the $\mathrm{CrOOH}$ component.

- Batch 3, nominally 1200 gal, for Integrated Test D. This batch contained the CrOOH solids component.

- The CrOOH solids slurry for the Shakedown/Functional Test and Integrated Tests A and B was obtained in two separate batches containing nominally 18 - and $36-\mathrm{kg}$ of $\mathrm{Cr}$ as $\mathrm{CrOOH}$.

\section{Discrepancies and Follow-on Tests}

There were no identified discrepancies.

Follow-on tests for consideration include:

1. The divergence of filter flux between the filter bundles during and after the backpulse sequence at PEP is a repeatable phenomenon without an established cause. Testing to study this phenomenon could lead to improved filtration and backpulsing strategies.

2. Understanding the effects of nitric and oxalic acid cleaning on the long-term performance of the filter elements would enable better scaling and comparison.

3. An evaluation of long-term (i.e., much greater than 36 hours) filter flux dynamics is recommended to assess their potential impacts on scaling of filtration performance.

4. Additional work is required to develop a strategy for determining the permanganate requirement for oxidative leaching. The WTP strategy to use laboratory-scale tests to predict the amount of permanganate was not shown to be successful by PEP testing. The implication is that some important aspect of the WTP process was not incorporated in the prescribed laboratory-scale test. 



\subsection{Introduction}

Pacific Northwest National Laboratory (PNNL) was tasked by Bechtel National Inc. (BNI) on the River Protection Project, Hanford Tank Waste Treatment and Immobilization Plant (RPP-WTP) project to conduct testing to demonstrate the performance of the WTP Pretreatment Facility (PTF) leaching and ultrafiltration processes at an engineering-scale. In addition to the demonstration, the testing was to address specific technical issues identified in Issue Response Plan for Implementation of External Flowsheet Review Team (EFRT) Recommendations - M12, Undemonstrated Leaching Processes. ${ }^{\text {(a) }}$ Testing was conducted in a $1 / 4.5$-scale mock-up ${ }^{(b)}$ of the PTF ultrafiltration system, the Pretreatment Engineering Platform (PEP). Parallel laboratory testing was conducted in various PNNL laboratories to allow direct comparison of process performance at an engineering-scale and a laboratory-scale. This report presents and discusses the results of those tests.

\subsection{Background}

The purpose of the RPP-WTP project is to design, construct, and commission a plant to pretreat and immobilize radioactive high-level waste (HLW) and low-activity waste (LAW) stored in underground storage tanks at the Hanford Site. The purpose of the PTF is to separate waste from the storage tanks into HLW and LAW streams that are then routed to their respective glass melters. Because production and storage of HLW glass is much more costly than LAW glass, the PTF will also be designed to remove species from the HLW stream that would limit glass loading and thereby minimize the quantity of HLW glass. The two prominent HLW glass-load limiting species are solid phase aluminum and chromium, which will be removed from the waste feed by leaching (i.e., dissolving), followed by washing and filtering to move them into the LAW stream.

In October 2005, an External Flowsheet Review Team (EFRT) was assembled to challenge and provide a critical review of the design of the WTP. The EFRT expressed concerns that the combined ultrafiltration, washing, and leaching process system had not been demonstrated for WTP conditions and that there was large uncertainty in projected throughput. Specifically, the EFRT was concerned that the ultrafilters were inadequately sized to provide the needed permeate throughput and that the washing and leaching process flowsheets were based on laboratory-scale tests that may not be indicative of the full-scale WTP leaching and washing process behavior. The EFRT noted that laboratory studies cannot simulate many full-scale issues, such as spatially dependent mixing and thermally hot and cold regions. These latter issues are best addressed by full-scale process experiments, but the costs of such a system and the chemicals it would consume in testing are prohibitive. Instead, the EFRT recommended these issues be evaluated with an engineering-scale test platform that is large enough to exhibit the same phenomena of the full-scale system but small enough for practical testing.

(a) Barnes SM and R Voke. 2006. "Issue Response Plan for Implementation of External Flowsheet Review Team (EFRT) Recommendations - M12: Undemonstrated Leaching Process. 24590-WTP-PL-ENG-06-0024 Rev. 0. Bechtel National Inc., Richland, Washington.

(b) The scale of $1 / 4.5$ was chosen because this scale enables the ultrafiltration loop to be configured to meet two important criteria: 1) using one filter bundle the ratio of solids in the feed tank to filter surface area will be the same as in the plant, and 2) using five filter bundles the type and extent of mixing in the feed vessel will be approximately prototypic during the solids washing processes. 
The WTP project and the U.S. Department of Energy (DOE) developed the Issue Response Plan for Implementation of External Flowsheet Review Team (EFRT) Recommendations - M12, Undemonstrated Leaching Processes (M12 Issue Response Plan [IRP]) ${ }^{(a)}$ to resolve the issue of undemonstrated leaching processes. The M12 IRP also addresses related topics that are not specifically in response to EFRT concerns. These include caustic addition and leaching concerns that were revealed since the EFRT report was issued, information to support revision of the contract design basis for the PTF, including system capacities, and earlier initiatives on enhancing plant throughput capacity.

The work described in this report represents only a part of the M12 IRP scope, specifically, only one of seven tasks. In addition to the engineering-scale demonstrations discussed in this report, the M12 IRP instigated studies to:

- Evaluate design enhancements to increase PTF throughput. ${ }^{(b)}$

- Model the impact of selected design enhancements. ${ }^{(c)}$

- Develop simulants for leaching and ultrafiltration testing. ${ }^{(\mathrm{d})}$

- Evaluate actual waste leaching and filtration characteristics.

- Incorporate laboratory- and engineering-scale findings into performance modeling and evaluate impacts. $^{(\mathrm{e})}$

- Identify what further studies and testing are needed. ${ }^{(\mathrm{f})}$

To meet the requirements for an engineering-scale demonstration of the ultrafiltration and leaching processes, the PEP was designed, constructed, and operated. The conceptual design of the PEP, including the process flow diagram, Functional Requirements for PEP, ${ }^{(\mathrm{g})}$ and PEP Phase I Process Description, ${ }^{\text {(h) }}$ was performed by WTP. Scaling was applied, to the extent practicable, to maintain key behaviors of the full-scale facility. Washington Group International, Engineered Products Department, and Tessenderlo-Kerley Services designed the PEP in modular units and constructed it in Carlsbad, NM. It was then shipped to and installed in the Process Development Laboratory-West (PDL-W) in Richland, WA. The PDL-W facility is owned by Battelle and is operated by PNNL staff.

(a) Barnes SM and R Voke. 2006. "Issue Response Plan for Implementation of External Flowsheet Review Team (EFRT) Recommendations - M12: Undemonstrated Leaching Process.” 24590-WTP-PL-ENG-06-0024 Rev. 0. Bechtel National Inc., Richland, Washington.

(b) Olson JW and EJ Slaathaug. 2007. Technical Report-Design Evaluations Supporting Resolution of External Flowsheet Review Team (EFRT) Issue M12 and Plant Capacity Issues Related to Ultrafiltration and Leaching. 24590-WTP-RPT-ENG-06-014, Rev. 0, River Protection Project, Waste Treatment Plant, Richland, Washington.

(c) Lee E. 2007. Preliminary Dynamic (G2) Flowsheet Results: Impact of Implementing M12 Proposed Modifications On the WTP Mission Duration. 24590-WTP-RPT-PO-06-003, Rev. 0, River Protection Project, Waste Treatment Plant, Richland, Washington.

(d) Sundar PS. 2008. Simulant Recommendation for Phase I Testing in the Pretreatment Engineering Platform. 24590-PTF-RPT-RT-08-006, Rev. 0, CCN 176990, Bechtel National, Inc., Richland, Washington.

(e) Deng Y. 2009. EFRT M12 IRP Phase 1 Task 6 Throughput Confirmation Modeling-Dynamic (G2) Model Results Report. 24590-WTP-MRR-PET-09-005, Rev. 1, River Protection Project, Waste Treatment Plant, Richland, Washington.

(f) Tamosaitis WL. 2008. M12 Phase II Study Report. CCN 188889, River Protection Project, Waste Treatment Plant, Richland, Washington.

(g) Stiver B. 2007. Functional Requirements for Pretreatment Engineering Platform (PEP). 24590-PTF-3YD-UFP-00002 Rev. 1, Bechtel National Incorporated, Richland, Washington.

(h) Lehrman S. 2008. Pretreatment Engineering Platform (PEP) Phase 1 Testing Process Description. 24590-WTP-RPT-PET-07-002, Rev 0, Bechtel National, Inc., Richland, Washington. 


\subsection{Technical Overview}

The M12 PEP testing program has two general objectives: 1) to qualitatively demonstrate the leaching and ultrafiltration processes, equipment design, and process control strategies, and 2) to obtain quantitative data to improve model projections of leaching and ultrafiltration process performance. ${ }^{\text {(a) }}$ This section provides short descriptions of the PTF processes, the engineering-scale PEP that was used to demonstrate them, and the testing strategy that was applied to achieve both the qualitative and quantitative objectives.

\subsubsection{Ultrafiltration and Leaching Process Description}

The PTF Ultrafiltration Process (UFP) includes caustic leaching (for dissolving aluminum solids), oxidative leaching (for dissolving chromium solids), and all ultrafiltration operations. The purpose of the UFP is to concentrate radioactive waste solids from various blended feeds, leach specific nonradioactive solids that limit HLW glass loading, and separate soluble species from the solids by washing. The integrated processes produce a concentrated solids slurry (the HLW stream), high-sodium solutions that are sent forward to the cesium ion-exchange process ${ }^{(a)}$ (the LAW stream), and low-sodium wash solutions that are sent to a process evaporator for reconcentration. Equipment and process descriptions are given in 24590-WTP-RPT-PET-07-002, Rev 0. ${ }^{\left({ }^{(b)}\right.}$

A simplified process flow diagram is shown in Figure 1.1. This figure includes four high-level process vessels (HLP-VSL-00022, HLP-VSL-0027A/B and HLP-VSL-0028) that are not UFP components, but are shown to indicate the primary feed and product vessels for the UFP. As indicated in Figure 1.1, the PTF will have two parallel ultrafiltration systems that are connected at various points. The ultrafiltration feed preparation vessels (UFP-VSL-00001A/B) have nominal working volumes of 54,000 gallons. They will receive feed from various sources and are used to blend and stage the feed for subsequent ultrafiltration. Blending within the feed preparation vessels is accomplished with pulse jet mixers (PJMs).

The ultrafiltration feed vessels (UFP-VSL-00002A/B) have nominal 26,000 gallon working volumes and use PJMs and air sparging to mix their contents. Waste slurries in the feed vessels are circulated through their respective ultrafilter loops by dual, 300-hp centrifugal pumps (UFP-PMP-00042A/B, $-00043 \mathrm{~A} / \mathrm{B}$ ) at about $2200 \mathrm{GPM}$. This high-volume slurry flow passes sequentially through five filter bundles, each composed of 241 parallel filter tubes. The solids content of the slurry is gradually increased by the permeation of liquid from the slurry, flowing on the inside of the filter tubes at high pressure, through the porous filter tubes to the low-pressure shellside of the filters. Only a small fraction of the liquid is removed as permeate during each pass through the filter-loop, and the slurry is cycled back to the feed vessels. The high-volume slurry flow greatly reduces the thickness of particulate cake at the filter surface, thereby increasing permeation rates. Heat from the filter-loop pumps is removed by chilled-water, spiral plate heat exchangers (UFP-HX-00001A/B).

(a) The PEP does not include all of the processing capability that will exist in the PTF (e.g., ion exchange and evaporators).

(b) Lehrman S. 2008. Pretreatment Engineering Platform (PEP) Phase 1 Testing Process Description. 24590-WTP-RPT-PET-07-002, Rev 0, Bechtel National Inc., Richland, Washington. 


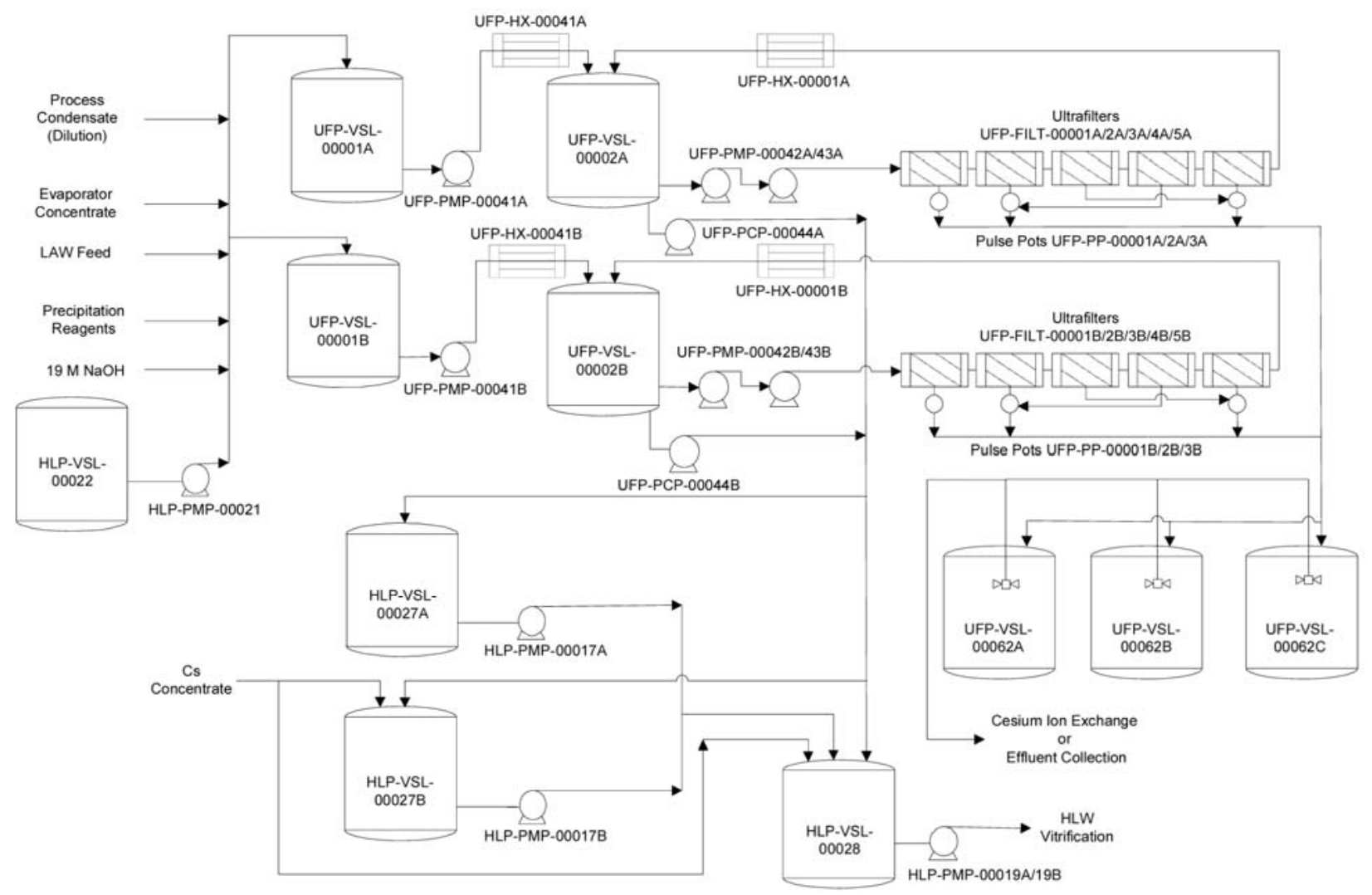

Figure 1.1. A Simplified Process Flow Diagram for the WTP Ultrafiltration and Leaching Process

Two process flowsheets are currently being evaluated for the UFP and leaching operations. The baseline flowsheet performs caustic leaching on blended waste feed in ultrafiltration feed preparation vessels (UFP-VSL-00001A/B). The alternative flowsheet performs caustic leaching after the blended waste has been concentrated by removing liquid by cross-flow ultrafiltration in the ultrafiltration feed vessels (UFP-VSL-00002A/B). In both flowsheets, caustic leaching is conducted by adding 19-M sodium hydroxide $(\mathrm{NaOH}$, caustic) to the waste slurry, heating the caustic slurry to an effective leaching temperature, and maintaining the leach temperature until a targeted amount of aluminum solids have been dissolved. After cooling, the leached slurry is concentrated and washed with inhibited water to remove dissolved species. If the waste is high in chromium solids, sodium permanganate reagent is added, and the slurry is circulated to dissolve and oxidize the chromium solids. Following the oxidative leaching of chromium solids, the slurry is washed to remove the dissolved chromium, concentrated to a final target solids concentration, and fed forward to the HLW lag storage and blend vessels.

\subsubsection{Pretreatment Engineering Platform}

The PEP was designed to mimic as many of the key process conditions of the plant as possible in an engineering-scale system. A simplified process diagram of the PEP is given in Figure 1.2. As evident from comparing Figure 1.1 with Figure 1.2, the PEP does not include two full parallel ultrafiltration trains like the PTF; only one ultrafiltration feed tank and set of ultrafilters is included in the PEP. However, both ultrafiltration feed preparation vessels UFP-VSL-T01A/B (henceforth Tanks T01A/B) are included 
in the PEP because both are needed to demonstrate the caustic leaching process conducted in those vessels.

The PEP was built as a $1 / 4.5$-scale version of the PTF because, at that scale, the ultrafiltration loop could be designed to meet two important criteria (Huckaby, ${ }^{(a)} \mathrm{Kuhn}$ et al. 2008). First, when a single, 10-ft-long filter bundle with 12 full-size filter tubes is used for filtering, the ratio of solids in the feed tank to filter surface area will be the same as in the plant. This prototypic solids/filter area ratio is important when simulating the decrease in filter flux with time. Second, when a full complement of three 10-ft and two 8-ft-long filter bundles (each with 12 full-size filter tubes) is used for filtering, the type and extent of mixing in the feed vessel will be approximately prototypic during the solids washing processes. Prototypic mixing in this vessel during washing is important to achieving prototypic wash efficiencies. While it is important to control many aspects of the integrated processes prototypically, only the two filtration issues mentioned here require a specific scale factor; the others can be scaled by the chosen $1 / 4.5$ factor with about the same ease as any other specific value in a reasonable range.

The three PEP vessels directly involved with leaching and ultrafiltration, Tanks UFP-VSL-T01A/B and UFP-VSL-T02A, were dimensionally scaled by the scale factor $\left({ }^{1} / 4.5\right)$ and are thus geometrically similar to their PTF counterparts. Internal structures in these vessels were also geometrically scaled as possible (e.g., the pulse jet mixers are geometrically scaled and located, but their supports are not). The spiral-plate UFP-HX-T02A chilled-water heat exchanger could not be scaled dimensionally, so it was scaled on velocity to be similar to its PTF counterpart (note that the PTF heat exchanger design that was not finalized prior to PEP testing has changed from the assumed velocity used for PEP scaling). Other vessels, most ancillary equipment, and the instrumentation and control equipment were designed or selected to achieve functionally prototypic behavior.

The distinction between prototypic and functionally prototypic is important here; prototypic processes in the PEP are designed to provide direct evidence of how the actual PTF process will perform, but functionally prototypic equipment and processes provide only limited evidence of PTF behavior. For example, the functionally prototypic flow monitoring instrumentation in the PEP was chosen to provide similar data to that expected in the PTF for monitoring and control, but inasmuch as the instruments are not identical to those of the PTF, failures or limitations of PEP instrumentation are not indicative of failures or limitations in the PTF instrumentation.

In addition to most of the PEP equipment (e.g., pumps, flowmeters, and transfer piping) being functionally prototypic and because thermal profiles and heat transfer do not scale in the same way as other aspects of this system, the caustic leaching process temperature is understood to be a functionally prototypic process parameter. Adding a prototypic (e.g., volumetrically scaled) quantity of steam to the leaching vessel will not cause a prototypic rise in the temperature of the vessel, nor will the distribution of temperature within the vessel necessarily be prototypic of the full-scale vessel. Similarly, the accumulation of steam condensate during the heating and caustic leaching process is inherently nonprototypic. Special steps were taken to achieve functionally prototypic quantities of condensate during testing. These issues are discussed further in Section 3.0.

(a) Huckaby JL and JR Markillie. 2008. Pretreatment Engineering Platform (PEP) Testing (Phase 1) Test Specification. 24590-PTF-TSP-RT-07-001, Rev 2, Bechtel National, Inc., Richland, Washington. 


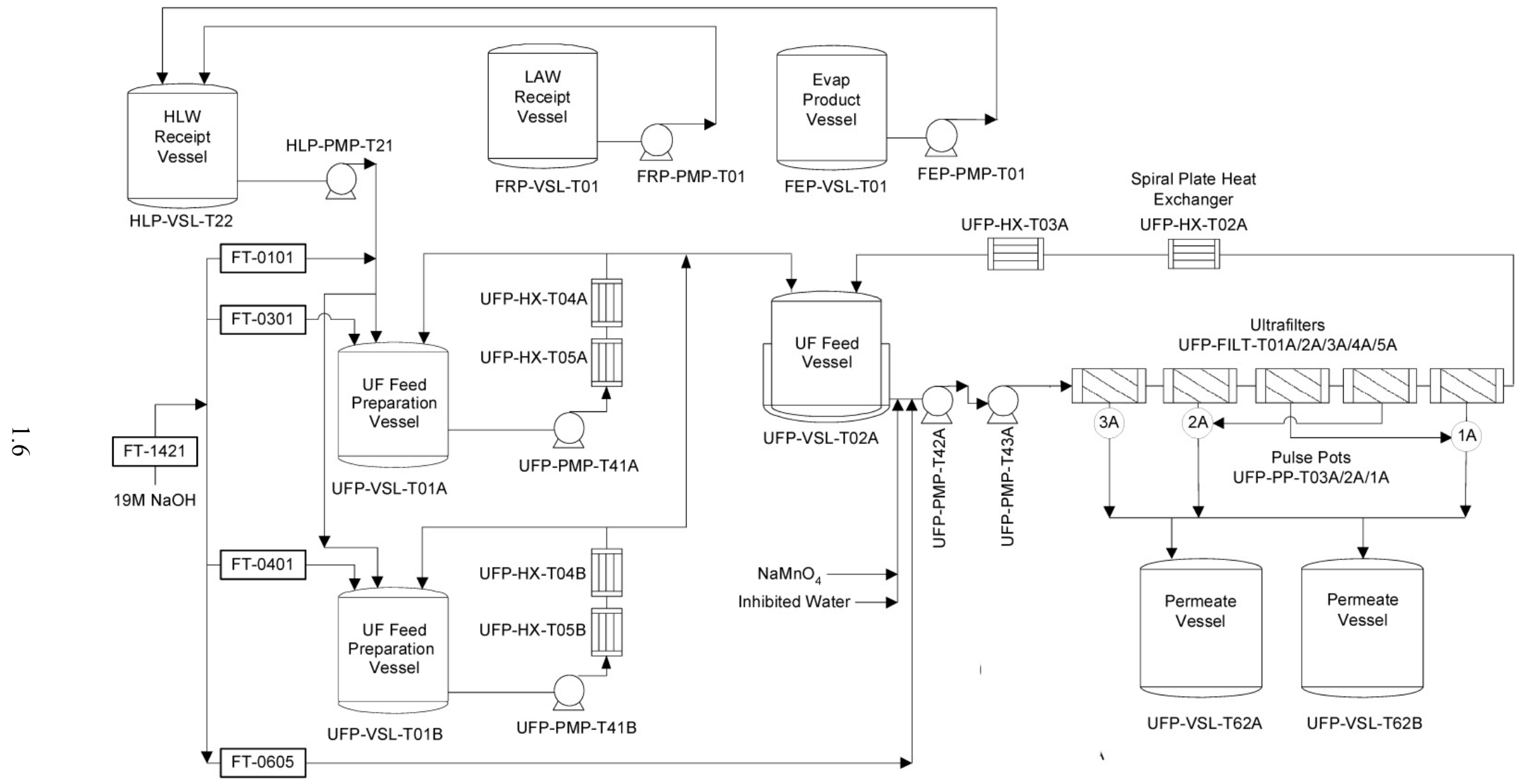

Figure 1.2. PEP Simplified Flow Diagram 


\subsubsection{PEP Test Campaign Strategy}

Testing was designed to address the two primary objectives - demonstrate the integrated process flowsheets and improve specific PTF performance predictions, with as few tests as possible. To qualitatively demonstrate the processes, equipment design, and process control strategies, three Integrated tests were conducted in the PEP. The tests were conducted with a single chemical waste simulant, which was processed through each step of the baseline process flowsheet and an alternative flowsheet.

The strategy to improve the model projections for plant leaching and ultrafiltration performance was based on testing under idealized conditions (i.e., in a laboratory), testing under plant-simulated conditions in the engineering-scale PEP, and analyses that relate the results of laboratory and PEP results to the full-scale PTF performance. Laboratory testing included characterization and parametric testing of both actual waste samples and simulants conducted in advance of, and apart from, the PEP testing as well as laboratory-scale performance testing conducted in parallel with PEP testing. PEP testing addressed two process flowsheets, but was limited to operations with a single, nonradioactive simulant during Phase 1 ( $^{\left({ }^{a}\right.}$ The cumulative laboratory and PEP testing were designed to provide complementary data so that PTF performance projections can be based on actual waste analyses without having to run the PEP with actual waste. $^{(b)}$

At a minimum, the M12 IRP required separate integrated process tests for the baseline and alternative process flowsheets and a demonstration of the baseline filter cleaning process. Additional testing was also needed for the scale-up of laboratory-to-PEP filter performance (that was best performed apart from the Integrated tests as discussed in Sections 4 and 5) and, in preparation for the Integrated tests, to verify PEP strategies to achieve prototypic quantities of steam condensate before and during caustic leaching. The test campaign strategy incorporated these and other needs as follows:

- Functional testing (covering both Shakedown and Functional Test steps), performed in conjunction with the PEP installation simulant Shakedown Test, attempted to demonstrate, with simulant, all operations and control schemes that would be conducted in the Integrated tests. This included caustic leaching in both Tank T01A and Tank T02A, during which the strategy for controlling steam condensate accumulation was successfully demonstrated. Additionally, Tank T01A and Tank T02A were tested for stratification of solids; in-line and in-tank slurry sampling methods were tested and compared; after an initial filter cleaning, the low-solids filter performance test was conducted (to maximize similarities, both PEP and Cells Unit Filter [CUF] filters needed to be chemically cleaned before this test); and the high-solids filter performance test was conducted after a suitable quantity of leached, washed slurry had been produced.

- Integrated Process Test A demonstrated the baseline process flowsheet with caustic leaching conducted in Tanks T01A/B on unconcentrated simulant. The boehmite simulant had been selected to mimic waste boehmite when leached at $100^{\circ} \mathrm{C}$, but the PEP was subsequently limited to operate at strictly less than $100^{\circ} \mathrm{C}$ to avoid excessive corrosion. Thus, caustic leaching was conducted in Integrated Test $\mathrm{A}$ at the target temperature of $98^{\circ} \mathrm{C}$. Six caustic-leach batches were

(a) Barnes SM and R Voke. 2006. "Issue Response Plan for Implementation of External Flowsheet Review Team (EFRT) Recommendations - M12: Undemonstrated Leaching Process. 24590-WTP-PL-ENG-06-0024, Rev. 0. Bechtel National Inc., Richland, Washington.

(b) Testing with the actual waste was not feasible due to the hazards and cost associated with radioactive materials. 
conducted: three with $100 \%$ of the caustic added in-line during the transfer of simulant from HLP-VSL-T22 and three with $80 \%$ in-line and 20\% in-tank caustic addition. Because the chromium solids simulant was extensively oxidized during the high-temperature caustic-leach step, it was omitted from the feed simulant and added (nonprototypically) after the post-caustic-leach wash step.

- Integrated Test B demonstrated the alternative process flowsheet, with caustic leaching conducted in Tank T02A on concentrated simulant. As with Integrated Test A, caustic leaching was conducted at $98^{\circ} \mathrm{C}$ and the chromium solids were added after post-caustic-leach washing. Because the PEP filter-loop volume was much larger than would be prototypic (i.e., about 82 gal instead of the prototypic $19.5 \mathrm{gal}$ ), the alternative process flowsheet could not be demonstrated with the selected simulant without some adjustment of post-caustic-leach slurry volumes. The chosen resolution of this problem was to conduct two separate caustic-leach batches in Tank T02A, storing the product of the first batch temporarily in Tank T01B until the second batch had been completed.

- Integrated Test D demonstrated the alternative process flowsheet like Integrated Test B, but with caustic leaching conducted at a target temperature of $85^{\circ} \mathrm{C}$. Though leaching the simulant boehmite was much slower than waste boehmite at this temperature and additional caustic was required to achieve measurable boehmite dissolution, the differences between leaching at $85^{\circ} \mathrm{C}$ and $98^{\circ} \mathrm{C}$ were potentially important enough to warrant this additional integrated test. The anticipated differences included impacts on mixing by air sparge mixers in Tank T02A (Kuhn et al. 2008), operation of the PJMs at high temperature, and variations in the leach vessel temperature profile (i.e., more hot spots and cold spots at $98^{\circ} \mathrm{C}$ ).

- Prototypic chemical filter cleaning was demonstrated with three strikes of nitric acid before laying up the PEP filters.

Integrated Test $\mathrm{C}$ was deleted from the scope of the testing (ICN-TP-RPP-WTP-506_R0.2). ${ }^{\text {(a) }}$

\subsection{PEP Operation and Testing Protocol}

Pretreatment Engineering Platform testing was governed by the Test Plan ${ }^{(b)}$ and performed according to detailed Test Instructions that are identified in each of the run reports (Josephson et al. 2009, Guzman-Leong et al. 2009, Geeting et al. 2009, Sevigny et al. 2009). The Test Instructions specified the sequence of operations, sample collection and analyses to be performed, and required process measurements. Each Test Instruction included a run sheet of process parameters that specified transfer rates, volumes, temperatures, filtration parameters, wash parameters, reagent additions, etc. The run sheet, developed by WTP, was based on batch-specific simulant characterization data and detailed spreadsheet models for boehmite leaching kinetics, solids washing, and solids concentration steps.

A Joint Test Group (JTG) was established as the decision-making committee to oversee and provide direction for the execution of Phase 1 testing. The JTG was composed of representatives from WTP, PNNL, and the U.S. Department of Energy, Office of River Protection. The group met regularly to

(a) Josephson GB, OP Bredt, JK Young, and DE Kurath. 2009. Test Plan for Pretreatment Engineering Platform (PEP) Testing (Phase I). TP-RPP-WTP-506, Rev 0.2, Pacific Northwest National Laboratory, Richland, Washington.

(b) Josephson GB, OP Bredt, JK Young, and DE Kurath. 2009. Test Plan for Pretreatment Engineering Platform (PEP) Testing (Phase I). TP-RPP-WTP-506, Rev 0.4, Pacific Northwest National Laboratory, Richland, Washington. 
approve run sheets, assess the progress of testing, determine whether the objectives of the testing were met, and provide direction to troubleshoot unexpected circumstances. The JTG provided direction to PNNL within the bounds of this Test Plan. In several instances, changes to the Test Plan were necessary and the JTG provided direction to WTP to process a Test Exception and PNNL to process an interim change notice.

Testing required 24-hr/day operation of the PEP. This was performed by teams of four to six operators, a shift supervisor, and a lead test engineer (LTE) working 12-hr shifts. ${ }^{(a)}$ Failure to meet conditions specified by the run sheets required the LTE to inform the on-duty test director. Changes to the run sheet required test director approval. All PEP operations were performed according to detailed operating procedures to which operators and shift supervisors were trained. The key operating procedures used in testing are documented in the filtration scale-up report (Daniel et al. 2009b).

\subsection{Report Structure}

This report summarizes the results of the Shakedown and Functional Testing, Integrated Test A, Integrated Test B, and Integrated Test D conducted on the PEP during Phase 1. It also includes the results of the key laboratory-scale testing and CUF testing conducted in support of the PEP Phase 1 testing. The report structure is:

- Section 2, Quality Assurance (QA)

- Section 3, Summary of the Scaling Approach Used During Testing

- Section 4, Description of the Testing Systems Configurations Used During Testing

- Section 5, Discussion of the Experimental Approach Used During Testing

- Section 6, Simulant Usage and Development

- Section 7, Summary of Functional Test Results

- Section 8, Summary of Filtration Test Results

- Section 9, Summary of Caustic Leaching Results

- Section 10, Summary of Solids Washing Results

- Section 11, Summary of Oxidative Leaching Results

- Section 12, UFP System Process Performance with a Focus on Material Balances

- Section 13, UFP System Operability and Functionality Reviewing Key Operations of the Pilot Plant

- Section 14, Summary and Conclusions

- Section 15, References.

(a) Sample handling teams were also on each shift that worked in conjunction with the testing team. 



\subsection{Quality Assurance}

The Pacific Northwest National Laboratory (PNNL) Quality Assurance Program is based upon the requirements as defined in the U.S. Department of Energy (DOE) Order 414.1C, Quality Assurance, and 10 CFR 830, Energy/Nuclear Safety Management, Subpart A-Quality Assurance Requirements (a.k.a. the Quality Rule). Pacific Northwest National Laboratory has chosen to implement the following consensus standards in a graded approach:

- ASME NQA-1-2000, Quality Assurance Requirements for Nuclear Facility Applications, Part 1, Requirements for Quality Assurance Programs for Nuclear Facilities.

- $\quad$ ASME NQA-1-2000, Part II, Subpart 2.7, Quality Assurance Requirements for Computer Software for Nuclear Facility Applications.

- ASME NQA-1-2000, Part IV, Subpart 4.2, Graded Approach Application of Quality Assurance Requirements for Research and Development.

The procedures necessary to implement the requirements are documented through PNNL's "How Do I...?" (HDI) system. ${ }^{\text {(a) }}$

PNNL implements the River Protection Project—Hanford Tank Waste Treatment and Immobilization Plant Support Program (RPP-WTP) quality requirements by performing work in accordance with the Quality Assurance Plan (RPP-WTP-QA-001). Work was performed to the quality requirements of ASME NQA-1-1989 Part I, Basic and Supplementary Requirements, NQA-2a-1990, Part 2.7, Quality Assurance Requirements for Computer Software for Nuclear Facility Applications, and DOE/RW-0333P, Rev 13, Quality Assurance Requirements and Descriptions (QARD), as applicable. These quality requirements are implemented through the River Protection Project-Waste Treatment Plant Support Program (RPP-WTP) Quality Assurance Manual (RPP-WTP-QA-003, QAM). The requirements of DOE/RW-0333P Rev 13, Quality Assurance Requirements and Descriptions (QARD) and 10 CFR 830, Subpart A, were not required for this work.

The RPP-WTP addresses internal verification and validation activities by conducting an Independent Technical Review of the final data report in accordance with RPP-WTP's procedure QA-RPP-WTP-604. This review procedure is part of PNNL's RPP-WTP Quality Assurance Manual (RPP-WTP-QA-003). Following this procedure, a technical review would verify that the reported results are traceable, that inferences and conclusions are soundly based, and the reported work satisfies the objectives.

Key analytes in the laboratory control sample (LCS) and PEP control sample were plotted over time to look for anomalies. The PEP control sample is a project-provided material generated from material very similar to the initial simulant feed. In general, the plots of concentrations associated with the inductively coupled plasma (ICP) and ion chromatography (IC) analysis of solutions show recovery within limits of $80 \%$ to $120 \%$.

Limited data reported for the upper and lower sparger air flowmeters in UFP-VSL-T02A (FT-1901 and FT-1977, respectively) are impacted by conditions specified in Nonconformance Report (NCR) 38767.1. The flowmeter vendor, Micro-Motion, identifies a minimum flow rate $(0.090-\mathrm{kg} / \mathrm{min})$ where the

(a) PNNL's system for managing the delivery of laboratory-level policies, requirements, and procedures. 
Coriolis flow uncertainty increases above $0.5 \%$. For the lowest flow rate reported $(0.012-\mathrm{kg} / \mathrm{min}$ on FT-1977), the estimated uncertainty is $\sim 4 \%$. Since these instruments are used primarily to indicate the approximate air flow rates, higher uncertainty in these data is not considered significant.

Nonconformance reports for each test are listed in the run reports (Josephson et al. 2009, Guzman-Leong et al. 2009, Geeting et al. 2009, and Sevigny et al. 2009). 


\subsection{Scaling Considerations}

The Pretreatment Engineering Platform (PEP) is not capable of simultaneously matching all aspects of the full-scale Pretreatment Facility (PTF) processes. The relationships between the PEP and PTF are different for different phenomena of interest - that is, different phenomena follow different scaling relationships. This means, for example, that the PEP can be operated to maximize the similarity of its ultrafiltration behavior to that of the PTF, but when this is done, the similarity of its mixing behavior to that of the PTF is not maximized. Though different scaling relationships may have prevented the PEP from behaving exactly like the PTF, PEP operating parameters were selected so that the most important aspects of the PTF processes were preserved in the PEP. This section summarizes the bases of the selected scaling of individual process steps (Section 3.1) and discusses the PEP design and operation to maximize its similarity to the PTF for performance-modeling improvements (Section 3.2).

\subsection{Bases for Scaling of Individual Process Steps}

One consequence of adjusting operating parameters to maximize similarities between the PEP and PTF is that some process steps were conducted at a rate that was 4.5 times that of the PTF (referred to as scale-time), and some required the same amount of time in the PEP as in the PTF (referred to as plant-time). Most transfers, for example, were conducted to maintain a fluid velocity similar to that of the PTF but in piping with diameters approximately ${ }^{1} / 4.5$ that of the PTF. The result was that the transfer of a prototypic volume (i.e., ${ }^{1} / 4.5^{3}$ that of the PTF) took only ${ }^{1} / 4.5$ as much time as it would have in the PTF (i.e., scale-time). Whether a given process operation was conducted at scale- or plant-time was based on the identification of which process parameters were most important to that operation. Table 3.1 indicates which process steps were to be conducted at scale-time and which at plant-time for each step of the three integrated process tests. The following subsections provide the bases of the chosen times for each process step.

Pulse jet mixer (PJM) operating parameters warrant a special note here. When a process step involved Newtonian slurry, the PJMs were operated to match the mixing power per unit volume of the PTF, and when it involved non-Newtonian slurry, the PJMs were operated to match the PJM nozzle velocity of the PTF (Kuhn et al. 2008). Because the transition from one set of PJM control parameters to the other generally required several hours of tuning to achieve target PJM stroke length and nozzle velocity, the transitions were only conducted between process steps. The result was that in all three integrated process tests, PJM mixing in Tanks T01A/B and T02A was operated to match the (mixing power)/volume ratio of the plant until the end of post-caustic-leach solids concentration, and then the Tank T02A PJMs were tuned to match the plant velocity. They were operated in that manner for the remainder of each test. 
Table 3.1. Summary of Integrated Test Steps

\begin{tabular}{|c|c|c|c|c|}
\hline \multicolumn{2}{|c|}{ Caustic Leaching in Tank T01A/B } & \multicolumn{3}{|c|}{ Caustic Leaching in Tank T02A } \\
\hline $\begin{array}{l}\text { Process Step } \\
\text { Feed } \\
\text { Preparation }\end{array}$ & $\begin{array}{c}\text { Integrated Test A } \\
\text { Phase } 1 \text { Simulant }\end{array}$ & $\begin{array}{l}\text { Process Step } \\
\text { Feed } \\
\text { Preparation }\end{array}$ & $\begin{array}{l}\text { Integrated Test B } \\
\text { Phase } 1 \text { Simulant }\end{array}$ & $\begin{array}{c}\text { Integrated Test D } \\
\text { Phase } 1 \text { Simulant + } \\
\text { Cr Solids }\end{array}$ \\
\hline \multirow{2}{*}{$\begin{array}{l}\text { Caustic addition } \\
(5-\rightarrow 3-w t \%)\end{array}$} & \multirow{2}{*}{$\begin{array}{c}\text { Scale-time } \\
\text { In-line at transfer } \\
\text { pump discharge }\end{array}$} & $\begin{array}{c}\text { Initial solids } \\
\text { concentration } \\
(5-\rightarrow 20-w t \%)\end{array}$ & $\begin{array}{c}\text { Plant-time } \\
1 \text { filter bundle } \\
25+5 /-5^{\circ} \mathrm{C}\end{array}$ & $\begin{array}{c}\text { Plant-time } \\
1 \text { filter bundle } \\
25+5 /-5^{\circ} \mathrm{C}\end{array}$ \\
\hline & & $\begin{array}{l}\text { Caustic addition } \\
(20-\rightarrow 12-w t \%)\end{array}$ & $\begin{array}{c}\text { Scale-time } \\
\text { In-line at filter-loop } \\
\text { pump suction }\end{array}$ & $\begin{array}{c}\text { Scale-time } \\
\text { In-line at filter-loop } \\
\text { pump suction }\end{array}$ \\
\hline $\begin{array}{c}\text { Heat-up, } \\
\text { caustic-leach, } \\
\& \text { cool-down } \\
(3-\rightarrow<2-w t \%)\end{array}$ & $\begin{array}{c}\text { Plant-time } \\
\text { leach for } \geq 16 \mathrm{hr} \\
\text { at } 98+2 /-2^{\circ} \mathrm{C}\end{array}$ & $\begin{array}{c}\text { Heat-up, } \\
\text { Caustic-leach, } \\
\& \text { cool-down } \\
(12-\rightarrow 5-w t \%)\end{array}$ & $\begin{array}{c}\text { Plant-time } \\
\text { leach for } \geq 16 \mathrm{hr} \\
\text { at } 98+2 /-2^{\circ} \mathrm{C}\end{array}$ & $\begin{array}{c}\text { Plant-time } \\
\text { leach for } \geq 24 \mathrm{hr} \\
\text { at } 80+2 /-2^{\circ} \mathrm{C}\end{array}$ \\
\hline $\begin{array}{l}\text { Post-caustic-leach } \\
\text { solids concentration } \\
(<2-\rightarrow 17-\mathrm{wt} \%)\end{array}$ & $\begin{array}{l}\text { Plant-time } \\
1 \text { filter bundle } \\
25+5 /-5^{\circ} \mathrm{C}\end{array}$ & $\begin{array}{l}\text { Post-caustic-leach } \\
\text { solids concentration } \\
\quad(5-\rightarrow 17-w t \%)\end{array}$ & $\begin{array}{c}\text { Scale-time } \\
5 \text { filter bundles } \\
25+5 /-5^{\circ} \mathrm{C}\end{array}$ & $\begin{array}{c}\text { Scale-time } \\
5 \text { filter bundles } \\
25+5 /-5^{\circ} \mathrm{C}\end{array}$ \\
\hline $\begin{array}{l}\text { Post-caustic-leach } \\
\text { slurry washing } \\
(\sim 17-w t \%)\end{array}$ & $\begin{array}{c}\text { Scale-time } \\
5 \text { filter bundles } \\
25+5 /-5^{\circ} \mathrm{C}\end{array}$ & $\begin{array}{l}\text { Post-caustic-leach } \\
\text { slurry washing } \\
(\sim 17-w t \%)\end{array}$ & $\begin{array}{c}\text { Scale-time } \\
5 \text { filter bundles } \\
25+5 /-5^{\circ} \mathrm{C}\end{array}$ & $\begin{array}{c}\text { Scale-time } \\
5 \text { filter bundles } \\
25+5 /-5^{\circ} \mathrm{C}\end{array}$ \\
\hline $\begin{array}{l}\text { Nonprototypic } \mathrm{Cr} \\
\text { solids addition } \\
(\sim 17-\mathrm{wt} \%)\end{array}$ & Yes & $\begin{array}{l}\text { Nonprototypic } \mathrm{Cr} \\
\text { solids addition } \\
(\sim 17 \text {-wt } \%)\end{array}$ & Yes & No \\
\hline $\begin{array}{l}\text { Permanganate } \\
\text { addition } \\
(\sim 17-w \mathrm{w} \%)\end{array}$ & $\begin{array}{c}\text { Scale-time } \\
\text { In-line at filter-loop } \\
\text { pump suction }\end{array}$ & $\begin{array}{l}\text { Permanganate } \\
\text { addition } \\
(\sim 17-\mathrm{wt} \%)\end{array}$ & $\begin{array}{c}\text { Scale-time } \\
\text { In-line at filter-loop } \\
\text { pump suction }\end{array}$ & $\begin{array}{c}\text { Scale-time } \\
\text { In-line at filter-loop } \\
\text { pump suction }\end{array}$ \\
\hline $\begin{array}{l}\text { Oxidative leaching } \\
\qquad(\sim 17-\mathrm{wt} \%)\end{array}$ & $\begin{array}{c}\text { Plant-time } \\
\text { leach for } \geq 6 \mathrm{hr} \\
\text { at } 25+0 /-5^{\circ} \mathrm{C}\end{array}$ & $\begin{array}{l}\text { Oxidative leaching } \\
\quad(\sim 17-\mathrm{wt} \%)\end{array}$ & $\begin{array}{c}\text { Plant-time } \\
\text { leach for } \geq 6 \mathrm{hr} \\
\text { at } 25+0 /-5^{\circ} \mathrm{C}\end{array}$ & $\begin{array}{c}\text { Plant-time } \\
\text { leach for } \geq 6 \mathrm{hr} \\
\text { at } 25+0 /-5^{\circ} \mathrm{C}\end{array}$ \\
\hline $\begin{array}{l}\text { Post-oxidative- } \\
\text { leach slurry } \\
\text { washing } \\
(\sim 17 \text {-wt } \%)\end{array}$ & $\begin{array}{c}\text { Scale-time } \\
5 \text { filter bundles } \\
25+5 /-5^{\circ} \mathrm{C}\end{array}$ & $\begin{array}{l}\text { Post-oxidative- } \\
\text { leach slurry } \\
\text { washing } \\
(\sim 17 \text {-wt } \%)\end{array}$ & $\begin{array}{c}\text { Scale-time } \\
5 \text { filter bundles } \\
25+5 /-5^{\circ} \mathrm{C}\end{array}$ & $\begin{array}{c}\text { Scale-time } \\
5 \text { filter bundles } \\
25+5 /-5^{\circ} \mathrm{C}\end{array}$ \\
\hline $\begin{array}{l}\text { Final solids } \\
\text { concentration } \\
(17-\rightarrow 20-\mathrm{wt} \%)\end{array}$ & $\begin{array}{c}\text { Scale-time } \\
5 \text { filter bundles } \\
25+5 /-5^{\circ} \mathrm{C}\end{array}$ & $\begin{array}{c}\text { Final solids } \\
\text { concentration } \\
(17-\rightarrow 20-\mathrm{wt} \%)\end{array}$ & $\begin{array}{c}\text { Scale-time } \\
5 \text { filter bundles } \\
25+5 /-5^{\circ} \mathrm{C}\end{array}$ & $\begin{array}{c}\text { Scale-time } \\
5 \text { filter bundles } \\
25+5 /-5^{\circ} \mathrm{C}\end{array}$ \\
\hline
\end{tabular}

\subsubsection{Initial and Post-Caustic-Leach Solids Concentration}

Cross-flow ultrafiltration of slurries with low-solids content results in filter depth-fouling by fine particles and this results in a gradual decrease in filter flux. The extent of depth-fouling depends on the ratio of (total solids)/(filtration area) for a given filtration step. To a first approximation, the depth-fouling of the initial solids concentration step in the PTF (for the Phase 1 simulant) was reproduced in the PEP by matching the primary filtration parameters, i.e., axial velocity, transmembrane pressure 
(TMP), and the (total solids)/(filtration area) ratio. The (total solids)/(filtration area) ratio was matched between the PTF and the PEP by using one 10-ft filter bundle in the PEP. Given similar depth-fouling and (total solids)/(filtration area), the initial and post-caustic-leach solids concentration steps took approximately the same amount of time in the PEP as they would in the PTF (plant-time).

The alternative, to employ all five filter bundles and conduct the solids concentration steps at scale-time, would have approximately preserved the amount of slurry mixing in Tank T02A during the solids concentration steps in the PEP as expected in the PTF. However, mixing within Tank T02A was expected (and observed) to be relatively vigorous and not a strong factor in the solids concentration processes, and, in this case, the (total solids)/(filtration area) in the PEP would not have been the same as in the PTF.

\subsubsection{Slurry Transfers and In-Line Additions of Caustic, Permanganate, and Wash-Water}

By design, the diameters of slurry transfer and filter-loop lines in the PEP are approximately ${ }^{1 / 4.5}$ those of the PTF. Consequently, to maintain line velocities in the PEP similar to those of the PTF (specifically to preclude solids settling and line plugging), volumetric flow rates in the PEP were approximately $1 / 4.5^{2}$ those of the PTF. Given that PEP vessel volumes are $1 / 4.5^{3}$ those of the PTF, slurry transfers (i.e., the transfer of simulant from one tank to another) were completed in the PEP in $1 / 4.5$ the times of the corresponding transfers in the PTF (scale-time).

In-line additions of caustic $(\mathrm{NaOH})$, permanganate, and wash-water in the PEP were controlled to match the PTF ratio of (addition flow rate)/(total flow rate). This resulted in the PEP having similar in-line ratios of (added chemical volume)/(slurry volume) and heats of solution as in the PTF. Given that PEP slurry transfer flow rates were $1 / 4.5$ those of the PTF, the chemical addition flow rates were also controlled to $1 / 4.5$ those of the PTF. Like the slurry transfers, in-line chemical and wash-water additions were conducted at scale-time.

\subsubsection{Heat-Up, Caustic-Leach, and Cool-Down}

The kinetics of aluminum dissolution required that the duration of the caustic leaching process (Kuhn et al. 2008) be the same in the PEP and full-scale facilities (plant-time). The heat-up and cool-down of the caustic-leach slurry was also controlled to mimic that expected in the PTF (plant-time), so the PEP exhibited approximately the same extent of aluminum dissolution during the heat-up and cool-down. An additional reason to conduct the cool-down at plant-time was to allow a prototypic time for the reprecipitation of the sodium oxalate that had dissolved at the elevated leaching temperature. To the extent that the post-caustic-leach cool-down was prototypic of the PTF, the formation of any precipitates in the filter permeate should be prototypic of the PTF (for this specific simulant).

\subsubsection{Post-Caustic-Leach and Post-Oxidative-Leach Slurry Washing}

An important aspect of slurry washing is the mixing of added wash-water with slurry in Tank T02A. It was therefore considered important that this mixing be similar between PEP and PTF. Because the mixing in Tank T02A was inherently a scale-time phenomenon during any ultrafiltration operation (due to the PEP design of the filter-loop and its return nozzle in Tank T02A), the objective of matching the 
mixing of the PTF vessel UFP-VSL-00002A in the PEP was best done by conducting the washing operations at scale-time also. The intent was to match overall washing performance by satisfying the following:

$$
\frac{\text { PEP slurry wash duration }}{\text { PEP mixing time }} \approx \frac{\text { PTF slurry wash duration }}{\text { PTF mixing time }}
$$

In Equation (3.1), the mixing time is some measure of the time to accomplish a level of mixing, such as the blend time or the turnover time. It is assumed here that the wash duration is controlled by the rate that permeate is generated, which in turn is proportional to the filtration area. Equation (3.1) was approximately satisfied by conducting the washing processes with all five filter bundles in the filter-loop.

When all five filter bundles are used in the PEP filter-loop, the PEP (total solids)/(filtration area) ratio will not match that of the PTF. However, slurry washing was conducted on slurries having roughly $17-w t \%$ solids (the actual concentration varied due to changing liquid densities and the dissolution of sodium oxalate after caustic leaching). At these relatively high-solids concentrations, ultrafilter-fouling behavior is different from its behavior at low-solids concentrations because of the formation of a layer of solids (cake) on the filter surface. The presence of a cake reduces depth-fouling to negligible levels, making the (total solids)/(filtration area) ratio unimportant and effectively resulting in the PEP having similar filter fluxes as the PTF. Thus, when the slurry solids concentrations were high enough to produce a cake on the filter surface, the filtration process was operated at scale-time (i.e., with all five filter bundles) without distorting the filter flux significantly.

\subsubsection{Oxidative Leaching}

The oxidative leaching process steps were given the same duration in the PEP as in the PTF (plant-time). The bases for this approach are essentially the same as the bases for conducting caustic leaching at plant-time - the rates of chemical reactions in the PEP are inherently plant-time.

\subsubsection{Final Solids Concentration}

The final solids concentration step was conducted at scale-time with five filter bundles in the filter-loop. This choice of filter-loop configuration was based on the facts that final solids concentration occurs immediately after the post-oxidative-leach wash, which uses all five filter bundles, and that the (total solids)/(filtration area) ratio was not expected to be important to achieving a prototypic filter flux.

\subsection{PEP as Indicator of PTF Performance}

Pretreatment Engineering Platform testing included special studies to verify or correct the following four specific PTF performance modeling assumptions:

1. Caustic leaching performance in the PTF will be the same as determined by laboratory testing.

2. Oxidative leaching performance in the PTF will be the same as determined by laboratory testing.

3. Ultrafiltration performance (i.e., filter flux and changes in flux due to depth-fouling or other phenomena) in the PTF will be the same as determined by laboratory testing. 
4. Slurry washing is approximated by an ideal, continuously stirred tank reactor; wash-water additions are assumed to be instantaneously blended throughout the slurry.

The first three assumptions involve scale-up issues (e.g., "Will the PTF achieve the same leaching rates as obtained from isothermal, mechanically stirred laboratory tests?") that have been evaluated by direct comparison of laboratory and PEP testing with the same simulants (see Sections 9, 11, and 8, respectively). The fourth assumption has been evaluated by directly measuring PEP slurry liquid concentrations during the slurry washing processes (see Section 10). Each of these four evaluations rely implicitly on the principle that the PEP quantitatively behaves similarly to the PTF and that PEP performance is essentially the same as the PTF performance would be with the same simulant. The following subsections provide the bases for this assumption and discuss its limitations.

\subsubsection{Caustic Leaching in Tank T01A/B (Functional Test and Integrated Test A)}

The PEP was designed to achieve prototypic caustic leaching performance in Tank T01A/B by employing the following design features: ${ }^{(a)}$

- The ultrafiltration feed preparation vessels, Tank T01A/B, are dimensionally prototypic with inlet and outlet nozzles and primary internal structures (e.g., PJMs) also sized and located prototypically.

- The mixing equipment in Tank T01A/B is prototypic. PJMs and PJM nozzles are dimensionally scaled and located to achieve prototypic mixing.

- The in-line caustic addition inlet is prototypically located on the outlet of HLP-PMP-T21.

The PEP design limitations, such as Tank T01A/B internal support structures that were not prototypic, were assumed to be of minor importance to prototypic performance.

Operation of the PEP to achieve prototypic caustic leaching was based on guidelines given in Technical Basis for Scaling Relationships for the Pretreatment Engineering Platform (Kuhn et al. 2008), the process description, ${ }^{(b)}$ and specific directions given in the Test Plan, Pretreatment Engineering Platform (PEP) Testing (Phase I). ${ }^{(\mathrm{c})}$ Key operational guidelines were:

- The caustic addition location and the (in-line caustic addition rate)/(slurry feed rate) ratio should match that of the PTF. Caustic should be added to the slurry transfer line leading to Tank T01A after the transfer pump to achieve similar blending to the PTF.

- Pulse jet mixer parameters should be adjusted to match the power/volume ratio of PTF PJMs to achieve prototypic mixing for blending of components and off-bottom suspension of particles in the Newtonian slurry expected during caustic leaching. Planned operations of the PJMs (i.e., turning off the vacuum refill above $60^{\circ} \mathrm{C}$ ) was also demonstrated.

(a) Stiver B. 2007. Functional Requirements for Pretreatment Engineering Platform (PEP). 24590-PTF-3YD-UFP-00002, Rev. 1, Bechtel National Inc., Richland, Washington.

(b) Lehrman S. 2008. Pretreatment Engineering Platform (PEP) Phase I Testing Process Description. 24590-WTP-RPT-PET-07-002, Rev. 1, Bechtel National Inc., Richland, Washington.

(c) Josephson GB, OP Bredt, JK Young, and DE Kurath. 2009. Test Plan for Pretreatment Engineering Platform (PEP) Testing (Phase I). TP-RPP-WTP-506, Rev. 0.4, Pacific Northwest National Laboratory, Richland, Washington. 
- The prototypic air sparge mixing from the steam ring air purge should also match the power/volume ratio of the PTF. Because air sparge mixing scales differently at different heights within a vessel, and because its most important impact is to mix the upper regions of the leaching vessel, the steam ring air sparge flow rate was chosen to match the superficial gas velocity of the PTF at about 48 -in., or about $73 \%$ of the normal batch depth in Tank T01A. Regions below this will receive somewhat more mixing than in the PTF, while regions above this will receive somewhat less mixing than the PTF; however, the integrated power/volume ratio in the purge air-mixed regions of the PEP and PTF vessels should be comparable (Kuhn et al. 2008).

- The heat-up method (i.e., direct steam injection), rate, duration, and final temperature should match those of the PTF.

- The dilution of reactants by steam condensate accumulation should match that of the PTF to the extent possible.

- Slurry, caustic, and steam condensate volumes should result in prototypic fluid levels throughout the leaching process. These could impact boehmite leaching because mixing can be a function of fluid depth.

Pretreatment Engineering Platform operations were evaluated by Mahoney et al. (2009) against these guidelines. It was concluded that, to the extent that the PEP design and operation allowed, caustic leaching for Integrated Test A was prototypic of the PTF.

\subsubsection{Caustic Leaching in Tank T02A (Functional Test and Integrated Tests B and D)}

Design and operational issues for prototypic caustic leaching in Tank T02A are analogous to those for leaching in Tanks T01A/B with the exception that Tank T02A has dedicated air sparge mixers to augment PJM mixing when the slurry level is high and the caustic is introduced upstream of PMP-T42A. The air sparge mixer flow rates were chosen, like the steam ring air purge, to match the superficial gas velocity at specific reference elevations and thereby achieve comparable integrated power/volume mixing to the PTF (Kuhn et al. 2008). The key guidelines for prototypic behavior were reasonably satisfied during Integrated Test B and Mahoney et al. (2009) concluded that, to the extent that the PEP design and operation allow, caustic leaching was prototypic of the PTF.

\subsubsection{Oxidative Leaching}

The PEP was designed to achieve prototypic oxidative leaching performance in Tank T02A by employing the following design features: ${ }^{\text {(a) }}$

- The ultrafiltration feed vessel (Tank T02A) is dimensionally prototypic with inlet and outlet nozzles and primary internal structures (e.g., PJMs) also sized and located prototypically.

- The mixing equipment in Tank T02A is prototypic. The PJMs, PJM nozzles, and filter-loop return nozzle are scaled and located to achieve prototypic mixing.

(a) Stiver B. 2007. Functional Requirements for Pretreatment Engineering Platform (PEP). 24590-PTF-3YD-UFP-00002, Rev. 1, Bechtel National Inc., Richland, Washington. 
- The in-line $\mathrm{NaMnO}_{4}$ reagent addition inlet is prototypically located at the inlet of PMP-T42A.

The PEP design limitations, such as tank internal support structures that were not prototypic, are assumed to be of minor importance to prototypic performance.

Operation of the PEP to achieve prototypic oxidative leaching was based on guidelines given in Technical Basis for Scaling Relationships for the Pretreatment Engineering Platform (Kuhn et al. 2008), PEP Process Description, ${ }^{(a)}$ and specific directions given in the Test Plan, Pretreatment Engineering Platform (PEP) Testing (Phase I). ${ }^{(\mathrm{b})}$ Key guidelines were:

- The location of the $\mathrm{NaMnO} 4$ reagent in-line addition and the (reagent addition rate)/(slurry feed rate) ratio should match that of the PTF. The reagent should be added to the filter-loop upstream of PMP-T42A to achieve similar blending to the PTF.

- Prototypic mixing for the non-Newtonian slurry during the leach is best achieved by adjusting PJM parameters and the filter-loop flow rate to match the planned nozzle velocities of the PTF. This resulted in greater mixing of the slurry than in the PTF, but was deemed necessary to maintain the prototypic PJM mixing cavity in Tank T02A in the non-Newtonian slurry.

- Prototypic air sparge mixing from the air sparge tubes and the steam ring air purge should match the power/volume ratio of the PTF. Because air sparge mixing scales differently at different heights within a vessel, and because its most important impact is to mix the upper regions of the leaching vessel, the steam ring air sparge flow rate was chosen to match the power/volume ratio of the PTF at about 39-in. or $60 \%$ of the normal batch depth in Tank T02A. Regions below this will receive somewhat less mixing than in the PTF; regions above this will receive somewhat more mixing than in the PTF.

- Slurry levels in Tank T02A should be prototypic of the PTF because mixing can be a function of fluid depth.

These operational parameters were generally satisfied and the oxidative leaching results are assumed to be reasonably prototypic of the PTF.

\subsubsection{Filtration Flux Testing}

The PEP was designed to achieve prototypic filter performance by employing the following design features: ${ }^{(\mathrm{c})}$

- The ultrafiltration feed vessel (Tank T02A) is dimensionally prototypic with inlet and outlet nozzles and primary internal structures (e.g., PJMs) also sized and located prototypically to achieve prototypic mixing.

(a) Lehrman S. 2008. Pretreatment Engineering Platform (PEP) Phase I Testing Process Description. 24590-WTP-RPT-PET-07-002, Rev. 1, Bechtel National Inc., Richland, Washington.

(b) Josephson G, O Bredt, J Young, and D Kurath. 2008. Pretreatment Engineering Platform (PEP) Testing (Phase I). TP-RPP-WTP-506, Rev 0.4, River Protection Project, Hanford Tank Waste Treatment and Immobilization Plant, Richland, Washington.

(c) Stiver B. 2007. Functional Requirements for Pretreatment Engineering Platform (PEP). 24590-PTF-3YD-UFP-00002, Rev. 1, Bechtel National Inc., Richland, Washington. 
- The dual ultrafilter-loop pumps, PMP-T42A and -T43A, are functionally prototypic of the PTF. They are centrifugal pumps, like in the PTF, capable of maintaining prototypic slurry flow rates and pressures.

- The ultrafilter tube bundles are similar to those in the PTF; each bundle is composed of multiple filter tubes arranged in parallel. The PEP filter bundle end caps, which serve as manifolds for the individual filter tubes, are also similar to those of the PTF. They mimic any entrance or exit effects on filter flux and cake formation.

- Ultrafilter pulse-pots are functionally prototypic of the PTF (e.g., a drop in pressure within the pulse-pot as it is emptied is volumetrically prototypic) and can be operated in a prototypic manner.

- Individual filter tubes are essentially identical to those to be used in the PTF, being 0.5 -in. inside diameter, sintered, stainless steel membranes of nominally $0.1-\mu \mathrm{m}$ pore size and the same lengths as to be used in the PTF.

- The PEP has three 10-ft-long and two 8-ft-long filter bundles, like the PTF, arranged similarly (in-series with two $90^{\circ}$ pipe bends between successive bundles) and oriented at 1:25 slope from the horizontal as the PTF per testing design ${ }^{\text {a }}$ (for drainage).

Operation of the PEP to achieve prototypic filtration performance was based on guidelines given in Technical Basis for Scaling Relationships for the Pretreatment Engineering Platform (Kuhn et al. 2008), PEP Process Description, ${ }^{(b)}$ and specific directions given in the Test Plan, Pretreatment Engineering Platform (PEP) Testing (Phase I). ${ }^{(\mathrm{c})}$ Key guidelines were:

- The average PEP axial flow velocity in the individual tubes should match that of the PTF. This is to provide similar flow conditions for cake formation.

- The TMP drop (average pressure difference between the tubeside and shellside of each filter bundle) should match that of the PTF. This matches the permeation driving force.

- Backpulsing should follow the same operational parameters (initial over-pressure, deadband pressure, etc.) and control sequence as in the PTF (fill, isolate, pressurize, drain to target, repressurize, backpulse) to achieve prototypic backpulse effectiveness.

These guidelines were generally achieved during the low-solids and high-solids filtration testing, and PEP filter performance was assumed to be prototypic of the PTF.

(a) WTP Engineering is considering reducing the PTF filter slope to 1:50

(b) Lehrman S. 2008. Pretreatment Engineering Platform (PEP) Phase I Testing Process Description. 24590-WTP-RPT-PET-07-002, Rev. 1, Bechtel National Inc., Richland, Washington.

(c) Josephson G, O Bredt, J Young, and D Kurath. 2008. Pretreatment Engineering Platform (PEP) Testing (Phase I). TP-RPP-WTP-506, Rev 0.4, River Protection Project, Hanford Tank Waste Treatment and Immobilization Plant, Richland, Washington. 


\subsubsection{Solids Washing}

The PEP was designed to achieve prototypic slurry washing performance by employing the following design features: ${ }^{\text {(a) }}$

- The ultrafiltration feed vessel, Tank T02A, is dimensionally prototypic of the PTF vessel with its filter-loop outlet and inlet nozzles located prototypically, and its primary internal structure (the PJM cluster) is also sized and located prototypically.

- Mixing equipment within Tank T02A is prototypic. The PJMs, PJM nozzles, and filter-loop return nozzle are dimensionally scaled and located to achieve prototypic mixing of non-Newtonian slurries. Air sparge mixers are prototypically located and can be operated to mix the region above the PJM mixing cavity to simulate their operation in the PTF. Mixing from the air purge of the steam injection ring can be controlled to simulate its effects in the PTF.

- The filter-loop is designed with pumps, filters, pulse-pots, wash-water inlet, a spiral-plate chiller, and all appropriate instruments and controls to operate prototypically.

- Five cross-flow ultrafilter bundles are installed in the filter-loop (three 10-ft bundles, two 8-ft bundles), each with 12 PTF-size filter tubes, to prototypically mimic the filtration rates and behavior of the PTF.

There are deviations from prototypic configuration. For example, the filter-loop is volumetrically larger than would be prototypic, and some of the Tank T02A internals (e.g., PJM support structure) are not prototypic and could affect mixing dynamics. Only the filter-loop volume is considered here to be of significant concern; it is discussed in Section 3.2.5.1.

Operation of the PEP to achieve slurry washing prototypic of the PTF is based on guidelines described in Technical Basis for Scaling Relationships for the Pretreatment Engineering Platform (Kuhn et al. 2008) and specific directions given in the Test Plan, Pretreatment Engineering Platform (PEP) Testing (Phase I). ${ }^{(b)}$ Key guidelines were:

- Prototypic mixing in Tank T02A is best achieved for non-Newtonian slurries by maintaining the same mixing jet velocities in the PEP as in the PTF. Specifically, PJMs should be operated to achieve $12-\mathrm{ft} / \mathrm{s}$ jet velocities and cycle times that are $1 / 4.5$ that of the PTF and the filter-loop flow rate should be 109 GPM to achieve a prototypic jet velocity at its return nozzle in Tank T02A. These choices result in mixing the contents of PEP Tank T02A approximately 4.5 times faster than in the PTF.

- The PEP filter-loop should be configured to employ all five filter bundles, resulting in an overall slurry wash duration that is approximately $1 / 4.5$ that of the PTF. This is necessary, given the mixing parameters chosen above, to maintain

(a) B Stiver. 2007. Functional Requirements for Pretreatment Engineering Platform (PEP). 24590-PTF-3YD-UFP-00002, Rev. 1, Bechtel National Inc., Richland, Washington.

(b) GB Josephson, OP Bredt, JK Young, and DE Kurath. 2009. Test Plan for Pretreatment Engineering Platform (PEP) Testing (Phase I). TP-RPP-WTP-506, Rev. 0.4, Pacific Northwest National Laboratory, Richland, Washington. 


$$
\frac{\text { PEP slurry wash duration }}{\text { PEP mixing time }} \approx \frac{\text { PTF slurry wash duration }}{\text { PTF mixing time }}
$$

Josephson et al. ${ }^{(a)}$ discuss the impacts of this choice on the solids/(filter area) ratio and on filter flux.

- The filter-loop operation should be controlled to match PTF axial velocity (in individual filter tubes), filter TMP, and temperature.

- Wash-water should be added at a prototypic location (i.e., upstream of PMP-T42A). The wash-water batch volume should maintain

$$
\frac{\text { PEP wash water batch volume }}{\text { PEP UFP }-2 \text { slurry volume }} \approx \frac{\text { PTF wash water batch volume }}{\text { PTF UFP }-2 \text { slurry volume }}
$$

and the wash-water addition rate should maintain

$$
\frac{\text { PEP wash water addition rate }}{\text { PEP filter - loop flow rate }} \approx \frac{\text { PTF wash water addition rate }}{\text { PTF filter - loop flow rate }}
$$

- The slurry level in Tank T02A should be prototypic of the level in PTF so the volume of slurry being mixed in this vessel is prototypic.

The air sparge and steam injection ring air purge flow rates were scaled in the PEP to approximately match the (mixing power)/volume ratio in the PTF in the region above the PJM mixing cavity (Kuhn et al. 2008). However, in all four slurry washing processes considered in this report, the lower air spargers were set to their idle flow rate (as they would be in the PTF) and slurry levels in Tank T02A were always below the upper air sparger (as they would be in the PTF). As such, the air sparge mixers were expected to contribute little to the mixing in Tank T02A. Matching (mixing power)/volume with the air spargers and steam injection ring air purge result in mixing times similar to those of the PTF and less mixing than in the PTF for a slurry wash duration that is $1 / 4.5$ times that of the PTF (as is the objective of bullets 1 and 2 above). Though the impact is expected to be very minor, the less-than prototypic air bubble mixing in the PEP should lead to less mixing in the PEP than in the PTF and slightly lower wash efficiencies in the PEP.

Two nonprototypic conditions that could impact the applicability of PEP wash efficiencies to PTF modeling were identified. First, the PEP filter-loop volume was significantly larger than would be prototypic of the PTF, so the total volume of slurry in the filter-loop and Tank T02A was larger than would be prototypic of the PTF. Second, not all PEP operational parameters (specified to achieve prototypic washing performance) could be maintained at their target values during PEP testing. These two issues are considered in Sections 3.2.5.1 and 3.2.5.2.

(a) Josephson GB, OP Bredt, JK Young, and DE Kurath. 2009. Test Plan for Pretreatment Engineering Platform (PEP) Testing (Phase 1). TP-RPP-WTP-506, Rev. 0.4, Pacific Northwest National Laboratory, Richland, Washington. 


\subsubsection{PEP Nonprototypic Filter-Loop Volume with Respect to Washing}

The PEP filter-loop volume, about 82 gal, was significantly larger than would be prototypic of the PTF; prototypic would be ${ }^{1780} / 4.5^{3}=19.5$ gal. ${ }^{(a)}$ In Integrated Test A, the post-caustic-leach wash prototypic volume of slurry in Tank T02A was about 185 gal and the total prototypic slurry volume should have been $19.5+185=204.5$ gal. The actual Integrated Test A volume was about $82+185=266$ gal. In Integrated Test B, the prototypic total slurry volume should have been about 77 gal, but actually was about 139 gal. Post-oxidative-leach wash slurry volumes were similar. Because the wash-water batch volume was a fixed quantity (11 gal) in the PEP (see operational parameter key bullets 4 and 5 above), an increase in the total volume of slurry being washed will increase the number of wash batches needed to achieve a targeted dilution. The nonprototypically large filter-loop volume also results in a greater fraction of the slurry residing in the filter-loop (where it does not participate in mixing within Tank T02A) and a longer time for the wash-water (which is introduced near the start of filter-loop) to reach Tank T02A.

To help assess the effects of the larger-than-prototypic PEP filter-loop volume on wash efficiency, Baldwin et al. (2009) developed and solved numerically a simple mathematical model of the system for conditions of interest. The model includes the time lag between the time that a water addition is started and the time the water-diluted slurry reaches Tank T02A as (filter-loop volume)/(filter-loop flow rate). Mixing within the filter-loop is assumed to be locally instantaneous, but the axial mixing is negligible. This is based on the view of the filter-loop as a pipe with turbulent plug flow, so the slurry that was diluted with wash-water moves as a slug from the point of water injection to the end of the loop at the return nozzle in TankT02A. Slurry entering Tank T02A is divided into a fraction that mixes instantaneously with the contents of Tank T02A and a fraction that bypasses the contents of the vessel and is fed directly into the filter-loop inlet. The model allows the slurry volume in Tank T02A to increase during wash-water addition (because water rate $>$ permeate production rate) and decrease when wash-water addition is stopped (because permeate production reduces total slurry volume). Wash-water additions were initiated when the slurry volume in Tank T02A dropped to a specified value (equivalent to the level-based control used in PEP), and stopped when the specified volume (11 gal) had been added. The point of the model is not to predict actual wash efficiencies, but rather to examine changes in wash efficiencies associated with different filter-loop volumes and flow rates.

An evaluation of the model in Baldwin et al. (2009) indicates that the primary effects associated with the larger than prototypic PEP filter-loop volume of 1) delaying the time that wash-water-diluted slurry reaches Tank T02A, and 2) changing the fraction of slurry that resides in the loop (and does not participate in mixing in Tank T02A) affect the wash efficiency by less than $1 \%$ in both Integrated Test A and Integrated Test B washing scenarios. When compared to observed differences between solute species, these effects were determined to be negligible (Baldwin et al. 2009).

\subsubsection{Washing Deviations of Operational Parameters from Targeted Values}

Drift in a filter-loop flowmeter reading and air entrainment at the filter-loop inlet resulted in poor control of the filter-loop flow rate during Integrated Test A slurry washing. This potentially had two important effects. First, if the actual slurry flow rate was much higher (or lower) than the prototypic

(a) Lehrman S. 2008. Pretreatment Engineering Platform (PEP) Phase 1 Testing Process Description. 24590-WTP-RPT-PET-07-002, Rev 0, Bechtel National, Inc., Richland, Washington. 
109 GPM, the filter-loop return nozzle jet velocity in Tank T02A would be higher (or lower), and mixing in Tank T02A from the return jet would be correspondingly greater (or less). Second, a nonprototypic filter-loop flow rate results in a nonprototypic amount of dilution in the filter-loop because of wash-water addition. Higher loop flow rates would result in less dilution by the wash-water addition stream and potentially higher wash efficiency during the period that wash-water is added.

Wash efficiencies in Integrated Test A, where washing was conducted with a minimum level in Tank T02A of $\sim 44$-in., and Integrated Test B, where the minimum level in Tank T02A was $\sim 17$-in., were both approximately 1 (Baldwin et al. 2009). This indicates that slurry mixing limitations in Tank T02A did not significantly impact washing efficiency. The impact of nonprototypic filter-loop return jet velocities, experienced in all three integrated process tests, is consequently assumed to have had negligible effects on the calculated wash efficiencies.

The impact of high and low filter-loop flow rate on the amount of dilution by the wash-water addition was also evaluated by Baldwin et al. (2009) This issue was evaluated using the model described above. The model indicates that flow rates ranging from 85 GPM (based on observed flow rates in Integrated Test B) to 140 GPM (an upper bound of flow rates experienced in Integrated Test A) have little effect on wash efficiencies, being generally less than $0.5 \%$ different. 


\subsection{Experimental Equipment}

Three test apparatuses were used in the process testing discussed in this report. These are distinguished as follows.

- Pretreatment Engineering Platform (PEP): The PEP was designed to perform engineering-scale demonstrations of the Hanford Tank Waste Treatment and Immobilization Plant (WTP) pretreatment ultrafiltration and leaching processes. To the extent possible in a scaled-down system, the PEP was designed and operated to exhibit approximately the same mixing behavior, chemical reaction rates, and ultrafiltration behavior as the Pretreatment Facility (PTF). The three vessels to be used for leaching, Tank T01A/B and Tank T02A, are geometrically similar to their WTP counterparts, with their heights and diameters scaled by ${ }^{1} / 4.5$. Key cross-flow ultrafiltration components, including all five filter bundles, are also prototypic of the PTF. Most other equipment, including a spiral plate heat exchanger, transfer piping, pumps, instrumentation, control valves, and ancillary reagent systems, is functionally prototypic, i.e., designed to achieve the same operational effect in the PEP as in the PTF. The PEP also includes nonprototypic equipment to increase the flexibility of testing, and nonprototypic instrumentation to enhance test data and diagnostics. The PEP is discussed in greater detail in Section 4.1.

- Cell Unit Filter (CUF): The CUF was designed to perform laboratory-scale cross-flow ultrafiltration experiments with a single 2-ft section of the PTF filter tubes. Unlike the PEP test system, CUF equipment and vessel dimensions are not prototypic of the PTF. Having nominally the same key equipment as the PTF ultrafiltration system, it can also be used to conduct leaching and solids washing operations, but differences in the mixing and heating systems between the CUF and PTF limit the extent that the CUF can be assumed to behave like the PTF. The CUF equipment and instrumentation are described in more detail in Section 4.2.

- Laboratory-scale stirred-beaker leaching system: Laboratory apparatus was developed to investigate caustic and oxidative leaching under well-mixed, isothermal conditions. Five separate (but essentially identical) systems were constructed, each composed of a 1-L covered plastic vessel with a rotating blade mixer and side mixing baffles. Heating tape controlled by a temperature sensor allowed ramped heating and temperature control above room temperature. A more complete description of these apparatuses is given in Section 4.3.

\subsection{Pretreatment Engineering Platform (PEP)}

This section discusses the equipment, instrumentation and controls, and sampling systems of the PEP. Detailed descriptions of the PEP are given by Daniel et al. (2009b).

\subsubsection{Process Equipment}

Figure 4.1 depicts the major components of the PEP, excluding reagent supply and utility systems. Prototypic equipment is shown in red on Figure 4.1 and is listed in Table 4.1. Functionally prototypic equipment (including transfer lines) is shown in black in Figure 4.1 and is listed in Table 4.2. Nonprototypic equipment (i.e., not in WTP) is shown in blue in Figure 4.1 and is listed in Table 4.3. 


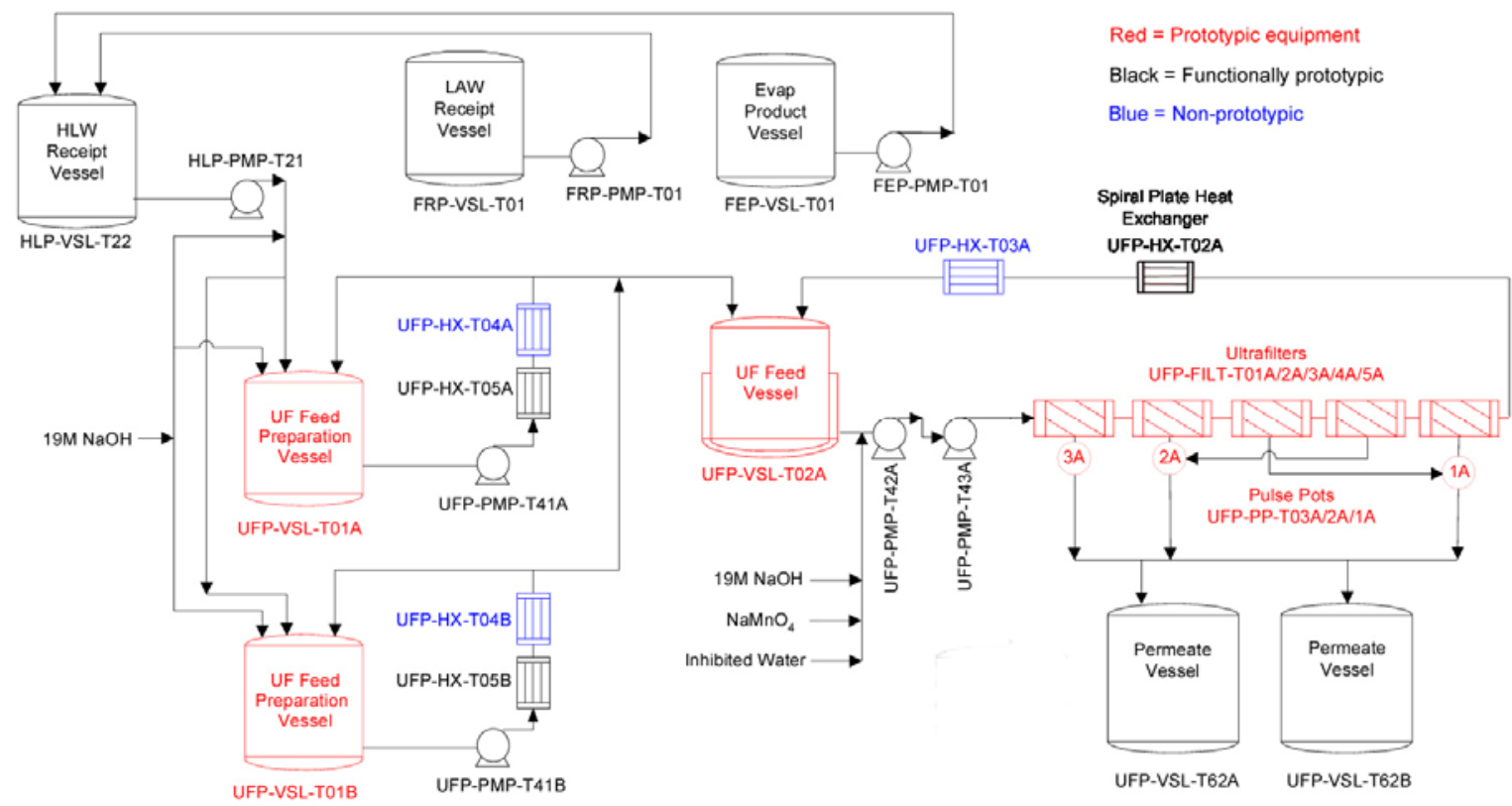

Figure 4.1. PEP Simplified Flow Diagram

Images of the equipment skids inside Process Development Laboratory-West (PDL-W) are shown in Figure 4.2 through Figure 4.5. A rendering of the PEP is shown in Figure 4.6. The equipment was provided on a total of 16 sections, or skids. Nine of the skids were installed inside of the PDL-W building, occupying an area approximately the size of a basketball court. The remaining skids (i.e., utilities) were installed outside the PDL-W building.

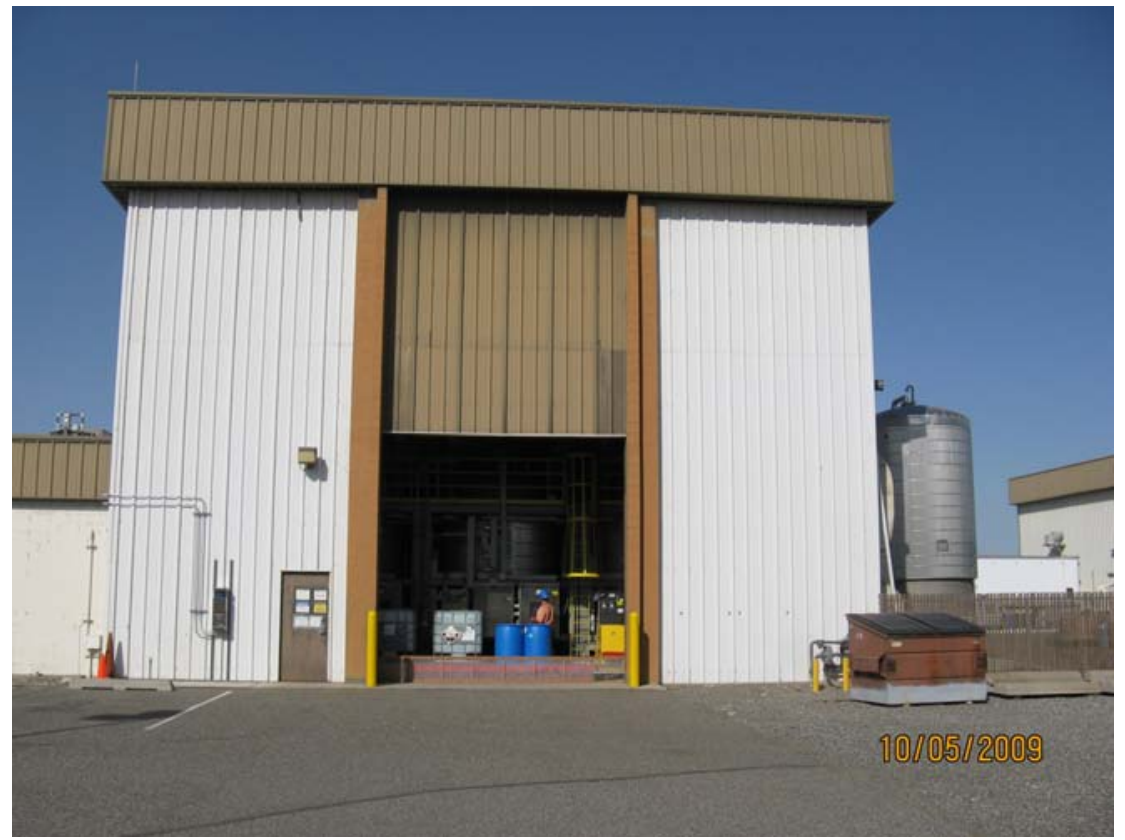

Figure 4.2. A Majority of the PEP Skids Were Moved into PDL-W and Assembled into the Two-Story Structure (looking North) 


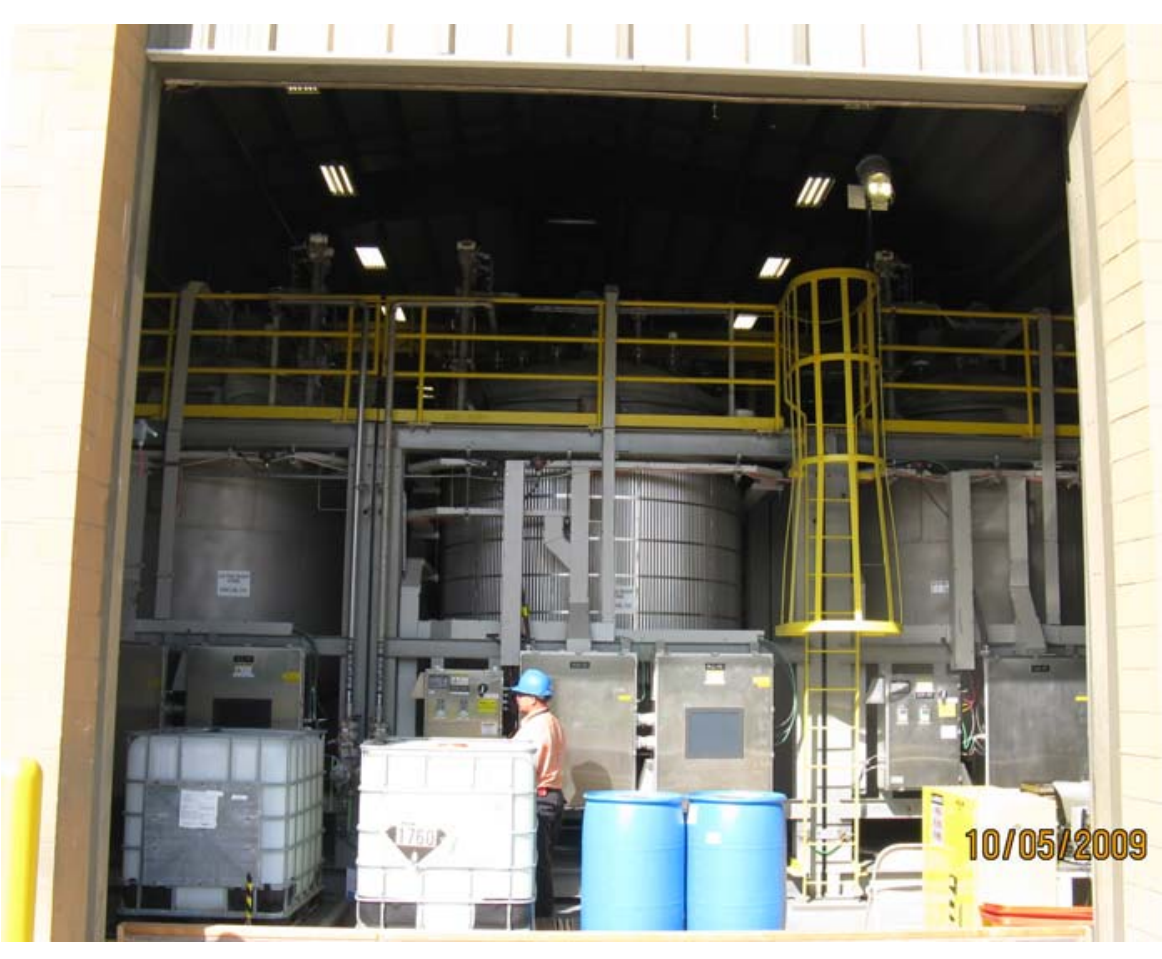

Figure 4.3. Vessels FRP-VSL-T01, HLP-VSL-T22, and FEP-VSL-T01 at Ground Level (looking North)

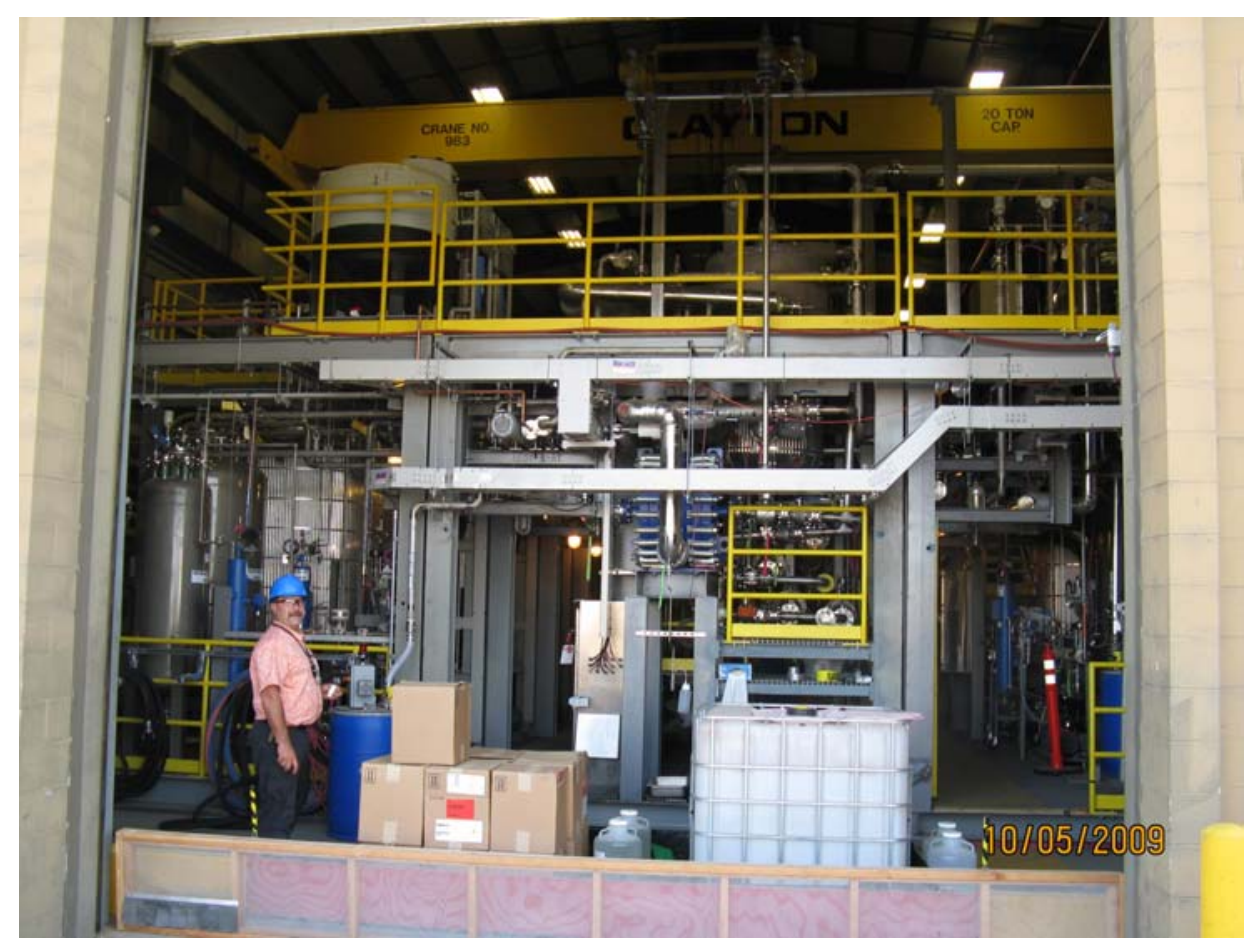

Figure 4.4. The PEP as Viewed Through the North Rollup Door on PDL-W 


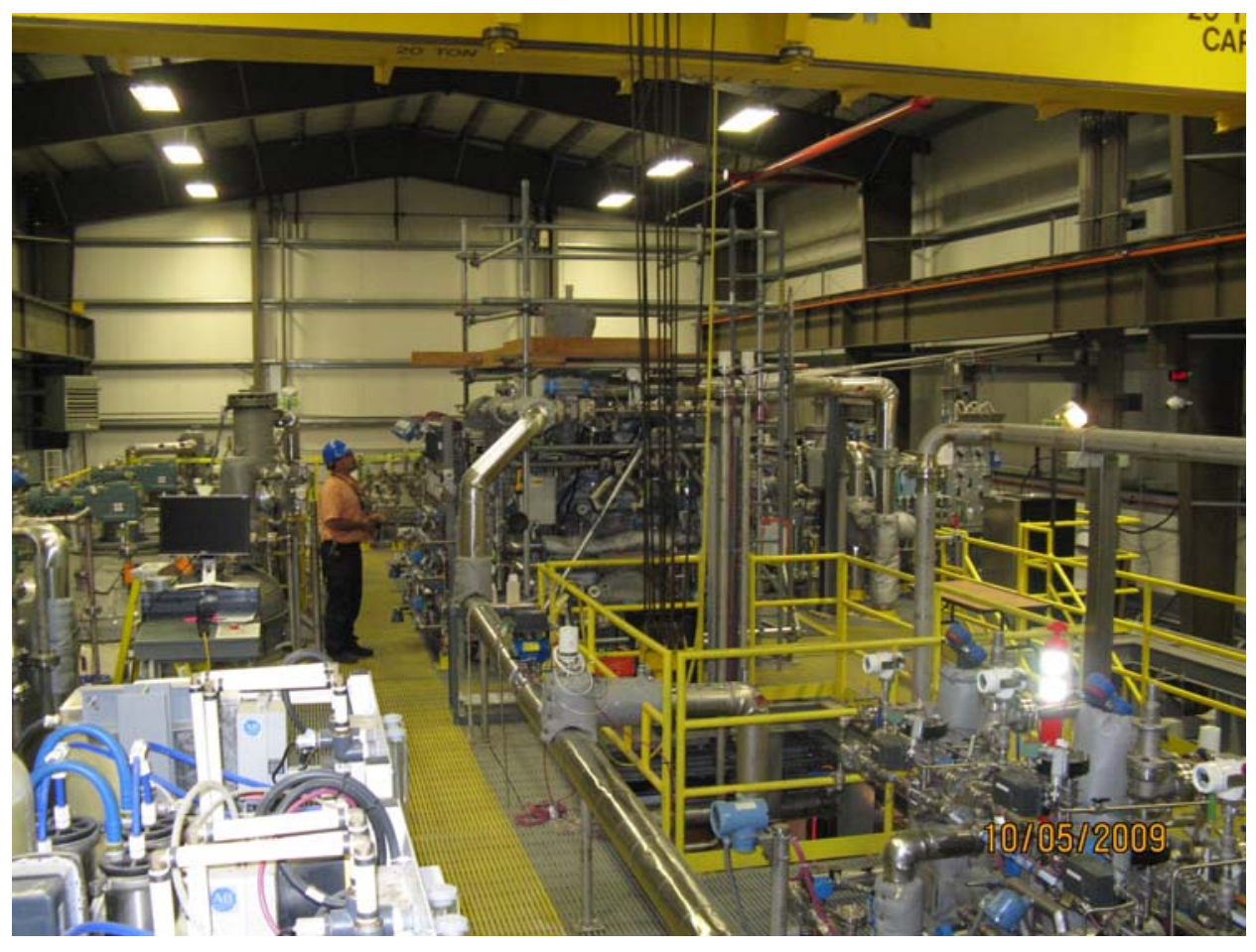

Figure 4.5. Looking South on the Second Floor of the PEP. Readings are being collected from instruments on the upper portion of Tank T02A. 


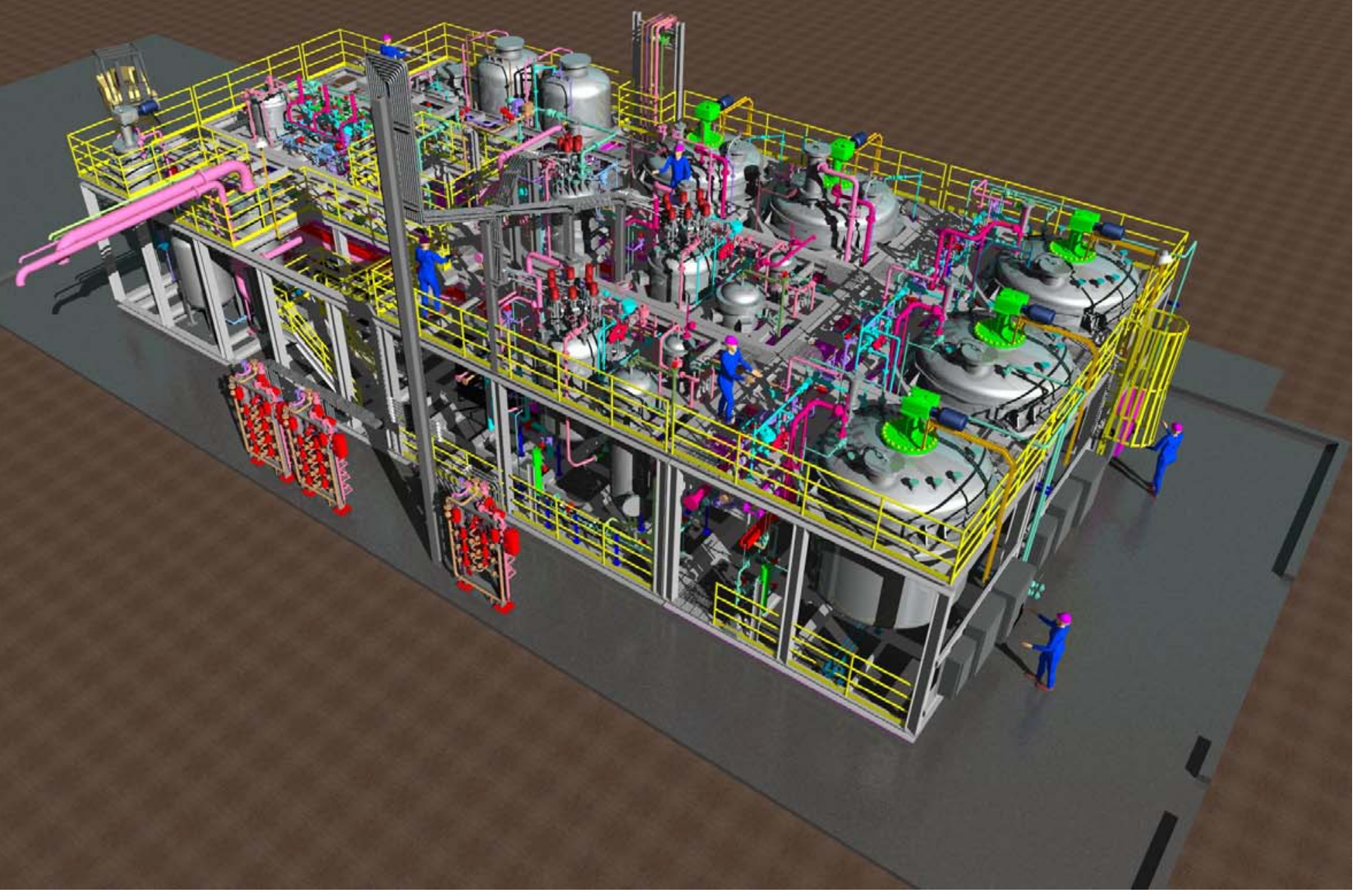

Figure 4.6. PEP Rendering (viewed from the Southwest—not to scale) 
Table 4.1. PEP Prototypic Major Equipment

\begin{tabular}{|c|c|c|}
\hline Name & Equipment Number & Comments \\
\hline $\begin{array}{l}\text { UFP feed preparation vessels } \\
\text { (including steam ring) }\end{array}$ & UFP-VSL-T01A/B & Dimensionally prototypic of UFP-VSL-00001A/B \\
\hline $\begin{array}{l}\text { UFP feed vessel } \\
\text { (including steam ring) }\end{array}$ & UFP-VSL-T02A & Dimensionally prototypic of UFP-VSL-00002A \\
\hline Air sparge mixers & $\begin{array}{l}\text { UFP-VSL-T02A } \\
\text { nozzles } 1-16\end{array}$ & $\begin{array}{l}\text { Provided mixing sparge air scaled to match the mixing } \\
\text { power per unit volume of the PTF in the upper region of } \\
\text { the vessels }\end{array}$ \\
\hline Pulse jet mixers (PJM) & $\begin{array}{l}8 \text { PJMs in each } \\
\text { UFP-VSL-T01A/B; } \\
6 \text { PJMs in } \\
\text { UFP-VSL-T02A }\end{array}$ & $\begin{array}{l}1 / 4.5 \text { scale of all PJM dimensions. The PJM stroke was } \\
\text { adjusted to match the plant stroke fractional volume }\end{array}$ \\
\hline Ultrafilters & $\begin{array}{l}\text { UFP-FILT-T01A/2A/ } \\
3 \mathrm{~A} / 4 \mathrm{~A} / 5 \mathrm{~A}\end{array}$ & $\begin{array}{l}\text { Three } 10 \text {-ft and two } 8 \text {-ft-long filter bundles connected } \\
\text { in-series, each containing } 12 \text { full-size PTF filter tubes. The } \\
\text { total filter area is } \sim(1 / 4.5)^{2} \text { that of the PTF; the filter area of } \\
\text { each filter bundle is } \sim(1 / 4.5)^{2} \text { of the corresponding PEP } \\
\text { filter bundle. }\end{array}$ \\
\hline Ultrafiltration pulse-pots & UFP-PP-T01A/2A/3A & $\begin{array}{l}\text { The volume of pulse-pots was scaled }(1 / 4.5)^{2} \text { to provide the } \\
\text { same backpulse volume per filter area. }\end{array}$ \\
\hline
\end{tabular}


Table 4.2. Functionally Prototypic Major PEP Equipment and Systems

\begin{tabular}{|c|c|c|}
\hline Name & Equipment Number & Comments \\
\hline $\begin{array}{l}\text { High-level waste (HLW) feed } \\
\text { receipt vessel }\end{array}$ & HLP-VSL-T22 & $\begin{array}{l}\text { Provide feed simulant storage. Agitated with } \\
\text { nonprototypic blade mixer. }\end{array}$ \\
\hline $\begin{array}{l}\text { Feed Evaporation Process } \\
\text { (FEP) vessel }\end{array}$ & FEP-VSL-T01A & $\begin{array}{l}\text { Provide feed simulant storage. Agitated with } \\
\text { nonprototypic blade mixer. }\end{array}$ \\
\hline $\begin{array}{l}\text { Feed Receipt Process (FRP) } \\
\text { vessel }\end{array}$ & FRP-VSL-T01A & $\begin{array}{l}\text { Provide feed simulant storage. Agitated with } \\
\text { nonprototypic blade mixer. }\end{array}$ \\
\hline $\begin{array}{l}\text { Filter permeate collection } \\
\text { vessels }\end{array}$ & UFP-VSL-T62A/B & $\begin{array}{l}\text { Provide storage of permeate. Agitated with nonprototypic } \\
\text { blade mixer. }\end{array}$ \\
\hline HLW lag storage vessel & HLP-VSL-T27A & Receive waste slurry after concentration. \\
\hline Heat exchanger (cooling) & UFP-HX-T05A/B & $\begin{array}{l}\text { Tube-in-shell (nonprototypic) heat exchanger to replicate } \\
\text { cooling of UFP-HX-00041A/B. }\end{array}$ \\
\hline Dual ultrafiltration pumps & UFP-PMP-T42A/43A & $\begin{array}{l}\text { Centrifugal pumps (like PTF), but having different pump } \\
\text { curves, impeller tip speed, etc. Provide }(1 / 4.5)^{2} \text { of full-scale } \\
\text { flow with capacity to increase axial slurry velocity up to } \\
20-\mathrm{ft} / \mathrm{sec} \text { in filter tubes. }\end{array}$ \\
\hline Transfer piping & multiple & $\begin{array}{l}\text { Generally scaled to approximate }(1 / 4.5)^{2} \text { of full-scale } \\
\text { cross-sectional area. Diameters were rounded to nearest } \\
\text { standard pipe size and sized down as necessary to maintain } \\
\text { turbulent flow. Neither transfer line pipe lengths nor their } \\
\text { configurations (e.g., number of elbows) are prototypic. }\end{array}$ \\
\hline Vessel vent system & multiple & $\begin{array}{l}\text { Collect vessel off-gas and remove from operating area. } \\
\text { Heat off-gas to prevent condensation. }\end{array}$ \\
\hline $\begin{array}{l}\text { Chemical supply systems for } \\
19-\mathrm{M} \mathrm{NaOH}, 2-\mathrm{M} \mathrm{NaOH}_{\text {, nitric }} \\
\text { acid, } 1-\mathrm{M} \mathrm{NaMnO} \text {, and } \\
\text { inhibited water }\end{array}$ & multiple & Provide process chemicals and flushing water. \\
\hline PJM air and vacuum systems & $\begin{array}{l}\text { VNT-CY-T01A/B, } \\
\text { vacuum pump }\end{array}$ & Utilities for testing. \\
\hline $\begin{array}{l}\text { Services and utilities (steam, } \\
\text { chilled water, deionized water) }\end{array}$ & multiple & Utilities for testing. \\
\hline Filter-loop heat exchanger & UFP-HX-T02A & $\begin{array}{l}\text { Prototypic spiral design. UFP-HX-T02A chilled-water } \\
\text { heat exchanger could not be scaled dimensionally, so it was } \\
\text { scaled on velocity and is geometrically to be similar to its } \\
\text { PTF counterpart }{ }^{(a)} \text {. }\end{array}$ \\
\hline
\end{tabular}

Table 4.3. Nonprototypic Major PEP Equipment

\begin{tabular}{lll}
\hline \multicolumn{1}{c}{ Name } & Equipment Number & \multicolumn{1}{c}{ Comments } \\
\hline $\begin{array}{l}\text { Ultrafiltration feed preparation } \\
\text { vessel steam heat exchangers }\end{array}$ & UFP-HX-T04A/B & $\begin{array}{l}\text { Tube-in-shell heat exchanger to supplement direct steam } \\
\text { injection when caustic leaching in UFP-VSL-T01A/B for } \\
\text { steam condensate management. }\end{array}$ \\
$\begin{array}{l}\text { Ultrafiltration feed vessel steam } \\
\text { heat exchanger }\end{array}$ & $\begin{array}{l}\text { Tube-in-shell heat exchanger to supplement direct steam } \\
\text { injection when caustic leaching in UFP-VSL-T02A for } \\
\text { steam condensate management. }\end{array}$ \\
\hline
\end{tabular}

(a) It should be noted that the PTF heat exchanger design, that was not finalized prior to PEP testing, has changed from the assumed velocity used for PEP scaling. 
The critical mixing vessels during the Integrated testing were UFP-VSL-T01A, UFP-VSL-T01B, and UFP-VSL-T02A (henceforth, Tank T01A, Tank T01B, and Tank T02A, respectively). In all three tanks, the main design features are the instrumentation, pulse jets, and steam rings. Additionally, in Tank T02A, the pump inlet to the filter-loop, the filter-loop return, and the air spargers are of importance.

\subsubsection{Tanks T01A and T01B}

Vessels UFP-VSL-T01A and UFP-VSL-T01B are the Ultrafiltration Process (UFP) feed preparation vessels. They are capable of heating the simulants and adding caustic to the simulant (if needed for the test process), and they act as storage for feeding UFP-VSL-T02A. Tank T01A and Tank T01B are of the same design with each vessel containing eight PJMs and a steam ring. The plan view from the top is shown in Figure 4.7, the photo of the delivered PJM assembly is in Figure 4.8, and the vessel cross-section is shown in Figure 4.9. The isometric of Tank T01A is shown in Figure 4.10.

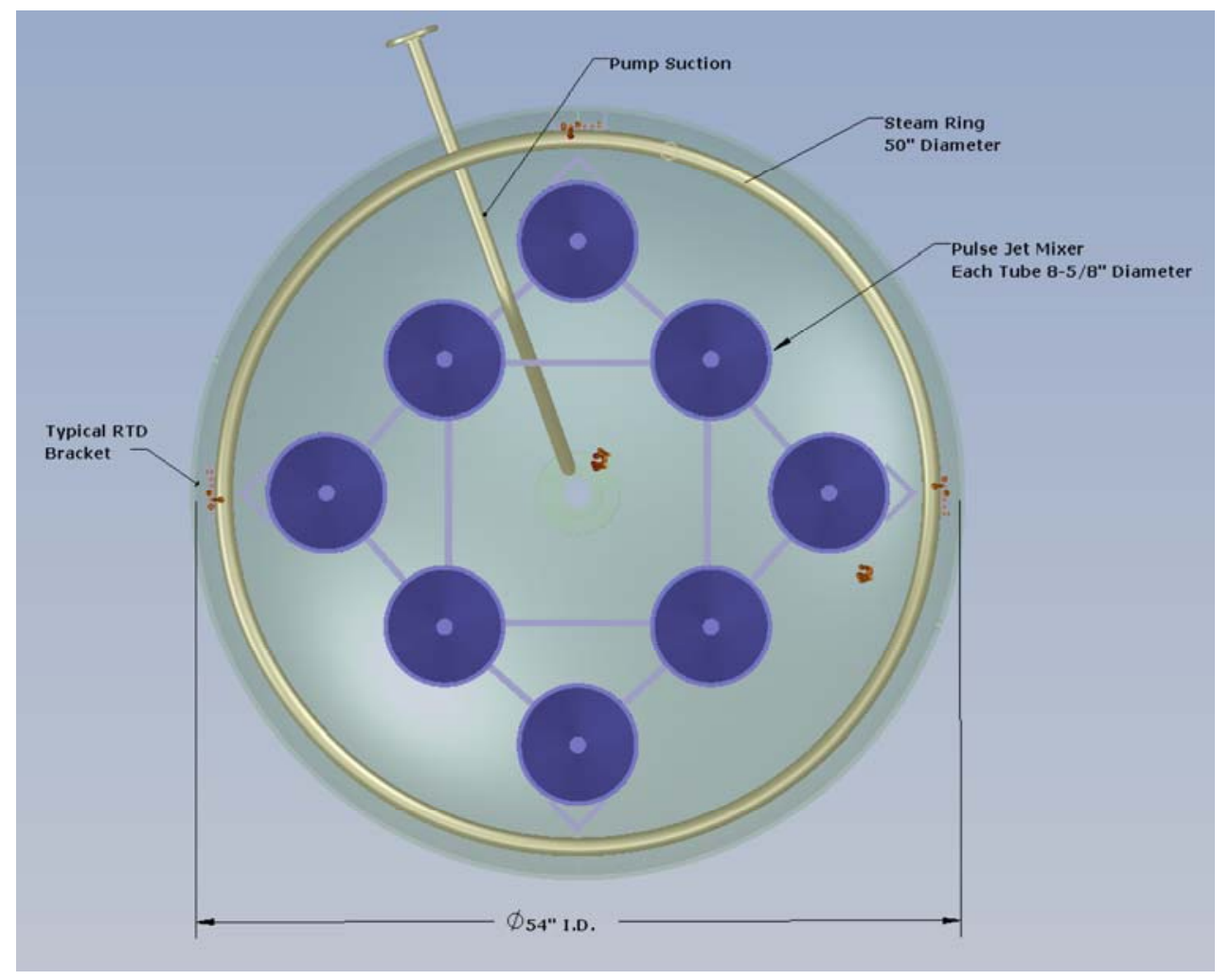

Figure 4.7. Plan View Illustration (not to scale and for information only) of Tank T01A/B 


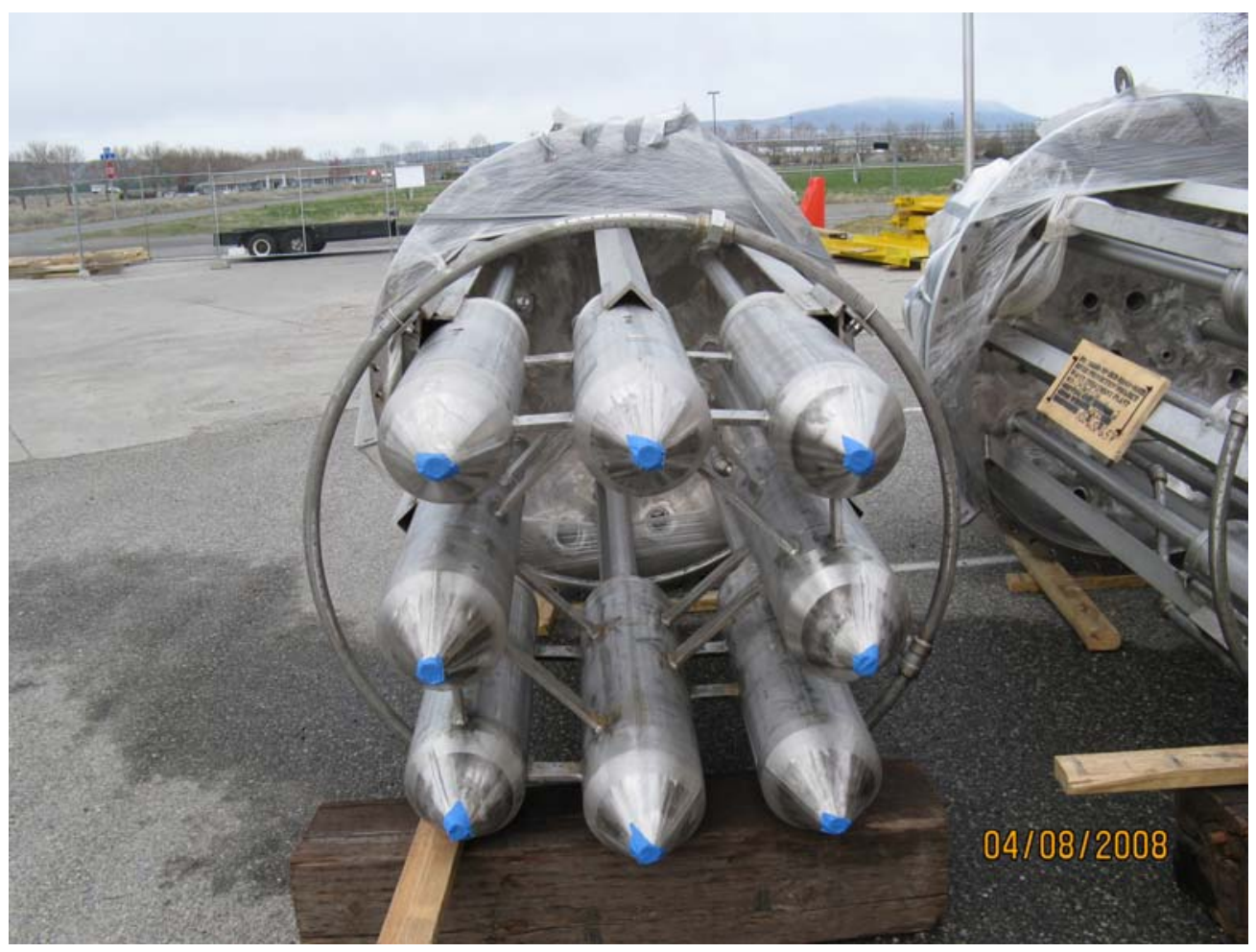

Figure 4.8. The Delivered PJM Before Installation into Tank T01A/B 


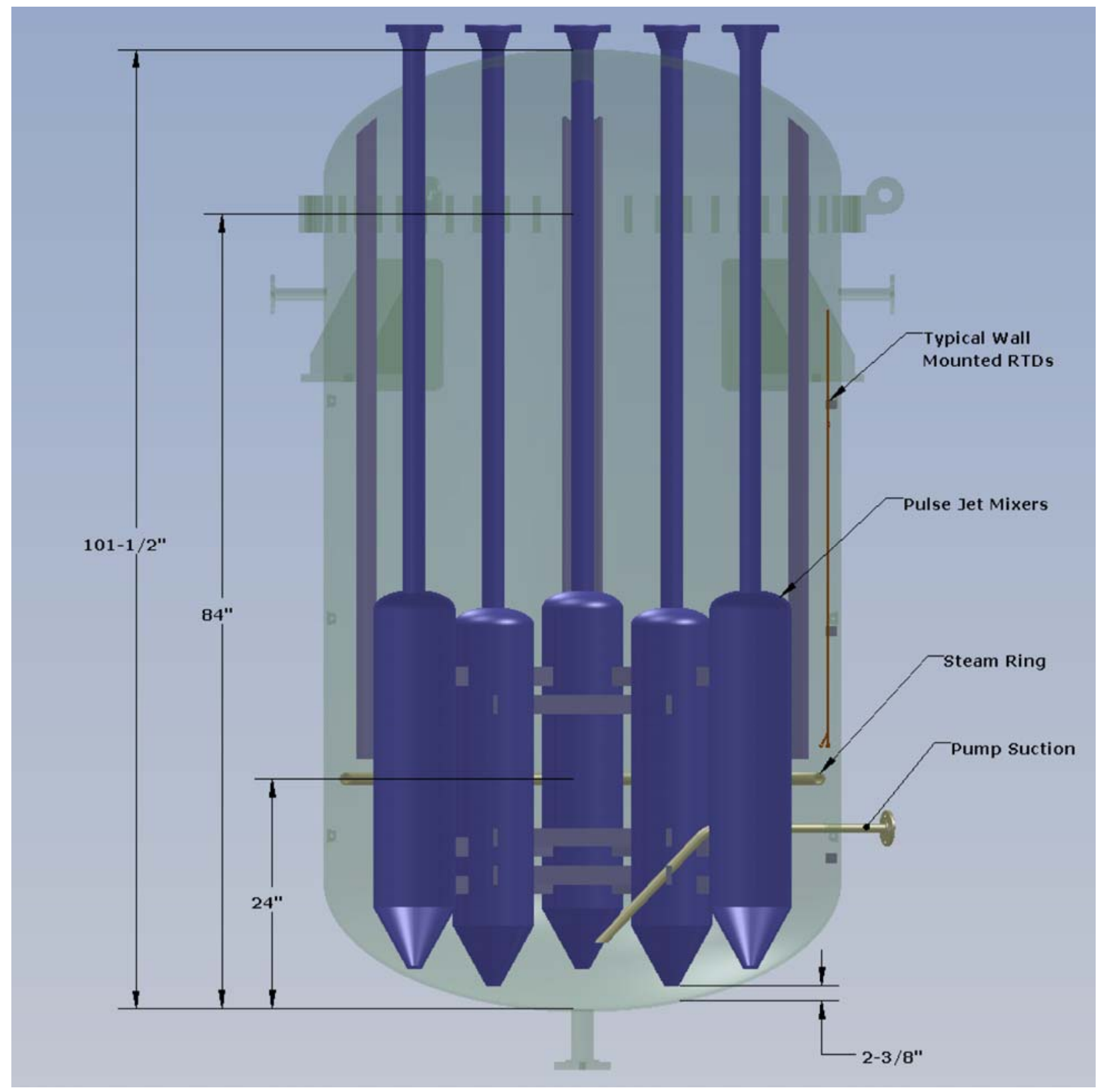

Figure 4.9. Cross-Sectional Illustration (not to scale and for information only) of TankT01A/B 


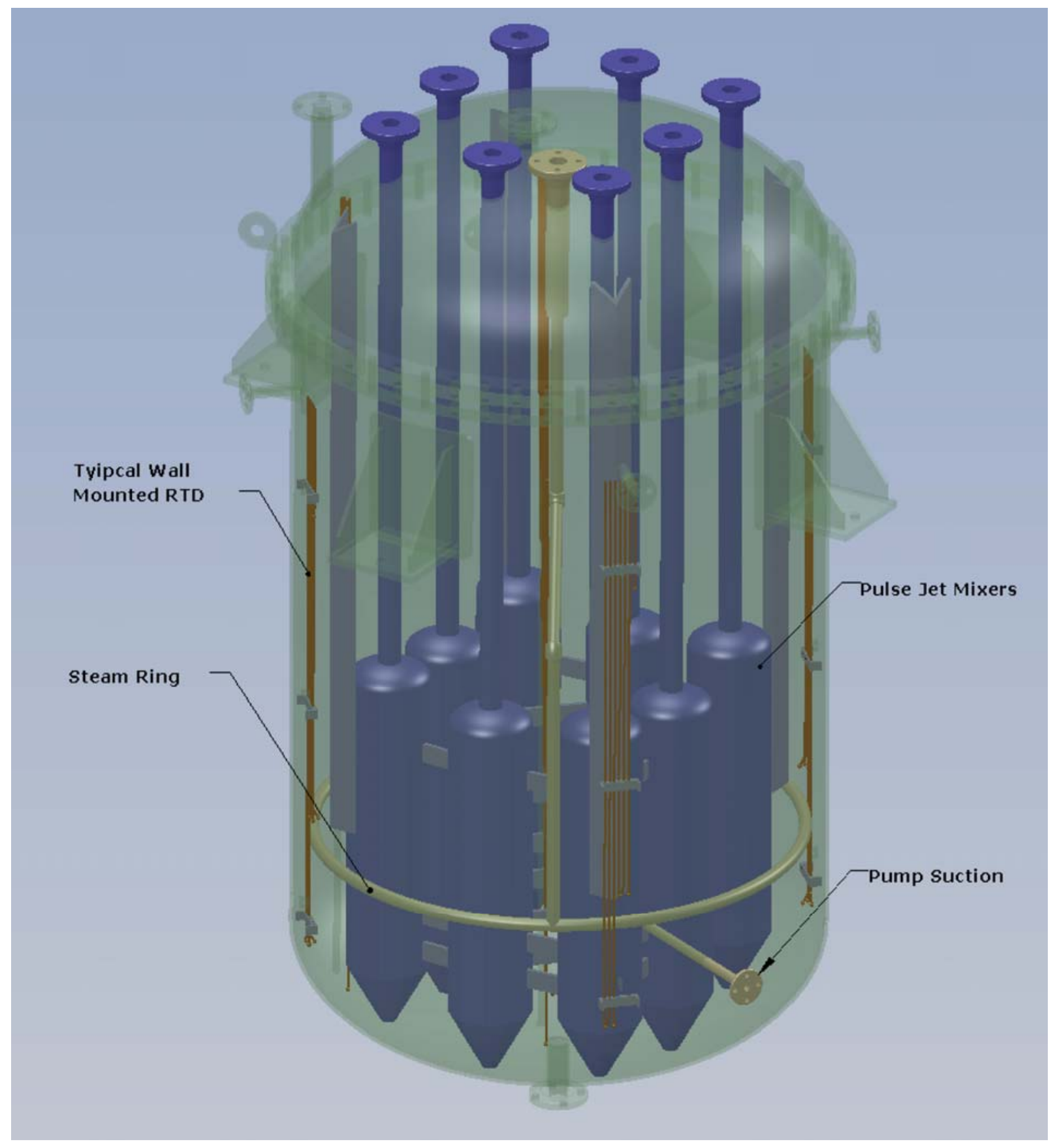

Figure 4.10. Isometric Illustration (not to scale and for information only) of TankT01A/B

The sketches in Figure 4.11 are intended to represent the approximate location of the temperature sensors in Tank T01A. This plan view shows the five sets of temperature sensors (dots). Sensors were inserted through nozzles N33, N34, and N36 (located at $0^{\circ}, 90^{\circ}$, and $270^{\circ}$, respectively) and clamped to the wall of the vessel. Sensors attached to stainless steel rods were also inserted through nozzles N19 and $\mathrm{N} 20$ on the tank top and measured the bulk fluid at various elevations. 


\section{N19 and N20- attached to SST rod}

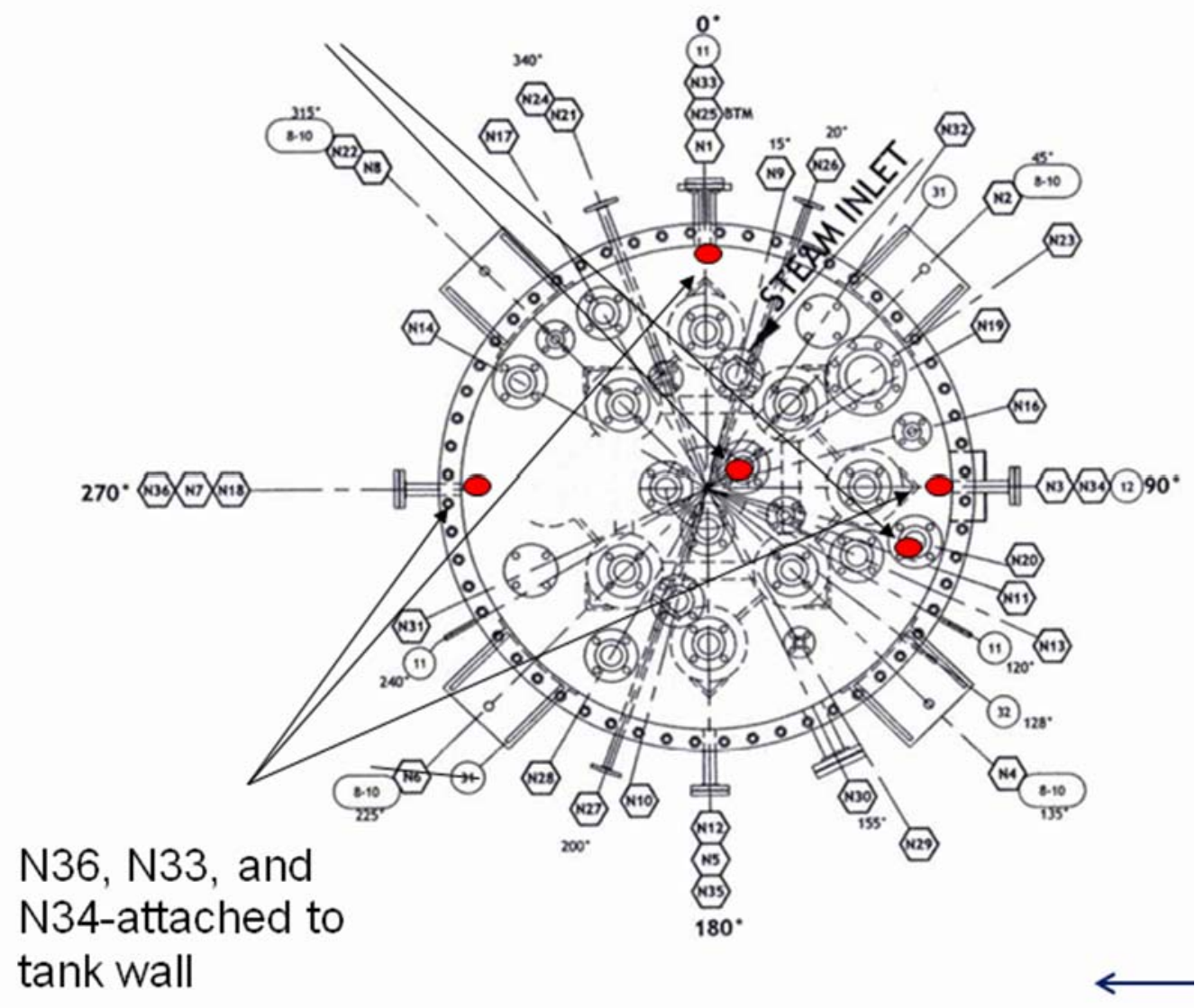

Figure 4.11. Tank T01A Plan View Showing Resistance Temperature Detector (RTD) Locations (not to scale)

Figure 4.12 represents the approximate location of the temperature sensors in Tank T01A. The RTDs clamped to the wall are installed in sets of three ( 0 -in., $5 / 8$-in., and 1.25-in. from the wall) at approximately 10- and 39-inch elevations, with a single RTD at the 70-inch elevation. The RTDs attached to the rod are spaced between 5 and 10 inches from an elevation of 1 inch to one of 74 inches. The actual RTD positions are listed in Table 13.8. 


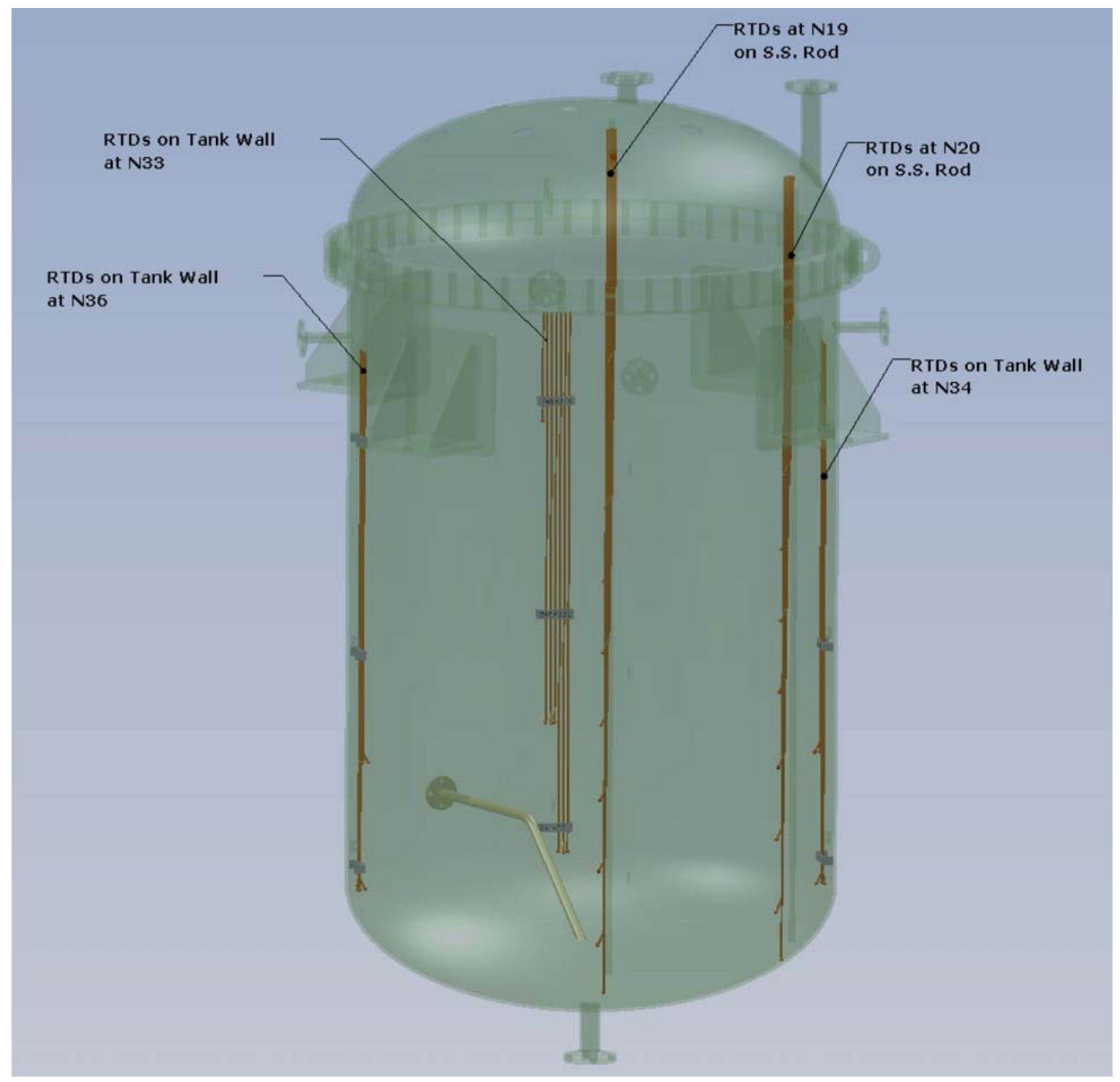

Figure 4.12. Tank T01A Elevation View Showing RTD Locations (not to scale)

\subsubsection{PEP Filtration System}

The PEP filtration system was composed of an ultrafiltration feed tank (Tank T02A), a slurry circulation and filter-loop, a permeate metering and collection system, and a filter backpulse and cleaning system. The PEP filtration system was instrumented to measure the feed flow rate and temperatures at four locations as well as the axial and transmembrane pressure (TMP) drop across each filter bundle. In addition, the system was configurable such that filter bundles 1 to 5 may be connected in-series to the slurry circulation loop or bypassed such that flow is directed through filter bundle 1 or through filter bundles 2 to 5 . The system can also be configured to bypass all five filter bundles. A list of full PEP 
process equipment may be found in TP-RPP-WTP-506 $6^{(\mathrm{a})}$ and the detailed instrumentation list for each test in the test run report (Josephson et al. 2009, Guzman-Leong et al. 2009, Geeting et al. 2009, and Sevigny et al. 2009).

\section{Ultrafiltration Feed Tank T02A}

Tank T02A serves as a primary supply and mixing reservoir for slurry being circulated through the filter-loop. The contents of this tank are mixed using a combination of pulse jet mixers (PJMs), air spargers and jet mixing by the filter-loop return nozzle (when the filter-loop pumps are operating). The array of six PJMs are dimensionally scaled copies of the PTF PJMs and are located prototypically within the vessel. ${ }^{(\text {b) }}$ Jet mixing is also introduced by the filter-loop return nozzle, which is prototypically sized and located. Additional mixing within Tank T02A is provided by air sparge mixers and the steam ring air purge, both of which were operated to match the power/volume of the PTF in the upper region of the vessel (Section 3.0). Ancillary systems for Tank T02A include a bubbler to measure slurry density and level, a laser level sensor, a Drexelbrook level sensor, and an array of RTDs to measure the tank temperature profile. Tank T02A is equipped with a functionally prototypic water jacket supplied with chilled water to cool the contained slurry. While the water jacket does not cover the same regions of the vessels as those at PTF and the size and volumes are not prototypic, the Tank T02A water jacket did provide the same functional capabilities during testing.

Tank T02A feeds the filter-loop, which makes the filter-loop pump's suction inlet and return to the vessel significant design elements. Additionally, the design has six PJMs (one in the center and five mounted around the center jet with outward projecting nozzles). The filter-loop flow schematic with process instrumentation is shown in Figure 4.13. The cross-sectional diagram of Tank T02A is shown in Figure 4.14, the plan view (as viewed from above) of the PJMs in Tank T02A is shown in Figure 4.15, and a photo of the PJMs is shown in Figure 4.16.

Isometric views of Tank T02A are shown in Figure 4.17 and Figure 4.18. The illustrations do not include the upper spargers. Figure 4.18 shows the close placement of the many components in the bottom of the tank. An isometric of Tank T02A with the lower spargers is in Appendix D.

(a) Josephson GB, OP Bredt, JK Young, and DE Kurath. 2009. Test Plan for Pretreatment Engineering Platform (PEP) Testing (Phase I). TP-RPP-WTP-506, Rev 0.4, Pacific Northwest National Laboratory, Richland, Washington.

(b) Stiver B. 2007. Functional Requirements for Pretreatment Engineering Platform (PEP), 24590-PTF-3YD-UFP-00002 Rev. 1, Bechtel National Incorporated, Richland, Washington. 


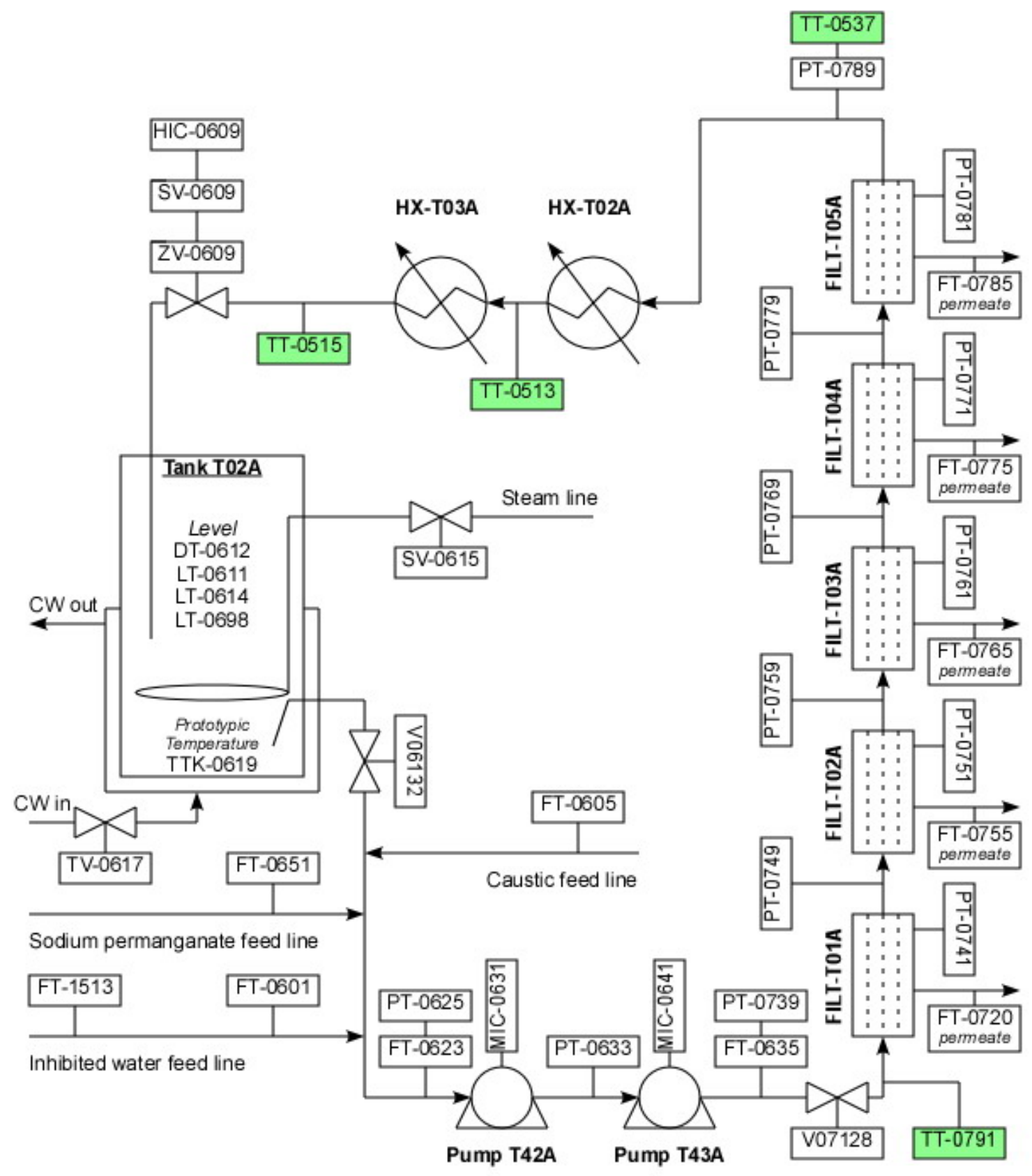

Figure 4.13. Schematic of Tank T02A Loop and Filtration. Note that HX-T03A was bypassed during the washing operations of all Integrated tests. $\left({ }^{\mathrm{a}}\right)$

(a) $\mathrm{DT}=$ density transmitter, $\mathrm{HX}=$ heat exchanger, $\mathrm{LT}=$ level transmitter, $\mathrm{FT}=$ flow transmitter (includes the matching $\mathrm{FE}$ or Flow Element), PT = pressure transmitter (includes the matching PI or Pressure Instrument),

$\mathrm{TT}=$ temperature transmitter (included the matching TE or Temperature Element), MIC = Motor Indicating Controller, $\mathrm{V}=$ Valve, SV=Solenoid Valve, $\mathrm{ZV}=$ Positioning Valve, and HIC= Human Interface Control. Instruments with Nonconformance Reports issued during testing are shaded. 


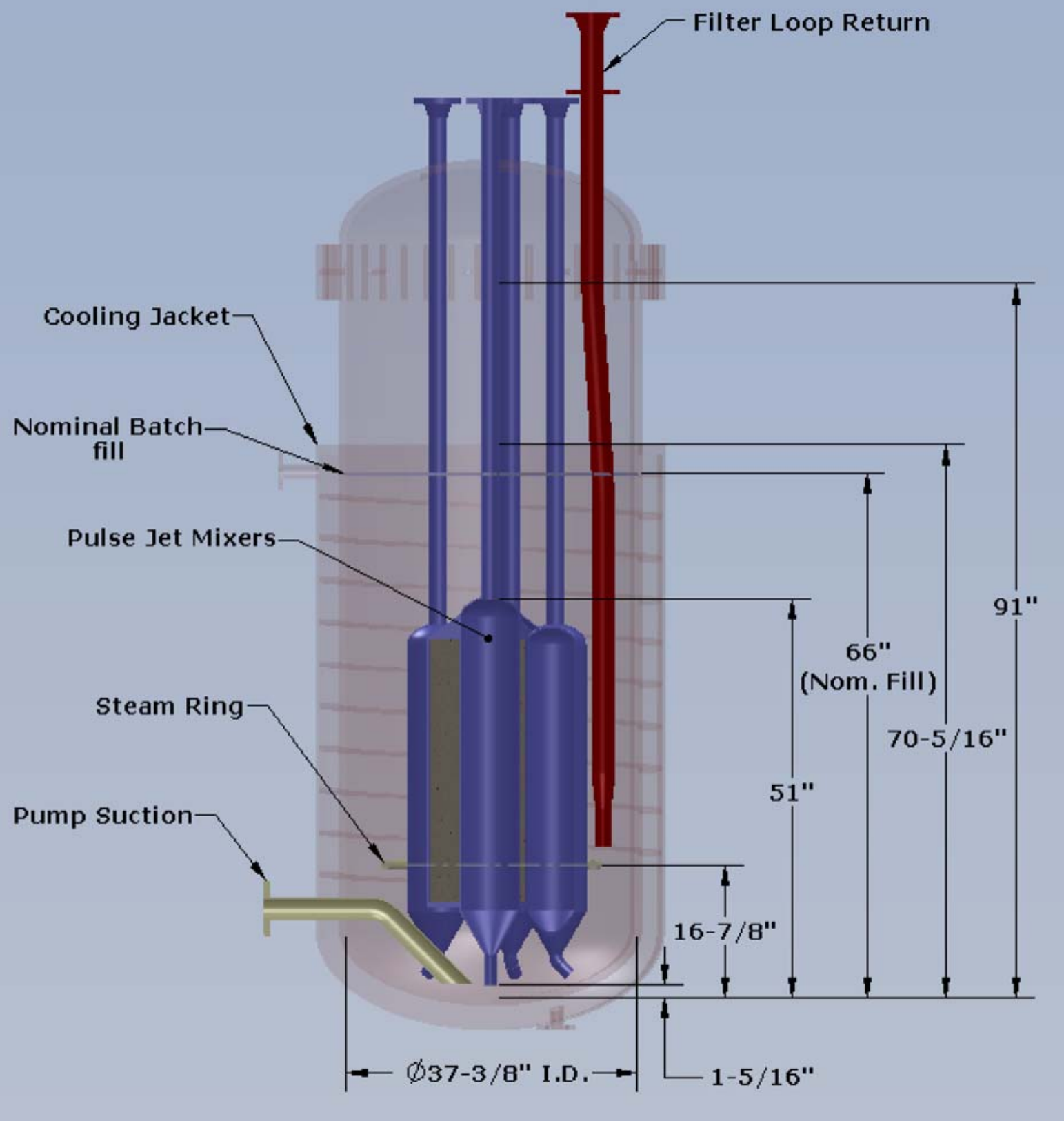

Figure 4.14. Cross-Sectional Illustration (not to scale and for information only) of Tank T02A

The Tank T02A dimensions are:

- Inside diameter is $373 / 8$ inches.

- Height from the inside center of the tank to the outside of the cooling water jacket is $705 / 16$ inches.

- Height from the inside center of the tank to the centerline of the tank flange is 91 inches. 


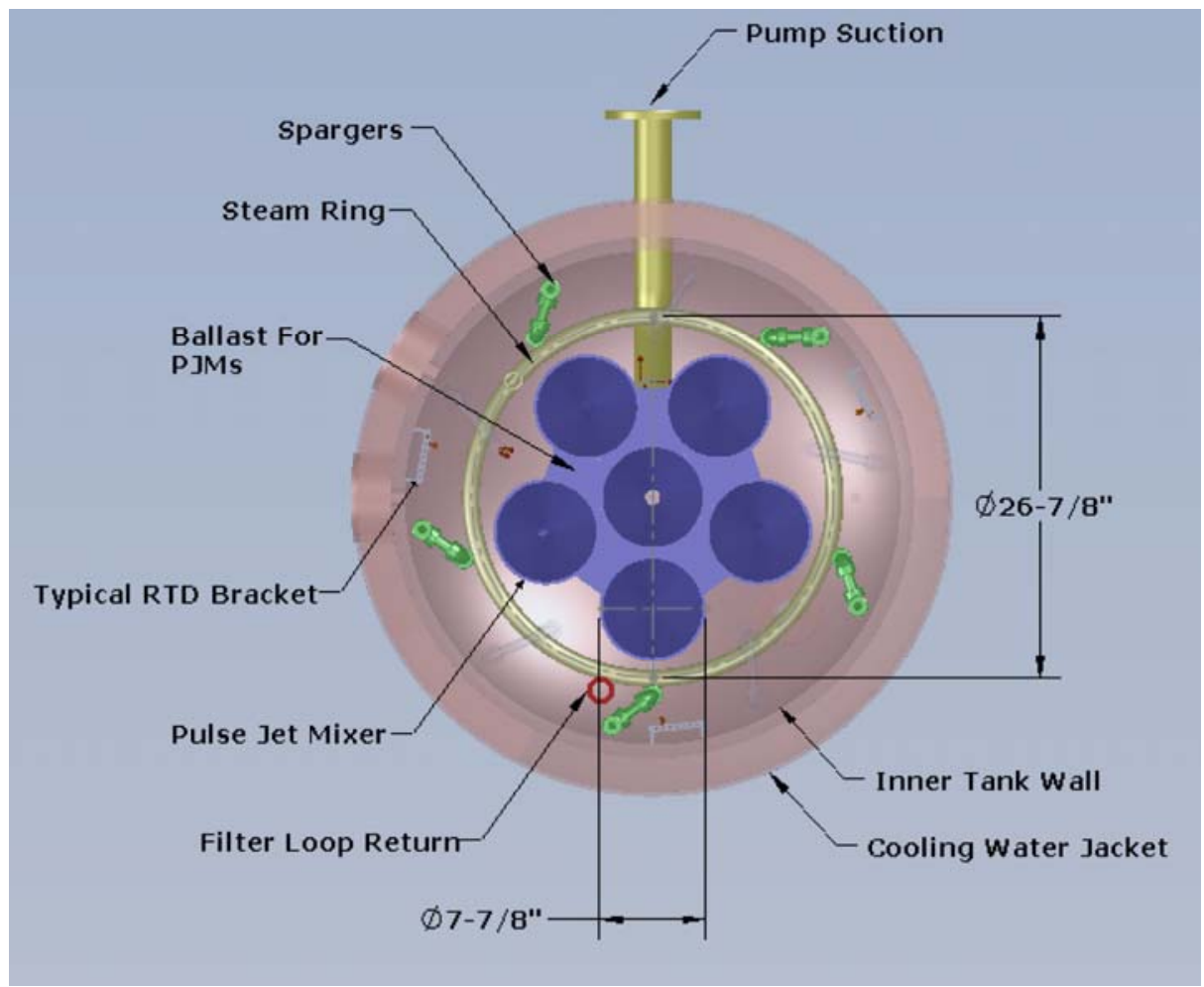

Figure 4.15. Plan View Illustration (not to scale and for information only) of Tank T02A

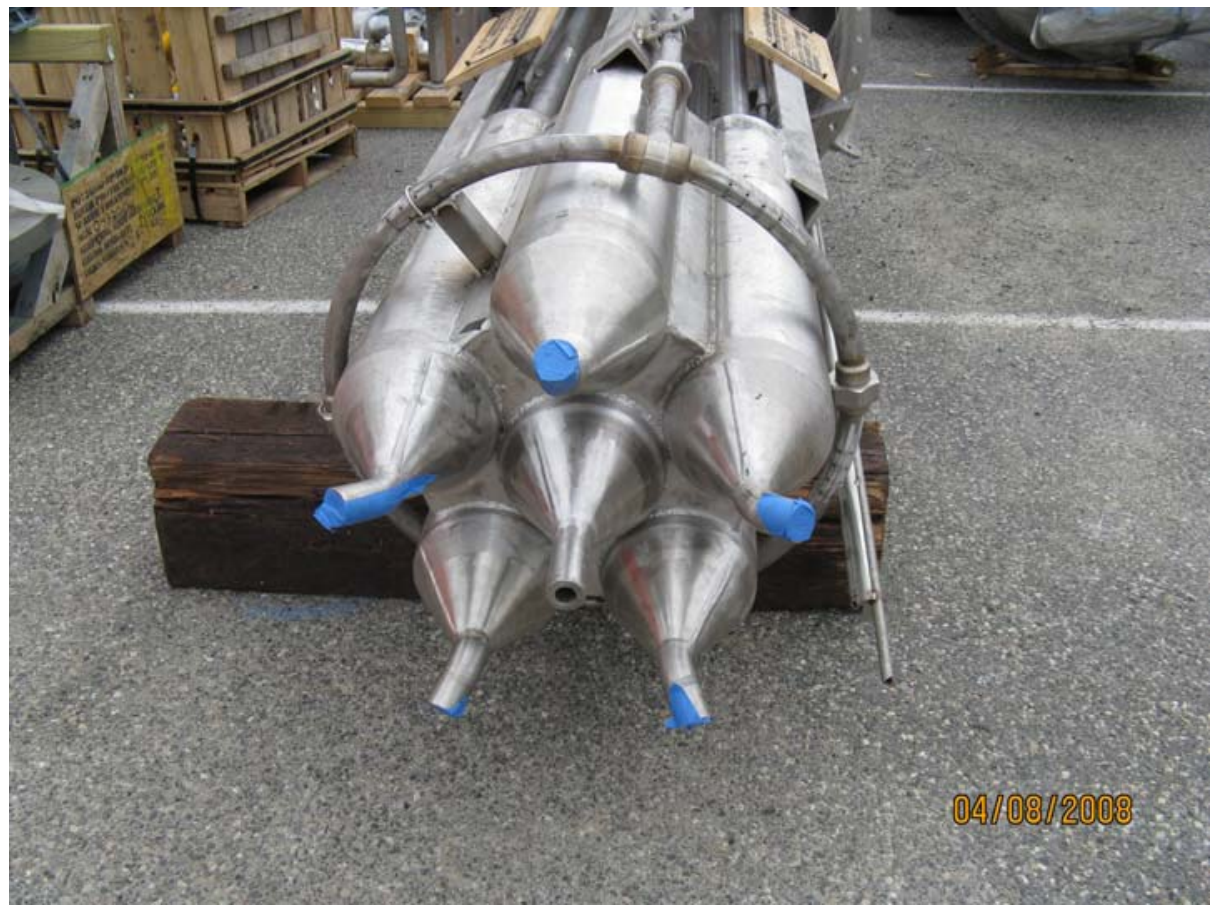

Figure 4.16. Delivered PJMs Before Installation into Tank T02A 


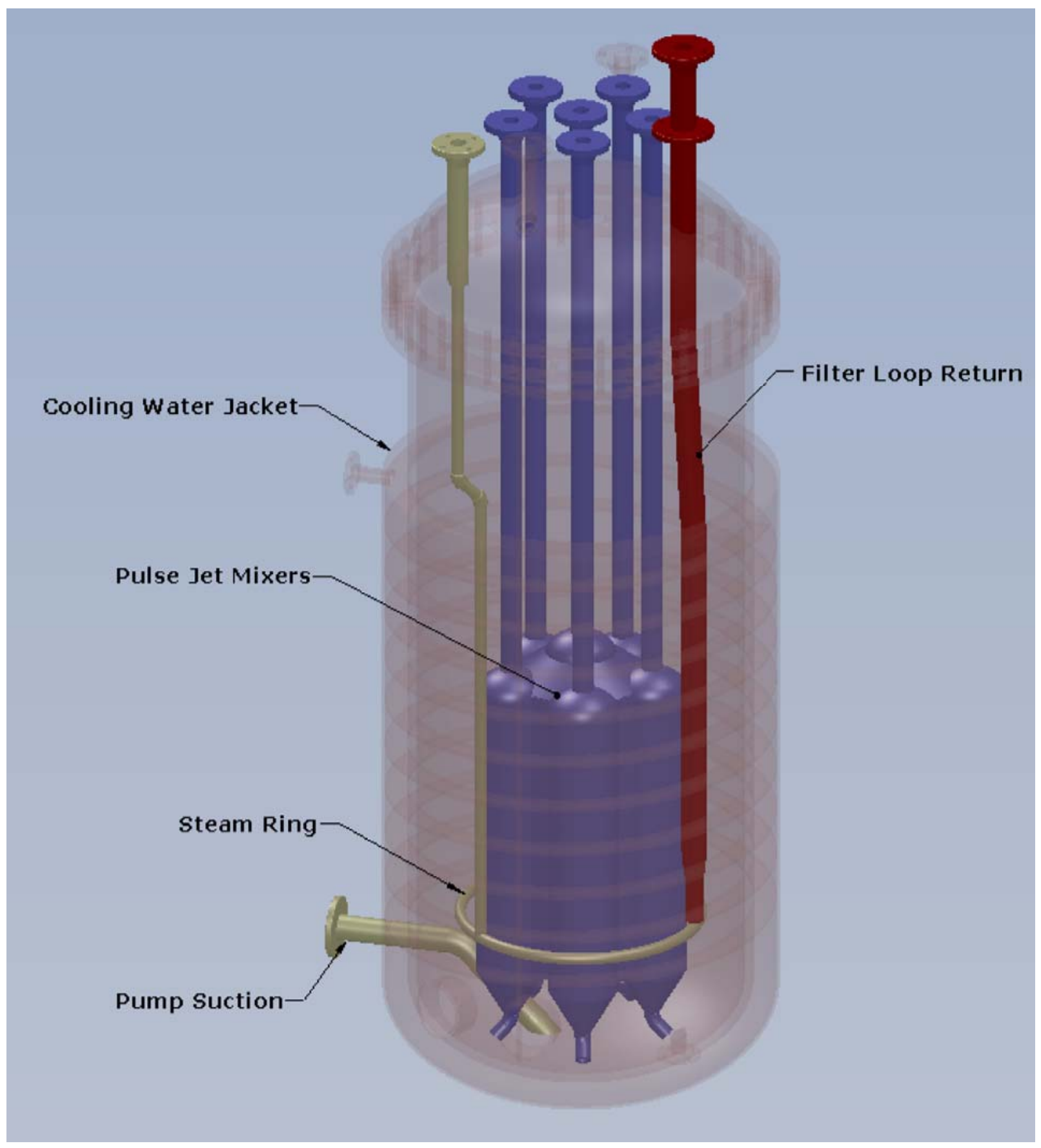

Figure 4.17. Isometric of Tank T02A Without the Lower Spargers (not to scale) 


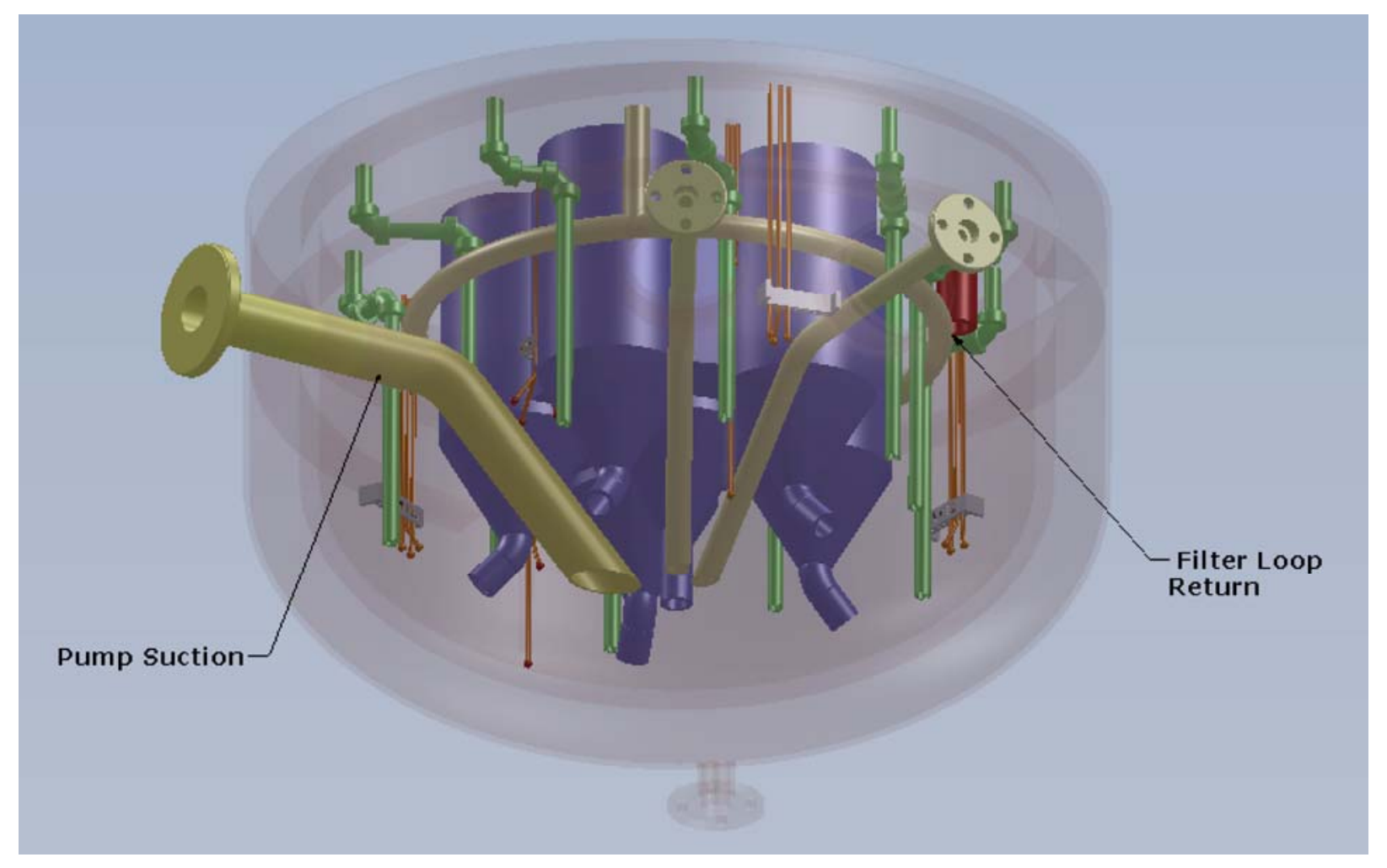

Figure 4.18. Isometric Detail of the Bottom of Tank T02A (not to scale)

Figure 4.19 is intended to represent the approximate location of the temperature sensors in Tank T02A. This plan view shows the six sets of temperature sensors (dots). Sensors entering through nozzles N39, N41, and N42 are clamped to the wall of the vessel and N52 is clamped to a PJM. Sensors N22 and N23 are attached to a stainless steel rod inserted through the tank top and measure the bulk fluid at various elevations. 


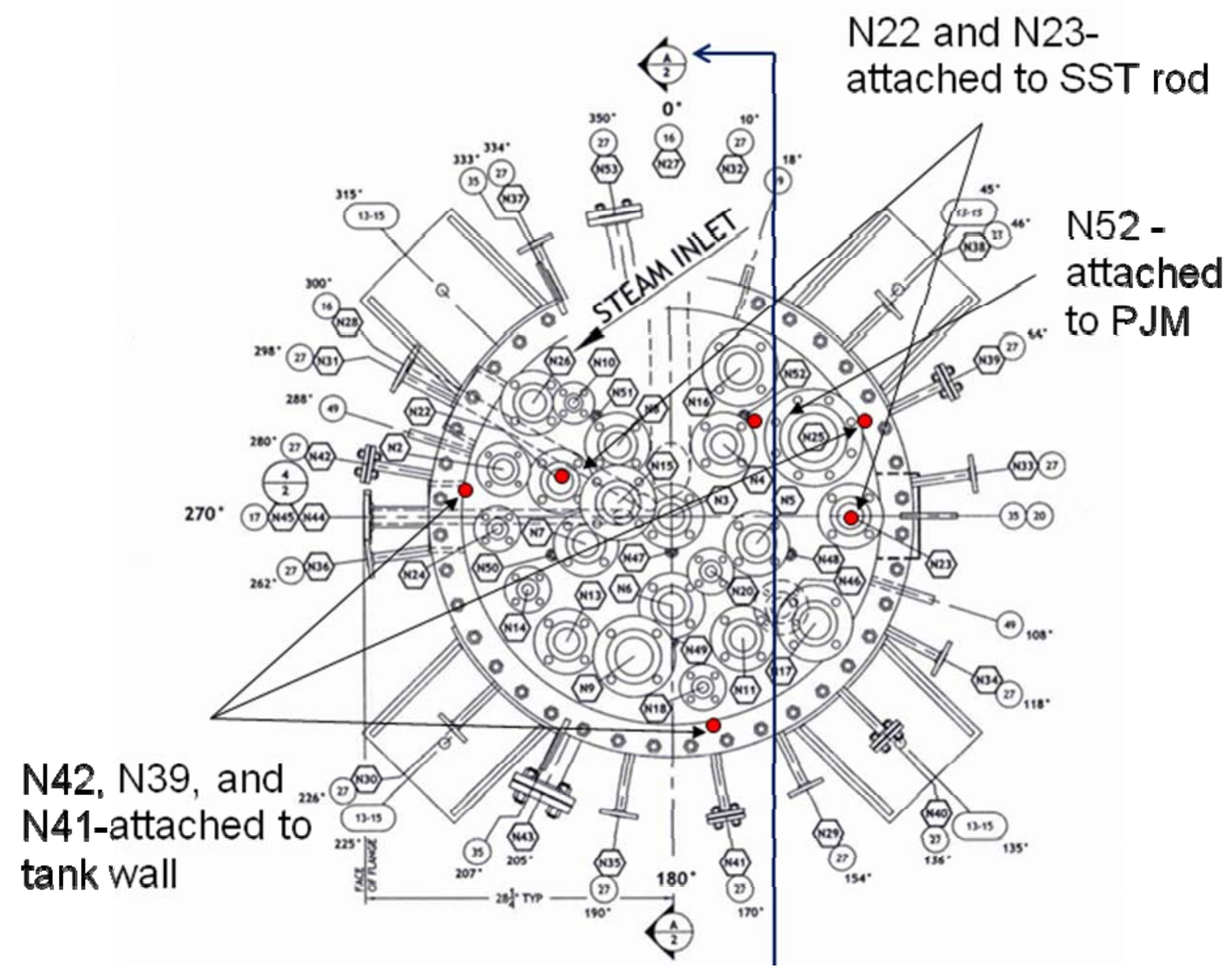

Figure 4.19. Tank T02A Plan View Showing RTD Locations (not to scale)

Figure 4.20 is intended to represent the approximate location of the temperature sensors in Tank T02A. The RTDs clamped to the wall/PJM are installed in sets of three (0-in., $5 / 8$-in., and 1.25-in. from the wall/PJM) with a single RTD at the highest elevation. The RTDs attached to the rod are spaced between 5 and 10 inches from an elevation of 1 inch to one of 74 inches. The actual RTD positions are listed in Table 13.8. 


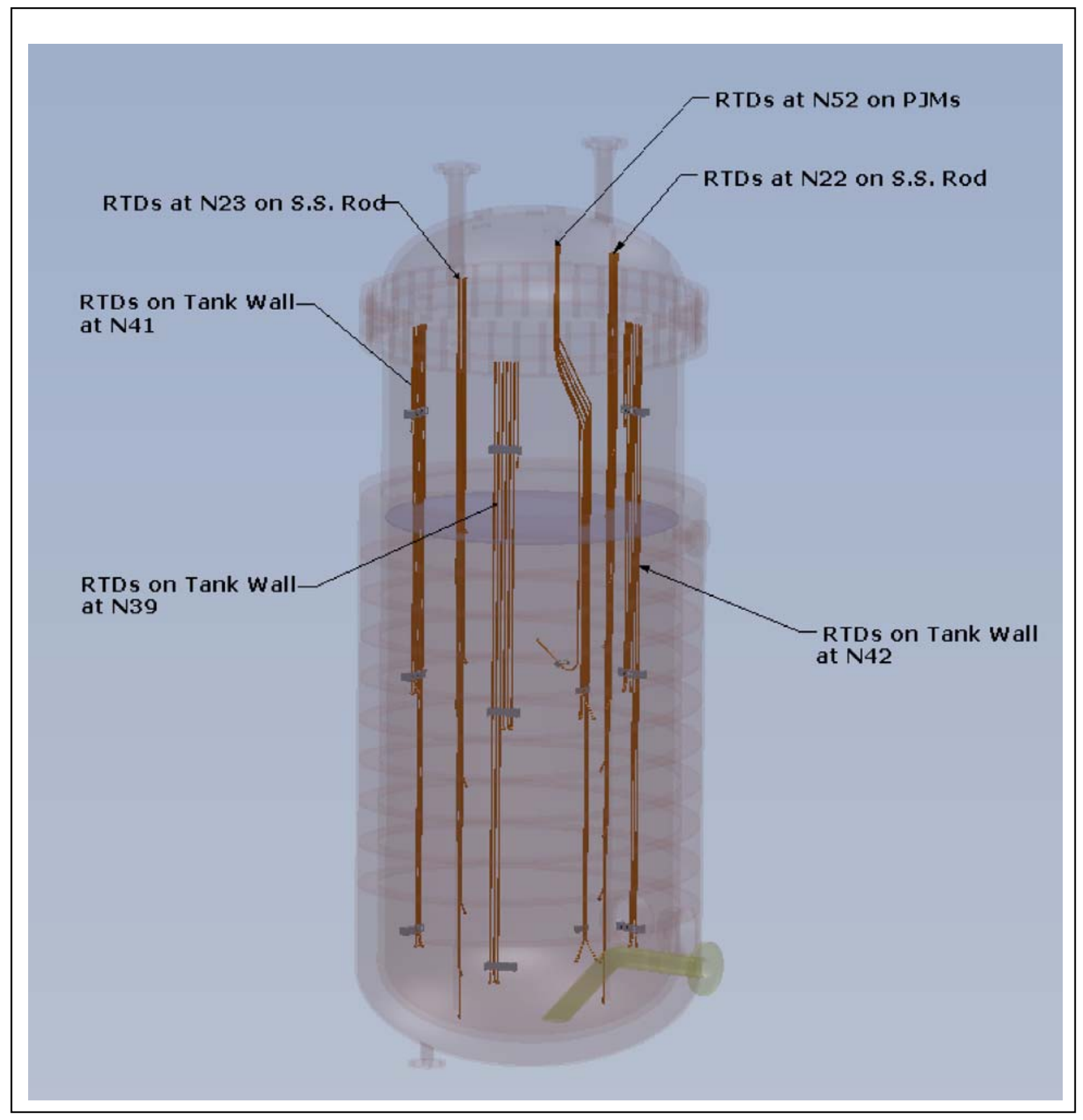

Figure 4.20. Tank T02A Elevation View Showing RTD Locations (not to scale)

\section{Ultrafiltration Loop}

The filter-loop contains process equipment that is key to slurry dewatering and washing operations. It is composed of two slurry pumps, a series of five filter bundles, and two heat exchangers (Figure 4.13).

Two functionally prototypic centrifugal slurry pumps, UFP-PMP-T42A and UFP-PMP-T43A (hereafter referred to as Pumps T42A and T43A, respectively), were operated in-series to provide the required slurry flow rate and pressure for the cross-flow filter bundles. The suction to Pump T42A was 
fed from Tank T02A. In addition, the feed to pump T42A was connected to process inhibited water ${ }^{(a)}$, caustic, permanganate, and reagent supplies used in the leaching, slurry washing, and dilution operations. The slurry discharged from pump T42A feeds the suction inlet for pump T43A. Slurry discharge from pump T43A can be fed through, or bypassed around, the cross-flow filter bundles. Pumps T42A and T43A were controlled ${ }^{(\mathrm{b})}$ to provide a combined filter-loop flow rate and pressure of up to $150 \mathrm{GPM}$ and 250 pounds-per-square-inch (psig).

The cross-flow filter system is the core of slurry liquid-solid separations. It is composed of five filter bundles operated in-series, prototypic of the PTF. These filter bundles are designated as UFP-FILT-T01A to -T05A (hereafter referred to as filter bundles 1 through 5). Each bundle consists of 12 microporous filter tubes supplied by Mott with a nominal pore size of $0.1-\mu \mathrm{m}$ and are the same type planned for use in PTF. These elements are microporous sintered stainless steel tubes of 0.5-in. inside diameter and a length of 8 or 10 feet. A summary of the geometries of the five filter bundles is provided in Table 4.4. In addition, Figure 4.21 and Figure 4.22 show the complete filter bundle assembly and filter element arrangement. The pipe-reducer end-caps on each filter bundle are similar to those of the PTF to provide similar entrance and exit effects.

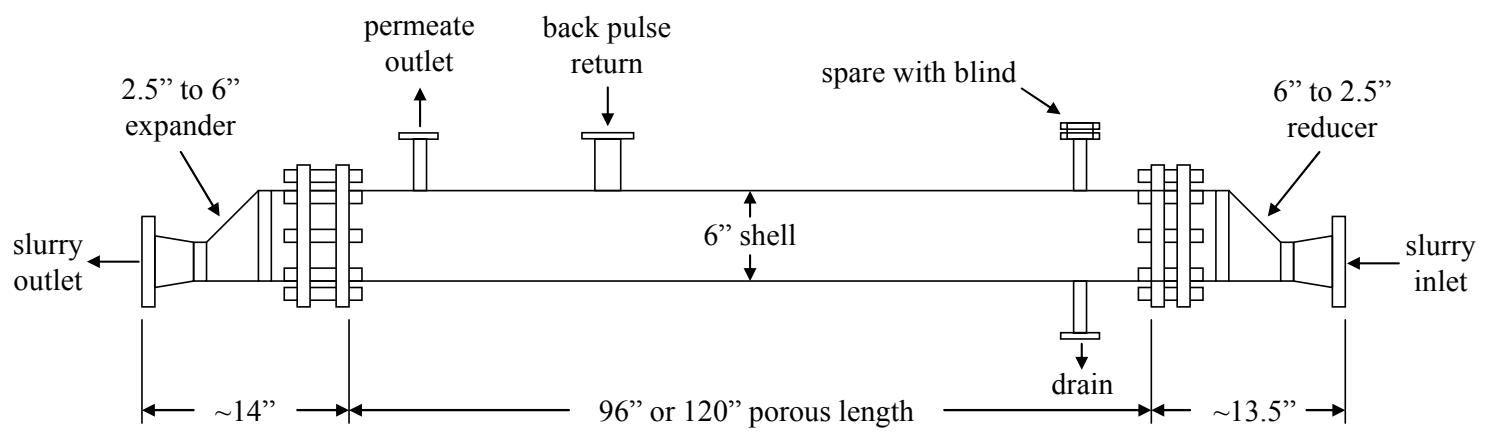

Figure 4.21. PEP Filter Bundle Assembly with Key Geometric Parameters Listed. It should be noted that the spare blind flange on filter bundles \#1, and \#5, have pressure relief valves installed versus blind flanges as shown in the illustration above. The filter bundles were installed at a 1:25 $5^{(\mathrm{c})}$ slope with the inlet being lower than the outlet.

(a) Inhibited water typically refers to a $0.01 \mathrm{M}$ solution of $\mathrm{NaOH}$.

(b) Without the controls, the pumps, when combined, were capable of providing over $400 \mathrm{psig}$.

(c) WTP Engineering is considering reducing the PTF filter slope to 1:50. 


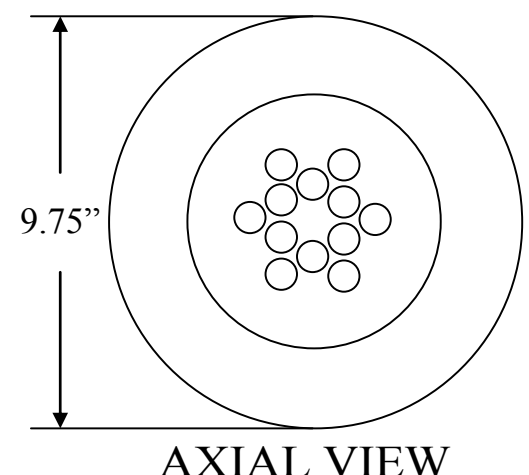

AXIAL VIEW
Twelve 96"/120" long, $0.5 "$

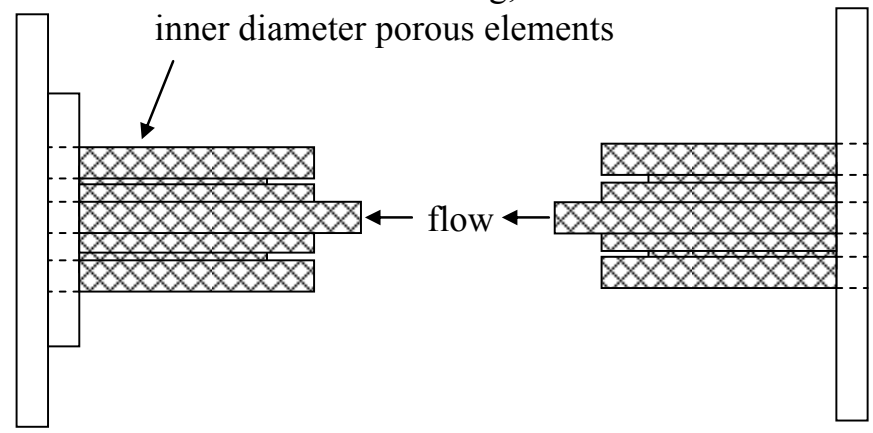

SIDE VIEW

Figure 4.22. PEP Filter Element Arrangement (axial and side views). The shell pipe diameter is six inches.

The PEP filtration system has a total surface area of up to $72.3-\mathrm{ft}^{2}$, which is approximately 276 times greater than that of the cold-CUF. It should be noted that relative to the plant-scale (WTP) filtration operations, the PEP filter banks have approximately ${ }^{1} /(4.5)^{2}$ less filtration area. The filtration area was scaled by maintaining the same number of filter bundles (and filter element length) and by reducing the number of filters in each bundle from 241 (plant scale) to 12 (PEP scale). The filter-loop is equipped with slurry bypass valves to allow slurry to flow through filter bundle 1 or filter bundles 2 through 5 or bypass all filter bundles. Each filter bundle is also equipped with a permeate valve, so filtration can be conducted with any single filter bundle or any combination of the five filter bundles. When operated with one of the 10-foot filter bundles, the PEP matches the (Tank T02A slurry volume)/(filter surface area) ratio of the PTF. When operated with all five filter bundles, the PEP can approximately match the (filtration rate)/(Tank T02A mixing rate) ratio of the PTF.

The slurry flow to pump T42A was measured by a magnetic flowmeter (FT-0623). The slurry discharge flow from pump T43A was measured by a second magnetic flowmeter (FT-0635) as shown in Figure 4.13. The circulation loop pressure was monitored by a series of pressure transducers located at the entrance to each slurry pump, filter bundle, and heat exchanger. The target PEP TMPs and axial velocities were to match those of the PTF to maximize the similarity of performance between the PEP and PTF.

The slurry filter-loop also includes two in-line heat exchangers that were available for temperature control of Tank T02A and/or the slurry filter-loop. The first heat exchanger, UFP-HX-T02A, is a functionally prototypic spiral-plate heat exchanger that uses chilled water to cool the circulating slurry. This heat exchanger was typically used to remove mechanical heat input to the slurry by pumps T42A and T43A. The second heat exchanger, UFP-HX-T03A, is a steam exchanger intended to heat the slurry (if needed for leaching operations) and is not prototypic of the PTF. For the Integrated testing, UFP-HX-T03A was not used. Both heat exchangers are equipped with a bypass loop so that they can be isolated from slurry flow. The temperature of the slurry flow was measured for performance monitoring and control by RTDs installed in thermowells in pipe T's on the filter-loop. However, it was discovered during PEP testing that the thermowells were too short (the temperature element did not extend into the 
flowing stream), and the measured temperatures did not always represent the bulk flow temperature (see NCR 42402.1). The final process element in the slurry circulation loop is a pressure control valve (ZV-0609), which can be adjusted in combination with the slurry pumps to provide adequate backpressure for permeate production. After passing through ZV-0609, the slurry is returned to Tank T02A.

Table 4.4. Specifications of the Five PEP Cross-Flow Filtration Bundles

\begin{tabular}{cccccc}
\hline Filter Bundle \# & Filter ID & $\begin{array}{c}\text { Number of } \\
\text { Elements in } \\
\text { Bundle }\end{array}$ & $\begin{array}{c}\text { Element } \\
\text { Inside } \\
\text { Diameter } \\
{[\text { inches }]}\end{array}$ & $\begin{array}{c}\text { Element } \\
\text { Length [ft] }\end{array}$ & $\begin{array}{c}\text { Bundle } \\
\text { Surface Area } \\
{\left[\mathrm{ft}^{2}\right]}\end{array}$ \\
\hline 1 & UFP-FILT-T01A & 12 & 0.5 & 10 & 15.7 \\
2 & UFP-FILT-T02A & 12 & 0.5 & 10 & 15.7 \\
3 & UFP-FILT-T03A & 12 & 0.5 & 10 & 15.7 \\
4 & UFP-FILT-T04A & 12 & 0.5 & 8 & 12.6 \\
5 & UFP-FILT-T05A & 12 & 0.5 & 8 & 12.6 \\
\hline Total & n/a & n/a & n/a & n/a & 72.3 \\
\hline
\end{tabular}

\section{Pulse-Pot System Filtration Backpulse Systems}

The pulse-pots are used for backpulsing the filter bundles. During backpulsing, one of the pulse-pots is isolated and charged with high-pressure air until the pressure reaches about $100 \mathrm{psig}$. The outlet near the middle of the pot is open, and the pulse-pot level is decreased to a specified level ( $\sim 9$ inches). Then the outlet valve is closed. The level is adjusted so that the backpulse will provide a consistent volume without blowing air through the filters. The pulse is repressurized until the pulse-pot pressure exceeds the tubeside pressure of the filter bundle to be backpulsed by a given amount (typically

40 pounds-per-square-inch differential pressure [psid]). After the target pulse-pot pressure is reached, the fast acting valve isolating the pulse-pot from the filter bundle is opened, and the permeate left in the pulse-pot flows back through the filter element until a lower pressure differential is reached. The lower pressure shut-off was typically set at 5 psid. The backflow of permeate removes any particles that are weakly entrained in the filter pores or that have caked on the filter surface.

The backpulsing function of the filter-loop can be operated only when actively filtering Tank T02A contents. During filtering, the operator initiated the backpulse cycle through the PEP human machine interface (HMI). For a "typical" backpulse cycle, the first step was to close all valves entering and leaving the pulse-pot. Next, the high pressure air line was opened, and the pulse-pot was pressurized to 50 psig. The high pressure air valve was closed, and the drain valve to Tank T62A/B was opened. The pulse-pot fluid level fell until reaching the Level Drain Set Point when the drain valve was closed. The high pressure air valve was opened again, and the pulse-pot was pressurized to the sum of the filter inlet pressure plus the backpulse pressure set point (100 psig $+40 \mathrm{psig}=140 \mathrm{psig}$ in the above example). The air valve was closed, and the backpulse cycle paused for 15 seconds. The fast-acting valve then opened, and the pressure in the pulse-pot pushed fluid back through the filter until the pressure in the pulse-pot was equal to the filter inlet pressure plus the deadband $(100 \mathrm{psig}+10 \mathrm{psig}=110 \mathrm{psig}$ in the above example). The final step was to return to filtering conditions. The fast-acting valve closed, and the filter outlet valve and pulse-pot outlet valve to Tank T62A/B (not the drain valve) were opened. 


\subsubsection{Controls and Instrumentation}

There are two types of instrumentation on the PEP: 1) instruments for monitoring and controlling the process, and 2) instruments for collecting quality-affecting data (NQA-1 instruments). The instrumentation and control for the test system is functionally prototypic of the plant, with the exception that the PJMs and pulse-pots have additional data capabilities to meet the PEP functional requirements. ${ }^{(a, b)}$ The PEP PJM control system was quite different than the system that will be used in the PTF and relied on level measurements in the pulse tubes or preset operational parameters. The PTF has a different type of air supply system using jet pump pairs and uses pressure measurements to control the PJMs. Process control strategies and control ranges were specified in the Pretreatment Engineering Platform (PEP) Phase I Testing Process Description. ${ }^{(\mathrm{c})}$

The output signal from each NQA-1 field sensor is kept separate from process controlling signals and stored in a separate data acquisition system (DAS). The analog to digital conversion system was calibrated to convert the instrument signals and the digital signals were stored in a "read only" data file to maintain the integrity of the process data from each test. The recorded data were time stamped by the DAS system so that they could be matched to process data sheets and log books. The raw stored instrument outputs (digitized voltage and amperage) were converted into process units (e.g., GPM or psig) with a data interrogation program, which was technically reviewed, validated, and verified according to QA-RPP-WTP-SCP, Software Control. The measurement and test equipment (M\&TE) lists for the PEP varied slightly for each test and can be found in the test run reports (Josephson et al. 2009, Guzman-Leong et al. 2009, Geeting et al. 2009, Sevigny et al. 2009).

The PEP has programmable logic controllers that provide functionally prototypic automatic control of complex operations such as PJM operation and ultrafiltration backpulsing to mimic plant operations. There was also automatic control of temperature, flow, and pressure to mimic plant operations.

The permeate metering and collection systems consist of Coriolis mass flowmeters, three pulse-pots connected to high pressure air supplies for backpulsing the filter bundles and two permeate collection tanks. Permeate (shellside) mass production rates from filter bundles 1 through 5 were monitored by Coriolis flowmeters. Permeate flow from each of the filter bundles was directed to three pulse-pots (designated as UFP-PP-T01A to UFP-PP-T03A). Similar to the PTF, pulse-pot UFP-PP-T03A serves filter bundle 1, pulse-pot UFP-PP-T02A serves filter bundles 2 and 4, and pulse-pot UFP-PP-T01A serves filter bundles 3 and 5. They were operated in the PEP in the same way as they would be in the PTF. The pulse-pots are filled with a sufficient volume of collected permeate to backpulse the filter bundles. Overflow from the pulse-pots may be directed to 1) permeate collection tanks (UFP-VSL-T62A and -T62B), or 2) Tank T02A during continuous recycle filtration operations. A summary of the permeate metering and pulse-pot systems is provided in Table 4.5 .

(a) Stiver B. 2007. Functional Requirements for Pretreatment Engineering Platform (PEP). 24590-PTF-3YD-UFP-00002 Rev. 1, Bechtel National Inc., Richland, Washington.

(b) PJM instrumentation and control will most closely resemble strategies employed during the PJM development tests. The instrumentation will provide more data regarding PJM operation than is expected to be available in the full scale. Control strategies for the full-scale plant employing less instrumentation are still being developed. PJM control optimization is not within this Phase 1 testing scope.

(c) Lehrman S. 2008. Pretreatment Engineering Platform (PEP) Phase 1 Testing Process Description. 24590-WTP-RPT-PET-07-002, Rev 0, Bechtel National, Inc., Richland, Washington. 
Table 4.5. Permeate Metering and Pulse-Pot Configurations for PEP

\begin{tabular}{ccc}
\hline Filter Bundle No./ID & $\begin{array}{c}\text { Permeate } \\
\text { Coriolis Meter }\end{array}$ & $\begin{array}{c}\text { Associated } \\
\text { Pulse-Pot }\end{array}$ \\
\hline 1 - UFP-FILT-T01A & FT-0720 & UFP-PP-T03A \\
2 - UFP-FILT-T02A & FT-0755 & UFP-PP-T02A \\
3 - UFP-FILT-T03A & FT-0765 & UFP-PP-T01A \\
4- UFP-FILT-T04A & FT-0775 & UFP-PP-T02A \\
5 - UFP-FILT-T05A & FT-0785 & UFP-PP-T01A \\
\hline
\end{tabular}

Additional information of the PEP instrumentation can be found in the run reports (Josephson et al. 2009, Guzman-Leong et al. 2009, Geeting et al. 2009, and Sevigny et al. 2009).

\subsubsection{Sampling Systems}

During PEP processes, slurry samples were collected using either in-tank or in-line samplers located throughout the system. In-line samples were obtained by drawing a side stream from the process flow. To obtain a sample, the lower valve in Figure 4.23 was opened, and then the upper valve (nearest the transfer line) was opened sufficiently to allow samples to be safely obtained. The sample line and valves, shown in Figure 4.23, were purged with at least three line volumes before samples were collected.

The in-tank sampling system for Tank T02A (Tanks T01A and T01B are similar) is shown in Figure 4.24. The in-tank sampling system was first purged by circulating process fluid through the sampling system and returning it to the tank. This was done to prevent cross-contamination with previous sampling events. A valve was then used to divert the entire flow to the sample bottle. Tanks T01A/B and Tank T02A can each be sampled from nine locations (three different radii and three elevations). The locations of the in-tank sampler ports are given in Table 4.6.

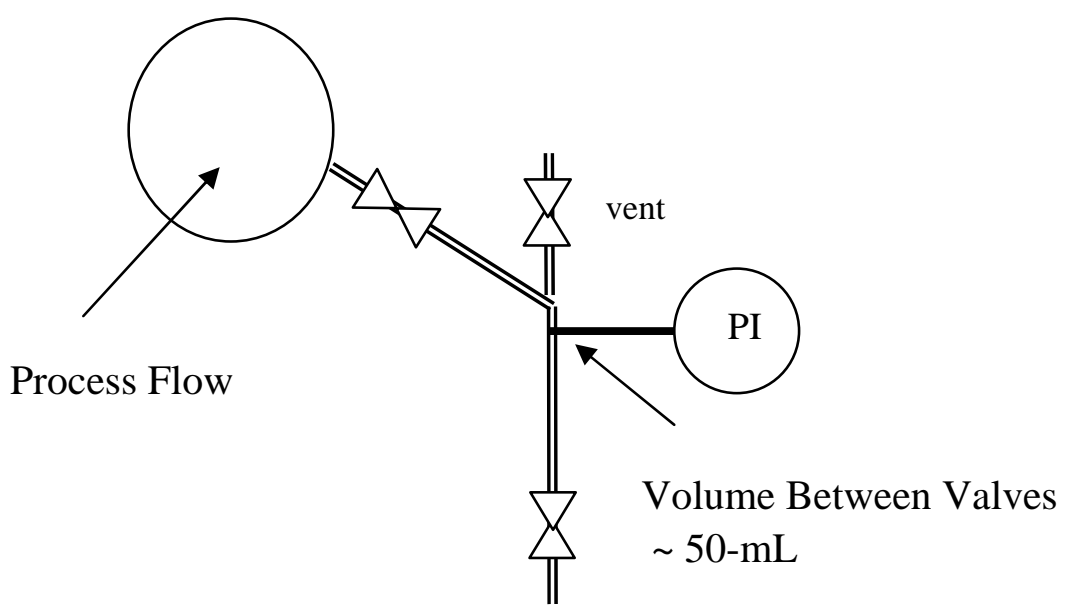

Figure 4.23. Simple In-Line Sample Valving 


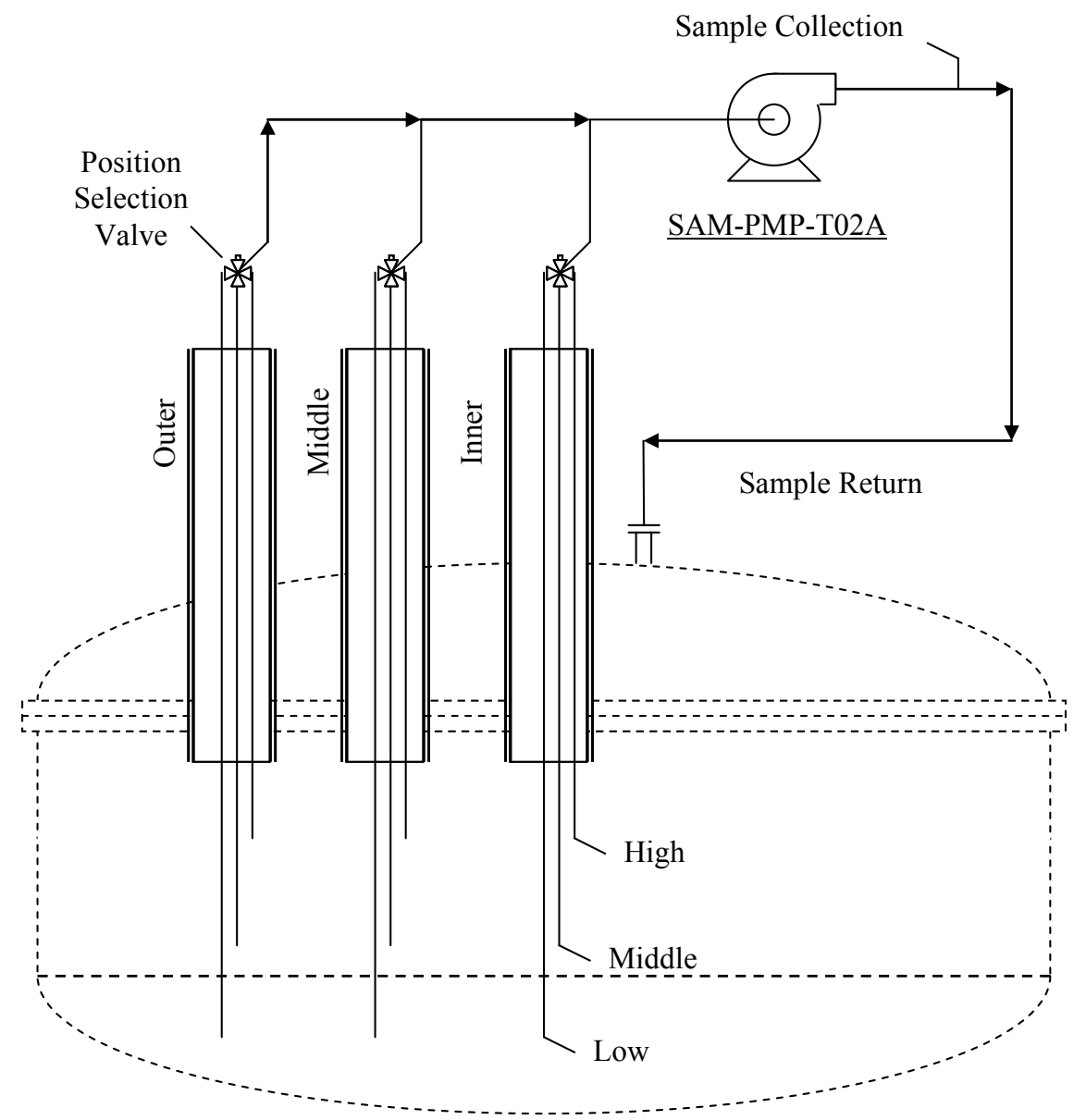

Figure 4.24. In-Tank Sampling for Tank T02A Showing the Three Radial Positions at Three Heights and Sampling Flow Loop 
Table 4.6. In-Tank Sampling Locations

\begin{tabular}{|c|c|c|c|}
\hline \multicolumn{4}{|c|}{ Tank T01 A/B Sampling Locations } \\
\hline $\begin{array}{l}\text { Radius of Access } \\
\text { Nozzle, r (in.) }\end{array}$ & $\begin{array}{c}\text { Fraction of Tank } \\
\text { Radius, } r / R\end{array}$ & $\begin{array}{l}\text { Height of Sample From } \\
\text { Bottom (in.) }\end{array}$ & Fraction of Full-Batch Height \\
\hline \multirow{3}{*}{4.7} & \multirow{3}{*}{0.17} & 2 & 0.03 \\
\hline & & 33 & 0.5 \\
\hline & & 64 & 0.97 \\
\hline \multirow{3}{*}{18.6} & \multirow{3}{*}{0.69} & 11 & 0.17 \\
\hline & & 33 & 0.5 \\
\hline & & 55 & 0.83 \\
\hline \multirow{3}{*}{24.2} & \multirow{3}{*}{0.90} & 11 & 0.17 \\
\hline & & 33 & 0.5 \\
\hline & & 55 & 0.83 \\
\hline \multicolumn{4}{|c|}{ Tank T02A Sampling Locations } \\
\hline \multirow{3}{*}{5} & \multirow{3}{*}{0.27} & 49.5 & 0.75 (2-in. above ballast) \\
\hline & & 56.5 & 0.86 \\
\hline & & 63.5 & 0.96 (2.5-in. below full batch) \\
\hline \multirow{3}{*}{15.1} & \multirow{3}{*}{0.81} & 2 & 0.03 (2-in. off bottom) \\
\hline & & 33 & 0.5 \\
\hline & & 55 & 0.83 \\
\hline \multirow{3}{*}{16.4} & \multirow{3}{*}{0.88} & 11 & 0.17 \\
\hline & & 33 & 0.5 \\
\hline & & 55 & 0.83 \\
\hline
\end{tabular}

\subsection{Cell Unit Filter (CUF)}

The laboratory-scale filtration tests were conducted in a small filtration system shown in Figure 4.22. The CUF system is composed of five main components: 1) a slurry reservoir tank, 2) a slurry recirculation loop, 3) a filter assembly, 4) a permeate flow loop, and 5) a permeate backpulse chamber. Figure 4.25 shows a piping diagram of the CUF. Figure 4.26 is a photograph of the assembled testing apparatus. The 3-hp electric motor and positive displacement pump that drives the filtration slurry simulant are shown to the left in this view. 


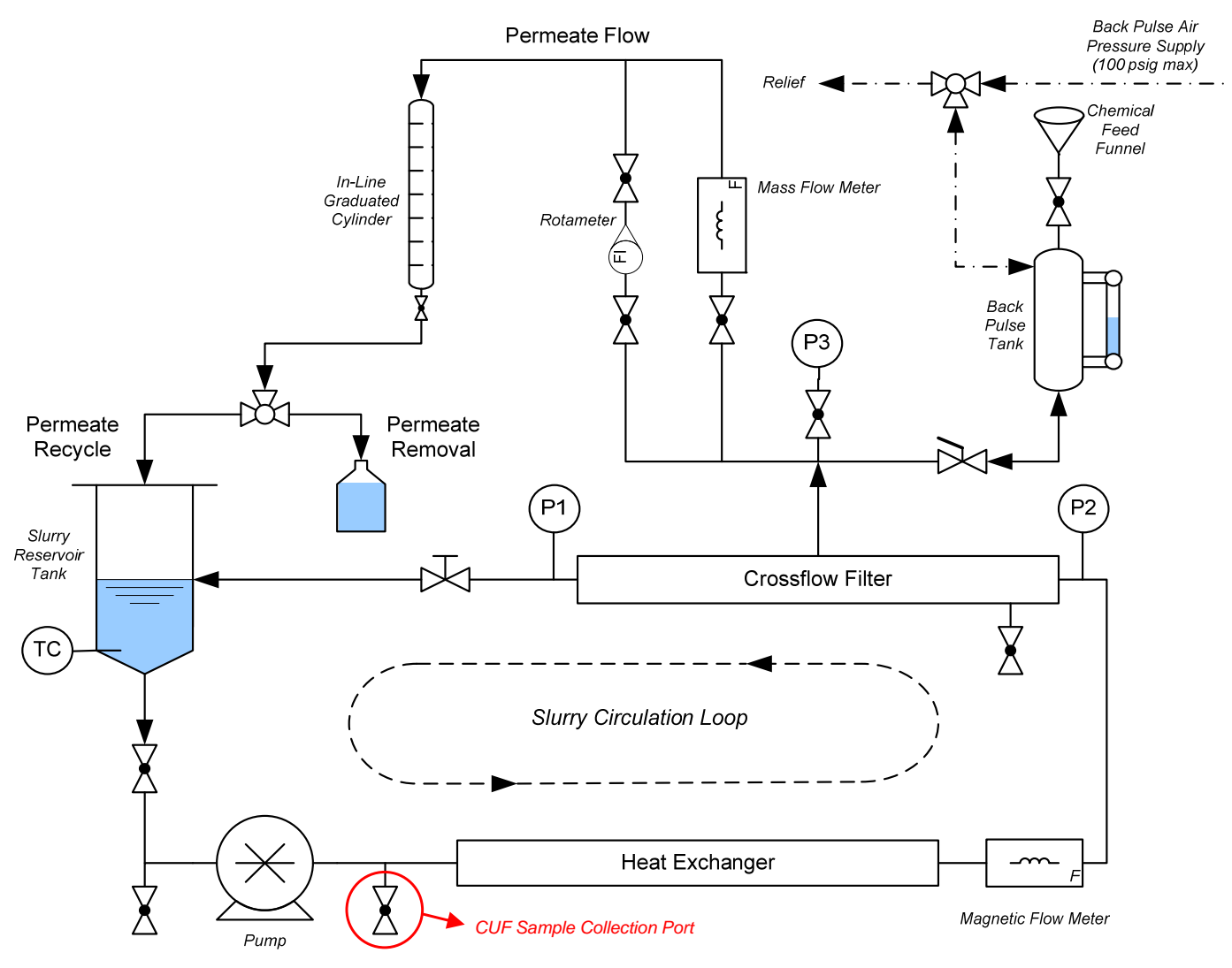

Figure 4.25. CUF Piping Diagram

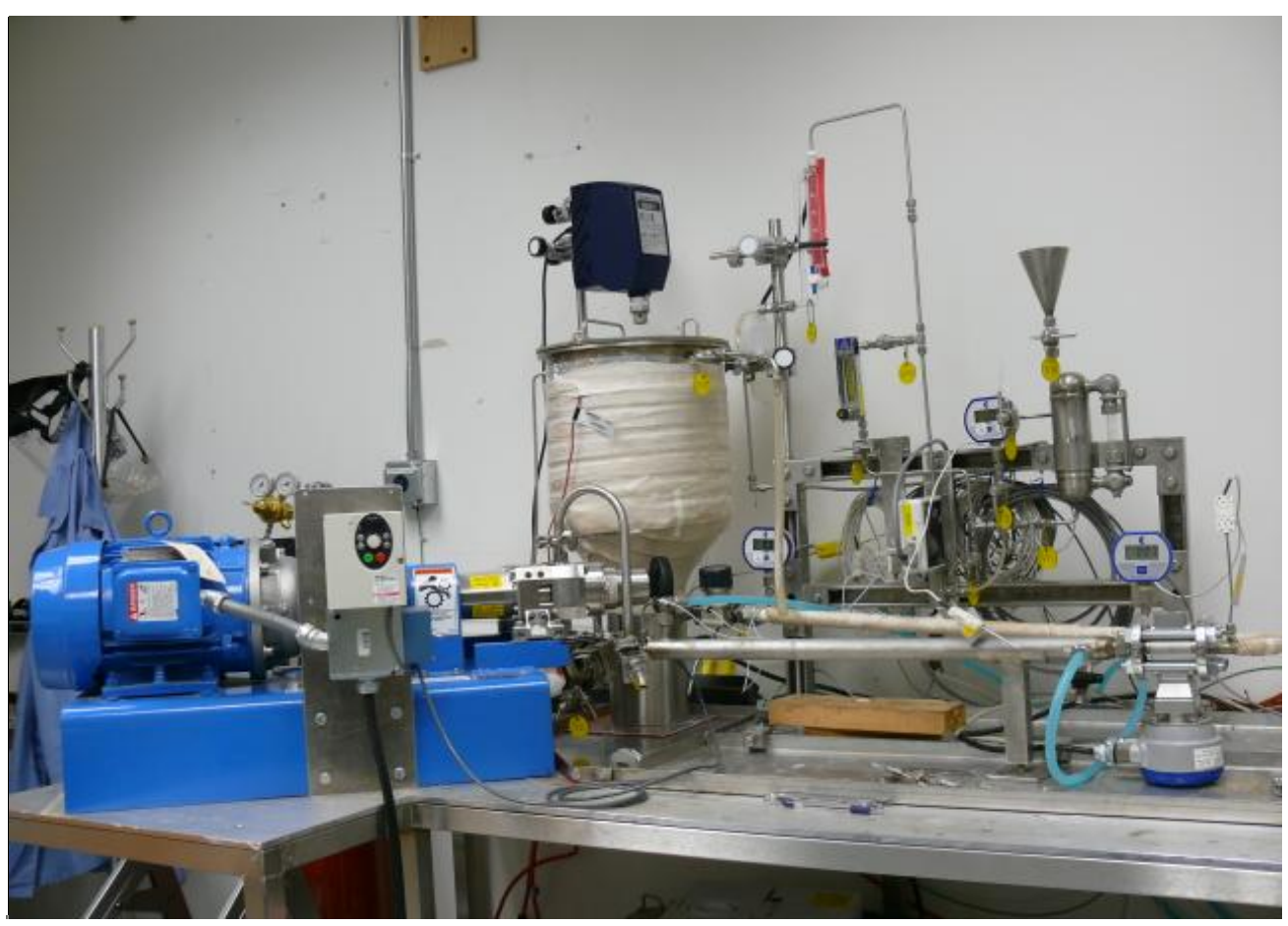

Figure 4.26. The Cold-CUF Apparatus 
The slurry reservoir tank was a 25-liter tank constructed of 304-L stainless steel. It was composed of two cylindrical sections of 5-in. and 12-in. inner diameter with a conical transition section between them. Both sections were appropriately baffled to enhance mixing with four baffles in the 12-in.-diameter section and transition section and three baffles in the 5-in.-diameter section. Agitation in the tank was provided from an overhead mixer using two impellers: 1) 2-in. diameter, 3-blade marine propeller at the end of the shaft at one tank radius from the bottom, and 2) 3-in.-diameter, pitched, 3-blade turbine positioned five inches above the propeller. Both impellers push fluid toward the suction line to the pump. To facilitate draining, the bottom of the vessel is sloped at a $15^{\circ}$ angle. The slurry reservoir thermocouple (TC) was installed near the bottom of the tank, extending just below the overhead mixing impeller.

In the slurry recirculation loop, a progressive cavity rotary-lobe pump directs slurry flow from the slurry reservoir through the heat exchanger, magnetic flow sensor, filter element, and back into the slurry reservoir. The bottom of the slurry reservoir is connected to the suction side of the slurry pump and the discharge of the pump first flows through a single-pass shell and-tube heat exchanger used to remove excess heat from mechanical energy input and heat generated from frictional flow. Next, the slurry flows through a magnetic flow sensor that monitors the volumetric flow of the slurry inside the slurry recirculation loop. The data from this device are used to calculate the axial velocity (AV) inside the filter element. The flowing slurry then enters the CUF filter assembly. All cold-CUF tests used a single filter element that was the same type and material as the filter material used in PEP and planned for the PTF. This element was received from Mott and installed in a tube-in-tube configuration. In this configuration, the outer tube (shell) surrounding the filter element has been added to capture the filtrate. The shell has two stainless steel tubes exiting from the filter assembly, one in the center to remove permeate from the filter, and the other near the inlet of the filter to function as a drain. Digital pressure gauges are installed on the inlet and outlet connections to measure the pressure inside the filter (P1 and P2 in Figure 4.25). Figure 4.27 and Figure 4.28 show the filter element assembly used in cold-CUF testing.

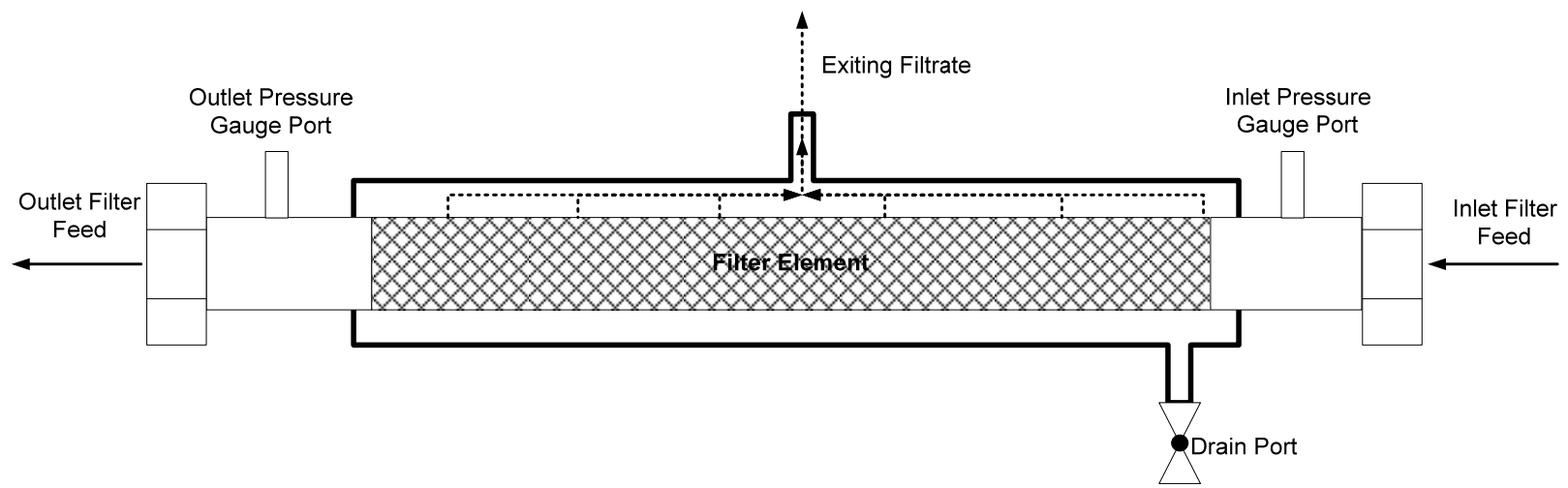

Figure 4.27. CUF Filter Assembly Sketch (not to scale) 


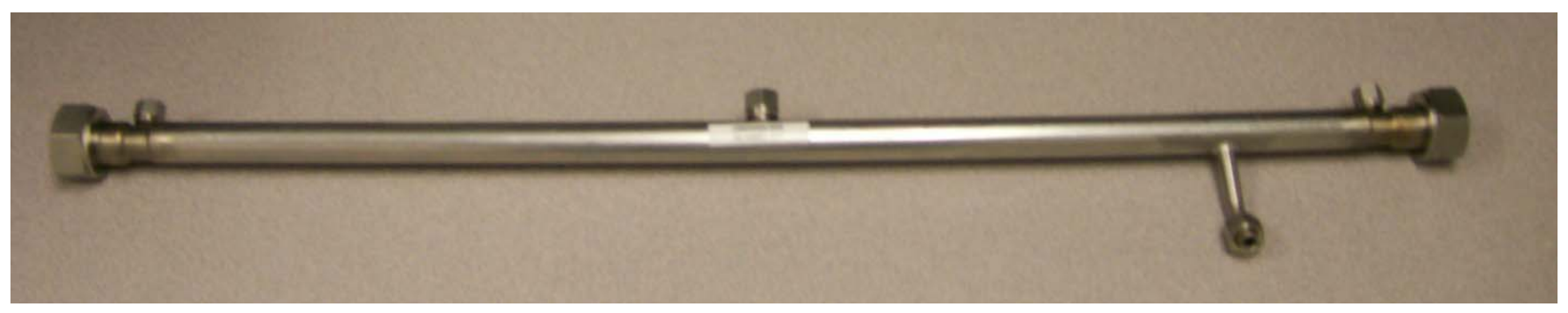

Figure 4.28. The Cell Unit Filter Assembly

Additional information on the CUF design and operation can be found in Daniel et al. (2009b).

\subsection{Laboratory-Scale Leaching Apparatus}

The laboratory-scale caustic and oxidative leaching tests were conducted in 1-L polymethylpentene (PMP) reaction vessels as depicted in Figure 4.29. The reaction vessels are straight-side beakers with an inside height of 116-mm and an inside diameter of 110-mm. Each has three PMP baffles, 92-mm long, 5-mm thick, and 19-mm wide, evenly spaced around the vessel wall. Figure 4.30 shows a picture of the testing vessel. A stainless steel stir shaft (8-mm diameter, 305- $\mathrm{mm}$ long) with a $95-\mathrm{mm}$ wide blade welded on the bottom is used to stir the vessel contents. The blade is $13-\mathrm{mm}$ tall, and each blade is angled $45^{\circ}$ from vertical. A heating jacket is wrapped around the vessel to maintain the test mixture at a constant temperature throughout the test. This heating capability was only needed for the caustic leaching experiments. The temperature is measured with a calibrated thermocouple and controlled with a calibrated temperature controller. The material to be leached is added to the reaction vessel through the sample port while stirring.

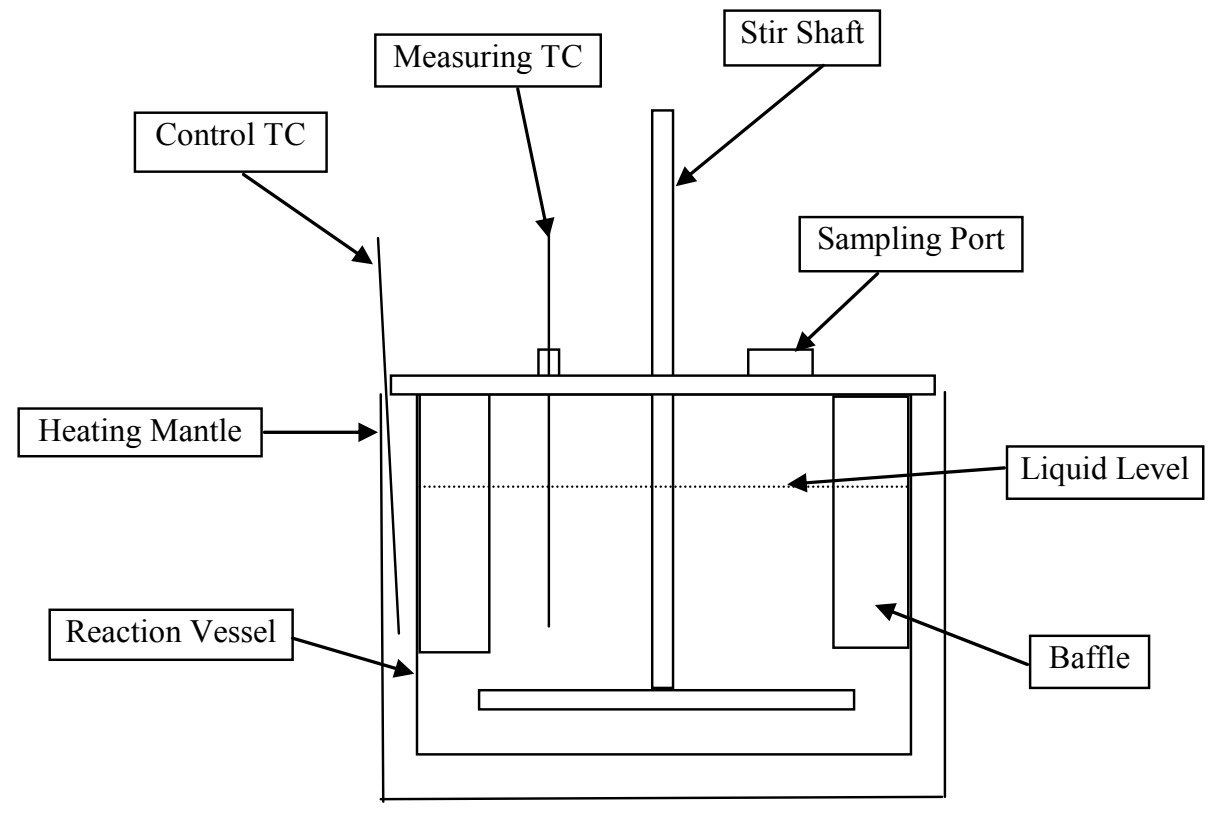

Figure 4.29. Schematic Drawing of the Caustic Leaching Test Setup 


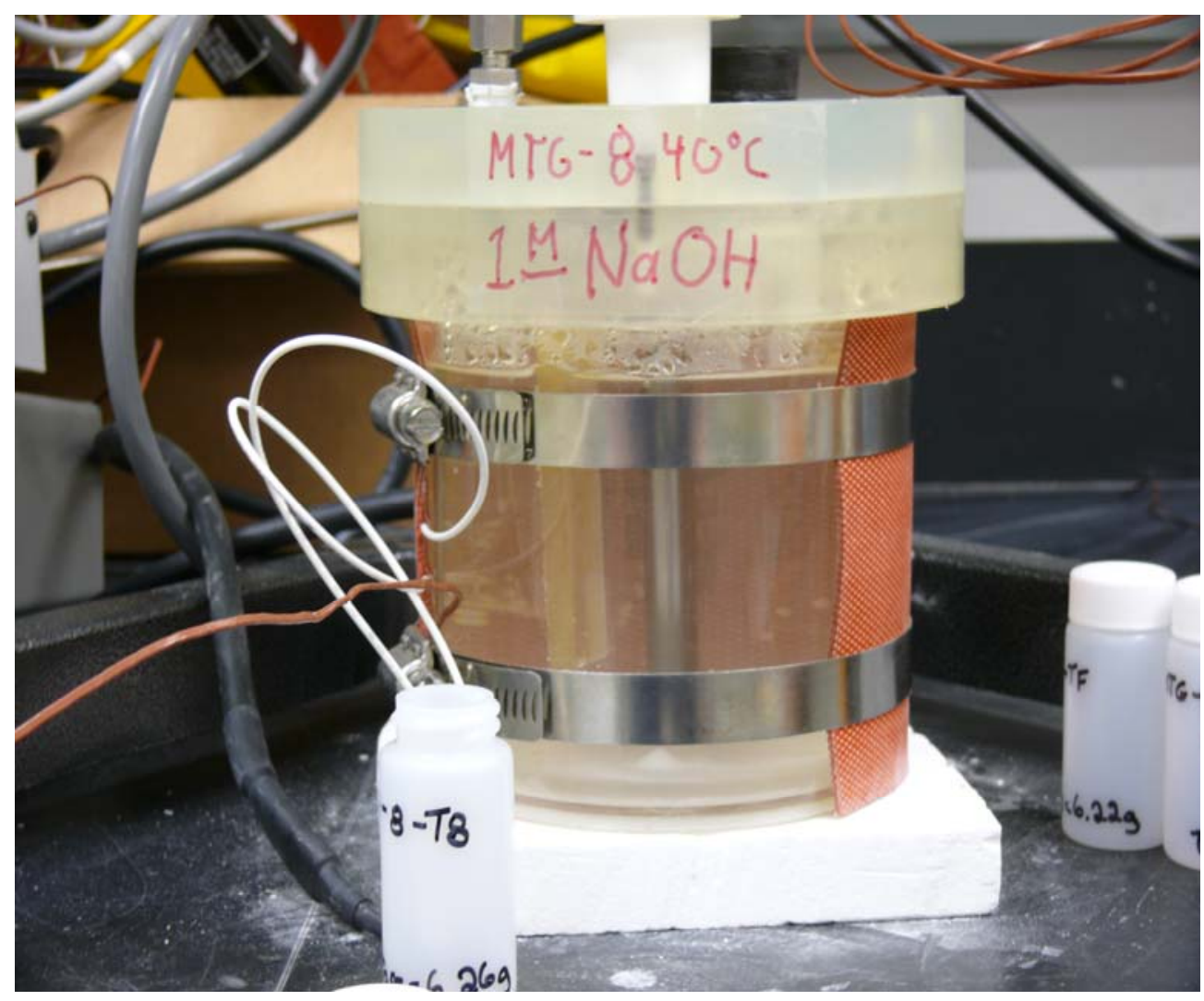

Figure 4.30. Simulant Leaching Vessel 


\subsection{Overview of Tests}

This section provides an overview of the Pretreatment Engineering Platform (PEP) and supporting laboratory tests. Selected test data and further details are provided, as needed, in Sections 7.0 through 13.0. Comprehensive descriptions of the tests, issues encountered, sample target analyses, and selected monitoring data are given in the following reports.

- PEP Functional Test: PEP Run Report for Functional Test (Josephson et al. 2009)

- Integrated Test A: PEP Run Report for Integrated Test A; Caustic Leaching in UFP-VSL-T01A at $98^{\circ} \mathrm{C}$ (Guzman-Leong et al. 2009)

- Integrated Test B: PEP Run Report for Integrated Test B; Caustic Leaching in UFP-VSL-T02A at $98^{\circ} \mathrm{C}$ (Geeting et al. 2009)

- Integrated Test D: PEP Run Report for Integrated Test D; Caustic Leaching in UFP-VSL-T02A at $85^{\circ} \mathrm{C}$ (Sevigny et al. 2009)

- CUF parallel low-solids and high-solids cross-flow filtration tests: Bench-Scale Filtration Testing in Support of the Pretreatment Engineering Platform (PEP) (Billing et al. 2009)

- Laboratory parallel caustic and oxidative leaching tests: PEP Support: Laboratory Scale Leaching and Permeate Stability Tests (Russell et al. 2009d)

- Permeate precipitate studies: Results of the Laboratory Precipitate Study from PEP Simulant (Russell et al. 2009e).

\subsection{General PEP Testing Information}

This section provides information about selected aspects of PEP testing that apply to all or most of the tests.

\subsubsection{Sample Collection and Handling}

Samples were collected by trained process operators following documented operating procedures using pre-labeled and bar-coded sample containers. Procedures required at least three line-volumes to be purged through the in-line and in-tank sampling systems (see Section 4.1.3) before samples were collected. Operators were generally assisted by sample handling personnel when multiple samples were collected to expedite sampling and prevent mistakes. Additional samples were collected for contingencies (as prescribed by the Test Plan ${ }^{(\mathrm{a})}$ ), processed the same way as other samples in the Process Development Laboratory-West (PDL-W), and held as archives.

Grab samples from tanks not equipped with dedicated samplers were collected with a portable sampling station (identical to the stationary in-tank samplers described in Section 4.1.3) using a hand-held dip-tube lowered to the desired elevation within the tank. Test-affecting grab samples were only collected

(a) Josephson GB, OP Bredt, JK Young, and DE Kurath. 2009. Test Plan for Pretreatment Engineering Platform (PEP) Testing (Phase I). TP-RPP-WTP-506, Rev 0.4, Pacific Northwest National Laboratory, Richland, Washington. 
from HLP-VSL-T22, FEP-VSL-T01 and FRP-VSL-T01. Grab samples collected from Tanks T62A/B were only collected to characterize the materials for waste disposal.

Slurry samples collected during caustic leaching were processed in PDL-W before being shipped to the analytical laboratory. Specifically, these samples were placed quickly in a $20^{\circ} \mathrm{C}$ water bath to halt further boehmite dissolution and held for 24 hours to allow precipitation of sodium oxalate and other sodium salts. The samples were then centrifuged, the supernate was decanted, and the separate phases were sent for analyses. Laboratory tests supporting the validity of this method are described in Appendix E.

Most samples were shipped to Southwest Research Institute (SwRI), located in San Antonio, TX, via an overnight delivery service. Further details of sample collection and handling are provided in Appendix E.

\subsubsection{Sample Analyses}

The analytes of interest, analytical techniques, and required estimated quantitative limits are listed in Table 5.1. Quantitative limits listed include processing factors associated with preparation and analyses. For techniques where additional analytes were measured, all analytes were reported. The preparative and analytical quality control (QC) requirements specified in Hanford Analytical Services Quality Assurance Requirements Documents (HASQARD), Rev. 2 (DOE-RL 1998) were applied to only the target analytes. All other analytes were considered opportunistic, and QC failures for these analytes did not require corrective action as described in HASQARD, Rev. 2. Opportunistic analytes were expected to include (but are not limited to) As, B, Sn, and Zn.

Details of the sampling, handling, analytical techniques, and sample naming conventions are provided in Appendix E.

\subsubsection{Visual Inspections}

Visual inspections of the slurry surface in PEP vessels are conducted by video camera. The camera is lowered through a nozzle and manually panned and tilted to view different regions. The camera is limited to specific objectives, such as to inspect for foam, help realign the laser level probe, and investigate unexpected behavior.

Maintenance outages allowed very limited visual inspections of disassembled PEP equipment internals for accumulated solids because maintenance procedures required thorough flushing and draining of equipment for worker safety before the equipment was disassembled.

\subsubsection{Line and Filter-Loop Flushing}

Pretreatment Facility transfer lines and equipment are to be flushed at specified times during operation to prevent plugging by settled solids and accumulation of flammable gas generated by the waste. Backflushing the ultrafilters to the ultrafiltration feed vessels also is planned to reduce the system heel between process batches. To minimize the amount of flush water introduced in the PTF, line flush 
water volumes are to be 1.5 times the volume of the line being flushed, and the filter-loop backflush is to be a single loop volume.

PEP transfer lines were designed to be flushed like the PTF; however, neither the configurations nor the volumes of the PEP transfer lines are prototypic of the PTF. (PEP line volumes are significantly larger than prototypic.) Because truly prototypic line flushes were not possible, and the amount of water introduced by line-flushing was determined to be very small (relative to the slurry volumes of the receiver vessels), PEP testing did not include routine line flushes. No line-plugging issues were observed.

Table 5.1. Estimated Quantitative Limits for Solids and Supernatants in Sample Loop Testing, PEP Operation, and Simulant Acceptance Samples

\begin{tabular}{|c|c|c|c|}
\hline Analyte & $\begin{array}{l}\text { Wet Solids } \\
\mu \mathrm{g} / \mathrm{g}\end{array}$ & $\begin{array}{l}\text { Liquid solution } \\
\mu \mathrm{g} / \mathrm{mL}\end{array}$ & Analytical Technique \\
\hline $\mathrm{Al}$ & $4.0 \mathrm{E}+01$ & $5.0 \mathrm{E}+00$ & \multirow{17}{*}{$\begin{array}{l}\text { Inductively Coupled Plasma Atomic } \\
\text { Emissions Spectroscopy }\end{array}$} \\
\hline $\mathrm{Ca}$ & $2.0 \mathrm{E}+01$ & $5.0 \mathrm{E}+00$ & \\
\hline $\mathrm{Ce}$ & $8.0 \mathrm{E}+00$ & $7.5 \mathrm{E}+01$ & \\
\hline $\mathrm{Cr}$ & $5.0 \mathrm{E}+00$ & $1.0 \mathrm{E}+00$ & \\
\hline $\mathrm{Fe}$ & $3.0 \mathrm{E}+02$ & $7.5 \mathrm{E}+01$ & \\
\hline $\mathrm{K}$ & $3.0 \mathrm{E}+01$ & $1.5 \mathrm{E}+01$ & \\
\hline $\mathrm{La}$ & $6.0 \mathrm{E}+00$ & $7.5 \mathrm{E}+01$ & \\
\hline $\mathrm{Mg}$ & $7.0 \mathrm{E}+00$ & $5.0 \mathrm{E}+00$ & \\
\hline $\mathrm{Mn}$ & $1.0 \mathrm{E}+01$ & $5.0 \mathrm{E}+00$ & \\
\hline $\mathrm{Na}$ & $3.0 \mathrm{E}+02$ & $7.5 \mathrm{E}+01$ & \\
\hline $\mathrm{Nd}$ & $1.0 \mathrm{E}+01$ & $5.0 \mathrm{E}+00$ & \\
\hline $\mathrm{Ni}$ & $2.0 \mathrm{E}+01$ & $3.0 \mathrm{E}+01$ & \\
\hline $\mathrm{P}$ & $5.0 \mathrm{E}+01$ & $1.0 \mathrm{E}+01$ & \\
\hline $\mathrm{Pb}$ & $3.0 \mathrm{E}+01$ & $7.5 \mathrm{E}+1$ & \\
\hline $\mathrm{Si}$ & $3.0 \mathrm{E}+03$ & $7.5 \mathrm{E}+01$ & \\
\hline $\mathrm{Sr}$ & $2.0 \mathrm{E}+01$ & $5.0 \mathrm{E}+00$ & \\
\hline $\mathrm{Zr}$ & $9.0 \mathrm{E}+01$ & 7.5E+01 & \\
\hline $\mathrm{Cs}$ & $\mathrm{N} / \mathrm{A}$ & $4 \mathrm{pg} / \mathrm{mL}$ & $\begin{array}{l}\text { Inductively Coupled Plasma Mass } \\
\text { Spectroscopy }\end{array}$ \\
\hline Chloride & NA & $1.2 \mathrm{E}+02$ & \multirow{6}{*}{$\begin{array}{l}\text { Ion Chromatography } \\
\text { (water-soluble species) }\end{array}$} \\
\hline Nitrite & NA & $1.2 \mathrm{E}+02$ & \\
\hline Nitrate & NA & $4.0 \mathrm{E}+01$ & \\
\hline Phosphate & NA & $1.2 \mathrm{E}+02$ & \\
\hline Sulfate & NA & $6.0 \mathrm{E}+01$ & \\
\hline Oxalate & NA & $2.5 \mathrm{E}+02$ & \\
\hline Hydroxide & $\mathrm{NA}$ & $5 \mathrm{E}-03-\mathrm{M}$ & Titration \\
\hline Total inorganic carbon & NA & $2.0 \mathrm{E}+02$ (as C) & Coulometer \\
\hline Density & $0.9-$ to $1.7-\mathrm{gm} / \mathrm{mL}$ & $0.9-$ to $1.7-\mathrm{gm} / \mathrm{mL}$ & Gravimetric \\
\hline
\end{tabular}

During Integrated process testing, the amount of slurry backflushed to Tank T02A was specified to be the prototypic filter-loop volume (i.e., about 19.5 gal), rather than the actual PEP filter-loop volume (i.e., about 82 gal) so that the slurry level in Tank T02A after the backflush was prototypic. The PEP ultrafiltration loop was then isolated and flushed with inhibited water (IW) to Tanks T62A/B. Like the PTF, the PEP filter-loop was left full of water when not in use and drained of water before slurry was reintroduced. 


\subsubsection{Pulse Jet Mixer Operation}

The prototypic pulse jet mixers (PJMs) in Tanks T01A/B and Tank T02A were operated differently when mixing Newtonian and non-Newtonian slurries. Simulant slurries having less than about 18 -wt $\%$ solids were assumed to be Newtonian, and higher solids slurries were assumed to be non-Newtonian. As discussed in Section 3.0, PJMs were controlled to match the (mixing power)/volume ratio of the PTF for Newtonian slurries and to match the nozzle velocity of the PTF for non-Newtonian slurries. Because changing PJM control parameters in the PEP to achieve targeted mixing involved a lengthy tuning process, the Pulse Jet (PJM) Operating Procedure ${ }^{(\mathrm{a})}$ was only conducted between process steps. Noteworthy points are that:

- Tank T01A/B contained only Newtonian slurries, so their PJMs were always run to match the (mixing power)/volume of the PTF.

- Tank T02A contained predominantly Newtonian slurries until the end of the post-caustic-leach solids concentration process. Its PJMs were therefore run to match the PTF (mixing power)/volume ratio through the end of that process step, further processing was paused while the PJMs were re-tuned to match PTF nozzle velocities, and the PJMs were run in that way throughout the remainder of the test.

- The PJM operation was checked, and adjusted if needed, after the target caustic leaching temperature was reached to make mixing during the caustic-leach as prototypic as possible.

As is planned in the PTF, operating the PJMs above $60^{\circ} \mathrm{C}$ (i.e., during the heat-up, caustic-leach, and cool-down) involved shutting off the vacuum refill and allowing the PJMs to refill by gravity. This was done in the Functional Test and Integrated Tests A, B, and D.

When operating above $65^{\circ} \mathrm{C}$, water condensate that formed in the PJM vent lines was drained to an external receptacle instead of being allowed to drain back into the leaching vessel. This was done to reduce the accumulation of water in the PEP leaching vessels and help achieve prototypic supernate concentrations. The ability to drain-off the PJM vent condensate was a modification of the PEP design, and a consequence of the modification was the loss of separate controls ${ }^{(b)}$ for each PJM (i.e., all PJMs were operated with the same drive time, drive pressure, etc. when configured to drain off condensate).

As PJMs empty and refill, the level of slurry outside the PJMs rises and falls appreciably. This results in an effective increase in the minimum pumping heel volume in a vessel when the PJMs are operating - the heel volume includes the volume to fill the vessel to the minimum pumping level plus the volume of slurry inside the filled PJMs. After post-caustic-leach solids concentration in Integrated Tests B and D, the slurry level in Tank T02A was prototypic, but it was so low that pumping problems were encountered when the PJMs were filled. To circumvent this problem, only the center PJM and one of the outer PJMs were operated at a time. Each outer PJM was operated for five strokes, and then a different outer PJM was operated for five strokes, etc., with each of the five outer PJMs being operated in turn. This PJM operating mode was referred to as "star mode" because the pattern of switching amongst the five outer PJMs traces out a star.

(a) OP-RPP-WTP-404, Pulse Jet (PJM) Operating Procedure.

(b) Since all the PJM were connected to a common drain header with leaching temperatures exceeded $60^{\circ} \mathrm{C}$, air pressures in any individual PJM could not be fine tuned. 


\subsubsection{Air Sparge Mixers and Steam Ring Air Purge}

Tank T02A, like its planned PTF counterpart, used air sparge mixers to provide mixing in the upper regions of the vessel. Based on the scaling analysis (Kuhn et al. 2008), the PEP used five open-ended air sparge tubes near the bottom of the vessel to mimic the 10 in the PTF and one air sparge tube above the PJM cluster to mimic the six in the PTF. As discussed in Section 3.0, the air flow rates in the PEP were chosen to match the mixing power/volume of the PTF in the upper region of the vessel. Table 5.2 shows the planned use of sparge air in the PTF and its use during testing in the PEP. In this table, "idle" refers to a trickle flow of air intended to keep slurry from filling up the air sparge tubes, and the ratio of (vessel slurry height)/(vessel diameter) is abbreviated as H/D. Kuhn et al. (2008) discuss the prototypic air flow rates used in the PEP.

Table 5.2. Tank T02A Air Sparge Mixer Operation

\begin{tabular}{|c|c|c|c|c|}
\hline & $\begin{array}{c}\mathrm{H} / \mathrm{D}<1.4 \text { and } \\
\text { Filter-Loop Pump } \\
\text { On }\end{array}$ & $\begin{array}{c}\mathrm{H} / \mathrm{D}<1.4 \text { and } \\
\text { Filter-Loop Pump } \\
\text { Off }\end{array}$ & $\begin{array}{c}\mathrm{H} / \mathrm{D}>1.4 \text { and } \\
\text { Filter-Loop Pump } \\
\text { On }\end{array}$ & $\begin{array}{c}\mathrm{H} / \mathrm{D}>1.4 \text { and } \\
\text { Filter-Loop Pump } \\
\text { Off }\end{array}$ \\
\hline Lower spargers flow & Idle & Full & Full $^{(a)}$ & Full \\
\hline Upper sparger flow & Idle & Idle & Full ${ }^{(a)}$ & Full \\
\hline
\end{tabular}

(a) During oxidative leaching, the spargers will be idle.

In addition to the air sparge mixers in Tank T02A, the steam rings in Tanks T01A/B and Tank T02A were to be purged with air whenever steam was not flowing.

It should be noted that when the filter-loop pumps were running during Integrated Tests $\mathrm{B}, \mathrm{D}$ and portions of Integrated Test A, the air spargers and even the steam ring air purge in Tank T02A were sometimes turned off to reduce air entrainment. The air entrainment issue is discussed in Section 13.

\subsubsection{Antifoam Agent}

All process tests (Functional and Integrated) were conducted with the antifoam agent (AFA) recommended by Ultrafiltration Process (UFP) Caustic Leaching Antifoam Performance ${ }^{(\mathrm{a})}$ added to simulant slurries. AFA was added to Tank T01A/B and/or Tank T02A as needed to achieve and maintain an AFA concentration of 350 parts per million (ppm), including AFA additions after every third wash-water batch addition. Details of the AFA usage and fate are discussed in Section 12.

\subsubsection{Material Balances}

The Test Specification (Huckaby and Markillie 2008) required that material balances be made on key components, such as aluminum, chromium, manganese, sodium, and oxalate, to evaluate leaching and washing process performance. The objective of the material balances was to determine the amounts of these components that were removed during each process step; i.e., their fates. Specific samples and

(a) White TL, TB Calloway, PR Burket, CL Crawford, EK Hansen, and KE Zeigler. 2006. Ultrafiltration Process (UFP) Caustic Leaching Antifoam Performance. SRNL-RPP-2005-00065, Rev. 0; SCT-M0SRLE60-00-99-00009 Rev. 00A; WSRC-TR-2005-00564 Rev.0; Westinghouse Savannah River Company, Aiken, South Carolina. 
analyses were specified by the Test Plan ${ }^{(a)}$ to collect the necessary composition data for these material balances. To improve estimates of slurry volumes, PEP testing included stable-level measurements at various points during the tests. Stable-level measurements were made in Tanks T01A/B and Tank T02A by (temporarily) shutting off any associated pumps, and stopping and venting the PJMs.

\subsection{PEP Functional Testing}

Functional process testing had the following objectives established in the Test Plan ${ }^{(a)}$ that were requested by the client in the PEP Testing (Phase 1) specifications: ${ }^{(b)}$

- Demonstrate that the PEP steam vessel heating control strategy heats the caustic leaching vessels to the required set point in the specified heat-up time and controls the vessel temperature at the leaching temperature for the duration of caustic leaching. The resulting accumulation of condensate should be approximately prototypic. The PEP vessels will not automatically mimic the thermal behavior of the PTF because of scaling issues associated with heat loss to the surroundings and the evaporation of water (i.e., into the vessel headspace, air sparge mixing bubbles, and steam ring air purge). Prototypic thermal behavior will be achieved in the PEP with nonprototypic controls that need to be tested before Integrated process testing.

- Demonstrate that the PEP vessel cool-down control strategy achieves calculated prototypic vessel temperatures when caustic leaching is conducted in the PEP Tank T02A vessel. As discussed above, prototypic thermal behavior in the PEP will require nonprototypic controls, and the controls to cool-down Tank T02A need to be tested before Integrated process testing.

- Demonstrate that the PEP slurry cool-down strategy achieves prototypic thermal quenching of the caustic-leach when caustic leaching is conducted in Tank T01A/B. As discussed above, prototypic thermal behavior in the PEP will require nonprototypic controls. In addition to general thermal scaling difficulties, the Tank T01A/B vessels do not have water jackets like the plant, so an additional (nonprototypic) process step has been introduced to achieve prototypic cooling of the vessel contents using an external heat exchanger. The strategy and controls used to cool-down Tank T01A need to be tested before Integrated process testing.

- Condition the five filter bundles using PEP Phase 1 simulant and collect filter conditioning data for comparison to analogous CUF filter conditioning (low-solids filter testing). The results to meet this objective are discussed in Section 8.2 and Daniel et al. (2009b).

- Collect data for the comparison of CUF and PEP filter performance under conditions that produce filter cake on the cross-flow filters (high-solids filter testing).

- Demonstrate the PEP filter-loop flush strategy. The PEP does not have equipment to prototypically mimic the filter-loop flush. This operation is being tested with a full-scale test platform. However, during Integrated testing, it is important to flush the filter-loop to recover the slurry contents without introducing excessive nonprototypic flush water to Tank T02A. This will be achieved by a nonprototypic filter-loop flush in the PEP, and the adequacy of this step needs to be understood before Integrated testing.

(a) Josephson GB, OP Bredt, JK Young, and DE Kurath. 2009. Test Plan for Pretreatment Engineering Platform (PEP) Testing (Phase I). TP-RPP-WTP-506, Rev 0.4, Pacific Northwest National Laboratory, Richland, Washington.

(b) Huckaby JL and JR Markillie. 2008. Pretreatment Engineering Platform (PEP) Testing (Phase 1) Test Specification. 24590-PTF-TSP-RT-07-001 Rev 2, Bechtel National, Inc., Richland, Washington. 
- Demonstrate that the PEP equipment and controls are adequate to conduct Integrated process testing. This objective addresses the need to verify that all system components are adequate to complete the Integrated process testing with the Phase 1 PEP simulant.

- Evaluate the stratification of solids in Tank T01A/B and Tank T02A under prototypic mixing conditions. If mixing in these vessels does not result in an approximately homogeneous distribution of solids (i.e., solids settling is negligible), then sample collection and analyses during Integrated process testing may need to be increased to properly characterize the vessel contents. The results to meet this objective are discussed in Sections 7.2 and 7.5.

- Evaluate the precision of filter-loop in-line slurry samples and their agreement with in-tank samples. In-line slurry sampling precision and accuracy are needed to calculate the uncertainties of test results, and the number of samples collected may need to be increased if sample precision is poor. The results to meet this objective are discussed in Section 7.3.

Additional information on meeting the PEP Functional Testing objectives may be found in Josephson et al. (2009).

\subsection{PEP Integrated Process Testing}

Integrated Tests A, B, and D were conducted to demonstrate transfers, solids concentration by ultrafiltration, chemical additions, caustic leaching, slurry washing, oxidative leaching, operability of prototypic equipment, and process durations and timing. The two process flowsheets that were demonstrated are summarized in Figure 5.1. General testing conditions and data to be obtained are summarized in the Test Plan ${ }^{(a)}$ and process control strategies; default process parameters and endpoints are given in Pretreatment Engineering Platform (PEP) Phase 1 Testing Process Description. ${ }^{(b)}$

(a) Josephson GB, OP Bredt, JK Young, and DE Kurath. 2009. Test Plan for Pretreatment Engineering Platform (PEP) Testing (Phase I). TP-RPP-WTP-506, Rev 0.4, Pacific Northwest National Laboratory, Richland, Washington.

(b) Lehrman S. 2008. Pretreatment Engineering Platform (PEP) Phase 1 Testing Process Description. 24590-WTP-RPT-PET-07-002, Rev 0, Bechtel National, Inc., Richland, Washington. 


\author{
Caustic Leaching in \\ UFP-T01A/B \\ Caustic Addition \\ Heat-up \\ Caustic Leach in UFP-VSL-T01 \\ Cool Down \\ Transfer to UFP-VSL-T02 \\ Post-Caustic-Leach Solids Concentration \\ Post-Caustic-Leach Wash \\ Permanganate \& Caustic Addition \\ Oxidative Leach \\ Post-Oxidative-Leach Wash \\ Post-Oxidative-Leach Solids Concentration
}

\author{
Caustic Leaching in \\ UFP-T02A \\ Initial Solids Concentration of Feed \\ Caustic Addition \\ Heat-up \\ Caustic Leach in UFP-VSL-T02 \\ Cool Down \\ Post-Caustic-Leach Solids Concentration \\ Post-Caustic-Leach Wash \\ Permanganate \& Caustic Addition \\ Oxidative Leach \\ Post-Oxidative-Leach Wash \\ Post-Oxidative-Leach Solids Concentration
}

Figure 5.1. Caustic- and Oxidative-Leach and Ultrafilter Operations

The chromium solids component of the simulant was added after the post-caustic-leach wash in Integrated Tests A and B. This circumvented the problem that the high-temperature caustic leaching process dissolved and oxidized most of the chromium solid simulant, leaving little with which to demonstrate the oxidative leaching process. The chromium solids were added as a slurry that significantly increased both the total slurry volume and the hydroxide concentration in Tank T02A and the filter-loop. Therefore, after the chromium slurry was added, the ultrafiltration loop was used to first reduce the volume of liquid, and then to wash the hydroxide concentration down to the targeted 0.25-M. This also decreased the concentrations of other soluble species, but was not expected to impact subsequent processes.

Chromium solids were included with the other simulant components in the feed for Integrated Test D. This was done to demonstrate the PTF permanganate addition strategy. Briefly, the PTF strategy requires that a sample be collected from the ultrafiltration feed preparation vessels (UFP-VSL-00001A/B) and be subjected to caustic leaching to determine the fraction of chromium dissolved. This allows the amount of permanganate reagent to be calculated in a batch-specific manner. Laboratory tests with the PEP simulant had suggested that only about $70 \%$ of the chromium solid simulant was dissolved during caustic leaching at the lower caustic leaching temperature of $85^{\circ} \mathrm{C}$ and that the remaining $30 \%$ was sufficient to demonstrate the oxidative leaching step. The PTF permanganate strategy was demonstrated in Integrated Test D by sampling the Integrated Test D feed simulant (containing chromium solids), conducting a 
laboratory stirred-beaker caustic leaching test on the sample, determining the fraction of chromium solids dissolved, and using this result to calculate the amount of permanganate reagent for oxidative leaching in the PEP.

\subsubsection{Integrated Test A: Caustic Leaching in Tank T01A/B at $98^{\circ} \mathrm{C}$}

At the start of Integrated Test A, slurry transfer lines and both Tank T01A/B vessels were empty (drained). All reagent supply lines had been filled. The filter-loop ${ }^{(a)}$ was full of IW, and Tank T02A contained a small heel estimated to be less than 5 gallons of IW. Control parameters for the PJMs in Tanks T01A/B and Tank T02A had been adjusted to achieve approximately prototypic (mixing power/volume) jet mixing using the undiluted simulant. A run sheet specifying all process control parameters, transfer volumes, transfer rates, process times, and endpoints had been developed, reviewed, and approved. The information from the run report was incorporated into the Test Instruction. The Test Plans, Test Instructions, and procedures used for Integrated Test A are provided in Guzman-Leong et al. (2009).

The test was started with the transfer of simulant from HLP-VSL-T22 to Tank T01A. Immediately after the start of this transfer, the in-line addition of 19-M NaOH (nominal concentration) was started just downstream of the transfer pump (Pump T21) at a flow rate designed to add the targeted amount of caustic evenly over the entire transfer period. Heat released by diluting the 19-M caustic raised the temperature of the slurry to about $48^{\circ} \mathrm{C}^{(\mathrm{b})}$. Once the transfer was complete, the Tank T01A recirculation loop was opened and the external (nonprototypic) steam heat exchanger HX-T04A was used to raise the slurry to an initial temperature of about $57^{\circ} \mathrm{C}$. The recirculation loop was then isolated (and drained), and direct steam injection was used to heat Tank T01A to the target leaching temperature of $98^{\circ} \mathrm{C}$ over a prototypic 3.8-hr heat-up period. By heating the slurry to $57^{\circ} \mathrm{C}$ before initiating direct steam injection, the total amount of steam condensate accumulated in Tank T01A at the end of the heat-up period was predicted to be prototypic of the PTF. During the heat-up, the PJMs were switched to gravity refill at about $60^{\circ} \mathrm{C}$, the PJM vent lines were configured to drain any condensate to an external receiver at about $65^{\circ} \mathrm{C}$, and the air purge of the steam ring was reduced to its high-temperature flow rate above $90^{\circ} \mathrm{C}$.

Once the caustic-leach temperature was reached in Tank T01A, the PJM control parameters were adjusted to achieve approximately prototypic (mixing power/volume) jet mixing for the dilute (Newtonian) slurry. Steam was directly injected to maintain the caustic leaching temperature for the 16-hr leaching period. Small amounts ( 3-L) of water were added each hour to Tank T01A via a nozzle in the head to simulate steam condensate; this had been calculated as necessary to maintain the prototypic amount of dilution of the slurry by steam condensate.

At the end of the caustic leaching period, the Tank T01A recirculation loop was opened and used to circulate the hot slurry through the HX-T05A chilled-water heat exchanger. Chilled water flow to this heat exchanger was controlled to reduce the temperature of Tank T01A to $60^{\circ} \mathrm{C}$ over the prototypic initial cool-down period of 2.75 hours. The rate of cooling to $60^{\circ} \mathrm{C}$ was controlled to mimic any further

(a) The ultrafilters had been cleaned with Oxalic acid on December 30, 2008 during functional testing and had not been cleaned prior to Integrated Test A.

(b) During the first transfer, simulant from HLP-VSL-T22, which had a starting temperature of $35^{\circ} \mathrm{C}$, was transferred to Tank T01A with an addition of $19-\mathrm{M}$ caustic. Temperatures in Tank T01A were $29^{\circ} \mathrm{C}$ prior to the transfer and the tank level was approximately 8 inches. The Tank T01A level after the transfer was approximately 72 inches and the tank temperature was $48^{\circ} \mathrm{C}$. 
boehmite dissolution that may occur. During the initial cool-down period, the PJM vents were reconfigured to drain to Tank $\mathrm{T} 01 \mathrm{~A}$, and at $60^{\circ} \mathrm{C}$, the PJMs were switched from gravity refill to vacuum refill. Once Tank T01A had reached $60^{\circ} \mathrm{C}$, the HX-T05A heat exchanger was set to control the output slurry temperature to $25^{\circ} \mathrm{C}$, and the slurry was routed to Tank T02A.

Tank T02A was filled to the prototypic level for post-caustic-leach solids concentration plus the volume needed to fill the filter-loop. After Tank T02A was filled, the Tank T01A recirculation loop was reconfigured to send the $25^{\circ} \mathrm{C}$ slurry back to Tank T01A. The filter-loop was drained of IW and allowed to fill with slurry from Tank T02A, and then Pumps T42A and T43A were started and adjusted to achieve the targeted 109 GPM. The solids concentration using the first 10-ft filter bundle, FILT-T01A, was then started. Make-up batches of 11 gal of leached slurry were transferred from Tank T01A each time the Tank T02A level dropped below its set point.

Meanwhile, the second caustic leaching batch had been initiated in Tank T01B according to nearly identical instructions. In Tank T01B, however, only $80 \%$ of the 19 -M caustic was added in-line. The remaining $20 \%$ was added directly to Tank T01B via a nozzle in its top head. This was done to demonstrate a proposed caustic control strategy that would be based on slurry samples collected from UFP-VSL-00001A/B.

When transfers from Tank T01A had reduced its inventory to its prototypic heel (nominally 63 gal), the solids concentration was continued with 11-gal make-up batches from the second caustic-leach batch. The heel in Tank T01A was left in place, and a third caustic-leach batch was started in Tank T01A. Six batches were leached, alternating between Tank T01A and Tank T01B until Tank T02A contained the prototypic level of slurry at a calculated 17-wt\% UDS concentration (i.e., the total amount of leached slurry transferred to Tank T02A was specified by the run sheet and was predicted to be $17-\mathrm{wt} \%$ UDS). Sample analyses later indicated that the actual solids concentration at this point was $18.3-\mathrm{wt} \%$ UDS. All three caustic-leach batches conducted in Tank T01A received $100 \%$ of the prescribed $19-\mathrm{M}$ caustic in-line, and all three in Tank T01B received $80 \%$ in-line and 20\% in-tank.

Filter backpulsing was used to improve permeate production during the post-caustic-leach solids concentration step, and different backpulse parameters were tested. The backpulse pressure and volume were varied, and the effect of repetitious backpulsing was investigated. In the post-caustic-leach solids concentration step, six leached batches were concentrated between 2/2/09, 01:34, and 2/14/09, 14:06.

At the end of the post-caustic-leach solids concentration step, the Tank T02A PJM control parameters were adjusted to achieve approximately $12.1-\mathrm{m} / \mathrm{s}$ peak-average nozzle velocities (PTF is planning on $12-\mathrm{m} / \mathrm{s}$ ). Filter permeate valves were closed, but flow continued at the targeted 109 GPM through the filter-loop while the PJMs were adjusted. On at least one occasion, a maladjustment resulted in one or more of the PJMs being completely emptied of slurry, and pressurized air was blown out of the PJM nozzle (an "overblow"). Associated with this was a gradual divergence in the readings of two flowmeters, one located just upstream of Pump T42A and the other just downstream of Pump T43A (used to control Pump T43A). There was a marked loss of pump efficiency. The flow rate problems were not understood at this point, and repeated attempts were made to increase the filter-loop flow rate, according to the lower-reading flowmeter, to its target value of 109 GPM. Though filter-loop flow control was difficult, the test was resumed. 
A small quantity of a CsBr solution was added to the inlet of Pump T42A to initiate the tracer test. Samples were then collected from the filter-loop and Tank T02A for 1 hour to monitor the spread of Cs with time. This was done to evaluate the impact of "short-circuiting" in Tank T02A, defined as the flow of slurry from the filter-loop return nozzle to the filter-loop suction nozzle without mixing with the other contents of Tank T02A.

It was thought that the filter-loop flow rate problem might be associated with the high liquid viscosity and slurry rheology, and that by proceeding with the post-caustic-leach wash, the flow rate problem might be resolved. The post-caustic-leach solids wash was therefore started, using all five filter bundles to remove supernate and adding 11-gallon batches of IW $(0.01-\mathrm{M} \mathrm{NaOH})$ to the inlet of PMP-T42A each time the slurry level in Tank T02A dropped to a set point value (nominally 44-in.). After seven wash-water batches, no significant improvement in flow control was observed, and the washing was stopped. Small bubbles could be seen in slurry samples, and a sample that was centrifuged showed about a $10 \%$ decrease in volume. Analyses of the filter-loop pump data and the performance of the pumps were consistent with entrainment of air in the slurry. A partial failure of the flowmeter downstream of Pump T43A contributed to the difficulties. After the completion of Integrated Test A, the flowmeter (FT-0635) was shown to read low and was replaced prior to the start of Integrated Test B. More details on the Integrated Test A air entrainment issue are given by Consuelo-Guzman et al. (2009), and a discussion of all PEP air entrainment issues is given in Section 13.6.

A delay of about 14 hours occurred between the seventh and eighth wash batches because of the filter-loop flow rate problem investigation. A total of 100 batches of wash-water were added during the post-caustic-leach wash.

When the post-caustic-leach wash was complete, a slurry of chromium oxyhydroxide solids in a sodium nitrate $(\sim 0.85-\mathrm{M})$, sodium hydroxide $(\sim 3.1-\mathrm{M})$ solution was added in-line to the filter-loop. ${ }^{(a)}$ The slurry was first concentrated to counteract the increases in slurry volume (about 144 gal of slurry was added) and hydroxide concentration of this nonprototypic addition. The concentrated slurry was then washed with forty-one 11-gal wash-water batches to reach an initial hydroxide concentration of 0.025-M. Dissolution of the chromium solids consumes hydroxide but higher concentrations of hydroxide are to be avoided (in the PTF) because it is thought to enhance plutonium dissolution (Fiskum et al. 2009).

Oxidative leaching was initiated by adding 1-M NaMnO 4 in-line, upstream of Pump T42A in the filter-loop. During the 6-hr oxidative leaching process, the slurry in Tank T02A was mixed with PJMs and circulated through the filter-loop (with permeate valves closed), but the air sparge mixers were run with their "idle" flow rate of air (see Section 5.1.6).

After oxidative leaching, the solids were washed with eighty-six 11-gal batches of wash-water, and then concentrated to 20 -wt $\%$ UDS (target was 20 -wt $\%$ UDS). This product slurry was pumped to plastic totes and saved for later use in the high-solids filter flux testing.

(a) Scheele RD, GN Brown, and DE Kurath. 2009. Scale-Up, Production, and Procurement of PEP Simulants. WTP-RPT-204, Pacific Northwest National Laboratory, Richland, Washington. 


\subsubsection{Integrated Test B: Caustic Leaching in Tank T02A at $98^{\circ} \mathrm{C}$}

At the start of Integrated Test B, slurry transfer lines and both Tank T01A/B vessels were empty (rinsed and drained). All reagent supply lines had been filled. The filter-loop had been cleaned with nitric acid, flushed, and filled with IW. Tank T02A contained a small heel estimated to be less than 5 gal of IW. Control parameters for the PJMs in Tanks T01A/B and Tank T02A had been adjusted to achieve approximately prototypic (mixing power)/volume. A run sheet specifying all process control parameters, transfer volumes, transfer rates, process times, and endpoints had been developed, reviewed, and approved. The information from the run report was incorporated into the Test Instruction. The Test Plans, Test Instructions, and procedures used for Integrated Test B are in Geeting et al. (2009).

The simulant having about 5.2-wt\% UDS was transferred from HLP-VSL-T22 to Tank T01A and then to Tank T02A. The filter-loop was drained, and then ultrafiltration used to concentrate the simulant feed using all five filter bundles. Eleven-gallon feed make-up batches were transferred from Tank T01A whenever the level in Tank T02A dropped below a set point (about 28-in.) until the slurry reached 20.3-wt \% UDS (target 20-wt\% UDS). Nineteen-molar caustic was then added, at the prototypic rate, in-line to the filter-loop upstream from PMP-T42A. Heat from dilution of the caustic as well as mechanical energy from the filter-loop pumps resulted in slurry temperatures increasing to $70^{\circ} \mathrm{C}$ by the end of caustic addition. Rather than valve-in and use the nonprototypic steam heat exchanger HX-T03A, the filter-loop pumps were used to raise the slurry to the target initial temperature of $71^{\circ} \mathrm{C}$. Direct steam injection was then used to raise the slurry to the target temperature for caustic leaching, $98^{\circ} \mathrm{C}$. External heat was used to raise the system to the initial temperature so that the prototypic amount of steam condensate was present in Tank T02A at the end of the heat-up period. During the heat-up, the PJMs were switched to gravity refill at about $60^{\circ} \mathrm{C}$, the PJM vent lines were configured to drain any condensate to an external receiver at about $65^{\circ} \mathrm{C}$, and the sparge air mixers and steam ring air purge flow rates were reduced to their high-temperature set points above $90^{\circ} \mathrm{C}$. An incorrect adjustment of the sparge air flow rate caused a greater hold-up of air in Tank T02A that in-turn caused a high-level shut-down of steam heating after the $98^{\circ} \mathrm{C}$ leach temperature had been reached. The slurry cooled to about $86^{\circ} \mathrm{C}$ before the problem was identified, and approximately one hour elapsed before the leach temperature was recovered. The boehmite kinetic model and observed temperatures were used to prescribe that an additional 53 minutes be added to the original 16-hr leach time.

Caustic leaching was conducted for 16 hours and $53 \mathrm{~min}$, with direct steam injection used to maintain the $98 \pm 2{ }^{\circ} \mathrm{C}$ target temperature. At the end of the caustic-leach, Tank T02A was cooled at a prototypic rate to $25^{\circ} \mathrm{C}$ over a 13.2 -hr period using its chilled water jacket. During the cool-down, sparge air mixers and steam ring air purge flow rates were increased to their low-temperature values at about $90^{\circ} \mathrm{C}$, the $\mathrm{PJM}$ vent lines were reconfigured to drain to Tank T02A at about $65^{\circ} \mathrm{C}$, and the PJMs were switched from gravity refill to vacuum refill at about $60^{\circ} \mathrm{C}$.

After reaching the $25^{\circ} \mathrm{C}$ filtration temperature, the leached slurry was transferred to Tank T01B using a portable diaphragm pump. A second caustic-leach batch was then conducted in Tank T02A, completely analogous to the first caustic-leach batch, with the exception that the initial solids concentration step was conducted with a single 10-ft filter bundle (FILT-T01A). Like the first batch, the second batch was leached at $98^{\circ} \mathrm{C}$ for 16 hours and cooled prototypically to $25^{\circ} \mathrm{C}$. The nonprototypic use of two caustic-leach batches with storage of the first batch in Tank T01B, etc., was needed to produce enough post-caustic-leach slurry to achieve prototypic slurry levels in Tank T02A in all subsequent steps. The 
second caustic-leach batch was essentially required to fill the larger-than prototypic PEP filter-loop (volume $\sim 82 \mathrm{gal}$, instead of the prototypic volume $\sim 19.5 \mathrm{gal}$ ).

A single 10-ft filter bundle (FILT-T01A) was used to concentrate post-caustic-leach solids by first concentrating the second caustic-leach batch to a mid-tank level set point (about 47-in.) and then transferring 11-gal make-up batches of caustically leached slurry from Tank T01B. Essentially all of the retrievable volume of the first caustic-leach batch was transferred to Tank T02A. This resulted in a prototypic volume (level) of slurry in Tank T02A having about 17.3-wt $\%$ UDS (target was 17-wt $\%$ UDS), but the total volume of slurry in the system (Tank T02A plus the filter-loop) was about 60 gal more than would be prototypic. Four filter backpulses, with standard control parameters, were performed during post-caustic-leach solids concentration in Integrated Test B.

At this point, the PJMs in Tank T02A were switched to operate in star mode (see Section 5.1.5), and their operation was adjusted to match the PTF nozzle velocity (about 12-m/s) to achieve prototypic mixing of non-Newtonian slurry. A CsBr tracer test was conducted, much like in Integrated Test A and with the same objective (see Section 5.3.1), but different in that the Tank T02A slurry level was about 15-in. in Integrated Test B instead of 41-in. to 43-in. in Integrated Test A.

The concentrated leached solids in Tank T02A were washed incrementally with fifty-two 11-gal batches of IW (0.01-M NaOH). Wash-water additions were initiated when the level in the vessel Tank T02A dropped below a set point (about 16-in.). Because the level in Tank T02A was below the filter-loop return nozzle, and air entrainment from the return jet was significant, filter-loop flow rates varied from about 60 to $100 \mathrm{GPM}$ during the post-caustic-leach solids wash.

When the post-caustic-leach wash was complete, a slurry of chromium oxyhydroxide solids in a sodium nitrate $(\sim 0.89-\mathrm{M})$, sodium hydroxide $(\sim 3.2-\mathrm{M})$ solution was added in-line to the filter-loop. To counteract the increases in slurry volume (about 82 gal of slurry was added) and hydroxide concentration of this nonprototypic addition, the slurry was first concentrated by ultrafiltration and then washed with twenty-one 11-gal wash-water batches.

Oxidative leaching was initiated by adding 1-M NaMnO 4 in-line, upstream of PMP-T42A in the filter-loop. During the 6-hr oxidative leaching process, the slurry in Tank T02A was mixed with PJMs and circulated through the filter-loop (with permeate valves closed), but the air sparge mixers were run with their "idle" flow rate of air (see Section 5.1.6). During oxidative leaching, the AFA concentrations were targeted at $350 \mathrm{ppm}$ (actuals are shown in Section 12).

After oxidative leaching, the solids were washed with forty-seven 11-gal batches of wash-water and then concentrated to 20.2-wt $\%$ UDS (target was 20-wt $\%$ UDS). Because the level in Tank T02A was very near the filter-loop return nozzle, and air entrainment from the return jet was significant, filter-loop flow rates varied from about 70 GPM to 100 GPM during the post-caustic-leach solids wash. The concentrated slurry from Integrated Test B was combined with that from Integrated Test A and used to conduct the high-solids filter flux test.

\subsubsection{Integrated Test D: Caustic Leaching in Tank T02A at $85^{\circ} \mathrm{C}$}

Integrated Test $\mathrm{D}$ was very similar to Integrated Test $\mathrm{B}$, with the primary differences that the Integrated Test $\mathrm{D}$ feed simulant contained the chromium oxyhydroxide solids, so none were added after 
the post-caustic-leach wash, and the caustic leaching temperature was $85^{\circ} \mathrm{C}$ instead of $98^{\circ} \mathrm{C}$ as in Integrated Test B. A run sheet specifying all process control parameters, transfer volumes, transfer rates, process times, and endpoints had been developed, reviewed, and approved, and the information from the run report was incorporated into the Test Instruction. The Test Plans, Test Instructions, and procedures used for Integrated Test D are in Sevigny et al. (2009).

In preparation for Integrated Test $\mathrm{D}$, the slurry transfer lines and Tanks T01A/B were rinsed and drained. Tank T02A was rinsed and contained less than an estimated 5 gal of IW (0.01-M NaOH). The filter-loop had been flushed (but not cleaned with acid) and filled with IW. Control parameters for the PJMs in Tanks T01A/B and Tank T02A had been adjusted to achieve approximately prototypic (mixing power)/volume. A run sheet specifying all process control parameters, transfer volumes, transfer rates, process times, and endpoints had been developed, reviewed, and approved.

Simulant having about 5-wt\% UDS was transferred from HLP-VSL-T22 to Tank T01B and then to Tank T02A. The filter-loop was drained, and then ultrafiltration was used to concentrate the simulant feed with a single 10-ft filter bundle (FILT-T01A). Eleven-gallon feed make-up batches were transferred from Tank T01B whenever the level in Tank T02A dropped below a set point (about 27-in.) until the slurry had about $23-\mathrm{wt} \%$ UDS (target 20 -wt $\%$ UDS). Nineteen-molar caustic was then added, at the prototypic rate, in-line to the filter-loop upstream from PMP-T42A. Heat from diluting the caustic as well as mechanical energy from the filter-loop pumps resulted in reaching the targeted $65^{\circ} \mathrm{C}$ initial temperature by the end of caustic addition. Higher than expected slurry levels in Tank T02A were observed, and foamy samples indicated the level was high because of air entrainment. Efforts to de-aerate the slurry were not successful, and after a short investigation of possible causes, additional AFA was added to Tank T02A. Approximately 25 gal. of slurry was removed via the filter-loop in-line sampling port.

The filter-loop was backflushed with a prototypic volume (about 16.3 gal) of water to Tank T02A, and direct steam injection was then used to raise the slurry to the target temperature for caustic leaching, $85^{\circ} \mathrm{C}$. External heat was used to raise the system to the initial temperature so that the prototypic amount of steam condensate was present in Tank T02A at the end of the heat-up period. During the heat-up, the PJMs were switched to gravity refill at about $60^{\circ} \mathrm{C}$, and the PJM vent lines were configured to drain any condensate to an external receiver at about $65^{\circ} \mathrm{C}$.

Caustic leaching was conducted for 24 hours, with direct steam injection used to maintain the $85 \pm 2^{\circ} \mathrm{C}$ target temperature. At the end of the caustic-leach, Tank T02A was cooled at a prototypic rate to $25^{\circ} \mathrm{C}$ over a 12.6-hr period using its chilled water jacket. During the cool-down, the PJM vent lines were reconfigured to drain to Tank $\mathrm{T} 02 \mathrm{~A}$ at about $65^{\circ} \mathrm{C}$, and the PJMs were switched from gravity refill to vacuum refill at about $60^{\circ} \mathrm{C}$.

After reaching the $25^{\circ} \mathrm{C}$ filtration temperature, the leached slurry was transferred to Tank T01A with a diaphragm pump. A second caustic-leach batch was then conducted in Tank T02A, completely analogous to the first caustic-leach batch with the exception that the initial solids concentration step was conducted with all five filter bundles. Like the first batch, the second batch was leached at $85^{\circ} \mathrm{C}$ for 24 hours and cooled prototypically to $25^{\circ} \mathrm{C}$. The nonprototypic use of two caustic-leach batches and storage of the first batch in Tank T01A etc. was needed to produce enough post-caustic-leach slurry to achieve prototypic slurry levels in Tank T02A in all subsequent steps. The second caustic-leach batch was essentially required to fill the larger than prototypic PEP filter-loop (volume $\sim 82 \mathrm{gal}$, instead of the prototypic volume $\sim 19.5$ gal). 
Post-caustic-leach solids were concentrated with all five filter bundles (FILT-T01A through -T05A) by first concentrating the second caustic-leach batch to a mid-tank level set point (about 53-in.) and then transferring 11-gal make-up batches of caustically leached slurry from Tank T01A. Essentially all of the retrievable volume of the first caustic-leach batch was transferred to Tank T02A. This resulted in a prototypic volume (level) of slurry in Tank T02A that was concentrated to 18.8-wt\% UDS (target was $17-w t \%$ UDS), but the total volume of slurry in the system (Tank T02A plus the filter-loop) was about 60 gal more than would be prototypic.

At this point, the PJMs in Tank T02A were switched to operate in star mode (see Section 5.1.5), and their operation was adjusted to match the PTF nozzle velocity (about 12-m/s) to achieve prototypic mixing of non-Newtonian slurry. The concentrated leached solids in Tank T02A were then washed incrementally with fifty-two 11-gal batches of IW. Wash-water additions were initiated when the level in Tank T02A dropped below a set point (about 17-in.).

When the post-caustic-leach wash was complete, oxidative leaching was initiated by adding 1-M $\mathrm{NaMnO}_{4}$ in-line, upstream of Pump T42A in the filter-loop. During the 6-hr oxidative leaching process, the slurry in Tank T02A was mixed with PJMs and circulated through the filter-loop (with permeate valves closed), but the air sparge mixers were run with their "idle" flow rate of air (see Section 5.1.6).

After oxidative leaching, the solids were washed with forty-five 11-gal batches of wash-water, and then concentrated to $20.7-\mathrm{wt} \%$ UDS (target was $20-\mathrm{wt} \%$ UDS).

\subsection{Supporting and Parallel Laboratory Testing}

The PTF design and flowsheet are based on results from laboratory tests conducted under ideal conditions (e.g., leaching in isothermal, well-mixed vessels). Model projections of leaching and ultrafiltration performance in the PTF have been based on the assumption that PTF performance will be the same as observed in laboratory-scale process tests. To verify or correct that assumption, laboratory tests have been conducted in parallel with PEP testing designed to evaluate differences between laboratory-scale and PEP performance. To simplify the comparison of PEP and laboratory results, slurry samples were collected from the PEP at appropriate times for use in the parallel laboratory tests. This section briefly describes the parallel laboratory tests.

\subsubsection{Parallel CUF Tests}

The CUF has historically been used to measure cross-flow ultrafiltration performance with actual waste samples (in the hot CUF) and evaluate filtration behavior as a function of various parameters with waste simulants (in the cold CUF). To maximize the comparability of previous testing to the parallel PEP tests, certain CUF operating parameters were made consistent with previous CUF testing, instead of making them consistent with PEP testing. For example, filter backpulsing was conducted with an overpressure of about 70 psi driving pressure in the CUF (to be consistent with previous CUF tests) instead of the 40 psi used in the PEP (and the current PTF plan). Billing et al. (2009) provide full details on CUF operation and choice of operating parameters.

Two types of parallel CUF and PEP testing were conducted to evaluate filter performance in the two regimes observed in the cross-flow ultrafiltration of waste. At low solids concentrations, permeate flux is 
controlled by its permeation through the filter media and any partial plugging of the media. At high solids concentrations and depending on the type of slurry, permeate flux may be controlled by its permeation through the cake of particles that forms on the filter media surface. The flux in the low-solids regime is a relatively weak function of the solids concentration and strongly affected by the filter history. The flux in the high-solids regime behaves much the opposite; it is a weak function of filter history and a strong function of solids concentration. Four parallel filter tests were conducted in the PEP and the CUF, two low- and two high-solids tests, but because the first PEP high-solids was problematic, only one of the high-solids tests is discussed in this report. The three CUF tests are summarized here.

- Low-Solids Filter Flux Test \#1: The CUF was prepared by oxalic acid cleaning to obtain an initial clean-water flux of at least $1.0 \mathrm{gal} / \mathrm{min} / \mathrm{ft}^{2}$. A sample of $6.9-\mathrm{wt} \%$ UDS undiluted simulant collected from the PEP was then introduced to the CUF. For 12 hours, the sample was filtered, matching the TMP and axial flow velocity of the PEP, with permeate being returned to the feed vessel so that the solids concentration remained essentially constant. At the end of the first 12-hr period, the filter was backpulsed once, and again every 30 minutes for 12 hours. At the end of the second 12-hr period, the filter was backpulsed once again (for a total of 25 backpulses) and run for a final 12 hours without backpulsing.

- $\quad$ Low-Solids Filter Flux Test \#2: This test was a repeat of the first low-solids filter test, starting with a chemically cleaned filter and was also performed with $6.9-\mathrm{wt} \%$ UDS undiluted simulant from the PEP.

- High-Solids Filter Flux Test: As with the low-solids filter tests, but unlike the PEP, the CUF high-solids filter test was initiated with a chemically cleaned filter. In this test, a sample of 15.3-wt\% UDS, post-caustic-leach, post-oxidative-leach, washed slurry sample was collected from the PEP and introduced to the CUF. This was concentrated by filtration to about $29.5-\mathrm{wt} \%$ UDS using the same TMP and axial flow velocity as the PEP. When fully concentrated, the permeate was added back to the feed vessel (for a measured 15.3-wt $\%$ UDS) and reconcentrated to $32.4-\mathrm{wt} \%$ UDS.

\subsubsection{Parallel Caustic and Oxidative Leaching Tests}

The parallel laboratory leaching tests conducted on PEP slurry samples were performed with the apparatus described in Section 4.3. Because the 1-L stirred beakers were baffled and stirred with an agitator at a fixed height above the bottom, the amount of material that could be removed for analyses was very limited - fewer and smaller samples were collected from the parallel laboratory leaching tests than from the PEP.

Parallel caustic-leaching tests were run for the Functional Test, the first caustic-leach batch of Integrated Test A, the second caustic-leach batch of Integrated Test B, and the second caustic-leach batch of Integrated Test D. Parallel oxidative leaching tests were run for Integrated Tests A, B, and D. All parallel leach tests were otherwise run according to the same time and temperature set points as the corresponding PEP tests. 


\subsection{Simulant Summary}

\subsection{Simulant Overview}

The Pretreatment Engineering Platform (PEP) process testing was performed with a nonradioactive, aqueous slurry of simulant waste chemicals and solids. The simulant composition and make-up recipe were provided by the Hanford Waste Treatment and Immobilization Plant (WTP) as documented in Simulant Recommendation for Phase 1 Testing in the Pretreatment Engineering Platform. ${ }^{(a)}$ Aqueous chemical concentrations were within the ranges expected for waste feeds to the PTF. The hydroxide concentration was marginally one standard deviation lower than the average concentration expected in the feeds to the plant. The oxalate and phosphate components were at the lower end of the expected ranges, but the oxalate component was at the solubility limit, and the phosphate component was at or near the solubility limit. The solids components and blend were selected to obtain targeted solids mass loss (by aluminum and chromium leaching and oxalate washing) and treatment time. The simulant was not selected to represent any particular Hanford tank waste type.

The simulant was blended from the components listed below. The basis for selecting the individual components and the comparison to actual waste behavior is provided where applicable in the indicated references:

- Boehmite (for Al) (Russell et al. 2009a)

- Gibbsite (for Al) (Russell et al. 2009b)

- Chromium oxyhydroxide (CrOOH) slurry (Rapko et al. 2007)

- Sodium oxalate

- Filtration simulant (Russell et al. 2009c)

- Supernate.

A separate chromium solids slurry simulant was prepared and added to the PEP process after post-caustic-leach washing (a nonprototypic addition) during the Shakedown/Functional Tests and Integrated Tests A and B. This approach was taken because laboratory-scale tests had shown that the high-temperature caustic leaching step dissolved significant amounts of the $\mathrm{CrOOH}$ solids (Russell et al. 2009a). In Integrated Test D, the chromium solids component of the simulant was added during the simulant make-up process to demonstrate the PTF permanganate addition strategy.

\subsection{Simulant Development Basis and Requirements}

The Simulant Recommendation for Phase 1 Testing in the Pretreatment Engineering Platform ${ }^{(a)}$ document provides the requirements, development strategy, and basis for the proposed Phase 1 PEP waste simulant. This simulant was prepared to meet the objectives outlined in the External Flowsheet Review

(a) PS Sundar. 2008. Simulant Recommendation for Phase I Testing in the Pretreatment Engineering Platform. 24590-PTF-RPT-RT-08-006, Rev. 0, CCN 176990, Bechtel National, Inc., Richland, Washington. 
Team M12 review ${ }^{(a)}$ and the M12 Issue Response Plan (IRP). ${ }^{(b)}$ The External Flowsheet Review Team recommended, "conducting a combined ultrafiltration/leaching system test of all leaching, washing and filtration scenarios at sufficient scale to demonstrate the effectiveness of the design and the adequacy of the mixing system."

Task 3.3 of the M12 IRP requires that the PEP simulant:

1. Support a demonstration of all aspects of the sludge solids concentration and sludge treatment flowsheet (e.g., water, caustic and oxidative leaching, and supporting process steps, such as filter cleaning and solids discharge).

2. Provide the basis for the expected compositions and concentrations of aluminum, chromium, and phosphate chemical forms (including mineral forms) expected in the Hanford tank wastes based upon existing technical data.

3. Composition selected from an assessment of the compositions of the waste delivered to the ultrafiltration process (UFP) system. The simulant shall be based upon an $80 \%$ confidence level that the composition is bounded based upon projected sludge mass loss, batch size, and treatment time.

The basic premise of the simulant development approach (as proposed in Task 3 of the M12-IRP ${ }^{(b)}$ ) was based on the development of component simulants that can be blended in a supernatant solution to form blended simulants with a wide variety of leaching and filtration characteristics. During Phase 1, as a part of Task 3.1 and 3.2 of the M12-IRP, initial formulations of two individual component simulants that represent the chemical leaching behaviors of aluminum were made available before preparing the blended simulant. These simulants represent the two dominant mineral species of aluminum (one each for gibbsite and boehmite) present in the wastes. The development of these initial formulations was based on the available waste leach kinetics and characterization data as well as a limited number of leach dissolution tests on commercially-available candidate gibbsite and boehmite compounds. The proposed simulant formulation meets the data needs as identified by Reynolds and Slaathaug ${ }^{(\mathrm{c})}$ (2007) from the PTF for the UFP evaluation during Phase 1 testing in the PEP.

Additionally, initial formulations of an individual component simulant for chromium and one that represents the ultrafiltration behavior during waste concentration were made available during Phase 1. The water soluble components in the solids phase were represented by crystalline sodium oxalate. The phosphate component was not included in the initial formulations for the solids phase during Phase 1.

Sundar $^{(\mathrm{d})}$ recommended that the simulant for Phase 1 testing in the PEP be a blend of the following components: 1) supernatant solution, 2) gibbsite and boehmite to represent the leachable aluminum, 3) sodium oxalate to represent soluble solids, including oxalates, sulfates, and phosphates, 4) chromium

(a) Bechtel. 2006. Comprehensive Review of the Hanford Waste Treatment Plant Flowsheet and Throughput - Assessment Conducted by an Independent Team of Experts. CCN 132846, Bechtel National, Inc., Richland, Washington.

(b) Bechtel. Issue Response Plan Implementation of the External Flowsheet Review Team (EFRT) Recommendations - M12 Undemonstrated Leaching Processes. 24590-WTP-PL-ENG-06-0024, Rev 0, Bechtel National, Inc., Richland, Washington.

(c) Reynolds J. and E. Slaathaug. 2007. Technical Basis for the Ultrafiltration System to be Evaluated in the Pretreatment Engineering Platform Tests. CCN 153208, Bechtel National, Inc., Richland, Washington

(d) Sundar PS. 2008. Simulant Recommendation for Phase I Testing in the Pretreatment Engineering Platform. 24590-PTF-RPT-RT-08-006, Rev. 0, CCN 176990, Bechtel National, Inc., Richland, Washington. 
oxyhydroxide to represent leachable chromium, and 5) a precipitated iron hydroxide sludge to represent the filtration characteristics.

\subsubsection{Simulant Selection Basis}

In accordance with the third requirement in Task 3.3 of the M12-IRP, ${ }^{(a)}$ the combination of individual components was adjusted to provide performance that is greater than that for $80 \%$ of the anticipated feed batches to the UFP system based upon the projected sludge mass loss (e.g. $80 \%$ of the anticipated batches will have a mass loss less than the PEP simulant), batch size, and treatment time (e.g. $80 \%$ of the anticipated batches will have a treatment time less than the PEP simulant) over the mission of the plant. Furthermore, the supernatant included all the major anions present in the feed to the WTP plant.

To accomplish this, a G2 flowsheet model run was used to determine the mass loss, batch size, and treatment time for caustic leaching in the UFP-VSL-00002A/B vessels (i.e., the alternative flowsheet described in Section 1.2.1). This information is documented in Run MRQ-07-0002, one of the G2 flowsheet model runs discussed in detail in Dynamic (G2) Flowsheet Assessment of the Effect of M12 Modifications on Pretreatment Capacity. ${ }^{(b)}$

The run MRQ-07-0002 incorporated all the proposed flowsheet modifications except for modifications PT3 described in Lee. ${ }^{\text {(b) }}$ Modification PT3 required caustic leaching to be carried out upfront in vessels UFP-VSL-00001A and UFP-VSL-00001B (the baseline flowsheet described in Section 1.2.1).

Each of the G2 flowsheet model runs concentrated the feed to $20-w t \%$ and a volume of 12,000 gal in vessel UFP-VSL-00002 A/B, regardless of subsequent processing. Since the batch size for these runs was invariant at 12,000 gals, it was not included in the analysis. The feed vectors to the plant, consisting of 20 LAW batches and 498 HLW batches, after concentration resulted in over 1500 batches of concentrate in the UFP-VSL-00002 A/B vessel. Each of these batches of concentrate was evaluated for total mass loss and treatment time in the UFP system.

The results from the G2 model process evaluation were normalized and plotted as percentages of the total batches as a function of processing duration (treatment time) and mass loss. These estimates were for a process configuration that carried out both the caustic-leach and the oxidative-leach in the UFP-VSL-00002A/B vessels. Based on the evaluation in Sundar ${ }^{(\mathrm{c})}$ Section 4, 80\% of the batches had a processing duration of less than 4.6 days in the UFP system and encountered approximately $\leq 59 \%$ mass loss. In the development of the simulant, the mass loss represents the amount of aluminum and the soluble salts (oxalates, phosphates and sulfates) that were removed during the leaching and washing operations.

(a) Bechtel. Issue Response Plan Implementation of the External Flowsheet Review Team (EFRT) Recommendations - M12 Undemonstrated Leaching Processes. 24590-WTP-PL-ENG-06-0024 Rev 000, Bechtel National, Inc., Richland, Washington.

(b) Lee E. 2007. Dynamic (G2) Flowsheet Assessment of the Effect of M12 Modifications on Pretreatment Capacity. 24590-WTP-RPT-PO-07-002, Rev 0, Bechtel National, Inc., Richland, Washington.

(c) Sundar PS. 2008. Simulant Recommendation for Phase I Testing in the Pretreatment Engineering Platform. 24590-PTF-RPT-RT-08-006, Rev. 0, CCN 176990, Bechtel National, Inc., Richland, Washington. 
Sundar ${ }^{(a)}$ also established the composition of aluminum, chromium, and oxalates in the feed solids in more than 3000 feed transfers from the UFP-VSL-00001 A/B vessels as a function of the bounding fraction of total number of batches. It was observed that feed solids in $80 \%$ of the feeds had less than approximately $60 \%$ aluminum, $8 \%$ oxalates, $4 \%$ phosphates, $2.5 \%$ chromium, and $1 \%$ sulfates. In addition to these, the waste solids included iron hydroxide sludge containing varying amounts of minor constituent metal hydroxides.

\subsubsection{Simulant Development Basis Conclusions}

The following conclusions come from Simulant Recommendation for Phase 1 Testing in the Pretreatment Engineering Platform: ${ }^{\text {(a) }}$

- The proposed simulant for Phase 1 testing in the PEP should be a blend of the following simulant components:

- gibbsite and boehmite to represent the leachable aluminum

- $\quad$ sodium oxalate to represent soluble solids, such as oxalates, sulfates, and phosphates

- chromium oxyhydroxide to represent leachable chromium

- precipitated iron hydroxide sludge to represent the filtration characteristics.

- The basis for selecting these components for the blended simulant depends on the desired performance of the blended simulant. The gibbsite, boehmite, and chromium simulants were selected based on 1) commercial availability, 2) confirmation of the mineral form through X-ray diffraction (XRD) analyses and chemical analyses, and 3) leaching kinetics relative to an actual waste.

- The chromium component should be added as a slurry during the dewatering cycles of post-caustic-leach wash periods. This is to prevent chromium from dissolving prematurely during caustic leaching.

- The simulant components are to be suspended in a simulant supernatant containing all the principal anions in a 5-M Na solution. The principal anions in the supernatant are at concentration levels that are within 1 standard deviation of the average value of the concentrations expected in the feeds to the plant. In the case of the $[\mathrm{OH}]$-anion, its concentration is near 1 standard deviation from the average. The supernatant $\mathrm{Na}$ concentration was selected at approximately the 5-M level to represent feed to the UFP-1 vessel.

- The sodium oxalate was to be added as a simple crystalline salt form. The composition of the inert filtration solids was based on the Slurry Integrated Pilot Plant simulant and CUF tests to verify the filtration flux. The composition of the inerts was simplified to make the simulant more practical to blend in larger batches. The blended simulant initial solids concentration (percent undissolved solids) was used as a controlled variable to satisfy the constraint for the processing duration for the initial solids concentration (waste feed dewatering) operation. The composition

(a) PS Sundar. 2008. Simulant Recommendation for Phase I Testing in the Pretreatment Engineering Platform. 24590-PTF-RPT-RT-08-006, Rev. 0, CCN 176990, Bechtel National, Inc., Richland, Washington. 
of the solids phase of the blended simulant is given in Table 1, that of the supernatant in Table 3, and for the filtration inerts in Table 4 of Sundar. ${ }^{\text {(a) }}$

- The proposed formulation for the PEP Phase 1 simulant was underpinned by flowsheet modeling, actual waste leaching data, extensive physical and chemical characterizations, and laboratory-scale and cold CUF filtration tests. The composition proposed has been tested for performance and stability. Therefore, the proposed formulation ${ }^{(a)}$ was expected to meet the M12-IRP objectives for the Phase 1 PEP simulant, and should support the demonstration of all aspects of the sludge solids concentration and sludge treatment flowsheets during Phase 1 demonstration of the process in the PEP.

\subsection{Simulant Development}

Smith et al. (2009) and others discuss the simulant preparation procedure for producing multi-component simulants for leaching and filtration studies. The approach is based on developing component simulants that can be blended to form a wide variety of filtration and leaching simulants. The PEP Phase 1 simulant preparation and component selection comply with the recommendations by Sundar $(2008)^{(a)}$ (see Section 6.2).

Scheele et al. (2009) ${ }^{(\mathrm{b})}$ have used the procedure presented by Smith et al, (2009) as a starting point to manufacture the simulant used in the PEP testing. Several minor (toxicity hazardous) components were removed to reduce costs and minimize the safety/environmental hazards associated with the simulant. Additionally, washing the precipitated iron hydroxide sludge component to remove nitrate was replaced with a cost-effective shimming strategy to adjust the liquid composition to that of the supernatant before blending the various components.

\subsection{Simulant Procurement}

The recipes used to prepare the PEP simulant and the $\mathrm{CrOOH}$ component are based on the simulant development work of Russell et al. (2009a, 2009b, 2009c) and Smith et al. (2009). The simulant recipe provided in Smith et al. (2009) was modified to remove selected components from the precipitated iron hydroxide (filtration) solids and supernatant.

Simulant was procured from NOAH Technologies Corporation (San Antonio, TX). Samples of each simulant batch were characterized to make certain that requirements for chemical and physical properties were met. Batches of the simulant were procured as follows:

- A 15-gallon trial batch of the blended simulant for laboratory testing to demonstrate the efficacy of the simulant fabrication procedure

- A 250-gallon scale-up batch of the blended simulant to demonstrate scale-up of the simulant fabrication procedure to an intermediate scale

(a) Sundar PS. 2008. Simulant Recommendation for Phase I Testing in the Pretreatment Engineering Platform. 24590-PTF-RPT-RT-08-006, Rev. 0, CCN 176990, Bechtel National, Inc., Richland, Washington.

(b) Scheele RD, GN Brown, and DE Kurath. 2009. Manufacture of PEP Simulants-Lessons Learned. WTP-RPT-204, Rev 0, PNNL-18678, Pacific Northwest National Laboratory, Richland, Washington. 
- Batches 0,1 , and 2, each nominally 3500 gallons, of blended simulant for the Shakedown/Functional Tests and Integrated Tests A and B. These batches did not contain the $\mathrm{CrOOH}$ component.

- Batch 3, nominally 1200 gal, for Integrated Test D. This batch contained the $\mathrm{CrOOH}$ solids component.

- The CrOOH solids slurry for the Shakedown/Functional Test and Integrated Tests A and B was obtained in two separate batches containing nominally 18 and 36-kg of $\mathrm{Cr}$ as $\mathrm{CrOOH}$.

In general, this manufacturing experience demonstrated that the scale-up strategy was effective in producing an acceptable simulant. This approach, beginning with a laboratory-scale preparation (15 gal) and followed by preparing a small industrial-scale preparation ( $250 \mathrm{gal})$, permitted manufacturing issues to be identified and resolved before beginning to prepare the full-scale batches to be used within the PEP.

The PEP simulant was procured as a concentrated slurry and a supernate in separate containers. This approach provided supernate to rinse residual solids from the shipping containers and to adjust the final UDS content to the target concentration.

\subsection{Simulant Compositions for Integrated Testing}

The composition of the simulant fed to the caustic-leach vessel in each test is shown in Table 6.1 and Table 6.2. The concentrations are the means of each set of triplicate samples obtained from HLP-VSL-T22. The \pm values in tables are standard deviations of the mean. They are calculated by linearized error propagation from laboratory uncertainty values (equivalent to a $95 \%$ confidence interval, or two standard deviations) that were supplied by the analytical organization for each concentration measurement. The laboratory uncertainty includes the noise of the analytical determination (which is related to the reporting limit) and uncertainty from instrumental techniques, including aliquoting, standards, standardization, and subsampling.

Note that the aluminum concentrations in Integrated Test A and Integrated Test B feeds differed by about $5 \%$, which is consistent with the variance in UDS measurements. A number of species had measured concentrations at or below the reporting limits in one or more of the replicate samples.

The simulant make-up sheets for the Integrated Test A and Integrated Test B feeds show that boehmite and gibbsite were added in equal masses during simulant production, which would yield a value of 0.435 for the mole fraction of solid-phase Al present as gibbsite. The mole fraction of Al as boehmite is one minus the fraction as gibbsite, or 0.565 .

The simulant feed compositions, in Table 6.1 and Table 6.2, were reviewed as a check on whether any of the gibbsite used in simulant make-up had dissolved. The check was prompted by the observation that the dissolved concentration of Al was 0.137-M in Integrated Test A feed and 0.145-M in Integrated Test $\mathrm{B}$ feed, which was higher than the $0.125-\mathrm{M}$ in the supernatant liquid that had been used in simulant make-up. ${ }^{\text {(a) }}$ This apparent increase suggested some of the gibbsite had dissolved. However, the Al concentration in the solids phase of the Integrated Test B simulant was calculated from slurry and liquid $\mathrm{Al}$ concentrations and wt $\%$ UDS and found to be $0.302-$ to $0.306-\mathrm{g} \mathrm{Al} / \mathrm{g}$ solid. Because this concentration

(a) These concentrations were all measured by inductively coupled plasma (ICP) at Southwest Research Institute (SwRI). 
was not less than the value of 0.283 expected from the simulant recipe, and because other measurements indicated no dissolution of other major solid constituents (oxalate by TOC was at predicted levels in both supernate and solids, and $\mathrm{Fe}$ was not found in the supernate), it was concluded that no perceptible dissolution of gibbsite had occurred. The gibbsite fraction in the solid was therefore considered to equal the recipe value at the start of each test.

Section 6 of Sundar ${ }^{(a)}$ provided the basis for the individual component selections. Table 6.1 summarizes the actual starting simulants used during Integrated Tests A and B, and Table 6.2 summarizes the starting simulant used during Integrated Test D.

(a) Sundar PS. 2008. Simulant Recommendation for Phase I Testing in the Pretreatment Engineering Platform. 24590-PTF-RPT-RT-08-006, Rev. 0, CCN 176990, Bechtel National, Inc., Richland, Washington. 
Table 6.1. Simulant Feed Composition for Integrated Tests A and B

\begin{tabular}{|c|c|c|c|c|c|c|}
\hline \multirow[b]{3}{*}{ Analyte } & \multicolumn{3}{|c|}{$\begin{array}{c}\text { PEP Leach in Tank T01A/B } \\
\text { (Integrated Test A) }\end{array}$} & \multicolumn{3}{|c|}{$\begin{array}{l}\text { PEP Leach in Tank T02A } \\
\text { (Integrated Test B) }\end{array}$} \\
\hline & \multirow{2}{*}{$\begin{array}{l}\text { Slurry } \\
\mu \mathrm{g} / \mathrm{g}\end{array}$} & \multicolumn{2}{|c|}{ Liquid Phase } & \multirow{2}{*}{$\begin{array}{l}\text { Slurry } \\
\mu \mathrm{g} / \mathrm{g}\end{array}$} & \multicolumn{2}{|c|}{ Liquid Phase } \\
\hline & & $\mu \mathrm{g} / \mathrm{g}$ & $\mathrm{m}^{(\mathrm{a})}$ & & $\mu \mathrm{g} / \mathrm{g}$ & $\mathrm{m}^{(\mathrm{a})}$ \\
\hline $\mathrm{Al}$ & $20023 \pm 344$ & $2977 \pm 52$ & $0.129 \pm 0.002$ & $18794 \pm 318$ & $3163 \pm 55$ & $0.137 \pm 0.002$ \\
\hline $\mathrm{Ca}$ & $154 \pm 4.0$ & $1^{(\mathrm{c})}$ & (c) & $155 \pm 3.0$ & $1^{(\mathrm{c})}$ & (c) \\
\hline $\mathrm{Ce}$ & $53.0 \pm 1.1$ & $0.01^{(\mathrm{c})}$ & (c) & $51.6 \pm 1.0$ & $0.013 \pm 0.001$ & $<1 \mathrm{E}-4$ \\
\hline $\mathrm{Cr}$ & $8^{(\mathrm{c})}$ & $1.32 \pm 0.03$ & $<1 \mathrm{E}-4$ & $8^{(\mathrm{c})}$ & $1.42 \pm 0.04$ & $<1 \mathrm{E}-4$ \\
\hline $\mathrm{Fe}$ & $4736 \pm 94$ & $3^{(\mathrm{c})}$ & (c) & $4945 \pm 98$ & $3^{(\mathrm{c})}$ & (c) \\
\hline $\mathrm{K}$ & $1029 \pm 17$ & $1090 \pm 20$ & $0.033 \pm 0.001$ & $999 \pm 17$ & $1063 \pm 19$ & $0.032 \pm 0.001$ \\
\hline $\mathrm{La}$ & $40.0 \pm 0.8$ & $0.010 \pm 0.001$ & $<1 \mathrm{E}-4$ & $39.5 \pm 0.8$ & $0.012 \pm 0.001$ & $<1 \mathrm{E}-4$ \\
\hline $\mathrm{Mg}$ & $105 \pm 2.9$ & $2.5^{(\mathrm{c})}$ & (c) & $94.9 \pm 1.8$ & $2^{(\mathrm{c})}$ & (c) \\
\hline $\mathrm{Mn}$ & $1027 \pm 20$ & $0.1^{(\mathrm{c})}$ & (c) & $1058 \pm 21$ & $0.1^{(\mathrm{c})}$ & (c) \\
\hline $\mathrm{Na}$ & $88920 \pm 1372$ & $91600 \pm 1587$ & $4.66 \pm 0.08$ & $90174 \pm 1400$ & $93233 \pm 1615$ & $4.73 \pm 0.08$ \\
\hline $\mathrm{Nd}$ & $108 \pm 2.1$ & $0.026 \pm 0.001$ & $<1 \mathrm{E}-4$ & $107 \pm 2.1$ & $0.031 \pm 0.001$ & $<1 \mathrm{E}-4$ \\
\hline $\mathrm{Ni}$ & $143 \pm 2.8$ & $0.12 \pm 0.029^{(\mathrm{c})}$ & (c) & $145 \pm 2.8$ & $0.1^{(\mathrm{c})}$ & (c) \\
\hline $\mathrm{P}$ & $1784 \pm 28$ & $1873 \pm 32$ & $0.0708 \pm 0.0012$ & $1581 \pm 25$ & $1643 \pm 29$ & $0.062 \pm 0.001$ \\
\hline $\mathrm{Si}$ & $48.7 \pm 5.7$ & $3^{(\mathrm{c})}$ & (c) & $106.5 \pm 8.0$ & $19 \pm 3^{(c)}$ & (c) \\
\hline $\mathrm{Sr}$ & $43.8 \pm 1.3$ & $0.1^{(\mathrm{c})}$ & (c) & $44.2 \pm 0.9$ & $0.120 \pm 0.017$ & $<1 \mathrm{E}-4$ \\
\hline $\mathrm{Zr}$ & $136 \pm 2.6$ & $0.737 \pm 0.022$ & $<1 \mathrm{E}-4$ & $141 \pm 2.7$ & $0.726 \pm 0.021$ & $<1 \mathrm{E}-4$ \\
\hline Chloride $\left(\mathrm{Cl}^{-}\right)$ & --- & $1137 \pm 20$ & $0.038 \pm 0.001$ & --- & $1013 \pm 18$ & $0.033 \pm 0.001$ \\
\hline Nitrite $\left(\mathrm{NO}_{2}^{-}\right)$ & --- & $18267 \pm 329$ & $0.465 \pm 0.008$ & --- & $17867 \pm 348$ & $0.453 \pm 0.009$ \\
\hline Nitrate $\left(\mathrm{NO}_{3}^{-}\right)$ & --- & $79333 \pm 1380$ & $1.50 \pm 0.026$ & --- & $75967 \pm 1333$ & $1.43 \pm 0.025$ \\
\hline $\begin{array}{l}\text { Phosphate } \\
\left(\mathrm{PO}_{4}{ }^{3-}\right)\end{array}$ & --- & $5547 \pm 96$ & $0.068 \pm 0.001$ & --- & $4893 \pm 85$ & $0.060 \pm 0.001$ \\
\hline Sulfate $\left(\mathrm{SO}_{4}{ }^{2-}\right)$ & --- & $14167 \pm 247$ & $0.173 \pm 0.003$ & --- & $13967 \pm 247$ & $0.170 \pm 0.003$ \\
\hline $\begin{array}{l}\text { Oxalate } \\
\left(\mathrm{C}_{2} \mathrm{O}_{4}{ }^{2-}\right)\end{array}$ & --- & $625 \pm 11$ & $0.008 \pm 0.0001$ & --- & $642 \pm 11$ & $0.009 \pm 0.0002$ \\
\hline Free hydroxide & --- & $15239 \pm 660$ & $1.05 \pm 0.045$ & --- & $12623 \pm 191$ & $0.866 \pm 0.013$ \\
\hline $\mathrm{TIC}^{(\mathrm{b})}$ & $1510 \pm 253$ & $6905 \pm 133$ & $0.673 \pm 0.013$ & $2023 \pm 90$ & $5577 \pm 107$ & $0.542 \pm 0.010$ \\
\hline $\mathrm{wt} \% \mathrm{UDS}$ & $5.52 \pm 0.03$ & & & $5.20 \pm 0.03$ & & \\
\hline Density (g/cc) & $1.278 \pm 0.006$ & 1.23 & 0.001 & $1.276 \pm 0.006$ & 1.23 & .005 \\
\hline $\mathrm{Wt} \% \mathrm{H}_{2} \mathrm{O}$ & $\mathrm{n} / \mathrm{m}$ & & 0.12 & $\mathrm{n} / \mathrm{m}$ & & .12 \\
\hline $\begin{array}{l}\text { Mass fraction } \\
\text { of solid-phase } \\
\text { Al that is in } \\
\text { gibbsite }\end{array}$ & 0.435 & & & 0.435 & & \\
\hline
\end{tabular}

(a) $\mathrm{m}=$ molality.

(b) TIC = total inorganic carbon.

(c) Concentration measurement is at or below the reporting limit.

“---“" = analysis not meaningful

"n/m" = not measured.

All concentrations are means of a triplicate set of samples. The \pm values represent 1 standard deviation; they are calculated using error propagation from the standard deviation of the mean and are derived from laboratory error. Because all samples were centrifuged before analysis, the slurry concentrations and their uncertainties were calculated from data for liquid concentration, centrifuged solids concentration, and the weight fraction of centrifuged solids in the slurry. The uncertainty assigned to the centrifuged solids weight fraction was based on the uncertainty of the weighing instrument. See Appendix C for more information. 
Table 6.2. Simulant Feed Composition for Integrated Test D

\begin{tabular}{|c|c|c|c|}
\hline \multirow[b]{3}{*}{ Analyte } & \multicolumn{3}{|c|}{ PEP Leach in Tank T02A (Integrated Test D) } \\
\hline & \multirow{2}{*}{$\begin{array}{l}\text { Slurry } \\
\mu \mathrm{g} / \mathrm{g}\end{array}$} & \multicolumn{2}{|c|}{ Liquid Phase } \\
\hline & & $\mu \mathrm{g} / \mathrm{g}$ & $\mathrm{m}^{(\mathrm{a})}$ \\
\hline $\mathrm{Al}$ & $18372 \pm 308$ & $3230 \pm 56$ & $0.140 \pm 0.002$ \\
\hline $\mathrm{Ca}$ & $131 \pm 2.6$ & $1^{\text {(c) }}$ & (c) \\
\hline $\mathrm{Ce}$ & $48.3 \pm 0.9$ & 0.01 & $<1 \mathrm{E}-4$ \\
\hline $\mathrm{Cr}$ & $800 \pm 15$ & $30.3 \pm 0.5$ & $<1 \mathrm{E}-4$ \\
\hline $\mathrm{Fe}$ & $4304 \pm 84$ & $2^{(\mathrm{c})}$ & (c) \\
\hline $\mathrm{K}$ & $1011 \pm 17$ & $1083 \pm 20$ & $0.032 \pm 0.001$ \\
\hline $\mathrm{La}$ & $36.8 \pm 0.7$ & 0.01 & $<1 \mathrm{E}-4$ \\
\hline $\mathrm{Mg}$ & $80.4 \pm 1.6$ & $2.4^{(\mathrm{c})}$ & (c) \\
\hline $\mathrm{Mn}$ & $965 \pm 19$ & $0.1^{(\mathrm{c})}$ & (c) \\
\hline $\mathrm{Na}$ & $95637 \pm 1492$ & $99900 \pm 1733$ & $5.10 \pm 0.09$ \\
\hline $\mathrm{Nd}$ & $100 \pm 2.0$ & $0.016 \pm 0.001$ & $<1 \mathrm{E}-4$ \\
\hline $\mathrm{Ni}$ & $140 \pm 2.7$ & $0.12^{(\mathrm{c})}$ & (c) \\
\hline $\mathrm{P}$ & $1941 \pm 31$ & $2057 \pm 36$ & $0.078 \pm 0.001$ \\
\hline $\mathrm{Si}$ & $80.2 \pm 2.2$ & $5.70 \pm 0.41$ & $<1 \mathrm{E}-4$ \\
\hline $\mathrm{Sr}$ & $41.6 \pm 0.8$ & $0.1^{(\mathrm{c})}$ & (c) \\
\hline $\mathrm{Zr}$ & $129 \pm 2.5$ & $0.588 \pm 0.020$ & $<1 \mathrm{E}-4$ \\
\hline Chloride $\left(\mathrm{Cl}^{-}\right)$ & --- & $1023 \pm 18$ & $0.034 \pm 0.001$ \\
\hline Nitrite $\left(\mathrm{NO}_{2}^{-}\right)$ & --- & $18200 \pm 363$ & $0.464 \pm 0.009$ \\
\hline Nitrate $\left(\mathrm{NO}_{3}^{-}\right)$ & --- & $75633 \pm 1332$ & $1.43 \pm 0.025$ \\
\hline Phosphate $\left(\mathrm{PO}_{4}{ }^{3-}\right)$ & --- & $5023 \pm 87$ & $0.062 \pm 0.001$ \\
\hline Sulfate $\left(\mathrm{SO}_{4}^{2-}\right)$ & --- & $14033 \pm 249$ & $0.171 \pm 0.003$ \\
\hline Oxalate $\left(\mathrm{C}_{2} \mathrm{O}_{4}{ }^{2-}\right)$ & --- & $619 \pm 11$ & $0.008 \pm 0.000$ \\
\hline Free hydroxide & --- & $13983 \pm 211$ & $0.965 \pm 0.015$ \\
\hline $\mathrm{TIC}^{(\mathrm{b})}$ & --- & $5766 \pm 116$ & $0.563 \pm 0.011$ \\
\hline $\begin{array}{l}\text { wt } \% \text { undissolved } \\
\text { solids (UDS) }\end{array}$ & $4.97 \pm 0.02$ & & \\
\hline Density (g/cc) & $1.276 \pm 0.006$ & 1.2 & \\
\hline $\mathrm{Wt} \% \mathrm{H}_{2} \mathrm{O}$ & $\mathrm{n} / \mathrm{m}$ & & \\
\hline $\begin{array}{l}\text { Mass fraction of } \\
\text { solid-phase Al that } \\
\text { is in gibbsite }\end{array}$ & 0.435 & & \\
\hline
\end{tabular}

(a) $\mathrm{m}=$ molality.

(b) $\mathrm{TIC}=$ total inorganic carbon.

(c) Concentration measurement is at or below the reporting limit.

"---_" = analysis not meaningful

"n/m" = not measured.

All concentrations are means of a triplicate set of samples. The \pm values represent 1 standard deviation; they are calculated using error propagation from the standard deviation of the mean and are derived from laboratory error. Because all samples were centrifuged before analysis, the slurry concentrations and their uncertainties were calculated from data for liquid concentration, centrifuged solids concentration, and the weight fraction of centrifuged solids in the slurry. The uncertainty assigned to the centrifuged solids weight fraction was based on the uncertainty of the weighing instrument. See Appendix C for more information. 



\subsection{Functional Tests}

Simulant Shakedown/Functional testing evaluated the performance of the individual components of the PEP and finalized the operational characteristics before starting the Integrated tests. This included testing the strategies for managing condensate during caustic leaching and tuning PJMs using simulant and operating spargers at elevated temperatures. The Functional Test performed simulant transfer, vessel mixing, heating, cooling, and filtration unit operations to 1) confirm testing procedures as well as equipment and instrument functions and performance, and 2) determine the limited baseline process/equipment performance needed to perform Integrated process testing. Details of the Shakedown/Functional Testing activities may be found in the Josephson et al. (2009) and Test Plan, TP-RPP-WTP-506. ${ }^{\text {(a) }}$ This section contains the results of certain data analysis efforts that were specified in the Test Plan.

\subsection{Transfer Line Flush}

Planned WTP operations are expected to include a line flush after some large-scale batch transfers and after defined operating periods. These flushes are intended to prevent line plugging and mitigate hydrogen accumulation. Routine line flushes were generally not employed during PEP testing since they were not required for PEP operation.

The effectiveness of the line flush protocol was assessed in a single test during Functional testing. Simulant was pumped from HLP-VSL-T22 to Tank T01B, and the transfer line to Tank T01B was flushed with approximately five line volumes of inhibited water to test the line flushing efficiency. The flush was conducted at the maximum achievable rate in PEP, $20 \mathrm{GPM}$, which was about $70 \%$ of the scaled prototypic rate of 28 GPM planned for the WTP. Flush samples were taken at approximately 20-s intervals, which was approximately every 6 gallons (1 line volume) transferred. The samples were analyzed, and Figure 7.1 shows the nitrate, free hydroxide, and density concentrations plotted as a function of line flush volume. Also shown is the expected concentration behavior assuming ideal plug flow. Based on the concentration and density profiles, it is concluded that 1 to 2 line volumes are required for an adequate flush of the line initially filled with the Phase 1 PEP simulant.

(a) Josephson GB, OP Bredt, JK Young, and DE Kurath. 2009. Test Plan for Pretreatment Engineering Platform (PEP) Testing (Phase I). TP-RPP-WTP-506, Rev 0.4, Pacific Northwest National Laboratory, Richland, Washington. 


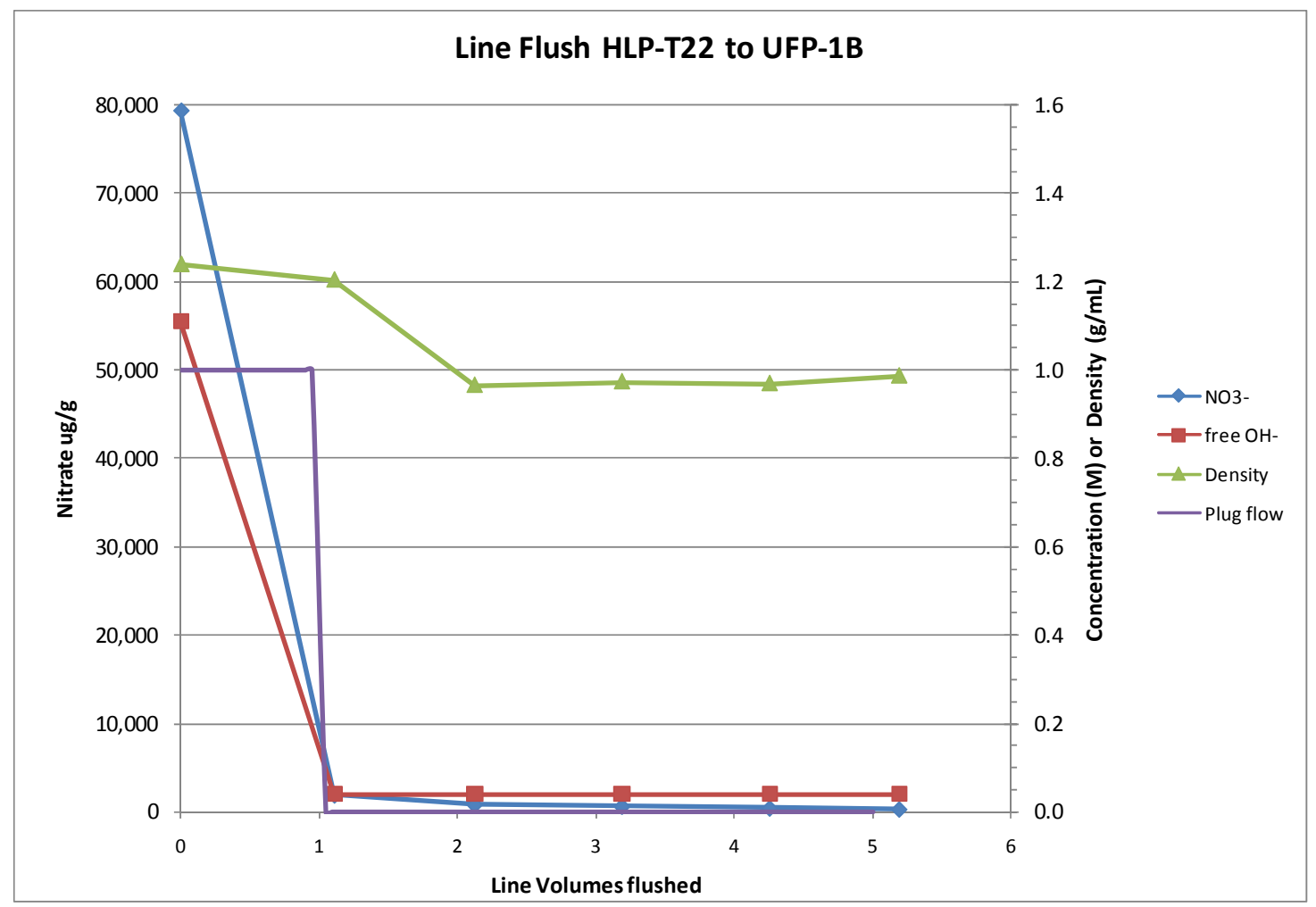

Figure 7.1. Simulant Line Flush Analytical Data

\subsection{Stratification Test in Tanks T01A/B}

Stratification tests were conducted with the neat simulant to determine whether solids stratified or "settled" over an extended period of time (i.e., 36 hours) in Tanks T01A/B. Prototypic mixing was maintained with the PJMs tuned by the operators to be near the operating targets (i.e., $4.8-\mathrm{m} / \mathrm{s}$ nozzle velocity, $80 \%$ stroke length, 35-s cycle time) and the air purge on the steam ring at the target flow rate $(0.13-\mathrm{kg} / \mathrm{min})$. Quadruplicate samples were taken from the inner-low, inner-middle, and inner-high sample locations near the center of the tank at $0,12,24$, and 36 hours and analyzed for wt $\%$ UDS. Two separate, nearly identical tests were conducted. The first test is denoted as "TI-062" (conducted in Tank 01A) and second as "TI-032" (conducted in Tank 01B). Several hours into the first test, it was discovered that the PJM nozzle velocity was too high. The PJMs were re-tuned to a lower drive velocity and the $36 \mathrm{hr}$ test time restarted. The second test was completed without incident.

Figure 7.2 shows the data for the first stratification test (TI-062). Data for the zero time are from the samples taken when the tank was being mixed with higher than intended PJM nozzle velocities.

Stratification testing is considered to have started when the PJMs were re-tuned to the lower velocity. It appears in Figure 7.2 that the low sampling elevation could have a slightly lower wt $\%$ UDS at the zero hour than the other two locations. 


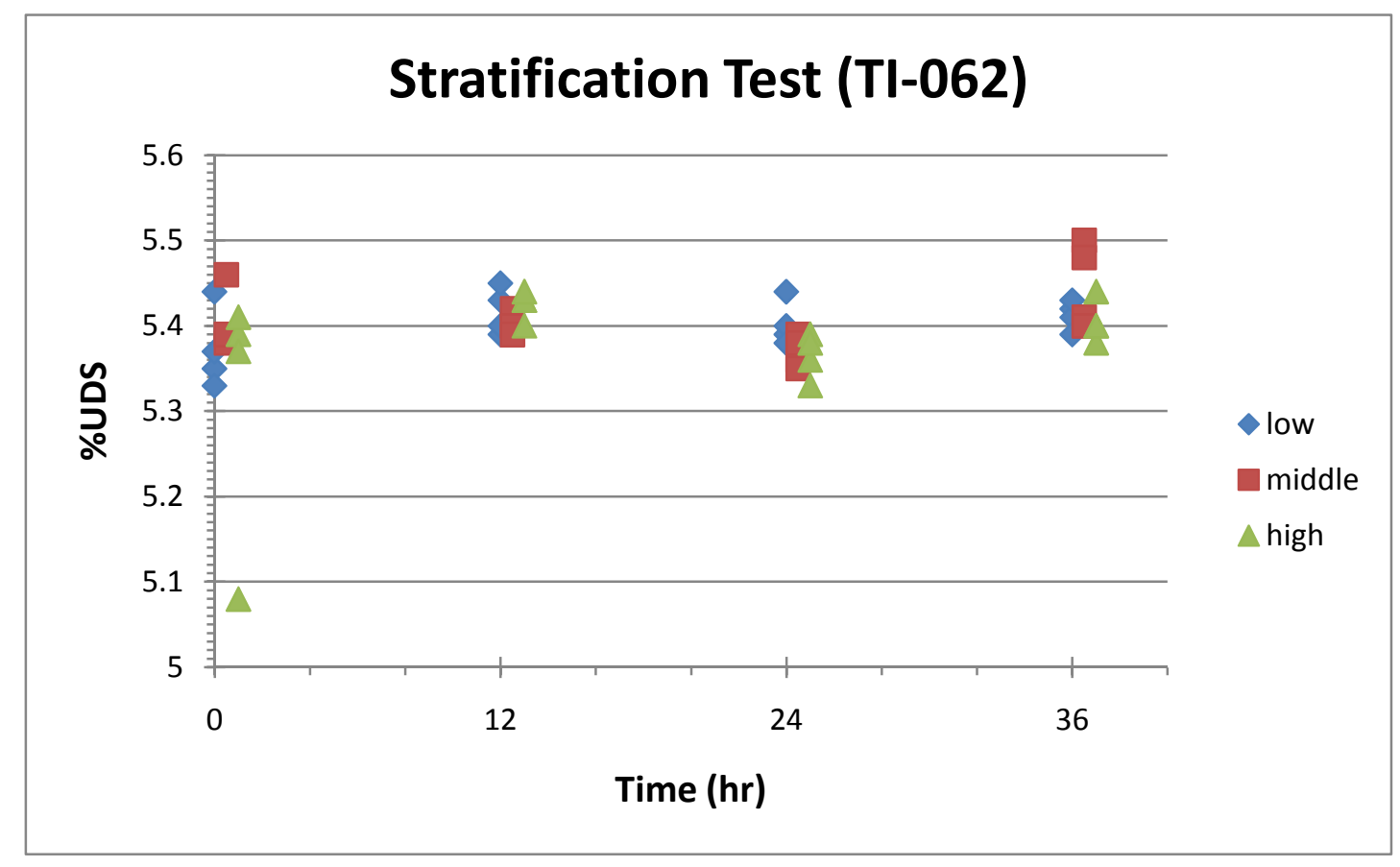

Figure 7.2. Tank T01A Wt\% UDS Analysis for All Stratification Samplings

Note: The high sample data at the zero hour appears to contain an outlier with an unusually low analysis. Coincidentally, this was the first sample taken during the sampling event. Likely, the sample station was not sufficiently purged before the sample was collected. This type of sampling error is part of the overall error of the actual sampling operation. Therefore, it has been retained for statistical analysis, and it is reflected as a wide 95\% confidence limit in Figure 7.3.

Figure 7.3 plots the means of each sampling event from the first stratification test with error bars showing a 95\% confidence of the mean (two standard deviations, population of four). When considering the analytical error, it is clear that the mean of the zero-hour sampling events at the high elevation is slightly lower than the other two elevations. However, the means of the wt $\%$ UDS are all within the 95\% confidence error bars. 


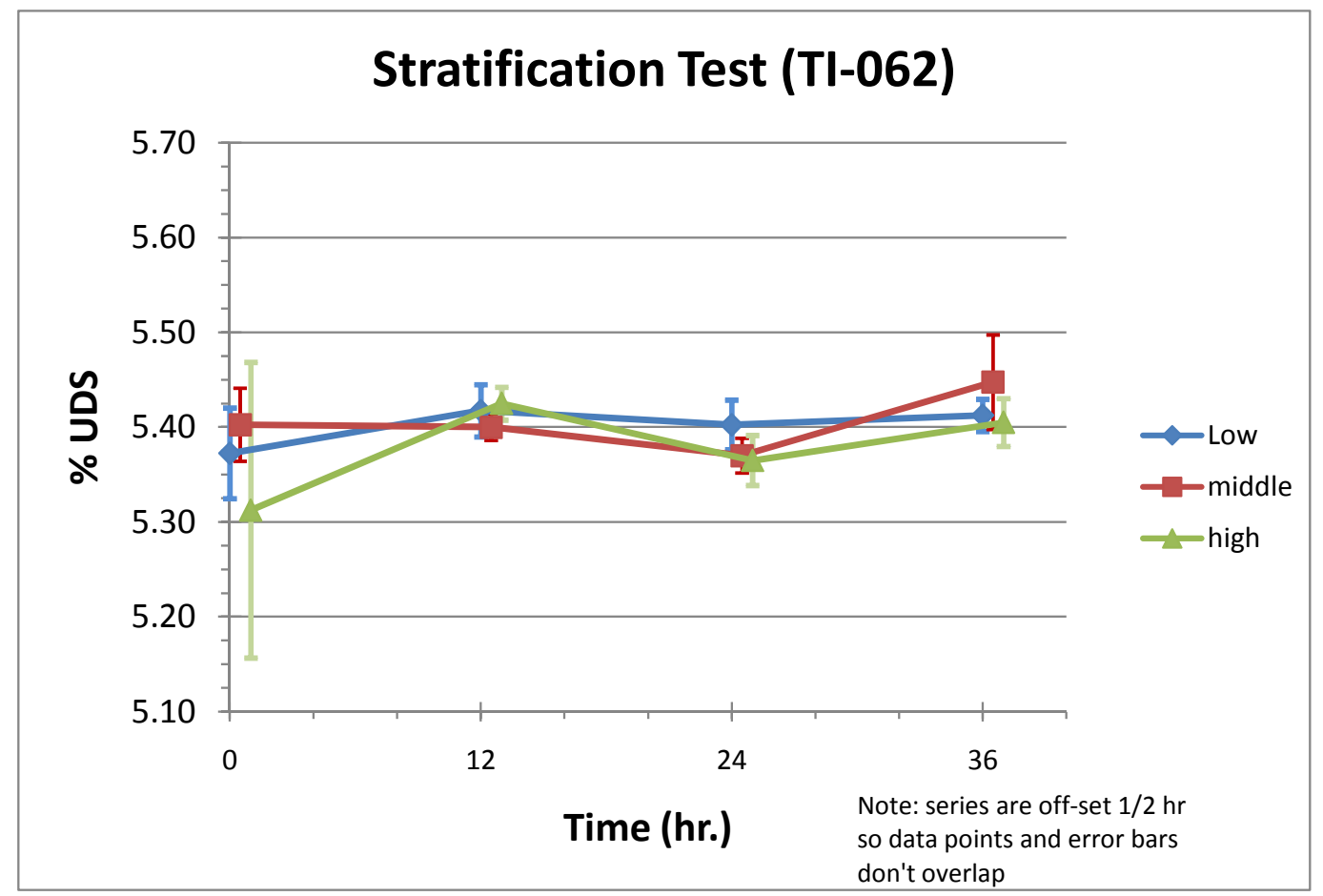

Figure 7.3. Tank T01A Stratification-Wt\% UDS Analyses Showing Sample Means with 95\% Confidence (2 std. dev.) Limits

Statistically, the data from each sampling event are consistent with the null hypothesis that there is no statistically significant difference between the data sets. Furthermore, from a physical standpoint, if settling occurs, the wt $\%$ UDS should be higher for the lower elevations, but this is not the case. ${ }^{(a)}$ The low elevation wt $\%$ UDS value is not statistically higher than the middle or upper elevations. For most of the sampling events, the highest wt\% UDS value is at some other elevation besides the lowest elevation.

Figure 7.3 connects each of the sampling elevations over time, better illustrating any trend in the data. Physically, if settling occurred, the upper sampling elevation should trend downward, and the lowest elevation should trend upward.

Figure 7.4 and Figure 7.5 show the same data for the second stratification test, TI-032. There is a general upward trend over time for the wt\% UDS at the lowest elevation. However, there is no accompanying trend downward for the upper elevation. Rather, it too tends to an upward trend. This is an artifact of the fact that the wt\% UDS analyses were higher for the 36-hr sampling event, but the increase is not statistically significant. Still, the conclusion is that there was no settling that caused a statistically significant difference in $\mathrm{wt} \%$ UDS.

(a) This observation assumes that the sampling ports provided representative samples of the local tank contents. The sampling analysis conducted in Tank 02A with higher mixing (see Section 7.3) supports the assumption that there was no bias between the sampling locations. The sampling stations in Tank 01A/B were of the same design, but were not tested independently. 


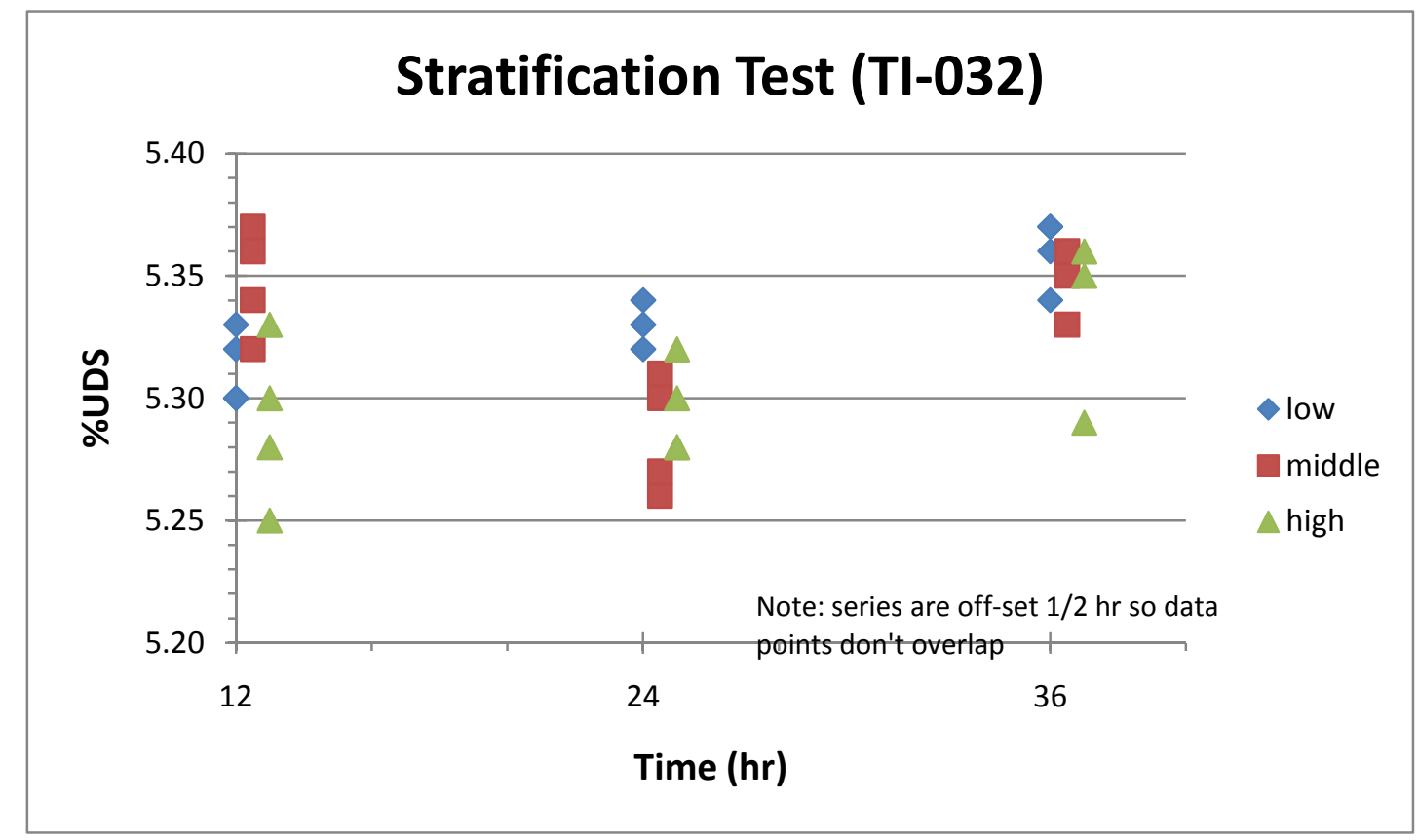

Figure 7.4. Tank T01B Stratification-Wt\% UDS Analysis for All Stratification Samplings from the Second Test

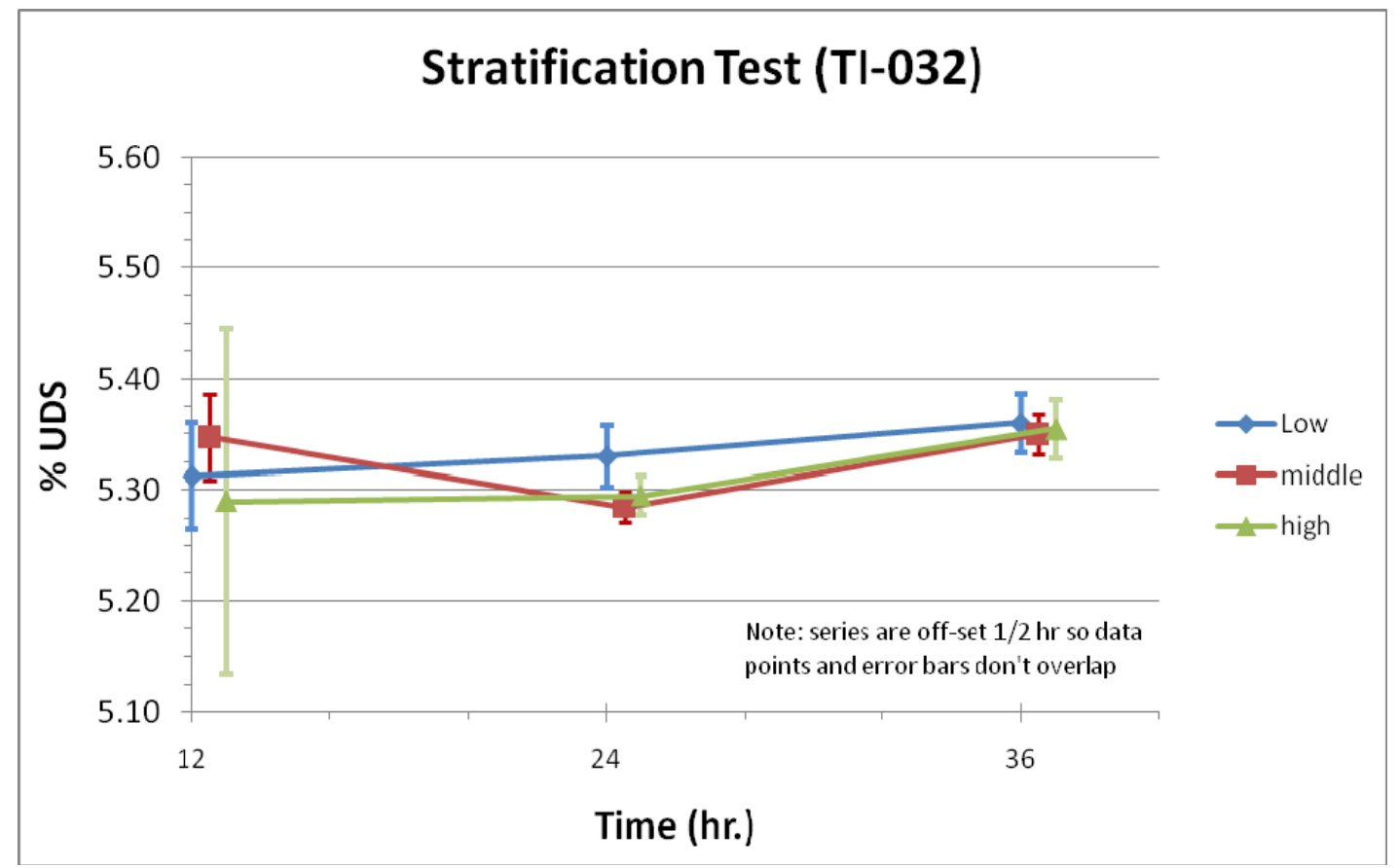

Figure 7.5. Tank T01B Stratification-Wt\% UDS Analyses Showing Sample Means with 95\% Confidence (2 std. dev.) Limits from the Second Test

These data were initially considered before Integrated process testing. Based upon these data, the test director concluded that the PJMs in Tanks T01A/B provided adequate mixing of the neat simulant when 
operated to match the power per unit volume of the PTF. The test director also concluded that for Integrated process testing, representative sampling of neat simulant in Tanks T01A/B could be achieved by sampling one location.

\subsection{Evaluation of In-Line and In-Tank Sampling Precision and Variability}

During the first hours of the low-solids filter test, five sets of six samples each were taken from the in-line filter-loop and from the Tank T02A middle-middle location to evaluate sampling variability. Each of the samples was collected in a separate bottle and analyzed in triplicate for wt $\%$ UDS. These results were statistically analyzed, and the results were used to determine the better sampling location for minimizing variance.

Figure 7.6 shows the means for each sampling event (each mean is computed from three replicates of six samples) with the $95 \%$ confidence intervals on the calculated mean. The times for the in-tank sampling data are shifted right by 0.1 hour for display purposes to allow easy viewing of the confidence width bands. The relatively wide confidence interval for in-tank sampling at hour 4 is due to one large wt $\%$ UDS value (7.86) compared to the other triplicate values at the same time.

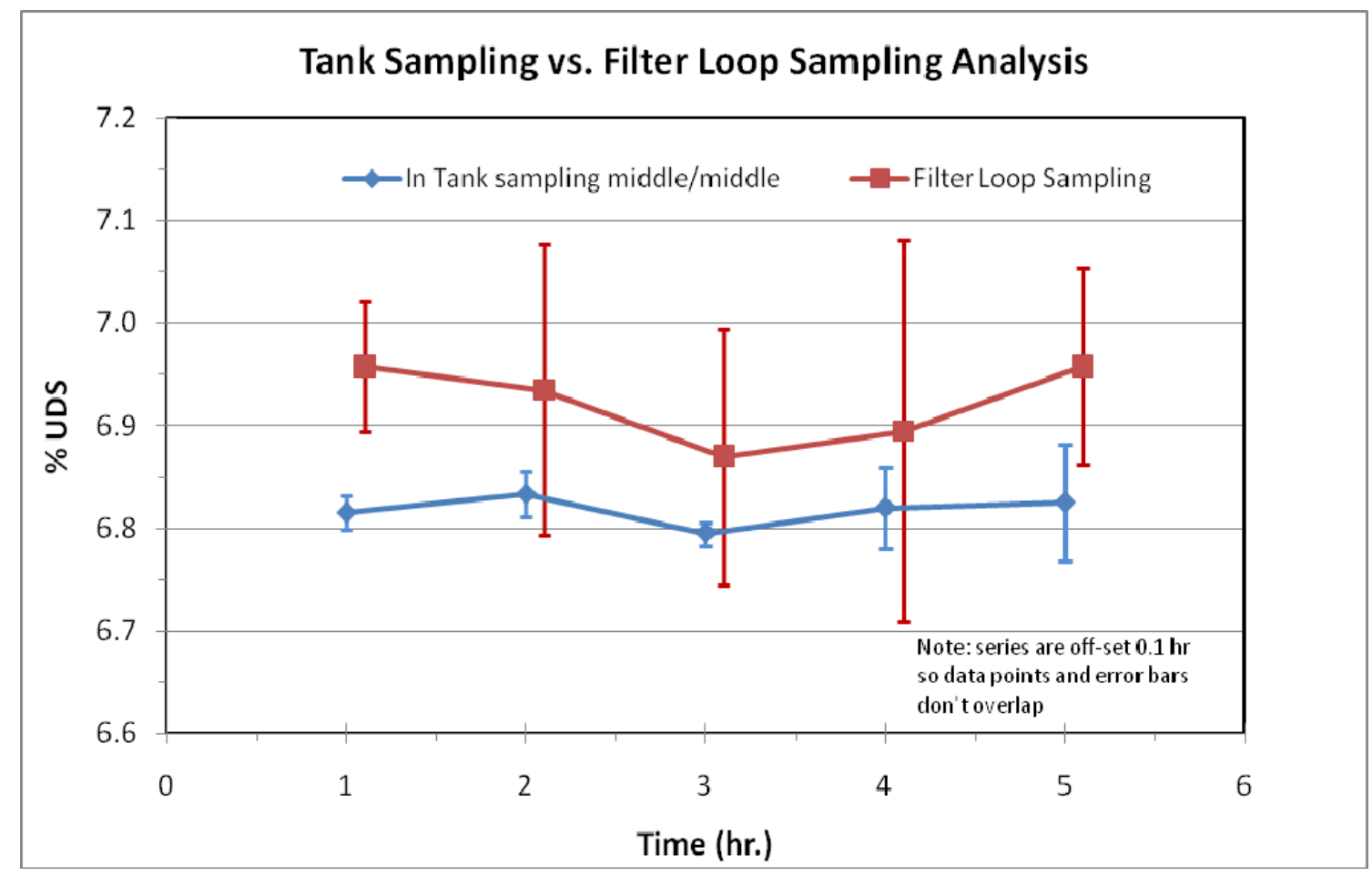

Figure 7.6. Sampling Comparison for In-Line Loop Sampling vs. Tank T02A In-Tank Sampling

Figure 7.6 illustrates that samples from the filter-loop had significantly more variance than samples collected from within the tank. The higher average wt $\%$ UDS results from the filter-loop are attributed to the increase in $\mathrm{wt} \%$ UDS due to permeate removal in the filters. In this test permeate was recycled to Tank T02A so there was no overall solids concentration. 
The variance of the values includes variations caused by slurry differences, sample acquisition and handling, and variations caused by subsequent laboratory analysis. The triplicate analyses of a single sample by the analytical laboratory allow separation of the variance due to the analytical procedure from the overall variance.

Although relatively large values of a single replicate for in-tank sampling at hours 4 and 5 drive up the triplicate laboratory-analysis variance, the analytical variance is approximately the same size as the variance due to slurry variations and sample collection. Based on the values in Table 7.1, the in-line sampling produces results with about five times the variance of similar samples drawn from within the tank. Based upon these observations, sampling for Tank T02A characterization during Integrated process testing was made directly from the tank through the CD sampling system.

Table 7.1. Variance Apportionment Between Analytical Measurements and All Other Sources of Variability (slurry variations, sample collection and handling)

\begin{tabular}{cclc}
\hline $\begin{array}{l}\text { Sampling } \\
\text { Location }\end{array}$ & $\begin{array}{l}\text { Variance Due to Triplicate Analyses } \\
\text { in the Laboratory (analytical } \\
\text { variability) }\end{array}$ & $\begin{array}{l}\text { Variance in the Means of Six Samples Collected } \\
\text { Every Hour (variability in slurry and collection } \\
\text { approach) }\end{array}$ \\
\hline In-tank & 0.0155 & & 0.0140 \\
In-line & 0.0003 & 0.0710 \\
\hline
\end{tabular}

Additional testing would need to be done to determine the sources of the increased variance from sampling at the in-line location. The in-line sampler employed a ball valve that had to be cracked to maintain a slow flow and could have increased variability. Such additional testing was outside the scope of the Test Plan.

\subsection{Evaluation of Mixing of $\mathrm{NaOH}$ After In-Line Addition}

The PEP testing Test Plan required the monitoring of Tank T01A and Tank T02A for evidence of slow or poor mixing of the $\mathrm{NaOH}$ added for caustic leaching. This was accomplished during execution of TI-032 by sampling at different locations shortly after adding $\mathrm{NaOH}$ to the vessels and analyzing the samples for free $\mathrm{OH}$. The added $\mathrm{NaOH}$ raised the free $\mathrm{OH}$ concentration from approximately 1-M in the simulant to 5-M for the Tank 01A leach or 8 to 9-M for the Tank 02A leach. Samples were obtained from Tank T01A at three elevations at the inner radial location. Samples were obtained from Tank T02A from the four sample ports (two elevations and two radial positions) that were immersed in the simulant. The other sample ports were above the slurry level.

The free hydroxide concentrations in Tank T01A after $\mathrm{NaOH}$ addition are shown in Table 7.2. Samples were collected from the inner radial location at each elevation (low, middle, and high) of the vessel. The collection occurred approximately 25 minutes after $\mathrm{NaOH}$ addition was complete. The less than $1 \%$ variation in results shows that the $\mathrm{NaOH}$ was mixed by the time samples were collected. 
Table 7.2. Free $\mathrm{OH}$ (molarity) in Tank T01A After In-Line NaOH Addition

\begin{tabular}{lccc}
\hline & \multicolumn{3}{c}{ Sample Locations } \\
& Inner & Middle & Outer \\
\hline High & $4.96-\mathrm{M}$ & - & - \\
Middle & $4.93-\mathrm{M}$ & - & - \\
Low & $4.98-\mathrm{M}$ & - & - \\
\hline "-_" Analysis not required & \\
\hline
\end{tabular}

The free hydroxide concentrations in Tank T02A after $\mathrm{NaOH}$ addition are shown in Table 7.3. Samples were collected approximately 15 minutes after $\mathrm{NaOH}$ addition was completed from submerged Coriolis densitometer ports. The predicted slurry level was approximately 40 inches, and all of the "inner" sample locations in Tank T02A were above this level.

The relative difference between the highest and lowest free hydroxide concentrations is $2.5 \%$, which is less than the laboratory-reported method uncertainty of $15 \%$. This small variation in results shows that the $\mathrm{NaOH}$ was mixed by the time the samples were obtained.

Table 7.3. Free Hydroxide (molarity) in Tank T02A After In-Line $\mathrm{NaOH}$ Addition

\begin{tabular}{lccc}
\hline & \multicolumn{3}{c}{$\begin{array}{c}\text { Sample Locations } \\
\text { Middle }\end{array}$} \\
\hline High & - & - & Outer \\
Middle & - & $8.43-\mathrm{M}$ & - \\
Low & - & $8.62-\mathrm{M}$ & $8.43-\mathrm{M}$ \\
\hline "-_" Coriolis densitometer port not submerged so sample not collected \\
\hline
\end{tabular}

\subsection{Stratification of Solids During Caustic Leaching (Tanks T01A and T02A)}

During the caustic-leach that was performed in Tanks T01A and T02A during the Functional testing (TI-032), samples were taken from each submerged CD location at hours 2 and 16 to look for evidence of stratification. Sampling data used to test for stratification of solids in Tank T01A during the caustic-leach step are provided in Table 7.4. 
Table 7.4. Sampling Data (wt $\%$ UDS and slurry density) Used to Test for Stratification of Solids in Tank T01A During Caustic-Leach

\begin{tabular}{|c|c|c|c|c|c|}
\hline \multirow[b]{2}{*}{ Hour } & \multirow{2}{*}{$\begin{array}{c}\text { Location } \\
\text { Radial Elevation }\end{array}$} & \multicolumn{2}{|c|}{ UDS } & \multicolumn{2}{|c|}{ Slurry Density } \\
\hline & & $\mathrm{Wt} \%$ & Unc. $^{\mathrm{a}}$ & $\mathrm{g} / \mathrm{cm}^{3}$ & $\mathrm{Unc}^{\mathrm{a}}$ \\
\hline 2 & Inner Middle & 2.54 & 0.04 & - & 一 \\
\hline 2 & Inner Middle & 2.40 & 0.04 & - & - \\
\hline 2 & Inner Middle & 2.36 & 0.04 & - & - \\
\hline 2 & Inner Low & 2.54 & 0.04 & 1.32 & 0.02 \\
\hline 2 & Middle Low & 2.36 & 0.04 & 1.33 & 0.02 \\
\hline 2 & Outer Low & 2.32 & 0.04 & 1.32 & 0.02 \\
\hline 2 & Outer Middle & 2.39 & 0.04 & 1.33 & 0.02 \\
\hline 2 & Middle Middle & 2.42 & 0.04 & 1.32 & 0.02 \\
\hline 2 & Outer High & 2.35 & 0.04 & 1.32 & 0.02 \\
\hline 16 & Inner Middle & 2.18 & 0.03 & - & - \\
\hline 16 & Inner Middle & 2.18 & 0.03 & - & - \\
\hline 16 & Inner Middle & 2.16 & 0.03 & - & - \\
\hline 16 & Inner Low & 2.28 & 0.04 & 1.31 & 0.02 \\
\hline 16 & Middle Low & 2.46 & 0.04 & 1.31 & 0.02 \\
\hline 16 & Outer Low & 2.11 & 0.03 & 1.30 & 0.02 \\
\hline 16 & Outer Middle & 2.12 & 0.03 & 1.31 & 0.02 \\
\hline 16 & Middle Middle & 2.16 & 0.03 & 1.30 & 0.02 \\
\hline 16 & Outer High & 2.09 & 0.03 & 1.31 & 0.02 \\
\hline
\end{tabular}

The analysis approach first grouped the sampling data by elevation or radial distance. Evidence of stratification can be inferred by systematic differences in the means of the grouped $\mathrm{wt} \%$ UDS or slurry density values (see Table 7.5). 
Table 7.5. Mean Values of Sampling Data (wt\% UDS and slurry density) Grouped by Elevation or Radial Distance Used to Test for Stratification of Solids in Tank T01A During Caustic-Leach

\begin{tabular}{|c|c|c|c|c|c|}
\hline \multicolumn{3}{|c|}{2 Hour wt $\%$ UDS Data Grouped by Elevation } & \multicolumn{3}{|c|}{2 Hour Density $\left(\mathrm{g} / \mathrm{cm}^{3}\right)$ Data Grouped by Elevation } \\
\hline Location & Mean & Std.Dev. & Location & Mean & Std. Dev. \\
\hline Low & 2.407 & 0.012 & Low & 1.325 & 0.006 \\
\hline Middle & 2.422 & 0.009 & Middle & 1.322 & 0.007 \\
\hline High & 2.350 & 0.020 & High & 1.317 & 0.010 \\
\hline \multicolumn{3}{|c|}{2 Hour wt $\%$ UDS Data Grouped by Radial Distance } & \multicolumn{3}{|c|}{$\begin{array}{c}2 \text { Hour Density }\left(\mathrm{g} / \mathrm{cm}^{3}\right) \text { Data Grouped by Radial } \\
\text { Distance }\end{array}$} \\
\hline Location & Mean & Std. Dev. & Location & Mean & Std. Dev. \\
\hline Inner & 2.460 & 0.010 & Inner & 1.322 & 0.011 \\
\hline Middle & 2.390 & 0.014 & Middle & 1.324 & 0.007 \\
\hline Outer & 2.353 & 0.012 & Outer & 1.322 & 0.006 \\
\hline \multicolumn{3}{|c|}{16 Hour wt $\%$ UDS Data Grouped by Elevation } & \multicolumn{3}{|c|}{16 Hour Density $\left(\mathrm{g} / \mathrm{cm}^{3}\right)$ Data Grouped by Elevation } \\
\hline Location & Mean & Std. Dev. & Location & Mean & Std. Dev. \\
\hline Low & 2.283 & 0.011 & Low & 1.308 & 0.006 \\
\hline Middle & 2.160 & 0.007 & Middle & 1.305 & 0.007 \\
\hline High & 2.090 & 0.015 & High & 1.312 & 0.010 \\
\hline \multicolumn{3}{|c|}{16 Hour $w t \%$ UDS Data Grouped by Radial Distance } & \multicolumn{3}{|c|}{$\begin{array}{l}16 \text { Hour Density }\left(\mathrm{g} / \mathrm{cm}^{3}\right) \text { Data Grouped by Radial } \\
\text { Distance }\end{array}$} \\
\hline Location & Mean & Std. Dev. & Location & Mean & Std. Dev. \\
\hline Inner & 2.200 & 0.008 & Inner & 1.311 & 0.010 \\
\hline Middle & 2.310 & 0.013 & Middle & 1.305 & 0.007 \\
\hline Outer & 2.107 & 0.009 & Outer & 1.308 & 0.006 \\
\hline
\end{tabular}

Several conclusions can be drawn regarding stratification of solids during caustic leaching in Tank T01A using tests of hypothesis of equal means, at the $95 \%$ confidence level, based on the total variability. In conducting this analysis, it is assumed that the total variability is 2.5 times the reported analytical variability. This is based on data used to evaluate the precision of the sampling and analysis of $\mathrm{wt} \%$ UDS data described in Section 7.3 that indicate that the analytical uncertainty is at most about half of the total uncertainty in wt\% UDS data. Using an assumption that the total variability is 2.5 times the reported analytical variability, one draws the following conclusions:

- Using 2 hour wt $\%$ UDS data, there is no evidence that the mean wt $\%$ UDS values are different at different elevations or different radial distances.

- Using 16-hour wt\% UDS data:

- The mean wt\% UDS value at the low elevation is statistically different (higher) at the $95 \%$ confidence level from the middle and high elevations. The ratio of the largest mean to the smallest mean is 1.093 .

- The mean wt $\%$ UDS value at the middle radial distance is statistically different (higher) at the $95 \%$ confidence level from the inner and outer distances. The ratio of the largest mean to the smallest mean is 1.097. 
Using density data, there is no statistical evidence that density varies by either elevation or radial distance at either 2 hours or 16 hours. ${ }^{(a)}$ However, density data are very insensitive to $w t \%$ UDS and would not be a good indicator of modest solids settling.

Both of the statistically significant results listed above result from the high wt $\%$ UDS at the middle-low location in Table 7.4. The sample from this location measured 2.46-wt $\%$ UDS. The next highest sample result was from the inner low location at 2.28-wt $\%$ UDS. All the other samples measured below 2.20-wt \% UDS. By statistics, there is a 5\% chance this difference in wt $\%$ UDS is purely coincidence. However, in this case, the statistics are consistent with the physical mechanism of solids settling although it should be noted that the sample from the outer-low sample port had a measured UDS value of $2.11-\mathrm{wt} \%$. Although this result is occurring in the tanks with the lowest PJM nozzle velocity where stratification would be most likely to occur it is reasonable to expect that if significant settling had been present that all of the UDS values obtained from the low sample ports would be high. Further complicating the analysis if the fact that steam was on and the PJMs were off for several minutes during portions of the sampling. When considered with other results with the neat simulant, which did not show any evidence of stratification, one can deduce that PJM mixing in Tanks T01A/B is adequate, but may not be so vigorous as to provide a completely homogeneous slurry in all cases.

Sampling data used to test for stratification of solids in Tank T02A during the caustic-leach step are provided in Table 7.6. The analysis approach used on the Tank T01A stratification of solids discussed above is used on the T02A data. The grouped data are shown in Table 7.7.

Several conclusions can be drawn regarding stratification of solids during caustic leaching in Tank T02A using tests of hypothesis of equal means, at the $95 \%$ confidence level, based on the total variability. In conducting this analysis, it is assumed that the total variability is 2.5 times the reported analytical variability. This is based on data used to evaluate the precision of the sampling and analysis of $\mathrm{wt} \%$ UDS data described in Section 7.3 that indicate that the analytical uncertainty is at most about half of the total uncertainty in wt $\%$ UDS data. Using an assumption that the total variability is 2.5 times the reported analytical variability, one draws the following conclusions:

- Using 2-hour wt $\%$ UDS data, there is no evidence that the mean wt $\%$ UDS values are different at different elevations or different radial distances.

- Using 16-hour wt\% UDS data:

- There is no evidence that the mean wt $\%$ UDS values are different at different elevations.

- The mean wt\% UDS value at the outer radial distance is statistically different (lower) at the $95 \%$ confidence level from the middle and inner distances. The lowest value occurs at the outer radial distance, and the ratio of the largest mean to the smallest mean at all radial distances is 1.048 .

(a) Note: The density measurement at low solids content is dominated by the density of the supernatant. A change from 2.1 to $2.3 \mathrm{wt} \%$ UDS would only cause a density change of $\sim 0.002 \mathrm{~g} / \mathrm{cm}^{3}$. 
Table 7.6. Sampling Data (wt\% UDS and slurry density) Used to Test for Stratification of Solids in T02A During Caustic-Leach

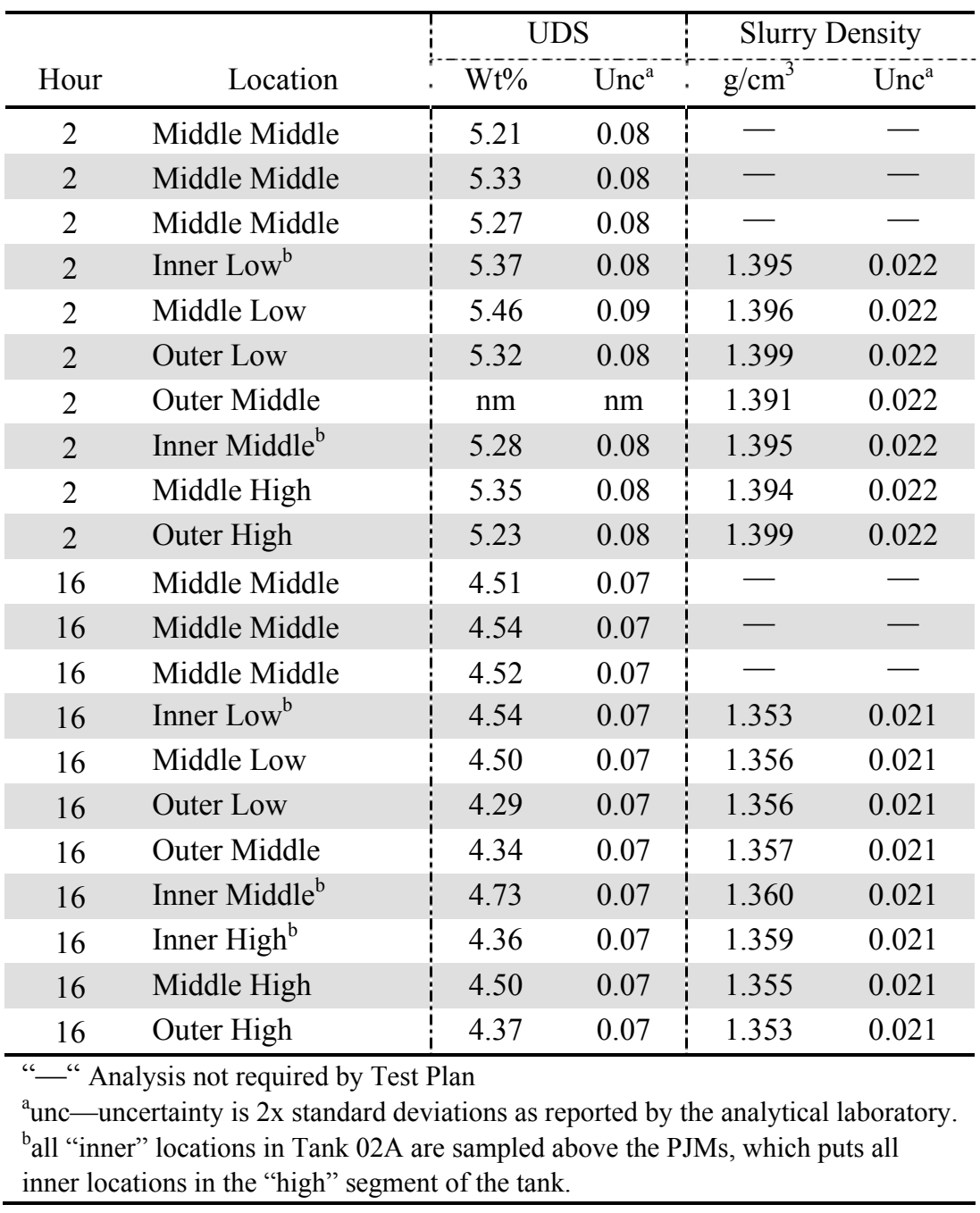

Using density data, there is no statistical evidence that density varies by either elevation or radial distance at either 2 hours or 16 hours. As previously noted, density data are very insensitive to wt\% UDS and would not be a good indicator of modest solids settling.

Given the physical conditions in the tank, the highest wt $\%$ UDS in the middle elevation of the tank during this test is not expected. Therefore, the apparent differences in $\mathrm{wt} \%$ UDS values may be due to sampling variability. Similar patterns are not evident in the density data. Therefore, no strong evidence for stratification of solids exists in Tank T02A during caustic-leach. 
Table 7.7. Mean Values of Sampling Data (wt\% UDS and slurry density) Grouped by Elevation or Radial Distance Used to Test for Stratification of Solids in Tank T02A During Caustic-Leach

\begin{tabular}{|c|c|c|c|c|c|}
\hline \multicolumn{3}{|c|}{2 Hour $w t \%$ UDS Data Grouped by Elevation } & \multicolumn{3}{|c|}{2 Hour Density $\left(\mathrm{g} / \mathrm{cm}^{3}\right)$ Data Grouped by Elevation } \\
\hline Location & Mean & Std. Dev. & Location & Mean & Std. Dev. \\
\hline Low & 5.390 & 0.030 & Low & 1.397 & 0.006 \\
\hline Middle & 5.270 & 0.023 & Middle & 1.393 & 0.008 \\
\hline High & 5.308 & 0.020 & High & 1.397 & 0.008 \\
\hline \multicolumn{3}{|c|}{2 Hour wt $\%$ UDS Data Grouped by Radial Distance } & \multicolumn{3}{|c|}{$\begin{array}{c}2 \text { Hour Density }\left(\mathrm{g} / \mathrm{cm}^{3}\right) \text { Data Grouped by Radial } \\
\text { Distance }\end{array}$} \\
\hline Location & Mean & Std. Dev. & Location & Mean & Std. Dev. \\
\hline Inner & 5.325 & 0.028 & Inner & 1.395 & 0.008 \\
\hline Middle & 5.324 & 0.018 & Middle & 1.395 & 0.008 \\
\hline Outer & 5.275 & 0.028 & Outer & 1.396 & 0.006 \\
\hline \multicolumn{3}{|c|}{16 Hour wt $\%$ UDS Data Grouped by Elevation } & \multicolumn{3}{|c|}{16 Hour Density $\left(\mathrm{g} / \mathrm{cm}^{3}\right)$ Data Grouped by Elevation } \\
\hline Location & Mean & Std. Dev. & Location & Mean & Std. Dev. \\
\hline Low & 4.395 & 0.025 & Low & 1.355 & 0.006 \\
\hline Middle & 4.478 & 0.018 & Middle & 1.359 & 0.007 \\
\hline High & 4.500 & 0.016 & High & 1.356 & 0.006 \\
\hline \multicolumn{3}{|c|}{16 Hour wt $\%$ UDS Data Grouped by Radial Distance } & \multicolumn{3}{|c|}{$\begin{array}{c}16 \text { Hour Density }\left(\mathrm{g} / \mathrm{cm}^{3}\right) \text { Data Grouped by Radial } \\
\text { Distance }\end{array}$} \\
\hline Location & Mean & Std. Dev. & Location & Mean & Std. Dev. \\
\hline Inner & 4.543 & 0.020 & Inner & 1.357 & 0.006 \\
\hline Middle & 4.514 & 0.016 & Middle & 1.356 & 0.007 \\
\hline Outer & 4.333 & 0.020 & Outer & 1.355 & 0.006 \\
\hline
\end{tabular}





\subsection{Analysis of PEP Filtration Activities}

Because cross-flow ultrafiltration permeate flux is typically a strong function of filter history and slurry properties, specific permeate fluxes observed during Integrated process testing are of limited value in assessing likely Pretreatment Facility (PTF) performance. Analyses of the integrated process filtration data, given in Sections 5.1 through 5.3, are therefore limited to qualitative observations and conclusions. Quantitative comparisons of Pretreatment Engineering Platform (PEP) and Cells Unit Filter (CUF) performance, based on dedicated parallel testing conducted apart from the Integrated tests, are described in (Daniel et al. 2009b). A summary of their analyses and results is presented in Section 8.2.

This section addresses the filtration-specific objectives outlined in Table S.1. The data presented here are discussed in terms of the filtration-specific success criteria provided in Table S.4. Those success criteria relevant to filtration are provided in Table 8.1. It should also be noted that significant presentations, analyses, and discussions of PEP filtration data are provided in the following reports:

- Filter scale-up report (WTP-RPT-185, Daniel et al. 2009b) provides extensive discussion and analysis of the filter conditioning tests performed during PEP Functional testing activities and the high-solids filtration test performed during close-out of Integrated Test A.

- Solids washing report (WTP-RPT-187, Baldwin et al. 2009) analyzes washing efficiencies for washing operations performed under Integrated Test A and Integrated Test B.

- Run report for Functional testing (WTP-RPT-190, Josephson et al. 2009) provides an in-depth summary of Functional testing operations and process/analytical data and results.

- Run report for Integrated Test A (WTP-RPT-191, Guzman-Leong et al. 2009) provides an in-depth summary of Integrated Test A operations and process/analytical data and results.

- Run report for Integrated Test B (WTP-RPT-192, Geeting et al. 2009) provides an in-depth summary of Integrated Test B operations and process/analytical data and results.

- $\quad$ Run report for Integrated Test D (WTP-RPT-193, Sevigny et al. 2009) provides an in-depth summary of Integrated Test D operations and process/analytical data and results.

These reports also help satisfy the success criteria outlined in Table S.4. Additionally, the run reports provide a detailed discussion of test events, bases, and performance. This section summarizes that information and provides mass balance estimates for UDS and DS and the dewatering and washing curves.

The current section analyzes the filtration performance for Integrated Tests A, B, and D. Because of process execution and sampling issues, a detailed analysis of dewatering and washing activities for Functional tests shall not be presented in this summary. A summary of process results for Functional testing is found in the run report for simulant Shakedown activities (Josephson et al. 2009). 
Table 8.1. Success Criteria Addressed in Executive Summary in the Section "Results and Performance Against Success Criteria"

\begin{tabular}{l} 
Success Criterion \\
\hline Measure the filter system performance at the nominal \\
flow velocity and TMPs for the solids concentration \\
and washing stages for the UFP-1 and UFP-2 \\
aluminum leaching flowsheets.
\end{tabular}

Evaluate the control strategy for make-up additions from UFP-VSL-00001A/B to UFP-VSL-00002A/B during initial dewatering process.

Verify that the dual, in-series pump configuration is controllable and maintains the required slurry velocity and pressures for ultrafilter operation.

Fipplicability
presented as temperature- and TMP-corrected filter fluxes as a function of time and as a function of UDS or DS solids content for Integrated Tests A, B, and D. Extensive discussion that describes the filter behavior across the UFP-1 and UFP-2 operating scenarios is provided in the current section.

The effectiveness and impact of batch transfers on solids concentration is evaluated using both UDS and filter flux results. The batch transfer strategies are described briefly. In all cases, the desired filtration operations were completed with no apparent complications caused by the batch transfer strategy employed.

Relevant process data presented in run reports for specific tests (Josephson et al. 2009, Guzman-Leong et al. 2009, Geeting et al. 2009, Sevigny et al. 2009) and in previous engineering ties transmittals (WTP/RPP-MOA-PNNL-00392 (a) $)$.

Process performance is discussed on a general basis to assess if the desired filtration goals were achieved. Additionally, backpulsing events for the Integrated Tests are evaluated (when applicable) and an assessment of backpulsing effectiveness provided.

Filter performance is characterized by filter flux as a function of time and solids concentration. Visual observations of filter bundles and elements are discussed in Section 13.4.

Relevant process data are presented in run reports (Josephson et al. 2009, Guzman-Leong et al. 2009, Geeting et al. 2009, Sevigny et al. 2009) for specific tests.

Relevant process data are presented in run reports (Josephson et al. 2009, Guzman-Leong et al. 2009, Geeting et al. 2009, Sevigny et al. 2009) for specific

(a) Letter from GH Beeman to H Hazen. "Subcontract No. 24590-QL-HC9-WA49-00001, Project No. 53569 (WA-024) Engineering Ties Data Transmittal: The electronic file enclosed with this letter has been reviewed for technical accuracy per the QA program.” WTP/RPP-MOA-PNNL-00392, dated 4/10/09. 
Table 8.1. Success Criteria Addressed in Executive Summary in the Section "Results and Performance Against Success Criteria"

\begin{tabular}{|c|c|}
\hline Success Criterion & Applicability \\
\hline & tests. \\
\hline Record operating time of each ultrafilter assembly. & $\begin{array}{l}\text { Summary tables of filter operating times for Integrated } \\
\text { Tests } A, B \text {, and D are provided in this section. }\end{array}$ \\
\hline $\begin{array}{l}\text { Record each ultrafilter assembly cleaning event } \\
\text { (backpulse, flush, chemical cleaning, etc.). }\end{array}$ & $\begin{array}{l}\text { Summary tables of filter backpulse events for } \\
\text { Integrated Tests A, B, and D are provided in this } \\
\text { section. Filter cleaning events are discussed in the run } \\
\text { reports (Josephson et al. 2009, Guzman-Leong et al. } \\
\text { 2009, Geeting et al. 2009, Sevigny et al. 2009). }\end{array}$ \\
\hline $\begin{array}{l}\text { Evaluation of the pulse-pot operation and backpulse } \\
\text { operation strategies contained in PEP Phase } 1 \text { Testing } \\
\text { Process Description. }\end{array}$ & $\begin{array}{l}\text { Pulse-pot and backpulse operations are discussed for } \\
\text { Integrated Tests where backpulsing was performed on } \\
\text { an "as-needed" basis. These backpulsing events are } \\
\text { evaluated and an assessment of backpulsing } \\
\text { effectiveness is provided. }\end{array}$ \\
\hline
\end{tabular}

\subsection{Equations and Theory}

The AV is defined as the superficial velocity of slurry flow through a filter element. Since the cross-sections of the filters are all geometrically the same, a single AV can be defined for all filter elements. Key to the definition of a single filter axial velocity are the assumptions that 1) flow and solids concentration is uniformly distributed across the cross-sectional area of the filter bundle, and 2) loss of permeate does not appreciably lower the volumetric flow rate of slurry through the filter-loop. Axial velocity is determined using the known filter geometry and the slurry volumetric flow through the filter-loop, which can be determined using the filter-loop volumetric flow rate measurements taken by FT-0623 (suction to pump T42A) or FT-0635 (discharge from pump T43A). While the flowmeter readings at these two locations should be the same, the readings sometimes diverged as a result of air entrainment. Additionally, FT-0623 was flagged as suspect (as a result of technical issues beyond air entrainment) for Integrated Test A operations between February 14 and February 27, 2009. ${ }^{\text {(a) }}$ These issues are discussed in more detail in the run reports.

The average pressure differential between tubeside of the filter element and the filter bundle shell is commonly called the TMP. For each filter bundle, TMP is calculated by subtracting the shellside pressure from the average of the filter bundle inlet and outlet pressures. Positive TMP occurs when the bundles are actively filtering; TMP is negative during filter backpulsing.

The PEP data acquisition system (DAS) records the mass flow rate of permeate produced by each filter bundle. The first step in calculating filter flux is to determine the volumetric flow rate of permeate $Q_{p}$ produced using each filter by dividing the mass flow rate $G$ by permeate density $\rho_{p}$. For solids concentration operations, density is typically assumed constant and determined by analyzing slurry samples taken immediately before, during, and after concentration. For washing operations, the permeate

(a) Described in NCR 42317.1 
density changes throughout the washing operation. Here, permeate density is estimated through a mass balance on the recirculating slurry and through interpolation of analytical permeate densities.

When the temperature of the slurry was not exactly $25^{\circ} \mathrm{C}$, the permeate flux rate was corrected to $25^{\circ} \mathrm{C}$ using (Geeting et al. 2003)

$$
Q_{t}(i)=Q_{p}(i) \exp \left[2500\left(\frac{1}{T+273}-\frac{1}{298}\right)\right]
$$

where $Q_{t}(i)$ is the corrected volumetric flow rate at $25^{\circ} \mathrm{C}, Q_{p}(i)$ is the volumetric flow rate of permeate (determined from the mass flow rate of permeate from each filter), $\mathrm{T}$ is the temperature $\left({ }^{\circ} \mathrm{C}\right)$, and $i$ is the filter bundle number (one to five).

As discussed in Daniel et al. (2009a), this equation corrects for both changes in permeate viscosity and cake structure with temperature. The slurry temperature used was based on the prototypic temperature resistance temperature detector (RTD) in Tank T02A (i.e., TTK-0619). In addition, corrections for deviations in the TMP from the target value were also applied using

$$
Q_{c}(i)=\left[\frac{T M P(i)}{T M P_{t}(i)}\right] \cdot Q_{t}(i)
$$

where $Q_{c}(i)$ is the TMP- and temperature-corrected volumetric flow rate, $\mathrm{TMP}_{\mathrm{t}}(i)$ is the target TMP for filter bundle $i$, and $i$ is the filter bundle number ( 1 to 5). Equation 8.2 is subject to the assumption that permeate production rates are directly proportion to TMP.

The TMP targets were 40 pounds per square inch differential (psid) for all tests. Equation 8.2 is intended to correct for persistent deviations in TMP from its target value. It is applied only to process pressure measurements that have been time averaged over 1 minute intervals for the current report.

After temperature and TMP corrections, the filter flux for filter $i$ may be determined by

$$
J(i)=\frac{Q_{c}(i)}{A(i)}
$$

where $J(i)$ is the filter flux of filter bundle $i, A(i)$ is the total filter surface area filter bundle $i$, and $i$ is the filter bundle number (one to five).

\subsubsection{Analysis of Solids Dewatering/Concentration Operations}

Dewatering operations affect a change in the slurry UDS concentration by removing permeate from the slurry. Because the filtration regime (either membrane- or cake-resistance controlled) and filter flux are strongly dependent on the solids concentration, knowledge of UDS throughout the dewatering process is crucial to understanding the dewatering behavior. Even though the permeate production rate was continuously monitored and recorded (typically at a frequency of $1 \mathrm{~Hz}$ ), only a limited number of analytical samples were taken during dewater operations. As a result, the concentration at which the 
dewatering curve may be assessed is restricted to the limited number of unique UDS concentrations measured. To overcome this limitation, a mass balance of the circulating slurry volume is typically performed to fill in the "gaps" between measured UDS concentrations. A detailed description of the mass balance equations for UDS estimates during solids concentration operations is given in Appendix B.

\subsubsection{Analysis of Slurry Washing Operations}

Washing operations reduce the concentration of slurry DS through batch transfers of inhibited water (IW) to Tank T02A and subsequent removal of the diluted solution via filtration. Tank T02A level is maintained by matching the volume of water added to the volume of permeate removed. The drop in supernate dissolved solids concentration typically yields a corresponding increase in filter permeate rates as a result of a drop in permeate viscosity (although other mechanisms may also affect flux). To allow calculation of filter flux in $\mathrm{GPM} / \mathrm{ft}^{2}$ as a function of the test time, the permeate density must also be determined as a function of test time. To do this, the permeate DS is estimated using a mass balance similar to that used to estimate UDS. As with slurry concentration operations, measurement of permeate DS is limited to the number of analytical samples taken during testing. These limited DS measurements can be supplemented by performing a material balance on the permeate DS. A detailed description of the mass balance equations for DS estimates during washing operations is given in Appendix B.

\subsubsection{Evaluation of Backpulsing Effectiveness}

The goal of backpulsing is to increase the rate of permeate production by disrupting or removing surface (typically solids cake) and depth-fouling that limits permeate flow. Backpulsing temporarily increases the filter rate at the cost of the mass of permeate forced back through the filters and the mass of permeate that could have been produced had filtration not been stopped to allow backpulsing. In addition to the loss of permeate produced, backpulsing may yield an increased potential for irreversible depth-fouling (via clearing of a protective cake layer), lowering the filter flux achieved over long duration filtration operations.

For backpulsing to be beneficial, the net permeate filtered in the backpulsed system must be greater than the permeate produced had there been no backpulsing. Backpulsing was implemented on an as-needed basis in Integrated Tests A and B. No parallel control filtration studies where the slurry was treated without backpulsing (either on other PEP filter bundles or as a complete separate test) were conducted. Because filter flux is strongly dependent on filter and backpulse history and because of the unusual fouling dynamics observed in the low-solids conditioning tests (see Daniel et al. [2009b]), a point of reference for non-backpulsed permeate production rates cannot be defined for the current studies. Consequently, it is not possible to evaluate the overall impact of backpulsing on the average rate of filtration.

For the current report, a rough assessment of individual backpulsing effectiveness is made from the limited test data available. These assessments compare the actual mass of permeate filtered during the interval between two adjacent backpulses to an estimate of the maximum mass of permeate that could have been produced had the first backpulse not taken place. A detailed description of how backpulsing effectiveness is assessed is given in Appendix B. 


\subsection{Filter Scaling Tests - Low- and High-Solids}

Daniel et al. (2009b) presents filter flux results obtained at laboratory-scale using a cold (i.e., designated for nonradioactive simulant test materials) CUF filtration system and the engineering-scale using the PEP. Scaling tests examined filtration operations in the membrane-resistance-limited (low-solids scaling tests) and in the cake-resistance-limited regimes (a high-solids scaling test). The low-solids scaling tests were conducted with a 6.9-wt\% UDS waste simulant slurry. The low-solids tests were also intended to condition the filter with the neat simulant. Scale-up comparison for dilute neat PEP simulant operating in a filter membrane-resistance controlled region was facilitated through two tests. These were:

- Low-Solids Scaling Test \#1: A 36-hr low-solids concentration continuous/backpulsed recycle filtration operation, conducted with neat simulant in the PEP and in the CUF.

- Low-Solids Scaling Test \#2: A repeat of the 36-hr low-solids concentration continuous/backpulsed recycle filtration operation, conducted with neat simulant in the PEP and in the CUF.

The high-solids scaling test employed a concentrated $\sim 15-\mathrm{wt} \%$ UDS leached and washed simulant slurry. This slurry was dewatered on both CUF and PEP filtration systems to UDS in excess of $27-\mathrm{wt} \%$. Concentration achieved filtration operations that were cake-resistance limited (as indicated by the presence of a dewatering knee at $\sim 21$-wt\% UDS in both CUF and PEP dewatering curves; see Figure 8.4).

\subsubsection{Summary of Low-Solids Scaling Test Results}

The low-solids scaling tests considered the performance of PEP filtration (as measured through filter flux corrected to standard temperatures and TMPs) against that observed on the CUF test system. A sample result for low-solids scaling test $\# 2$ is shown in Figure 8.1. As indicated in the figure, each low-solids scaling test was comprised of an initial 12-hr run in period, a second 12-hr period during which the filters were backpulsed every 30 minutes, and a final 12-hr run-in period. 


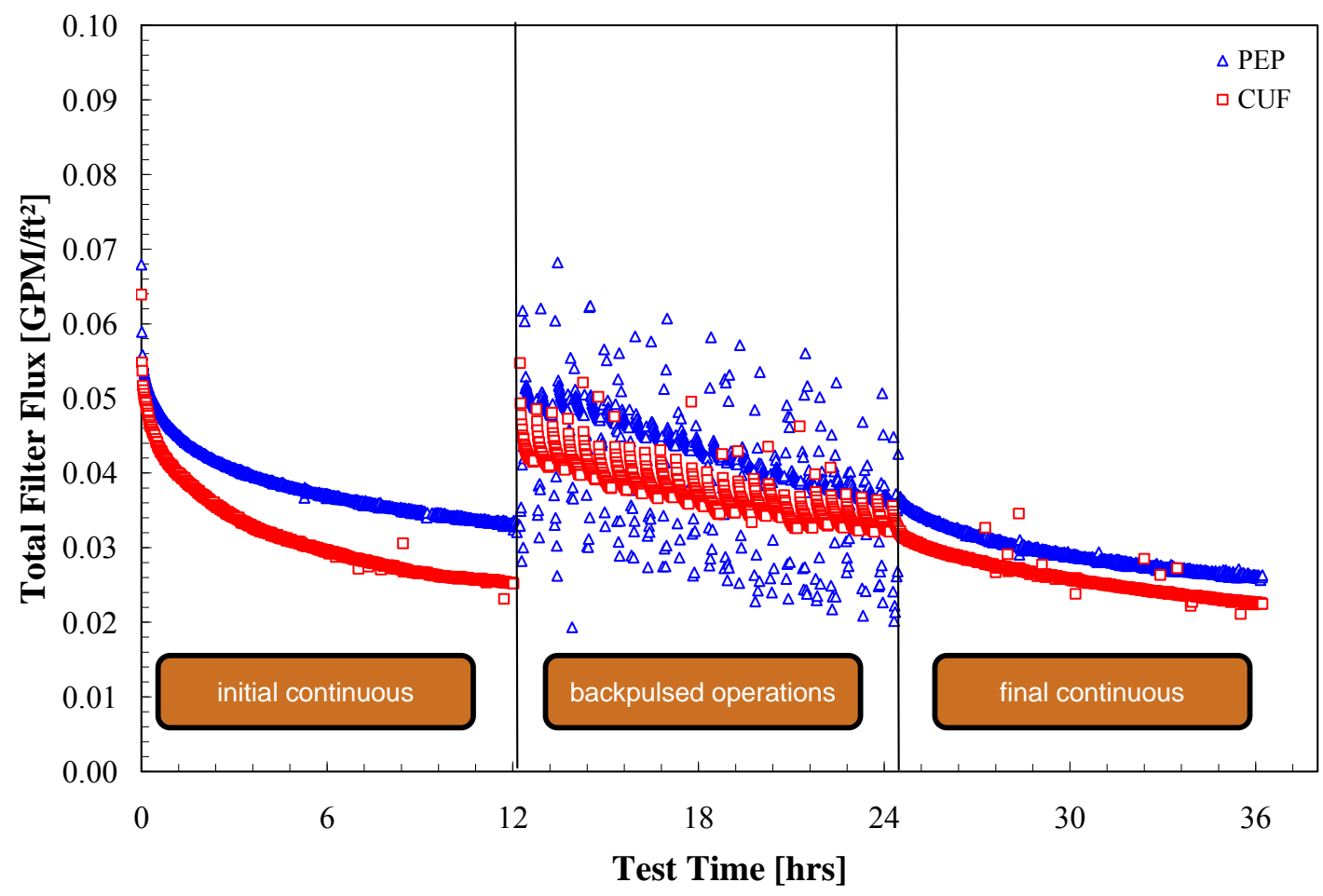

Figure 8.1. A Comparison of PEP Total (area-averaged) Flux to CUF Flux as Measured in Low-Solids Scaling Test \#2

The scaling factor for low-solids testing was defined as the ratio of PEP filter flux to CUF filter flux. Flux results for the low-solids scaling tests indicate that for similarly conditioned filters, the CUF flux is comparable to, but slightly less than, the total (area averaged) flux obtained at PEP. The final filter scaling factors based on total (area-averaged) PEP flux for low-solids tests \#1 and \#2 were both 1.1 \pm 0.1 . To provide a conservative estimate for process scaling, a scaling factor of 1.0 was recommended for scaling low-solids filtration operations. A summary of results for the low-solids scaling tests (and key operational parameters) is included in Table 8.2.

Table 8.2. Results for Low-Solids Scaling Tests

\begin{tabular}{|c|c|c|c|c|}
\hline Item & CUF & PEP & CUF & PEP \\
\hline Test Description & \multicolumn{2}{|c|}{ Low-Solids Test \#1 } & \multicolumn{2}{|c|}{ Low-Solids Test \#2 } \\
\hline Target axial velocity (AV) (ft/s) & 15.0 & $15.0 \pm 1.4$ & 15.0 & $15.0 \pm 1.4$ \\
\hline Actual average AV (ft/s) & $14.9 \pm 0.7$ & 14.8 & $15.0 \pm 0.6$ & 14.8 \\
\hline Target TMP (psid) & 40 & $40 \pm 4$ & 40 & $40 \pm 4$ \\
\hline Actual TMP (psid) & $40.2 \pm 0.8$ & 39.8 & $40.2 \pm 0.4$ & 39.9 \\
\hline Filtration area $\left(\mathrm{ft}^{2}\right)$ & 0.262 & 72.3 & 0.262 & 72.3 \\
\hline Solids-to-filter area ratio $\left(\mathrm{kg} / \mathrm{ft}^{2}\right)$ & 1.5 & 1.1 & 1.4 & 1.4 \\
\hline Flux scaling factor range (S) & \multicolumn{2}{|c|}{1.1 to 1.4} & \multicolumn{2}{|c|}{1.1 to 1.2} \\
\hline Recommended scaling factor & \multicolumn{2}{|c|}{1.0} & \multicolumn{2}{|c|}{1.0} \\
\hline
\end{tabular}


With regard to the alternate goal of filter conditioning, which was to minimize the effects of differences in PEP and CUF filter history by exposing the filter elements to a similar slurry, the conditioning of the filters appears to have been successful from a total (area-averaged) flux standpoint. Specifically, PEP and CUF flux differ substantially (up to 40\%) during the initial run-in period of 12-hrs. In both low-solids scaling tests, a convergence of total filter flux is observed during the second 12-hr period of backpulsed operations, yielding similar CUF and PEP fluxes during the final 12-hrs of operation. Overall, exposure of the filter membrane to slurry solids appears to have reduced potential impacts from differing CUF and PEP histories. However, it should be noted that any flux effects caused by differences in filter history are difficult to distinguish from potential scaling effects. Additionally, frequent backpulsing of the filter appears to be the best driver of filter conditioning. It is speculated that frequent disruption of the protective cake layer allows significant exposure and contact between the filter membrane and slurry solids.

The low-solids scaling test also provided an opportunity to assess the impact of differences in the backpulsing strategies for CUF and PEP on flux recovery. The run report for Functional Testing (Josephson et al., 2009), summarizes the backpulse strategy for PEP as follows:

Backpulsing had five steps, which were automatically controlled:

1. Isolate filters connected to the pulse-pot (close outlet valves).

2. Empty the pulse-pot to a prescribed level.

3. Pressurize the pulse-pot to a prescribed target pressure (40 psi) above the inlet pressure of the filter tubes.

4. Open a fast-acting valve to pressurize the filter shell and cause permeate to flow backwards through the filter until the pulse-pot pressure reached a prescribed target ( 5 psi above inlet pressure on the tube-side of the filter).

5. Open the pulse-pot valves to the permeate system and restart TMP control on the filter shell.

Backpulsing was conducted at 30-minute intervals during hours 12 to 24 of the 36-hr filter conditioning. Execution of backpulsing was operationally easy, being entirely automatic after the operator "initiated" a backpulse.

During the first 12 hours of filter conditioning, all five filters demonstrated approximately the same flux performance. Each filter began with a very high flux that dropped nearly exponentially and then leveled off at a gradual rate of decline. Backpulsing began at the 12-hr mark (shown by random fluxes as data occurred at different points in the backpulse cycle). The 12 hours of backpulsing ended at hour 24, and each filter demonstrated very different behavior than at the beginning of the backpulsing. After backpulsing, filter 1 had a noticeably higher flux than filter 2 , which is higher than filter three, etc. The fundamental cause is presumed to be related to a redistribution of fines that cause depth-fouling, with the fines moving down the flow path from filter 1 to filter 2, etc. It should be noted that during TI-062 the backpulse sequence usually (but not always) was \#2,\#3, \#1, \#4, \#5. The first three filters would be backpulsed rapidly, almost simultaneously. After the backpulse was completed on filters \#2 and \#3 and the permeate level raised in the pulse-pot, filters \#4 and \#5 would be rapidly backpulsed. During TI-032, the sequence was usually $\# 1, \# 2, \# 3, \# 4, \# 5$. 
As discussed in Daniel et al. (2009b), the sequence for backpulsing of the CUF filter element is as follows. First, the backpulse chamber is vented to atmospheric pressure. Next, the toggle valve isolating the backpulse chamber from the permeate collection lines is opened, and permeate is allowed to fill the backpulse chamber. Once the chamber is half full of permeate (as seen from the sight-glass installed on the backpulse chamber), the toggle valve is closed. Next, the permeate in the backpulse chamber is pressurized with 80 psig compressed air. Following pressurization, the backpulse chamber is isolated. Next, the slurry pressure inside the filter is decreased below 20 psig. The toggle valve isolating the backpulse chamber from the shellside of the filter is opened, allowing the pressurized permeate inside the chamber to flow backwards through the filter element. The toggle valve is closed when the permeate level drops below the visible portion of the backpulse chamber sight glass. After the backpulse has been applied to the filter, the backpulse chamber is vented to atmospheric pressure.

As can be seen from these descriptions, backpulsing of CUF and PEP differ significantly in the overpressure employed ( 40 psid for PEP versus $>60$ psid for CUF), in the number of filters backpulsed (single element versus five bundles), and in terms of the filter area backpulsed. It is interesting to note that despite these differences, the flux behavior observed in the total PEP flux and CUF flux during backpulsed operations in Figure 8.1 compare well. Specifically, both CUF and PEP show the similar flux declines (and also exhibit a total area-averaged flux scaling factor of $\sim 1.1$ for backpulsed operations). This suggests that the backpulse strategies employed at both scales yield comparable disruption of any solids cake formed and similar removal of any particles that depth-foul the filter. In both cases, a similar decline in the flux recovered through backpulsing is observed as backpulsed operations progress. Overall, the observed similarity suggests that backpulsed operations scale well and that the "effectiveness" of backpulsing is not impacted by differences in CUF and PEP backpulsing strategies.

It should be noted that this low-solids operations scaling factor estimate is subject to limitations associated with the test. These limitations derive from the following:

- Divergence of filter flux from individual PEP filter bundles - divergence refers to the observation that, downstream PEP filter bundles \#3, \#4, and \#5 appear to foul rapidly relative to upstream filter bundles \#1 and \#2 during backpulsed operations (see Figure 8.2). Divergence is discussed in detail in the paragraphs that follow.

- Differences in the state of PEP and CUF initial filter conditioning - the recommended low-solids scaling factor of 1.0 is based on filter fluxes measured on similarly conditioned filters. When unconditioned filters were employed, scaling factors of $1.4 \pm 0.2$ and $1.2 \pm 0.1$ resulted for first and second low-solids scaling tests, respectively.

- Insufficient process test time to achieve filtration steady-state - for both low-solids scaling tests performed on the PEP and CUF filtration systems, the 12-hr test segments were insufficient to reach a process steady state (or even to assess the existence/value of a steady state flux). The lack of a filtration steady state (and continued decline of filter flux throughout the test) does not appear to impact agreement (and subsequent scaling factor analyses) of total PEP and CUF filter fluxes - the scaling factors observed for conditioned filters in the low-solids scaling tests showed little time-dependence and were close to 1.0. However, continued flux decay throughout the test introduces uncertainty with respect to PEP and CUF scaling over time frames longer than those tested. 
Flux divergence was observed in both low-solids scaling tests. The mechanism for flux divergence across filter bundles in the low-solids scaling tests is not currently understood. The three primary characteristics of the divergence are:

- Significant (noticeable) flux divergence appears to only occur during backpulsed operation of the filter bundles.

- Only the performance of the downstream filter bundles are strongly impacted during the course of the current tests.

- For affected filters, backpulsing does not restore the loss in filter flux - any recovery is typical of that associated with cake disruption (see filter bundle 3 in Figure 8.2).

A number of potential causes for the flux divergence during backpulsed operations can be proposed based on these observations. First, it can be speculated that the divergence results from irreversible depth-fouling of the porous filter element with fine particulate slurry solids. This depth-fouling occurs shortly after each backpulse during the interim period between filter cake disruption and reformation when the filter surface is exposed. For a single backpulse event, the degree of depth-fouling may not be significant enough to observe. However, given repeated backpulsing (such as that done in the second period of operation), the incremental impact of depth-fouling becomes apparent. Under this mechanism, depth-fouling would not occur during continuous non-backpulsed operations because the filter cake forms a protective surface, which reduces the opportunity for fines to reach the porous filter membrane.

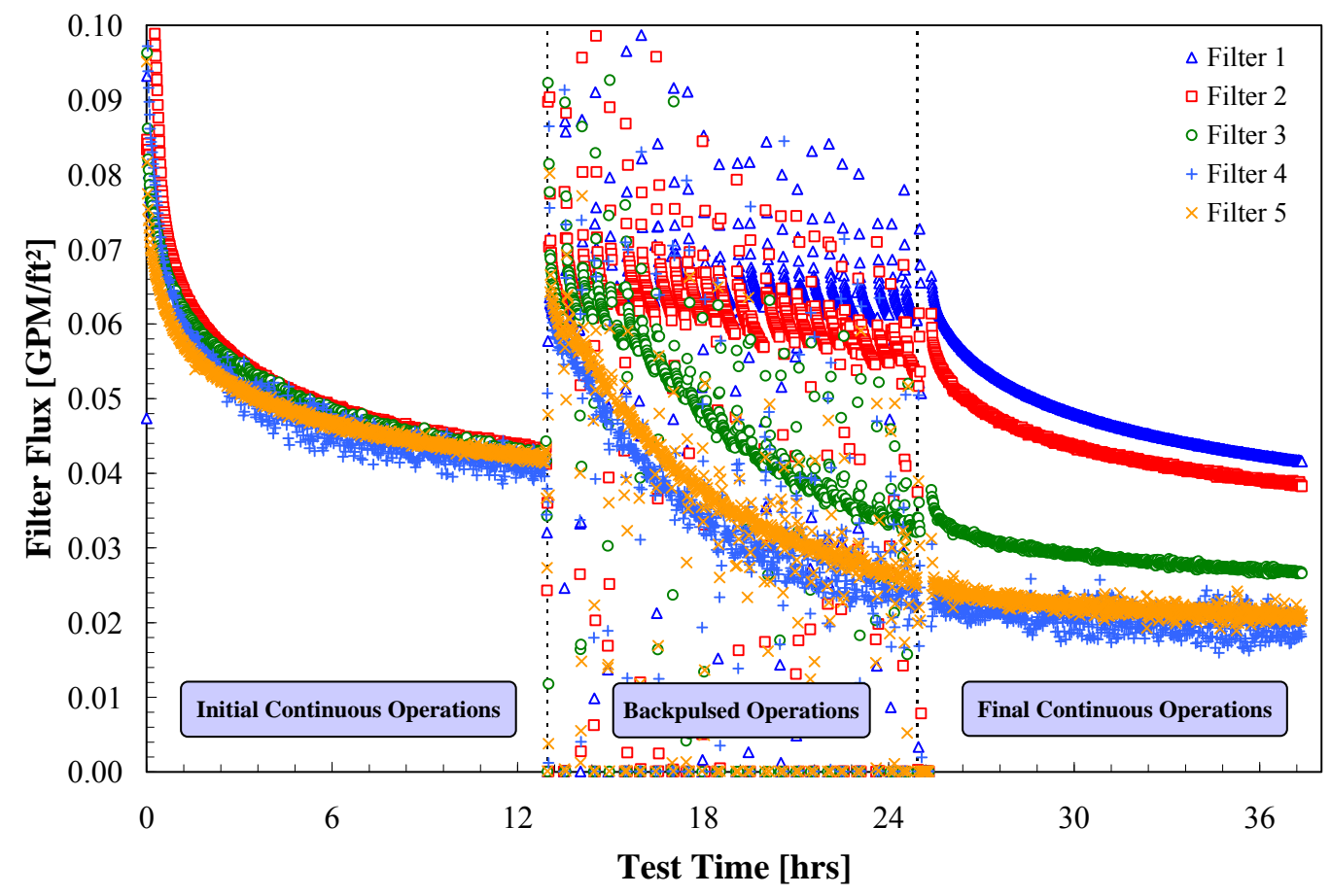

Figure 8.2. Individual Permeate Flux for PEP Filters (corrected for variation in TMP and temperature) During Low-Solids Scaling Test \#1

While the depth-fouling mechanism outlined in the preceding paragraph explains flux decline for individual filters, it does not explain why only the downstream filters would be affected. It can be 
speculated that the downstream filters are observing "downstream" fines that have been collected on and subsequently released from (as a result of backpulsing) upstream filter bundles. Such a mechanism would be believable if 1 ) the slurry residence time in the filter-loop were near to or greater than the period of time between the backpulsing of each bundle, and 2) the filters were backpulsed in order (i.e., one through five).

For low-solids scaling test \#1, filter bundles one, two, and three were backpulsed within a one minute of each other, and then filters 4 and 5 were backpulsed as soon as the pulse-pots refilled (estimated to be two to eight minutes after the backpulse of filters one through three). As such, the time between backpulsing of the upstream bundles and downstream bundles ( two to eight minutes) is much larger than the residence time of the slurry in the filter-loop ( $\sim 45$ seconds $)$. This means that fines released from upstream filter bundle cake disruption should have sufficient time to adequately disperse through the loop and Tank T02A before backpulsing of the downstream filters. However, the backpulsing order in Low-Solids Test \#2 was switched during testing such that the downstream filters were backpulsed first and the upstream filters were backpulsed two to nine minutes later. If dispersed fines released during backpulsing were the cause of the irrecoverable flux loss, then the switching of the backpulse order should have evidenced a decline in the upstream filter flux in Low-Solids Test \#2 (which was not observed).

Additionally, flux loss could result from an immediate downstream effect (where fines dispersed immediately foul the downstream filter at the time of backpulsing). However, if an immediately downstream effect were the cause of flux divergence, then it is expected that filter three (which is immediately downstream of two backpulsed filters and is disrupted at the same time as the upstream filters) would be the most likely candidate for strong fouling. As shown by the test results, this is not the case.

Another potential mechanism for flux divergence relies on fines depletion. That is, fines capable of fouling the filter elements could become trapped in the filter cake during continuous backpulse operations. In this case, ordered backpulsing of the filters (with the upstream filters being backpulsed first) would release these fines back into the slurry facilitating filter-fouling. However, because of the residence time, the fines would be available for fouling only after they are remixed into the slurry in Tank T02A. If the time required to remix the fines ( one to two minutes) is less than the time it takes to reform a protective cake layer, then the upstream filters would not foul. In contrast, downstream filters would be backpulsed just as the fines completed mixing and were returned to the filter-loop. As such, the remixed fines would have access to the downstream filter surface and porous substructure during backpulsing, facilitating significant fouling of the downstream filters. However, if this mechanism were correct, then irrecoverable losses on upstream filters would be expected in instances where the backpulse order was switched (Low-Solids Scaling Test \#2). This is not the case.

Thus, several mechanisms can be proposed to account for irrecoverable loss of filter flux during backpulsed operations in the low-solids scaling test, but these mechanisms do not account for the divergence of filter flux given the PEP operating conditions. Moreover, the current PEP and/or CUF filter flux data reported herein are not sufficient to identify and validate which of these proposed mechanisms (if any) are correct. The mechanisms outlined above focus on fouling with particulate matter; however, given the presence of entrained air in many other PEP operations, and also given that backpulsing operations sometimes completely drained the pulse-pots of permeate, it is possible that air entrainment in the filters may have occurred. Captive threads of air could potentially block filter pores, causing a loss of 
permeate production. If air entrapment were caused by low pulse-pot levels, the downstream filters would be more strongly subject to these effects given that the filters share pulse-pots and are subject to low levels more often because two separate filters are backpulsed in close succession.

With regard to filter scaling, divergence does not appear to impact agreement between PEP total (area-averaged) flux and CUF flux. However, because divergence was not expected and is currently not understood, additional testing beyond the scope of the low-solids scaling tests was recommended to further identify, revise, and/or validate the mechanisms for the filter flux divergence and their impact on filter flux scaling.

\subsubsection{Summary of High-Solids Scaling Test Results}

A high-solids filter flux test was conducted following completion of Integrated Test B activities. Briefly, this test combined leached solids from Integrated Test A with those from Integrated Test B, and the combined slurry was further concentrated. The goal of this test was to assess scaling effects that exist between PEP engineering-scale filtration operations and CUF laboratory-scale filtration operations in the solids-cake-limited filtration regime. To this end, PEP operations were replicated on the CUF filtration system located at the Applied Process and Engineering Laboratory using a sub-aliquot of the leached and washed simulant slurry employed in PEP. Both CUF and PEP used this slurry to evaluate dewatering over slurry UDS concentrations spanning $15-\mathrm{wt} \%$ to $25-\mathrm{wt} \%$ (and beyond). Detailed results and analysis for this high-solids filter test are provided in Daniel et al. (2009b). A brief summary is given in the following paragraphs.

The dependence of the overall filter resistance on slurry solids concentration is key for assessing the dewatering behavior. A typical dependence observed during dewatering operation of Hanford tank waste simulants is shown in Figure 8.3. For dilute slurries and when turbulent flow conditions exist, the filter resistance is usually constant and characterized by the resistance of the porous filter element $\left(R_{m}\right)$ such that:

$$
J \sim \frac{\Delta P_{m}}{\mu_{\text {permeate }} R_{m}}
$$

At the higher slurry solids concentrations that occur during washing and dewatering operations, the filter cake resistance plays a more significant role in determining filter flux. The filter cake resistance is dependent on system operational properties like AV. Treatment of filtration data against the Darcy equation is complicated by the need to account for the dependence of filter cake resistance on AV and slurry concentration. Ultimately, the slurry can only be dewatered to a maximum UDS concentration limit at a given TMP. This limiting concentration is known as the gel concentration and is typically similar to a slurry's centrifuged solids concentration. As the simulant slurry's solid concentration approaches the gel concentration, the filter flux can be described as:

$$
J=k \cdot \ln \left[\frac{C_{s}}{C_{g}}\right]
$$


where $C_{s}$ is the slurry UDS concentration, $C_{g}$ is the slurry gel concentration at a given TMP, and $k$ is the constant for a given TMP and AV (note that $\mathrm{k}$ is a negative value and is typically termed the "mass transfer coefficient).

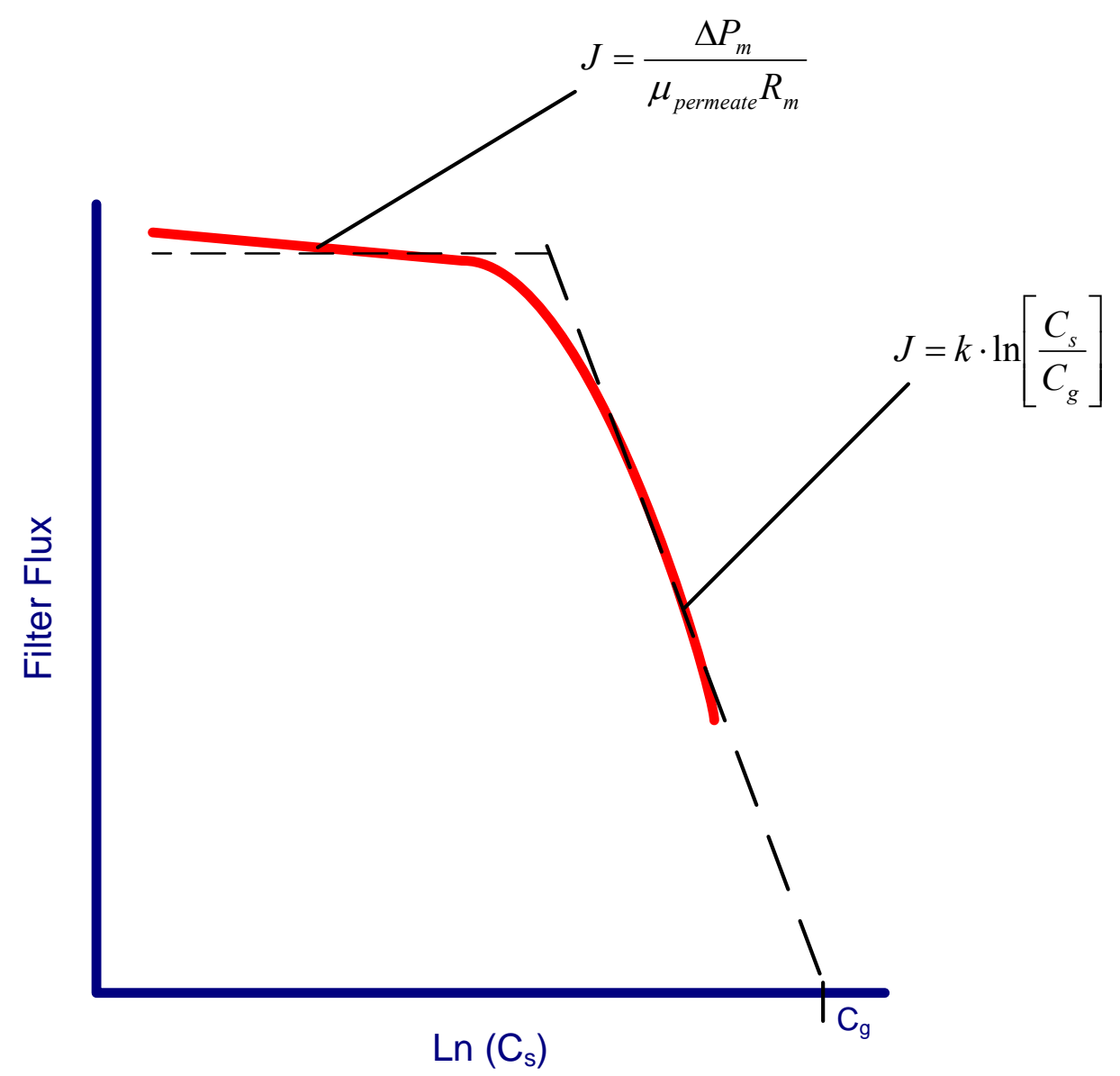

Figure 8.3. Typical Filter Flux Behavior as a Function of Solids Concentration

The CUF and PEP dewatering curves are shown in Figure 8.4. Here, filter flux has been corrected for deviations in temperature (from $25^{\circ} \mathrm{C}$ ) and TMP (from 40 psid). All curves evidence a slope discontinuity ranged from $21.2-$ to $21.7-\mathrm{wt} \%$ that is indicative of a transition from filter membrane resistance limited to cake resistance limited filtration. In the filter resistance limited regime $(<21-\mathrm{wt} \%)$, the filter flux exhibits differences between PEP and CUF that are suspected to result from differences in filter history. These differences are expected because the CUF filter was cleaned immediately before the initial high-solids filter test while at the start of PEP high-solids testing, the PEP filters had not been cleaned since the start of Integrated Test B operations and had seen significant filtration time. Filter flux at concentrations below $21-\mathrm{wt} \%$ also show decline that is likely associated with filter-fouling.

Filter flux at concentrations higher than 21.7-wt\% appear to follow the behavior expected of cake resistance limited filtration. For CUF, flux declines are relatively linear with the logarithm of UDS concentration (as shown by the fits of the gel polarization model to the results) up to $27-\mathrm{wt} \%$ UDS. It is speculated that the non-linearity in the CUF dewatering curves at concentrations higher than $27-w t \%$ result from temperature deviations and inability to meet the increased pumping requirements dictated by 
the high APD. For the PEP dewatering curve, the curve beyond $21.7-w t \%$ is generally log-linear, but shows slight deviations near $21.7-\mathrm{wt} \%$ and from $25-\mathrm{wt} \%$ to $27-\mathrm{wt} \%$. These deviations are associated with variations in both filter AV and slurry temperatures deviations not fully accounted for by the flux correction equations.

Overall, the filter flux curves for PEP and CUF compare well over 21- to $27-w \mathrm{t} \%$. The dewatering curves show similar slope and tend toward a similar UDS axis intercept. While the PEP and CUF curves do not fall on top of one another, the differences in absolute filter flux can be attributed to differences in the filter history between CUF and PEP.

High-solids scaling factor analysis considered scaling in terms of the parameters characterizing filtration dewatering performance at concentrations approaching the limiting gel concentration, which is the maximum solids concentration achievable through dewatering and is functionally similar to the concentration achievable in a layer of settled/centrifuged solids. These parameters are the dewatering mass transfer coefficient $(k)$ and the slurry limiting gel concentration $\left(C_{g}\right)$. Two separate scaling factors were defined - the first is the ratio of PEP $k$ to CUF $k$, and the second is the ratio of PEP $C_{g}$ to CUF $C_{g}$. The high-solids dewatering curves are analyzed using a gel-polarization model to determine the best fit values of $k$ and $C_{g}$. The results of this analysis are shown in the gel-polarization equation fits in the upper-right-hand corner of Figure 8.4. These results form the basis of the scaling factor analysis for high-solids dewatering operations.

Analysis of PEP and CUF high-solids dewatering curves indicates scaling factors of $0.97 \pm 0.03$ and $0.96 \pm 0.05$ for both $k$ and $C_{g}$, respectively. These results indicate that the high-solids filtration performance CUF and PEP are indistinguishable from one another. Based on the best information currently available, the scaling factor for high-solids dewatering operations appears to be one. That is, CUF appears to provide an accurate indication of PEP filter flux performance during high-solids dewatering operations approaching the gel point. A summary of results for the high-solids scaling test (and key operational parameters) is included in Table 8.3.

Table 8.3. Results for High-Solids Scaling Test

\begin{tabular}{l|cc}
\hline Item & CUF & PEP \\
\hline Test Description & \multicolumn{2}{|c}{ High Solids Test } \\
\hline Target AV $(\mathrm{ft} / \mathrm{s})$ & 15.0 & $15.0 \pm 1.4$ \\
Actual average AV $(\mathrm{ft} / \mathrm{s})$ & $15.0 \pm 0.1$ & 14.7 \\
Target TMP $(\mathrm{psid})$ & 40 & $40 \pm 4$ \\
Actual TMP $(\mathrm{psid})$ & $41 \pm 1$ & 39.8 \\
Filtration area $\left(\mathrm{ft}^{2}\right)$ & 0.262 & 15.7 \\
Solids-to-filter area ratio $\left(\mathrm{kg} / \mathrm{ft}^{2}\right)$ & 14.5 & 13.9 \\
Dewatering mass transfer coefficient $\left(\mathrm{GPM} / \mathrm{ft}^{2}\right)$ & $-0.112 \pm 0.001$ & $-0.108 \pm 0.003$ \\
Limiting gel concentration $(\mathrm{wt} \%)$ & $35.7 \pm 0.5$ & $34.3 \pm 1.9$ \\
Mass transfer scaling factor $\left(\mathrm{S}_{\mathrm{k}}\right)$ & \multicolumn{2}{|c}{$0.97 \pm 0.03$} \\
Limit gel concentration scaling factor $\left(\mathrm{S}_{\mathrm{g}}\right)$ & \multicolumn{2}{|c}{$0.96 \pm 0.05$} \\
Recommended scaling factor & \multicolumn{2}{|c}{1.0} \\
\hline
\end{tabular}




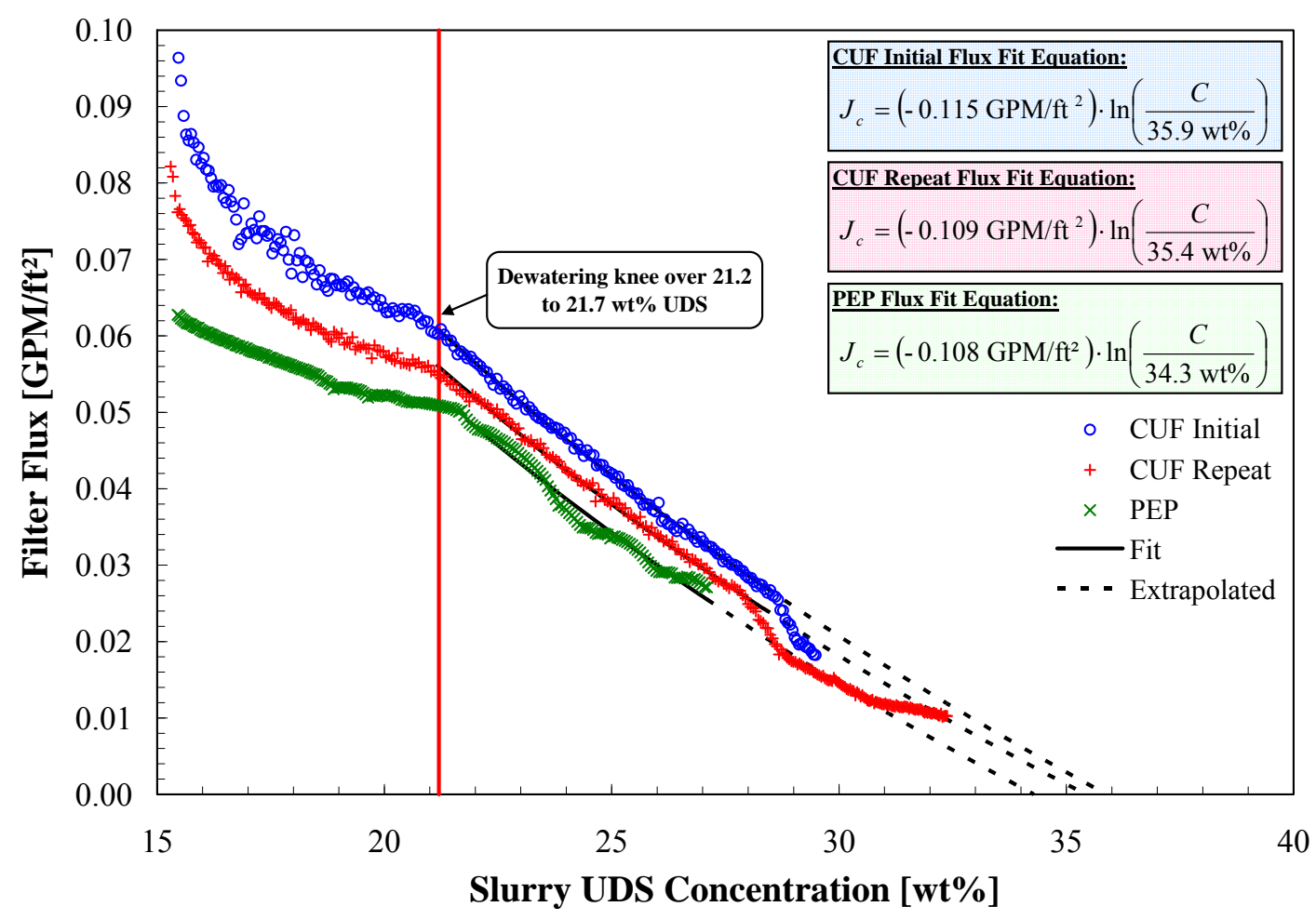

Figure 8.4. Summary of PEP and CUF Dewatering Curves for the High-Solids Filter Tests Performed at the End of Integrated Test B Operations

\subsection{Integrated Test A}

Integrated Test A included five filtration operations considered in this section. These were:

- Post-Caustic-Leach Concentration. A caustic leached slurry was dewatered from $2-w t \%$ to $17-w t \%$ UDS using only filter bundle \#1.

- $\quad$ Post-Caustic-Leach Wash. The caustic-leached and concentrated slurry was washed, reducing the DS from $\sim 27-\mathrm{wt} \%$ to $\sim 1-\mathrm{wt} \%$.

- $\quad$ Post-Chromium Solids Concentration and Wash. Following addition of a slurry of chromium solids slurry to the post-caustic-leach washed slurry, the slurry was dewatered and washed with IW.

- $\quad$ Post-Oxidative-Leach Wash. After oxidative leaching, the slurry was washed with IW, reducing the DS from $2.6-\mathrm{wt} \%$ to $0.1-\mathrm{wt} \%$.

- $\quad$ Post-Oxidative-Leach Concentration. After oxidative leaching and washing, the slurry dewatering operation concentrated the slurry to 20 -wt $\%$ UDS. 


\subsubsection{Post-Caustic-Leach Concentration}

Integrated Test A post-caustic-leach concentration was intended to concentrate a caustic-leached slurry to $17-\mathrm{wt} \%$ UDS. Concentration of caustic-leached slurry was accompanied by batch transfer of leached slurry from Tanks T01A and T01B. Filtration operations were carried-out using filter bundle one.

During Integrated Test A post-caustic-leach concentration operations, a series of backpulses were performed in an attempt to improve filtration rates and investigate backpulsing effectiveness. These backpulses were conducted over a period starting on February 5 and ending on February 14, 2009. For the current analysis and discussion, these backpulses are presented as 38 separate backpulse events performed on UFP-FILT-T01A. The sequence of events for each backpulse was typically as follows:

1. Permeate collection was stopped.

2. The pulse-pot was drained to the target pulse level (typically around 10 inches).

3. The pulse-pot was charged to the target overpressure, defined as the difference between pulse-pot pressure and filter inlet pressure.

4. The fast-acting valve between the pulse-pot and filter was opened, allowing the high pressure in the pulse-pot to pressurize the filter shell and force a small amount of the liquid in the filter shell backward through the filter elements.

5. When the pressure inside the pulse-pot was reduced to the target deadband pressure, the fast-acting valve was closed.

6. The permeate valve was opened and permeate production resumed.

Backpulses typically used an overpressure target of 40 psid, but overpressures from $\sim 20$ psid to $\sim 60$ psid were tested. A summary of backpulse operations conducted during Integrated Test A and an assessment of their effectiveness is provided in Appendix B. With only a few exceptions, the backpulsing schedule as employed for Integrated Test A appears to have effectively increased the local filter flux, as the effectiveness (or percent increase in filtrate produced as a result of each backpulse) is generally around $10 \%$ or greater. The results also indicate that a single backpulse is effective in restoring filter flux and that multiple backpulses (performed in quick succession) do not provide any additional recovery in filter flux. Finally, comparison of backpulses performed at different overpressures indicate no difference in recovered flux. As such, all overpressures employed for backpulsing appear to have disrupted the filter cake and removed depth-fouled solids to similar extents.

Figure 8.5 compares the measured UDS values to those predicted by the calculated mass balance. A final UDS concentration of $17-w t \%$ was obtained. The UDS concentration progression is non-linear as a result of the significant number of batch transfers, backpulsing, and long filtration time. Figure 8.6 shows the temperature- (to $25^{\circ} \mathrm{C}$ ) and TMP- (to $40 \mathrm{psid}$ ) corrected filter flux measured during the post-caustic-leach concentration. As the result of the backpulsing regimen employed for testing, the flux shows a repeated recovery and decline. This is accompanied by a gradual decline in both average filter flux and flux recovered after backpulsing and is indicative of either a weak UDS dependence or filter depth-fouling. The overall decline in flux is does not appear to occur uniformly with time. A strong localized flux decline occurs on $2 / 8 / 2009$. This decline could be associated with the relatively frequent backpulsing (similar to the flux divergence observed in the low-solids scaling test). It could result from a 
downward trend in flux obscured by frequent backpulsing prior to the drop (i.e., every three to four hours) followed by the relatively long filtration period (10 hours) during which the decline was noted. Given the variability in period of time between backpulses and accompanying batch transfers, it is difficult to determine if the decline observed on 2/8/2009 is significant.

The flux as a function of wt $\%$ UDS is shown in Figure 8.7. Trends in corrected filter flux with UDS are obscured by repeated backpulsing and batch transfers. However, Figure 8.7 does not evidence a dewatering knee, and as such, filter operations are likely filter resistance limited.

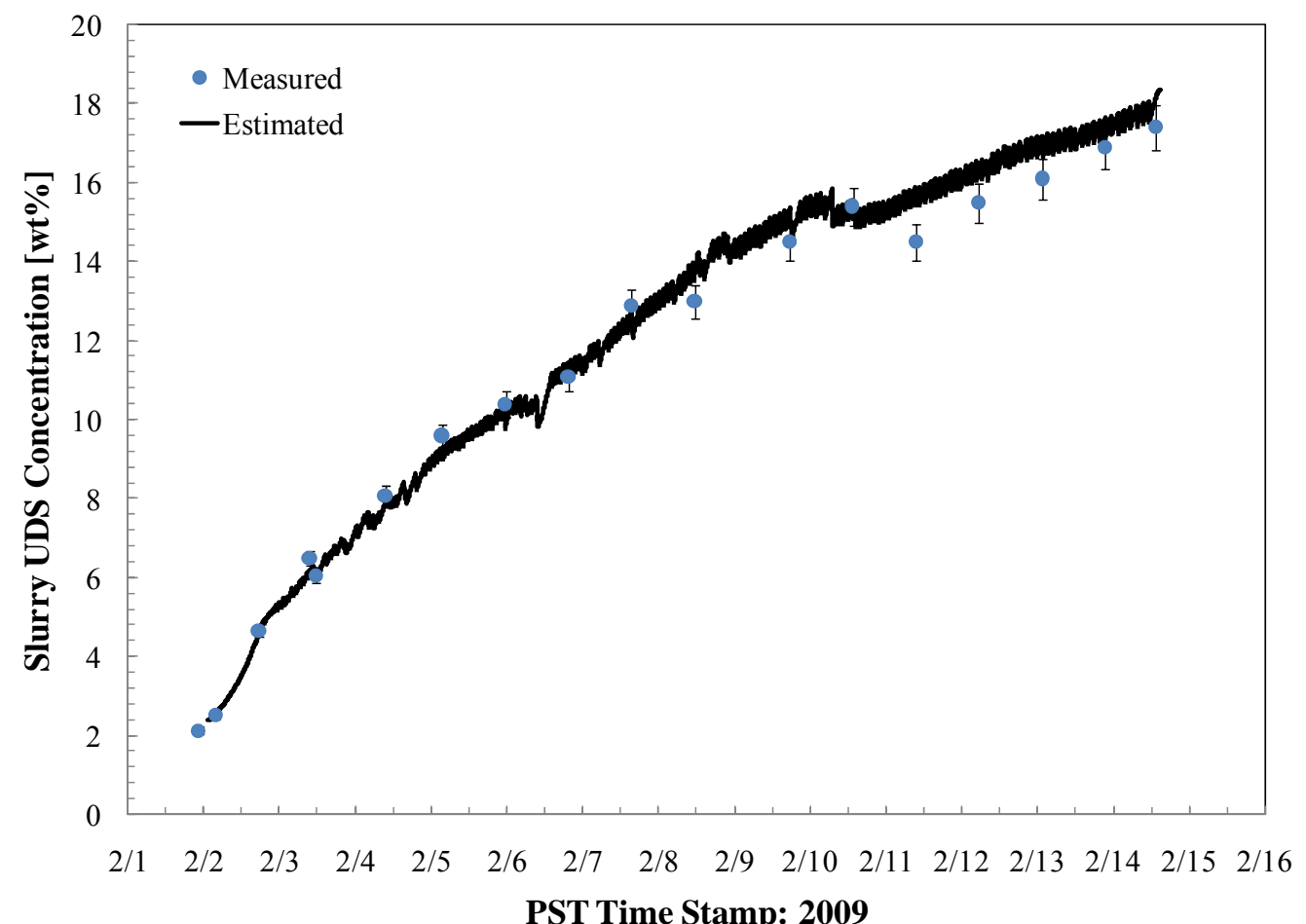

Figure 8.5. Comparison of Measured to Calculated UDS During Integrated Test A Post-Caustic-Leach Concentration 


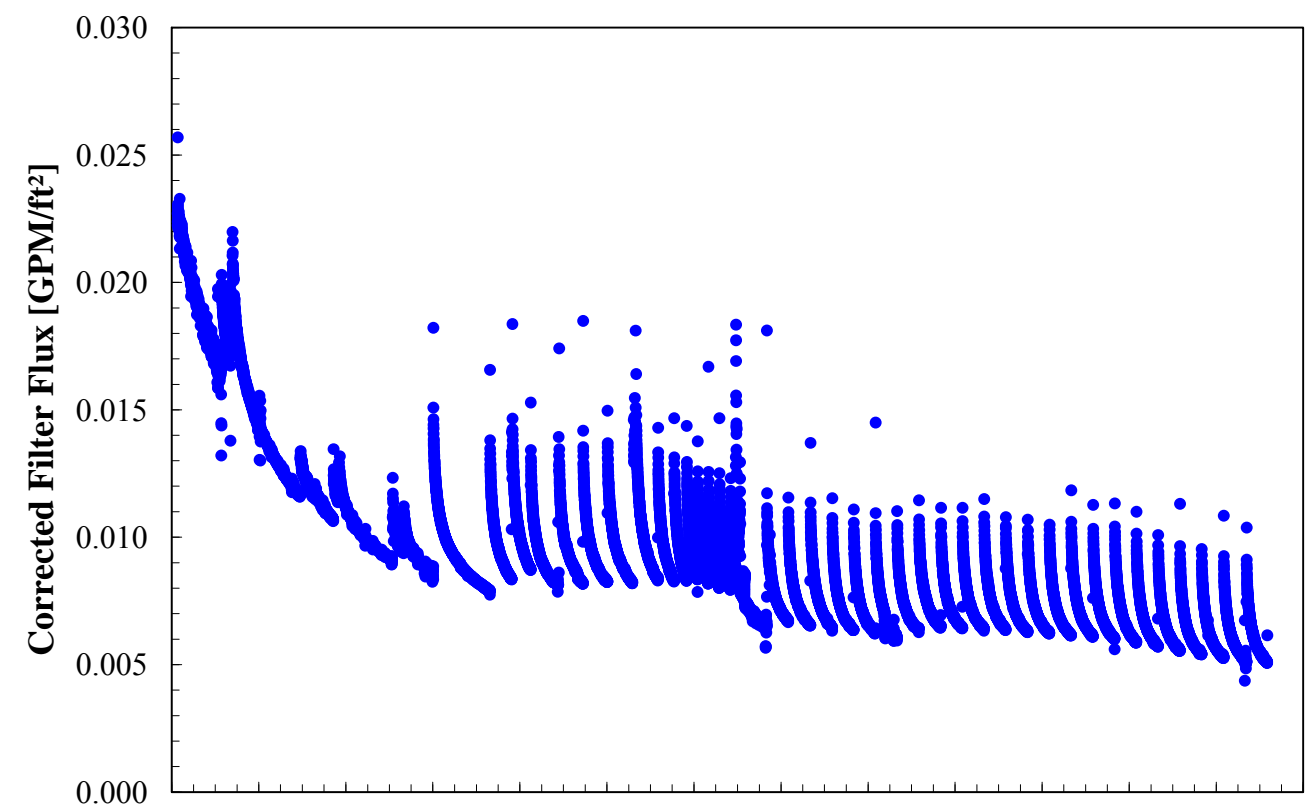

$\begin{array}{llllllllllllllllllll}02 / 02 & 02 / 03 & 02 / 04 & 02 / 05 & 02 / 06 & 02 / 07 & 02 / 08 & 02 / 09 & 02 / 10 & 02 / 11 & 02 / 12 & 02 / 13 & 02 / 15\end{array}$

PST Time Stamp

Figure 8.6. Filter \#1 Flux (corrected for TMP and temperature variations) for Integrated Test A Post-Caustic-Leach Concentration as a Function of Time

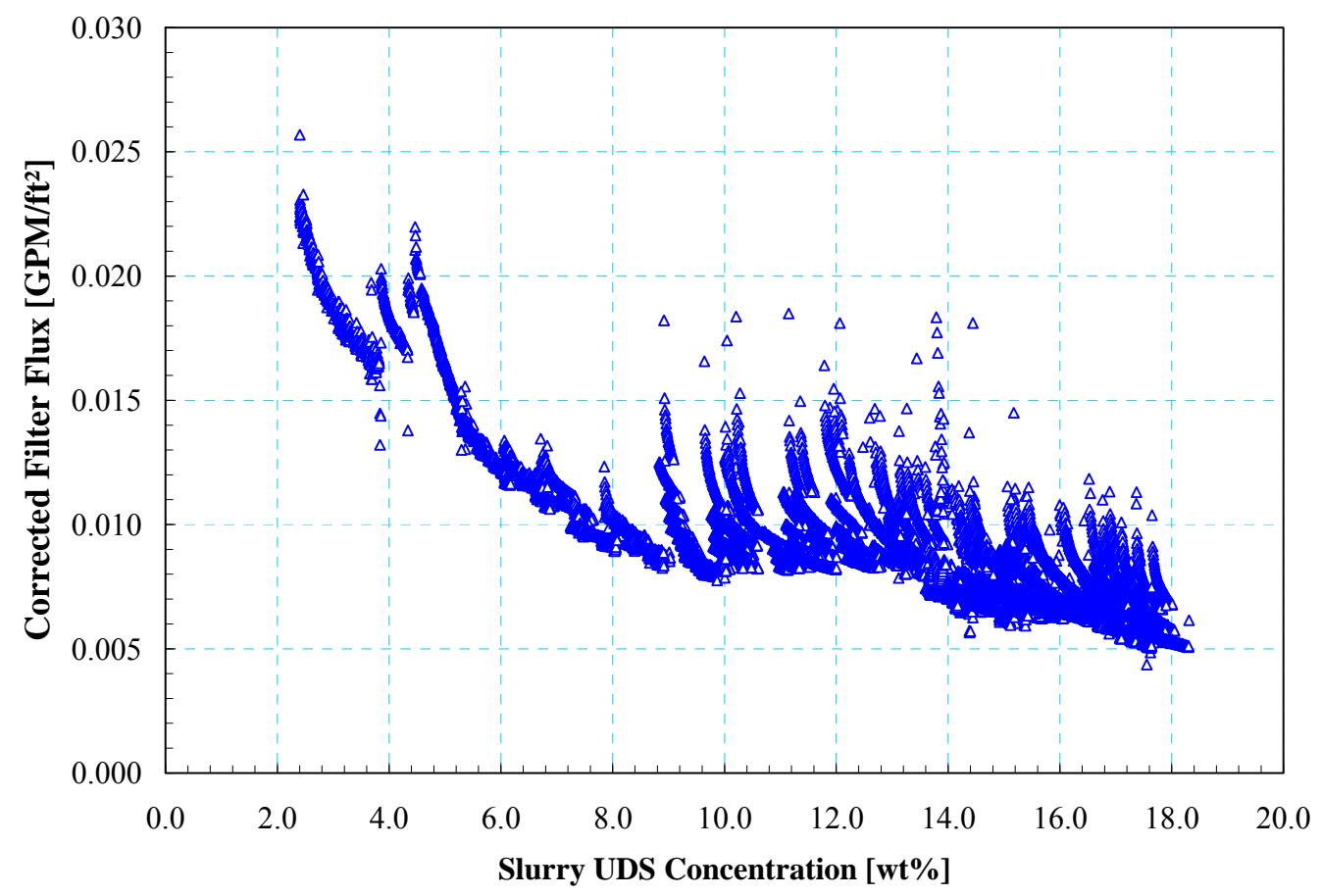

Figure 8.7. Corrected Filter \#1 Flux for Integrated Test A Post-Caustic-Leach Concentration as a Function of Slurry UDS 


\subsubsection{Post-Caustic-Leach Wash}

The post-caustic-leach slurry was washed with IW to remove soluble solids. Specific solids washing operational parameters and objectives are discussed in Section 10. The wash was conducted using five filter bundles. With five filters, the duration of this process step in the PEP should have been only 1/4.5 times its duration (with similar filter histories and the same slurry) in the PTF. As explained in Section 3, this was done to match the (permeate generation rate)/(mixing rate) of the PTF. Filter-loop flow rate problems were observed during post-caustic-leach washing. These problems were a result of entrainment of air in the slurry.

Figure 8.8 compares the measured DS values to those predicted by the calculated mass balance. Predicted values form the basis for continuous filter flux calculations during washing operations. After the initial drop in dissolved solids at $0150 \mathrm{hrs}$, filtration was halted due to low filter-loop flow rates caused by air entrainment and not restarted until $\sim 1600 \mathrm{hrs.} \mathrm{No} \mathrm{other} \mathrm{discontinuities} \mathrm{were} \mathrm{observed} \mathrm{in}$ the DS concentration vs. time curve, with the exception of a 20 minute segment beginning at $1759 \mathrm{hrs}$. During this time, filtration was paused for operations crew shift turnover, then restarted. Washing reduced the dissolved solids concentration from $\sim 27-\mathrm{wt} \%$ to $\sim 1-\mathrm{wt} \%$.

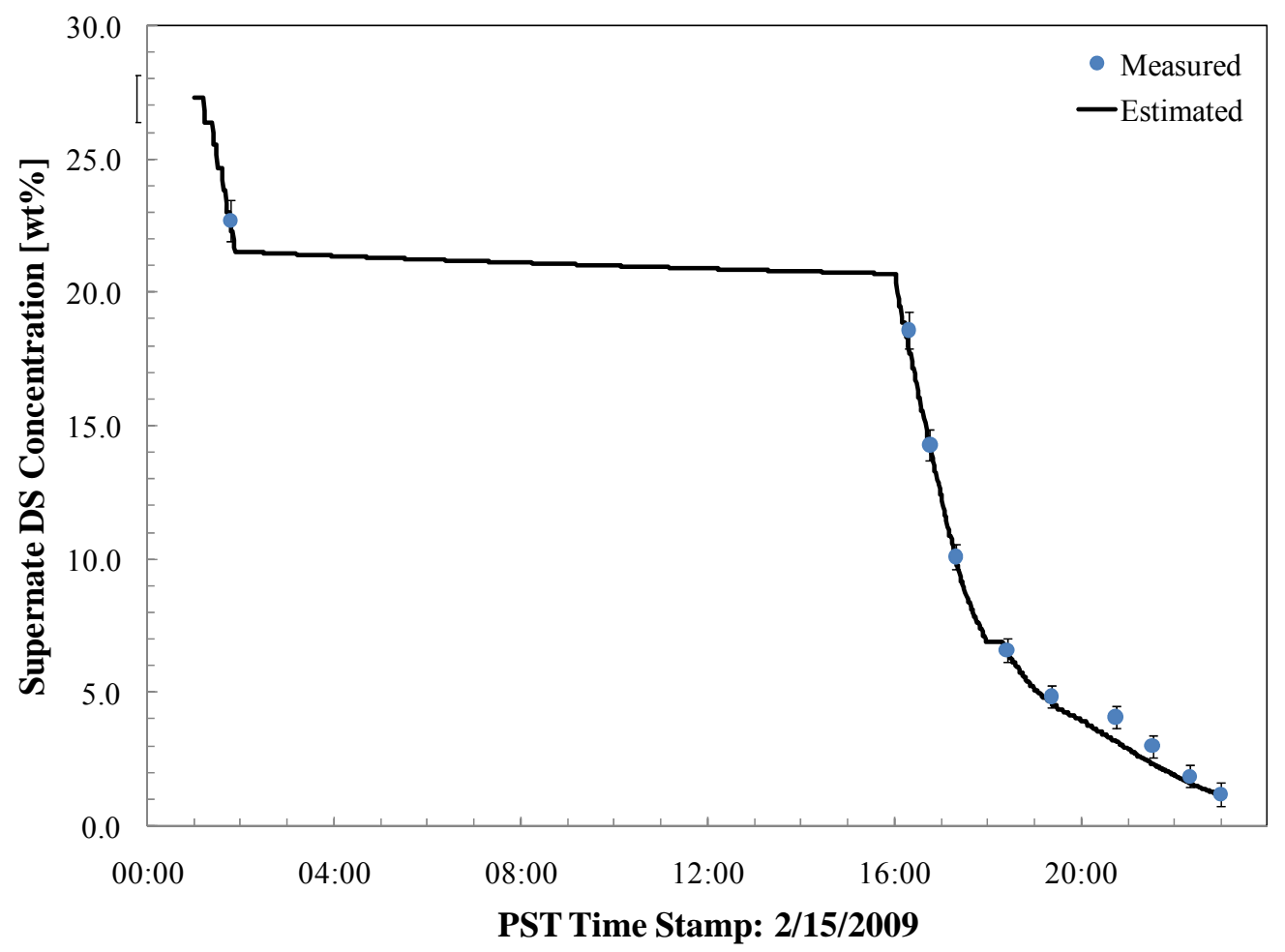

Figure 8.8. Comparison of Measured to Calculated DS During Integrated Test A Leached Slurry Washing

Figure 8.9 shows the total temperature- (to $25^{\circ} \mathrm{C}$ ) and TMP- (to 40 psid) corrected filter flux measured during the post-caustic-leach wash. The filter flux is the area-averaged (total) flux across all filter bundles. The long pause in filtration from 0150 to $1600 \mathrm{hrs}$ corresponds to the filtration stoppage described above. Over 1600 to $2300 \mathrm{hrs,} \mathrm{filter} \mathrm{flux} \mathrm{shows} \mathrm{significant} \mathrm{oscillation} \mathrm{characterized} \mathrm{by} \mathrm{an}$ 
initial rapid increase in flux followed by a rapid decrease and subsequent recovery. It is speculated that this oscillation is associated with air entrainment in the slurry. Flux loss could result from trapping of air bubbles in the filter membranes, which would effectively foul/block the filter pores and decrease overall filtration performance. The phenomena impacted all filters, as oscillation is observed in the individual filter flux for all five bundles (see Figure 8.10). It should be noted that oscillations were not observed in post-caustic-leach wash fluxes in Integrated Test B; however, Integrated Test D flux did show some minor oscillation toward the end of the washing operation. While air entrainment is also a suspected cause of Integrated Test D flux oscillation, low filter AV were also present during the Integrated Test D oscillations.

Figure 8.11 presents the corrected flux as a function of supernate DS concentration. Addition of IW yielded significant increases in filter flux between $10-\mathrm{wt} \%$ and $26-\mathrm{wt} \%$ dissolved solids. At lower dissolved solids concentrations, the pump complications may obscure flux trends associated with solely the change in dissolved solids concentrations. Post-caustic-leach washing operations for Integrated Tests B and D indicate minimal increase in flux with DS reductions below $\sim 10$-wt $\%$ DS. During washing operations, reduction of the dissolved solids content corresponds to a decrease in permeate viscosity from $\sim 4 \mathrm{cP}$ at the start of washing to $\sim 1 \mathrm{cP}$ at the end of washing. The increase in flux from $\sim 0.02 \mathrm{GPM} / \mathrm{ft}^{2}$ to $\sim 0.06 \mathrm{GPM} / \mathrm{ft}^{2}$ does not fully reflect the increase expected from a $4 \mathrm{x}$ reduction in permeate viscosity. This supports speculation that permeate production is hindered, either by air entrapment or possibly fouling of filter.

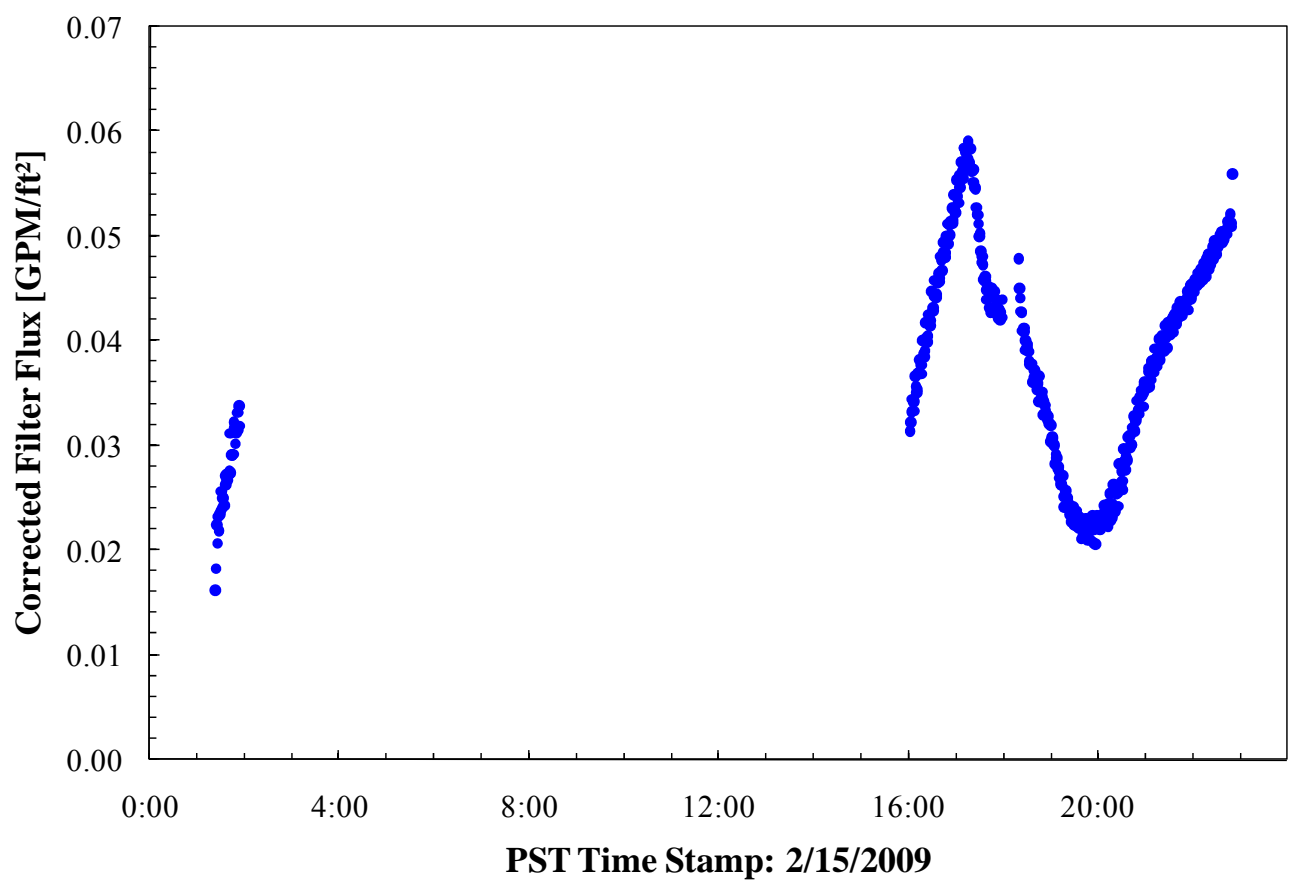

Figure 8.9. Total Filter Flux (corrected for TMP and temperature variations) for Integrated Test A Leached Slurry Washing as a Function of Time 


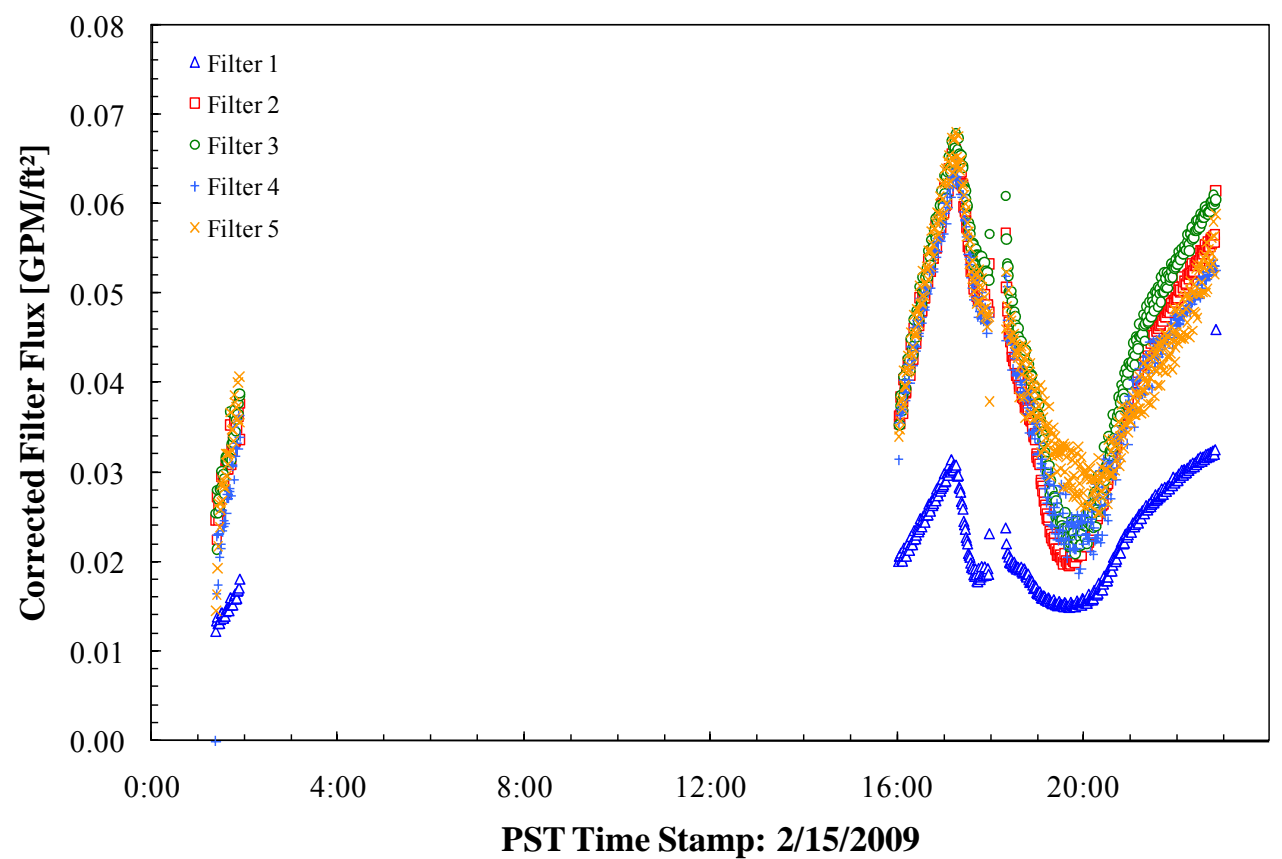

Figure 8.10. Individual Filter Flux (corrected for TMP and temperature variations) for Integrated Test A Leached Slurry Washing as a Function of Time (showing oscillation on all 5 filter bundles)

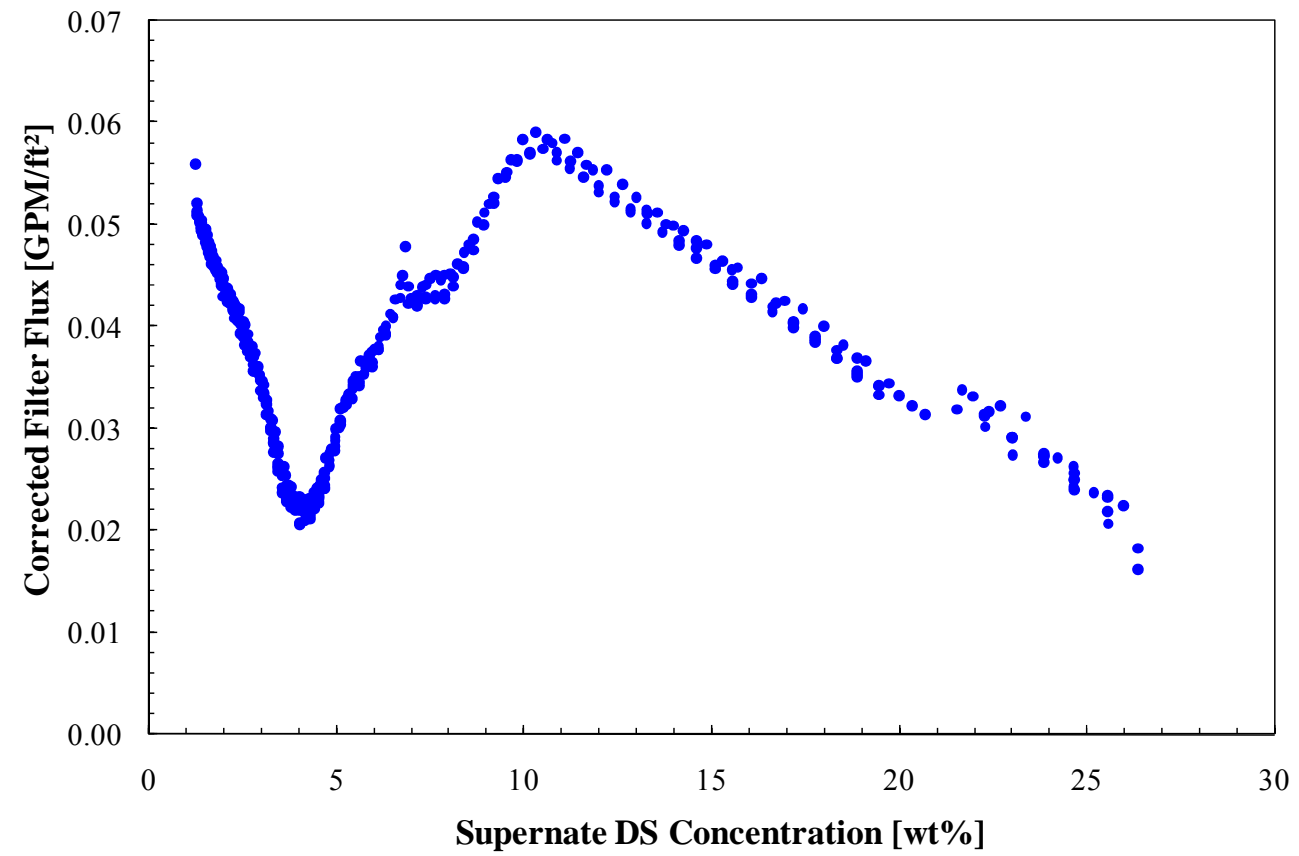

Figure 8.11. Total Filter Flux (corrected for TMP and temperature variations) for Integrated Test A Leached Slurry Washing as a Function of Supernate DS Concentration 


\subsubsection{Post-Chromium Slurry Addition Concentration and Wash}

Before Integrated Test A oxidative-leach operations, a chromium solids slurry was added to the post-caustic-leach washed slurry. Excess liquid introduced with the chromium solids was removed with all five ultrafilter bundles. After dewatering, additional solids washing was performed. No mass balance on these operations could be performed because insufficient analytical samples were taken.

\subsubsection{Post-Oxidative-Leach Wash}

After oxidative leaching, the slurry was washed with IW. Washing operations employed all five filter bundles and as such, the duration of this process step in the PEP is $\sim 1 / 4.5$ times its expected duration in the PTF. A mass balance was used to estimate the DS as shown in Figure 8.12 and was performed to facilitate calculation of filter flux. Washing operations reduced the DS from $\sim 3-w t \%$ to $\sim 0.1-w t \%$.

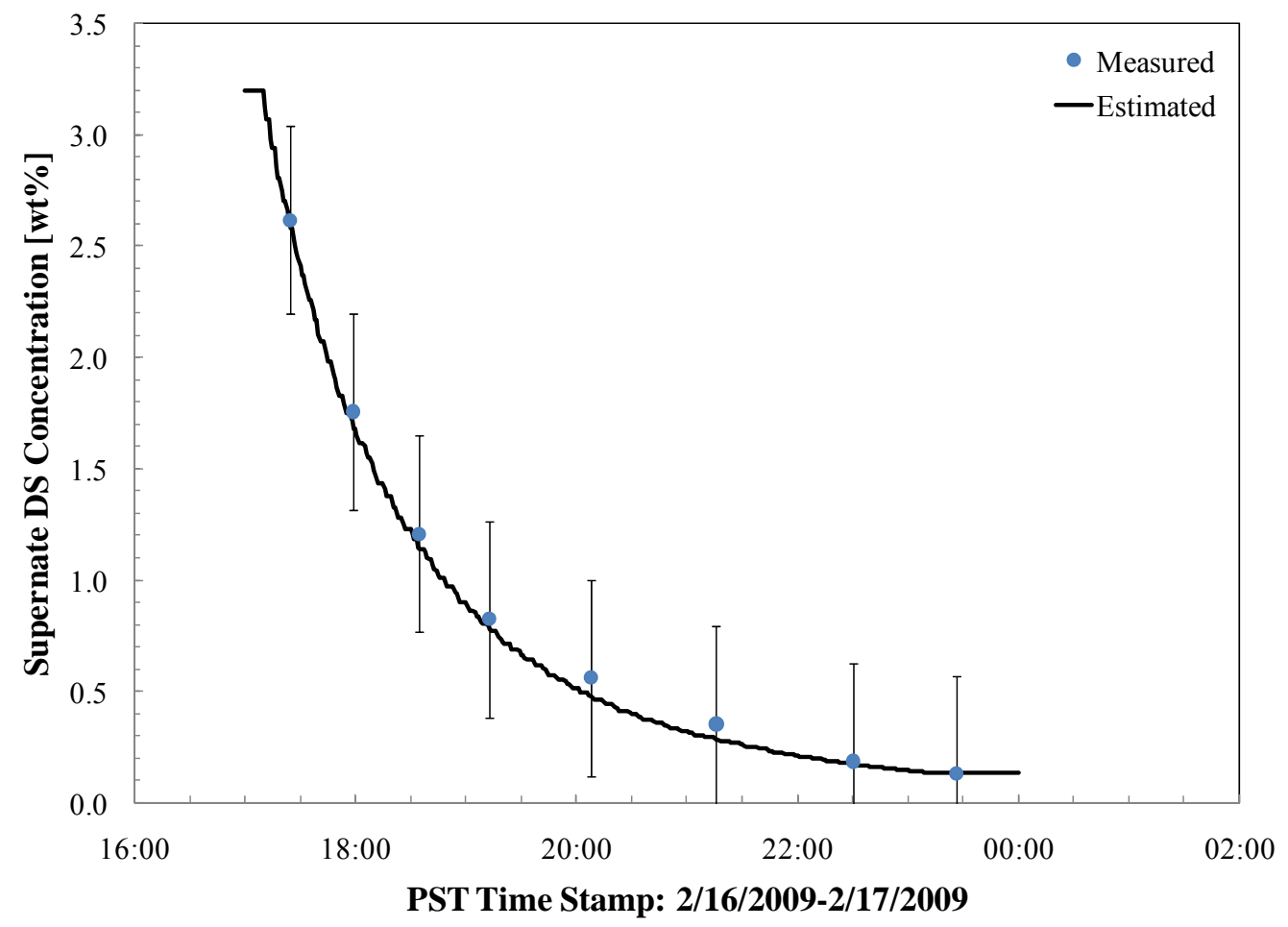

Figure 8.12. Comparison of Measured to Calculated DS During Integrated Test A Post-Oxidative-Leached Slurry Washing

Figure 8.13 shows the total temperature (to $25^{\circ} \mathrm{C}$ ) and TMP (to $40 \mathrm{psid}$ ) corrected filter flux measured during the post-oxidative-leach wash. The dewatering curve for the post-oxidative-leach wash is shown in Figure 8.14. The flux declines gradually as DS decreases over the duration of the washing operation from 1700 to $2100 \mathrm{hrs}$. This decline does not correspond to a change in the permeate viscosity, as the starting and ending permeate viscosity during the was step is $\sim 1 \mathrm{cP}$. Post-oxidative-leach washing operations for Integrated Tests B and D do not show declines over this DS range, but instead show a relatively constant flux. The cause for steady decline in Integrated Test A post-oxidative-leach wash operations is unknown, but may be related to issues associated with air entrainment. Likewise, the steady 
decline in flux over time could also be indicative of fouling of the filters, either by existing slurry solids or by solids that precipitate at low DS. At supernate concentrations below 1-wt $\%$ DS, the flux behavior with DS is consistent with the behaviors observed in Integrated Tests B and D.

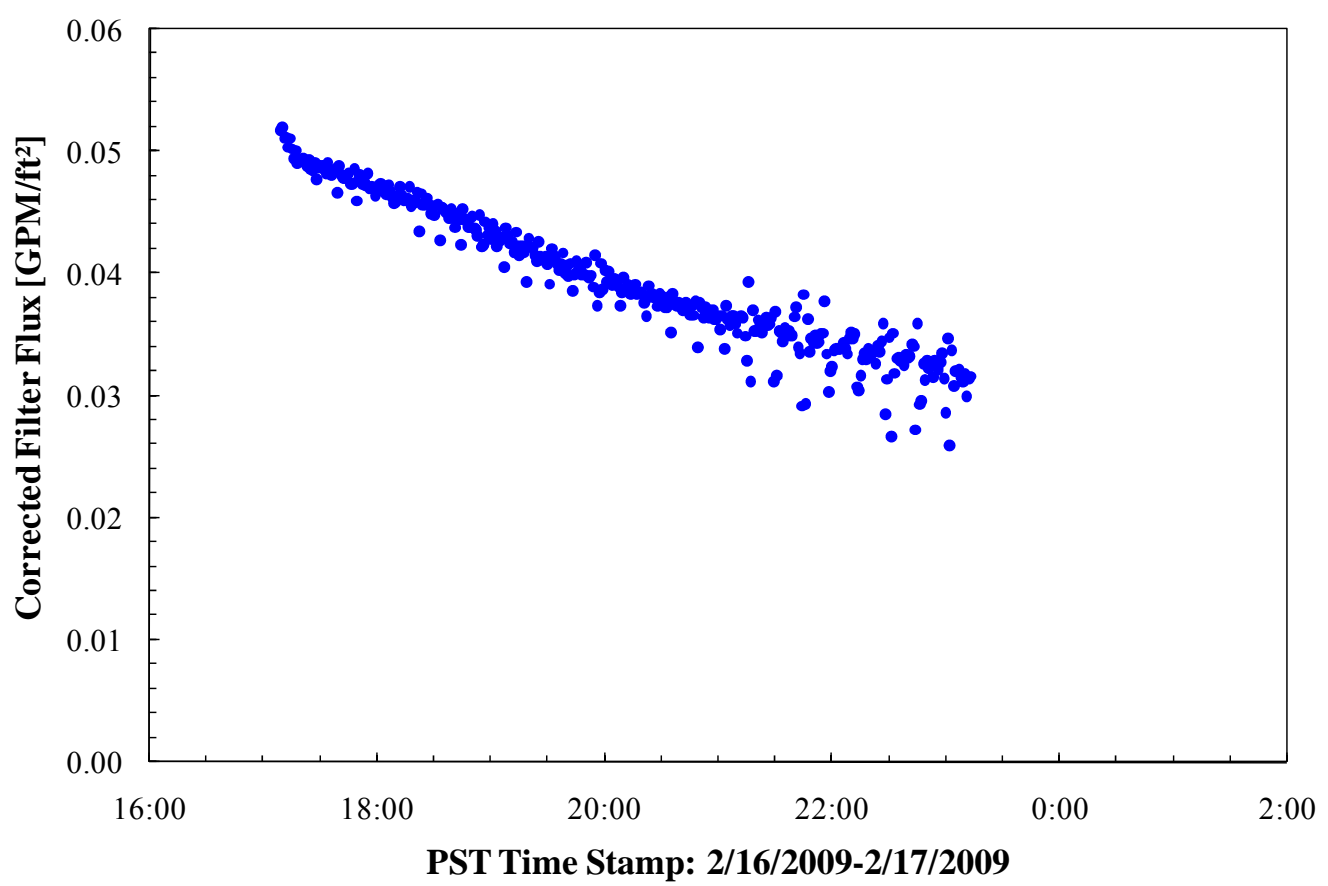

Figure 8.13. Total Filter Flux (corrected for TMP and temperature variations) for Integrated A Post-Oxidative-Leach Washing as a Function of Time 


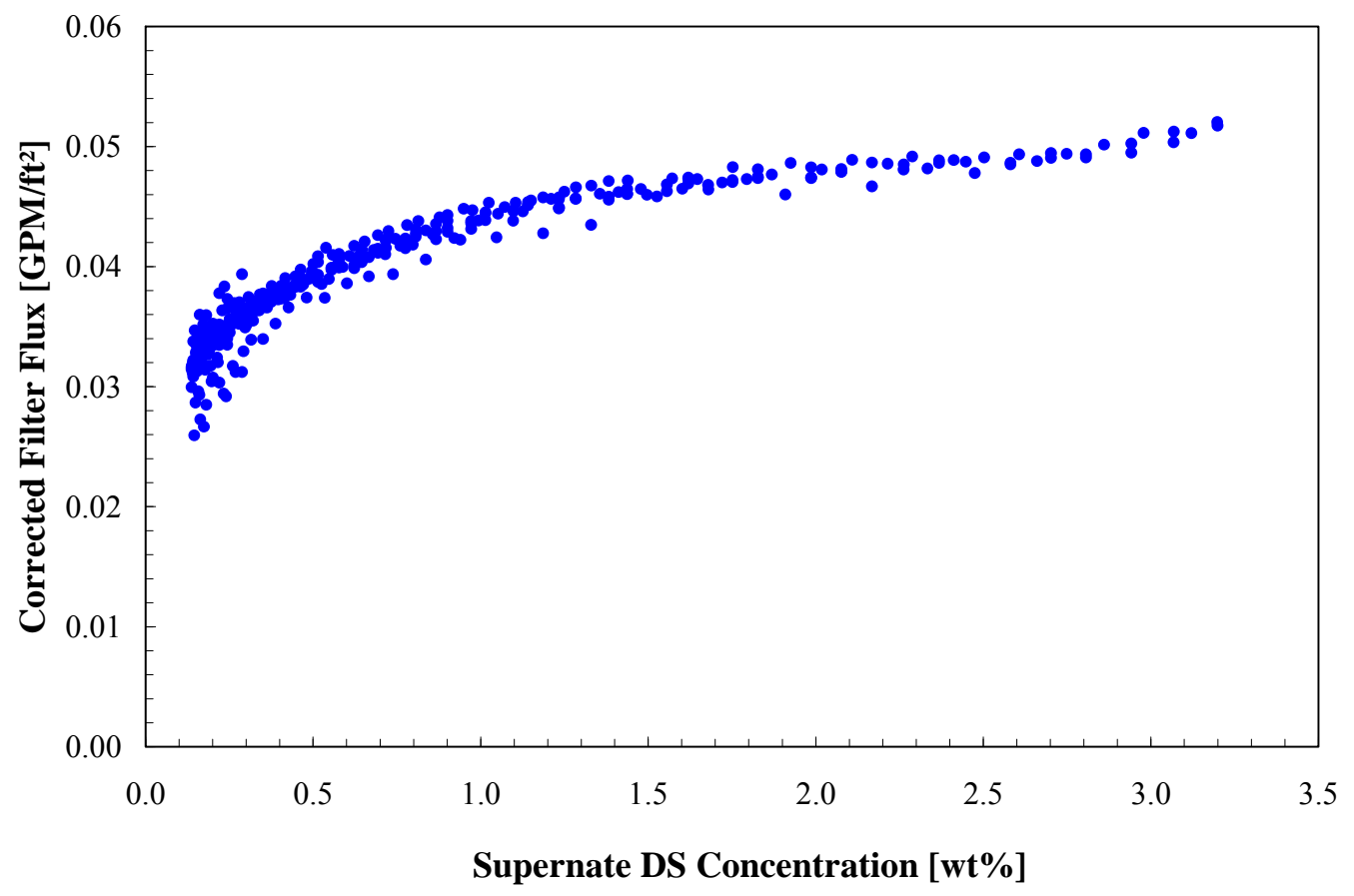

Figure 8.14. Total Filter Flux (corrected for TMP and temperature variations) for Integrated A Post-Oxidative-Leach Washing as a Function of Supernate DS Concentration

\subsubsection{Post-Oxidative-Leach Concentration}

Post-oxidative-leach concentration was performed using all five filters on February 20, 2009 from $2124 \mathrm{hrs}$ to $2140 \mathrm{hrs}$. During this step air entrainment issues persisted as discussed previously (Guzman-Leong et al. 2009, provide a narrative of events and data, Section 14.1.7 discusses the PEP air entrainment issue). Because insufficient analytical samples were taken during this operation, no mass balance was performed during the post-oxidative-leach concentration. Sufficient analytical data support estimation of filter flux performance. Filtration produced a temperature- and TMP-corrected flux of about $0.024 \mathrm{GPM} / \mathrm{ft}^{2}$.

\subsection{Integrated Test B}

The filtration events conducted for Integrated Test B operations are as follows:

- $\quad$ Pre-leach simulant concentration. Two batches of unmodified pre-leach simulant were concentrated from $5-\mathrm{wt} \%$ to $20-\mathrm{wt} \%$ UDS.

- $\quad$ Post-caustic-leach concentration. The simulant was concentrated following caustic leaching.

- $\quad$ Post-caustic-leach washing. The concentrated post-caustic-leach slurry was washed with IW.

- Pre-oxidative-leach washing and concentration. A chrome-containing slurry was added to the caustic-leached, washed slurry to provide a defined target for oxidative leaching. 
- $\quad$ Post-oxidative-leach washing. The slurry was washed following the oxidative-leach in a manner consistent with post-caustic-leach washing.

\subsubsection{Pre-Caustic-Leach Solids Concentration Batch \#1}

Pre-caustic-leach concentration operations were intended to increase the UDS concentration of the as-prepared waste simulant slurry to $\sim 20$-wt $\%$. Pre-caustic-leach concentration operations consisted of two separate batch dewatering operations of waste simulant slurry. After an initial transfer of simulant to Tank T02A, the slurry was dewatered using all five filter bundles. During dewatering operations, the level of slurry in Tank T02A was maintained by batch transfer of neat slurry from Tank T01A.

The slurry UDS concentration, from sample analyses and as estimated by mass balance, is presented in Figure 8.15. Filtration concentrated the slurry to a concentration in excess of $20-w t \%$ in four steps. Autobatch transfers were active during the first two periods of filtration during which the slurry was sampled heavily. The total (filter area-averaged) filter permeate flux corrected for temperature (to $25^{\circ} \mathrm{C}$ ) and TMP (to $40 \mathrm{psid}$ ) is given in Figure 8.16. Figure 8.17 presents the average filter flux as a function of $\mathrm{wt} \%$ UDS. The discontinuity at 8 -wt $\%$ UDS corresponds to the first pause in filtration. The drop in filter flux at this point is consistent with the expectation that portions of the filter cake are lost when the permeate valves are closed. Other discontinuities exist toward the filtration end point as a result of pauses at 16 - and 18 -wt $\%$ UDS. The impact of these pauses is obscured by significant AV variation at concentrations greater than $16-\mathrm{wt} \%$ UDS. Although there is significant discontinuity in the dewatering curve above 16-wt \%, the curve does not appear to evidence a change in flux behavior that would be characteristic of a transition to cake-resistance limited filtration. 


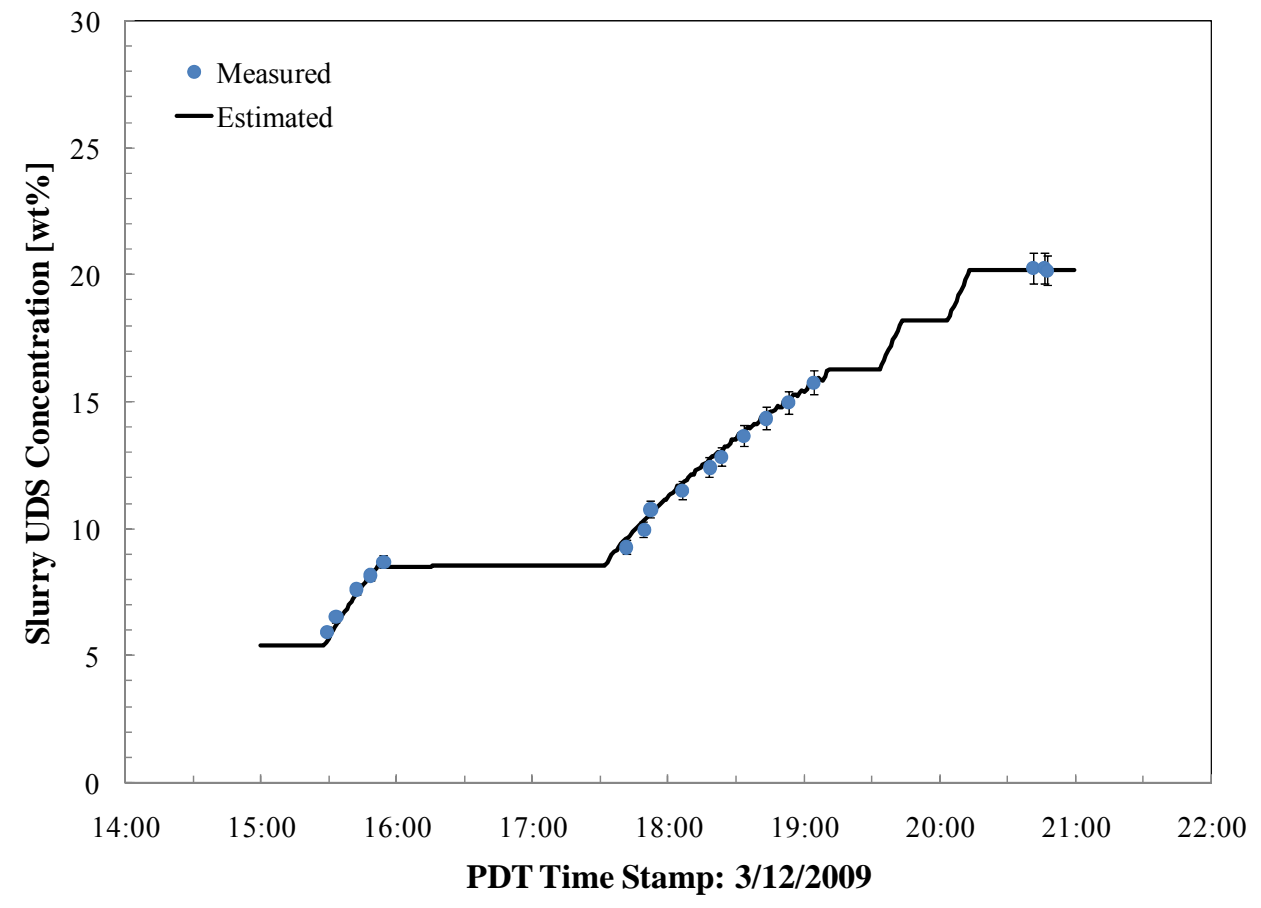

Figure 8.15. Measured and Estimated (by mass balance) Slurry UDS Concentration for Pre-Caustic-Leach Concentration Batch \#1, Integrated Test B

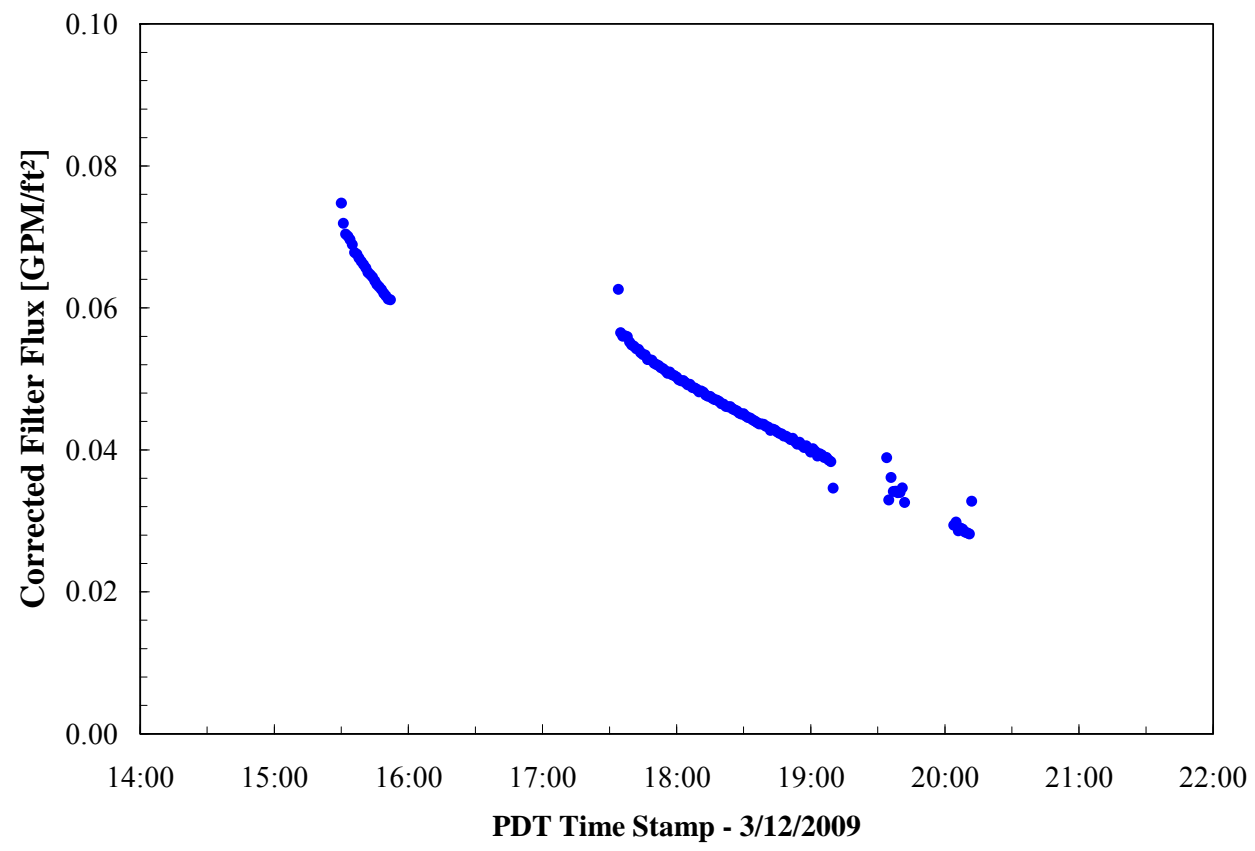

Figure 8.16. Corrected Total Filter Flux for Pre-Caustic-Leach Solids Concentration, Integrated Test B, Caustic-Leach Batch \#1 


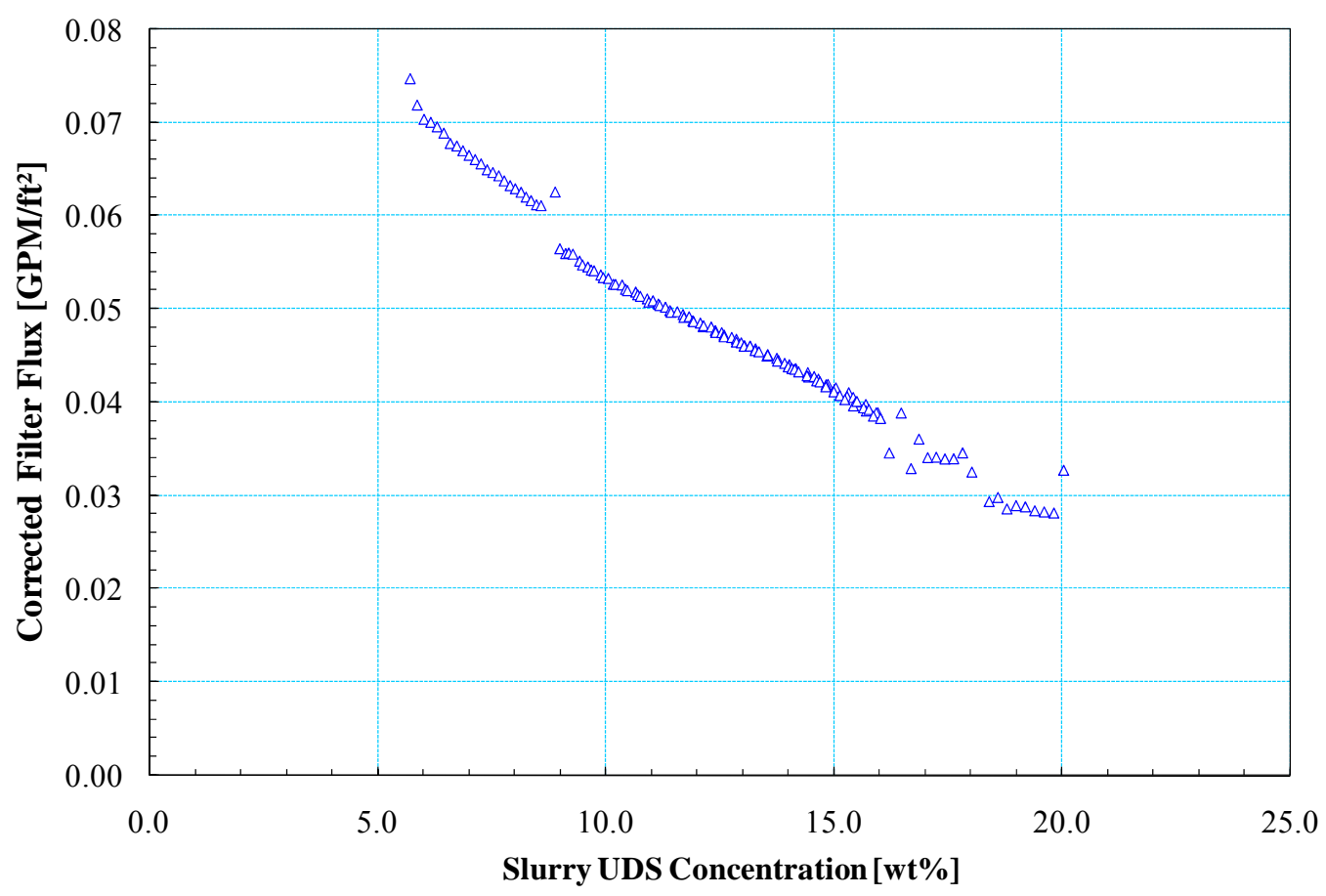

Figure 8.17. Filter Flux as a Function of wt $\%$ UDS for Pre-Caustic-Leach Solids Concentration, Integrated Test B, Caustic-Leach Batch \#1

\subsubsection{Pre-Caustic-Leach Concentration Batch \#2}

The slurry UDS concentration evolution for Batch \#2 pre-caustic-leach concentration is presented in Figure 8.18. The slurry was dewatered to concentrations in excess of $20-w t \%$ using a single filter bundle. The impact of batch transfers of source slurry from Tank T01A is clearly visible by the saw-tooth pattern. Relative to Batch \#1, Batch \#2 concentration required significantly more time because only one filter bundle was employed. After completion of batch transfers, filtration proceeded rapidly (as indicated by the sharp increase in the estimated UDS curve at $1100 \mathrm{hrs}$ on March 15, 2009).

Permeate flux corrected for temperature $\left(25^{\circ} \mathrm{C}\right)$ and TMP $(40 \mathrm{psid})$ is given in Figure 8.19. Discontinuities in the permeate flux versus time data correspond to pauses in filtration to allow refill of Tank T01A and as a result of process condition upsets (see Geeting et al. 2009 for details). Apart from these discontinuities, the filter flux declines smoothly and its behavior is consistent with that of pre-caustic-leach solids concentration Batch \#1. Filter flux as a function of wt $\%$ UDS is presented in Figure 8.20. The dewatering curve does not evidence a dewatering knee, indicating that dewater operations fall in the membrane resistance limited regime (and should not be a strong function of UDS concentration). Figure 8.20 shows that the filter flux declines with increasing solids concentration. This behavior is not expected for low-solids concentration operations in the filter-membrane resistance limited region. This decrease is likely a result of membrane fouling.

Although the curve does not appear to exhibit a clearly identifiable dewatering-knee (indicating a transition to cake-controlled filtration), there is a discontinuity in the dewatering slope near $16-\mathrm{wt} \%$. This discontinuity occurs because make-up batch transfers were stopped at this point and the continued 
removal of permeate had a larger effect on wt $\%$ UDS. This discontinuity would have existed even if the filter flux had been constant throughout the process.

Finally, a comparison of Batch \#1 and Batch \#2 pre-leach dewatering curves is given in Figure 8.21. The comparison shows that Batch \#1 operations yielded higher filter fluxes relative to Batch \#2 operations. This is expected, given the suspected depth-fouling of the filter. That is, Batch \#1 operations using all five filters yields fouling on filter bundle 1(and the other filters), which in turn, causes lower average flux when filter bundle 1 is employed for Batch \#2. However, it is interesting to note that the reverse behavior (i.e., Batch \#2 shows higher flux) is observed in Integrated Test D pre-caustic-leach concentration operations. Batch \#2 operations for Integrated Test D employ all 5 filter bundles. As such, when considered with the current results for Integrated Test B pre-leach operations, the Integrated Test D results may suggest that the number of filter bundles employed could impact filter flux.

Another notable feature of Figure 8.21 is that Batch \#1 and Batch \#2 show similar declines in filter flux over the duration of testing. Because Batch \#1 occurs much more rapidly than Batch \#2, this suggests that filter-fouling that is functionally proportional to the total volume of filtrate (which is similar for both batches). Such fouling behavior is consistent with pore blocking models described in Hermia (1981).

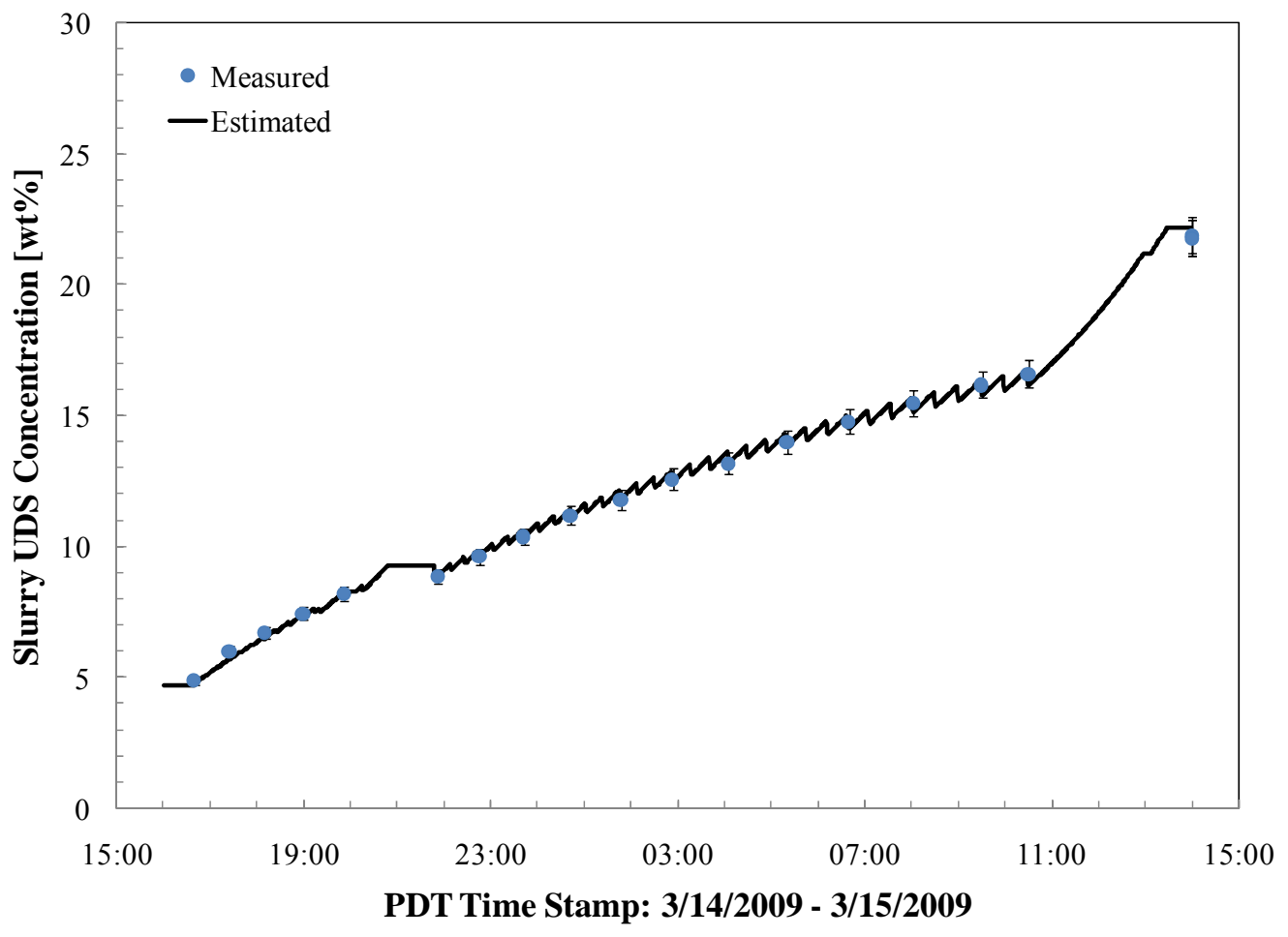

Figure 8.18. Measured and Estimated (by mass balance) Slurry UDS Concentration for Pre-Caustic-Leach Solids Concentration, Integrated Test B, Caustic-Leach Batch \#2 


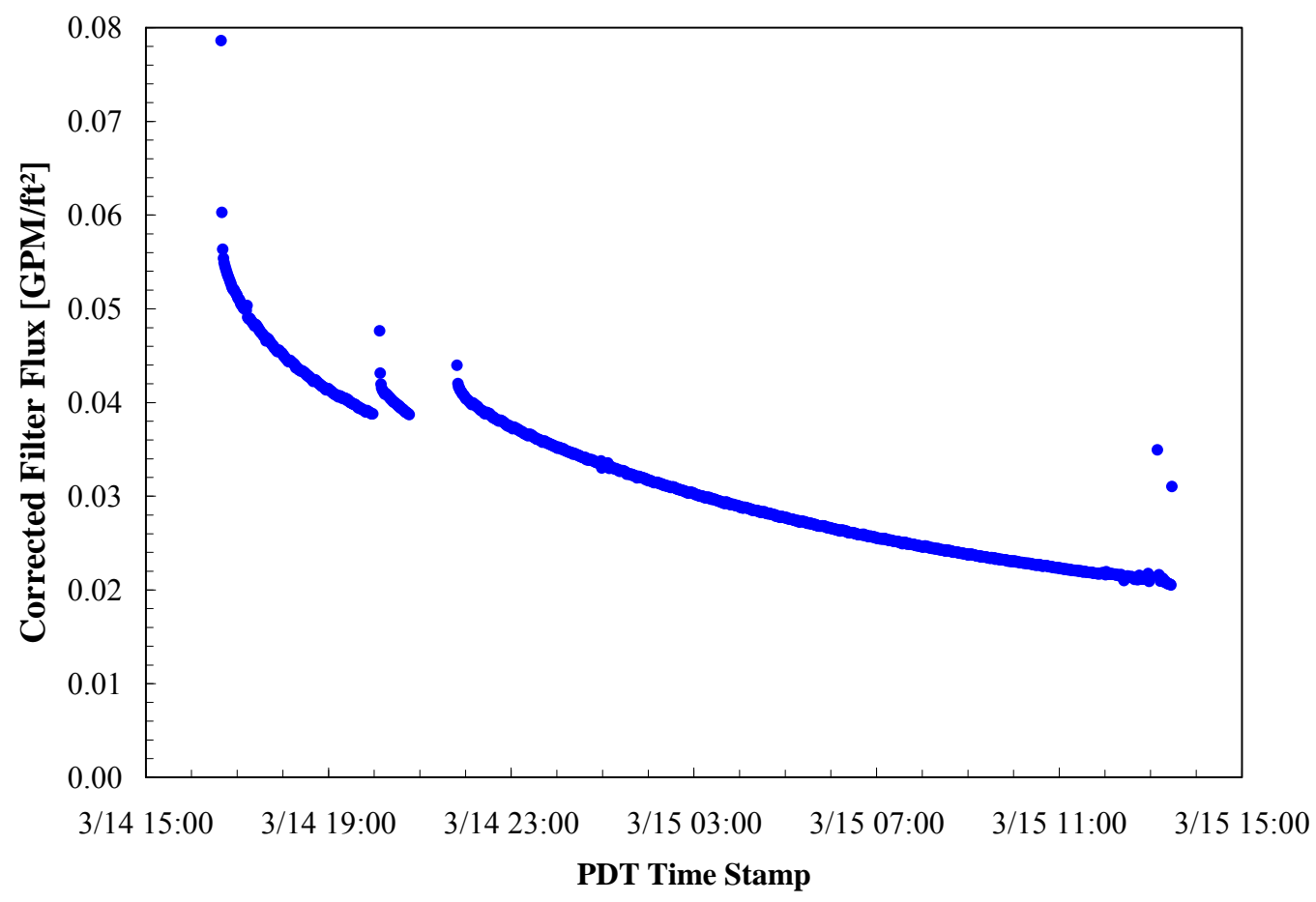

Figure 8.19. Corrected Total Filter Flux for Pre-Caustic-Leach Solids Concentration, Integrated Test B, Caustic-Leach Batch \#2

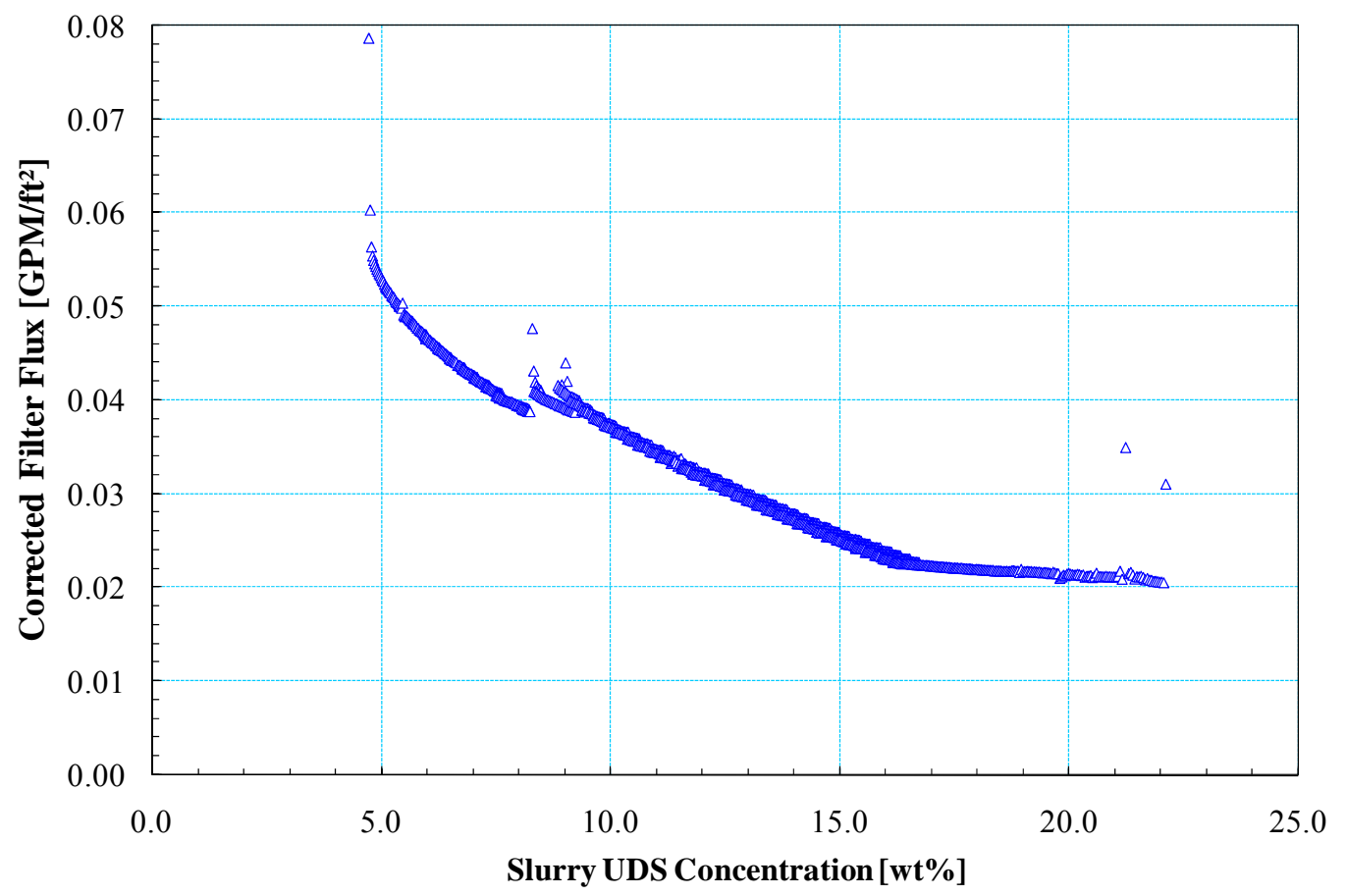

Figure 8.20. Dewatering Curve for Pre-Caustic-Leach Solids Concentration, Integrated Test B, Caustic-Leach Batch \#2 


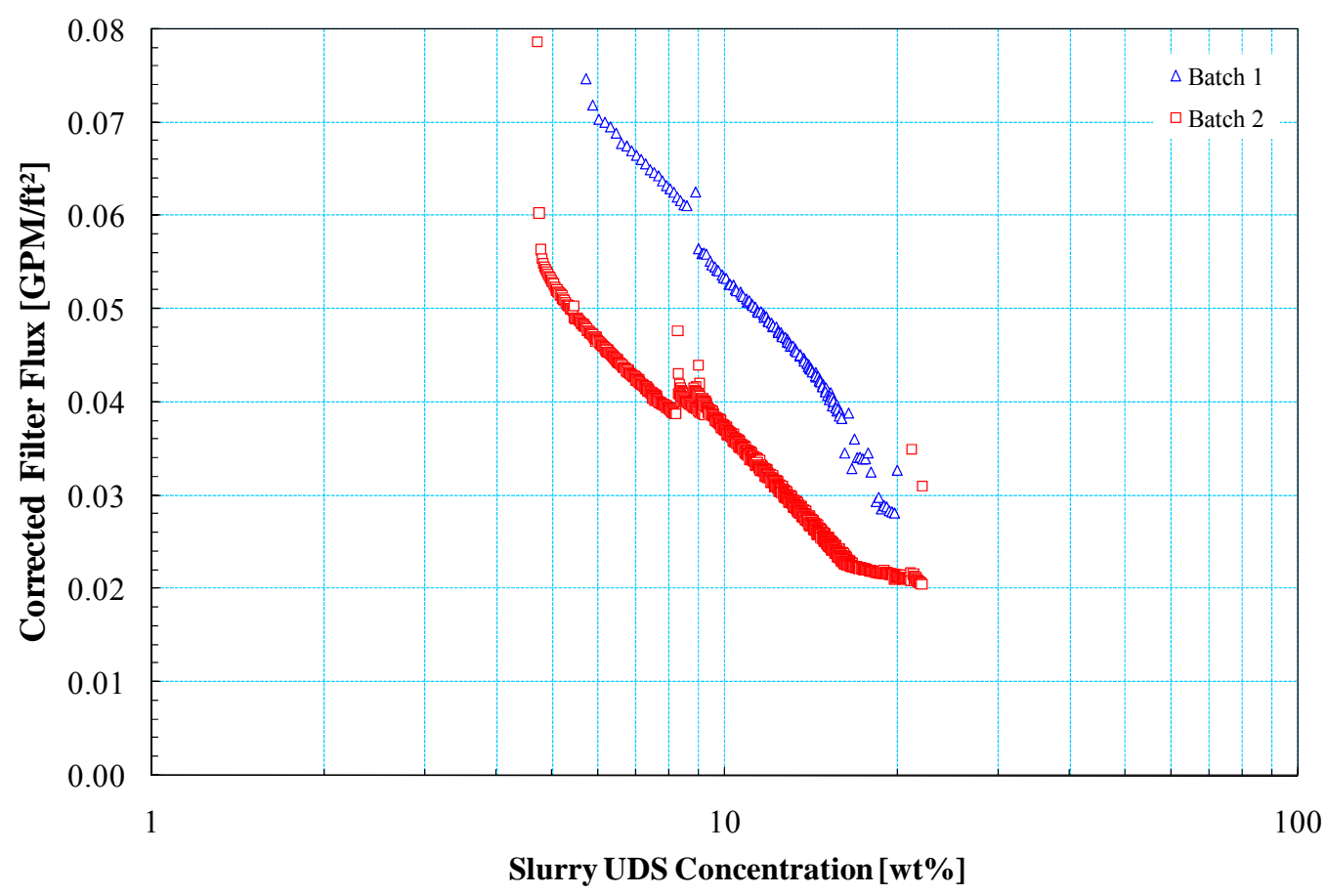

Figure 8.21. Comparison of Flux as a Function of UDS Concentration for Batch \#1 and Batch \#2 Pre-Caustic-Leach Solids Concentration, Integrated Test B

\subsubsection{Post-Caustic-Leach Concentration}

Post-caustic-leach concentration activities was intended to increase the concentration of leached solids to approximately $17-\mathrm{wt} \%$ UDS. The level in Tank T02A was maintained through batch transfers of leached slurry from Tank T01B. During the course of post-caustic-leach concentration operations, backpulsing was performed on an as-needed basis using the following guidelines:

- Backpulse when the permeate rate drops below 0.6-kg/min

- Backpulse no more often than once every six hours

- Backpulse with the following parameters: 1 ) overpressure $=40 \mathrm{psi}, 2$ ) deadband $=5 \mathrm{psi}$, and 3) pulse-pot level $=10$ inches.

The effect of backpulsing on permeate production was transitory. Suspending filtration or turning the circulation pumps off also resulted in similar transient improvements of permeate production. An analysis of the effectiveness of backpulsing in Integrated Test B post-caustic-leach concentration is given in Appendix B. The results suggest that backpulsing did not appear to significantly improve flux.

The slurry UDS concentration, both as measured from analytical samples taken during post-caustic-leach concentration operations and as estimated by mass balance, is presented in Figure 8.22. The UDS curve confirms that the slurry was dewatered to concentrations in excess of $17-\mathrm{wt} \%$. Batch transfers from Tank T01B took place up to $2100 \mathrm{hrs}$ on March 18, 2009 and yield a downward curvature to the UDS curve. After batch transfers were complete, the rate of dewatering accelerated. Toward the 
end, dewatering was briefly paused, yielding the two horizontal plateaus in UDS behavior around $16-\mathrm{wt} \%$.

Figure 8.23 and Figure 8.24 show temperature $\left(25^{\circ} \mathrm{C}\right)$ and TMP $(40$ psid $)$ corrected flux as a function of test time and estimated slurry UDS concentration. Figure 8.23 evidences discontinuities, four of which are associated with filter backpulsing performed to restore filter flux (see Appendix B for analysis of backpulsing effectiveness) and the remainder of which are associated with pauses in permeate production. For most of the continuous periods of filter operation, filter flux is smooth and declines gradually. The latter gradual decline was associated with membrane-fouling. Toward the end of filtration, control of AV became difficult because of a combination of low Tank T02A level (and possibly increased slurry rheology), yielding increased scatter in the corrected filter flux profile.

Because of the filtration stoppages and filter backpulsing, the dewatering curve in Figure 8.24 is not smooth or continuous. The declines in flux after backpulse/stoppage events is associated with filter cake reformation. However, the impact of filtration disruptions on the overall dewatering curve is minimal given the long filtration. That is, the dewatering behavior has not been obscured by attempts to recover flux. The dewatering curve does not evidence a dewater-knee that would indicate transition to cake-controlled filtration. As with pre-caustic-leach concentration Batch \#2, the dewatering curve appears to be steeper during periods where batch transfers are active (5-wt $\%$ to 8 -wt $\%$ in Figure 8.24 ).

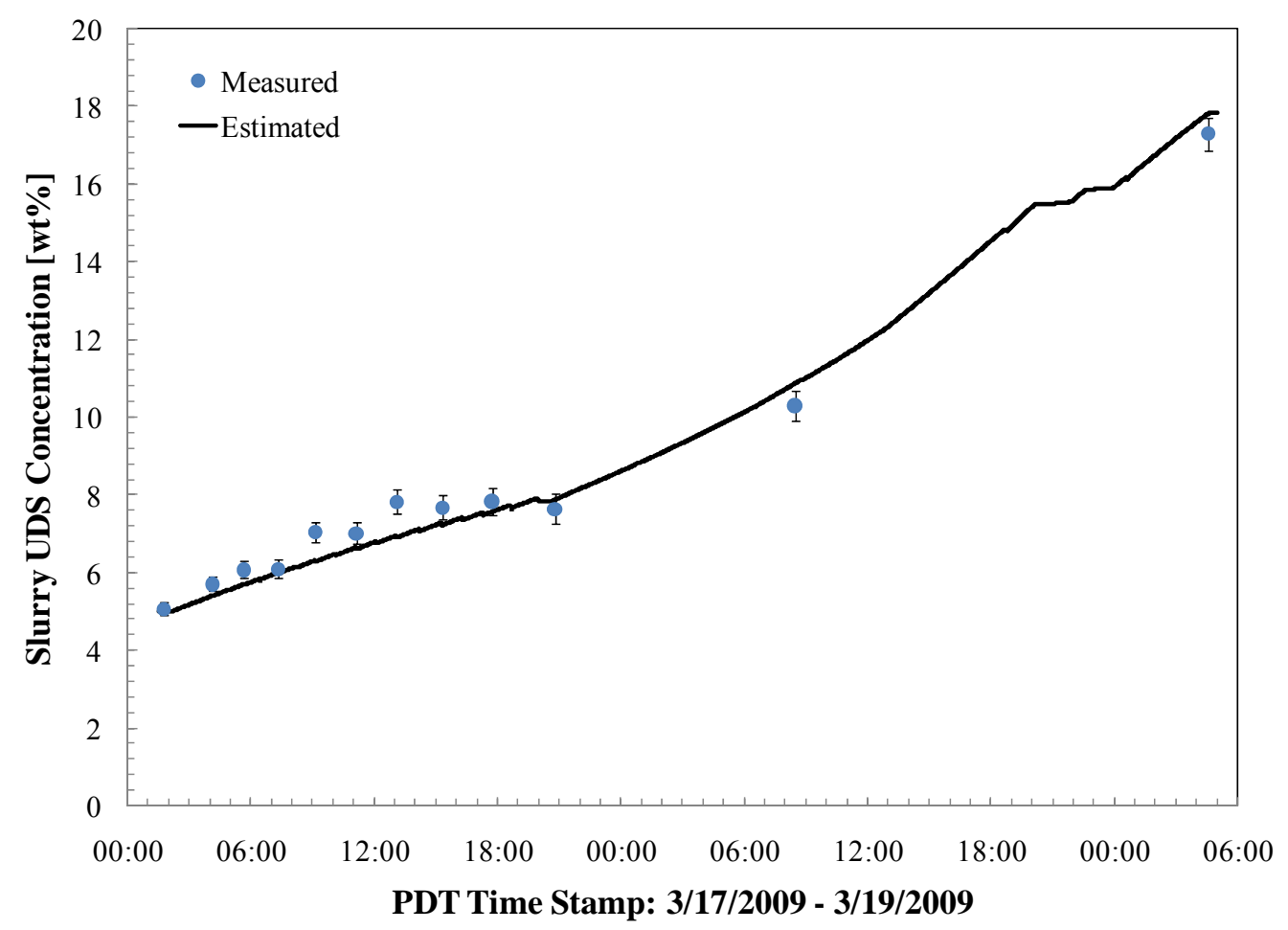

Figure 8.22. Measured and Estimated (by mass balance) Slurry UDS Concentration for Post-Caustic-Leach Concentration, Integrated Test B 


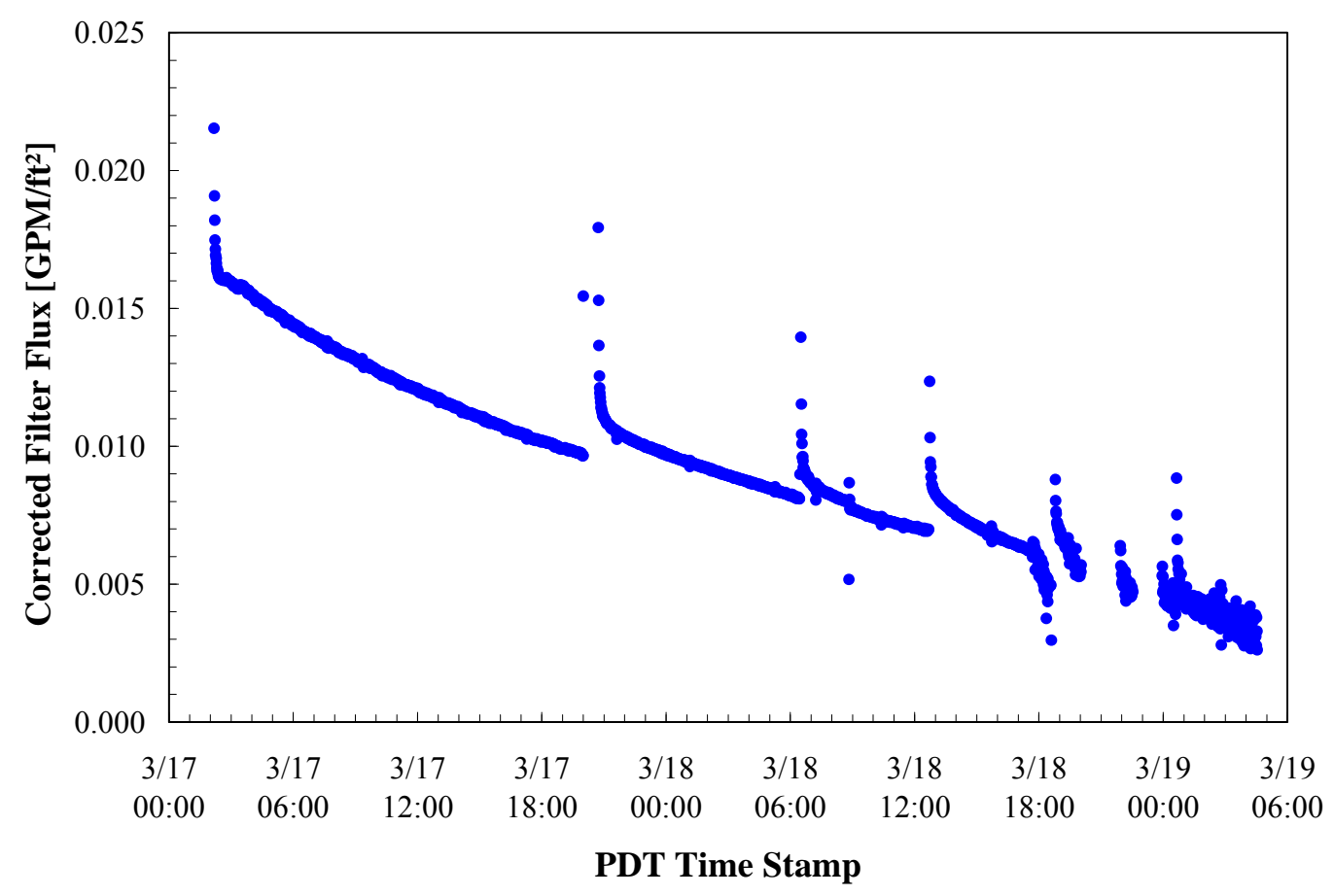

Figure 8.23. Corrected Filter Flux for Filter 1 During Post-Caustic-Leach Concentration, Integrated Test B. This is equivalent to the total corrected filter flux for this test, since only Filter 1 was used to concentrate this slurry.

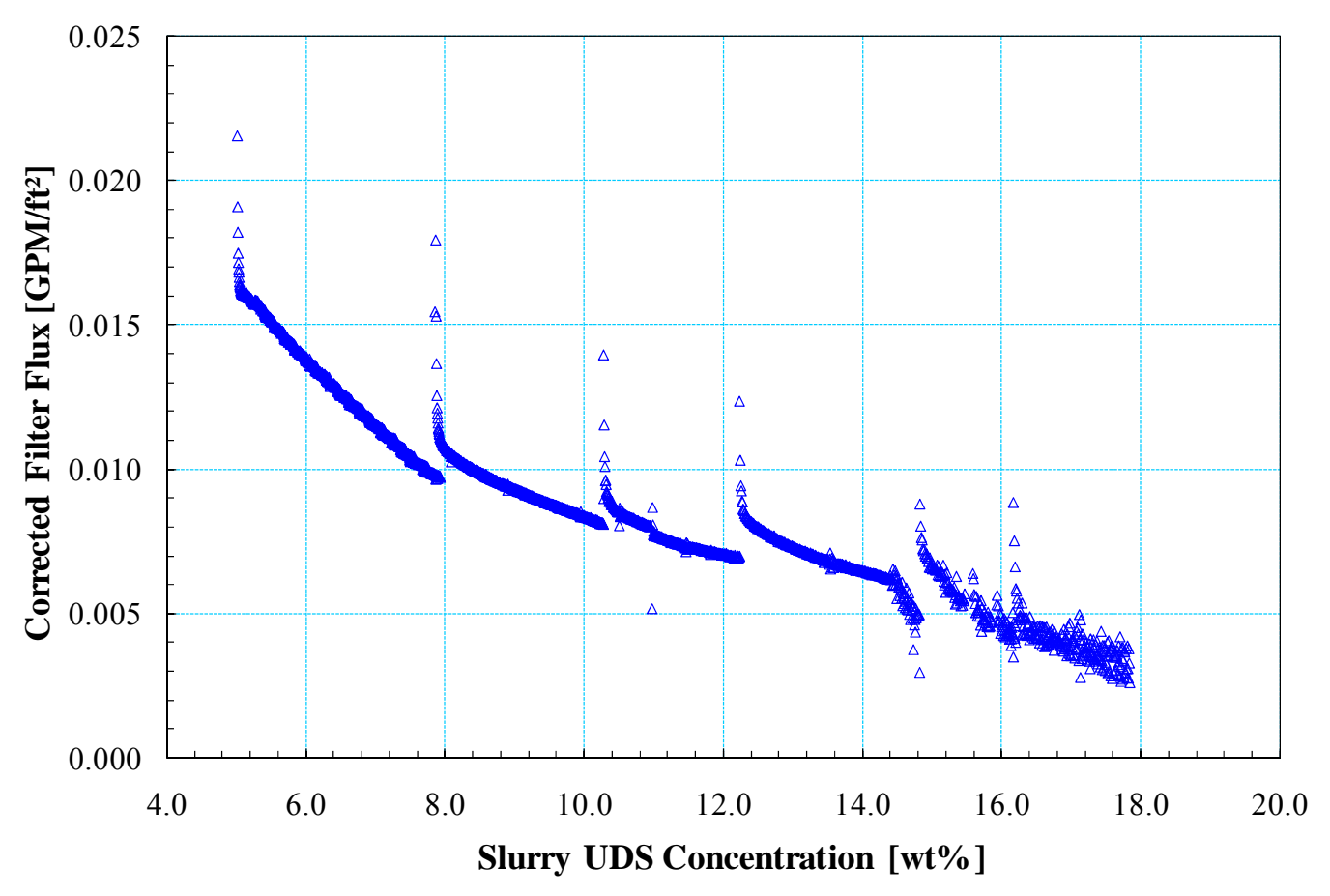

Figure 8.24. Corrected Filter Flux for Filter 1 During Post-Caustic-Leach Concentration as a Function of the Slurry UDS Concentration, Integrated Test B 


\subsubsection{Post-Caustic-Leach Washing}

To reduce the concentration of dissolved solids in the caustic-leached slurry permeate, a water wash of the leached slurry was performed. A detailed analysis of post-caustic-leach washing for Integrated Test B is provided in Section 10. Washing was conducted using all five filter bundles. The duration of this process step in the PEP is $\sim 1 / 4.5$ times (scale time) its expected duration in the PTF. The measured (from analytical samples taken during post-caustic-leach washing) and estimated (by mass balance) supernate dissolved solids concentrations are shown in Figure 8.25. The curve indicates the progress of dissolved solids concentrations from the initial value of $35-\mathrm{wt} \%$ to the final value near $2-\mathrm{wt} \%$. Batch additions of IW are clearly evidenced through the step-wise nature of the DS progression.

Figure 8.26 shows the temperature (to $25^{\circ} \mathrm{C}$ ) and TMP (to 40 psid) corrected flux for post-caustic-leach washing operations as a function of time. The filter flux is the area-averaged (total) flux across all filter bundles. Washing with IW yields significant increases in filter flux from $\sim 0.005 \mathrm{GPM} / \mathrm{ft}^{2}$ to $\sim 0.025 \mathrm{GPM} / \mathrm{ft}^{2}$. The flux increase is not as great as expected based on the factor of $\sim 9$ increase in permeate viscosity from $8.9 \mathrm{cP}$ at the start of washing to $1.0 \mathrm{cP}$ at the end of washing. This indicates the possibility that flux is hindered as washing proceeds. Several possibilities exist by which filtration could be hindered, including a change in the type of solids interacting with the filter, the way in which the existing solids interact with the filter, or air entrainment in the filters. Post-caustic-leach washing operations for Integrated Tests A and D show flux oscillation that has been (speculatively) associated with air entrainment in the filter circulation loop. Although Integrated Test B post-caustic-leach washing shows no oscillation in permeate flux, there is reason to suspect air entrainment in the slurry as the flowmeter readings for Pump T42A suction and Pump T43A discharge diverge.

Figure 8.27 expresses the filter flux during washing as a function of the dissolved solids concentration. This result appears to indicate that most of the gain in filter flux occurs from $35-\mathrm{wt} \%$ to $5-w t \%$ DS. Relative to flux behavior in Integrated Tests A and D, the filter flux behavior in Integrated Test B post-caustic-leach washing operations is relatively well behaved. Unlike the other tests, the flux steadily approaches a flux of $\sim 0.025 \mathrm{GPM} / \mathrm{ft}^{2}$ as dissolved solids concentration is reduced below 5 -wt $\%$. 


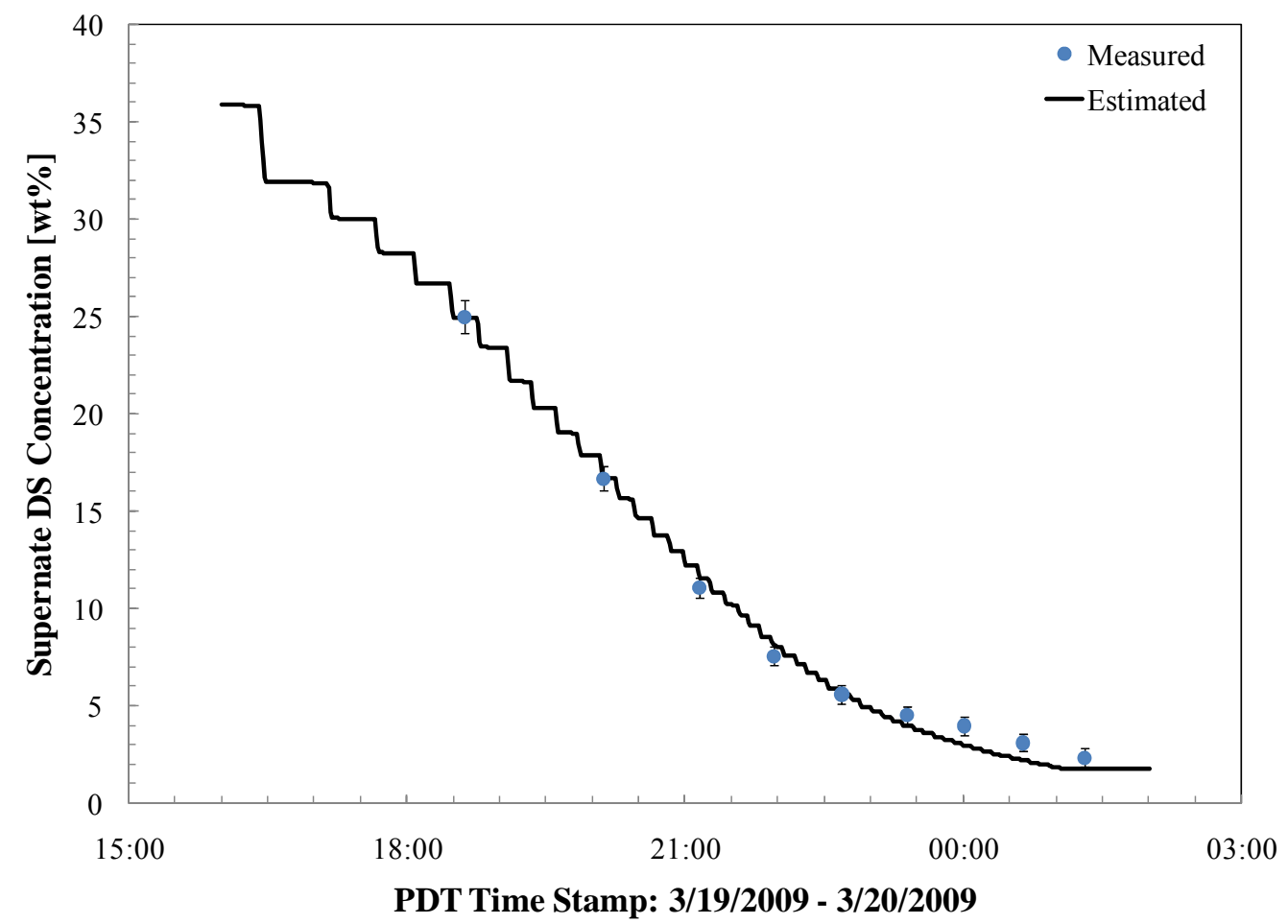

Figure 8.25. Measured and Estimated (by mass balance) Supernate Dissolved Solids Concentration for Post-Caustic-Leach Washing, Integrated Test B

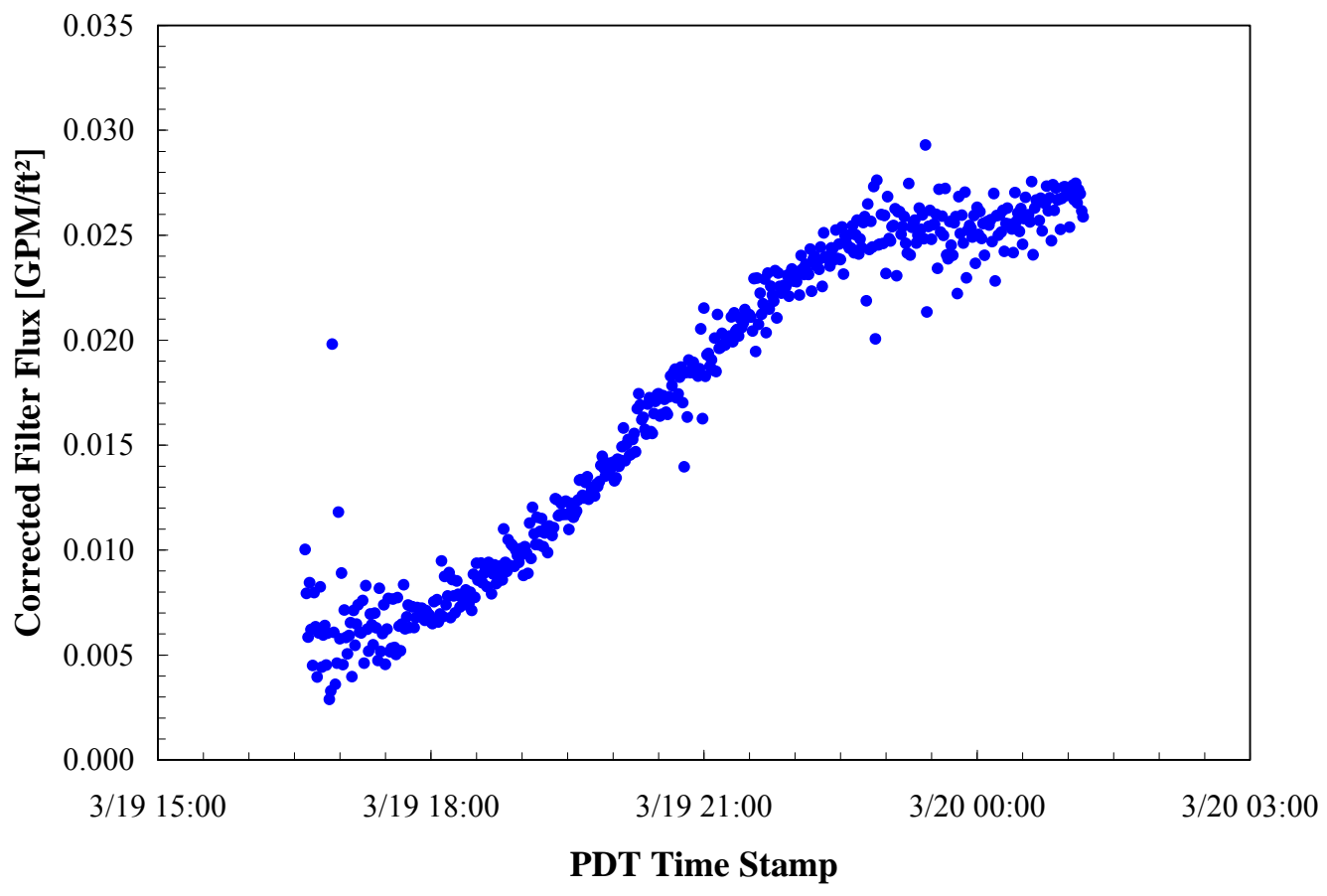

Figure 8.26. Total Corrected Filter Flux for Post-Caustic-Leach Washing, Integrated Test B 


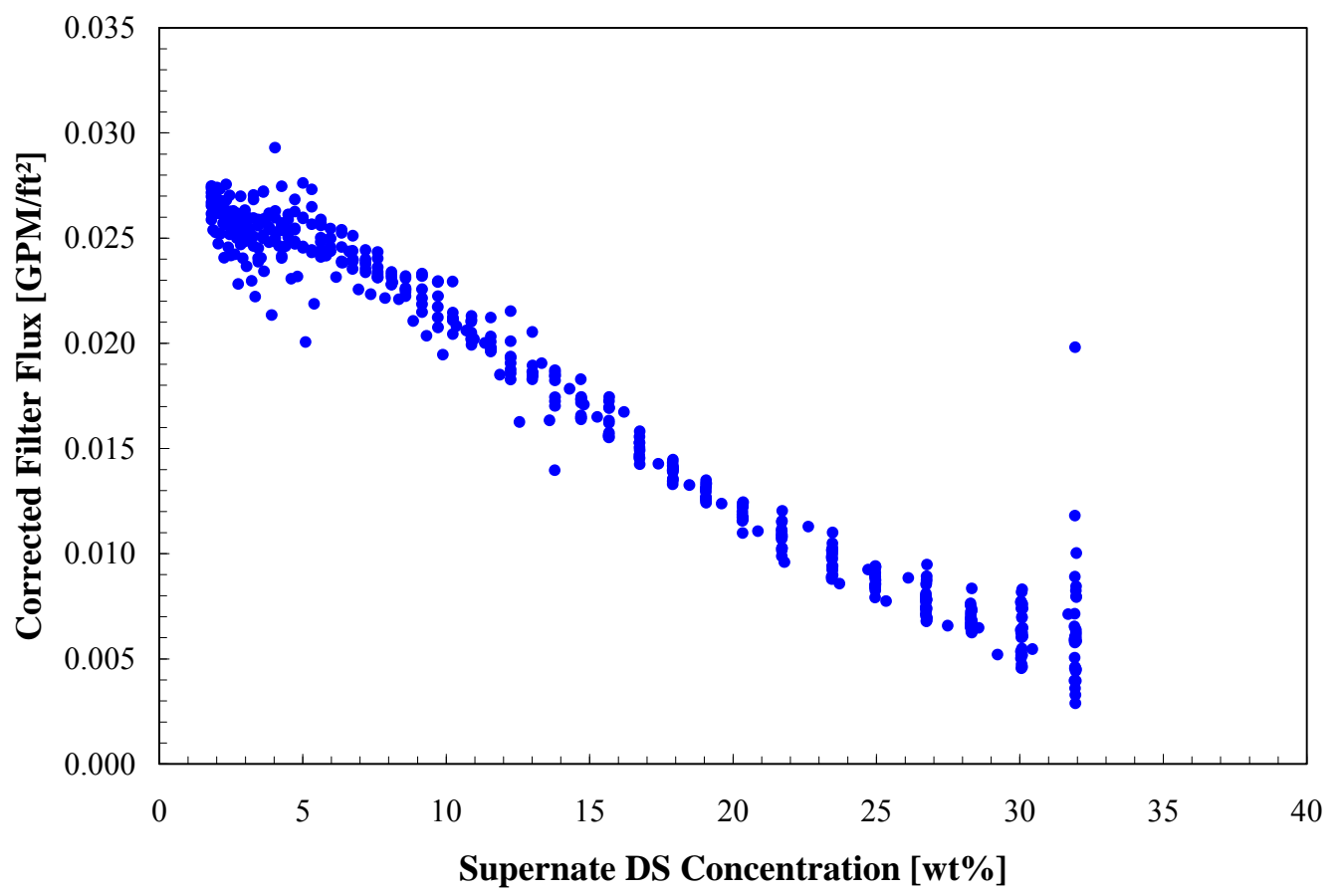

Figure 8.27. Total Corrected Filter Flux as a Function of Supernate DS Concentration for Post-Caustic-Leach Washing, Integrated Test B

\subsubsection{Pre-Oxidative-Leach Washing and Concentration}

Before execution of oxidative-leaching operations, chromium was added as a $\mathrm{CrOOH}$ slurry to the simulant after caustic leaching and washing operations. After the chromium slurry addition, permeate was removed to reduce the level of the slurry in Tank T02A. Subsequently, the slurry was washed with IW. Because insufficient analytical data exist to facilitate a mass balance for this operation, further evaluation of this nonprototypic process step is not provided.

\subsubsection{Post-Oxidative-Leach Washing}

One of the final process steps of Integrated Test B was a water wash of the oxidative-leached slurry. As with previous washing steps, washing was conducted at scale-time using all five filter bundles. The duration of this process step in the PEP is $\sim 1 / 4.5$ times its expected duration in the PTF. The measured (from analytical samples taken during post-oxidative-leach washing operations) and estimated (by mass balance) supernate dissolved solids concentrations are presented in Figure 8.28. Post-oxidative-leach washing facilitates a drop in the supernate dissolved solids concentration from $3.5-\mathrm{wt} \%$ to $0.3-\mathrm{wt} \%$.

Figure 8.29 shows temperature (to $25^{\circ} \mathrm{C}$ ) and TMP (to 40 psid) corrected flux as a function of time on an individual filter and total (area-averaged) flux basis, respectively. The flux varies from $\sim 0.06 \mathrm{GPM} / \mathrm{ft}^{2}$ at the start of washing down to $\sim 0.04 \mathrm{GPM} / \mathrm{ft}^{2}$ at the end of washing. The decline in flux starts halfway through the washing operation (at $\sim 1700 \mathrm{hrs}$ ). Similar decline was observed in Integrated Test A post-oxidative-leach washing, but was present throughout the entire washing operation. Like Integrated Test A, the decline in flux over time can indicate of fouling of the filters, either by trapped air in the 
porous filter structure, existing slurry solids, or precipitated solids. Because the divergence in the flowmeter readings at the suction to Pump T42A and the discharge to Pump T43A increases at $~ 1700$ hrs, entrainment of air in the circulation may be the cause of flux decline. The decline in flux does not appear to be related to changes in permeate viscosity, as permeate viscosity is $\sim 1.0 \mathrm{cP}$ throughout the washing process.

The trend of filter flux with permeate dissolved concentration is shown in Figure 8.30. The data indicate that for most of the DS concentration range, flux is approximately $0.06 \mathrm{GPM} / \mathrm{ft}^{2}$ and is insensitive to changes in DS. With respect to the flux magnitude, the $0.06 \mathrm{GPM} / \mathrm{ft}^{2}$ flux observed is significantly higher than the flux at the end of post-caustic-leach washing operations $\left(0.03 \mathrm{GPM} / \mathrm{ft}^{2}\right)$. This difference cannot be explained by differences in permeate viscosity, as viscosity at the end of post-caustic-leach washing operations $(\sim 1.0 \mathrm{cP})$ is similar to that during post-oxidative-leach operations $(\sim 1.0 \mathrm{cP})$. With respect to the behavior shown in other Integrated Tests, the post-oxidative-leach wash flux measured in Integrated Test D does not show a similar increase in flux between post-caustic and post-oxidative-leach wash operations. On the other hand, the Integrated Test B post-oxidative-leach wash flux is comparable to that measured during Integrated Test A post-oxidative-leach washing. As such, the difference in Integrated Tests B and D may result from process steps associated with addition of chromium to the slurry.

As the DS falls below $\sim 0.7-w t \%$, the flux begins to decline. The rate of decline appears to accelerate as the DS nears the lower end of the tested range. This decline could indicate a change in how the slurry solids interact with the filter. The decline is indicative of the pore blocking mechanisms that appear to start near 1700 hrs.

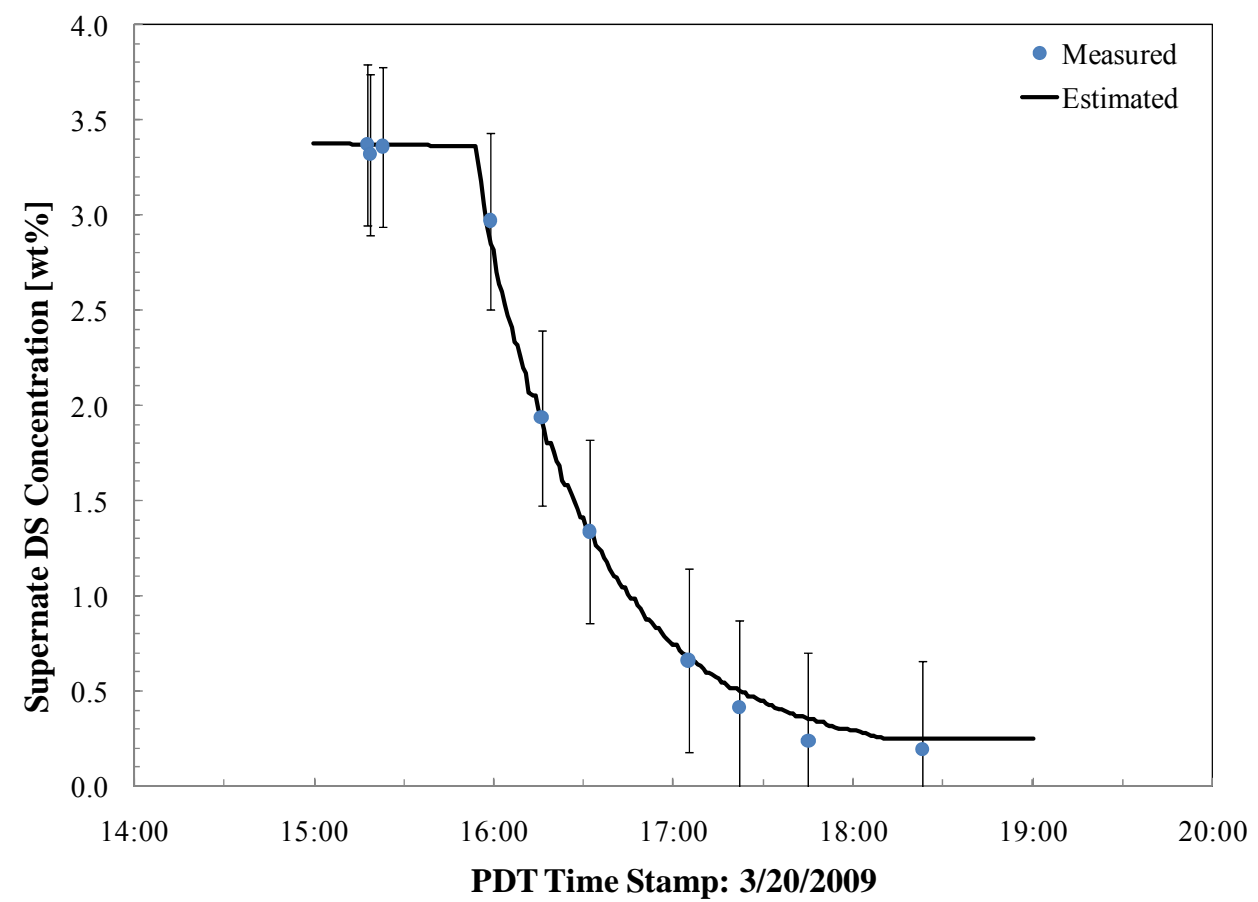

Figure 8.28. Measured and Estimated (by mass balance) Supernate Dissolved Solids Concentration for Post-Oxidative-Leach Washing, Integrated Test B 


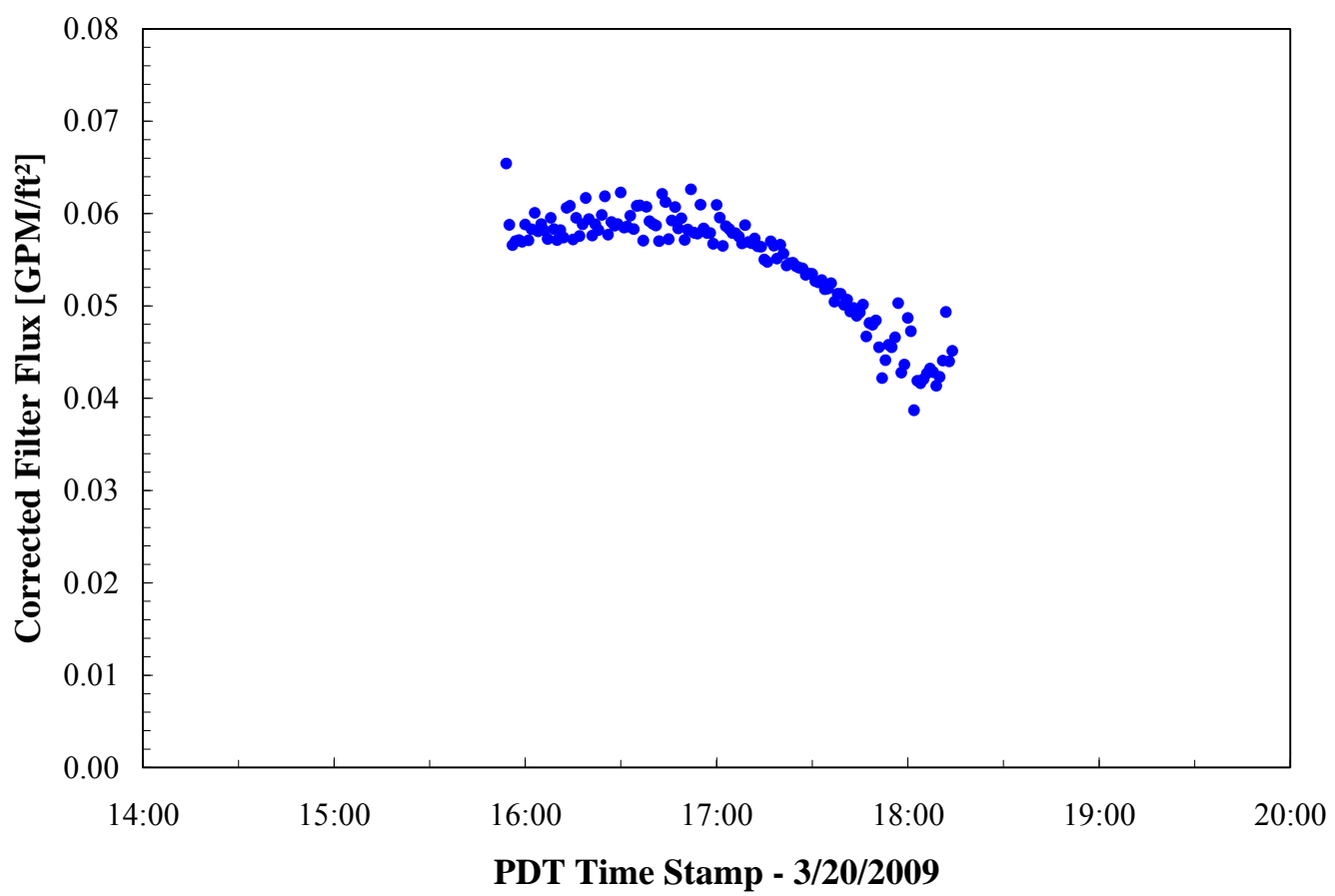

Figure 8.29. Corrected Total Filter Flux for Post-Oxidative-Leach Washing, Integrated Test B

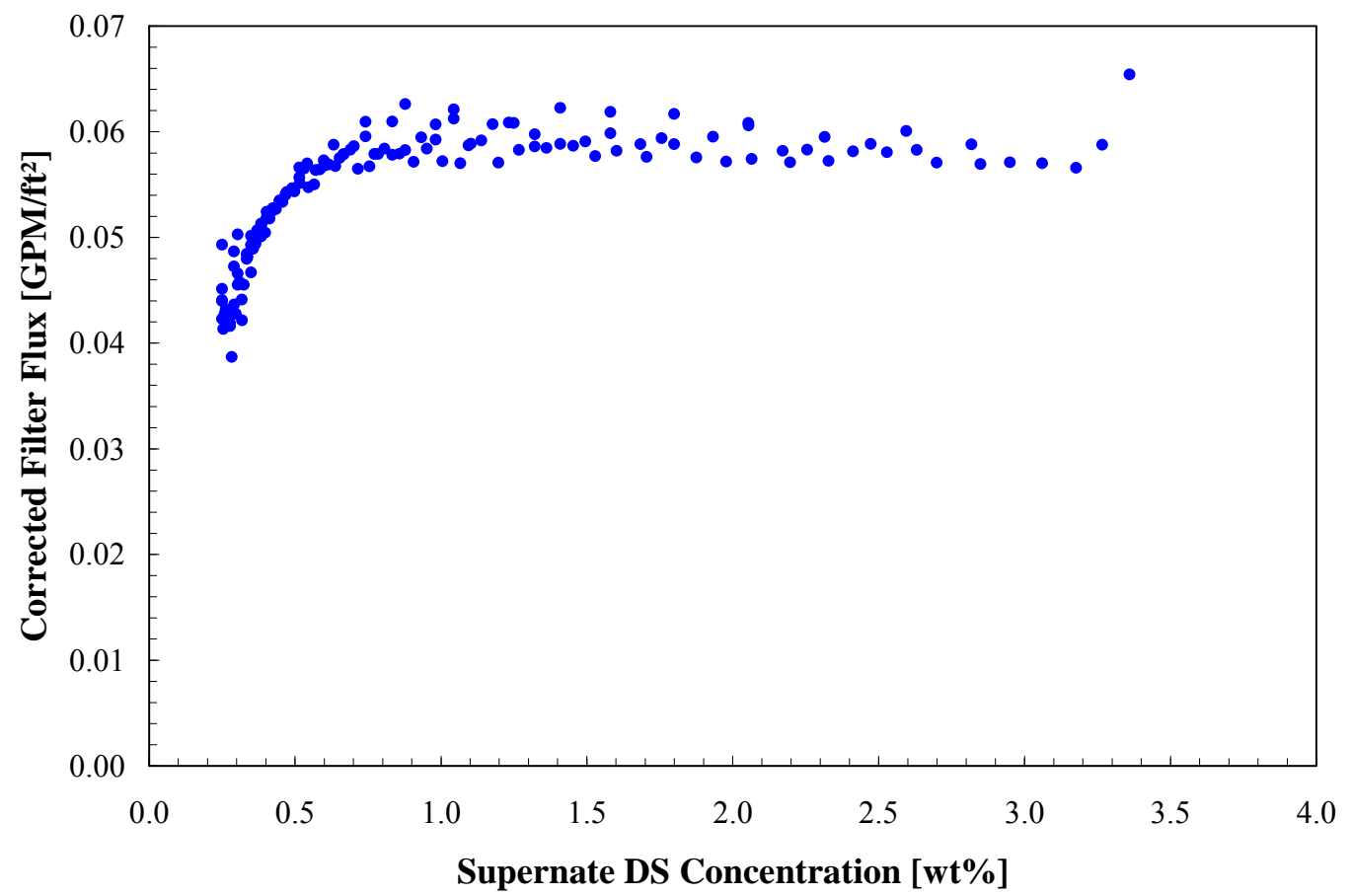

Figure 8.30. Corrected Total Filter Flux as a Function of Supernate DS Concentration for Post-Oxidative-Leach Washing, Integrated Test B 


\subsection{Integrated Test D}

Integrated Test $\mathrm{D}$ included five filtration processes of interest. These were:

- $\quad$ Pre-leach simulant concentration. Two separate dewatering operations that concentrated two batches of neat simulant from $\sim 5-\mathrm{wt} \%$ UDS to greater than 20 -wt $\%$ UDS.

- $\quad$ Post-caustic-leach concentration. The caustic-leached simulant was concentrated to UDS concentrations in excess of $17-\mathrm{wt} \%$ UDS.

- Post-caustic-leach washing. The concentrated post-caustic-leach slurry was washed with IW.

- Post-oxidative-leach washing. The oxidative-leached slurry was washed with IW.

- $\quad$ Post-oxidative-leach wash concentration. Following oxidative leaching and washing, the slurry was dewatered to $\sim 20$-wt $\%$ UDS.

No backpulsing of the filter bundles was performed during the dewatering or washing steps of Integrated Test D.

\subsubsection{Pre-Caustic-Leach Concentration Batch \#1}

Integrated Test D pre-caustic-leach concentration was intended to increase the slurry concentration 20 -wt $\%$ UDS. Dewatering operations began after transfer of an initial volume of waste simulant slurry to Tank T02A. During dewatering operations, the slurry level in Tank T02A was maintained by periodic batch transfers of neat simulant from Tank T01B. After completion of batch transfers, the contents of Tank T02A were further concentrated. Pre-caustic-leach concentration operations were split across two batches. Batch \#1 pre-leach filtration activities employed a single filter bundle.

Figure 8.31 compares the measured UDS values from analytical samples taken during the pre-caustic-leach concentration of Batch \#1 to those estimated by the filtration dewatering mass balance. This figure confirms that the dewatering operation concentrated the slurry concentration from $6-\mathrm{wt} \%$ to $24-\mathrm{wt} \%$. Batch transfers continued to approximately $17-\mathrm{wt} \%$. Final dewatering of the slurry from $17-w \mathrm{t} \%$ to $24-\mathrm{wt} \%$, during which time the tank level was allowed to decrease, occurred rapidly.

Figure 8.32 and Figure 8.33 show the temperature and TMP corrected filter flux measured during the pre-caustic-leach concentration of Batch \#1 as functions of the time stamp or the UDS concentration. The flux behavior is consistent with Integrated Test B pre-leach batch concentration. Flux versus time shows a steady decline that can be associated with filter-fouling. The dewatering curve (Figure 8.33) does not evidence a dewatering knee, and as such, the limiting resistance for filtration is assumed to be the filter membrane. The dewatering curve has a slope discontinuity near $17-\mathrm{wt} \%$ that can be associated with the stop of batch transfers (and the acceleration in the rate of slurry concentration). The slope discontinuity supports the conclusion that flux decline is associated with fouling of the filter (rather than increases in UDS). 


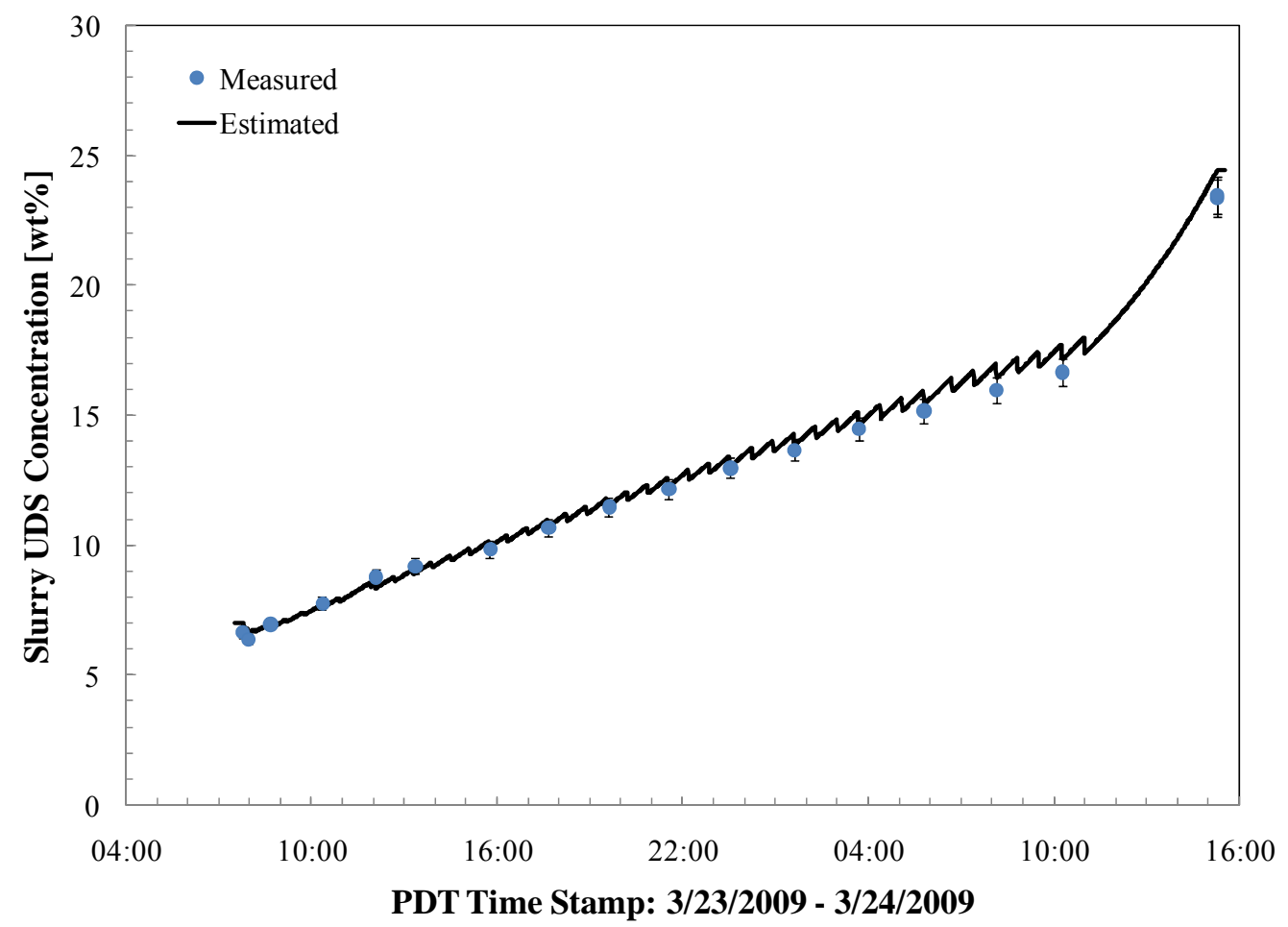

Figure 8.31. Comparison of Measured to Calculated UDS During Integrated Test D Batch \#1 Pre-Caustic-Leach Concentration

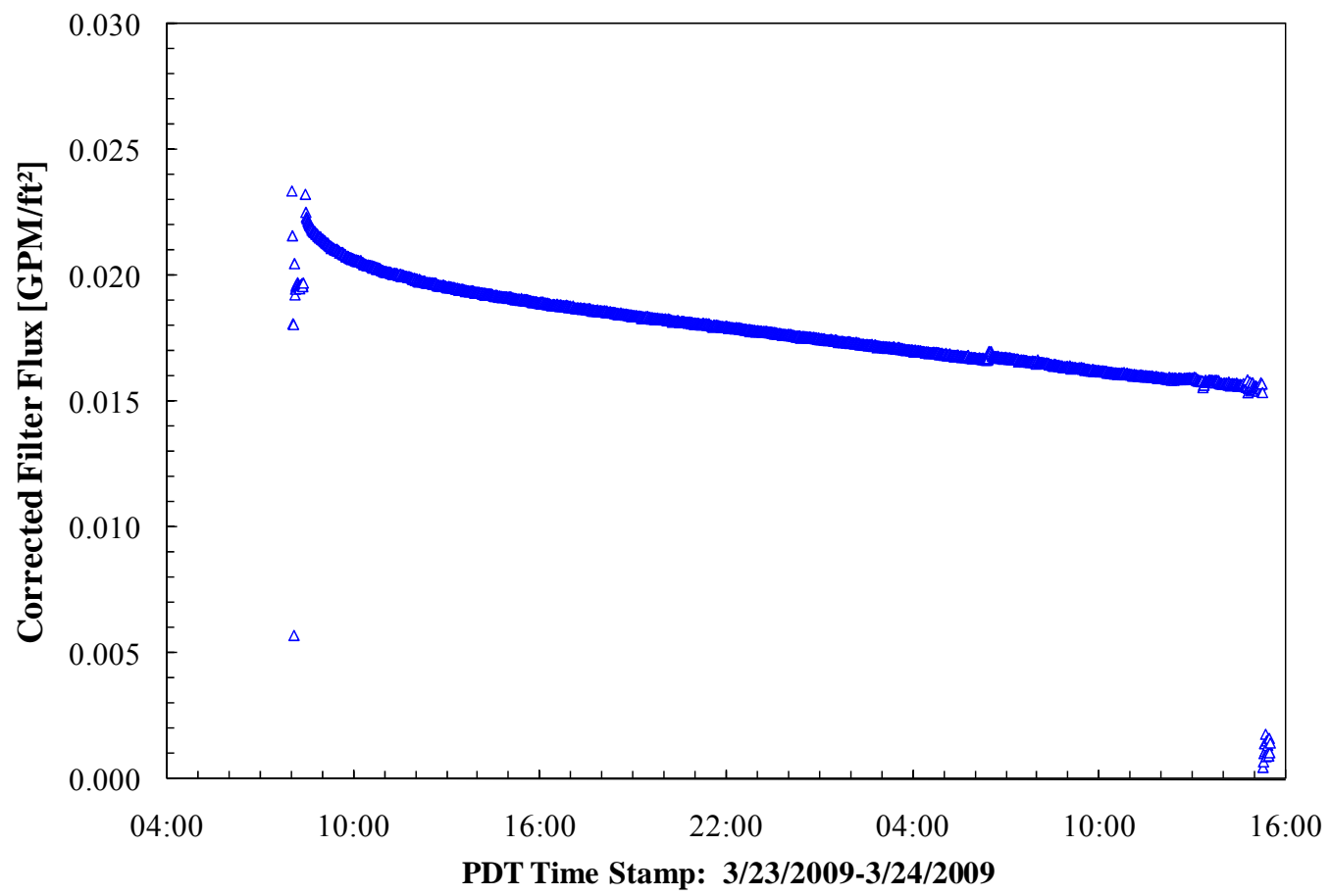

Figure 8.32. Filter \#1 Flux (corrected for TMP and temperature variations) for Integrated Test D Batch \#1 Pre-Caustic-Leach Concentration as a Function of Time 


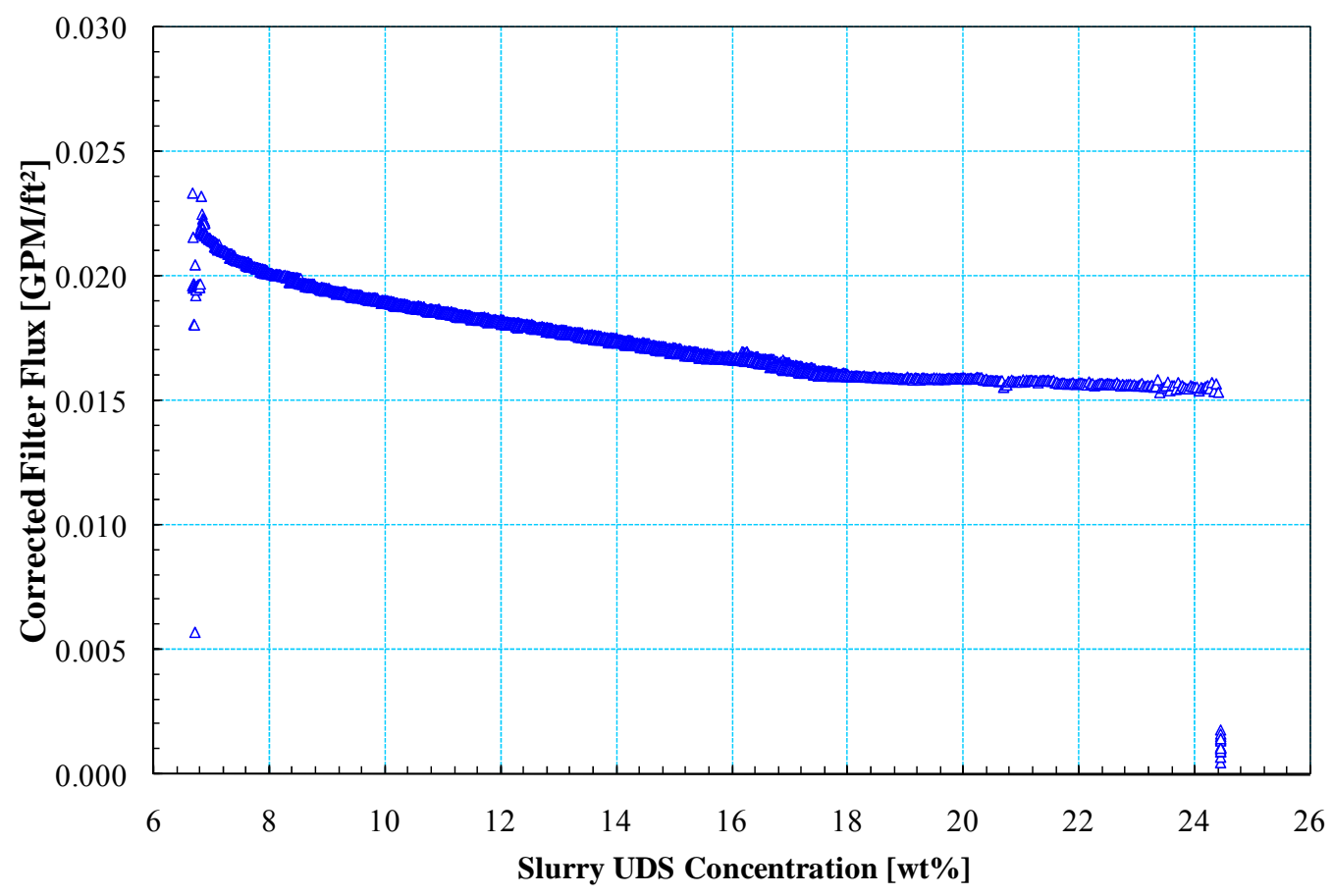

Figure 8.33. Corrected Filter \#1 Flux for Integrated Test D Batch \#1 Pre-Caustic-Leach Concentration as a Function of Slurry UDS

\subsubsection{Pre-Caustic-Leach Concentration Batch \#2}

Batch \#2 pre-caustic-leach concentration activities employed all five filter bundles. Figure 8.34 compares the measured UDS values from samples taken during Batch \#2 concentration to those estimated by filtration dewatering mass balance. The estimated and measured UDS confirm that dewatering operations successfully concentrated the slurry from $6-\mathrm{wt} \%$ to $24-\mathrm{wt} \%$. Batch transfers were active at UDS concentrations below 17-wt\%. After completion of batch transfers from Tank T01B at 17-wt\%, there is an acceleration in the rate of UDS increase.

Figure 8.35 and Figure 8.36 show the total temperature and TMP corrected filter flux measured during the pre-caustic-leach concentration of Batch \#2 as functions of the time stamp or the UDS concentration. The filtration stoppage from 0900 to $1000 \mathrm{hrs}$ caused a discontinuous jump in filter flux below 11-wt\% UDS in the dewatering curve. Such jumps indicate disruption and removal of filter cake as a result of the stoppage. Apart from this jump, the filtration behavior below $19-\mathrm{wt} \%$ is smooth and is consistent with previous pre-leach batch concentrations that showed membrane resistance limited filtration. Specifically, flux declines slowly with increasing solids concentrations up until batch transfers are stopped; this decline has been associated with fouling of the filter and does not appear to be associated with UDS increase. At $19-w t \%$, the flux begins to decline rapidly. This change is immediate and shows the characteristics of a dewatering knee (i.e., a transition to cake controlled filtration). However, the point at which flux begins to decline also corresponds to a point where control of the filter AV became difficult. As such, the flux decline may also be attributable to loss of filtration velocity. 
Figure 8.37 shows a comparison of the total flux achieved in Batch \#1 and Batch \#2. The two key differences immediately visible in this comparison are that Batch \#2 achieved a higher flux over most of the concentration range relative to Batch $\# 1$ and Batch $\# 1$ does not show a dewatering knee even though the same range of concentration as Batch \#2 was achieved. With respect to the difference in flux, the results are similar to those observed for pre-leach batch concentration in Integrated Test B, with the major exception that now Batch \#2 shows the higher flux.

The lack of a dewatering knee in the Batch \#1 dewatering curve is likely a result of lower flux. Specifically, it is reasonable that the lower fluxes would drive and hold fewer solids to the filter surface for the same AV. Thus to see a dewatering knee in Batch \#1 concentration, a larger final UDS concentration would have to be achieved relative to Batch \#2.

Higher filter flux in Batch \#2 (relative to Batch \#1) is unexpected and is not consistent with the observations of pre-caustic-leach concentration in Integrated Test B. Because Integrated Test D Batch \#1 pre-caustic-leach concentration activities are expected to foul the single filter bundle used (and minimally foul the other filters which were in-line to slurry flow), Batch \#2 filter flux should be comparable to or lower than Batch \#1 flux. This is not the case, even when only the flux for filter bundle \#1 is compared between the two batches. Indeed, filter bundle \#1 (which is used in both batch concentrations) shows substantially higher flux for Batch $\# 2$ operations. This anomaly is currently unexplained. Suspected causes could include (but are not limited to):

- Filter-loop flush operations between Batch \#1 and Batch \#2 dewatering operations that effectively cleaned the filter bundles

- Potential differences in the way solids distribute on the filters as a result of using all five filter bundles.

Relative to Integrated Test B, the filter flux achieved in Integrated Test D during pre-caustic-leach concentration is generally lower. This is expected, as the filters had not been cleaned since prior to the execution of Integrated Test B. For Integrated Test D operations, the filters are expected to be significantly fouled from Integrated Test B operations. 


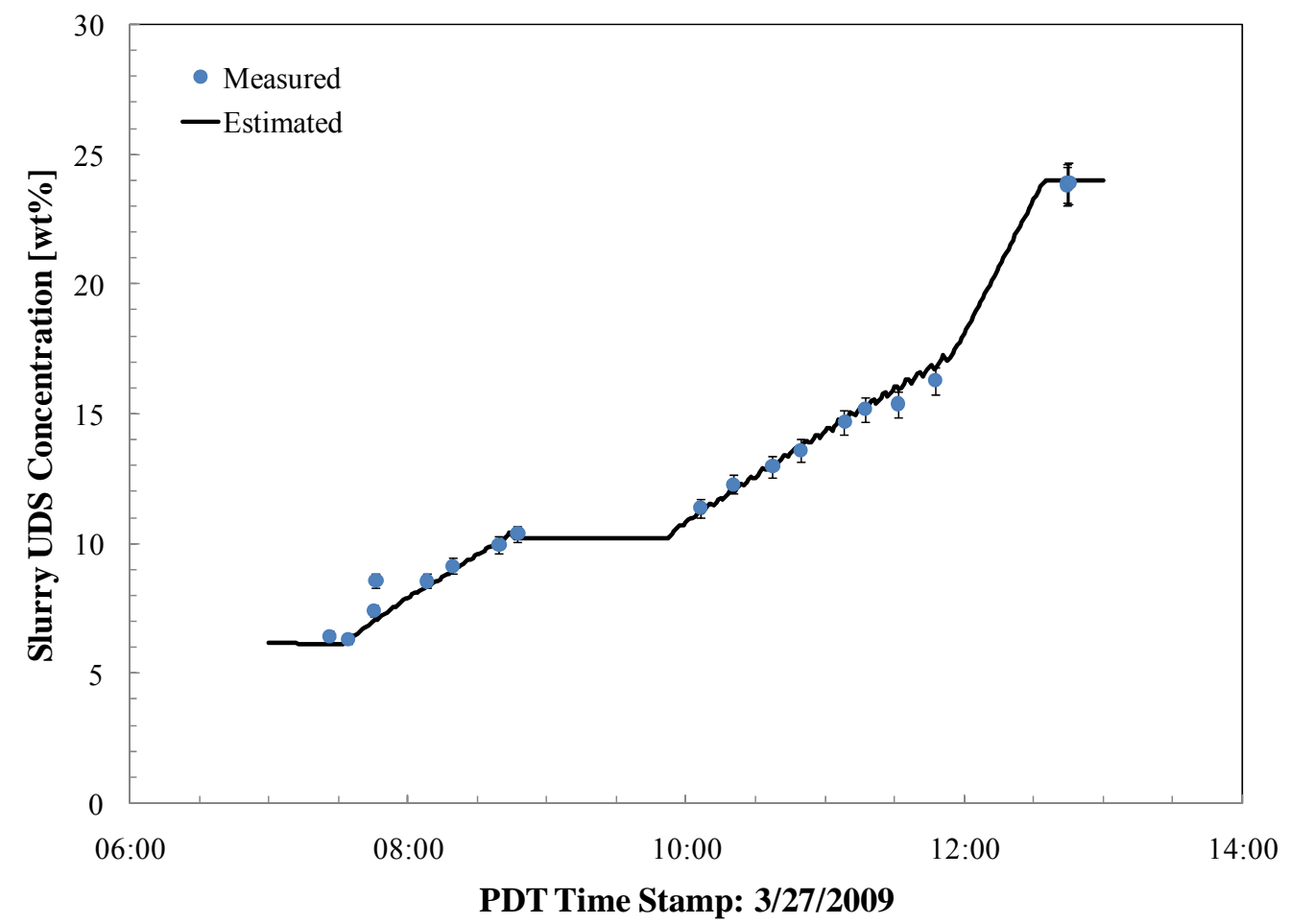

Figure 8.34. Comparison of Measured to Calculated UDS During Integrated Test D Batch \#2 Pre-Caustic-Leach Concentration

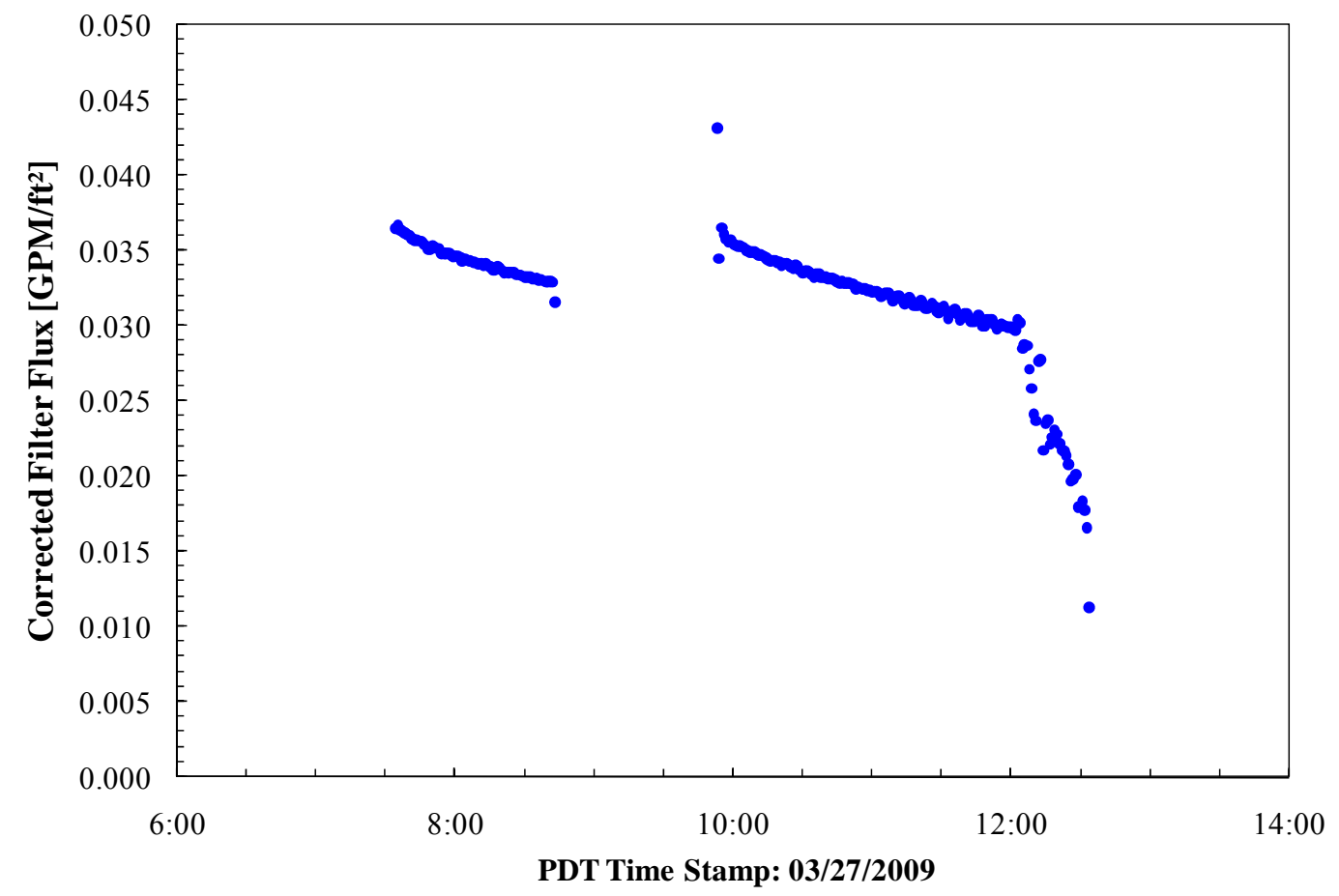

Figure 8.35. Total Filter Flux (corrected for TMP and temperature variations) for Integrated Test D Batch \#2 Pre-Caustic-Leach Concentration as a Function of Time 


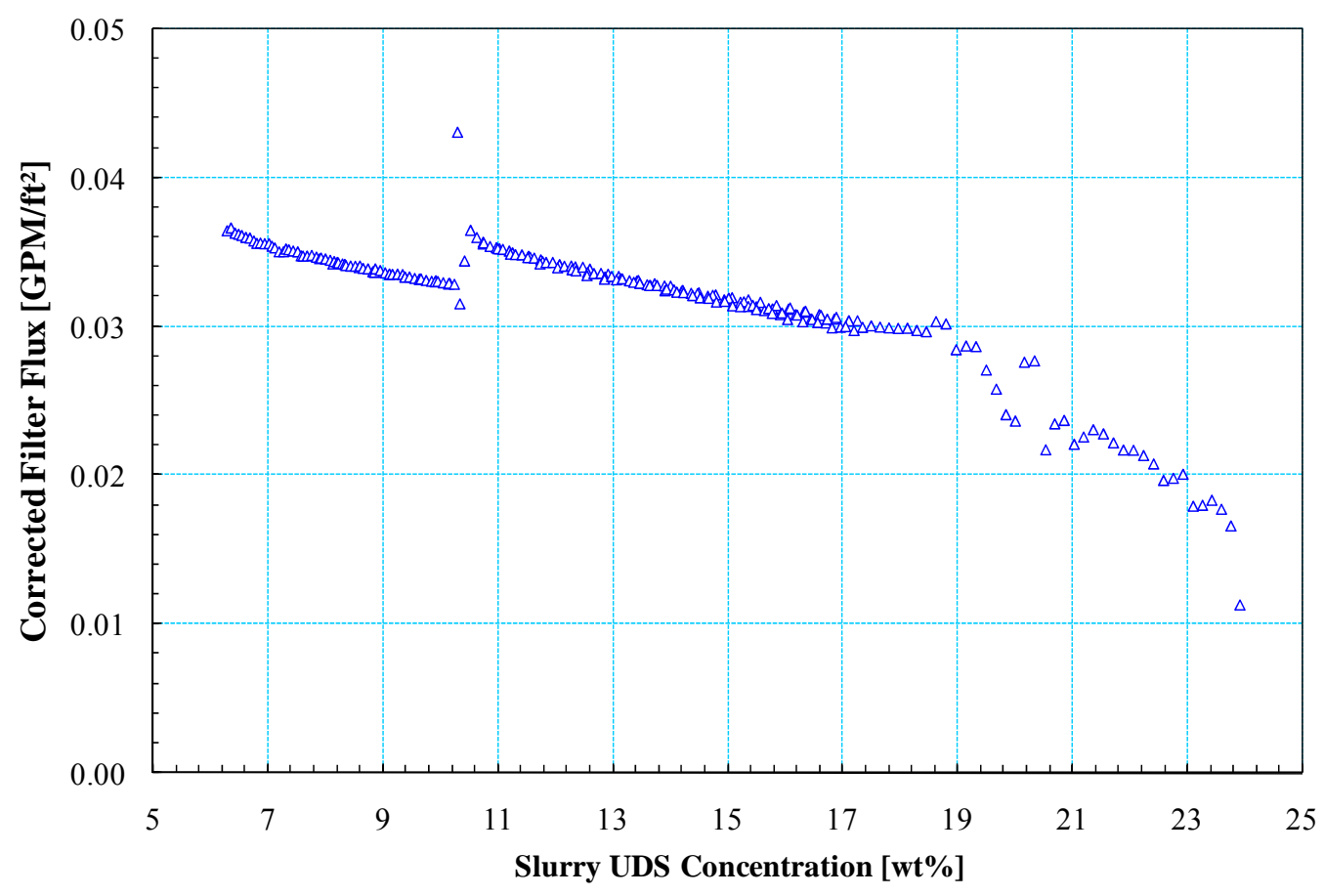

Figure 8.36. Corrected Total Filter Flux for Integrated Test D Batch \#2 Pre-Caustic-Leach Concentration as a Function of Slurry UDS

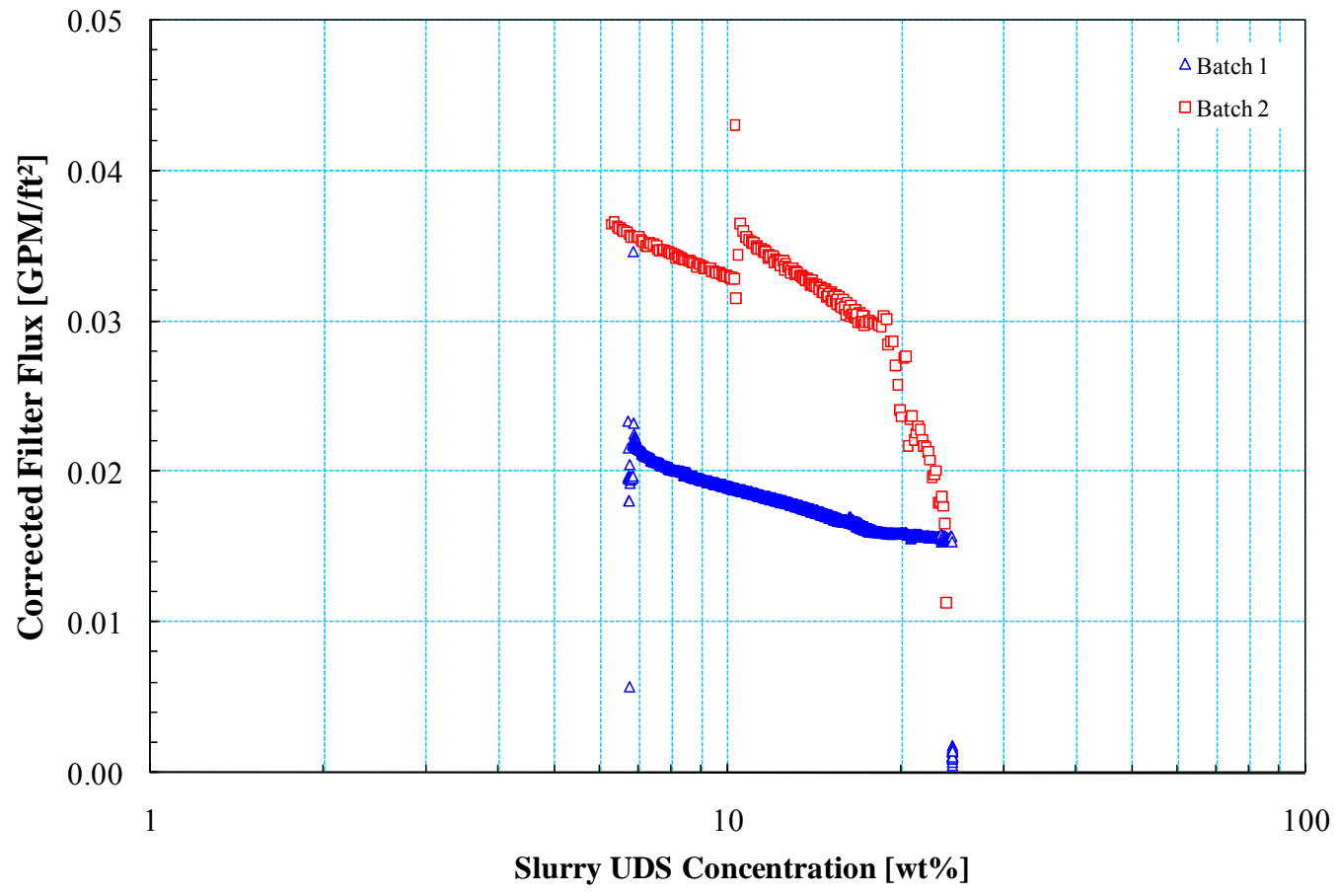

Figure 8.37. Total Filter Flux (corrected for TMP and temperature variations) Comparison of Integrated Test D Batch \#1 to Batch \#2 Pre-Caustic-Leach Concentration as a Function of Slurry UDS 


\subsubsection{Leached Slurry Concentration}

Post-caustic-leach concentration activities were intended to increase the concentration of leached solids to approximately $17-\mathrm{wt} \%$ UDS. The level in Tank T02A was maintained using batch transfers of caustic-leached slurry from Tank T01A. The caustic-leached solids were concentrated using all five filter bundles (which differed from post-caustic-leach concentration activities in previous Integrated tests, which employed only a single filter bundle).

Figure 8.38 compares the measured UDS values from samples taken during post-caustic-leach slurry concentration to those estimated by a dewatering mass balance. The measured and estimated UDS values confirm that the slurry concentration was increased to concentrations greater than $17-\mathrm{wt} \%$ UDS. Batch transfers only continued until 8-wt $\%$ UDS. After completion of batch transfers, the UDS increased more quickly save for the periods were the filtration operations were stopped to allow transfer of the remaining Tank T02A contents and a short stoppage near $2200 \mathrm{hrs}$ (to allow a change in the mode of PJM operation). Because these transfers were made using a portable pump, the slurry transfer was not metered as for the batch transfers. As such, these transfers were not accounted for in the material balance, which accounts for the slight disparity in measured and predicated UDS after $1300 \mathrm{hrs}$.

Figure 8.39 and Figure 8.40 show the total temperature and TMP corrected filter flux measured during the post-caustic-leach concentration as functions of the time stamp or the UDS concentration. The filter flux in both figures shows significant scatter. This scatter appears to result from TMP oscillation during filtration operations; it did not prevent the filtration target concentration of $17-\mathrm{wt} \%$ from being reached. The filter flux curves also contain three discontinuities that can be associated filtration stoppages. Apart from these discontinuities, the filter flux appears to decrease throughout the filtration operation. Figure 8.39 indicates that the decline in flux accelerates toward the end of the dewatering operation. In previous tests, gradual declines were associated with filter-fouling. For the current dewatering operation, the accelerated decline is likely a combination of filter-fouling and loss of AV toward the end of the test. The dewatering curve evidences no changes in slope that would indicate a transition to cake-controlled filtration (i.e., a dewatering knee). 


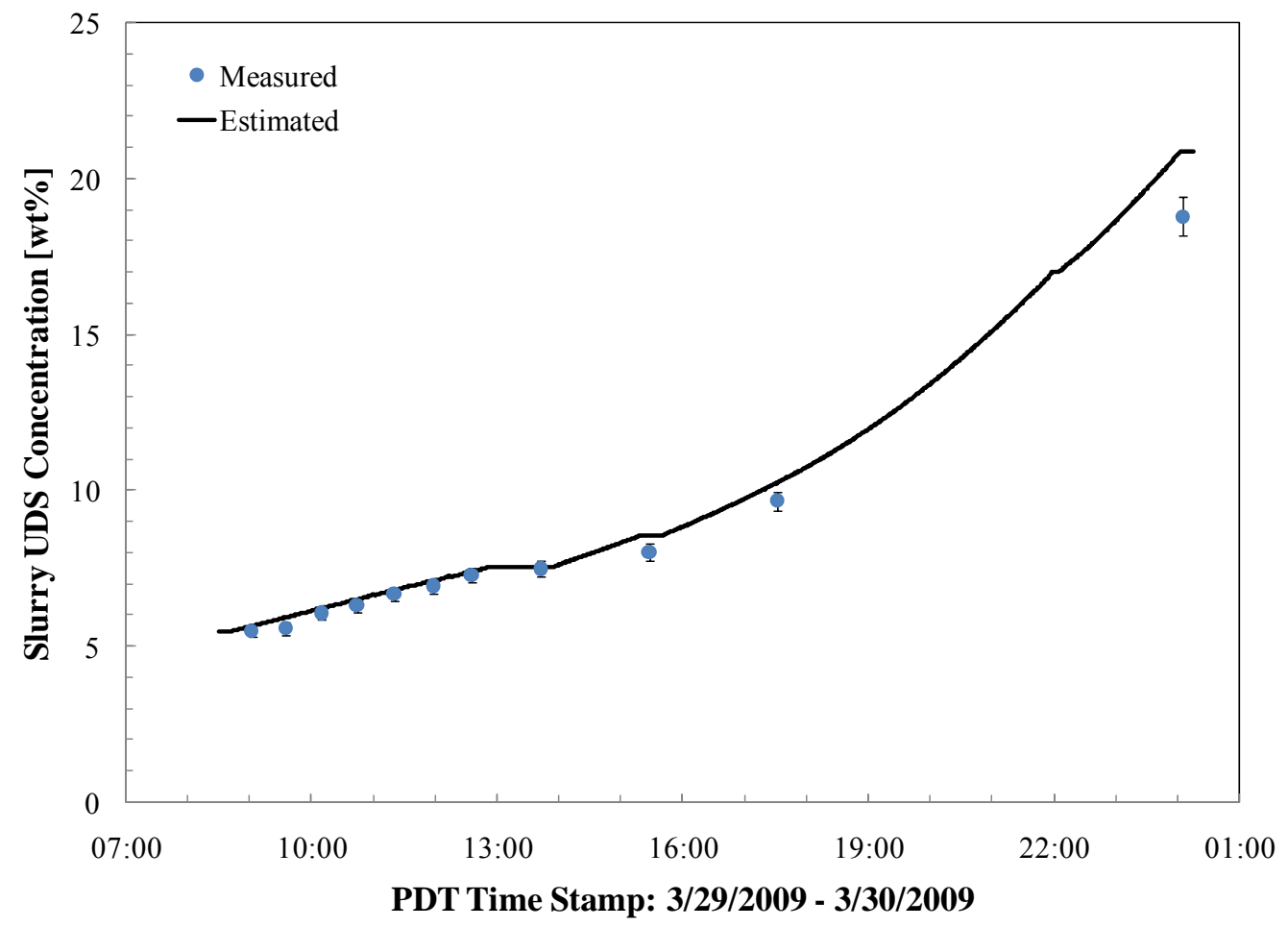

Figure 8.38. Comparison of Measured to Calculated UDS During Integrated Test D Post-Caustic-Leach Concentration

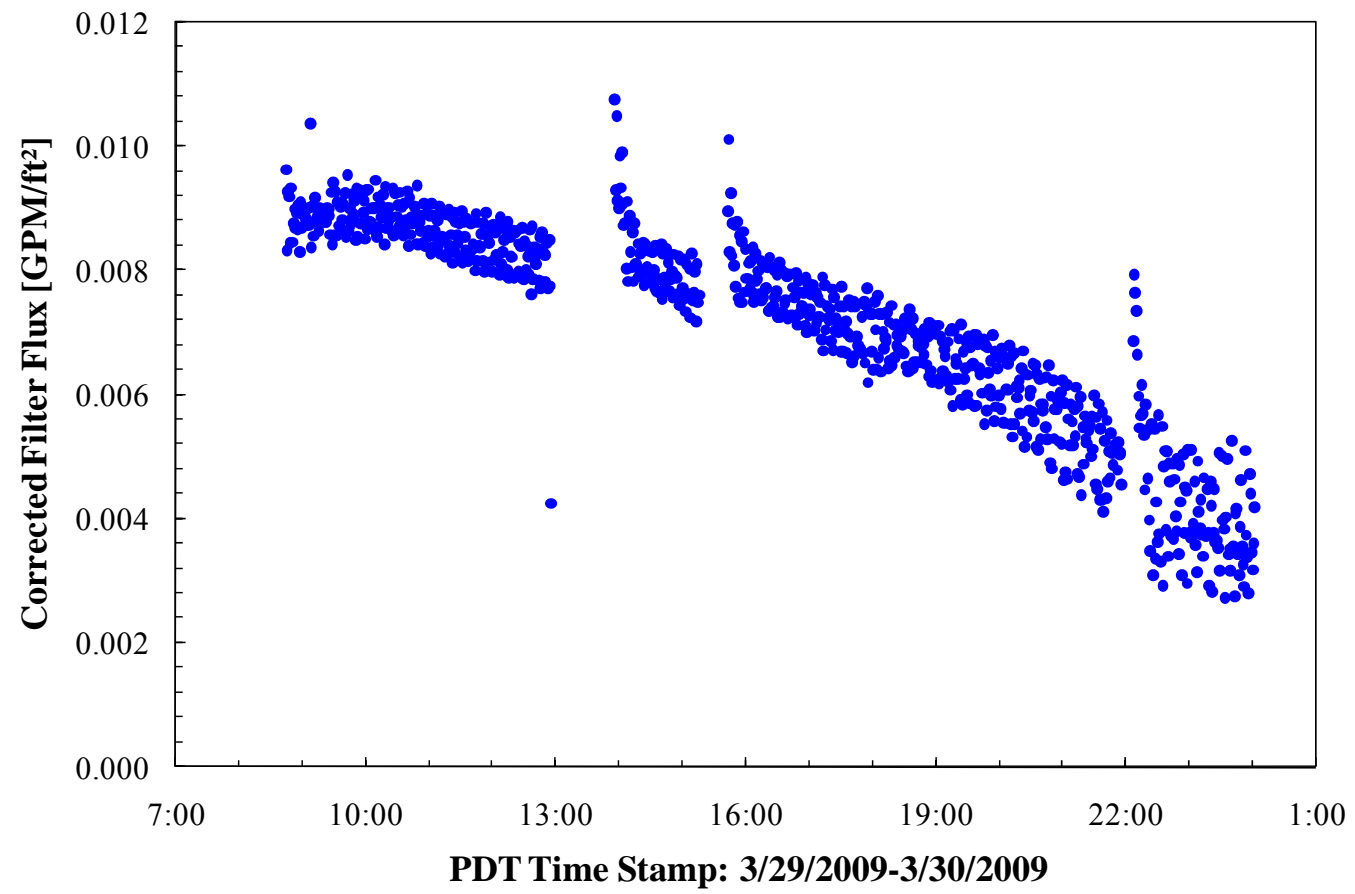

Figure 8.39. Total Filter Flux (corrected for TMP and temperature variations) for Integrated Test D Post-Caustic-Leach Concentration as a Function of Time 


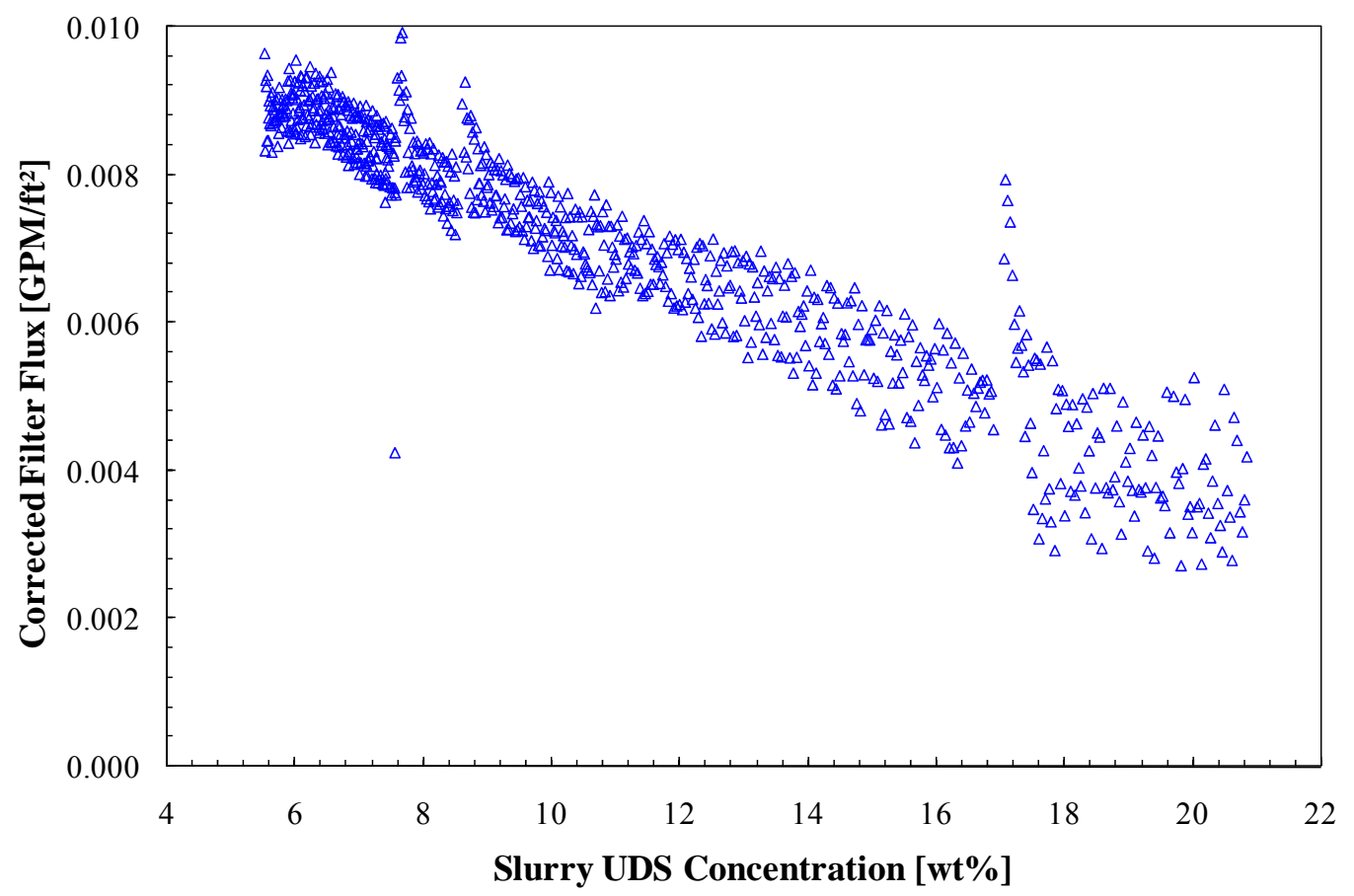

Figure 8.40. Corrected Total Filter Flux for Integrated Test D Post-Caustic-Leach Concentration as a Function of Slurry UDS

\subsubsection{Post-Caustic-Leach Slurry Washing}

Following post-caustic-leach concentration, the slurry was washed to reduce dissolved solids content. A detailed analysis of post-caustic-leach washing operations is provided in Section 10. Filter flux as a function of time and DS concentration are presented in this section. Filtration during post-caustic-leach washing operations employed all five filter bundles. The duration of this process step in the PEP is $\sim 1 / 4.5$ times its expected duration in the PTF.

Figure 8.41 compares the measured UDS values from samples taken during leached slurry washing to those predicted by washing mass balance estimates. The estimated curve is required for calculation of filter flux. The curve shows washing operations yield a progression of dissolved solids concentrations from the initial value of $37-\mathrm{wt} \%$ to the final value near $2-\mathrm{wt} \%$. The curve is functionally similar to the DS curve for Integrated Test B post-caustic-leach washing.

Figure 8.42 and Figure 8.43 show the temperature and TMP corrected filter flux measured during the post-caustic-leach washing operation as functions of the time stamp or the DS concentration. As the washing progressed, the filtering rate improved significantly. Washing of dissolved solids from the supernate reduced the viscosity from the initial value of $\sim 11 \mathrm{cP}$ to a final value of $\sim 1 \mathrm{cP}$. The factor of 11 reduction in viscosity is not reflected by the increase in filter flux from $\sim 0.005 \mathrm{GPM} / \mathrm{ft}^{2}$ at the start of washing to $\sim 0.030 \mathrm{GPM} / \mathrm{ft}^{2}$ at the end of washing. As with previous operations, this suggests that flux could be hindered by fouling, precipitation of solids, or entrainment of air in the filter membrane. 
The filter flux behavior is similar to that observed for Integrated Test B post-caustic-leach wash operations. The primary difference for the Integrated Test $\mathrm{D}$ curve is the secondary decline and flux recovery in flux between $10-\mathrm{wt} \%$ and $2-\mathrm{wt} \%$ (which is not present in the curve for Integrated Test B operations but which was observed to a greater extent in Integrated Test A operations). For Integrated Test D operations, the oscillatory behavior appears to be to be associated with either air entrainment issues throughout test (as evidenced by a flowmeter divergence between Pump T42A suction and Pump T43A discharge readings) or the reduction in filter AV toward the end of testing.

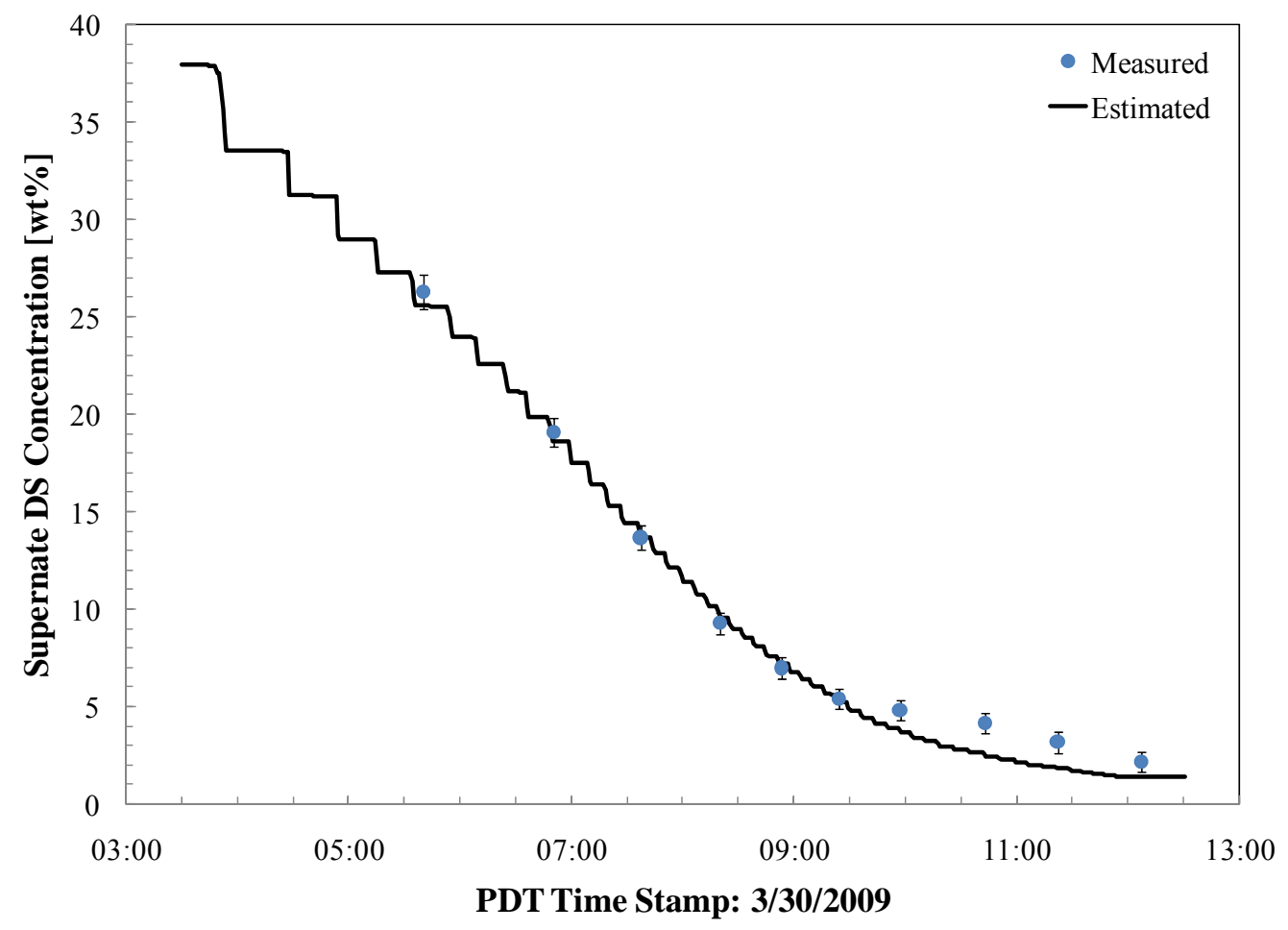

Figure 8.41. Comparison of Measured to Calculated DS During Integrated Test D Leached Slurry Washing 


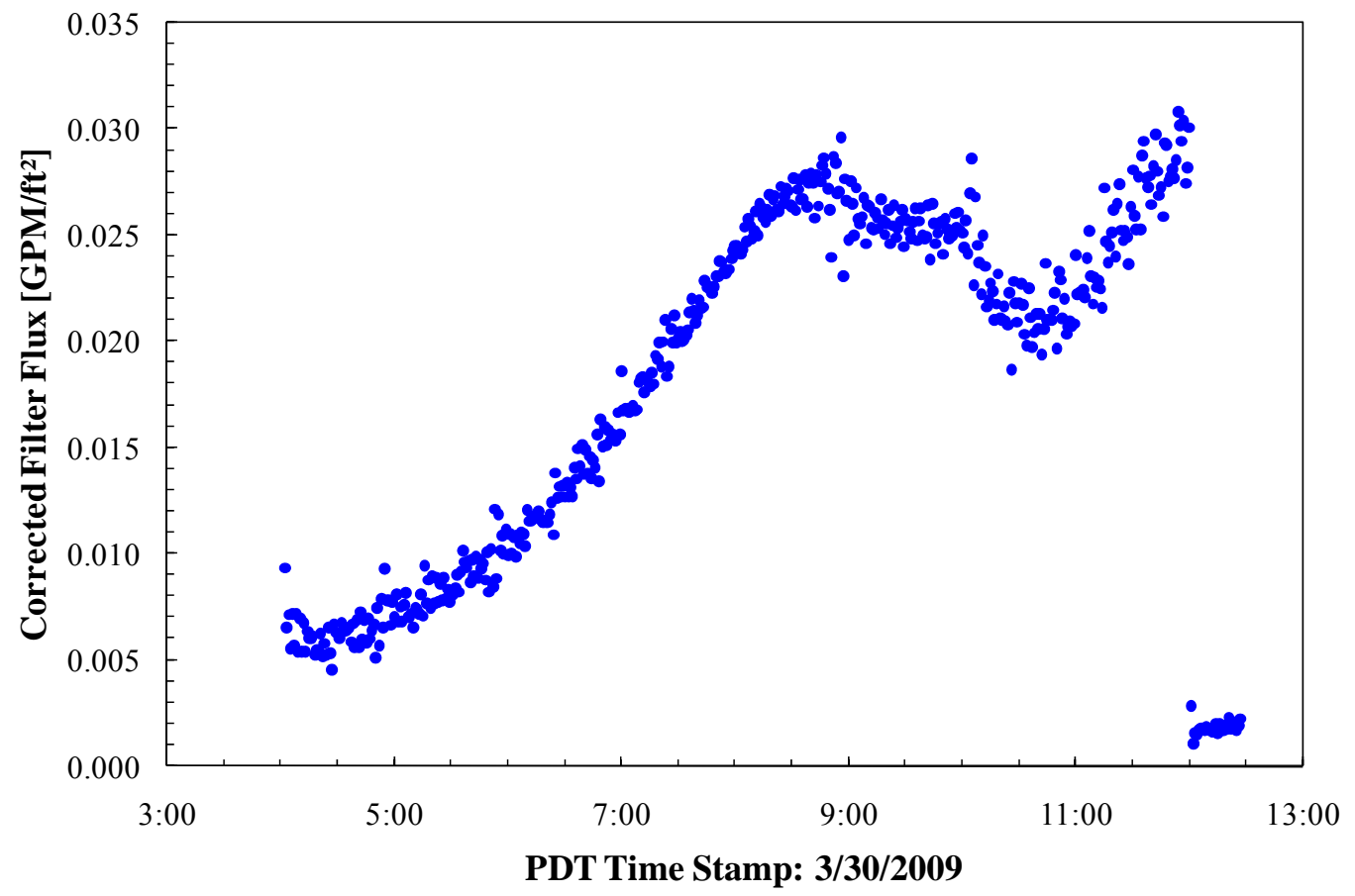

Figure 8.42. Total Filter Flux (corrected for TMP and temperature variations) for Integrated Test D Leached Slurry Washing as a Function of Time

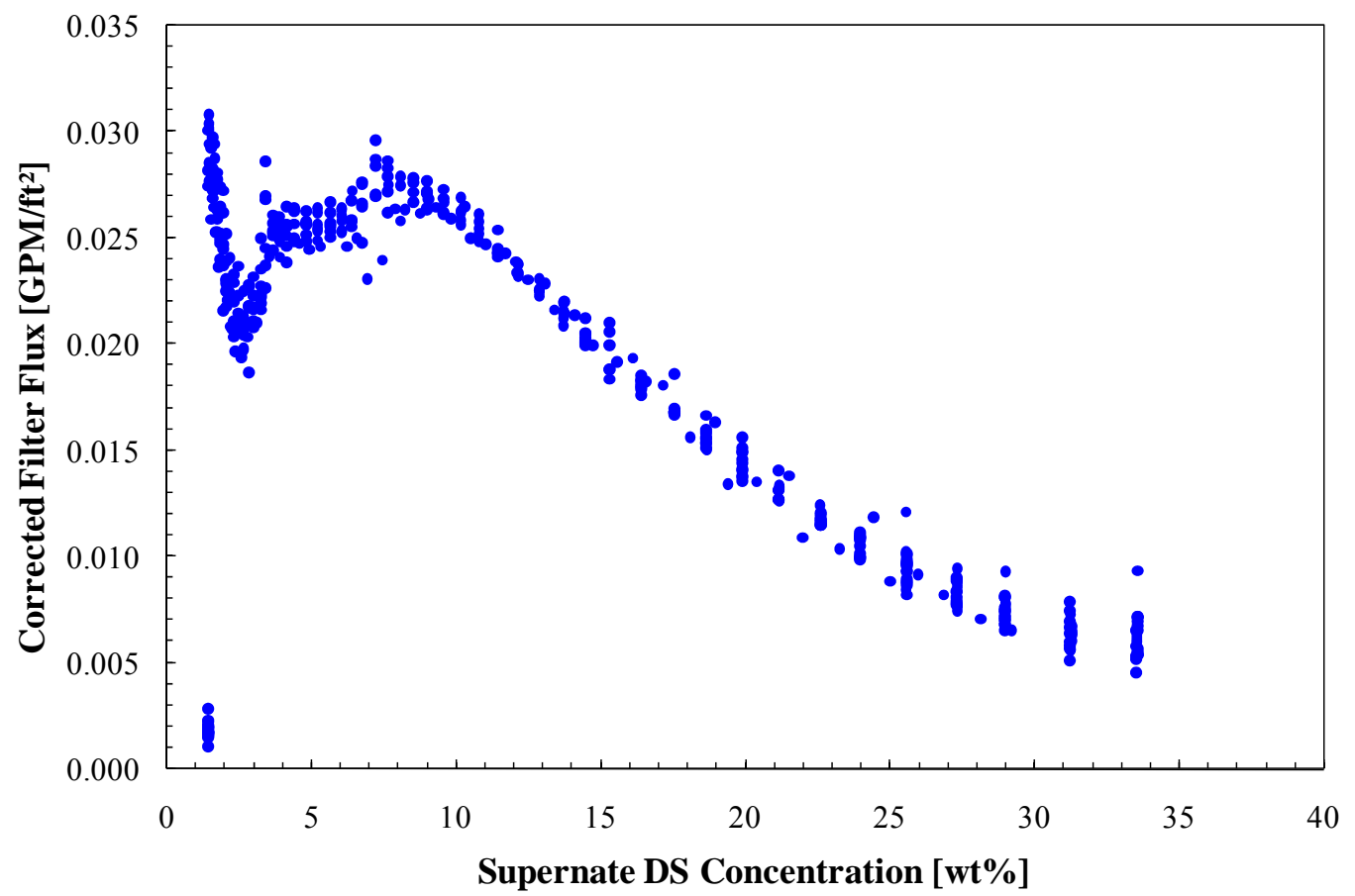

Figure 8.43. Total Filter Flux (corrected for TMP and temperature variations) for Integrated Test D Leached Slurry Washing as a Function of Supernate DS Concentration 


\subsubsection{Post-Oxidative-Leach Washing}

Following oxidative leaching operations, the leached slurry was washed and dewatered. The washing and concurrent dewatering operations employed all five filter bundles. The duration of this process step in the PEP is $\sim 1 / 4.5$ times its expected duration in the PTF. Figure 8.44 compares the measured DS values from samples taken during the oxidative leaching and washing operations to those predicted by the calculated mass balance. Post-oxidative-leach washing facilitates a drop in the supernate dissolved solids concentration from $2.8-\mathrm{wt} \%$ to $0.3-\mathrm{wt} \%$.

Figure 8.45 and Figure 8.46 show the temperature and TMP corrected filter flux measured during the post-oxidative-leach washing operation as functions of the time stamp or the DS concentration. Post-oxidative-leach wash operations for Integrated Test D show significant filter flux scatter relative to Integrated Test B operations. This difference derives from significant variation ( \pm 6 psid $)$ in the TMP during post-oxidative-leach activities in Integrated Test D. The TMP variation was accompanied by difficulty in meeting target $\mathrm{AV}$, the latter of which may indicate possible air entrainment/pumping issues. These difficulties did not ultimately prevent completion of washing operations.

The filter flux appears to be relatively insensitive to changes in dissolved solids content, although any trends may be masked by flux variation. The filter flux achieved during post-oxidative-leach washing is low $\left(0.015 \mathrm{GPM} / \mathrm{ft}^{2}\right)$ relative to that observed at the end of post-caustic-leach washing $\left(0.03 \mathrm{GPM} / \mathrm{ft}^{2}\right)$. This contrasts with the behavior observed in Integrated Test B, where the post-oxidative wash flux was much higher than the corresponding flux at the end of post-caustic-leach washing. Integrated Test D post-oxidative-leach washing operations were conducted at low AV of 9-10 ft/s relative to previous operations $(>11 \mathrm{ft} / \mathrm{s})$. As such, the relatively low filter flux observed in Figure 8.45 and Figure 8.46 may be caused by the atypically low AV employed for washing. In this test step, the filter-loop flow rate was reduced in an attempt to manage air entrainment in the slurry.

Figure 8.46 hints at a flux decline as the DS concentration falls below $0.5-w t \%$. Throughout post-oxidative-leach washing operations, permeate viscosity is relatively constant at $\sim 1.0 \mathrm{cP}$. As such, a change in permeate viscosity is not responsible for the observed flux behavior. The observed flux decline is consistent with the low DS flux decline observed in Integrated Test B operations, which was associated with filter-fouling (via a change in how the slurry solids interact with the filter or solids precipitation) or entrainment of air in the porous filter element (driven by air entrainment in the circulation loop). 


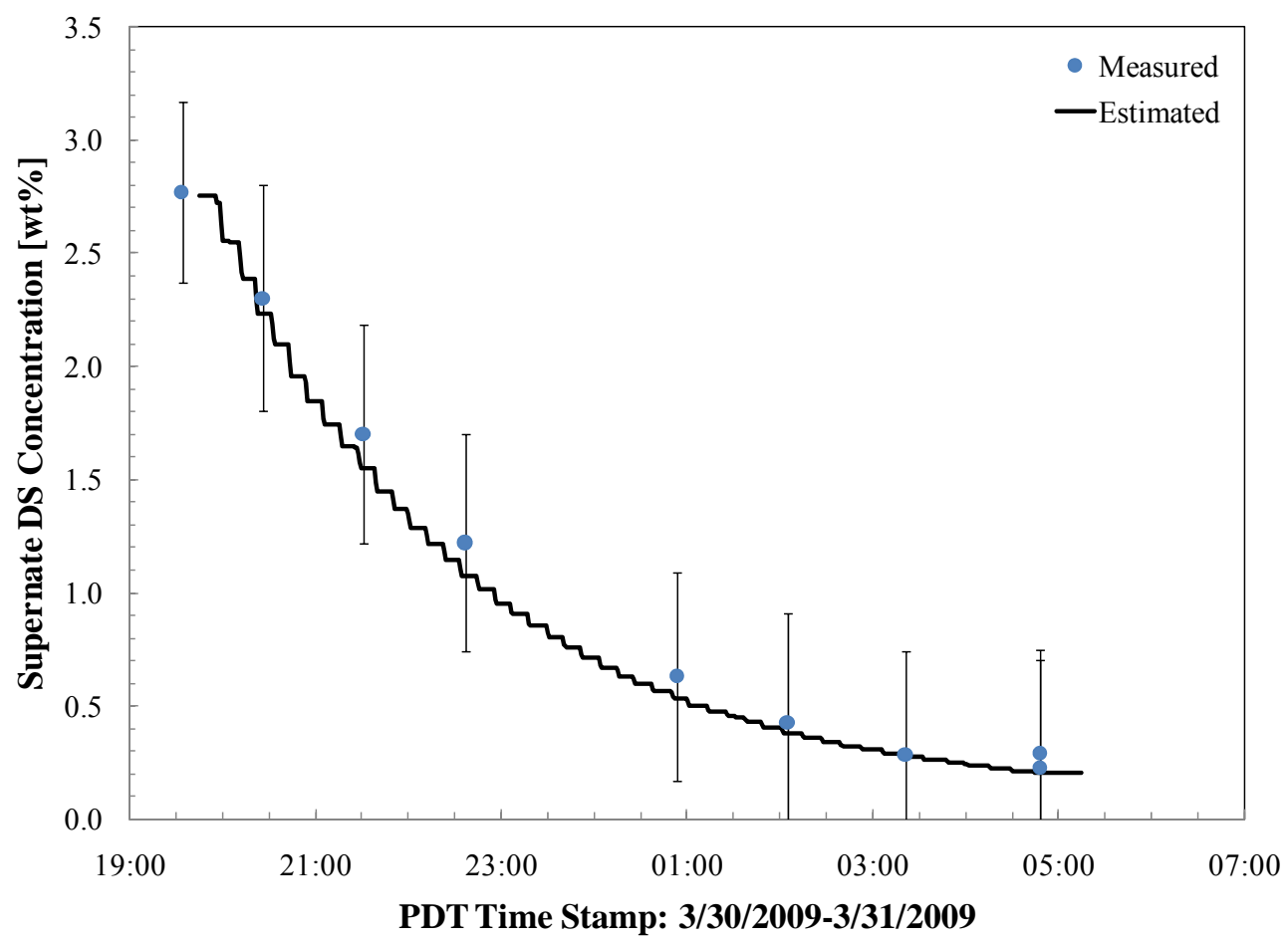

Figure 8.44. Comparison of Measured to Calculated DS During Integrated Test D Oxidative Leaching and Washing

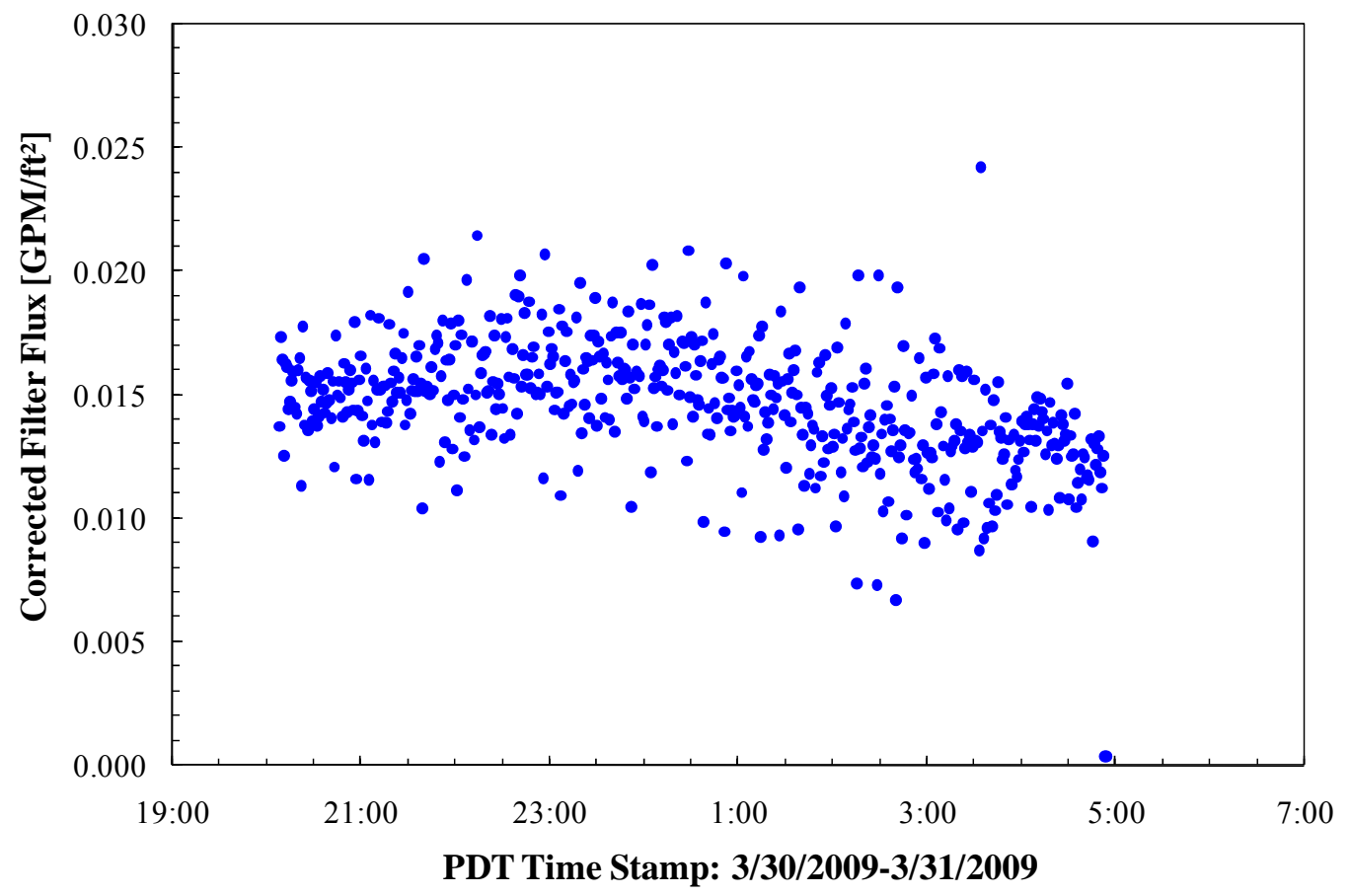

Figure 8.45. Total Filter Flux (corrected for TMP and temperature variations) for Integrated Test D Oxidative Leaching and Washing as a Function of Time 


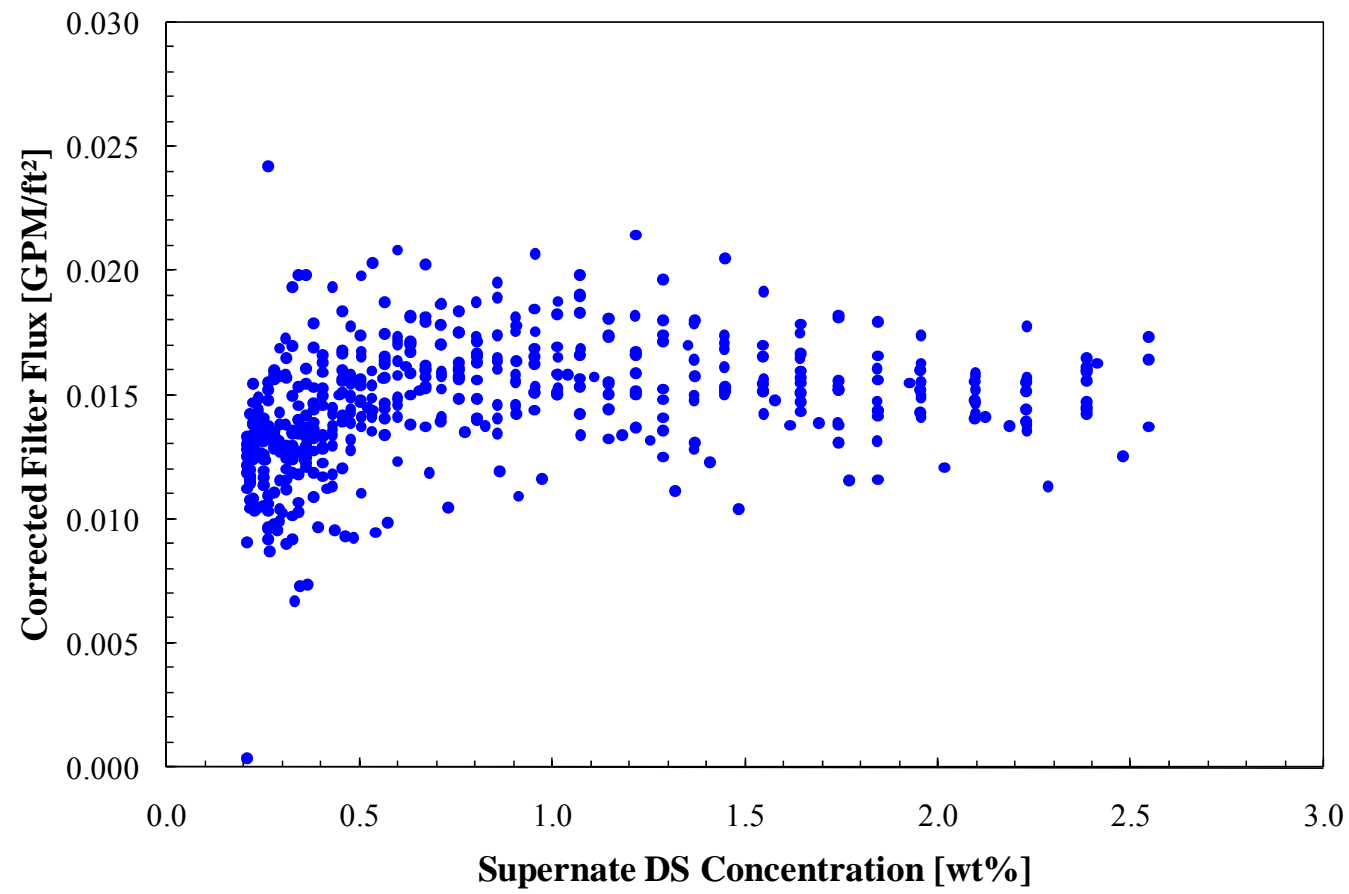

Figure 8.46. Total Filter Flux (corrected for TMP and temperature variations) for Integrated Test D Oxidative Leaching and Washing as a Function of Supernate DS Concentration

\subsubsection{Post-Oxidative Wash Concentration}

After washing of the oxidative leached slurry was complete, a final dewatering operation on the leached and washed slurry was performed. Concentration was performed using all five filter bundles. Because of insufficient sampling, a mass balance calculation could not be performed for this operation. Sufficient permeate density information was available to estimate the average flux for this process. It was determined to be approximately $0.013 \mathrm{GPM} / \mathrm{ft}^{2}$.

\subsection{Summary of Integrated Test Filtration}

Integrated testing examined a number of filtration operations with as-prepared, leached, and leached and washed PEP simulant slurry. Filtration operations were successfully completed for Integrated Test A, although the high-solids filter test was postponed until the completion of Integrated Test B activities.

Notable observations for Integrated Test A operations are:

- Post-caustic-leach concentration required significant time to complete (which was expected given the large volume of slurry supernate). Fluxes were lower than initially anticipated, and backpulsing of the filters was attempted to restore filter flux and evaluate the effectiveness of backpulsing. A series of 38 backpulse "events" was conducted. Analysis of the permeate production rates before and after each backpulse indicates that backpulse was effective at temporarily restoring filter flux . The backpulsing schedule applied in Integrated Test A was effective in that it appears to have reduced the time required to remove the volume of supernate 
targeted by Integrated Test A post-caustic-leach concentration operations (see Appendix B). The overall impact of backpulsing on filter performance is difficult to quantify given 1) that post-leach concentration operations were accompanied by increasing UDS concentration and potential filter-fouling, and 2) given that a control (non-backpulsed) dewatering curve was not measured.

- Evaluation of backpulsing during post-caustic-leach concentration indicates that single backpulses are effective in temporarily restoring permeate production rate and that multiple backpulses (performed in quick succession) do not provide any additional recovery in permeate production rate. Additionally, comparison of backpulses performed at different overpressures indicate no notable difference in recovered rates. As such, all overpressures employed for backpulsing appear to have disrupted the filter cake and removed depth-fouled solids to similar extents.

- Post-caustic-leach concentration dewatering operations do not evidence a dewatering knee (i.e., an abrupt change in the dewatering curve slope indicating transition from a membrane-limited to a cake-limited filtration regime) over the range of UDS examined (2- to 18-wt $\%$ ). As such, dewatering operations for Integrated Test A are likely filter membrane-resistance limited.

- During post-caustic-leach washing operations, the filter flux showed significant oscillation characterized by an initial rapid increase in flux followed by a rapid decrease and subsequent recovery. It is speculated that this oscillation is associated with filter-loop air entrainment. Flux loss could result from trapping of air bubbles in the filter membranes, which would effectively foul/block the filter pores and decrease overall filtration performance. The phenomena impacted all filters, as oscillation is observed in the individual filter flux for all five bundles. It should be noted that oscillations were not observed in post-caustic-leach wash fluxes in Integrated Test B; however, Integrated Test D flux did show some minor oscillation toward the end of the washing operation. While air entrainment is also a suspected cause of Integrated Test D flux oscillation, low filter AV were also present during the Integrated Test D oscillations.

- Post-caustic-leach: A gradual decline in the filter flux measured during post-oxidative-leach washing operations is observed for Integrated Test A. This decline does not correspond to a change in the permeate viscosity, as the starting and ending permeate viscosity during the was step is $\sim 1 \mathrm{cP}$. Post-oxidative-leach Filter flux measured during post-oxidative-leach washing steps for Integrated Tests B and D do not show declines over this DS range, but instead show a relatively constant flux. The cause for steady decline in Integrated Test A post-oxidative-leach wash operations are unknown, but may be related to issues associated with suspected air entrainment. Likewise, the steady decline in flux over time could also be indicative of fouling of the filters, either by existing slurry solids or by solids that precipitate at low DS.

Table 8.4 provides a summary of filtration times for Integrated Test A activities. The time scale for each process operation (see Section 3.0) is also indicated. Filtration activities in Integrated Test A required a total filtration duty time of $315 \mathrm{hrs}$ on Filter 1 and $15.3 \mathrm{hrs}$ on Filters 2 through 5. 
Table 8.4. Integrated Test A Filtration Times (at target TMP and AV)

\begin{tabular}{|c|c|c|c|c|c|c|c|}
\hline \multirow[t]{2}{*}{ Operation } & Operation & \multicolumn{6}{|c|}{ Time Filtered (hr) } \\
\hline & Time Scale $^{(\mathrm{a})}$ & Bundle 1 & Bundle 2 & Bundle 3 & Bundle 4 & Bundle 5 & Total \\
\hline $\begin{array}{l}\text { Post-caustic- } \\
\text { leach } \\
\text { concentration }\end{array}$ & Plant & 299.7 & 0 & 0 & 0 & 0 & 299.7 \\
\hline $\begin{array}{l}\text { Post-caustic- } \\
\text { leach washing }\end{array}$ & Scale & 7.0 & 7.0 & 7.0 & 7.0 & 7.0 & 35.0 \\
\hline $\begin{array}{l}\text { Post-chromium } \\
\text { wash } \\
\text { concentration }\end{array}$ & Not prototypic & 2.0 & 2.0 & 2.0 & 2.0 & 2.0 & 10.0 \\
\hline $\begin{array}{c}\text { Post-oxidative } \\
\text { leach wash }\end{array}$ & Scale & 6.1 & 6.1 & 6.1 & 6.1 & 6.1 & 30.5 \\
\hline $\begin{array}{l}\text { Post-oxidative- } \\
\text { leach wash } \\
\text { concentration }\end{array}$ & Scale & 0.2 & 0.2 & 0.2 & 0.2 & 0.2 & 1.0 \\
\hline Total & -- & 315.0 & 15.3 & 15.3 & 15.3 & 15.3 & 376.2 \\
\hline
\end{tabular}

Filtration operations for Integrated Test B were not subject to any significant issues that prevented completion of test activities. There were slurry conditions that challenged the pumping system's ability to deliver the required AV for filtration without air entrainment. Notable observations for Integrated Test B filtration include:

- Pre-caustic-leach concentration operations were split across two batch dewatering operations. Comparison of the filter flux behavior shows that Batch \#1 operations yielded higher filter fluxes relative to Batch \#2 operations. This is expected, given the suspected depth-fouling of the filter. Specifically, Batch \#1 operations using all five filters fouls all filter bundles (including bundle 1). This pre-existing fouling then causes lower average flux on filter bundle 1 when it is subsequently used (by itself) for Batch \#2. However, it is interesting to note that the reverse behavior (i.e., Batch \#2 shows higher flux) is observed in Integrated Test D pre-caustic-leach concentration operations. Batch \#2 operations for Integrated Test D employ all 5 filter bundles. As such, when considered with the current results for Integrated Test B pre-leach operations, the Integrated Test $\mathrm{D}$ results may suggest that the number of filter bundles employed could impact filter flux.

- Filter flux for pre-caustic-leach concentration operations show a gradual decline in flux. This decline does not appear to depend strongly on or result solely from increases in slurry UDS concentration. Instead, it has been associated with filter-fouling and appears to be proportional to the volume of permeate passed through the filter.

- Four backpulses were performed during post-caustic-leach concentration activities. Analysis of the permeate produced between each backpulse suggest that backpulsing did not appear to significantly improve filtrate production.

- All Integrated Test B operations appear to operate in a filter membrane resistance limited filtration regime and did not evidence a dewatering knee over the range of concentration tested (5-to $\sim 20$-wt $\%$ UDS for pre-caustic-leach concentration and 5- to 18 -wt $\%$ for post-leach concentration). 
- Relative to post-caustic leaching wash operations for Integrated Tests A and D, the filter flux for Integrated Test B filter flux is relatively well behaved. Washing with IW yields significant increases in filter flux from $\sim 0.005 \mathrm{GPM} / \mathrm{ft}^{2}$ to $\sim 0.025 \mathrm{GPM} / \mathrm{ft}^{2}$ during the washing step. The flux increase is not as great as expected based on the factor of $\sim 9$ decrease in permeate viscosity from $8.9 \mathrm{cP}$ at the start of washing to $1.0 \mathrm{cP}$ at the end of washing. This indicates the possibility that flux is hindered as washing proceeds. Several possibilities exist by which filtration could be hindered, including a change in the type of solids interacting with the filter, the way in which the existing solids interact with the filter, or air entrainment in the filters. Post-caustic-leach washing operations for Integrated Tests A and D show flux oscillation. It is suspected that this oscillation is associated with air entrainment in the filter circulation loop. Although Integrated Test B post-caustic-leach washing shows no oscillation, there is reason to suspect air entrainment as the flowmeter readings for Pump T42A suction and Pump T43A discharge diverge.

- The flux observed during post-oxidative-leach washing varies from $\sim 0.06 \mathrm{GPM} / \mathrm{ft}^{2}$ at the start of washing down to $\sim 0.04 \mathrm{GPM} / \mathrm{ft}^{2}$ at the end of washing. The decline in flux starts halfway through the washing operation. Similar decline was observed in Integrated Test A post-oxidative-leach washing, but was present throughout the entire washing operation. Like Integrated Test A, the decline in flux over time can indicate of fouling of the filters, either by trapped air in the porous filter structure, existing slurry solids, or precipitated solids. Because the divergence in the flowmeter readings at the suction to Pump T42A and the discharge to Pump T43A increases at the same point flux begins to decrease, so it is likely that entrainment of air in the filter-loop is the cause of flux decline.

Table 8.5 provides a summary of filtration times for Integrated Test B activities. Filtration activities in Integrated Test B required a filtration duty of $85.1 \mathrm{hrs}$ on filter bundle one and $15.8 \mathrm{hrs}$ on the remaining bundles. 
Table 8.5. Integrated Test B Filtration Times (at target TMP and AV)

\begin{tabular}{|c|c|c|c|c|c|c|c|}
\hline \multirow{2}{*}{ Operation } & \multirow{2}{*}{$\begin{array}{c}\text { Operation } \\
\text { Time Scale }^{(\mathrm{a})}\end{array}$} & \multicolumn{6}{|c|}{ Time Filtered (hr) } \\
\hline & & Bundle 1 & Bundle 2 & Bundle 3 & Bundle 4 & Bundle 5 & Total \\
\hline $\begin{array}{c}\text { Pre-caustic-leach } \\
\text { concentration Batch } \\
\# 1\end{array}$ & Scale & 2.3 & 2.3 & 2.3 & 2.3 & 2.3 & 11.5 \\
\hline $\begin{array}{c}\text { Pre-caustic-leach } \\
\text { concentration Batch } \\
\# 2\end{array}$ & Plant & 19.5 & 0 & 0 & 0 & 0 & 19.5 \\
\hline $\begin{array}{l}\text { Post-caustic-leach } \\
\text { concentration }\end{array}$ & Plant & 46 & 0 & 0 & 0 & 0 & 46 \\
\hline $\begin{array}{l}\text { Post-caustic-leach } \\
\text { washing }\end{array}$ & Scale & 8.6 & 8.6 & 8.6 & 8.6 & 8.6 & 43 \\
\hline $\begin{array}{l}\text { Post-chromium } \\
\text { addition washing } \\
\text { concentration }\end{array}$ & $\begin{array}{l}\text { Not } \\
\text { prototypic }\end{array}$ & 2.5 & 2.5 & 2.5 & 2.5 & 2.5 & 12.5 \\
\hline $\begin{array}{c}\text { Post-oxidative-leach } \\
\text { washing }\end{array}$ & Scale & 2.4 & 2.4 & 2.4 & 2.4 & 2.4 & 12 \\
\hline $\begin{array}{l}\text { High-solids filter } \\
\text { test }^{(\mathrm{b})}\end{array}$ & Plant & 3.8 & 0 & 0 & 0 & 0 & 3.8 \\
\hline Total & -- & 85.1 & 15.8 & 15.8 & 15.8 & 15.8 & 148.3 \\
\hline
\end{tabular}

(a) See Section 3.0. Plant time is 1 times PTF duration. Scale time is $1 / 4.5$ times PTF duration.

(b) The High-Solids Scaling Test (see Section 8.2.2) was conducted after Integrated Test B operations.

Execution of filtration activities for Integrated Test D was similar in many respects to that for Integrated Test B. Specifically, filtration operations for Integrated Test D were not subject to any significant issues that prevented completion of test activities. There were conditions that challenged the pumping system's ability to deliver the required AV or filtration without air entrainment. These issues appear to increase the scatter in filter flux data. Notable observations for Integrated Test D filtration include:

- Pre-caustic-leach concentration operations were split across two batch dewatering operations. Comparison of the filter flux behavior shows that Batch \#2 concentration (performed using all five filter bundles) achieved a higher flux over most of the concentration range relative to Batch \#1 (which employed only a single filter bundle). Higher filter flux in Batch \#2 is unexpected and is not consistent with the observations of pre-caustic-leach concentration in Integrated Test B. Because Integrated Test D Batch \#1 pre-caustic-leach concentration activities are expected to foul the single filter bundle used (and minimally foul the other filters which were in-line to slurry flow), Batch \#2 filter flux was expected to be comparable to or lower than Batch \#1 flux. This is not the case, even when only the flux for filter bundle \#1 is compared between the two batches. Indeed, filter bundle \#1 (which is used in both batch concentrations) shows substantially higher flux for Batch \#2 operations. This flux anomaly is currently unexplained. Suspected causes could include but are not limited to 1) filter-loop flush operations between Batch \#1 and Batch \#2 dewatering operations that effectively cleaned the filter bundles, and/or 2) potential differences in the way solids distribute on the filters as a result of using all five filter bundles.

- The dewatering curve for Batch \#2 pre-caustic-leach concentration exhibited a dewatering knee at 19-wt $\%$ UDS (suggesting a transition to cake resistance limited filtration). In contrast, the dewatering curve for Batch \#1 of pre-caustic-leach concentration did not exhibit a dewatering 
knee. The lack of dewatering knee in Batch \#1 operations may result from 1) a shift in the location of the filtration regime transition because of lower filter flux in Batch \#1 operations, or 2) masking of the transition because of lower Batch \#1 filter flux. The dewatering curves for all other remaining dewatering operations in Integrated Test D appear to fall in the membrane-resistance-limited regime and do not evidence dewatering knees.

- The filter flux during post-caustic-leach dewatering operations decreases throughout the filtration operation. Unlike previous dewatering curves in Integrated Tests A and B, in which decline with time was uniform, the post-leach dewatering curve for Integrated Test D indicates that the decline in flux accelerates toward the end of the dewatering operation. In previous tests, gradual declines were associated with filter-fouling. For the current dewatering operation, the accelerated decline is likely a combination of filter-fouling and loss of AV.

- Similar to Integrated Test A, a flux oscillation was observed during Integrated Test D post-caustic-leach washing operations. Relative to Integrated Test A, the oscillatory behavior in Integrated Test $\mathrm{D}$ is less severe and appears to be to be associated with either air entrainment issues throughout test (as evidenced by a flowmeter divergence between Pump T42A suction and Pump T43A discharge readings) or the reduction in filter AV.

- The filter flux achieved during post-oxidative-leach washing is low $\left(0.015 \mathrm{GPM} / \mathrm{ft}^{2}\right)$ relative to that observed at the end of post-caustic-leach washing $\left(0.03 \mathrm{GPM} / \mathrm{ft}^{2}\right)$. This contrasts with the behavior observed in Integrated Test B, where the post-oxidative wash flux was much higher than the corresponding flux at the end of post-caustic-leach washing. Integrated Test D post-oxidative-leach washing operations were conducted at low AV of 9-10-ft/s relative to Integrated Test B post-oxidative-leach washing operations (which operated with AVs in excess of 11-ft/s). As such, the relatively low filter flux observed in Integrated Test D may be caused by the atypically low AV employed for washing.

Table 8.6 provides a summary of filtration times for Integrated Test D activities. Filtration activities in Integrated Test D required a filtration duty of $66.1 \mathrm{hrs}$ on filter bundle 1 and $34.9 \mathrm{hrs}$ on the remaining bundles. 
Table 8.6. Integrated Test D Filtration Times (at target TMP and AV)

\begin{tabular}{|c|c|c|c|c|c|c|c|}
\hline \multirow[b]{2}{*}{ Operation } & \multirow{2}{*}{$\begin{array}{c}\text { Operation } \\
\text { Time } \\
\text { Scale(a) }\end{array}$} & \multicolumn{6}{|c|}{ Time Filtered (hr) } \\
\hline & & Bundle 1 & Bundle 2 & Bundle 3 & Bundle 4 & Bundle 5 & Total \\
\hline $\begin{array}{c}\text { Pre-caustic- } \\
\text { leach } \\
\text { concentration } \\
\text { Batch } \# 1\end{array}$ & Plant & 31.2 & 0 & 0 & 0 & 0 & 31.2 \\
\hline $\begin{array}{c}\text { Pre-caustic- } \\
\text { leach } \\
\text { concentration } \\
\text { Batch \#2 }\end{array}$ & Scale & 3.8 & 3.8 & 3.8 & 3.8 & 3.8 & 19.0 \\
\hline $\begin{array}{l}\text { Post-leach } \\
\text { concentration }\end{array}$ & Scale & 13.8 & 13.8 & 13.8 & 13.8 & 13.8 & 69.0 \\
\hline $\begin{array}{l}\text { Post-caustic- } \\
\text { leach washing }\end{array}$ & Scale & 8.0 & 8.0 & 8.0 & 8.0 & 8.0 & 40.0 \\
\hline $\begin{array}{l}\text { Post-oxidative- } \\
\text { leach washing }\end{array}$ & Scale & 8.8 & 8.8 & 8.8 & 8.8 & 8.8 & 44.0 \\
\hline $\begin{array}{c}\text { Post-oxidative } \\
\text { wash } \\
\text { concentration }\end{array}$ & Scale & 0.5 & 0.5 & 0.5 & 0.5 & 0.5 & 2.5 \\
\hline Total & -- & 66.1 & 34.9 & 34.9 & 34.9 & 34.9 & 205.7 \\
\hline
\end{tabular}

Finally, Table 8.7 provides a summary of average filter flux for Integrated Test filtration operations. These results are provided for comparison against each other only. Care must be taken when comparing these results, as they include 1) transitory flux effects such as flux decline from fouling and flux oscillation that is suspected to be a consequence of air entrainment, 2) UDS and DS concentration effects, and 3) filter history effects. They can only be compared against filter operations employing similar times, UDS/DS ranges, filter histories, and a similar waste simulant. 
Table 8.7. Average Filter Flux for Integrated Test Filtration Operations

\begin{tabular}{|c|c|c|c|c|c|c|}
\hline \multirow[b]{2}{*}{ Operation } & \multicolumn{6}{|c|}{ Average Filter Flux $\left(\mathrm{GPM} / \mathrm{ft}^{2}\right)$} \\
\hline & Bundle 1 & Bundle 2 & Bundle 3 & Bundle 4 & Bundle 5 & Total \\
\hline \multicolumn{7}{|l|}{ Integrated Test A: } \\
\hline $\begin{array}{l}\text { Post-caustic-leach } \\
\text { concentration }\end{array}$ & 0.0092 & -- & - & -- & -- & 0.0092 \\
\hline $\begin{array}{l}\text { Post-caustic-leach } \\
\text { washing }\end{array}$ & 0.0222 & 0.0412 & 0.0440 & 0.0402 & 0.0423 & 0.0377 \\
\hline $\begin{array}{l}\text { Post-chromium } \\
\text { wash concentration }\end{array}$ & $\mathrm{n} / \mathrm{a}$ & $\mathrm{n} / \mathrm{a}$ & $\mathrm{n} / \mathrm{a}$ & $\mathrm{n} / \mathrm{a}$ & $\mathrm{n} / \mathrm{a}$ & $\mathrm{n} / \mathrm{a}$ \\
\hline $\begin{array}{l}\text { Post-oxidative } \\
\text { leach wash }\end{array}$ & 0.0129 & 0.0398 & 0.0501 & 0.0504 & 0.0488 & 0.0396 \\
\hline $\begin{array}{l}\text { Post-oxidative- } \\
\text { leach wash } \\
\text { concentration }\end{array}$ & 0.0073 & 0.0219 & 0.0283 & 0.0279 & 0.0366 & 0.0237 \\
\hline \multicolumn{7}{|l|}{ Integrated Test B: } \\
\hline $\begin{array}{l}\text { Pre-caustic-leach } \\
\text { concentration Batch } \\
\# 1\end{array}$ & 0.0478 & 0.0480 & 0.0491 & 0.0467 & 0.0478 & 0.0479 \\
\hline $\begin{array}{l}\text { Pre-caustic-leach } \\
\text { concentration Batch } \\
\# 2\end{array}$ & 0.0315 & -- & -- & -- & -- & 0.0315 \\
\hline $\begin{array}{l}\text { Post-caustic-leach } \\
\text { concentration }\end{array}$ & 0.0094 & -- & -- & -- & -- & 0.0094 \\
\hline $\begin{array}{l}\text { Post-caustic-leach } \\
\text { washing }\end{array}$ & 0.0171 & 0.0176 & 0.0175 & 0.0169 & 0.0168 & 0.0172 \\
\hline $\begin{array}{l}\text { Post-chromium } \\
\text { addition washing } \\
\text { concentration }\end{array}$ & $\mathrm{n} / \mathrm{a}$ & $\mathrm{n} / \mathrm{a}$ & $\mathrm{n} / \mathrm{a}$ & $\mathrm{n} / \mathrm{a}$ & $\mathrm{n} / \mathrm{a}$ & $\mathrm{n} / \mathrm{a}$ \\
\hline $\begin{array}{l}\text { Post-oxidative- } \\
\text { leach washing }\end{array}$ & 0.0521 & 0.0565 & 0.0572 & 0.0522 & 0.0546 & 0.0546 \\
\hline $\begin{array}{l}\text { High-solids filter } \\
\text { test }\end{array}$ & 0.0479 & -- & -- & -- & -- & 0.0479 \\
\hline \multicolumn{7}{|l|}{ Integrated Test D: } \\
\hline $\begin{array}{l}\text { Pre-caustic-leach } \\
\text { concentration Batch } \\
\# 1\end{array}$ & 0.0177 & -- & - & - & - & 0.0177 \\
\hline $\begin{array}{l}\text { Pre-caustic-leach } \\
\text { concentration Batch } \\
\# 2\end{array}$ & 0.0303 & 0.0296 & 0.0304 & 0.0354 & 0.0343 & 0.0317 \\
\hline $\begin{array}{l}\text { Post-leach } \\
\text { concentration }\end{array}$ & 0.0060 & 0.0072 & 0.0068 & 0.0078 & 0.0076 & 0.0070 \\
\hline $\begin{array}{l}\text { Post-caustic-leach } \\
\text { washing }\end{array}$ & 0.0183 & 0.0179 & 0.0174 & 0.0167 & 0.0176 & 0.0176 \\
\hline $\begin{array}{l}\text { Post-oxidative- } \\
\text { leach washing }\end{array}$ & 0.0129 & 0.0131 & 0.0133 & 0.0150 & 0.0199 & 0.0146 \\
\hline $\begin{array}{l}\text { Post-oxidative wash } \\
\text { concentration }\end{array}$ & 0.0122 & 0.0129 & 0.0132 & 0.0140 & 0.0152 & 0.0134 \\
\hline
\end{tabular}




\subsection{Caustic-Leach Results}

The M12 testing program included the following simulant tests that involved caustic leaching:

- Shakedown/Functional Testing: Tested process operations, including slurry transfers, steam heating of the vessels, and the accumulation of condensate as well as certain test functions (e.g., in-line slurry sampling accuracy and precision).

- Integrated Test A: Demonstrated integrated processing when caustic leaching $\left(98^{\circ} \mathrm{C}\right)$ is performed in UFP-VSL-00001A/B (in which 19-M NaOH is added to unconcentrated waste slurry at $3-w t \%$ to $8-w t \%$ solids) without the $\mathrm{Cr}$ simulant component present.

- Integrated Test B: Demonstrated integrated processing when the caustic leaching $\left(98^{\circ} \mathrm{C}\right)$ is performed in UFP-VSL-00002A (in which $19-\mathrm{M} \mathrm{NaOH}$ is added to concentrated waste slurry at nominal $20-\mathrm{wt} \%$ solids) without the $\mathrm{Cr}$ simulant component present.

- Integrated Test D: Demonstrated integrated processing when the caustic leaching is performed at a lower temperature $\left(85^{\circ} \mathrm{C}\right)$ in UFP-VSL-00002A and with the $\mathrm{Cr}$ simulant component added to the initial batch of simulant.

Of these, the Integrated Tests generated caustic-leach data that were prototypic and appropriate for evaluating the caustic-leach process. Two "parallel" laboratory-scale caustic leaching tests were performed to support each of the PEP Integrated tests. The term "parallel" refers only to the laboratory-scale tests that were carried out using slurry taken from a PEP batch; the other PEP support tests are not included in this category or in this report. In the case of the PEP Functional Test performed under Test Instruction TI-032, a total of four laboratory tests were performed for each leach, two parallel to the batch leached in Tank T01A and two parallel to the batch leached in Tank T02A. For each pair of parallel laboratory-scale tests, slurry that had not yet undergone constant-temperature leaching and had not been diluted with condensate was taken from the PEP caustic-leach vessel for one batch. This slurry from the PEP vessel was used as feed for both of the corresponding laboratory-scale tests.

This section discusses the dissolution of aluminum from the gibbsite and boehmite components of the simulant during caustic leaching. The removal of chromium that occurred during the caustic leaching portion of Integrated Test D is discussed in Section 11 together with oxidative leaching results.

Many of the objectives, success criteria, and R\&T test conditions pertinent to caustic leaching are addressed in this section, though some are addressed elsewhere in the report. The locations of discussions of the various test requirements are given in Table 9.1 .

The results of the caustic-leach tests (PEP and parallel) carried out during Shakedown/Functional testing are not presented in this report. The primary purposes of the caustic leaches carried out during Functional testing were to test the PEP operation with simulant, work out process issues that might arise, and assess the methods used to predict condensate accumulation and analyze caustic-leach data. Certain analytical limitations were discovered as a result of Shakedown/Functional Tests. 
Table 9.1. Roadmap to Discussions of Relevant Test Requirements

\begin{tabular}{|c|c|}
\hline Requirement & Discussion \\
\hline \multicolumn{2}{|l|}{ Test Objectives } \\
\hline $\begin{array}{l}\text { Caustic-leach process: Compare engineering- and laboratory-scale results to determine } \\
\text { impact of scale-up. }\end{array}$ & Section 9.5 . \\
\hline Process integration: Evaluate the chemical addition operations. & Section 9.2 . \\
\hline $\begin{array}{l}\text { Perform mass balances for aluminum, chromium, manganese, sodium, hydroxide, } \\
\text { oxalate, phosphate, sulfate, and water. }\end{array}$ & Section 12. \\
\hline \multicolumn{2}{|l|}{ Success Criteria } \\
\hline $\begin{array}{l}\text { Measure the aluminum leaching performance of the PEP and laboratory systems as a } \\
\text { function of time under WTP UFP-1 and UFP-2 projected leaching conditions at } \\
\text { bounding high and low process temperatures (nominally } 100^{\circ} \mathrm{C} \text { and } 80^{\circ} \mathrm{C} \text { ). }\end{array}$ & Section 9.5 . \\
\hline $\begin{array}{l}\text { Compare aluminum leach performance in UFP- } 1 \text { where all of the } \mathrm{NaOH} \text { is added in-line } \\
\text { to the case where a fraction of the total } \mathrm{NaOH} \text { is added directly to the tank. }\end{array}$ & Section 9.5 \\
\hline $\begin{array}{l}\text { Evaluate the process control strategy for specification of additions of } \mathrm{NaOH} \text { provided in } \\
\text { the PEP Phase } 1 \text { Testing Process Description. }\end{array}$ & Sections 9.2 and 9.5. \\
\hline $\begin{array}{l}\text { Perform mass balances for selected constituents, including aluminum, chromium, } \\
\text { manganese, sodium, hydroxide, oxalate, phosphate, sulfate, and water, to evaluate } \\
\text { leaching and washing process performance. }\end{array}$ & Section 12. \\
\hline $\begin{array}{l}\text { Measure solids distribution under scaled mixing conditions before and after caustic } \\
\text { leaching evolutions. }\end{array}$ & Section 7 . \\
\hline $\begin{array}{l}\text { Measure the rheology of the slurry simulant and shear strength of the settled solids } \\
\text { before and after each leaching and washing unit operation and following final } \\
\text { concentration. }\end{array}$ & $\begin{array}{l}\text { Run reports: Guzman-Leong et al. } \\
\text { (2009), Geeting et al. (2009), and } \\
\text { Sevigny et al. (2009). }\end{array}$ \\
\hline $\begin{array}{l}\text { Estimate the quantity of excess hydroxide added in the process that may not be needed } \\
\text { to keep aluminate in solution following filtration. }\end{array}$ & Section 9.7. \\
\hline $\begin{array}{l}\text { Confirm whether the elevated temperature pulse jet mixer (PJM) operating strategy is } \\
\text { adequate for stable PEP and WTP operation. }\end{array}$ & Section 13. \\
\hline $\begin{array}{l}\text { Measure the heat-up rate and controllability of the PEP UFP-VSL-00001 and } \\
\text { UFP-VSL-00002 vessels and the cooling performance for UFP vessels. }\end{array}$ & Section 9.3 . \\
\hline $\begin{array}{l}\text { Measure the performance of the in-line addition of process chemicals into the simulated } \\
\text { waste. }\end{array}$ & Section 9.2. \\
\hline Determine the extent of blending in the process vessels. & Section 7. \\
\hline \multicolumn{2}{|l|}{ R\&T Test Conditions } \\
\hline $\begin{array}{l}\text { Perform mass balances for selected constituents, including aluminum, chromium, } \\
\text { manganese, sodium, hydroxide, oxalate, phosphate, sulfate, and water, to evaluate } \\
\text { leaching and washing process performance. }\end{array}$ & Section 12. \\
\hline Assess the blending achieved during in-line additions of leaching solutions. & Section 7. \\
\hline $\begin{array}{l}\text { Maintain the caustic leaching temperature at the required set point and record steam } \\
\text { usage to remain in the temperature range. }\end{array}$ & Section 9.3 . \\
\hline $\begin{array}{l}\text { Obtain periodic samples during the leaching operations to monitor the amount of } \\
\text { aluminum that has dissolved and concentrations of the reactants and products in the } \\
\text { liquid fraction in the vessel. }\end{array}$ & Section 9.5 . \\
\hline Provide data to demonstrate the WTP process control strategy for the caustic addition. & Section 9.5 . \\
\hline $\begin{array}{l}\text { Measure the rheology of the slurry simulant and shear strength of the settled solids } \\
\text { before and following each leaching unit operation. }\end{array}$ & $\begin{array}{l}\text { Run reports: Guzman-Leong et al. } \\
\text { (2009), Geeting et al. (2009), and } \\
\text { Sevigny et al. (2009). }\end{array}$ \\
\hline
\end{tabular}


Unlike the practice in Integrated tests, all liquid concentration measurements in the PEP Functional Tests were made using Raman analysis. The functional laboratory-scale tests used both Raman analysis and a suite of IC and inductively coupled plasma (ICP) analyses. The intent at that time was to make Raman the primary analysis method for laboratory-scale tests. However, it was found that the samples that could be taken from the beakers were smaller than the volume needed for accurate Raman analyses. This was a major reason for changing over from Raman to IC, ICP, and $\mathrm{OH}$ titration for the liquid analyses in the Integrated Tests. A quantitative comparison between the Functional Test and Integrated Test rate constants is of dubious usefulness because different analytical methods were used to measure liquid concentrations in the Functional and Integrated Tests, and some bias was observed between dissolved aluminum concentrations measured by Raman and ICP.

In addition, the initial data analysis showed that the rate constants and leach factors calculated from laboratory-scale Functional Test data were considerably higher than the range for the Integrated Tests. The cause was found to be unreasonably low aluminum concentrations in the initial slurry, possibly the result of measurements that were biased low. In the Integrated Tests, multiple measurements of initial aluminum concentration were available to allow cross-checking (as discussed in Section 4.2.1 of Mahoney et al. (2009). These cross-checks were not available in the Functional Tests. Further analysis of the laboratory-scale test results was not pursued.

\subsection{Overview of Caustic-Leach Data Analysis Approach}

Of the test requirements listed in Table 9.1, the ones that are discussed in this section fall into four broad categories:

- Assess the amount of condensate added to the leached slurry, the steam addition, and the controllability of the heat-up rate and temperature maintenance.

- Evaluate the performance of $\mathrm{NaOH}$ reagent addition and the success of the strategy used to determine the quantity of reagent to add.

- Determine the rates at which gibbsite and boehmite dissolve during caustic leaching under different process conditions and evaluate the scale-up factors.

- Determine whether $\mathrm{NaOH}$ in the product liquid is in excess of what is needed to maintain aluminum in solution.

Sections 9.1.1, 9.1.2, 9.1.3, and 9.1.4 give overviews of the approaches used to meet these requirements.

\subsubsection{Approach for Condensate Accumulation Analyses}

To assess condensate accumulation in the PEP vessels, it was necessary to distinguish volume changes due to thermal effects and the dissolution of solids from the net water volume changes caused by steam addition and evaporation. The bulk slurry volume and mass at a point in time were characterized from data for vessel level, slurry density, liquid density, and mass fraction of UDS in the slurry.

The only level data that could be used to calculate slurry volume were those taken during stable level measurement periods when the PJM were turned off and vented and the dedicated sparger airflow in 
Tank T02A was typically turned off. The steam ring purge air in all vessels was (most often) left on. The total slurry volumes could be derived from four sources of level measurements: 1) the vessel bubbler pressure data (i.e., both lower and upper legs) converted to slurry level using analytically measured ("corrected") slurry density data, 2) the as-is or "raw" vessel bubbler pressure data using the apparent slurry density (specific gravity) derived from the difference in bubbler pressures, 3 ) the DrexelBrook (DB) capacitance probe located in the Tank T01A and Tank T02A vessels (not in the PJMs), and 4) laser level data. The corrected bubbler values (Method 1 above) used analytical density data for samples taken at the point in the process closest to the time of the stable level measurement. These techniques allowed the change in volume to be calculated from level measurements.

The requisite slurry and liquid density data were taken from samples at laboratory temperature; these densities had to be corrected to the slurry temperature before they could be combined with the level data. A simple model, based on the known change in water density with temperature and an assumed density of UDS (2.8- $\mathrm{kg} / \mathrm{L}$ average), was used to estimate the bulk slurry density at the vessel temperature from analytical slurry liquid density data $\left(\right.$ at $\sim 23^{\circ} \mathrm{C}$ ). The temperature-corrected slurry liquid density $\left(\rho_{\text {liq }}\right)$ at vessel temperature $T$ for a density measured at temperature $T_{r e f}\left(\right.$ e.g., $\left.23^{\circ} \mathrm{C}\right)$ was estimated by

$$
\rho_{l i q}(T)=\rho_{l i q}\left(T_{r e f}\right) \frac{\rho_{w}(T)}{\rho_{w}\left(T_{r e f}\right)}
$$

where $\rho_{w}$ is the density of water from literature.

The temperature-corrected bulk slurry density $\left(\rho_{s l}\right)$ at the same vessel temperature was estimated from the corrected liquid density as

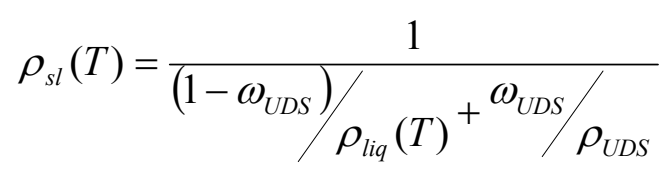

where $\rho_{U D S}$ and $\omega_{U D S}$ are the density and mass fraction of UDS, respectively.

This method, together with UDS and liquid density data, allowed the thermal expansion of the liquid fraction of the slurry to be accounted for.

Two different methods were used to calculate the volume of condensate added. In Method 1, the change in slurry volume was used with estimates of the initial liquid volume and the change in volume of UDS to calculate the condensate volume

$$
V_{c}=\Delta V+\left(\Delta V_{U D S}-V_{l i q, 0}\right)\left[\frac{\rho_{w, 0}}{\rho_{w}(T)}-1\right]
$$

where:

$V_{c} \quad=$ net volume of accumulated steam condensate

$\Delta V=$ measured change in slurry volume from the initial condition, after $\mathrm{NaOH}$ addition

$\Delta V_{U D S}=V_{U D S}-V_{U D S, 0}$; change in volume of UDS in the slurry 


$$
\begin{aligned}
& V_{\text {liq, } 0}=\text { volume of liquid at the initial condition, after } \mathrm{NaOH} \text { addition } \\
& \rho_{w, 0}=\text { density of water at the initial temperature (after } \mathrm{NaOH} \text { addition) }
\end{aligned}
$$

The bracketed density correction term in Equation (9.3) accounts for the thermal expansion of the initial slurry liquid phase and any newly dissolved solids. An underlying assumption of Equation (9.3) is that condensate and slurry volumes are additive. This is an approximation and neglects the non-ideal mixing properties of concentrated salt solutions.

To estimate the volume of condensate during the caustic-leach process using Equation (9.3), it is necessary to track changes in the bulk slurry and UDS volumes and to specify the initial volume of slurry liquid. To this end, the volume fractions of total slurry liquid and UDS must be determined. The volume fraction of total liquid in the bulk slurry, $v_{\text {liq }}$, and the total liquid volume, $V_{\text {liq }}$, are given by

$$
v_{l i q}=\frac{\rho_{s l}\left(1-\omega_{U D S}\right)}{\rho_{l i q}}
$$

and

$$
V_{l i q}=v_{l i q} V_{s l}
$$

where $V_{s l}$ is the slurry volume.

Applying Equations (9.4) and (9.5) for the initial condition gives the initial liquid volume $V_{l i q, 0}$. The liquid and slurry densities are calculated from Equations (9.1) and (9.2).

The volume fraction, $v_{U D S}$, and the volume of UDS at any point in the process are used, with the measured slurry volume, to calculate the change in UDS volume. They are determined by difference

$$
v_{U D S}=1-v_{l i q}
$$

and

$$
V_{U D S}=v_{U D S} V_{s l}=V_{s l}-V_{l i q}
$$

Equation (9.7) is applied throughout the caustic leaching process to determine the volume of remaining UDS and the change in UDS volume needed for Equation (9.3) to compute the condensate volume by Method 1.

To compute the condensate mass by Method 1, the volume of condensate calculated using Equation (9.3) is multiplied by the density of water at the measurement temperature.

Method 2 is more direct. After accounting for any sources or sinks of mass in the caustic-leach vessel other than steam addition and evaporation of water, the change in slurry mass from the start of direct steam injection is equal to the net mass of condensate accumulated. The total mass of slurry at any point in the process is the product of the slurry volume and the bulk slurry density at temperature, where the 
latter is estimated using Equation (9.2). Method 2 is not impacted by non-ideal solution properties, and it is, therefore, the preferred basis for mass balance calculations (see Section 12).

The level-based estimates of condensate accumulation were cross checked by calculating changes in total liquid mass in the vessel from the liquid volume (Equation [9.5]) and temperature-corrected liquid density (Equation [9.1]). These total liquid dilution values, which include aluminum dissolved in the course of the leaching process as well as accumulated condensate, are directly comparable to measured changes in the concentration of liquid chemical tracers (which may include nitrate, nitrite, and chloride). The total liquid mass-dilution factors determined from volume change data are compared to the results derived from liquid chemical tracer analyses in Section 9.3.

In addition, the cumulative amount of steam added converted to an equivalent condensed water volume at the vessel temperature was calculated from the measurements of volumetric steam flow, pressure, and temperature. The liquid equivalent steam volume is compared to the volume of condensate determined by Method 1 in Section 9.3. The total mass of steam added, the net mass of condensate accumulated (Method 2), and by difference, the mass of water vented with air from the system are used in an overall process mass balance (see Section 12).

\subsubsection{Approach for Reagent Addition Analyses}

The reagent addition analyses that are discussed below fall under two areas:

- $\quad$ Measure the performance of the in-line addition of process chemicals into the simulated waste. Level and flow data were used to calculate the mass of reagent added; level data were handled in the same manner as for calculating condensate accumulation (see Section 9.5). This mass was compared to the mass required by the process specifications in the Test Instruction. The results of this assessment are given in Section 9.2.

- Evaluate the process control strategy for specifying additions of $\mathrm{NaOH}$ provided in the PEP Phase 1 Testing Process Description. Bechtel National Inc. calculated how much $\mathrm{NaOH}$ reagent was needed to produce a desired target boehmite conversion in the allotted leaching time as well as to allow an excess of caustic over that needed to keep the dissolved Al in solution. Section 9.5 compares the boehmite dissolution target to the boehmite leach factor that was actually achieved.

\subsubsection{Approach for Caustic-Leach Analysis}

The central purpose of caustic-leach analysis is to provide boehmite leach scale-up factors to be used in predicting the caustic leaching performance of the PTF. The G2 model, which contains a boehmite leach sub-model consisting of a kinetic equation that is based on laboratory-scale tests with actual tank waste samples, is used for performance predictions for caustic leaching. The inputs to the G2 model are initial boehmite mass, initial liquid volume and density, initial free hydroxide and aluminate concentrations in the liquid, and the temperature maintained during the constant-temperature part of the leaching process. The initial concentrations of aluminate and free hydroxide are based on the assumptions that all the:

- condensate (whether generated during heat-up or during maintenance of constant digestion temperature) is added at once at the beginning 
- gibbsite has been dissolved by the time boehmite dissolution starts and is in the form of aluminate ion at the beginning of the boehmite dissolution.

The G2 model steps through time, integrating an ordinary differential kinetic equation and using mass balances to account for the consumption of free hydroxide and the generation of aluminate ion as boehmite is dissolved at constant temperature. The dissolution of boehmite during heat-up is treated as being zero. The saturated concentration of aluminate, a variable used in the kinetic equation, is calculated by $\mathrm{G} 2$ at the initial free hydroxide concentration. It is not recalculated as hydroxide is consumed. This is the same approach taken in performing the data correlations that provided the form of, and the constants in, the kinetic equation.

The kinetic equation in the $\mathrm{G} 2$ boehmite leaching sub-model is based on laboratory-scale experiments. The pertinent PEP test requirement is to determine the impact of scaling up from laboratory-scale to the engineering-scale process. The scale factor is applied to the boehmite leaching kinetic rate constant. It was obtained by finding the rate constants that provided the best fits of the simulant kinetic model to PEP test data and data from laboratory-scale tests that were run on slurry from the PEP vessels. The scale-up factor is the ratio of the PEP rate constant to the laboratory-scale rate constant and is to be applied in G2 by using it as a multiplying factor for the boehmite dissolution rate constant that is used in G2, based on laboratory-scale experiments with tank waste.

The differential equation for kinetically controlled boehmite dissolution in the simulant is

$$
\frac{d}{d t}\left(\frac{n_{b s}}{n_{b s, i}}\right)=-k C_{O H L, i}\left(\frac{n_{b s}}{n_{b s, i}}\right)^{2 / 3}\left(1-\frac{C_{A l L, i}}{C_{A l^{*} L, i}}\right)\left(1-\frac{C_{A l L}}{C_{A l^{*} L, i}}\right) e^{\frac{E_{a}}{R}\left(\frac{1}{373}-\frac{1}{T}\right)}
$$

where:

$$
\begin{aligned}
& n_{b s} \quad=\quad \text { mol of solid-phase boehmite at time } t \\
& n_{b s, i}=\text { mol of solid-phase boehmite at time } t=t_{i} \text { (start of constant-temperature } \\
& \text { leaching, after heat-up is complete and assumed to be before any boehmite has } \\
& \text { dissolved) } \\
& k=\text { rate constant }\left(\mathrm{hr}^{-1} *[\text { mol total hydroxide } / \mathrm{L}]^{-1}\right) \\
& C_{O H L, i}=\mathrm{mol} / \mathrm{L} \text { of total hydroxide (free hydroxide plus } 1 \mathrm{~mol} \text { of hydroxide per mole of } \\
& \text { aluminate) in the liquid phase at time } t=t_{i} \\
& C_{A l L}=\mathrm{mol} / \mathrm{L} \text { of } \mathrm{Al} \text { in the liquid phase at time } t \\
& C_{A L L, i}=\mathrm{mol} / \mathrm{L} \text { of } \mathrm{Al} \text { in the liquid phase at time } t=t_{i} \\
& C_{A l^{*}, i}=\mathrm{mol} / \mathrm{L} \text { of } \mathrm{Al} \text { that would exist at saturation in the liquid for the total } \mathrm{OH} \\
& \text { concentration and temperature present at time } t=t_{i} \\
& E_{a} \quad=\text { activation energy for simulant, } 120,000 \mathrm{~J} / \mathrm{mol} \\
& R=\text { ideal gas constant, } 8.314 \mathrm{~J} / \mathrm{mol} \mathrm{K} \\
& T=\text { absolute temperature, } \mathrm{K} \text {. }
\end{aligned}
$$

The equation is consistent with a shrinking-core model of boehmite dissolution (which gives $\mathrm{a}^{2} / 3$ exponent on the boehmite moles) and with a dissolution mechanism that matches the stoichiometry of reaction, giving a linear dependence of rate on total hydroxide concentration. The saturated concentration of aluminum in the liquid is a function of total hydroxide concentration, as well as of temperature (Panias et al. 2001). The boehmite solubility expression was stated by its developers to be valid for initial sodium 
hydroxide concentrations between 60 and 140-g Na $2 \mathrm{O} / \mathrm{L}$ liquid (the total hydroxide is expressed in terms of equivalent $\mathrm{Na}_{2} \mathrm{O}$ ) and for temperature between $30^{\circ} \mathrm{C}$ and $150^{\circ} \mathrm{C}$. The Integrated Test $\mathrm{B}$ and Integrated Test $\mathrm{D}$ hydroxide concentrations were above the upper end of the range. The development of the boehmite dissolution rate equation is described in Appendix A of Russell et al. (2009d), and some other details about the application of the rate equation are given in Section A.4 of Mahoney et al. (2009).

The kinetic equation was derived on the assumption of constant liquid volume throughout the process. The G2 model makes the same assumption of constant volume; it uses the liquid volume that is calculated at the point of maximum slurry dilution - the end of the leaching process, when all condensate has been added. This is the presently accepted treatment of the boehmite reaction in PTF modeling. In actuality, the liquid volume in the PTF will be less than the maximum-dilution volume at the beginning of the leaching reaction and will increase during leaching. It will equal the maximum-dilution volume only at the end of reaction.

The first step in kinetic analysis of the data from the present series of PEP and laboratory-scale tests (Section 9.4) is the normalization of all liquid concentrations to a constant volume. The volume at maximum dilution is used to match the assumptions in the G2 model. The parallel laboratory-scale experiments were designed to begin with a dilution that matched that in the corresponding PEP test, according to the preliminary information available at the time of the laboratory experiment. Therefore, the PEP test liquid concentrations were normalized to the volume at the end of the test. The laboratory-scale test concentrations were normalized to the volume at the beginning of the test before any evaporation had occurred. Ratios of the concentrations of liquid tracers - species present only in the liquid phase - were used to carry out normalization since the concentrations of liquid tracers are inversely proportional to the amount of liquid present.

As in the PTF, the PEP liquid volume increased during the constant-temperature digestion. In the laboratory-scale tests, the liquid volume was greatest at the beginning of the test when water had been added to represent condensate. From then on, it decreased as a result of evaporation. Because the G2 model employs a constant-volume (maximum-volume) assumption to model boehmite leaching in the PTF, it was necessary to employ the same assumption in kinetic data analysis to provide scale-up factors that are consistent with the G2 model approach. The constant-volume assumption is also consistent with data analysis in past laboratory-scale experiments.

Equation (9.8) was integrated over time to predict the boehmite leach factor, starting from measurement-based initial conditions. The initial condition for boehmite leaching was considered to be at 0 hours and leach temperature. All gibbsite was assumed to be dissolved at this point (consistent with observations made by Russell et al. 2009b). All aluminum remaining in the solid phase was assumed to be in the form of boehmite. The dissolved aluminum concentration was calculated from the boehmite at each modeled time step, based on mass balances, and compared to the normalized measured dissolved aluminum concentrations. The rate constant, $k$, was treated as an adjustable parameter in the equation and solved for by numerically determining the best fit between predicted and measured (normalized) concentrations of dissolved aluminum. Finally, the ratio of the PEP rate constant to the laboratory-scale rate constant was calculated to provide the scale-up factor.

To provide a cross-check of the kinetic model predictions, total aluminum leach factors were calculated directly from aluminum and tracer concentration data, using both liquid and solid tracers to account for changes in the total slurry mass. These aluminum leach factors were then used to calculate 
boehmite leach factors, independent of the kinetic model. The equation for the total aluminum leach factor, based on a solid-phase tracer (a species present only in solid phase), is

$$
f_{A l s, P}=1-\left(\frac{c_{q, 0}}{c_{q, P}}\right) \frac{c_{A l, P}-\left(1-\omega_{s, P}\right) c_{A l L, P}}{c_{A l, 0}-\left(1-\omega_{s, 0}\right) c_{A l L, 0}}
$$

The equation for the total aluminum leach factor, based on a liquid-phase tracer, is

$$
f_{A I L, P}=\frac{\left(1-\omega_{s, 0}\right)\left(\frac{c_{k L, 0}}{c_{k L, P}} c_{A L L, P}-c_{A l L, 0}\right)}{c_{A l, 0}-\left(1-\omega_{s, 0}\right) c_{A l L, 0}}
$$

where:
$f_{A l s, P}=$ cumulative $\mathrm{Al}$ leach factor since the initial reference time, based on a solid tracer
$f_{A L L, P}=$ cumulative $\mathrm{Al}$ leach factor since the initial reference time, based on a liquid tracer
$c_{q, 0}=$ concentration of solid tracer $q$ in the slurry at the initial reference time, $\mathrm{g} q / \mathrm{g}$ slurry
$c_{q, P}=$ concentration of solid tracer $q$ in the slurry at the time of sample $P, \mathrm{~g} q / \mathrm{g}$ slurry
$c_{k L, 0}=$ concentration of liquid tracer $k$ in the liquid phase at the initial reference time, $\mathrm{g} k / \mathrm{g}$ liquid
$c_{k L, P}=$ concentration of liquid tracer $k$ in the liquid phase at the time of sample $P, \mathrm{~g} k / \mathrm{g}$ liquid
$c_{A l, 0}=$ concentration of $\mathrm{Al}$ in the slurry at the initial reference time, $\mathrm{g} \mathrm{Al} / \mathrm{g}$ slurry
$c_{A l, P}=$ concentration of $\mathrm{Al}$ in the slurry at the time of sample $P, \mathrm{~g} \mathrm{Al} / \mathrm{g}$ slurry
$c_{A L L, 0}=$ concentration of $\mathrm{Al}$ in the liquid phase at the initial reference time, $\mathrm{g} \mathrm{Al} / \mathrm{g}$ liquid
$c_{A L L, P}=$ concentration of $\mathrm{Al}$ in the liquid phase at the time of sample $P, \mathrm{~g} \mathrm{Al} / \mathrm{g}$ liquid
$\omega_{s, 0}=$ weight fraction UDS in the slurry at the initial reference time, g UDS/g slurry
$\omega_{s, P}=$ weight fraction UDS in the slurry at the time of sample $P, \mathrm{~g}$ UDS/g slurry

The relationship between the boehmite leach factor, $f_{b}$, and the total aluminum leach factor, $f_{A l}$, at any point in time is

$$
f_{b}=\frac{f_{A l}-\phi_{A \mathrm{lg}, 0}}{1-\phi_{A \mathrm{lg}, 0}} \text { for } f_{A l}>\phi_{A \mathrm{lg}, 0}
$$

where $\phi_{A l g, 0}$ is the fraction of the solid-phase $\mathrm{Al}$ that is present in gibbsite at the initial reference time. (Recall that the fraction of the solid-phase Al that is present in boehmite is equal to one minus the fraction in gibbsite, since solid-phase Al is present only as gibbsite or boehmite.) The boehmite leach fraction is zero so long as only gibbsite is being leached.

The uncertainty of the scale-up factor, and of the intermediate results of calculations leading up to it, was of crucial interest. The complexity of the data analysis made it impossible to carry through uncertainty calculations without using a stochastic computational approach. In the selected computational method, a Monte Carlo method, the full set of equations in the data analysis is solved a large number of 
times. Each solution is termed a realization. In each realization, every measurement value that is used has a different perturbation, representing measurement error, added to its measured value. Each perturbation is randomly chosen from a normal distribution that has a median of zero (in other words, an unbiased error) and a standard deviation equal to the known standard deviation of the measurement (as supplied by the analytical laboratory that carried out the analysis). The results that are calculated when all perturbations are zero (i.e., when the inputs are exactly as measured) are referred to as the deterministic values. More detail about the calculation of stochastic inputs is given in Appendix $\mathrm{C}$ of Mahoney et al. (2009). The bases for the measurement standard deviations, which are derived from estimates of preparative and analytical error, are described in Appendix E, Section E.3.

The result of Monte Carlo calculations is a population distribution for every calculated value. In some cases, the population distribution of a calculated value is symmetrical and normal and can be described by a median and standard deviation. In others, the distribution is less simple and must be described by confidence intervals around the median. A 95\% confidence interval implies that only the lowest $2.5 \%$ and the highest $2.5 \%$ of the distribution are excluded and that there is a $95 \%$ probability that the true value lies between the upper and lower limits of the interval. In a normal distribution, a 95\% confidence interval is equivalent to almost exactly two standard deviations.

Section 9.5 discusses the specific data analyses carried out to calculate the leach factors, boehmite dissolution rate constants, and scale-up factors for the various PEP and laboratory-scale tests.

\subsubsection{Approach for Excess Caustic Analysis}

A separate laboratory study was carried out to determine the extent of aluminum saturation that was present at ambient temperature in liquids generated by caustic leaching and by post-caustic-leach washing. Samples of permeate from post-caustic-leach solids concentration and from partway through post-caustic-leach washing were mixed with gibbsite solids and allowed to sit for 11 weeks. The initial compositions and densities of the permeate liquids were characterized to provide data to support Bechtel National Inc. computational modeling of Al solubility. Samples of the liquid phase were taken at several times and analyzed to determine the changes in the dissolved Al concentration.

The increase in dissolved $\mathrm{Al}$ as a result of dissolution of gibbsite was taken as an indication of the presence of excess caustic in the liquid. However, it was difficult to translate this value back into an excess hydroxide quantity because gibbsite solubility is not dictated by caustic concentration alone. There are many other variables (such as ionic strength or competing anion effects) that make it difficult to quantify the relationship between additional dissolved aluminum and excess caustic. Thus, the presence of excess caustic was shown but not quantified.

The results of the excess-caustic analysis can be found in Section 9.7.

\subsection{PEP Caustic Reagent Addition and Batch Components}

One objective of the caustic-leach tests was to determine whether the final boehmite leach factors could be accurately predicted given known amounts of $\mathrm{NaOH}$ reagent and simulant. The tests set a target amount of reagent to add, a target amount of simulant to which reagent was to be added, and a target boehmite leach factor that was predicted to result. Because the leach factor depends on the proportion of 
reagent to simulant, the reagent and simulant targets must be met in order for success at meeting leach targets to be meaningful. This section discusses the manner in which the reagent and simulant components of each PEP test batch were calculated. The calculations also include estimates of the amount of heel in Batches 3 through 6 of PEP Integrated Test A. In addition, these analyses support the mass-balance calculations in Section 12 by providing the masses of simulant and $\mathrm{NaOH}$ that were flushed from the filter-loop to the waste tanks in Integrated Tests B and D.

The reagent used in the caustic-leach process is concentrated sodium hydroxide solution $(\mathrm{NaOH}$, caustic), nominally of $19-\mathrm{M} \mathrm{NaOH}$ concentration. The simulant to which the reagent is added contains the solid-phase aluminum species that are targeted for dissolution in the process. For leaching in the Tank T01A and Tank T01B vessels, the feed simulant containing $\sim 5$-wt $\%$ solids is mixed directly with caustic before heating to the target digestion temperature. In the case of leaching in the Tank T02A vessel, the solids concentration of the feed simulant is increased to $\sim 20-\mathrm{wt} \%$ by filtration before caustic addition and heating. The ratio of caustic to simulant varied according to process conditions and test goals. In all PEP test cases, the amount of reagent and simulant was dictated by Test Instruction.

The mass of caustic and simulant added to the vessel is greater than the mass in the batch that is heated to and held at the digestion temperature for an extended period (e.g., 16 to 24 hours). Some of the added slurry is held up in the heat exchanger recirculation flow loops (for Tank T01A and Tank T01B) or in the Tank T02A filter-loop. The loop hold-up is isolated from the leach vessel; it is not heated to digestion temperature. Therefore, it is not part of the defined caustic-leach batch.

This section compares the added reagent and simulant amounts to the Test Instruction targets and summarizes the amounts of the components in the initial caustic-leach batches. Also summarized in this section are the masses of steam condensate added as a result of the steam injection used to heat the slurry. See Section 9.3 for additional discussion of condensate accumulation throughout the leaching process.

\subsubsection{Integrated Test A}

Table 9.2 and Table 9.3 summarize the TI-WTP-PEP-065 target reagent and simulant amounts for the Integrated Test A caustic-leach batches in Tanks T01A and T01B, respectively. ${ }^{(a)}$ The Test Instruction targets are compared to the amounts measured post-experimentally using data acquisition system (DAS) data for the appropriate flowmeters. For the batches in Tank T01A, the total amount of caustic reagent was added in-line to the simulant that was being pumped to the vessel. The following fill process was used to make sure that all the in-line $\mathrm{NaOH}$ was added to the vessel: 1) the flow of simulant alone was established, 2) the caustic was added in-line to the simulant pump inlet with continued simulant flow, and 3) after the target amount of $\mathrm{NaOH}$ was added, simulant flow continued until the total slurry volume target was reached. In the Tank T01B batches, $\sim 80 \%$ of the caustic was added in-line in a similar manner, and the remaining $\sim 20 \%$ of the caustic was subsequently added directly to the top of Tank T01B (in-tank addition, flow transmitter FT-0401). The in-line and in-tank caustic amounts are called out separately in the Test Instruction and in Table 9.3.

The amount of simulant added in the Integrated Test A batches was not measured independently of the in-line caustic. Rather, a flowmeter (FT-0119) registered the combined volumetric flow of simulant

(a) As noted in Mahoney et al. (2009), the TI-065 target amounts of NaOH reagent were based on an assumption that 17.9-M $\mathrm{NaOH}$ was used in the PEP test, whereas actual analyses indicate that 19.2-M was used in the Test A batches. 
and $\mathrm{NaOH}$. Knowing the densities of reagent and simulant and the mass of in-line caustic added by an independent measurement (e.g., primary flowmeter FT-0101) allowed the mass of simulant added to be estimated. Two calculation methods were used:

- Method A: The total mass of simulant $+\mathrm{NaOH}$ slurry mixture added to the vessel was determined by assuming that the total volume added by flowmeter (FT-0119) had an average mixture density that could be estimated from measured properties for samples subsequently taken from the vessel. The mass of simulant was determined by the difference of the total mass and the independently determined $\mathrm{NaOH}$ mass. Regarding the density of the average slurry mixture flowing through the flowmeter, the following approach was used: 1) the slurry was assumed to be room temperature (neglecting the heat of dilution) and, therefore, no temperature correction was applied, 2) for the first batch in Tank T01A/B (i.e., Integrated Test A, Batch 1 in Tank T01A and Integrated Test A, Batch 2 in Tank T01B), the mixture density was assumed to be equal to the measured density of the "after $\mathrm{NaOH}$ " sample taken from the vessel, and 3) in the remaining Integrated Test A batches, the vessels contained heel material from the prior leach batches. Calculations were made to estimate the density of the newly added slurry mixture from the density of the heel material (which is like the 16-hr sample of the preceding batch), the density of caustic (which is needed to back out the in-tank $\mathrm{NaOH}$ contribution in the Tank T01B batches), and the density of the "after $\mathrm{NaOH}$ " sample (which included the heel material and in-tank added $\mathrm{NaOH})$.

- Method B: The volume of $\mathrm{NaOH}$ added is determined from the mass of $\mathrm{NaOH}$ added and the density of $\mathrm{NaOH}(1.529-\mathrm{kg} / \mathrm{L}$ in Test A). The volume of simulant is determined by the difference of the total added slurry volume and the $\mathrm{NaOH}$ volume. Finally, the simulant mass is calculated from the simulant volume and the simulant density measurement taken before $\mathrm{NaOH}$ was added $(1.278-\mathrm{kg} / \mathrm{L}$ in Integrated Test A).

The simulant amounts calculated by these methods are summarized in Table 9.2 for the Tank T01A batches and in Table 9.3 for the Tank T01B batches. 
Table 9.2. Caustic-Leach Reagent Additions for Tank T01A Batches in Integrated Test A

\begin{tabular}{|c|c|c|c|c|}
\hline Reagents & Value & $\begin{array}{l}\text { Integrated Test } \\
\text { A, Batch } 1\end{array}$ & $\begin{array}{c}\text { Integrated Test } \\
\text { A, Batch } 3\end{array}$ & $\begin{array}{c}\text { Integrated Test } \\
\text { A, Batch } 5\end{array}$ \\
\hline \multirow{4}{*}{$\begin{array}{l}\sim 19-\mathrm{M} \mathrm{NaOH} \\
\text { added in-line }\end{array}$} & TI-065 target mass ${ }^{(\mathrm{a})}(\mathrm{kg})$ & $639 \pm 10$ & $629 \pm 5$ & $625 \pm 5$ \\
\hline & $\begin{array}{l}\text { Measured mass, } \\
\text { primary meter }{ }^{(b)}(\mathrm{kg})\end{array}$ & 636.7 & 627.0 & 622.7 \\
\hline & $\begin{array}{l}\text { Measured mass, } \\
\text { secondary meter }{ }^{(\mathrm{c})}(\mathrm{kg})\end{array}$ & 635.7 & 627.1 & 625.0 \\
\hline & Calculated volume $^{(\mathrm{d})}$ (gal) & 110.0 & 108.3 & 107.6 \\
\hline \multirow{2}{*}{$\begin{array}{l}\text { Slurry (simulant + } \\
\sim 19-\mathrm{M} \mathrm{NaOH} \text { ) } \\
\text { added in-line }\end{array}$} & TI-065 target volume ${ }^{(\mathrm{e})}$ (gal) & $501 \pm 5$ & $426 \pm 5$ & $415 \pm 5$ \\
\hline & Measured volume $^{(\mathrm{f})}(\mathrm{gal})$ & 497.8 & 451.8 & 412.5 \\
\hline \multirow{2}{*}{ Simulant added ${ }^{(g)}$} & $\begin{array}{l}\text { Calculated mass, } \\
\text { Method A (kg) }\end{array}$ & 1930 & 1690 & 1496 \\
\hline & $\begin{array}{l}\text { Calculated mass, } \\
\text { Method B (kg) }\end{array}$ & 1877 & 1662 & 1476 \\
\hline
\end{tabular}

(a) The TI-065 target amount of $\mathrm{NaOH}$ reagent was based on an assumption that $17.9-\mathrm{M} \mathrm{NaOH}$ was used in the PEP test whereas actual analyses indicate that 19.2-M was used (Mahoney et al. 2009).

(b) FT-0101 is the primary flow transmitter for the integrated mass of $\mathrm{NaOH}$ added in-line.

(c) FT-1421 is the primary flow transmitter for the mass flow rate of $\mathrm{NaOH}$ added in-line, and it is the secondary device for integrated $\mathrm{NaOH}$ mass.

(d) The volume (L) is determined by dividing the $\mathrm{NaOH}$ mass (e.g., primary meter value in $\mathrm{kg}$ ) by the $\mathrm{NaOH}$ density (1.529-kg/L estimated for 19.2-M NaOH from literature data). Volume (gal) = Volume (L)/3.785-L/gal.

(e) The original TI-065 showed the volume of simulant to be added. The final TI was redlined to show the target total volume of slurry including the simulant and the $\mathrm{NaOH}$ added in-line. The total slurry volume targets are shown in this table.

(f) FT-0119 is the flow transmitter for the integrated volume of slurry (simulant $+\mathrm{NaOH}$ ) added in-line.

(g) The amount of simulant added is determined by the difference of the total slurry (simulant $+\mathrm{NaOH}$ ) added and the amount of $\mathrm{NaOH}$ added. Two calculation methods are used; see the report discussion for additional details. 
Table 9.3. Caustic-Leach Reagent Additions for Tank T01B Batches in Integrated Test A

\begin{tabular}{|c|c|c|c|c|}
\hline Reagents & Value & $\begin{array}{c}\text { Integrated Test } \\
\text { A, Batch } 2 \\
\end{array}$ & $\begin{array}{c}\text { Integrated Test } \\
\text { A, Batch } 4 \\
\end{array}$ & $\begin{array}{c}\text { Integrated Test } \\
\text { A, Batch } 6 \\
\end{array}$ \\
\hline \multirow{4}{*}{$\begin{array}{l}\sim 19-\mathrm{M} \mathrm{NaOH} \text { added } \\
\text { in-line }\end{array}$} & TI-065 target mass ${ }^{(\mathrm{a})}(\mathrm{kg})$ & $511 \pm 5$ & $504 \pm 5$ & $499 \pm 5$ \\
\hline & $\begin{array}{l}\text { Measured mass, primary meter }{ }^{(\mathrm{b})} \\
(\mathrm{kg})\end{array}$ & 508.8 & 501.7 & 496.4 \\
\hline & $\begin{array}{l}\text { Measured mass, secondary } \\
\text { meter }^{(\mathrm{c})}(\mathrm{kg})\end{array}$ & 507.4 & 502.2 & 495.2 \\
\hline & Calculated volume $^{(\mathrm{d})}$ (gal) & 87.9 & 86.7 & 85.8 \\
\hline \multirow{2}{*}{$\begin{array}{l}\sim 19-\mathrm{M} \mathrm{NaOH} \text { added } \\
\text { in-tank } \\
\text { (e) }\end{array}$} & TI-065 target mass ${ }^{(\mathrm{a})}(\mathrm{kg})$ & $128 \pm 2$ & $126 \pm 2$ & $125 \pm 2$ \\
\hline & $\begin{array}{l}\text { Measured mass, primary meter }{ }^{(\mathrm{f})} \\
(\mathrm{kg})\end{array}$ & 127.9 & 125.8 & 124.8 \\
\hline \multirow{2}{*}{$\begin{array}{l}\text { Slurry (simulant }+ \\
\sim 19-\mathrm{M} \mathrm{NaOH} \text { ) } \\
\text { added in-line }\end{array}$} & TI-065 target volume ${ }^{(\mathrm{g})}$ (gal) & $479 \pm 5$ & $393 \pm 5$ & $393 \pm 5$ \\
\hline & Measured volume $\mathrm{h}^{(\mathrm{h})}$ (gal) & 474.7 & 390.2 & 390.7 \\
\hline \multirow{2}{*}{ Simulant added ${ }^{(i)}$} & $\begin{array}{l}\text { Calculated mass, } \\
\text { Method A }(\mathrm{kg})\end{array}$ & 1894 & 1503 & 1506 \\
\hline & $\begin{array}{l}\text { Calculated mass, } \\
\text { Method B }(\mathrm{kg})\end{array}$ & 1872 & 1469 & 1476 \\
\hline
\end{tabular}

(a) The TI-065 target amount of $\mathrm{NaOH}$ reagent was based on an assumption that $17.9-\mathrm{M} \mathrm{NaOH}$ was used in the PEP test whereas actual analyses indicate that 19.2-M was used (Mahoney et al. 2009).

(b) FT-0101 is the primary flow transmitter for the integrated mass of $\mathrm{NaOH}$ reagent added in-line.

(c) FT-1421 is the primary flow transmitter for the mass flow rate of $\mathrm{NaOH}$ reagent added in-line, and it is the secondary device for integrated $\mathrm{NaOH}$ mass.

(d) The volume (L) is determined by dividing the $\mathrm{NaOH}$ reagent mass (e.g., primary meter value in $\mathrm{kg}$ ) by the $\mathrm{NaOH}$ density $(1.529-\mathrm{kg} / \mathrm{L}$ estimated for $19.2-\mathrm{M} \mathrm{NaOH}$ from literature data). Volume (gal) = Volume (L)/ 3.785-L/gal.

(e) The $2^{\text {nd }} \mathrm{NaOH}, \sim 20 \%$ of the total, is added to the top of the Tank T01B vessel ("in-tank" without simulant).

(f) FT-0401 is the primary flow transmitter for the integrated mass of $\mathrm{NaOH}$ reagent added to the top of Tank T01B. The results of the secondary flowmeter, FT-1421, agree to within 1-kg in each batch.

(g) The original TI-065 showed the volume of simulant to be added. The final TI was redlined to show the target total volume of slurry, including the simulant and the $\mathrm{NaOH}$ added in-line. The total slurry volume targets are shown in this table.

(h) FT-0119 is the flow transmitter for the integrated volume of slurry (simulant $+\mathrm{NaOH}$ ) added in-line.

(i) The amount of simulant added is determined by difference of the total slurry (simulant $+\mathrm{NaOH}$ ) added and the amount of $\mathrm{NaOH}$ reagent added. Two calculation methods are used; see the report discussion for additional details. 
Table 9.2 and Table 9.3 show that the amount of caustic added was within the target range for all six caustic-leach batches of Integrated Test A. This was true whether the $\mathrm{NaOH}$ was added in-line or in-tank. Further, the results shown for the secondary caustic flowmeter (FT-1421) are also universally within the target range.

The measured total slurry volumes also met the target ranges for all batches of Integrated Test A, except for Batch 3. The target for that batch was $426 \pm 5$ gal and the measured volume was $\sim 452$ gal. The 26-gal excess was presumably simulant because the added amount of caustic reagent was as planned (627-kg [108 gal] measured vs. a $629 \pm 5-\mathrm{kg}$ target). Using Method B, 344 gal (= 452 gal total measured - 108 gal $\mathrm{NaOH})$ was added compared to a target of 318 gal (= 426 gal total target -108 gal $\mathrm{NaOH}$ ). This is an excess of $\sim 8 \%$ of the target amount of simulant (= $26 \mathrm{gal} / 318 \mathrm{gal})$. Therefore, the caustic reagent to simulant mass ratio in Batch 3 of Integrated Test A may have been somewhat lower than expected.

The reagent and simulant additions noted in Table 9.2 and Table 9.3 correspond to, but are not equal to, the batch component masses shown in Table 9.4 (Tank T01A batches) and Table 9.5 (Tank T01B batches). The simulant amounts in the later tables are derived from the Method A and B values shown in the earlier tables, and the batch-component caustic amounts are derived from the primary flowmeter values. In addition to the freshly added caustic and simulant, the $2^{\text {nd }}$ and $3^{\text {rd }}$ batches in each vessel also contained $\sim 10$-in. of heel slurry material from the preceding caustic-leach batch (e.g., post-caustic-leach Batch 1 slurry is present as a heel in Batch 3; both batches leached in Tank T01A). The initial heel volume in the vessel before fresh simulant and caustic reagent addition was determined by stable level measurement. The heel was assumed to have the composition and density of the final 16-hr sample of the prior batch processed in the vessel. Using this bulk density, the initial mass of heel in the vessel was calculated. Heel slurry is identified as a third initial batch component in Table 9.4 and Table 9.5.

After caustic reagent and simulant additions were completed, recirculation of the slurry mixture through the heat exchanger recirculation loops of Tank T01A/B commenced in order to pre-heat the batch to a target temperature (e.g., $\sim 57^{\circ} \mathrm{C}$ in Integrated Test A). In the first batches in Tank T01 A (Integrated Test A, Batch 1) and in Tank T01B (Integrated Test A, Batch 2), the respective recirculation loops were assumed to be empty. In the subsequent batches, the recirculation loops were assumed to be filled with $\sim 9$ gal of slurry having the same composition as the vessel heel material (as a result of prior transfers to Tank T02A). Therefore, the pre-heat process combined any slurry in the recirculation loop with the contents in the vessel (heel, if any, and added simulant $+\mathrm{NaOH}$ ). Following the pre-heating process and (typically) before the start of direct steam injection, the contents of the heat exchanger recirculation loop were isolated from the reaction vessel. ${ }^{(a)}$ The slurry remaining in the vessel at that point is defined as the initial caustic-leach batch. The total initial mass of heel, simulant, and $\mathrm{NaOH}$ reagent in the vessel was determined from the slurry mixture volume in the vessel, as calculated from a stable level measurement and a temperature-corrected bulk slurry density. The masses of the individual heel, simulant, and $\mathrm{NaOH}$ components in the initial batch shown in Table 9.4 and Table 9.5 were obtained with the $\mathrm{NaOH} /$ simulant mass fractions derived fromTable 9.2 and Table 9.3 along with the estimated total mass of heel material initially present in the vessel and heat exchanger recirculation loop.

(a) In Integrated Test A Batch 2 in Tank T01B, direct steam injection started during the pre-heat process; see Section 9.3.2.2 for additional discussion. 
Table 9.4 and Table 9.5 also summarize the net mass of condensate accumulated in the batches after the $\sim 16-\mathrm{hr}$ leach was completed. The mass-based Method 2 results are used for overall process mass balance calculations (see Section 12). As determined by Method 2 and shown in Table 9.4, the mass of condensate in the three Tank T01A batches is quite consistent, ranging from 364 to $371-\mathrm{kg}$ of condensate and corresponding to $12.6-$ to $13.6-\mathrm{wt} \%$ of the final batch mass. Of the three batches in Tank T01B, the mass of condensate in Batch \#2 was somewhat higher (377-kg) than Batches \#4 and \#6 (321- and 320-kg, respectively). However, the spread of the final batch condensate mass fractions (12.1- to 13.4-wt\%) was not much different than the Tank T01A batches. Processing differences in the six batches that could contribute to the variation in condensate accumulation are addressed in Section 9.3.2.

Table 9.4. Caustic-Leach Batch Component Masses for Tank T01A Batches in Integrated Test A

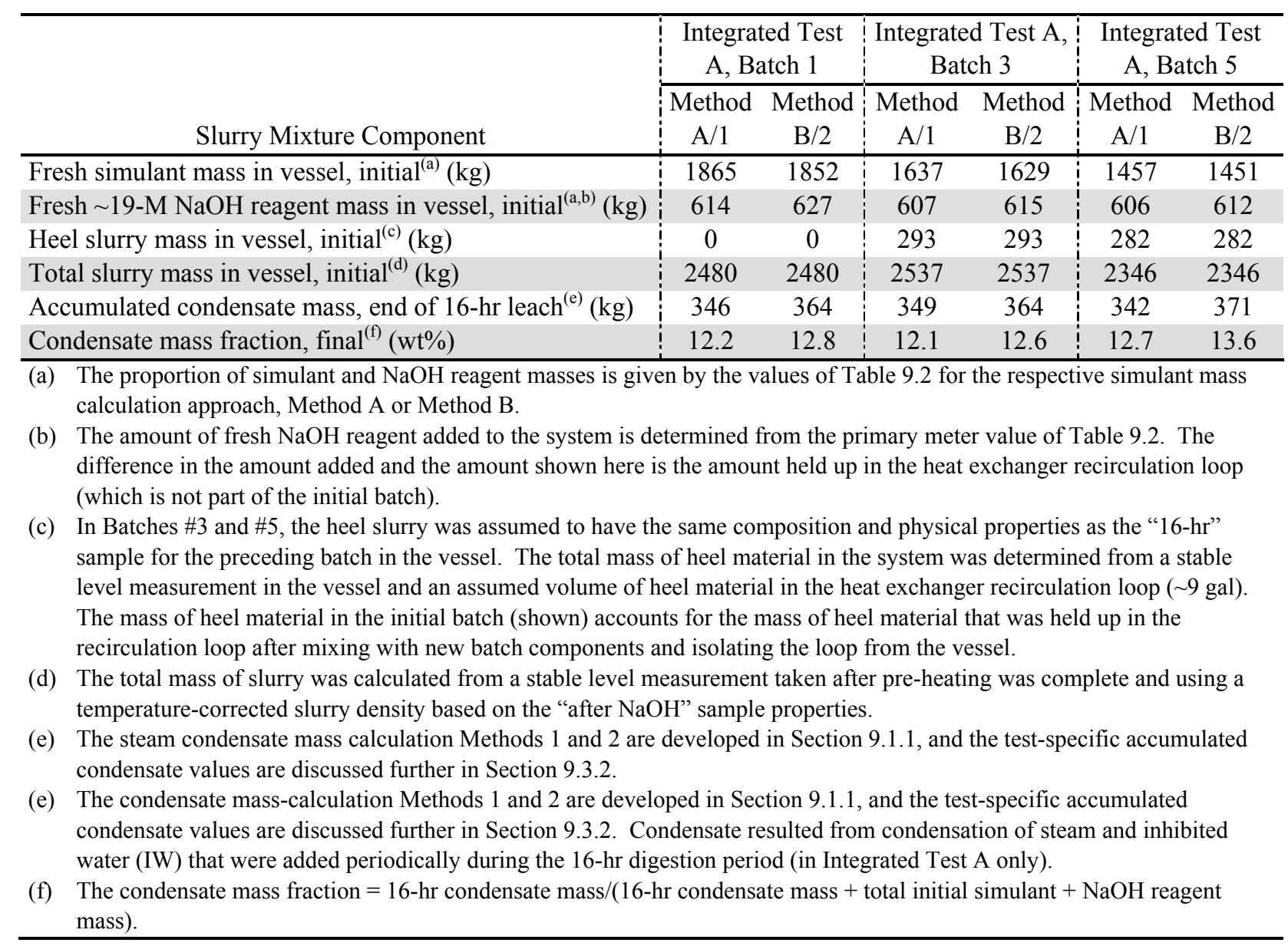


Table 9.5. Caustic-Leach Batch Component Masses for Tank T01B Batches in Integrated Test A

\begin{tabular}{|c|c|c|c|c|c|c|}
\hline \multirow[b]{2}{*}{ Slurry Mixture Component } & \multicolumn{2}{|c|}{$\begin{array}{l}\text { Integrated Test } \\
\quad \mathrm{A}, \text { Batch } 2\end{array}$} & \multicolumn{2}{|c|}{$\begin{array}{l}\text { Integrated Test } \\
\qquad \mathrm{A}, \text { Batch } 4\end{array}$} & \multicolumn{2}{|c|}{$\begin{array}{l}\text { Integrated Test } \\
\qquad \mathrm{A}, \text { Batch } 6\end{array}$} \\
\hline & $\begin{array}{l}\text { Method } \\
\mathrm{A} / 1\end{array}$ & $\begin{array}{l}\text { Method } \\
\text { B/2 }\end{array}$ & $\begin{array}{l}\text { Method } \\
\text { A/1 }\end{array}$ & $\begin{array}{c}\text { Method } \\
\mathrm{B} / 2\end{array}$ & $\begin{array}{l}\text { Method } \\
\text { A/1 }\end{array}$ & $\begin{array}{c}\text { Method } \\
\mathrm{B} / 2\end{array}$ \\
\hline Fresh simulant mass in vessel, initial ${ }^{(\mathrm{a})}(\mathrm{kg})$ & 1787 & 1781 & 1421 & 1411 & 1426 & 1418 \\
\hline Fresh $\sim 19-\mathrm{M} \mathrm{NaOH}$ reagent mass in vessel, initial ${ }^{(\mathrm{a}, \mathrm{b})}(\mathrm{kg})$ & 601 & 606 & 593 & 603 & 588 & 597 \\
\hline Heel slurry mass in vessel, initial ${ }^{(\mathrm{c})}(\mathrm{kg})$ & 0 & 0 & 299 & 299 & 300 & 300 \\
\hline Total slurry mass in vessel, initial ${ }^{(\mathrm{d})}(\mathrm{kg})$ & 2387 & 2387 & 2313 & 2313 & 2314 & 2314 \\
\hline Accumulated condensate mass, end of 16-hr leach ${ }^{(\mathrm{e})}(\mathrm{kg})$ & 347 & 377 & 300 & 321 & 299 & 320 \\
\hline Condensate mass fraction, final $^{(\mathrm{f})}(\mathrm{wt} \%)$ & 12.5 & 13.4 & 11.5 & 12.2 & 11.5 & 12.1 \\
\hline $\begin{array}{l}\text { (a) The proportion of simulant and } \mathrm{NaOH} \text { reagent masses is give } \\
\text { calculation approach, Method } \mathrm{A} \text { or Method } \mathrm{B} \text {. } \\
\text { (b) The amount of fresh } \mathrm{NaOH} \text { reagent added to the system is de } \\
\text { difference in the amount added and the amount shown here } \mathrm{i} \\
\text { (which is not part of the initial batch). }\end{array}$ & $\begin{array}{l}\text { y the valu } \\
\text { mined fron } \\
\text { e amount } 1\end{array}$ & $\begin{array}{l}\text { es of Tabl } \\
\text { held up in }\end{array}$ & $\begin{array}{l}\text { ary meter } \\
\text { the heat-e }\end{array}$ & $\begin{array}{l}\text { value of } \mathrm{T} \text {. } \\
\text { xchanger } \mathrm{r}\end{array}$ & $\begin{array}{l}\text { able } 9.3 . \mathrm{T} \\
\text { ecirculatio }\end{array}$ & $\begin{array}{l}\text { The } \\
\text { on loop }\end{array}$ \\
\hline $\begin{array}{l}\text { In Batches } \# 4 \text { and } \# 6 \text {, the heel slurry was assumed to have th } \\
\text { sample for the preceding batch in the vessel. The total mass } \\
\text { level measurement in the vessel and an assumed volume of } \\
\text { The mass of heel material in the initial batch (shown) accour } \\
\text { recirculation loop after mixing with new batch components a }\end{array}$ & $\begin{array}{l}\text { ame comp } \\
\text { meel materi } \\
\text { material it } \\
\text { or the mas } \\
\text { isolating tl }\end{array}$ & osition anc & material th & $\begin{array}{l}\text { properties } \\
\text { determine } \\
\text { recirculati } \\
\text { at was held } \\
\text { sel. }\end{array}$ & d up in the & $\begin{array}{l}\text {-hr" } \\
\text { stable } \\
\text { gal). }\end{array}$ \\
\hline $\begin{array}{l}\text { The total mass of slurry was calculated from a stable level m } \\
\text { temperature-corrected slurry density based on the "after } \mathrm{NaC}\end{array}$ & $\begin{array}{l}\text { urement ta } \\
\text { sample pr }\end{array}$ & $\begin{array}{l}\text { ken after } \\
\text { operties. }\end{array}$ & pre-heating & g was comp & plete and $\mathrm{u}$ & using a \\
\hline $\begin{array}{l}\text { The condensate mass calculation Methods } 1 \text { and } 2 \text { are develd } \\
\text { condensate values are discussed further in Section 9.3.2. Co } \\
\text { added periodically during the 16-hr digestion period (in Inte }\end{array}$ & $\begin{array}{l}\text { in Sectio } \\
\text { nsate resul } \\
\text { ed Test A }\end{array}$ & $\begin{array}{l}\text { n } 9.1 .1 \text {, an } \\
\text { lted from } \\
\text { only). }\end{array}$ & $\begin{array}{l}\text { d the test- } \\
\text { condensati }\end{array}$ & $\begin{array}{l}\text { specific ac } \\
\text { on of stean }\end{array}$ & m and IW t & that were \\
\hline $\begin{array}{l}\text { The condensate mass fraction }=16-\mathrm{hr} \text { condensate } \text { mass } /(16-1 \\
\text { mass }) \text {. }\end{array}$ & ondensate & mass + tot & al initial s & imulant +1 & $\mathrm{NaOH}$ reag & gent \\
\hline
\end{tabular}

\subsubsection{Integrated Test B}

Table 9.6 summarizes the target caustic reagent amounts for the Integrated Test B caustic-leach batches in Tank T02A. These were specified in TI-WTP-PEP-066 for an assumed 18.6-M NaOH concentration (Mahoney et al. 2009). The actual concentration of caustic used in the Integrated Test B batches was later determined to be slightly higher, 18.7-M. Table 9.6 also shows the measured amount of caustic added, as determined by integrating the mass flow rate recorded for two independent flowmeters located in-series on the feed line. The primary flow transmitter, FT-0605, was used to control the total amount of $\mathrm{NaOH}$ added in the process. The other flow transmitter, FT-1421, was used to control the addition rate and provides a secondary (post-experimental) estimate of the amount of caustic added. Table 9.6 indicates that the target $\mathrm{NaOH}$ mass $(720 \pm 5-\mathrm{kg})$ was met in both Integrated Test $\mathrm{B}$ batches (721-kg measured) according to the primary process control flowmeter. In Batch 1, the second meter agreed reasonably well $(728-\mathrm{kg})$. However, in Batch 2, the second meter shows a significant discrepancy (674-kg), which is not explained. 
Table 9.6. Caustic-Leach Reagent Additions for Tank T02A Batches in Integrated Test B

\begin{tabular}{|c|c|c|c|c|c|}
\hline \multirow[b]{2}{*}{ Reagents } & \multirow[b]{2}{*}{ Value } & \multicolumn{2}{|c|}{$\begin{array}{c}\text { Integrated Test B, } \\
\text { Batch } 1\end{array}$} & \multicolumn{2}{|c|}{$\begin{array}{c}\text { Integrated Test B, } \\
\text { Batch } 2\end{array}$} \\
\hline & & $\begin{array}{c}\text { Method } \\
\text { A }\end{array}$ & $\begin{array}{l}\text { Method } \\
\text { B }\end{array}$ & $\begin{array}{c}\text { Method } \\
\text { A }\end{array}$ & $\begin{array}{c}\text { Method } \\
\text { B }\end{array}$ \\
\hline \multirow{4}{*}{$\begin{array}{l}\sim 19-\mathrm{M} \mathrm{NaOH} \text { added in- } \\
\text { line }\end{array}$} & TI-066 target mass ${ }^{(\mathrm{a})}(\mathrm{kg})$ & \multicolumn{2}{|c|}{$720 \pm 5$} & \multicolumn{2}{|c|}{$720 \pm 5$} \\
\hline & Measured mass, primary meter ${ }^{(b)}(\mathrm{kg})$ & \multicolumn{2}{|c|}{720.6} & \multicolumn{2}{|c|}{720.7} \\
\hline & Measured mass, secondary meter ${ }^{(\mathrm{c})}(\mathrm{kg})$ & \multicolumn{2}{|c|}{727.9} & \multicolumn{2}{|c|}{673.5} \\
\hline & Calculated volume ${ }^{(\mathrm{d})}(\mathrm{gal})$ & \multicolumn{2}{|c|}{125.3} & \multicolumn{2}{|c|}{125.3} \\
\hline \multirow{2}{*}{$\begin{array}{l}\text { Concentrated simulant } \\
\text { present }^{(\mathrm{e})}\end{array}$} & Volume $^{(\mathrm{e})}(\mathrm{gal})$ & \multicolumn{2}{|c|}{190.2} & \multicolumn{2}{|c|}{166.8} \\
\hline & $\operatorname{Mass}^{(\mathrm{f})}(\mathrm{kg})$ & \multicolumn{2}{|c|}{992.5} & \multicolumn{2}{|c|}{889.4} \\
\hline \multirow{2}{*}{$\begin{array}{l}\text { Component mass fractions } \\
\text { in } \text { batch }^{(\mathrm{g})}\end{array}$} & $\mathrm{NaOH}(\mathrm{wt} \%)$ & 42.1 & 42.3 & 44.8 & 43.1 \\
\hline & Conc. simulant $(\mathrm{wt} \%)$ & 57.9 & 57.7 & 55.2 & 56.9 \\
\hline \multicolumn{6}{|c|}{ (a) TheTI-066 target amount of $\mathrm{NaOH}$ reagent was based on an assumption that 18.6-M NaOH was available in PEP } \\
\hline \multicolumn{6}{|c|}{ Integrated Test B, whereas actual analyses indicate that 18.7-M was used (Mahoney et al. 2009). } \\
\hline \multicolumn{2}{|c|}{ FT-1421 is the primary flow transmitter for the mass flow rate of $\mathrm{NaOH}$} & $\begin{array}{l}\text { reagent ad } \\
\text { added in-lin }\end{array}$ & $\begin{array}{l}\mathrm{d} \text { in-line. } \\
\text { and it is th }\end{array}$ & secondary & vice for \\
\hline (1.519-kg/L estimated to & $\begin{array}{l}\text { ed by dividing the } \mathrm{NaOH} \text { reagent mass (e.g., } \\
8.7-\mathrm{M} \mathrm{NaOH} \text { from literature data). Volume }\end{array}$ & $\begin{array}{l}\text { orimary me } \\
\text { gal })=\text { Volu }\end{array}$ & $\begin{array}{l}\text { value in } \mathrm{k} \\
(\mathrm{L}) / 3.785\end{array}$ & $\begin{array}{l}\text { by the } \mathrm{Na} \\
\text { L/gal. }\end{array}$ & H density \\
\hline The calculated amount pr & sent in the vessel and filter-loop following filt & ation and $\mathrm{b}$ & pre caustic & ddition. & \\
\hline $\begin{array}{l}\text { The mass of simulant wa } \\
\text { analytical sample (1.379- }\end{array}$ & $\begin{array}{l}\text { determined from the volume of simulant and } \mathrm{t} \\
\mathrm{g} / \mathrm{L} \text { in Batch } 1 \text { and } 1.408-\mathrm{kg} / \mathrm{L} \text { in Batch } 2) \text {. }\end{array}$ & he bulk slur & density of & e "before l & OH” \\
\hline Method A and Method B & using the mass of $\mathrm{NaOH}$ reagent from the prin & & dary mete & & \\
\hline
\end{tabular}

For determining the actual initial batch make-up of caustic-leach batches in Tank T02A, it is the amount of $\sim 20$-wt $\%$ concentrated simulant present in the system when caustic is added that is significant, not the amount of $\sim 5-\mathrm{wt} \%$ feed simulant required to produce the concentrated simulant. Table 9.6 shows the volume and mass of concentrated simulant initially present in the system for each Integrated Test B batch. The initial system consists of the Tank T02A vessel and the tubeside of the filter recirculation loop (where permeate is collected on the shellside). The volume of $\sim 20-\mathrm{wt} \%$ concentrated simulant present in the vessel was determined from a stable vessel level measurement (e.g., PJMs and filter pumps off) that was made after filtration and before caustic addition. It was also assumed that the filter-loop contained 82 gal of concentrated simulant on the tubeside (pumps turned off). The sum of these volumes was the total amount of concentrated simulant present in the system during caustic addition. Samples of the concentrated simulant taken before $\mathrm{NaOH}$ addition provide the bulk slurry density needed to convert the simulant volume to mass.

Table 9.6 also shows the mass fractions of caustic and concentrated simulant reagents in the Integrated Test $\mathrm{B}$ batches. To cover the possible uncertainty in the amount of caustic added, mass fractions were developed for both the primary and secondary $\mathrm{NaOH}$ flowmeters. The Method $\mathrm{A}$ and Method B results are based on the primary and secondary meters, respectively. Note, however, that this approach does not address uncertainties in the amount of simulant that arise from other factors, such as vessel level measurements, level-volume correlations, filter-loop volume measurements and assumptions, representative sampling, and sample analytical measurements.

After caustic addition, recirculation of the simulant and $\mathrm{NaOH}$ slurry mixture through the filter-loop (no permeate collected) continued in order to pre-heat the batch to a target temperature (e.g., $\sim 71^{\circ} \mathrm{C}$ in Integrated Test B) using pump heat. Following the pre-heating process and before the start of direct 
steam injection, a fraction of the slurry in the filter-loop was flushed into Tank T02A using $0.01-\mathrm{M} \mathrm{NaOH}$. None of the flush liquid was expected to enter the vessel, and the filter-loop was isolated from the vessel. The slurry remaining in the vessel at that point is defined as the initial caustic-leach batch. The total initial mass of simulant and $\mathrm{NaOH}$ reagent in the vessel was determined from the slurry mixture volume in the vessel, as calculated from a stable level measurement and a temperature-corrected bulk slurry density. The masses of the individual $\mathrm{NaOH}$ and concentrated simulant components in the initial batch were obtained using the mass fractions of Table 9.6. The calculated initial batch component masses for the Integrated Test B batches are summarized in Table 9.7. The results for Methods A and B in Table 9.7 parallel the evaluation of reagent mass fractions by two methods in Table 9.6.

Table 9.7 also summarizes the net mass of condensate accumulated in the batches after the $\sim 16-\mathrm{hr}$ leach was completed. For overall process mass balance calculations (see Section 12), the mass-based Method 2 results are used. As shown in Table 9.7, the condensate mass in Integrated Test B, Batch 1 is more than 50-kg greater than in Batch 2 (e.g., 297-kg vs. 242-kg). Also, the condensate mass fraction of the final batch mass is $\sim 3 \%$ higher in Batch 1 (e.g., $18.7 \%$ vs. $15.9 \%$ ). This may be influenced in part by the variation in $\mathrm{NaOH} /$ simulant ratios in the two batches (Table 9.6 and Table 9.7), which would result in differences in water vapor pressure and rates of evaporation of water into air that is vented from the system. Other processing differences in the execution of the two batches that could contribute to the discrepancies in condensate accumulation are addressed in Section 9.3.3.

Table 9.7. Caustic-Leach Batch Component Masses for Tank T02A Batches in Integrated Test B

\begin{tabular}{|c|c|c|c|c|}
\hline \multirow[b]{2}{*}{ Slurry Mixture Component } & \multicolumn{2}{|c|}{$\begin{array}{c}\text { Integrated Test B, } \\
\text { Batch } 1\end{array}$} & \multicolumn{2}{|c|}{$\begin{array}{c}\text { Integrated Test B, } \\
\text { Batch } 2\end{array}$} \\
\hline & $\begin{array}{c}\text { Method } \\
\text { A/1 }\end{array}$ & $\begin{array}{c}\text { Method } \\
\text { B/2 }\end{array}$ & $\begin{array}{c}\text { Method } \\
\text { A/1 }\end{array}$ & $\begin{array}{c}\text { Method } \\
\mathrm{B} / 2\end{array}$ \\
\hline Simulant mass in vessel, initial ${ }^{(\mathrm{a})}(\mathrm{kg})$ & 746 & 743 & 707 & 728 \\
\hline$\sim 19-\mathrm{M} \mathrm{NaOH}$ reagent mass in vessel, initial ${ }^{(\mathrm{a})}(\mathrm{kg})$ & 542 & 545 & 573 & 551 \\
\hline Simulant $+\mathrm{NaOH}$ reagent mass in vessel, initial ${ }^{(\mathrm{a})}(\mathrm{kg})$ & 1288 & 1288 & 1280 & 1280 \\
\hline Accumulated steam condensate mass, end of $16-\mathrm{hr}$ leach ${ }^{(\mathrm{b})}(\mathrm{kg})$ & 274 & 297 & 221 & 242 \\
\hline Condensate mass fraction $^{(\mathrm{c})}(\mathrm{wt} \%)$ & 17.5 & 18.7 & 14.7 & 15.9 \\
\hline \multicolumn{5}{|c|}{$\begin{array}{l}\text { (a) The total initial mass of simulant and } \mathrm{NaOH} \text { reagent in the vessel was determined from the slurry mixture volume in the } \\
\text { vessel (after partially flushing the filter-loop into Tank } \mathrm{T} 02 \mathrm{~A} \text { and isolating the filter-loop, and before direct steam injection) } \\
\text { and a temperature-corrected bulk slurry density. The mass fractions of simulant and } \mathrm{NaOH} \text { reagent are given by the values } \\
\text { of Table } 9.6 \text { for the respective calculation approach, Method } \mathrm{A} \text { or Method } \mathrm{B} \text {. }\end{array}$} \\
\hline \multicolumn{5}{|c|}{$\begin{array}{l}\text { (b) The steam condensate mass calculation Methods } 1 \text { and } 2 \text { are developed in Section 9.1.1, and the test-specific accumulated } \\
\text { condensate values are discussed further in Section 9.3.3. }\end{array}$} \\
\hline \multicolumn{5}{|c|}{$\begin{array}{l}\text { (c) The condensate mass fraction }=16-\mathrm{hr} \text { condensate mass } /(16-\mathrm{hr} \text { condensate mass }+ \text { total initial simulant }+\mathrm{NaOH} \text { reagent } \\
\text { mass }) \text {. }\end{array}$} \\
\hline
\end{tabular}

\subsubsection{Integrated Test D}

The two Integrated Test D caustic-leach batches were also conducted in Tank T02A. The processing steps were analogous to those of Integrated Test B. Therefore, the following development mirrors that for Integrated Test B in Section 9.2.3.

Table 9.8 summarizes the target caustic reagent amounts for the Integrated Test D caustic-leach batches that were specified in TI-WTP-PEP-082. The table also shows the measured amount of caustic 
added, as determined by integrating the mass flow rate recorded for two independent flowmeters located in-series on the feed line. The primary flow transmitter, FT-0605, was used to control the total amount of $\mathrm{NaOH}$ added in the process. The other flow transmitter, FT-1421, was used to control the addition rate and provides a secondary (post-experimental) estimate of the amount of caustic added. Table 9.8 indicates that the target $\mathrm{NaOH}$ mass $(935 \pm 5-\mathrm{kg})$ was met in both Integrated Test $\mathrm{D}$ batches according to the primary process control flowmeter (932-kg measured in Batch 1 and 935-kg measured in Batch 2). In both batches, the secondary meter result was outside the target range, but not by more than $5-\mathrm{kg}$.

For determining the actual initial batch make-up of caustic-leach batches in Integrated Test $\mathrm{D}$, it is the amount of $\sim 20$-wt $\%$ concentrated simulant present in the system when caustic is added that is significant, not the amount of $\sim 5-\mathrm{wt} \%$ feed simulant required to produce the concentrated simulant. Table 9.8 shows the volume and mass of concentrated simulant initially present in the system for each Integrated Test D batch. The initial system consists of the Tank T02A vessel and the tubeside of the filter recirculation loop (where permeate is collected on the shellside). The volume of $\sim 20-\mathrm{wt} \%$ concentrated simulant present in the vessel was determined from a stable vessel level measurement (e.g., PJMs and filter pumps off) that was made after filtration and before caustic addition. It was also assumed that the filter-loop contained 82 gal of concentrated simulant on the tubeside (pumps turned off). The sum of these volumes was the total amount of concentrated simulant present in the system during caustic addition. Samples of the concentrated simulant taken before $\mathrm{NaOH}$ addition provide the bulk slurry density needed to convert the simulant volume to mass. While the caustic reagent amount is comparable in both batches, the total mass of simulant is somewhat higher in Batch $2(859-\mathrm{kg})$ than in Batch $1(781-\mathrm{kg})$.

Table 9.8. Caustic-Leach Reagent Additions for Tank T02A Batches in Integrated Test D

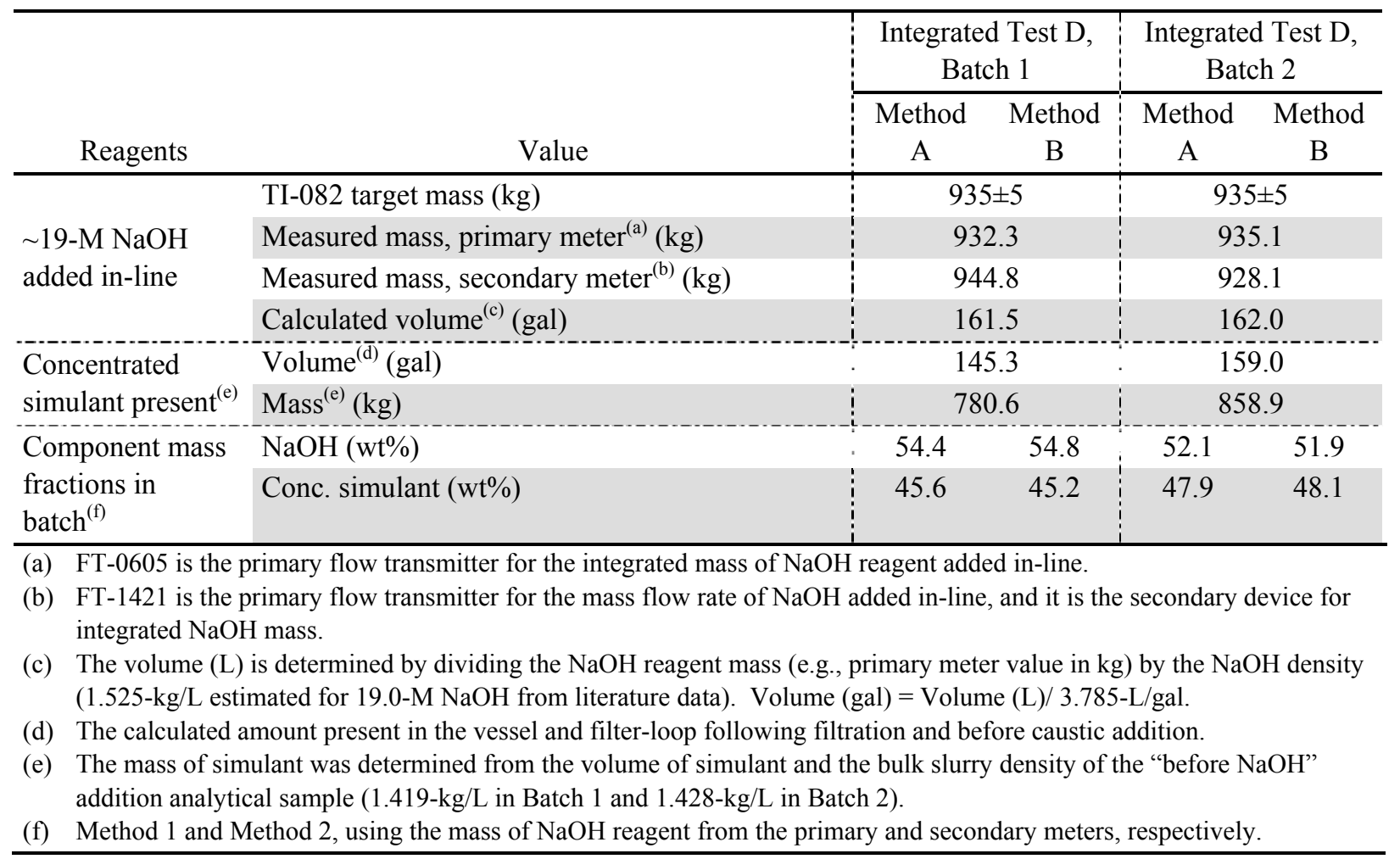


Table 9.8 also shows the mass fractions of caustic and concentrated simulant reagents in the Integrated Test $\mathrm{D}$ batches. To cover the possible uncertainty in the amount of caustic added, mass fractions were developed for both the primary and secondary $\mathrm{NaOH}$ flowmeters. The Method $\mathrm{A}$ and Method B results are based on the primary and secondary meters, respectively. Note, however, that this approach does not address uncertainties in the amount of simulant that arise from other factors, such as vessel level measurements, level-volume correlations, filter-loop volume measurements and assumptions, representative sampling, and sample analytical measurements.

After caustic addition, recirculation of the simulant and $\mathrm{NaOH}$ slurry mixture through the filter-loop (no permeate collected) continued in order to pre-heat the batch to a target temperature (e.g., $\sim 65^{\circ} \mathrm{C}$ in Integrated Test $\mathrm{D}$, Batch 1 and $\sim 70^{\circ} \mathrm{C}$ in Integrated Test $\mathrm{D}$, Batch $2^{(\mathrm{a})}$ ) using pump heat. The filter-loop was isolated from the vessel after the pre-heating process and before the start of direct steam injection. In Batch 1, a fraction of the slurry in the filter-loop ( 20 gal) was flushed into Tank T02A before isolating the loop from the vessel, but later, $\sim 137-\mathrm{kg}$ of the slurry was removed from the vessel. ${ }^{(\mathrm{b})}$ In Batch 2, no filter-loop flush into Tank T02A was completed before isolating the loop, and no slurry was removed from the vessel. In both batches, the slurry remaining in the vessel before direct steam injection was defined as the initial caustic-leach batch. The total initial mass of simulant and $\mathrm{NaOH}$ reagent in the vessel was determined from the slurry mixture volume in the vessel, as calculated from a stable level measurement, and a temperature-corrected bulk slurry density. The masses of the individual $\mathrm{NaOH}$ and concentrated simulant components in the initial batch were obtained using the mass fractions of Table 9.8. The calculated initial batch component masses for the Integrated Test D batches are summarized in Table 9.9. The results for Methods A and B in Table 9.9 parallel the evaluation of reagent mass fractions by two methods in Table 9.8 .

Table 9.9 also summarizes the net mass of condensate accumulated in the batches after the $\sim 24-\mathrm{hr}$ leach was completed. The mass-based Method 2 results are used for overall process mass balance calculations (see Section 12). As shown in Table 9.9, the condensate mass in the two Integrated Test D batches differed by less than 15-kg (i.e., 269-kg in Batch 1 and 256-kg in Batch 2), and the condensate mass fractions of the final batch masses differed by only $1 \%$ (i.e., 17.2-wt $\%$ in Batch 1 and $16.2-w t \%$ in Batch 2). Additional details of the Integrated Test $\mathrm{D}$ processing conditions and condensate accumulation are addressed in Section 9.3.4.

(a) The higher pre-heat temperature in Batch 2 was a redline modification to TI-082.

(b) Slurry was removed as result of concerns that the slurry level in the vessel would be too high by the end of the caustic-leach period when condensate accumulation was at a maximum. 
Table 9.9. Caustic-Leach Batch Component Masses for Tank T02A Batches in Integrated Test D

\begin{tabular}{|c|c|c|c|c|}
\hline \multirow[b]{2}{*}{ Slurry Mixture Component } & \multicolumn{2}{|c|}{$\begin{array}{l}\text { Integrated Test D, } \\
\text { Batch } 1\end{array}$} & \multicolumn{2}{|c|}{$\begin{array}{l}\text { Integrated Test D, } \\
\quad \text { Batch } 2\end{array}$} \\
\hline & $\begin{array}{l}\text { Method } \\
\text { A/1 }\end{array}$ & $\begin{array}{l}\text { Method } \\
\text { B/2 }\end{array}$ & $\begin{array}{l}\text { Method } \\
\text { A/1 }\end{array}$ & $\begin{array}{l}\text { Method } \\
\text { B/2 }\end{array}$ \\
\hline Simulant mass in vessel, initial ${ }^{(\mathrm{a})}(\mathrm{kg})$ & 589 & 584 & 635 & 637 \\
\hline $\mathrm{NaOH}$ reagent mass in vessel, initial ${ }^{(\mathrm{a})}(\mathrm{kg})$ & 703 & 707 & 691 & 689 \\
\hline Simulant $+\mathrm{NaOH}$ reagent mass in vessel, initial ${ }^{(\mathrm{a})}(\mathrm{kg})$ & 1292 & 1292 & 1326 & 1326 \\
\hline Accumulated steam condensate mass, end of $24-\mathrm{hr}$ leach ${ }^{(b)}(\mathrm{kg})$ & 225 & 269 & 226 & 256 \\
\hline Condensate mass fraction $^{(\mathrm{c})}(\mathrm{wt} \%)$ & 14.8 & 17.2 & 14.5 & 16.2 \\
\hline \multicolumn{5}{|c|}{$\begin{array}{l}\text { (a) The total initial mass of simulant and } \mathrm{NaOH} \text { reagent in the vessel was determined from the slurry mixture volume in the } \\
\text { vessel (after partially flushing the filter-loop into Tank T02A and isolating the filter-loop, and before direct steam injection) } \\
\text { and a temperature-corrected bulk slurry density. The mass fractions of simulant and } \mathrm{NaOH} \text { reagent are given by the values } \\
\text { of Table } 9.8 \text { for the respective calculation approach, Method } \mathrm{A} \text { or Method } \mathrm{B} \text {. }\end{array}$} \\
\hline \multicolumn{5}{|c|}{$\begin{array}{l}\text { (b) The steam condensate mass calculation Methods } 1 \text { and } 2 \text { are developed in Section 9.1.1, and the test-specific accumulated } \\
\text { condensate values are discussed further in Section 9.3.4. }\end{array}$} \\
\hline \\
\hline
\end{tabular}

\subsection{PEP Caustic-Leach Process Description}

The details of caustic leaching processing during the PEP tests can be found in the run reports for the various tests. This section provides an overview of processing conditions and draws attention to features of the tests that were not as expected or planned and that were potentially relevant to the interpretation of the caustic leaching data. The major focuses are the temperature and condensate accumulation.

In the PTF UFP vessels, direct injection of steam will be used to heat the process slurry to the caustic leaching temperature and maintain it. The rate of temperature increase during the heating ramp with a fixed steam addition rate, the amount of steam required to maintain a constant leaching temperature, and the net amount of steam condensate accumulated in the slurry batch depend on a number of factors. These include 1) the masses and specific heat capacities of the process slurry and vessel structural components, 2) heat transfer rates from the outer vessel surfaces, 3) heat loss due to heating of air used in PJMs, 4) steam ring purge and spargers, and 5) evaporation of water into the air streams. The net amount of condensate accumulated in the vessel during the leach process is the difference between the amount of steam added and the amount of water leaving the vessel with air in the PJM and vessel headspace ventilation system. A Mathcad model was developed and applied to assess the heating (and cooling) temperature profiles and the expected amount of condensate accumulation for some representative caustic-leach processes in the PTF UFP-VSL-00001A/B and UFP-VSL-00002 vessels. ${ }^{(a)}$

Applying similar models and considering volumetric scaling provide the basis of expected condensate accumulation in the PEP UFP vessels. Neither the temperature profile nor the condensate accumulation rates in the PEP could be expected to be naturally prototypic of the PTF because heat transfer rates in the PEP vessels do not scale volumetrically. Although all heating in the PTF is carried out using steam injection, the same approach was not used in the PEP. Various process manipulations were carried out to

(a) Rassat SD, RP Pires, and DE Kurath. 2008. Analysis of Transient Heat Transfer in the Waste Treatment Plant (WTP) Ultrafiltration Feed Preparation and Process (UFP) Vessels - Modeling Approach, Assumptions, and Results. WTP-RPT-159, Rev 0, PNNL- 17835, Rev 0, Pacific Northwest National Laboratory, Richland, Washington. 
achieve functionally prototypic conditions in the PEP. For leaching in Tanks T01A/B an initial pre-heat with external heat exchangers before direct-steam injection was needed to emulate the expected condensate accumulation in the PTF UFP vessels. Further, in the Integrated Test A leach batches in Tanks T01A/B, (IW, 0.01-M NaOH) was added throughout the $98^{\circ} \mathrm{C}$ leach period to maintain the expected condensate accumulation rate. For leaching in Tank T02A, the necessary pre-heating was accomplished with the heat of dilution as the 19-M caustic was added as well as heating due to mechanical energy from the filter-loop pumps. The object of the procedures was to provide both temperature profiles (heating rate, constant leaching temperature, and cooling rate) and condensate accumulation profiles that would be representative of the PTF caustic leaching processes.

The subsections that follow are broken out first by test and then by topic. Sections 9.3.1, 9.3.2, 9.3.3, and 9.3.4 cover the Shakedown/Functional Tests, Integrated Test A, Integrated Test B, and Integrated Test $\mathrm{D}$, respectively. The following topics are discussed in each Integrated Test section:

- A brief description of the caustic leaching test sequence.

- Process temperature profiles at the prototypic vessel temperature sensor for each caustic leaching batch.

- A steam addition and condensate accumulation analysis for each caustic leaching batch, carried out by the methods described in Section 9.1.1.

- A summary of the potentially significant departures from expected conditions.

The total condensate masses have already been presented in Section 9.2 as part of the evaluation of simulant, reagent, and condensate components of each caustic leaching batch. This section focuses on the time variation of the delta-volume of the slurry (the change from the volume before steam injection) and the rates of condensate accumulation and steam addition. (See the earlier caustic leaching report [Mahoney et al. 2009] for representative examples of the manner in which the total slurry volume varies with time.)

Note, also, that preliminary assessments of condensate accumulation in the two PEP test batches, using a subset of the techniques described below, were a basis for the amount of water added as diluent in the laboratory-scale caustic-leach tests (see Section 9.4). The initial condensate analyses were typically completed within days of the PEP caustic leaching tests. The subsequent availability of analytical solid weight fractions (UDS), slurry densities, and liquid densities permitted refinement of the original volume-based analyses and incorporation of mass-based calculations, as described below.

\subsubsection{Integrated Test A}

As described in more detail in Sections 4.1 and 4.2 of Guzman-Leong et al. (2009), six batches of unconcentrated simulant were processed during Integrated Test A. The caustic-leach process included addition of $\mathrm{NaOH}$ reagent, heat-up to leach temperature $\left(98^{\circ} \mathrm{C}\right)$, and digestion at constant temperature. The simulant that underwent caustic leaching in Integrated Test A did not include the Cr component, which was added later in the process.

Caustic leaching operations alternated in parallel between Tank T01A (Batches 1, 3, and 5) and Tank T01B (Batches 2, 4, and 6). For the odd-numbered batches, all the $\mathrm{NaOH}$ reagent was added in-line between HLP-VSL-T22 and Tank T01A. For the even-numbered batches, $80 \%$ of the $\mathrm{NaOH}$ was added 
in-line between HLP-VSL-T22 and Tank T01B and 20\% was added through a line in the top of Tank T01B.

\subsubsection{Integrated Test A Temperature Profiles}

Figure 9.1 through Figure 9.6 show the temperature-versus-time profiles in Tanks T01A and T01B during caustic leaching of Batches 1 through 6 . The time axis is expressed in terms of time relative to the start of the constant-temperature leach as determined from the point that the target leaching temperature, $98^{\circ} \mathrm{C}$, was first reached (see tables in Appendix A for the elapsed time zero clock time). The temperature is measured at the prototypic temperature sensor for each vessel (TTK-0325 in Tank T01A; TTK-0425 in Tank T01B); the sensors are located near the vessel bottoms. Each figure also shows the temperature-versus-time targets outlined in the Test Instruction (TI-065). The x- and y-error bars correspond to the TI target ranges. As noted previously, the TI temperature profile targets in the heating and cooling regimes were derived from versions of WTP UFP vessel heat transfer models.

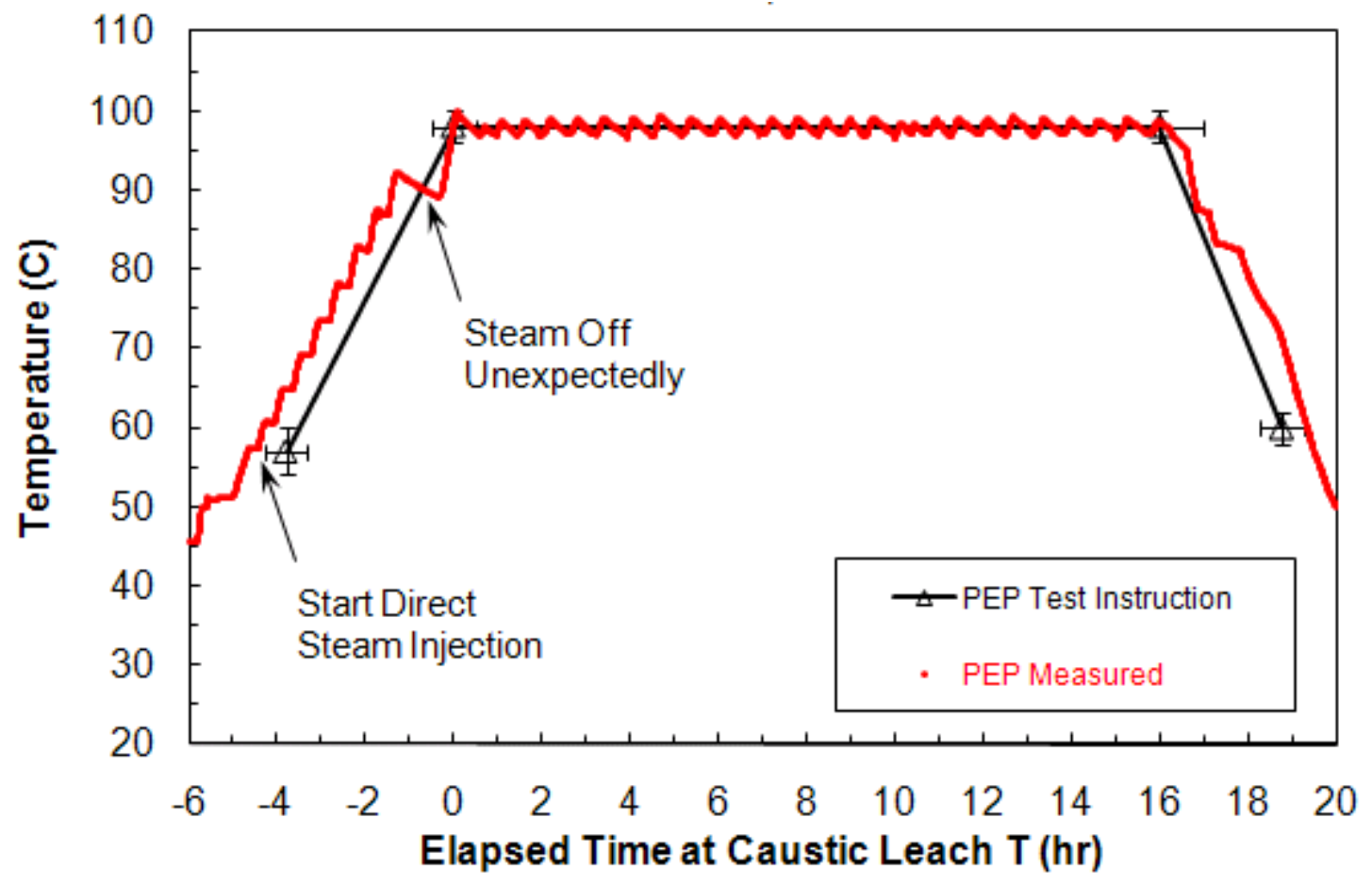

Figure 9.1. Temperature Measured at the Prototypic Sensor in PEP Vessel Tank T01A During Integrated Test A, Batch 1 


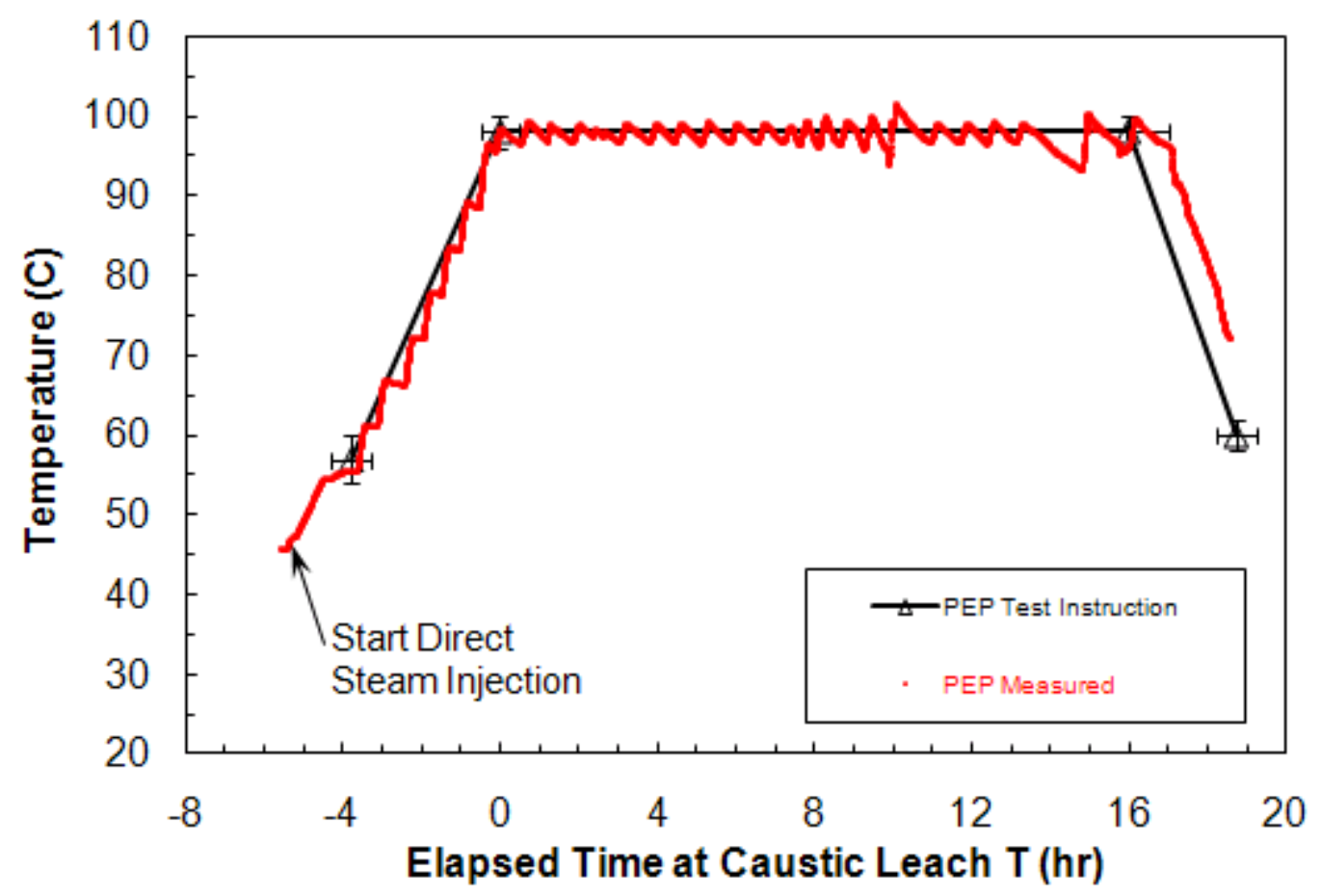

Figure 9.2. Temperature Measured at the Prototypic Sensor in PEP Vessel Tank T01B During Integrated Test A, Batch 2

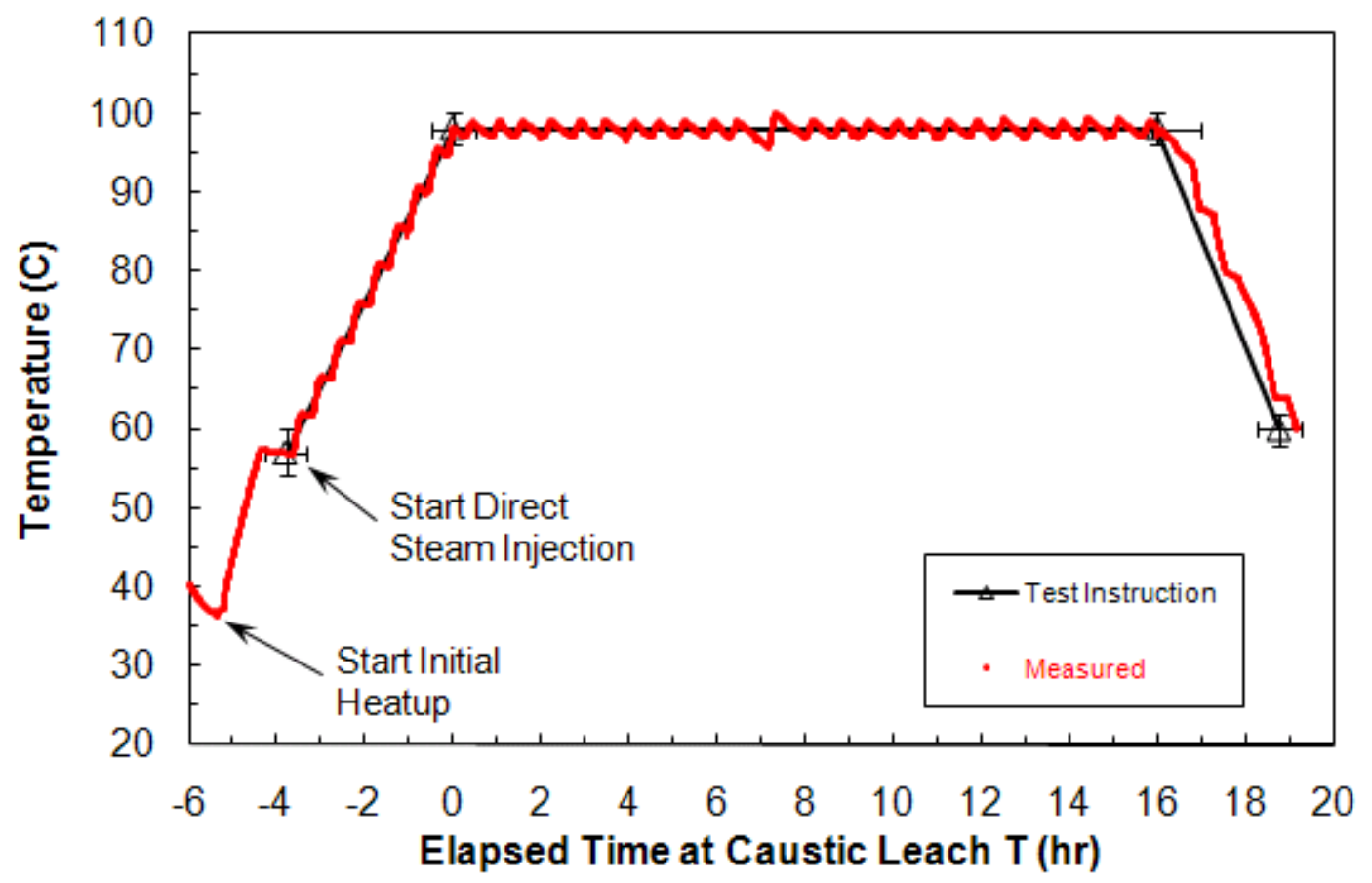

Figure 9.3. Temperature Measured at the Prototypic Sensor in PEP Vessel Tank T01A During Integrated Test A, Batch 3 


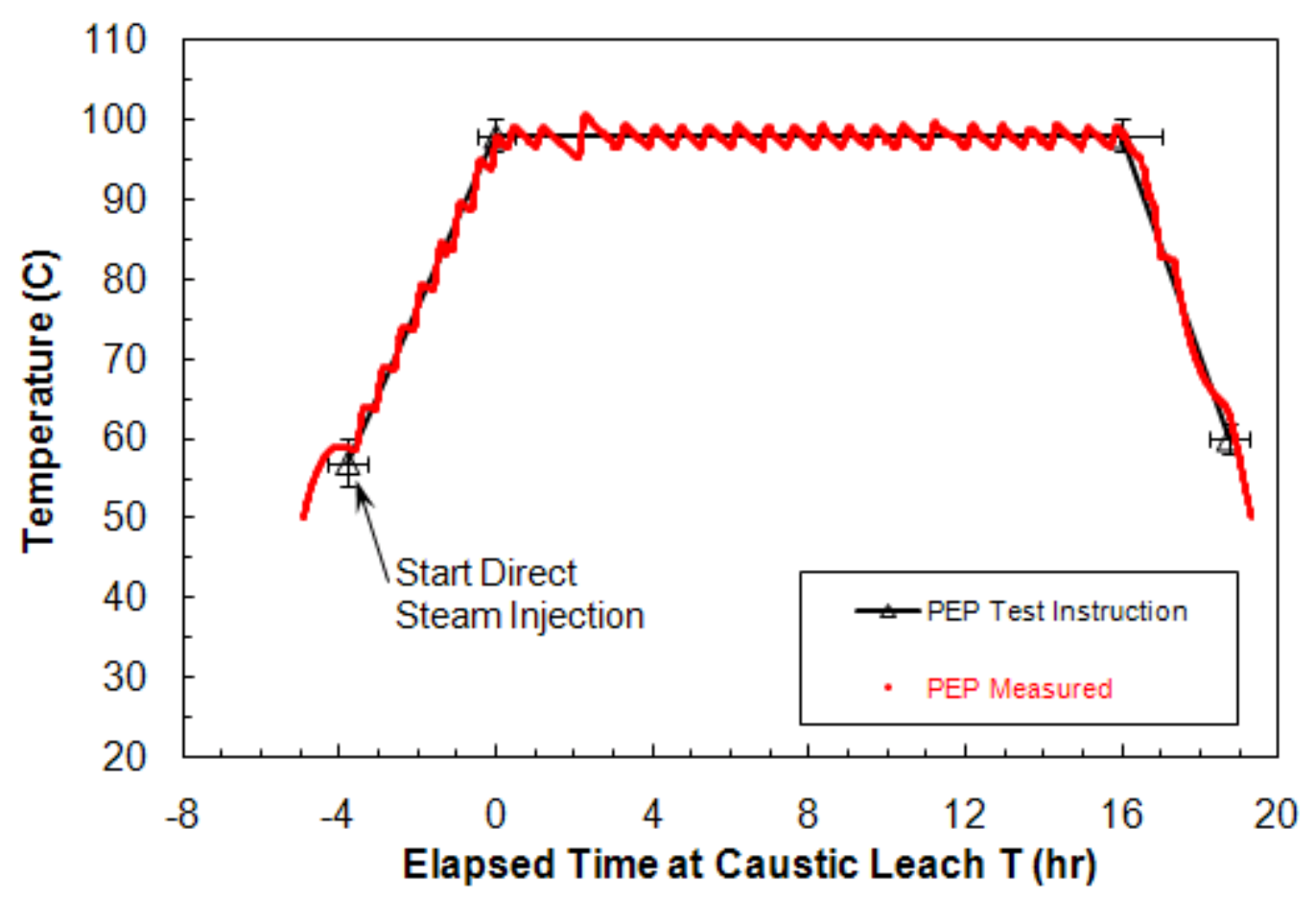

Figure 9.4. Temperature Measured at the Prototypic Sensor in PEP Vessel Tank T01B During Integrated Test A, Batch 4

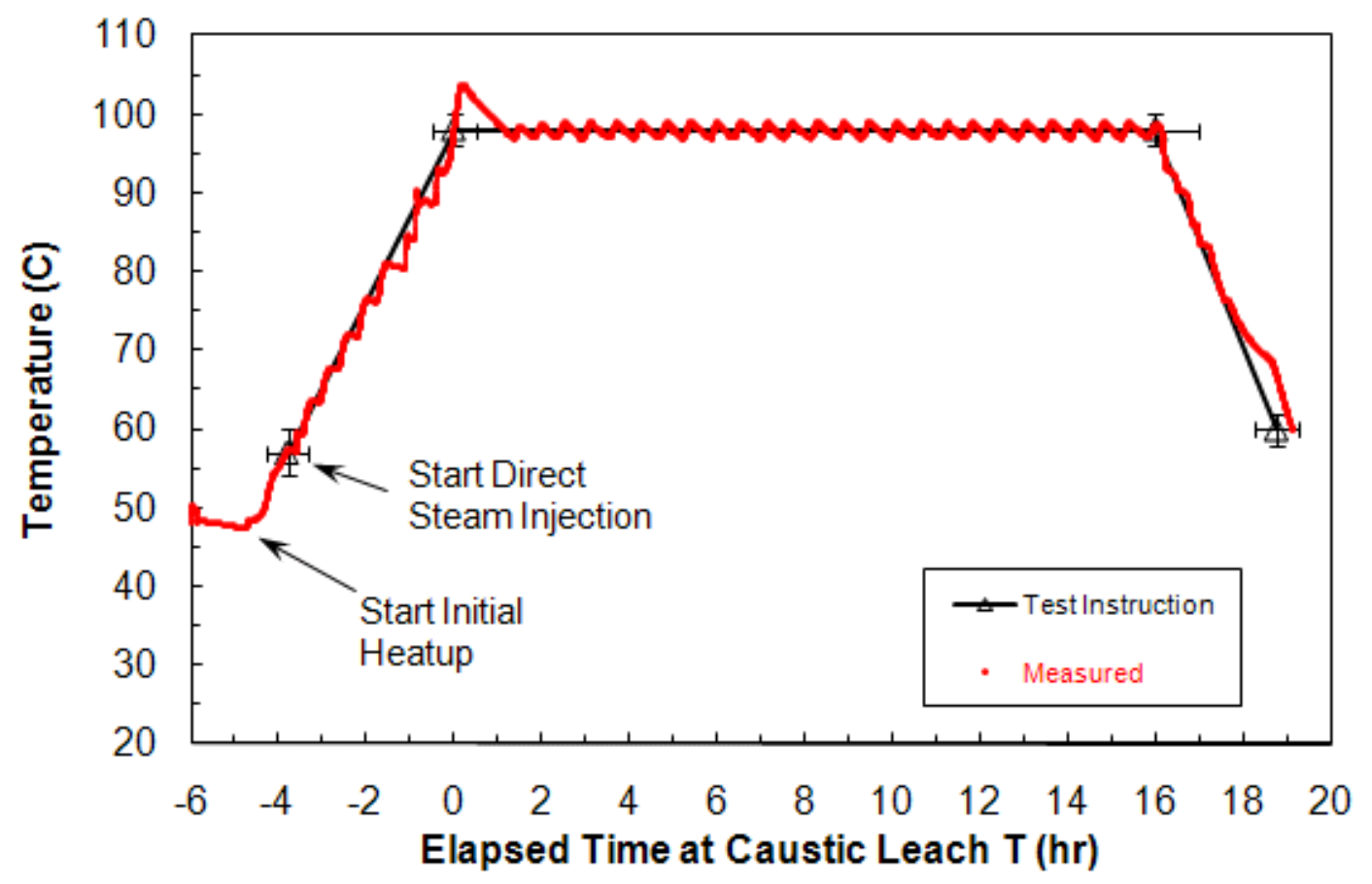

Figure 9.5. Temperature Measured at the Prototypic Sensor in PEP Vessel Tank T01A During Integrated Test A, Batch 5 


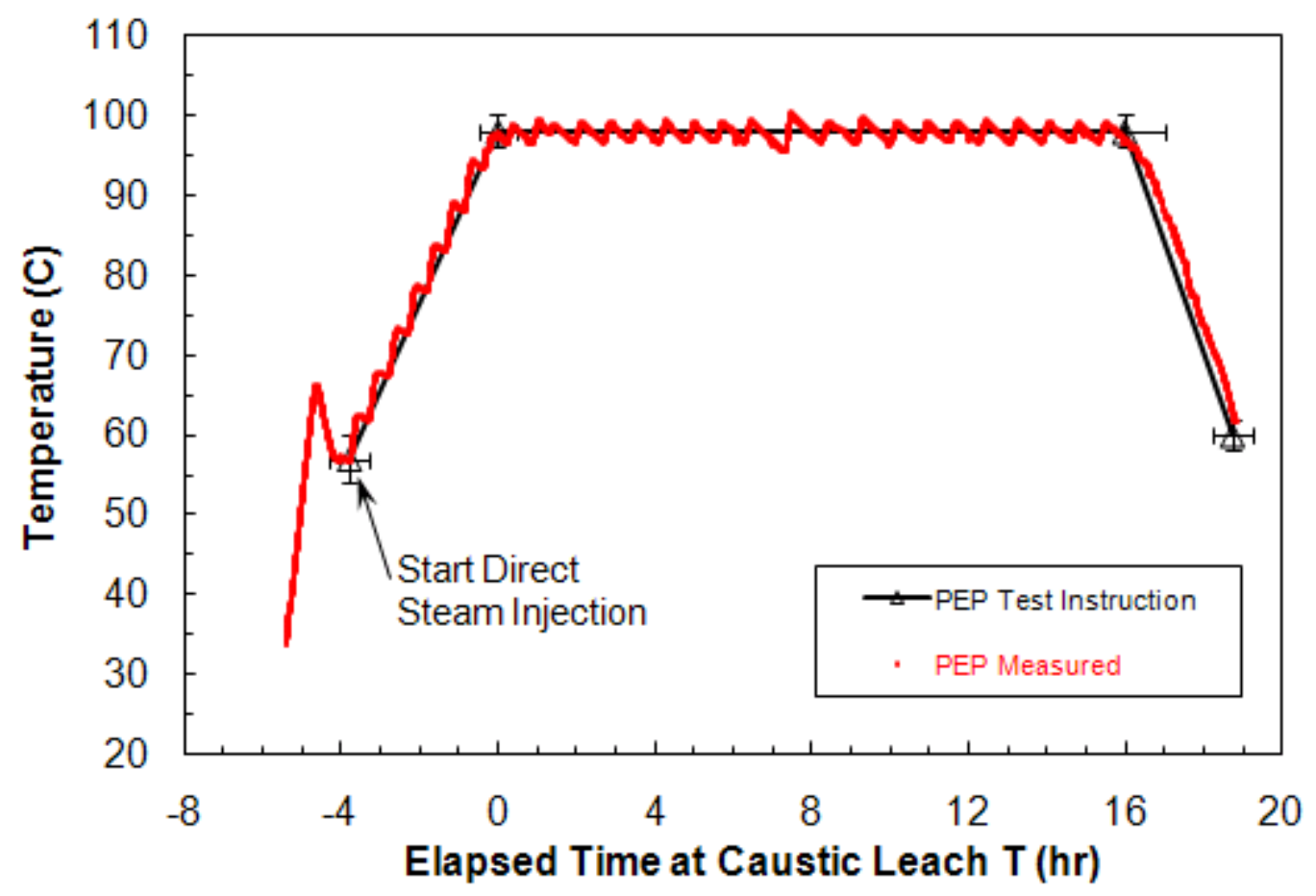

Figure 9.6. Temperature Measured at the Prototypic Sensor in PEP Vessel Tank T01B During Integrated Test A, Batch 6

Text and arrows in Figure 9.1 highlight a few key temperature-control events in the caustic leaching process for Batch 1 (the batch used for caustic-leach scale-up for Integrated Test A). The final heating duration was slightly longer than the target range (4.3-hr maximum). The delayed heat-up period was due to an undetected switch in steam control from automatic to manual mode between -1.3 and -0.3 hours. This problem effectively resulted in an additional 0.6 hours of caustic leaching in a temperature range of $89^{\circ} \mathrm{C}$ to $92^{\circ} \mathrm{C}$. Otherwise, the heating-phase profile paralleled the Test Instruction temperature trajectory. The average temperature during the $16-\mathrm{hr}$ leach period of Integrated Test $\mathrm{A}$, Batch 1 was $97.9^{\circ} \mathrm{C}$. A detailed examination of the prototypic temperature sensor data shows that the temperature was maintained within the target range $98 \pm 2{ }^{\circ} \mathrm{C}$ throughout the leach. Figure 9.1 also shows the measured temperature during the initial cool-down phase after the 16-hr leach compared to the Test Instruction target cooling profile. As shown in the figure, cooling proceeded with only a small increase in cooling time compared to the schedule.

Figure 9.2 through Figure 9.6 show that temperature control was consistent, and the batch temperature was kept close to the target profile for most of the times during Batches 2 through 6 of Integrated Test $\mathrm{A}$. The exceptions were short in duration, compared to the targeted leaching time, and usually had one of two causes. In the first case, high-high level alarms shut down steam injection and PJMs, causing a drop in temperature; sometimes steam injection was turned back on before PJMs were restarted, leading to a temperature spike during recovery. The second common reason was that the steam controller operation mode changed from automatic to manual for unknown reasons and was not switched back until the temperature drop was noticed. The causes of the irregularities that can be seen in Figure 9.2 through Figure 9.6 were: 
- At the beginning of heat-up for Batch 2, steam injection was mistakenly started at about $46^{\circ} \mathrm{C}$ in conjunction with pre-heating in the external heat exchange loop instead of at the $57^{\circ} \mathrm{C}$ target (marked by a cross in Figure 9.2). Injection continued for 47 minutes, after which heat-up to $57^{\circ} \mathrm{C}$ was completed using the external heat exchanger. Steam injection commenced again at $57^{\circ} \mathrm{C}$.

- The increase in the amplitude of temperature cycling between hour seven and hour nine in Batch 2 appears at the same time that the Tank T01B vessel vent was opened (1040 to 1155 on February 1,2009) in an attempt to improve laser level instrument performance.

- The decrease and subsequent spike in temperature at hour 10 in Batch 2 followed a high-high level alarm.

- The temperature drop about hour 14 into leaching of Batch 2 was caused by the shutdown of steam injection and PJMs, apparently related to continuing difficulties with both laser and bubbler level instruments.

- The small irregularity in temperature at about hour seven in Batch 3 was caused by a high-high level alarm on the laser level instrument.

- The irregularity in temperature at about hour two in Batch 4 was caused by a shutdown of pump PMP-T41A, which occurred for no apparent reason and caused the steam to Tank T01B to shut off.

- In Batch 5, the temperature spike at the prototypic temperature sensor $\left(103.6^{\circ} \mathrm{C}\right)$ followed a period when, for unknown reasons, PJMs were off while steam injection was on. Because the prototypic TC was located lower in the vessel than was the steam ring, in the absence of PJM mixing, there was a delay between the start of steam injection and the point when the temperature increase reached the TC.

- The visible temperature overshoot during heat-up in Batch 6 occurred during $\mathrm{NaOH}$ addition; the effect of the exothermic dilution of $\mathrm{NaOH}$ was greater than expected, partly because the $\mathrm{NaOH}$ addition rate was higher than target. The external heat exchanger was used to cool the contents of Tank T01B from a peak of $66^{\circ} \mathrm{C}$ at the prototypic temperature sensor to the initial heat-up temperature target of $57^{\circ} \mathrm{C}$.

- The cause of the small irregularity in temperature at about hour seven in Batch 6 is unknown. The steam controller was switched to manual at about this time (1935 February 10,2009) after a high temperature alarm in Tank T01B.

\subsubsection{Integrated Test A Steam Addition and Condensate Accumulation}

Figure 9.7 through Figure 9.12 show a series of volume changes associated with the process of direct steam injection and condensate accumulation for the six caustic leaching batches of Integrated Test A. Each figure depicts three elements of the process from the start of direct steam injection through the end of the caustic leaching digestion period:

- The total increase in the volume of slurry-condensate mixture relative to the slurry volume at the start of steam injection, $\Delta V$, including contributions due to thermal expansion and accumulation of condensate, which results from injected steam and additions of IW. 
- Of this, the estimated volume of condensate accumulated, $V_{c}$, as determined by Method 1 of Section 9.1.1, Equation (9.3).

- The total amount of steam added, as an equivalent liquid volume at the vessel temperature.

Like the corresponding temperature profiles in Section 9.3.2.1, the $\mathrm{x}$-axis values in Figure 9.7 through Figure 9.12 are the elapsed time from when the target leaching temperature of $98^{\circ} \mathrm{C}$ was first attained (time zero). Negative elapsed time is during heat-up. The figures track the measured volume changes throughout the caustic leaching process in two primary phases: heating the initial slurry volume from the pre-heated temperature $\left(\sim 57^{\circ} \mathrm{C}\right)$ to the leach temperature with direct steam injection and maintaining the leach temperature $\left(98^{\circ} \mathrm{C}\right)$ for the specified duration of the leach $(16$ hours $)$. The difference between the amount of steam added as an equivalent liquid volume and the actual volume is due to evaporation.

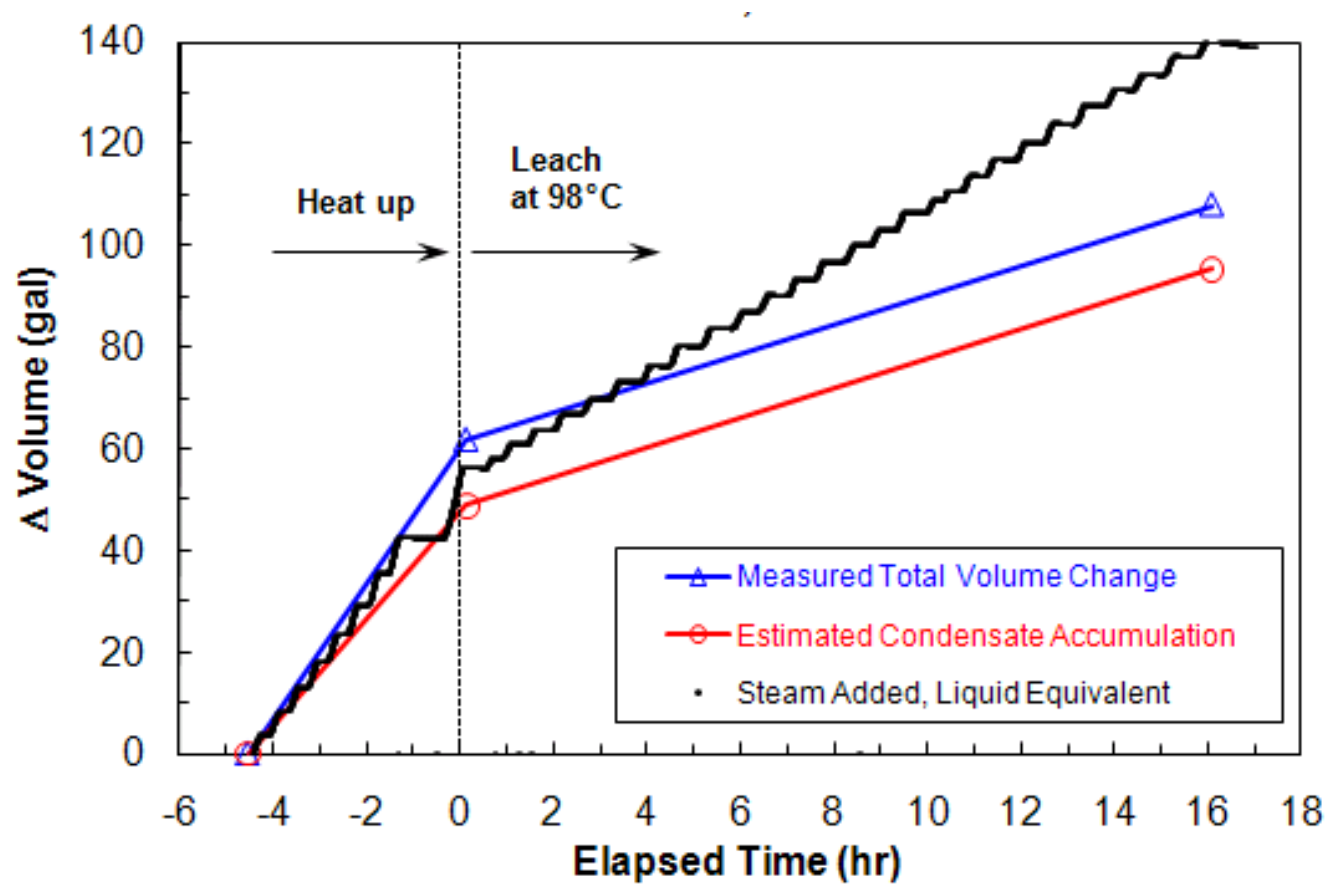

Figure 9.7. Slurry Component Volume Changes ( $\Delta$ volume) in Tank T01A Associated with Direct Steam Injection and IW Addition During the Heat-Up and Caustic-Leach Periods of Integrated Test A, Batch 1 


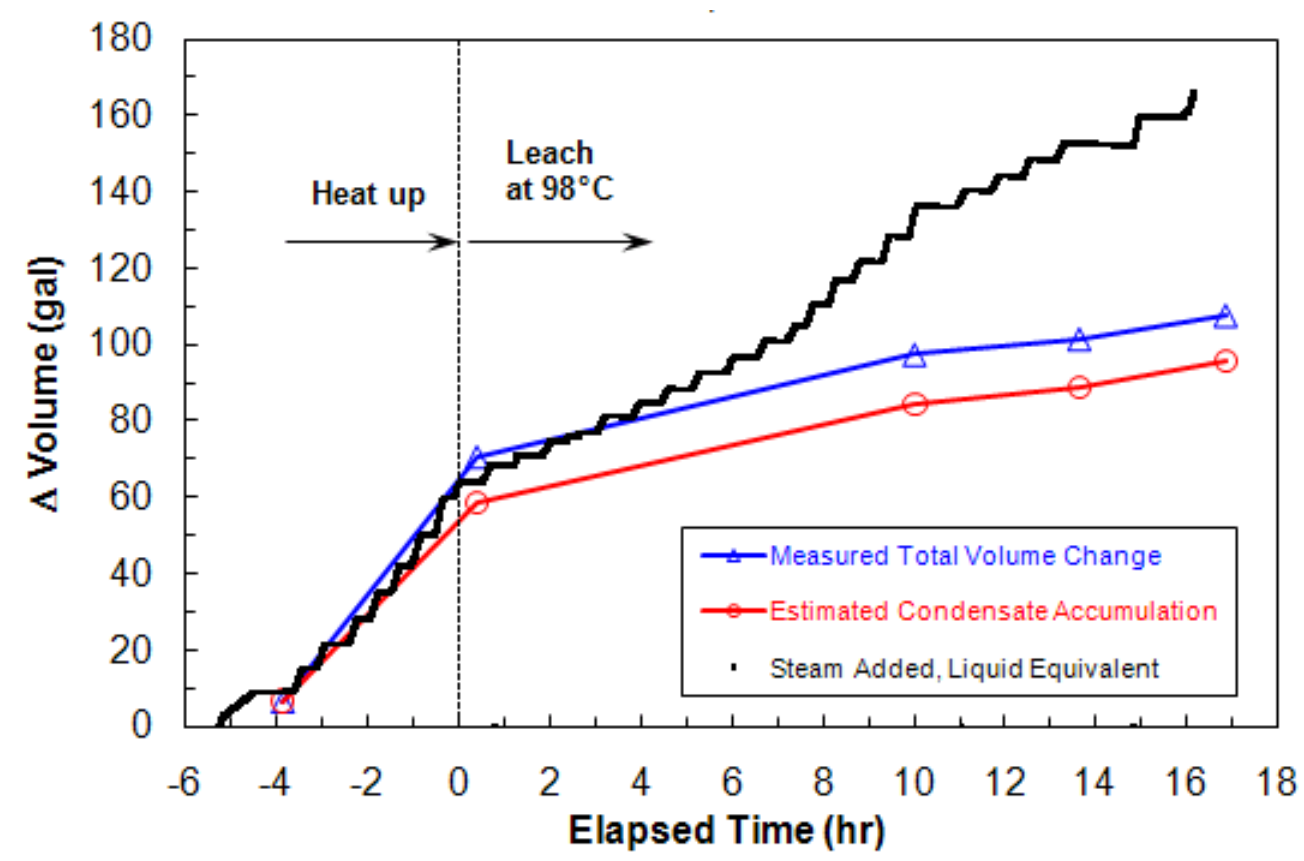

Figure 9.8. Slurry Component Volume Changes ( $\Delta$ volume) in Tank T01B Associated with Direct Steam Injection and IW Addition During the Heat-Up and Caustic-Leach Periods of Integrated Test A, Batch 2

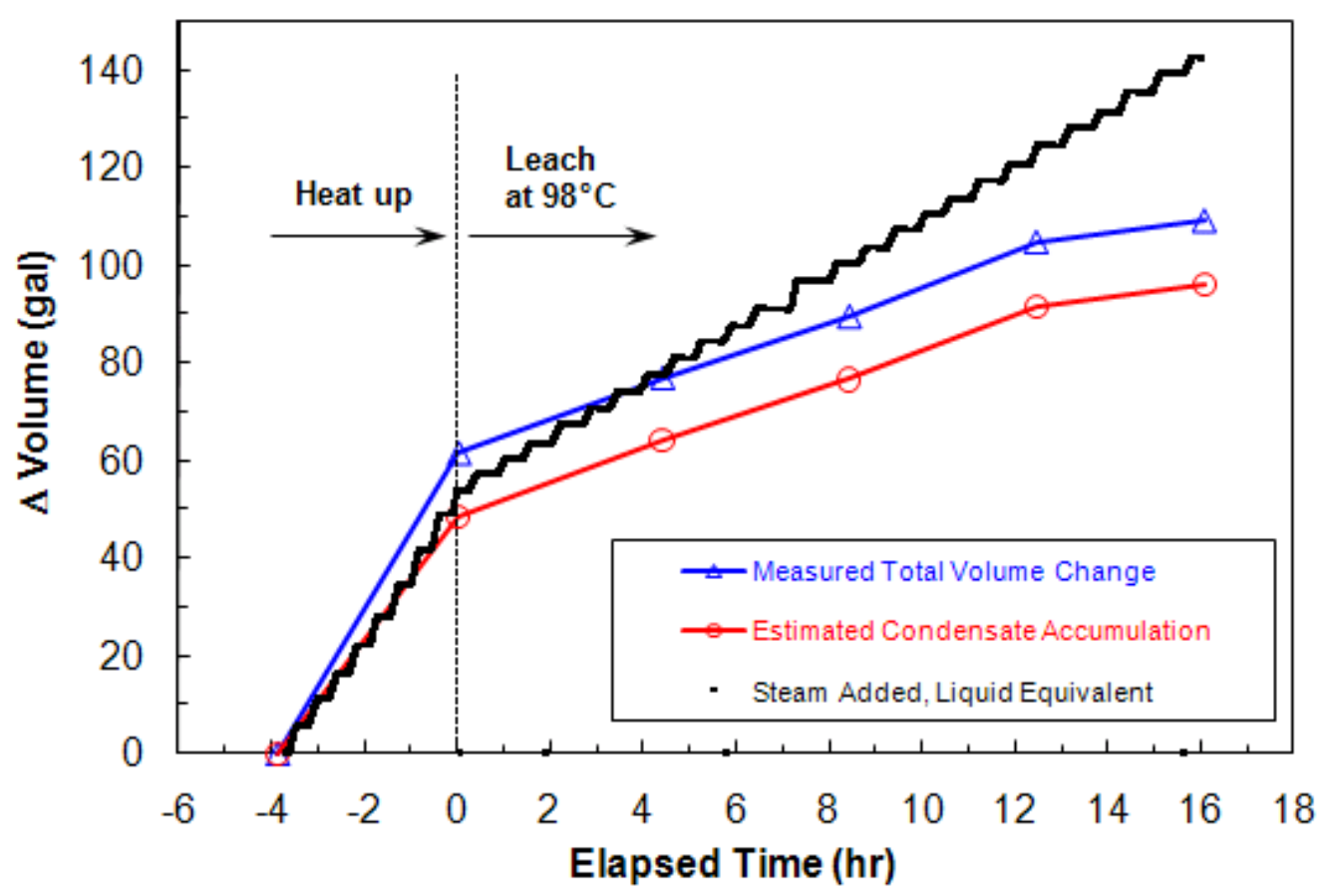

Figure 9.9. Slurry Component Volume Changes ( $\Delta$ volume) in Tank T01A Associated with Direct Steam Injection and IW Addition During the Heat-Up and Caustic-Leach Periods of Integrated Test A, Batch 3 


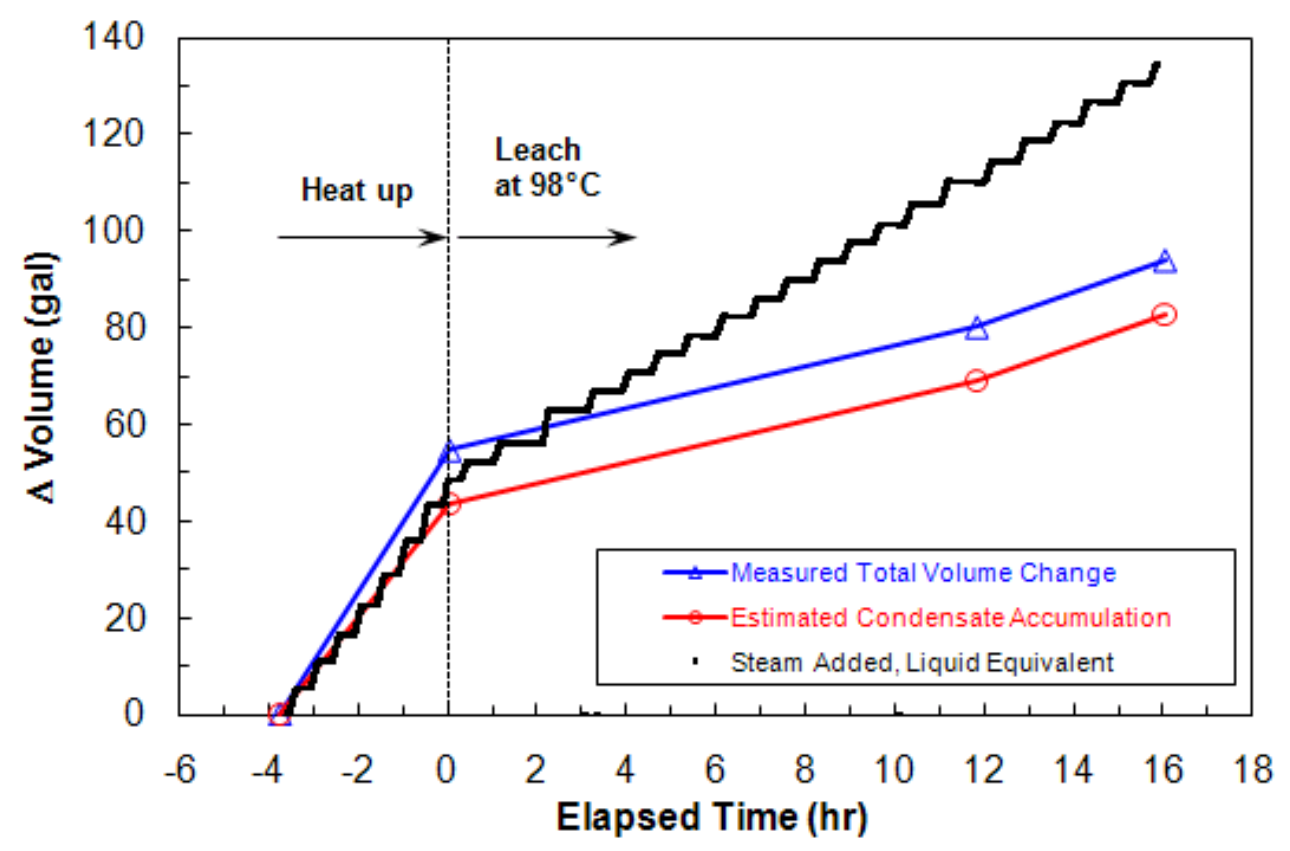

Figure 9.10. Slurry Component Volume Changes ( $\Delta$ volume) in Tank T01B Associated with Direct Steam Injection and IW Addition During the Heat-Up and Caustic-Leach Periods of Integrated Test A, Batch 4

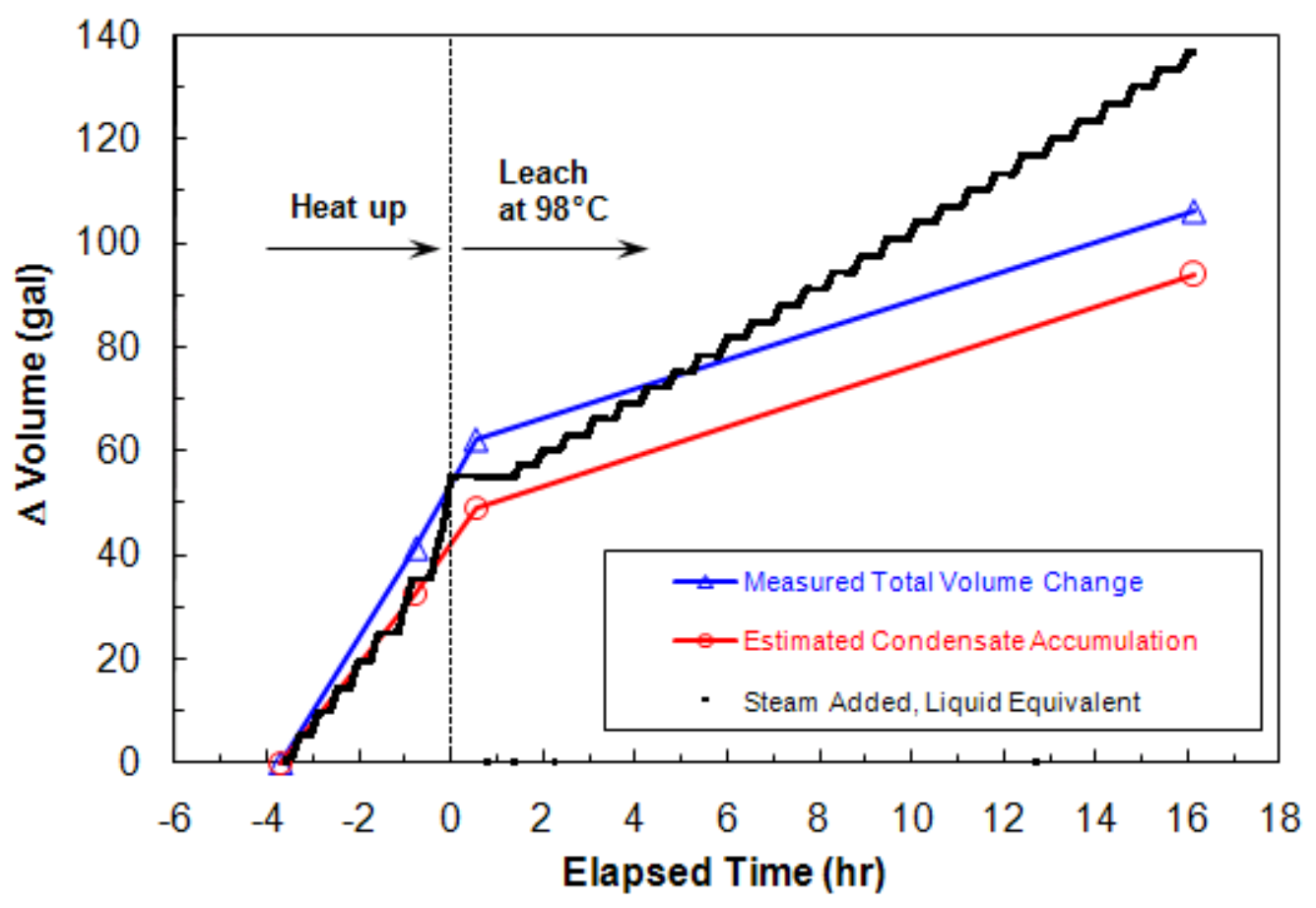

Figure 9.11. Slurry Component Volume Changes ( $\Delta$ volume) in Tank T01A Associated with Direct Steam Injection and IW Addition During the Heat-Up and Caustic-Leach Periods of Integrated Test A, Batch 5 


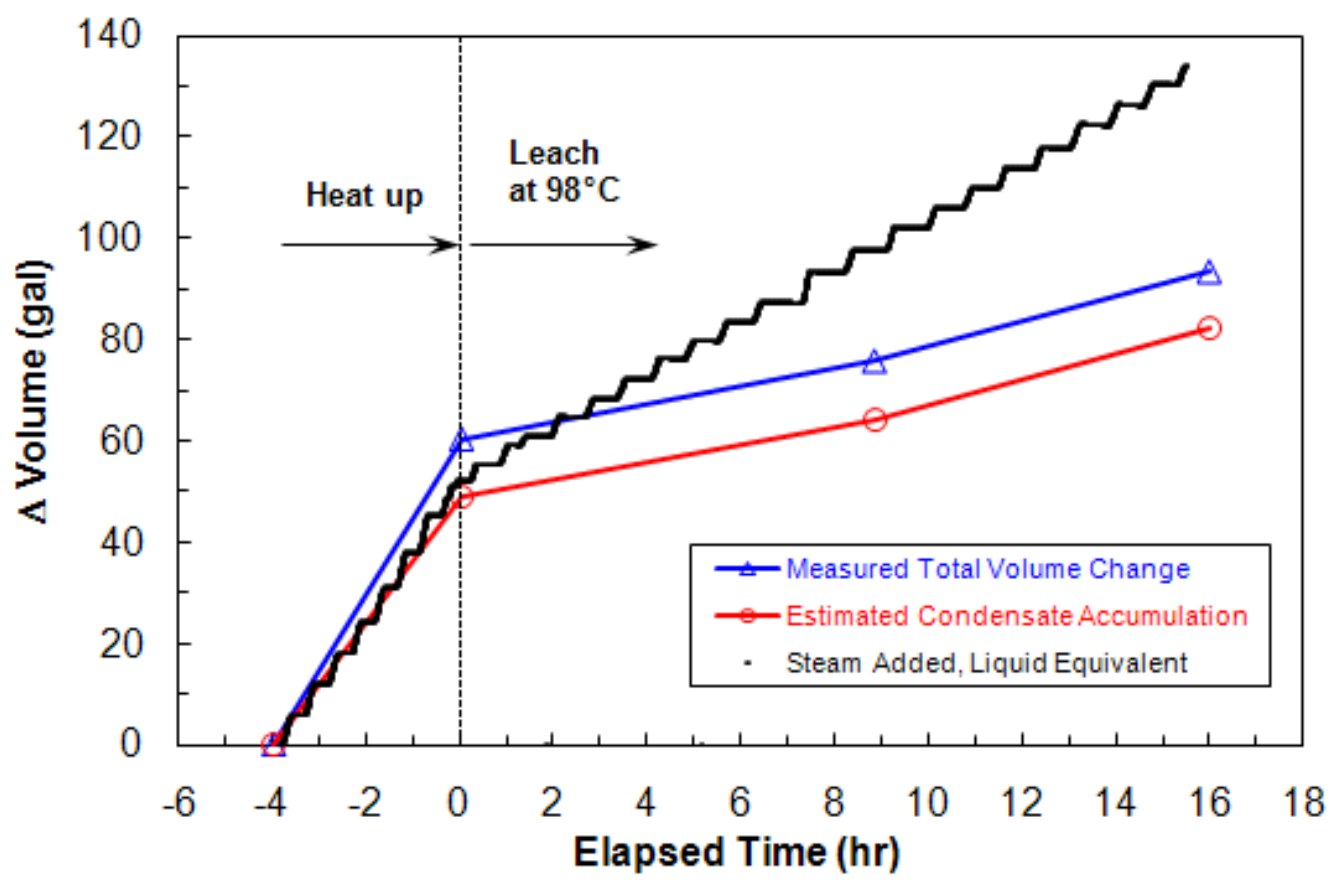

Figure 9.12. Slurry Component Volume Changes ( $\Delta$ volume) in Tank T01B Associated with Direct Steam Injection and IW Addition During the Heat-Up and Caustic-Leach Periods of Integrated Test A, Batch 6

In the Integrated Test A batches, the net accumulation of condensate results from steam condensation and water added periodically during the leach period. Approximately $2.9-\mathrm{L}$ ( 0.77 gal) IW was added through the top of the vessel to Tank T01A and Tank T01B each hour of the $98^{\circ} \mathrm{C}$ hold period (starting at hour 1 and ending at hour 15) to achieve the dilution expected in equivalent WTP operations. The known amounts of these water additions (44 to $46-\mathrm{kg}$ total in each test), the measurement of the quantity of added steam, and the calculation of the net quantity of condensate accumulated in a batch provides a means to estimate the mass of water vapor vented from the system in air streams. A simple water mass balance around the process is given by the following:

mass of steam added + mass of water added $=$ mass accumulated + mass vented

Such a water mass balance and the results of the analyses described in this section are used in the development of an overall process mass balance in Section 12.

The measured slurry volume changes shown in Figure 9.7 through Figure 9.12 were derived from stable vessel level measurements and the corresponding total slurry volumes. The PJMs were turned off and vented during all defined stable level measurement periods. Typically, the steam ring purge air flow, or in a few instances steam flow, was left on for these measurements. In Integrated Test A, the purge air flow rate to the Tank T01A/B vessels was $>0.14-\mathrm{kg} / \mathrm{min}$ until after $90^{\circ} \mathrm{C}$ was reached, and in several cases, the higher flow rate was maintained until the vessel achieved $98^{\circ} \mathrm{C}$. The steam ring purge air flow was generally reduced to between 0.10 and $0.13-\mathrm{kg} / \mathrm{min}$ for the remainder of the caustic-leach period. See the Integrated Test A run report for additional operations information (Guzman-Leong et al. 2009). 
In a caustic leaching process evaluation report (Mahoney et al. 2009), the measured total slurry volume in Tank T01A during processing of Integrated Test A, Batch 1 was shown, and the translation to Figure 9.7 was discussed. As noted in the earlier report, the measured total slurry volumes in Tank T01A were derived from four sources: 1) vessel bubbler pressure data (i.e., both lower and upper legs) converted to slurry level using temperature-corrected slurry density data (Equation [9.2]), 2) the as-is or raw vessel bubbler pressure data using the apparent slurry density (specific gravity) derived from the difference in bubbler pressures, 3) a laser level instrument, and 4) a DrexelBrook capacitance probe located in the vessel (not in the PJMs). A vessel capacitance probe was not installed in Tank T01B, so only three level measurement options existed for those tests.

In all six Integrated Test A batches shown in Figure 9.7 through Figure 9.12, the density-corrected bubbler or laser measurement approaches were selected; in some cases, the bubblers or laser failed intermittently, and a combination of the two measurement methods was used to represent the entire leaching period. The density-corrected bubbler and laser measurements agreed quite well in most Tank T01A/B test conditions. However, in these analyses, preference was typically given to the corrected bubbler data because the PTF UFP vessel specifications include bubblers as the level instrumentation, and applying the temperature-adjusted analytical slurry density should correct the measured level (and corresponding volume) for any gas retained in the slurry at the time of the measurement.

Several features are consistently present in Figure 9.7 through Figure 9.12:

- The rate of steam addition was greater during heat up than during the constant temperature leaching period. More steam was used during the temperature ramp because of the heating required to bring the slurry and vessel structure up to temperature (i.e., sensible heating).

- The volume of condensate accumulated during heat-up ranged from 43 gal to 49 gal. (Tank T01B Batch 2, Figure 9.8, is an exception. See discussion below.) The volume of steam added in the same period was only slightly (e.g., 3 to 7 gal) higher, indicating that most of the steam was condensed in this phase of the process.

- Owing to thermal expansion effects, the total increase in the slurry-condensate mixture volume was greater than the estimated volume of condensate. At $98^{\circ} \mathrm{C}$, the thermal expansion contribution was $\sim 11$ to $\sim 13$ gal.

- The volume of condensate accumulated at the end of the leaching period, including all condensed steam and the IW added during the constant temperature digestion period, ranged from 82 gal to 96 gal. As shown in Table 9.4 and Table 9.5 for Method 1, this corresponds to 299- to 349-kg of condensate. (Method 2 condensate masses shown in the tables are somewhat higher, ranging from 320- to $377-\mathrm{kg}$.)

- The total amount of steam added ranged from 130 to 140 gal of liquid equivalent ( $480-\mathrm{kg}$ to $\sim 520-\mathrm{kg}$ ) and the rate of steam addition was essentially linear in each phase of the process (i.e., heat up and constant temperature hold). (Tank T01B Batch 2, Figure 9.8, is an exception. See discussion below.)

- Summing IW and steam additions and subtracting the net mass of condensate accumulated (as determined by two methods) gives the mass of water vapor vented from the system: for condensate mass Method 1, the amount of vented water in each batch ranged from 201- to 232-kg, and for condensate mass Method 2, the vented water mass ranged from 172- to 210-kg. (Again, Tank T01B Batch 2, Figure 9.8, is an exception. See discussion below.) 
As noted above and shown in Figure 9.8, Tank T01B Batch 2 was anomalous in several ways. These anomalies are related to the temperature profile deviations shown in Figure 9.2 and discussed in the previous section. First, direct steam injection was started at $\sim 46^{\circ} \mathrm{C}$ during the pre-heating phase. This resulted in $\sim 9$ gal of steam liquid equivalent $(\sim 33-\mathrm{kg})$ being added by the time the pre-heat temperature target was reached (i.e., the normal start of direct steam injection) and greater volume of condensate accumulated by the time the digestion temperature was reached ( $\sim 58 \mathrm{gal})$. If corrected by this excess initial steam quantity, the condensate accumulation at elapsed time zero is 49 gal (= 58 gal -9 gal), which is consistent with the other Integrated Test A batches. Figure 9.8 also shows an upturn in the steam addition rate starting at $\sim 7$ hours elapsed and continuing until $\sim 10$ hours elapsed. This could be related to opening a port on Tank T01B in an attempt to improve the performance of the laser level instrument, as discussed in the previous section. Overall, $>\sim 80-\mathrm{kg}$ more steam was used in Integrated Test A, Batch 2 ( $\sim 166$ gal liquid equivalent, $\sim 603-\mathrm{kg}$ ) than the other batches. However, the estimated mass of water vapor vented was also greater (Method 1 condensate, 299-kg vented; Method 2 condensate, 269-kg vented) than the other batches by $\sim 60-\mathrm{kg}$ (or more). Therefore, although the net condensate mass accumulated in Batch 2 was the highest of the six batches (Method 1, 347-kg; Method 2, 377-kg), it was greater by $<10-\mathrm{kg}$ of the next nearest batches (as shown in Table 9.4 and Table 9.5).

A method for cross-checking the condensate accumulation trends against calculated and analytically measured liquid dilution factors was described in Section 9.1.1. The results of such analyses are summarized in Table 9.10 for the Tank T01A batches of Integrated Test A and in Table 9.11 for the Tank T01B batches. For each batch, liquid dilution factors over the course of the test are determined from liquid chemical tracer analytical measurements and vessel level-based calculations (in conjunction with temperature-corrected liquid densities). The dilution factors determined from chemical tracers tend to be slightly higher than the level-based results, but the difference was always $<3-\mathrm{wt} \%$ and generally $<2$-wt\%. Using the 16-hr Tank T01A Batch 3 results of Table 9.10 as a worst case example, the final tracer liquid dilution factor was $18.5-\mathrm{wt} \%$ compared to $15.6-\mathrm{wt} \%$ obtained from level information. The level-based dilution factors of Table 9.10 and Table 9.11 are also consistent in trend with final condensate mass fractions shown in Table 9.4 and Table 9.5. For example, the least diluted batch (e.g., Batch 6 in Tank T01B) had a final liquid dilution factor of 14.4-wt\% (Table 9.11) and a final condensate mass fraction of 12.1-wt\% (Table 9.5), whereas the most diluted batch (e.g., Batch 5 in Tank T01A) had a final liquid dilution factor of 16.8-wt\% (Table 9.10) and a final condensate mass fraction of 13.6-wt\% (Table 9.4). Note that the liquid dilution factors and condensate mass fractions are not expected to equal each other because the liquid mass changes as a result of solids dissolution as well as condensate accumulation. 
Table 9.10. Dilution of Liquid Phase During Integrated Test A Caustic-Leach Batches in Tank T01A

\begin{tabular}{|c|c|c|c|c|c|c|}
\hline \multirow[b]{3}{*}{$\begin{array}{l}\text { Approximate Point } \\
\text { in Process }\end{array}$} & \multicolumn{6}{|c|}{ Total Liquid Mass Dilution (wt\%) } \\
\hline & \multicolumn{2}{|c|}{ Integrated Test A, Batch 1} & \multicolumn{2}{|c|}{ Integrated Test A, Batch 3} & \multicolumn{2}{|c|}{ Integrated Test A, Batch 5} \\
\hline & $\begin{array}{c}\text { Nitrate } \\
\left(\mathrm{NO}_{3}^{-}\right) \\
\text {Tracer }^{(\mathrm{a}, \mathrm{b})}\end{array}$ & $\begin{array}{c}\text { Tank T01A } \\
\text { Level } \\
\text { Changes }^{(c)}\end{array}$ & $\begin{array}{c}\text { Nitrate } \\
\left(\mathrm{NO}_{3}^{-}\right) \\
\text {Tracer }^{(\mathrm{a}, \mathrm{d})}\end{array}$ & $\begin{array}{c}\text { Tank T01A } \\
\text { Level } \\
\text { Changes }^{(\mathrm{c})}\end{array}$ & $\begin{array}{c}\text { Nitrate } \\
\left(\mathrm{NO}_{3}{ }^{-}\right) \\
\text {Tracer }^{(\mathrm{a}, \mathrm{d})}\end{array}$ & $\begin{array}{c}\text { Tank T01A } \\
\text { Level } \\
\text { Changes }^{(\mathrm{c})}\end{array}$ \\
\hline $\begin{array}{c}\text { After } \mathrm{NaOH} \\
\text { addition; before } \\
\text { steam addition }\end{array}$ & $0.0 \%$ & $0.0 \%$ & $0.0 \%$ & $0.0 \%$ & $0.0 \%$ & $0.0 \%$ \\
\hline At $88^{\circ} \mathrm{C}$ & $8.1 \%$ & $\mathrm{n} / \mathrm{m}$ & $7.3 \%$ & $\mathrm{n} / \mathrm{m}$ & $8.8 \%$ & $\mathrm{n} / \mathrm{m}$ \\
\hline $0 \mathrm{hr}$ & $8.2 \%$ & $8.2 \%$ & $8.7 \%$ & $7.9 \%$ & $11.3 \%$ & $8.4 \%$ \\
\hline $1 \mathrm{hr}$ & $11.5 \%$ & $\mathrm{n} / \mathrm{m}$ & $10.0 \%$ & $\mathrm{n} / \mathrm{m}$ & $10.1 \%$ & $\mathrm{n} / \mathrm{m}$ \\
\hline $2 \mathrm{hr}$ & $10.4 \%$ & $\mathrm{n} / \mathrm{m}$ & $10.5 \%$ & $\mathrm{n} / \mathrm{m}$ & $11.0 \%$ & $\mathrm{n} / \mathrm{m}$ \\
\hline $4 \mathrm{hr}$ & $11.9 \%$ & $\mathrm{n} / \mathrm{m}$ & $10.9 \%$ & $10.0 \%$ & $11.9 \%$ & $\mathrm{n} / \mathrm{m}$ \\
\hline $8 \mathrm{hr}$ & $11.7 \%$ & $\mathrm{n} / \mathrm{m}$ & $14.0 \%$ & $12.5 \%$ & $15.1 \%$ & $\mathrm{n} / \mathrm{m}$ \\
\hline $10 \mathrm{hr}$ & $15.3 \%$ & $\mathrm{n} / \mathrm{m}$ & $15.1 \%$ & $\mathrm{n} / \mathrm{m}$ & $15.4 \%$ & $\mathrm{n} / \mathrm{m}$ \\
\hline $12 \mathrm{hr}$ & $15.3 \%$ & $\mathrm{n} / \mathrm{m}$ & $16.4 \%$ & $15.4 \%$ & $\mathrm{n} / \mathrm{m}$ & $\mathrm{n} / \mathrm{m}$ \\
\hline $14 \mathrm{hr}$ & $18.2 \%$ & $\mathrm{n} / \mathrm{m}$ & $18.4 \%$ & $\mathrm{n} / \mathrm{m}$ & $\mathrm{n} / \mathrm{m}$ & $\mathrm{n} / \mathrm{m}$ \\
\hline $16 \mathrm{hr}$ & $17.4 \%$ & $15.7 \%$ & $18.5 \%$ & $15.6 \%$ & $19.7 \%$ & $16.8 \%$ \\
\hline \multicolumn{7}{|c|}{$\begin{array}{l}\text { The initial/reference state is the mass of liquid in the PEP vessel after } \mathrm{NaOH} \text { was added as determined from the stable level } \\
\text { measurement nearest to the start of direct steam injection. The liquid mass is calculated from 1) the total slurry volume (at } \\
\text { level), 2) the estimated volume fraction of liquid (from wt } \% \text { UDS, temperature-corrected liquid density and the density of } \\
\text { remaining solids [2.8-kg/L assumed]), and 3) a temperature-corrected liquid density. The mass dilution fraction is the } \\
\text { change in liquid mass/initial liquid mass. }\end{array}$} \\
\hline \multicolumn{7}{|c|}{$\begin{array}{l}\text { An "after NaOH" IC sample was not obtained. Therefore, the reference concentration of chloride ion, which is the tracer } \\
\text { selected for caustic-leach factor analysis, is not available to assess liquid mass dilution. The results shown for Batches } 3 \\
\text { and } 5 \text { are based on nitrate ion concentrations (molar) determined using Raman spectroscopy. The measured liquid density } \\
\text { is used to convert the volume-based concentration units (molar) to the mass-based concentration units needed for this } \\
\text { analysis. } \\
\text { - not measured }\end{array}$} \\
\hline
\end{tabular}


Table 9.11. Dilution of Liquid Phase During Integrated Test A Caustic-Leach Batches in Tank T01B

\begin{tabular}{|c|c|c|c|c|c|c|}
\hline \multirow[b]{3}{*}{$\begin{array}{l}\text { Approximate Point } \\
\text { in Process }\end{array}$} & \multicolumn{6}{|c|}{ Total Liquid Mass Dilution (wt\%) } \\
\hline & \multicolumn{2}{|c|}{ Integrated Test A, Batch 2} & \multicolumn{2}{|c|}{ Integrated Test A, Batch 4} & \multicolumn{2}{|c|}{ Integrated Test A, Batch 6} \\
\hline & $\begin{array}{c}\text { Nitrate } \\
\left(\mathrm{NO}_{3}{ }^{-}\right) \\
\text {Tracer }^{(\mathrm{a}, \mathrm{b})}\end{array}$ & $\begin{array}{c}\text { Tank T01B } \\
\text { Level } \\
\text { Changes }^{(\mathrm{c})}\end{array}$ & $\begin{array}{c}\text { Nitrate } \\
\left(\mathrm{NO}_{3}{ }^{-}\right) \\
\text {Tracer }^{(\mathrm{a}, \mathrm{b})}\end{array}$ & $\begin{array}{l}\text { Tank T01B } \\
\text { Level } \\
\text { Changes }^{(c)}\end{array}$ & $\begin{array}{l}\text { Chloride } \\
\qquad\left(\mathrm{Cl}^{-}\right) \\
\text {Tracer }^{(\mathrm{a}, \mathrm{d})}\end{array}$ & $\begin{array}{c}\text { Tank T01B } \\
\text { Level } \\
\text { Changes }^{(c)}\end{array}$ \\
\hline $\begin{array}{l}\text { After } \mathrm{NaOH} \text {; } \\
\text { before steam } \\
\text { addition }\end{array}$ & $0.0 \%$ & $0.0 \%$ & $0.0 \%$ & $0.0 \%$ & $0.0 \%$ & $0.0 \%$ \\
\hline At $88^{\circ} \mathrm{C}$ & $7.1 \%$ & $\mathrm{n} / \mathrm{m}$ & $4.8 \%$ & $\mathrm{n} / \mathrm{m}$ & $6.0 \%$ & $\mathrm{n} / \mathrm{m}$ \\
\hline $0 \mathrm{hr}$ & $9.8 \%$ & $9.4 \%$ & $6.8 \%$ & $7.4 \%$ & $9.4 \%$ & $8.5 \%$ \\
\hline $1 \mathrm{hr}$ & $11.3 \%$ & $\mathrm{n} / \mathrm{m}$ & $7.5 \%$ & $\mathrm{n} / \mathrm{m}$ & $8.9 \%$ & $\mathrm{n} / \mathrm{m}$ \\
\hline $2 \mathrm{hr}$ & $12.0 \%$ & $\mathrm{n} / \mathrm{m}$ & $9.1 \%$ & $\mathrm{n} / \mathrm{m}$ & $9.8 \%$ & $\mathrm{n} / \mathrm{m}$ \\
\hline $4 \mathrm{hr}$ & $14.0 \%$ & $\mathrm{n} / \mathrm{m}$ & $7.6 \%$ & $\mathrm{n} / \mathrm{m}$ & $10.9 \%$ & $\mathrm{n} / \mathrm{m}$ \\
\hline $8 \mathrm{hr}$ & $\mathrm{n} / \mathrm{m}$ & $\mathrm{n} / \mathrm{m}$ & $9.6 \%$ & $\mathrm{n} / \mathrm{m}$ & $13.3 \%$ & $11.2 \%$ \\
\hline $10 \mathrm{hr}$ & $15.8 \%$ & $14.4 \%$ & $12.1 \%$ & $\mathrm{n} / \mathrm{m}$ & $12.8 \%$ & $\mathrm{n} / \mathrm{m}$ \\
\hline $12 \mathrm{hr}$ & $17.7 \%$ & $\mathrm{n} / \mathrm{m}$ & $13.0 \%$ & $12.1 \%$ & $15.1 \%$ & $\mathrm{n} / \mathrm{m}$ \\
\hline $14 \mathrm{hr}$ & $17.0 \%$ & $15.5 \%$ & $13.6 \%$ & $\mathrm{n} / \mathrm{m}$ & $16.0 \%$ & $\mathrm{n} / \mathrm{m}$ \\
\hline $16 \mathrm{hr}$ & $18.2 \%$ & $16.8 \%$ & $14.6 \%$ & $14.8 \%$ & $16.0 \%$ & $14.4 \%$ \\
\hline
\end{tabular}

(a) Liquid mass dilution is determined from the change in liquid tracer concentration (e.g., in $\mu g$ analyte/g of liquid) relative to the "after $\mathrm{NaOH"} \mathrm{sample} \mathrm{initial/reference} \mathrm{state.}$

(b) An "after $\mathrm{NaOH"} \mathrm{IC} \mathrm{sample} \mathrm{was} \mathrm{not} \mathrm{obtained.} \mathrm{Therefore,} \mathrm{the} \mathrm{reference} \mathrm{concentration} \mathrm{of} \mathrm{chloride} \mathrm{ion,} \mathrm{which} \mathrm{is} \mathrm{the} \mathrm{tracer}$ selected for caustic-leach factor analysis, is not available to assess liquid mass dilution. The results shown are based on nitrate ion concentrations (molar) determined using Raman spectroscopy for Batches 2 and 4 . The measured liquid density is used to convert the volume-based concentration units (molar) to the mass-based concentration units needed for this analysis.

(c) The initial/reference state is the mass of liquid in the PEP vessel after $\mathrm{NaOH}$ was added, as determined from the stable level measurement nearest to the start of direct steam injection. The liquid mass is calculated from 1) the total slurry volume (at level), 2) the estimated volume fraction of liquid (from wt\% UDS, temperature-corrected liquid density and the density of remaining solids [2.8-kg/L assumed]), and 3) a temperature-corrected liquid density. The mass dilution fraction is the change in liquid mass/initial liquid mass.

(d) Chloride ion concentrations determined by IC for Batch 6.

$\mathrm{n} / \mathrm{m}$ - not measured

\subsubsection{Integrated Test A Process Deviations}

One recurring difficulty during Integrated Test A, though one that did not seriously hamper mixing, was that the level measurements did not well support tuning the PJMs at the leaching temperature.

Problems with level probes led to repeated PJM overblows. In addition, the PJM drive pressures were not stable. Temporary losses of, or changes in, PJM mixing are not thought to have affected leaching performance, except in cases (in particular, Batch 5) where unusual temperature variations occurred as a result. The temperature profiles for the six batches can be found in Section 9.3.1.1.

In Batches 1, 3, and 4 of Integrated Test A, there were no departures from expected conditions or sample-acquisition techniques that would have been likely to affect caustic leaching data analysis. (Variations between $95.5^{\circ} \mathrm{C}$ and $100.5^{\circ} \mathrm{C}$ were outside the targeted range of $98 \pm 2^{\circ} \mathrm{C}$, but were not considered significantly so.) 
In Batch 2 of Integrated Test A, the departures from the expected conditions were the following:

- During heat-up, steam injection was inadvertently turned on for 47 minutes during the early part of heat-up when the external heat exchanger was supposed to be used. Heat-up was completed using the heat exchanger.

- At about the 10-hr point, the temperature at the prototypic (near-bottom) temperature sensor reached $101.4^{\circ} \mathrm{C}$; PJMs were off while steam injection was on. Several other sensors reached peak temperatures between $102^{\circ} \mathrm{C}$ and $103^{\circ} \mathrm{C}$. The excursion above $100^{\circ} \mathrm{C}$ lasted about 18 minutes (February 1, 2009, 13:25 to 13:43).

- At about hour 14 into the leach, the temperature at the prototypic sensor dropped below $96^{\circ} \mathrm{C}$; the excursion lasted 50 minutes (February 1, 2009, 17:28 to 18:18), and the low-point temperatures were between $93^{\circ} \mathrm{C}$ and $94^{\circ} \mathrm{C}$. Both PJMs and steam injection were off.

In Batch 5 of Integrated Test A, there was one departure from expected conditions where at the end of heat-up, the temperature at the prototypic (near-bottom) sensor peaked at $103.6^{\circ} \mathrm{C}$; PJMs were off while steam injection was on. Several other sensors reached peak temperatures between $108^{\circ} \mathrm{C}$ and $109^{\circ} \mathrm{C}$. The excursion above $100^{\circ} \mathrm{C}$ lasted about 55 minutes (February 7, 2009, 1717 to 1812). For comparison, the 0-hr and 1-hr samples were taken at 1740 and 1834 on February 7, 2009.

In Batch 6 of Integrated Test A, there was one departure from expected conditions where the temperature rise during $\mathrm{NaOH}$ addition was higher than planned because of the high $\mathrm{NaOH}$ addition rate. As a result, it was necessary to use the external heat exchanger to cool the contents of Tank T01B from a peak of $66^{\circ} \mathrm{C}$ at the prototypic sensor to the initial heat-up temperature target of $57^{\circ} \mathrm{C}$.

\subsubsection{Integrated Test B}

As described in more detail in Sections 4.2 and 4.3 of Geeting et al. (2009) (the Integrated Test B run report), two batches of solids-concentrated simulant were processed during Integrated Test $\mathrm{B}$. The caustic-leach processing included in-line addition of $\mathrm{NaOH}$ reagent in the filter-loop, heat-up to leaching temperature $\left(98^{\circ} \mathrm{C}\right)$, and digestion at constant temperature. The simulant that underwent caustic leaching in Integrated Test B did not include the Cr component, which was added later in the process.

Caustic-leach operations were carried out in vessel Tank T02A, with the completed first batch being stored in Tank T01B during the leaching of the second. The $\mathrm{NaOH}$ reagent was added in-line in the filter-loop.

\subsubsection{Integrated Test B Temperature Profiles}

Figure 9.13 and Figure 9.14 show the temperature-versus-time profiles in vessel Tank T02A during caustic leaching of Batches 1 and 2. The time axis is expressed in terms of time relative to the start of the constant-temperature leach (see tables in Appendix A for the elapsed time zero clock time). The temperature is measured at the prototypic temperature sensor, TTK-0619; the sensor is located near the vessel bottom. Each figure also shows the temperature-versus-time targets outlined in the TI. The x- and y-error bars correspond to the TI target ranges. As noted previously, the TI temperature profile targets in the heating and cooling regimes were derived from versions of WTP UFP vessel heat transfer models. 


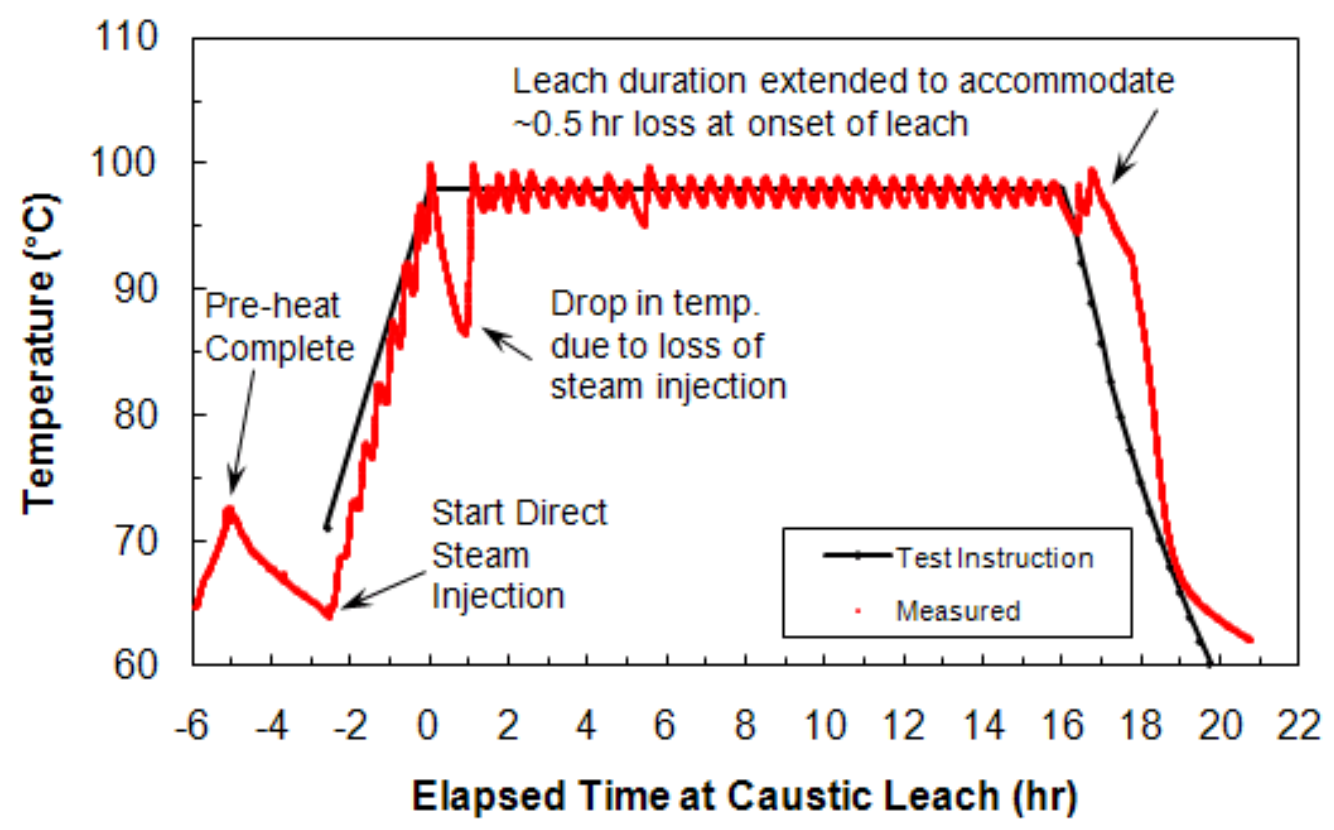

Figure 9.13. Temperature Measured at the "Prototypic" Sensor in PEP Vessel Tank T02A During Integrated Test B, Batch 1

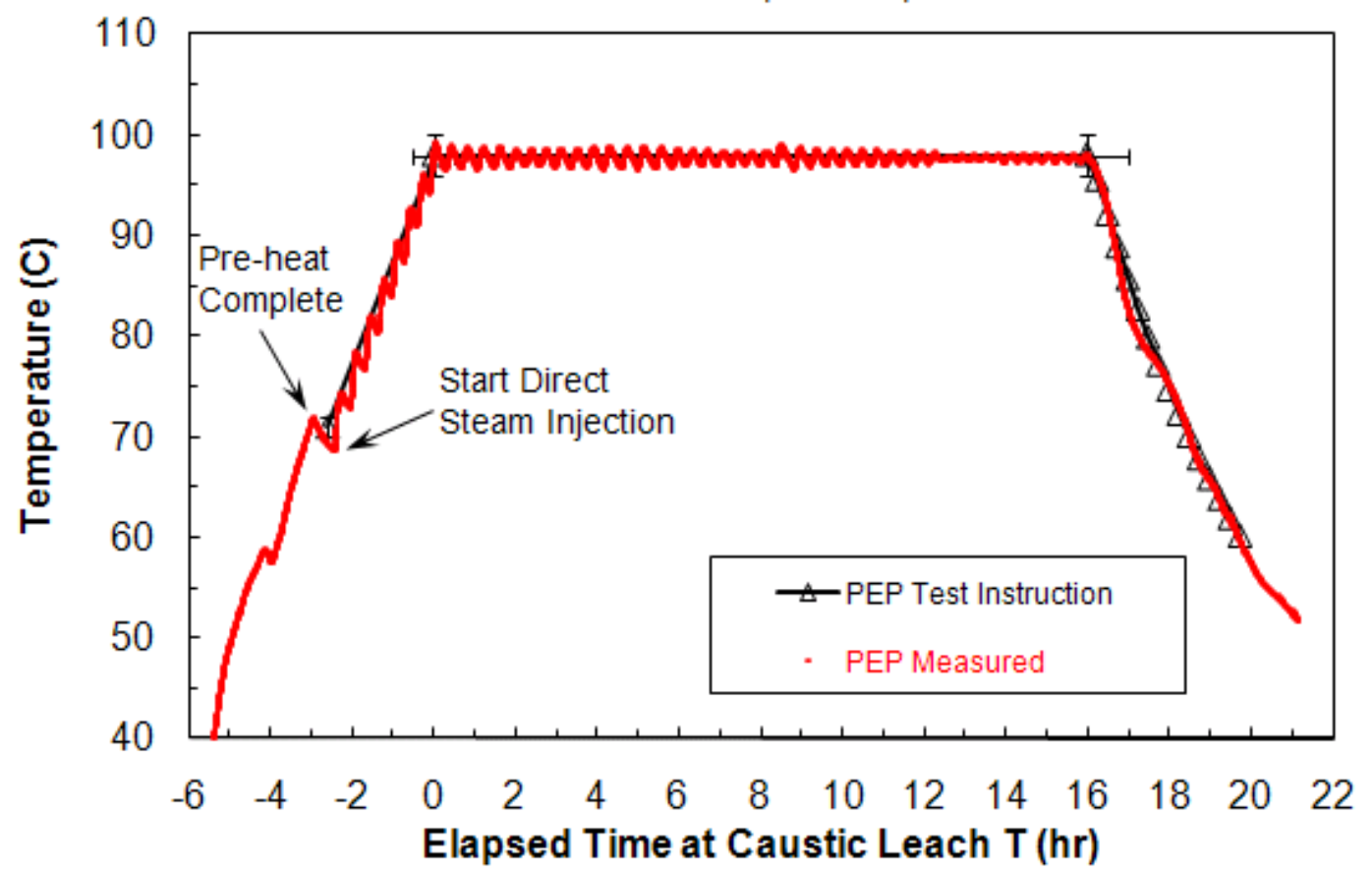

Figure 9.14. Temperature Measured at the "Prototypic" Sensor in PEP Vessel Tank T02A During Integrated Test B, Batch 2 
The temperature profile for Batch 1 (Figure 9.13) shows a number of departures from the target temperature profile. In the first departure, there was a loss of temperature just after the pre-heat had been completed using the external heat exchanger because operations were shut down to decide how to deal with a leak in the filter-loop. On restart, the unavailability of the loop and external heat exchangers meant that steam injection had to be used for the entire heat-up; this was expected to add more condensate to the slurry than the target value. The remaining temperature drops, at about hours 0,5 , and 16 into leach, were caused when steam injection was shut off by high-high level alarms. High air sparge rates and foaming was implicated in at least one of these. (More details are given in Section 9.3.3.) The leaching period was extended to offset the loss of temperature at hour 0 .

Caustic leaching in Batch 2 (the scale-up batch for Integrated Test B) was uneventful and the temperature profile (Figure 9.14) was on target. The target pre-heat temperature was $71 \pm 1{ }^{\circ} \mathrm{C}$, and the expected duration of the final heat-up to the target leach temperature $\left(98^{\circ} \mathrm{C}\right)$ was $2.6 \pm 0.5$ hours. The batch was initially pre-heated to $72^{\circ} \mathrm{C}$, but the temperature fell to $69^{\circ} \mathrm{C}$ at the time direct steam injection started (-2.4 hours). Although steam heating started a degree below the target range, the final heating duration was well within the period specified in the Test Instruction. The average temperature during the 16-hr leaching period of Batch 2 was $97.7^{\circ} \mathrm{C}$, and a detailed examination of the prototypic temperature sensor data shows that the temperature was maintained within the target range $98 \pm 2^{\circ} \mathrm{C}$ throughout the leaching period.

\subsubsection{Integrated Test B Steam Addition and Condensate Accumulation}

Figure 9.15 and Figure 9.16 show a series of volume changes associated with the process of direct steam injection and condensate accumulation for Batch 1 and Batch 2, respectively, of Integrated Test B. Each figure depicts three elements of the process from the start of direct steam injection through the end of the caustic leaching digestion period:

- The total increase in the slurry-condensate mixture volume relative to the slurry volume at the start of steam injection, $\Delta V$, including contributions due to thermal expansion.

- Of this, the estimated volume of condensate accumulated, $V_{c}$, as determined by Method 1 of Section 9.1.1, Equation (9.3).

- The total amount of steam added, as an equivalent liquid volume at the vessel temperature.

Like the corresponding temperature profiles in Section 9.3.3.1, the $\mathrm{x}$-axis values in Figure 9.15 and Figure 9.16 are the elapsed time since the target leaching temperature of $98^{\circ} \mathrm{C}$ was first attained (time zero). The negative elapsed time is during heat-up. The figures track the measured volume changes throughout the caustic leaching process in two primary phases: heating the initial slurry volume from the pre-heated temperature $\left(\sim 71^{\circ} \mathrm{C}\right)$ to the leach temperature with direct steam injection and maintaining the leach temperature $\left(98^{\circ} \mathrm{C}\right)$ for the specified duration of the leach (16 hours). The difference between the amount of steam added as an equivalent liquid volume and the actual volume is due to evaporation.

In the Integrated Test B batches, the net accumulation of condensate results from steam condensation alone (no water was added to adjust the amount of water present). A simple water mass balance around the process is given by:

$$
\text { mass of steam added }=\text { mass accumulated }+ \text { mass vented }
$$


Such a water mass balance and the results of the analyses described in this section were used to develop an overall process mass balance in Section 12. In the case of Batch 2, 1.2 gal of condensate had accumulated by the time the initial stable level measurement was taken. The calculations supporting Figure 9.16, and the figure itself, have been corrected to include this condensate volume.

The measured slurry volume changes shown in Figure 9.15 and Figure 9.16 were derived from stable vessel level measurements and the corresponding total slurry volumes. The PJMs were turned off and vented, and the spargers were turned off (generally speaking) during all defined stable level measurement periods. Typically, the steam ring purge air flow, or in a few instances steam flow, was left on for these measurements; in Integrated Test B, the purge air flow rate to Tank T02A was $0.14-\mathrm{kg} / \mathrm{min}$ during heat-up to $90^{\circ} \mathrm{C}$ and $0.09-\mathrm{kg} / \mathrm{min}$ after the vessel reached $90^{\circ} \mathrm{C}$. See the Integrated Test B run report for additional operations information (Geeting et al. 2009).

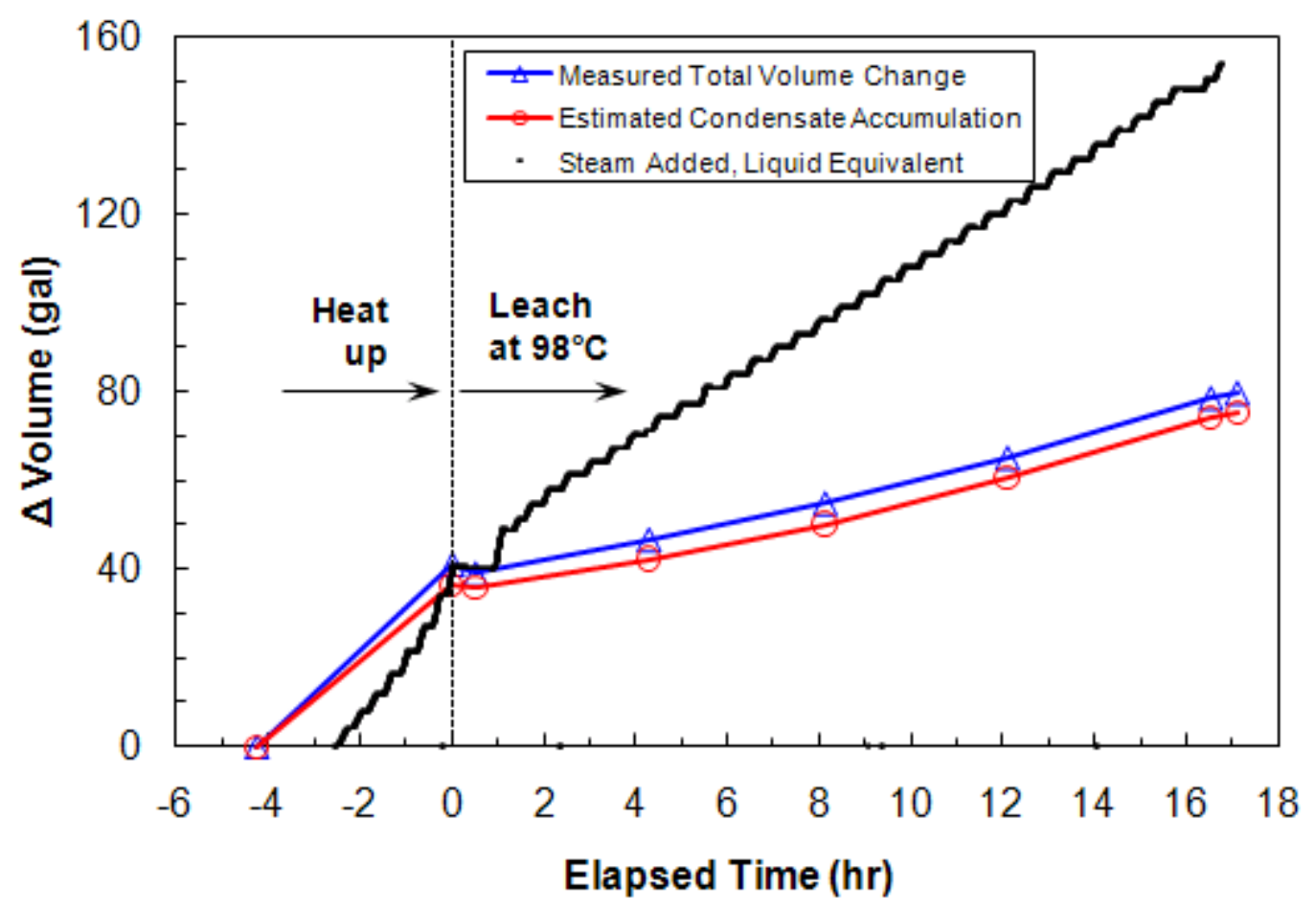

Figure 9.15. Slurry Component Volume Changes ( $\Delta$ volume) in Tank T02A Associated with Direct Steam Injection During the Heat-Up and Caustic-Leach Periods of Integrated Test B, Batch 1 


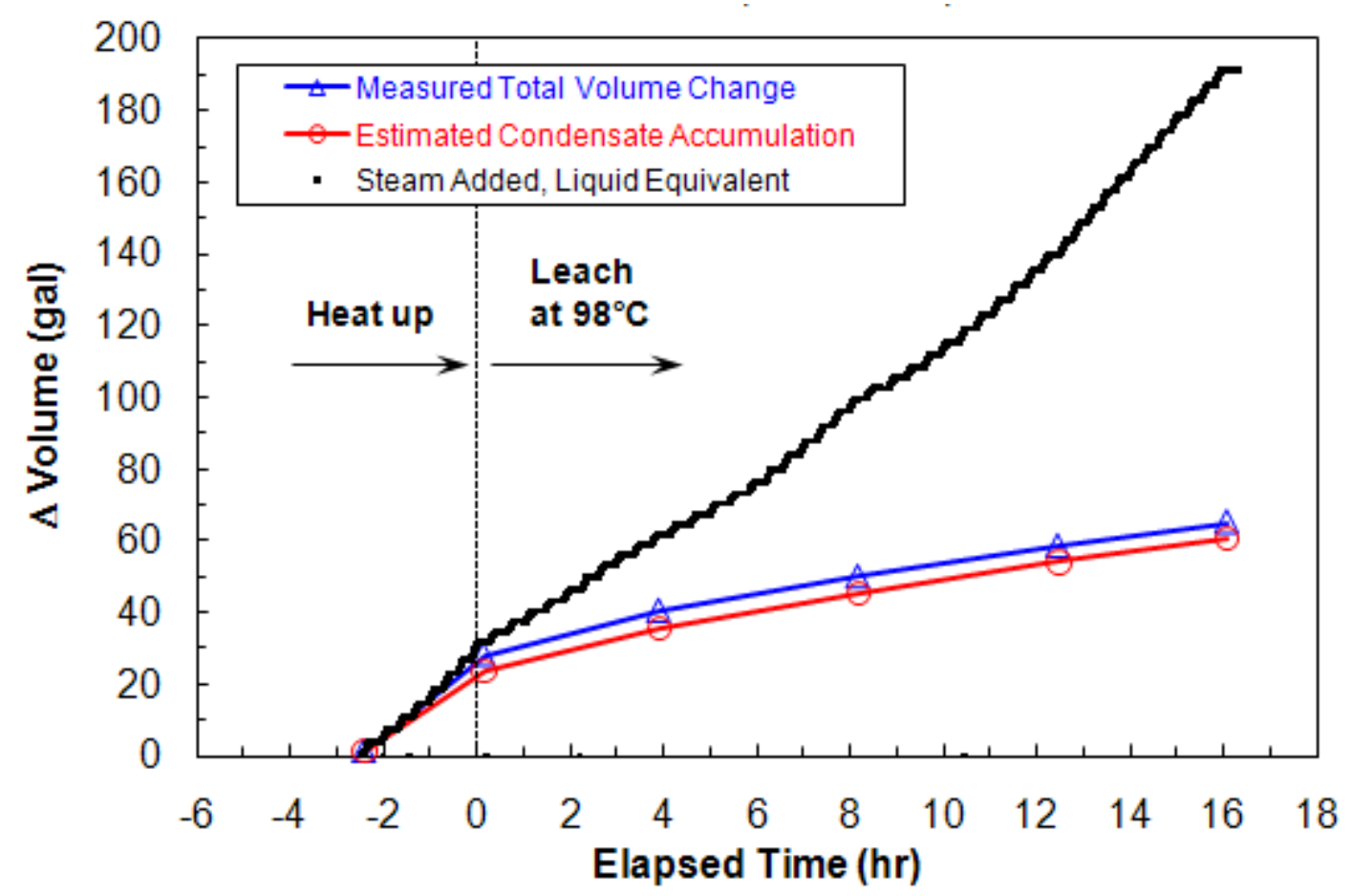

Figure 9.16. Slurry Component Volume Changes ( $\Delta$ volume) in Tank T02A Associated with Direct Steam Injection During the Heat-Up and Caustic-Leach Periods of Integrated Test B, Batch 2

The measured total slurry volume in Tank T02A during processing of Integrated Test B, Batch 2 was shown in a caustic leaching process evaluation report (Mahoney et al. 2009), and the translation to Figure 9.16 was discussed. As noted in the earlier report, measured total slurry volumes in Tank T02A were derived from four sources: 1) vessel bubbler pressure data (i.e., both lower and upper legs) converted to slurry level using temperature-corrected slurry density data (Equation [9.2]), 2) the as-is or raw vessel bubbler pressure data using the apparent slurry density (specific gravity) derived from the difference in bubbler pressures, 3) a laser level instrument, and 4) a DrexelBrook capacitance probe located in the vessel (not in the PJMs).

In both Integrated Test B batches, the density-corrected bubbler or laser measurement approaches were selected; in some cases, the bubblers or laser failed intermittently, and a combination of the two measurement methods was used to represent the entire leaching period. In these analyses, preference was typically given to the corrected bubbler data because the PTF UFP vessel specifications include bubblers as the level instrumentation, and application of the temperature-adjusted analytical slurry density should correct the measured level (and corresponding volume) for any gas retained in the slurry at the time of the measurement.

Several features are present in both Figure 9.15 and Figure 9.16:

- The rate of steam addition was greater during heat up than during the constant temperature leaching period. More steam was used during the temperature ramp because of the heating required to bring the slurry and vessel structure up to temperature (i.e., sensible heating). 
- The volume of condensate accumulated during heat-up was 36 gal in Batch 1 and 24 gal in Batch 2. The volume of steam added in the same period was slightly higher for Batch 1 (3 gal), indicating that most of the steam was condensed in this phase of the process, and somewhat higher for Batch 2 (8 gal).

- Owing to thermal expansion effects, the total increase in the slurry-condensate mixture volume was greater than the estimated volume of condensate. At $98^{\circ} \mathrm{C}$, the thermal expansion contribution was 4 to 5 gal.

- The volume of condensate accumulated at the end of the leaching period was 75 gal in Batch 1 and $61 \mathrm{gal}$ in Batch 2. As shown in Table 9.7 for Method 1, this corresponds to 274- and 221-kg of condensate, respectively. (Method 2 condensate masses shown in the table are somewhat higher, 297- and 242-kg.)

- The total amount of steam added was 154 gal in Batch 1 and 192 gal in Batch 2 (559-kg and 696-kg).

- In Batch 1, the rate of steam addition was essentially linear in each phase of the process (i.e., heat-up and constant temperature hold). In Batch 2, the rate of addition after 12 hours was visibly greater (Figure 9.16) than it had been between hours 0 and 6 . The test records do not contain any events (such as the vessel vent being opened or closed) that would explain the change.

- Subtracting the net mass of condensate accumulated (as determined by two methods) from the mass of steam added gives the mass of water vapor vented from the system: for condensate mass Method 1, the amount of vented water in each batch was 285-kg for Batch 1 and 475-kg for Batch 2; and for condensate mass Method 2, the vented water mass was 262-kg for Batch 1 and 454-kg for Batch 2. The difference in vented vapor between the two batches suggests some difference in vessel venting, among other possible explanations, but as noted above, the test records show no evidence. It is surprising that the vented vapor mass for Batch 1 is less than for Batch 2, considering that in the first few hours of the constant-temperature hold, the sparge flow rates were much higher in Batch 1 than in Batch 2 (see Section 9.3.3.3).

Figure 9.15 is potentially misleading in that at first glance, there appears to have been more condensate accumulated than steam added during heat-up. This is an artifact; the test was on hold because of a filter-loop leak. This produced some hours delay between the initial level measurement and the beginning of steam injection. Hence, the line drawn between the initial point and the post-heat-up point gives the false appearance that volume was accumulating in Tank T02A during the delay.

A method for cross-checking the condensate accumulation trends against calculated and analytically measured liquid dilution factors was described in Section 9.1.1. The results of such analyses are summarized in Table 9.12. For each batch, liquid dilution factors over the course of the test are determined from liquid chemical tracer analytical measurements and vessel level-based calculations (in conjunction with temperature-corrected liquid densities). In Integrated Test A, it was typical for the dilution factors determined from chemical tracers to tend to be slightly higher than the level-based dilution factors, with a difference that was always $<3-\mathrm{wt} \%$ and generally $<2-\mathrm{wt} \%$. This pattern was followed by Batch 2 of Integrated Test B, but reversed by Batch 1 of Integrated Test B. The reason for the difference is unknown. 
A final note: in comparing condensate fractions in Table 9.7 to liquid dilution fractions in Table 9.12, bear in mind that the liquid dilution factors and condensate mass fractions are not expected to equal each other. A difference is expected because the liquid mass changes as a result of solids dissolution as well as condensate accumulation.

Table 9.12. Dilution of Liquid Phase During Integrated Test B Caustic-Leach Batches in Tank T02A

\begin{tabular}{|c|c|c|c|c|c|c|}
\hline \multirow[b]{3}{*}{$\begin{array}{l}\text { Approximate Point } \\
\text { in Process }\end{array}$} & \multicolumn{6}{|c|}{ Total Liquid Mass Dilution (wt\%) } \\
\hline & \multicolumn{3}{|c|}{ Integrated Test B, Batch 1} & \multicolumn{3}{|c|}{ Integrated Test B, Batch 2} \\
\hline & $\begin{array}{c}\text { Nitrate } \\
\left(\mathrm{NO}_{3}{ }^{-}\right) \\
\text {Tracer }^{(\mathrm{a})}\end{array}$ & $\begin{array}{l}\text { Chloride } \\
\qquad\left(\mathrm{Cl}^{-}\right) \\
\text {Tracer }^{(a)}\end{array}$ & $\begin{array}{c}\text { Tank T02A } \\
\text { Level } \\
\text { Changes }^{(b)}\end{array}$ & $\begin{array}{c}\text { Nitrate } \\
\left(\mathrm{NO}_{3}{ }^{-}\right) \\
\text {Tracer }^{(\mathrm{a})}\end{array}$ & $\begin{array}{l}\text { Chloride } \\
\qquad\left(\mathrm{Cl}^{-}\right) \\
\text {Tracer }^{(a)}\end{array}$ & $\begin{array}{c}\text { Tank T02A } \\
\text { Level } \\
\text { Changes }^{(b, c)}\end{array}$ \\
\hline $\begin{array}{l}\text { After } \mathrm{NaOH} ; \\
\text { before steam } \\
\text { addition }\end{array}$ & $0.0 \%$ & $0.0 \%$ & $0.0 \%$ & $0.0 \%$ & $0.0 \%$ & $0.0 \%$ \\
\hline At $88^{\circ} \mathrm{C}$ & $5.4 \%$ & $4.7 \%$ & $\mathrm{n} / \mathrm{m}$ & $7.1 \%$ & $7.4 \%$ & $\mathrm{n} / \mathrm{m}$ \\
\hline $0 \mathrm{hr}$ & $10.6 \%$ & $9.8 \%$ & $12.7 \%$ & $11.8 \%$ & $11.2 \%$ & $8.9 \%$ \\
\hline $1 \mathrm{hr}$ & $9.1 \%$ & $8.8 \%$ & $\mathrm{n} / \mathrm{m}$ & $13.7 \%$ & $14.4 \%$ & $\mathrm{n} / \mathrm{m}$ \\
\hline $2 \mathrm{hr}$ & $11.7 \%$ & $11.3 \%$ & $\mathrm{n} / \mathrm{m}$ & $14.4 \%$ & $14.4 \%$ & $\mathrm{n} / \mathrm{m}$ \\
\hline $4 \mathrm{hr}$ & $13.1 \%$ & $11.9 \%$ & $15.6 \%$ & $16.1 \%$ & $17.5 \%$ & $13.2 \%$ \\
\hline $8 \mathrm{hr}$ & $16.7 \%$ & $14.5 \%$ & $18.8 \%$ & $18.2 \%$ & $17.0 \%$ & $16.8 \%$ \\
\hline $10 \mathrm{hr}$ & $18.9 \%$ & $18.8 \%$ & $\mathrm{n} / \mathrm{m}$ & $20.1 \%$ & $19.6 \%$ & $\mathrm{n} / \mathrm{m}$ \\
\hline $12 \mathrm{hr}$ & $19.2 \%$ & $19.3 \%$ & $21.9 \%$ & $23.4 \%$ & $22.7 \%$ & $20.4 \%$ \\
\hline $14 \mathrm{hr}$ & $23.3 \%$ & $23.1 \%$ & $\mathrm{n} / \mathrm{m}$ & $26.4 \%$ & $24.3 \%$ & $\mathrm{n} / \mathrm{m}$ \\
\hline $16 \mathrm{hr}^{(\mathrm{d})}$ & $23.7 \%$ & $20.6 \%$ & $26.2 \%$ & $26.0 \%$ & $25.6 \%$ & $22.5 \%$ \\
\hline
\end{tabular}

(a) Liquid mass dilution is determined from the change in liquid tracer concentration (e.g., in $\mu \mathrm{g}$ analyte/g of liquid) relative to the "after $\mathrm{NaOH}$ " sample initial/reference state. Nitrate and chloride ion concentrations were determined by IC.

(b) Change in liquid mass/initial liquid mass.

(c) The initial/reference state is the mass of liquid in the PEP vessel after $\mathrm{NaOH}$ addition, as determined from the stable level measurement nearest to the start of direct steam injection, subtracting the estimated quantity of steam condensate added to that point $(\sim 4.4-\mathrm{kg})$. The liquid mass is calculated from 1$)$ the total slurry volume (at level), 2) the estimated volume fraction of liquid (from wt $\%$ UDS, temperature-corrected liquid density and the density of remaining solids [2.8- $\mathrm{kg} / \mathrm{L}$ assumed]), and 3) a temperature-corrected liquid density.

(d) In Integrated Test B, Batch 1, the "16-hr" sample was collected at approximately 17-hr elapsed time from the time $98^{\circ} \mathrm{C}$ was first reached.

$\mathrm{n} / \mathrm{m}$ - not measured

\subsubsection{Integrated Test B Process Deviations}

In Integrated Test B, Batch 1, the departures from expected conditions were the following:

- After the contents of Tank T02A had been heated to $71^{\circ} \mathrm{C}$, the initial heat-up target temperature, a leak was found in the filter-loop and operations were put on hold. During the delay of an hour, the temperature fell to $64^{\circ} \mathrm{C}$. When operations restarted, the temperature loss was recovered with steam injection. 
- Immediately after caustic addition, the level in Tank T02A was seven inches higher than expected; it rose an additional two inches during the next three hours of heat-up. The cause of the extra level was believed to be high air sparge rates and foaming.

- When the vessel temperature reached $90^{\circ} \mathrm{C}$, the upper and lower sparger flow rates were mistakenly increased instead of decreased. The high air flow caused an additional level increase that caused high-high level alarms. The lower sparger rate was corrected down at about 0.7 hours into leaching, and the upper sparger rate was corrected down at about 2.5 hours into leaching.

- High-high level alarms caused by high air sparge rates, foaming, PJM overblows, and PJM tuning caused steam injection to stop at several points during the leaching process. The temperature had reached $98^{\circ} \mathrm{C}$ at hour 0 into the leach; immediately after that, the steam shut-off caused temperatures to fall below $96^{\circ} \mathrm{C}$ for about 50 minutes, dropping to about $86^{\circ} \mathrm{C}$. To make up for this loss of temperature, the batch leach time was extended to 17 hours instead of 16 hours. Two other temperature drops occurred, at about hours 5.3 and 16.1; these caused the temperature to drop below $96^{\circ} \mathrm{C}$ for 10 to 20 minutes apiece. The plan had been for Batch 1 to be used for caustic-leach scale-up data analyses, but because of the operational disturbances, Batch 2 was used instead.

There were no significant departures from expected conditions during the leaching of Batch 2 of Integrated Test B. The level at the end of caustic addition was 3 inches higher than expected, suggesting that some foaming was occurring, but not to the same extent as in Batch 1.

The temperature profiles for the two batches can be found in Section 9.3.2.1.

\subsubsection{Integrated Test D}

As described in more detail in Sections 4.3 and 4.5 of Sevigny et al. (2009) (the run report for Integrated Test D), two batches of solids-concentrated simulant were processed during Integrated Test D. The caustic leaching processing included in-line addition of $\mathrm{NaOH}$ reagent in the filter-loop, heat-up to leaching temperature $\left(85^{\circ} \mathrm{C}\right)$, and digestion at constant temperature. The simulant that underwent caustic leaching in Integrated Test D included the Cr component.

Caustic leaching operations were carried out in vessel Tank T02A with the completed first batch being stored in Tank T01A during the leaching of the second. The $\mathrm{NaOH}$ reagent was added in-line in the filter-loop.

\subsubsection{Integrated Test D Temperature Profiles}

Figure 9.17 and Figure 9.18 show the temperature-versus-time profiles in Tank T02A during caustic leaching of Batches 1 and 2. The time axis is expressed in terms of time relative to the start of the constant-temperature leach (see tables in Appendix A for the elapsed time zero clock time). The temperature is measured at the prototypic temperature sensor, TTK-0619; the sensor is located near the vessel bottom. Each figure also shows the temperature-versus-time targets outlined in TI-082. The xand y-error bars correspond to the TI target ranges. As noted previously, the TI temperature profile targets in the heating and cooling regimes were derived from versions of WTP UFP vessel heat-transfer models. 
The temperature profile for Batch 1 (Figure 9.17) is, at first glance, consistent with the target profile. However, before the plotted period, the temperature was held between 50 and $65^{\circ} \mathrm{C}$ for about 19 hours while apparent high slurry levels in Tank T02A were investigated and found to be caused (possibly) by foaming. The energy to maintain temperature was supplied by pump work (PMP-T42A and -T43A). Section 9.3.4.3 gives more information about this occurrence. The brief temperature irregularities at about 0 hours and 14 hours into leaching are of undetermined origin.

Caustic leaching in Batch 2 (the scale-up batch for Integrated Test D) included several short excursions from the targeted temperature profile during the 24-hr leaching period, as can be seen in Figure 9.18. The temperature drop between hour 1 and 2 occurred after a steam shut-off was caused by high-high level alarms, possibly related to foaming. The temperature irregularities between hour 14 and the end of leaching had similar causes; the accumulation of condensate exacerbated the high-level problems that had been seen at the beginning of leach. After some of these shut-offs. the steam injection was restarted before the PJMs were turned on, allowing a temporary local temperature increase during recovery.

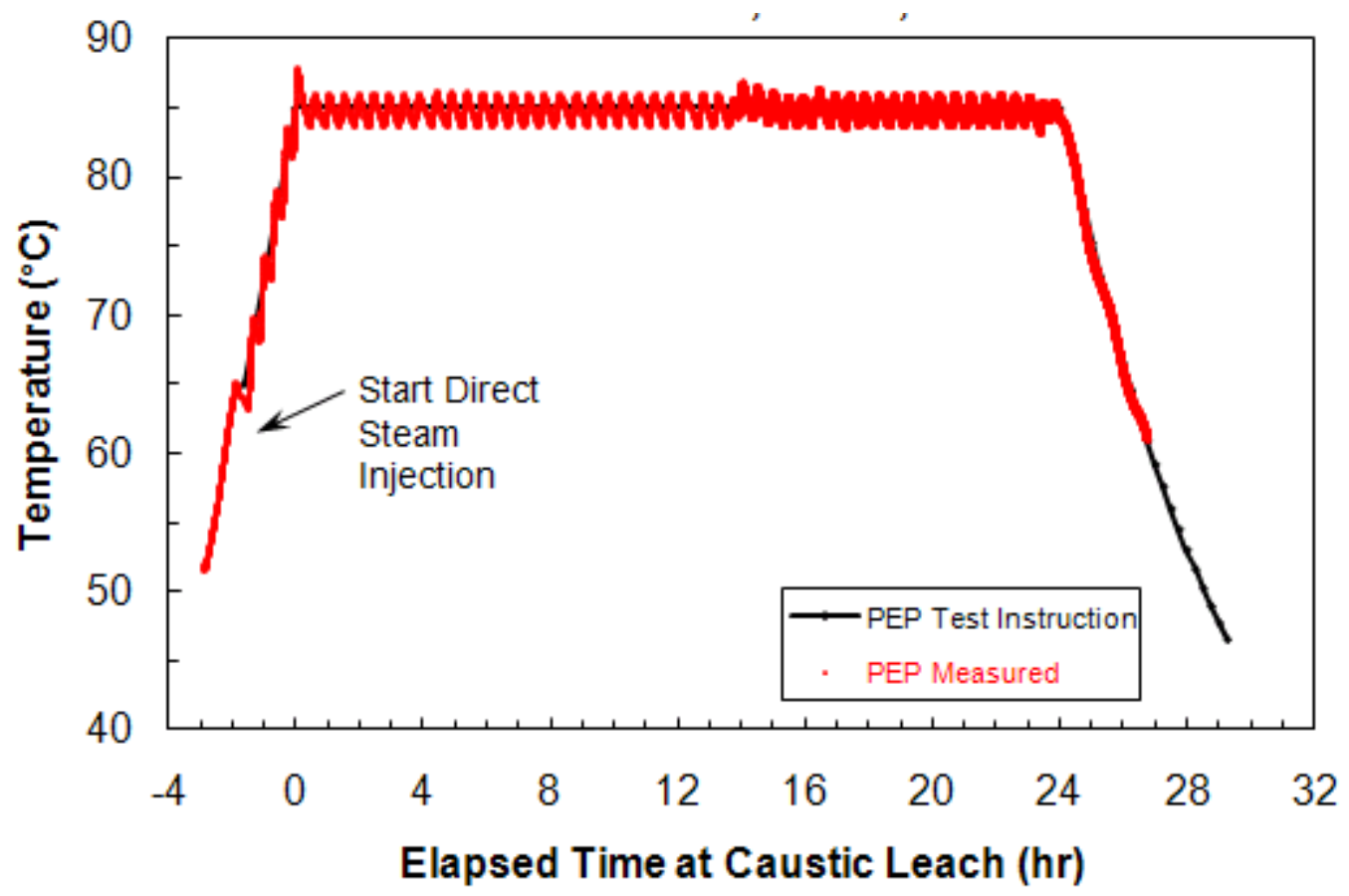

Figure 9.17. Temperature Measured at the "Prototypic" Sensor in PEP Vessel Tank T02A During Integrated Test D, Batch 1 


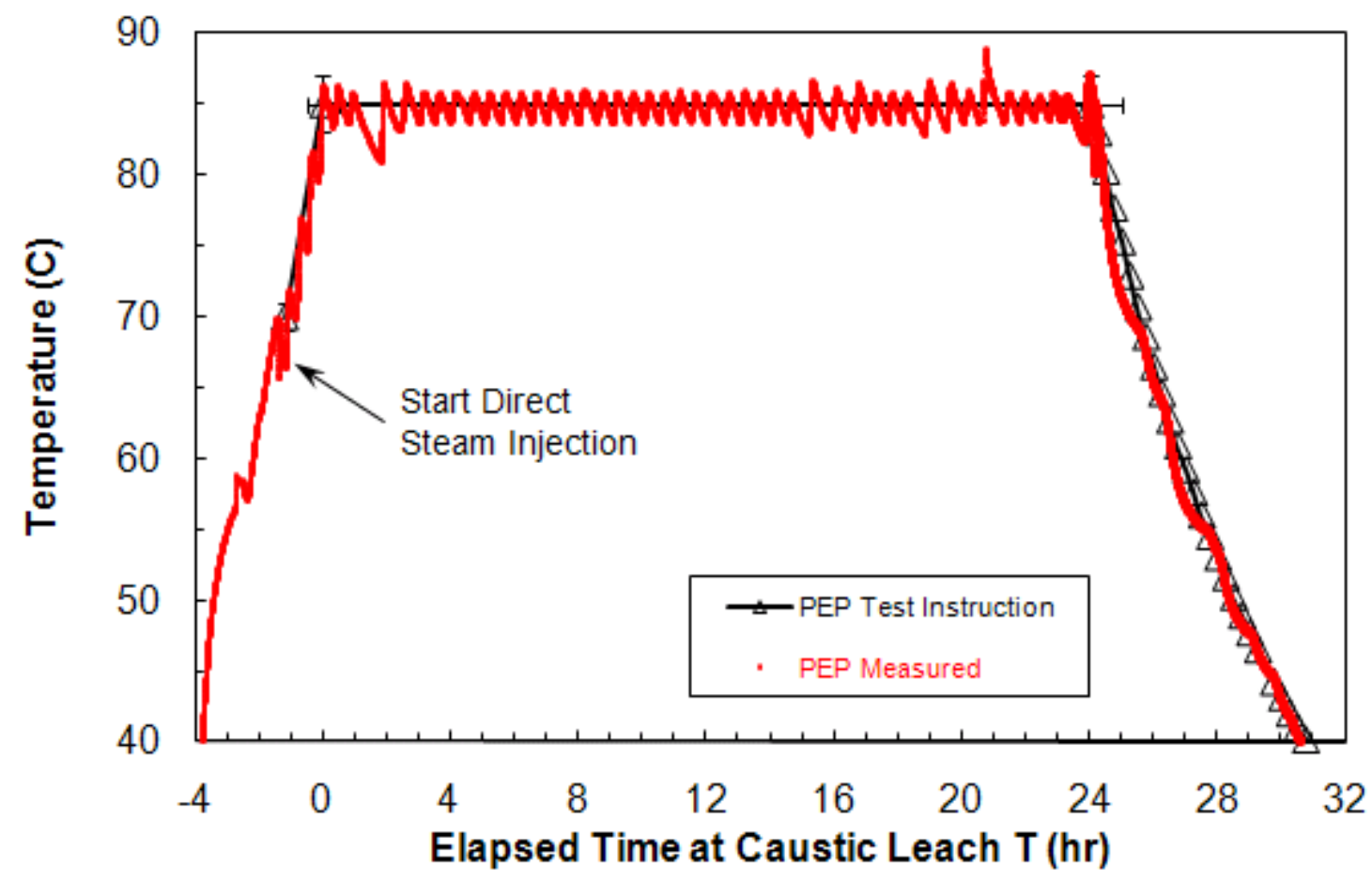

Figure 9.18. Temperature Measured at the "Prototypic" Sensor in PEP Vessel Tank T02A During Integrated Test D, Batch 2

\subsubsection{Integrated Test D Steam Addition and Condensate Accumulation}

Figure 9.19 and Figure 9.20 show a series of volume changes associated with the process of direct steam injection and condensate accumulation for Batch 1 and Batch 2, respectively, of Integrated Test D. Each figure depicts three elements of the process from the start of direct steam injection through the end of the caustic-leaching digestion period:

- Total increase in the slurry-condensate mixture volume relative to the slurry volume at the start of steam injection, $\Delta V$, including contributions due to thermal expansion.

- Of this, the estimated volume of condensate accumulated, $V_{c}$, as determined by Method 1 of Section 9.1.1, Equation (9.3).

- Total amount of steam added as an equivalent liquid volume at the vessel temperature.

Like the corresponding temperature profiles in Section 9.3.4.1, the $\mathrm{x}$-axis values in Figure 9.19 and Figure 9.20 are the elapsed time since the target leaching temperature of $85^{\circ} \mathrm{C}$ was first attained (time zero). The negative elapsed time is during heat-up. The figures track the measured volume changes throughout the caustic leaching process in two primary phases: heating the initial slurry volume from the pre-heated temperature $\left(\sim 65^{\circ} \mathrm{C}\right)$ to the leach temperature with direct steam injection and maintaining the leach temperature $\left(85^{\circ} \mathrm{C}\right)$ for the specified duration of the leach $(24$ hours). The difference between the amount of steam added as an equivalent liquid volume and the actual volume is due to evaporation. 


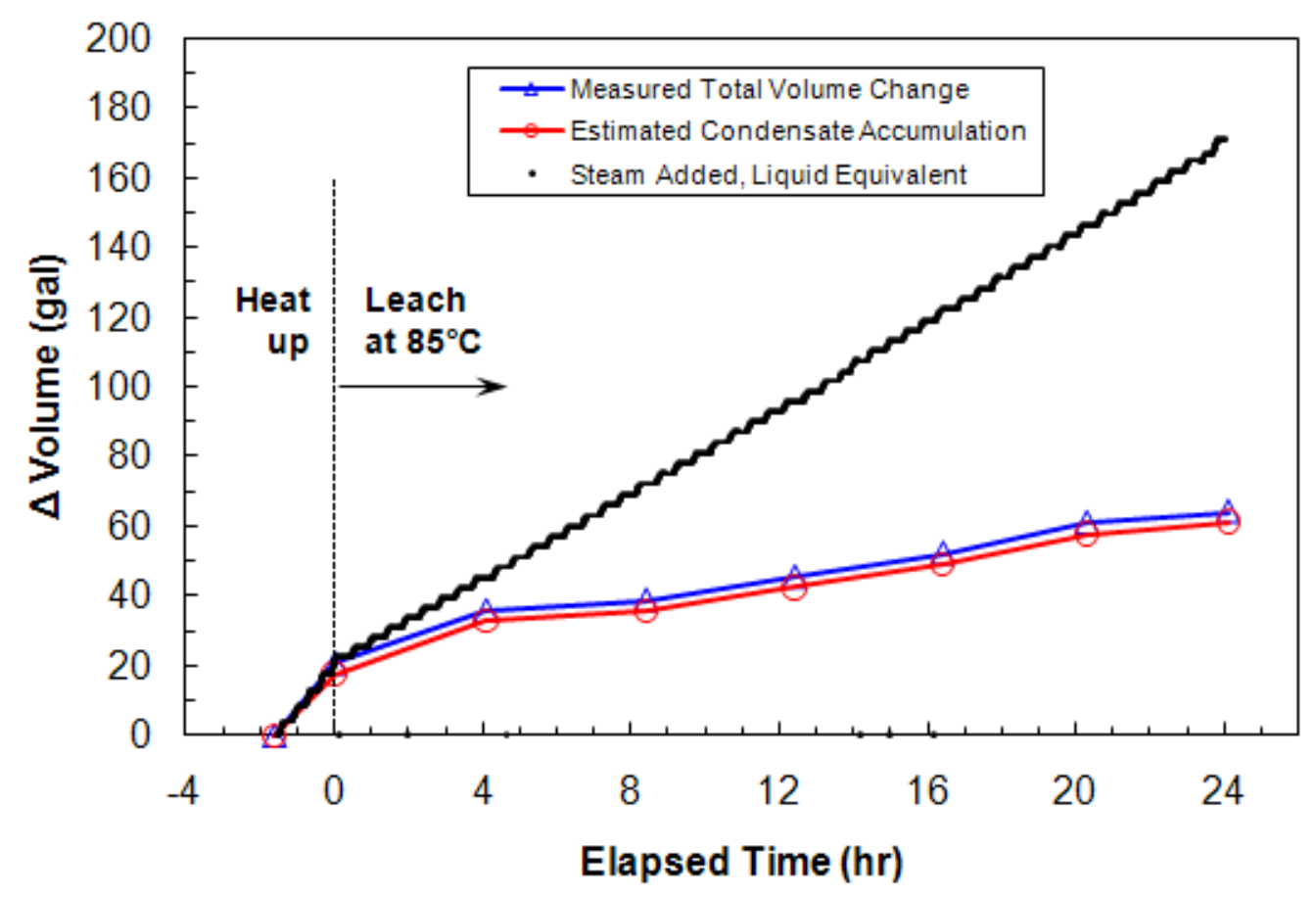

Figure 9.19. Slurry Component Volume Changes ( $\Delta$ volume) in Tank T02A Associated with Direct Steam Injection During the Heat-Up and Caustic-Leach Periods of Integrated Test D, Batch 1

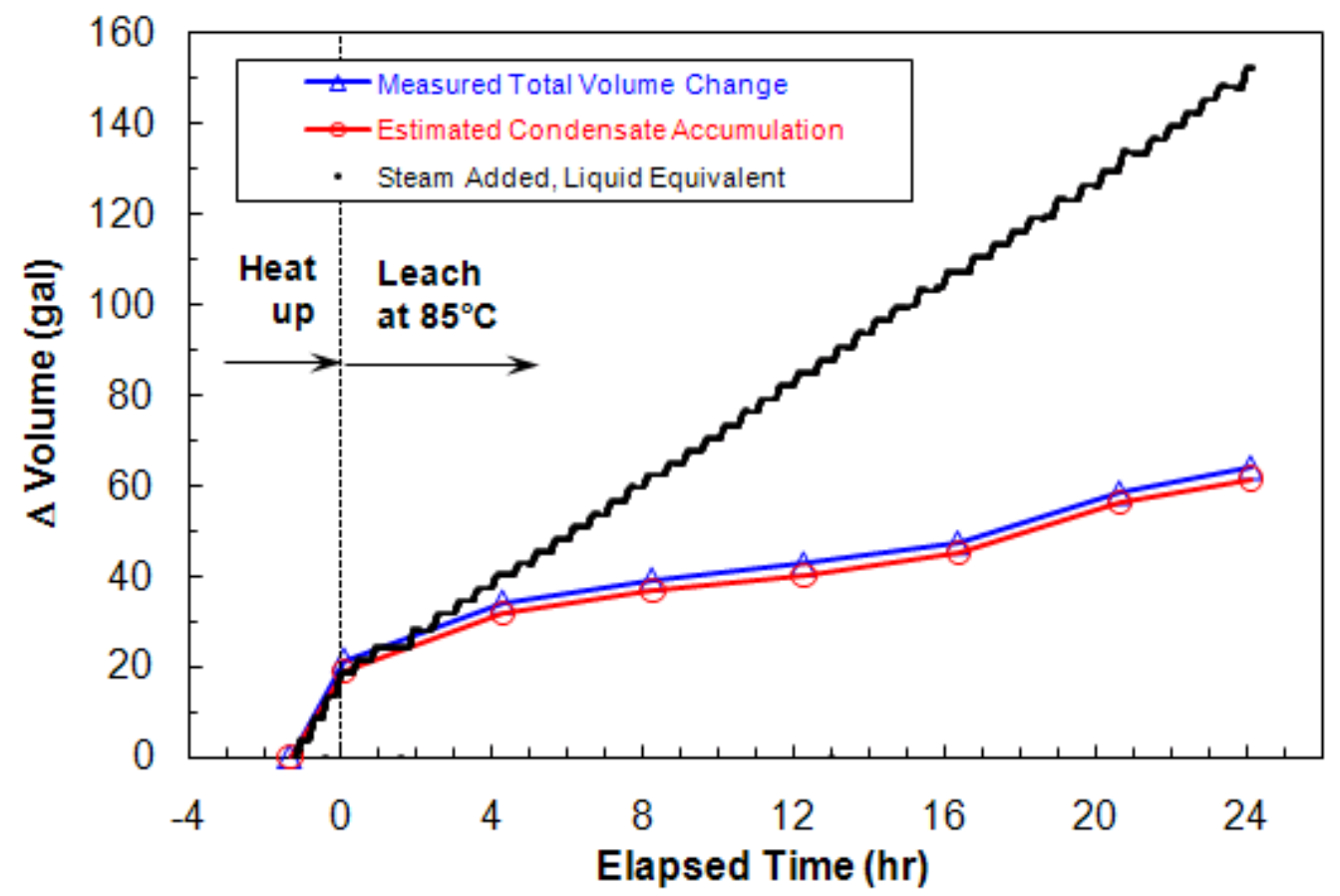

Figure 9.20. Slurry Component Volume Changes ( $\Delta$ volume) in Tank T02A Associated with Direct Steam Injection During the Heat-Up and Caustic-Leach Periods of Integrated Test D, Batch 2 
In the Integrated Test $\mathrm{D}$ batches, the net accumulation of condensate results from steam condensation alone (no water was added to adjust the amount of water present). A simple water mass balance around the process is given by

$$
\text { mass of steam added }=\text { mass accumulated }+ \text { mass vented }
$$

Such a water mass balance and the results of the analyses described in this section were used to develop an overall process mass balance in Section 12.

The measured slurry volume changes shown in Figure 9.19 and Figure 9.20 were derived from stable vessel level measurements and the corresponding total slurry volumes. The PJMs were turned off and vented, and the spargers were turned off (generally speaking), during all defined stable level measurement periods. Typically, the steam ring purge air flow, or in a few instances, steam flow, was left on for these measurements. See the Integrated Test D run report for additional operations information (Sevigny et al. 2009).

Measured total slurry volumes in Tank T02A were derived from four sources: 1) vessel bubbler pressure data (i.e., both lower and upper legs) converted to slurry level using temperature-corrected slurry density data (Equation [9.2]), 2) the as-is or raw vessel bubbler pressure data using the apparent slurry density (specific gravity) derived from the difference in bubbler pressures, 3) a laser level instrument, and 4) a DrexelBrook capacitance probe located in the vessel (not in the PJMs).

In both Integrated Test D batches, the density-corrected bubbler or laser measurement approaches were selected; in some cases, the bubblers or laser failed intermittently, and a combination of the two measurement methods was used to represent the entire leaching period. In these analyses, preference was typically given to the corrected bubbler data because the PTF UFP vessel specifications include bubblers as the level instrumentation, and application of the temperature-adjusted analytical slurry density should correct the measured level (and corresponding volume) for any gas retained in the slurry at the time of the measurement.

Several features are present in both Figure 9.19 and Figure 9.20:

- The rate of steam addition was greater during heat-up than during the constant temperature leaching period. More steam was used during the temperature ramp because of the heating required to bring the slurry and vessel structure up to temperature (i.e., sensible heating).

- The volume of condensate accumulated during heat up was 18 gal in Batch 1 and 19 gal in Batch 2. The volume of steam (liquid equivalent) added in the same period was slightly higher for Batch 1 (3 gal), indicating that most of the steam was condensed in this phase of the process, almost exactly equal for Batch 2.

- Owing to thermal expansion effects, the total increase in the volume of the slurry-condensate mixture was greater than the estimated volume of the condensate. At $85^{\circ} \mathrm{C}$, the thermal expansion contribution was 2 to 3 gal.

- The volume of condensate accumulated at the end of the leaching period was 61 gal in Batch 1 and 62 gal in Batch 2. As shown in Table 9.9 for Method 1, this corresponds to 225- and 226-kg of condensate, respectively. (Method 2 condensate masses shown in the table are somewhat higher, 269- and 256-kg.) 
- The total amount of steam added was 171 gal in Batch 1 and 152 gal in Batch 2 (628-kg and $559-\mathrm{kg})$.

- In both batches, the rate of steam addition was essentially linear in each phase of the process (i.e., heat-up and constant temperature hold).

- Subtracting the net mass of condensate accumulated (as determined by two methods) from the mass of steam added gives the mass of water vapor vented from the system: for condensate mass Method 1, the amount of vented water in each batch was 403-kg for Batch 1 and 333-kg for Batch 2, and for condensate mass Method 2, the vented water mass was 359-kg for Batch 1 and $303-\mathrm{kg}$ for Batch 2.

A method for cross-checking the condensate accumulation trends against calculated and analytically measured liquid dilution factors was described in Section 9.1.1. The results of such analyses are summarized in Table 9.13. For each batch, liquid dilution factors over the course of the test were determined from liquid chemical tracer analytical measurements and vessel level-based calculations (in conjunction with temperature-corrected liquid densities). In Integrated Test A, it was typical for the dilution factors determined from chemical tracers to tend to be slightly higher than the level-based dilution factors, with a difference that was always $<3-\mathrm{wt} \%$ and generally $<2-\mathrm{wt} \%$. This pattern was not followed by either batch of Integrated Test D. The reason for the difference is unknown.

A final note - in comparing condensate fractions in Table 9.7 to liquid dilution fractions in Table 9.12, bear in mind that the liquid dilution factors and condensate mass fractions are not expected to equal each other. A difference is expected because the liquid mass changes as a result of dissolving solids as well as accumulating condensate.

\subsubsection{Integrated Test D Process Deviations}

In Integrated Test D, Batch 1, the departures from expected conditions that might have affected caustic leaching or sampling were the following:

- The samples before $\mathrm{NaOH}$ was added, which are the reference point for $\mathrm{Al}$ leach factor calculations, were taken at a time when the sampling pump was having priming problems.

- About 19 hours (at temperatures of 50 to $65^{\circ} \mathrm{C}$ ) elapsed between the end of $\mathrm{NaOH}$ addition and the time the "after $\mathrm{NaOH}$ " addition sample was taken. This delay was due to efforts to investigate an abnormally high slurry level in the vessel. Foaming was one possibility, so additional antifoaming agent was added. A total of $\sim 137-\mathrm{kg}$ of slurry was removed from the filter-loop to counteract the high levels. The removed slurry contained a significant amount of bubbles. The test continued without further departures after stable level conditions had been established. The plan had been for Batch 1 to be used for caustic-leach scale-up data analyses, but because of the operational disturbances, Batch 2 was used instead.

In Integrated Test D, Batch 2, the departures from expected conditions were the following:

- The samples before $\mathrm{NaOH}$ was added were taken from the filter-loop port (while there was flow through the loop). All subsequent samples were taken from the middle-lower CD port in the vessel. 
- The PEP characterization samples after $\mathrm{NaOH}$ was added, hours 0 and 24, were taken while the PJMs and spargers were turned off for stable level measurements. The PJMs and spargers were turned on in the middle of sample collection after $\mathrm{NaOH}$ was added, making it unclear whether the samples used for feed to the laboratory-scale experiments were taken with the PJMs and spargers off.

- There were repeated events in which high-high level alarms in Tank T02A, possibly caused by foaming, forced steam injection and PJM operation to shut down. As a result, there were several short drops in temperature that went below the $84^{\circ} \mathrm{C}$ lower bound by a few degrees or less.

The temperature profiles for the two batches can be found in Section 9.3.3.1.

Table 9.13. Dilution of Liquid Phase During Integrated Test D Caustic-Leach Batches in Tank T02A

\begin{tabular}{|c|c|c|c|c|c|c|}
\hline \multirow[b]{3}{*}{$\begin{array}{l}\text { Approximate Point } \\
\text { in Process }\end{array}$} & \multicolumn{6}{|c|}{ Total Liquid Mass Dilution (wt\%) } \\
\hline & \multicolumn{3}{|c|}{ Integrated Test $\mathrm{D}$, Batch 1} & \multicolumn{3}{|c|}{ Integrated Test $\mathrm{D}$, Batch 2} \\
\hline & $\begin{array}{c}\text { Nitrate } \\
\left(\mathrm{NO}_{3}{ }^{-}\right) \\
\text {Tracer }^{(\mathrm{a})}\end{array}$ & $\begin{array}{l}\text { Chloride } \\
\qquad\left(\mathrm{Cl}^{-}\right) \\
\text {Tracer }^{(a)}\end{array}$ & $\begin{array}{c}\text { Tank T02A } \\
\text { Level } \\
\text { Changes }^{(b)}\end{array}$ & $\begin{array}{c}\text { Nitrate } \\
\left(\mathrm{NO}_{3}{ }^{-}\right) \\
\text {Tracer }^{(\mathrm{a})}\end{array}$ & $\begin{array}{l}\text { Chloride } \\
\qquad\left(\mathrm{Cl}^{-}\right) \\
\text {Tracer }^{(a)}\end{array}$ & $\begin{array}{c}\text { Tank T02A } \\
\text { Level } \\
\text { Changes }^{(b, c)}\end{array}$ \\
\hline $\begin{array}{l}\text { After } \mathrm{NaOH} \text {; } \\
\text { before steam } \\
\text { addition }\end{array}$ & $0.0 \%$ & $0.0 \%$ & $0.0 \%$ & $0.0 \%$ & $0.0 \%$ & $0.0 \%$ \\
\hline At $75^{\circ} \mathrm{C}$ & $3.6 \%$ & $2.8 \%$ & $\mathrm{n} / \mathrm{m}$ & $-2.5 \%$ & $0.5 \%$ & $\mathrm{n} / \mathrm{m}$ \\
\hline $0 \mathrm{hr}$ & $7.5 \%$ & $7.7 \%$ & $7.0 \%$ & $-1.5 \%$ & $-2.1 \%$ & $6.0 \%$ \\
\hline $1 \mathrm{hr}$ & $8.5 \%$ & $7.7 \%$ & $\mathrm{n} / \mathrm{m}$ & $-0.3 \%$ & $-2.1 \%$ & $\mathrm{n} / \mathrm{m}$ \\
\hline $2 \mathrm{hr}$ & $9.4 \%$ & $10.2 \%$ & $\mathrm{n} / \mathrm{m}$ & $0.0 \%$ & $-0.8 \%$ & $\mathrm{n} / \mathrm{m}$ \\
\hline $4 \mathrm{hr}$ & $9.7 \%$ & $7.7 \%$ & $13.8 \%$ & $0.3 \%$ & $-0.3 \%$ & $10.2 \%$ \\
\hline $8 \mathrm{hr}$ & $14.1 \%$ & $11.0 \%$ & $14.9 \%$ & $3.3 \%$ & $4.3 \%$ & $12.4 \%$ \\
\hline $12 \mathrm{hr}$ & $15.2 \%$ & $13.9 \%$ & $17.4 \%$ & $8.3 \%$ & $9.9 \%$ & $13.8 \%$ \\
\hline $14 \mathrm{hr}$ & $18.8 \%$ & $16.7 \%$ & $\mathrm{n} / \mathrm{m}$ & $9.9 \%$ & $11.9 \%$ & $\mathrm{n} / \mathrm{m}$ \\
\hline $16 \mathrm{hr}$ & $18.1 \%$ & $15.4 \%$ & $19.9 \%$ & $13.9 \%$ & $16.2 \%$ & $15.6 \%$ \\
\hline $18 \mathrm{hr}$ & $20.0 \%$ & $19.6 \%$ & $\mathrm{n} / \mathrm{m}$ & $9.9 \%$ & $13.7 \%$ & $\mathrm{n} / \mathrm{m}$ \\
\hline $20 \mathrm{hr}$ & $22.0 \%$ & $21.2 \%$ & $22.7 \%$ & $15.1 \%$ & $18.8 \%$ & $19.5 \%$ \\
\hline $22 \mathrm{hr}$ & $21.6 \%$ & $19.6 \%$ & $\mathrm{n} / \mathrm{m}$ & $15.1 \%$ & $19.2 \%$ & $\mathrm{n} / \mathrm{m}$ \\
\hline $24 \mathrm{hr}$ & $22.9 \%$ & $21.2 \%$ & $24.7 \%$ & $16.7 \%$ & $18.2 \%$ & $21.7 \%$ \\
\hline
\end{tabular}

(a) Liquid mass dilution is determined from the change in liquid tracer concentration (e.g., in $\mu \mathrm{g}$ analyte/g of liquid) relative to the "after $\mathrm{NaOH"} \mathrm{sample} \mathrm{initial/reference} \mathrm{state.} \mathrm{Nitrate} \mathrm{and} \mathrm{chloride} \mathrm{ion} \mathrm{concentrations} \mathrm{were}$ determined by IC.

(b) Change in liquid mass/initial liquid mass.

(c) The initial/reference state is the mass of liquid in the PEP vessel after $\mathrm{NaOH}$ was added as determined from the stable level measurement nearest to the start of direct steam injection, subtracting the estimated quantity of steam condensate added to that point $(\sim 4.4-\mathrm{kg})$. The liquid mass is calculated from 1$)$ the total slurry volume (at level), 2) the estimated volume fraction of liquid (from wt $\%$ UDS, temperature-corrected liquid density, and the density of remaining solids $[2.8-\mathrm{kg} / \mathrm{L}$ assumed]), and 3) a temperature-corrected liquid density.

$\mathrm{n} / \mathrm{m}$ - not measured 


\subsection{Laboratory-Scale Leach Process Description and Conditions}

For the purpose of scale-up, parallel laboratory-scale tests were performed twice each for Integrated Test A, B, and D conditions:

- Integrated Test A-1: Slurry-caustic mixture from Batch 1 sampled from Tank T01A 10 minutes or more after $\mathrm{NaOH}$ was added and before heat-up.

- Integrated Test A-2: Feed slurry sampled from HLP-VSL-T22 (before $\mathrm{NaOH}$ was added).

- Integrated Test B-1: Slurry-caustic mixture from Batch 2, sampled from Tank T02A at about $71^{\circ} \mathrm{C}$ temperature after in-line $\mathrm{NaOH}$ addition was complete; the filter-loop had been partially flushed into Tank T02A, and Tank T02A had been isolated from the loop and mixed for at least 10 minutes.

- Integrated Test B-2: As for Integrated Test B-1.

- Integrated Test D-1: Slurry-caustic mixture from Batch 2, sampled from Tank T02A at about $59^{\circ} \mathrm{C}$ temperature after in-line $\mathrm{NaOH}$ addition was complete; there had been no filter-loop flush into Tank T02A, and Tank T02A had been isolated from the loop and mixed for at least 5 minutes.

- Integrated Test D-2: As for Integrated Test D-1.

Two 1-L bottles of sample were drawn from PEP to supply each of the laboratory-scale feed batches. The Integrated Test A-1 sample was taken from the inner-middle region of Tank T01A using the Coriolis densitometer (CD) sampler, while the sample for Test A-2 was a grab sample taken from the middle depth (approximately 108 inches from simulant surface) of HLP-VSL-T22. In the case of Integrated Tests B and $\mathrm{D}$, the samples used in laboratory-scale tests were taken from separate 1-L bottles, both of which were collected from the middle-low region of Tank T02A using the CD sampler.

The in-tank sampling system for Tank T02A is shown in Figure 4.5. The systems for Tank T01A and Tank T01B were similar in essentials to the system in Tank T02A. The samples were rapidly cooled to ambient temperature $^{(a)}$ to minimize any further leaching reaction. The laboratory-scale feed was stored at laboratory ambient temperature until it was used. The delay between the time when the feed was acquired from PEP and the time laboratory-scale testing started was about 9 days for Integrated Tests A-1 and A-2 (from January 31, 2009 to February 9, 2009), about 4 days for Integrated Test B (from March 15, 2009 to March 19, 2009), and about 12 days for Integrated Test D (from March 27, 2009 to April 8, 2009).

The slurry feed, distilled water, and, in Integrated Test A-2, $\mathrm{NaOH}$ reagent added in the laboratory was placed in a closed vessel and agitated by an impeller rotating at $120 \mathrm{rpm}$. The distilled water was added before the laboratory-scale leach process to simulate the net addition of condensate in the PEP vessel at the end of the 16-hr leach process. The slurry mixture was then mixed, heated to the digestion temperature, and held there. The temperature was measured with a calibrated thermocouple and controlled using a calibrated temperature controller. More information about the caustic-leach apparatus and procedure may be found in Russell et al. (2009d).

(a) According to an interview with the lead sample handler, for one of the Test B laboratory-scale 1-L samples, rapid cooling proceeded only for about 1 hour before it had to be moved from the cold-water bath to make room in the bath for analytical PEP samples. Cooling of the laboratory-scale 1-L sample was continued by running it under cold water in the sink. 
Table 9.14 through Table 9.16 show the measured experimental parameters for laboratory-scale Integrated Tests A, B, and D, respectively, together with the target values for those parameters. These data are taken from TI-WTP-PEP-075, Rev. 0, Caustic Leaching of Aluminum Solids Test \#A, TI-WTP-PEP-682, Rev. 0, Caustic Leaching of Aluminum Solids Test \#B, and TI-WTP-PEP-684, Rev. 0, Caustic Leaching of Aluminum Solids Test \#D.

Table 9.14. Experimental Parameters for Laboratory-Scale Versions of Integrated Test A

\begin{tabular}{|c|c|c|c|c|}
\hline & $\begin{array}{l}\text { Measured } \\
\text { for A-1 }\end{array}$ & Target for A-1 & $\begin{array}{l}\text { Measured } \\
\text { for A-2 }\end{array}$ & Target for A-2 \\
\hline Mass of slurry from PEP (g) & 684.01 & 684 & 510.01 & 510 \\
\hline Mass of distilled water (g) & 116.04 & $116^{(\mathrm{a})}$ & 124.00 & $124^{(\mathrm{a})}$ \\
\hline Mass of $\mathrm{NaOH}$ reagent $(\mathrm{g})$ & -- & -- & 166.01 & $166^{(\mathrm{a})}$ \\
\hline $\mathrm{NaOH}$ concentration in reagent $(\mathrm{M})$ & -- & -- & $19.2^{(b)}$ & $19.2^{(\mathrm{b})}$ \\
\hline Initial temperature $\left({ }^{\circ} \mathrm{C}\right)$ & 23.2 & ambient & 23.2 & ambient \\
\hline Digestion temperature $\left({ }^{\circ} \mathrm{C}\right)$ & $98.0 \pm 0.20$ & $98^{(a)}$ & $98.0 \pm 0.27$ & $98^{(a)}$ \\
\hline Heat-up time (hr) & $\begin{array}{c}5.3, \text { from } \\
23 \text { to } 98^{\circ} \mathrm{C}^{(\mathrm{c})}\end{array}$ & $\begin{array}{l}4.2, \text { from } \\
57 \text { to } 98^{\circ} \mathrm{C}^{(a)}\end{array}$ & $\begin{array}{c}5.3, \text { from } \\
23 \text { to } 98^{\circ} \mathrm{C}^{(\mathrm{c})}\end{array}$ & $\begin{array}{l}4.2, \text { from } \\
57 \text { to } 98^{\circ} \mathrm{C}^{(a)}\end{array}$ \\
\hline $\begin{array}{l}\text { Digestion time to the nominal } 16-\mathrm{hr} \\
\text { sample }(\mathrm{hr})\end{array}$ & 16.0 & $16.1^{(\mathrm{a})}$ & 16.0 & $16.1^{(\mathrm{a})}$ \\
\hline
\end{tabular}

(a) Indicates values based on the PEP test.

(b) Corresponds to $50.4-\mathrm{wt} \% \mathrm{NaOH}$ in the reagent.

(c) The length of time between $57^{\circ} \mathrm{C}$ and $98^{\circ} \mathrm{C}$ is not recorded in the TI.

Table 9.15. Experimental Parameters for Laboratory-Scale Versions of Integrated Test B

\begin{tabular}{|c|c|c|c|c|}
\hline & $\begin{array}{l}\text { Measured } \\
\text { for B-1 }\end{array}$ & Target for B-1 & $\begin{array}{l}\text { Measured } \\
\text { for B-2 }\end{array}$ & Target for B-2 \\
\hline Mass of slurry from PEP (g) & 669.02 & 669.0 & 669.01 & 669.0 \\
\hline Mass of distilled water (g) & 131.00 & $131.0^{(\mathrm{a})}$ & 131.02 & $131.0^{(\mathrm{a})}$ \\
\hline Mass of $\mathrm{NaOH}$ reagent $(\mathrm{g})$ & -- & -- & -- & -- \\
\hline $\mathrm{NaOH}$ concentration in reagent $(\mathrm{M})$ & -- & -- & -- & -- \\
\hline Initial temperature $\left({ }^{\circ} \mathrm{C}\right)$ & 23.4 & ambient & 23.5 & ambient \\
\hline Digestion temperature $\left({ }^{\circ} \mathrm{C}\right)$ & $98.0 \pm 0.13$ & $98^{(a)}$ & $98.0 \pm 0.11$ & $98^{(a)}$ \\
\hline Heat-up time (hr) & $\begin{array}{c}3.8, \text { from } \\
23 \text { to } 98^{\circ} \mathrm{C}^{(\mathrm{b})}\end{array}$ & $\begin{array}{c}2.6, \text { from } \\
71 \text { to } 98^{\circ} \mathrm{C}^{(a)}\end{array}$ & $\begin{array}{c}3.8, \text { from } \\
23 \text { to } 98^{\circ} \mathrm{C}^{(\mathrm{b})}\end{array}$ & $\begin{array}{c}2.6, \text { from } \\
71 \text { to } 98^{\circ} \mathrm{C}^{(a)}\end{array}$ \\
\hline $\begin{array}{l}\text { Digestion time to the nominal } 16-\mathrm{hr} \\
\text { sample }(\mathrm{hr})\end{array}$ & 16.0 & $16.0^{(\mathrm{a})}$ & 16.4 & $16.0^{(\mathrm{a})}$ \\
\hline
\end{tabular}

(a) Indicates values that were chosen to match those measured in the PEP test.

(b) The length of time between $71^{\circ} \mathrm{C}$ and $98^{\circ} \mathrm{C}$ is not recorded in the TI. 
Table 9.16. Experimental Parameters for Laboratory-Scale Versions of Integrated Test D

\begin{tabular}{|c|c|c|c|c|}
\hline & $\begin{array}{l}\text { Measured } \\
\text { for D-1 }\end{array}$ & $\begin{array}{c}\text { Target for } \\
\text { D-1 }\end{array}$ & $\begin{array}{l}\text { Measured } \\
\text { for D-2 }\end{array}$ & $\begin{array}{l}\text { Target for } \\
\text { D-2 }\end{array}$ \\
\hline Mass of slurry from PEP (g) & 685.02 & 685.0 & 685.01 & 685.0 \\
\hline Mass of distilled water $(\mathrm{g})$ & 115.01 & $115.0^{(\mathrm{a})}$ & 115.01 & $115.0^{(\mathrm{a})}$ \\
\hline Mass of $\mathrm{NaOH}$ reagent $(\mathrm{g})$ & -- & -- & -- & -- \\
\hline $\mathrm{NaOH}$ concentration in reagent $(\mathrm{M})$ & -- & -- & -- & -- \\
\hline Initial temperature $\left({ }^{\circ} \mathrm{C}\right)$ & 23.8 & ambient & 23.8 & ambient \\
\hline Digestion temperature $\left({ }^{\circ} \mathrm{C}\right)$ & $85.0 \pm 0.13$ & $85^{(a)}$ & $85.0 \pm 0.14$ & $85^{(a)}$ \\
\hline Heat-up time (hr) & $\begin{array}{c}1.5, \text { from } \\
72 \text { to } 85^{\circ} \mathrm{C}\end{array}$ & $\begin{array}{c}1.6, \text { from } \\
70 \text { to } 85^{\circ} \mathrm{C}^{(\mathrm{a})}\end{array}$ & $\begin{array}{l}1.4, \text { from } \\
73 \text { to } 85^{\circ} \mathrm{C}\end{array}$ & $\begin{array}{c}1.6, \text { from } \\
70 \text { to } 85^{\circ} \mathrm{C}^{(\mathrm{a})}\end{array}$ \\
\hline Digestion time to the nominal 24-hr sample (hr) & 24.0 & $24.0^{(a)}$ & 24.0 & $24.0^{(\mathrm{a})}$ \\
\hline
\end{tabular}

(a) Indicates values that were chosen to match those measured in the PEP test.

\subsection{Caustic-Leach Performance}

The major data analysis result needed from caustic-leach testing was the scale-up factor for boehmite leaching. Gibbsite leaching is rapid with gibbsite expected to be dissolved by the time the final leach temperature is reached (per observations made by Russell et al. 2009b). Therefore, boehmite leach rates were the main focus of the caustic-leach tests. Aluminum and boehmite leach factors were calculated by more than one method to provide cross-checks.

The tests were completed at the laboratory-scale and in the PEP. Two parallel laboratory-scale caustic leaching tests were performed for one batch from each of the PEP tests. For each of the selected PEP batches, unleached slurry was taken from the PEP caustic leaching vessel and used as feed for both of the corresponding laboratory-scale tests. Sections 9.5.1, 9.5.2, and 9.5.3 cover Integrated Test A, Integrated Test $\mathrm{B}$, and Integrated Test $\mathrm{D}$, respectively.

\subsubsection{Integrated Test A}

The data for Batches 2 through 6 of PEP Integrated Test A were analyzed with the same methods used in Mahoney et al. (2009) to study Batch 1. The analyses of data from laboratory-scale tests A-1 and A-2, which were conducted on slurry from Batch 1, were also reported in that document. As for Batch 1, IC and ICP analytical methods were used to supply the concentrations of metals and anions used in leach factor and kinetic calculations. In Batches 1 and 6, the free $\mathrm{OH}$ measurements were made by $\mathrm{OH}$ titration; in Batches 2 though 5, Raman spectroscopy was used. The concentration and physical properties data from the PEP batches and laboratory tests that were used in leach factor and kinetics calculations can be found in Appendix A, as can sample times and a summary of temperature statistics. 
Figure 9.21 through Figure 9.26 show the bulk concentration dilution trends for Batches 1 through 6 of Integrated Test A. ${ }^{\text {(a) }}$ These values are ratios of the concentrations in the samples to the concentration of the reference sample (the feed before $\mathrm{NaOH}$ was added). The first point on the left represents the reference point and is unity, being the reference concentration divided by itself. The included species are the total $\mathrm{Al}$ in the slurry, total $\mathrm{Sr}$, total $\mathrm{Fe}$, total $\mathrm{Na}$, and bulk concentrations of the liquid tracer species, nitrate $\left(\mathrm{NO}_{3}{ }^{-}\right)$, nitrite $\left(\mathrm{NO}_{2}{ }^{-}\right)$, and chloride $\left(\mathrm{Cl}^{-}\right)$. The liquid-phase concentrations are multiplied by the mass fraction of liquid in the slurry to put them on a bulk-slurry basis.

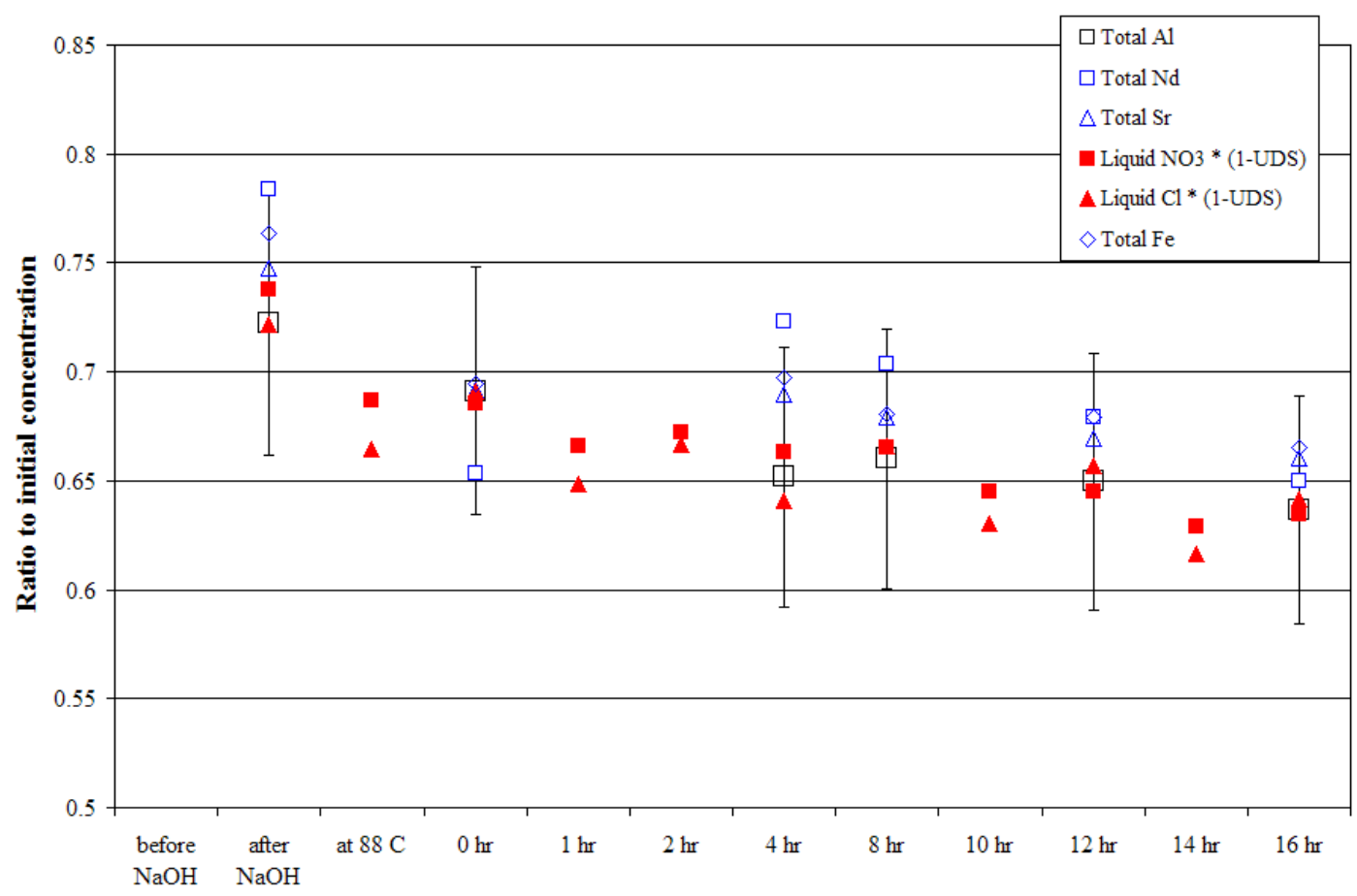

Figure 9.21. Dilution Factors with 95\% Confidence Intervals During Batch 1 of PEP Integrated Test A (caustic leaching in Tank T01A).

(Reproduced from Mahoney et al. (2009) Figure 4.1 with expanded y axis.)

(a) The dilution trend plot for Batch 1 of Test A is Figure 4.1 of Mahoney et al. (2009). The dilution trends for laboratory-scale tests A-1 and A-2 are given in Figure 4.3 of the same document. It was observed that the slurry Al concentration measured in the laboratory beakers was lower than expected, based on the concentration in the PEP slurry. Possible causes of the decrease, and the approach taken to evaluate it, are discussed in Section 4.2 of the document. 


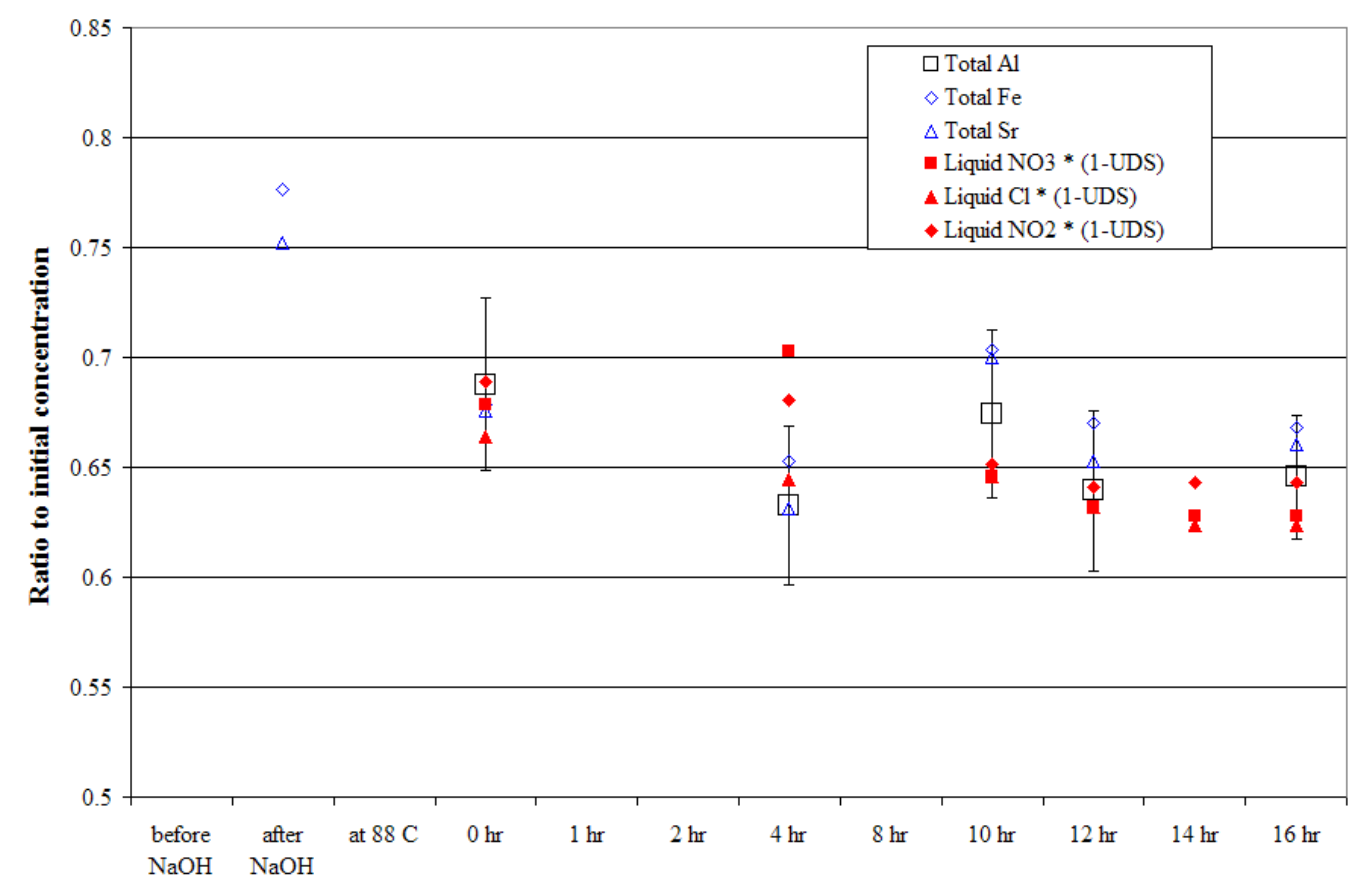

Figure 9.22. Dilution Factors with 95\% Confidence Intervals During Batch 2 of PEP Integrated Test A (caustic leaching in Tank T01B)

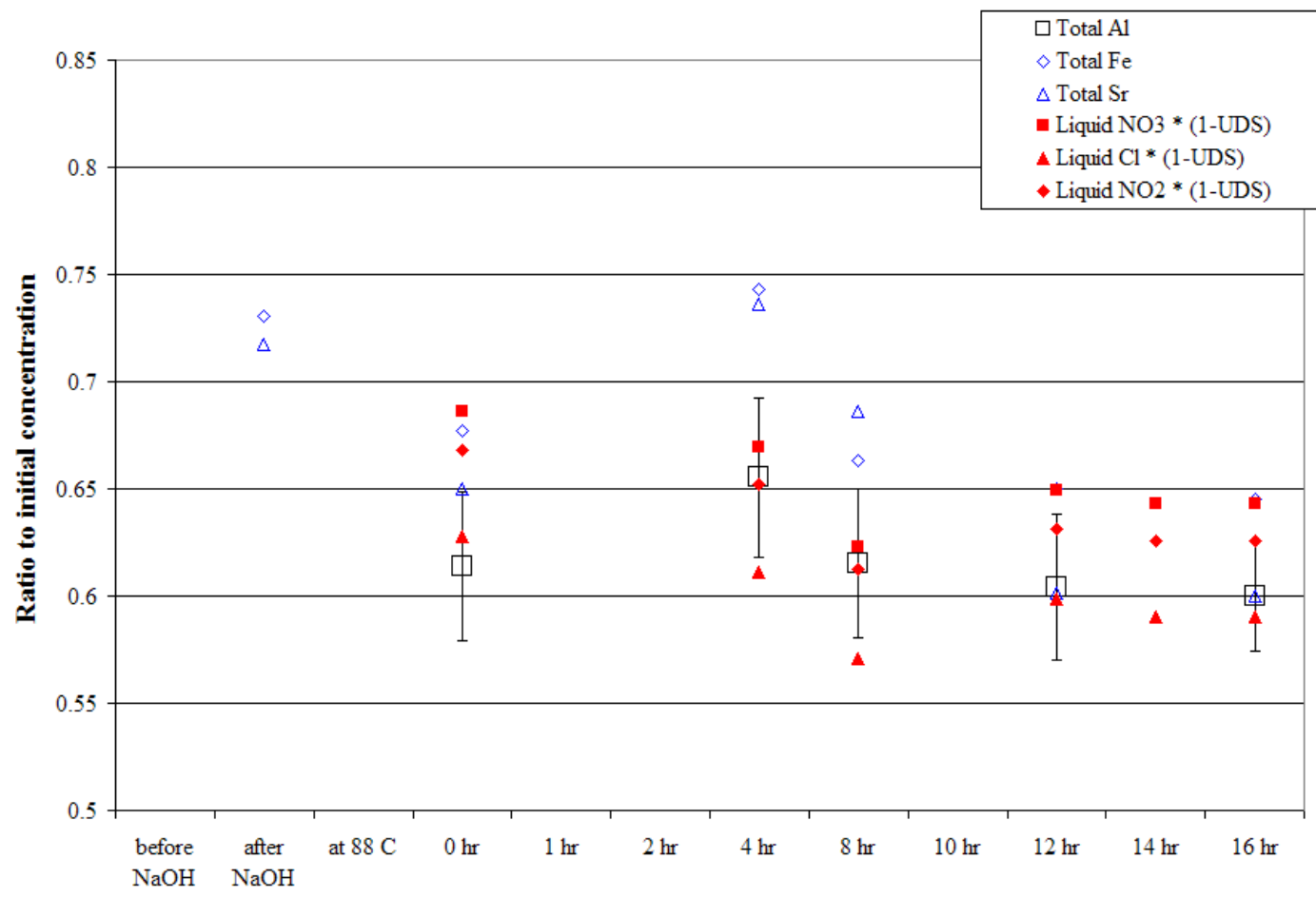

Figure 9.23. Dilution Factors with 95\% Confidence Intervals During Batch 3 of PEP Integrated Test A (caustic leaching in Tank T01A) 


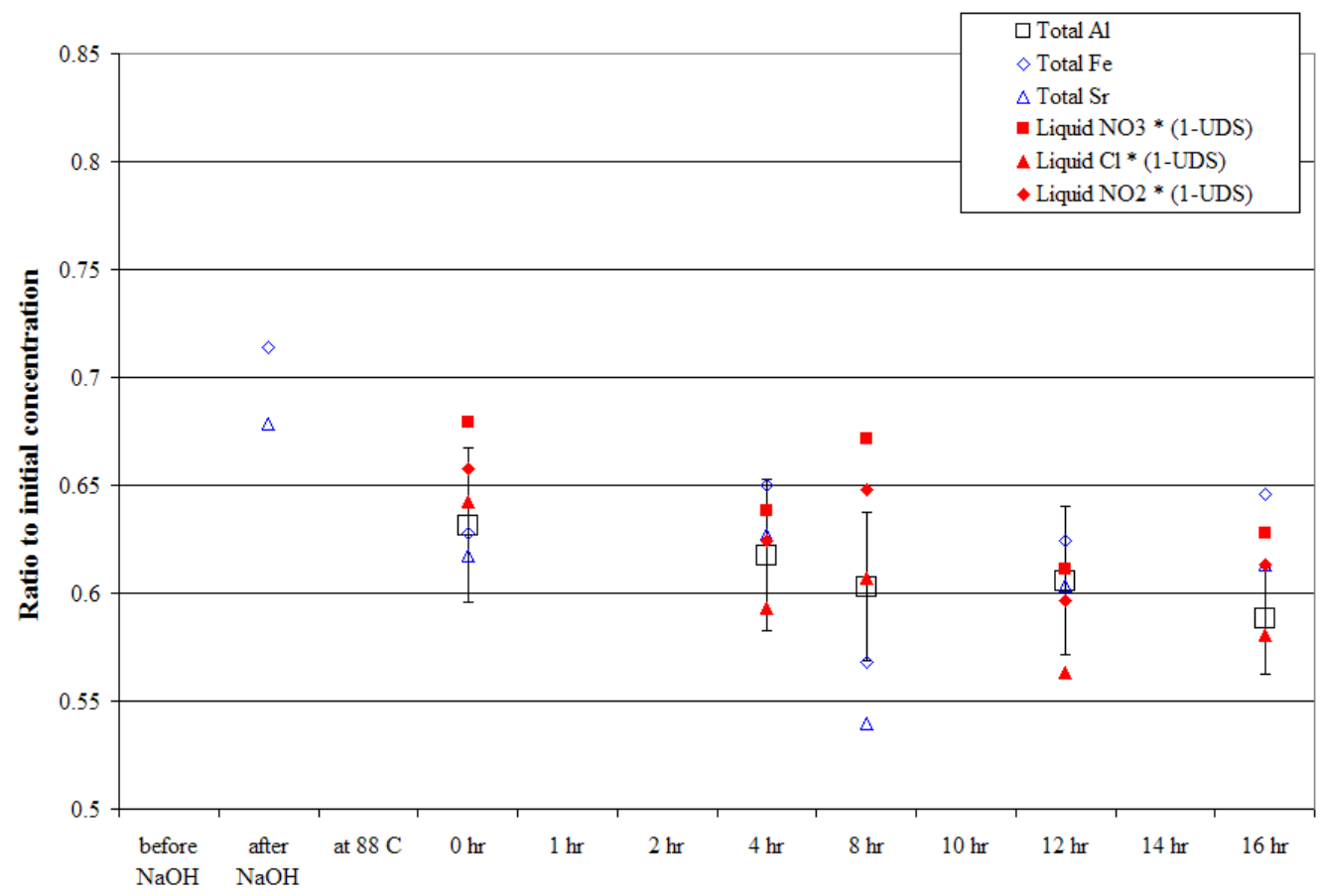

Figure 9.24. Dilution Factors with 95\% Confidence Intervals During Batch 4 of PEP Integrated Test A (caustic leaching in Tank T01B)

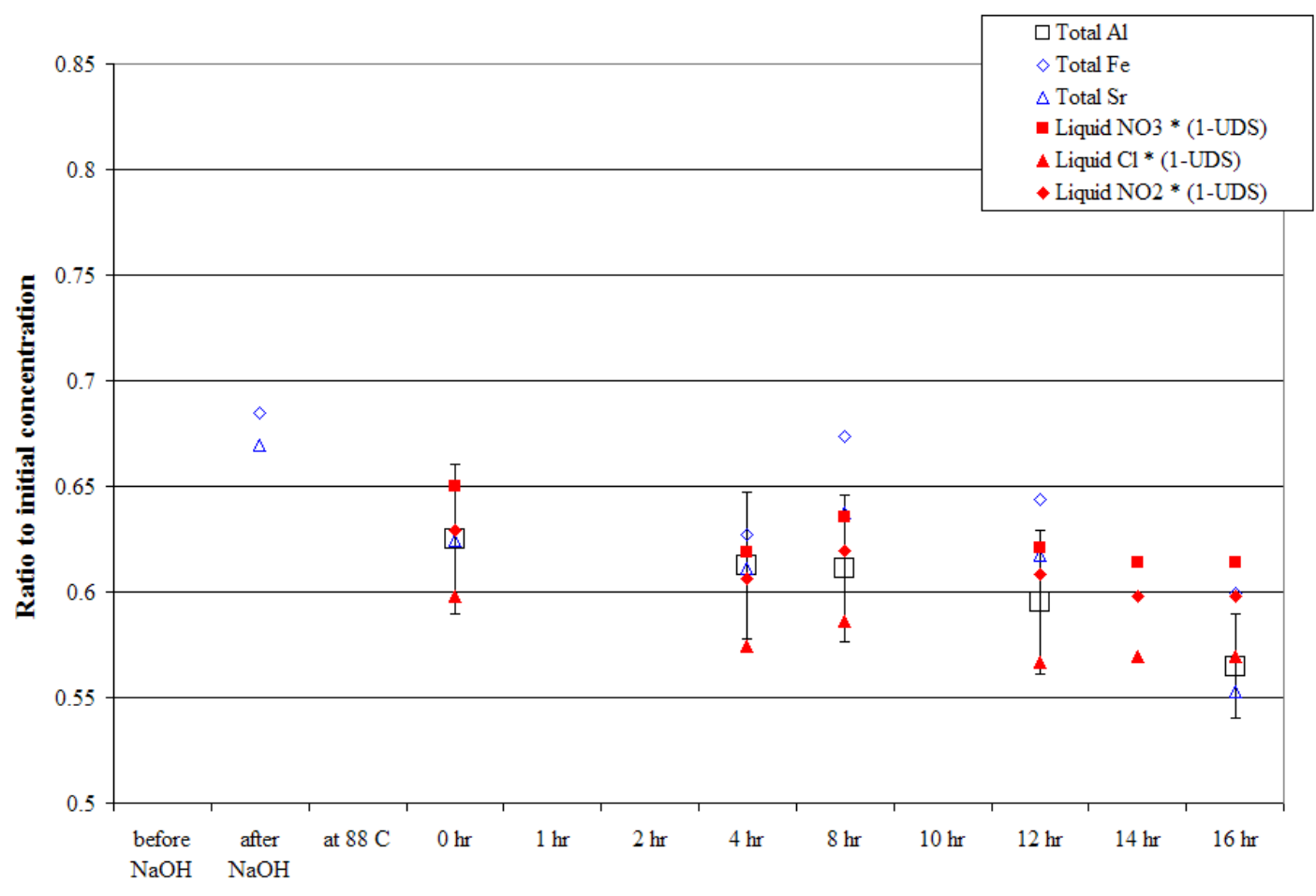

Figure 9.25. Dilution Factors with $95 \%$ Confidence Intervals During Batch 5 of PEP Integrated Test A (caustic leaching in Tank T01A) 


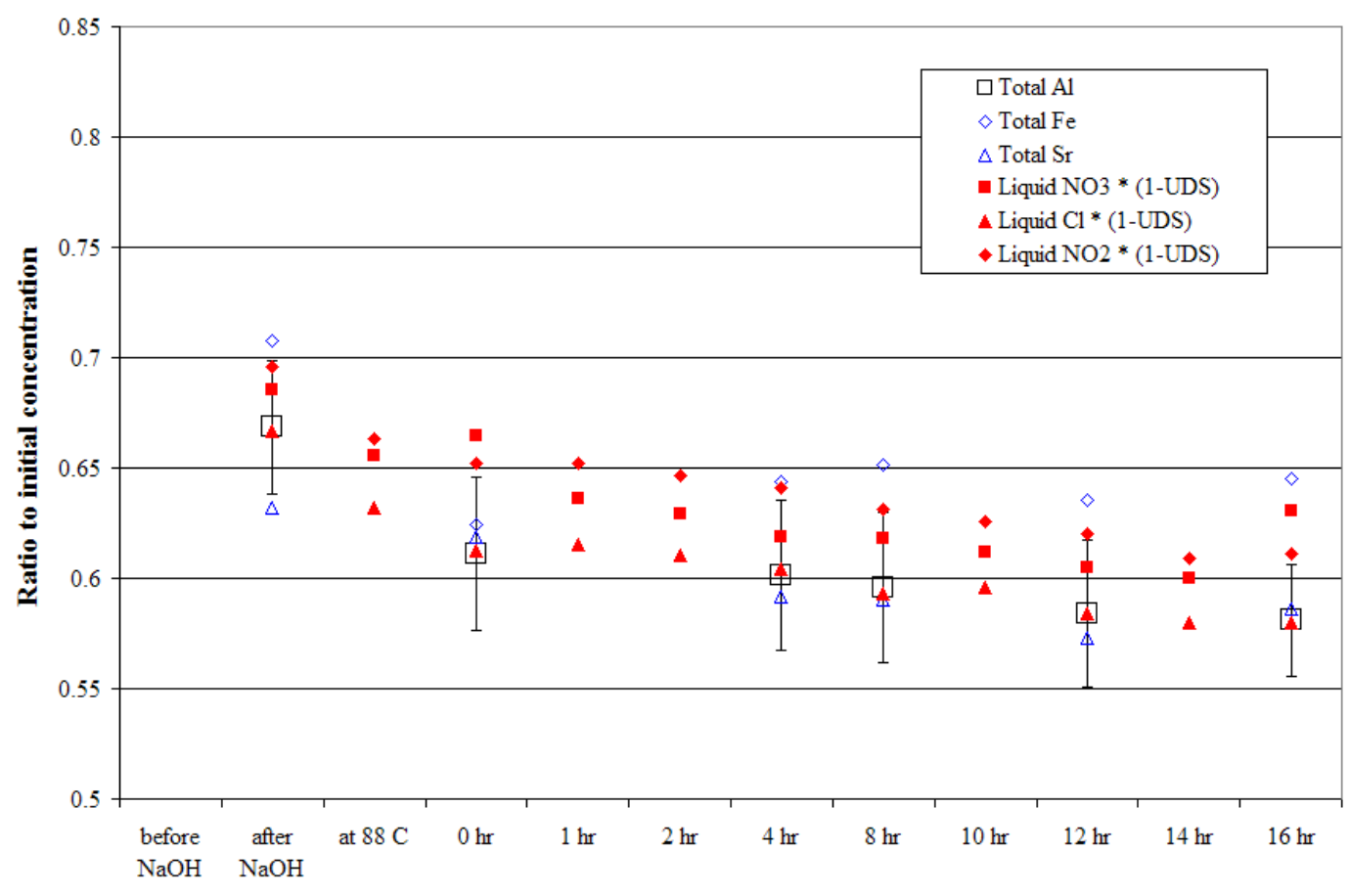

Figure 9.26. Dilution Factors with 95\% Confidence Intervals During Batch 6 of PEP Integrated Test A (caustic leaching in Tank T01B)

In general, the dilution trends are smooth, and the tracer dilution factors lie within the $95 \%$ confidence intervals (error bars on the plots) for the slurry Al factors. The 4-hr samples in Batches 2 and 3 seemed to break away from the trend, and the Al concentration in the 0-hr sample in Batch 3 may be low. If so, this could lead to an overestimate of the boehmite dissolution rate constant.

As was done for data analysis in Mahoney et al. (2009), tracers were selected from those whose dilution trends generally matched the slurry Al trend, although it was not always possible to pick a tracer that matched every point. The chosen tracers were $\mathrm{Cl}^{-}$(liquid tracer) and $\mathrm{Sr}$ (solid tracer) for all batches except Batch 5, where Fe was used instead of Sr. In some cases, there was a separation between the dilution trend for slurry $\mathrm{Al}$ concentration and the trends for liquid and solid tracers. This separation is a sign that there were changes from the reference condition that did not affect all species in the same way. The most likely cause is analytical variability from one analytical batch to another. This change from the before- $\mathrm{NaOH}$ reference condition causes an offset in the dilution ratios and in the set of calculated leach factors, but cancels out in kinetic calculations and does not affect the kinetic rate constant. Noise in the liquid tracer concentration that occurs between 0 hours and the end of leach may affect the rate constant, however. In the following cases, tracer dilution ratios lie outside the $95 \%$ confidence interval of the slurry Al:

- Batch 3: at hours 4 and 8, $\mathrm{Sr}$ and $\mathrm{Cl}$ both diverge from the slurry $\mathrm{Al}$, and in opposite directions.

- Batch 4: at hour 8, Sr diverges, and at hour 12, $\mathrm{Cl}$.

- Batch 5: at hour 4, $\mathrm{Cl}$ diverges, and at hours 8 hours and 12, Fe. 
Batches 2 and 6 both show generally smoother tracer behavior, as did Batch 1 .

The total Al leach factors (based on the amount of $\mathrm{Al}$ leached since before- $\mathrm{NaOH}$ conditions) were calculated using liquid tracer and solid tracer methods (Equation [9.10] and [9.9]). In all cases, the Al leach factor at 0 hours was within one standard deviation of 0.435 , the fraction of the solid-phase $\mathrm{Al}$ in gibbsite in the feed, or was greater. It was therefore reasonable to assume that all the solid-phase $\mathrm{Al}$ that was still present at 0 hours was in the form of boehmite.

The kinetic-modeling data analysis was carried out using the following assumptions and methods:

- Using ratios of liquid tracer concentrations, all dissolved $\mathrm{Al}$ concentrations were normalized to the maximum liquid volume to apply the constant-volume assumption in the kinetic model (see Section A.4 of Mahoney et al. 2009).

- Total hydroxide concentrations ${ }^{(a)}$ were calculated for each point in time, normalized to the maximum liquid volume and averaged to provide the total hydroxide concentration input for the kinetic model.

- Saturated Al concentration in the liquid was calculated from the total hydroxide in the same way described in Section A.4 of Mahoney et al. (2009).

- The initial boehmite concentration ${ }^{(\mathrm{b})}$ for the PEP test was determined by calculating the concentration of solid-phase $\mathrm{Al}$ at 0 hours and assuming that all of it was present as boehmite because all of the gibbsite had dissolved.

- The initial slurry Al concentration in the beaker for the laboratory-scale test was calculated as an average from the concentrations of three independent samples (Table 4.7 and surrounding text in Mahoney et al. 2009).

- The initial boehmite concentration for the laboratory-scale test was determined by assuming that the dissolved $\mathrm{Al}$ at 0 hours consisted of all the gibbsite plus the original simulant supernatant $\mathrm{Al}$. This amount of Al was subtracted from the initial slurry Al concentration to give boehmite Al, as is explained in more detail in Section 4.2.1 of Mahoney et al. (2009). ${ }^{(c)}$

- The temperature used in modeling was a function of time: for the PEP tests, the average over all submerged sensors at 1-minute intervals and for the laboratory-scale tests, an interpolation between the temperatures measured at the times samples were taken.

- The kinetic model (the rate equation in Equation [9.8]) was fit to the dissolved aluminum concentration data using two fitting parameters, the rate constant, $\mathrm{k}$, and an initial dissolved $\mathrm{Al}$ concentration (distinct from the measured value).

(a) The total hydroxide concentration, in molarity units, is the sum of the free hydroxide and one mole of hydroxide per mole of the aluminate ion complex, $\mathrm{Al}(\mathrm{OH}) 4$-. See Equation (A.65) of Mahoney et al. (2009). The normalized total hydroxide concentration is constant over time, assuming the only reaction that affects hydroxide is the aluminum leaching reaction.

(b) The terminology "boehmite concentration" is used for convenience. It is not actually a concentration, but a ratio of moles of solid-phase Al to volume of liquid - in effect, it is the concentration increase in dissolved Al that would be generated if all the boehmite dissolved.

(c) This assumes both that all the gibbsite is dissolved by $0 \mathrm{hr}$ and that none of the boehmite has dissolved before or during heatup. Boehmite dissolution has been observed to be slow at temperatures of $60^{\circ} \mathrm{C}$ or less (Russell et al. 2009a). 
Table 9.17 shows the initial conditions used for the Integrated Test A kinetic calculations. These are the deterministic value \pm one standard deviation as calculated by 500 realizations of the Monte Carlo method. The Monte Carlo calculations used the estimates of laboratory error in measurements as the basis for estimating error in the initial conditions. The fitted initial Al concentrations are shown as well as the measured. In all cases, the fitted initial concentration is nearly equal to the measured value.

Batches 2 through 6 all had higher total hydroxide concentrations than Batch 1. This does not appear to be merely a matter of measuring free hydroxide by Raman spectroscopy rather than titration, as was done for samples from Batches 2 through 5, because Batch 6 (titration) also shows higher hydroxide. All other factors being equal, a higher hydroxide concentration for the same leach factor leads to a lower value for the fitted rate constant.

Table 9.18 and Table 9.19 show the boehmite leach factors that were calculated from the Al leach factors for the PEP batches and for the laboratory-scale tests using liquid tracer and solid tracer methods. The 16-hr boehmite leach factor calculated by the fitted kinetic model is also shown. Recall that the Al leach factors are calculated by comparing data for one leached sample and one "before $\mathrm{NaOH}$ " sample (the reference point), while the fitted kinetic model is based on liquid-phase information for the entire set of data taken during leaching. To some extent, these three types of boehmite leach factors are independent. When the predictions do not match well, it indicates an internal inconsistency in the data.

In Batch 1 at hour four, the liquid tracer and solid tracer estimates of the boehmite leach factor are 0.042 and 0.11 , respectively; they differ by more than one standard deviation. The reason for the difference is not clear from the data (Figure 4.1, Mahoney et al. 2009). However, most of the leach factors from liquid and solid tracers match closely, and the 16-hr prediction of the best-fit kinetic model matches the liquid and solid tracer values.

In Batch 4 at hour eight, the liquid tracer and solid tracer estimates of the boehmite leach factor are 0.23 and 0.15 , respectively. At hour 12 , they are 0.40 and 0.29 . As already noted, the solid tracer diverged from the slurry $\mathrm{Al}$ at hour eight and the liquid tracer diverged at hour 12 . The tracer behavior explains the difference between the boehmite leach factors calculated by the two methods. Both of the tracer methods give boehmite leach factors at hour 16 that agree with the prediction of the best-fit kinetic model.

In Batch 5 at hour four, the liquid tracer and solid tracer estimates of the boehmite leach factor are 0.21 and 0.15 , respectively. The liquid tracer did diverge at hour four, explaining the difference in leach factors. More unexpected is the low value of the 16-hr boehmite leach factor predicted by the best-fit kinetic model, only 0.30 , where the liquid tracer and solid tracer boehmite leach factors are 0.38 and 0.43 . The difference appears to come at least in part from the difference in reference points. The leach factors calculated by the liquid tracer and solid tracer methods are referenced to the unleached condition. The leach factor from the kinetic model is effectively referenced to 0 hours, a point at which the liquid tracer method calculates that a boehmite leach factor of $0.049 \pm 0.047$ may have already existed. The dissolution of a fraction of the boehmite before the leach period proper, possibly because of the temperature spike (up to $108^{\circ} \mathrm{C}$ at some sensors) that began before the 0 -hr sample was taken, would account for part of the lower leach factor calculated by the kinetic model (starting from 0 hours).

Table 9.20 contains population statistics for the scale-up factors for boehmite dissolution rate constants and for the boehmite leach factors at hour 16 of leaching. The statistics were predicted by the 
best-fit kinetic model, using 500 Monte Carlo realizations. The deterministic $\mathrm{R}^{2}$ for the model fit to the normalized dissolved data is also included in the table. The $\mathrm{R}^{2}$ is lower for Batches 3 , 4, and 5, partly because of noise in liquid tracer concentrations in those three batches, as was mentioned earlier. 
Table 9.17. Integrated Test A Initial Conditions for Kinetic Rate Constant Fit

\begin{tabular}{|c|c|c|c|c|c|c|c|c|}
\hline \multirow[b]{2}{*}{$\begin{array}{l}\text { Concentrations at } \\
0 \mathrm{hr} \text {, Normalized to } \\
\text { Liquid Volume at } \\
\text { Maximum Dilution }\end{array}$} & \multicolumn{8}{|c|}{$\begin{array}{l}\text { Integrated Test A Caustic Leaching in Tank T01A/T01B }\left(98^{\circ} \mathrm{C}\right) \\
\text { Value } \pm 1 \text { Standard Deviation }\end{array}$} \\
\hline & $\begin{array}{l}\text { PEP Batch } 1 \\
\quad(\mathrm{~T} 01 \mathrm{~A})\end{array}$ & $\begin{array}{l}\text { PEP Batch } 2 \\
\text { (T01B) }\end{array}$ & $\begin{array}{l}\text { PEP Batch } 3 \\
\text { (T01A) }\end{array}$ & $\begin{array}{l}\text { PEP Batch } 4 \\
\text { (T01B) }\end{array}$ & $\begin{array}{l}\text { PEP Batch } 5 \\
\text { (T01A) }\end{array}$ & $\begin{array}{l}\text { PEP Batch } 6 \\
\text { (T01B) }\end{array}$ & $\begin{array}{l}\text { Laboratory- } \\
\text { Scale Test A-1 } \\
\text { (NaOH added } \\
\text { in PEP) }\end{array}$ & $\begin{array}{c}\text { Laboratory- } \\
\text { Scale Test A-2 } \\
\text { (NaOH added } \\
\text { in beaker) }\end{array}$ \\
\hline $\begin{array}{l}\text { Measured initial } \\
\text { dissolved } \mathrm{Al}(\mathrm{M})\end{array}$ & $0.318 \pm 0.010$ & $0.321 \pm 0.015$ & $0.301 \pm 0.014$ & $0.296 \pm 0.015$ & $0.299 \pm 0.014$ & $0.308 \pm 0.015$ & $0.321 \pm 0.017$ & $0.279 \pm 0.016$ \\
\hline $\begin{array}{l}\text { Fitted initial } \\
\text { dissolved } \mathrm{Al}(\mathrm{M})\end{array}$ & $0.312 \pm 0.008$ & $0.316 \pm 0.013$ & $0.306 \pm 0.012$ & $0.302 \pm 0.013$ & $0.305 \pm 0.012$ & $0.307 \pm 0.013$ & $0.312 \pm 0.010$ & $0.287 \pm 0.010$ \\
\hline $\begin{array}{l}\text { Total hydroxide } \\
\text { (M) }\end{array}$ & $4.29 \pm 0.11$ & $4.50 \pm 0.16$ & $4.76 \pm 0.17$ & $5.13 \pm 0.19$ & $5.07 \pm 0.20$ & $4.68 \pm 0.11$ & $4.04 \pm 0.14$ & $3.88 \pm 0.13$ \\
\hline $\begin{array}{l}\text { Initial saturated } \\
\mathrm{Al} \text { at temperature } \\
\text { (M) }\end{array}$ & $0.859 \pm 0.028$ & $0.897 \pm 0.040$ & $0.954 \pm 0.045$ & $1.06 \pm 0.05$ & $1.10 \pm 0.06$ & $0.936 \pm 0.029$ & $0.788 \pm 0.030$ & $0.753 \pm 0.028$ \\
\hline $\begin{array}{l}\text { Initial moles } \\
\text { boehmite/liters } \\
\text { liquid volume }\end{array}$ & $0.306 \pm 0.011$ & $0.310 \pm 0.016$ & $0.260 \pm 0.013$ & $0.265 \pm 0.013$ & $0.282 \pm 0.014$ & $0.261 \pm 0.013$ & $0.192 \pm 0.021$ & $0.239 \pm 0.019$ \\
\hline
\end{tabular}

Entries are deterministic estimate \pm one standard deviation calculated by 500 Monte Carlo realizations. Estimates of laboratory error in measurements were the basis for estimating error in the initial conditions. 
Table 9.18. Integrated Test A Boehmite Leach Factors Using Liquid Tracers

\begin{tabular}{|c|c|c|c|c|c|c|c|c|}
\hline \multirow[b]{2}{*}{$\begin{array}{l}\text { Point in } \\
\text { Process }\end{array}$} & \multicolumn{8}{|c|}{$\begin{array}{c}\text { Integrated Test A Caustic Leaching in Tank T01A/T01B }\left(98^{\circ} \mathrm{C}\right) \\
\text { Boehmite Leach Factor } \pm 1 \text { Standard Deviation }\end{array}$} \\
\hline & $\begin{array}{l}\text { PEP Batch } 1 \\
(\text { Tank T01A) }\end{array}$ & $\begin{array}{l}\text { PEP Batch } 2 \\
\text { (Tank T01B) }\end{array}$ & $\begin{array}{l}\text { PEP Batch } 3 \\
(\text { Tank T01A) }\end{array}$ & $\begin{array}{l}\text { PEP Batch } 4 \\
\text { (Tank T01B) }\end{array}$ & $\begin{array}{l}\text { PEP Batch } 5 \\
\text { (Tank T01A) }\end{array}$ & $\begin{array}{l}\text { PEP Batch } 6 \\
\text { (Tank T01B) }\end{array}$ & $\begin{array}{c}\text { Laboratory- } \\
\text { Scale Test A-1 } \\
\text { (NaOH added in } \\
\text { PEP) }\end{array}$ & $\begin{array}{c}\text { Laboratory- } \\
\text { Scale Test A-2 } \\
\text { (NaOH added in } \\
\text { beaker) }\end{array}$ \\
\hline $0 \mathrm{hr}$ & $0 \pm 0.023$ & $0.024 \pm 0.040$ & $0.021 \pm 0.04$ & $0.009 \pm 0.035$ & $0.049 \pm 0.047$ & $0.054 \pm 0.048$ & $0^{(\mathrm{a})}$ & $0^{(\mathrm{a})}$ \\
\hline $1 \mathrm{hr}$ & $0 \pm 0.029$ & $\mathrm{n} / \mathrm{m}$ & $\mathrm{n} / \mathrm{m}$ & $\mathrm{n} / \mathrm{m}$ & $\mathrm{n} / \mathrm{m}$ & $0.044 \pm 0.046$ & $-0.04 \pm 0.11$ & $0.07 \pm 0.07$ \\
\hline $2 \mathrm{hr}$ & $0.045 \pm 0.046$ & $\mathrm{n} / \mathrm{m}$ & $\mathrm{n} / \mathrm{m}$ & $\mathrm{n} / \mathrm{m}$ & $\mathrm{n} / \mathrm{m}$ & $0.078 \pm 0.053$ & $-0.04 \pm 0.11$ & $0.07 \pm 0.07$ \\
\hline $4 \mathrm{hr}$ & $0.042 \pm 0.045$ & $0.085 \pm 0.053$ & $0.13 \pm 0.06$ & $0.17 \pm 0.06$ & $0.21 \pm 0.06$ & $0.13 \pm 0.06$ & $0.09 \pm 0.10$ & $-0.04 \pm 0.07$ \\
\hline $8 \mathrm{hr}$ & $0.16 \pm 0.06$ & $\mathrm{n} / \mathrm{m}$ & $0.28 \pm 0.06$ & $0.23 \pm 0.06$ & $0.24 \pm 0.06$ & $0.25 \pm 0.06$ & $0.17 \pm 0.10$ & $0.22 \pm 0.08$ \\
\hline $10 \mathrm{hr}$ & $0.19 \pm 0.06$ & $0.25 \pm 0.06$ & $\mathrm{n} / \mathrm{m}$ & $\mathrm{n} / \mathrm{m}$ & $\mathrm{n} / \mathrm{m}$ & $0.28 \pm 0.07$ & $0.16 \pm 0.10$ & $0.27 \pm 0.08$ \\
\hline $12 \mathrm{hr}$ & $0.25 \pm 0.07$ & $0.26 \pm 0.06$ & $0.28 \pm 0.07$ & $0.40 \pm 0.07$ & $0.34 \pm 0.07$ & $0.34 \pm 0.07$ & $0.22 \pm 0.11$ & $0.28 \pm 0.08$ \\
\hline $14 \mathrm{hr}$ & $0.25 \pm 0.07$ & $\mathrm{n} / \mathrm{m}$ & $\mathrm{n} / \mathrm{m}$ & $\mathrm{n} / \mathrm{m}$ & $\mathrm{n} / \mathrm{m}$ & $0.38 \pm 0.07$ & $0.30 \pm 0.11$ & $0.31 \pm 0.08$ \\
\hline $16 \mathrm{hr}$ & $0.32 \pm 0.05$ & $0.36 \pm 0.05$ & $0.35 \pm 0.05$ & $0.38 \pm 0.05$ & $0.38 \pm 0.05$ & $0.40 \pm 0.05$ & $0.30 \pm 0.11$ & $0.33 \pm 0.08$ \\
\hline $18 \mathrm{hr}$ & $\mathrm{n} / \mathrm{m}$ & $\mathrm{n} / \mathrm{m}$ & $\mathrm{n} / \mathrm{m}$ & $\mathrm{n} / \mathrm{m}$ & $\mathrm{n} / \mathrm{m}$ & $\mathrm{n} / \mathrm{m}$ & $0.30 \pm 0.11$ & $0.31 \pm 0.08$ \\
\hline $20 \mathrm{hr}$ & $\mathrm{n} / \mathrm{m}$ & $\mathrm{n} / \mathrm{m}$ & $\mathrm{n} / \mathrm{m}$ & $\mathrm{n} / \mathrm{m}$ & $\mathrm{n} / \mathrm{m}$ & $\mathrm{n} / \mathrm{m}$ & $0.38 \pm 0.11$ & $0.39 \pm 0.08$ \\
\hline $22 \mathrm{hr}$ & $\mathrm{n} / \mathrm{m}$ & $\mathrm{n} / \mathrm{m}$ & $\mathrm{n} / \mathrm{m}$ & $\mathrm{n} / \mathrm{m}$ & $\mathrm{n} / \mathrm{m}$ & $\mathrm{n} / \mathrm{m}$ & $0.44 \pm 0.11$ & $0.43 \pm 0.08$ \\
\hline $24 \mathrm{hr}$ & $\mathrm{n} / \mathrm{m}$ & $\mathrm{n} / \mathrm{m}$ & $\mathrm{n} / \mathrm{m}$ & $\mathrm{n} / \mathrm{m}$ & $\mathrm{n} / \mathrm{m}$ & $\mathrm{n} / \mathrm{m}$ & $0.44 \pm 0.11$ & $0.46 \pm 0.09$ \\
\hline $\begin{array}{l}16 \mathrm{hr} \text {, calc. } \\
\text { by kinetic } \\
\text { model }\end{array}$ & $0.33 \pm 0.05$ & $0.32 \pm 0.06$ & $0.36 \pm 0.07$ & $0.41 \pm 0.08$ & $0.30 \pm 0.07$ & $0.37 \pm 0.07$ & $0.35 \pm 0.08$ & $0.31 \pm 0.06$ \\
\hline $\begin{array}{l}\text { The factors } \mathrm{w} \\
\text { model calcula } \\
\text { (a) The boeh } \\
\text { " } \mathrm{n} / \mathrm{m} \text { " = not } \mathrm{n}\end{array}$ & $\begin{array}{l}\text { alculated usin } \\
\text { which was bo } \\
\text { leach factor is } \\
\text { ured }\end{array}$ & $\begin{array}{l}\text { on } 500 \text { realiz } \\
\text { umed to be ze }\end{array}$ & $\begin{array}{l}\text { it } 0 \text { hours. } \\
\text { istimate }\end{array}$ & laboratory & measurem & $\begin{array}{l}5000 \text { Monte } \\
\text { ere the basis } f\end{array}$ & $\begin{array}{l}\text { realizations }(\mathrm{ex} \\
\text { timating uncerts }\end{array}$ & $\begin{array}{l}\text { pt for the kinetic } \\
y \text { in the results. }\end{array}$ \\
\hline
\end{tabular}


Table 9.19. Integrated Test A Boehmite Leach Factors Using Solid Tracers

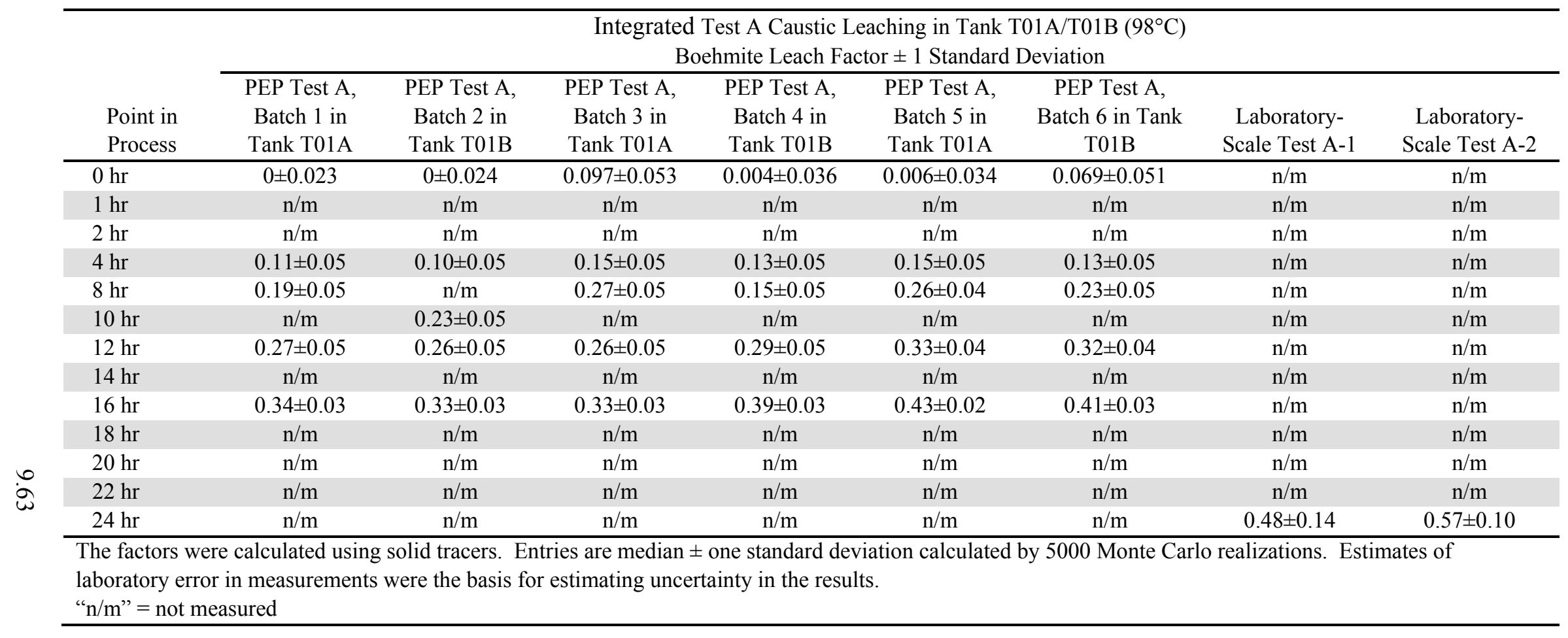


Table 9.20. Scale-Up Factors and Related Leach Information for PEP Integrated Test A and Parallel Laboratory Tests

\begin{tabular}{|c|c|c|c|c|c|c|c|c|}
\hline & \multicolumn{8}{|c|}{ Integrated Test A Caustic Leaching in Tank T01A/T01B $\left(98^{\circ} \mathrm{C}\right)$} \\
\hline & $\begin{array}{l}\text { PEP Batch } 1 \\
\text { (T01A) }\end{array}$ & $\begin{array}{l}\text { PEP Batch } 2 \\
\text { (T01B) }\end{array}$ & $\begin{array}{l}\text { PEP Batch } 3 \\
\text { (T01A) }\end{array}$ & $\begin{array}{l}\text { PEP Batch } 4 \\
\text { (T01B) }\end{array}$ & $\begin{array}{l}\text { PEP Batch } 5 \\
\text { (T01A) }\end{array}$ & $\begin{array}{l}\text { PEP Batch } 6 \\
\text { (T01B) }\end{array}$ & $\begin{array}{c}\text { Laboratory-Scale } \\
\text { Test A-1 (NaOH } \\
\text { added in PEP) }\end{array}$ & $\begin{array}{l}\text { Laboratory-Scale } \\
\text { Test } \mathrm{A}-2(\mathrm{NaOH} \\
\text { added in beaker })\end{array}$ \\
\hline $\begin{array}{l}\text { Scale-up factor, } \\
k_{P E P} / k_{\text {lab }}\end{array}$ & $\mathrm{n} / \mathrm{a}$ & $\begin{array}{l}\text { Batch } 2 \text { not } \\
\text { used for scale- } \\
\text { up }\end{array}$ & $\begin{array}{l}\text { Batch } 3 \text { not } \\
\text { used for scale- } \\
\text { up }\end{array}$ & $\begin{array}{l}\text { Batch } 4 \text { not } \\
\text { used for scale- } \\
\text { up }\end{array}$ & $\begin{array}{l}\text { Batch } 5 \text { not } \\
\text { used for scale- } \\
\text { up }\end{array}$ & $\begin{array}{l}\text { Batch } 6 \text { not } \\
\text { used for } \\
\text { scale-up }\end{array}$ & $\begin{array}{l}\text { low 95\%: } 0.44 \\
\text { low 50\%: } 0.64 \\
\text { median: } 0.79 \\
\text { high 50\%: } 0.97 \\
\text { high 95\%: } 1.45\end{array}$ & $\begin{array}{l}\text { low 95\%: } 0.55 \\
\text { low 50\%: } 0.78 \\
\text { median: } 0.95 \\
\text { high 50\%: } 1.15 \\
\text { high } 95 \%: 1.64\end{array}$ \\
\hline $\begin{array}{l}\text { Rate constant } k \\
\left(\mathrm{hr}^{-1} *[\mathrm{~mol} \text { total }\right. \\
\left.\mathrm{OH} / \mathrm{L}]^{-1}\right)\end{array}$ & $\begin{array}{l}\text { low } 95 \% \text { : } \\
0.0128 \\
\text { low } 50 \% \text { : } \\
0.0165 \\
\text { median: } 0.0186 \\
\text { high } 50 \% \text { : } \\
0.0206 \\
\text { high } 95 \% \text { : } \\
0.0250\end{array}$ & $\begin{array}{l}\text { low } 95 \% \text { : } \\
0.0102 \\
\text { low } 50 \% \text { : } \\
0.0144 \\
\text { median: } \\
0.0167 \\
\text { high } 50 \% \text { : } \\
0.0189 \\
\text { high } 95 \% \text { : } \\
0.0242\end{array}$ & $\begin{array}{l}\text { low } 95 \% \text { : } \\
0.0092 \\
\text { low } 50 \% \text { : } \\
0.0134 \\
\text { median: } \\
0.0161 \\
\text { high } 50 \% \text { : } \\
0.0185 \\
\text { high } 95 \% \text { : } \\
0.0246\end{array}$ & $\begin{array}{l}\text { low } 95 \% \text { : } \\
0.0096 \\
\text { low } 50 \% \text { : } \\
0.0131 \\
\text { median: } \\
0.0152 \\
\text { high } 50 \% \text { : } \\
0.0179 \\
\text { high } 95 \% \text { : } \\
0.0235\end{array}$ & $\begin{array}{l}\text { low } 95 \% \text { : } \\
0.0058 \\
\text { low } 50 \% \text { : } \\
0.0094 \\
\text { median: } \\
0.0104 \\
\text { high } 50 \% \text { : } \\
0.0125 \\
\text { high } 95 \% \text { : } \\
0.0162\end{array}$ & $\begin{array}{l}\text { low } 95 \% \text { : } \\
0.0103 \\
\text { low } 50 \% \text { : } \\
0.0144 \\
\text { median: } \\
0.0169 \\
\text { high } 50 \% \text { : } \\
0.0192 \\
\text { high } 95 \% \text { : } \\
0.0247\end{array}$ & $\begin{array}{l}\text { low } 95 \% \text { : } \\
0.0144 \\
\text { low } 50 \% \text { : } \\
0.0195 \\
\text { median: } \\
0.0227 \\
\text { high } 50 \% \text { : } \\
0.0279 \\
\text { high } 95 \% \text { : } \\
0.0384\end{array}$ & $\begin{array}{l}\text { low 95\%: } \\
0.0126 \\
\text { low } 50 \% \text { : } \\
0.0168 \\
\text { median: } \\
0.0194 \\
\text { high } 50 \% \text { : } \\
0.0224 \\
\text { high } 95 \% \text { : } \\
0.0298\end{array}$ \\
\hline $\begin{array}{l}\text { Boehmite leach } \\
\text { factor at } 16 \text { hours } \\
\text { as predicted by } \\
\text { the best-fit kinetic } \\
\text { model }\end{array}$ & $\begin{array}{l}\text { lower 95\%: } \\
0.23 \\
\text { median: } \\
0.33 \\
\text { upper 95\%: } \\
0.41\end{array}$ & $\begin{array}{l}\text { lower } 95 \% \text { : } \\
0.21 \\
\text { median: } \\
0.32 \\
\text { upper } 95 \% \text { : } \\
0.44\end{array}$ & $\begin{array}{l}\text { lower } 95 \% \text { : } \\
0.22 \\
\text { median: } \\
0.36 \\
\text { upper } 95 \% \text { : } \\
0.59\end{array}$ & $\begin{array}{l}\text { lower 95\%: } \\
0.27 \\
\text { median: } \\
0.41 \\
\text { upper } 95 \% \text { : } \\
0.57\end{array}$ & $\begin{array}{l}\text { lower } 95 \% \text { : } \\
0.16 \\
\text { median: } \\
0.30 \\
\text { upper } 95 \% \text { : } \\
0.44\end{array}$ & $\begin{array}{l}\text { lower 95\% } \\
0.24 \\
\text { median: } \\
0.37 \\
\text { upper 95\%: } \\
0.52\end{array}$ & $\begin{array}{l}\text { lower } 95 \%: 0.22 \\
\text { median: } 0.35 \\
\text { upper } 95 \%: 0.54\end{array}$ & $\begin{array}{l}\text { lower } 95 \%: 0.20 \\
\text { median: } 0.31 \\
\text { upper } 95 \%: 0.43\end{array}$ \\
\hline $\begin{array}{l}\text { Deterministic } \mathrm{R}^{2} \\
\text { for the kinetic } \\
\text { model fit }\end{array}$ & 0.977 & 0.980 & 0.933 & 0.932 & 0.958 & 0.994 & 0.965 & 0.971 \\
\hline
\end{tabular}


The median rate constants for five of the six batches (Batches 1 through 4 and Batch 6) are close in value, ranging from a maximum of $0.0186 \mathrm{hr}^{-1} *(\mathrm{~mol} \text { total } \mathrm{OH} / \mathrm{L})^{-1}$ to a minimum of $0.0152 \mathrm{hr}^{-1} *(\mathrm{~mol}$ total $\mathrm{OH} / \mathrm{L})^{-1}$. The rate constant for Batch 2 is equal to the arithmetic average of the five constants, and the five constants all fall within the 50\% confidence interval for Batch 2 -a closer grouping than might have been expected from the calculated uncertainty. This result implies that there is a probability of $50 \%$ or less that the rate constants for the five batches differ from each other. The rate constant for Batch 5 is about a third lower than the lowest value for the other five batches; however, this batch cannot be considered representative because of the high temperature spike at the beginning of the constant-temperature leach.

There is no sign of a systematic difference in rate constants between Batches 1 and 3 and Batches 2, 4, and 6. These sets of batches were distinguished by different methods of $\mathrm{NaOH}$ addition: $100 \%$ of the reagent added in-line, for Batches 1 and 3 in Tank T01A, versus $80 \%$ added in-line and $20 \%$ at the vessel top, for Batches 2, 4, and 6 in Tank T01B. The two methods of $\mathrm{NaOH}$ addition do not produce perceptibly different outcomes.

The 16-hr boehmite leach factor for Integrated Test A, Batch 1 is 0.33 as predicted by the best-fit kinetic model, 0.32 as calculated from the liquid tracer $\mathrm{Al}$ leach factor, and 0.34 as calculated from the solid tracer Al leach factor. This indicates more leaching than was expected from the WTP target projection $^{(a)}$ of 0.28 for the 16-hr boehmite leach factor for PEP Integrated Test A. The two values are separated by about one standard deviation of the kinetic model prediction population.

For a cross-check, the Al mass-balance data for Integrated Test A that are given in Table 12.2 were used to calculate a leach factor over the entire process. The total Al inflows were 169.2-kg solid-phase and $27.7-\mathrm{kg}$ liquid-phase, while the outflows were $59.8 \mathrm{-kg}$ solid-phase and 129.8-kg liquid-phase. Assuming that $43.5 \%$ of the initial solid-phase Al was in gibbsite, the overall change in solid-phase Al implied a boehmite leach factor of 0.37 , while the overall change in liquid-phase Al implied a boehmite leach factor of 0.30. These overall leach factors are consistent with the batch leach factors in Table 9.18 and Table 9.19.

The median scale-up factor for (Batch 1/Test A-1) is 0.79 , and the median for (Batch 1/Test A-2) is 0.95 . The probability that the scale-up factor is unity or greater is about $21 \%$ for Integrated Test $A /$ Test A-1 and $43 \%$ for Integrated Test A/Test A-2.

\subsubsection{Integrated Test B}

The data for Batch 1 of PEP Integrated Test B were analyzed with the same methods used in Mahoney et al. (2009) to study Batch 2. The analyses of data from laboratory-scale Tests B-1 and B-2, which were conducted on slurry from Batch 2, were also reported in that document. The data used in leach factor and kinetic calculations for both batches included metals measured by ICP, anions by IC, and free hydroxide measured by $\mathrm{OH}$ titration. The concentration and physical properties data from the PEP

(a) The boehmite leach factor was projected by WTP and transmitted to DE Kurath and LA Mahoney by e-mail from JL Huckaby on June 15, 2009 (6:25 AM). The projection was made using Equation (9.8), a rate constant of $0.015 \mathrm{hr}-1 *(\mathrm{~mol}$ total $\mathrm{OH} / \mathrm{L}$ )-1 that had been determined from preliminary laboratory tests, and run sheet values for simulant, condensate, and reagent volumes. 
batches and laboratory tests that were used in leach factor and kinetics calculations can be found in Appendix A, as can sample times and a summary of temperature statistics.

Figure 9.27 and Figure 9.28 show the bulk concentration dilution trends for Batches 1 and 2 of PEP Integrated Test $\mathrm{B} .{ }^{(a)}$ These values are ratios of the concentrations in the samples to the concentration of the reference sample (the solids-concentrated feed before $\mathrm{NaOH}$ was added). The first point on the left represents the reference point and is unity, being the reference concentration divided by itself. The included species are the total $\mathrm{Al}$ in the slurry, total $\mathrm{Sr}$, total $\mathrm{Fe}$, total $\mathrm{Na}$, and bulk concentrations of the liquid tracer species, nitrate $\left(\mathrm{NO}_{3}{ }^{-}\right)$, nitrite $\left(\mathrm{NO}_{2}{ }^{-}\right)$, and chloride $\left(\mathrm{Cl}^{-}\right)$. The liquid-phase concentrations are multiplied by the mass fraction of liquid in the slurry to put them on a bulk-slurry basis.

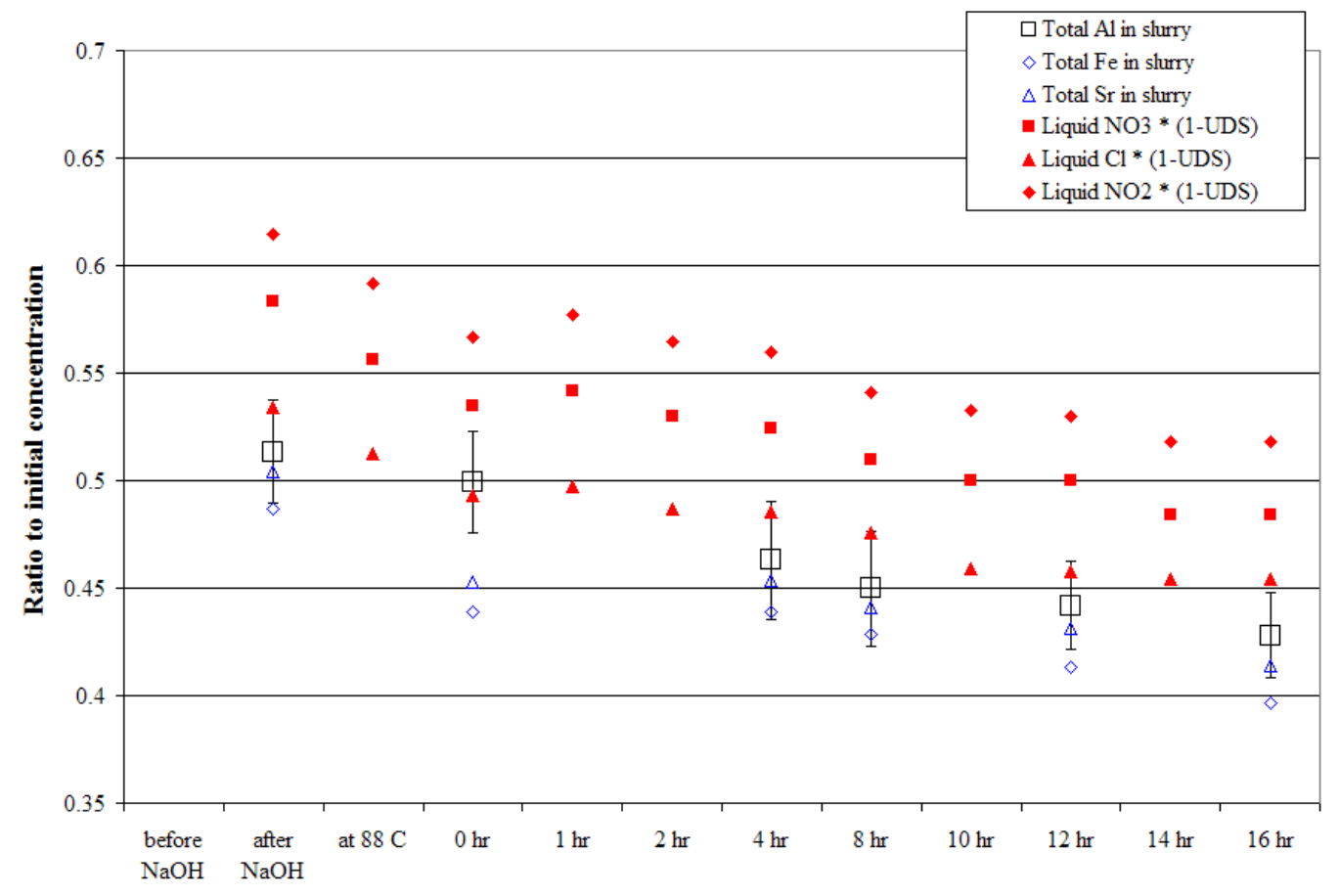

Figure 9.27. Dilution Factors with 95\% Confidence Intervals During Batch 1 of PEP Integrated Test B (caustic leaching in Tank T02A, $98^{\circ} \mathrm{C}$ )

(a) The dilution trend plot for Batch 2 of Test B is Figure 4.2 of WTP-RPT-186. The dilution trends for laboratory-scale tests B-1 and B-2 are given in Figure 4.4 of the same document. It was observed that the slurry Al concentration measured in the laboratory beakers was lower than expected, based on the concentration in the PEP slurry. Possible causes of the decrease, and the approach taken to evaluate it, are discussed in Section 4.2 of the document. 


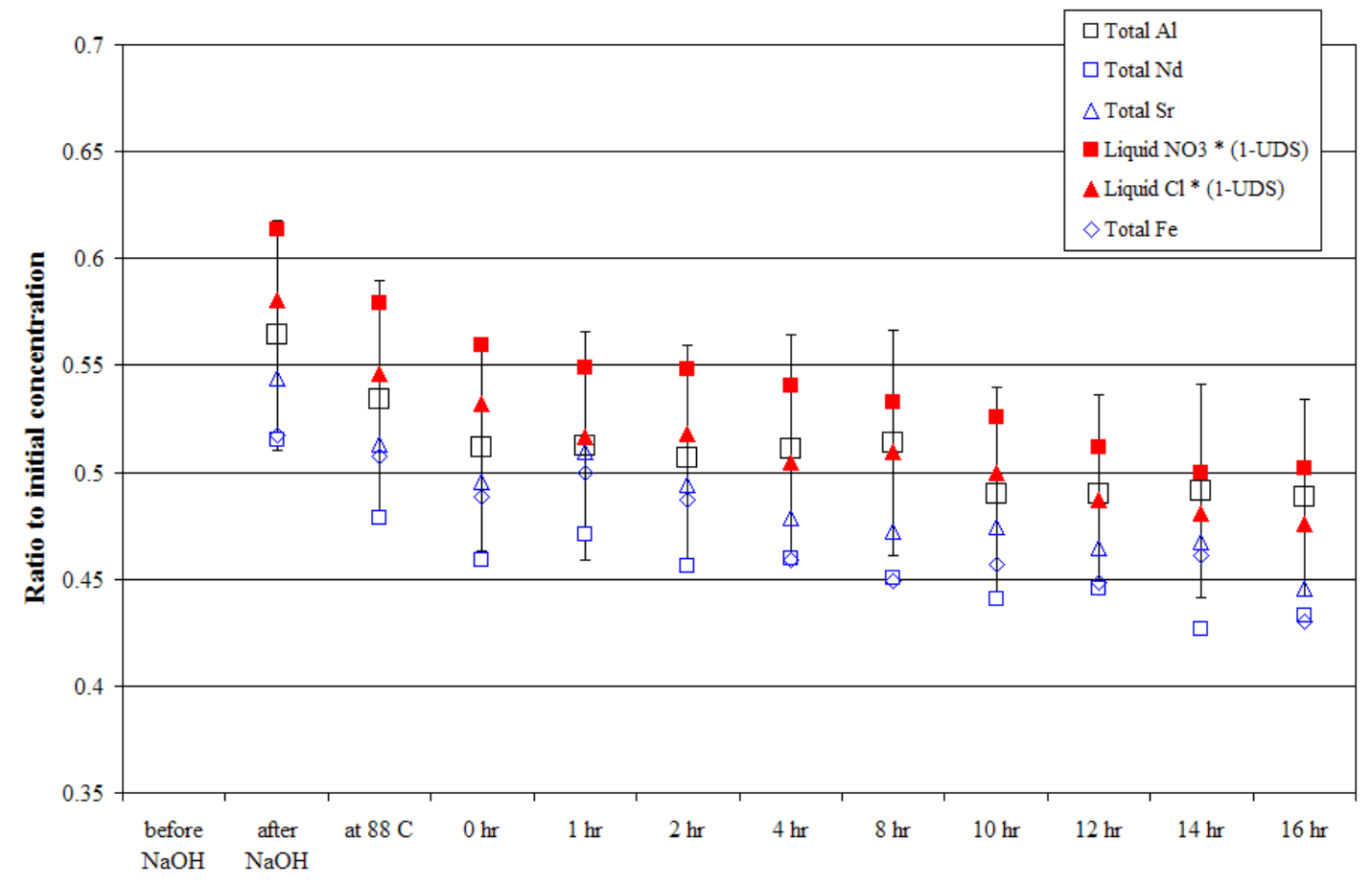

Figure 9.28. Dilution Factors with 95\% Confidence Intervals During Batch 2 of PEP Integrated Test B (caustic leaching in Tank T02A)

(Reproduced from Mahoney et al. (2009) Figure 4.2 with expanded y axis.)

In general, the dilution trends are smooth. As was done for data analysis in Mahoney et al. (2009), tracers were selected from those whose dilution trends generally matched the slurry Al trend, although it was not always possible to pick a tracer that matched every point. The chosen tracers were $\mathrm{Cl}^{-}$(liquid tracer) and $\mathrm{Fe}$ (solid tracer) for Batch 1. The tracers for Batch 2 had been $\mathrm{Cl}^{-}$and Sr. There was a separation between the dilution trend for slurry $\mathrm{Al}$ concentration and the trends for liquid and solid tracers. This separation is a sign that there were changes from the reference condition that did not affect all species in the same way. The most likely cause is analytical variability from one analytical batch to another. This change from the "before $\mathrm{NaOH}^{2}$ reference condition causes an offset in the dilution ratios and in the set of calculated leach factors, but cancels out in kinetic calculations and does not affect the kinetic rate constant.

The total Al leach factors (based on the amount of $\mathrm{Al}$ leached since before- $\mathrm{NaOH}$ conditions) were calculated using liquid tracer and solid tracer methods (Equations [9.10] and [9.9]). The Al leach factors for the PEP batches are given in Table 9.21. In Batch 2, the Al leach factor at 0 hours was very close to 0.435, the fraction of the solid-phase $\mathrm{Al}$ in gibbsite in the feed. It was therefore reasonable to assume that all the solid-phase Al that was still present at 0 hours in Batch 2 was in the form of boehmite. In Batch 1, the $\mathrm{Al}$ leach factor is not within one standard deviation of 0.435 at 0 hours. It does not rise to that point until hour two, and the Batch $1 \mathrm{Al}$ leach factor trails behind the Batch 2 factor by roughly two hours for the rest of the batch. The time lag is probably the result of the temperature drop at the beginning of the batch, possibly added to by the later, smaller temperature drops. 
Table 9.21. PEP Integrated Test B Total Aluminum Leach Factors Using Liquid Tracers

\begin{tabular}{|c|c|c|}
\hline \multirow[b]{2}{*}{ Point in Process } & \multicolumn{2}{|c|}{$\begin{array}{c}\text { Integrated Test B Caustic Leaching in } \\
\text { Tank T02A }\left(98^{\circ} \mathrm{C}\right) \\
\text { Aluminum Leach Factor } \pm 1 \text { Standard Deviation }\end{array}$} \\
\hline & PEP Batch 1 & PEP Batch 2 \\
\hline After $\mathrm{NaOH}$ & $0.39 \pm 0.02$ & $0.38 \pm 0.02$ \\
\hline At $88^{\circ} \mathrm{C}$ & $0.39 \pm 0.02$ & $0.42 \pm 0.02$ \\
\hline $0 \mathrm{hr}$ & $0.39 \pm 0.02$ & $0.43 \pm 0.02$ \\
\hline $1 \mathrm{hr}$ & $0.39 \pm 0.02$ & $0.45 \pm 0.03$ \\
\hline $2 \mathrm{hr}$ & $0.42 \pm 0.02$ & $0.46 \pm 0.03$ \\
\hline $4 \mathrm{hr}$ & $0.44 \pm 0.02$ & $0.50 \pm 0.03$ \\
\hline $8 \mathrm{hr}$ & $0.48 \pm 0.03$ & $0.53 \pm 0.03$ \\
\hline $10 \mathrm{hr}$ & $0.53 \pm 0.03$ & $0.56 \pm 0.03$ \\
\hline $12 \mathrm{hr}$ & $0.55 \pm 0.02$ & $0.56 \pm 0.02$ \\
\hline $14 \mathrm{hr}$ & $0.57 \pm 0.03$ & $0.61 \pm 0.03$ \\
\hline $16 \mathrm{hr}$ & $0.58 \pm 0.02$ & $0.62 \pm 0.03$ \\
\hline
\end{tabular}

The leach factor includes all the leached Al, not just boehmite, and was calculated using liquid tracers. Entries are median \pm one standard deviation calculated by 5000 Monte Carlo realizations. Estimates of laboratory error in measurements were the basis for estimating uncertainty in the results.

The kinetic-modeling data analysis was carried out using the following assumptions and methods:

- Using ratios of liquid tracer concentrations, all dissolved $\mathrm{Al}$ concentrations were normalized to the maximum liquid volume in order to apply the constant-volume assumption in the kinetic model (see Section A.4 of Mahoney et al. 2009).

- The total hydroxide concentrations ${ }^{(a)}$ were calculated for each point in time, normalized to the maximum liquid volume, and averaged to provide the total hydroxide concentration input for the kinetic model.

- The saturated Al concentration in the liquid was calculated from the total hydroxide in the same way as described in Section A.4 of Mahoney et al. (2009).

- The initial boehmite concentration ${ }^{(b)}$ for the PEP test was determined by calculating the concentration of solid-phase $\mathrm{Al}$ at 0 hours and assuming that all of it was present as boehmite because all of the gibbsite had dissolved.

(a) The total hydroxide concentration, in molarity units, is the sum of the free hydroxide and one mole of hydroxide per mole of the aluminate ion complex, $\mathrm{Al}(\mathrm{OH}) 4$-. See Equation (A.65) of Mahoney et al. (2009). The normalized total hydroxide concentration is constant over time, assuming that the only reaction that affects hydroxide is the aluminum leaching reaction.

(b) The terminology "boehmite concentration" is used for convenience. It is not actually a concentration, but a ratio of moles of solid-phase Al to volume of liquid - in effect, it is the concentration increase in dissolved Al that would be generated if all the boehmite dissolved. 
- The initial slurry Al concentration in the beaker for the laboratory-scale test was calculated as an average from the concentrations of three independent samples (Table 4.7 and surrounding text in Mahoney et al. 2009).

- The initial boehmite concentration for the laboratory-scale test was determined by assuming that the dissolved $\mathrm{Al}$ at 0 hours consisted of all the gibbsite plus the original simulant supernatant $\mathrm{Al}$ and subtracting this amount of $\mathrm{Al}$ from the initial slurry $\mathrm{Al}$ concentration to give boehmite $\mathrm{Al}$, as is explained in more detail in Section 4.2.1 of Mahoney et al. (2009). ${ }^{\text {(a) }}$

- The temperature used in modeling was a function of time: for the PEP tests, the average over all submerged sensors at 1-minute intervals, and, for the laboratory-scale tests, an interpolation between the temperatures measured at the times samples were taken.

- The kinetic model (the rate equation in Equation [9.8]) was fit to the dissolved aluminum concentration data using two fitting parameters, the rate constant $k$ and an initial dissolved $\mathrm{Al}$ concentration (distinct from the measured value).

Table 9.22 shows the initial conditions used for the Integrated Test B kinetic calculations. These are the deterministic value \pm one standard deviation as calculated by 500 realizations of the Monte Carlo method. The Monte Carlo calculations used the estimates of laboratory error in measurements as the basis for estimating error in the initial conditions. The fitted initial Al concentrations are shown as well as the measured. In both cases, the fitted initial concentration is nearly equal to the measured value.

Table 9.22. Integrated Test B Initial Conditions for Kinetic Rate Constant Fit

\begin{tabular}{|c|c|c|c|c|}
\hline \multirow{4}{*}{$\begin{array}{l}\text { Concentrations at } 0 \mathrm{hr} \text {, } \\
\text { Normalized to Liquid } \\
\text { Volume at Maximum } \\
\text { Dilution }\end{array}$} & \multicolumn{4}{|c|}{$\begin{array}{c}\text { Integrated Test B Caustic Leaching in Tank T02A }\left(98^{\circ} \mathrm{C}\right) \\
\text { (Value } \pm 1 \text { Standard Deviation) }\end{array}$} \\
\hline & & & Laboratory-Scale & Laboratory-Scale \\
\hline & & & Test B-1 & Test B-2 \\
\hline & PEP Batch 1 & PEP Batch 2 & $(\mathrm{NaOH}$ added in $\mathrm{PEP})$ & ( $\mathrm{NaOH}$ added in PEP) \\
\hline $\begin{array}{l}\text { Measured initial } \\
\text { dissolved Al (M) }\end{array}$ & $0.561 \pm 0.018$ & $0.720 \pm 0.023$ & $0.638 \pm 0.037$ & $0.584 \pm 0.034$ \\
\hline $\begin{array}{l}\text { Fitted initial } \\
\text { dissolved } \mathrm{Al}(\mathrm{M})\end{array}$ & $0.558 \pm 0.016$ & $0.721 \pm 0.020$ & $0.641 \pm 0.021$ & $0.595 \pm 0.020$ \\
\hline Total hydroxide (M) & $6.37 \pm 0.14$ & $6.27 \pm 0.14$ & $6.07 \pm 0.20$ & $5.88 \pm 0.20$ \\
\hline $\begin{array}{l}\text { Initial saturated } \mathrm{Al} \text { at } \\
\text { temperature }(\mathrm{M})\end{array}$ & $1.49 \pm 0.05$ & $1.44 \pm 0.05$ & $1.35 \pm 0.07$ & $1.29 \pm 0.07$ \\
\hline $\begin{array}{l}\text { Initial moles } \\
\text { boehmite/liters } \\
\text { liquid volume }\end{array}$ & $0.800 \pm 0.028$ & $0.795 \pm 0.029$ & $0.769 \pm 0.049$ & $0.803 \pm 0.047$ \\
\hline
\end{tabular}

Entries are deterministic estimate \pm one standard deviation calculated by 500 Monte Carlo realizations. Estimates of laboratory error in measurements were the basis for estimating error in the initial conditions.

Table 9.23 and Table 9.24 show the boehmite leach factors that were calculated from the Al leach factors for the PEP batches and for the laboratory-scale tests using liquid tracer and solid tracer methods. The 16-hr boehmite leach factor calculated by the fitted kinetic model is also shown. Recall that the Al

(a) This assumes both that all the gibbsite is dissolved by $0 \mathrm{hr}$ and that none of the boehmite has dissolved before or during heatup. Boehmite dissolution has been observed to be slow at temperatures of $60^{\circ} \mathrm{C}$ or less (Russell et al. 2009a). 
leach factors are calculated from data for one leached sample and one sample before $\mathrm{NaOH}$ was added (the reference point), while the fitted kinetic model is based on liquid-phase information for the entire set of data taken during leaching. To some extent, these three types of boehmite leach factors are independent. When the predictions do not match well, it indicates an internal inconsistency in the data.

Table 9.23. Integrated Test B Boehmite Leach Factors Using Liquid Tracers

\begin{tabular}{|c|c|c|c|c|}
\hline \multirow[b]{2}{*}{ Point in Process } & \multicolumn{4}{|c|}{$\begin{array}{c}\text { Integrated Test B Caustic Leaching in Tank T02A }\left(98^{\circ} \mathrm{C}\right) \\
\text { Boehmite Leach Factor } \pm 1 \text { Standard Deviation }\end{array}$} \\
\hline & PEP Batch 1 & PEP Batch 2 & $\begin{array}{c}\text { Laboratory-Scale } \\
\text { Test } \mathrm{B}-1 \\
(\mathrm{NaOH} \text { added in } \mathrm{PEP})\end{array}$ & $\begin{array}{c}\text { Laboratory-Scale } \\
\text { Test } \mathrm{B}-2 \\
(\mathrm{NaOH} \text { added in PEP) }\end{array}$ \\
\hline $0 \mathrm{hr}$ & $0 \pm 0.001$ & $0 \pm 0.017$ & $0^{(\mathrm{a})}$ & $0^{(\mathrm{a})}$ \\
\hline $1 \mathrm{hr}$ & $0 \pm 0.004$ & $0.024 \pm 0.036$ & $0.03 \pm 0.05$ & $0.07 \pm 0.05$ \\
\hline $2 \mathrm{hr}$ & $0 \pm 0.014$ & $0.045 \pm 0.040$ & $0.05 \pm 0.05$ & $0.09 \pm 0.05$ \\
\hline $4 \mathrm{hr}$ & $0.015 \pm 0.031$ & $0.11 \pm 0.05$ & $0.08 \pm 0.05$ & $0.08 \pm 0.05$ \\
\hline $8 \mathrm{hr}$ & $0.087 \pm 0.047$ & $0.17 \pm 0.05$ & $0.16 \pm 0.05$ & $0.18 \pm 0.05$ \\
\hline $10 \mathrm{hr}$ & $0.18 \pm 0.05$ & $0.22 \pm 0.06$ & $0.18 \pm 0.05$ & $0.21 \pm 0.05$ \\
\hline $12 \mathrm{hr}$ & $0.20 \pm 0.04$ & $0.23 \pm 0.04$ & $0.22 \pm 0.06$ & $0.24 \pm 0.05$ \\
\hline $14 \mathrm{hr}$ & $0.25 \pm 0.06$ & $0.31 \pm 0.06$ & $0.26 \pm 0.06$ & $0.29 \pm 0.05$ \\
\hline $16 \mathrm{hr}$ & $0.26 \pm 0.04^{(b)}$ & $0.33 \pm 0.04$ & $0.28 \pm 0.06$ & $0.34 \pm 0.06$ \\
\hline $18 \mathrm{hr}$ & $\mathrm{n} / \mathrm{m}$ & $\mathrm{n} / \mathrm{m}$ & $0.29 \pm 0.06$ & $0.39 \pm 0.06$ \\
\hline $20 \mathrm{hr}$ & $\mathrm{n} / \mathrm{m}$ & $\mathrm{n} / \mathrm{m}$ & $0.33 \pm 0.06^{(\mathrm{c})}$ & $0.39 \pm 0.06^{(\mathrm{c})}$ \\
\hline $22 \mathrm{hr}$ & $\mathrm{n} / \mathrm{m}$ & $\mathrm{n} / \mathrm{m}$ & $\mathrm{n} / \mathrm{m}$ & $\mathrm{n} / \mathrm{m}$ \\
\hline $24 \mathrm{hr}$ & $\mathrm{n} / \mathrm{m}$ & $\mathrm{n} / \mathrm{m}$ & $0.37 \pm 0.06$ & $0.42 \pm 0.06$ \\
\hline $\begin{array}{l}16 \mathrm{hr} \text {, calc. by } \\
\text { kinetic model }\end{array}$ & $0.32 \pm 0.03$ & $0.34 \pm 0.04$ & $0.27 \pm 0.04$ & $0.31 \pm 0.04$ \\
\hline \multicolumn{5}{|c|}{$\begin{array}{l}\text { The boehmite leach factor was calculated using liquid tracers. Entries are median } \pm \text { one standard deviation } \\
\text { calculated by } 5000 \text { Monte Carlo realizations (except for the kinetic model calculation, which was based on } 500 \\
\text { realizations). Estimates of laboratory error in measurements were the basis for estimating uncertainty in the results. } \\
\text { (a) The boehmite leach factor is assumed to be zero at } 0 \text { hours. } \\
\text { (b) Sample taken at } 16.9 \text { hours. } \\
\text { (c) Sample taken at } 21 \text { hours. } \\
\text { " } \mathrm{n} / \mathrm{m} \text { " = not measured }\end{array}$} \\
\hline
\end{tabular}


Table 9.24. Integrated Test B Boehmite Leach Factors Using Solid Tracers

\begin{tabular}{|c|c|c|c|c|}
\hline \multirow[b]{2}{*}{ Point in Process } & \multicolumn{4}{|c|}{$\begin{array}{c}\text { Integrated Test B Caustic Leaching in Tank T02A }\left(98^{\circ} \mathrm{C}\right) \\
\text { Boehmite Leach Factor } \pm 1 \text { Standard Deviation }\end{array}$} \\
\hline & PEP Batch 1 & PEP Batch 2 & $\begin{array}{c}\text { Laboratory-Scale } \\
\text { Test } \mathrm{B}-1 \\
(\mathrm{NaOH} \text { added in PEP) }\end{array}$ & $\begin{array}{c}\text { Laboratory-Scale } \\
\text { Test } \mathrm{B}-2 \\
(\mathrm{NaOH} \text { added in PEP }) \\
\end{array}$ \\
\hline $0 \mathrm{hr}$ & $0 \pm 0.000$ & $0 \pm 0.022$ & $\mathrm{n} / \mathrm{m}$ & $\mathrm{n} / \mathrm{m}$ \\
\hline $1 \mathrm{hr}$ & $\mathrm{n} / \mathrm{m}$ & $0.026 \pm 0.040$ & $\mathrm{n} / \mathrm{m}$ & $\mathrm{n} / \mathrm{m}$ \\
\hline $2 \mathrm{hr}$ & $\mathrm{n} / \mathrm{m}$ & $0.041 \pm 0.044$ & $\mathrm{n} / \mathrm{m}$ & $\mathrm{n} / \mathrm{m}$ \\
\hline $4 \mathrm{hr}$ & $0.007 \pm 0.035$ & $0.041 \pm 0.044$ & $\mathrm{n} / \mathrm{m}$ & $\mathrm{n} / \mathrm{m}$ \\
\hline $8 \mathrm{hr}$ & $0.098 \pm 0.051$ & $0.091 \pm 0.051$ & $\mathrm{n} / \mathrm{m}$ & $\mathrm{n} / \mathrm{m}$ \\
\hline $10 \mathrm{hr}$ & $\mathrm{n} / \mathrm{m}$ & $0.21 \pm 0.05$ & $\mathrm{n} / \mathrm{m}$ & $\mathrm{n} / \mathrm{m}$ \\
\hline $12 \mathrm{hr}$ & $0.19 \pm 0.03$ & $0.18 \pm 0.03$ & $\mathrm{n} / \mathrm{m}$ & $\mathrm{n} / \mathrm{m}$ \\
\hline $14 \mathrm{hr}$ & $\mathrm{n} / \mathrm{m}$ & $0.25 \pm 0.05$ & $\mathrm{n} / \mathrm{m}$ & $\mathrm{n} / \mathrm{m}$ \\
\hline $16 \mathrm{hr}$ & $0.27 \pm 0.03^{(\mathrm{a})}$ & $0.23 \pm 0.03$ & $\mathrm{n} / \mathrm{m}$ & $\mathrm{n} / \mathrm{m}$ \\
\hline $18 \mathrm{hr}$ & $\mathrm{n} / \mathrm{m}$ & $\mathrm{n} / \mathrm{m}$ & $\mathrm{n} / \mathrm{m}$ & $\mathrm{n} / \mathrm{m}$ \\
\hline $20 \mathrm{hr}$ & $\mathrm{n} / \mathrm{m}$ & $\mathrm{n} / \mathrm{m}$ & $\mathrm{n} / \mathrm{m}$ & $\mathrm{n} / \mathrm{m}$ \\
\hline $22 \mathrm{hr}$ & $\mathrm{n} / \mathrm{m}$ & $\mathrm{n} / \mathrm{m}$ & $\mathrm{n} / \mathrm{m}$ & $\mathrm{n} / \mathrm{m}$ \\
\hline $24 \mathrm{hr}$ & $\mathrm{n} / \mathrm{m}$ & $\mathrm{n} / \mathrm{m}$ & $0.40 \pm 0.09$ & $0.41 \pm 0.08$ \\
\hline
\end{tabular}

The boehmite leach factor was calculated using solid tracers. Entries are median \pm one standard deviation calculated by 5000 Monte Carlo realizations. Estimates of laboratory error in measurements were the basis for estimating uncertainty in the results.

" $\mathrm{n} / \mathrm{m}$ " = not measured.

(a) sample taken at 16.9 hours.

The agreement between the leach factors calculated by different methods is good in Integrated Test B, except that most of the solid tracer boehmite leach factors for Batch 2 are less than the liquid tracer leach factors. This may be the result of a persistent offset between solid tracer and slurry Al dilution factors, as well as between solid tracer and liquid tracer dilution factors (see Figure 9.28). The liquid tracer tracks the slurry Al more closely than the solid tracer and is expected to provide a closer estimate.

Table 9.25 contains population statistics for the scale-up factors, for boehmite dissolution rate constants, and for the boehmite leach factors at hour 16 of the leach. The statistics were predicted by the best-fit kinetic model using 500 Monte Carlo realizations. The deterministic $\mathrm{R}^{2}$ for the model fit to the normalized dissolved data is also included in the table.

The median rate constant for Batch 1 is lower than for Batch 2. The lower rate constant is consistent with the apparent lag in reaction of about 2 hours. The various operational problems that occurred during Batch 1 make it of dubious value as a source of kinetic information. 
The 16-hr boehmite leach factor for Integrated Test B, Batch 2 is 0.34 as predicted by the best-fit kinetic model, 0.33 as calculated from the liquid tracer $\mathrm{Al}$ leach factor, and 0.23 as calculated from the solid tracer $\mathrm{Al}$ leach factor (which is probably underestimated). This indicates less leaching than was expected from the WTP target projection ${ }^{(a)}$ of 0.38 for the 16 -hr boehmite leach factor for PEP Integrated Test $\mathrm{B}$. The two values are separated by about one standard deviation of the kinetic model prediction population.

For a cross-check, the Al mass-balance data for Test B that are given in Table 12.4 were used to calculate a leach factor over the entire process. The total Al inflows were 94.7-kg solid-phase and 18.0-kg liquid-phase, after adjusting for the fraction of the feed that was flushed from the filter-loop into the waste tanks. The loss from the loop was not prototypic and was not included as an Al outflow in the leach factor calculations. The total $\mathrm{Al}$ outflows were $39.1-\mathrm{kg}$ solid-phase and 72.4-kg liquid-phase, excluding the Al lost to the loop flush. Assuming that $43.5 \%$ of the initial solid-phase Al was in gibbsite, the overall change in solid-phase $\mathrm{Al}$ implied a boehmite leach factor of 0.27 , while the overall change in liquid-phase $\mathrm{Al}$ implied a boehmite leach factor of 0.25 . These overall leach factors are consistent with the batch leach factors in Table 9.23 and Table 9.24.

The median scale-up factor for Integrated Test B-1, Batch 2 is 1.51 and for Integrated Test B-2, Batch 2 is 1.26 . The probability that the scale-up factor is unity or greater is about $93 \%$ for Integrated Test B/Test B-1 and 77\% for Integrated Test B/Test B-2.

(a) The boehmite leach factor was projected by WTP and transmitted to DE Kurath and LA Mahoney by e-mail from JL Huckaby on June 15, 2009 (6:25 AM). The projection was made using Equation (9.8), a rate constant of $0.015 \mathrm{hr}^{-1} *\left(\mathrm{~mol}^{\circ}\right.$ total $\mathrm{OH} / \mathrm{L})^{-1}$ that had been determined from preliminary laboratory tests, and run sheet values for simulant, condensate, and reagent volumes. 
Table 9.25. Scale-Up Factors and Related Leach Information for PEP Integrated Test B and Parallel Laboratory Tests

\begin{tabular}{|c|c|c|c|c|}
\hline & \multicolumn{2}{|c|}{$\begin{array}{c}\text { Integrated Test B } \\
\left(\text { Caustic-Leach in Tank T02A at } 98^{\circ} \mathrm{C}\right)\end{array}$} & \multicolumn{2}{|c|}{$\begin{array}{l}\text { Laboratory-Scale Tests } \\
\left(98^{\circ} \mathrm{C}, \mathrm{NaOH} \text { added in PEP }\right)\end{array}$} \\
\hline & Batch 1 & Batch 2 & B-1 & B-2 \\
\hline $\begin{array}{l}\text { Scale-up factor, } \\
k_{P E P} / k_{\text {lab }}\end{array}$ & $\begin{array}{l}\text { Batch } 1 \text { not used for } \\
\text { scale-up }\end{array}$ & $\mathrm{n} / \mathrm{a}$ & $\begin{array}{c}\text { low 95\%: } 0.89 \\
\text { low 50\%: } 1.20 \\
\text { median: } 1.51 \\
\text { high 50\%: } 1.83 \\
\text { high 95\%: } 2.63\end{array}$ & $\begin{array}{l}\text { low 95\%: } 0.77 \\
\text { low 50\%: } 1.03 \\
\text { median: } 1.26 \\
\text { high 50\%: } 1.53 \\
\text { high 95\%: } 2.14\end{array}$ \\
\hline $\begin{array}{l}\text { Rate constant } k \\
\left(\mathrm{hr}^{-1} *[\text { mol total }\right. \\
\left.\mathrm{OH} / \mathrm{L}]^{-1}\right)\end{array}$ & $\begin{array}{c}\text { low 95\%: } 0.0107 \\
\text { low 50\%: } 0.0127 \\
\text { median: } 0.0138 \\
\text { high 50\%: } 0.0151 \\
\text { high 95\%: } 0.0184\end{array}$ & $\begin{array}{c}\text { low 95\%: } 0.0182 \\
\text { low 50\%: } 0.0224 \\
\text { median: } 0.0251 \\
\text { high 50\%: } 0.0280 \\
\text { high 95\%: } 0.0344\end{array}$ & $\begin{array}{c}\text { low 95\%: } 0.0113 \\
\text { low 50\%: } 0.0147 \\
\text { median: } 0.0166 \\
\text { high 50\%: } 0.0192 \\
\text { high 95\%: } 0.0251\end{array}$ & $\begin{array}{c}\text { low 95\%: } 0.0139 \\
\text { low 50\%: } 0.0176 \\
\text { median: } 0.0199 \\
\text { high 50\%: } 0.0227 \\
\text { high 95\%: } 0.0290\end{array}$ \\
\hline $\begin{array}{l}\text { Boehmite leach factor } \\
\text { at } 16 \mathrm{hr} \text { as predicted } \\
\text { by the best-fit kinetic } \\
\text { model }\end{array}$ & $\begin{array}{c}\text { lower 95\%: } 0.26 \\
\text { median: } 0.32 \\
\text { upper } 95 \%: 0.39\end{array}$ & $\begin{array}{c}\text { lower 95\%: } 0.26 \\
\text { median: } 0.34 \\
\text { upper } 95 \%: 0.43\end{array}$ & $\begin{array}{c}\text { lower 95\%: } 0.20 \\
\text { median: } 0.27 \\
\text { upper 95\%: } 0.36\end{array}$ & $\begin{array}{c}\text { lower 95\%: } 0.24 \\
\text { median: } 0.31 \\
\text { upper 95\%: } 0.40\end{array}$ \\
\hline $\begin{array}{l}\text { Deterministic } \mathrm{R}^{2} \text { for } \\
\text { the kinetic model fit }\end{array}$ & 0.987 & 0.984 & 0.997 & 0.978 \\
\hline
\end{tabular}

The scale-up factor and $k$ entries show the $95 \%$ confidence interval and $50 \%$ confidence interval around the median, as calculated by 500 Monte Carlo realizations. Estimates of laboratory error in measurements were the basis for estimating all error.

\subsubsection{Integrated Test D}

The data analysis for the two batches of PEP Integrated Test D and for the two laboratory-scale tests (D-1 and D-2) that were conducted using slurry from Batch 2 has not been previously reported. The Integrated Test $\mathrm{D}$ data were analyzed with the same methods used in Mahoney et al. (2009). The data used in leach factor and kinetic calculations for both batches included metals measured by ICP, anions by $\mathrm{IC}$, and free hydroxide measured by $\mathrm{OH}$ titration. The concentration and physical properties data for the PEP batches and laboratory tests can be found in Appendix A, as can sample times and a summary of temperature statistics.

One of the first features noted was that the slurry Al concentrations in Tests D-1 and D-2 were too low to be consistent with the concentrations in the PEP slurry. This apparent loss of Al between PEP and the beaker had also been seen in other laboratory-scale tests. The fractional loss in Tests D-1 and D-2 was comparable to that in Integrated Test B.

Figure 9.29 shows the bulk concentration dilution factors for the laboratory-scale tests that parallel PEP Integrated Test D. All of these values are ratios of the concentration in the beaker to the concentration of the reference sample (the concentrated simulant before $\mathrm{NaOH}$ was added in PEP). The first point on the left represents the reference point and is unity, being the reference concentration divided by itself. The included species are the total $\mathrm{Al}$ in the slurry, total $\mathrm{Sr}$, total Fe, total $\mathrm{Na}$, and bulk 
concentrations of liquid-phase nitrate $\left(\mathrm{NO}_{3}{ }^{-}\right)$and chloride $\left(\mathrm{Cl}^{-}\right)$. The liquid concentrations are multiplied by the mass fraction of liquid in the slurry to put them on a bulk-slurry basis.
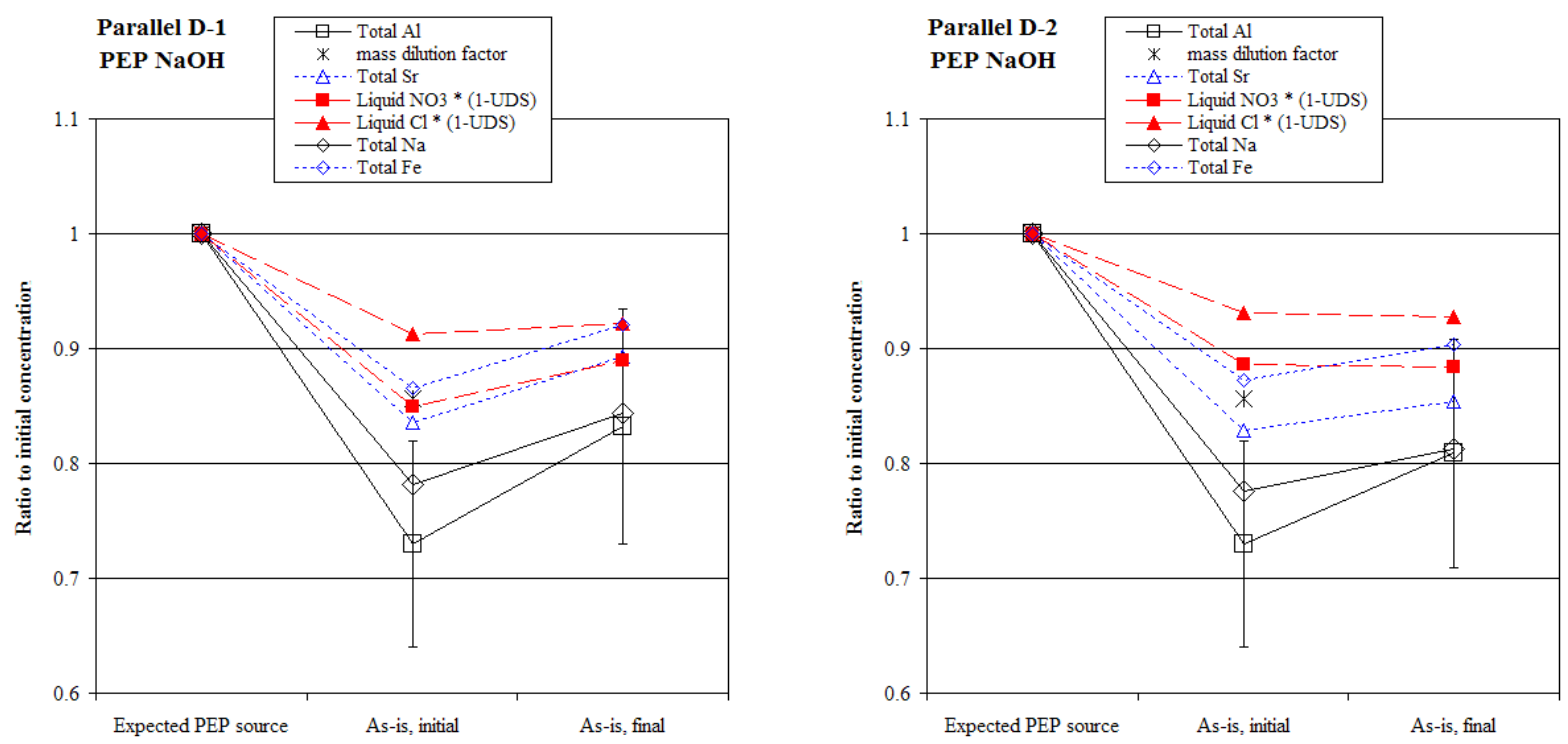

Figure 9.29. Dilution Factors with $95 \%$ Confidence Intervals for Laboratory-Scale Tests Paralleling Integrated Test D (caustic leaching in Tank T02A at $85^{\circ} \mathrm{C}$ )

The mass dilution factors expected to result from adding DI water in the laboratory were calculated from information in the Test Instruction and are also included in the plots (they are shown as asterisks near the plot center). The Test Instruction dilution factors are the ratios of simulant mass to total mass in the slurry and serve as an accurate cross-check on the initial dilution factors calculated from concentration ratios. Ideally, at the initial condition in the beaker (shown in the center column of the plot), the dilution factors for all species would equal the Test Instruction mass dilution factor. Because of evaporation of water during the test, all concentrations increase between the initial and final measurement; this is the reason for the increase in dilution factor from the initial to final points on the plot.

It is evident from Figure 9.29 that the dilution factors of the various species frequently do not match each other within two standard deviations (which can be judged from the error bar on the total Al). Specifically, the similarities and discrepancies are the following:

- The dilution of the total $\mathrm{Na}$ in the slurry at the initial diluted condition matches the dilution factor calculated from the Test Instruction to within two standard deviations.

- The liquid tracers indicate less dilution (have larger dilution factors) than the Test Instruction value at the initial diluted condition. Their trend from initial to final indicates less evaporation than other species seem to indicate.

- The solid tracer Sr reasonably matches the initial dilution factor from the Test Instruction in both laboratory-scale tests. The tracer Fe is higher and provides a better match to the TI initial dilution factor. The solid tracers and $\mathrm{Na}$ all show about the same increase from initial to final conditions. 
- The total Al trend indicates substantially less Al present in the beaker than would be expected from the composition of the PEP slurry. The upward trend in total Al from the initial to the final condition is closer to being parallel to the solid tracers and $\mathrm{Na}$ than to the liquid tracers.

The loss of $\mathrm{Al}$ is comparable (in percentage terms) to that in Integrated Tests B-1 and B-2, but there is more internal inconsistency in tracer and Al trends in Integrated Tests D-1 and D-2 than in Integrated Tests B-1 and B-2. The reasons for the inconsistencies noted above are unknown, but certain conclusions can be drawn:

- The inconsistency between the initial-to-final trends of the liquid tracer species and those of other indicators of system volume may have an impact on the kinetic data analysis. If evaporation was greater than indicated by the liquid tracers, then some of the observed increase in dissolved $\mathrm{Al}$ concentration may be attributed to the reaction when it should be attributed to evaporation. An overestimation of leach factors and rate constants may result.

- The differences between the initial dilution factors for the various species make it doubtful whether the amount of Al leached in the beaker can be related back to the reference condition in PEP, the samples before $\mathrm{NaOH}$ was added. This was also true for other laboratory-scale tests.

More than one explanation has been proposed (Mahoney et al. 2009) for the changes in concentration from the PEP to the beaker initial condition. The most plausible explanation is that a small fraction of the solid Al was left behind in the bottles of PEP slurry from which the beakers were filled as a result of settling that occurred between mixing and pouring.

Figure 9.30 and Figure 9.31 show the dilution trends for Batch 1 and Batch 2 of PEP Integrated Test D. The reference sample for these trend plots, as for Figure 9.29, was the PEP sample concentration after solids concentration and before $\mathrm{NaOH}$ was added. The trends in PEP are generally downward because of the increasing dilution from condensate. The trend in Batch 2 of Integrated Test D is unusual among the PEP tests in that the dilution factor for all species remains essentially constant from the "after-NaOH" sample to the 4-hr sample, as if no condensate were accumulating. However, the change in slurry level during this time showed that substantial condensate was accumulating. The level-based and tracer-based estimates of liquid dilution are roughly equal at and after hour 16, but before that time, all slurry components showed less dilution (higher concentration) than the level indicates. The reason for the difference is unknown. Two of the samples during this period were taken while vessel mixing was off for a few minutes. This is not considered to be the explanation for the flat trend because other samples in the period were taken while PJMs and spargers were on. 


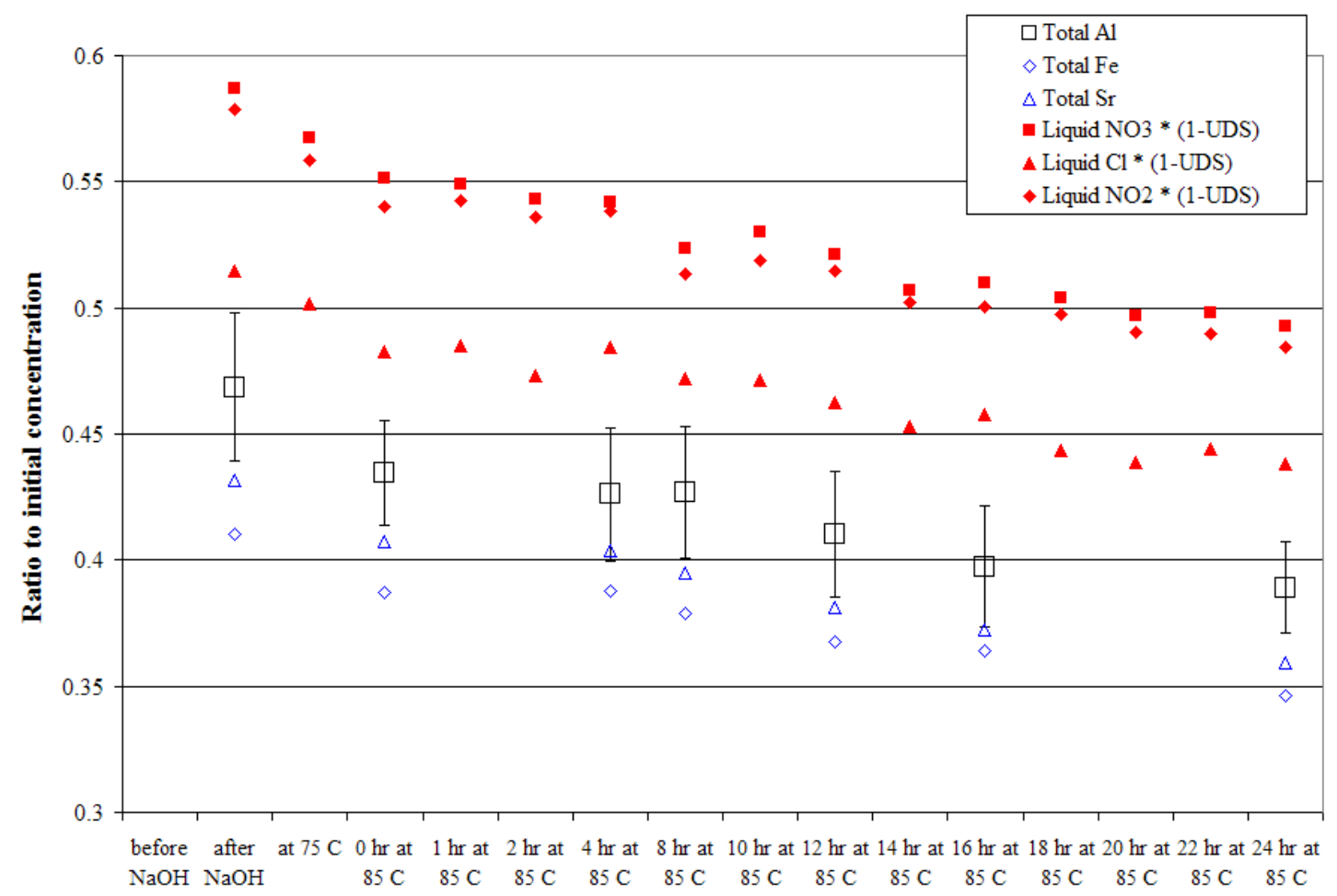

Figure 9.30. Dilution Factors with $95 \%$ Confidence Intervals for Batch 1 of PEP Integrated Test D (caustic leaching in Tank $\mathrm{T} 02 \mathrm{~A}$ at $85^{\circ} \mathrm{C}$ ) 


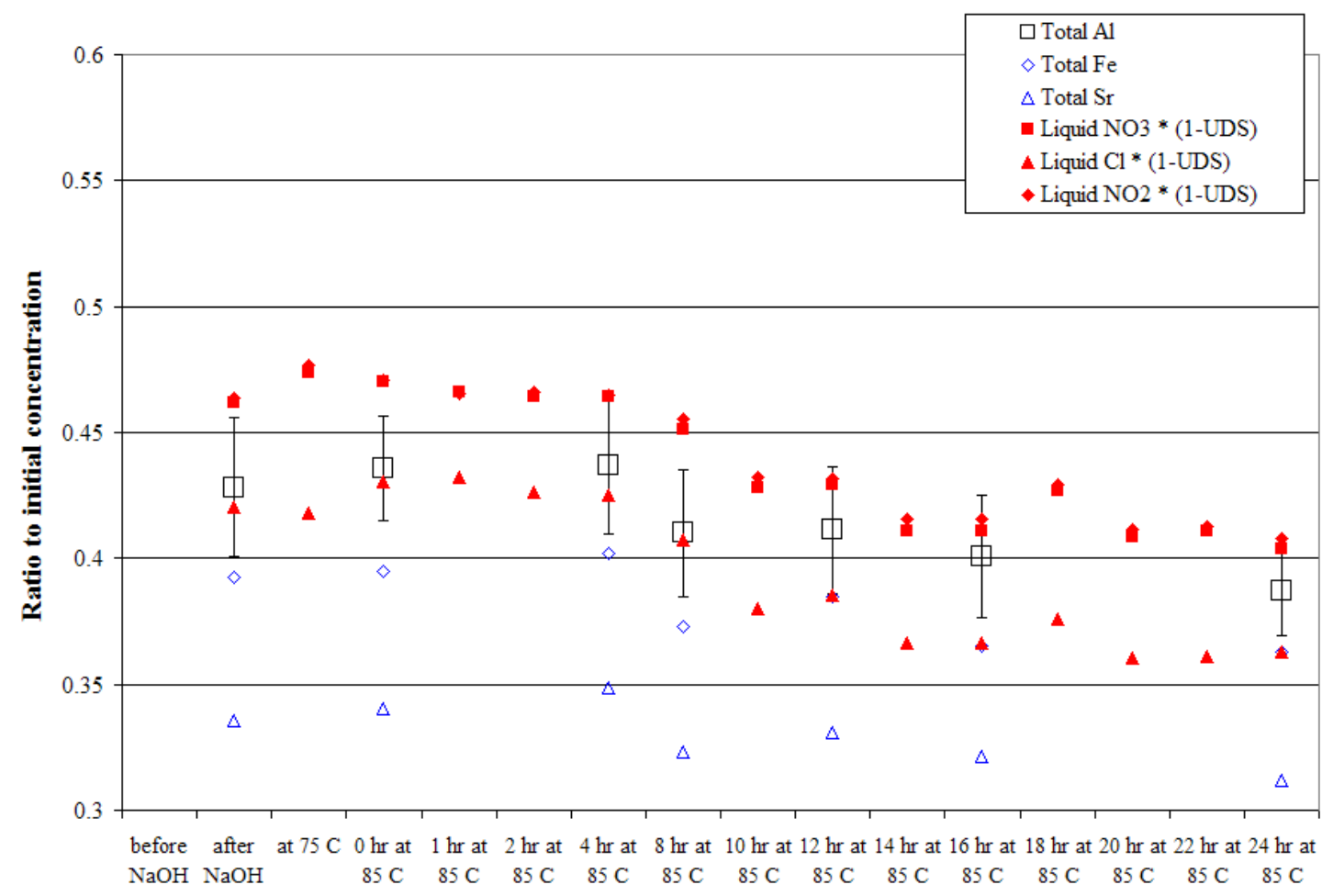

Figure 9.31. Dilution Factors with 95\% Confidence Intervals for Batch 2 of PEP Integrated Test D (caustic leaching in Tank $\mathrm{T} 02 \mathrm{~A}$ at $85^{\circ} \mathrm{C}$ )

Figure 9.30 and Figure 9.31 show a separation between the dilution trend for slurry Al concentration and the trends for liquid and solid tracers. This separation is a sign that there were changes from the reference condition that did not affect all species in the same way. It is less pronounced in Batch 2 (Figure 9.30) than in Batch 1 (Figure 9.30). The most likely cause is analytical variability from one analytical batch to another. This reference-condition shift causes a consistent offset in the set of calculated leach factors, but cancels out in kinetic calculations and does not affect the kinetic rate constant. The tracers $\mathrm{Cl}$ and $\mathrm{Sr}$ were chosen for Batch 1 of PEP Integrated Test $\mathrm{D}$, and $\mathrm{Cl}$ and $\mathrm{Fe}$ were chosen for Batch 2 as having the trends closest to those of the slurry Al.

Table 9.26 and Table 9.27 show the total Al leach factors that were calculated using liquid tracer and solid tracer methods. For the PEP data, leach factors are referenced to the solid-phase Al concentrations present in Tank T02A after solids concentration and before $\mathrm{NaOH}$ was added. For the laboratory-scale data, the leach factors are not referenced back to PEP_-because the solid-phase Al loss and other internal inconsistencies already discussed make that kind of comparison dubious - but to the initial diluted conditions in the beakers.

The Al leach factor was less than 0.435 (the fraction of solid Al in gibbsite in the feed) for all of Batch 1 and until sometime between hour 4 and 10 in Batch 2. Superficially, this suggests that gibbsite was not $100 \%$ dissolved in either batch in PEP Integrated Test D until well past the 0 hour point. It would have been surprising if this were the case, particularly in Batch 1 where operational problems had caused the slurry to be held at temperatures between $50^{\circ} \mathrm{C}$ and $65^{\circ} \mathrm{C}$ for 19 hours after adding the $\mathrm{NaOH}$ 
reagent. The high-caustic, elevated-temperature conditions should have dissolved most or all of the gibbsite (per observations in Russell et al. 2009b).

The apparent low solubility of gibbsite seemed unlikely but needed to be pursued, in part because of the implications for dissolution during the constant-temperature leach. If the solid-phase Al in the PEP tests was not $100 \%$ boehmite at 0 hours, the measured dissolution rates would not be accurate descriptions of boehmite dissolution. In addition, the possibility would be raised that the solid-phase $\mathrm{Al}$ in the laboratory-scale tests was not $100 \%$ boehmite at and after 0 hours. In previous laboratory-scale tests, the absence of gibbsite at and after 0 hours had been assumed because it had been plausible based on PEP data. This assumption was required for the determination of the initial boehmite concentration in laboratory-scale tests; there were not enough independent data within the laboratory tests to allow the assumption to be checked.

The low Al leach factors for both batches of the PEP Integrated Test D were not the result of the differences between the dilution trends of tracer species that were shown in Figure 9.30 and Figure 9.31. Adjusting the tracer concentrations in the reference sample to let the tracer trends match the slurry $\mathrm{Al}$ trend as closely as possible did not raise the 0 -hr Al leach factor to 0.435 . The reference values of the slurry $\mathrm{Al}$ concentration would have to have been lower by $10 \%$ to $15 \%$ for both batches to account for the low leach factors. This is a large change but is not inconceivable. 
Table 9.26. Integrated Test D Total Aluminum Leach Factors Using Liquid Tracers

\begin{tabular}{|c|c|c|c|c|}
\hline \multirow[b]{2}{*}{ Point in Process } & \multicolumn{4}{|c|}{$\begin{array}{c}\text { Integrated Test D Caustic Leaching in Tank T02A }\left(85^{\circ} \mathrm{C}\right) \\
\text { Aluminum Leach Factor } \pm 1 \text { Standard Deviation }\end{array}$} \\
\hline & PEP Batch 1 & PEP Batch 2 & $\begin{array}{l}\text { Laboratory-Scale } \\
\text { Test } \mathrm{D}-1^{\text {(a) }} \\
(\mathrm{NaOH} \text { added in } \\
\text { PEP) }\end{array}$ & $\begin{array}{c}\text { Laboratory- } \\
\text { Scale Test } \mathrm{D}-2^{(a)} \\
(\mathrm{NaOH} \text { added in } \\
\mathrm{PEP})\end{array}$ \\
\hline After $\mathrm{NaOH}$ & $0.34 \pm 0.02$ & $0.37 \pm 0.02$ & $\mathrm{n} / \mathrm{m}$ & $\mathrm{n} / \mathrm{m}$ \\
\hline Initial diluted & $\mathrm{n} / \mathrm{m}$ & $\mathrm{n} / \mathrm{m}$ & $0^{(a)}$ & $0^{(a)}$ \\
\hline At $75^{\circ} \mathrm{C}$ & $0.31 \pm 0.02$ & $0.39 \pm 0.02$ & $0.013 \pm 0.040$ & $0.007 \pm 0.047$ \\
\hline $0 \mathrm{hr}$ & $0.31 \pm 0.01$ & $0.39 \pm 0.02$ & $0.027 \pm 0.041$ & $0.018 \pm 0.048$ \\
\hline $1 \mathrm{hr}$ & $0.33 \pm 0.02$ & $0.40 \pm 0.02$ & $0.045 \pm 0.041$ & $0.026 \pm 0.047$ \\
\hline $2 \mathrm{hr}$ & $0.34 \pm 0.02$ & $0.40 \pm 0.02$ & $0.059 \pm 0.042$ & $0.030 \pm 0.048$ \\
\hline $4 \mathrm{hr}$ & $0.33 \pm 0.02$ & $0.42 \pm 0.02$ & $0.091 \pm 0.043$ & $0.061 \pm 0.049$ \\
\hline $8 \mathrm{hr}$ & $0.36 \pm 0.02$ & $0.41 \pm 0.02$ & $0.11 \pm 0.04$ & $0.082 \pm 0.049$ \\
\hline $10 \mathrm{hr}$ & $0.37 \pm 0.02$ & $0.46 \pm 0.03$ & $0.14 \pm 0.04$ & $0.11 \pm 0.05$ \\
\hline $12 \mathrm{hr}$ & $0.39 \pm 0.02$ & $0.46 \pm 0.03$ & $0.16 \pm 0.05$ & $0.16 \pm 0.05$ \\
\hline $14 \mathrm{hr}$ & $0.36 \pm 0.02$ & $0.47 \pm 0.03$ & $0.21 \pm 0.05$ & $0.16 \pm 0.05$ \\
\hline $16 \mathrm{hr}$ & $0.38 \pm 0.02$ & $0.49 \pm 0.03$ & $0.19 \pm 0.05$ & $0.21 \pm 0.06$ \\
\hline $18 \mathrm{hr}$ & $0.40 \pm 0.02$ & $0.49 \pm 0.03$ & $0.21 \pm 0.05$ & $0.24 \pm 0.06$ \\
\hline $20 \mathrm{hr}$ & $0.42 \pm 0.02$ & $0.51 \pm 0.03$ & $0.18 \pm 0.05$ & $0.21 \pm 0.06$ \\
\hline $22 \mathrm{hr}$ & $0.42 \pm 0.02$ & $0.52 \pm 0.03$ & $\mathrm{n} / \mathrm{m}$ & $\mathrm{n} / \mathrm{m}$ \\
\hline $24 \mathrm{hr}$ & $0.43 \pm 0.01$ & $0.52 \pm 0.02$ & $0.23 \pm 0.05$ & $0.24 \pm 0.06$ \\
\hline \multicolumn{5}{|c|}{$\begin{array}{l}\text { The leach factor includes all the leached } \mathrm{Al} \text {, not just boehmite, and was calculated using liquid tracers. } \\
\text { Entries are median } \pm \text { one standard deviation calculated by } 5000 \text { Monte Carlo realizations. Estimates of } \\
\text { laboratory error in measurements were the basis for estimating uncertainty in the results. } \\
\text { (a) For the laboratory-scale tests, the total Al leach factors are expressed in terms of the solid-phase Al } \\
\text { initially present in the beaker and are not directly comparable to the PEP leach factors for total Al. } \\
\text { The entries for these tests are italicized to distinguish them. }\end{array}$} \\
\hline
\end{tabular}

Another possibility considered was that some of the gibbsite had already leached in PEP by the time of the "before $\mathrm{NaOH"} \mathrm{samples,} \mathrm{which} \mathrm{were} \mathrm{the} \mathrm{reference} \mathrm{points} \mathrm{for} \mathrm{Al} \mathrm{leach} \mathrm{factors} \mathrm{in} \mathrm{PEP.} \mathrm{If} \mathrm{so,} \mathrm{all} \mathrm{the}$ remaining gibbsite would be dissolved at an $\mathrm{Al}$ leach factor that was less than 0.435 . However, the liquid concentration in the Integrated Test D feed was essentially equal to that in the "before $\mathrm{NaOH}$ " samples. This observation is not consistent with significant leaching of gibbsite before $\mathrm{NaOH}$ was added.

A sample of Integrated Test D feed simulant and archived samples ${ }^{(a)}$ taken at hours 0 and 24 in Batch 2 of Integrated Test D were all examined to identify the Al-containing solid phases that were present. Figure 9.32 shows the Fourier Transform Infra-Red (FTIR) spectra of the solids in an unwashed, air-dried sample of unprocessed simulant. The gibbsite and boehmite bands were observed at the same locations in the simulant spectrum as in the pure-substance standards (whose spectra are included for comparison). This observation establishes that the presence of other compounds (metal compounds and sodium salts) in the solid phase did not shift the bands for gibbsite and boehmite away from the standard band locations.

(a) The 0-hr and 24-hr samples were taken from the outer middle CD port of UFP-T02A. For comparison, the samples used for leach factor and kinetic data analysis were taken from the middle lower port. 
Table 9.27. Integrated Test D Total Aluminum Leach Factors Using Solid Tracers

\begin{tabular}{|c|c|c|c|c|}
\hline \multirow[b]{2}{*}{ Point in Process } & \multicolumn{4}{|c|}{$\begin{array}{c}\text { Integrated Test D Caustic Leaching in Tank T02A }\left(85^{\circ} \mathrm{C}\right) \\
\text { Aluminum Leach Factor } \pm 1 \text { Standard Deviation }\end{array}$} \\
\hline & PEP Batch 1 & PEP Batch 2 & $\begin{array}{c}\text { Laboratory-Scale } \\
\text { Test } \mathrm{D}-1^{\text {(a) }} \\
\text { (NaOH added in } \\
\text { PEP) }\end{array}$ & $\begin{array}{l}\text { Laboratory-Scale } \\
\text { Test } \mathrm{D}-2^{(a)} \\
(\mathrm{NaOH} \text { added in } \\
\text { PEP })\end{array}$ \\
\hline After $\mathrm{NaOH}$ & $\mathrm{n} / \mathrm{m}$ & $\mathrm{n} / \mathrm{m}$ & $\mathrm{n} / \mathrm{m}$ & $\mathrm{n} / \mathrm{m}$ \\
\hline Initial diluted & $\mathrm{n} / \mathrm{m}$ & $\mathrm{n} / \mathrm{m}$ & $0^{(a)}$ & $0^{(a)}$ \\
\hline At $75^{\circ} \mathrm{C}$ & $0.32 \pm 0.04$ & $0.30 \pm 0.04$ & $\mathrm{n} / \mathrm{m}$ & $\mathrm{n} / \mathrm{m}$ \\
\hline $0 \mathrm{hr}$ & $0.31 \pm 0.03$ & $0.32 \pm 0.03$ & $\mathrm{n} / \mathrm{m}$ & $\mathrm{n} / \mathrm{m}$ \\
\hline $1 \mathrm{hr}$ & $\mathrm{n} / \mathrm{m}$ & $\mathrm{n} / \mathrm{m}$ & $\mathrm{n} / \mathrm{m}$ & $\mathrm{n} / \mathrm{m}$ \\
\hline $2 \mathrm{hr}$ & $\mathrm{n} / \mathrm{m}$ & $\mathrm{n} / \mathrm{m}$ & $\mathrm{n} / \mathrm{m}$ & $\mathrm{n} / \mathrm{m}$ \\
\hline $4 \mathrm{hr}$ & $0.35 \pm 0.04$ & $0.36 \pm 0.04$ & $\mathrm{n} / \mathrm{m}$ & $\mathrm{n} / \mathrm{m}$ \\
\hline $8 \mathrm{hr}$ & $0.35 \pm 0.04$ & $0.35 \pm 0.04$ & $\mathrm{n} / \mathrm{m}$ & $\mathrm{n} / \mathrm{m}$ \\
\hline $10 \mathrm{hr}$ & $\mathrm{n} / \mathrm{m}$ & $\mathrm{n} / \mathrm{m}$ & $\mathrm{n} / \mathrm{m}$ & $\mathrm{n} / \mathrm{m}$ \\
\hline $12 \mathrm{hr}$ & $0.40 \pm 0.03$ & $0.39 \pm 0.04$ & $\mathrm{n} / \mathrm{m}$ & $\mathrm{n} / \mathrm{m}$ \\
\hline $14 \mathrm{hr}$ & $\mathrm{n} / \mathrm{m}$ & $\mathrm{n} / \mathrm{m}$ & $\mathrm{n} / \mathrm{m}$ & $\mathrm{n} / \mathrm{m}$ \\
\hline $16 \mathrm{hr}$ & $0.40 \pm 0.03$ & $0.39 \pm 0.04$ & $\mathrm{n} / \mathrm{m}$ & $\mathrm{n} / \mathrm{m}$ \\
\hline $18 \mathrm{hr}$ & $\mathrm{n} / \mathrm{m}$ & $\mathrm{n} / \mathrm{m}$ & $\mathrm{n} / \mathrm{m}$ & $\mathrm{n} / \mathrm{m}$ \\
\hline $20 \mathrm{hr}$ & $\mathrm{n} / \mathrm{m}$ & $\mathrm{n} / \mathrm{m}$ & $\mathrm{n} / \mathrm{m}$ & $\mathrm{n} / \mathrm{m}$ \\
\hline $22 \mathrm{hr}$ & $\mathrm{n} / \mathrm{m}$ & $\mathrm{n} / \mathrm{m}$ & $\mathrm{n} / \mathrm{m}$ & $\mathrm{n} / \mathrm{m}$ \\
\hline $24 \mathrm{hr}$ & $0.44 \pm 0.02$ & $0.45 \pm 0.02$ & $0.25 \pm 0.08$ & $0.24 \pm 0.09$ \\
\hline \multicolumn{5}{|c|}{$\begin{array}{l}\text { The leach factor includes all the leached Al, not just boehmite, and was calculated using solid tracers. } \\
\text { Entries are median } \pm \text { one standard deviation calculated by } 5000 \text { Monte Carlo realizations. Estimates of } \\
\text { laboratory error in measurements were the basis for estimating uncertainty in the results. } \\
\text { (a) For the laboratory-scale tests, the total Al leach factors are expressed in terms of the solid-phase Al } \\
\text { initially present in the beaker and are not directly comparable to the PEP leach factors for total Al. } \\
\text { The entries for these tests are italicized to distinguish them. }\end{array}$} \\
\hline
\end{tabular}

Figure 9.33 shows the FTIR spectra of water-washed air-dried solids from the 0-hr and 24-hr samples from Batch 2. No gibbsite bands are visible in either spectrum, and boehmite bands are visible in both. The bands at 1075 and $729 \mathrm{~cm}^{-1}$ in the 0 -hr sample characterize boehmite, as do the hydroxyl stretching bands at 3080 and $3265 \mathrm{~cm}^{-1}$. In the 24-hr sample, these bands are less evident, but the band at $1075 \mathrm{~cm}^{-1}$ is consistent with boehmite. This band is perceptibly smaller in the 24-hr sample than in the 0-hr sample, and the other bands are not apparent; this decrease is consistent with some leaching of boehmite relative to other solid compounds. The spectral evidence indicates that gibbsite was not detectably present at 0 hours and that some boehmite was leached between 0 hours and 24 hours. The broad hump between about $3600 \mathrm{~cm}^{-1}$ and $2400 \mathrm{~cm}^{-1}$ is consistent with the presence of water either as free water or as water of hydration. In the present case, where the solids are dry, the cause is water of hydration. This feature was not clear in the unprocessed simulant solids, but may have been masked by the presence of other solids that since then have been leached. It is not necessarily a sign of the formation of a new solid containing water of hydration.

Because the FTIR at 0 hours shows no sign of gibbsite, it is concluded that the leach factor calculations do not adequately represent the actual amount of leaching in Batch 2 of Integrated Test D. However, the leach trends in Table 9.26 and Table 9.27 are reasonable in behavior (monotonically increasing, overall), which implies the error could be an offset in the leach factor. 
Such an offset could come from a discrepancy in the reference sample itself (as distinct from analytical variation). It may be relevant that in both batches of Integrated Test $\mathrm{D}$, there were some unusual sampling conditions before $\mathrm{NaOH}$ was added. In Batch 1, the sampling pump was having priming problems at that point in the process. In Batch 2, the "before $\mathrm{NaOH}$ " sample was the only one in the caustic-leach sampling sequence that was taken from the filter-loop (because of sample pump problems) instead of from the middle-lower CD port. However, these conditions were not expected to cause a change in the representativeness of samples.

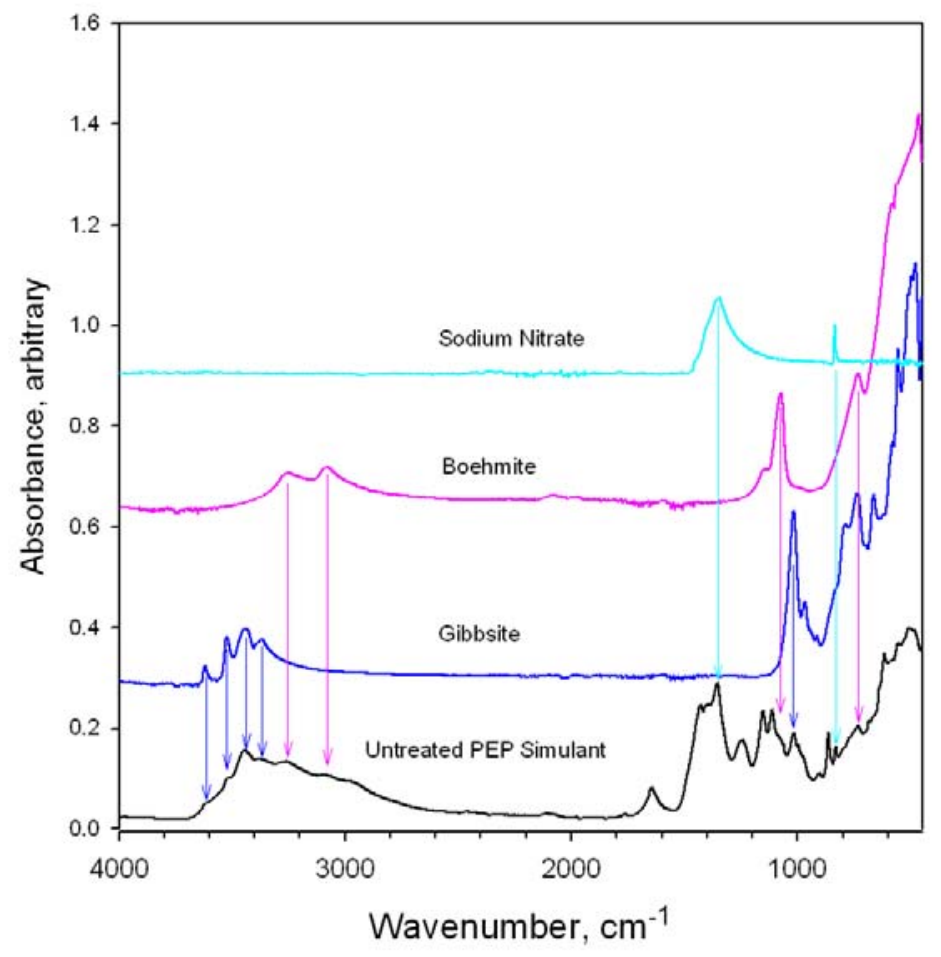

Figure 9.32. FTIR Spectrum for Unprocessed Integrated Test D Simulant 


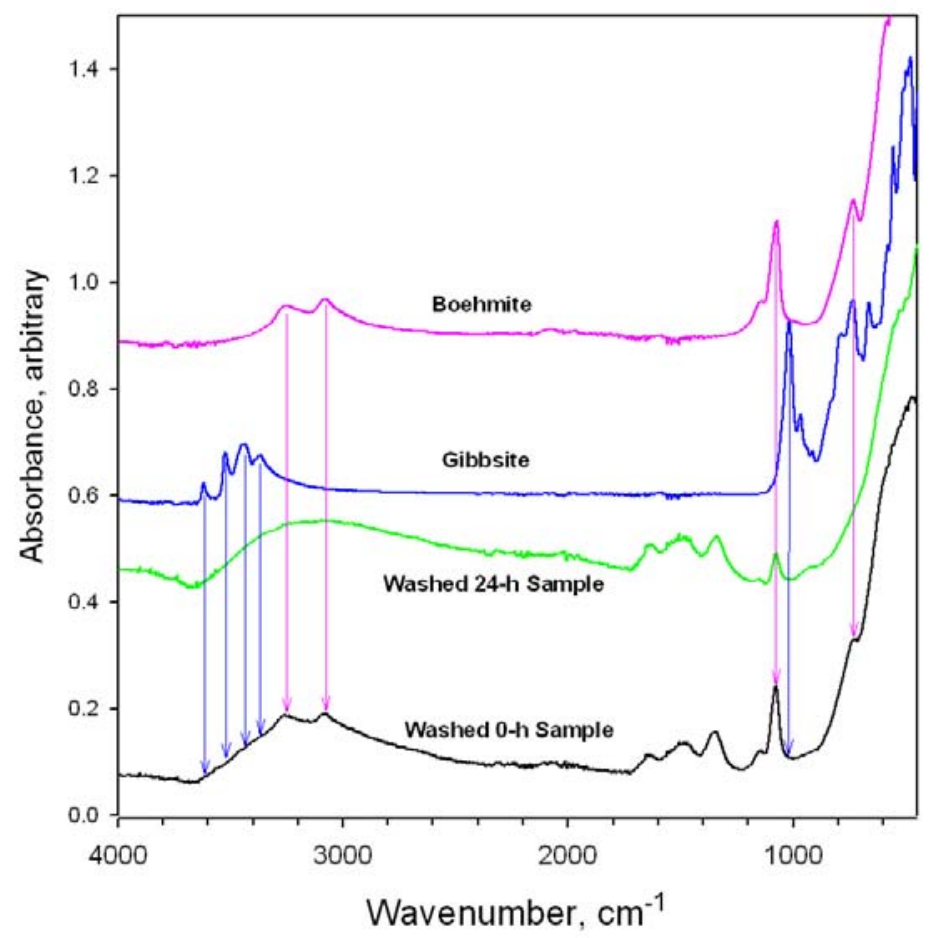

Figure 9.33. FTIR Spectrum for Water-Washed Solids from 0-hr and 24-hr Slurry from Integrated Test D, Batch 2

Theoretically, another source of offset might be that gibbsite and boehmite dissolved at the leaching temperature, consistent with the FTIR findings, but then partly reprecipitated in the form of some other Al compound when the samples were cooled, consistent with the leach factor findings. This reprecipitation could, in theory, result from different aluminum solubility chemistry at the high- $\mathrm{NaOH}$ conditions that were unique to Integrated Test D. For example, sodium aluminate is known to form at sufficiently high $\mathrm{NaOH}$ concentration. However, if $\mathrm{Al}$ had precipitated as sodium aluminate, which is highly soluble in water, it would have redissolved early in the post-leach washing and produced elevated concentrations of dissolved Al. These were not observed, as is shown by Figure 10.20. The FTIR spectra of the water-washed solids from the $0-\mathrm{hr}$ and $24-\mathrm{hr}$ slurry were checked for sodium aluminate, which was not seen, but which is a highly-soluble compound that would not have remained after washing. Owing to a lack of standard spectra, the FTIR spectra for the processed slurry were not checked for other forms of precipitated aluminum, such as bayerite, nordstrandite, and amorphous aluminum hydroxide.

In general, re-precipitation is considered to be an unlikely explanation of the observations. If $\mathrm{Al}$ solids had precipitated in samples during cooling, presumably it would have done the same in the liquid in the slurry, which consequently would be saturated in $\mathrm{Al}$ at room temperature. The excess $\mathrm{NaOH}$ tests for Integrated Test D (Section 9.7) showed that samples of the permeate removed from the slurry after caustic leaching was still capable of dissolving gibbsite, and therefore, could not be considered saturated.

Although the cause of the low Al leach factors in Integrated Test D was not pinpointed, it seemed clear that the calculated Al leach factors were unrealistically low. Therefore, they were not used to calculate boehmite leach factors, which would have been misleading. It also seemed clear that it was 
reasonable to carry out the kinetic data analysis using the same assumption made in previous analyses, namely, that gibbsite was dissolved by the time constant-temperature leaching began. In general, the same data analysis assumptions and methods were used for Integrated Test D as for Integrated Tests A and B (Mahoney et al. 2009):

- Using ratios of liquid tracer concentrations, all dissolved $\mathrm{Al}$ concentrations were normalized to the maximum liquid volume in order to apply the constant-volume assumption in the kinetic model (see Section A.4 of Mahoney et al. 2009).

- Total hydroxide concentrations ${ }^{(a)}$ were calculated for each point in time, normalized to the maximum liquid volume, and averaged to provide the total hydroxide concentration input for the kinetic model.

- The saturated Al concentration in the liquid was calculated from the total hydroxide in the same way as described in Section A.4 of Mahoney et al. (2009).

- The initial boehmite concentration ${ }^{(b)}$ for the PEP test was determined by calculating the concentration of solid-phase $\mathrm{Al}$ at 0 hours and assuming that all of it was present as boehmite because all of the gibbsite had dissolved.

- The initial slurry Al concentration in the beaker for the laboratory-scale test was calculated as an average from the concentrations of three independent samples (Table 9.28) by using the method discussed in Section 4.2.1 of Mahoney et al. (2009).

- The initial boehmite concentration for the laboratory-scale test was determined by assuming that the dissolved $\mathrm{Al}$ at 0 hours consisted of all the gibbsite plus the original simulant supernatant $\mathrm{Al}$ and subtracting this amount of $\mathrm{Al}$ from the initial slurry $\mathrm{Al}$ concentration to give boehmite $\mathrm{Al}$, as is explained in more detail in Section 4.2.1 of Mahoney et al. (2009). ${ }^{(\mathrm{c})}$

- The temperature used in modeling was a function of time: for the PEP tests, the average over all submerged sensors at 1-minute intervals, and, for the laboratory-scale tests, an interpolation between the temperatures measured at the times samples were taken.

- The kinetic model (the rate equation in Equation [9.8]) was fit to the dissolved aluminum concentration data using two fitting parameters, the rate constant $\mathrm{k}$ and an initial dissolved $\mathrm{Al}$ concentration (distinct from the measured value).

Table 9.29 shows the initial conditions used for the Integrated Test D kinetic calculations. These are the deterministic value \pm one standard deviation as calculated by 500 realizations of the Monte Carlo method. The Monte Carlo calculations used the estimates of laboratory error in measurements as the basis for estimating error in the initial conditions. The fitted initial Al concentrations are shown as well as the measured. In both cases, the fitted initial concentration is nearly equal to the measured value.

(a) The total hydroxide concentration, in molarity units, is the sum of the free hydroxide and one mole of hydroxide per mole of the aluminate ion complex, $\mathrm{Al}(\mathrm{OH}) 4-$. See Equation (A.65) of Mahoney et al. (2009). The normalized total hydroxide concentration is constant over time, assuming that the only reaction that affects hydroxide is the aluminum leaching reaction.

(b) The terminology "boehmite concentration" is used for convenience. It is not actually a concentration, but a ratio of moles of solid-phase Al to volume of liquid - in effect, it is the concentration increase in dissolved Al that would be generated if all the boehmite dissolved.

(c) This assumes both that all the gibbsite is dissolved by $0 \mathrm{hr}$ and that none of the boehmite has dissolved before or during heatup. Boehmite dissolution has been observed to be slow at temperatures of $60^{\circ} \mathrm{C}$ or less (Russell et al. 2009a). 
Table 9.30 contains population statistics for the scale-up factors, for boehmite dissolution rate constants, and for the boehmite leach factors at hours 16 and 24 of the leach. The statistics were predicted by the best-fit kinetic model, using 500 Monte Carlo realizations. The deterministic R2 for the model fit to the normalized dissolved data is also included in the table. The 24-hr boehmite leach factor for Integrated Test D, Batch 2 is 0.22 , which compares well with the WTP target projection of 0.21 for the final boehmite leach factor for PEP Integrated Test D.

For a cross-check, the Al mass-balance data for Integrated Test D that are given in Table 12.6 were used to calculate a leach factor over the entire process. The total $\mathrm{Al}$ inflows were $83.5 \mathrm{-kg}$ solid-phase and $16.8-\mathrm{kg}$ liquid-phase, after adjusting for the fraction of the feed that was flushed from the filter-loop into the waste tanks. The loss from the loop was not prototypic and was not included as an Al outflow in the leach factor calculations. The total $\mathrm{Al}$ outflows were $44.0 \mathrm{-kg}$ solid-phase and $61.7-\mathrm{kg}$ liquid-phase, excluding the Al lost to the loop flush. Assuming that $43.5 \%$ of the initial solid-phase Al was in gibbsite, the overall change in solid-phase $\mathrm{Al}$ implied a boehmite leach factor of 0.068 , while the overall change in liquid-phase Al implied a boehmite leach factor of 0.18 . The solid-inventory leach factor is substantially lower than either of the 24-hr batch boehmite leach factors in Table 9.30, but the liquid-inventory leach factor is consistent. A change of 4-kg Al in the Al phase distribution in the mass balance would be enough to make the overall boehmite leach factors more consistent with the batch values. That is, if the solid-phase Al outflow in Table 12.6 was 4-kg lower (a decrease of 9\%) and the liquid-phase outflow was 4-kg higher (an increase of $6 \%$ ), the overall boehmite leach factors would become 0.15 (based on solid $\mathrm{Al}$ inventory) and 0.27 (liquid inventory). The adjusted values bracket the batch boehmite leach factors, and the change required to do so is within the limits of accuracy of the mass balance.

The median scale-up factors are about equal to unity. The probability that the scale-up factor is unity or greater is about $73 \%$ for Tests $\mathrm{D} / \mathrm{D}-1$ and $53 \%$ for Tests $\mathrm{D} / \mathrm{D}-2$.

The results suggest that the conditions present during Integrated Test D produce lower scale-up factors than those in Integrated Test B. However, the Integrated Test B and Integrated Test D scale-up factors are within each other's $95 \%$ confidence intervals, and so, are not conclusively different. It should be noted that the difference in scale-up factors might be the result not of different reaction behaviors under Integrated Test B and Integrated Test D conditions, but some difference in conditions that was not completely accounted for by the kinetic model. The higher hydroxide concentration in Integrated Test D is the most obvious candidate. 
Table 9.28. Slurry Al Concentration in the Initial Diluted Slurry in Laboratory-Scale Tests for Integrated Test D

\begin{tabular}{|c|c|c|}
\hline \multirow[b]{2}{*}{ Basis (concentrations normalized to slurry mass after initial dilution) } & \multicolumn{2}{|c|}{$\begin{array}{c}\text { Integrated Test D } \\
\text { (Caustic-leach in Tank T02A at } 85^{\circ} \mathrm{C} \text { ) }\end{array}$} \\
\hline & $\begin{array}{l}\text { Laboratory-Scale } \\
\text { Test D-1 }\end{array}$ & $\begin{array}{l}\text { Laboratory-Scale } \\
\text { Test D-2 }\end{array}$ \\
\hline $\begin{array}{l}\text { Expected from PEP source sample after in-laboratory dilution } \\
\text { ( } \mu \mathrm{g} \mathrm{Al} / \mathrm{g} \text { slurry) }\end{array}$ & $25935 \pm 669$ & $25935 \pm 669$ \\
\hline Sample from initial diluted slurry in beaker ( $\mu \mathrm{g} \mathrm{Al} / \mathrm{g}$ slurry) & $22111 \pm 745$ & $22111 \pm 745$ \\
\hline $\begin{array}{l}\text { Sample from final slurry in beaker normalized to initial dilution } \\
\text { ( } \mu \mathrm{g} \mathrm{Al} / \mathrm{g} \text { slurry) }\end{array}$ & $23686 \pm 1388$ & $23643 \pm 1385$ \\
\hline $\begin{array}{l}\text { Sample from the leftover feed that did not go into beaker normalized to } \\
\text { initial dilution ( } \mu \mathrm{g} \mathrm{Al} / \mathrm{g} \text { slurry) }\end{array}$ & $22179 \pm 750$ & $22521 \pm 761$ \\
\hline Average & $22657 \pm 580$ & $22757 \pm 581$ \\
\hline
\end{tabular}

Table 9.29. Integrated Test D Initial Conditions for Kinetic Rate Constant Fit

\begin{tabular}{|c|c|c|c|c|}
\hline \multirow[b]{2}{*}{$\begin{array}{l}\text { Concentrations at } 0 \text { hours, Normalized to } \\
\text { Liquid Volume at Maximum Dilution }\end{array}$} & \multicolumn{4}{|c|}{$\begin{array}{c}\text { Integrated Test D Caustic Leaching in Tank T02A }\left(85^{\circ} \mathrm{C}\right) \\
\text { Value } \pm 1 \text { Standard Deviation }\end{array}$} \\
\hline & PEP Batch 1 & PEP Batch 2 & $\begin{array}{l}\text { Laboratory-Scale } \\
\text { Test } \mathrm{D}-1 \\
\text { (NaOH added in } \\
\text { PEP) }\end{array}$ & $\begin{array}{c}\text { Laboratory- } \\
\text { Scale Test D-2 } \\
\text { (NaOH added } \\
\text { in PEP) }\end{array}$ \\
\hline Measured initial dissolved $\mathrm{Al}(\mathrm{M})$ & $0.533 \pm 0.017$ & $0.561 \pm 0.018$ & $0.490 \pm 0.026$ & $0.539 \pm 0.028$ \\
\hline Fitted initial dissolved $\mathrm{Al}(\mathrm{M})$ & $0.539 \pm 0.013$ & $0.560 \pm 0.015$ & $0.502 \pm 0.015$ & $0.535 \pm 0.016$ \\
\hline Total hydroxide (M) & $7.41 \pm 0.16$ & $7.92 \pm 0.18$ & $7.86 \pm 0.26$ & $8.29 \pm 0.28$ \\
\hline Initial saturated $\mathrm{Al}$ at temperature $(\mathrm{M})$ & $1.70 \pm 0.07$ & $1.90 \pm 0.09$ & $1.86 \pm 0.12$ & $2.08 \pm 0.14$ \\
\hline Initial moles boehmite/liters liquid volume & $0.889 \pm 0.031$ & $0.819 \pm 0.029$ & $0.711 \pm 0.040$ & $0.679 \pm 0.042$ \\
\hline
\end{tabular}


Table 9.30. Scale-Up Factors and Related Leach Information for PEP Integrated Test D and Parallel Laboratory Tests

\begin{tabular}{|c|c|c|c|c|}
\hline & \multicolumn{2}{|c|}{$\begin{array}{c}\text { Integrated Test D } \\
\left.\text { (Caustic-Leach in Tank T02A at } 85^{\circ} \mathrm{C}\right)\end{array}$} & \multicolumn{2}{|c|}{$\begin{array}{c}\text { Laboratory-Scale Tests } \\
\left(85^{\circ} \mathrm{C}, \mathrm{NaOH} \text { added in PEP }\right)\end{array}$} \\
\hline & Batch 1 & Batch 2 & D-1 & D-2 \\
\hline $\begin{array}{l}\text { Scale-up factor, } \\
k_{P E P} / k_{l a b}\end{array}$ & $\begin{array}{l}\text { Batch } 1 \text { not used for } \\
\text { scale-up }\end{array}$ & $\mathrm{n} / \mathrm{a}$ & $\begin{array}{l}\text { low 95\%: } 0.69 \\
\text { low 50\%: } 0.98 \\
\text { median: } 1.19 \\
\text { high 50\%: } 1.43 \\
\text { high 95\%: } 2.07\end{array}$ & $\begin{array}{l}\text { low 95\%: } 0.60 \\
\text { low 50\%: } 0.85 \\
\text { median: } 1.03 \\
\text { high 50\%: } 1.22 \\
\text { high 95\%: } 1.75\end{array}$ \\
\hline $\begin{array}{l}\text { Rate constant } k \\
\left(\mathrm{hr}^{-1} *[\text { mol total }\right. \\
\left.\mathrm{OH} / \mathrm{L}]^{-1}\right)\end{array}$ & $\begin{array}{l}\text { low 95\%: } 0.0093 \\
\text { low 50\%: } 0.0117 \\
\text { median: } 0.0130 \\
\text { high 50\%: } 0.0145 \\
\text { high 95\%: } 0.0171\end{array}$ & $\begin{array}{l}\text { low 95\%: } 0.0099 \\
\text { low 50\%: } 0.0123 \\
\text { median: } 0.0140 \\
\text { high 50\%: } 0.0156 \\
\text { high 95\%: } 0.0186\end{array}$ & $\begin{array}{ll}\text { low } 95 \%: & 0.0073 \\
\text { low 50\%: } & 0.0100 \\
\text { median: } & 0.0117 \\
\text { high 50\%: } & 0.0135 \\
\text { high 95\%: } & 0.0175\end{array}$ & $\begin{array}{l}\text { low 95\%: } 0.0088 \\
\text { low 50\%: } 0.0118 \\
\text { median: } 0.0135 \\
\text { high 50\%: } 0.0156 \\
\text { high 95\%: } 0.0200\end{array}$ \\
\hline $\begin{array}{l}\text { Boehmite leach factor } \\
\text { at } 16 \mathrm{hr} \text { as predicted } \\
\text { by the best-fit kinetic } \\
\text { model }\end{array}$ & $\begin{array}{l}\text { lower 95\%: } 0.091 \\
\text { median: } 0.13 \\
\text { upper 95\%: } 0.17\end{array}$ & $\begin{array}{l}\text { lower 95\%: } 0.11 \\
\text { median: } 0.15 \\
\text { upper 95\%: } 0.20\end{array}$ & $\begin{array}{l}\text { lower 95\%: } 0.087 \\
\text { median: } 0.14 \\
\text { upper } 95 \%: 0.20\end{array}$ & $\begin{array}{l}\text { lower 95\%: } 0.11 \\
\text { median: } 0.18 \\
\text { upper 95\%: } 0.24\end{array}$ \\
\hline $\begin{array}{l}\text { Boehmite leach factor } \\
\text { at } 24 \mathrm{hr} \text { as predicted } \\
\text { by the best-fit kinetic } \\
\text { model }\end{array}$ & $\begin{array}{l}\text { lower 95\%: } 0.13 \\
\text { median: } 0.18 \\
\text { upper 95\%: } 0.23\end{array}$ & $\begin{array}{l}\text { lower 95\%: } 0.16 \\
\text { median: } 0.22 \\
\text { upper 95\%: } 0.28\end{array}$ & $\begin{array}{l}\text { lower 95\%: } 0.13 \\
\text { median: } 0.20 \\
\text { upper 95\%: } 0.29\end{array}$ & $\begin{array}{l}\text { lower 95\%: } 0.16 \\
\text { median: } 0.25 \\
\text { upper 95\%: } 0.34\end{array}$ \\
\hline $\begin{array}{l}\text { Deterministic } \mathrm{R}^{2} \text { for } \\
\text { the kinetic model fit }\end{array}$ & 0.926 & 0.962 & 0.920 & 0.954 \\
\hline
\end{tabular}

The scale-up factor and $k$ entries show the $95 \%$ confidence interval and 50\% confidence interval around the median, as calculated by 500 Monte Carlo realizations. The initial conditions consist of a deterministic estimate \pm a standard deviation calculated by 500 Monte Carlo realizations. Estimates of laboratory error in measurements were the basis for estimating all error.

\subsection{Results Based on Samples from Multiple Locations}

As discussed in Sections 7.4 and 7.5, the Shakedown and Functional Tests had shown no significant signs of poor mixing of $\mathrm{NaOH}$ or of solids stratification during caustic leaching in the T01A or T02A vessels. However, the apparent low caustic-leach factors in Integrated Test D (Section 9.5.4) raised a number of questions, including whether the slurry in the vessel was homogeneous under Integrated Test D conditions and whether slurry samples were representative. This section describes an examination of this question using archived samples taken during caustic-leach in all three of the Integrated Tests.

The slurry compositions, leach factors, boehmite dissolution rate constants, and scale factors discussed in Section 9.5 were all based on samples taken from one sampling location in each vessel (hereafter called the "primary port"). The sample location used for Integrated Test A was the inner-middle CD port of UFP-T01A or -T01B, while the middle-low CD port was used to sample UFP-T02A in Integrated Tests B and D. The only exceptions were the samples taken before $\mathrm{NaOH}$ was 
added to Batch 2 in Test D; these samples were taken from the filter-loop because of problems with the CD sampling system.

The aluminum concentrations in samples that had been taken from non-primary ports at $0 \mathrm{hr}$ during the batches used for scale-up calculations were determined and compared to those of primary-port samples. The boehmite dissolution rate constants and scale-up factors were also re-calculated using an average of all 0 -hr concentrations instead of an average of the 0 -hr primary port concentrations alone, as in Section 9.5. These multi-port scale-up factors are reported as a matter of interest and to give insight into the uncertainty of the caustic-leach scale-up factors. They were not selected as the scale-up factors to use for design purposes.

The samples taken from non-primary ports at $0 \mathrm{hr}$ were centrifuged, the supernatant liquid portion was decanted from the centrifuged solids, and both portions were archived, since the Test Plan did not require characterization of the multi-port samples. To support the tests for homogeneity and sample representativeness, the centrifuged solids portions of the non-primary samples were retrieved and analyzed for Al. The archived liquids were analyzed by IC (which provided liquid tracer concentrations) but were not analyzed by ICP for dissolved Al, since the intent was to look for differences in the $\mathrm{Al}$ in the solid phase. The centrifuged solids fractions in the non-primary samples were used, together with the non-primary $\mathrm{Al}$ concentrations in centrifuged solids and the primary concentration of dissolved $\mathrm{Al}$, to calculate slurry Al concentrations in the non-primary samples. (Equation [A.58] from Mahoney et al. [2009] was used.) The slurry Al concentrations that were obtained are shown in Table 9.31, Table 9.32, and Table 9.33 for Integrated Test A, Batch 1, Integrated Test B, Batch 2, and Integrated Test D, Batch 2 respectively.

For the batches from Integrated Tests A and D, the slurry Al concentrations appeared to be slightly higher at the primary port than at non-primary ports. The higher concentrations came from the centrifuged solids portion of the slurry, since the same dissolved Al concentration was used for all ports. The $\mathrm{Al}$ recoveries for the laboratory controls (obsidian and basalt rock) were reviewed, as were the $\mathrm{Al}$ measurements for the PEP solid control samples (a matrix similar to the centrifuged solids of raw simulant). In all cases the recoveries were closer to unity for the batches in which the primary-port samples were analyzed than for the batches with the non-primary samples. The latter had recoveries of less than one $(95 \%$ to $98 \%)$.

A comparison of these QC results for the different preparative and analytical batches in which the primary and non-primary samples were included showed the following ratios of concentrations for centrifuged-solids $\mathrm{Al}$ concentrations when the mean of the primary-port samples was divided by the mean of the non-primary-port samples:

- Test A, Batch 1: 109\% for the data samples, 103\% for the PEP solid control samples.

- Test B, Batch 2: $99 \%$ for the data samples, 105\% for the PEP solid control samples.

- Test D, Batch 2: $104 \%$ for the data samples, $106 \%$ for the PEP solid control samples.

The ratios of primary to non-primary for the laboratory controls were also all greater than one, showing that the bias was not strongly dependent on the nature of the solid matrix. In two out of the three cases the ratios showed bias in the same direction (greater than one) for the data samples and the PEP solid control samples. This suggests that the difference in the centrifuged-solids Al concentrations was at 
least partly analytical in origin, rather than being entirely the result of a physical difference between samples. This result is consistent with the finding of the Shakedown/Functional Test (Section 7.5) that solids stratification was not present during caustic-leach.

The non-primary centrifuged-solids Al concentrations were averaged into the 0 -hr concentration used for kinetic calculations. The non-primary liquid tracer concentrations were also averaged with the primary port measurements. Because the difference between concentrations at primary and non-primary ports was analytical rather than physical in origin, the averaging of the two data sets could not be carried out by simply adding all the samples' concentrations together and dividing by the total number of samples. This approach would have overestimated the significance of the non-primary samples. Instead, the triplicate sample results at the primary port were averaged into a primary mean; the non-primary sample results were averaged into a non-primary mean; and the primary and non-primary means were averaged together to obtain the multi-port mean concentration. The standard deviations of the averages of the sets of samples were combined into a standard deviation of the multi-port mean using a similar two-step process.

Boehmite dissolution kinetic calculations were performed in the same manner described in Section 9.5, but using the multi-port concentrations of $\mathrm{Al}$ and liquid tracer at $0 \mathrm{hr}$ to determine the boehmite concentration at the initial condition. Table 9.34 shows the rate constants and scale-up factors for the primary-port and multi-port initial conditions. The arithmetic means of each pair of scale-up factors (for the two parallel tests) were:

- Test A, Batch 1: 0.88 for the single port, 0.94 for multiple ports.

- Test B, Batch 2: 1.38 for the single port, 1.32 for multiple ports.

- Test D, Batch 2: 1.10 for the single port, 1.02 for multiple ports.

In all cases the scale-up factors were nearer unity for multi-port than for single-port initial conditions. It is worth noting that if the change in analytical recovery from the primary-port batches to the non-primary port batches had happened to be in the opposite direction, the scale-up factors would also have changed in the opposite direction.

Generally speaking, it would be expected that taking advantage of more data would produce a more meaningful result; this logic would lead to choosing the multi-port scale-up factors as the values for design purposes. However, Al recoveries were less than unity in the non-primary samples (though still well within the range required by QA) and were nearer unity in the primary-port samples. Because of this and because the change in scale-up factors produced by using multi-port data was well within the uncertainty of the calculation, the primary-port scale-up factors were chosen for design use. 
Table 9.31. Aluminum Concentrations at Multiple CD Ports, Integrated Test A Batch 1

\begin{tabular}{|c|c|c|c|}
\hline \multirow[b]{3}{*}{ CD Port Elevation } & \multirow{2}{*}{\multicolumn{3}{|c|}{$\begin{array}{l}\text { Slurry Al Concentration } \\
(\mu \mathrm{g} \mathrm{Al} / \mathrm{g} \text { slurry) at } 0 \mathrm{hr} \text { of Leach } \\
\text { CD Port Radial Location }\end{array}$}} \\
\hline & & & \\
\hline & Inner & Middle & Outer \\
\hline High & 13200 & 13200 & 13300 \\
\hline Middle & $\begin{array}{l}13900 \\
13800 \\
13800\end{array}$ & 13100 & 13400 \\
\hline Low & 13100 & 13200 & 13400 \\
\hline
\end{tabular}

Table 9.32. Aluminum Concentrations at Multiple CD Ports, Integrated Test B Batch 2

\begin{tabular}{|c|c|c|c|}
\hline \multirow[b]{3}{*}{ CD Port Elevation } & \multirow{2}{*}{\multicolumn{3}{|c|}{$\begin{array}{l}\text { Slurry Al Concentration } \\
\text { ( } \mu \mathrm{g} \mathrm{Al} / \mathrm{g} \text { slurry) at } 0 \mathrm{hr} \text { of Leach } \\
\text { CD Port Radial Location }\end{array}$}} \\
\hline & & & \\
\hline & Inner & Middle & Outer \\
\hline High & $\mathrm{n} / \mathrm{m}$ & 32600 & 32700 \\
\hline Middle & 32700 & 32900 & 32700 \\
\hline \multirow{3}{*}{ Low } & \multirow{3}{*}{32600} & 31900 & \multirow{3}{*}{32400} \\
\hline & & 32600 & \\
\hline & & 32700 & \\
\hline \multicolumn{4}{|c|}{$\begin{array}{l}\text { Triplicate samples were taken at the middle-low port, which was the } \\
\text { primary sampling port. } \\
\text { " } \mathrm{n} / \mathrm{m} \text { " = not measured. The inner-high sample could not be taken } \\
\text { because of low slurry level. }\end{array}$} \\
\hline
\end{tabular}


Table 9.33. Aluminum Concentrations at Multiple CD Ports, Integrated Test D Batch 2

\begin{tabular}{|c|c|c|c|}
\hline \multirow[b]{3}{*}{ CD Port Elevation } & \multirow{2}{*}{\multicolumn{3}{|c|}{$\begin{array}{c}\text { Slurry Al Concentration } \\
\text { ( } \mu \mathrm{g} \mathrm{Al} / \mathrm{g} \text { slurry) at } 0 \mathrm{hr} \text { of Leach } \\
\text { CD Port Radial Location }\end{array}$}} \\
\hline & & & \\
\hline & Inner & Middle & Outer \\
\hline High & $\mathrm{n} / \mathrm{m}$ & 30100 & 30400 \\
\hline Middle & 30600 & 29900 & $\mathrm{n} / \mathrm{m}$ \\
\hline Low & 30400 & $\begin{array}{l}31000 \\
30300 \\
31200\end{array}$ & 29900 \\
\hline \multicolumn{4}{|c|}{$\begin{array}{l}\text { Triplicate samples were taken at the middle-low port, which was the } \\
\text { primary sampling port. } \\
\text { " } \mathrm{n} / \mathrm{m} \text { " = not measured. The inner-high sample could not be taken } \\
\text { because of low slurry level, and the outer-middle sample was used for } \\
\text { the FTIR study described in Section 9.5.4. }\end{array}$} \\
\hline
\end{tabular}

Table 9.34. Comparison of Single-Port and Multi-Port Kinetic Results and Scale-Up Factors

\begin{tabular}{|c|c|c|}
\hline & $\begin{array}{l}\text { Rate Constant } k \\
\left(\mathrm{hr}^{-1} *[\mathrm{~mol} \text { total } \mathrm{OH} / \mathrm{L}]^{-1}\right)\end{array}$ & $\begin{array}{l}\text { Scale-Up Factor, } k_{P E P} / k_{\text {lab }} \\
\text { (values for both laboratory-scale } \\
\text { parallel tests are shown, } \\
\text { separated by commas) }\end{array}$ \\
\hline $\begin{array}{l}\text { PEP Test A, Batch } 1 \\
\text { (Caustic-leach in Tank T01A at } 98^{\circ} \mathrm{C} \text { ) } \\
\text { Using Primary Port Concentrations }\end{array}$ & $\begin{array}{l}\text { low 95\%: } 0.0128 \\
\text { median: } 0.0186 \\
\text { upper 95\%: } 0.0250\end{array}$ & $\begin{array}{l}\text { low } 95 \%: 0.44,0.55 \\
\text { median: } 0.79,0.95 \\
\text { upper 95\%: } 1.45,1.64\end{array}$ \\
\hline $\begin{array}{l}\text { PEP Test A, Batch } 1 \\
\text { (Caustic-leach in Tank T01A at } 98^{\circ} \mathrm{C} \text { ) } \\
\text { Using Multi-Port Concentrations }\end{array}$ & $\begin{array}{l}\text { low 95\%: } 0.0140 \\
\text { median: } 0.0201 \\
\text { upper 95\%: } 0.0268\end{array}$ & $\begin{array}{l}\text { low } 95 \%: 0.48,0.59 \\
\text { median: } 0.86,1.02 \\
\text { upper } 95 \%: 1.55,1.76\end{array}$ \\
\hline $\begin{array}{l}\text { PEP Test B, Batch } 2 \\
\text { (Caustic-leach in Tank T02A at } 98^{\circ} \mathrm{C} \text { ) } \\
\text { Using Primary Port Concentrations }\end{array}$ & $\begin{array}{l}\text { low } 95 \%: 0.0182 \\
\text { median: } 0.0251 \\
\text { upper } 95 \%: 0.0344\end{array}$ & $\begin{array}{l}\text { low } 95 \%: 0.89,0.77 \\
\text { median: } 1.51,1.26 \\
\text { upper } 95 \%: 2.63,2.14\end{array}$ \\
\hline $\begin{array}{l}\text { PEP Test B, Batch } 2 \\
\text { (Caustic-leach in Tank T02A at } 98^{\circ} \mathrm{C} \text { ) } \\
\text { Using Multi-Port Concentrations }\end{array}$ & $\begin{array}{l}\text { low } 95 \%: 0.0174 \\
\text { median: } 0.0240 \\
\text { upper } 95 \%: 0.0329\end{array}$ & $\begin{array}{l}\text { low 95\%: } 0.84,0.73 \\
\text { median: } 1.44,1.20 \\
\text { upper 95\%: } 2.50,2.05\end{array}$ \\
\hline $\begin{array}{l}\text { PEP Test D, Batch } 2 \\
\text { (Caustic-leach in Tank T02A at } 85^{\circ} \mathrm{C} \text { ) } \\
\text { Using Primary Port Concentrations }\end{array}$ & $\begin{array}{l}\text { low } 95 \%: 0.0099 \\
\text { median: } 0.0140 \\
\text { upper } 95 \%: 0.0186\end{array}$ & $\begin{array}{l}\text { low 95\%: } 0.69,0.60 \\
\text { median: } 1.19,1.03 \\
\text { upper 95\%: } 2.07,1.75\end{array}$ \\
\hline $\begin{array}{l}\text { PEP Test D, Batch } 2 \\
\text { (Caustic-leach in Tank T02A at } 85^{\circ} \mathrm{C} \text { ) } \\
\text { Using Multi-Port Concentrations }\end{array}$ & $\begin{array}{l}\text { low 95\%: } 0.0091 \\
\text { median: } 0.0128 \\
\text { upper 95\%: } 0.0172\end{array}$ & $\begin{array}{l}\text { low } 95 \%: 0.62,0.54 \\
\text { median: } 1.09,0.94 \\
\text { upper } 95 \%: 1.88,1.59\end{array}$ \\
\hline
\end{tabular}




\subsection{Presence of Excess Caustic}

\subsubsection{Introduction}

In planning the PEP tests, the amount of $\mathrm{NaOH}$ reagent required for caustic leaching was determined based partly on providing a high enough reaction rate to dissolve the target boehmite by the end of leach, and partly on ensuring aluminum would remain in solution after cooling and after the dilution produced by washing. The information needed to calculate the required $\mathrm{NaOH}$ included 1) the amount of gibbsite present in the slurry and its laboratory-measured solubility under the reaction conditions, 2) the mass of boehmite expected to be dissolved given the initial mass, the laboratory-measured temperature-dependent boehmite dissolution rate constant, and the total elevated-temperature reaction time, and 3) the aluminate solubility as a function of caustic concentration, as given by an empirical model developed by Misra (1970). A calculation method was developed by BNI to determine the mass of $\mathrm{NaOH}$ reagent required for each batch and predict the hydroxide needed to maintain Al in solution after leaching. Because the relation between hydroxide concentration and gibbsite solubility was uncertain, an extra $10 \%$ (or more in the case of Integrated Test $\mathrm{D}$ ) was added to the minimum required $\mathrm{NaOH}$ to ensure that all the dissolved aluminum would remain in solution.

As per Table 9.1, one of the success criteria of the PEP caustic leaching tests was to "estimate the quantity of excess hydroxide added in the (caustic-leach) process that may not be needed to keep aluminate in solution following filtration." This issue cannot be directly addressed since it requires precise knowledge of aluminum trihydroxide (gibbsite) solubility for the conditions of the experiment. The empirical model developed by Misra (1970) was based on experimental data collected using reagent grade $\mathrm{Al}_{2} \mathrm{O}_{3}-\mathrm{Na}_{2} \mathrm{O}-\mathrm{H}_{2} \mathrm{O}$ systems. Strictly speaking, it cannot be applied here because the PEP simulant contains a wide variety of additional cationic and anionic species. Therefore a quantitative determination of the excess hydroxide concentration is not calculated.

A qualitative measure of the success of adding excess hydroxide above the minimum predicted as needed to maintain $\mathrm{Al}$ in solution can be obtained by determining the amount of aluminum that can be accommodated by the excess caustic present in the permeate. A separate laboratory experiment was designed to determine this and involved adding extra gibbsite to samples of the PEP test permeate solutions and analyzing the filtrate to determine the amount of aluminum that dissolved.

\subsubsection{Experimental Procedure}

For the laboratory study, $\sim 1$-L permeate samples of the caustic leaching and washing solutions were collected from the filter-loop during PEP Integrated Tests A, B, and D. Caustic leaching solutions were collected immediately after the first post-caustic-leach solids concentration, and permeate washing solutions were collected after every wash batch. Permeate wash samples containing $~ 3.5-\mathrm{M}$ Na were selected for the study by estimating the wash batch number at which the Na concentration had dropped to the specified concentration. Since a limited number of wash samples had been analyzed for $\mathrm{Na}$, the sample selection was based on interpolation of the Na concentration values.

Triplicate $\sim 365$-gram samples were weighed from each PEP test sample and apportioned into separate bottles, and $\sim 15$ grams were removed from each bottle, filtered, and then divided for analysis (density and TDS, ICP for dissolved metals, IC for dissolved anions, TIC and TOC, and titration for free $\mathrm{OH}^{-}$). The 
data on the initial compositions and densities of the permeate liquids will support BNI computational modeling of $\mathrm{Al}$ solubility.

After the initial characterization samples were taken, $\sim 14$-g gibbsite was added to each sample bottle and weights were taken, and then the bottles were placed in a $25^{\circ} \mathrm{C}$ shaker bath. Aliquots of approximately 10-mL each were removed from each sample bottle after 3 days, 1, 2, 4, 6 and 11 weeks, and sent for anion and dissolved metal analysis.

\subsubsection{Results}

\subsubsection{Initial Permeate Sample Analysis}

The compositions of the six initial permeate samples are shown in Table 9.35. As expected, the wash samples (AW, BW, and DW) have lower densities, total dissolved solid weight percents, and aluminate, sodium, hydroxide, and anion concentrations than seen in the leach samples (AL, BL, and DL). Only sodium and aluminum concentrations are reported from the ICP analysis since the concentrations of the other metal components were near or below the detection limit and not significant in terms of the overall charge and mass balance.

Table 9.35. Composition of Initial Permeate Samples

\begin{tabular}{lcccccc}
\hline & $\begin{array}{c}\text { AW } \\
\text { Test A, } \\
\text { Puring } \\
\text { wash) }\end{array}$ & $\begin{array}{c}\text { BW } \\
\text { (Test B, } \\
\text { during } \\
\text { wash) }\end{array}$ & $\begin{array}{c}\text { DW } \\
\text { Test D, } \\
\text { during } \\
\text { wash) }\end{array}$ & $\begin{array}{c}\text { AL } \\
\text { (Test A, } \\
\text { before } \\
\text { wash) }\end{array}$ & $\begin{array}{c}\text { BL } \\
\text { (Test B, } \\
\text { before } \\
\text { wash) }\end{array}$ & $\begin{array}{c}\text { DL } \\
\text { (Test D, } \\
\text { before } \\
\text { wash) }\end{array}$ \\
\hline Density $(\mathrm{g} / \mathrm{ml})$ & 1.178 & 1.248 & 1.214 & 1.307 & 1.312 & 1.348 \\
$\mathrm{Wt} \% \mathrm{TDS}$ & $21.3 \%$ & $26.3 \%$ & $24.1 \%$ & $33.5 \%$ & $35.4 \%$ & $37.8 \%$ \\
$\mathrm{Al}(\mu \mathrm{g} / \mathrm{g})$ & 5377 & 12600 & 8820 & 8637 & 16467 & 13367 \\
\hline $\mathrm{Na}(\mu \mathrm{g} / \mathrm{g})$ & 78033 & 97300 & 96133 & 127000 & 129000 & 147333 \\
\hline Free hydroxide $(\mathrm{M})$ & 2.61 & 3.95 & 4.11 & 4.58 & 5.50 & 6.95 \\
\hline Total hydroxide $(\mathrm{M})$ & 2.85 & 4.53 & 4.51 & 5.00 & 6.30 & 7.61 \\
\hline Chloride $(\mu \mathrm{g} / \mathrm{g})$ & 388 & 289 & 209 & 642 & 386 & 316 \\
\hline Nitrate $(\mu \mathrm{g} / \mathrm{g})$ & 28368 & 23763 & 16447 & 48257 & 32020 & 25557 \\
\hline Nitrite $(\mu \mathrm{g} / \mathrm{g})$ & 7457 & 6570 & 4739 & 10906 & 8730 & 7219 \\
\hline Oxalate $(\mu \mathrm{g} / \mathrm{g})$ & 740 & 255 & 239 & 93 & 49 & $19^{(\mathrm{a})}$ \\
\hline Phosphate $(\mu \mathrm{g} / \mathrm{g})$ & 2719 & 1329 & 1281 & 1168 & 875 & 859 \\
Sulfate $(\mu \mathrm{g} / \mathrm{g})$ & 5248 & 4643 & 4415 & 8628 & 6120 & 4868 \\
\hline TIC $(\mu \mathrm{g} / \mathrm{g})$ & 2340 & 2083 & 1820 & 3879 & 2659 & 2417 \\
\hline TOC $(\mu \mathrm{g} / \mathrm{g})$ & 300 & 200 & 199 & 125 & 146 & 198 \\
\hline
\end{tabular}

(a) Denotes concentration is at the detection limit. 


\subsubsection{Increase in Aluminum Solubility}

The measured aluminum concentrations were converted into molar units. The difference between the initial permeate concentration and the values measured during the test are plotted in Figure 9.34 through Figure 9.36 for PEP Integrated Tests A, B, and D, respectively. The error bars in the plots represent 2 standard deviations, based on preparative and analytical uncertainty. The plots indicate that all samples had reached equilibrium by the time the test was complete at 11 weeks. Table 9.36 through Table 9.38 contain the source data for these figures.

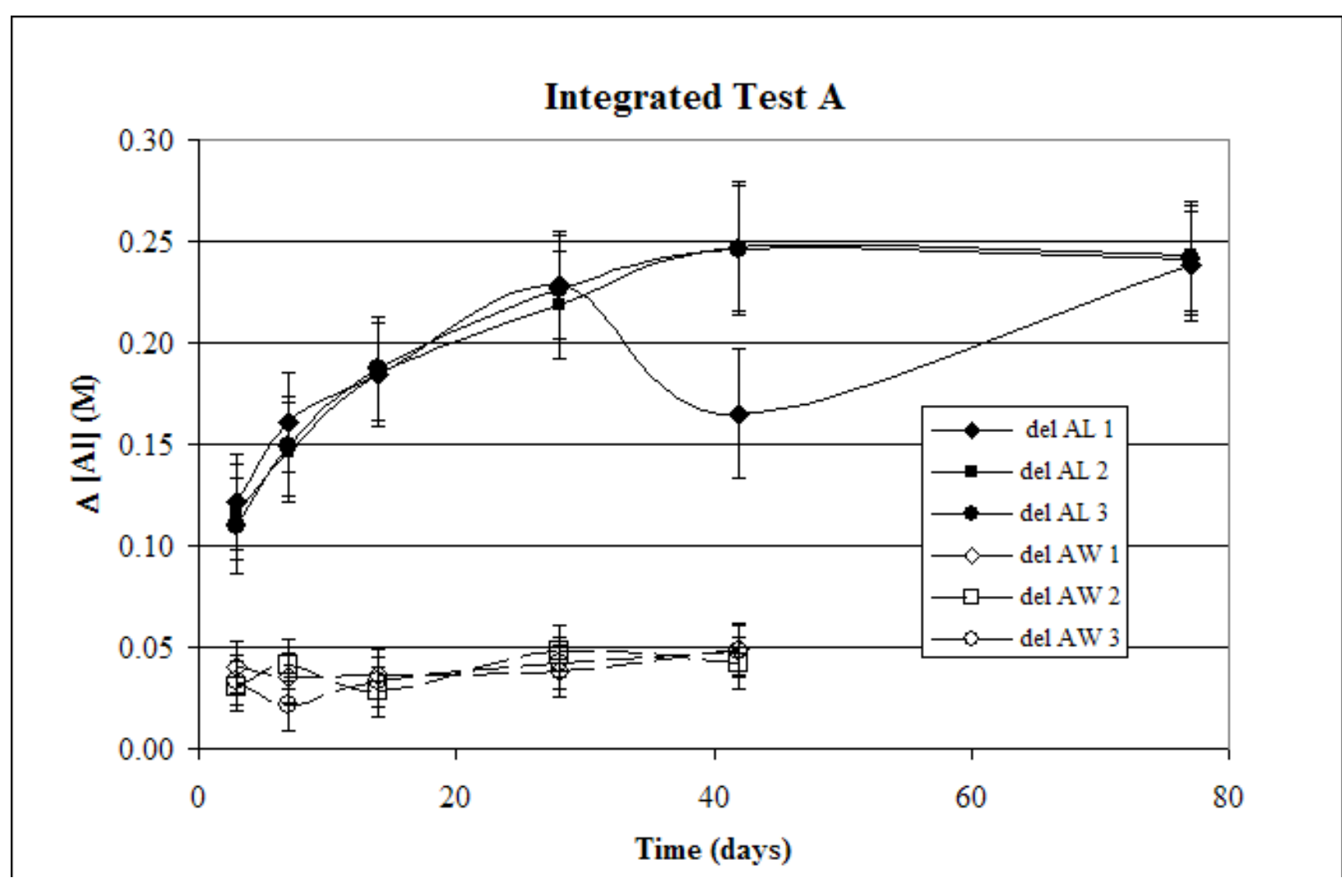

Figure 9.34. Increase in Dissolved Aluminum (change from initial) as a Function of Time After 14-g Gibbsite Was Added to Integrated Test A Permeate Samples. The concentrations for the Integrated Test A wash permeate samples (AW 1, AW 2, and AW 3) appear to have stabilized within 28 days of the initial treatment. It was not until after 42 days that the aluminum concentrations in the caustic-leach permeate samples (AL 1, AL 2, and AL 3) stabilized. 


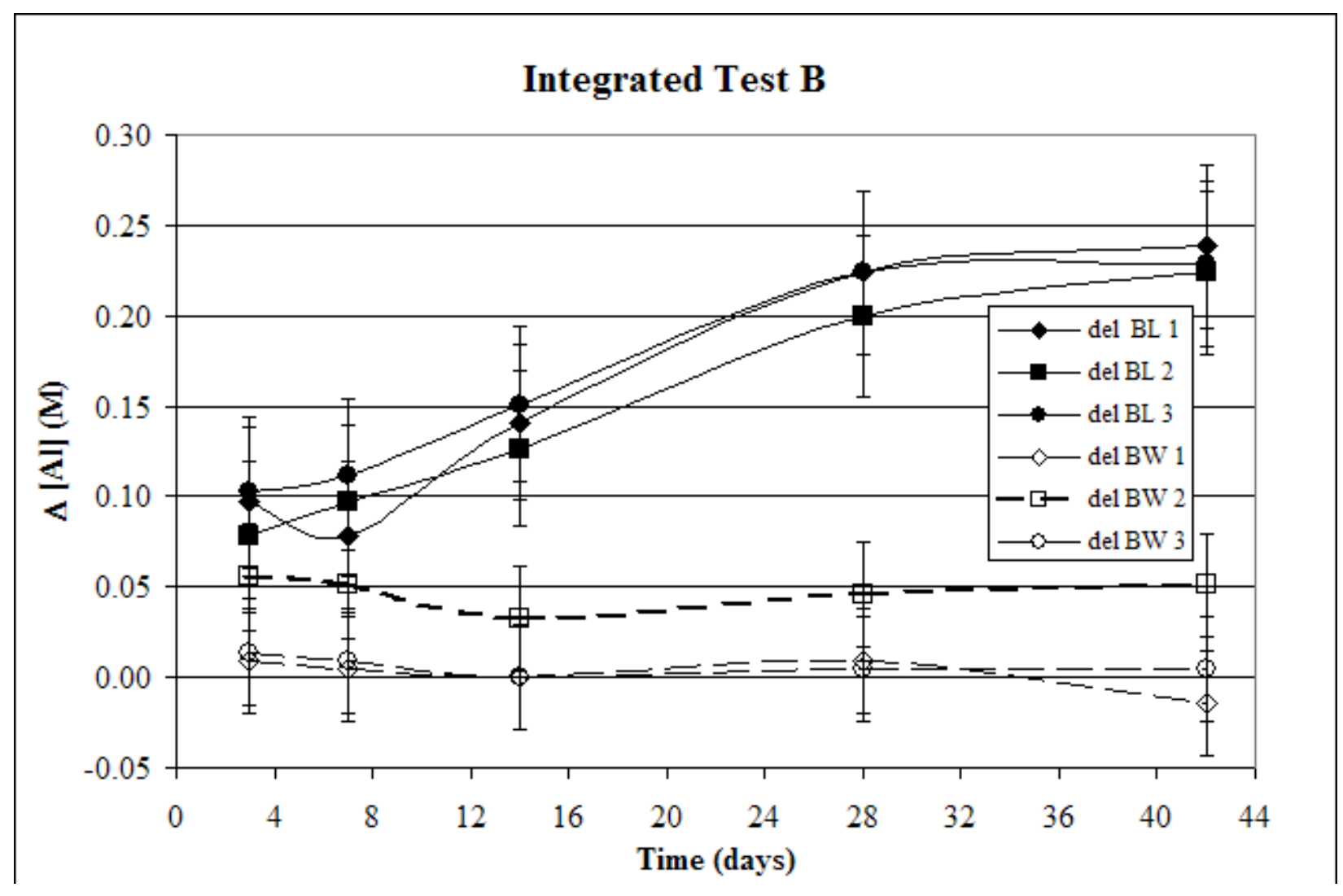

Figure 9.35. Increase in Dissolved Aluminum (change from initial) as a Function of Time After 14-g Gibbsite Was Added to Integrated Test B Permeate Samples. The concentrations for the Integrated Test B wash permeate samples (BW 1, BW 2, and BW 3) appear to have stabilized within 3 days of the initial treatment. The aluminum concentrations in the caustic-leach permeate samples (BL 1, BL 2, and BL 3) stabilized after 28 days. 


\section{Integrated Test D}

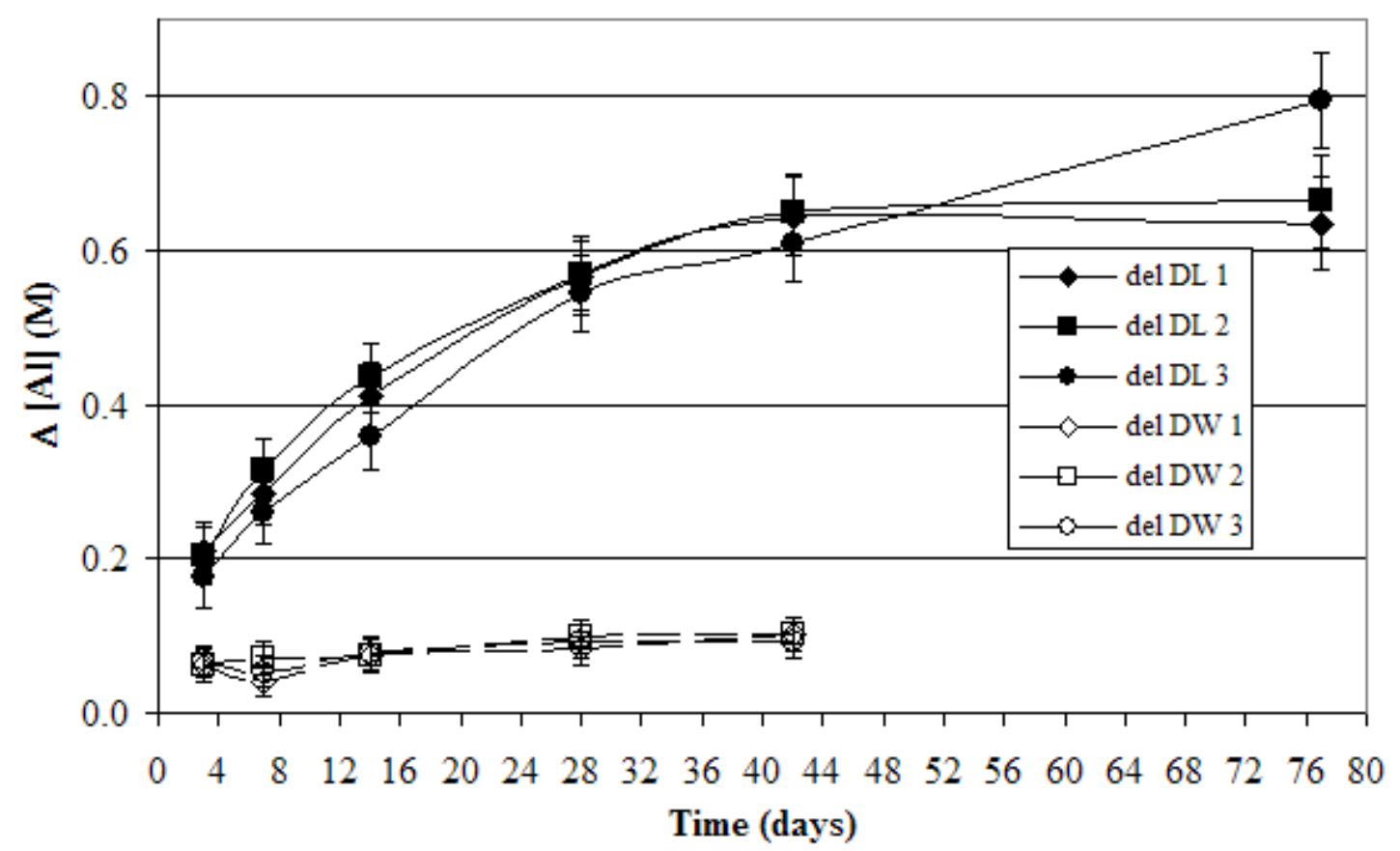

Figure 9.36. Increase in Dissolved Aluminum (change from initial) as a Function of Time After 14-g Gibbsite was Added to Integrated Test D Permeate Samples. The concentrations for the Integrated Test D wash permeate samples (DW 1, DW 2, and DW 3) appear to have stabilized within 28 days of the initial treatment. The aluminum concentrations in the caustic-leach permeate samples (DL 1, DL 2, and DL 3) did not stabilize until 42 days after the initial treatment.

Table 9.36. Source Data for Figure 9.34; Aluminum Dissolution for Integrated Test A Samples

\begin{tabular}{ccccccc}
\hline & \multicolumn{5}{c}{ Dissolved Al Concentration (M) } \\
\cline { 2 - 7 } Days Since & Sample & Sample & Sample & Sample & Sample & Sample \\
Gibbsite Added & AL 1 & AL 2 & AL 3 & AW 1 & AW 2 & AW 3 \\
\hline 0 & 0.426 & 0.411 & 0.418 & 0.235 & 0.233 & 0.237 \\
3 & 0.547 & 0.528 & 0.528 & 0.275 & 0.263 & 0.270 \\
7 & 0.586 & 0.557 & 0.567 & 0.270 & 0.274 & 0.258 \\
14 & 0.610 & 0.596 & 0.606 & 0.272 & 0.261 & 0.270 \\
28 & 0.654 & 0.630 & 0.644 & 0.273 & 0.281 & 0.279 \\
42 & 0.591 & 0.659 & 0.664 & 0.284 & 0.275 & 0.284 \\
77 & 0.664 & 0.654 & 0.659 & $\mathrm{n} / \mathrm{m}$ & $\mathrm{n} / \mathrm{m}$ & $\mathrm{n} / \mathrm{m}$ \\
\hline All
\end{tabular}

All concentrations are dissolved Al in molar units. The ICP analysis uncertainty is assumed to be $6 \%$ based on laboratory uncertainties provided for similar samples from PEP.

" $\mathrm{n} / \mathrm{m} "=$ not measured. The AW samples were considered to have stabilized by 42 days, so the 77 -day samples were not taken. 
Table 9.37. Source Data for Figure 9.35, Aluminum Dissolution for Integrated Test B Samples

\begin{tabular}{ccccccc}
\hline Days Since & \multicolumn{5}{c}{ Dissolved Al Concentration (M) } \\
\cline { 2 - 7 } Gibbsite & Sample & Sample & Sample & Sample & Sample & Sample \\
Added & BL 1 & BL 2 & BL 3 & BW 1 & BW 2 & BW 3 \\
\hline 0 & 0.798 & 0.803 & 0.803 & 0.597 & 0.560 & 0.592 \\
3 & 0.895 & 0.881 & 0.905 & 0.606 & 0.615 & 0.606 \\
7 & 0.876 & 0.900 & 0.915 & 0.602 & 0.611 & 0.602 \\
14 & 0.939 & 0.929 & 0.953 & 0.597 & 0.592 & 0.592 \\
28 & 1.022 & 1.002 & 1.026 & 0.606 & 0.606 & 0.597 \\
42 & 1.036 & 1.026 & 1.031 & 0.583 & 0.611 & 0.597
\end{tabular}

All concentrations are dissolved Al in molar units. The ICP analysis uncertainty is assumed to be $6 \%$ based on laboratory uncertainties provided for similar samples from PEP.

Table 9.38. Source Data for Figure 9.36, Aluminum Dissolution for Integrated Test D Samples

\begin{tabular}{ccccccc}
\hline Days Since & \multicolumn{5}{c}{ Dissolved Al Concentration (M) } \\
\cline { 2 - 6 } $\begin{array}{c}\text { Gibbsite } \\
\text { Added }\end{array}$ & Sample & Sample & Sample & Sample & Sample & Sample \\
& DL 1 & DL 2 & DL 3 & DW 1 & DW 2 & DW 3 \\
\hline 0 & 0.675 & 0.660 & 0.670 & 0.397 & 0.393 & 0.401 \\
3 & 0.885 & 0.865 & 0.845 & 0.459 & 0.455 & 0.468 \\
7 & 0.960 & 0.975 & 0.930 & 0.439 & 0.464 & 0.455 \\
14 & 1.085 & 1.095 & 1.030 & 0.473 & 0.468 & 0.477 \\
28 & 1.240 & 1.230 & 1.215 & 0.482 & 0.491 & 0.495 \\
42 & 1.320 & 1.310 & 1.280 & 0.500 & 0.495 & 0.495 \\
77 & 1.310 & 1.325 & 1.464 & $\mathrm{n} / \mathrm{m}$ & $\mathrm{n} / \mathrm{m}$ & $\mathrm{n} / \mathrm{m}$ \\
\hline
\end{tabular}

All concentrations are dissolved $\mathrm{Al}$ in molar units. The ICP analysis uncertainty is assumed to be $6 \%$ based on laboratory uncertainties provided for similar samples from PEP.

" $\mathrm{n} / \mathrm{m} "=$ not measured. The DW samples were considered to have stabilized by 42 days, so the 77 -day samples were not taken.

\subsubsection{Discussion and Conclusions}

Overall, the results show that in five of the six cases, the permeate solutions were capable of dissolving gibbsite to an extent that increased the initial dissolved $\mathrm{Al}$ concentration by $10 \%$ or more. The exception was the wash permeate from Integrated Test B, whose initial Al concentration was the highest of the three wash samples.

The leach permeate samples were found to dissolve more gibbsite than the wash samples. This is an expected result since the hydroxide concentrations in post-leach permeate are greater than those in the wash permeate solutions.

The BW wash solution stabilized 3 days after excess gibbsite was added and, as Table 9.39 shows, there was only a small increase, $3 \%$, in the dissolved aluminum concentration. The AW and DW wash solutions needed 28 days to stabilize, and the increases in dissolved aluminum concentrations were 19\% and $24 \%$, respectively. Given the magnitude of the standard deviation on the Integrated Test B wash 
result, it can be concluded that no statistically significant amount of gibbsite dissolved, indicating that there was no significant excess caustic present in this sample.

The leach solutions took longer to stabilize after excess gibbsite was added. This is to be expected since these solutions have much higher free hydroxide levels, compared with the wash solutions. The BL leach solution required 4 weeks to stabilize and was capable of dissolving $28 \%$ more aluminum. The AL and DL leach solutions did not stabilize until after 6 weeks had passed, and the increases in dissolved aluminum were 58 and $96 \%$, respectively.

Table 9.39. Final Dissolved Al Concentration Increase Resulting from Gibbsite Addition

\begin{tabular}{lcccc}
\hline & $\begin{array}{c}\text { Initial } \\
\text { Dissolved Al } \\
(\mathrm{M})\end{array}$ & $\begin{array}{c}\text { Additional Al } \\
\text { Dissolved } \\
(\mathrm{M})\end{array}$ & $\begin{array}{c}\text { Uncertainty of } \\
\text { Additional Al } \\
(\mathrm{M})\end{array}$ & $\begin{array}{c}\text { Percent } \\
\text { Increase in } \\
\text { Dissolved } \\
\mathrm{Al}\end{array}$ \\
\hline Solution & 0.235 & 0.044 & 0.013 & 19 \\
$\mathrm{AW}$ & 0.583 & 0.019 & 0.029 & 3 \\
\hline $\mathrm{DW}$ & 0.397 & 0.096 & 0.022 & 24 \\
$\mathrm{AL}$ & 0.418 & 0.244 & 0.029 & 58 \\
\hline $\mathrm{BL}$ & 0.801 & 0.223 & 0.045 & 28 \\
$\mathrm{DL}$ & 0.668 & 0.642 & 0.056 & 96 \\
\hline $\begin{array}{l}\text { The uncertainty of the increases in dissolved Al concentration was calculated as } \\
\text { the sum of the squares of the uncertainties of the concentrations whose difference } \\
\text { was taken. Uncertainty is equal to two standard deviations. }\end{array}$ \\
\hline
\end{tabular}

As was noted earlier, Misra's empirical model of gibbsite solubility cannot be used to quantify the excess caustic because it was developed using data collected from reagent grade reagent grade $\mathrm{Al}_{2} \mathrm{O}_{3}-\mathrm{Na}_{2} \mathrm{O}-\mathrm{H}_{2} \mathrm{O}$ systems and strictly speaking is applicable only to those conditions. The PEP simulant contains a wide variety of additional cationic and anionic species, so there is not expected to be good agreement between the aluminum solubility measured in these excess caustic tests and that calculated using Misra's equation. Figure 9.37 shows how much divergence there is between theory and the PEP experiments. The figure shows the final stabilized aluminum concentrations as a function of the total hydroxide present in the permeate solutions, where the total hydoxide (molar) is equal to the sum of the initial molar concentrations of free hydroxide and dissolved aluminum. As can be seen, the Misra model does a good job of predicting equilibrium solubilities for the AW, AL and DL samples, but it underpredicts the equilibrium solubility for both BW and BL samples by about $10 \%$ and overpredicts for the DW sample by $9 \%$. 


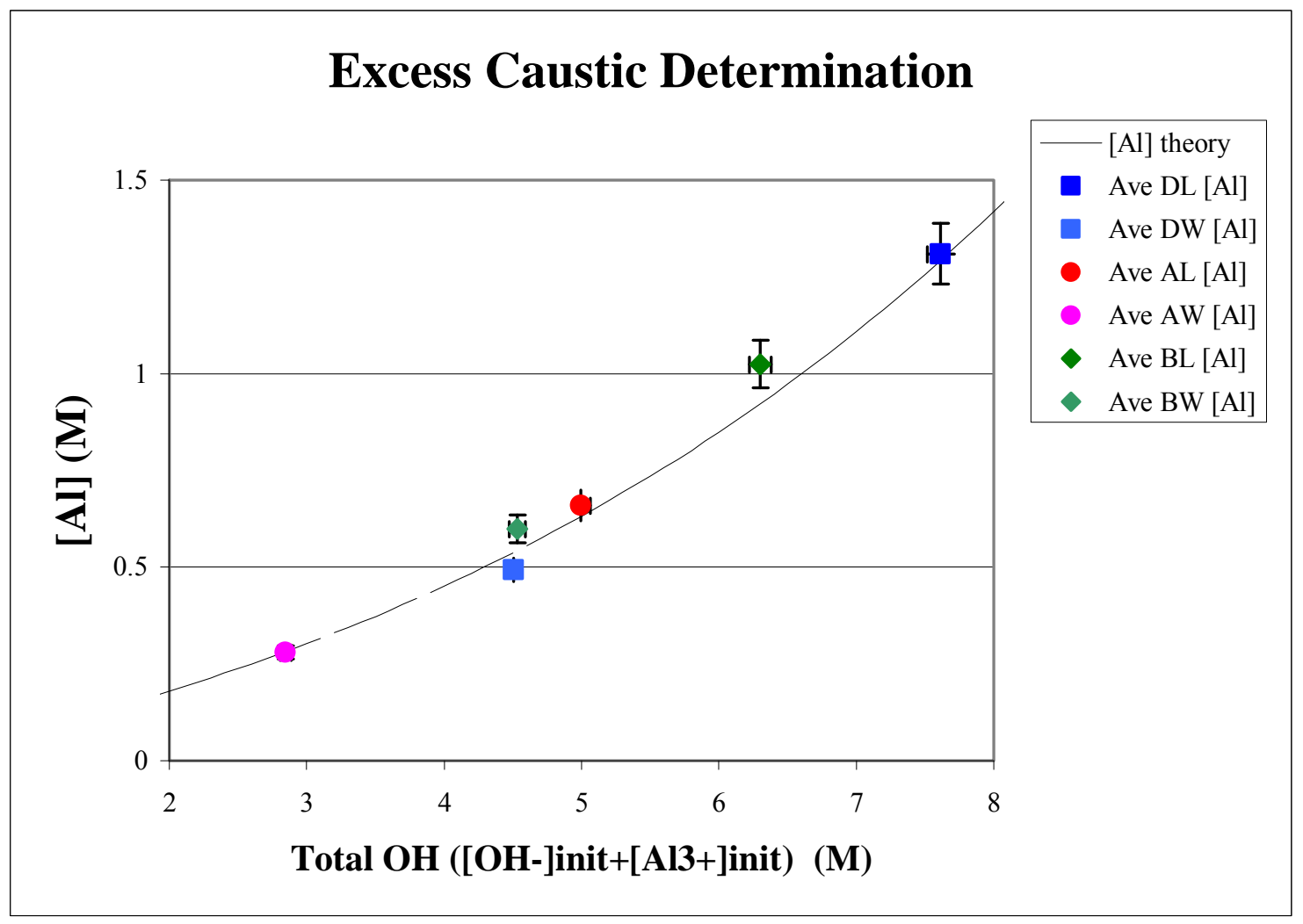

Figure 9.37. Plot of the Final Dissolved Aluminum Concentrations as a Function of the Initial Total Hydroxide Present in the Permeate Samples. The symbols denote the different test samples, the solid line plots the saturated aluminum concentrations predicted using Misra's empirical model.

\subsection{Conclusions}

\subsubsection{Temperature Control and Condensate Accumulation}

Neither the temperature profile nor the condensate accumulation rates in the PEP could be expected to be naturally prototypic of the PTF because heat transfer rates in the PEP vessels do not scale volumetrically. Although all heating in the PTF is carried out using steam injection, the same approach was not used in the PEP. Various process manipulations were carried out to achieve functionally prototypic conditions in the PEP. For leaching in Tanks T01A/B, an initial pre-heat with external heat exchangers before direct-steam injection was needed to emulate the expected condensate accumulation in the PTF UFP vessels. Further, in the Integrated Test A leach batches in Tanks T01A/B, IW (0.01-M $\mathrm{NaOH}$ ) was added throughout the $98^{\circ} \mathrm{C}$ leach period to maintain the expected condensate accumulation rate. For leaching in Tank T02A, the necessary pre-heating was accomplished with the heat of dilution as the 19-M caustic was added as well as heating due to mechanical energy from the filter-loop pumps. The object of the procedures was to provide both temperature profiles (heating rate, constant leaching temperature, and cooling rate) and condensate accumulation profiles that would be representative of the PTF caustic-leaching processes. 
Target temperature-versus-time profiles were specified in the Test Instructions. The temperature profiles measured at the prototypic temperature sensors in each vessel were compared to the targets and found to be good matches for most of the time. Significant divergences from the target (differences that were outside the allowable range stated in the Test Instruction) were most often the result of process disturbances caused by high-high level alarms, some of which were possibly associated with foaming (in Integrated Tests B and D). The high-high level alarm shut off steam injection and PJMs, causing a drop in temperature that was sometimes followed by a temperature spike if steam was turned on before PJMs were started (producing a local temperature increase owing to the lack of mixing). Additionally, restarting steam flow with PJMs on and transitioning from the temperature ramp up to a steady temperature hold sometimes resulted in a slight temperature overshoot, due to the tuning of the temperature controller.

Changes in slurry volume during caustic leaching were used to determine how much condensate had been added as a result of steam injection. The increases in liquid volume that were due to thermal expansion and volume added by solids dissolution were accounted for, using density and UDS data from samples, in determining the volume of condensate alone.

Several features are present in condensate accumulation in most or all of the batches in Integrated Tests A, B, and D:

- The volume of steam (liquid equivalent) added during heat up was only slightly (e.g., 3 to 8 gal) greater than the amount of condensate, indicating that little of the added steam was vented. A considerably smaller fraction of the added steam remained as liquid volume during constant-temperature hold; by the same token, a larger fraction was vented as a result of evaporation.

- Steam was added at a constant rate (a linear function of time) during both heat-up and constant-temperature hold. Exceptions to this rule were found in Integrated Test A, Batch 2 and Integrated Test B, Batch 2. In Integrated Test A, Batch 2, the Tank T01B vessel vent was open for part of the time (in an attempt to clear the laser level sensor). The reason for the change in the steam addition rate during Integrated Test B, Batch 2 is not evident in test records; the change is much less than in the Integrated Test A case, suggesting a more subtle cause.

Table 9.40 gives the condensate mass fraction (the fraction of the final slurry that was condensate) at the end of the constant-temperature hold period for all the caustic-leaching batches considered in this report. Generally speaking, the final condensate fraction is consistent from batch to batch in a test. Integrated Test $\mathrm{B}$ appears to be the exception. In addition to slight variations in the $\mathrm{NaOH}$ reagent to simulant mass ratio in the batches, the higher condensate fraction in Integrated Test B, Batch 1 may be related to the lower temperature at the start of direct-steam injection in Batch 1, the extension of leach time from 16 hours to nearly 17 hours to compensate for loss of temperature caused by steam shut-off periods in Batch 1, and possible undocumented vessel venting during Batch 2. 
Table 9.40. Summary of Condensate Mass Fractions

\begin{tabular}{lccc}
\hline & \multicolumn{3}{c}{$\begin{array}{c}\text { Mass Fraction of Final Slurry } \\
\text { Contributed by Condensate }\end{array}$} \\
\cline { 2 - 4 } & $\begin{array}{c}\text { In } \\
\text { Integrated } \\
\text { Test A }\end{array}$ & $\begin{array}{c}\text { In } \\
\text { Integrated } \\
\text { Test B }\end{array}$ & $\begin{array}{c}\text { In } \\
\text { Integrated } \\
\text { Test D }\end{array}$ \\
\hline Batch 1 & $12.2 \%$ & $17.5 \%$ & $14.8 \%$ \\
Batch 2 & $12.5 \%$ & $14.7 \%$ & $14.5 \%$ \\
Batch 3 & $12.1 \%$ & $\mathrm{n} / \mathrm{m}$ & $\mathrm{n} / \mathrm{m}$ \\
Batch 4 & $11.5 \%$ & $\mathrm{n} / \mathrm{m}$ & $\mathrm{n} / \mathrm{m}$ \\
Batch 5 & $12.7 \%$ & $\mathrm{n} / \mathrm{m}$ & $\mathrm{n} / \mathrm{m}$ \\
Batch 6 & $11.5 \%$ & $\mathrm{n} / \mathrm{m}$ & $\mathrm{n} / \mathrm{m}$ \\
\hline In Integrated Test A, Batches 1,3, and 5 were in Tank \\
T01A; the others were in Tank T01B. \\
"n $/ \mathrm{m}$ " = not measured \\
\hline
\end{tabular}

\subsubsection{NaOH Reagent Addition}

The success of the strategy used to define the quantity of $\mathrm{NaOH}$ reagent that had to be added to achieve target leach factors was assessed by comparing to measured Al leach factors. Before the achieved leach factor could meaningfully be compared to the target, it was necessary to confirm that the intended amount of reagent had been added in the test. The mass of reagent added was calculated from data obtained by more than one instrument and was compared to the reagent target set by the Test Instruction for the test. In general the comparison showed no significant discrepancies..

Because the ratio of reagent to simulant was an important aspect of the tests, the amount of simulant that was combined with the reagent was calculated to support possible later studies of leaching performance. In the case of leaching in Tanks T01A/B (Integrated Test A), Batches 3 through 6 contained heels left by previous batches. The masses of heel were also calculated and were typically roughly 10 to $15 \%$ of the total mass of each batch. Note that the amount of $\mathrm{NaOH}$ addition required for the heel was disproportionately low, compared to that required for the fresh simulant, because the heel already contained $\mathrm{NaOH}$ and had been previously leached.

The total slurry volume in the vessel after $\mathrm{NaOH}$ reagent addition was compared to the Test Instruction target as another approach to checking the ratio of reagent to simulant in Integrated Test A. The total slurry volumes in Integrated Test A were within the ranges specified except for Batch 3 , where the added simulant was in excess by 26 gal over the 426-gal target. In Integrated Tests B and D, the mass of $\mathrm{NaOH}$ reagent added was consistent from batch to batch in a test. However, the ratio of reagent to concentrated simulant varied from batch to batch within each test: the reagent:simulant ratio was found to be slightly lower in Batch 1 of Integrated Test B than in Batch 2 (Section 9.2.2); and in Integrated Test D, the reagent to simulant mass ratio was somewhat greater in Batch 1 than in Batch 2 (Section 9.2.3). 
The success of the strategy used to determine the amount of reagent to add was evaluated by comparing the final boehmite leach factor that was achieved (as calculated by the kinetic model fit) to the target leach factor. For the PEP batches used in scale-up, the results were:

- $\quad$ Integrated Test A, Batch 1: $\quad$ target $=0.28$ actual $=0.33$ (with a $95 \%$ confidence interval from 0.23 to 0.41 )

- $\quad$ Integrated Test B, Batch 2: $\quad$ target $=0.38$ actual $=0.34$ (with a $95 \%$ confidence interval from 0.26 to 0.43 )

- $\quad$ Integrated Test D, Batch 2: $\quad$ target $=0.21$ actual $=0.22$ (with a $95 \%$ confidence interval from 0.16 to 0.28 ).

The final boehmite leach factors were within one standard deviation (calculated by a Monte Carlo technique, as described in Section 9.5) of the targets, which are considered to be a good match. Since the $\mathrm{NaOH}$ additions matched the targets, and the target boehmite leach factors were met, the strategy was found workable.

\subsubsection{Caustic-Leach Performance}

Caustic-leach scale-up factors for use in the G2 model were developed from experimental rate constants for boehmite dissolution. A kinetic model (Equation [9.8]) was fitted to the time history of dissolved aluminum concentrations measured in samples taken over the course of leaching. The rate constants were developed from one caustic-leach batch from each of three PEP tests, Integrated Test A, Batch 1 (caustic-leach in vessel Tank T01A at $98^{\circ} \mathrm{C}$ ), Integrated Test B, Batch 2 (caustic-leach in vessel Tank T02A at $98^{\circ} \mathrm{C}$ ), and Integrated Test $\mathrm{D}$, Batch 2 (caustic-leach in vessel Tank T02A at $85^{\circ} \mathrm{C}$ ), and from six laboratory-scale tests. Two of the laboratory tests (A-1 and A-2) were carried out on slurry taken from PEP Integrated Test A samples, two (B-1 and B-2) on slurry from PEP Integrated Test B, and two (D-1 and D-2) on slurry from PEP Integrated Test D. The rate constants from the PEP were divided by those from the laboratory-scale tests to give PEP/laboratory scale-up factors. Because the PEP was designed and operated to be prototypic of the PTF, and its operation reasonably satisfied prototypic operational criteria, the PEP/laboratory scale-up factor is assumed to be the same as the plant/laboratory scale-up factor, and the former can be used directly in the G2 model.

The uncertainty in the measured concentrations and temperatures was accounted for in data analysis by using a Monte Carlo approach. Each equation required for data analysis was solved a number of times, each time varying all the data within normal distributions defined by the uncertainty of the laboratory analytical method (assuming a normal distribution of uncertainty around a mean of zero). The resulting populations of parameters could be defined in terms of a median and standard deviation, in some cases, or in terms of a median and the lower and upper bounds of a $95 \%$ confidence interval around the median. Table 9.41 shows the results of the stochastic kinetic model. Much of the uncertainty comes from uncertainty in the initial-condition concentrations used as inputs to the kinetic model. 
Table 9.41. Scale-Up Factors and Kinetic Rate Constants for PEP and Parallel Laboratory-Scale Tests

\begin{tabular}{|c|c|c|}
\hline & $\begin{array}{l}\text { Rate Constant } k \\
\left(\mathrm{hr}^{-1} *[\text { mol total }\right. \\
\left.\mathrm{OH} / \mathrm{L}]^{-1}\right)\end{array}$ & $\begin{array}{l}\text { Scale-Up Factor, } \\
k_{P E P} / k_{l a b}\end{array}$ \\
\hline $\begin{array}{l}\text { PEP Integrated Test A, } \\
\text { Batch } 1 \text { (caustic-leach in } \\
\text { Tank T01A at } 98^{\circ} \mathrm{C} \text { ) }\end{array}$ & $\begin{array}{l}\text { low 95\%: } 0.0128 \\
\text { median: } 0.0186 \\
\text { upper 95\%: } 0.0250\end{array}$ & --- \\
\hline $\begin{array}{l}\text { Laboratory-Scale Test A-1 } \\
(\mathrm{NaOH} \text { added in PEP) }\end{array}$ & $\begin{array}{l}\text { low 95\%: } 0.0144 \\
\text { median: } 0.0227 \\
\text { upper 95\%: } 0.0384\end{array}$ & $\begin{array}{l}\text { low 95\%: } 0.44 \\
\text { median: } 0.79 \\
\text { upper } 95 \%: 1.45\end{array}$ \\
\hline $\begin{array}{l}\text { Laboratory-Scale Test A-2 } \\
\text { ( NaOH added in } \\
\text { laboratory) }\end{array}$ & $\begin{array}{l}\text { low 95\%: } 0.0126 \\
\text { median: } 0.0194 \\
\text { upper 95\%: } 0.0298\end{array}$ & $\begin{array}{l}\text { low } 95 \%: 0.55 \\
\text { median: } 0.95 \\
\text { upper } 95 \%: 1.64\end{array}$ \\
\hline $\begin{array}{l}\text { PEP Integrated Test B, } \\
\text { Batch } 2 \text { (caustic-leach in } \\
\text { Tank T02A at } 98^{\circ} \mathrm{C} \text { ) }\end{array}$ & $\begin{array}{l}\text { low 95\%: } 0.0182 \\
\text { median: } 0.0251 \\
\text { upper 95\%: } 0.0344\end{array}$ & --- \\
\hline $\begin{array}{l}\text { Laboratory-Scale Test } \mathrm{B}-1 \\
(\mathrm{NaOH} \text { added in PEP) }\end{array}$ & $\begin{array}{l}\text { low 95\%: } 0.0113 \\
\text { median: } 0.0166 \\
\text { upper 95\%: } 0.0251\end{array}$ & $\begin{array}{l}\text { low } 95 \%: 0.89 \\
\text { median: } 1.51 \\
\text { upper: } 2.63\end{array}$ \\
\hline $\begin{array}{l}\text { Laboratory-Scale Test } \mathrm{B}-2 \\
(\mathrm{NaOH} \text { added in PEP) }\end{array}$ & $\begin{array}{l}\text { low 95\%: } 0.0139 \\
\text { median: } 0.0199 \\
\text { upper 95\%: } 0.0290\end{array}$ & $\begin{array}{l}\text { low } 95 \%: 0.77 \\
\text { median: } 1.26 \\
\text { upper: } 2.14\end{array}$ \\
\hline $\begin{array}{l}\text { PEP Integrated Test D, } \\
\text { Batch } 2 \text { (caustic-leach in } \\
\text { Tank T02A at } 85^{\circ} \mathrm{C} \text { ) }\end{array}$ & $\begin{array}{l}\text { low 95\%: } 0.0099 \\
\text { median: } 0.0140 \\
\text { upper 95\%: } 0.0186\end{array}$ & --- \\
\hline $\begin{array}{l}\text { Laboratory-Scale Test D-1 } \\
(\mathrm{NaOH} \text { added in PEP) }\end{array}$ & $\begin{array}{l}\text { low 95\%: } 0.0073 \\
\text { median: } 0.0117 \\
\text { upper 95\%: } 0.0175\end{array}$ & $\begin{array}{l}\text { low 95\%: } 0.69 \\
\text { median: } 1.19 \\
\text { upper } 95 \%: 2.07\end{array}$ \\
\hline $\begin{array}{l}\text { Laboratory-Scale Test D-2 } \\
(\mathrm{NaOH} \text { added in PEP) }\end{array}$ & $\begin{array}{l}\text { low 95\%: } 0.0088 \\
\text { median: } 0.0135 \\
\text { upper 95\%: } 0.0200\end{array}$ & $\begin{array}{l}\text { low } 95 \%: 0.60 \\
\text { median: } 1.03 \\
\text { upper } 95 \%: 1.75\end{array}$ \\
\hline \multicolumn{3}{|c|}{$\begin{array}{l}\text { The scale-up factor and } k \text { entries show the } 95 \% \text { confidence interval around the median, a } \\
\text { calculated by } 500 \text { Monte Carlo realizations. Estimates of laboratory error in } \\
\text { measurements were the basis for estimating all error. }\end{array}$} \\
\hline
\end{tabular}

To put this in context, the uncertainty of any single measurement is generally $6 \%$ or less. ${ }^{(a)}$ The combination of measurement uncertainties for unit conversions, concentration normalization, and calculation of the fraction of solid-phase $\mathrm{Al}$ present as boehmite leads to a higher propagated uncertainty in the kinetic initial conditions. The need to adjust for changes in liquid volume, which is done by using liquid tracer concentrations, accounts for a significant amount of uncertainty. Most of the rest of the

(a) This paragraph is based on a more detailed discussion in Section 4.3 of WTP-RPT-186 and is repeated from the conclusions of that report. 
uncertainty is attributable to the analytical uncertainty in determining the concentration of aluminum in solution. In the case of the laboratory-scale tests, there is one more source of uncertainty, the uncertainty in the initial boehmite concentration that results from uncertainty in the initial slurry $\mathrm{Al}$ concentration.

Given the broad overlapping confidence intervals, the rate constants from the six PEP and laboratory-scale tests are not statistically distinguishable from each other at a $95 \%$ confidence level. The scale-up factors for Integrated Tests A, B, and D were calculated as the median of the joined populations of scale-up factors for both laboratory-scale tests:

- Integrated Test A versus Tests A-1 and A-2: median 0.88, 95\% confidence interval 0.47 to 1.56 .

- Integrated Test B versus Tests B-1 and B-2: median 1.38, 95\% confidence interval 0.80 to 2.41.

- Integrated Test D versus Tests D-1 and D-2: median 1.10, 95\% confidence interval 0.64 to 2.02.

It is possible that the scale-up factor is unity or greater both for caustic leaching in Tank T01A and Tank T02A. ${ }^{\text {(a) }}$ The probability of this hypothesis is about $21 \%$ for Integrated Test A/Test A-1, 43\% for Integrated Test A/Test A-2, 93\% for Integrated Test B/Test B-1, 77\% for Integrated Test B/Test B-2, 73\% for Integrated Test D/Test D-1, and 53\% for Integrated Test D/Test D-2. These probabilities were calculated on the assumption that no systematic biases were introduced by experimental, sampling, or analytical laboratory methods.

The results suggest that the conditions present during caustic-leach at $98^{\circ} \mathrm{C}$ in Tank T02A (Integrated Test B) might produce higher scale-up factors than the other tested conditions. The reasons for scale-up factors significantly less than or greater than one are not completely clear, but could include temperature and solids-concentration variation within the vessel. However, the Integrated Test B scale-up factors are within the $95 \%$ confidence intervals of the factors from other tests, and so are not conclusively different from them.

\subsubsection{Presence of Excess Caustic}

Gibbsite was added to PEP process permeate samples to determine whether the liquids were capable of dissolving more $\mathrm{Al}$ than that already present. This provided an indication of whether the $\mathrm{NaOH}$ reagent added was sufficient to allow excess caustic over that needed to keep aluminum in solution after cooling and during washing. Although the ratio of freshly-dissolved Al to initially-dissolved $\mathrm{Al}$ is not necessarily the same as the ratio of excess $\mathrm{NaOH}$ to required $\mathrm{NaOH}$, it does indicate the extent of the margin that is present to maintain $\mathrm{Al}$ in solution.

For each PEP Integrated Test, one sample of post-leach permeate and one of post-leach wash permeate were used in excess caustic testing, a total of six cases. As shown in Table 9.42, in five of the six cases the permeate solutions were found to be capable of dissolving gibbsite to a significant extent. The exception was the wash permeate from Integrated Test B; no statistically significant amount of gibbsite dissolved, indicating that there was no significant excess caustic present at this point in the process.

(a) The upper limit on the scale-up factor is, effectively, equal to the upper bound of the $95 \%$ confidence interval. 
Table 9.42. Final Dissolved Al Concentration Increase Resulting from Gibbsite Addition

\begin{tabular}{lcc}
\hline Solution & $\begin{array}{c}\text { Initial } \\
\text { Dissolved Al } \\
(\mathrm{M})\end{array}$ & $\begin{array}{c}\text { Percent } \\
\text { Increase in } \\
\text { Dissolved Al }\end{array}$ \\
\hline Wash, Integrated Test A & 0.235 & 19 \\
Wash, Integrated Test B & 0.583 & 3 \\
Wash, Integrated Test D & 0.397 & 24 \\
Leachate, Integrated Test A & 0.418 & 58 \\
Leachate, Integrated Test B & 0.801 & 28 \\
Leachate, Integrated Test D & 0.668 & 96 \\
\hline
\end{tabular}




\subsection{Solids Wash Results}

This section discusses the results of the solids washing tests for Integrated Tests A, B, and D. The results of Integrated Tests A and B have been previously discussed in Baldwin et al. (2009) but are summarized here for completeness and to allow comparisons between the different tests. Since the washing results for Integrated Test D have not been previously discussed, many of the details for Integrated Test $\mathrm{D}$ are presented here. The following details relating to solids washing in Integrated Tests A and B may be found in Baldwin et al. (2009): tables of analyte concentrations, incremental wash efficiencies, and details of the process description.

\subsection{Slurry Properties}

Because the high-temperature caustic leaching of the Shakedown/Functional Test and Integrated Tests $\mathrm{A}$ and $\mathrm{B}$ dissolved significant amounts of the $\mathrm{CrOOH}$ solids, the chromium solids simulant was prepared and added as slurry to the PEP process after post-caustic-leach washing (a nonprototypic addition). In Integrated Test $\mathrm{D}$, the same chromium solids component of the simulant was added to the feed to demonstrate the PTF permanganate addition strategy.

Significant differences may be seen in the slurry concentration of slurry components for Integrated Tests A, B, and D at the start of washing. Table 10.1 shows the composition of the slurry components for each of the Integrated Tests A, B, and D in Tank T02A after caustic-leach and solids concentration which is the initial condition for the post-caustic-leach wash.

Table 10.2 shows the composition of the slurry components for Integrated Tests A, B, and D in Tank T02A after oxidative-leach - the initial condition for the final post-oxidative-leach wash. Note that the initial composition of the solids in the slurry was measured by inductively coupled plasma (ICP) only; neither ion chromatography (IC) nor titration can be measured on slurry material, only on the decanted supernate. The decanted supernate from centrifuged slurry samples provides the results for the liquid-phase columns.

The solids concentrations given in Table 10.1 and 10.2 are on a wet solids basis, and thus may not be directly comparable with one another; each analyzed wet solid sample most likely had a different liquid content. This explains why the solids concentration of many analytes is larger at the start of the post-oxidative-leach wash than at the start of the post-caustic-leach wash. The liquid phase concentrations, which are of greater interest in washing operations, are directly comparable. 
Table 10.1. Initial Slurry Composition for Post-Caustic-Leach Wash for Integrated Tests A, B, and D

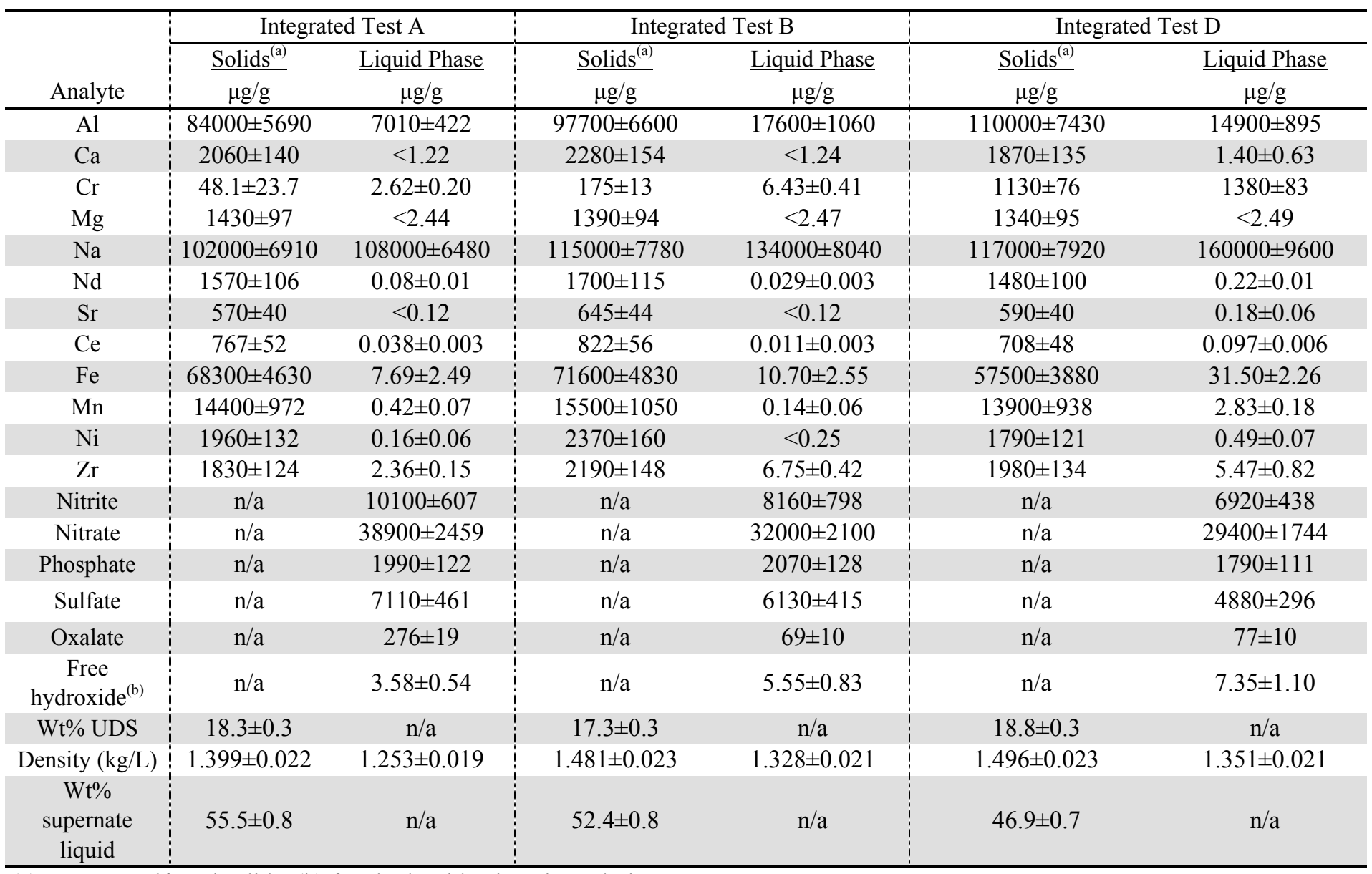

(a) Wet, centrifuged solids; (b) free hydroxide given in molarity. 
Table 10.2. Initial Slurry Composition for Post-Oxidative-Leach Wash for Integrated Tests A, B, and D

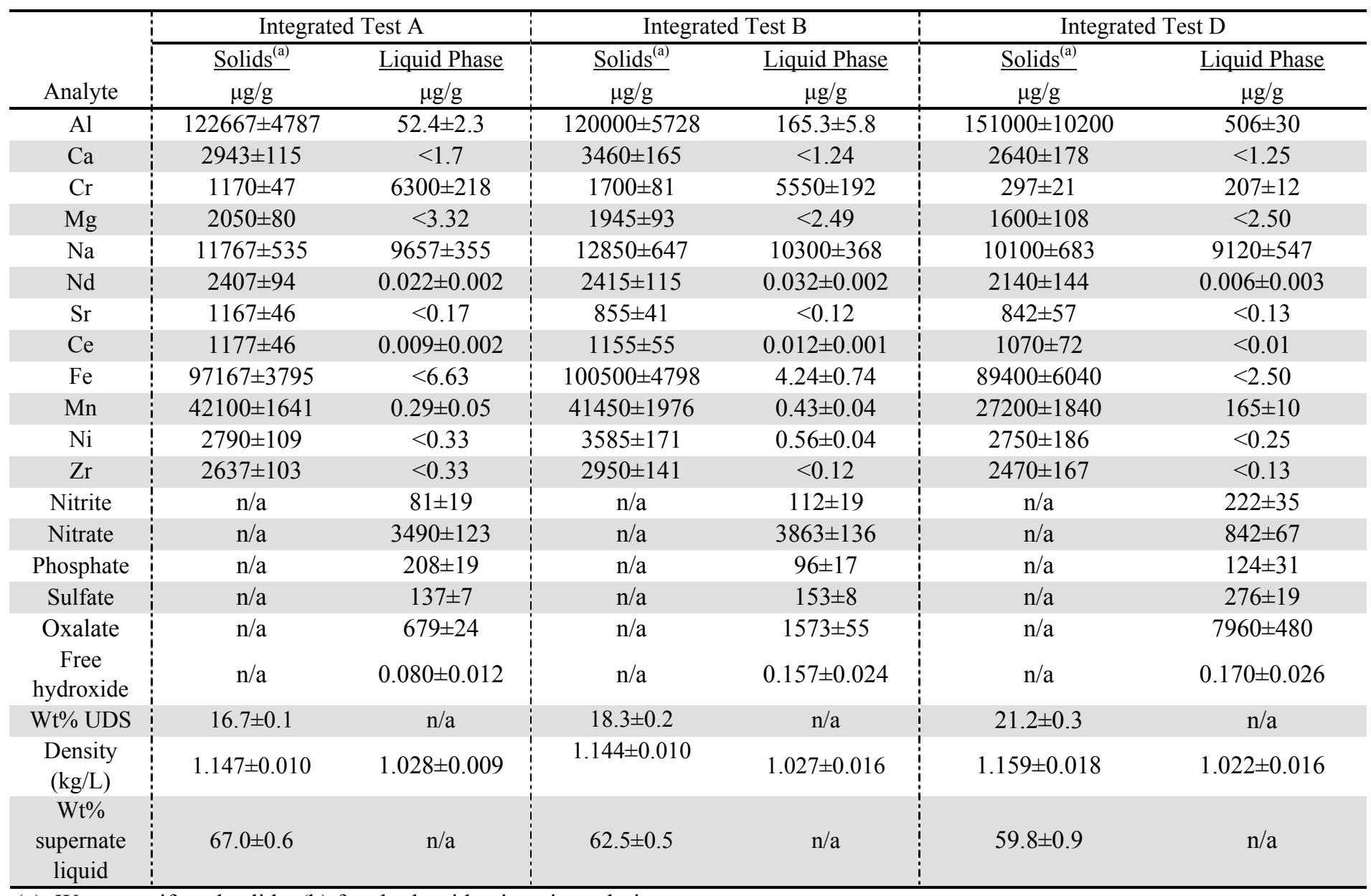

(a) Wet, centrifuged solids; (b) free hydroxide given in molarity. 


\subsection{Wash Process Conditions}

The behavior of a wash depends on several process conditions, including the slurry temperature, permeate flux, slurry volume, filter-loop flow rate, and filter pressures. In addition, there are changes in physical properties of the slurry as the wash proceeds. Three of these properties were determined at several intervals: bulk density, supernate density, and UDS. To facilitate comparison between analytical results and process conditions, the data are presented as a function of the batch number. Each value is the state of the system at the beginning of each batch, that is, the moment when IW begins to flow into the filter-loop at the suction of Pump T42A. In contrast, all samples were taken at a nominal one to two minutes after the end of the IW injection. In this section, the wash process conditions for Integrated Test $\mathrm{D}$ are presented.

\subsubsection{Integrated Test D}

In Integrated Test D, T02A caustic-leach test, feed with simulant at 6.5 -wt $\%$ UDS was transferred to Tank T02A in two batches, using Tanks T01A/B as feed or storage vessels. The feed was concentrated to $\sim 23-\mathrm{wt} \%$ UDS, and then 19-M NaOH (nominal concentration) was added in-line to the slurry. Caustic leaching was carried out by using steam injection to raise the temperature to $85^{\circ} \mathrm{C}$ for 24 hours, following which the slurry was cooled to $25^{\circ} \mathrm{C}$ and was ultrafiltered to concentrate the slurry to $18.8-\mathrm{wt} \%$ UDS.

The concentrated caustic-leached solids in Tank T02A were washed incrementally with 0.01-M $\mathrm{NaOH}$. The wash liquid was added in steps, 11 gallons target volume each step, 53 steps total. During every third or fourth wash step, antifoam agent (AFA) was added to maintain a target concentration of $350 \mathrm{ppm}$. Wash liquid additions were initiated when the level in Tank T02A dropped below a set value. Permeate was continuously removed at a rate between $2-$ and $8-\mathrm{kg} / \mathrm{min}$ by ultrafiltration through all five filter bundles.

During Integrated Test D, the flow rate in the filter-loop was unable to meet the targeted rate of 109 GPM when the level in the tank was below $\sim 22$-in. This is the approximate level at which the return leg of the slurry coming back into Tank T02A is exposed (i.e., the slurry in the tank is lower than the return leg). The result was air entrainment into the slurry, which resulted in decreased performance of the pumps. However, air entrainment due to low tank levels probably is not the full answer to the reason for the low filter-loop flow rate. It turns out that air entrainment decreases pump performance. However, the degassing protocol applied in Integrated Test D did not result in lower slurry levels or increased pumping rates. Simulant properties may very well play a role in air entrainment, but there is probably not enough data at the current time to definitively conclude this. A lower than targeted loop flow rate should imply conservative wash efficiencies due to less vigorous mixing than originally targeted.

When the post-caustic-leach wash was complete, a chromium oxidation-leach step was performed. The oxidative-leach step was conducted by adding 9.6 gal of 1- $\mathrm{M} \mathrm{NaMnO}_{4}$, and the slurry was mixed for 6 hours at a temperature of $25^{\circ} \mathrm{C}$. The oxidative-leached solids in Tank T02A were washed incrementally with 45 batches of $0.01-\mathrm{M} \mathrm{NaOH}$. AFA was added during every third batch to maintain a target concentration of $350 \mathrm{ppm}$. The method of washing was similar to that used after caustic leaching, with additions of 11 gal of wash liquid being offset by equal-volume continuous removal of permeate through all five filter bundles. 
In the Integrated Test D post-caustic-leach wash, the pulse jet mixers (PJMs) were operated in star mode, in which only the center PJM and one radial PJM were operated at any given time (switching to a different radial PJM after five cycles). This mode was used due to the very low slurry level in Tank T02A in an effort to minimize air entrainment. The flow rates at PMP-T42A and -T43A (flowmeters FT-0623 and FT-0635) measured generally between 90 and 120 GPM. Mixing during the post-caustic-leach wash did not employ steam ring air purge or air sparging in order to minimize entrainment of air by the filter-loop pumps.

In the Integrated Test D post-oxidative-leach wash, the PJMs operated in star mode with similar conditions to the post-caustic-leach wash. Mixing in Tank T02A during the post-oxidative-leach washing also did not employ steam ring air purge or sparging air flow. The flow rates of PMP-T42A and -T42B measured between 60 and 80 GPM.

The ratio between the total volume of wash liquid added and the average volume of slurry and liquid present in the slurry were calculated for each wash for each of the Integrated Tests A, B, and D. Table 10.3 shows the average values of the slurry volume and the slurry liquid volume as well as their ratio to the total amount of IW added during the wash processes for each Integrated Test A, B, and D. The uncertainty in each value is based on two standard deviations of the value.

Table 10.3. Wash Volume Parameters for Integrated Tests A, B, D

\begin{tabular}{|c|c|c|c|c|c|}
\hline $\begin{array}{c}\text { Integrated } \\
\text { Test }\end{array}$ & $\begin{array}{c}\text { Total Wash } \\
\text { Volume (gal) }\end{array}$ & $\begin{array}{l}\text { Average } \\
\text { Slurry } \\
\text { Volume } \\
\text { (gal) }\end{array}$ & $\begin{array}{c}\text { Average } \\
\text { Liquid } \\
\text { Volume in } \\
\text { Slurry (gal) }\end{array}$ & $\begin{array}{l}\text { Ratio of Wash } \\
\text { Volume to } \\
\text { Slurry Volume }\end{array}$ & $\begin{array}{l}\text { Ratio of Wash } \\
\text { Volume to } \\
\text { Slurry Liquid } \\
\text { Volume }\end{array}$ \\
\hline \multicolumn{6}{|c|}{ Post-Caustic-Leach Wash } \\
\hline A & $1,120 \pm 20$ & $269 \pm 1$ & $246 \pm 6$ & $4.2 \pm 0.1$ & $4.6 \pm 0.2$ \\
\hline B & $580 \pm 10$ & $154 \pm 3$ & $138 \pm 3$ & $3.8 \pm 0.1$ & $4.2 \pm 0.2$ \\
\hline $\mathrm{D}$ & $610 \pm 40$ & $157 \pm 3$ & $140 \pm 4$ & $3.9 \pm 0.3$ & $4.3 \pm 0.4$ \\
\hline \multicolumn{6}{|c|}{ Post-Oxidative-Leach Wash } \\
\hline A & $960 \pm 20$ & $297 \pm 1$ & $273 \pm 2$ & $3.3 \pm 0.1$ & $3.5 \pm 0.1$ \\
\hline $\mathrm{B}$ & $530 \pm 10$ & $173 \pm 1$ & $158 \pm 3$ & $3.1 \pm 0.1$ & $3.4 \pm 0.1$ \\
\hline $\mathrm{D}$ & $510 \pm 10$ & $165 \pm 2$ & $149 \pm 2$ & $3.1 \pm 0.1$ & $3.4 \pm 0.1$ \\
\hline
\end{tabular}

\subsubsection{Post-Caustic-Leach Wash for Integrated Tests A, B, and D}

The post-caustic-leach wash bulk and supernate density in Integrated Tests A, B, and D are shown in Figure 10.1 and Figure 10.2. The figures show that the density continuously decreases during the washing as soluble components are removed from the slurry. A close similarity is seen in both bulk and supernate density between Integrated Tests B and D throughout the wash process, though in Figure 10.1, Integrated Test $\mathrm{D}$ does show slightly higher (20\%) bulk density towards the end of the wash. This density similarity in Integrated Tests B and D, particularly at the start of the wash, implies little sensitivity of the resulting bulk and supernate density during the wash process to the significant differences in time and temperature of the caustic-leach process. 


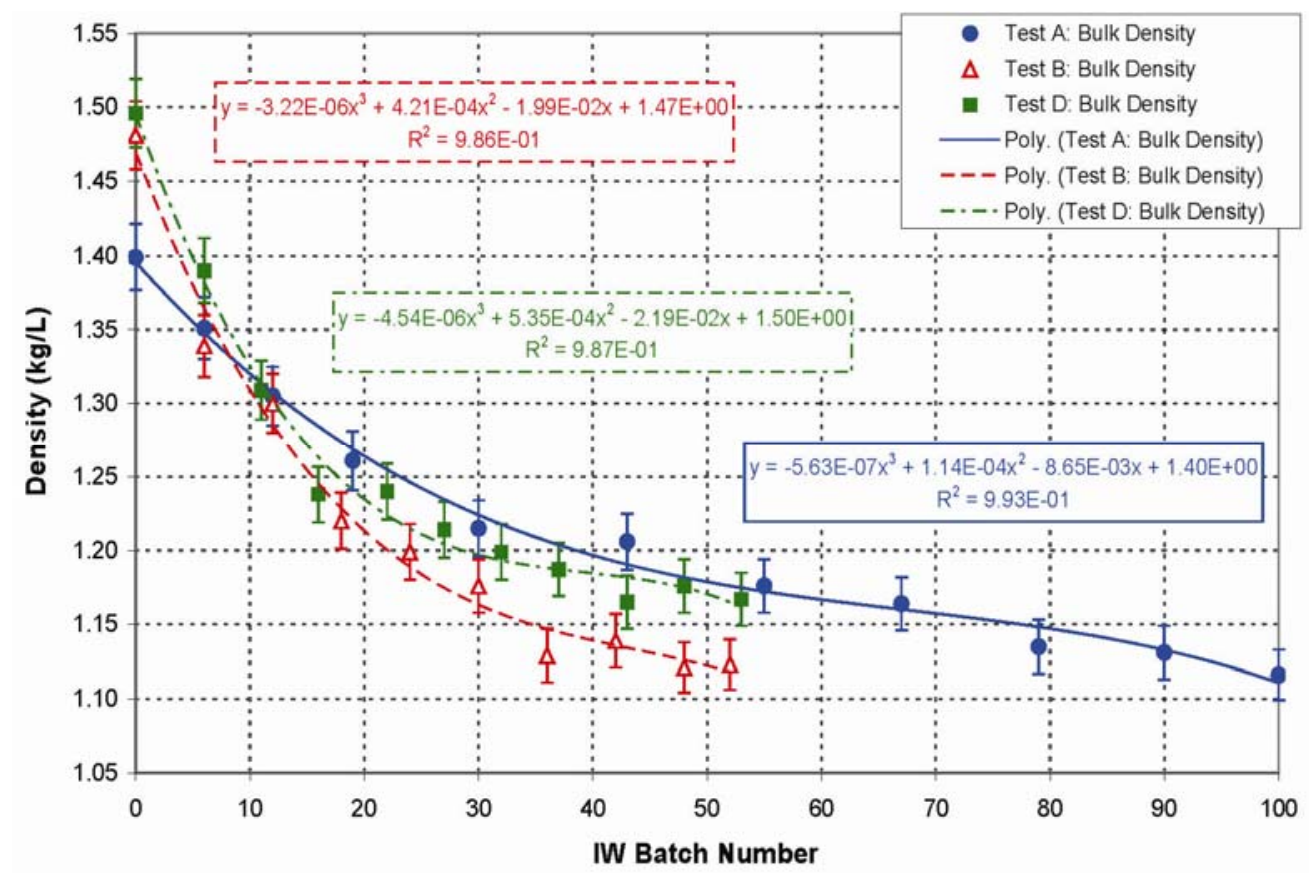

Figure 10.1. Bulk Densities Measured During the Post-Caustic-Leach Wash of the Three Integrated Tests

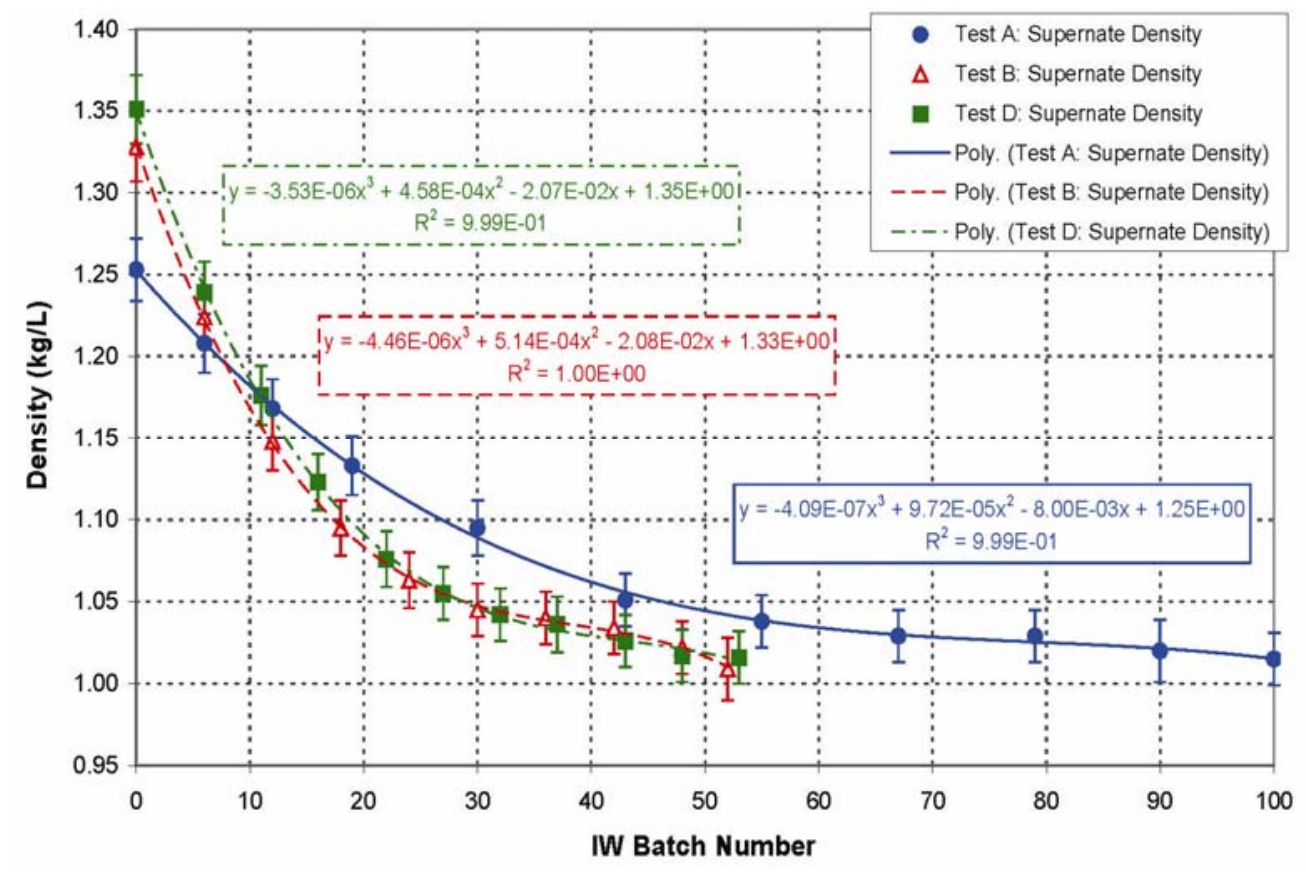

Figure 10.2. Supernate Densities Measured During the Post-Caustic-Leach Wash of the Three Integrated Tests 
Figure 10.3 is a plot of the UDS during the post-caustic-leach wash for Integrated Tests A, B, and D. All three tests show an increase in UDS on the final data point. The high final point may be explained by the late sampling, 5 to 15 minutes after the permeate valves were closed, allowing additional mixing to occur. The lower mid-wash UDS values measured in Integrated Tests A and B (highs of 0.195 to 0.205 mass fraction) may reflect the higher leach temperature $\left(98^{\circ} \mathrm{C}\right)$ of those tests compared to Integrated Test $\mathrm{D}$, which had about $10 \%$ higher UDS, to nearly 0.23 mass fraction, with the lower $85^{\circ} \mathrm{C}$ leach temperature.

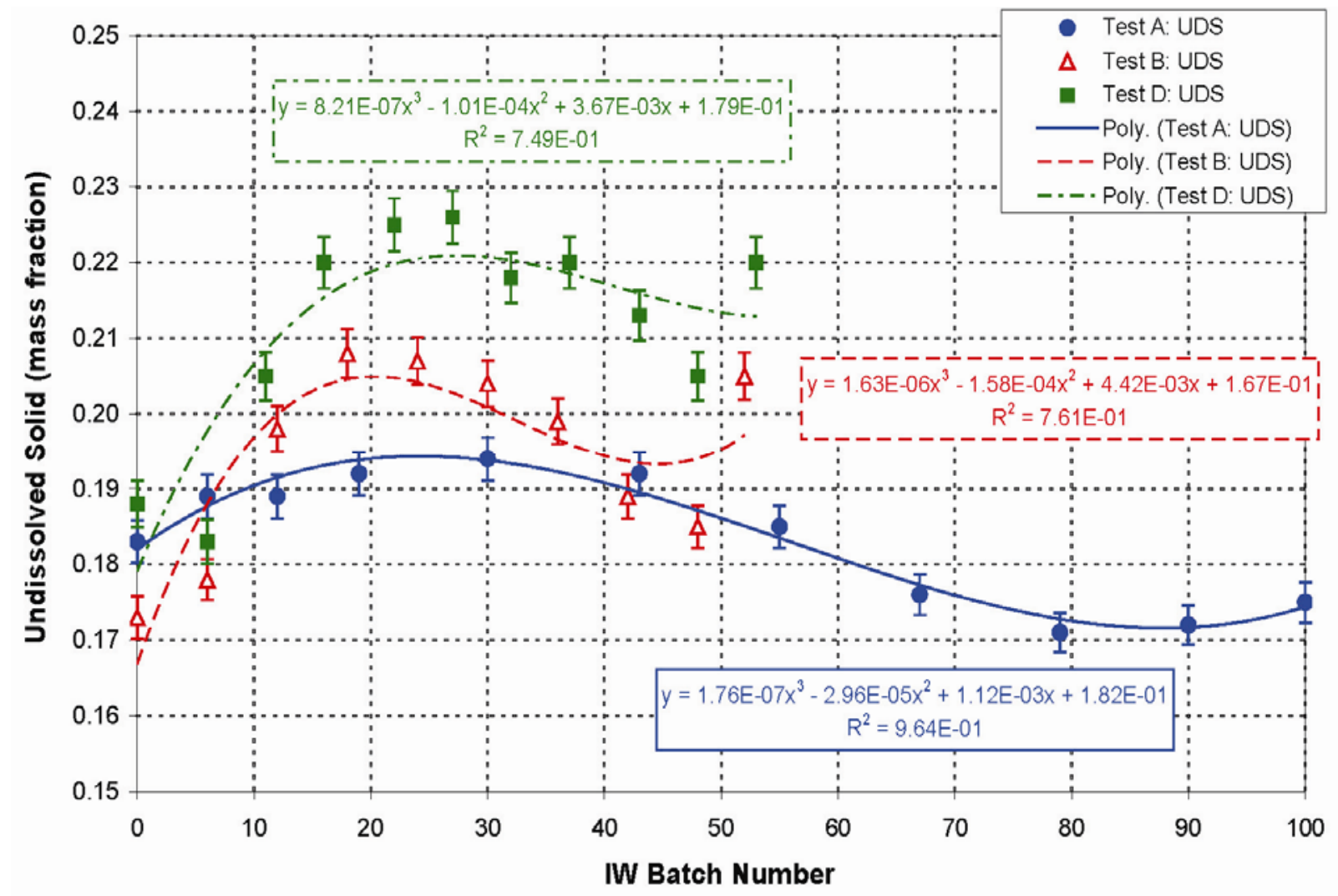

Figure 10.3. Undissolved Solids Measured During the Post-Caustic-Leach Wash of the Three Integrated Tests

Figure 10.4 shows the post-caustic-leach wash temperatures in Tank T02A for Integrated Tests A, B, and D. There were higher temperatures for the initial 8 to 10 washes for Integrated Tests A and D, of up to 27 to $28^{\circ} \mathrm{C}$, compared to the mostly stable temperatures of $24^{\circ} \mathrm{C}$. Integrated Test B starts slightly lower at mostly 22 to $23^{\circ} \mathrm{C}$, before suddenly increasing to between 25 to $26^{\circ} \mathrm{C}$. 


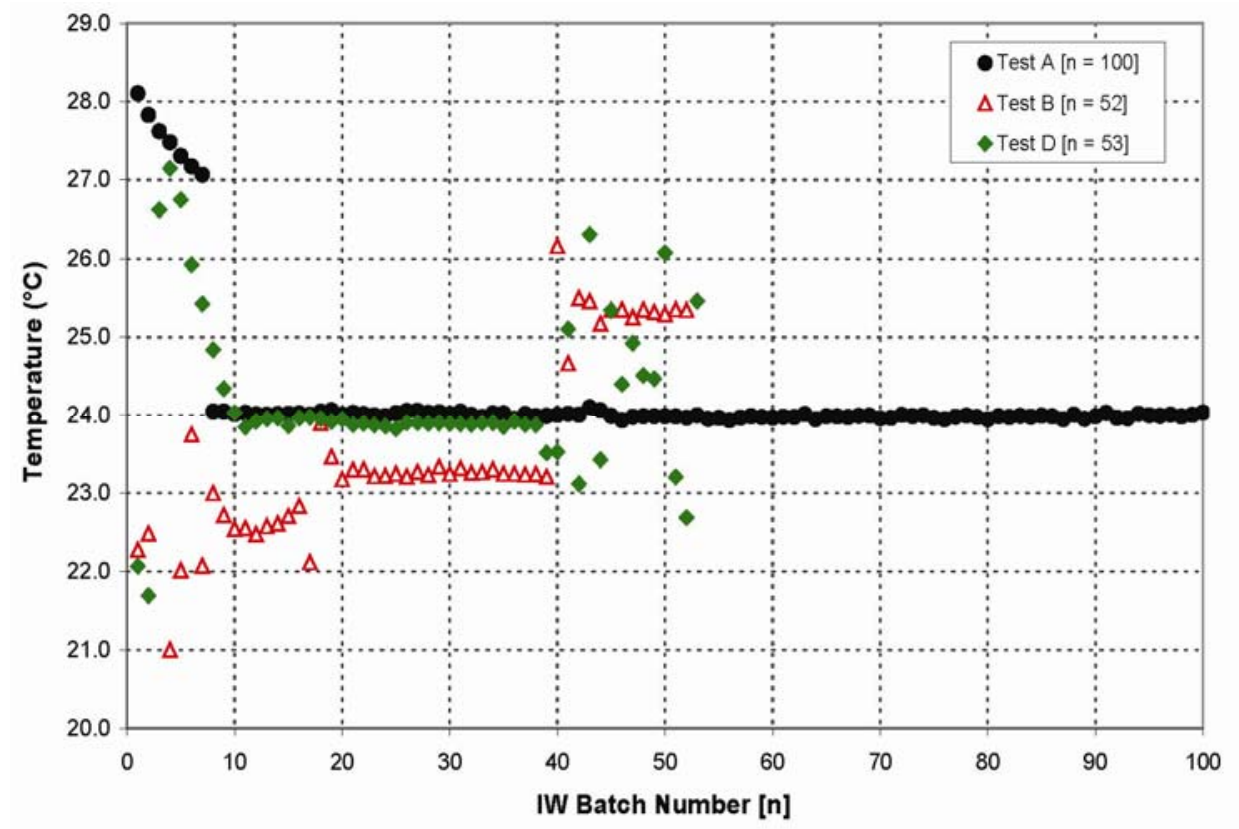

Figure 10.4. Temperature Measured in Tank T02A During the Post-Caustic-Leach Wash of Integrated Tests A, B, and D

The laser level measurements in Tank T02A during post-caustic-leach wash for all three Integrated Tests are shown in Figure 10.5. There is very close agreement between Integrated Tests B and D. The higher level shown for Integrated Test A reflects the fact that much more leached material is provided for this leaching approach.

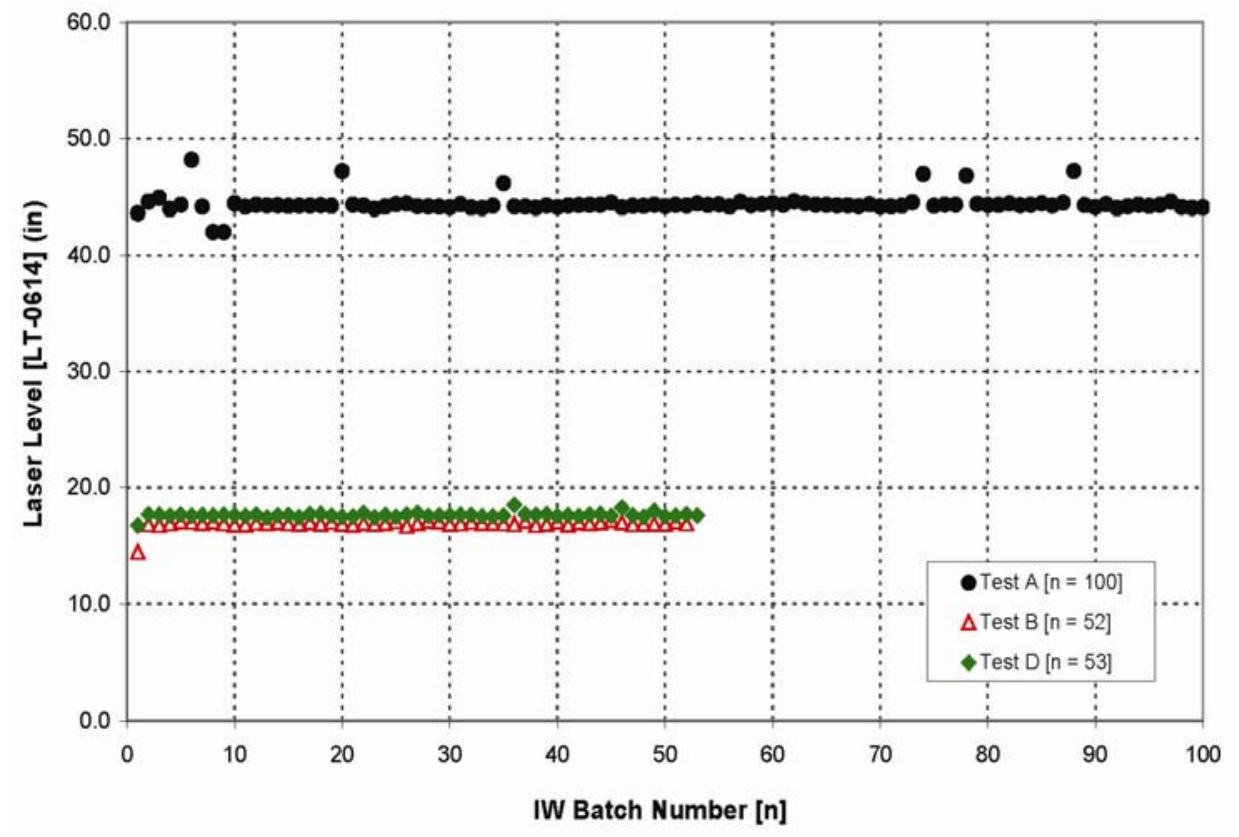

Figure 10.5. Laser Level Measured in Tank T02A During the Post-Caustic-Leach Wash of Integrated Tests A, B, and D 
The post-caustic-leach wash filter-loop flow rates for Integrated Tests A, B, and D are shown in Figure 10.6. For Integrated Tests B and D, there was fairly good agreement in each test between the two flowmeters, one that precedes the pumps (FT-0623) and one that follows the pumps (FT-0635). There was failure of FT-0635 (see below discussion on nonconformance report) along with air entrainment issues that resulted in an uncertain flow rate (Baldwin et al. 2009). There was a higher than target flow rate in Integrated Test A with FT-0623 reporting up to 143 GPM, a lower than target flow rate in Integrated Test B with FT-0623 reporting only up to 99 GPM, and a higher than target flow rate in Integrated Test D with FT-0623 reporting up to 122 GPM. In Integrated Test D, this high flow rate was followed by a precipitous drop at batch number 38 to a flow rate of only about 95 GPM to the end of the wash. This decrease was a preemptive operational choice to avoid air entrainment issues; the pump speed/power was reduced at this point. In Integrated Tests B and D, the two flowmeters were generally close, with FT-0635 about 20\% lower than FT-0623.

There was a nonconformance report, NCR 42317.1, that impacted this solids washing work involving a failure of flowmeter FE-0635. (a) The NCR stated that, "FE-0635 was reporting suspect flow values. A post failure evaluation by the manufacturer indicated the flow element liner was damaged and the instrument was providing low readings. Data from FE-0635 is unusable from 2/14/2009 through 2/27/2009." This flowmeter was replaced after testing concluded on 2/27/09. This information was taken into account throughout this report and Baldwin et al. (2009).

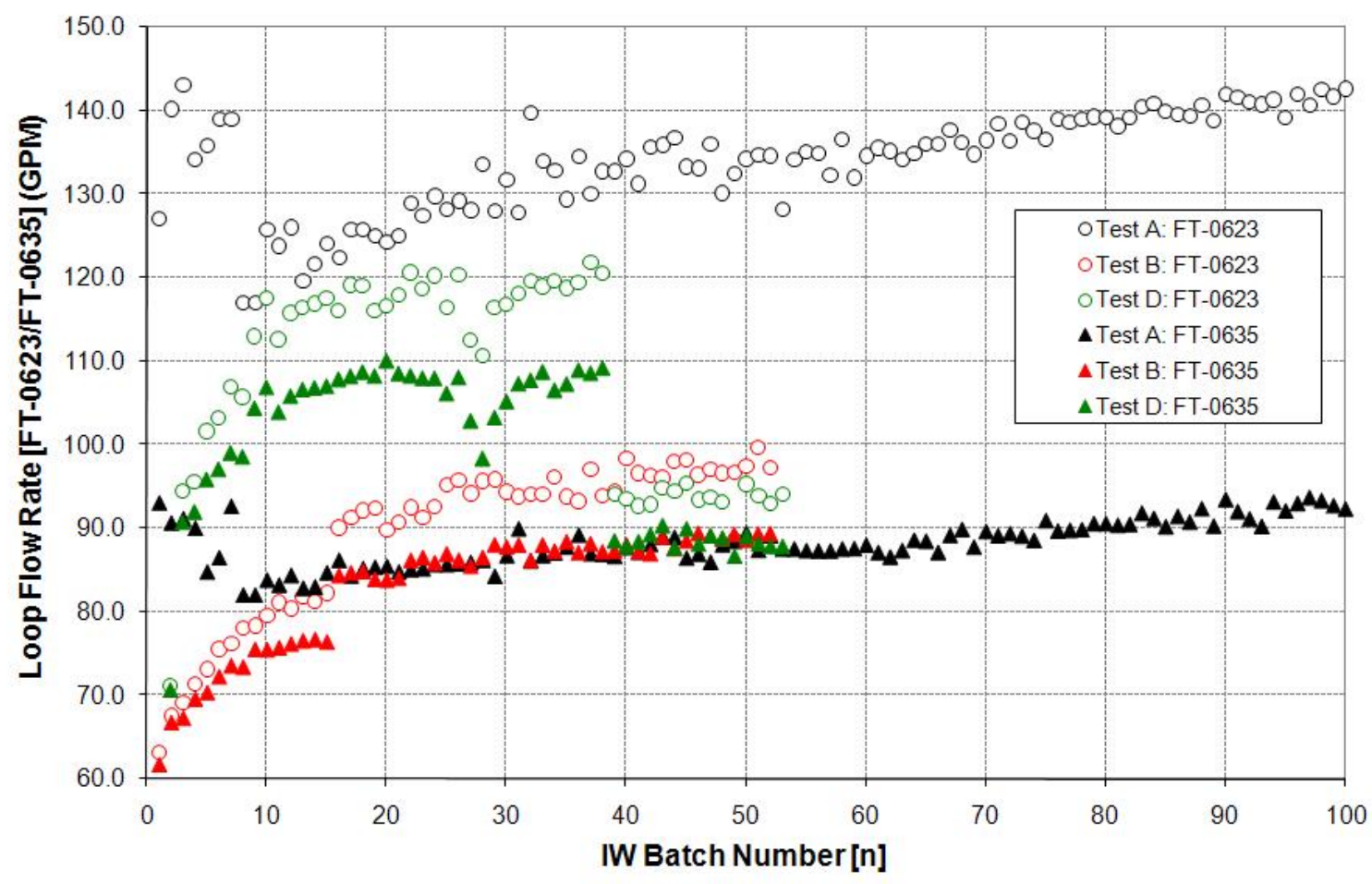

Figure 10.6. Flow Rates in the Filter-Loop During the Post-Caustic-Leach Wash of Integrated Tests A, B, and D. Note that FT-0623 is located before the pumps, and FT-0635 is located after.

(a) This instrument is also designated as FT-0635 since the flow element (FE) and the flow transmitter are integrated into a single instrument. 
Figure 10.7 shows the total normalized filter flux from all five filters in GPM/ $\mathrm{ft}^{2}$, during the post-caustic-leach wash. Integrated Test A exhibited a largely unexplained variation in the total normalized filter flux, as shown in Figure 10.7, with a large increase to $0.28 \mathrm{GPM} / \mathrm{ft}^{2}$ followed by a decrease to $0.10 \mathrm{GPM} / \mathrm{ft}^{2}$ and then increasing back to $0.25 \mathrm{GPM} / \mathrm{ft}^{2}$. For Integrated Tests $\mathrm{B}$ and $\mathrm{D}$, there is similarity, mostly within 10 to $20 \%$, between the two tests, showing a generally smoothly increasing total normalized filter flux up to a maximum of 0.13 to $0.16 \mathrm{GPM} / \mathrm{ft}^{2}$ by mid-wash, though with slightly more variability in Integrated Test D. The variability at the end of Integrated Test D may be a result of the decreased filter-loop flow rate. Both tests start with a very low total normalized filter flux of 0.0 to $0.01 \mathrm{GPM} / \mathrm{ft}^{2}$ and a general increase in total permeate rate over time. The filter flux is normalized using corrections for both temperature and transmembrane pressure (TMP). ${ }^{(a)}$

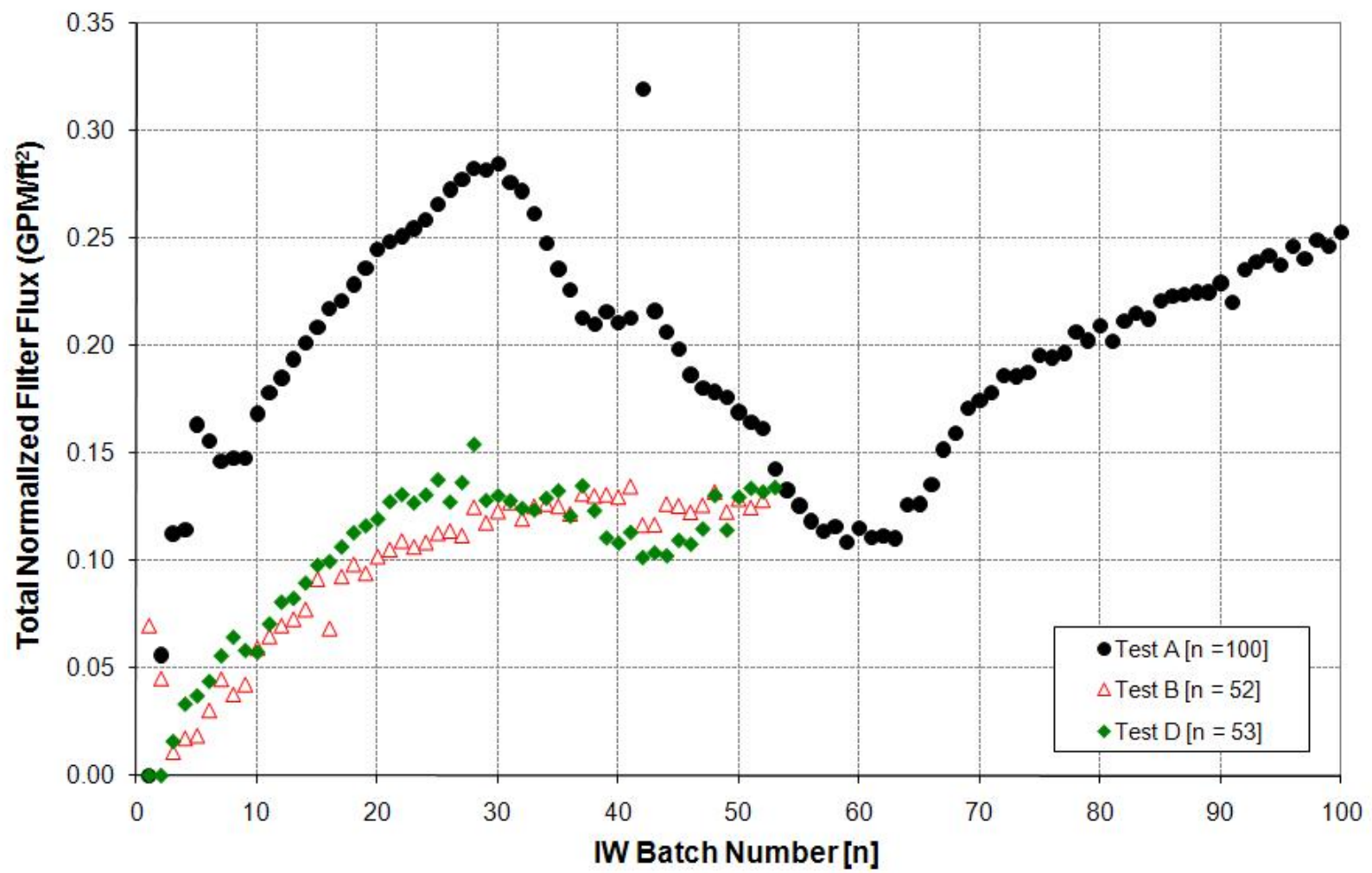

Figure 10.7. Total Normalized Filter Flux Measured During the Post-Caustic-Leach Wash of Integrated Tests A, B, and D

\subsubsection{Post-Oxidative-Leach Wash for Integrated Tests A, B, and D}

Figure 10.8 and Figure 10.9 show very similar respective bulk and supernate densities for each of the three tests with very little respective significant differences for post-oxidative-leach wash densities for Integrated Tests A, B, and D.

(a) For more information on filtration and normalized flux methodology, see Daniel et al. (2009b). 


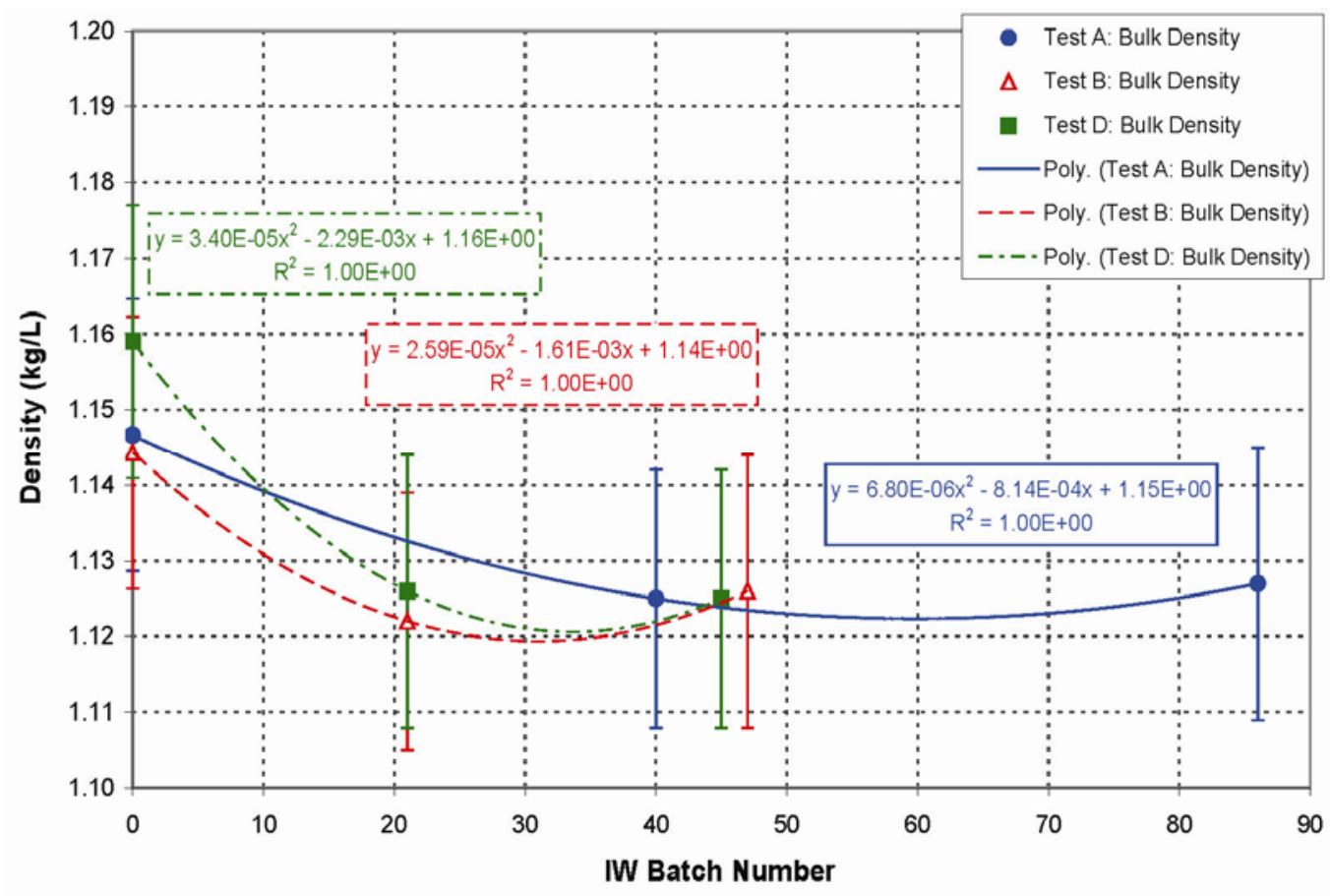

Figure 10.8. Bulk Densities Measured During the Post-Oxidative-Leach Wash of the Three Integrated Tests A, B, and D

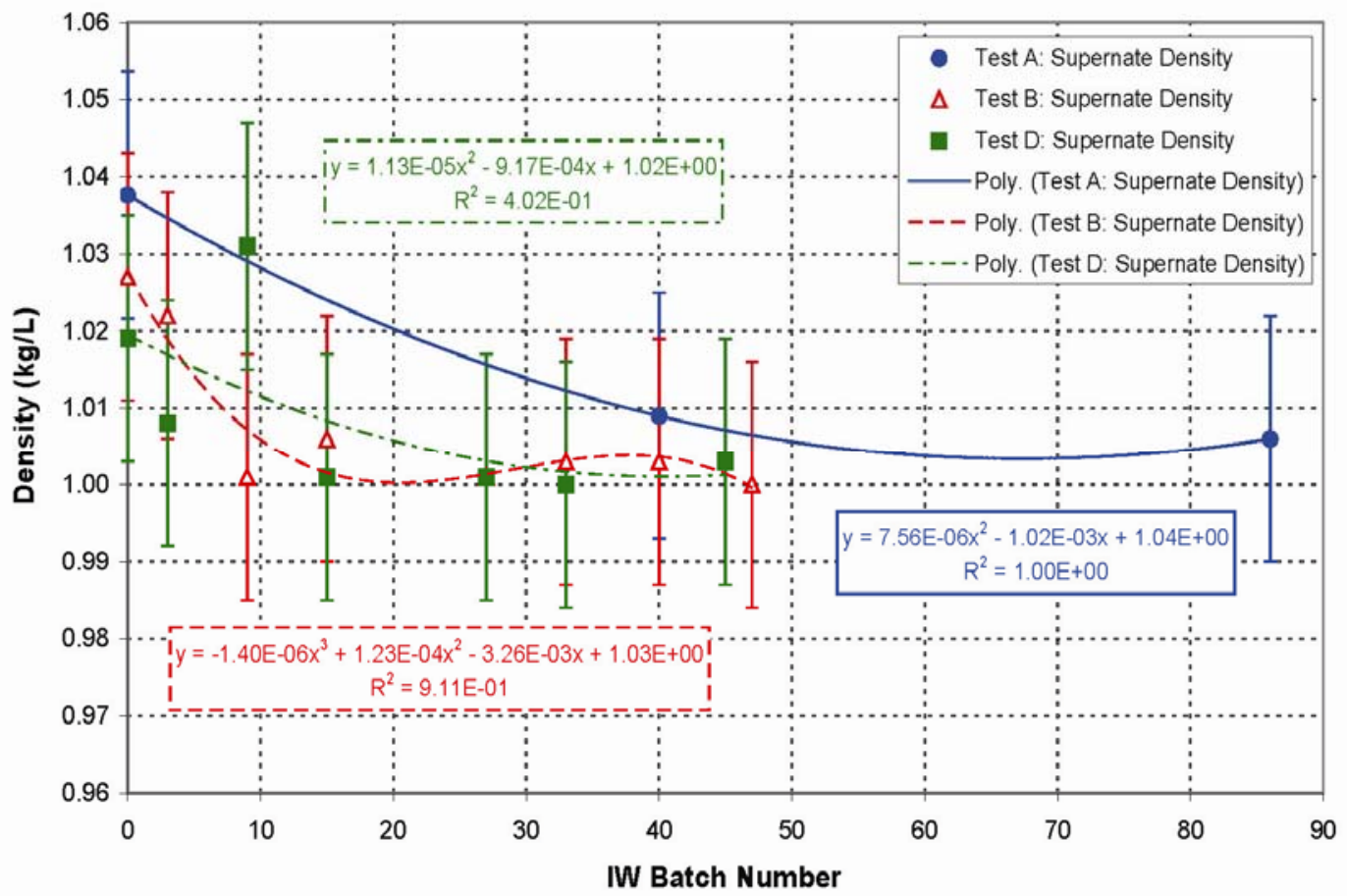

Figure 10.9. Supernate Densities Measured During the Post-Oxidative-Leach Wash of the Three Integrated Tests A, B, and D 
Figure 10.10 shows a similar relationship between the three tests as was seen in the post-caustic-leach wash UDS for post-oxidative-leach wash UDS for Integrated Tests A, B, and D post-caustic-leach. Integrated Test $\mathrm{A}$ is lowest, ranging from below 0.17 to 0.177 mass fraction UDS. Integrated Test $\mathrm{B}$ is slightly higher at 0.18 to 0.20 mass fraction UDS. Integrated Test D is slightly higher still with 0.19 to 0.21 mass fraction UDS. In general, the Integrated Test D UDS was always higher throughout the entire test compared with Integrated Tests A and B.

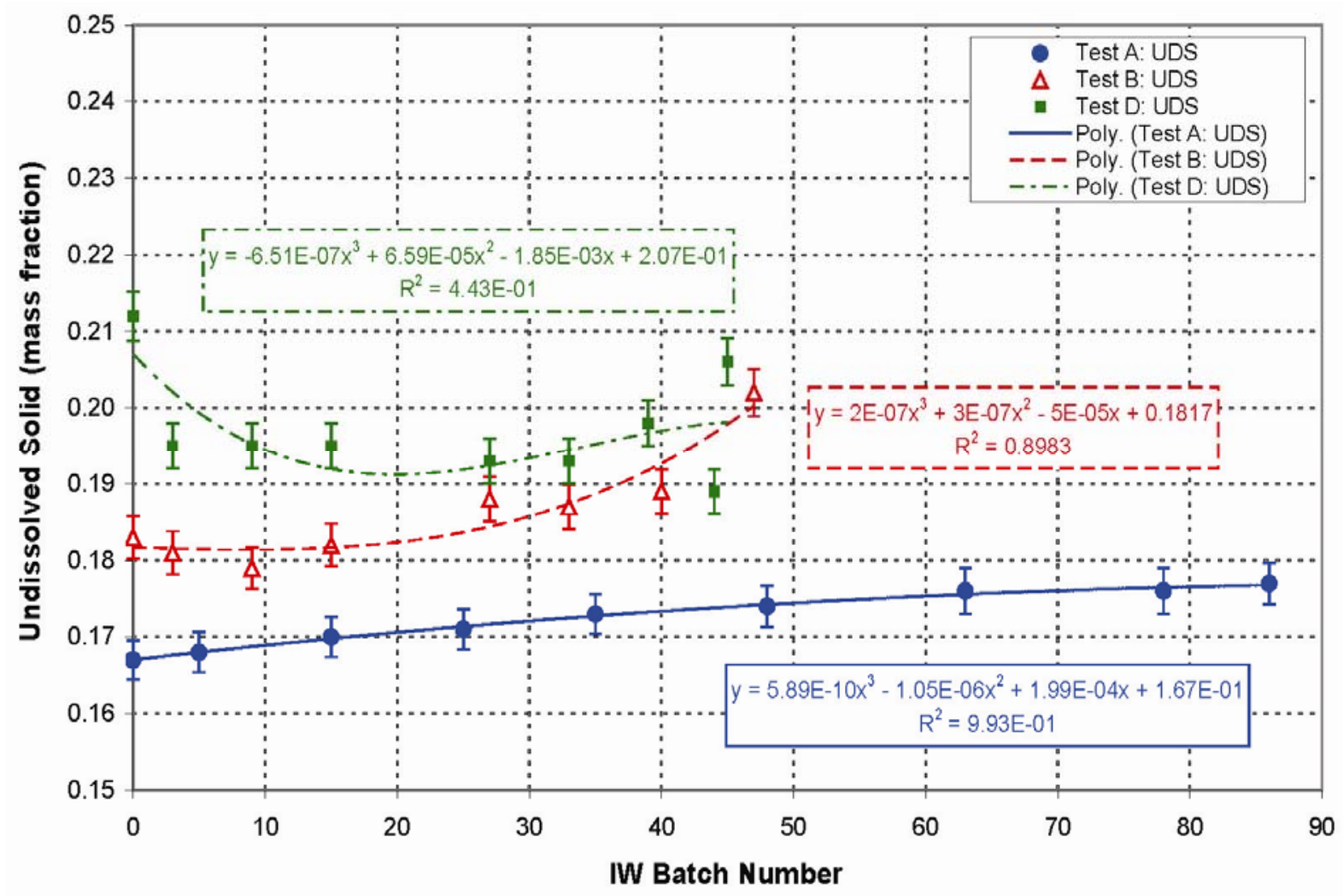

Figure 10.10. Undissolved Solids Measured During the Post-Oxidative-Leach Wash of the Three Integrated Tests $\mathrm{A}, \mathrm{B}$, and $\mathrm{D}$

Figure 10.11 shows good consistency in vessel temperature for all three tests, ranging from 23 to $25^{\circ} \mathrm{C}$ throughout the respective wash processes for the post-oxidative-leach wash temperature in Tank T02A. 


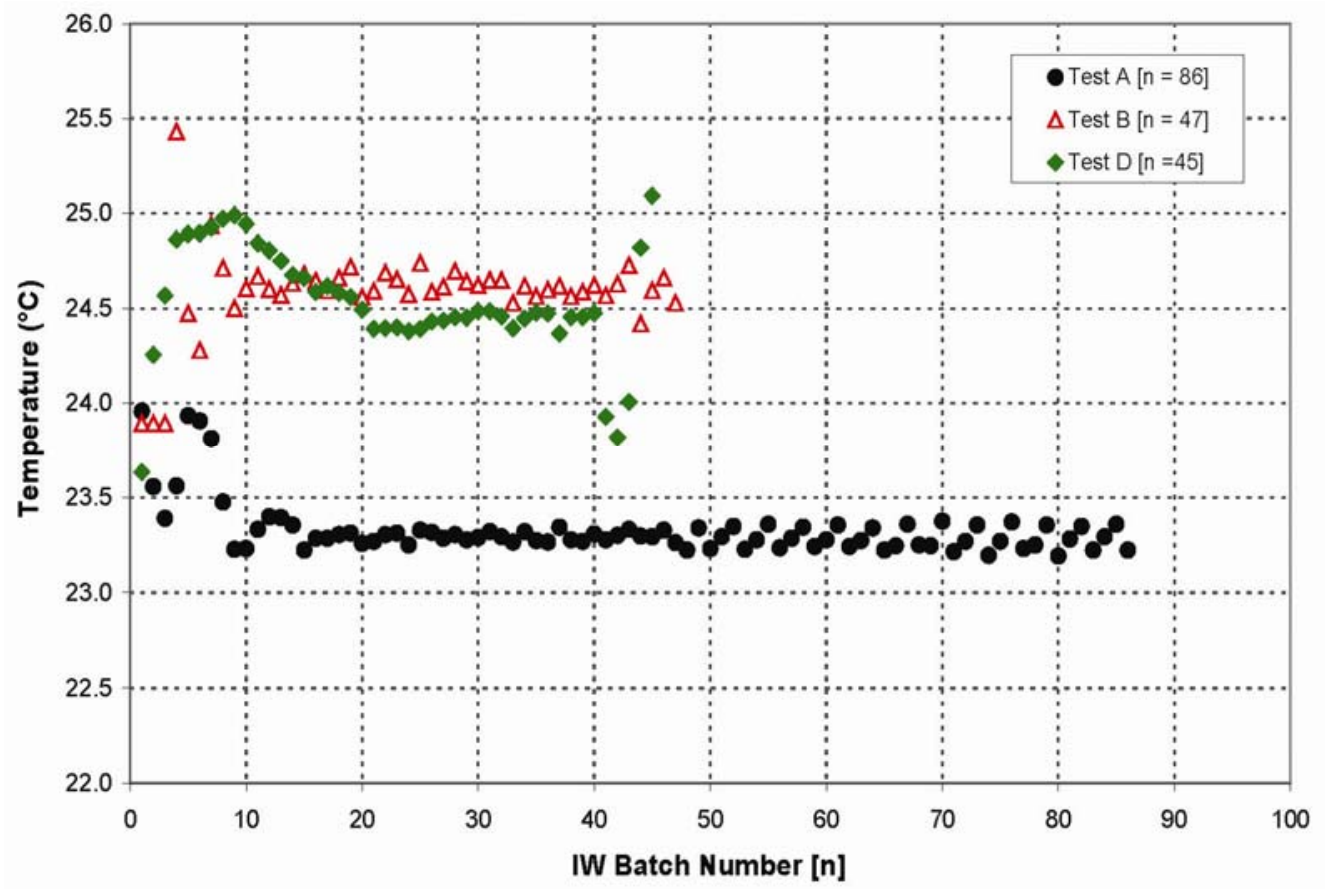

Figure 10.11. Temperature Measured in Tank T02A During the Post-Oxidative-Leach Wash of Integrated Tests $\mathrm{A}, \mathrm{B}$, and $\mathrm{D}$

Figure 10.12 shows very close agreement between Integrated Tests B and D for laser level measurements in Tank T02A for the post-oxidative-leach wash for all three Integrated Tests A, B, and D.

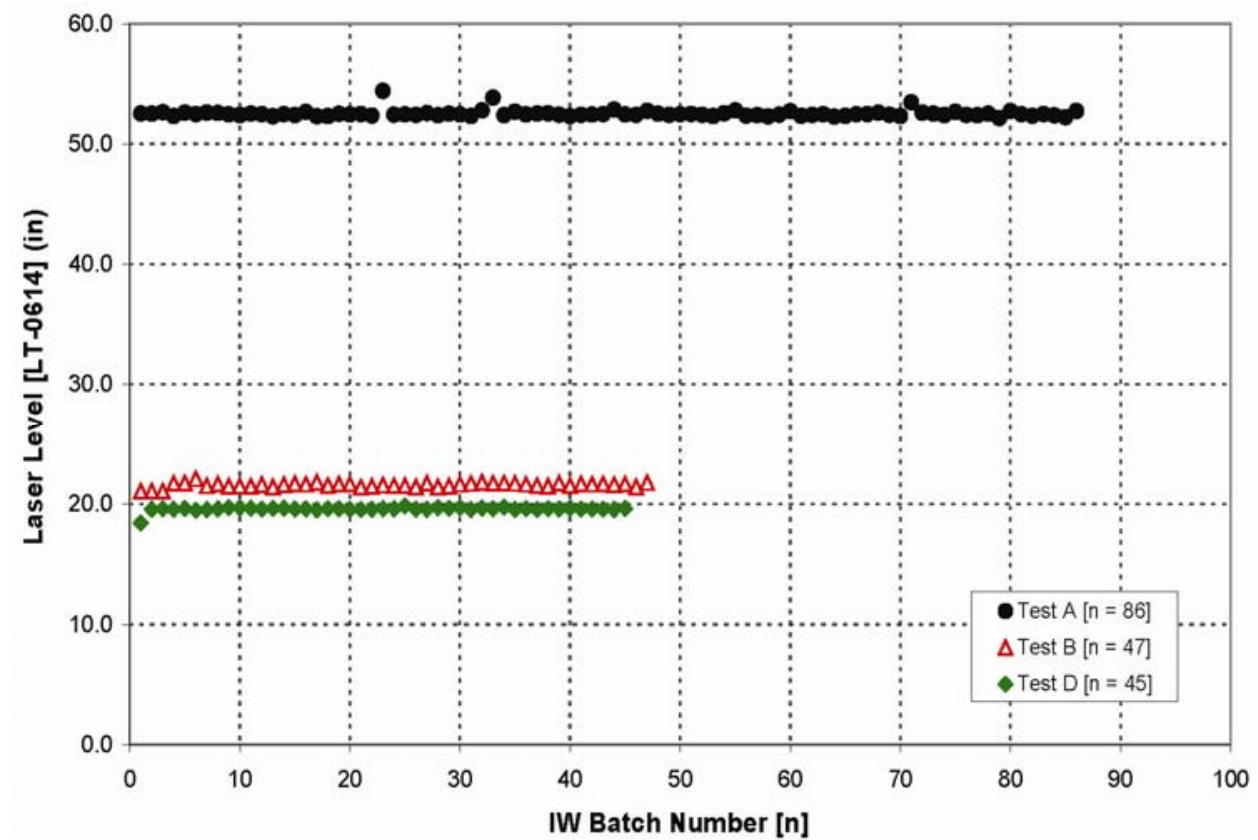

Figure 10.12. Laser Level Measured in Tank T02A During the Post-Oxidative-Leach Wash of Integrated Tests A, B, and D 
Both flowmeters were again plotted in Figure 10.13 for the filter-loop flow rate for the post-oxidative-leach wash for Integrated Tests A, B, and D: one that precedes the pumps (FT-0623) and one that follows the pumps (FT-0635). See Baldwin et al. (2009) for more discussion of flowmeter problems during Integrated Test A, and see above for a discussion on Figure 10.6 of the nonconformance report, NCR 42317.1. In Integrated Test B, after FT-0635 was replaced, the flowmeters were more consistent, but the flow rate never reached the target recirculation rate of $109 \mathrm{GPM}$, reaching only 80 to 100 GPM on FT-0623. Entrained gas was the suspected cause. Similarly, in Integrated Test D, the loop flow rate was also low, even further below target, reaching only 60 to 80 GPM on the two flowmeters. This very low Integrated Test D loop flow rate during the post-oxidative-leach wash contributes to the low normalized filter flux seen in Figure 10.14. However, it is important to note that the decrease in flow rate observed towards the end of Integrated Test $\mathrm{D}$ was because of management direction in an attempt to minimize air entrainment (see Sevigny et al. 2009 for details).

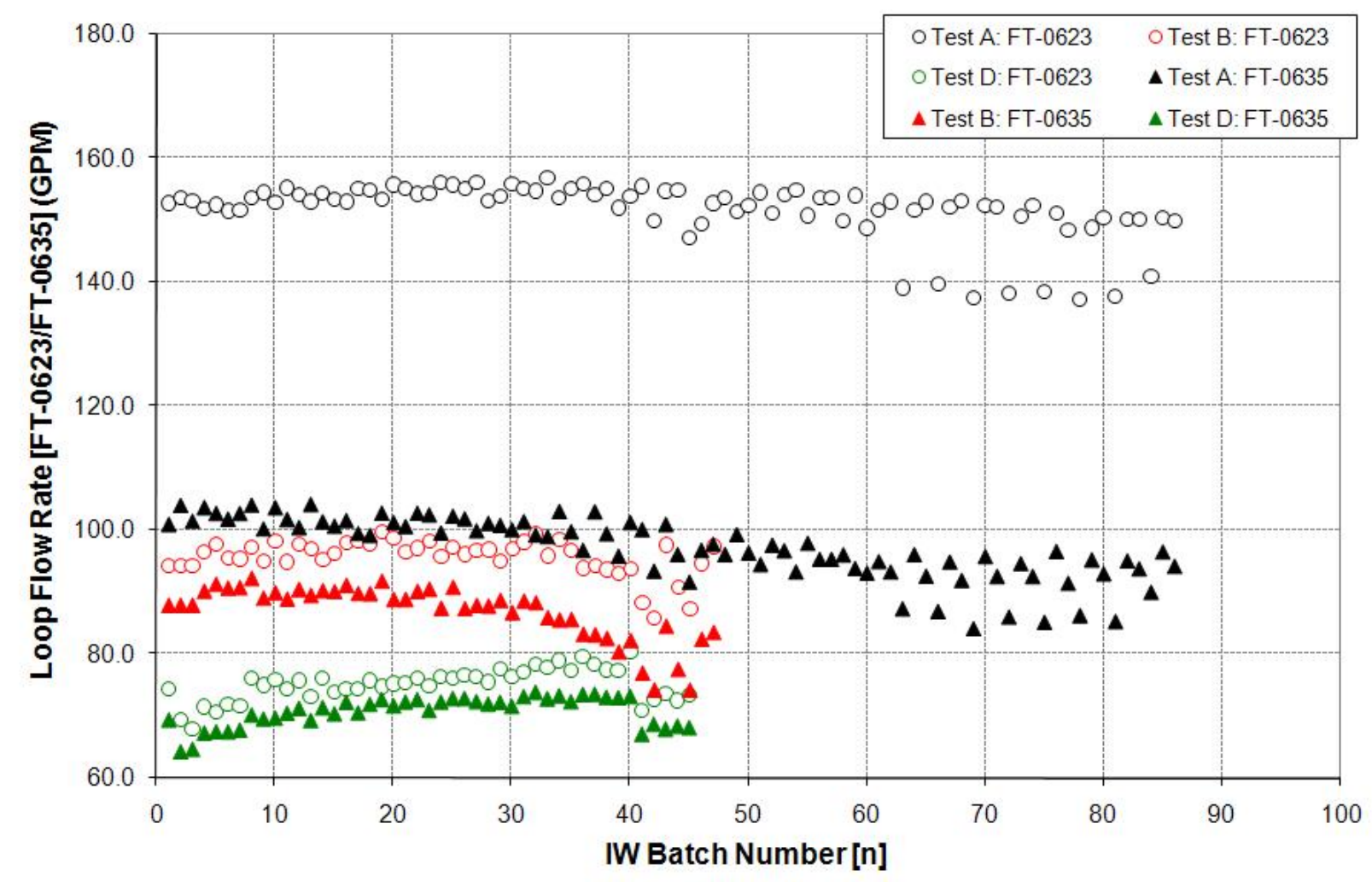

Figure 10.13. Flow Rates in the Filter-Loop During the Post-Oxidative-Leach Wash of Integrated Tests A, B, and D. Note that FT-0623 is located before the pumps and FT-0635 is located after.

Figure 10.4 shows the total normalized filter flux for all five filters, in $\mathrm{GPM} / \mathrm{ft}^{2}$, during the post-oxidative-leach wash for Integrated Tests A, B, and D. In this figure (Figure 10.14), Integrated Tests A and B showed similar rates, both starting fairly high and smoothly decreasing ranging from 0.34 down to $0.13 \mathrm{GPM} / \mathrm{ft}^{2}$. In contrast, Integrated Test $\mathrm{D}$ has a much lower total normalized filter flux at a low and fairly flat 0.05 to $0.10 \mathrm{GPM} / \mathrm{ft}^{2}$. One likely reason for low Integrated Test $\mathrm{D}$ total permeate rate was that the filters were not cleaned before Integrated Test D whereas they had been cleaned before Integrated Tests A and B. Hence, the filters in Integrated Test D were likely more fouled. The significantly lower filter-loop flow rate, and hence the lower axial velocity, in Integrated Test D may also 
be an explanation as to why the total normalized filter flux was significantly lower than in Integrated Test B. The filter history, simulant properties, and axial velocity will all have an impact on permeate removal and filter flux. The flux is normalized using corrections for both temperature and TMP. ${ }^{(a)}$

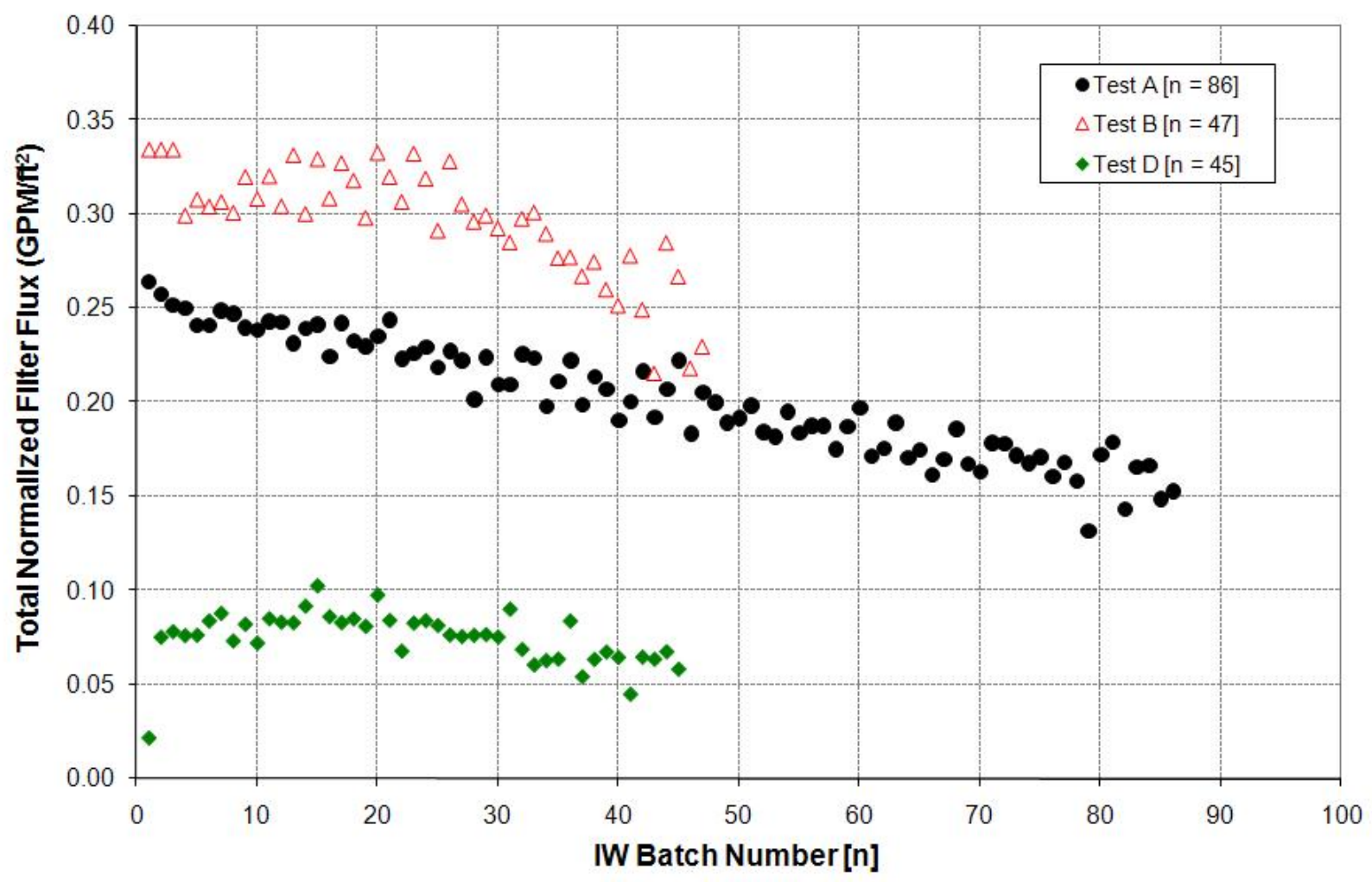

Figure 10.14. Total Normalized Filter Flux Measured During the Post-Oxidative-Leach Wash of Integrated Tests $\mathrm{A}, \mathrm{B}$, and $\mathrm{D}$

\subsection{Process Parameters}

Target process parameters for the Integrated Tests were derived principally from Pretreatment Engineering Platform (PEP) Phase 1 Testing Process Description. ${ }^{(\mathrm{b})}$ For Integrated Tests A and B, the target and actual process parameters are given in Baldwin et al. (2009), Appendix A. For Integrated Test D, the target and actual process parameters are included in Sevigny et al. (2009). The specific target run parameters for each test were developed as part of the Test Instruction for each Integrated process test and were provided as approved run sheets by the Joint Test Group (JTG). Each list contains a comparison of the target value run parameters and actual data acquisition system (DAS) parameters for each test, plus comments on any deviation.

(a) For more information on filtration and normalized flux methodology, see Daniel et al. (2009b).

(b) Lehrman SD. 2008. Pretreatment Engineering Platform (PEP) Phase 1 Testing Process Description. 24590-WTP-RPT-PET-07-002, Rev 1, Bechtel National Inc., Richland, Washington. 


\subsection{Sampling}

Sampling and analysis are described in the Test Plan, TP-RPP-WTP-506, Rev 0.4. ${ }^{\text {(a) }}$ Pacific Northwest National Laboratory (PNNL) implements the RPP-WTP quality requirements by performing work in accordance with the River Protection Project-Hanford Tank Waste Treatment and Immobilization Plant Support Program (RPP-WTP) Quality Assurance Plan. A simplified discussion of the PEP sampling scheme is described in the following sections.

All samples were taken at a nominal 1 to 2 minutes after the end of the IW injection. However, this timeframe was broad, and mixing was not necessarily complete at the time of sampling. Analyses were performed at SwRI unless otherwise indicated. Solids samples were submitted for metals analysis by ICP-atomic emission spectrometry (AES). Slurry samples were submitted for analysis of density, metals content, and $\mathrm{wt} \%$ UDS. The decanted supernate from centrifuged slurry samples was submitted for metals content, anions content, and free-hydroxide concentration (the last performed by PNNL's Analytical Support Operations [ASO]).

A single 50-mL sample was centrifuged and the supernatant decanted to allow multiple laboratories to perform several analyses simultaneously on the supernatant. To perform this phase separation, the original sample was centrifuged at $\sim 4500 \mathrm{G}$ with a swinging bucket rotor in PDL-W. The centrifuging time was initially set for 10 minutes. This centrifuging time was sufficient to cause phase separation during Shakedown, Integrated Test A, and oxidative leaching. However, during some of the Integrated Test B and Integrated Test D process steps, phase separation was not achieved after 10 minutes, so the samples were centrifuged for an hour. The actual centrifuging time is recorded on the sample bench sheets.

\subsection{Equations and Definitions}

The definition of wash efficiency is the quantity of a fully soluble solute actually removed divided by the quantity of solute expected to be removed, assuming an ideal permeate concentration. In the G-2 washing model, the ideal permeate (liquid phase) concentration is defined as

$$
C_{n}^{*}=C_{n-1} V_{L} /\left(V_{L}+V_{w}\right)
$$

where:

$n=$ wash step number, where each step adds an increment of $V_{w}$ volume (targeted at 11 gallons) of wash liquid and removes $V_{w}$ volume of permeate

$C_{n}^{*} \quad=$ ideal permeate concentration of a species as defined by the G-2 model

$C_{n-1}=$ molar concentration of a species at the end of the preceding wash step

$C_{n}=$ molar concentration of a species at the current wash step

$V_{w}=$ volume of IW added at each wash step (targeted at 11 gallons)

$V_{L} \quad=$ volume of liquid in the slurry before wash liquid is added.

This equation assumes that the wash-water, after being injected into the loop, mixes instantaneously with the slurry to achieve a new ideal equilibrium solute concentration $C_{n}{ }^{*}$. A wash efficiency of exactly

(a) Josephson GB, OP Bredt, JK Young, and DE Kurath. 2009. Pretreatment Engineering Platform (PEP) Testing (Phase I). TP-RPP-WTP-506, Rev 0.4, Pacific Northwest National Laboratory, Richland Washington. 
one is achieved if the permeate removed has an ideal concentration of $C_{n}{ }^{*}$. A wash efficiency of less than one occurs when the concentration of solute in the permeate is less than ideal, i.e., when

$$
\mathrm{Cn}<\mathrm{Cn}-1 \mathrm{VL} /(\mathrm{VL}+\mathrm{Vw})
$$

The model is developed starting with a component mass balance of the form

$$
C_{n} V_{L}=C_{n-1} V_{L}-C_{n} V_{w} w_{e f f}
$$

where $w_{\text {eff }}$ is the wash efficiency, which is assumed to be constant.

Note that if the wash efficiency is equal to one, the ideal permeate concentration from the G-2 model is recovered from Equation (10.2). The wash efficiency defined by Equation (10.2) is a measure of the removal of dissolved species and should not be confused with the "wash factor" used elsewhere as a measure of the dissolution of soluble species.

The liquid volume in the slurry is calculated using the following relationship

$$
V_{L}=\frac{\rho V\left(1-\omega_{s}\right)}{\rho_{L}}
$$

where:

$$
\begin{aligned}
& \rho=\text { slurry density, as determined by analytical samples } \\
& V \quad=\quad \text { slurry volume, as determined by level in Tank T02A } \\
& \omega_{s}=\text { mass fraction of UDS, as determined by analytical samples } \\
& \rho_{L} \quad=\text { liquid phase density, as determined by analytical samples. }
\end{aligned}
$$

The liquid volume is not constant, and it needed to be calculated for each wash step. The slurry volume was determined at every $n$ using the level in Tank T02A, a correction for the volume in the PJM tubes, and the known volume in the filter-loop. However, the physical properties were not measured at every $n$, so they were modeled as functions of $n$ to calculate $V_{L}$ at all the steps where analytical concentrations were measured. The slurry density, supernate density, and mass fraction of UDS were calculated at every batch. Finally, $V_{L}$ was modeled by a cubic polynomial as a function of $n$. This approach was used for all of the washes discussed in this report.

As described by Equation (10.2), the wash efficiency is a measure of how closely the PEP process matches the G-2 washing model predictions. If the washing liquid were instantaneously added and mixed with the slurry, $w_{\text {eff }}$ would be equal to one, and the amount of solute currently in the system $\left(C_{n} V_{L}\right)$ would be the previous amount $\left(C_{n-1} V_{L}\right)$ less the amount removed via filtration $\left(C_{n} V_{w}\right)$. The assumed mixing behavior requires that the permeate be removed at the current concentration (which is instantaneously achieved) and in amounts equivalent to the amount of IW that was added. A wash efficiency that is not equal to one indicates that the permeate was removed at a concentration other than the ideal $C_{n}{ }^{*}$. It can be thought of as water that does not participate in the process, i.e., a fraction of the water was not ideally mixed with the slurry, and the dilution of analytes would be less than expected.

Equation (10.2) can be applied to the washing data by a simple rearrangement: 


$$
\frac{C_{n-1}}{C_{n}}=1+\frac{V_{w}}{V_{L}} w_{e f f} .
$$

Equation 10.4 could be solved algebraically for $w_{\text {eff }}$; however, analytical concentrations were not measured at every $n$. It was expected that the wash efficiency should be constant or nearly so, and therefore a useful approach is to model the entire wash with $w_{\text {eff }}$ as an adjustable parameter. A model can be constructed by referencing each IW batch where samples were taken back to $C_{o}$, yielding the expression

$$
\left(\frac{C_{n-1}}{C_{n}}\right)\left(\frac{C_{n-2}}{C_{n-1}}\right) \ldots\left(\frac{C_{o}}{C_{n-(n-1)}}\right)=\left(\frac{C_{o}}{C_{n}}\right)=\left(1+\frac{V_{w}}{V_{L}} w_{e f f}\right)^{n} .
$$

In this case, the subscript $\mathrm{n}$ refers to the IW batches at which concentrations were measured. For instance, if a sample was taken at $n=6$, then

$$
\left(\frac{C_{5}}{C_{6}}\right)\left(\frac{C_{4}}{C_{5}}\right) \ldots\left(\frac{C_{o}}{C_{1}}\right)=\left(\frac{C_{o}}{C_{6}}\right)=\left(1+\frac{V_{w}}{V_{L}} w_{\text {eff }}\right)^{6} .
$$

A straightforward way to determine the parameter $w_{\text {eff }}$ is to compare the right-hand side of Equation (10.5) (expected concentration ratio) with the left-hand side (actual concentration ratio). This can be done by calculating the residuals at each $n$, defined as

$$
\Delta_{n}=\left[\left(\frac{C_{o}}{C_{n}}\right)-\left(1+\frac{V_{w}}{V_{L}} w_{e f f}\right)^{n}\right]^{2}
$$

where $\Delta_{n}$ is the residual at $n$.

At this point, the model is developed in two different directions, providing two types of wash efficiency, each with a different purpose. A single wash efficiency for each analyte may be determined using a weighted least squares best fit of the entire data set. This is shown in Equation (10.8). This provides an overall wash efficiency of the entire wash process. Alternatively, an incremental step-by-step wash efficiency may be determined to provide a quantitative measure of wash performance throughout the wash process and to test the assumption that $w_{\text {eff }}$ is approximately constant. This is described in Equations (10.9 to 10.11).

\subsubsection{Weighted Least Squares Method}

In the classical sum of the least squares method, the residuals as given in Equation (10.7) were summed over the range of interest, and $w_{\text {eff }}$ was selected to minimize that sum. A modification to that approach is to weight the sum using the magnitude of the analytical measurements. The weighing normalizes the contributions of each residual to the least squares calculation: 


$$
\bar{\Delta}_{w}=\sum \Delta_{w, n}=\sum\left[\frac{\left(\frac{C_{o}}{C_{n}}\right)-\left(1+\frac{V_{w}}{V_{L}} w_{e f f}\right)^{n}}{\left(\frac{C_{o}}{C_{n}}\right)}\right]^{2}
$$

where $\bar{\Delta}_{w}$ is the quantity to be minimized by varying $w_{\text {eff, }}$, and the subscript $w$ denotes that the residuals were weighted. The weighted least squares (WLS) approach of Equation (10.8) was used to determine $w_{\text {eff }}$ by an iterative solution method, subject to the constraint $0 \leq w_{\text {eff }} \leq 2$.

\subsubsection{Incremental Method}

The incremental method was used in support of the EFRT solids washing report, Baldwin et al. (2009), but not in this report; it is presented here for information. To obtain an idea of the performance during the wash, Equation (10.4) can also be rearranged to determine the wash efficiency algebraically:

$$
w_{\text {eff }}=\left[\left(\frac{C_{n-1}}{C_{n}}\right)-1\right]\left(\frac{V_{L}}{V_{w}}\right)
$$

Equation (10.9) can be applied incrementally to compute the wash efficiency over a small number of wash steps. If analytical information is available at two steps, $n_{1}$ and $n_{2}$, then

$$
w_{e f f, i}=\left[\left(\frac{C_{n_{1}}}{C_{n_{2}}}\right)^{\frac{1}{n_{2}-n_{1}}}-1\right]\left(\frac{\left\langle V_{L}\right\rangle}{V_{w}}\right)
$$

where $\left\langle V_{L}\right\rangle$ is the average liquid volume over the increment, and the subscript $i$ indicates that the wash efficiency is incremental. Equation (10.10) as written requires that $n_{2}$ occurs after $n_{1}$. For example, in the post-caustic-leach wash of Integrated Test A, samples were taken for $n=3$ and $n=6$. This can be written

$$
w_{\text {eff }, i}=\left[\left(\frac{C_{3}}{C_{6}}\right)^{\frac{1}{6-3}}-1\right]\left(\frac{\left\langle V_{L}\right\rangle}{V_{w}}\right)
$$

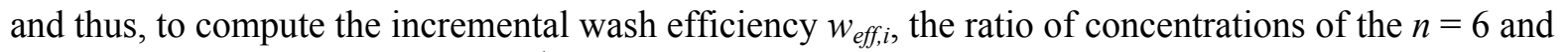
$n=3$ samples will be raised to the $1 / 3$ power. The result of the calculation using Equation (10.11) would be the wash efficiency for Batches 4,5, and 6. The incremental calculation has the added benefit of providing feedback on the assumption that $w_{\text {eff }}$ is a constant over an entire wash since it is calculated for only a few steps at a time. 
A comment may be made about the definition of wash efficiency to help clarify the reader's understanding of the limits of the sensitivity of the expression to potential mixing problems. The current definition of wash efficiency results in a factor that can be applied directly to a G-2 type model of washing. However, in and of itself, it may be a limited indicator as a sensitive measure of washing or an indication of perfect mixing in Tank T02A.

For example, to examine the wash efficiency sensitivity a little closer, the worst case scenario of IW addition but with absolutely no mixing occurring may be examined. This scenario is not expected and would not be considered reasonable but only used as an exercise. In this exercise, after IW is added, the slurry and IW are assumed filtered out in proportion to the amount of volume present. Even though the volume is assumed to be constant, the slurry volume decreases with each wash as it is replaced by IW that does not blend in. In the case of Integrated Test A with a 246-gal liquid volume, after one wash of 11 gallons but no mixing, the wash efficiency is still 1.00 with a concentration ratio $C_{n} / C_{o}$ of 1.05 . After five washes with no mixing, the wash efficiency is 0.93 , and the $\mathrm{C}_{\mathrm{n}} / \mathrm{C}_{\mathrm{o}}$ concentration ratio is at 1.22 . In the case of Integrated Tests B or D with the smaller 139-gal liquid volume, we see slightly more effect. After one wash of IW addition but no mixing, the wash efficiency is 0.99 , and the $\mathrm{C}_{n} / \mathrm{C}_{\mathrm{o}}$ is 1.08 . After five washes with no mixing, the wash efficiency is 0.87 , and the $\mathrm{C}_{\mathrm{n}} / \mathrm{C}_{\mathrm{o}}$ is 1.38 .

One can see from this exercise how initially the amount of mixing is not very important because the wash efficiency is still 1.0 or close to 1.0 in the no-mixing scenario. It does start to matter eventually with no mixing occurring and with enough IW addition and permeate removal. One can clearly see this in the $\mathrm{C}_{\mathrm{n}} / \mathrm{C}_{\mathrm{o}}$ ratio better than the wash efficiency. The conclusion is that the sensitivity limits on the wash efficiency to mixing issues should be understood by the reader.

\subsection{Results}

The standard analytical methods for measuring analyte concentrations used for the results discussed here include ICP-AES, IC, and titration, discussed in Section 10.6.1. These methods are described in more detail in Appendix E. In addition, the method of Raman was used, and the results are discussed below in Section 10.6.2. Further comparison of the Raman method with the standard methods by comparing phosphate results is discussed in Section 10.6.3. Comparisons of measured oxalate concentration to calculated oxalate solubility expression values are evaluated and discussed in Section 10.6.4. Discussion of method of uncertainty evaluation is presented in Section 10.6.5.

\subsubsection{Standard Analytical Method Results}

The presentation of results includes the plotted and tabulated washing efficiencies and concentration behavior for all selected analytes for Integrated Test D. The full results for Integrated Tests A and B were presented in Baldwin et al. (2009). Wash efficiencies were calculated using the model and equations described in Section 10.5 and the supporting references. The post-caustic-leach and post-oxidative-leach wash efficiencies are discussed separately below. In addition, included here is a discussion of significant differences between the three Integrated Tests, A, B, and D.

The corresponding wash efficiencies calculated by the weighted least squares method for all three

Integrated Tests A, B, and D for soluble analytes are shown in Table 10.4. The Integrated Test D results all indicate an ideal washing behavior, with the exception of sulfate during post-caustic-leach wash. 
Sulfate has a lower wash efficiency $(0.84)$ because of a problematic initial concentration, $\mathrm{C}_{\mathrm{o}}$. As shown in the footnote, if the initial concentration is ignored and the wash efficiency recalculated using all the other concentration data, the result is 1.04 . The revised average for all five analytes then becomes $1.02 \pm 0.02$. This average value for Integrated Test D post-caustic-leach wash compares with the average values 0.99 and 1.01, respectively, for Integrated Tests A and B. The Integrated Test D post-oxidative-leach wash value is $0.96 \pm 0.02$, compared to 0.99 and 1.00 for the Integrated Tests A and B post-oxidative-leach wash, respectively.

Table 10.4. Summary of Weff Results (Weighted Least Squares Method) for All Analytes, for Integrated Tests A, B, and D

\begin{tabular}{|c|c|c|c|c|}
\hline \multicolumn{5}{|c|}{ Post-Caustic-Leach Wash $\mathrm{W}_{\text {eff }}$} \\
\hline & Analyte & Integrated Test A & Integrated Test B & Integrated Test D \\
\hline & Aluminum & $1.00 \pm 0.03$ & $1.01 \pm 0.03$ & $0.98 \pm 0.02$ \\
\hline & Sulfate & $1.00 \pm 0.03$ & $1.02 \pm 0.03$ & $0.84 \pm 0.03^{(a)}$ \\
\hline & Nitrate & $1.00 \pm 0.02$ & $1.01 \pm 0.03$ & $1.05 \pm 0.03$ \\
\hline & Nitrite & $1.01 \pm 0.03$ & $1.02 \pm 0.04$ & $1.02 \pm 0.03$ \\
\hline & $\mathrm{OH}$ & $0.93 \pm 0.05$ & $0.99 \pm 0.06$ & $1.01 \pm 0.05$ \\
\hline & Average & $0.99 \pm 0.01$ & $1.01 \pm 0.02$ & $0.98 \pm 0.02$ \\
\hline \multicolumn{5}{|c|}{ Post-Oxidative-Leach Wash $\mathrm{W}_{\text {eff }}$} \\
\hline & Analyte & Integrated Test A & Integrated Test B & Integrated Test D \\
\hline & $\mathrm{Cr}$ & $0.98 \pm 0.02$ & $1.01 \pm 0.02$ & $0.93 \pm 0.03$ \\
\hline & Oxalate & $1.00 \pm 0.04$ & $0.99 \pm 0.03$ & $0.98 \pm 0.03$ \\
\hline & Average & $0.99 \pm 0.02$ & $1.00 \pm 0.02$ & $0.96 \pm 0.02$ \\
\hline (a) & $\begin{array}{l}\text { The value o } \\
\text { efficiency i }\end{array}$ & $\begin{array}{l}\text { itial sulfate concentra } \\
\text { ulated using all the of }\end{array}$ & $\begin{array}{l}\text { storts this result. If it } \\
\text { ncentration data, the }\end{array}$ & $\begin{array}{l}\text { red and the wash } \\
1.04 \text {. }\end{array}$ \\
\hline
\end{tabular}

The overall wash efficiency for the post-caustic-leach wash, averaged over all analytes for all of the Integrated Tests A, B, and D, is $1.00 \pm 0.01$. For the post-oxidative-leach wash, the overall wash efficiency averaged over all analytes for all of the Integrated Tests A, B, and D is $0.98 \pm 0.01$. The overall conclusion is that all three Integrated tests show consistent wash efficiency values of 1.0 or very close to 1.0 .

All wash-step analyte concentration data and $\mathrm{C}_{n} / \mathrm{C}_{\mathrm{o}}$ ratios for all analytes of interest are shown in Tables C.1 and C.2 in Appendix C for the post-caustic-leach wash. For the post-oxidative-leach wash, the corresponding wash-step analyte concentration data for analytes of interest are shown in the Table C.3 in Appendix C. Corresponding tables of Integrated Tests A and B data are found in Baldwin et al. (2009).

The semi-log of the ratio, $\mathrm{C}_{\mathrm{n}} / \mathrm{C}_{\mathrm{o}}$, of the measured concentration at each step to the initial measured concentration is shown graphically below, comparing all three Integrated Tests A, B, and D for all the major analytes. The semi-log view provides two benefits-1) True log-linearity should result if the analyte is subject to and exhibits ideal mixing. The expected ideal concentration ratio is provided for reference; by definition, ideal behavior is when the wash efficiency is equal to 1 in Equation (10.3). So any deviation from log-linearity may indicate continual dissolution or precipitation (though precipitation is not observed in these PEP tests) of analytes, an approach to the measurement detection limit, mixing problems due to analyte segregation in system dead volumes, or other concentration behavior problems. 
2) The semi-log view provides greater detail of concentration behavior as the end of washing is approached. In each case, the ideal wash efficiency curve, $\mathrm{W}_{\text {eff }}=1$, is included for comparison. Similar figures for Integrated Tests A and B were shown in Section 5 of Baldwin et al. (2009), though the incremental wash efficiency curves are not included here for clarity.

A closer examination of the comparative concentration ratio curves for Integrated Tests A, B, and D is made here. Figure 10.15 through Figure 10.19 are for the post-caustic-leach wash. We see generally very similar $\mathrm{C}_{\mathrm{n}} / \mathrm{C}_{\mathrm{o}}$ curves for Integrated Tests $\mathrm{B}$ and $\mathrm{D}$, as expected for those two similar tests. In fact, the ideal Integrated Tests B and D curves exactly fall over one another for the post-caustic-leach wash. In Figure 10.17 showing the sulfate data, the Integrated Test D data demonstrates clearly how the weighted least squares calculation suffers from a poor or inaccurate initial concentration as the $C_{n} / C_{0}$ curves fall significantly away from the ideal $\mathrm{W}_{\text {eff }}=1$ curve. However, note how that curve does follow fairly well the slope of the ideal line. The explanation is an erroneous initial sulfate concentration value for the Integrated Test D PCLW.

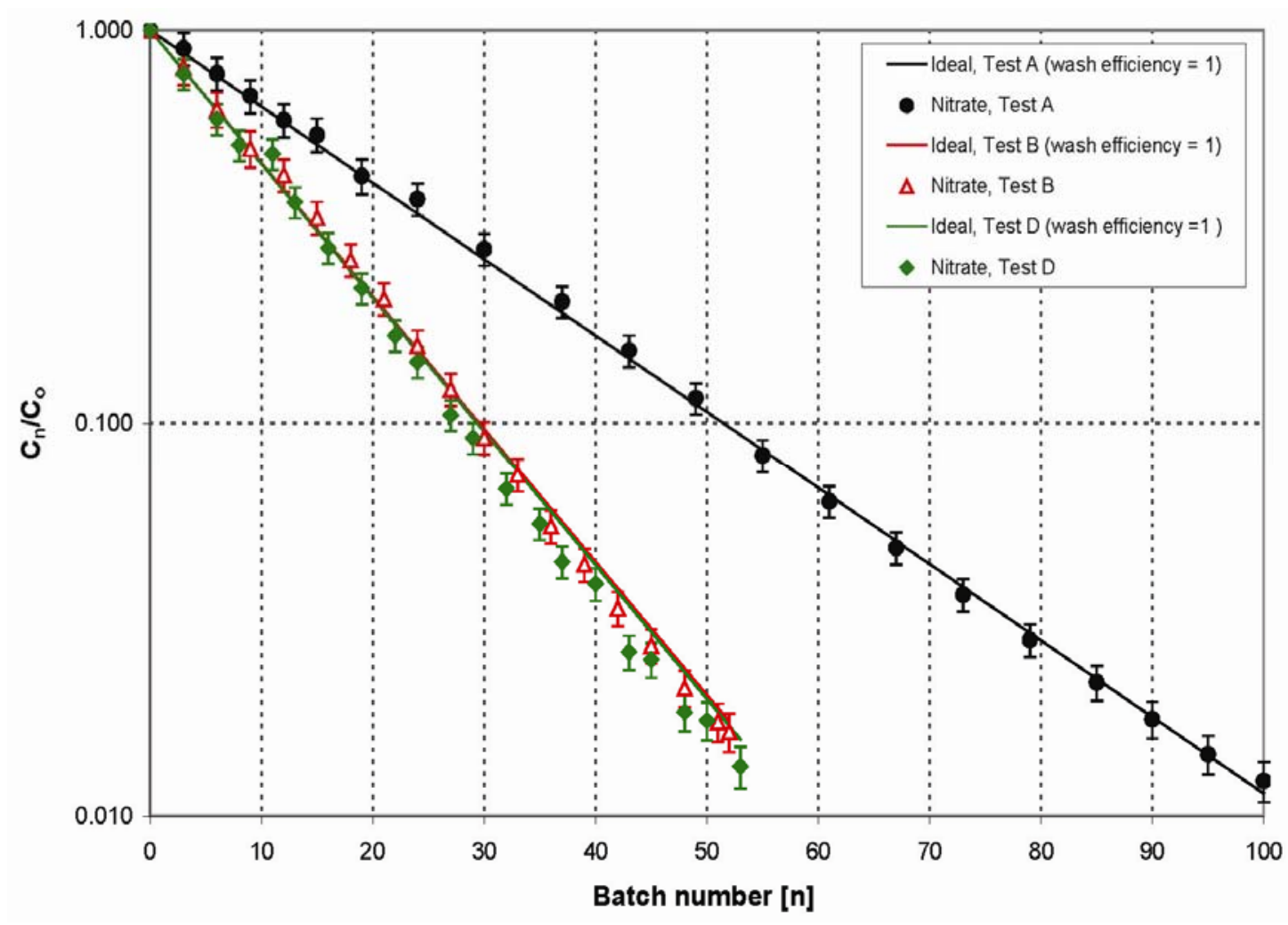

Figure 10.15. Concentration Ratio $(\mathrm{Cn} / \mathrm{Co})$ for Nitrate During the Post-Caustic-Leach Wash. The ideal behavior (assuming a wash efficiency of 1) is also provided for each Integrated test. 


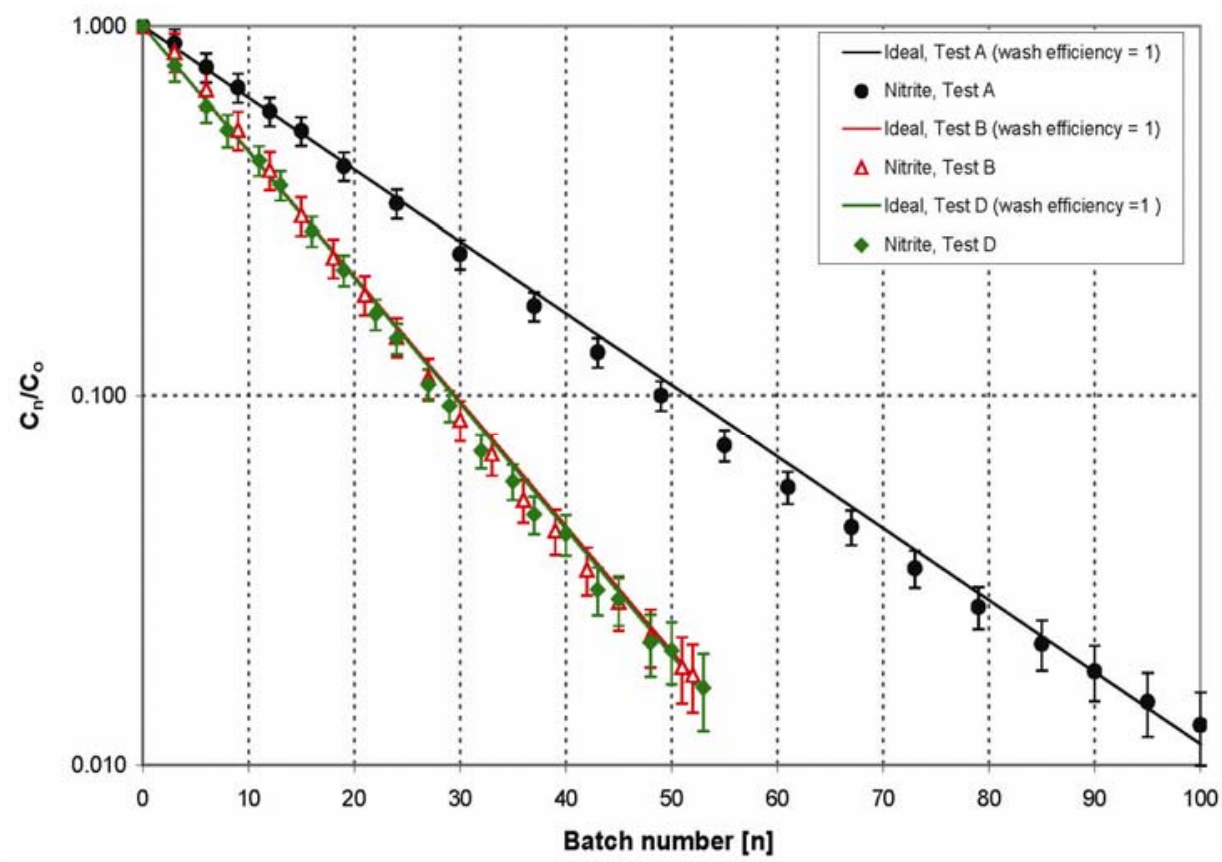

Figure 10.16. Concentration Ratio $(\mathrm{Cn} / \mathrm{Co})$ for Nitrite During the Post-Caustic-Leach Wash. The ideal behavior (assuming a wash efficiency of 1 ) is also provided for each Integrated Test.

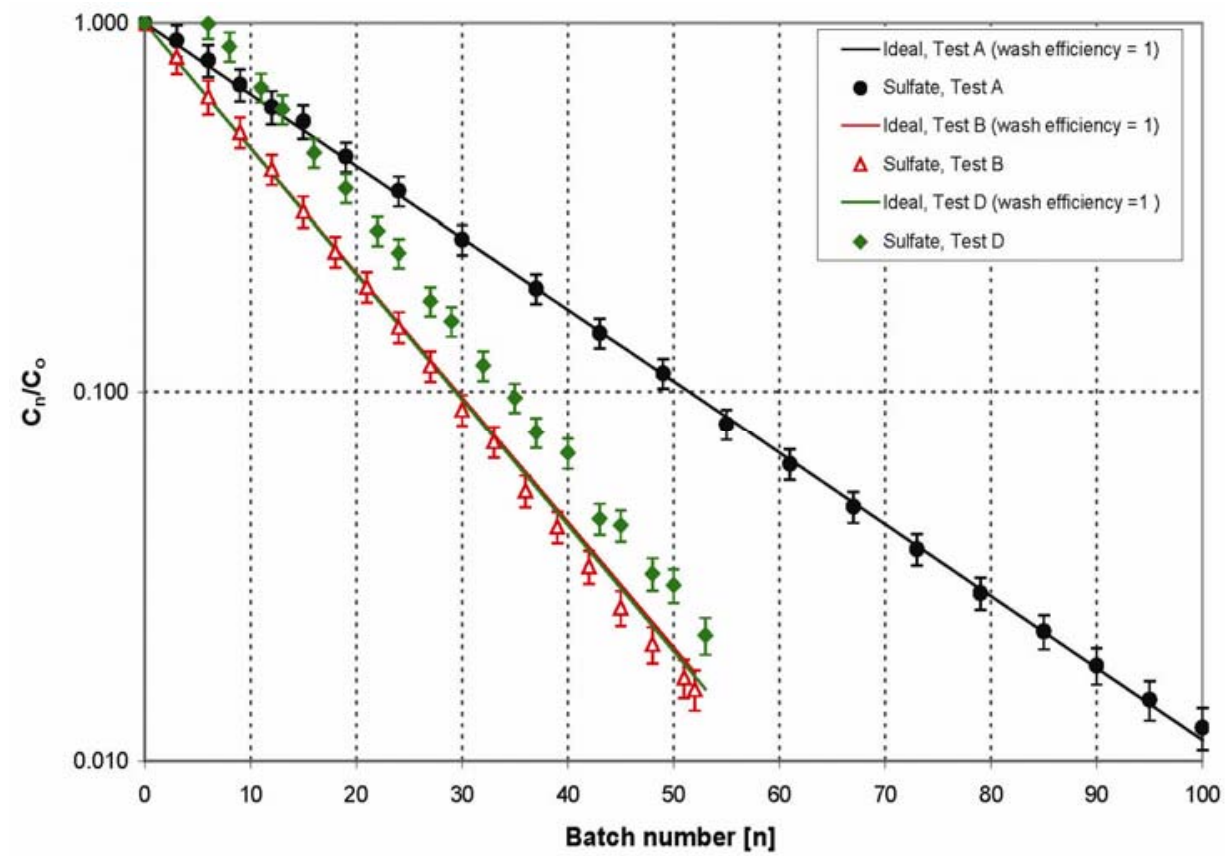

Figure 10.17. Concentration Ratio $(\mathrm{Cn} / \mathrm{Co})$ for Sulfate During the Post-Caustic-Leach Wash. The ideal behavior (assuming a wash efficiency of 1) is also provided for each Integrated test. Note that during Integrated Test D a low initial concentration shifts the sulfate concentration ratios upward for the rest of the test. 


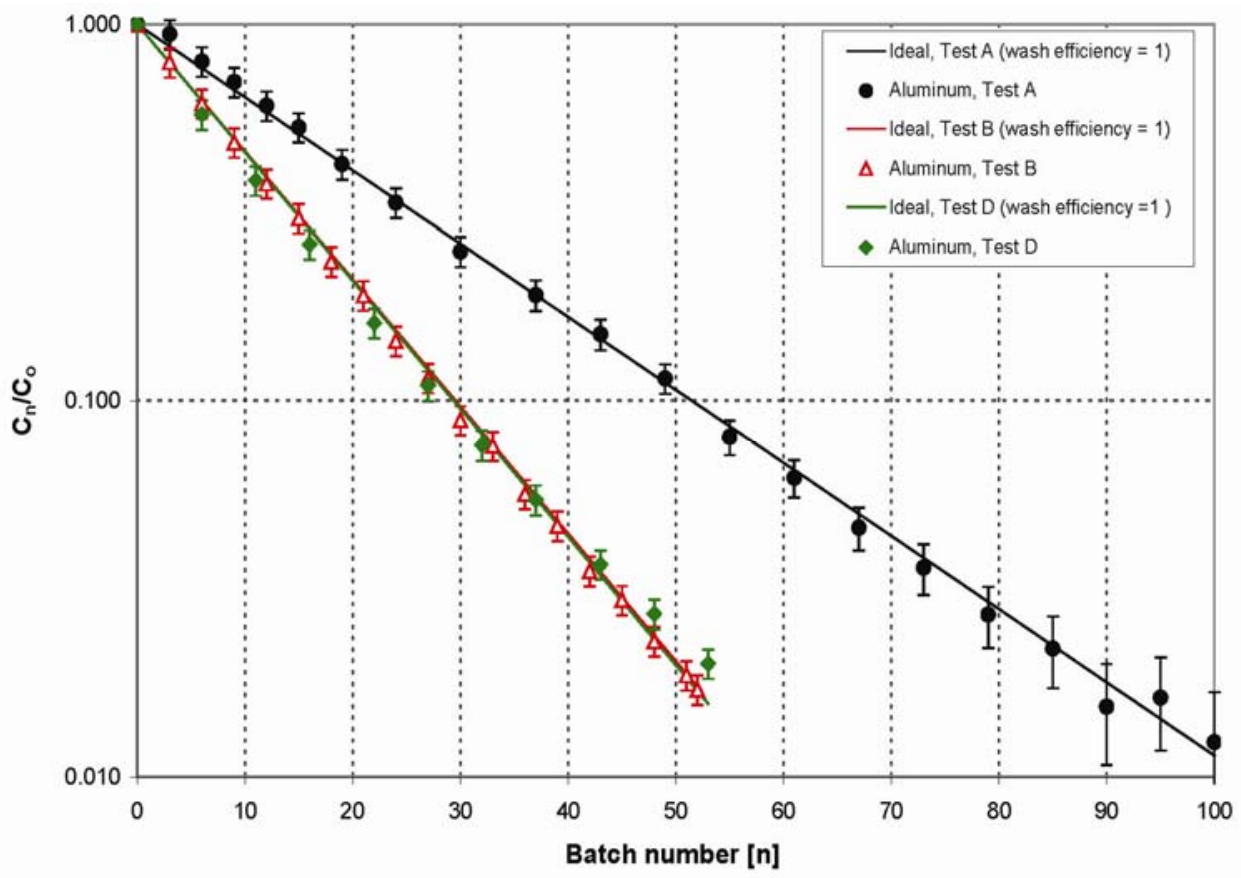

Figure 10.18. Concentration Ratio $(\mathrm{Cn} / \mathrm{Co})$ for Aluminum During the Post-Caustic-Leach Wash. The ideal behavior (assuming a wash efficiency of 1) is also provided for each Integrated test.

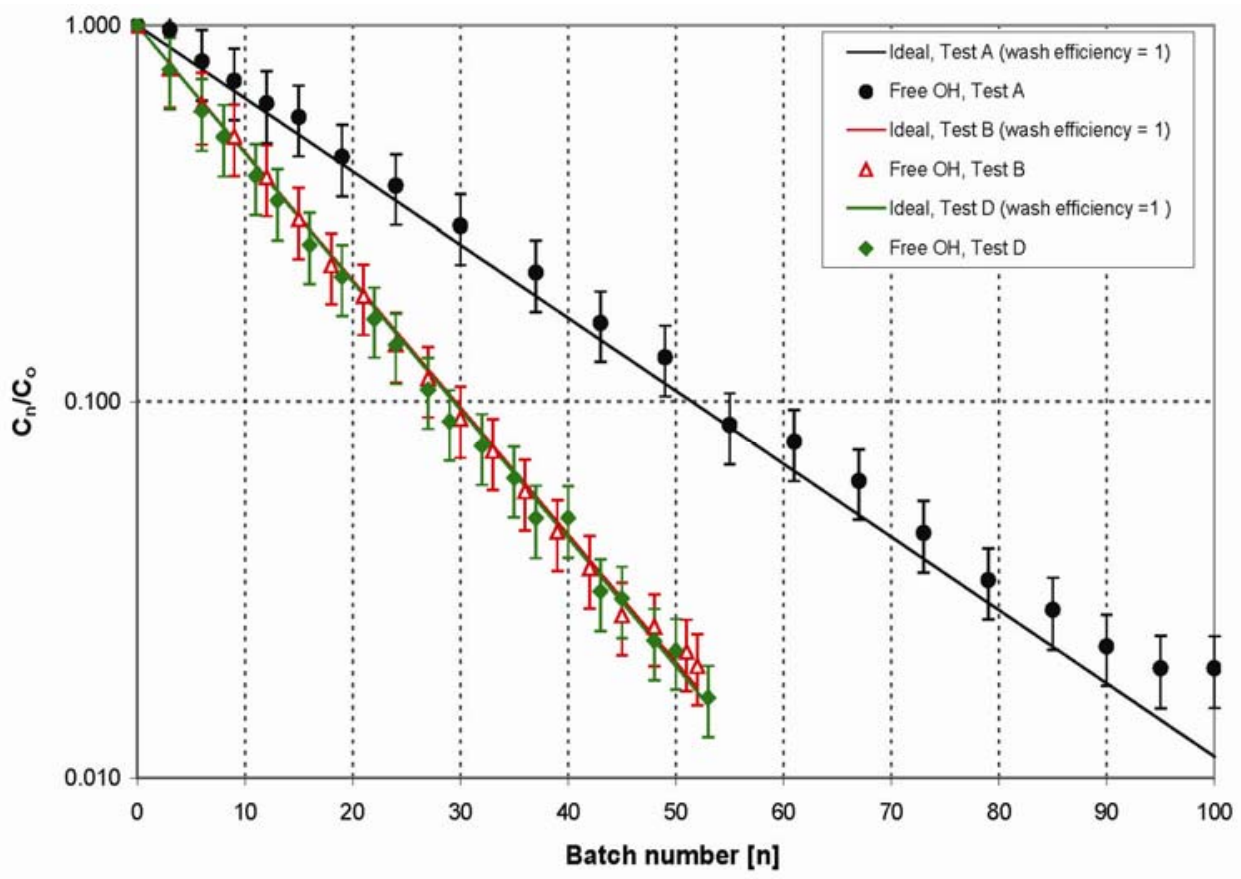

Figure 10.19. Concentration Ratio $(\mathrm{Cn} / \mathrm{Co})$ for Free Hydroxide During the Post-Caustic-Leach Wash. The ideal behavior (assuming a wash efficiency of 1) is also provided for each Integrated test. 
Figure 10.20 through Figure 10.22 show overlaid as-measured concentration curves for post-caustic-leach wash for each test and allows visual comparison of the major analytes of interest. One can note that the oxalate and phosphate show similar peaked curve shapes in all cases, caused by the dissolution of the solids followed by washing out. Sodium phosphate and sodium oxalate are sparingly soluble. Due to the high sodium concentration some of the phosphate and oxalate is present as solid sodium phosphate and sodium oxalate. As sodium is washed out the oxalate and phosphate solubility increases. Eventually the sodium concentration drops so that the oxalate and phosphate no longer exceed the solubility limit, are completely in soluble form, and continue washing out along with the other soluble analytes. One can see in each of the Figures 10.20-10.22 the point at which sodium has a slight rise upward matching exactly the peak in oxalate. This is the wash step when dissolution of the remaining solid sodium compounds is complete and full washing out begins. In Integrated Test D, Figure 10.22, as noted above, the artifact jog early in the sulfate curve is due to an erroneous initial sulfate concentration value.

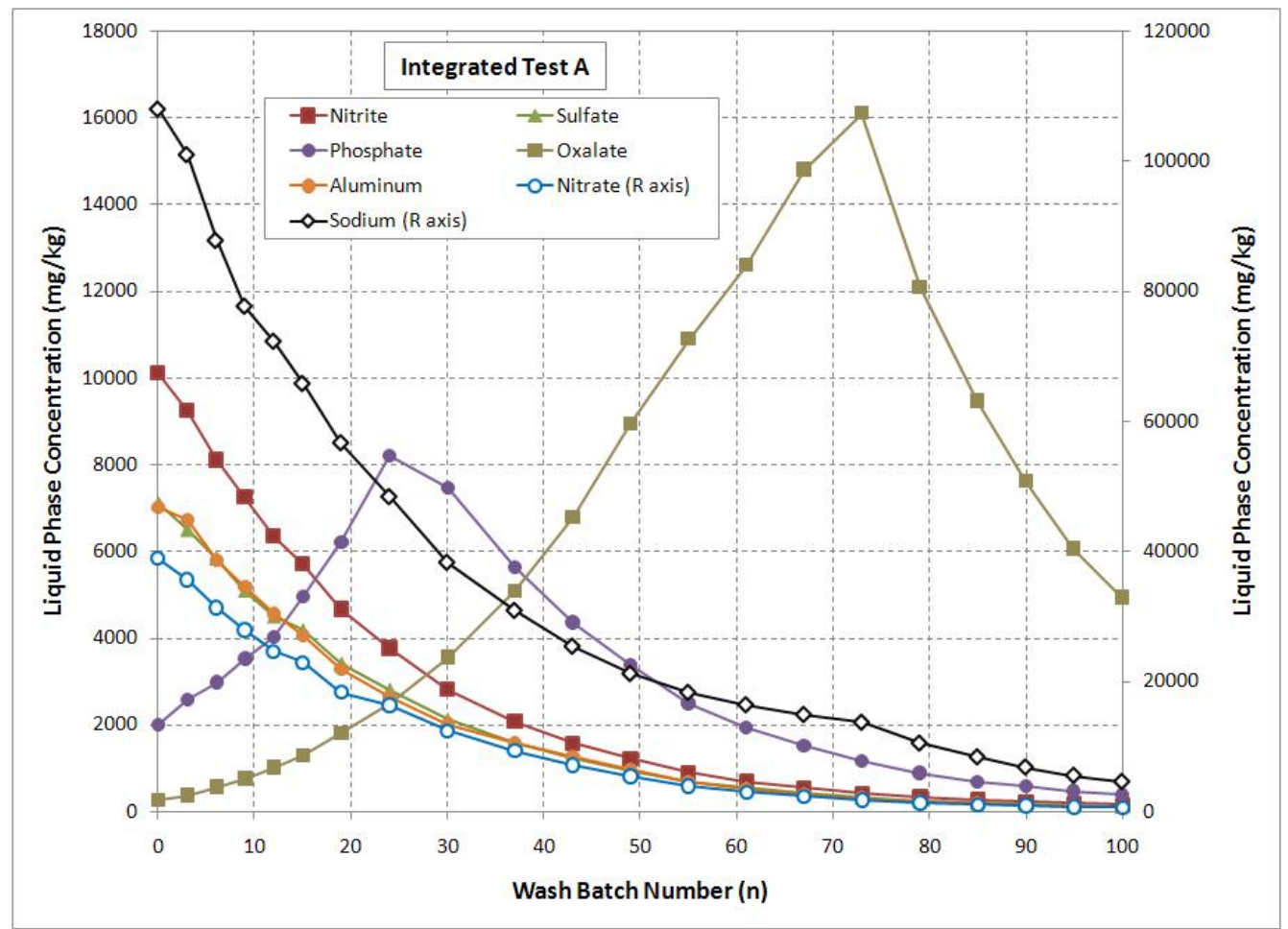

Figure 10.20. As-Measured Concentration Curves Overlaid, for Integrated Test A Post-Caustic-Leach Wash, to Allow Visual Comparison of Major Analytes of Interest. Note that sodium and phosphate are plotted on the right-hand axis. 


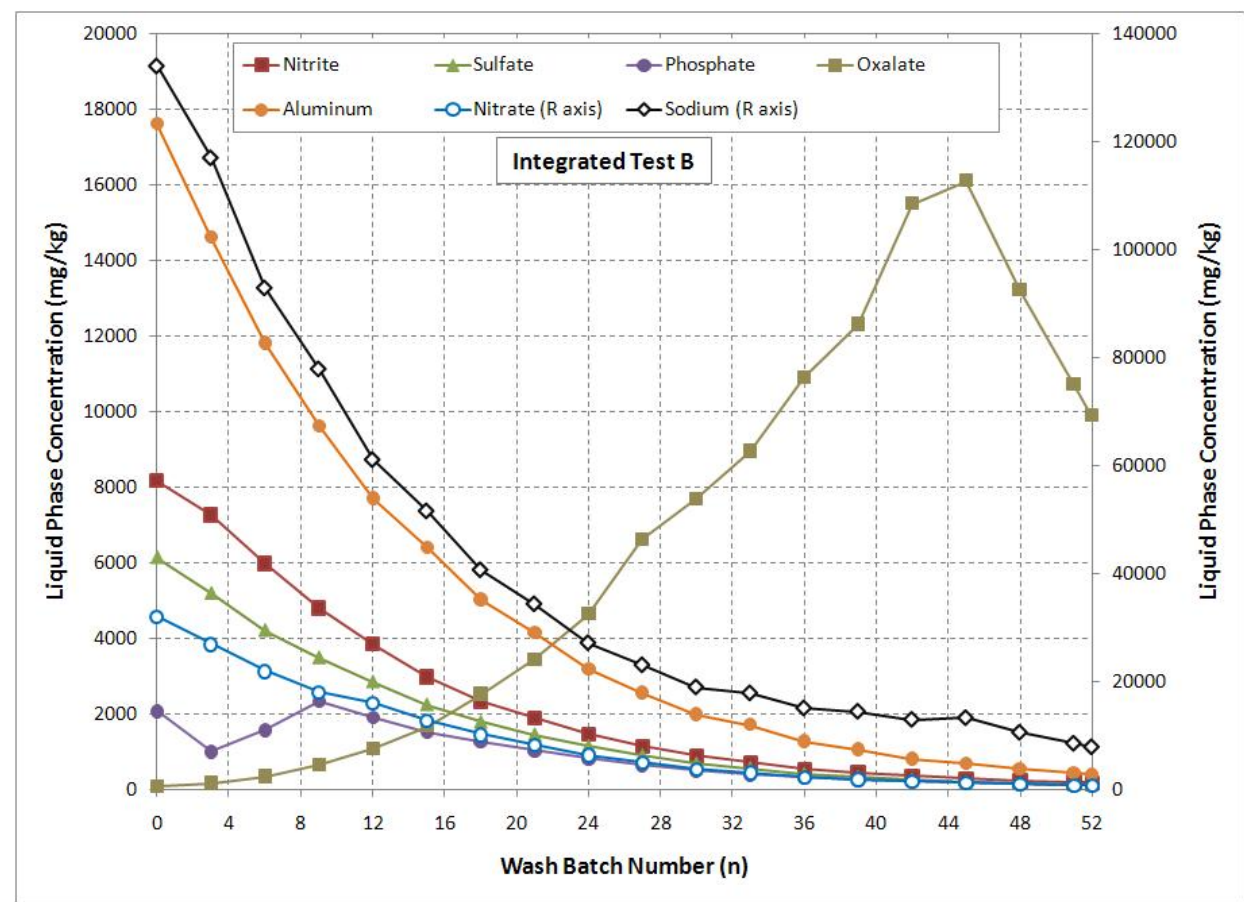

Figure 10.21. As-Measured Concentration Curves Overlaid, for Integrated Test B Post-Caustic-Leach Wash, to Allow Visual Comparison of Major Analytes of Interest. Note that sodium and phosphate are plotted on the right-hand axis.

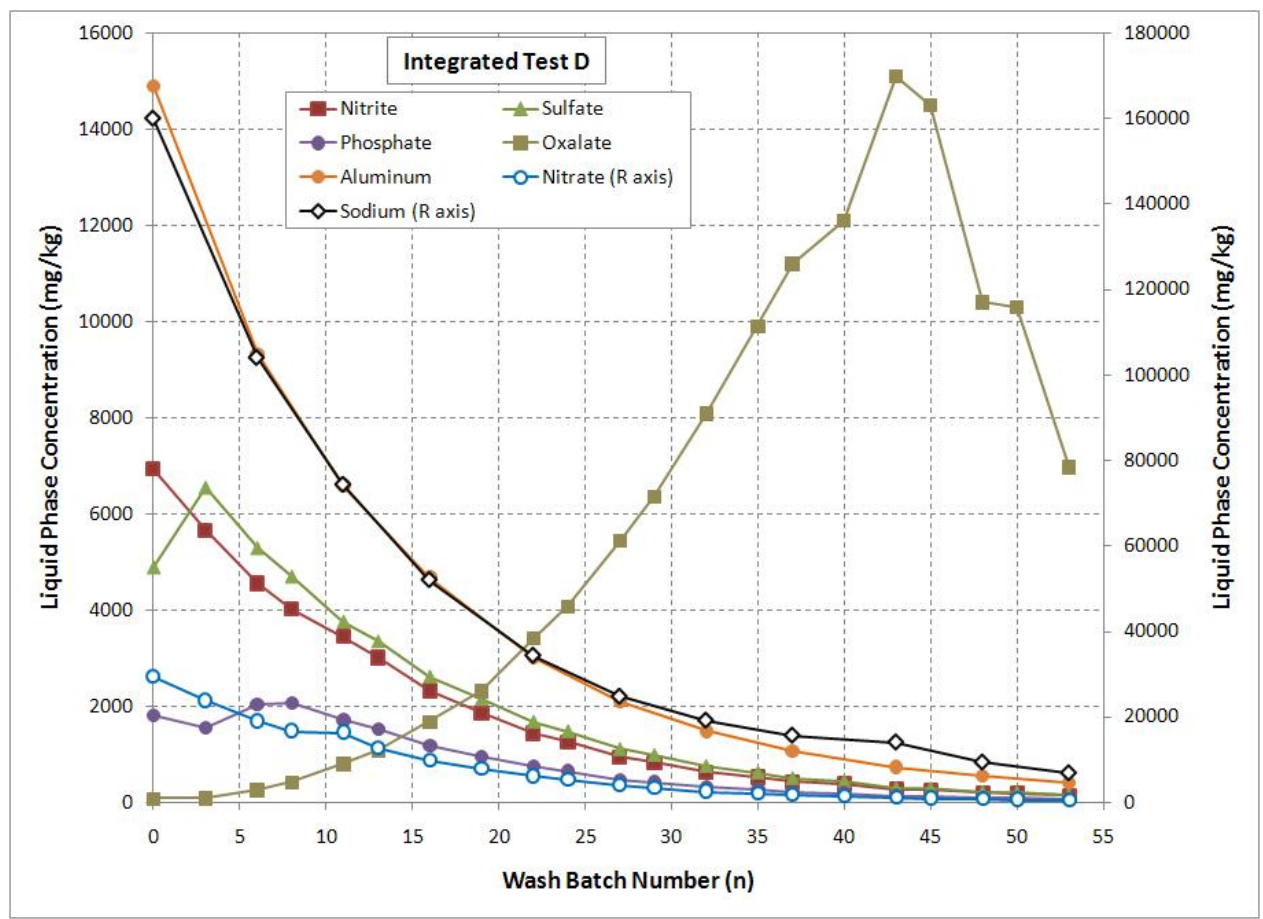

Figure 10.22. As-Measured Concentration Curves Overlaid, for Integrated Test D Post-Caustic-Leach Wash, to Allow Visual Comparison of Major Analytes of Interest. Note that sodium and phosphate are plotted on the right-hand axis. 
Figure 10.23 through Figure 10.27 are for post-oxidative-leach wash. We see several examples of non-ideal behavior, mainly for nitrate, sodium, and TDS. See discussion and full explanations of this behavior in Section 10.7. Only chromium and oxalate show good log-linear behavior, as discussed in Section 10.7.

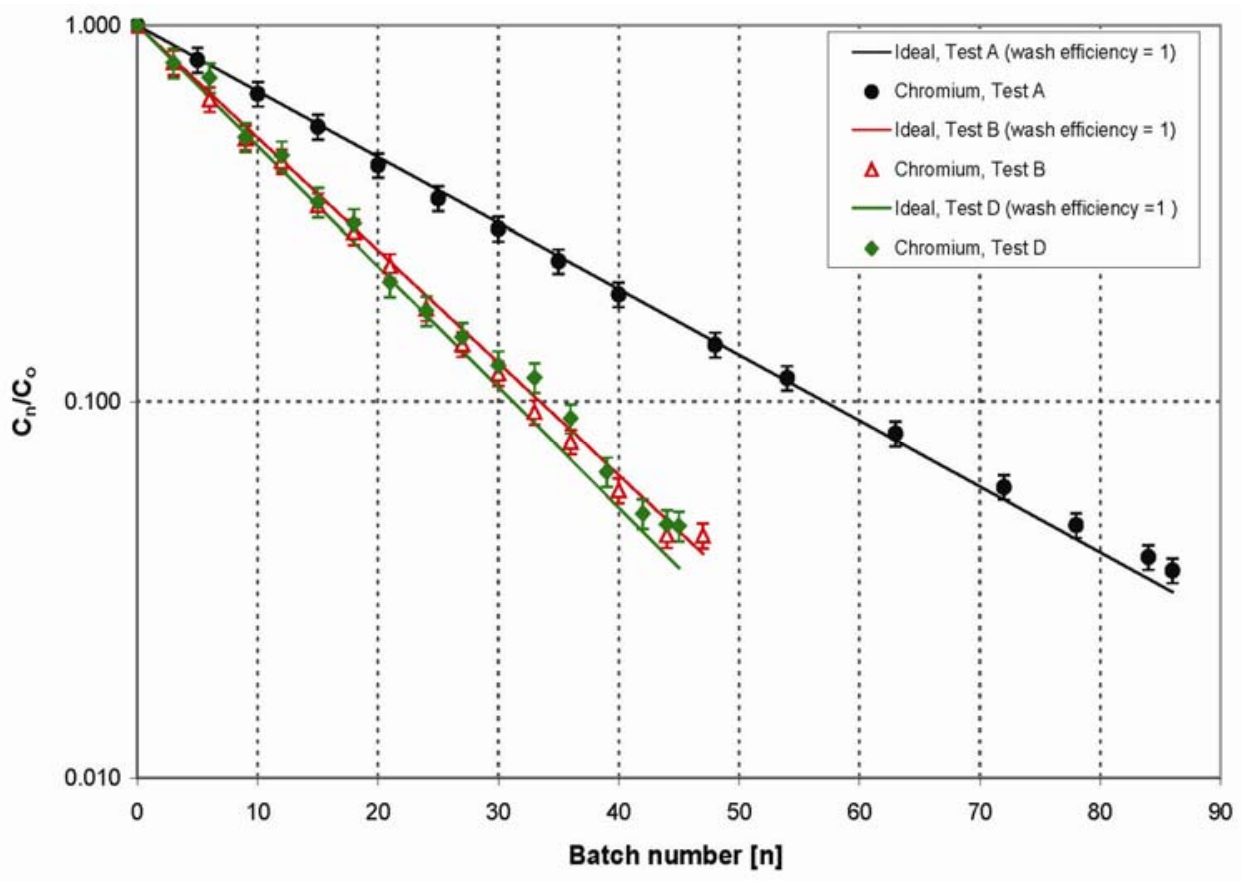

Figure 10.23. Concentration Ratio $(\mathrm{Cn} / \mathrm{Co})$ for Chromium During the Post-Oxidative-Leach Wash. The ideal behavior (assuming a wash efficiency of 1 ) is also provided for each Integrated test. 


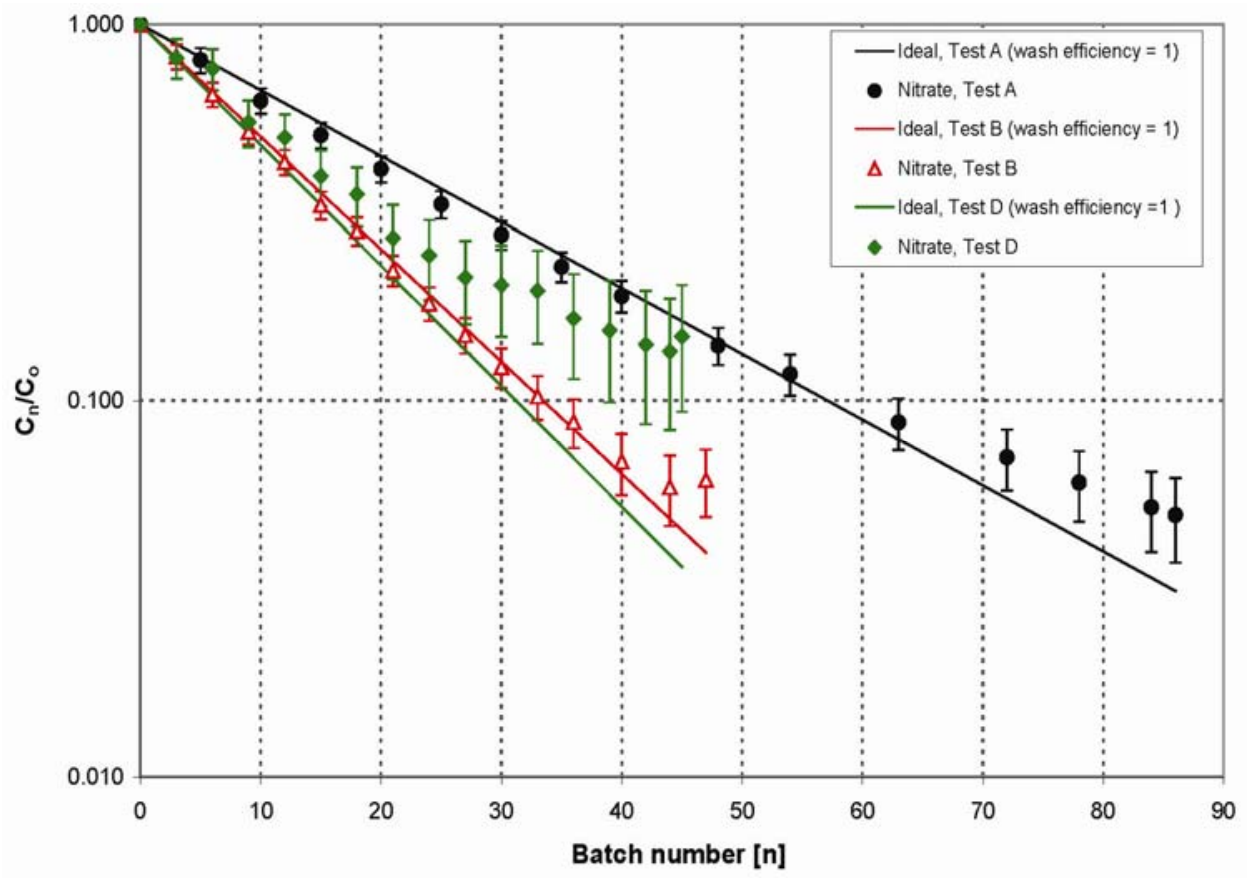

Figure 10.24. Concentration Ratio $(\mathrm{Cn} / \mathrm{Co})$ for Nitrate During the Post-Oxidative-Leach Wash. The ideal behavior (assuming a wash efficiency of 1) is also provided for each Integrated test.

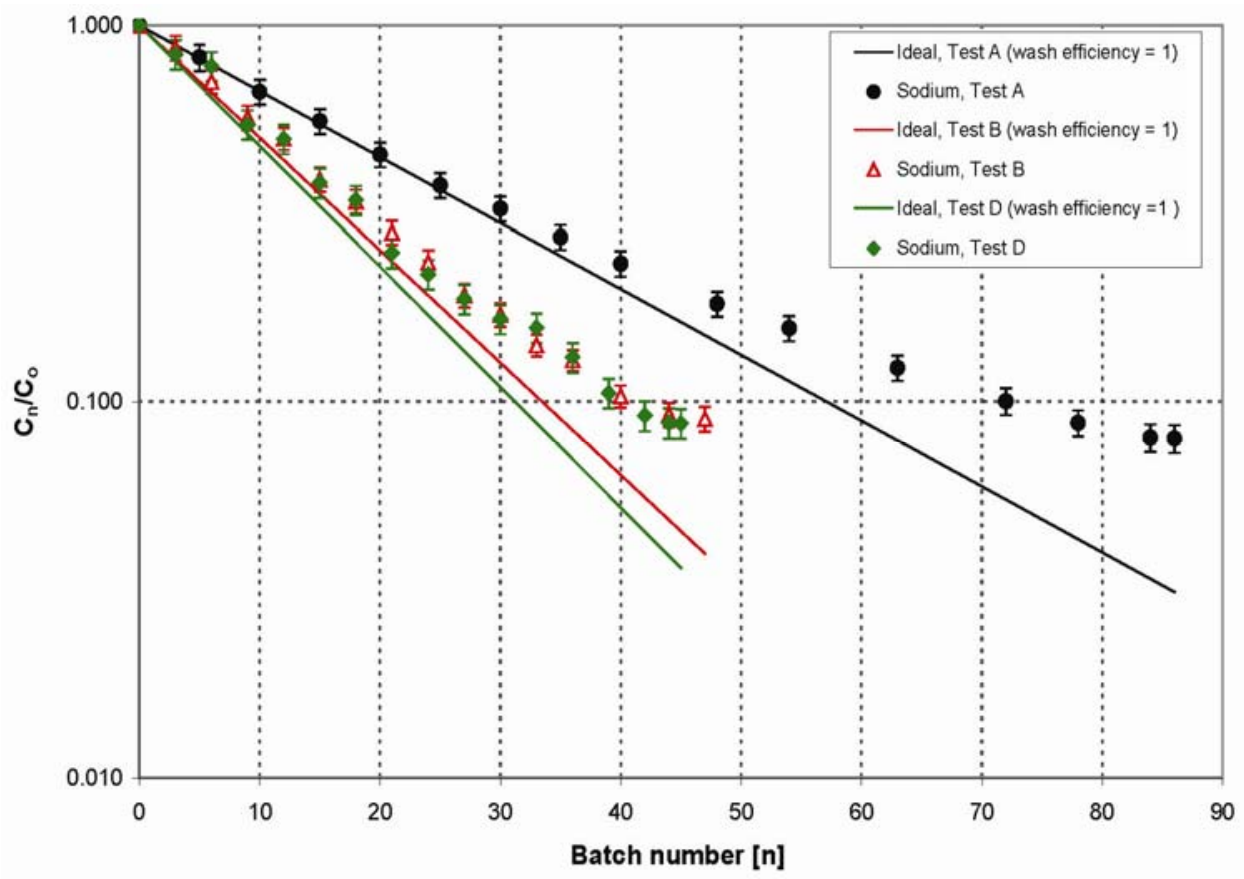

Figure 10.25. Concentration Ratio $(\mathrm{Cn} / \mathrm{Co})$ for Sodium During the Post-Oxidative-Leach Wash. The ideal behavior (assuming a wash efficiency of 1 ) is also provided for each Integrated test. 


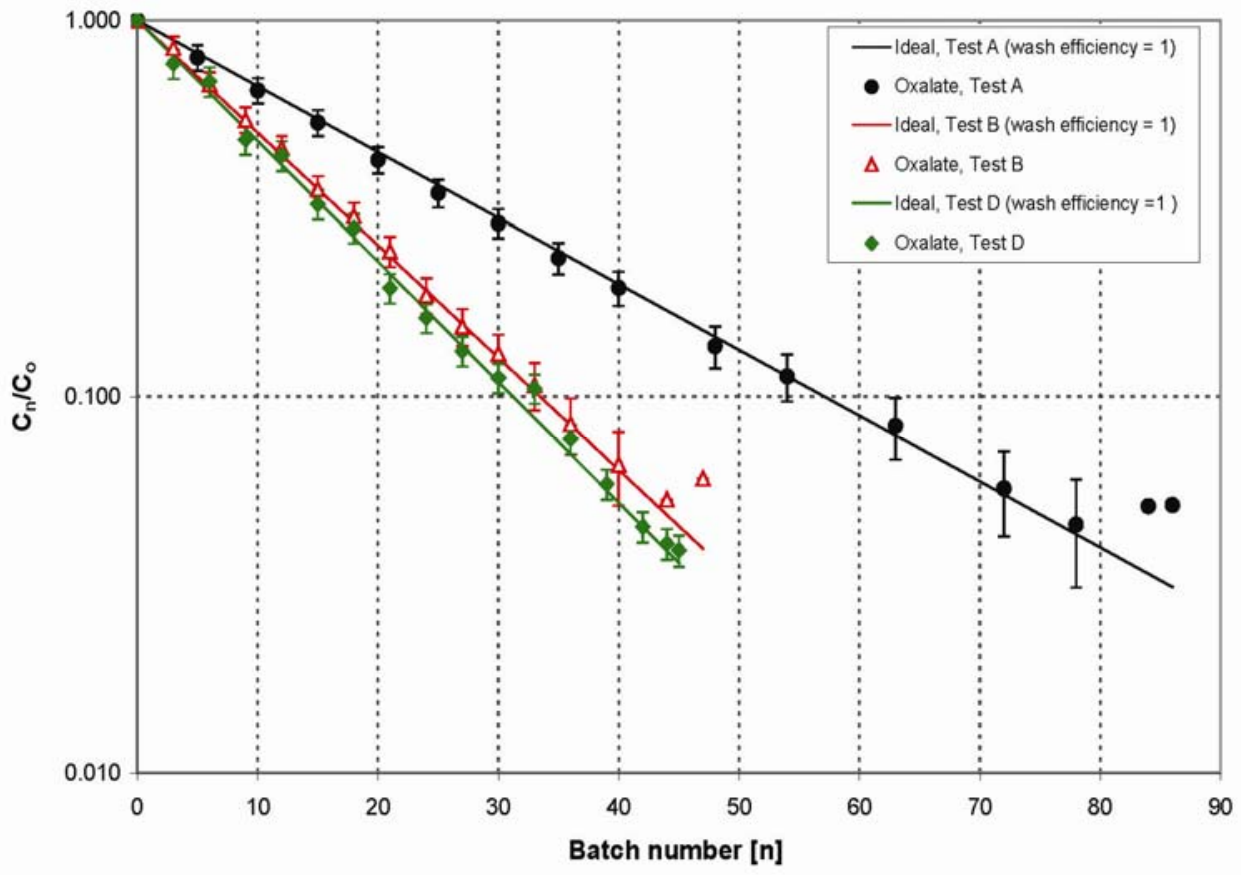

Figure 10.26. Concentration Ratio $(\mathrm{Cn} / \mathrm{Co})$ for Oxalate During the Post-Oxidative-Leach Wash. The ideal behavior (assuming a wash efficiency of 1 ) is also provided for each Integrated test. Note that the final two points in Integrated Tests A and B do not have error bars. This is because they were not used in the analysis, and thus, an uncertainty could not be generated.

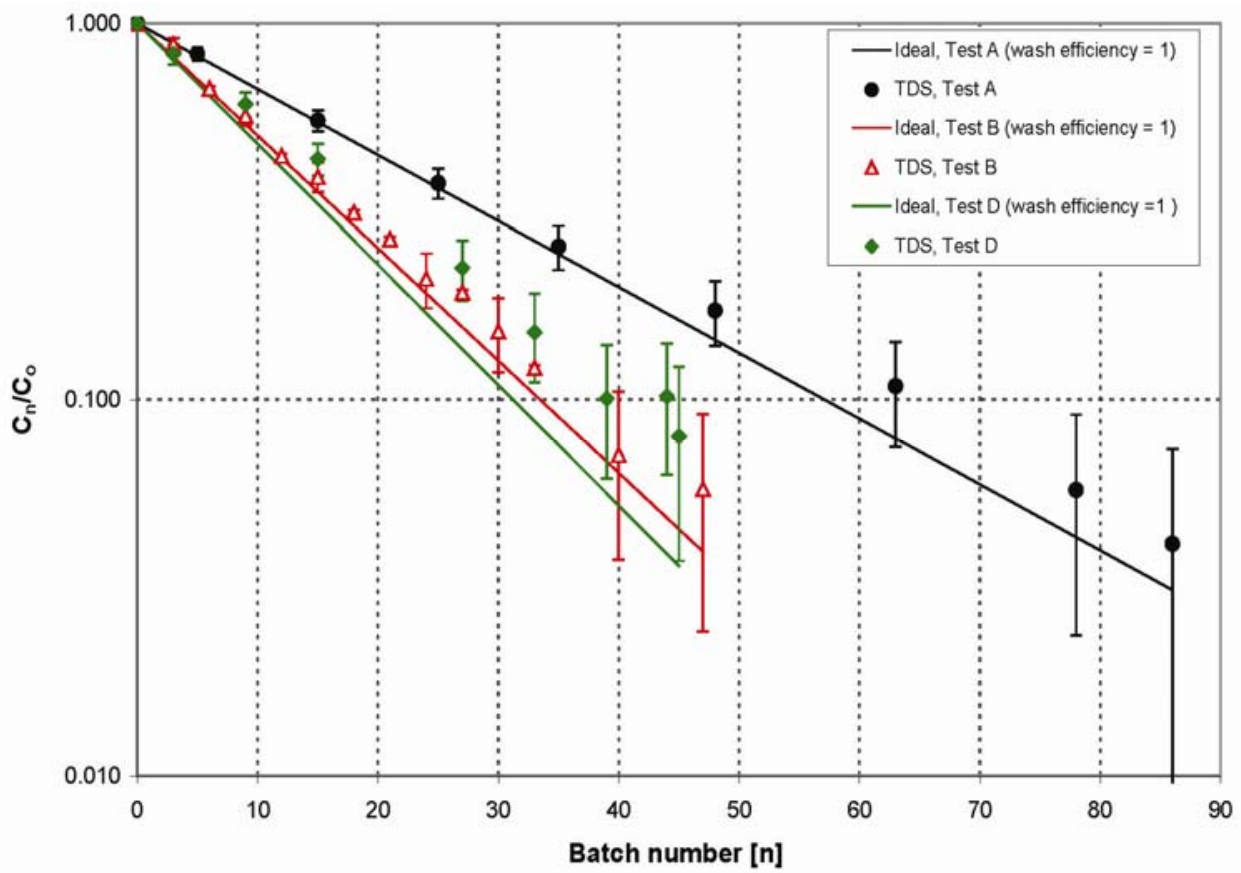

Figure 10.27. Concentration Ratio ( $\mathrm{Cn} / \mathrm{Co}$ ) for TDS During the Post-Oxidative-Leach Wash. The ideal behavior (assuming a wash efficiency of 1) is also provided for each Integrated test. 
Figure 10.28 through Figure 10.30 show overlaid as-measured concentration curves for post-oxidative-leach wash for each test and will allow visual comparison of the major analytes of interest. For the post-oxidative-leach wash, we see the decreasing order of analyte concentration is different from the case of the post-caustic-leach wash. Here we see identical ordering of analyte concentration for Integrated Tests A and B but very different for Integrated Test D, as expected, due to the different operational strategies of the three tests. Integrated Test D oxalate is at a much higher concentration than Integrated Tests $\mathrm{A}$ and $\mathrm{B}$ oxalate because of the Cr slurry additions. In Integrated Tests $\mathrm{A}$ and $\mathrm{B}, \mathrm{Cr}$ slurry was added between the post-caustic-leach wash and the post-oxidative-leach wash and additional washing was conducted bringing the oxalate level in Tank T02A down. Since the oxalate is fully soluble at that point, it was washed out. This is why there is a large step change between the end of the post-caustic-leach wash and the start of the post-oxidative-leach wash in Integrated Tests A and B if the concentrations are compared. However in Integrated Test D, there was no special addition of Cr slurry as the $\mathrm{Cr}$ was in the original simulant, so there was no additional washing step performed. Without that additional washing step, it should be expected that the analyte concentrations at the start of the post-oxidative-leach wash would be similar to the end of post-caustic-leach wash since the oxidative-leach step does not add a lot of dilutive volume. Indeed this is what we see with the oxalate in Integrated Test D. The concentration at the end of the post-caustic-leach wash was about $8000-\mathrm{mg} / \mathrm{kg}$ and the concentration at the start of post-oxidative-leach wash was also about the same. Oxalate is the only analyte for which this is obvious because the Cr slurry also had sodium and nitrate in it, which are the other analytes we track in the post-oxidative-leach wash plots.

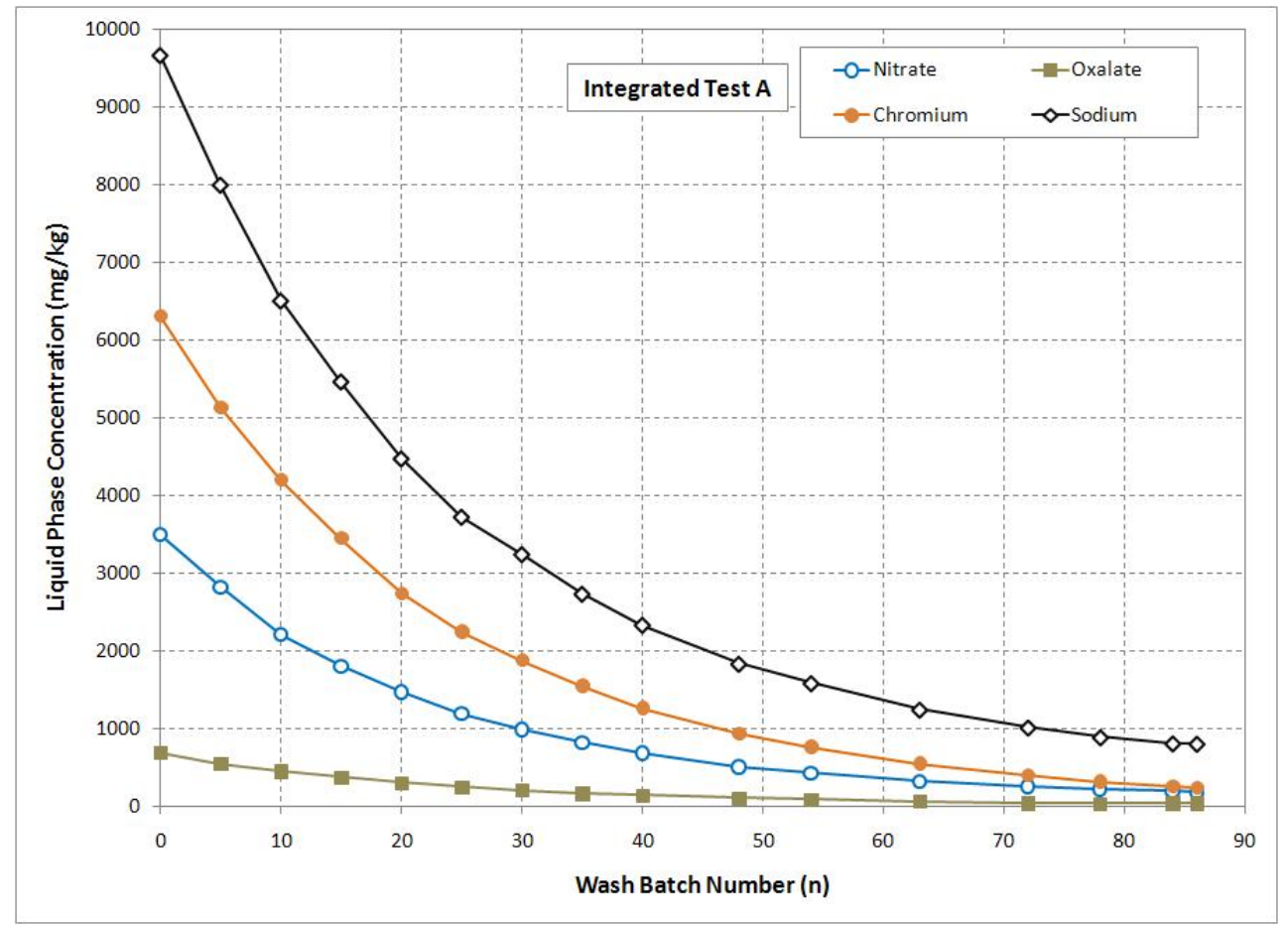

Figure 10.28. As-Measured Concentration Curves Overlaid, for Integrated Test A Post-Oxidative-Leach Wash, to Allow Visual Comparison of Major Analytes of Interest 


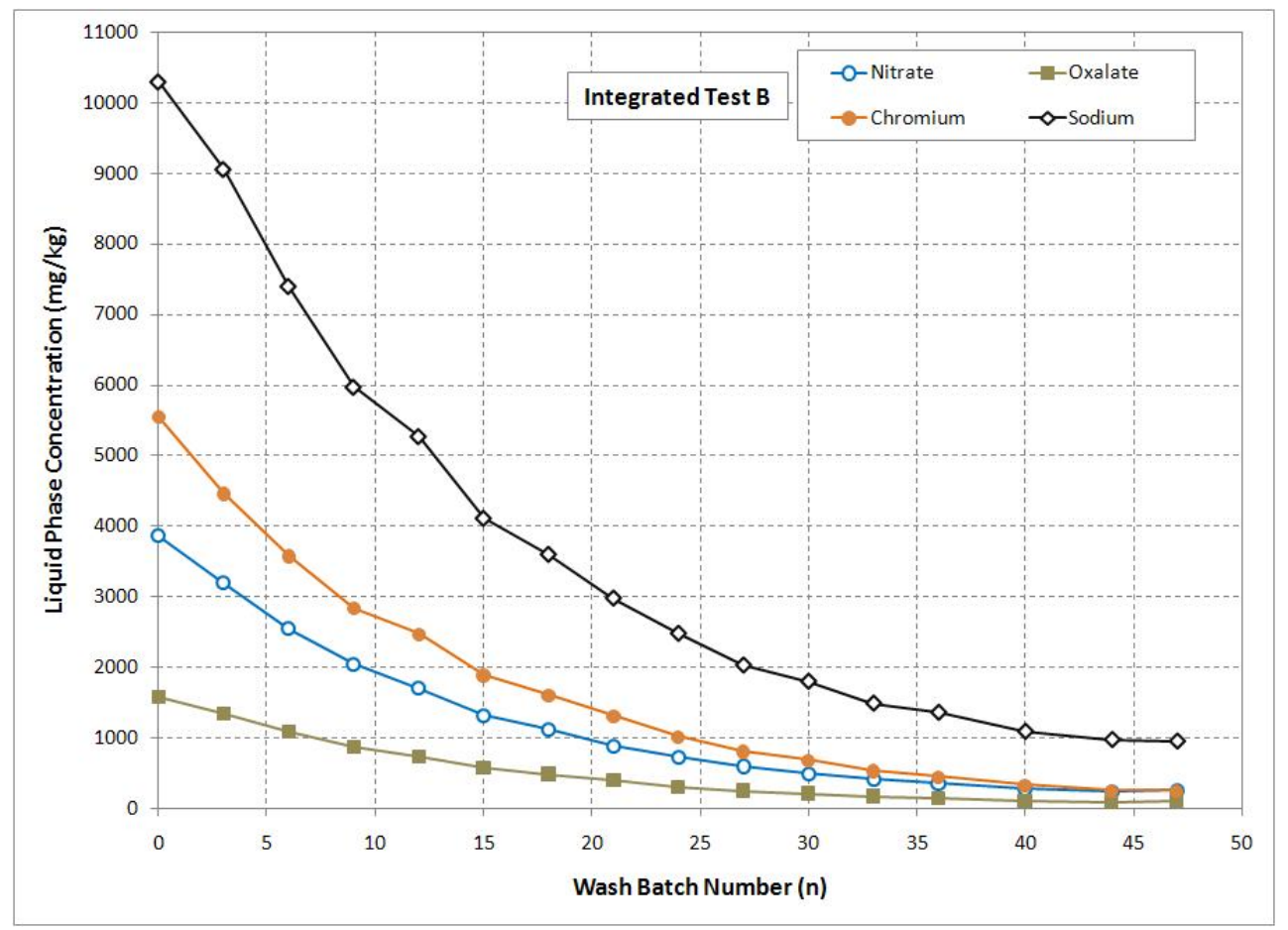

Figure 10.29. As-Measured Concentration Curves Overlaid, for Integrated Test B Post-Oxidative-Leach Wash, to Allow Visual Comparison of Major Analytes of Interest

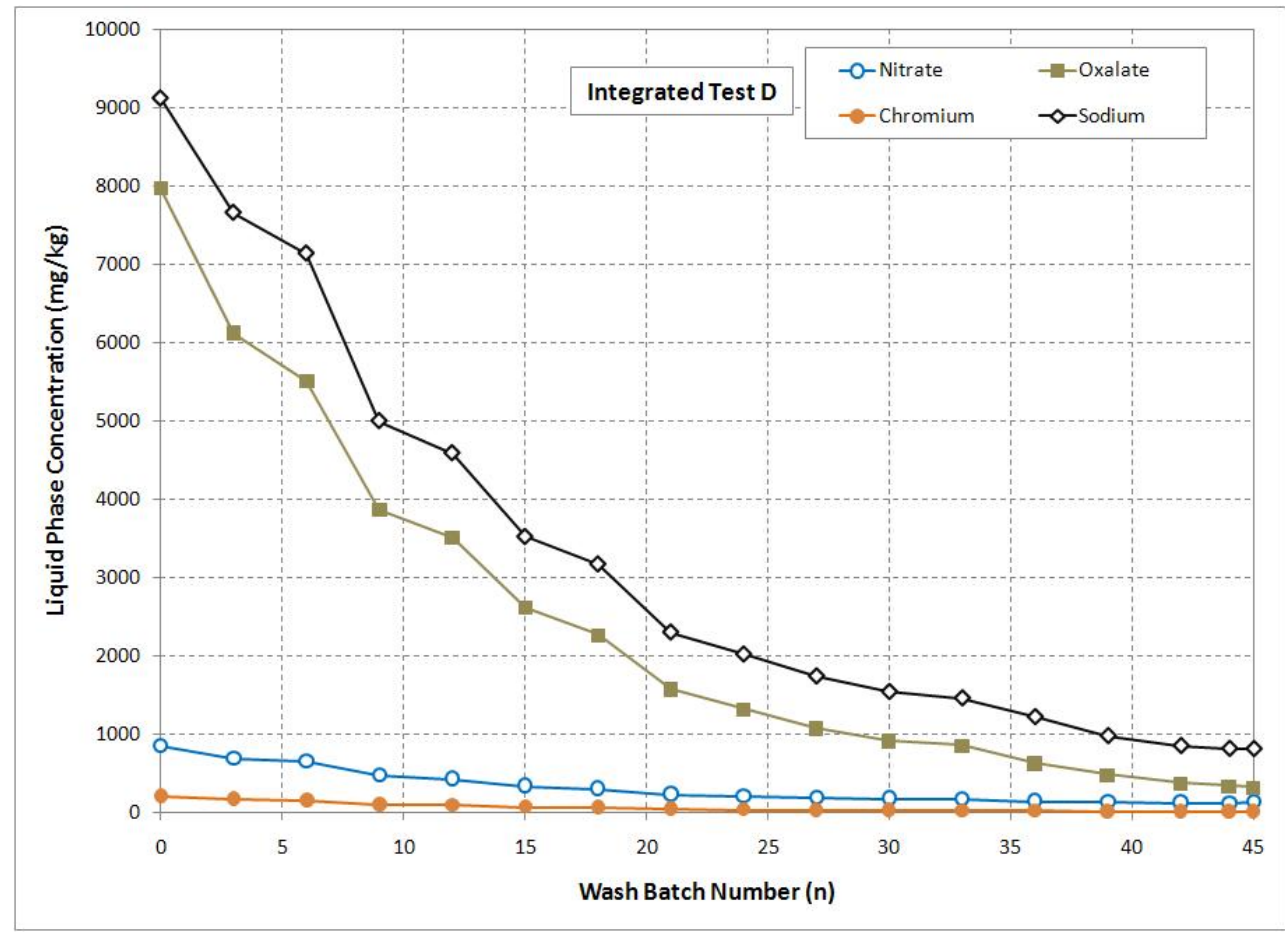

Figure 10.30. As-Measured Concentration Curves Overlaid, for Integrated Test D Post-Oxidative-Leach Wash, to Allow Visual Comparison of Major Analytes of Interest 
One of the success criteria for the PEP testing was to "evaluate the process control strategy for specification of required reagent additions, including $\mathrm{NaOH}, \mathrm{NaMnO}_{4}$, and wash solutions provided in the PEP Phase 1 Testing Process Description." The target endpoint for post-caustic-leach solids washing is a free $\mathrm{OH}$ concentration of $0.25-\mathrm{M}$. The evaluation was conducted by comparing the number of IW batches required to reach the target free $\mathrm{OH}$ concentration to the number of IW batches predicted by WTP in developing the run sheets for the Integrated tests. Based on the measured free $\mathrm{OH}$ concentrations, the number of IW batches required to reach the target was determined to be 64 batches for Integrated Test A, 39 batches for Integrated Test B, and 43 batches for Integrated Test D. These are compared to the WTP projections of 64 batches for Integrated Test A, 38 batches for Integrated Test B, and 45 batches for Integrated Test D. Since the projected number of batches is quite close to the actual number of batches, it is concluded that the WTP process control strategy for specifying the number of wash batches for post-caustic-leach washing is successful.

\subsubsection{Raman Method Results}

The Raman method is an alternative method that was implemented for the PEP tests in an effort to improve the turnaround time and reduce costs. The Raman method can provide results in $<1$ day, due to availability of dedicated instrument and analysts, compared with $>3$ days for the standard methods such as IC and ICP using offsite analysis. The Raman method has the potential to reduce costs because analytes targeted by the Raman method normally require four separate methods: IC, ICP, titration for hydroxide, and TIC/TOC for carbonate.

Raman was used to quantify aluminate, carbonate, chromate, hydroxide, nitrate, nitrite, oxalate, phosphate, and sulfate following procedure RPG-CMC-240. If precipitate formed in the solution samples submitted for Raman before the analysis, then the samples were centrifuged, and aliquots of the liquid were pipetted and analyzed. Two sets of Raman results were reported for Shakedown, Integrated Test A, and some of the Integrated Test B samples. The first set of results was generated using calibrations that were periodically adjusted to optimize the performance of QC check samples. The second set of results was recalculated based on the original calibration parameters. The generation of these two sets of results and the discovery of the calibration adjustments are documented as RPP-WTP CAR, number 42708.1. Only Raman results from the recalculation are provided. As a result of using the original calibration parameters, an occasional quality control (QC) sample falls outside of established performance limits. QC samples were generated at the analytical workstation and included a sample replicate determination, preparation blank, blank spike, and matrix spike. The wet solids were vortexed three times to suspend and rinse the solids. The rinsate was split into sub-samples for ICP and Raman analysis.

Table 10.5 shows the results of determining wash efficiency, $\mathrm{W}_{\text {eff }}$, using the WLS method, for the Raman data for Integrated Test A. This is compared with the corresponding wash efficiencies based on the standard analytical techniques of IC, ICP, or titration. Wash efficiencies based on the Raman method result in some analytes having a significantly wider spread in values, ranging from a low of 0.90 for nitrate to a high of 1.09 for aluminate. However, several analytes are within experimental uncertainty equal to one, such as nitrite, hydroxide, carbonate, and chromate. The Raman data for two analytes, hydroxide and chromate, in fact, result in values closer to 1.0 than for the standard methods. 
Table 10.5. Comparison of the Weighted Least Squares Wash Efficiency Calculated Using Concentrations from Standard Analytical Technique and Raman Data

\begin{tabular}{cccc}
\hline Analyte & Wash & $w_{\text {eff }}(\mathrm{IC} / \mathrm{ICP} /$ Titration $)$ & $w_{\text {eff }}$ (Raman) \\
\hline Nitrate & PCLW & 1.00 & 0.90 \\
Nitrite & PCLW & 1.01 & 0.93 \\
Sulfate & PCLW & 1.00 & 0.93 \\
Hydroxide & PCLW & 0.93 & 1.00 \\
Al/Aluminate & PCLW & 1.00 & 1.09 \\
Carbonate & PCLW & -- & 1.02 \\
Cr/Chromate & POLW & 0.98 & 1.00 \\
\hline
\end{tabular}

The figures below show the comparison between the concentration data for each of the analytes in the table. The standard analytical technique is in black closed circles, and the Raman data are in red open circles. Two limits are used and shown for the Raman data only. A solid red line is drawn at the Raman estimated quantification limit (EQL). Below this line, the analyte is still detected, but the result is considered qualitative. Raman data that are below the Raman detection limit (DL, the dotted red line) may be shown for information only. These two limits are not to be confused with the limit used by SwRI for the standard methods. i.e., the SwRI reporting limit (RL), described earlier, that is "an achievable concentration determined on a daily basis." In general, the RL for the IC and ICP methods is significantly lower than the Raman EQL or DL, which is why the decision was made to rely mostly on the IC/ICP analytical techniques.

Upon closer examination of the plots in Figure 10.31 to Figure 10.37, we see that for most analytes, there is good agreement between Raman and the standard method at the higher concentrations. As the wash steps progress and the concentration approaches the EQL, the Raman data start diverging significantly from the standard method. The analyte that compares poorest at the higher concentrations is nitrate, in agreement with the results in Table 10.5. Another good agreement is in the Raman data for phosphate, showing relatively good agreement with the standard method. This closely follows the unique curve shape, and there is a rise to the peak concentration at wash step 30 followed by a decrease toward the baseline as washing continues. 


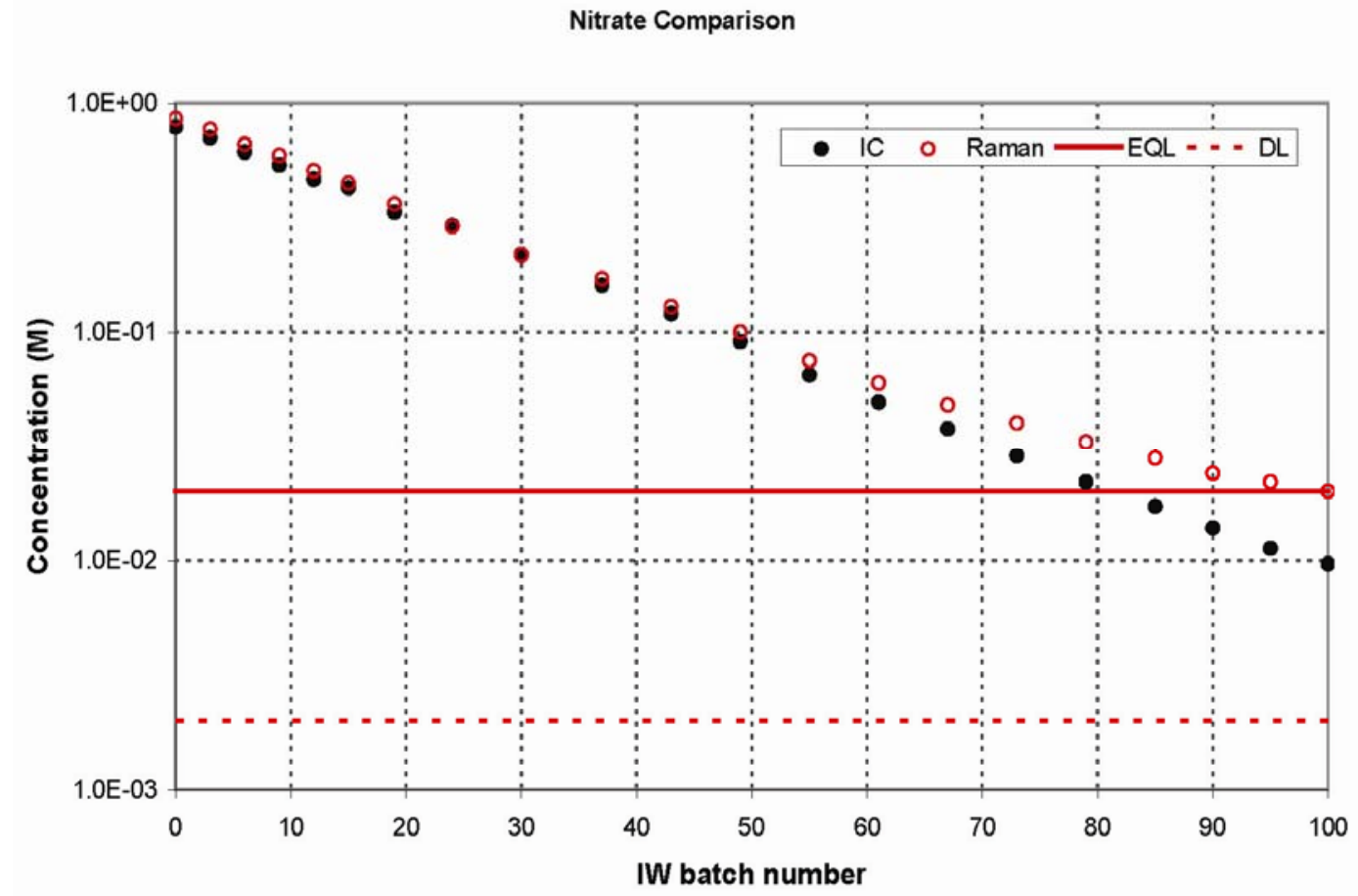

Figure 10.31. Concentration of Nitrate During Integrated Test A Post-Caustic-Leach Wash as Measured by Two Analytical Methods. Raman data below the EQL are considered qualitative.

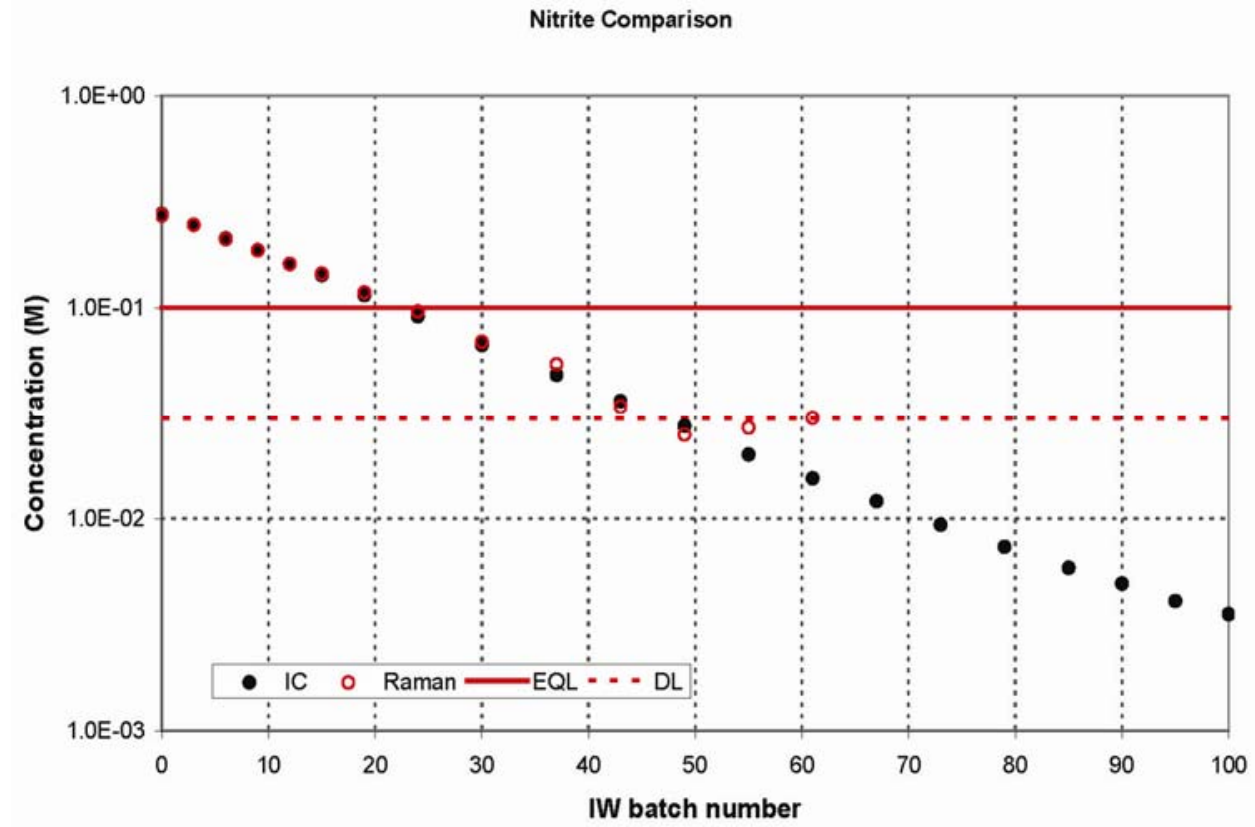

Figure 10.32. Concentration of Nitrite During Integrated Test A Post-Caustic-Leach Wash as Measured by Two Analytical Methods. Raman data below the EQL are considered qualitative. The Raman data below the DL are shown for information only. 


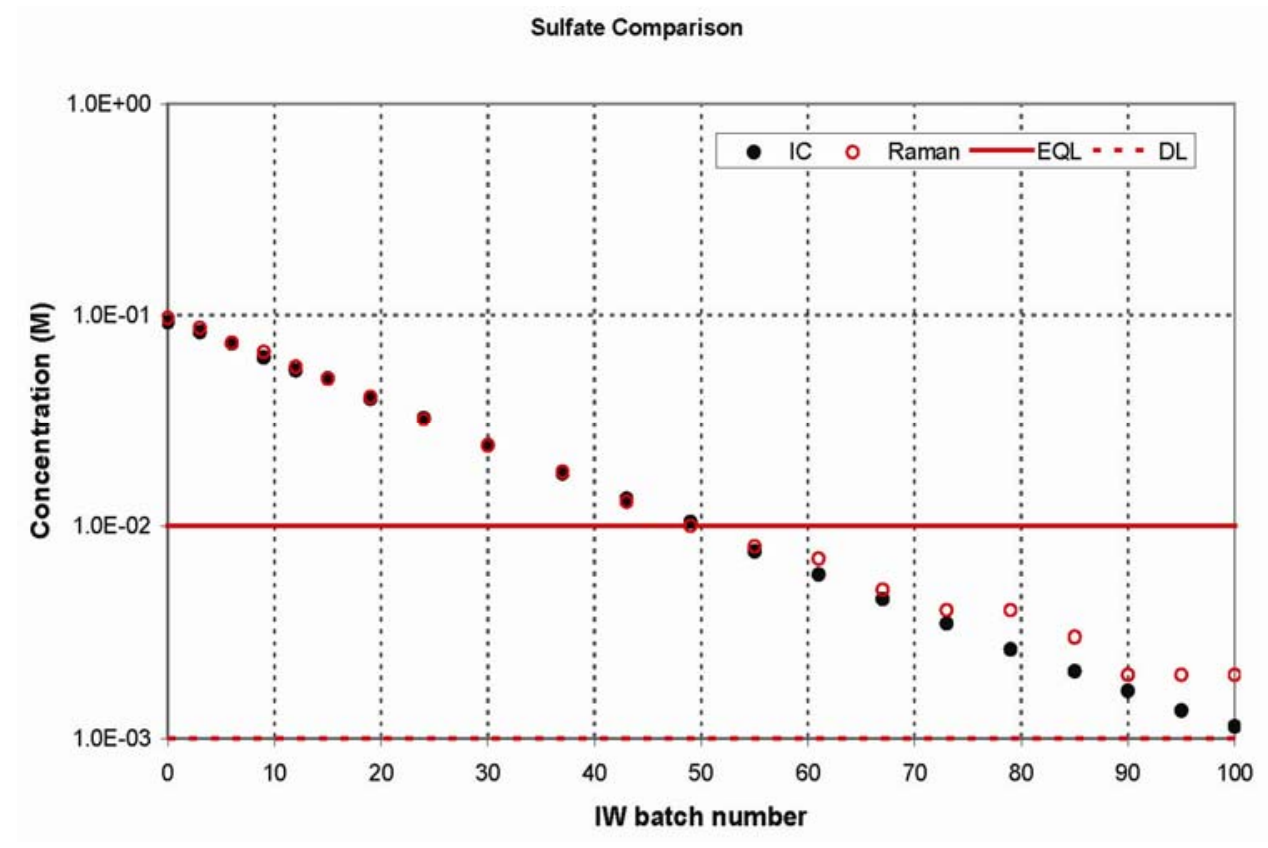

Figure 10.33. Concentration of Sulfate During Integrated Test A Post-Caustic-Leach Wash as Measured by Two Analytical Methods. Raman data below the EQL are considered qualitative.

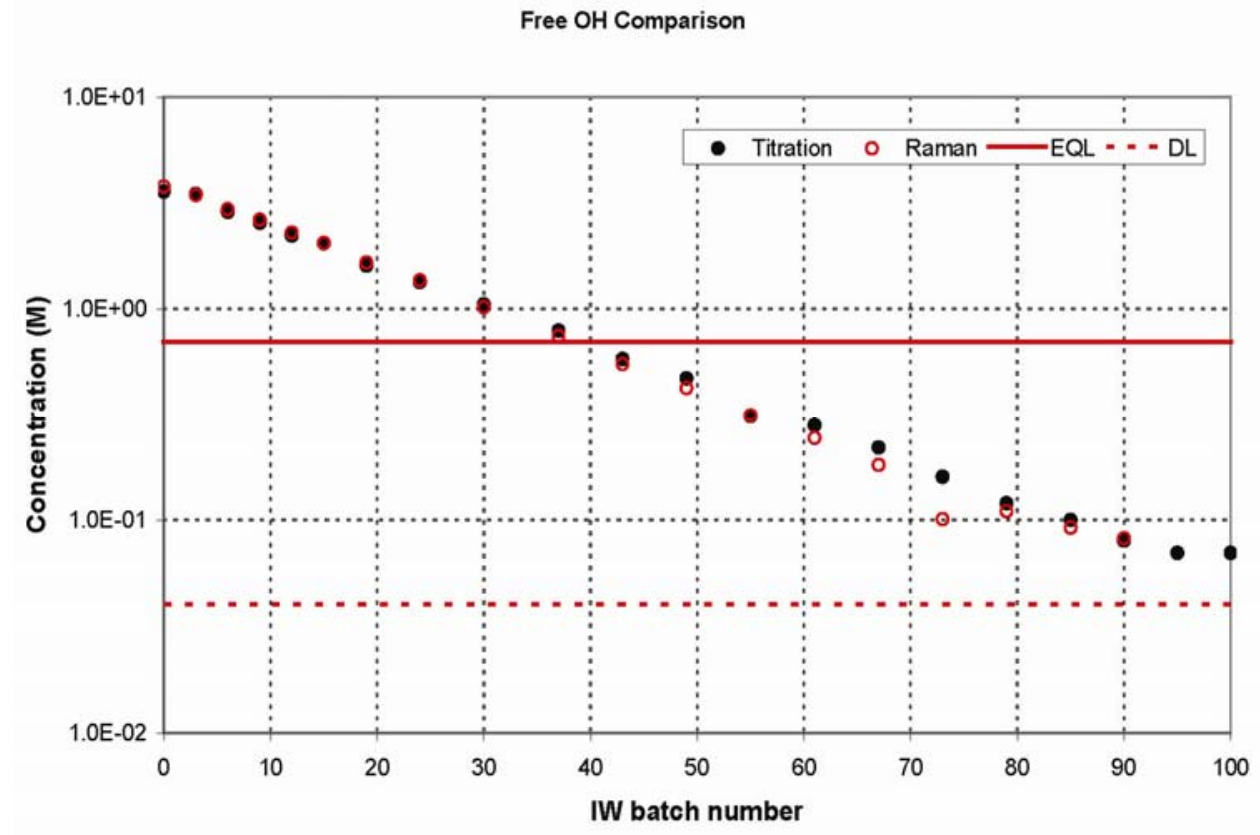

Figure 10.34. Concentration of Free Hydroxide During Integrated Test A Post-Caustic-Leach Wash as Measured by Two Analytical Methods. Raman data below the EQL are considered qualitative. 


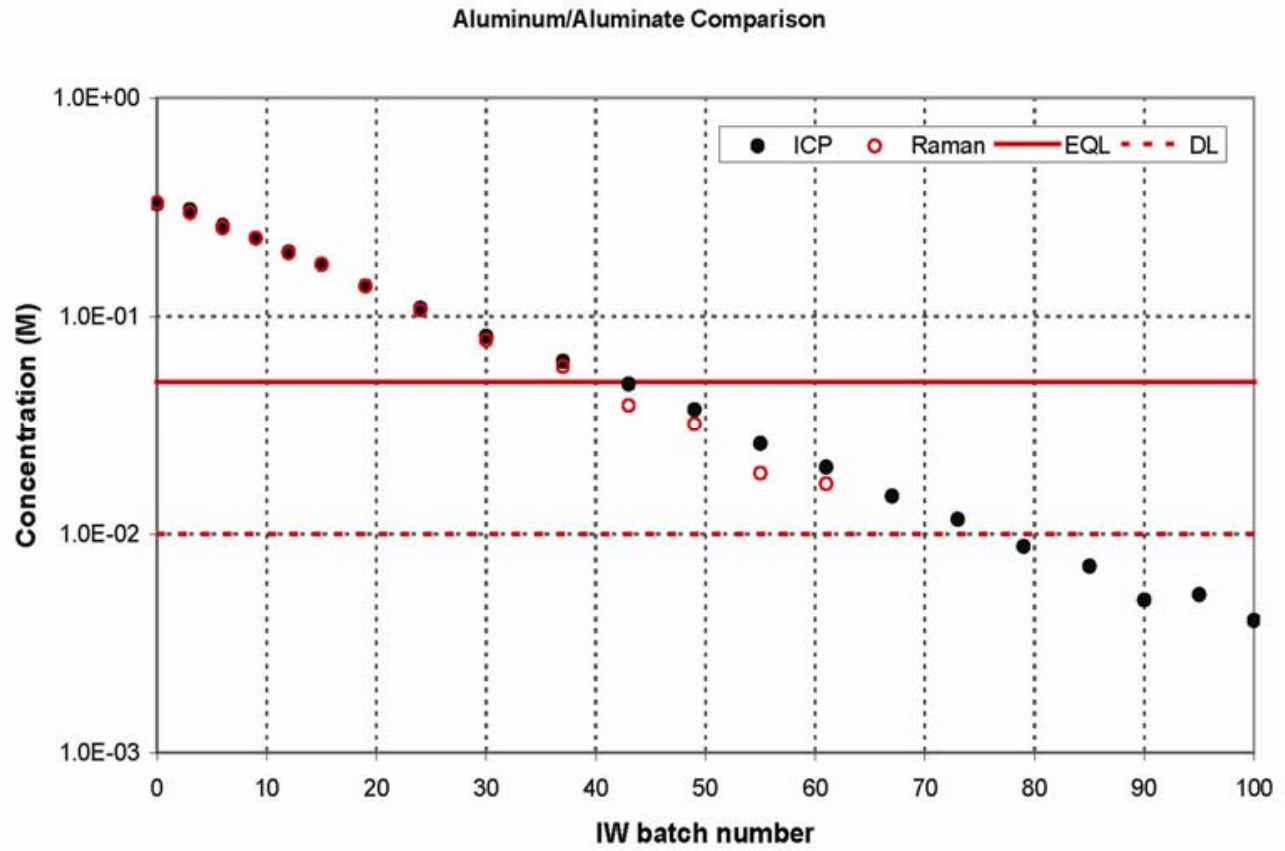

Figure 10.35. Concentration of Aluminum/Aluminate During Integrated Test A Post-Caustic-Leach Wash as Measured by Two Analytical Methods. Raman data below the EQL are considered qualitative. The Raman data below the DL are shown for information only.

Chromium/Chromate Comparison

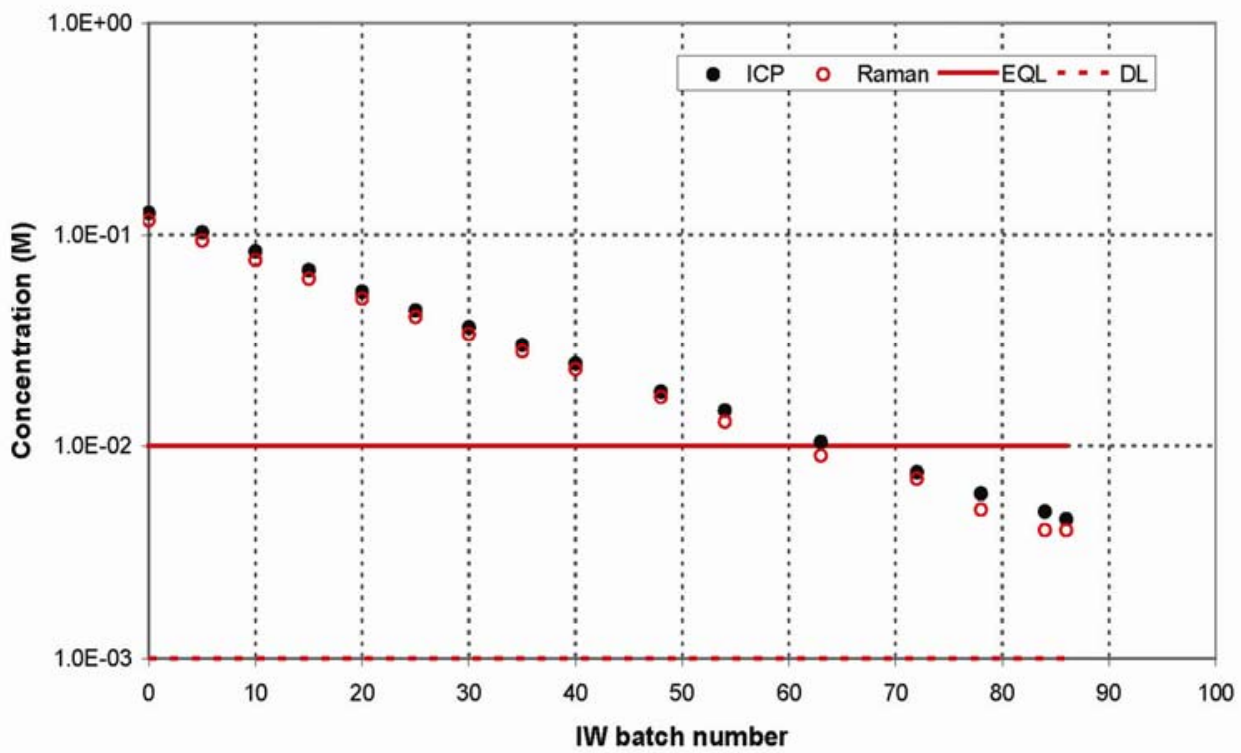

Figure 10.36. Concentration of Chromium/Chromate During Integrated Test A Post-Oxidative-Leach Wash as Measured by Two Analytical Methods. Raman data below the EQL are considered qualitative. 


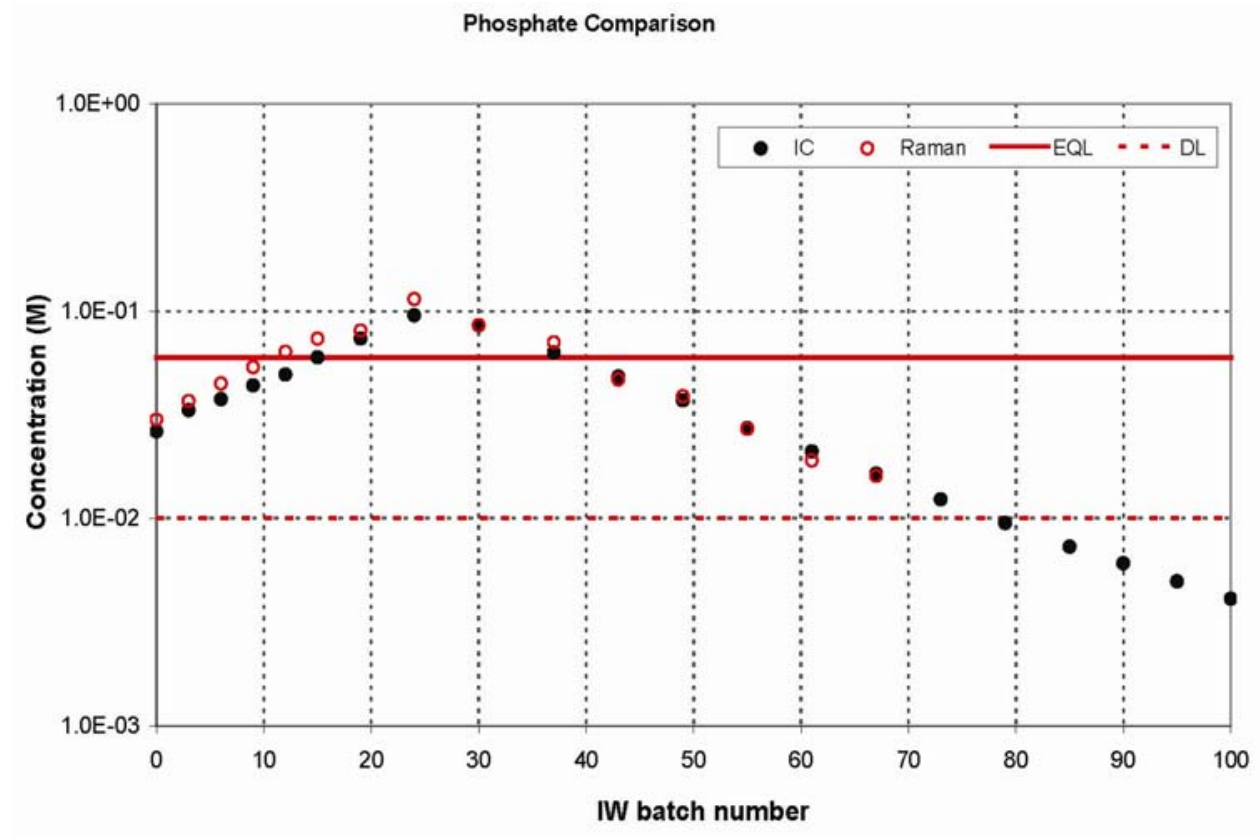

Figure 10.37. Concentration of Phosphate During Integrated Test A Post-Oxidative-Leach Wash as Measured by Two Analytical Methods. Raman data below the EQL are considered qualitative. The Raman data below the DL are shown for information only.

In Figure 10.38, we see the Raman data for carbonate in Integrated Test A, the only such data for carbonate resulting from all the PEP tests. The Raman data for carbonate show relatively good agreement with the $\mathrm{W}_{\text {eff }}=1.0$ line, as can be seen from wash step $=0$ to near mid-wash at wash step $=30$. At that point, with decreasing carbonate concentration, the Raman data show diversion from the ideal wash model. However, the wash efficiency, based on the Raman carbonate data (shown in Table 10.5), still results in a near-ideal value of 1.02 . 


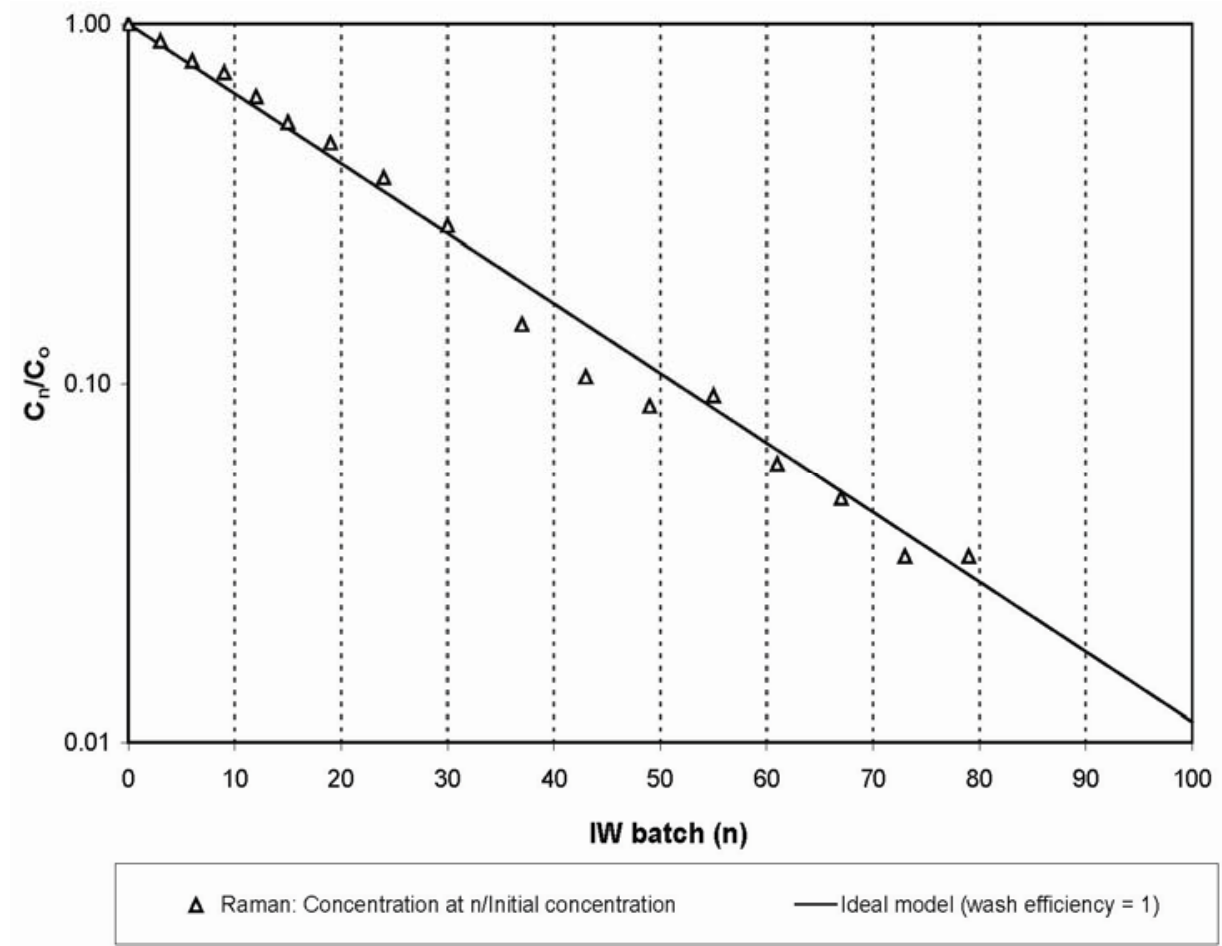

Figure 10.38. Raman Data for Carbonate Compared to Ideal Wash Efficiency Prediction for the Post-Caustic-Leach Wash of Integrated Test A. The carbonate data after $n=79$ are not included because they are below the Raman detection limit.

\subsubsection{Additional Comparison of Raman with Other Methods}

Additionally, Raman results may be compared with other methods by examining phosphate. Phosphate is one analyte that occurs throughout the wash process in adequate concentrations, and it is also measured by three independent methods. Phosphate, $\mathrm{PO}_{4}$, is measured by Raman in molarity units and measured by IC in $\mathrm{mg} / \mathrm{kg}$ units. Elemental phosphorus, $\mathrm{P}$, is measured by ICP in $\mathrm{mg} / \mathrm{kg}$ units and may be converted to the corresponding quantity of phosphate in $\mathrm{mg} / \mathrm{kg}$ for purposes of comparison. In the post-caustic-leach wash data, there is adequate phosphate throughout the wash process, while in the post-oxidative-leach wash, the levels of phosphate reach non-detectible limits by mid-wash; therefore, only Integrated Test A post-caustic-leach wash data will be examined here.

For illustration, two wash steps have been examined as representative of the whole: the initial concentration at IW Batch 0, and the wash step at near peak phosphate concentration, IW Batch 19. The calculated, comparative results may be seen in Table 10.6.

At start of wash at IW Batch 0, the phosphate concentration measured by all three methods ranges from 1990- to 2274-mg/kg phosphate, for an average of $2140-\mathrm{mg} / \mathrm{kg} \pm 7 \%$ Relative Standard Deviation (RSD). Raman is seen to be the highest measured value, though within experimental uncertainty.

At near the peak phosphate concentration, IW Batch 19, the phosphate concentration ranges from 6210- to $8372-\mathrm{mg} / \mathrm{kg}$, or an average of $7120-\mathrm{mg} / \mathrm{kg} \pm 16 \% \mathrm{RSD}$. In this example, the Raman result is mid-range near the average while the ICP result is at the high end. 
Two conclusions are reached by examining these results: 1) this example shows relatively good agreement between all three methods and provides confidence in using Raman as a useful near-real-time process monitoring analytical method, and 2) this provides confidence and a check on the comparative data provided by SwRI in three completely independent methods.

Table 10.6. Comparison of Phosphate Concentration Data by Three Methods. Data are from wash step $\mathrm{n}=0$ and $\mathrm{n}=19$ during the post-caustic-leach wash of Integrated Test A. Wash step 19 is near the peak phosphate concentration during the wash.

\begin{tabular}{cccc}
\hline Wash Step & IC $(\mathrm{mg} / \mathrm{kg})$ & Raman $(\mathrm{mg} / \mathrm{kg})$ & $\mathrm{ICP}(\mathrm{mg} / \mathrm{kg})$ \\
\hline 0 & 1990 & 2274 & 2150 \\
19 & 6210 & 6790 & 8372 \\
\hline
\end{tabular}

\subsubsection{Comparison of Measured to Calculated Oxalate Concentration}

The measured oxalate data for each of Integrated Tests A, B, and D post-caustic-leach wash are compared to the oxalate solubility expression as used in the G-2 model, evaluated for each test. The questions of interest are how well do the measured data match the model and how close to full saturation does the oxalate come during the wash process.

Measured oxalate data are shown in Figure 10.39 to Figure 10.41 plotting measured oxalate (blue circles) versus IW batch number (n). Also plotted is a second curve, the calculated oxalate concentration values (red diamonds) based on the WTP oxalate solubility expression using the measured sodium and oxalate concentrations, slurry volume, mass of water present, and measured total dissolved solids. 


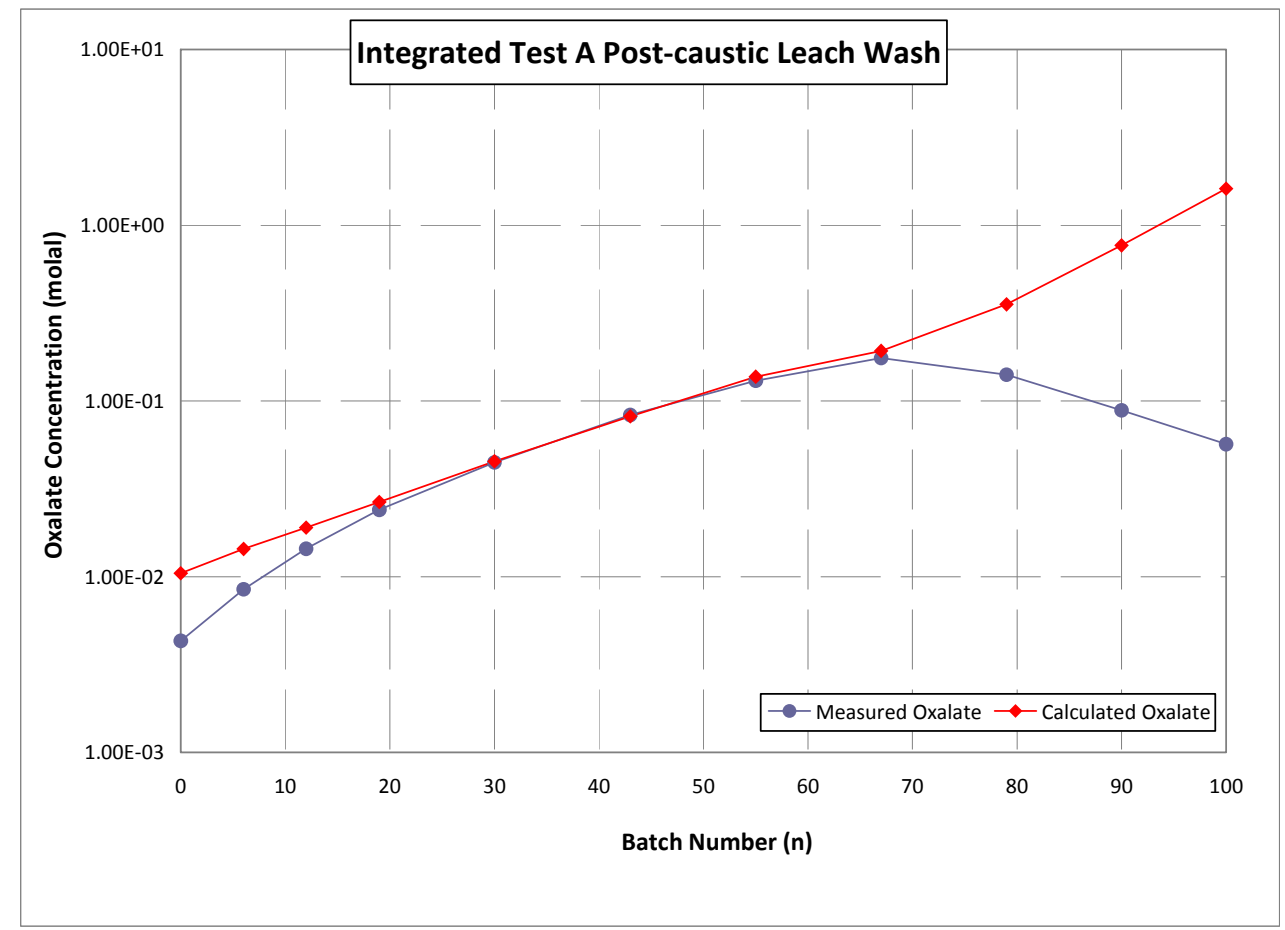

Figure 10.39. Comparison of Measured to Calculated Oxalate Concentration for Integrated Test A Post-Caustic-Leach Wash.

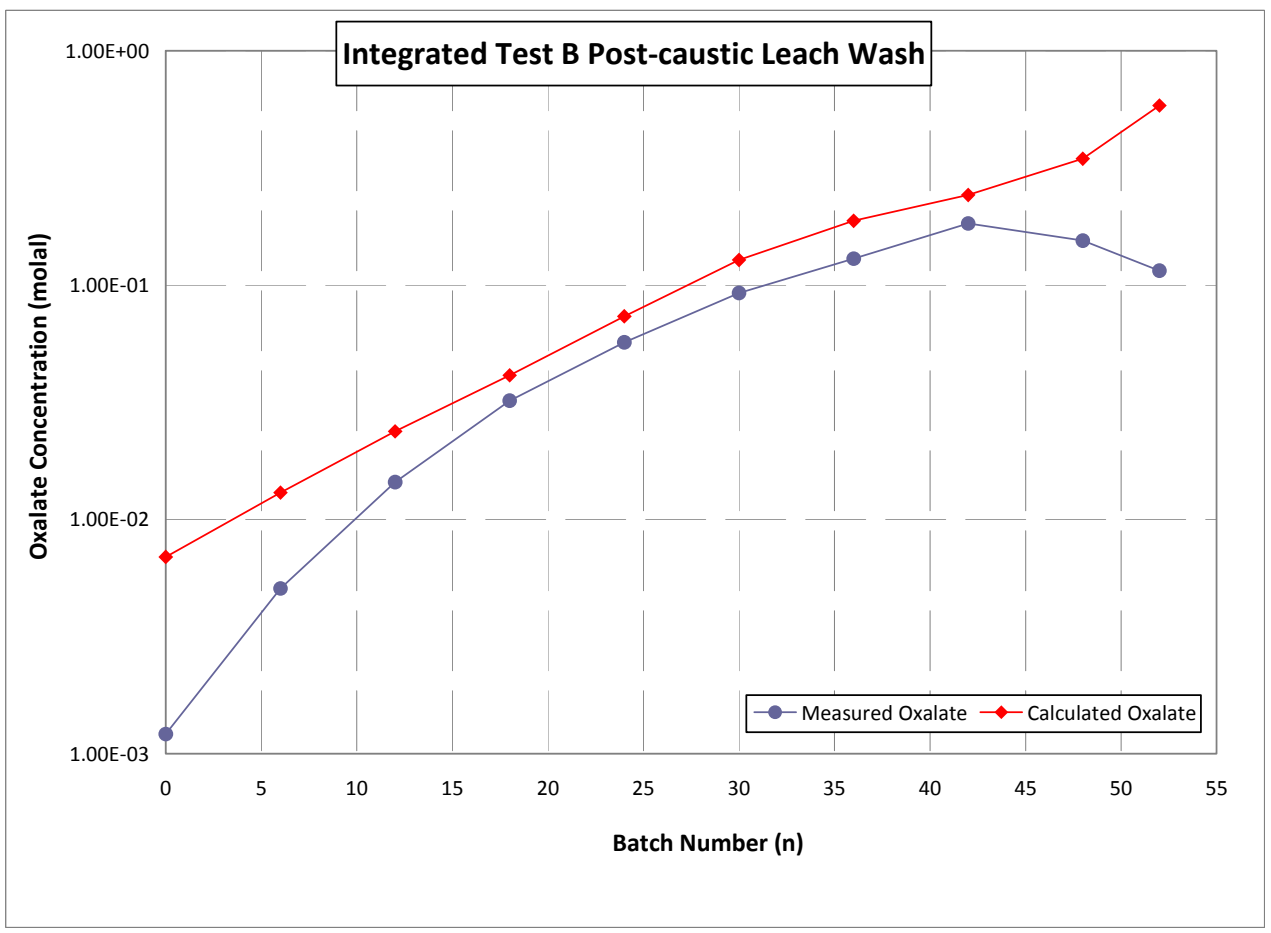

Figure 10.40. Comparison of Measured to Calculated Oxalate Concentration for Integrated Test B Post-Caustic-Leach Wash. 
For Integrated Test A, shown in Figure 10.39, the interesting result is that throughout the mid-wash region of $n=19$ to $n=67$ at the measured peak, the agreement of measured oxalate to calculated oxalate at full solubility is excellent, ranging from 0 to $10 \%$, implying both mixing and kinetics are adequate to maintain oxalate at essentially full saturation until dissolution is complete. At the measured peak, no solids remain, and oxalate is fully dissolved and washing out.

In addition, because the PEP used all five filter bundles during the wash steps, it was actually operating $4.5 x$ times faster than the plant (see Section 3.0 on scale-time). That is, if the PEP took six hours for a solids wash step, the plant will require 27 hours. That longer time will make the likelihood of saturating the supernate with the more soluble salts much better.

The results for Integrated Tests B and D are shown in Figure 10.40 and Figure 10.41. For these tests, a consistent offset or bias between the two curves is seen at near mid-wash, with the measured oxalate consistently at $\sim 25 \%$ lower at mid-wash compared to the calculated solubility expression result. One likely reason for this discrepancy is that the oxalate solubility expression is more reliable at the lower sodium concentrations as found in Integrated Test A. For the higher sodium concentrations seen in Integrated Tests B and D, the oxalate solubility expression generates predictions with more scatter and less reliability.

In addition, slurry samples collected in the standard time of 1 min after completing a wash-water addition should have been more representative of the system in Integrated Tests B and D ( 140 gal) rather than in Integrated Test A ( 240 gal), implying that Integrated Tests B and D should have shown greater mixing, not less. Therefore, the conclusion from the Integrated Test A comparison result still stands, that in the PEP, mixing and kinetics are adequate to maintain oxalate at essentially full saturation until fully dissolved. 


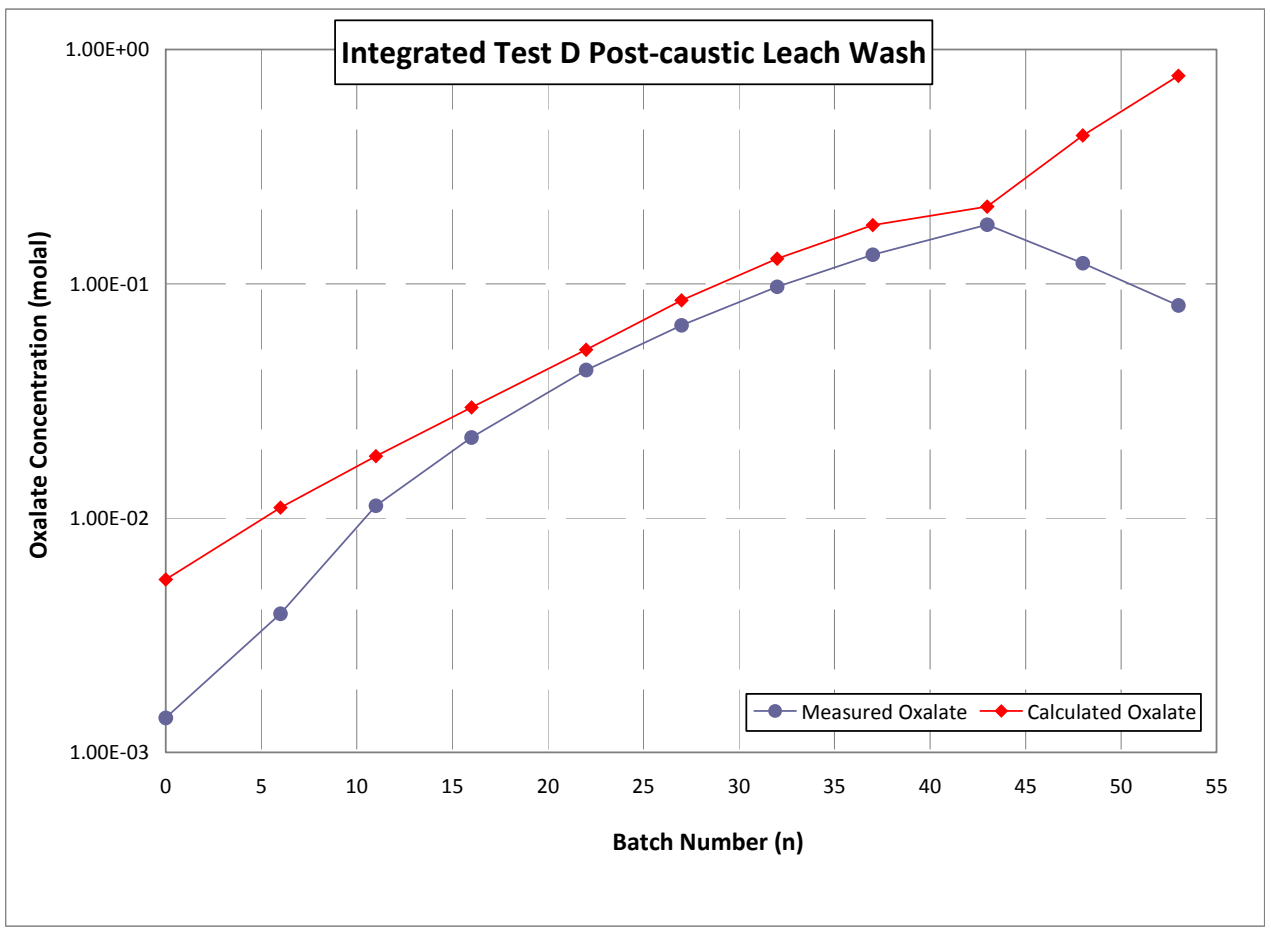

Figure 10.41. Comparison of Measured to Calculated Oxalate Concentration for Integrated Test D Post-Caustic-Leach Wash.

\subsubsection{Uncertainty Evaluation for Solids Washing}

Uncertainties shown throughout this Section 10 and the accompanying Appendix $C$ are evaluated by different methods. For all sample data as shown in Tables 10.1 to 10.3, the uncertainties associated with the sample results shown were determined and reported by the analytical laboratories. For the calculated wash efficiencies and calculated concentration ratios shown in Table 10.4 or Appendix C, a Monte Carlo approach was used to evaluate uncertainty. An exact Monte Carlo approach was used rather than approximate error propagation approaches because the accuracy of the approximations is poor when the denominator of a ratio is small.

Uncertainties in the washing efficiencies and concentration ratios were based on the uncertainties in measured data or data provided by analytical laboratories. The measurement and analytical uncertainties were all assumed to be unbiased and normally distributed. Each stochastic value used in the Monte Carlo analysis of the equations was the sum of the specific measurement or laboratory value and a random uncertainty term. The random uncertainty term was generated from a normal distribution with zero mean and a standard deviation obtained from laboratory reports or known instrument uncertainty.

\subsection{Discussion}

In Section 10.5, wash efficiency was defined as applicable only to those analytes that were fully dissolved throughout the entire washing procedure. For the post-caustic-leach wash, these are dissolved aluminum, free hydroxide, nitrate, nitrite, and sulfate. Other originally considered analytes, including sodium, oxalate, phosphate, and TDS, clearly show evidence of partial solubility or continual dissolution 
of solids throughout the wash steps with resulting non-ideal concentration behavior and are therefore unsuitable for use in monitoring wash efficiency.

Also for the post-oxidative-leach wash, the selected analytes for determining wash efficiency were those analytes that both remain fully dissolved throughout the entire washing procedure and are well above measurement detection limits. The fully dissolved analytes of interest are dissolved chromium and oxalate. All other originally considered analytes, including sodium, manganese, nitrate, and TDS, show clear deviations from the expected linear behavior on a semi-log plot. Therefore, they are unsuitable for use in monitoring wash efficiency. For example, these other analytes may show deviation from ideal washing behavior possibly associated with the dead volume of the filter-loop. There are other possible reasons for specific analytes for deviation from ideal behavior. For example, sodium $\mathrm{C}_{\mathrm{n}} / \mathrm{C}_{\mathrm{o}}$ behavior shows significant curvature. The reason for this upward-curving $C_{n} / C_{0}$ concentration curve for sodium is likely because $0.01-\mathrm{M} \mathrm{NaOH}$ was used for washing, and the concentration for sodium was asymptotically approaching this value. This effect should only be significant during the post-oxidative-leach wash with all analytes at lower concentrations; the effect is probably insignificant during the post-caustic-leach wash. This behavior makes sodium unsuitable for monitoring washing efficiency. Manganese shows large washing portions below the detection limit. Nitrate shows a large curvature in the $\mathrm{C}_{\mathrm{n}} / \mathrm{C}_{\mathrm{o}}$ curve towards the end of the washing steps, likely related to approaching the reporting limit near the end of the wash. In addition, other analytes, such as aluminum, phosphate, sulfate, nitrite, and TDS, are at low concentrations, all within $10 \times$ of the reporting limit for most or all of the wash steps. For carbonate, there was little Raman data obtained during the post-oxidative wash.

In addition, there is another likely explanation for deviation from $\log$-linear $\mathrm{C}_{\mathrm{n}} / \mathrm{C}_{\mathrm{o}}$ concentration behavior observed for these other analytes in the post-oxidative-leach wash. Material in the $\sim 9$ gal of filter-loop dead-legs is gradually exchanged with the filter-loop contents, but at such a slow rate that it generally has an insignificant impact on concentrations. However; at the end of the post-oxidative-leach wash, the concentrations are so small that the exchange of sodium, nitrate, sulfate, phosphate, etc., from the dead-legs to the filter-loop may be significant and measureable. This would result in a positive deviation from ideal washing. Chromium and oxalate do not exhibit this because their concentrations in the dead-leg volumes are very small. When the dead-legs were filled (drainable dead-legs were filled after caustic-leach cool-down; nondrainable dead-legs probably do not matter), there was almost no chromium in the slurry. Liquid-phase oxalate concentration was suppressed by sodium levels, and the large solid oxalate particles either settled down into the filter-loop flow from the two large vertical dead-legs that point up, or they settled to the obscurity of the bottoms of dead-legs pointing down. The PTF will have dead volumes in the loop too.

In addition, there is potential impact on the partially-soluble analyte species (i.e., oxalate and phosphate) due to the time required to take and process samples. While the time required to handle and centrifuge the slurry should have no impact on wash efficiency (i.e., on the species that were totally dissolved throughout the entire wash process), liquid phase analyses for the partially-soluble dissolving species (oxalate and phosphate) may imply phase equilibria that didn't actually exist when the sample was collected. Again this should not affect wash efficiency values or conclusions; it may impact the reported sample results and specific resulting curve shapes of those partially-soluble analytes. On the other hand, the fact that the sodium oxalate dissolved and washed out about when it was predicted to (Section 10.6.4) implies it must have been near its saturation concentration the entire process. 
Integrated Test D wash efficiencies are very similar to those of Integrated Tests A and B for all fully soluble analytes. The soluble species all indicate an ideal wash process. Analytes that were expected to be partially soluble based on experience with both Integrated Test A and Integrated Test B post-oxidative-leach wash data had very similar concentration curves in the Integrated Test D post-oxidative-leach wash. Bulk density and supernate density appear to behave as expected for Integrated Test D and are consistent with the results of Integrated Test B. The Integrated Test D post-caustic-leach wash total permeate rate is consistent with the results in Integrated Test B. The Integrated Test $\mathrm{D}$ post-oxidative-leach wash total permeate rate is approximately ${ }^{1} / 4$ of the rate in Integrated Test $\mathrm{B}$, with no clear explanation. The temperatures in both Integrated Test $\mathrm{D}$ washes were within one degree of $25^{\circ} \mathrm{C}$ with the exception of a small departure ( $<3$ degrees) for the first 10 batches of post-caustic-leach wash.

Two nonprototypic conditions that could impact the applicability of PEP wash efficiencies to PTF modeling were identified. First, the PEP filter-loop volume was significantly larger than would be prototypic of the PTF, so the total volume of slurry in the filter-loop and Tank T02A was larger than would be prototypic of the PTF. Second, not all PEP operational parameters (specified to achieve prototypic washing performance) could be maintained at their target values during PEP testing, particularly filter-loop flow rate.

For the first nonprototypic condition, the PEP filter-loop volume was significantly larger than would be prototypic of the PTF. In all PEP tests, the actual slurry volumes used were significantly larger than the expected prototypic slurry volumes for both the post-caustic-leach wash and the post-oxidative-leach wash. Because the wash-water batch volume was a fixed quantity in the PEP, an increase in the total volume of slurry being washed would increase the number of wash batches needed to achieve a targeted dilution. The nonprototypically large filter-loop volume also resulted in a greater fraction of the slurry residing in the filter-loop (where it does not participate in mixing within Tank T02A) and a longer time for the wash-water (which was introduced near the start of filter-loop) to reach Tank T02A.

To help assess the effects of the larger-than-prototypic PEP filter-loop volume on wash efficiency, a simple mathematical model of the system was developed and solved numerically for conditions of interest. Details of the model are shown in Baldwin et al. (2009). The model includes the time lag between the time that a water addition is started and the time the water-diluted slurry reaches Tank T02A (filter-loop volume)/(filter-loop flow rate). Mixing within the filter-loop is assumed to be locally instantaneous, but the axial mixing is negligible. This is based on the view of the filter-loop as a pipe with a turbulent plug flow, so the slurry that was diluted with wash-water moves as a slug from the point of water injection to the end of the loop at the return nozzle in Tank T02A. Slurry entering Tank T02A is divided into a fraction that mixes instantaneously with the contents of Tank T02A and a fraction that bypasses the contents of the vessel and is fed directly into the filter-loop inlet. The model allows the slurry volume in Tank T02A to increase during wash-water addition (because water rate $>$ permeate production rate), and decrease when wash-water addition is stopped (because permeate production reduces total slurry volume). Wash-water additions are initiated when the slurry volume in Tank T02A drops to a specified value (equivalent to the level-based control used in PEP) and stopped when the specified volume has been added. The point of the model was not to predict actual wash efficiencies, but rather to examine changes in wash efficiencies associated with different filter-loop volumes and flow rates. The general result of the modeling was that the larger-than-prototypic filter-loop volume of the PEP leads to slightly lower wash efficiencies. 
For the second nonprototypic condition, drift in a filter-loop flowmeter reading and air entrainment at the filter-loop inlet resulted in poor control of the filter-loop flow rate during Integrated Test A slurry washing for both post-caustic-leach wash and post-oxidative-leach wash. The actual slurry flow rate may have been much higher than the prototypic 109 GPM, with correspondingly higher filter-loop return nozzle velocities in Tank T02A and potentially better mixing in that vessel. An increase in the filter-loop flow rate also decreases the amount of dilution in the filter-loop while wash-water is being added, improving the wash efficiency during the period that wash-water is added. The opposite was experienced during Integrated Test B for both wash processes; filter-loop flow rates were generally less than 100 GPM, resulting in slightly less mixing in Tank T02A and higher local dilution while wash-water was added. In contrast, filter-loop flow rates in Integrated Test D post-caustic-leach wash were much closer to target values. However, in the Integrated Test D post-oxidative-leach wash, the filter-loop flow rates were far below target values, and ranged from 60 to $80 \mathrm{GPM}$.

Filter-loop flow rate deviation modeling was performed (Baldwin et al. 2009) with the result being that the higher filter-loop flow rate is predicted to result in a slightly higher wash efficiency, but the difference is small and assumed to be negligible in this study. Given that the direction of the error is conservative (wash efficiencies would be slightly higher if the flow rate had been at its target value) and the impact on the wash efficiency is very small, this aspect of the nonprototypic flow rate is assumed to be negligible.

One suspected cause of low flow rate in the filter-loop in both Integrated Tests B and D was air entrainment in the slurry, which decreased performance of the pumps. The entrained air impacted the pump performance and the target flow rate often could not be achieved. In some cases the pump speed and flow rate was manually limited in an effort to minimize air entrainment.

The standard methods of analysis used with results reported for this project were ICP, IC, and titration. Raman was used as an alternative method for several analytes in Integrated Test A to evaluate the method for use as near-real-time monitoring in the PTF. Raman results were compared with the other methods by examining phosphate, with phosphate being one analyte that occurs throughout the post-caustic-leash wash process in adequate concentrations. Phosphate was also measured by three independent methods. The example shows relatively good agreement between all three methods and provides confidence in using Raman as a useful near-real-time process monitoring analytical method. This provides confidence and a check on the comparative data provided by SwRI in three very independent methods.

Since Raman was used successfully only in Integrated Test A post-caustic-leach wash, this provided the only carbonate data obtained in these PEP tests. The Raman data for carbonate showed relatively good agreement with the ideal wash efficiency $\mathrm{W}_{\text {eff }}=1.0$ line to near mid-wash. At that point with decreasing carbonate concentration, the Raman data show diversion from the ideal wash model. However, the wash efficiency based on the Raman carbonate data still resulted in a near-ideal value of 1.02 .

The measured oxalate data for each of Integrated Tests A, B, and D post-caustic-leach wash was compared to the oxalate solubility expression as used in the G-2 model. For Integrated Test A, the most applicable test, the agreement of measured oxalate to calculated oxalate at full solubility was excellent, ranging from 0 to $10 \%$ throughout mid-wash, implying mixing and kinetics are adequate to maintain oxalate at essentially full saturation until the peak. In addition, because the PEP used all 5 filter bundles 
during the wash steps, it was actually operating $4.5 \mathrm{x}$ times faster than the plant will (see Section 3.0 on scale-time) i.e., if the PEP took $6 \mathrm{hr}$ for a solids wash step, the plant will require $27 \mathrm{hr}$. That, of course, increased the likelihood of essentially saturating the supernate with the more soluble salts.. For Integrated Tests B and D, a consistent offset between measured and calculated values is seen, with the measured oxalate at $\sim 25 \%$ lower at mid-wash compared to the calculated result. A likely reason for this discrepancy is that the oxalate solubility expression is more reliable at the lower sodium concentrations as seen in Integrated Test A. For the higher sodium concentrations seen in Integrated Tests B and D, the oxalate solubility expression generates predictions with more scatter and less reliability. Therefore, the conclusion from the Integrated Test A comparison result still stands, that in the PEP, mixing and kinetics are adequate to maintain oxalate at essentially full saturation until dissolution is complete.

\subsection{Solids Washing Conclusions}

Several major conclusions were reached regarding the washing operations in the PEP based on the results of Integrated Tests A, B, and D:

- Washing operations in PEP across all three Integrated Tests A, B, and D were conducted successfully as per the approved Test Instructions. Minor instrumentation problems occurred, and some of the process conditions specified in the run sheets were not met during the wash operations, such as filter-loop flow rate targets, as discussed in Section 10.7.

- For the post-caustic-leach wash, for Integrated Tests A, B, and D, five analytes were selected based on full solubility and were monitored as successful indicators of washing efficiency: aluminum, sulfate, nitrate, nitrite, and free hydroxide. Other analytes, including sodium, oxalate, phosphate, and TDS, were affected by continual dissolution of solids and therefore were unsuitable for monitoring washing efficiency.

- For the post-oxidative-leach wash, for Integrated Tests A, B, and D, two analytes with full solubility and good concentration behavior were selected as suitable indicators of washing efficiency: chromium and oxalate. All other originally considered analytes, including sodium, manganese, nitrate, and TDS, show clear deviations from the expected linear behavior on a semi-log plot, due to a variety of causes as discussed in Section 10.7.

- An overall wash efficiency, combining all data for all Integrated Tests A, B, and D, was determined to be $1.00 \pm 0.01$ for the post-caustic-leach wash. Similarly, the overall wash efficiency for the post-oxidative-leach wash was determined to be $0.98 \pm 0.01$. These wash efficiencies were based on the weighted least squares fit of the full data sets for each applicable analyte and are an average of several analytes traced during the washing steps in all of Integrated Tests A, B, and D.

- The number of IW batches required to reach the target of $0.25-\mathrm{M}$ free hydroxide following the aluminum leaching stage was 64 batches for Integrated Test A, 39 batches for Integrated Test B, and 43 batches for Integrated Test D. As part of an assessment of the WTP process control strategy, these are compared to the WTP projections to reach the target of $0.25-\mathrm{M}$ free hydroxide of 64 for Integrated Test A, 38 for Integrated Test B, and 45 for Integrated Test D. It is concluded that the WTP process control strategy for specifying the number of wash batches for post-caustic-leach washing is successful. 
- The measured oxalate concentrations for each of Integrated Tests A, B, and D post-caustic-leach wash were compared to the oxalate solubility expression as used in the G-2 model. For the most applicable test, Integrated Test A, the agreement of measured oxalate to calculated oxalate at full solubility is excellent, implying both mixing and kinetics were adequate to maintain oxalate at essentially full saturation throughout the wash process until oxalate was fully dissolved. 



\subsection{Oxidative Leaching of Chromium}

\subsection{Introduction}

The work described in this section provides the test results that are related to the efficiency of the oxidative leaching process in Integrated Tests A, B and D. The tests were completed in parallel at laboratory-scale and in the PEP. The PEP test data included in this chapter are those from Integrated Test A(Tank T01A/B caustic leaching) and Integrated Tests B and D (Tank T02A caustic leaching). Whether caustic leaching is carried out in Tanks T01A/B (Integrated Test A) or Tank T02A (Integrated Tests B and D), all oxidative leaching processes occur in Tank T02A. An analysis of Integrated Tests A and B oxidative leaching has already been published (Rapko et al. 2009).

There are two major goals associated with the work described in this section.

- To evaluate the $\mathrm{Cr}$ leach factors during leaching for both the PEP and laboratory-scale testing to determine a scale up factor for prior laboratory-scale testing

- To evaluate process control strategies for reagent additions, specifically here quantifying the amount of added permanganate.

\subsection{Experimental Approach}

This section provides an overview of the experimental approach for the oxidative leaching tests conducted in the PEP and laboratory-scale equipment.

\subsubsection{PEP Oxidative-Leach}

For Integrated Tests A and B, a chromium oxyhydroxide slurry was added in-line at the end of the post-caustic-leach washing step. In Integrated Test D, the chromium was added at the beginning of the test and so was exposed to both caustic and oxidative leaching. Following the $\mathrm{Cr}$ addition, the slurry was then dewatered, and the slurry was washed to reduce the $\mathrm{OH}^{-}$to a targeted concentration of $\approx 0.25-\mathrm{M}$. During these washing steps, antifoam agent (AFA) was added periodically. Following washing of the Cr-containing slurry, a sample of the slurry was taken for use in the laboratory-scale oxidative leaching tests (described below). Then, the oxidative-leach was begun by adding nominally $1-\mathrm{M} \mathrm{NaMnO}_{4}$ upstream of the filter-loop pumps at the prototypic ratio of $\left(\mathrm{NaMnO}_{4}\right.$ addition rate)/(filter-loop flow rate), until the target of approximately 1 mole of permanganate/mole of chromium had been added to the system. For the Integrated Tests $\mathrm{A}$ and $\mathrm{B}$, the initial mass of $\mathrm{Cr}$ in the slurry was known with reasonable certainty because the $\mathrm{Cr}$ solids were added just before oxidative leaching. However, for Integrated Test $\mathrm{D}$, the solids were subjected to a prior caustic-leach process, a process known to slowly oxidize $\mathrm{Cr}(\mathrm{III})$ at a rate markedly dependent on the $\mathrm{Cr}(\mathrm{III})$ source, the hydroxide concentration, and the contact temperature (Rapko et al. 2004, Rapko et al. 2007). To estimate the extent of Cr dissolution during caustic leaching in Integrated Test D and so determine the target amount of permanganate, a preliminary experiment was performed that involved exposing the $\mathrm{Cr}$-containing PEP simulant to the caustic-leach conditions and then measuring the amount of leached $\mathrm{Cr}$ (Scheele et al. 2009) ${ }^{(\mathrm{a})}$. It is important to note

(a) Scheele RD, GN Brown, and DE Kurath. 2009. Manufacture of PEP Simulants—Lessons Learned. WTP-RPT-204, Rev 0, PNNL-18678, Pacific Northwest National Laboratory, Richland, Washington. 
that this preliminary laboratory-scale caustic leaching test included the sparging of air during the test to simulate the use of sparge air in the PEP. As a result of this test, what was thought to be a conservative caustic-leach factor of 0.7 was used to determine the target permanganate to $\mathrm{Cr}$ ratio of $1: 1$ in Integrated Test D.

To complete the oxidative leaching in PEP, the slurry was continuously pumped through the filter-loop at approximately the prototypic flow rate and mixed with the pulse jet mixers for 6 hours at a targeted temperature of $25^{\circ} \mathrm{C}$. PJMs were operated to match the planned PTF nozzle velocities and cycled at 4.5 times the rate as planned in the PTF. The specific PEP experimental test conditions for oxidative leaching during Integrated Tests A, B, and D are summarized in Section 11.3.

Analytical samples were collected using the in-tank sampling system as described earlier in this report (Section 4.1.3). In the PEP, the slurry samples were quickly ( $\approx 10 \mathrm{~min}$ ) separated in a centrifuge into liquid and wet solids fractions for analysis. Analyses were performed as described in Appendix E. Solids samples were submitted for metals analysis by inductively coupled plasma-atomic emission spectroscopy (ICP-AES). Slurry samples were submitted for analysis of density, metals content, and wt $\%$ UDS. Supernatant samples were submitted for the determination of metals content, anions content, and free-hydroxide concentration.

\subsubsection{Laboratory-Scale Oxidative-Leach}

For the purposes of scale-up, the laboratory-scale testing was performed once under Integrated Test A (Tanks T01A/B caustic leaching) conditions using the Integrated Test A simulant and once under Integrated Test B (Tank T02A caustic leaching) conditions using the Integrated Test B simulant. The slurry was sampled from Tank T02A immediately before the permanganate reagent was added. Note that while an oxidative-leach was performed only once for Integrated Tests A and B, an examination of the oxidative-leach process was performed with two batches at differing target permanganate-to-Cr ratios in Integrated Test D.

The laboratory-scale oxidative leaching tests were carried out with roughly 700 -g batches of PEP simulant taken just before the beginning of oxidative leaching within the covered 1-L reaction vessel described in Section 4.3. The system's temperature was controlled by electrical resistance wrap heaters to maintain $25 \pm 1{ }^{\circ} \mathrm{C}$ and was continuously mixed at $120 \mathrm{rpm}$ with an overhead stir motor as described in Russell et al. (2009d). One molar $\mathrm{NaMnO}_{4}$ was added to achieve a target ratio of 1:1 permanganate to $\mathrm{Cr}$ for Integrated Tests A, B, and D.

Before and immediately after adding 1-M NaMnO , two 30-mL analytical samples of the initial slurry were obtained, with one sample (for washed sludge metals analyses) being washed and the other sample remaining unaltered. The slurry sample washing was completed using three equal volumes of $0.01-\mathrm{M}$ $\mathrm{NaOH}$; mixing and centrifuging were performed each time to separate and decant the wash solution. In addition, a third sample was recovered to obtain an initial supernate sample. This 6-mL slurry sample was filtered through a $0.45-\mu \mathrm{m}$ syringe filter to separate the solids from the desired supernate.

Additional 6-mL analytical samples were taken and filtered with a $0.45-\mu \mathrm{m}$ filter each hour over the 8 hours of reaction, timed from the initial addition of $1-\mathrm{M} \mathrm{NaMnO}_{4}$. At the end of the test, two more 30-mL slurry analytical samples were obtained. Again, one sample was washed, and the other remained unaltered. 
As noted above, prior to Integrated Test $\mathrm{D}$, a sample of the Cr-containing slurry as it existed before any leaching, was taken and subjected to caustic leaching (Scheele et al. 2009) ${ }^{(\mathrm{a})}$. The experimental conditions for the caustic-leach were $85^{\circ} \mathrm{C}$ and a 24 -hr contact time with air sparging throughout caustic leaching. This leach test was done to evaluate the amount of $\mathrm{Cr}$ that might be expected to have dissolved during the caustic leaching performed at PEP prior to oxidative leaching. With this information for this preliminary test, the amount of $\mathrm{Cr}$ remaining after PEP caustic leaching could be estimated and the amount of permanganate needed to achieve the targeted permanganate-to- $\mathrm{Cr}$ ratio for the oxidative-leach can be calculated. This is the approach currently envisioned to determine the amount of permanganate at the pretreatment facility.

Analyses were performed at SwRI unless otherwise indicated. Solids samples were submitted for metals analysis by ICP-AES. Slurry samples were submitted for analysis of density, metals content, and wt $\%$ UDS. Supernatant samples were submitted for metals content, anions content, and free-hydroxide concentration (the last performed by PNNL's ASO).

\subsection{Results}

\subsubsection{Starting Slurry Compositions}

The amount of $\mathrm{Cr}$ dissolution during caustic leaching during Integrated Test $\mathrm{D}$ must be considered because chromium was present in the solids before caustic leaching instead of being introduced afterwards as in Integrated Tests A and B.

Table 11.1 presents the initial slurry and liquid phase composition at the start of the oxidative-leach for Integrated Tests A, B and D. The amount of Cr in Integrated Test D is much smaller than in Integrated Tests A and B. However, the Cr slurry concentration was $3798 \pm 74-\mu \mathrm{g} / \mathrm{g}$ and $3817 \pm 74-\mu \mathrm{g} / \mathrm{g}$ at the start of caustic-leach Batches \#1 and \#2 in Integrated Test D. This clearly illustrates that a significant amount of $\mathrm{Cr}$ dissolution occurred in Integrated Test D during the caustic-leach batches.

(a) Scheele RD, GN Brown, and DE Kurath. 2009. Manufacture of PEP Simulants-Lessons Learned. WTP-RPT-204, Rev 0, PNNL-18678, Pacific Northwest National Laboratory, Richland, Washington. 
Table 11.1. Initial Oxidative-Leach Slurry Composition for Integrated Tests A, B, and D

\begin{tabular}{|c|c|c|c|c|c|c|}
\hline \multirow[b]{3}{*}{ Analyte } & \multicolumn{2}{|c|}{ Integrated Test A } & \multicolumn{2}{|c|}{ Integrated Test B } & \multicolumn{2}{|c|}{ Integrated Test D } \\
\hline & Slurry & Liquid Phase & Slurry & Liquid Phase & Slurry & Liquid Phase \\
\hline & $\mu \mathrm{g} / \mathrm{g}$ & $\mu \mathrm{g} / \mathrm{g}$ & $\mu \mathrm{g} / \mathrm{g}$ & $\mu \mathrm{g} / \mathrm{g}$ & $\mu \mathrm{g} / \mathrm{g}$ & $\mu \mathrm{g} / \mathrm{g}$ \\
\hline $\mathrm{Al}$ & $42870 \pm 836$ & $71.7 \pm 1.3$ & $42881 \pm 834$ & $189 \pm 3$ & $41934 \pm 1167$ & $461 \pm 6$ \\
\hline $\mathrm{Ca}$ & $1068 \pm 23$ & $2.9 \pm 0.3^{(\mathrm{a})}$ & $1279 \pm 25$ & $2.5 \pm 0.3^{(\mathrm{a})}$ & $1113 \pm 24$ & $2.3 \pm 0.2^{(\mathrm{a})}$ \\
\hline $\mathrm{Cr}$ & $7429 \pm 144$ & $23.2 \pm 0.3$ & $7394 \pm 144$ & $17.8 \pm 0.2$ & $218 \pm 4$ & $33.4 \pm 0.5$ \\
\hline $\mathrm{Fe}$ & $3459 \pm 676$ & $14.7 \pm 1.0$ & $37365 \pm 728$ & $6.8 \pm 0.5$ & $36368 \pm 709$ & $4.6 \pm 0.5^{(a)}$ \\
\hline $\mathrm{Mg}$ & $734 \pm 15$ & $5.5 \pm 0.6^{(\mathrm{a})}$ & $767 \pm 15$ & $5.0 \pm 0.5^{(a)}$ & $693 \pm 15$ & $4.6 \pm 0.5^{(a)}$ \\
\hline $\mathrm{Mn}$ & $7416 \pm 145$ & $0.74 \pm 0.03$ & $8235 \pm 905$ & $0.61 \pm 0.03$ & $8189 \pm 159$ & $0.31 \pm 0.02$ \\
\hline $\mathrm{Na}$ & $9843 \pm 122$ & $9674 \pm 148$ & $10966 \pm 137$ & $10856 \pm 148$ & $8332 \pm 94$ & $8317 \pm 114$ \\
\hline $\mathrm{Nd}$ & $859 \pm 17$ & $0.248 \pm 0.004$ & $889 \pm 17$ & $0.112 \pm 0.002$ & $856 \pm 17$ & $0.031 \pm 0.001$ \\
\hline $\mathrm{Sr}$ & $415 \pm 8$ & $0.32 \pm 0.03^{(a)}$ & $320 \pm 6$ & $0.25 \pm 0.03^{(a)}$ & $337 \pm 7$ & $0.23 \pm 0.02^{(\mathrm{a})}$ \\
\hline Cs & $0.68 \pm 0.05$ & $0.53 \pm 0.01$ & $1.09 \pm 0.06$ & $0.68 \pm 0.01$ & $0.38 \pm 0.05^{(\mathrm{a})}$ & $\underset{f}{0.009} \pm 0.001^{(\mathrm{a}}$ \\
\hline Nitrite & $\mathrm{n} / \mathrm{a}$ & $70 \pm 9$ & $\mathrm{n} / \mathrm{a}$ & $93 \pm 9$ & $\mathrm{n} / \mathrm{a}$ & $150 \pm 10$ \\
\hline Nitrate & $\mathrm{n} / \mathrm{a}$ & $3617 \pm 64$ & $\mathrm{n} / \mathrm{a}$ & $3757 \pm 66$ & $\mathrm{n} / \mathrm{a}$ & $514 \pm 16$ \\
\hline Phosphate & $\mathrm{n} / \mathrm{a}$ & $201 \pm 9$ & $\mathrm{n} / \mathrm{a}$ & $81 \pm 8$ & $\mathrm{n} / \mathrm{a}$ & $69 \pm 9$ \\
\hline Sulfate & $\mathrm{n} / \mathrm{a}$ & $33 \pm 3$ & $\mathrm{n} / \mathrm{a}$ & $55 \pm 3$ & $\mathrm{n} / \mathrm{a}$ & $142 \pm 4$ \\
\hline $\begin{array}{c}\text { Free } \\
\text { hydroxide } \\
\text { (M) }\end{array}$ & $\mathrm{n} / \mathrm{a}$ & $0.26 \pm 0.01$ & $\mathrm{n} / \mathrm{a}$ & $0.28 \pm 0.01$ & $\mathrm{n} / \mathrm{a}$ & $0.12 \pm 0.01$ \\
\hline wt $\%$ UDS & $18.7 \pm 0.1$ & $\mathrm{n} / \mathrm{a}$ & $17.0 \pm 0.1$ & $\mathrm{n} / \mathrm{a}$ & $22.0 \pm 0.1$ & $\mathrm{n} / \mathrm{a}$ \\
\hline $\begin{array}{l}\text { Density } \\
(\mathrm{g} / \mathrm{mL})\end{array}$ & $1.147 \pm 0.005$ & $1.035 \pm 0.007$ & $1.071 \pm 0.005$ & $1.015 \pm 0.005$ & $1.173 \pm 0.005$ & $1.017 \pm 0.005$ \\
\hline $\mathrm{wt} \% \mathrm{H} 2 \mathrm{O}$ & $79.4 \pm 0.1$ & $98.1 \pm 0.1$ & $80.8 \pm 0.1$ & $97.8 \pm 0.1$ & $75.8 \pm 0.1$ & $97.8 \pm 0.1$ \\
\hline
\end{tabular}

(a) At least one of the triplicate values contained in this average value was at or below the detection limit.

\subsubsection{PEP Experimental Process Conditions}

Details of the experimental PEP process conditions are covered in the run reports (Guzman-Leong et al. 2009, Geeting et al. 2009, Sevigny et al. 2009). The details of the laboratory-scale test conditions are provided in Russell et al. (2009d). Neither the PEP nor the laboratory-scale testing documentation revealed any operational issues.

Unlike the PEP temperature profiles as reported in Rapko et al. (2009), the PEP temperature profile in Tank T02A during oxidative leaching in Integrated Test D showed no initial spike in temperature. The explanation for the initial temperature spike observed during oxidative leaching is the heat contribution resulting from the exothermic behavior of the permanganate/Cr(III) reaction. As noted below, the $\mathrm{Cr}$ (III) slurry mass in the Integrated Test D slurry are more than an order of magnitude below those present in Integrated Tests A and B. All other conditions being equal, such lower $\mathrm{Cr}(\mathrm{III})$ initial masses implies less material available for oxidation, which leads to less heat being generated by oxidative leaching. This implies that there is less impetus for a temperature spike. 


\subsubsection{Temperatures During Oxidative Leaching Laboratory-Scale Testing}

The laboratory-scale temperature profile in Tank T02A during Integrated Tests A and B is covered in an earlier report (Rapko et al. 2009). To summarize those prior results, an initial spike in temperature of several degrees Celsius was observed, followed by a slow decrease over the 8-hr time scale of oxidative leaching. Like that observed during Integrated Test D at PEP, no initial temperature spike was observed during laboratory-scale Test D oxidative leaching. Again, this is attributed to the very low initial $\mathrm{Cr}$ concentration, leading to lower amounts of heat being generated by the exothermic Cr oxidation by permanganate.

\subsubsection{Initial Permanganate-to-Chromium Ratios}

The reaction of permanganate with $\mathrm{Cr}(\mathrm{III})$ can be expressed in the following equation:

$$
\mathrm{Cr}(\mathrm{OH})_{3}(\mathrm{~s})+\mathrm{MnO}_{4}{ }^{-}(\mathrm{sol})+\mathrm{OH}^{-}(\mathrm{sol}) \longleftrightarrow \mathrm{CrO}_{4}{ }^{2-}(\mathrm{sol})+\mathrm{MnO}_{2}(\mathrm{~s})+2 \mathrm{H}_{2} \mathrm{O}(\mathrm{sol})
$$

The reaction also applies to $\mathrm{C}(\mathrm{O})(\mathrm{OH})(\mathrm{s})$ as the $\mathrm{Cr}(\mathrm{III})$ source; the difference is that in the latter there is only one water molecule on the right side of the equation. In both instances, the molar stoichiometry for permanganate to oxidize all of the $\mathrm{Cr}$ (III) is 1. The reaction in Equation 11.1 is exothermic (Wagman et al. 1982) ${ }^{(a)}$ with a standard-state reaction enthalpy, $\Delta \mathrm{H}$, of $-119.9 \mathrm{~kJ} / \mathrm{mol}$ (Rapko et al. 2009), which may have led to difficulties in maintaining temperature control at the targeted $25^{\circ} \mathrm{C}$ as noted earlier. Table 11.2 summarizes the stoichiometry of permanganate to $\mathrm{Cr}$ based on the total mass of $\mathrm{Cr}$ in the test and the amount of permanganate added. Using the stoichiometry in Equation (11.1), we should expect maximum Cr leach factors of 0.97 for Integrated Test A (Tank T01A/B caustic leaching), of 0.98 or greater for Integrated Test B (Tank T02A caustic leaching), and 1 for Integrated Test D oxidative leaching. Indeed, the permanganate-to-Cr ratios for Integrated Test $\mathrm{D}$ were all over 10:1. This is much greater than targeted, and the primary identified cause is due to the much higher than expected dissolution of $\mathrm{Cr}$ during caustic leaching, as discussed below.

This addition of excess permanganate raises concerns about the method used to predict needed permanganate. It is unclear as to why the initial caustic-leach method failed: as noted below, the laboratory-scale and PEP-scale oxidative leach factors are very similar, and it is unclear why the oxidative leach test should be different (Scheele et al. 2009) ${ }^{(\mathrm{b})}$. During caustic leaching, oxygen in air is believed to be the oxidant for the $\mathrm{Cr}$ (III) to Cr(VI) conversion, However, both the PEP and laboratory-scale tests experienced air sparging, so it is unlikely that either the PEP or the laboratory-scale test slurry were lacking in oxidant. So lack of oxidant in the laboratory caustic-leach is unlikely to be the explanation for its lower Cr leach factor.

The actual value for the mass of added permanganate used to calculate the permanganate-to-slurry-Cr ratio depends on the method chosen to calculate an added permanganate volume. The volume of permanganate added to the slurry for oxidative Cr leaching can be estimated in three ways: 1) integrating the flow rate as reported by the flowmeter FT-0651 with respect to time during permanganate addition,

(a) Data for enthalpy calculation taken from: DD Wagman, WH Evans, VB Parker, RH Schumm, I Halow, SM Bailey, KL Churney, and RL Nuttall. 1982. "The NBS Tables of Chemical Thermodynamic Properties." Journal of Physical and Chemical Reference Data. Volume 11, Supplement 2.

(b) Scheele RD, GN Brown, and DE Kurath. 2009. Manufacture of PEP Simulants-Lessons Learned. WTP-RPT-204, Rev 0, PNNL-18678, Pacific Northwest National Laboratory, Richland, Washington. 
2) calculating the change in total slurry volume before and after permanganate addition, and 3) solving the Mn mass balance equation to back-calculate the volume of added permanganate.

The permanganate addition is controlled using the flow rate measurement from flowmeter FT-0651, and the Test Instruction run sheet reports the amount of added permanganate as 31 liters. The data from FT-0651indicated a flow rate of 9 to 10 GPM when permanganate flow should be 0 , and a decrease to 4 to 6 GPM during the time of the actual permanganate addition. Under the assumption that the flowmeter only works properly when fluid is flowing through it, replacing spurious data with 0 s and numerically integrating the flow rate with respect to time gives the volume of permanganate added as 36 liters.

Estimating the volume of permanganate added to the slurry from stable level measurements gives an added permanganate volume of 54 liters. Finally, the volume of $\mathrm{NaMnO}_{4}$ added, which was necessary to exactly close the mass balance on manganese before and after permanganate addition, gives a volume of 40 liters.

Of these methods, the one chosen to calculate the permanganate-to-slurry-Cr ratio is the mass balance method, which yields 40 liters of added permanganate. Because the flowmeter clearly gives spurious results under certain conditions and did not agree well with the mass-balance or volumetric methods, it was not used here. Both the level volume and the mass balance method seem valid, but the level volume after permanganate addition might be high if there were any foaming in the tank following permanganate addition. So the mass balance method was selected as being the most reliable. In truth, all methods yield the same conclusion: that the permanganate-to-slurry-Cr ratio is substantially greater than the targeted 1:1 mole ratio.

One final conclusion can be made from evaluating these alternative methods of tank volume estimation. The flowmeter (36-L) and the mass balance methods (40-L) both give similar results. If one assumes that the higher stable level volume is due to foaming accompanying the introduction of permanganate, the difference (ca. 14 gallons) indicates, at worst, that a relatively small fraction of foaming (slightly above $2 \%$ of the slurry volume) occurs on top of the 600 -plus liters of slurry. 
Table 11.2. Mn:Cr Experimental Ratio

\begin{tabular}{lccc}
\hline \multicolumn{1}{c}{ Experiment } & Moles $\mathrm{MnO}_{4}{ }^{-}$ & Moles $\mathrm{Cr}$ & $\mathrm{MnO}_{4}{ }^{-} \mathrm{Cr}$ \\
\hline Integrated Test A & 149.6 & 153.7 & 0.97 \\
\hline Laboratory-Scale Test A & 0.084 & 0.083 & 1.01 \\
Integrated Test B & 83.5 & 84.9 & 0.98 \\
Laboratory-Scale Test B & 0.087 & 0.093 & 0.93 \\
Integrated Test D & 38.4 & 3.0 & 12.8 \\
Laboratory-Scale Test D \#1 & 0.042 & 0.003 & 14.3 \\
Laboratory-Scale Test D \#2 & 0.030 & 0.003 & 10.1 \\
\hline (a) Moles of permanganate added based on a best-fit mass balance to the total final Mn \\
\end{tabular}

\subsubsection{Results-Cr Leach Factors}

\subsubsection{Methods for Calculating Cr Leach Factors}

Leach factors for Cr were calculated using two different methods (Rapko et al. 2009): total Cr mass changes in the initial and final solids (see Equation [11.2] and [11.3]) and an implied mass balance based on the measured $\mathrm{Cr}$ inventory in the supernatant as compared to the initial amount of $\mathrm{Cr}$ present (Equation [11.4] and [11.5]).

The specific data needed for leach factor calculations are identified in the equations below. Each method has two equations. The first describes how the leach factor was calculated using information from the PEP tests, and the second describes how the leach factor was calculated using information from the parallel tests.

Method 1 calculates the $\mathrm{Cr}$ leach factor based on change in inventory of $\mathrm{Cr}$ in the solid phase. For the PEP tests,

$$
f_{C r, 1}=1-\frac{m_{C r S}}{m_{C r S, 0}}=1-\frac{V_{B} \rho_{B} \omega_{c s} c_{C r, c s}}{V_{B, 0} \rho_{B, 0} \omega_{c s, 0} c_{C r, c s, 0}}
$$

and for the parallel tests,

$$
f_{C r, 1}=1-\frac{m_{C r S}}{m_{C r S, 0}}=1-\frac{m_{s}\left(\frac{\omega_{s}}{\omega_{r s}}\right) c_{C r, r s}\left(\frac{m_{s, 0}}{m_{s}}\right)}{m_{s, 0}\left(\frac{\omega_{s, 0}}{\omega_{r s, 0}}\right) c_{C r, r s, 0}}=1-\frac{\left(\frac{\omega_{s}}{\omega_{r s}}\right) c_{C r, r s}}{\left(\frac{\omega_{s, 0}}{\omega_{r s, 0}}\right) c_{C r, r s, 0}}
$$

where:

$$
\begin{array}{ll}
f_{C r, 1} & =\mathrm{Cr} \text { leach factor using method } 1 \\
m_{C r S} & =\text { mass of } \mathrm{Cr} \text { in the solid phase at time } \mathrm{t} \\
m_{C r S, 0} & =\text { initial mass of } \mathrm{Cr} \text { in the solid phase }
\end{array}
$$




$\begin{array}{ll}V_{B} & =\text { volume of the process slurry at time } \mathrm{t} \\ V_{B, 0} & =\text { initial volume of the process slurry } \\ \rho_{B} & =\text { density of process slurry at time } \mathrm{t} \\ \rho_{B, 0} & =\text { initial density of the process slurry } \\ \omega_{c s} & =\text { weight fraction of centrifuged solids (mass of centrifuged solids/mass of slurry) } \\ & =\text { at time } \mathrm{t} \\ \omega_{c s, 0} & =\text { initial weight fraction of centrifuged solids } \\ c_{C r, c s} & =\text { concentration of } \mathrm{Cr} \text { in the centrifuged solids at time } \mathrm{t} \\ c_{C r, c s, 0} & =\text { initial concentration of Cr in the centrifuged solids } \\ m_{s} & =\text { mass of the slurry at time } \mathrm{t} \\ m_{s, 0} & =\text { initial mass of the slurry } \\ \omega_{s} & =\text { weight fraction of undissolved solids in the slurry } \\ \omega_{s, 0} & =\text { initial weight fraction of undissolved solids in the slurry } \\ \omega_{r s} & =\text { weight fraction of undissolved solids in the rinsed wet solids } \\ \omega_{r s, 0} & =\text { initial weight fraction of undissolved solids in the rinsed wet solids } \\ c_{C r, r s} & =\text { concentration of Cr in the rinsed solids at time } \mathrm{t} \\ c_{C r, r s, 0} & =\text { initial concentration of Cr in the rinsed solids. }\end{array}$

Differences in equation 11.2 and 11.3 occur because different quantities were measured in each test configuration. Note that the quantities $c_{C r, c s}$ and $c_{C r, r s}$ listed above are measuring the same thing. They had been given different subscripts to associate them with corresponding weight fractions which are measuring different quantities ( $\omega_{c s}$ vs. $\left.\omega_{r s}\right)$. The mass of slurry in PEP is calculated using the volume and density of the process slurry, whereas in the parallel tests it was measured directly. In the PEP testing, the concentration of $\mathrm{Cr}$ is scaled to a slurry basis using the fraction of the sample which was centrifuged solids. In the parallel tests, the UDS of the slurry and the rinsed wet solids are used to scale the $\mathrm{Cr}$ concentration. An additional correction is necessary in the parallel test expression to account for removal of sample mass, which cannot be neglected. A simple ratio is used to place the mass of slurry at time $t$ on the same basis as the original slurry (at $\mathrm{t}=0$ ). The use of a ratio is a simplification that is justified by the observation that the $\mathrm{Cr}$ is leached almost completely within the first few minutes.

Method 2 calculates the $\mathrm{Cr}$ leach factor using the initial amount of $\mathrm{Cr}$ in the solid phase and the change in the $\mathrm{Cr}$ liquid phase concentration. For the PEP tests,

$$
f_{C r, 2}=\frac{m_{C r L}-m_{C r L, 0}}{m_{C r S, 0}}=\frac{V_{B} \rho_{B}\left(1-\omega_{S}\right) c_{C r L}-V_{B, 0} \rho_{B, 0}\left(1-\omega_{s, 0}\right) c_{C r L, 0}}{V_{B, 0} \rho_{B, 0} c_{C r, c s, 0} \omega_{c s, 0}}
$$

and for the parallel tests, 


$$
\begin{aligned}
& f_{C r, 2}=\frac{m_{C r L}-m_{C r L, 0}}{m_{C r S, 0}}=\frac{\left(\frac{m_{s, 0}}{m_{s}}\right) m_{s}\left(1-\omega_{S}\right) c_{C r L}-m_{s, 0}\left(1-\omega_{s, 0}\right) c_{C r L, 0}}{m_{s, 0} c_{C r, r s, 0}\left(\frac{\omega_{s, 0}}{\omega_{r s, 0}}\right)} \\
& =\frac{\left(1-\omega_{S}\right) c_{C r L}-\left(1-\omega_{s, 0}\right) c_{C r L, 0}}{c_{C r, r s, 0}\left(\frac{\omega_{s, 0}}{\omega_{r s, 0}}\right)}
\end{aligned}
$$

where:

$$
\begin{array}{lll}
f_{C r, 2} & = & \mathrm{Cr} \text { leach factor using method } 2 \\
m_{C r L} & = & \text { mass of } \mathrm{Cr} \text { in the liquid phase at time } \mathrm{t} \\
m_{C r L, 0} & = & \text { initial mass of } \mathrm{Cr} \text { in the liquid phase } \\
c_{C r L} & = & \text { concentration of } \mathrm{Cr} \text { in the liquid phase at time } \mathrm{t} \\
c_{C r L, 0} & = & \text { initial concentration of } \mathrm{Cr} \text { in the liquid phase. }
\end{array}
$$

The same differences observed in equations 11.2 and 11.3 also appear in equations 11.4 and 11.5. The liquid phase concentrations are comprised of both the supernate concentration and the rinsate concentration at the initial and final samples points. The liquid phase concentrations at intermediate leaching times are the supernate concentration only. Note that the leach factors are calculated with the same denominator, and since it is expected that $m_{C r L}-m_{C r L, 0}=m_{C r S, 0}-m_{C r S}$, the two leach factors are equivalent.

Each method has its own advantages. Method 1 is more straightforward and is similar to previous calculations of $\mathrm{Cr}$ leach factors, but requires sampling and analyzing the $\mathrm{Cr}$ solids every time the leach factor is calculated. Method 2 is more complex; however, calculation of intermediate leach factors is simpler because only the liquid phase needs to be sampled and analyzed.

\subsubsection{Results from PEP Cr Caustic Leaching}

Figure 11.1 summarizes Cr leaching during the caustic leaching in PEP during Integrated Test D. Both batches show similar behavior with respect to $\mathrm{Cr}$ dissolution during caustic leaching. The temperature is already elevated at the beginning of sampling, presumably because of pump heat and the heat of dilution of a concentrated sodium hydroxide solution. This higher-than-ambient temperature is presumably why noticeable $\mathrm{Cr}$ dissolution can be observed even at time 0 . The temperatures rapidly ramp up to their target of $85^{\circ} \mathrm{C}$, which is when the caustic-leach time begins $(\mathrm{t}=0 \mathrm{hr})$.

Shows a steady but decreasing rate of $\mathrm{Cr}$ being dissolved over the contact time of the experiment at the targeted leach temperature. During the cool-down part of Integrated Test D (post-24 hours leach time), no further $\mathrm{Cr}$ dissolution is observed. This lack of $\mathrm{Cr}$ dissolution could be due to the lower rates of oxidation expected at lower temperatures or the exhaustion of more readily oxidizable forms of $\mathrm{Cr}$ in the simulant. 


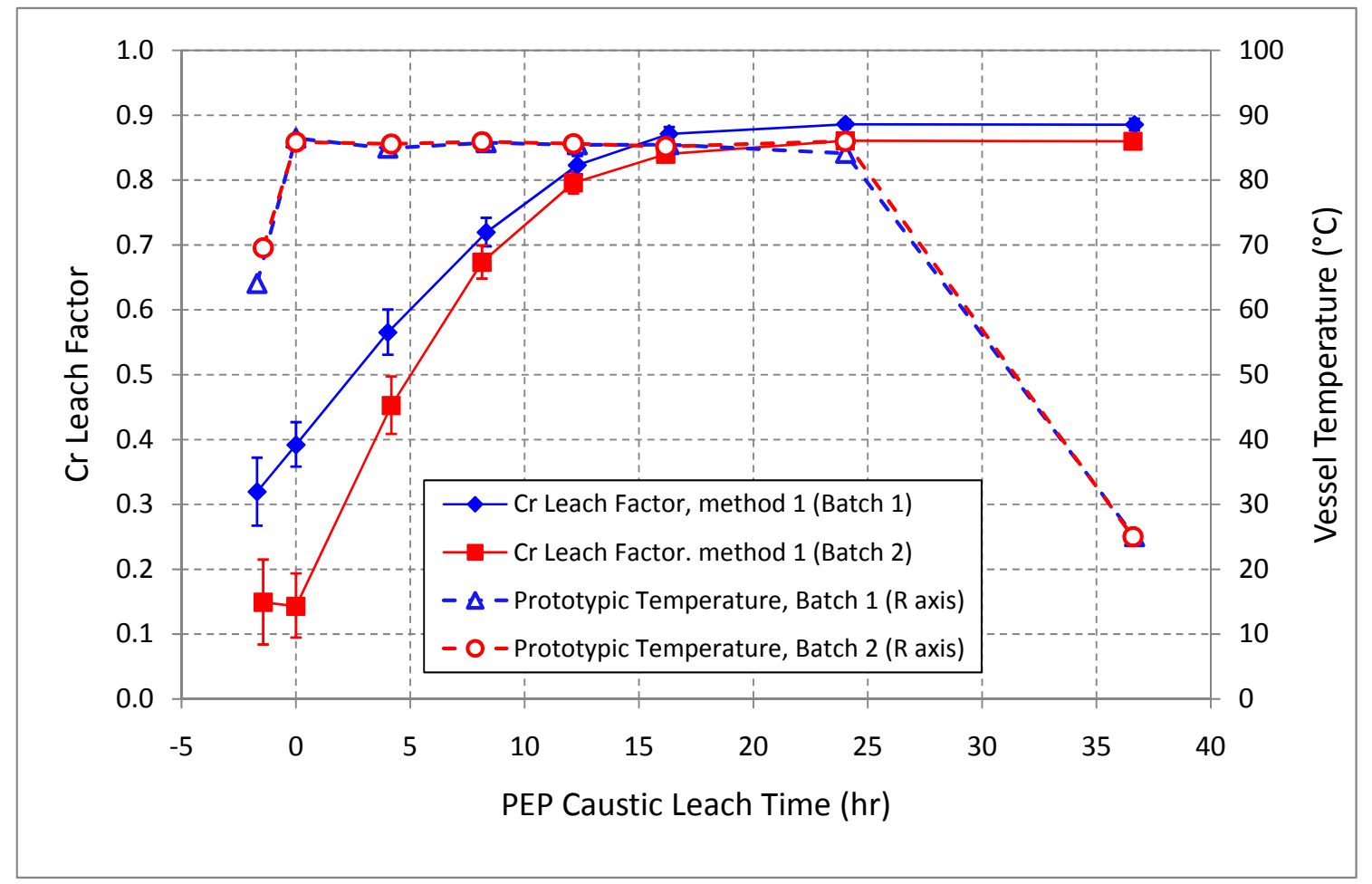

Figure 11.1. Dissolution of Cr During Integrated Test D Caustic Leaching as Determined by Method 1. Blue diamonds refer to the Cr leach factors during Batch 1 leaching; red squares refer to the $\mathrm{Cr}$ leach factors during Batch 2 leaching. Blue triangles and red circles refer to the temperature (right y-axis) as a function of leach time. The caustic-leach time of $0 \mathrm{hr}$ refers to the point where the vessel temperature reached $85^{\circ} \mathrm{C}$.

\subsubsection{Results from Cr Oxidative Leach Factor Calculations}

Oxidative Cr leach factors calculated by Methods 1 and 2 for the PEP and laboratory-scale testing are summarized in Table 11.3. Figure 11.2 shows the $\mathrm{Cr}$ concentrations in the supernate for Integrated Tests A, B and D as a function of leach time.

Table 11.3. Final Cr Oxidative-Leach Factors for the PEP (6-hr contact time) and Laboratory-Scale Tests A, B, and D (8-hr contact time) as Calculated by Methods 1 and 2 (95\% confidence values in parenthesis)

\begin{tabular}{ccc}
\hline Test & Cr Leach Factor - Method 1 & Cr Leach Factor - Method 2 \\
\hline Integrated Test A & $0.94(0.94-0.95)$ & $0.95(0.90-1.00)$ \\
Laboratory-Scale Test A & $0.91(0.90-0.92)$ & $0.85(0.73-0.97)$ \\
Integrated Test B & $0.91(0.90-0.91)$ & $0.88(0.83-0.94)$ \\
Laboratory-Scale Test B & $0.93(0.92-0.94)$ & $0.89(0.77-1.01)$ \\
Integrated Test D & $0.38(0.33-0.43)$ & $0.93(0.85-1.00)$ \\
Laboratory-Scale Test D-1 & $0.46(0.40-0.51)$ & $0.45(0.40-0.50)$ \\
Laboratory-Scale Test D-2 & $0.49(0.43-0.54)$ & $0.45(0.40-0.50)$ \\
\hline
\end{tabular}




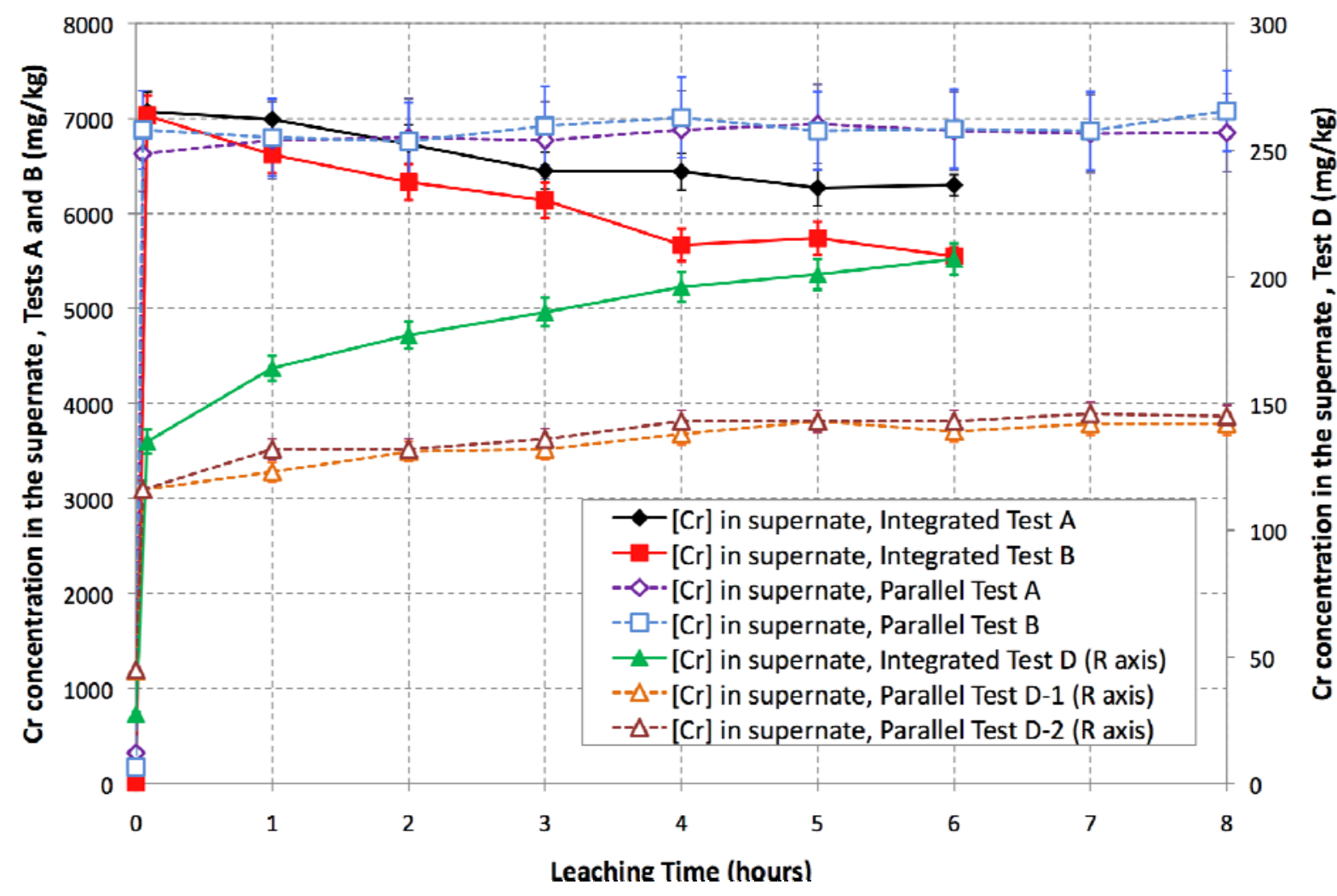

Figure 11.2. Cr Concentrations in the Supernate for Integrated Tests A, B and D and Bench-Scale Test D as a Function of Time (hours).

The following conclusions can be readily made. First, the final $\mathrm{Cr}$ leach factors for Integrated Tests A and B are all high, with leach factors of 0.85 to 0.94 , with most of the values being of 0.90 or greater. Second, even by the initial sampling, the reaction appears essentially over, with the final leach factors unchanged from those obtained after only a few minutes of reaction time. This factor implies that the mixing in both the PEP and laboratory-scale tests must allow for contact of the permanganate with the $\mathrm{Cr}$ solids almost immediately. Third, there is essentially no difference between the $\mathrm{Cr}$ leach factors obtained from PEP and laboratory-scale testing. Fourth, there is essentially no difference between the leach factors calculated from Integrated Test A (Tank T01 A/B caustic leaching) and Integrated Test B (Tank T02A caustic leaching).

The leach factors for Integrated Test D are markedly different in some respects but similar in others. As with the Integrated Test A and B results, the Cr leach factors as calculated by Method 1 are similar between the PEP and laboratory scale tests, although PEP leach factor may be slightly lower. Integrated Test $\mathrm{D}$ is also similar to Integrated Tests $\mathrm{A}$ and $\mathrm{B}$ in that the Cr leaching that does occur appears to be complete almost immediately upon mixing. However, Integrated Test D is markedly different from Integrated Tests A and B in the extent of Cr removal during oxidative leaching; the leach factor for Integrated Test D is approximately half that of those found in Integrated Tests A and B.

The most likely explanation for this discrepancy between Integrated Test D and Integrated Tests A and $\mathrm{B}$ is that the bulk of the Cr was removed during the prior caustic-leach in Integrated Test $\mathrm{D}$, leaving a much smaller fraction of leachable $\mathrm{Cr}$ available for the oxidative-leach portion of Integrated Test $\mathrm{D}$. This 
is supported by the results of Table 11.4. which examines the cumulative leached $\mathrm{Cr}$ from both caustic leaching and oxidative leaching. When cumulative leach factors are considered, the values for Integrated Test $\mathrm{D}$ range from 0.92 to 0.93 , in close agreement with the range of values of 0.91 to 0.94 found for Integrated Tests A and B.

Figure 11.3 summarizes the $\mathrm{Cr}$ leach factors calculated using Method 2. This allows for many of the same conclusions as those drawn from Table 11.4. For Integrated Tests A and B, the only difference between Methods 1 and 2 is that the Cr leach factors are slightly lower, 0.95 and 0.88 , using Method 2 as compared to 0.94 and 0.91 using Method 1. The Laboratory-scale test results for Integrated Test D are consistent with each other and with the results calculated using Method 1. However, for Integrated Test D, the Cr leach factor for oxidative leaching is more than twice as large as for the Laboratory-scale D tests and for the results obtained using Method 1. Even the cumulative leach factors for $\mathrm{Cr}$ are slightly higher for Integrated Test D as calculated by Method 2 than with all of the other results. Such differences suggest that something was different from the other tests in the conditions experienced during oxidative leaching in Integrated Test D.

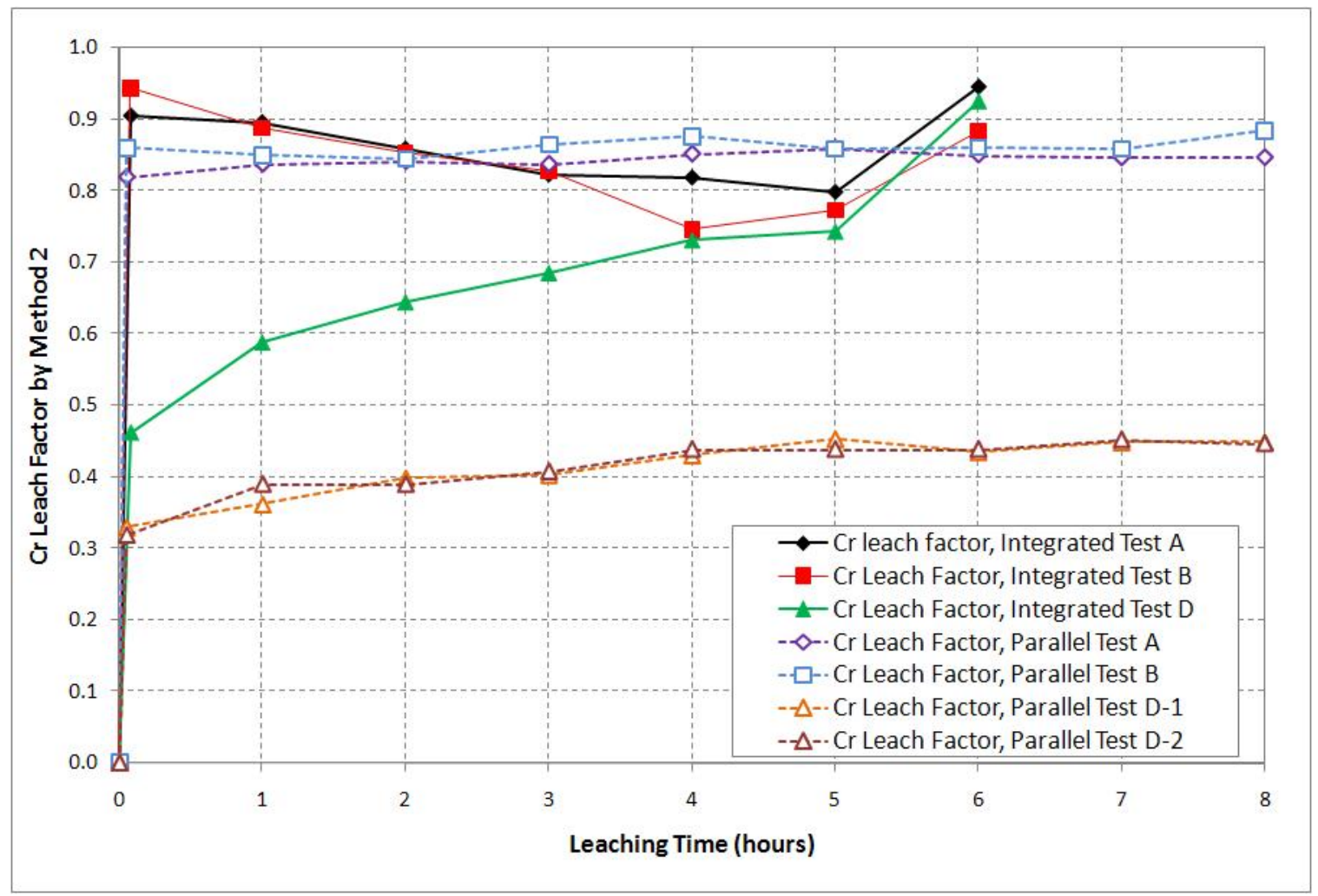

Figure 11.3. Cr Leach Factors During Oxidative Leaching as a Function of Time (hours) for the PEP and Laboratory-Scale Tests A and B as Calculated by Method 2 
Table 11.4. Cumulative Leach Factors for Cr in Tests A, B, and D as Calculated by Methods 1 and 2 (95\% confidence range in parenthesis)

\begin{tabular}{ccc}
\hline Test & Cr Leach Factor - Method 1 & Cr Leach Factor - Method 2 \\
\hline Integrated Test A & $0.94(0.94-0.95)$ & $0.95(0.90-1.00)$ \\
Laboratory-Scale Test A & $0.91(0.90-0.92)$ & $0.85(0.73-0.97)$ \\
Integrated Test B & $0.91(0.90-0.91)$ & $0.88(0.83-0.94)$ \\
Laboratory-Scale Test B & $0.93(0.92-0.94)$ & $0.89(0.77-1.01)$ \\
Integrated Test D & $0.92(0.91-0.93)$ & $0.99(0.98-1.00)$ \\
Laboratory-Scale Test D-1 & $0.93(0.92-0.94)$ & $0.94(0.91-0.96)$ \\
Laboratory-Scale Test D-2 & $0.93(0.93-0.94)$ & $0.94(0.91-0.96)$ \\
\hline
\end{tabular}

The cumulative leach factors given in Table 11.4 compare favorably with the fate of species calculations performed for $\mathrm{Cr}$ in Section 12, and shown in Table 11.5 below. The percentage of $\mathrm{Cr}$ removed from the system in the permeate should be equivalent to the amount that was leached provided there were no other Cr sinks in the system. These values are presented in Table 12.12 for Integrated Tests A, B and D. Table 11.5 illustrates that the leach factors determined from two different approaches are in good agreement.

Table 11.5. Comparison of Leach Factors Determined from Mass Balance Calculations (Section 12, Table 12.12) and Oxidative-Leach Calculations (current section, Table 11.4).

\begin{tabular}{ccc}
\hline Test & Cr Leach Factor, Table $12.12^{(\text {a) }}$ & Cr Leach Factor - Method 1/2 \\
\hline Integrated Test A & 0.901 & $0.94 / 0.95$ \\
Integrated Test B & 0.956 & $0.91 / 0.88$ \\
Integrated Test D & 0.974 & $0.92 / 0.99$
\end{tabular}

(a) These values are the adjusted numbers from Table 12.12. Note they are listed as percentages in the source table but as decimals here for better comparison with the leach factors of this section.

One possible concern involving an alternative source of $\mathrm{Cr}$ available for oxidative leaching is the $\mathrm{Cr}$ present in the PEP components. To evaluate this concern, a mass-balance calculation was performed, comparing the total initial amount of $\mathrm{Cr}$ as determined by sample analysis just before beginning oxidative leaching with the total amount of $\mathrm{Cr}$ present at the conclusion of oxidative leaching. The results of this comparison are summarized in Table 11.6.

Table 11.6. Mass Summary of Cr for Oxidative Leaching in Integrated Tests A, B, and D

\begin{tabular}{cccccc}
\hline Test & Leach Time & $\begin{array}{c}\text { Mass Cr in } \\
\text { Solids }(\mathrm{g})\end{array}$ & $\begin{array}{c}\text { Mass Cr in } \\
\text { Liquids }(\mathrm{g})\end{array}$ & $\begin{array}{c}\text { Total Mass Cr } \\
(\mathrm{g})\end{array}$ & \% Difference \\
\hline A & 0 & 8798 & 22 & 8820 & -- \\
A & 6 & 495 & 8338 & 8833 & $0.15 \%$ \\
B & 0 & 4282 & 9 & 4290 & -- \\
B & 6 & 397 & 3789 & 4186 & $-2.51 \%$ \\
D & 0 & 138 & 18 & 156 & -- \\
D & 6 & 85 & 146 & 231 & $48.0 \%$ \\
\hline
\end{tabular}

(a) Round-off errors may lead to slightly different values for sums versus individual components as written. 
The good agreement in mass balance for both Integrated Tests A and B indicates that the added Cr is the sole source for leached $\mathrm{Cr}$ during oxidative leaching. However, the higher values for total $\mathrm{Cr}$ present in Integrated Test D suggest an additional source. It is proposed that during Integrated Test $\mathrm{D}$, additional $\mathrm{Cr}$ is leached from the PEP components, thus contributing to a high apparent leach factor using the Method 2 calculation. Because this source of $\mathrm{Cr}$ is not initially present in the solids, a Method 1-based leach factor calculation would not pick up this additional $\mathrm{Cr}$ dissolution.

But why would this behavior only be observed during Integrated Test D oxidative leaching but not during Integrated Tests A and B? Two factors must be taken into account. One is that, given the smaller mass of $\mathrm{Cr}$ present in Integrated Test D (less than $10 \%$ of the mass of $\mathrm{Cr}$ present in the solids in Integrated Tests $\mathrm{A}$ and $\mathrm{B}$ ), a small contribution in the total dissolved $\mathrm{Cr}$ would be more noticeable in Integrated Test $\mathrm{D}$. The second factor has to do with the rapid reaction of permanganate with sludge $\mathrm{Cr}$. Both the Method 1-based leach-factor calculations and Method 2-based leach-factor calculations for Integrated Tests $\mathrm{A}$ and $\mathrm{B}$ show a rapid reaction with permanganate. With the initial permanganate-tosludge $\mathrm{Cr}$ of 1 present in Integrated Tests $\mathrm{A}$ and $\mathrm{B}$, this would leave little to no permanganate available for a slower reaction with the $\mathrm{Cr}$ in the PEP components. But with the $>10$ permanganate-to-sludge-Cr ratio present in Integrated Test $\mathrm{D}$, significant amounts of the excess permanganate were present throughout the oxidative leaching step and were available to react with the PEP components.

This interpretation is supported by the data presented in Figure 11.3. For all Integrated Tests A and $\mathrm{B}$, the reaction appears to be over immediately after mixing. For Integrated Test D, however, the data show an initial spike followed by a slow increase in the amount of dissolved $\mathrm{Cr}$.

It should be noted that a key finding is that the scale-up factor for laboratory-scale oxidative-leach testing is unity. This is a result of the closeness of the leach factors between the PEP and laboratory-scale testing for both Integrated Test A and B and in Integrated Test D as calculated by Method 1, which, for the reasons described above, appears to be the more reliable analysis method for Integrated Test D.

A second key point comes from Integrated Test D and shows the importance of accurately knowing the extent of $\mathrm{Cr}$ dissolution during caustic leaching. An incorrect determination of the $\mathrm{Cr}$ dissolution during caustic leaching can lead to detrimental results, such as dissolution of $\mathrm{Cr}$ from plant equipment and the potential introduction of soluble permanganate into any downstream operations.

\subsection{Summary and Conclusions}

A comparison was made between the $\mathrm{Cr}$ leach factors found for PEP Integrated Tests $\mathrm{A}, \mathrm{B}$, and $\mathrm{D}$ and laboratory-scale testing using the same simulant and permanganate-to-Cr ratios of approximately 1 or greater. The following observations were made:

- No significant operational issues (e.g., excess foaming) were reported during any of the oxidative-leach testing.

- The actual permanganate-to-chromium ratios used in Integrated Tests A and B were all close to the targeted ratio of 1 . In Integrated Test D, the method for determining the amount of solid phase $\mathrm{Cr}$ remaining after caustic leaching did not work well. An underestimation of the amount of $\mathrm{Cr}$ that would dissolve during caustic leaching led to permanganate-to-slurry-Cr initial ratios of $>10$ during Integrated Test D oxidative leaching. The source of the discrepancy between $\mathrm{Cr}$ 
dissolution during the preliminary caustic-leach experiment (Scheele et al. 2009) ${ }^{(a)}$ as opposed to the results in PEP is unknown.

- Two methods were used to calculate leach factors: one method was based on comparing the initial and final mass of $\mathrm{Cr}$ in the residual solids, and a second method compares the amount of $\mathrm{Cr}$ dissolved in the leachate with the total mass of $\mathrm{Cr}$ present in the initial solids.

- The kinetic behavior observed with respect to the $\mathrm{Cr}$ leach factors indicates that the rate of $\mathrm{Cr}$ oxidative dissolution is extremely fast for the Cr(III) form used in the simulant. For both the laboratory-scale and PEP tests, the fraction of dissolved $\mathrm{Cr}$ reached its final value within a few minutes of permanganate contact time

- A Cr mass balance for Integrated Test D indicated an excess of $47 \% \mathrm{Cr}$ in the solution at the end of the oxidative leaching step. It is proposed that the excess permanganate may have leached $\mathrm{Cr}$ from the PEP components.

- Consistent with a rapid, exothermic reaction, an initial increase in slurry temperature was observed upon permanganate addition to the more concentrated $\mathrm{Cr}$ slurries used in Integrated Tests A and B. The superior temperature control in the PEP allows for more rapid cooling (returning to the target temperature within 1 hour of leaching) than with the laboratory-scale testing (return to the initial temperature not observed after the conclusion [eight hours] of leaching). For Integrated Test D, no observable increase in temperature was observed. It is proposed that the much lower Cr-slurry concentration did not result in enough heat being generated to generate a noticeable increase in temperature.

- The cumulative fraction of $\mathrm{Cr}$ removed by leaching gives a leach factor of approximately $0.9+$ regardless of the test and regardless of test scale. This allows a key conclusion to be made - namely, that the scale up factor from laboratory-scale oxidative leaching to PEP-scale testing is 1 .

- Test conditions specified to allow direct application of PEP results to PTF performance (i.e., prototypic performance) were met, so the scale-up of laboratory-scale results to the PTF is 1.

(a) Scheele RD, GN Brown, and DE Kurath. 2009. Manufacture of PEP Simulants-Lessons Learned. WTP-RPT-204, Rev 0, PNNL-18678, Pacific Northwest National Laboratory, Richland, Washington. 



\subsection{UFP System Process Performance}

\subsection{Introduction}

Performing mass balances on PEP tests is an important part of evaluating the process performance. However, the number and type of analytical samples taken during testing, though sufficient for several other types of data analysis, did not permit a complete mass balance to be performed; that is, an attempt was not made to close the mass balance. This was by design, as the analysis and sampling specified in the Test Plan ${ }^{(a)}$ were only intended to calculate the fates of various constituents. In particular, solutes removed by filtration were determined by difference because the permeate solute concentrations were not measured. Despite this, it still remains that accounting for species of interest throughout the process is of value.

The mass balance was simplified to facilitate tracking process streams and species of interest in each of the Integrated tests. The Functional Test was not considered in this section. The species of interest were outlined in the Test Plan ${ }^{(a)}$. Performing inventory tracking on these species is one of the success criteria of PEP testing.

\subsection{Methodology}

The mass balance was performed for each Integrated test in two parts. In the first part, the overall mass of process streams was determined. The total inputs and outputs of each test was summed, with the difference being the accumulation. This will be referred to as the global mass balance. In the second part, individual species were inventoried. It used the global masses from the first part and concentration data from samples to track species through each integrated test and determine the fate of constitutents of interest. This will be referred to as a "fate of species" calculation.

\subsubsection{Global Mass Balance}

Though each test had some unique features, the global mass balance approach is essentially the same for all the tests. First, each test was divided into five sections. The delineations among these five sections are signficant points in the test timeline, located at either the beginning or end of a major process step. These points also represented events that were thoroughly sampled (as specified in the Test Plan ${ }^{(a)}$ ), and thus, there is confidence that the slurry at the chosen points in time is well-characterized. A diagram of the Integrated tests and their five sections is shown in Figure 12.1. The box highlighted red was included in the calculations for Integrated Tests $\mathrm{A}$ and $\mathrm{B}$, which had a step where $\mathrm{CrOOH}$ slurry was added, but was not needed for Integrated Test D, which did not have a CrOOH slurry addition.

(a) Josephson GB, OP Bredt, JK Young, and DE Kurath. 2009. Pretreatment Engineering Platform (PEP) Testing (Phase I). TP-RPP-WTP-506, Rev 0.4, Pacific Northwest National Laboratory, Richland Washington. 


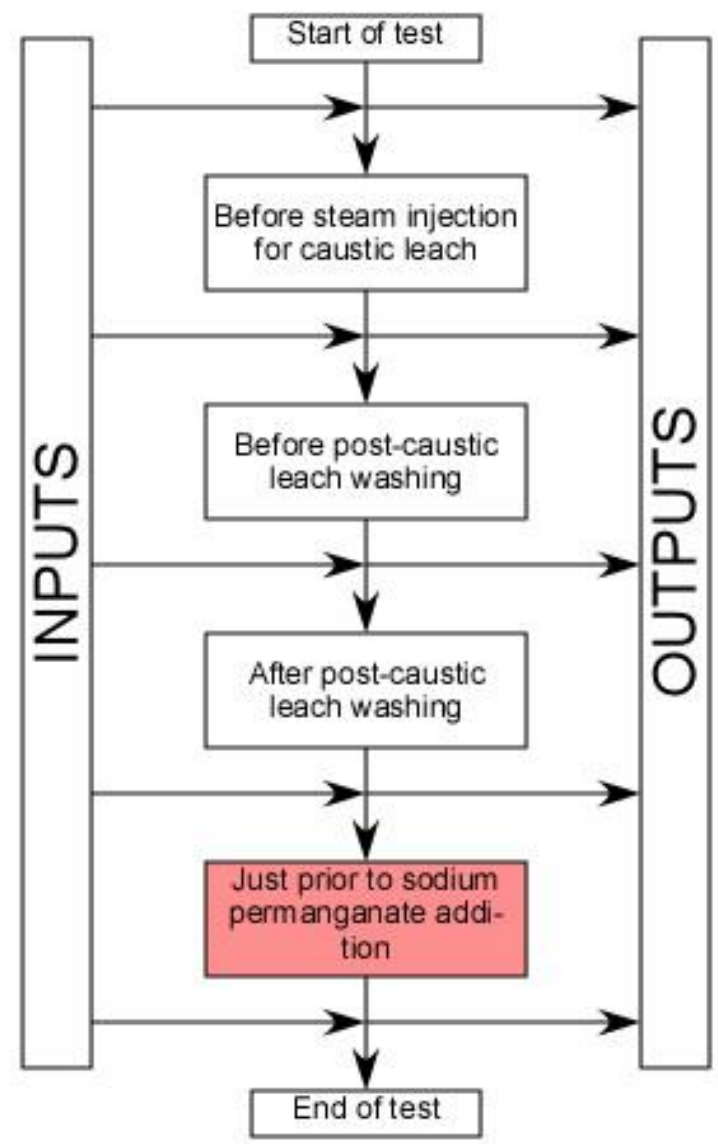

Figure 12.1. Schematic Used for Mass Balance in the Integrated Tests. The process step in the highlighted box was not necessary for Integrated Test D calculations.

Second, the mass balance envelope for each test was chosen to capture the essential information. The envelopes used in the mass balance are shown in Figure 12.2. Integrated Test A, in which caustic leaching was performed up-front in Tanks T01A/B, required a larger envelope than Integrated Tests B and $\mathrm{D}$, in which Tanks T01A/B are essentially slurry feed or holding tanks. Note that the mass balance envelopes exclude consideration of simulant before it reaches the leach vessels and does no accounting of the state of chemical feed tanks or waste vessels. Utility process streams were also not included, e.g., air flows or cooling water. 


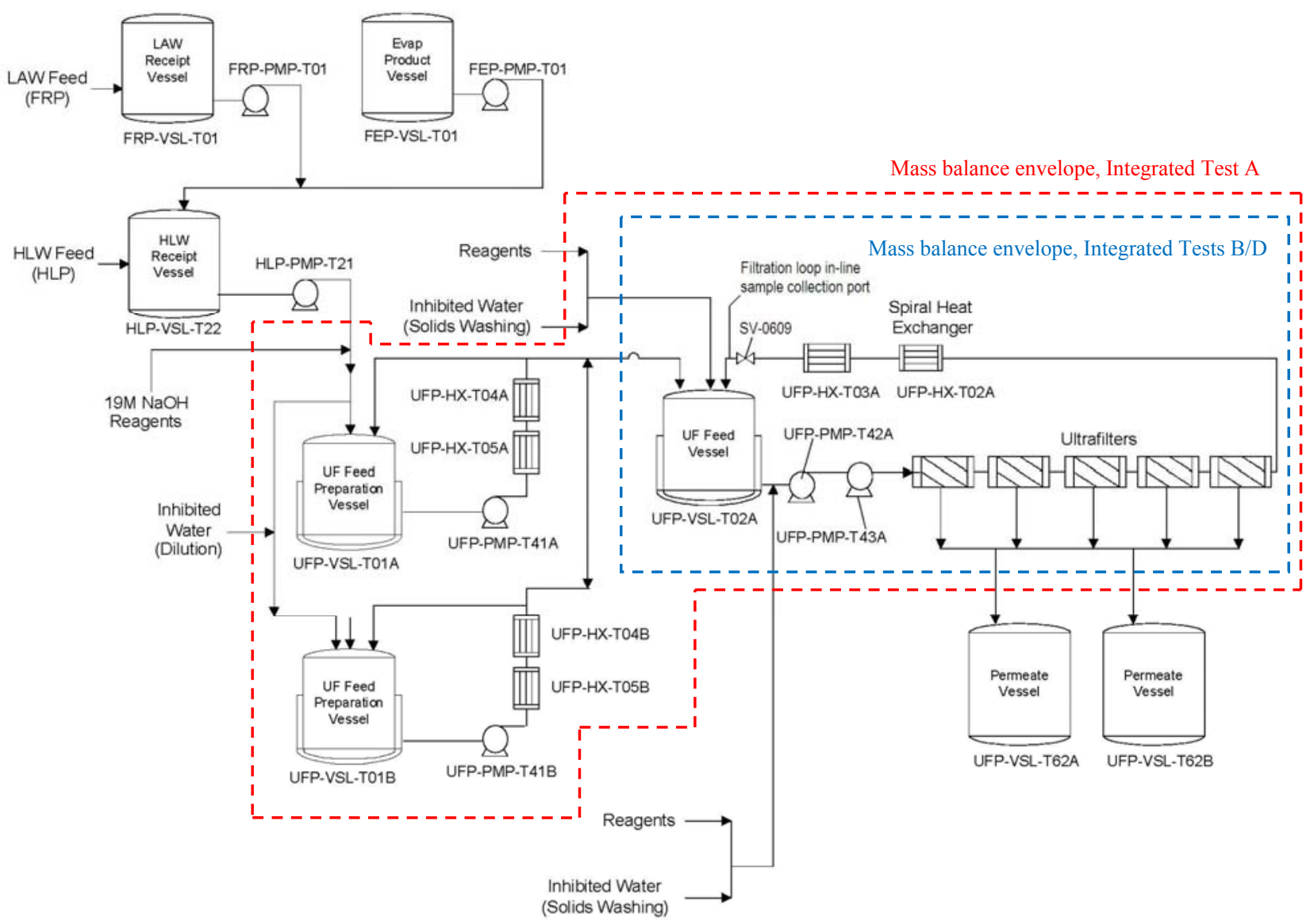

Figure 12.2. Mass Balance Envelope Used in the Calculations Presented in this Section. Note the envelope is not identical for all three tests.

The major process streams in each section of the test were totaled within the mass balance envelope. In most cases, process streams were totaled by integrating data collected from mass flowmeters over time using $1-\mathrm{Hz}$ data. A few of the process flows were measured by volumetric flowmeters, in which case a sample density was used to convert the volume delivered to a mass delivered. It was assumed that the density was representative of the fluid. In some instances, a second flowmeter supplied verification of the total (i.e., flowmeters in the caustic or inhibited water [IW] header); the integrated mass from the upstream flowmeter was always used in derivative calculations. Vessel levels, along with appropriate level-volume correlations and densities, could have been used to calculate masses for most process streams, but they suffer from two drawbacks; not all vessels (in particular feed chemical storage vessels) had NQA-1 calibrated level instruments, and stable level measurements were not always taken at the points of interest.

The process streams that were not totalized using integration of flowmeter data were the mass of steam added and the mass of water vented with air during caustic leaching and the slurry flush in Integrated Tests B and D. The mass of the steam and water vent streams was calculated according to Method 2 as described in Section 9.1.1 and Section 9.3. The slurry flush to waste that occurred in Integrated Tests B and D was calculated on a volume displacement basis. In both of the tests, IW was added in-line to the filter-loop to flush approximately 20 gallons (out of a total filter-loop volume of 82 gallons) of slurry to vessel Tank T02A. This left a volume of slurry in the loop, which was later flushed 
to a waste receipt vessel. It was assumed that the IW volume added (say $\mathrm{V}_{\mathrm{IW}}$ ) displaced an equivalent amount of slurry into Tank T02A, leaving behind a volume of waste slurry given by $\mathrm{V}_{\mathrm{ws}}=\mathrm{V}_{\mathrm{LOOP}}-\mathrm{V}_{\mathrm{IW}}$, where $\mathrm{V}_{\mathrm{LOOP}}$ is the volume of the filter-loop. This volume was converted to a mass using an analytical density measured in Tank T02A just before the flush, assuming the loop contents have the same density.

Separate but repeated process streams that entered or exited the mass balance envelope during each caustic-leach batch were totaled over all the batches. This includes the feed simulant, caustic, steam input, vent output, slurry flush to waste, and IW flushing inputs. All other process streams occur only once during any particular test. Process streams that were not included in the calculation include:

- mass removed during sample events

- mass added with antifoam agent (AFA) solutions

- mass added with the tracer solution

- mass of condensate drained from pulse jet mixer (PJM) tubes

- mass lost during off-normal events (leaks, etc.)

- mass remaining in transfer lines or other dead volumes

- mass lost via evaporation or volitalization (except during caustic-leach).

All of these masses are considered to be small in magnitude compared to the major process streams with the exception of the evaporation/volatilization losses, which may have been significant but were not measured.

The accumulation of mass in the system was calculated at the end of each of the five sections shown in Figure 12.1. Mass was considered to be accumulated when it remained within the mass balance envelope as drawn in Figure 12.2 at the conclusion of each section. The final accumulation is what was left in the system at the end of the test.

\subsubsection{Fate of Species}

The fate of species calculation builds on the framework described in Section 12.2.1. Nine species were included in the species mass balance as specified by the Test Plan. ${ }^{(a)}$ The nine species were aluminum, sodium, chromium, manganese, oxalate, sulfate, phosphate, free hydroxide, and water. The fate of AFA, which is the other constituent identified in the Test Plan ${ }^{(a)}$, will be discussed separately in Section 12.6.

For these nine species, the masses of input streams that contained one or more species were used in conjunction with concentration data to determine mass inputs to the system. A running total of the mass in the important process vessels (Tanks T01A/B and Tank T02A for Integrated Test A, Tank T02A only for Integrated Tests B and D) was kept using the results of the global mass balance calculations. By stepping through the process, points where the inventory of a species was expected to change, including significant changes in phase, were identified. Concentrations at these points were used to determine the

(a) GB Josephson, OP Bredt, JK Young, and DE Kurath. 2009. Pretreatment Engineering Platform (PEP) Testing (Phase I). TP-RPP-WTP-506, Rev 0.4, Pacific Northwest National Laboratory, Richland Washington. 
current inventory. Generally speaking, outputs (which are overwhelmingly permeate streams that were not sampled during testing) were then determined by difference.

The mass balance was not "closed" around process steps. For the first half of the test (up to the start of the post-caustic-leach wash), slurry and liquid phase concentration data were readily available. For this portion of the calculation, the inventory in the liquid and slurry phase was simply updated with the new concentration data. The solid phase was calculated by difference. It was compared to the expected inventory (based on the inputs and outputs to the system) to check for significant irregularities, but unless there was a large disagreement in inventory (approximately $25 \%$ across a process step), the calculation proceeded with the updated value.

For the second half of the test, the majority of concentration data used was in the liquid phase only. Some assumptions were made about the phase behavior of the species, and the rest of the inventory was calculated using these assumptions. For instance, sulfate was assumed to be fully soluble by the start of post-caustic-leach washing (as confirmed by analysis of the wash), and thus, the difference in amounts between the beginning and end of the wash was considered to be removed in the permeate. The accumulation term in the fate of species calculations is what is calculated to be left in Tank T02A and the filter-loop at the conclusion of the test.

The results of the fate of species calculations are presented in a table that is split into three sections. The first section contains all the input streams and is concluded by a total of all the inputs. The second section contains all of the output streams and is concluded by a total of all the outputs. The third section shows what was left in the final slurry and the amount of each species for which the fate is unknown. The unknown fate is calculated as "TOTAL IN-TOTAL OUT - Accumulated in final slurry." It should be considered to be an estimate of the error in the inventory calculations for a particular species.

Besides the assumptions used, the fate of species calculations has an uncertainty because of the uncertainty in the analytical and process measurements. The uncertainties are acknowledged to affect the accuracy of the calculations, but the full impact of the uncertainties on the mass balance was not analyzed. The accuracy of these calculations is also tethered to the accuracy of the global mass balance. Constituent masses are derived based on the total mass at an instant in time; temporal fluctuations in the total mass are also reflected in the individual constituent masses and affect the magnitude of the uncertainty in the inventory calculations.

More specific information about the calculations is discussed in the next three sections.

\subsection{Mass Balance of Integrated Test A}

The results of the global mass balance calculations for Integrated Test A are presented in Table 12.1. Recall that Integrated Test A had six caustic-leach batches in total performed in Tanks T01A/B. Combining simulant and caustic produced $13,603-\mathrm{kg}$ in aggregate, to which $3097-\mathrm{kg}$ of steam and $264-\mathrm{kg}$ of liquid water were added. During the caustic-leach, it is estimated that 1244-kg of water was lost to the vent system. The batches, as they were completed, were sent to Tank T02A to be concentrated. The entirety of Batches \#5 (Tank T01A) and \#6 (Tank T01B) were not sent to Tank T02A to be concentrated, leaving heels in each of those vessels (1851-kg in total). The 1851-kg of unused slurry was eventually sent to a waste receipt vessel. For convenience, it was assumed that this was completed sometime between the end of the caustic-leach and the start of the post-caustic-leach wash. 
Table 12.1. Global Mass Balance for Integrated Test A

\begin{tabular}{|c|c|c|c|c|c|}
\hline \multirow[b]{2}{*}{ Process Steps } & \multicolumn{2}{|c|}{ Input } & \multicolumn{2}{|c|}{ Output } & \multirow{2}{*}{\begin{tabular}{|l} 
Accumulated \\
Amount $^{(\mathrm{a})}(\mathrm{kg}$
\end{tabular}} \\
\hline & Stream & $\begin{array}{l}\text { Amount }^{(\mathrm{a})} \\
(\mathrm{kg})\end{array}$ & Stream & $\begin{array}{l}\text { Amount }^{(\mathrm{a})} \\
(\mathrm{kg})\end{array}$ & \\
\hline \multirow{2}{*}{$\begin{array}{l}\text { Start of test } \\
\text { to just before } \\
\text { caustic-leach } \\
\text { steam } \\
\text { injection }\end{array}$} & $\begin{array}{c}\text { Simulant (6 leach } \\
\text { batches total) }\end{array}$ & 9832 & - & - & 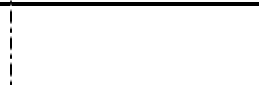 \\
\hline & $\begin{array}{c}\text { Caustic (6 leach } \\
\text { batches total) }\end{array}$ & 3772 & - & - & 13603 \\
\hline \multirow{3}{*}{$\begin{array}{l}\text { Caustic-leach } \\
\text { steam } \\
\text { injection to } \\
\text { just before } \\
\text { the } \\
\text { post-caustic- } \\
\text { leach wash }\end{array}$} & $\begin{array}{c}\text { Steam (6 leach } \\
\text { batches total) }\end{array}$ & 3097 & $\begin{array}{c}\text { Slurry left as } \\
\text { heels in leach } \\
\text { vessels }\end{array}$ & 1851 & = \\
\hline & $\begin{array}{c}\text { Liquid water (6 } \\
\text { leach batches } \\
\text { total) }\end{array}$ & 264 & $\begin{array}{l}\text { Permeate, } \\
\text { leachate }^{(c)}\end{array}$ & 12319 & 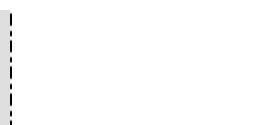 \\
\hline & - & - & $\begin{array}{l}\text { Vent (6 leach } \\
\text { batches total) }\end{array}$ & 1244 & 1550 \\
\hline \multirow{2}{*}{$\begin{array}{l}\text { Post-caustic- } \\
\text { leach wash }\end{array}$} & $\begin{array}{c}\text { Wash-water, } \\
\text { wash }\end{array}$ & 4251 & $\begin{array}{c}\text { Permeate, post- } \\
\text { caustic-leach } \\
\text { wash }^{(\mathrm{d})}\end{array}$ & 4789 & : \\
\hline & $\begin{array}{l}\text { Inhibited water, } \\
\text { off-normal }^{\text {(b) }}\end{array}$ & 114 & - & - & 1127. \\
\hline \multirow{2}{*}{$\begin{array}{l}\text { After post- } \\
\text { caustic-leach } \\
\text { wash to just } \\
\text { before } \\
\text { oxidative } \\
\text { leach }\end{array}$} & CrOOH slurry & 652 & $\begin{array}{c}\text { Permeate, post- } \\
\text { wash }\end{array}$ & 2031 & . \\
\hline & $\begin{array}{l}\text { Wash-water, } \\
\text { post-CrOOH } \\
\text { slurry wash }\end{array}$ & 1593 & - & - & 1341 \\
\hline \multirow{2}{*}{$\begin{array}{l}\text { Oxidative- } \\
\text { leach to end } \\
\text { of test }\end{array}$} & permanganate & 156 & $\begin{array}{c}\text { Permeate, post- } \\
\text { oxidative-leach } \\
\text { wash }\end{array}$ & 3792 & $;$ \\
\hline & $\begin{array}{c}\text { Wash-water, } \\
\text { post-oxidative- } \\
\text { leach wash }\end{array}$ & 3657 & $\begin{array}{l}\text { Permeate, final } \\
\text { concentration }\end{array}$ & 97 & 1265 \\
\hline $\begin{array}{l}\text { ENTIRE } \\
\text { TEST }\end{array}$ & TOTAL IN: & 27387 & TOTAL OUT: & 26122 & 1265 \\
\hline
\end{tabular}

(a) The numbers presented in this table are rounded to the nearest whole number. Note that performing mathematical operations using these numbers may result in slightly different results.

(b) Amount of water added to compensate for an observed level that was too low before the start of washing.

(c) Assumes that only the shell of filter \#1 was filled during post-caustic-leach concentration.

(d) Assumes that the other four filter shells were filled during the post-caustic-leach wash.

The post-caustic-leach concentration in Tank T02A removed 12,319-kg of permeate through the first filter, UFP-FILT-T01A. This value assumes that 1) only the shell of the first filter was filled during the concentration, and 2) the amount of mass in the shell, which is not measured by the permeate flowmeter, can be estimated using a volume calculation in conjunction with the density of the supernate at the end of the concentration step. There was $1550-\mathrm{kg}$ of leached and concentrated slurry present at the start of the post-caustic-leach wash.

Before the wash began, the stable level in Tank T02A was below the run sheet target. To increase the level to the correct value, 114-kg of IW was added. During the wash, 4251-kg of IW was added in batches of 11 gallons (nominal) and 4789-kg of permeate was removed. The mass of permeate removed 
assumes that the four filters that were not used during the concentration step were filled with permeate during this step. The mass in the shells was calculated in the same way as in the post-caustic-leach concentration. This left $1127-\mathrm{kg}$ of washed slurry in Tank T02A and the filter-loop before the $652-\mathrm{kg}$ of CrOOH slurry was added.

The washed/CrOOH slurry was washed again to return the level in Tank T02A to the run sheet target. This required adding 1593-kg of IW while removing 2031-kg of permeate. Before the oxidative-leach began, there was $1341-\mathrm{kg}$ of slurry.

The oxidative-leach was conducted by adding $156-\mathrm{kg}$ of sodium permanganate. After the leach, the slurry was washed again with $3657-\mathrm{kg}$ of IW added and 3792-kg of permeate removed. A final concentration of the slurry removed an additional $97-\mathrm{kg}$ of permeate.

In total, 27,387-kg of material was input, and 26,122-kg of material was output, leaving $1265-\mathrm{kg}$ of slurry at the end of the test. An independent estimation of the final mass at the end of Integrated Test A was conducted by using the final level in vessel Tank T02A. It was determined to be $1070-\mathrm{kg}$. The final accumulated mass determined by the global mass balance is greater by $195-\mathrm{kg}(18 \%)$; this difference is less than $1 \%$ of the total material input. Considering the assumptions used to calculate the global mass balance for Integrated Test A, a difference of $18 \%$ between the two final masses is a very reasonable agreement.

The fate of species inventory for Integrated Test A is shown in Table 12.2. If it was assumed that a species was not present in a process stream, it is listed as N/A. Some of the species were present in trace amounts in the $\mathrm{CrOOH}$ slurry. If this was the case, the word "negligible" is used.

The species calculations of Integrated Test A are complicated by the presence of heels during the first four caustic-leach batches. When a leach batch was complete, most of the leached slurry was transferred to Tank T02A for the ongoing solids concentration. Some material was left in the leach vessels (Tanks T01A/B) and mixed in with the simulant and caustic when the next batch began. For the inventory calculations, the amount of material in the heel was not precisely determined and thus may be a source of error. The last two batches (\#5 and 6) had heels that were "wasted." These were more precisely calculated and are shown separately in Table 12.2.

It should also be mentioned that in Integrated Test A, unlike Integrated Tests B and D, a large portion of the liquid phase concentration data obtained during caustic leaching was analyzed by Raman. However, not all the liquid phase data were analyzed by Raman, and thus a mixture of analytical data were used.

The aluminum in Integrated Test A entered the process only in the feed simulant (approximately 197-kg in total). By the time the $\mathrm{CrOOH}$ slurry was added, all the soluble aluminum had been removed as permeate. The final slurry contained $53.5-\mathrm{kg}$ Al that was essentially all in the solid phase. This is consistent with expectations. 
Table 12.2. Fate of Species During Integrated Test $A$

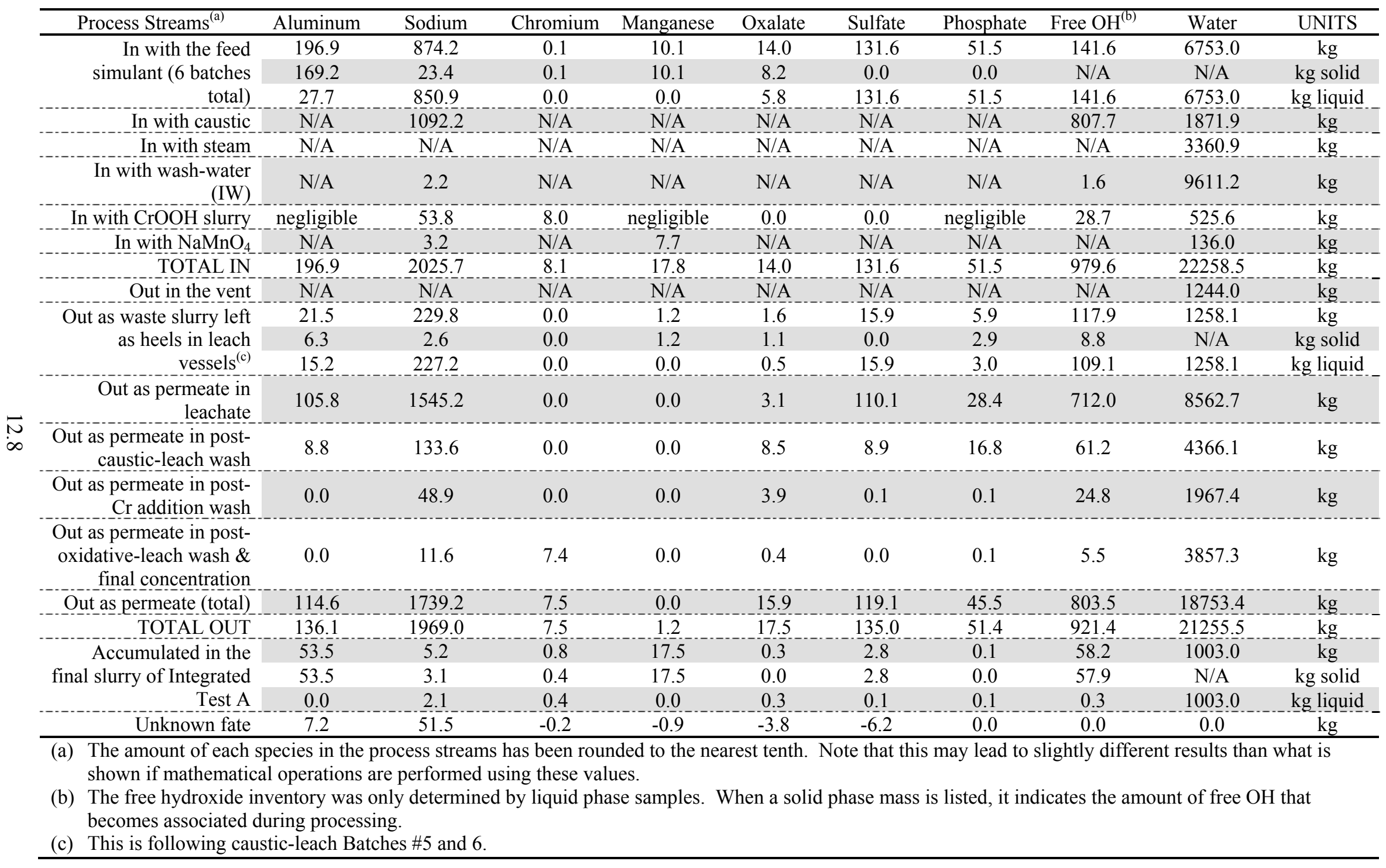


Other metal species were also distributed as expected. Sodium enters and exits the process in large amounts, leaving approximately $5-\mathrm{kg}$ in the final slurry. Chromium does not enter the process in an appreciable amount until the $\mathrm{CrOOH}$ slurry is added. Of the $8.0-\mathrm{kg}$ added, $7.5-\mathrm{kg}$ was removed after the oxidative-leach in the permeate. This left less than 1-kg in the final slurry. Manganese is never removed from the Integrated Test A slurry. The amount added in the sodium permanganate combines with the amount in the feed simulant to leave around $17.5-\mathrm{kg}$ of solid $\mathrm{Mn}$ in the final slurry. None of the inventory calculations for the metal species were subject to large discrepancies.

The anion calculations in Integrated Test A had a larger relative error than the metal species; that is, the amount for which the fate is unknown is a greater percentage of the total amount input to the system. This is primarily due to a larger number of assumptions being required since concentration information was only available in the liquid phase. Sulfate (131.6-kg in feed) and phosphate (51.5-kg in feed) were entirely removed from the final slurry. The solid sulfate in Integrated Test A final slurry is probably an artifact of the uncertainty in the liquid phase concentrations and should not be considered to be real. The free hydroxide was also nearly gone from the final slurry. Note that the "solid" OH is really hydroxide that becomes consumed or associated during the caustic-leach. This amount is calculated by difference since it was not measured directly.

The inventory calculation for oxalate was subject to the most problems. This is reflected in the largest relative error of any species (a 3.8- $\mathrm{kg}$ discrepancy out of 14.0-kg input). The slurry phase concentration was only sampled at three points in the process and analyzed for total organic carbon (TOC) in the feed simulant before the post-caustic-leach wash and also after the post-caustic-leach wash. It was assumed that oxalate was the only species measured in the TOC analysis. However, inventory calculations around the post-caustic-leach wash using the slurry phase concentrations indicated a decrease in oxalate mass that could not be reconciled with the liquid phase concentration data. The approach settled on in the calculation was to use the initial slurry and liquid phase concentration at the start of the wash, assume all the oxalate goes into solution during the wash, and use the final liquid phase concentration to estimate the amount of permeate removed. The amount of solid oxalate is assumed to be negligible at this point.

A second point of reference is available by using the maximum liquid phase concentration during the wash. At this point, all the oxalate should be in solution. For Integrated Test A, this gives a mass of $15.6-\mathrm{kg}$ of oxalate. The mass was calculated to be $13.1-\mathrm{kg}$ at the beginning of the wash, using the liquid and slurry phase samples. This discrepancy is fairly large and could not be resolved. The oxalate species inventory given in Table 12.2 should be considered within this context.

The final slurry, which was calculated by global mass balance to be approximately $1265-\mathrm{kg}$, was estimated to contain 1003-kg of water at the conclusion of Integrated Test A. The final supernate was essentially $100 \%$ water; the rest of the slurry $(20.3-w t \%)$ was UDS. The water inventory calculation closes perfectly since all the calculations have one unknown, which was determined by difference. Total dissolved solids data were used to check the amount of water at various points; no large discrepancies were observed.

Unknown fates that are small in magnitude, relatively speaking, should not be understood to indicate that a species mass balance was rigorously closed. Rather, it indicates that the global mass balance 
calculations, concentration data, and assumptions used qualitatively agree on the fate of the species in the system.

It is worth pointing out that the unknown fates calculated for some species in Integrated Test A are larger in magnitude than in Integrated Tests B and D. Primarily, this is due to the interference of the heels in inventory calculations. It may also be due to a dependence on Raman data. However, none of the discrepancies, with the exception of oxalate, represent even $10 \%$ of the total amount that entered the process.

\subsection{Integrated Test B}

The results of the global mass balance calculations for Integrated Test B are presented in Table 12.3. Integrated Test B had two caustic-leach batches in total performed in Tank T02A. The feed simulant (7134-kg) was concentrated before the caustic was added by removing 5238-kg of permeate. This value assumes that the shells of the five filters were filled only once (during Batch \#1 concentration, but not Batch \#2). A total of 1441-kg of caustic was added to the concentrated slurry. Before steam was added, $157-\mathrm{kg}$ of IW was used to flush some slurry from the filter-loop into Tank T02A. The remaining 655-kg of slurry was flushed to a waste tank along with $929-\mathrm{kg}$ of IW.

The two batches (2682-kg of simulant and caustic) required $1255-\mathrm{kg}$ of steam to heat to $98^{\circ} \mathrm{C}$ and in the process, $717-\mathrm{kg}$ of water was vented. Following the leach, 2026-kg of permeate was removed from the leachate leaving $1195-\mathrm{kg}$ in the slurry. Note that the mass of leachate permeate, which was derived from totalizing flowmeter data, includes data that were below the given tolerance of one or more of the flowmeters. The leached, concentrated slurry was washed with 2204-kg of IW, and 2486-kg of permeate was removed.

The CrOOH slurry (371-kg) was added to $913-\mathrm{kg}$ of washed slurry and then washed with $900-\mathrm{kg}$ of IW. This left $914-\mathrm{kg}$ of slurry after $1270-\mathrm{kg}$ of permeate was removed. The oxidative-leach was then conducted using $87-\mathrm{kg}$ of sodium permanganate. At the conclusion of the oxidative-leach, the slurry was washed with $1998-\mathrm{kg}$ of IW while $2124-\mathrm{kg}$ of permeate was removed. Note that the final concentration step was not performed in Integrated Test B.

For the entire test, 15,390-kg of material was added and 14,515-kg removed, leaving a final slurry mass of $875-\mathrm{kg}$ in the system. An independent estimation of the final mass at the end of Integrated Test B was conducted by using the final level in Tank T02A. It was determined to be $738-\mathrm{kg}$. The final accumulated mass determined by the global mass balance was greater by $137-\mathrm{kg}(19 \%)$; this difference is less than $1 \%$ of the total material input. Considering the assumptions used to calculate the global mass balance for Integrated Test B, a difference of $19 \%$ between the two final masses is a very reasonable agreement. 
Table 12.3. Global Mass Balance for Integrated Test B

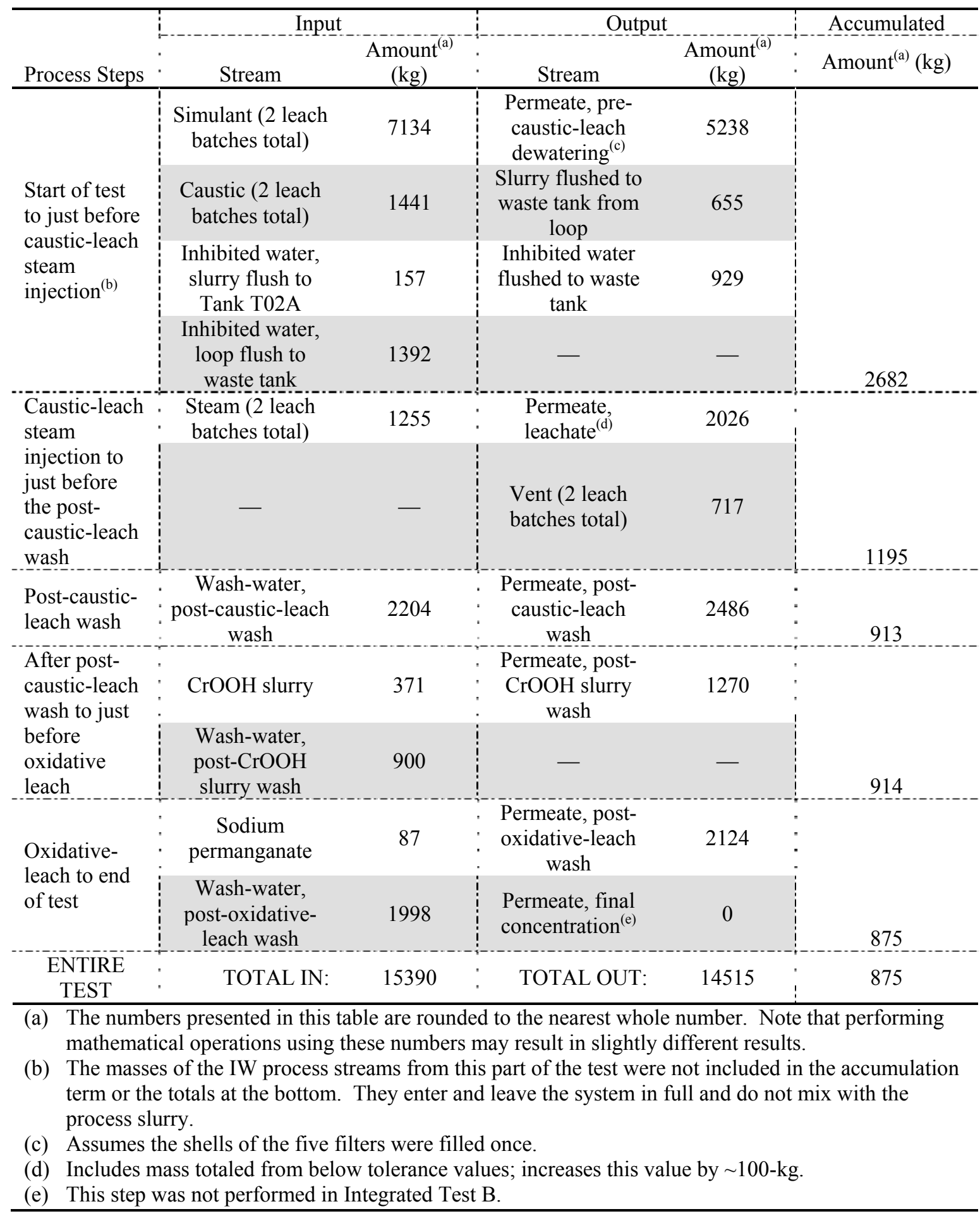

The fate of species inventories for Integrated Test B is shown in Table 12.4. If it was assumed that a species was not present in a process stream, it is listed as N/A. Some of the species were present in trace amounts in the $\mathrm{CrOOH}$ slurry. If this was the case, the word "negligible" is used. As was mentioned in 
Section 12.3, Integrated Test B analysis did not depend on any Raman data. Instead, only data from traditional analytical techniques were used.

The aluminum in Integrated Test B entered the process only in the feed simulant (approximately 134-kg in total). By the time the $\mathrm{CrOOH}$ slurry was added, all the soluble aluminum had been removed as permeate. The final slurry contained $39-\mathrm{kg}$ of solid Al. This is consistent with expectations. A smaller fraction of aluminum was removed during Integrated Test B than in Integrated Test A (for more information, see Table 12.12).

Other metal species were also distributed as expected. Sodium enters and exits the process in large amounts, with approximately $12-\mathrm{kg}$ winding up in the final slurry. Chromium does not enter the process in an appreciable amount until the $\mathrm{CrOOH}$ slurry is added; of the 4.5-kg added, 4.4-kg was removed after the oxidative-leach in the permeate. This left only a small amount in the final slurry. Manganese was never removed from the Integrated Test B slurry. The amount added in the sodium permanganate combines with the amount in the feed simulant to leave around 12-kg of solid $\mathrm{Mn}$ in the final slurry. None of the inventory calculations for the metal species were subject to large discrepancies.

The results of the anion calculations in Integrated Test B were similar to that of Integrated Test A. Sulfate (94.5-kg in the feed) and phosphate (33.1-kg in the feed) were entirely removed from the final slurry. The free hydroxide was also nearly gone from the final slurry. Note that the "solid" $\mathrm{OH}$ is really hydroxide that becomes consumed or associated during the caustic-leach. This amount was calculated by difference since it was not measured directly. Anecdotally, more $\mathrm{kg}$ of $\mathrm{OH}$ were consumed per $\mathrm{kg}$ of $\mathrm{Al}$ removed during Integrated Test B than Integrated Test A.

As before, the inventory of oxalate was subject to the most problems. This is reflected in the largest relative error of any species (a 2.2-kg discrepancy out of 11.3-kg input). In Integrated Test B, inventory calculations around the post-caustic-leach wash using the slurry phase concentrations indicated a decrease in oxalate mass that could not be reconciled with the liquid phase concentration data.

A second point of reference is available by using the maximum liquid phase concentration during the wash. At this point, all the oxalate should be in solution. For Integrated Test B, this gives a mass of 8.6-kg of oxalate. At the beginning of the wash, using the liquid and slurry phase samples, the mass was calculated to be $8.4-\mathrm{kg}$. The agreement between the two values was good, and thus, there is a higher amount of confidence in the oxalate calculation in Integrated Test B than in Integrated Test A; however, it is still advisable to treat oxalate results in Table 12.4 with caution.

The final slurry, which was calculated by global mass balance to be approximately $875-\mathrm{kg}$, was estimated to contain $697-\mathrm{kg}$ of water at the conclusion of Integrated Test B. The final supernate was essentially $100 \%$ water with the balance of the final slurry being UDS (20.2-wt\%). The water inventory calculation closes perfectly since all the calculations have one unknown, which was determined by difference. Total dissolved solids data were used to check the amount of water at various points; no large discrepancies were observed. 
Table 12.4. Fate of Species During Integrated Test $B$

\begin{tabular}{|c|c|c|c|c|c|c|c|c|c|c|}
\hline Process Streams $^{(\mathrm{a})}$ & Aluminum & Sodium & Chromium & Manganese & Oxalate & Sulfate & Phosphate & Free $\mathrm{OH}^{(\mathrm{b})}$ & Water & UNITS \\
\hline \multirow{3}{*}{$\begin{array}{r}\text { In with the feed simulant ( } 2 \\
\text { batches total) }\end{array}$} & 134.1 & 643.3 & 0.1 & 7.5 & 11.3 & 94.5 & 33.1 & 85.4 & 5236.3 & $\mathrm{~kg}$ \\
\hline & 112.7 & 12.8 & 0.0 & 7.5 & 6.9 & 0.0 & 0.0 & $\mathrm{~N} / \mathrm{A}$ & N/A & $\mathrm{kg}$ solid \\
\hline & 21.4 & 630.5 & 0.0 & 0.0 & 4.3 & 94.5 & 33.1 & 85.4 & 5236.3 & $\mathrm{~kg}$ liquid \\
\hline In with caustic & $\mathrm{N} / \mathrm{A}$ & 408.8 & $\mathrm{~N} / \mathrm{A}$ & $\mathrm{N} / \mathrm{A}$ & $\mathrm{N} / \mathrm{A}$ & $\mathrm{N} / \mathrm{A}$ & $\mathrm{N} / \mathrm{A}$ & 302.3 & 854.6 & $\mathrm{~kg}$ \\
\hline In with steam & $\mathrm{N} / \mathrm{A}$ & $\mathrm{N} / \mathrm{A}$ & $\mathrm{N} / \mathrm{A}$ & $\mathrm{N} / \mathrm{A}$ & $\mathrm{N} / \mathrm{A}$ & N/A & $\mathrm{N} / \mathrm{A}$ & N/A & 1255.2 & $\mathrm{~kg}$ \\
\hline In with wash-water (IW) & $\mathrm{N} / \mathrm{A}$ & 1.2 & $\mathrm{~N} / \mathrm{A}$ & N/A & $\mathrm{N} / \mathrm{A}$ & $\mathrm{N} / \mathrm{A}$ & $\mathrm{N} / \mathrm{A}$ & 0.9 & 5100.0 & $\mathrm{~kg}$ \\
\hline In with CrOOH slurry & negligible & 31.0 & 4.4 & negligible & 0.0 & 0.0 & 0.0 & 16.8 & 299.4 & $\mathrm{~kg}$ \\
\hline In with $\mathrm{NaMnO}_{4}$ & $\mathrm{~N} / \mathrm{A}$ & 1.8 & N/A & 4.3 & $\mathrm{~N} / \mathrm{A}$ & N/A & N/A & $\mathrm{N} / \mathrm{A}$ & 75.8 & $\mathrm{~kg}$ \\
\hline TOTAL IN & 134.1 & 1086.1 & 4.5 & 11.9 & 11.3 & 94.5 & 33.1 & 405.4 & 12821.3 & $\mathrm{~kg}$ \\
\hline $\begin{array}{l}\text { Out as permeate in pre- } \\
\text { caustic solids concentration }\end{array}$ & 16.2 & 496.5 & 0.0 & 0.0 & 3.3 & 73.9 & 25.8 & 63.5 & 4138.8 & $\mathrm{~kg}$ \\
\hline Out in the vent & $\mathrm{N} / \mathrm{A}$ & $\mathrm{N} / \mathrm{A}$ & $\mathrm{N} / \mathrm{A}$ & $\mathrm{N} / \mathrm{A}$ & $\mathrm{N} / \mathrm{A}$ & $\mathrm{N} / \mathrm{A}$ & $\mathrm{N} / \mathrm{A}$ & $\mathrm{N} / \mathrm{A}$ & 716.9 & $\mathrm{~kg}$ \\
\hline \multirow{3}{*}{$\begin{array}{r}\text { Out as waste slurry from } \\
\text { loop flushes }\end{array}$} & 21.4 & 102.9 & 0.0 & 1.5 & 1.6 & 4.0 & 1.4 & 63.6 & 383.4 & $\mathrm{~kg}$ \\
\hline & 12.3 & 4.6 & 0.0 & 1.5 & 1.5 & 2.2 & 0.1 & 8.3 & $\mathrm{~N} / \mathrm{A}$ & $\mathrm{kg}$ solid \\
\hline & 9.1 & 98.2 & 0.0 & 0.0 & 0.0 & 1.8 & 1.3 & 55.3 & 383.4 & $\mathrm{~kg}$ liquid \\
\hline Out as permeate in leachate & 38.9 & 300.9 & 0.0 & 0.0 & 0.1 & 12.3 & 2.8 & 139.0 & 1471.5 & $\mathrm{~kg}$ \\
\hline $\begin{array}{l}\text { Out as permeate in post- } \\
\text { caustic-leach wash }\end{array}$ & 17.1 & 126.7 & 0.0 & 0.0 & 1.3 & 6.0 & 2.9 & 69.3 & 2129.8 & $\mathrm{~kg}$ \\
\hline $\begin{array}{r}\text { Out as permeate in post-Cr } \\
\text { addition wash }\end{array}$ & 0.1 & 28.7 & 0.0 & 0.0 & 6.0 & 0.0 & 0.0 & 14.6 & 1165.3 & $\mathrm{~kg}$ \\
\hline $\begin{array}{l}\text { Out as permeate in post- } \\
\text { oxidative-leach wash }\end{array}$ & 0.1 & 9.9 & 4.4 & 0.0 & 1.1 & 0.0 & 0.0 & 3.8 & 2118.6 & $\mathrm{~kg}$ \\
\hline Out as permeate (total) & 72.4 & 962.7 & 4.4 & 0.0 & 11.8 & 92.2 & 31.6 & 290.3 & 11024.0 & $\mathrm{~kg}$ \\
\hline TOTAL OUT & 93.8 & 1065.6 & 4.4 & 1.5 & 13.4 & 96.2 & 33.0 & 353.9 & 12124.2 & $\mathrm{~kg}$ \\
\hline \multirow{3}{*}{$\begin{array}{l}\text { Accumulated in the final } \\
\text { slurry of Integrated Test B }\end{array}$} & 39.1 & 11.8 & 0.2 & 11.8 & 0.1 & 0.0 & 0.0 & 51.5 & 697.0 & $\mathrm{~kg}$ \\
\hline & 39.1 & 11.1 & 0.0 & 11.8 & 0.0 & 0.0 & 0.0 & 51.3 & N/A & $\mathrm{kg}$ solid \\
\hline & 0.0 & 0.7 & 0.2 & 0.0 & 0.1 & 0.0 & 0.0 & 0.2 & 697.0 & $\mathrm{~kg}$ liquid \\
\hline Unknown fate & 1.2 & 8.7 & -0.1 & -1.5 & -2.2 & -1.8 & 0.0 & 0.0 & 0.0 & $\mathrm{~kg}$ \\
\hline \multicolumn{11}{|c|}{$\begin{array}{l}\text { (a) The amount of each species in the process streams has been rounded to the nearest tenth. Note this may lead to slightly different results than what is } \\
\text { shown if mathematical operations are performed using these values. } \\
\text { (b) The free hydroxide inventory was only determined by liquid phase samples. When a solid phase mass is listed, it indicates the amount of free OH that } \\
\text { becomes associated during processing. }\end{array}$} \\
\hline
\end{tabular}


The unknown fates for Integrated Test B, in particular for species expected to reside mostly in the liquid phase (sulfate, phosphate, free $\mathrm{OH}$, water) were very small. This should not be taken to mean that the mass balance was closed. Since there were no complications, such as caustic-leach heels and mixed analytical data sets, the calculations supporting Table 12.4 close near-perfectly by definition because of the absence of slurry phase sample data.

\subsection{Integrated Test D}

The results of the global mass balance for Integrated Test D are presented in Table 12.5. Integrated Test $\mathrm{D}$ also had two caustic-leach batches performed in Tank T02A, where 7003-kg of simulant was concentrated by removing 5202-kg of permeate. The amount of permeate assumes that the shells of the five filters were filled only once, and they were not drained between batches. A total of $1867-\mathrm{kg}$ of caustic was added to the concentrated slurry.

In Batch \#1, there was concern about the level in Tank T02A being too high, and so $137-\mathrm{kg}$ of slurry was removed from the vessel and placed into totes. Before steam was added to the first batch, 78-kg of IW was used to flush some slurry from the filter-loop into Tank T02A. This was not done for Batch \#2. The contents of the filter-loop (777-kg of slurry) were flushed to a waste receipt vessel along with $1193-\mathrm{kg}$ of IW.

Tank T02A was heated to $85^{\circ} \mathrm{C}$ using $1187-\mathrm{kg}$ of steam. During the caustic-leach, 662-kg of water was vented. After the caustic-leach, $2107-\mathrm{kg}$ of permeate was removed to concentrate the slurry for washing.

The post-caustic-leach wash removed $2563-\mathrm{kg}$ of permeate from the slurry as it was washed with 2308-kg of IW. Since chromium was already present in the Integrated Test D feed, CrOOH slurry was not added. Instead, Integrated Test D proceeded straight to the oxidative-leach, which required 40-kg of sodium permanganate. The leached slurry was washed with 1931-kg of IW, and 1982-kg of permeate was removed. A final concentration step removed an additional 107-kg of permeate.

Integrated Test D had 14,336-kg of material enter the process and 13,536-kg removed from it. The final accumulation in Tank T02A was $801-\mathrm{kg}$. An independent estimation of the final mass at the end of Integrated Test D was conducted by using the final level in Tank T02A. It was determined to be $640-\mathrm{kg}$. The final accumulated mass determined by the global mass balance is greater by $160-\mathrm{kg}(25 \%)$; this difference is approximately $1 \%$ of the total material input. Considering the assumptions used to calculate the global mass balance for Integrated Test D, a difference of $25 \%$ between the two final masses is very reasonable agreement.

The fate of species inventory for Integrated Test D is shown in Table 12.6. If it was assumed that a species was not present in a process stream, it is listed as N/A. As was the case for Integrated Test B, Integrated Test $\mathrm{D}$ analysis did not depend on any Raman data. 
Table 12.5. Global Mass Balance for Integrated Test D

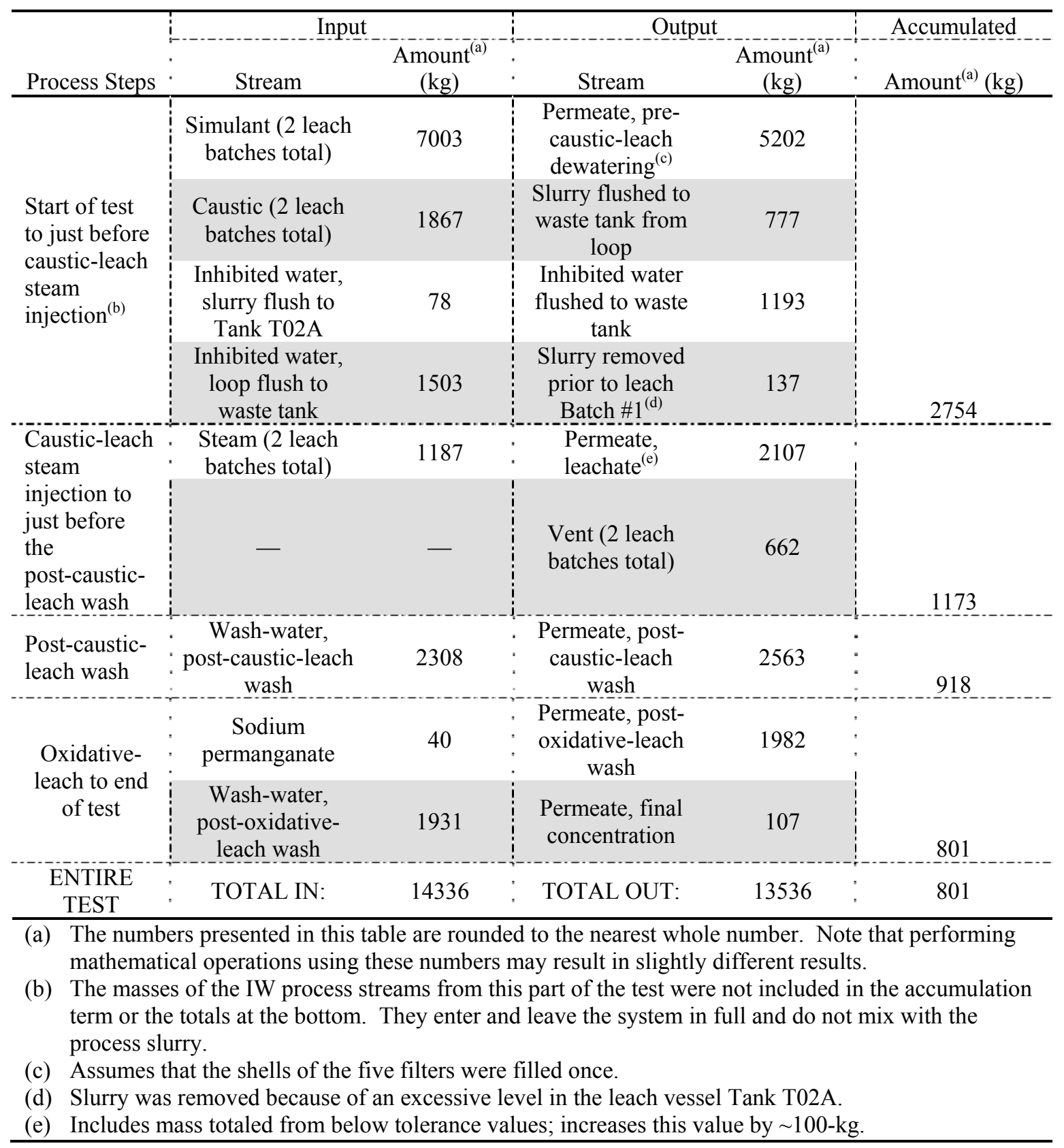


Table 12.6. Fate of Species During Integrated Test $D$

\begin{tabular}{|c|c|c|c|c|c|c|c|c|c|c|}
\hline Process Streams ${ }^{(a)}$ & Aluminum & Sodium & Chromium & Manganese & Oxalate & Sulfate & Phosphate & $\begin{array}{l}\text { Free } \\
\mathrm{OH}^{(\mathrm{b})}\end{array}$ & Water & UNITS \\
\hline \multirow{3}{*}{$\begin{array}{r}\text { In with the feed simulant (2 batches } \\
\text { total) }\end{array}$} & 128.7 & 669.8 & 5.6 & 6.8 & 8.1 & 93.4 & 33.4 & 93.1 & 5119.6 & $\mathrm{~kg}$ \\
\hline & 107.2 & 4.9 & 5.4 & 6.8 & 4.0 & 0.0 & 0.0 & N/A & N/A & kg solid \\
\hline & 21.5 & 664.9 & 0.2 & 0.0 & 4.1 & 93.4 & 33.4 & 93.1 & 5119.6 & $\mathrm{~kg}$ liquid \\
\hline In with caustic & $\mathrm{N} / \mathrm{A}$ & 536.0 & $\mathrm{~N} / \mathrm{A}$ & N/A & N/A & N/A & $\mathrm{N} / \mathrm{A}$ & 396.4 & 934.9 & $\mathrm{~kg}$ \\
\hline In with steam & $\mathrm{N} / \mathrm{A}$ & $\mathrm{N} / \mathrm{A}$ & $\mathrm{N} / \mathrm{A}$ & N/A & N/A & $\mathrm{N} / \mathrm{A}$ & $\mathrm{N} / \mathrm{A}$ & $\mathrm{N} / \mathrm{A}$ & 1186.7 & $\mathrm{~kg}$ \\
\hline In with wash-water (IW) & N/A & 1.0 & $\mathrm{~N} / \mathrm{A}$ & N/A & N/A & $\mathrm{N} / \mathrm{A}$ & $\mathrm{N} / \mathrm{A}$ & 0.7 & 4237.3 & $\mathrm{~kg}$ \\
\hline In with $\mathrm{NaMnO}_{4}$ & $\mathrm{~N} / \mathrm{A}$ & 0.8 & $\mathrm{~N} / \mathrm{A}$ & 2.4 & $\mathrm{~N} / \mathrm{A}$ & $\mathrm{N} / \mathrm{A}$ & $\mathrm{N} / \mathrm{A}$ & $\mathrm{N} / \mathrm{A}$ & 34.5 & $\mathrm{~kg}$ \\
\hline TOTAL IN & 128.7 & 1207.6 & 5.6 & 9.2 & 8.1 & 93.4 & 33.4 & 490.2 & 11513.0 & $\mathrm{~kg}$ \\
\hline $\begin{array}{r}\text { Out as permeate in pre-caustic solids } \\
\text { concentration }\end{array}$ & 17.2 & 538.1 & 0.1 & 0.0 & 3.2 & 73.5 & 26.3 & 74.3 & 4113.5 & $\mathrm{~kg}$ \\
\hline Out in the vent & $\mathrm{N} / \mathrm{A}$ & $\mathrm{N} / \mathrm{A}$ & $\mathrm{N} / \mathrm{A}$ & N/A & $\mathrm{N} / \mathrm{A}$ & $\mathrm{N} / \mathrm{A}$ & $\mathrm{N} / \mathrm{A}$ & $\mathrm{N} / \mathrm{A}$ & 661.5 & $\mathrm{~kg}$ \\
\hline \multirow{3}{*}{ Out as waste slurry from loop flushes } & 28.4 & 167.1 & 1.4 & 1.9 & 1.2 & 4.9 & 1.8 & 103.7 & 483.1 & $\mathrm{~kg}$ \\
\hline & 17.3 & 4.7 & 1.0 & 1.8 & 1.2 & 4.1 & 0.2 & 9.1 & N/A & kg solid \\
\hline & 11.1 & 162.5 & 0.4 & 0.0 & 0.0 & 0.8 & 1.6 & 94.6 & 483.1 & $\mathrm{~kg}$ liquid \\
\hline Out as permeate in leachate & 30.3 & 337.1 & 2.9 & 0.0 & 0.0 & 12.8 & 3.2 & 195.1 & 1392.0 & $\mathrm{~kg}$ \\
\hline $\begin{array}{l}\text { Out as permeate in post-caustic-leach } \\
\text { wash }\end{array}$ & 13.9 & 147.7 & 1.3 & 0.0 & 4.7 & 4.6 & 1.7 & 87.2 & 2196.9 & $\mathrm{~kg}$ \\
\hline $\begin{array}{l}\text { Out as permeate in post-oxidative- } \\
\text { leach wash }\end{array}$ & 0.2 & 5.5 & 0.0 & 0.0 & 5.0 & 0.1 & 0.0 & 1.5 & 2031.9 & $\mathrm{~kg}$ \\
\hline Out as permeate (total) & 61.7 & 1028.3 & 4.4 & 0.0 & 12.9 & 90.9 & 31.2 & 358.0 & 9734.3 & $\mathrm{~kg}$ \\
\hline TOTAL OUT & 90.1 & 1195.5 & 5.8 & 1.9 & 14.1 & 95.8 & 32.9 & 461.7 & 10878.9 & $\mathrm{~kg}$. \\
\hline \multirow{3}{*}{$\begin{array}{r}\text { Accumulated in the final slurry of } \\
\text { Integrated Test D }\end{array}$} & 44.0 & 7.2 & 0.1 & 8.4 & 0.0 & 0.0 & 0.0 & 28.5 & 634.1 & $\mathrm{~kg}$ \\
\hline & 44.0 & 6.5 & 0.1 & 8.4 & 0.0 & 0.0 & 0.0 & 28.2 & $\mathrm{~N} / \mathrm{A}$ & $\mathrm{kg}$ solid \\
\hline & 0.0 & 0.7 & 0.0 & 0.0 & 0.0 & 0.0 & 0.0 & 0.3 & 634.1 & $\mathrm{~kg}$ liquid \\
\hline Unknown fate & -5.5 & 5.0 & -0.3 & -1.1 & -6.1 & -2.5 & 0.5 & 0.0 & 0.0 & $\mathrm{~kg}$ \\
\hline
\end{tabular}

(a) The amount of each species in the process streams has been rounded to the nearest tenth. Note that this may lead to slightly different results than what is shown if mathematical operations are performed using these values.

(b) The free hydroxide inventory was only determined by liquid phase samples. When a solid phase mass is listed, it indicates the amount of free OH that becomes associated during processing. 
The aluminum in Integrated Test $\mathrm{D}$ entered the process only in the feed simulant (approximately $129-\mathrm{kg}$ in total). By the time the oxidative-leach began, all the soluble aluminum had been removed as permeate. The final slurry contained $44-\mathrm{kg}$ of solid Al. This is consistent with expectations. A smaller fraction of aluminum was removed during Integrated Test D than in Integrated Test A or B (for more information, see Table 12.12).

Other metal species were also distributed as expected. Sodium enters and exits the process in large amounts, with approximately $7-\mathrm{kg}$ left in the final slurry. In contrast to Integrated Tests A and B, chromium was present in the feed simulant $(5.6-\mathrm{kg})$. It was nearly all removed by the time the oxidative-leach began. This left only a small amount in the final slurry. Manganese was never removed from the Integrated Test D slurry. The amount added in the sodium permanganate was combined with the amount in the feed simulant to leave around $8.4-\mathrm{kg}$ of solid $\mathrm{Mn}$ in the final slurry. None of the inventory calculations for the metal species were subject to large discrepancies.

The results of the anion calculations in Integrated Test D were similar to the other two Integrated tests. Sulfate (93.4-kg in the feed) and phosphate (33.4-kg in the feed) were entirely removed from the final slurry. The free hydroxide was also nearly gone from the final slurry. Note that the "solid" $\mathrm{OH}$ is really hydroxide that becomes consumed or associated during the caustic-leach. This amount is calculated by difference since it was not measured directly. Note that although Integrated Tests B and D are very similar, the amount of associated $\mathrm{OH}$ during Integrated Test $\mathrm{D}$ is significantly smaller than in Integrated Test B. Consequently, Integrated Test D had approximately the same ratio of $\mathrm{kg}$ of consumed $\mathrm{OH}$ to $\mathrm{kg}$ of removed $\mathrm{Al}$ as Integrated Test $\mathrm{A}$.

As before, the inventory of oxalate was subject to the most problems. This is reflected in the largest relative error of any species (a $6.1-\mathrm{kg}$ discrepancy out of $8.1-\mathrm{kg}$ input). In Integrated Test $\mathrm{D}$, as before, inventory calculations around the post-caustic-leach wash using the slurry phase concentrations indicated a decrease in oxalate mass that could not be reconciled with the liquid phase concentration data. There is also a significant disagreement between the amount of oxalate according to the slurry concentration at the start of the post-caustic-leach wash and the running total calculated to that point $(9.7-\mathrm{kg}$ vs. $3.7-\mathrm{kg})$.

A second point of reference is available by using the maximum liquid phase concentration during the wash. At this point, all the oxalate should be in solution. For Integrated Test D, this gave a mass of $8.3-\mathrm{kg}$ of oxalate. At the beginning of the wash, using the liquid and slurry phase samples, the mass was calculated to be $9.7-\mathrm{kg}$. The large discrepancies for oxalate calculations in Integrated Test D should temper the conclusions drawn from oxalate amounts in Table 12.6.

The final slurry, which was calculated by global mass balance to be approximately $801-\mathrm{kg}$, was estimated to contain 634-kg of water at the conclusion of Integrated Test D. The final supernate was essentially $100 \%$ water with the balance of the final slurry being UDS (20.5-wt\%). The water inventory calculation closes perfectly since all the calculations have one unknown that was determined by difference. Total dissolved solids data were used to check the amount of water at various points; no large discrepancies were observed.

The unknown fates calculated for Integrated Test D, in particular for species expected to reside mostly in the liquid phase (sulfate, phosphate, free $\mathrm{OH}$, water) were very small. This should not be taken to mean that the mass balance was closed. Since there were no complications, such as caustic-leach heels 
and mixed analytical data sets, the calculations supporting Table 12.6 close near-perfectly by definition because of the absence of slurry phase sample data.

\subsection{Fate of AFA}

The antifoam additive, Dow Corning ${ }^{\circledR}$ Q2-3183A Antifoam, was tracked by analyzing the concentrations of polydimethylsiloxane (PDMS), polypropylene glycol (PPG) and silicon (Si) in samples taken at various points in each of the Integrated tests: 1) the simulant feed, 2) the start of the post-caustic-leach wash, 3) the end of the post-caustic-leach wash, 4) before permanganate was added for the oxidative-leach, 5) the end of the oxidative-leach, and 6) the end of the post-oxidative-leach wash. Solid and liquid fractions were analyzed separately.

Dow Corning ${ }^{\circledR}$ Q2-3183A Antifoam is a mixture of several different components. The analytical reports from Dow Corning Analytical Solutions analysis laboratory indicate that Q2-3183A is approximately $42 \%$ by mass PDMS, approximately $40 \%$ by mass PPG, Octylphenoxy polyethoxy ethanol (3-7-wt\%), Polyether polyol (3-7-wt\%) and treated silica (1-5-wt\%). Detecting either of these components would most likely indicate the presence of non-degraded AFA. Silicon is one of the elements in the PDMS compound and is present in other components of Q2-3183A. Silicon was not an intentional component of the slurry simulant but was detected in the feed (see the first column of Tables 12.7, 12.8 and 12.9). Silicon is a legacy contaminant left from some of the reagents used to make the simulant. None of the reagents added during the Integrated tests were Si based components. Therefore, detecting Si above the baseline concentration present in the feed simulant indicates the presence of either Q2-3183A, Q2-3183A degradation products, or both.

Table 12.7, Table 12.8, and Table 12.9 show the results of the analyses for Integrated Test A, B, and $\mathrm{D}$, respectively. In each table, the state of the process slurry at the six points where AFA samples were taken is presented, along with amount of AFA that had been added up to that point in the process. The remainder of each table presents the solid and liquid phase disposition of PDMS, PPG, and Si at each point, as well as the total mass of each present in the slurry. Table 12.10 summarizes the concentration of Q2-3183A in the slurry ( $\mathrm{ppm}$ ) for all three tests. Note that the Q2-3183A concentration was available both from PDMS and PPG samples since these were analyzed separately.

There are some similarities in AFA behavior between all the tests. First, in all three Integrated Tests, only limited liquid phase information was obtained. Most of the time, the PDMS was not detected in the samples and the PPG could not be measured because the solvent extraction failed during sample analysis. Second, keeping in mind that Q2-3183A is roughly equal parts PDMS and PPG by mass, there was also a large (a factor of ten or greater) disagreement between PDMS and PPG solid phase samples in all three tests. It is possible that the PDMS, which has a consistently lower concentration between the two, was systematically under-recovered during sample analysis. This possibility is supported by quality control samples in which known amounts of Q2-3183A were added to PEP simulant. Both of the quality control samples measured a PDMS concentration that was below the expected concentration by a factor of approximately ten. Third, the components of Q2-3183A appear to partition to the solid phase by the end of the post-caustic-leach wash, where they remain throughout the rest of the tests. This third point is difficult to state with certainty since liquid phase AFA information is scarce and incomplete. 
In Integrated Test A (see Table 12.7), little to no PDMS or PPG was detected until the end of the post-caustic-leach wash. At the end of the post-caustic-leach wash, the amount of PDMS, PPG, and Si in the solid phase increases substantially. This could indicate that all the AFA added prior to the wash during Integrated Test A (5420-g) was removed in the permeate during post-caustic-leach solids concentration or that high caustic concentrations interfere with the AFA analysis. Until the end of the oxidative-leach, the amount of PDMS remains approximately constant. The amount of PPG drops significantly before the permanganate is added. Meanwhile, the amount of Si increases during this period, suggesting that PPG was removed or driven into the liquid phase during the washing that occurred after the $\mathrm{CrOOH}$ slurry was added in Integrated Test $\mathrm{A}$. Note that the $\mathrm{CrOOH}$ slurry contains a small amount of Si (much like the feed simulant) but it is not enough to cause the observed increase.

The oxidative-leach does not appear to degrade the AFA, as amounts of PDMS, PPG, and Si are stable or increasing. By the end of the post-oxidative-leach wash, the amount of PDMS and PPG has decreased significantly, again suggesting that the AFA components are washing out or moving into the liquid phase. The amount of Si increases during this same period. Overall, 8892-g of AFA were added during Integrated Test A. The largest amount of Q2-3183A estimated to be present at the end of the test is $1269-\mathrm{g}$ (based on the solid phase PPG sample), meaning that less than $15 \%$ of the total AFA added remained detectable at the conclusion of Integrated Test A. 
Table 12.7. AFA Inventory During Integrated Test A

\begin{tabular}{|c|c|c|c|c|c|c|}
\hline & $\begin{array}{l}\text { Initial } \\
\text { Simulant } \\
\text { Feed }\end{array}$ & $\begin{array}{c}\text { Beginning of } \\
\text { Post-Caustic- } \\
\text { Leach Slurry } \\
\text { Wash }\end{array}$ & $\begin{array}{l}\text { End of Post- } \\
\text { Caustic- } \\
\text { Leach Slurry } \\
\text { Wash }\end{array}$ & $\begin{array}{c}\text { Before } \\
\text { Permanganate } \\
\text { Addition }\end{array}$ & $\begin{array}{c}\text { End of } \\
\text { Oxidative- } \\
\text { Leach }\end{array}$ & $\begin{array}{c}\text { End of } \\
\text { Post- } \\
\text { Oxidative- } \\
\text { Leach } \\
\text { Wash }\end{array}$ \\
\hline Slurry mass $(\mathrm{kg})$ & 9832 & 1551 & 1127 & 1341 & 1497 & 1362 \\
\hline UDS, $\%$ & 5.5 & 18.3 & 17.5 & 18.7 & 16.7 & 17.7 \\
\hline Solids mass (kg) & 543 & 284 & 197 & 251 & 250 & 241 \\
\hline Liquid mass (kg) & 9289 & 1267 & 929 & 1090 & 1247 & 1121 \\
\hline Cumulative AFA added (g) & 0 & 5420 & 6916 & 7630 & 7630 & 8892 \\
\hline $\begin{array}{l}\text { PDMS, solids ( } \mathrm{mg} / \mathrm{kg} \\
\text { slurry) }\end{array}$ & 7 & ND & 47 & 55 & 53 & 23 \\
\hline PDMS, solids (g) & 67.1 & ND & 53.1 & 74.1 & 79.1 & 31.0 \\
\hline $\begin{array}{l}\text { PDMS, liquid (mg/kg } \\
\text { liquid) }\end{array}$ & ND & ND & ND & ND & ND & ND \\
\hline PDMS, liquid (g) & ND & ND & ND & ND & ND & ND \\
\hline PPG, solids (mg/kg slurry) & Trace & 77 & 821 & 452 & 737 & 391 \\
\hline PPG, solids (g) & Trace & 118.9 & 925.0 & 605.6 & 1103.3 & 532.0 \\
\hline PPG, liquid (mg/kg liquid) & ND & 6 & SX failed & SX failed & SX failed & SX failed \\
\hline PPG, liquid (g) & ND & 7.2 & SX failed & SX failed & SX failed & SX failed \\
\hline $\mathrm{Si}$, solids (mg/kg solid) & 1040 & 1113 & 2527 & 3030 & 2806 & 3940 \\
\hline $\mathrm{Si}$ in solids $(\mathrm{g})$ & 564.4 & 315.8 & 498.2 & 759.5 & 701.3 & 949.6 \\
\hline $\mathrm{Si}$, liquid (mg/kg liquid) & 3.1 & 68.2 & 37.20 & 70.2 & 25.2 & 22.0 \\
\hline $\mathrm{Si}$, liquid $(\mathrm{g})$ & 28.5 & 86.4 & 34.6 & 76.5 & 31.4 & 24.7 \\
\hline Total mass of PDMS (g) & $67.1(\mathrm{sp})$ & ND & $53.1(\mathrm{sp})$ & $74.1(\mathrm{sp})$ & $79.1(\mathrm{sp})$ & $31.0(\mathrm{sp})$ \\
\hline Total mass of PPG $(\mathrm{g})$ & Trace & 126 & $925.0(\mathrm{sp})$ & $605.6(\mathrm{sp})$ & $1103.3(\mathrm{sp})$ & $532.0(\mathrm{sp})$ \\
\hline Total mass of Si $(\mathrm{g})$ & 593 & 402 & 533 & 836 & 733 & 974 \\
\hline
\end{tabular}

Similarly, in Integrated Test B (see Table 12.8), little to no PDMS or PPG was detected until the end of the post-caustic-leach wash. The PDMS concentration during this test remained very low throughout the entire process. At the end of the post-caustic-leach wash, the amount of PPG and Si in the solid phase increases substantially. This could indicate that all the AFA added prior to the wash during Integrated Test B (3532-g) was removed in the permeate during solids concentration or that high caustic concentrations interfere with the AFA analysis. The amount of PPG decreases, but not as significantly as in Integrated Test A, before the permanganate is added. A small amount of PPG may have been removed or driven into the liquid phase during the washing that occurred after the $\mathrm{CrOOH}$ slurry was added in Integrated Test B. The oxidative-leach does not appear to degrade the AFA, as amounts of PDMS, PPG, and $\mathrm{Si}$ are approximately constant. The AFA was not sampled for at the end of the post-oxidative-leach wash. Up to the end of the oxidative-leach, 4806-g of AFA were added during Integrated Test B. The largest amount of Q2-3183A estimated to be present at the end of the test is 937-g (based on the PPG solid phase sample) meaning that less than $20 \%$ of the total AFA added remained detectable at this point in the process. 
Table 12.8. AFA Inventory During Integrated Test $B$

\begin{tabular}{|c|c|c|c|c|c|c|}
\hline & $\begin{array}{l}\text { Initial } \\
\text { Simulant } \\
\text { Feed }\end{array}$ & $\begin{array}{c}\text { Beginning of } \\
\text { Post-Caustic- } \\
\text { Leach Slurry } \\
\text { Wash }\end{array}$ & $\begin{array}{l}\text { End of Post- } \\
\text { Caustic- } \\
\text { Leach Slurry } \\
\text { Wash }\end{array}$ & $\begin{array}{c}\text { Before } \\
\text { Permanganate } \\
\text { Addition }\end{array}$ & $\begin{array}{c}\text { End of } \\
\text { Oxidative- } \\
\text { Leach }\end{array}$ & $\begin{array}{c}\text { End of } \\
\text { Post- } \\
\text { Oxidative- } \\
\text { Leach } \\
\text { Wash }^{(a)}\end{array}$ \\
\hline Slurry mass (kg) & 7134 & 1195 & 913 & 914 & 1001 & 875 \\
\hline UDS, $\%$ & 5.2 & 17.3 & 20.5 & 16.9 & 18.3 & 20.2 \\
\hline Solids mass (kg) & 371 & 207 & 187 & 154 & 183 & 177 \\
\hline Liquid mass $(\mathrm{kg})$ & 6763 & 988 & 726 & 760 & 818 & 698 \\
\hline Cumulative AFA added (g) & 0 & 3532 & 4368 & 4806 & 4806 & 5510 \\
\hline $\begin{array}{l}\text { PDMS, solids ( } \mathrm{mg} / \mathrm{kg} \\
\text { slurry) }\end{array}$ & ND & ND & 1.7 & 3.3 & 1.5 & $\mathrm{n} / \mathrm{a}$ \\
\hline PDMS, solids (g) & ND & ND & 1.6 & 3.0 & 1.5 & $\mathrm{n} / \mathrm{a}$ \\
\hline $\begin{array}{l}\text { PDMS, liquid ( } \mathrm{mg} / \mathrm{kg} \\
\text { liquid) }\end{array}$ & ND & ND & ND & ND & 0.48 & $\mathrm{n} / \mathrm{a}$ \\
\hline PDMS, liquid (g) & ND & ND & ND & ND & 0.4 & $\mathrm{n} / \mathrm{a}$ \\
\hline PPG, solids (mg/kg slurry) & ND & ND & 433 & 418 & 395 & $\mathrm{n} / \mathrm{a}$ \\
\hline PPG, solids $(\mathrm{g})$ & ND & ND & 395.2 & 381.8 & 395.6 & $\mathrm{n} / \mathrm{a}$ \\
\hline PPG, liquid (mg/kg liquid) & ND & ND & SX failed & SX failed & SX failed & $\mathrm{n} / \mathrm{a}$ \\
\hline PPG, liquid $(\mathrm{g})$ & ND & ND & SX failed & SX failed & SX failed & $\mathrm{n} / \mathrm{a}$ \\
\hline $\mathrm{Si}$, solids (mg/kg solid) & 874 & 1272 & 3064 & 3130 & 2889 & $\mathrm{n} / \mathrm{a}$ \\
\hline $\mathrm{Si}$ in solids $(\mathrm{g})$ & 324.3 & 262.9 & 573.6 & 483.6 & 529.3 & $\mathrm{n} / \mathrm{a}$ \\
\hline $\mathrm{Si}$, liquid (mg/kg liquid) & 2.9 & 144 & 75.10 & 67.8 & 35.4 & $\mathrm{n} / \mathrm{a}$ \\
\hline $\mathrm{Si}$, liquid $(\mathrm{g})$ & 19.3 & 142.3 & 54.5 & 51.5 & 29.0 & $\mathrm{n} / \mathrm{a}$ \\
\hline Total mass of PDMS (g) & ND & ND & $1.6(\mathrm{sp})$ & $3.0(\mathrm{sp})$ & 1.9 & $\mathrm{n} / \mathrm{a}$ \\
\hline Total mass of PPG $(\mathrm{g})$ & ND & ND & $395.2(\mathrm{sp})$ & $381.8(\mathrm{sp})$ & $395.6(\mathrm{sp})$ & $\mathrm{n} / \mathrm{a}$ \\
\hline Total mass of $\mathrm{Si}(\mathrm{g})$ & 344 & 405 & 628 & 535 & 558 & $\mathrm{n} / \mathrm{a}$ \\
\hline
\end{tabular}

In Integrated Test D (see Table 12.9), little to no PDMS was detected until the end of the post-caustic-leach wash. The PPG concentration was noticeably higher at the beginning of Integrated Test D than in Integrated Test A or B. At the end of the post-caustic-leach wash, the amount of PDMS, PPG and Si in the solid phase increased substantially. This could indicate that all the AFA added prior to the wash during Integrated Test D (5236-g) was removed in the permeate during solids concentration or that high caustic concentrations interfere with the AFA analysis. Whereas in Integrated Tests A and B a $\mathrm{CrOOH}$ slurry was added and then the slurry was washed, in Integrated Test D this did not occur. No significant processing was done between the end of the post-caustic-leach wash and the permanganate addition; the samples were taken approximately seven minutes apart. The concentrations between the two samples should be the same; the existence of significant differences suggests the PDMS and PPG measurements may be subject to significant uncertainty.

In Integrated Test D, the oxidative-leach appears to have degraded the AFA, as the amount of PDMS and PPG decreased while the amount of $\mathrm{Si}$ is constant. This was probably not observed during Integrated Tests A and B since there was not large amounts of excess permanganate in those tests; Integrated Test D, however, had Mn:Cr molar ratios greater than ten (see Section 11). There was a large increase, especially in PDMS, at the end of the post-oxidative-leach wash. The reason for this is unknown, as it was not observed in Integrated Test A. Overall, 6688-g of AFA were added during Integrated Test D. The largest amount of Q2-3183A estimated to be present at the end of the test is 1443-g (based on the solid phase 
PPG sample), meaning that less than $22 \%$ of the total AFA added remained detectable at the end of the test.

Table 12.9. AFA Inventory During Integrated Test D

\begin{tabular}{|c|c|c|c|c|c|c|}
\hline & $\begin{array}{l}\text { Initial } \\
\text { Simulant } \\
\text { Feed }\end{array}$ & $\begin{array}{l}\text { Beginning of } \\
\text { Post- } \\
\text { Caustic- } \\
\text { Leach Slurry } \\
\text { Wash }\end{array}$ & $\begin{array}{l}\text { End of Post- } \\
\text { Caustic- } \\
\text { Leach Slurry } \\
\text { Wash }\end{array}$ & $\begin{array}{c}\text { Before } \\
\text { Permanganate } \\
\text { Addition }\end{array}$ & $\begin{array}{c}\text { End of } \\
\text { Oxidative- } \\
\text { Leach }\end{array}$ & $\begin{array}{c}\text { End of } \\
\text { Post- } \\
\text { Oxidative- } \\
\text { Leach } \\
\text { Wash }\end{array}$ \\
\hline Slurry mass $(\mathrm{kg})$ & 7004 & 1174 & 919 & 919 & 959 & 908 \\
\hline UDS, $\%$ & 5.0 & 18.8 & 22.0 & 22.0 & 21.2 & 20.6 \\
\hline Solids mass (kg) & 348 & 221 & 202 & 202 & 203 & 187 \\
\hline Liquid mass (kg) & 6655 & 953 & 717 & 717 & 756 & 721 \\
\hline Cumulative AFA added (g) & 0 & $5236^{(\mathrm{a})}$ & 5984 & 5984 & 5984 & 6688 \\
\hline $\begin{array}{l}\text { PDMS, solids (mg/kg } \\
\text { slurry) }\end{array}$ & ND & ND & 51.9 & 75.6 & 24.1 & 399 \\
\hline PDMS, solids (g) & ND & ND & 47.7 & 69.5 & 23.1 & 362.5 \\
\hline $\begin{array}{l}\text { PDMS, liquid ( } \mathrm{mg} / \mathrm{kg} \\
\text { liquid) }\end{array}$ & ND & ND & ND & ND & ND & ND \\
\hline PDMS, liquid (g) & ND & ND & ND & ND & ND & ND \\
\hline PPG, solids (mg/kg slurry) & 14 & 68 & 1253 & 1024 & 598 & 667 \\
\hline PPG, solids (g) & 96.4 & 79.4 & 1151.4 & 941.6 & 573.3 & 605.7 \\
\hline PPG, liquid (mg/kg liquid) & 1.4 & 98.4 & SX failed & SX failed & SX failed & SX failed \\
\hline $\mathrm{PPG}$, liquid $(\mathrm{g})$ & 9.4 & 93.8 & SX failed & SX failed & SX failed & SX failed \\
\hline Si, solids (mg/kg solid) & 970 & 1439 & 2330 & 2406 & 2320 & 3286 \\
\hline $\mathrm{Si}$ in solids $(\mathrm{g})$ & 337.5 & 317.7 & 471.1 & 486.6 & 471.7 & 614.9 \\
\hline $\mathrm{Si}$, liquid (mg/kg liquid) & 3.6 & 240 & 17.7 & 17.7 & 12.1 & 29.0 \\
\hline $\mathrm{Si}$, liquid $(\mathrm{g})$ & 23.8 & 228.8 & 12.7 & 12.7 & 9.1 & 20.9 \\
\hline Total mass of PDMS (g) & ND & ND & $47.7(\mathrm{sp})$ & $69.5(\mathrm{sp})$ & $23.1(\mathrm{sp})$ & $362.5(\mathrm{sp})$ \\
\hline Total mass of PPG $(\mathrm{g})$ & 106 & 173 & $1151.4(\mathrm{sp})$ & $941.6(\mathrm{sp})$ & $573.3(\mathrm{sp})$ & $605.7(\mathrm{sp})$ \\
\hline Total mass of Si $(\mathrm{g})$ & 361 & 547 & 484 & 499 & 481 & 636 \\
\hline
\end{tabular}

The concentration of Q2-3183A at the six process points is shown in Table 12.10. The target concentration in the process slurry during all the integrated tests was $350 \mathrm{ppm}$. Just as in Table 12.7, Table 12.8, and Table 12.9, there is a large difference between Q2-3183A concentrations derived from PDMS analysis versus PPG analysis. There is no evidence of a consistent trend across the three tests. In Integrated Test A, the Q2-3183A concentration is either too small (PDMS analysis) by a factor of approximately three or too large (PPG analysis) by a factor of three or greater. In Integrated Test B, the Q2-3183A concentration is almost zero according to the PDMS analysis and approximately a factor of three too large according to the PPG analysis. Integrated Test D is similar to Integrated Test A, except the Q2-3183A concentration by PPG analysis is even greater than it was in Integrated Test A. Based on the incomplete analytical results it is difficult to conclude that the $350 \mathrm{ppm}$ target was successfully maintained in any of the Integrated tests.

If, in fact, there was a systematic bias in the PDMS sample analysis such as what was suggested by the quality control samples, then the Q2-3183A concentrations in Table 12.10 for PDMS would increase by a factor of around ten. This would bring the Q2-3183A concentrations into approximate agreement for Integrated Test A, and less so for Integrated Test D. It should be noted that the quality control samples 
were liquid phase samples and the bulk of the Q2-3183A concentration data was derived from solid phase samples; thus, if a systematic bias does exist, it may be different for the solid phase samples.

Table 12.10. Q2-3183A Concentration in Process Slurry During the Integrated Tests.

\begin{tabular}{|c|c|c|c|c|c|c|c|}
\hline Test & $\begin{array}{c}\text { Q2-3183A } \\
\text { As } \\
\text { Determined } \\
\text { from } \\
\text { Analysis for: }\end{array}$ & $\begin{array}{l}\text { Initial } \\
\text { Simulant } \\
\text { Feed } \\
\text { (ppm) }\end{array}$ & $\begin{array}{c}\text { Beginning } \\
\text { of Post- } \\
\text { Caustic- } \\
\text { Leach Slurry } \\
\text { Wash (ppm) }\end{array}$ & $\begin{array}{l}\text { End of Post- } \\
\text { Caustic- } \\
\text { Leach Slurry } \\
\text { Wash (ppm) }\end{array}$ & $\begin{array}{c}\text { Before } \\
\text { Permanganate } \\
\text { Addition } \\
\text { (ppm) }\end{array}$ & $\begin{array}{c}\text { End of } \\
\text { Oxidative- } \\
\text { Leach } \\
\text { (ppm) }\end{array}$ & $\begin{array}{l}\text { End of Post- } \\
\text { Oxidative- } \\
\text { Leach Wash } \\
\text { (ppm) }\end{array}$ \\
\hline \multirow{2}{*}{$\begin{array}{c}\text { Integrated } \\
\text { Test A }\end{array}$} & $\mathrm{PDMS}^{(\mathrm{a})}$ & 17 & ND & 118 & 138 & 130 & 59 \\
\hline & $\mathrm{PPG}^{(\mathrm{b})}$ & Trace & 188 & 1954 & 1077 & 1756 & 932 \\
\hline \multirow{2}{*}{$\begin{array}{l}\text { Integrated } \\
\text { Test B }\end{array}$} & $\mathrm{PDMS}^{(\mathrm{a})}$ & ND & ND & 4 & 8 & 7 & $\mathrm{n} / \mathrm{a}$ \\
\hline & $\mathrm{PPG}^{(\mathrm{b})}$ & ND & ND & 1017 & 987 & 936 & $\mathrm{n} / \mathrm{a}$ \\
\hline \multirow{2}{*}{$\begin{array}{l}\text { Integrated } \\
\text { Test D }\end{array}$} & $\mathrm{PDMS}^{(\mathrm{a})}$ & ND & ND & 129 & 187 & 61 & 998 \\
\hline & $\mathrm{PPG}^{(\mathrm{b})}$ & 37 & 283 & 2961 & 2435 & 1410 & 1589 \\
\hline
\end{tabular}

Given the significant scatter in the data, the substantial disagreement between PDMS and PPG sample analysis, the lack of liquid phase information, and the troubling results of the quality control sampling, it is difficult to quantify the fate of AFA during the Integrated tests with any certainty. The AFA was rarely detected at the $350 \mathrm{ppm}$ target concentration in any test although the testing records indicate that the specified quantities of AFA were added. For all three tests the detectable AFA components appear to partition to the solids by the end of the post-caustic-leach wash and remain there until the end of the tests. Oxidative leaching did not appear to degrade AFA unless there were large excesses of permanganate, like there was in Integrated Test D. Comparison between the amount of AFA added throughout the tests and the final Q2-3183A concentration suggests around $75-85 \%$ of the AFA added during processing was not present in the final slurry. The AFA components were likely removed during the filtration and washing steps although some degradation may also have occurred post-oxidative-leach.

\subsection{Conclusions}

Global mass balances were performed for Integrated Tests A, B, and D. All major process streams were totalized, and the accumulated mass in the system was calculated at five points in the test timeline. In all three tests, the calculated final accumulation was approximately $20 \%$ greater than the final mass of slurry that was determined from the level in Tank T02A at the end of the test. The difference is approximately $1 \%$ of the total amount of material input to the system in each test. This is good agreement considering:

- that several process streams were neglected in the calculation (either small in magnitude or difficult to estimate)

- the uncertainty in the process flow instrumentation and analytical densities

- that assumptions were used to estimate certain amounts, e.g., the permeate in filter shells or the mass of water vented during caustic-leach. 
When the process stream masses were compared with run sheet targets, the amounts were in agreement. This gives further confidence in the calculations.

Inventory calculations for nine species were also performed for the Integrated tests. The calculation was built on the results of the global mass balance using concentration data to track constituents of interest through each test. Qualitatively, the results for each species were as expected, and are summarized as follows:

- Aluminum: Enters only in the feed simulant. A large fraction was removed in the permeate by the end of the post-caustic-leach wash with a smaller fraction left in the solid phase in the final slurry. There was some difference between the tests (see Table 12.11). In Integrated Test A, $60.3 \%$ of the total $\mathrm{Al}$ was removed by the end of the post-caustic-leach solids concentration and $65.3 \%$ was removed by the conclusion of the post-caustic-leach wash. In Test B, the percentages removed were $48.9 \%$ and $64.1 \%$, respectively. Similar for Integrated Test D, where the percents removed were $47.4 \%$ and $61.2 \%$.

- Sodium: Entered and exited the process in significant amounts. A small amount remained in the final slurry. The fate of sodium was similar between the tests (see Table 12.11). In Integrated Test A, $86.0 \%$ of the sodium introduced into the system was removed by the end of the post-caustic-leach solids concentration. By the end of the tests, around $0.3 \%$ was left in the final concentrated slurry. In Test B, the distribution was $81.1 \%$ and $1.2 \%$, respectively. Integrated Test $\mathrm{D}$ had $84.1 \%$ of the sodium removed and $0.7 \%$ remaining in the final slurry.

- Chromium: In Integrated Tests A and B, there was a negligible amount until late in the process, after which almost all of it was removed following the oxidative-leach. In Integrated Test D, the starting amount in the feed was mostly gone by the start of the oxidative leach.

- Manganese: Accumulates in the final slurry through adding the sodium permanganate reagent; essentially all of it remains in the solid phase.

- Oxalate: Is carried along in the process until the start of post-caustic-leach wash, where mostly solid oxalate goes into solution and only a trace amount remains by the end of the tests. These calculations suffer from a higher degree of uncertainty.

- Sulfate/Phosphate: These liquid anions were removed almost completely with the permeate by the end of the tests, leaving only trace amounts in the washed, concentrated slurry.

- Free OH: Enters the system with the feed simulant and is combined with larger amounts of caustic added during the caustic leaching step, a portion of which was consumed during the caustic-leach. There was almost no free hydroxide present in the washed slurry at the end of the test.

- Water: Is always present in large amounts and constitutes a significant amount of permeate. At the conclusion of each test, the supernate in the washed slurry was essentially $100 \%$ water (by weight).

The fate of AFA was discussed in detail in Section 12.6. To summarize, the AFA was rarely detected at the $350 \mathrm{ppm}$ target concentration in any test although the testing records indicate that the specified quantities of AFA were added. The measurable components of AFA (PDMS, PPG, and Si) partitioned to the solid phase in each test. However, this represented only a smaller portion of the AFA: by the end of the tests only around $15-25 \%$ of the AFA that was added during the tests was detected in the final slurry. 
The balance of the AFA components were either removed during the filtration and washing steps, undetected by the analytical methods or degraded during processing. Only Integrated Test D had evidence of degradation caused by oxidative leaching, which was probably a result of excess permanganate. More quantitative conclusions were not possible due to incomplete analytical results.

Quantitatively, each species inventory calculation, with the exception of oxalate, had a reasonable $(<10 \%)$ error. It should be mentioned that the amounts shown in the fate of species tables are only as good as the assumptions used to calculate them. Many of the values around process steps were calculated by difference, thus guaranteeing zero error. Analytical uncertainty will also impact accuracy. Each Integrated test can be thought of as a total process flow where the amount of a particular species participating in the process can be compared with the amount removed by all the process steps during the testing.

Table 12.12 shows one possible measure of test performance. It presents the percent of species removed for each Integrated test. The first column for each test is determined using the simple calculation

$$
\% \text { removed }=\left(1-\frac{m_{a c c}}{m_{\text {in }}}\right) \times 100 \%
$$

where $m_{a c c}$ is the amount of a species accumulated in the final slurry, and $m_{i n}$ is the total amount of a specie's input to the process. This is something like a process efficiency for each species, assuming that the objective was to remove that species from the feed simulant.

The efficiency was corrected for nonprototypic steps (such as flushing the filter-loop to waste receipt vessels where the simulant went unprocessed or materials left in the bottom of the vessels since they were not needed to achieve test objectives) in the second column. This negates penalties to the efficiency by accounting for amounts that were not completely processed. This calculation is governed by the equation

$$
\% \text { removed, adjusted }=\left(\frac{m_{i n}-m_{n p}-m_{a c c}}{m_{i n}-m_{n p}}\right) \times 100 \%
$$

where $m_{n p}$ is the amount of a species that was removed in nonprototypic steps. The adjusted percent removed is a more representative calculation of the removal efficiency.

The table can be used to compare the removal performance of a species for each of the process conditions and sequences. As an example, during Integrated Test A, the sequence of process conditions removed $69.5 \%$ of the aluminum added with the feed simulant. During Integrated Test D, the changes in process steps and conditions reduced the removal performance for aluminum to $56.1 \%$.

A removal efficiency of $100 \%$ should not be interpreted to mean the total removal of a species. Trace amounts of the species are still present in the system. Manganese is a special case since it is not removed from the process. It accumulates in the final slurry, and this leads to the near-zero efficiency seen in Table 12.12. By reviewing Table 12.12, it can be concluded that the process steps and conditions from 
Integrated Test A resulted in higher adjusted removal rates (for the species listed) than were experienced during Integrated Test B or Integrated Test D.

Table 12.11. Distribution of Aluminum and Sodium at Important Process Points. The percentages were calculated on a mass basis, adjusted for nonprototypic processing. ${ }^{\text {(a) }}$

\begin{tabular}{|c|c|c|c|c|}
\hline Test & $\begin{array}{c}\text { \% Al Removed By End of } \\
\text { Post-Caustic-Leach Solids } \\
\text { Concentration }\end{array}$ & $\begin{array}{c}\text { \% Al Removed By } \\
\text { End of Post- } \\
\text { Caustic-Leach } \\
\text { Wash }\end{array}$ & $\begin{array}{c}\text { \% Na Removed By End of } \\
\text { Post-Caustic-Leach Solids } \\
\text { Concentration }\end{array}$ & $\begin{array}{c}\text { \% Na Left in Final } \\
\text { Concentrated Slurry }\end{array}$ \\
\hline A & $60.3 \%$ & $65.3 \%$ & $86.0 \%$ & $0.3 \%$ \\
\hline B & $48.9 \%$ & $64.1 \%$ & $81.1 \%$ & $1.2 \%$ \\
\hline D & $47.4 \%$ & $61.2 \%$ & $84.1 \%$ & $0.7 \%$ \\
\hline
\end{tabular}

(a) The percentages calculated in Table 12.11 and Table 12.12 were formulated differently. Table 12.12 uses the mass left in the final slurry to determine what is removed. Table 12.11 uses the mass of the permeate streams to determine what is removed. Since the mass balance had some unknown fates and did not close perfectly (particularly for the metal species), these values will not be in exact agreement. For instance, Table 12.12 states that $56.1 \%$ of the aluminum was removed by the end of Integrated Test D. Table 12.11 states that $61.2 \%$ of the aluminum was removed by the end of the post-caustic-leach wash of Integrated Test D. However, using the Table 12.12 formulation and values from Table 12.6, the percentage of aluminum removed by the end of the post-caustic-leach wash is $(128.7-\mathrm{kg}-28.4-\mathrm{kg}-(44.0-\mathrm{kg}+0.2-\mathrm{kg})) /(128.7-\mathrm{kg}-28.4-\mathrm{kg})=55.9 \%$. The approximately $5 \%$ difference arises from the unknown fate of the $5.5-\mathrm{kg}$ of aluminum in Integrated Test D. Other differences between Table 12.11 and 12.12 may exist for the same reason.

Table 12.12. Percent Removed of Each Species During Integrated Tests A, B, and D

\begin{tabular}{|c|c|c|c|c|c|c|}
\hline \multirow[b]{2}{*}{ Species } & \multicolumn{2}{|c|}{ Integrated Test A } & \multicolumn{2}{|c|}{ Integrated Test B } & \multicolumn{2}{|c|}{ Integrated Test D } \\
\hline & $\%$ Removed & $\begin{array}{c}\text { \% Removed, } \\
\text { Adjusted }^{(a)}\end{array}$ & $\%$ Removed & $\begin{array}{l}\text { \% Removed, } \\
\text { Adjusted }^{(\mathrm{a})}\end{array}$ & $\%$ Removed & $\begin{array}{c}\text { \% Removed, } \\
\text { Adjusted }^{(\mathrm{a})}\end{array}$ \\
\hline Aluminum & $72.8 \%$ & $69.5 \%$ & $70.8 \%$ & $65.3 \%$ & $65.8 \%$ & $56.1 \%$ \\
\hline Sodium & $99.7 \%$ & $99.7 \%$ & $98.9 \%$ & $98.8 \%$ & $99.4 \%$ & $99.3 \%$ \\
\hline Chromium & $90.1 \%$ & $90.1 \%$ & $95.6 \%$ & $95.6 \%$ & $98.1 \%$ & $97.4 \%$ \\
\hline Manganese & $1.7 \%$ & $-5.4 \%$ & $0.8 \%$ & $-13.5 \%$ & $8.6 \%$ & $-14.5 \%$ \\
\hline Oxalate & $97.9 \%$ & $97.6 \%$ & $99.1 \%$ & $99.0 \%$ & $99.5 \%$ & $99.4 \%$ \\
\hline Sulfate & $97.9 \%$ & $97.6 \%$ & $100.0 \%$ & $100.0 \%$ & $100.0 \%$ & $100.0 \%$ \\
\hline Phosphate & $99.8 \%$ & $99.8 \%$ & $100.0 \%$ & $100.0 \%$ & $99.9 \%$ & $99.9 \%$ \\
\hline Free $\mathrm{OH}$ & $94.1 \%$ & $93.2 \%$ & $87.3 \%$ & $84.9 \%$ & $94.2 \%$ & $92.6 \%$ \\
\hline Water & $95.5 \%$ & $95.2 \%$ & $94.6 \%$ & $94.4 \%$ & $94.5 \%$ & $94.3 \%$ \\
\hline
\end{tabular}

(a) Adjusted for nonprototypic process steps such as leaving heels in vessels or flushing filter-loop slurries to the waste receipt vessels. 


\subsection{UFP System Operability and Functionality}

This section contains a discussion of a number of topics that were identified as success criteria for the UFP system operability and functionality in the PEP Test Plan but were not conveniently covered in other sections of this report.

\subsection{Pulse Jet Mixing Evaluation}

Pulse jet mixer operation during PEP testing is evaluated in this section. The use of gravity to refill the PJMs, when high temperatures prevent the use of a vacuum to refill the PJMs, is discussed in Section 13.1.1. Variability in PJM operation with time, temperature, slurry depth, etc., is discussed in Section 13.1.2. Section 13.1.3 discusses the apparent plugging of a PJM during Integrated Test B. PJM operation during PEP testing is evaluated in this section. ${ }^{\text {(a) }}$

\subsubsection{Gravity Refill}

The refill of PJMs is generally assisted by applying a vacuum to the PJM air lines. This allows the PJMs to be filled when the slurry level in the tank is low and accelerates the refilling when the slurry level is high. It is also possible, when the fluid level in the tank is high, to simply vent the PJMs and allow the hydrostatic pressure of the fluid in the tank to fill the PJMs (gravity refill). Gravity refill is used at elevated temperatures (i.e., during caustic leaching) when evacuating the PJMs could cause flashing and excessive evaporation. Demonstrating gravity refill of PJMs is important because incomplete filling of PJMs could result in overblows.

The PEP used gravity refill of PJMs whenever the slurry temperature was above $\approx 60^{\circ} \mathrm{C}$ and vacuum refill below $\approx 60^{\circ} \mathrm{C}$. When above $60^{\circ} \mathrm{C}$ (i.e., during the heat-up, caustic-leach, and cool-down), the slurries were Newtonian, and slurry levels were prototypic (i.e., 1/4.5) of the PTF. During testing with gravity refill, PEP did NOT encounter any problems with overblows. The PJMs were, therefore, filling satisfactorily with only the tank level as the driving force. Because the Drexelbrook probes did not operate at the elevated temperatures, the actual time to refill the PJM couldn't be measured. Therefore, a best-estimate for the refill time was determined using the Bernoulli equation ${ }^{\mathrm{b}}$ (see Appendix A of Bontha et al. 2005) as applied for the discharge but using only the tank level as the driving force. The bestestimate refill times for the Tank 1 and Tank 2 during PEP testing are shown in Figure 13.1 and Figure 13.2, respectively.

(a) High uncertainties are expected in the data and methods used to evaluate PJM parameters. Many of the periods evaluated for this section had not collected $10-\mathrm{Hz}$ data, so the analyses had to rely primarily on $1-\mathrm{Hz}$ data. The use of $1-\mathrm{Hz}$ data, rather than $10-\mathrm{Hz}$ data, increases uncertainties related to averaging and is likely to under-represent the peak data information for short PJM drive times.

(b) The nozzle loss coefficient in the Bernoulli equation was estimated based upon refill data at low temperature when the Drexelbrook probes functioned properly. There was no data at the high-temperature condition so the same loss coefficient was assumed. This was considered a 'worst-case' estimate because as temperature rises viscosity goes down and the loss coefficient should remain constant or decrease. 


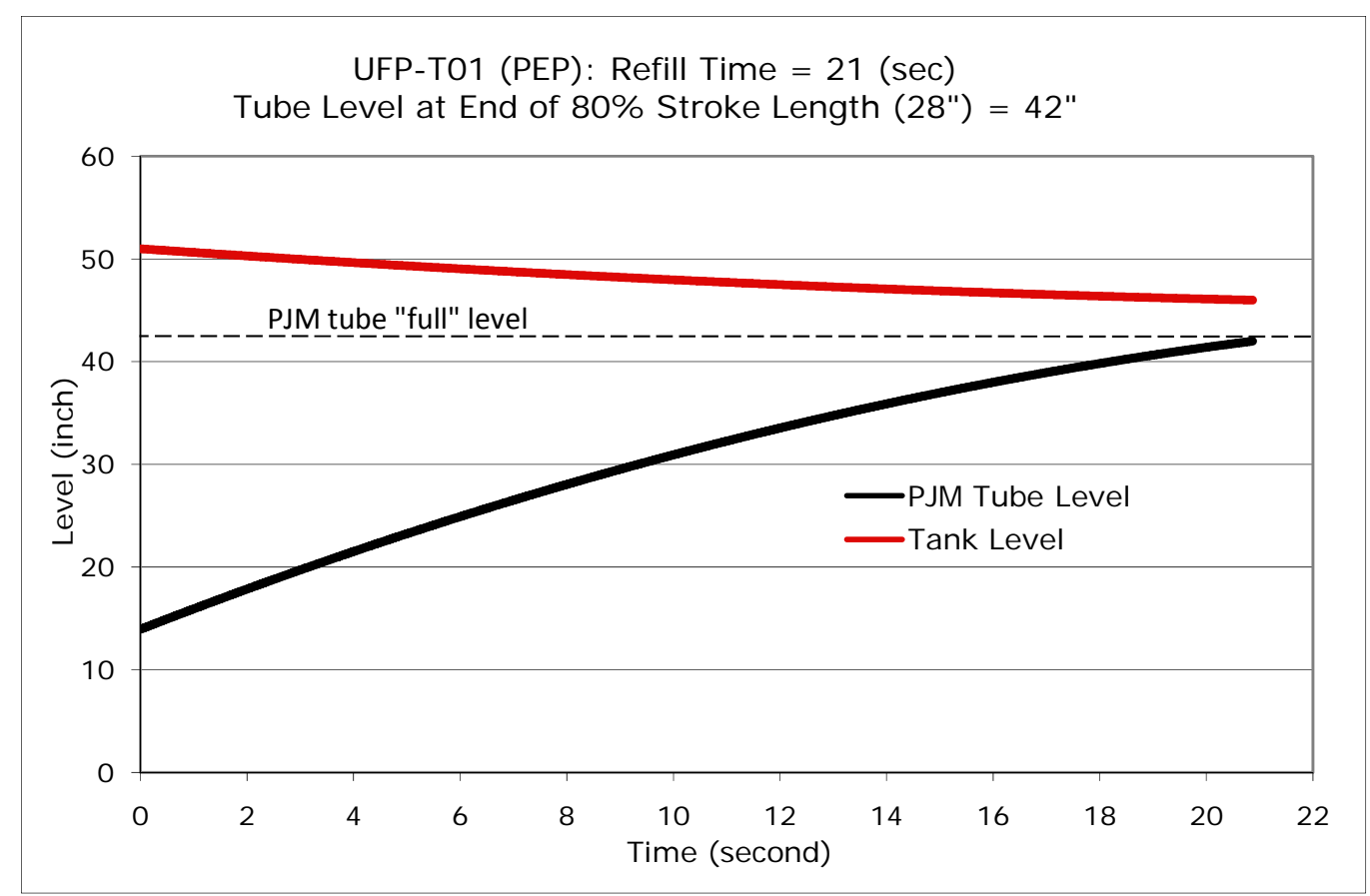

Figure 13.1. Tank T01A/B Gravity Refill

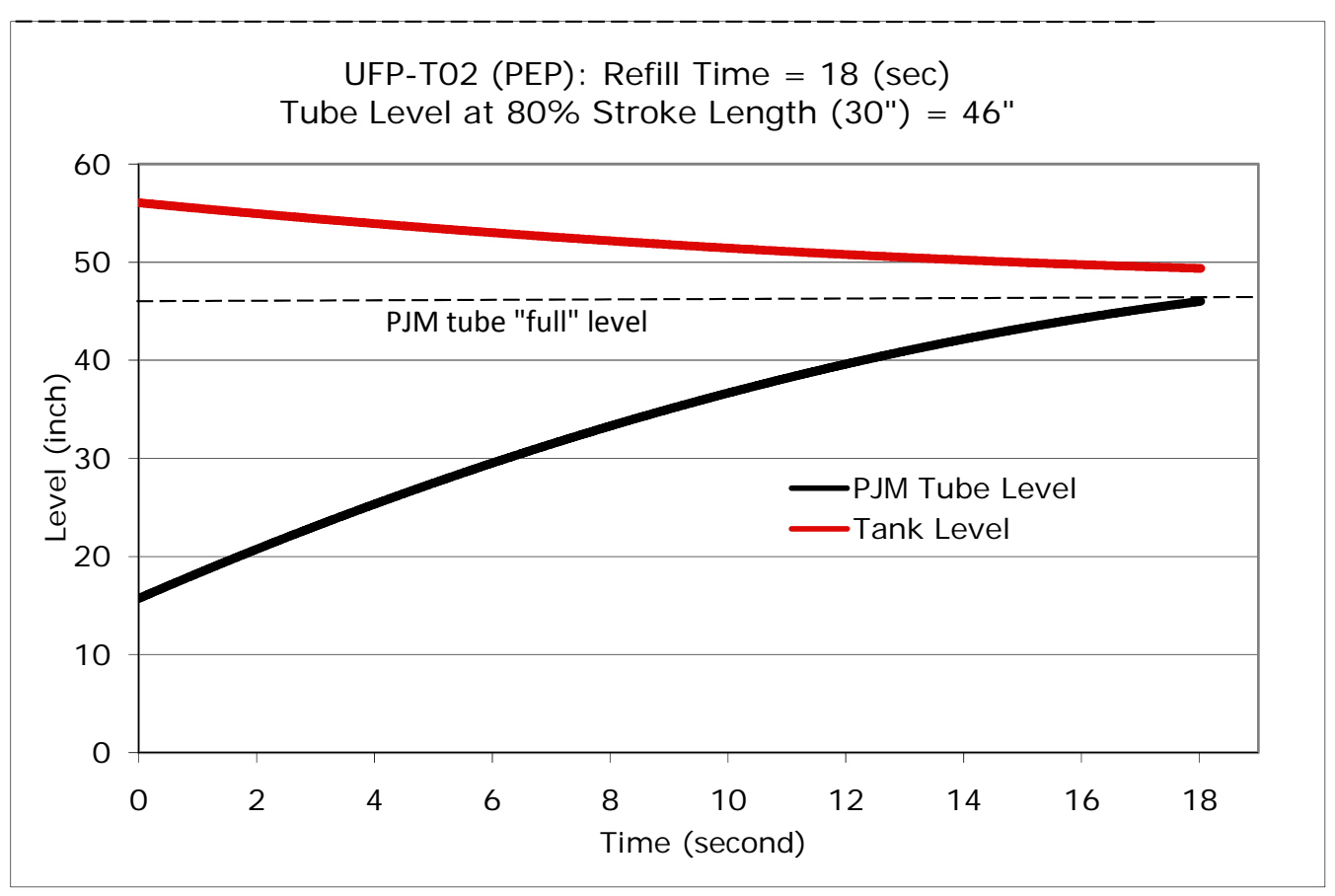

Figure 13.2. Tank T02A Gravity Refill

The figures above show that the best-estimate refill times for Tanks T01A/B and Tank T02A were approximately 21 seconds and 18 seconds, respectively. Table 13.1 shows the refill times with typical 
discharge times, total cycle times, and "excess" times for each vessel during its respective caustic-leach. Excess time is the time available after the PJM has filled before the next drive is to start.

Table 13.1. “Excess” Times for Tanks T01A/B and T02A with Gravity Refill.

\begin{tabular}{lcccc}
\hline \multicolumn{1}{c}{ Total Cycle } & Time, \\
Vessel & seconds & $\begin{array}{c}\text { Refill Time, } \\
\text { seconds }\end{array}$ & $\begin{array}{c}\text { Drive Time, } \\
\text { seconds }\end{array}$ & $\begin{array}{c}\text { Excess, } \\
\text { seconds }\end{array}$ \\
\hline Tanks T01 A/B & 35 & 21 & 12 & 2 \\
Tank T02A & 33 & 18 & 7 & 8 \\
\hline
\end{tabular}

During PEP testing, gravity refill was successful. The PJMs refilled sufficiently to prevent overblows from occurring. However, the "success" of gravity refill for PEP does not automatically confirm that gravity refill will work in WTP. In WTP the linear dimensions of the PJMs are 4.5 times larger so it is expected to take longer to fill the tube, but the nozzle flow should be higher because the level difference between the tank and PJM is 4.5 times larger. To estimate WTP gravity refill based upon PEP results the refill time for WTP PJMs was estimated by applying the Bernoulli equation (see Appendix A of Bontha et al. 2005) using the same nozzle coefficient determined for the PEP nozzle and applying WTP tank levels as the driving force (4.5 times larger than PEP). The estimated levels in the tanks and the pulse tubes during gravity refill are shown in Figure 13.3 and Figure 13.4 for Tanks T01A/B and T02A, respectively.

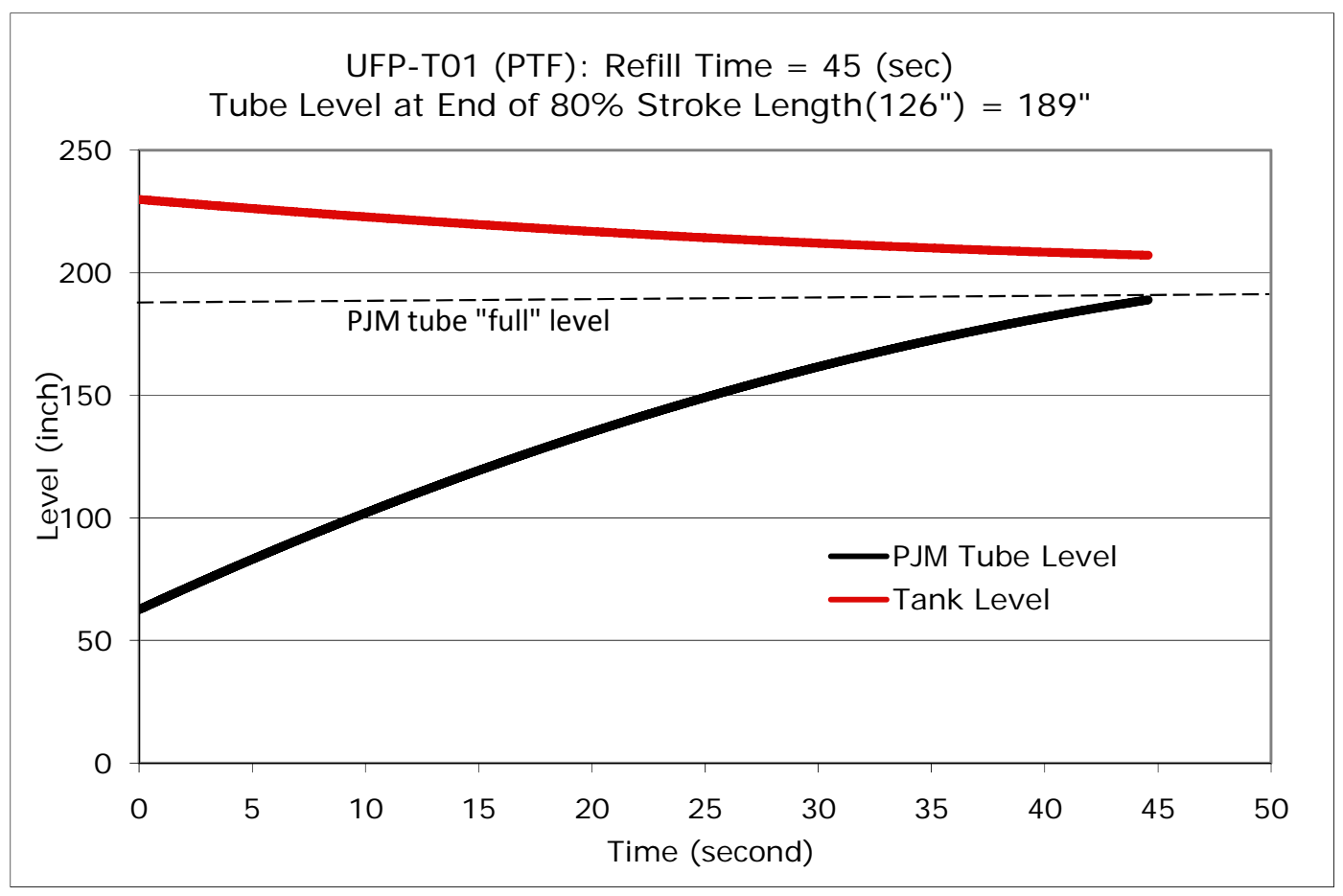

Figure 13.3. UFP-VSL-T0001A/B Full-Scale PJM Gravity Refill 


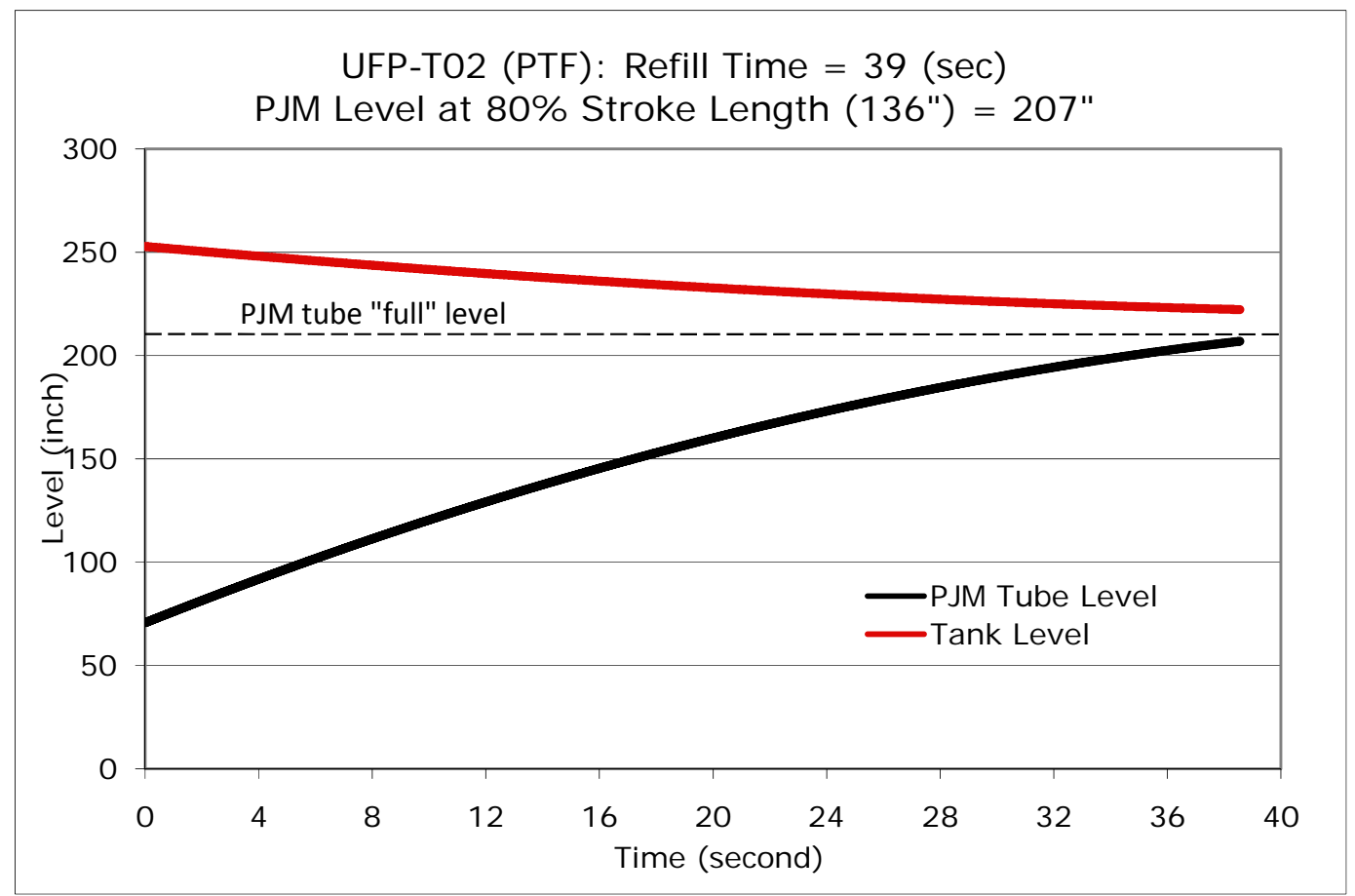

Figure 13.4. UFP-VSL-T0002A Full-Scale PJM Gravity Refill

The figures above show that the best-estimate refill times for the equivalent WTP vessels, UFP-VSL-00001 and UFP-VSL-00002, were approximately 45 seconds and 39 seconds, respectively. Table 13.2 shows the refill times with typical discharge times, total cycle times, and "excess" times for each vessel during its respective caustic-leach. Excess time is the time available after the PJM has filled before the next drive is to start.

Table 13.2. Excess Times for WTP Vessels UFP-VSL-00001 and UFP-VSL-00002 with Gravity Refill

\begin{tabular}{cccccc}
\hline Vessel & $\begin{array}{c}\text { Nozzle } \\
\text { Velocity, } \\
\mathrm{m} / \mathrm{s}\end{array}$ & $\begin{array}{c}\text { Total Cycle } \\
\text { Time, } \\
\text { seconds }^{\mathrm{a}}\end{array}$ & $\begin{array}{c}\text { Refill Time, } \\
\text { seconds }\end{array}$ & $\begin{array}{c}\text { Drive Time, } \\
\text { seconds }^{\mathrm{b}}\end{array}$ & $\begin{array}{c}\text { Excess, } \\
\text { seconds }\end{array}$ \\
\hline UFP-VSL-00001 & 8 & 96 & 45 & 33 & 18 \\
UFP-VSL-00002 & 12 & 91 & 39 & 19 & 33 \\
\hline
\end{tabular}

The results of Table 13.2 are encouraging in that they show that the gravity refill of the full-scale PJMs can be accomplished within the available cycle time, and the excess times exceed those modeled for PEP operation. Although the results are encouraging, they cannot be considered definitive. There is a key assumption that must be emphasized: The Bernoulli loss coefficient for PEP is based upon very limited data and the coefficient is assumed to be the same for the larger nozzle in WTP. The result should be corroborated with additional tests using different size nozzles to verify the Bernoulli loss coefficient, literature data and/or more advanced models of the PJM flow. It should also be noted that the rheological

(a) Bechtel. 2007. UFP-VSL-T01A/B and UFP-VSL-T02A Pulse Jet Mixer (PJM) and Sparger Design Information. CCN 151777, Bechtel, Inc., Richland, Washington.

(b) Estimated drive time is scaled as PEP drive time $\mathrm{x}(4.5)^{2 / 3}$ 
properties for the caustic-leach (operated at elevated temperature and after caustic addition) are less challenging than the bounding rheological properties assumed for the PTF (e.g., Bingham plastic with a yield stress of $30 \mathrm{~Pa}$ and a consistency of $30 \mathrm{cp}$ ).

\subsubsection{Assessment of PEP PJM Operational Stability}

This subsection provides an assessment of how the PEP process changes in simulant level, density, and temperature affected the performance of the PJMs used in mixing Tanks T01 A/B and T02A. The assessment is based on data from the Functional Test and Integrated Test B (these tests had data for conducting the analysis for the full range of conditions). The PJM performance parameters shown in this section are calculated from PJM pressure data using a method similar to that described in Appendix F of Geeting et al. (2009). The mixing provided by the PJMs was a critical PEP operating parameter so these results provide some insight into the stability of the mixing provided by the PJMs during the testing.

It should be noted that PJM control parameters were adjusted in each Integrated test at the start of the first caustic-leach batch in each tank to provide prototypic PJM mixing during the caustic-leach steps for the Newtonian caustic-leach slurry. The control parameters were adjusted again after post-caustic-leach solids concentration to achieve prototypic PJM mixing of the non-Newtonian slurry. No other adjustments that would significantly affect nozzle velocities were made (e.g., drive pressure was not adjusted other than at the two times specified). Small adjustments to maintain a stroke length of approximately $80 \%$ and avoid overblows were made as deemed necessary, with the understanding that the optimized PTF automatic PJM stroke control will be more robust than that of the PEP. Between tests, the PJMs in Tank T02A were readjusted, generally using just previously recorded control parameters, so that they would provide prototypic mixing of Newtonian fluid at the start of the following test. Thus, PJM performance in the PEP was established at specific times and allowed to change with process conditions, similar to the current PTF control strategy for PJMs.

The PEP testing employed three different PJM operation modes. These modes were as follows:

1. Standard mode: Vacuum and vent phases operated according to the level in the PJM, and each PJM was controlled independently. This mode mimics the full cycle mode for PTF. In PTF the full condition of each PJM body is detected by a subtle pressure deviation during refill. PEP could not employ this method and attempted to provide the same control information using the Drexelbrook level probes.

2. Simple mode: Vacuum and vent phases operated according to a fixed preselected time, and all PJMs in a tank were controlled by the same timing sequence. This was a fall-back mode necessitated when the Drexelbrook level probes didn't function properly.

3. Star mode (Tank T02A only): The center PJM and only one outer PJM operated at any time. The center PJM was always operated, and the outer PJMs were each operated for about five cycles on a rotating basis. The pattern of operation of the outer PJMs formed a star. This mode was adapted from the PTF short-stroke mode to be applied at low tank levels. In the short-stroke mode the stroke each PJM is filled completely and the discharge stroke is shortened to about $20 \%$ to avoid aspirating at low tank levels. During short-stroke significant volume of fluid is held in the PJM bodies. During PEP testing it was considered that the volume of fluid held in the PJMs removed too much workable fluid from the vessel and could impact the test results so the star mode was adapted. 
Normally, the PJMs were intended to operate in standard mode. However, the simple mode was used for most of the testing because the nonprototypic Drexelbrook PJM level probes were not functioning properly (i.e., when slurry was inadvertently pulled into the PJM neck and with a slurry temperature above about $60^{\circ} \mathrm{C}$ ). The star mode was used to limit the drop in tank slurry level due to PJM filling and thereby allow pumping from Tank T02A at slurry levels very near the pump heel level. It should also be noted that the PEP PJM air supply and control systems differ from the planned PTF systems.

\subsubsection{PJM Variability Under Constant Conditions (tank conditions fixed)}

During the solids stratification test conducted as part of the Functional Test in Tank T01A on November 24, 2008, seven analyses were performed over a 12-hour period (approximately every 2 hours) to determine PJM peak average nozzle velocity, stroke length, and cycle time. No transfers in or out of the tank were conducted, and changes in conditions (level, temperature, rheology, density) were minimal. Analyses indicate that the PJM operating parameters were reasonably constant. Based on data sets evaluated at 2-hour intervals over the 12-hour period, the peak average PJM nozzle velocity exhibited a maximum change of $0.4-\mathrm{m} / \mathrm{sec}(3.2-3.6-\mathrm{m} / \mathrm{s} ; \sim 8 \%$ ), the stroke length varied only about $5 \%$ (70 to $75 \%$ of full stroke), and the cycle time, an operator-specified parameter, was constant.

The PJM stability was also checked when tank conditions were constant in Tank T02A during the backpulsing period of the low-solids filtration test conducted in November 2008. During the course of this 12 -hr test, the stroke length varied from 72 to $73 \%$ of full stroke and the PJM nozzle velocity was constant at $7.5-\mathrm{m} / \mathrm{s}$.

\subsubsection{PJM Variability During Post-Caustic-Leach Washing}

During the post-caustic-leach wash in Tank T02A for Integrated Test B, the PJMs were operated in star mode. Over the course of the washing, the PJM nozzle velocity increased about 17\% (from 9.2- to $10.8-\mathrm{m} / \mathrm{s}$ ), and the stroke length increased from 58 to $71 \%$ of full stroke. Since the PJM control parameters were held constant during the wash, this increase was probably due to the decrease in slurry density from washing.

\subsubsection{PJM Variability During Temperature Change in Tank T02A}

The variability of the PJM operating characteristics, based on 1-Hz data, is shown in Table 13.3 for the heat-up before caustic leaching in Tank T02A during the Functional Test. Here the PJMs were operated in simple mode with PJM temperature compensation enabled. ${ }^{(a)}$ Temperature-corrected values for the slurry density were calculated based on analytically determined slurry and supernatant densities of samples. Note that the decrease in density is due both to thermal expansion and the addition of steam condensate, and there was a small increase in slurry level. As indicated in Table 13.3, the nozzle velocities and stroke were approximately constant over the initial $20^{\circ} \mathrm{C}$ temperature rise and after PJM

(a) The standard and simple mode operations incorporated a temperature linearization variable that reduced the drive time to prevent overblows as temperature increased. The variable was expressed as a slope, the percent of drive time decrease per degree Celsius increase from zero degrees Celsius. This function was largely untested; a modest $0.25 \%$ linearization factor was used in early testing and adopted for the remainder of testing simply because it seemed to work, and further optimization was not conducted (Geeting et al. 2009). 
adjustments over the final $9^{\circ} \mathrm{C}$ rise. Table 13.4 gives analogous results for the post-caustic-leach cool-down, and similarly small changes in PJM performance were found.

Table 13.3. PJM Variability During Heating in Tank T02A

\begin{tabular}{cccccc}
\hline $\begin{array}{c}\text { Data Set } \\
\begin{array}{c}\text { Date: Time in PST at Start } \\
(\mathrm{mm} / \mathrm{dd} / \text { year })(\mathrm{hr}: \mathrm{min})\end{array}\end{array}$ & $\begin{array}{c}\text { Tank } \\
\text { Temperature } \\
\left({ }^{\circ} \mathrm{C}\right)\end{array}$ & $\begin{array}{c}\text { Calculated } \\
\text { Slurry Density } \\
\left(\mathrm{kg} / \mathrm{m}^{3}\right)\end{array}$ & $\begin{array}{c}\text { PJM Nozzle } \\
\text { Velocity } \\
(\mathrm{m} / \mathrm{s})\end{array}$ & $\begin{array}{c}\text { Stroke Length } \\
(\text { in. })(\%)\end{array}$ & $\begin{array}{c}\text { PJM Cycle } \\
\text { Time }(\mathrm{s})\end{array}$ \\
\hline 1/2/2009 12:01 & 66 & 1409 & 6.2 & $13.135 \%$ & 33 \\
$1 / 2 / 200912: 31$ & 75 & 1395 & 6.4 & $13.435 \%$ & 33 \\
$1 / 2 / 200913: 24$ & 86 & 1379 & 6.3 & $12.734 \%$ & 33 \\
$1 / 2 / 200913: 31$ & PJM drive time and pressure were increased at this time. & & 33 \\
$1 / 2 / 200913: 34$ & 86 & 1379 & 7.5 & $24.665 \%$ & 33 \\
\hline $1 / 2 / 200914: 06$ & 95 & 1343 & 7.8 & $25.467 \%$ & 33 \\
\hline
\end{tabular}

Table 13.4. PJM Variability During Cool-Down in Tank T02A

\begin{tabular}{|c|c|c|c|c|c|}
\hline Data Set & Tank & Calculated & PJM Nozzle & Stroke & \\
\hline $\begin{array}{l}\text { Date: Time in PST at Start } \\
(\mathrm{mm} / \mathrm{dd} / \mathrm{year})(\mathrm{hr}: \mathrm{min})\end{array}$ & $\begin{array}{c}\text { Temperature } \\
\left({ }^{\circ} \mathrm{C}\right)\end{array}$ & $\begin{array}{l}\text { Slurry Density } \\
\left(\mathrm{kg} / \mathrm{m}^{3}\right)\end{array}$ & $\begin{array}{l}\text { Velocity } \\
(\mathrm{m} / \mathrm{s})\end{array}$ & $\begin{array}{l}\text { Length } \\
\text { (in.) }(\%)\end{array}$ & $\begin{array}{l}\text { PJM Cycle } \\
\text { Time (s) }\end{array}$ \\
\hline $1 / 3 / 200906: 38$ & 97 & 1307 & 7.3 & $27.472 \%$ & 33 \\
\hline 1/3/2009 09:15 & 80 & 1322 & 7.1 & $27.873 \%$ & 33 \\
\hline 1/3/2009 09:44-10:42 & \multicolumn{5}{|c|}{$\begin{array}{l}\text { No analysis done during this period due to adjustments to PJM settings, } \\
\text { including reduced drive time. Note that after this time, PJMs did not show even } \\
\text { pressure distribution. }\end{array}$} \\
\hline $1 / 3 / 200910: 52$ & 57 & 1339 & 6.5 & $26.269 \%$ & 33 \\
\hline 1/3/2009 14:06 & 40 & 1349 & 6.4 & $26.269 \%$ & 33 \\
\hline $1 / 3 / 200922: 32$ & 24 & 1356 & 6.3 & $27.071 \%$ & 33 \\
\hline
\end{tabular}

\subsubsection{PJM Variation During Level Change}

Large tank level changes occurred in Tank T01A during the pre-caustic-leach solids concentration step before caustic leaching in Tank T02A (Functional testing). During this process, the Tank T01A contained neat simulant and its PJMs were operated in standard mode. Data obtained during the functional testing shown in Table 13.5 indicate that the 16-in. decrease in level caused about a 10\% increase in nozzle velocity. Qualitatively, this is the expected result. The variation in calculated stroke length given in Table 13.5 may be due to the variability of the calculation or the nonprototypic PEP PJM controls. No change in stroke length was expected due to the use of the standard PJM control mode (which stops the drive at a set PJM level). 
Table 13.5. PJM Variation During Level Change in Tank T01A

\begin{tabular}{ccccc}
\hline $\begin{array}{c}\text { Data Set } \\
\begin{array}{c}\text { Date: Time in PST at Start } \\
\text { (mm/dd/year) (hr:min) }\end{array}\end{array}$ & $\begin{array}{c}\text { Starting Tank } \\
\text { Level }^{(\mathrm{a})} \\
\text { (in.) }\end{array}$ & $\begin{array}{c}\text { PJM Nozzle } \\
\text { Velocity } \\
\text { (m/s) }\end{array}$ & $\begin{array}{c}\text { Stroke Length } \\
\text { (in.) }(\%)\end{array}$ & $\begin{array}{c}\text { PJM Cycle } \\
\text { Time (s) }\end{array}$ \\
\hline $11 / 30 / 200822: 59$ & 63 & 4.4 & $31.088 \%$ & 35 \\
$11 / 30 / 200823: 22$ & 57 & 4.5 & $29.885 \%$ & 35 \\
$11 / 30 / 200823: 39$ & 52 & 4.8 & $30.988 \%$ & 35 \\
$12 / 1 / 2008$ 00:23 & 47 & 4.9 & $28.581 \%$ & 35 \\
\hline & & & & \\
\hline (a) Tank level is presented for information only. & & & &
\end{tabular}

\subsubsection{Conclusions-PEP PJM Operational Stability}

Based on the limited data sets evaluated to assess the PJM operational stability, the following is concluded:

- During test steps in which the density, temperature, and level in the vessel were constant, the PJMs' operating characteristics were stable.

- Changes in density during post-caustic-leach wash resulted in modest changes in PJM performance when operating in star mode. Over the course of the washing, the PJM nozzle velocity increased about $17 \%$ (from $9.2-10.8-\mathrm{m} / \mathrm{s}$ ), and the stroke length increased from $58-71 \%$ of full stroke.

- Based on data obtained during the pre-caustic-leach solids concentration for PJMs operating in Tank T01A a 16-in decrease in level caused about a 10\% increase in nozzle velocity.

\subsubsection{PJM Plugging Issue}

During Integrated Test B, one of the PJMs in Tank T01A displayed unusual level behavior as indicated by the Drexelbrook level probe and was inoperative during most of the test. The level in the PJM was observed to be unchanged even though the expected air pressure was being applied during the drive phase. An intentional overblow resolved the issue for approximately 1 hour. However, the level probe displayed the same behavior again and the PJM was disabled when additional overblows did not resolve the issue. The source of the behavior was thought to be a plug, but could not be verified during testing because this would have required disrupting the chemical processes during the test. If a plug was present it likely occurred in the 2-in. air supply line above the PJM. The Drexelbrook level probes were inserted through the air line at the top of the PJM, and a plastic spacer was added to the level probe to stabilize it. This spacer provided a significant constriction in the air supply line a few inches above the top of the PJM tube. It is suggested that some of the simulant caked around the level probe spacer and eventually plugged the air supply line. Extensive post-test inspections did not reveal any plug in the air line or the PJM nozzle. A simulant plug may have been rinsed out by the flushing operations that were conducted before inspection. Instrument and equipment failures were also investigated as possible causes after testing was complete. The post-test inspection verified that the air supply was properly functioning, including the valves and the regulator. After rinsing and flushing the level probe was also verified to work properly. 
If plugging was due to the constriction in the air supply line, this problem is not expected to occur in the PTF PJMs because they do not have Drexelbrook level probes and spacers. In addition, the PTF has an air supply wash-down system designed to clean the PJM air supply lines that the PEP does not have.

\subsection{In-Line Chemical Addition}

Many of the chemicals introduced into PEP processes were added in-line to the filter-loop while recirculating slurry. This includes caustic, IW, CrOOH slurry, and sodium permanganate. The 19-M $\mathrm{NaOH}$ was also added in-line during simulant transfer to Tanks T01A/B during Integrated Test $\mathrm{A}$. The in-line additions during each Integrated test were performed successfully. The amount of chemical delivered in-line met target amounts as given in the run sheets; the in-line delivery was precisely controlled and consistently reproducible.

One of the early concerns identified in the design of the WTP was the possibility that fluid returning to the ultrafiltration feed vessels from the filter-loop would be channeled into the suction of the filter-loop pumps, thereby reducing the effectiveness of the mixing in the vessels. This "short-circuiting" could occur because fluid, which is entering the vessels at a high velocity through the recirculation loop nozzle, may flow directly to the suction pump inlet for the filter-loop. During PEP Integrated testing, three tracer tests were performed to evaluate the system for evidence of short-circuiting and provide qualitative information about the blending time in the PEP filtration system.

Originally, the Test Plan called for two tracer tests to evaluate short-circuiting in Tank T02A at the very beginning of the post-caustic-leach wash (i.e., when the slurry is $\sim 17$-wt $\%$ UDS, and liquid viscosity is high): the first when the slurry level in Tank T02A is low (i.e., when caustic leaching is conducted in Tank T02A, tracer test 1), and the second when the level in Tank T02A is high (i.e., when caustic leaching is conducted in T01A, tracer test 2). Difficulty in obtaining target mixing conditions necessitated that the tracer test be repeated for the high vessel level in Tank T02A (tracer test 3).

In each test, a $\mathrm{CsBr}$ tracer was injected into the suction of the filter-loop pumps. Chemical tracer tests were performed to evaluate this issue with a relatively high slurry level in Tank T02A ( 41- to 43-in.) and with a relatively low slurry level ( $\sim 15$-in.). Samples were obtained from two locations: in the filter-loop downstream of the injection point and the outer-lower sample location in Tank T02A. These are shown in Table 13.6 at 2, 4, and 60 minutes from tracer injection. In all three tests, the Cs concentration at the two sample locations was essentially the same within 4 minutes. In tracer test 3 , which was performed at the prototypic flow rate of 109 GPM, the concentrations were in agreement within 2 minutes. Thus, it was concluded that the majority of the blending was achieved in around 2 to 4 minutes ( $\sim 3$ to 4 filter-loop residence times).

It should be pointed out that this does not imply that Tank T02A was completely mixed in 2 to 4 minutes. A decrease in tracer concentration was observed between the 4- and 60-min samples ranging from 8 to $10 \%$ in all three tracer tests. The decrease was generally within the limits of the analytical uncertainty, but the consistency of this decay suggests there was a portion of the volume that mixed much more slowly than the rest. This could be from several sources: gradual mixing of the tracer with the dead volume in the filter-loop (estimated to be 9 gallons), slurry in the PJM tubes isolated from larger-scale mixing behavior, or other inhomogeneities. 
All three tracer tests suggest that mixing, subject to the qualifications mentioned above, was achieved within 2 to 4 minutes of tracer injection ${ }^{\mathrm{a}}$. This implies that short-circuiting was not a significant problem. The filter-loop flow rates and other mixing parameters were not consistent across the tests, so the process conditions should be taken into account when predicting mixing performance. For more detailed information, the tracer tests are discussed in Baldwin (2009), Section 5.3.

Further evidence that in-line addition effectively blends chemicals was observed during other PEP operations. For example, the IW during both post-caustic-leach and post-oxidative-leach washing was added in-line to the filter-loop. It was found that soluble species were removed as expected (a wash efficiency of approximately 1). This is consistent with the notion that IW blends quickly into the slurry, diluting the soluble species so they can be removed by the ultrafilters. During the oxidative-leach, sodium permanganate was also added in-line to the filter-loop. It blended quickly with the slurry, as evidenced by the oxidative-leach reaction going to completion in under 5 minutes. As discussed in section 7.4, caustic was found to be well mixed in Tank T01A by the time the first samples were obtained 25 minutes after adding the caustic. The caustic was found to be well mixed in Tank T02A by the time the first samples were obtained 15 minutes after adding the caustic.

Table 13.6. Cesium Concentration Data as Measured by ICP-MS from Tracer Tests Performed During Integrated Tests A and B

\begin{tabular}{|c|c|c|c|c|c|c|}
\hline \multirow[b]{2}{*}{$\begin{array}{l}\text { Time Since } \\
\text { Tracer } \\
\text { Injection }\end{array}$} & \multicolumn{2}{|c|}{ Tracer Test 1} & \multicolumn{2}{|c|}{ Tracer Test 2} & \multicolumn{2}{|c|}{ Tracer Test 3} \\
\hline & $\begin{array}{l}\text { Cs }(\mathrm{mg} / \mathrm{kg}) \\
\text { Filter-Loop }\end{array}$ & $\begin{array}{l}\mathrm{Cs}(\mathrm{mg} / \mathrm{kg}) \\
\text { Tank T02A }\end{array}$ & $\begin{array}{l}\text { Cs }(\mathrm{mg} / \mathrm{kg}) \\
\text { Filter-Loop }\end{array}$ & $\begin{array}{l}\mathrm{Cs}(\mathrm{mg} / \mathrm{kg}) \\
\text { Tank T02A }\end{array}$ & $\begin{array}{l}\text { Cs }(\mathrm{mg} / \mathrm{kg}) \\
\text { Filter-Loop }\end{array}$ & $\begin{array}{l}\mathrm{Cs}(\mathrm{mg} / \mathrm{kg}) \\
\text { Tank T02A }\end{array}$ \\
\hline $\begin{array}{l}2 \text { min after } \\
\text { tracer }\end{array}$ & $139 \pm 8$ & $111 \pm 7$ & $145 \pm 9$ & $94.6 \pm 5.7$ & $110 \pm 7$ & $107 \pm 6$ \\
\hline $\begin{array}{c}4 \text { min after } \\
\text { tracer }\end{array}$ & $112 \pm 7$ & $108 \pm 6$ & $108 \pm 7$ & $107 \pm 6$ & $107 \pm 6$ & $106 \pm 6$ \\
\hline $\begin{array}{l}60 \text { min after } \\
\text { tracer }\end{array}$ & $101 \pm 6$ & $101 \pm 6$ & $96.9 \pm 5.8$ & $96.0 \pm 5.8$ & $97.4 \pm 5.9$ & $98.0 \pm 5.9$ \\
\hline $\begin{array}{c}\text { Mixing } \\
\text { parameters }\end{array}$ & $\begin{array}{c}\text { Loop flow: } \\
\text { Spargers, s } \\
\text { PJMs }\end{array}$ & $\begin{array}{l}0-140 \text { GPM } \\
\text { n purge ON } \\
2.1-\mathrm{m} / \mathrm{s}\end{array}$ & $\begin{array}{r}\text { Loop flow } \\
\text { Spargers, st } \\
\text { PJMs at } 11.7\end{array}$ & $\begin{array}{l}\text { 5-75 GPM } \\
\text { t purge OFF } \\
\text { s (star mode) }\end{array}$ & $\begin{array}{c}\text { Loop flow: } \\
\text { Spargers, st } \\
\text { PJMs }\end{array}$ & $\begin{array}{l}\text { 9-111 GPM } \\
\text { purge OFF } \\
1.6-\mathrm{m} / \mathrm{s}\end{array}$ \\
\hline
\end{tabular}

\subsection{Flushing}

In WTP, lines and equipment are periodically flushed to prevent plugging with settled solids and to prevent accumulation of flammable gas (e.g., hydrogen). The flushing of the ultrafilters is considered especially important because of the greater potential to plug the tubes with non-Newtonian slurry. Transfer line volumes in PEP are significantly larger than prototypic, so flushing lines between transfers would either cause nonprototypic dilution of the process stream or incomplete flushing. In general, the PEP process lines were not flushed after transfers, and no line plugging issues were encountered. The ultrafilters were flushed with IW whenever the filter-loop was to be isolated for an extended time (e.g., during caustic leaching in Tank T02A). Typically, a specified amount of the slurry (the prototypic filter-loop volume, not the actual PEP filter-loop volume) was flushed from the filter-loop pumps forward

(a) The filter loop flow rate and mixing in Tank T02A was at scale-time during all three tracer tests so the mixing in the PTF vessels would be expected to be $\sim 4.5 \mathrm{x}$ slower. 
to the Tank T02A. A second much larger volume flush of the ultrafilters to the storage tanks T62A/B was then conducted to avoid excess dilution of the slurry in Tank T02A and prevent gel formation in the filters. After the second flush volume, the filter-loop was left full of IW, which was drained immediately before the next use. Because the PEP was not designed to perform filter-loop backflushing at the high prototypic flow rate, the effectiveness of the PTF filter backflushing operation could not be demonstrated.

\subsection{Solids Accumulations}

This subsection covers the success criterion that any solids accumulations observed during any operating stage or maintenance evolution be recorded.

Small amounts of solids were observed when PEP components were dismantled for maintenance, though the volume of solids was not significant enough to impair operations. The solids were found in line drains that were not cycled during testing, pump casing cleanout valves, and other low points in the system that were not in the main process flow. It should be noted that the PEP design and/or operation of the low points and clean outs was not prototypic of the PTF. In general, significant solids accumulation was not observed and was not an issue during testing.

After completing Integrated Test D, the PEP filters and process vessels and lines were cleaned out (Sevigny et al. 2009). The results of the filter cleaning effort are discussed in section 13.5. When the Tank T01A sampler recirculation loop was cleaned out, a small deadleg was found to have sediment build-up that needed to be blown out with pressurized air. This build-up was due to not cleaning the sampling system lines at the end of testing.

Two different cleaning processes where used for process vessels Tank T01A and Tank T02A. Tank T01A was cleaned with inhibited water and Tank T02A was cleaned with a prototypic nitric acid wash.

In the cleanout of Tank T01A, the empty tank was filled with 0.01-Molar (caustic) IW that was heated to $85^{\circ} \mathrm{C}$. The steam ring was valved out, and the pulse jet mixers were operated during flushing. The tank was recirculated through HX-T04A and HX-T05A and both HX bypass lines. The heated IW rinse left a film on the wall that can be seen in Figure 13.5 and Figure 13.6. 


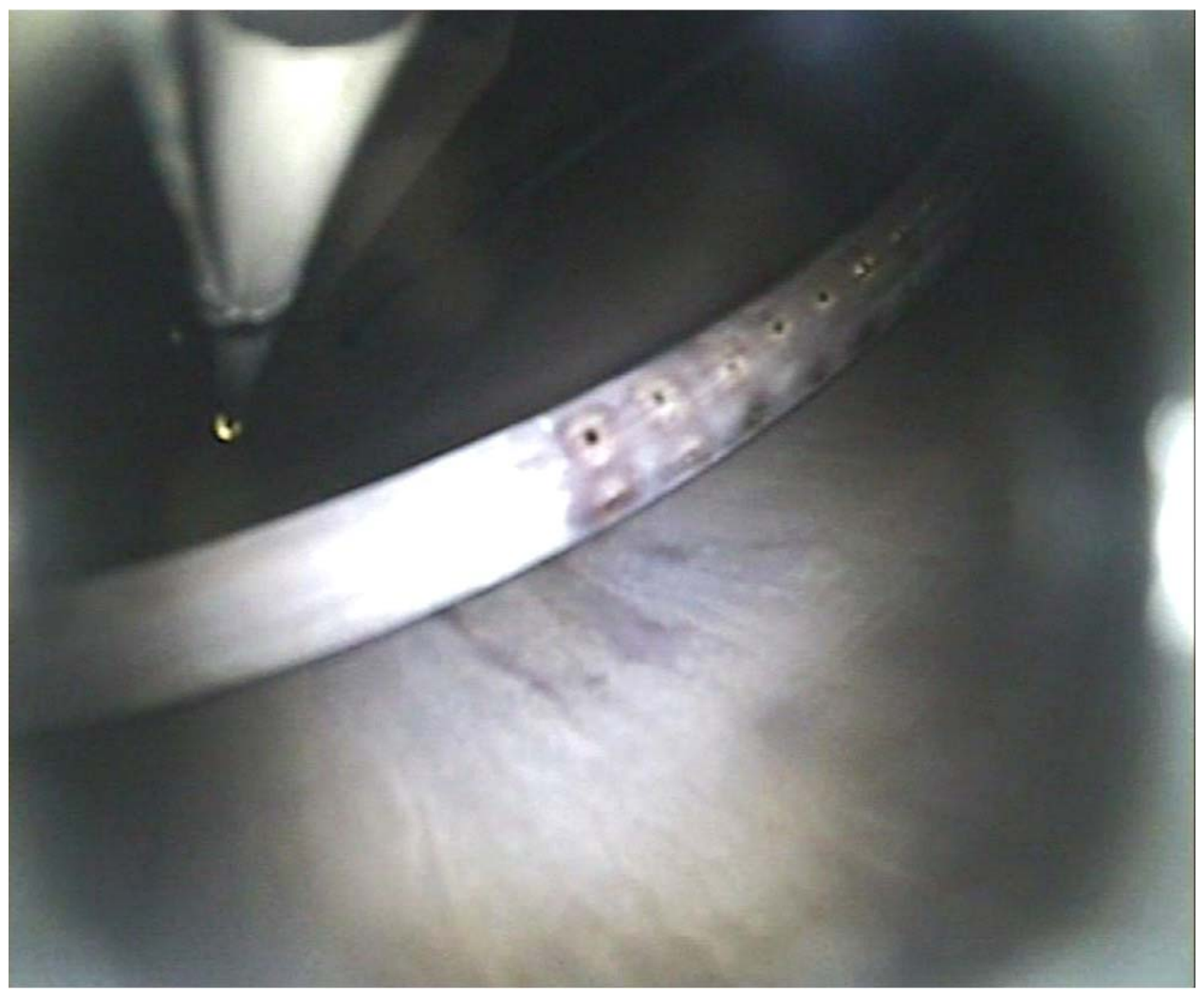

Figure 13.5. The Tank Bottom and Steam Ring in Tank T01A After IW Cleaning

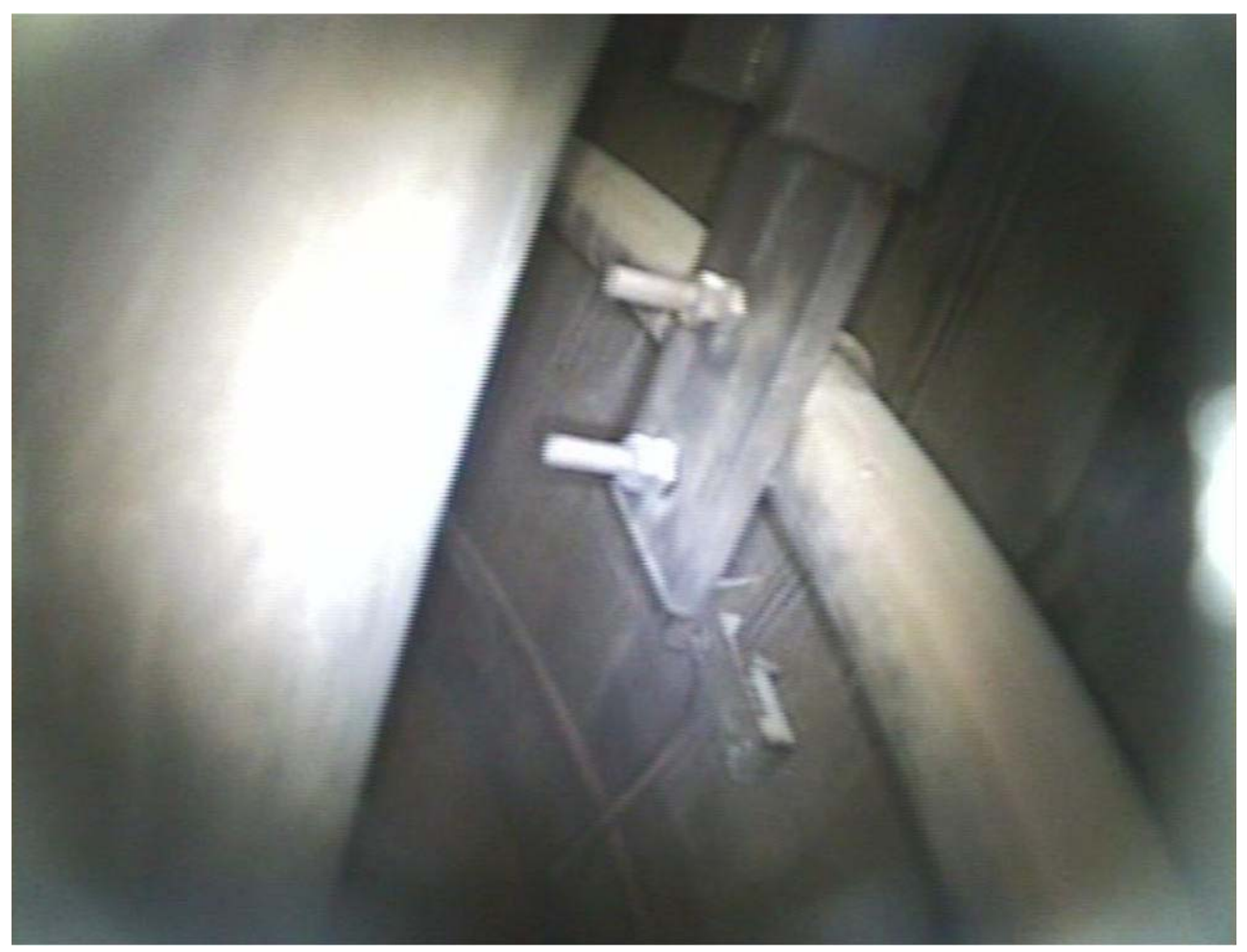

Figure 13.6. The Steam Ring and Bracket in Tank T01A After IW Cleaning 
In the cleanout of Tank T02A, the vessel was drained of process slurries and then cleaned with nitric acid during the prototypic filter cleaning (see Section 13.5 and Sevigny et al. 2009 for a more detailed description). After the completion of Integrated Test D, 2-M nitric acid was placed in Tank T02A to conduct the prototypic ultrafilter cleaning (Sevigny et al. 2009). After the prototypic ultrafilter cleaning was completed, Tank T02A was inspected for solids accumulation using a video camera. The prototypic cleaning process left the tank well cleaned in those portions of the vessel exposed to the acid (Figure 13.7). The upper portions of the vessel that were not substantially exposed to the nitric acid show some splatter remaining after the wash (Figure 13.8).

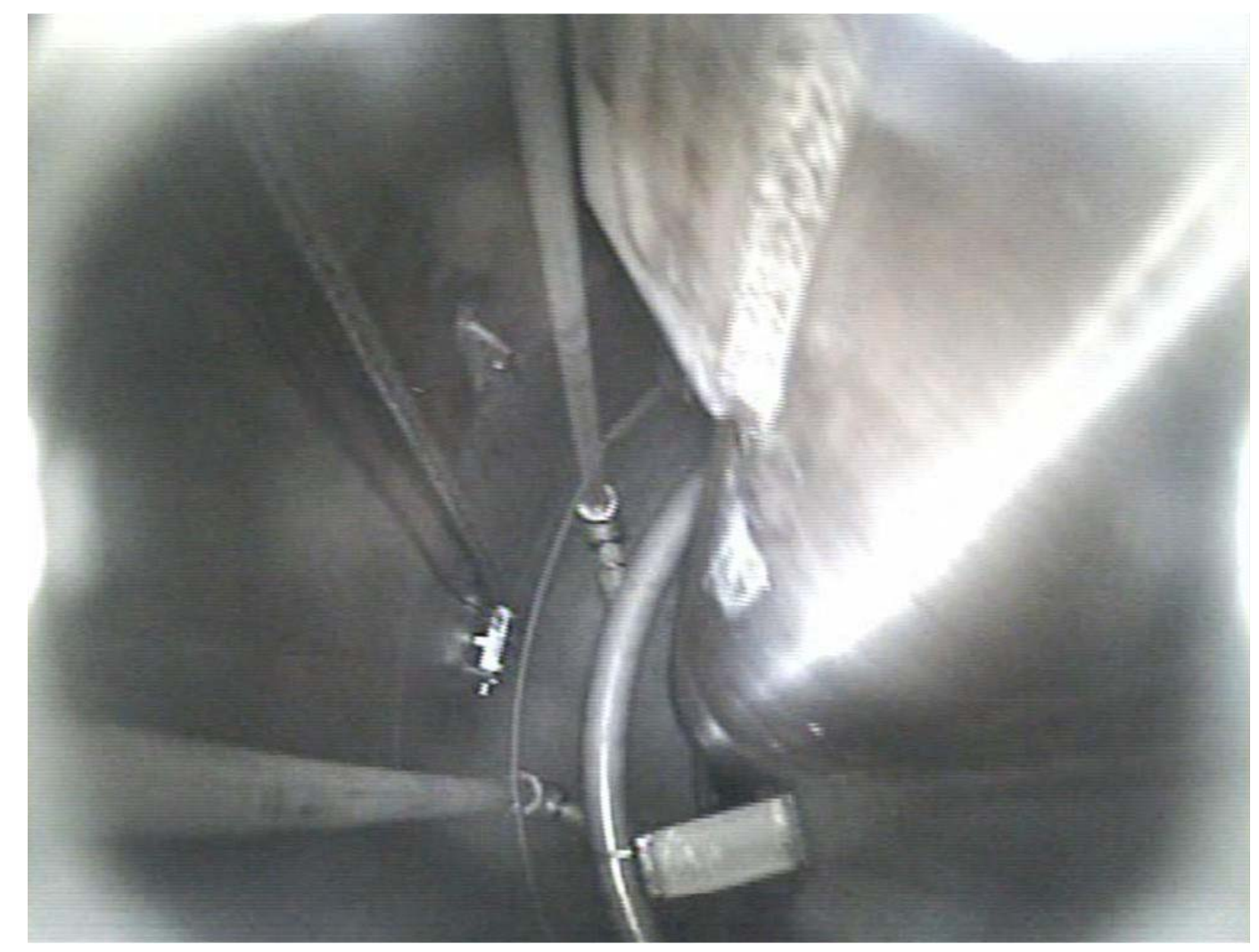

Figure 13.7. Tank T02A After the Prototypic Nitric Acid Cleaning. This is the portion of the tank that was exposed to acid during the cleaning process. 


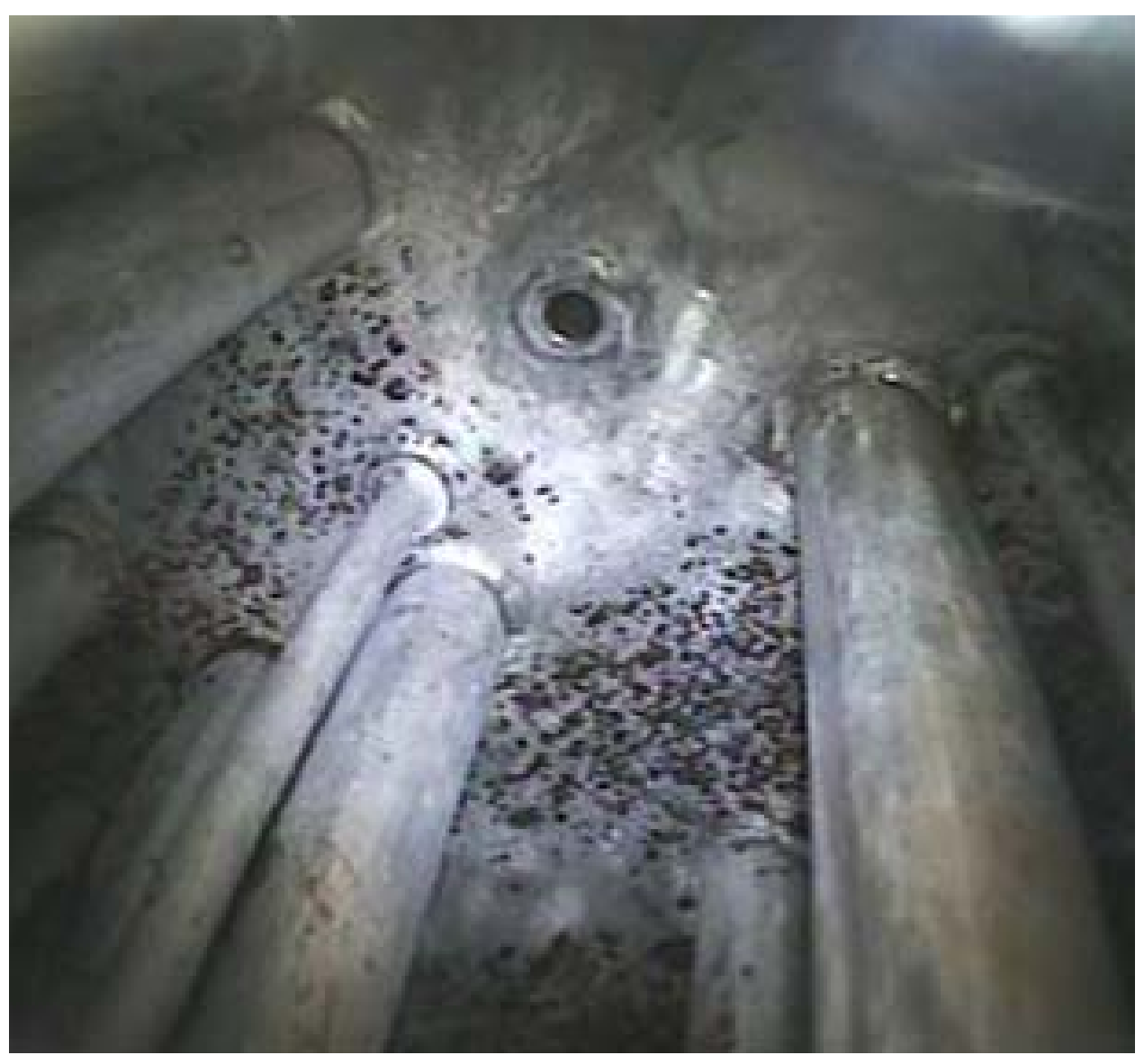

Figure 13.8. Tank T02A After the Prototypic Nitric Acid Cleaning. This is the portion of the tank that was above the acid during the cleaning process.

The effectiveness of the prototypic nitric acid cleanout in Tank T02A is shown in Figure 13.9 (the before-acid wash image) and in Figure 13.10 (the after-acid wash images). 


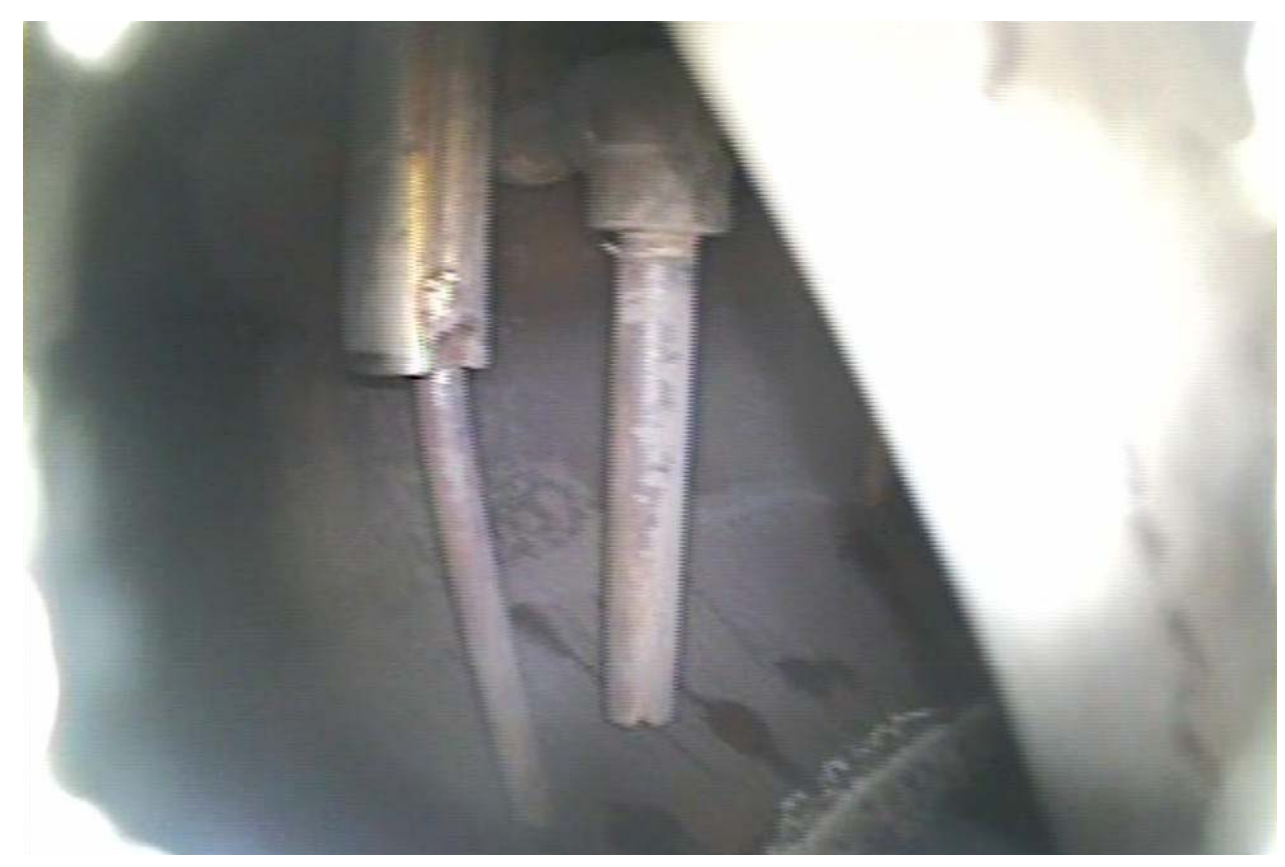

Figure 13.9. Tank T02A Before the Prototypic Nitric Acid Cleaning

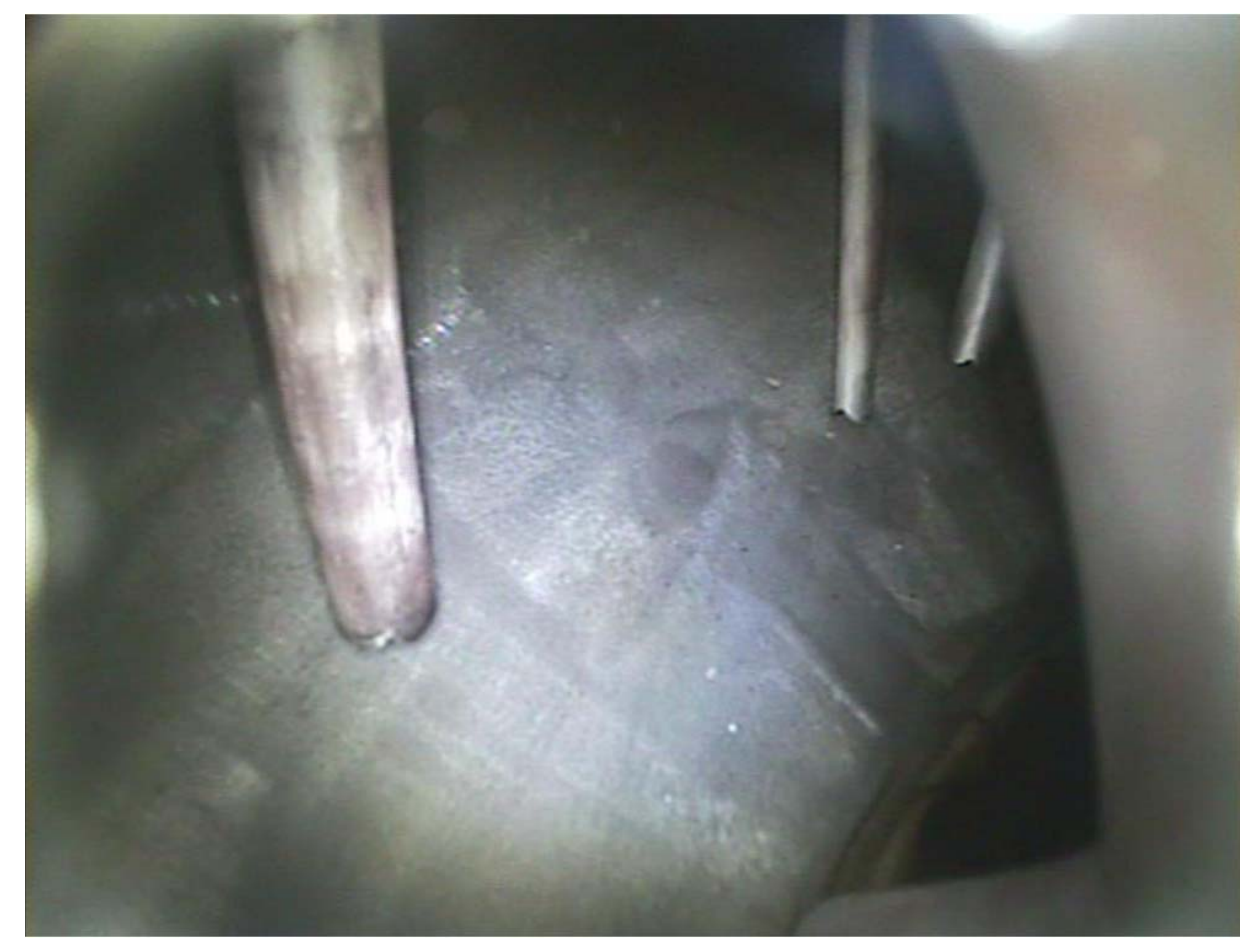

Figure 13.10. Tank T02A After the Prototypic Nitric Acid Cleaning 


\subsection{Ultrafilter Assembly Cleaning Events and Final Filter Inspection}

During the PEP Shakedown/Functional testing and the three Integrated test runs, ultrafilter cleaning was conducted using oxalic acid and nitric acid processes. These clean out events are listed in Table 13.7. The PEP ultrafilter chemical cleaning was based in part on the Cell Unit Filter (CUF) testing discussed in Section 13.5.1. The prototypic nitric acid clean out was conducted after the completion of Integrated Test $\mathrm{D}$ and the clean out is documented in Section 13.5.2. The oxalic acid clean out process was not prototypic of the planned WTP operations.

Table 13.7. Filter Cleaning Events

\begin{tabular}{|c|c|c|c|}
\hline \multirow[b]{2}{*}{ Cleaning Event } & \multirow[b]{2}{*}{ Wash Acid } & \multicolumn{2}{|c|}{ Date } \\
\hline & & Start & Finish \\
\hline $\begin{array}{l}\text { 1st cleaning event: } 0.5-\mathrm{M} \\
\text { oxalic conducted during } \\
\text { Functional testing }\end{array}$ & Oxalic acid & $11 / 7 / 20081600$ & 11/7/2008 22:00 \\
\hline $\begin{array}{l}\text { 1st cleaning event: } 0.5-\mathrm{M} \\
\text { oxalic repeated conducted } \\
\text { during Functional testing }\end{array}$ & Oxalic acid & $11 / 11 / 2009 \quad 2: 20$ & 11/13/2008 8:00 \\
\hline $\begin{array}{l}\text { 2nd cleaning: Before } \\
\text { simulant added } 0.5-\mathrm{M} \\
\text { oxalic conducted during } \\
\text { Functional testing }\end{array}$ & Oxalic acid & $11 / 15 / 2008 \quad 22: 59$ & $11 / 18 / 2008 \quad 10: 01$ \\
\hline $\begin{array}{l}\text { 3rd cleaning: Oxalic acid } \\
\text { conducted during } \\
\text { Functional testing }\end{array}$ & Oxalic acid & $11 / 21 / 2008 \quad 22: 00$ & $11 / 22 / 2008 \quad 18: 00$ \\
\hline $\begin{array}{l}\text { 4th cleaning: Oxalic acid } \\
\text { conducted during } \\
\text { Functional testing }\end{array}$ & Oxalic acid & $12 / 27 / 2008 \quad 0: 00$ & $12 / 28 / 2008$ \\
\hline $\begin{array}{l}\text { 4th cleaning: Oxalic acid } \\
\text { conducted during } \\
\text { Functional testing }\end{array}$ & Oxalic acid & $12 / 28 / 2008 \quad 0: 00$ & $12 / 30 / 2008 \quad 0: 00$ \\
\hline $\begin{array}{l}\text { 5th cleaning: Conducted } \\
\text { after Integrated Test } \mathrm{A} \text { and } \\
\text { before Integrated Test B- } \\
1 \text { st attempt at } \mathrm{HNO}_{3} \\
\text { cleaning }\end{array}$ & Nitric acid & $3 / 1 / 20095: 00$ & $3 / 1 / 2009 \quad 7: 35$ \\
\hline $\begin{array}{l}\text { 6th cleaning: 2nd attempt } \\
\mathrm{HNO}_{3} \text { (diaphragm pump } \\
\text { instead of loop pumps) } \\
\text { before Integrated Test B }\end{array}$ & Nitric acid & $3 / 7 / 2009 \quad 13: 00$ & $3 / 7 / 200923: 30$ \\
\hline $\begin{array}{l}\text { 7th cleaning: Final } \\
\text { prototypic nitric acid clean } \\
\text { conducted after Integrated } \\
\text { Test D }\end{array}$ & Nitric acid & $4 / 28 / 2009 \quad 9: 00$ & $4 / 29 / 2009 \quad 20: 22$ \\
\hline
\end{tabular}

\subsubsection{CUF Ultrafilter Cleaning}

Before beginning the laboratory-scale scaling tests using the cold-CUF, several tests were conducted to support water and simulant Shakedown testing at the PEP, including a study of the PEP process water that was found to be fouling the ultrafilter bundles in the PEP. Billing et al. (2009) describe the steps and 
results of an oxalic acid and nitric acid filter cleaning on the CUF. The summary result of the CUF filter cleaning tests were:

- Flushing with deionized (DI) water resulted in minimal improvement in filter flux.

- Adding 25 ppm Alconox detergent resulted in dissolution and visible removal of dye from the filter with an accompanying increase in flux.

- $\quad 1-\mathrm{M} \mathrm{NaOH}$ cleaning resulted in no further improvement and actually led to a decline in flux as compared to the previous step.

- Adding $1000 \mathrm{ppm}$ Alconox detergent and heating to $60^{\circ} \mathrm{C}$ caused the flux to return to the level observed in the previous Alconox cleaning step.

- 2-M $\mathrm{HNO}_{3}$ cleaning resulted in no improvement.

- $\quad 0.5-\mathrm{M}$ oxalic acid cleaning resulted in the restoration of flux to the filter baseline.

These results led to the early use of oxalic acid for filter cleaning in the PEP. At the end of testing, a prototypic nitric acid cleaning was done to demonstrate the planned PTF filter cleaning process.

\subsubsection{Prototypic Filter Cleaning with Nitric Acid}

At the conclusion of Integrated Test D, the tank, pumps, and filters were flushed out with IW to prepare for cleaning with nitric acid. The Tank T02A vessel was inspected with a small video camera inserted thorough a flange in the top of the vessel (DVD titled "UFP-02A tank inspection" on 4/23/09). The video included inner tank walls, bottom head, upper vessel head, steam pipe and ring (top and bottom), and other internals (look for bathtub ring and deposits on internals, especially near upper simulant levels) before introducing the IW.

A visual inspection was performed at the inlet to ultrafilter UFP-FILT-T01A. The inspection was performed on 4/23/09, after Integrated Test D, Phase I. Valve V07128 was removed from the filter-loop to provide access to the inlet of filter T01A.

The following steps were completed before obtaining the video:

- Simulant slurry remaining in the filter-loop at the end of Integrated Test D was drained to totes (March 31, 2009).

- A single 0.01-M IW flush was performed of the filter-loop and T02A.

- The filters were layed up in 0.01-M IW after the flush.

- $\quad$ Filter T01A was drained just before the video.

The visual inspection consisted of two parts. The first part was performed using a Mirion C911 Series inspection camera. The camera was connected to a Dell flat-panel monitor and Panasonic DMR-EZ48V DVD recorder. This part of the inspection was recorded to a DVD-RW. The camera was inserted into the filter inlet and positioned by hand to observe features of the filter head.

The second part of the inspection was performed using an Olympus 1F8S2-20 fiberscope and ILK-4 cold light supply. This part of the inspection was not recorded. The fiberscope was also inserted into the 
filter inlet and positioned by hand to observe features of the filter head. No unique observations were noted during the inspection with the fiberscope.

\subsubsection{Visual Inspection Results}

The inlet to filter T01A (piping and filter head) had a light brown discoloration as shown in Figure 13.11 that was due to residual simulant film on the metal surfaces. Darker areas of heavier simulant deposition were also observed on the filter head. No significant solids buildup was observed at the filter inlet.

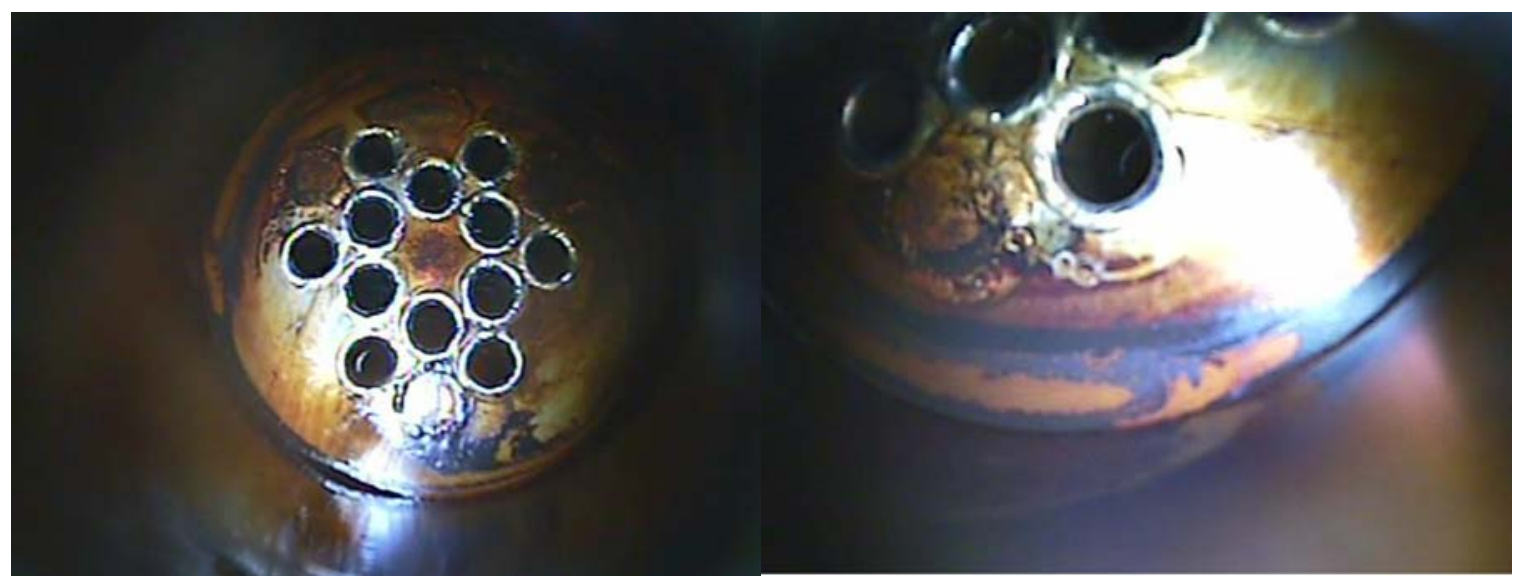

Figure 13.11. Inspections of Filter T01A Inlet

Several small (approximately $1 / 2$ - to 1 -mm) reflective beads were observed near the inlet of the individual ultrafilter tubes. The 8- $\mathrm{ft}$ spare ultrafilter shown in Figure 13.12 was inspected for comparison and also found to have reflective beads near the ultrafilter tube inlet. These beads appeared to be materials from welding and other fabrication activities.

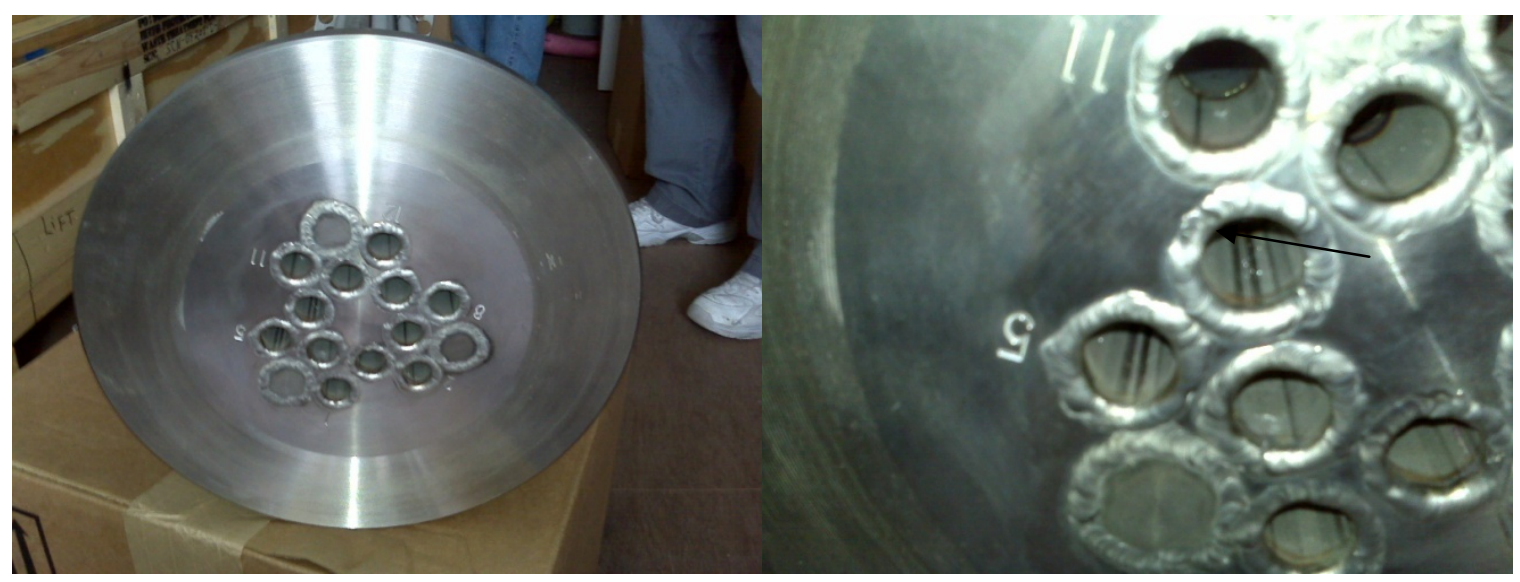

Figure 13.12. Inspections of 8-ft Spare Ultrafilter 


\subsubsection{Ultrafilter Cleaning Conclusions}

No significant solids were observed at the inlet to UFP-FILT-T01A during the April 23, 2009 inspection. The visual inspection did not identify any indications of flow mal-distribution or evidence of potential filter failure.

The beads observed near the inlet to the individual ultrafilter tubes appeared to be stray weld material from the fabrication process and did not appear to be large enough to affect filter performance.

The filter cleaning approach worked well (Sevigny et al. 2009) with permeate rates increasing from the initial clean water flux of about $0.1-\mathrm{kg} / \mathrm{min}-\mathrm{ft}^{2}$ to approximately 0.2 , then 0.8 , and finally about $1.5-\mathrm{kg} / \mathrm{min}-\mathrm{ft}^{2}$ after the three nitric acid contacts. After the acid was neutralized, the final IW permeate rate was approximately $0.8-\mathrm{kg} / \mathrm{min}-\mathrm{ft}^{2}$. The TMP was set at $40 \mathrm{psid}$. If $40 \mathrm{psid}$ could not be maintained, a lower TMP was acceptable. The permeate rates have been corrected to $25^{\circ} \mathrm{C}$ and a TMP of 40 psid.

\subsection{Air Entrainment in the Filter-Loop}

During the Integrated Test A, and to a lesser extent during Integrated Tests B and D, air entrainment in the filter-loop presented significant operational challenges during portions of the filter-loop operations. This problem was first observed after the completion of the post-caustic-leach dewatering step in Integrated Test A. This problem was evident by increased vibration in the filter-loop pumps, increased axial pressure drop across the filter bundles, and most importantly, a loss of filter-loop pump efficiency. Entrained air reduces pump efficiency similar to cavitation, but true cavitation occurs when the pressure inside the pump drops below the vapor pressure of the liquid and bubbles of vapor form (i.e., the liquid boils).

The potential sources of the air were identified as follows:

- Entrainment of air by the filter-loop return nozzle slurry jet: The filter-loop return nozzle in the PEP was approximately 22 inches above the bottom center of Tank T02A with the discharge pointing straight down (refer to Figures 4.14 - 4.18 for a description of the internals of Tank T02A). As the slurry level dropped below the return nozzle, the returning jet entrained air into the slurry, which was then swept into the filter-loop pump suction nozzle. This problem was most evident as the slurry level dropped to near the 22-in. level in the vessel. A video obtained from the tank during Integrated Test A with the filter-loop pumps operating appeared to show the air entrainment into the slurry. Even with the return nozzle covered (estimated to be several inches from video), a vortex was observed that appeared to be drawing surface foam into the slurry. There was minimal evidence of air entrainment during the Functional testing. This is thought to be due to the location of the filter-loop return nozzle which was located such that the return jet directly impacted the sparge ring. This appeared to break up the returning jet and minimized air entrainment. Prior to the start of Integrated Test A, the location filter-loop return nozzle was modified so that the returning jet did not hit any of the tank internals.

- PJM overblows: Although difficult to confirm, it is hypothesized that some of the entrained air was present due to overblows of the PJMs that occurred during tuning of the PJMs while the filter-loop pumps were operating. Some of the large overblow bubbles were likely swept into the filter-loop pump suction nozzle. Some PJM overblows are thought to have occurred during PJM tuning around the time air entrainment became a significant issue in Integrated Test A. 
- Air spargers: Some of the lower air spargers are located near the filter-loop pump suction nozzle. Evaluations during Integrated Test A indicated that some air from the spargers was ingested into the pumps, and in some cases, this reduced the pump performance (Guzman-Leong et al. 2009).

- Bubbler Level instruments: Instruments used to measure the liquid level in the vessel were located near the pump intake, and some of the air purge that was continuously flowing through them may have been swept into the pump intake. An evaluation indicated that this was not a significant source of entrained air in the slurry.

- Air purge of the steam ring: An air purge was supplied continuously through the steam ring when the steam was not on. Since the jet from the filter-loop return nozzle barely cleared the steam ring, it is likely that some of this air was swept into the pump intake.

- Air leak into the Pump T42A suction line: The suction line to Pump T42A operates at a lower pressure air leakage into the suction line was evaluated as a source of entrained air. Potential leak points were sealed with no impact on the air entrainment in the slurry.

\subsubsection{Integrated Test A Data Observations and Estimate of Air Entrainment in the Filter-Loop}

For Integrated Test A, vibration in the filter-loop pumps and an increasing axial pressure drop across the filters were first observed during PJM tuning for Non-Newtonian slurry in preparation for the tracer test (2/14/09). In addition, the filter-loop flow rate and TMP unstable behavior were other symptoms of air entrainment that emerged at the start of post-caustic-leach washing. The pump flanges and connections were checked for leaks and none were found so additional sources of air were evaluated.

The PJM overblowing in Tank T02A was identified as a potential air source. Prior to performing the tracer test, PJM tuning efforts to achieve a higher nozzle velocity may have resulted in PJM overblowing although examination of PJM pressure data does not provide a clear indication that there were any PJM overblows. As a result, the assumption that PJM overblowing was a source to the air entrainment in the filter-loop is based on operator observations and not on measurable, quantified data. It should also be noted that PJM overblows in Tank T02A were noted during the post-caustic-leach dewatering step with little evidence of air entrainment. The change in filter alignment, going from the alignment of UFP-FILT-T01A to the alignment of UFP-FILT-T02A through Filter -T05A in preparation for the tracer test, may also have introduced air into the filter-loop.

Air entrainment issues for Integrated Tests B and D include Tank T02A level operations that took place near the filter-loop return nozzle elevation. For Integrated Test A, however, a low Tank T02A level operation is not considered as a cause for air entrainment. In Integrated Test A, the tracer test and post-caustic-leach washing were conducted at laser tank levels of 48.9 and 44.3 inches, respectively. Consequently, air was not introduced into Tank T02A in Integrated Test A from the exposed filtration return nozzle because these Tank T02A levels are $\sim 20$ inches above the filter-loop return nozzle (tank surface level is shown in Figure 13.9). Video observations provided some indication that foam on the surface of the simulant may have been entrained into a vortex around the returning jet.

Another cause of air entrainment is attributed to the malfunction of the flowmeter downstream from Pump T43A as noted on NCR 42317.1. The filter-loop pump setting adjustments were made in response to the low filter-loop flow rates reported by the defective flowmeter on the Pump T43A discharge line. It 
is likely that the flow rates reported by this defective flowmeter were actually higher; therefore, adjusting the pump settings to increase the filter-loop flow rate exacerbated the air entrainment already present in the filter-loop.

Several investigations took place in attempts to identify the air source(s) causing lower than target filter-loop pump flow rates. These investigations varied filter-loop pump settings, and turned PJMs, steam ring air, bubblers, lower and upper spargers on and off. Refer to Guzman-Leong et al. (2009) for descriptions of filter-loop pump settings and air source (bubblers, steam ring, lower and upper spargers) combinations performed to reach the target filter-loop flow rate. Although the target filter-loop flow rate of 109 GPM was not achieved, the following summarizes what was qualitatively observed with stable pump settings (no adjustments):

- With the PJMs, steam ring, lower and upper spargers operating in UFP-VSL-T02A, turning the bubblers on had minimal effect on the filter-loop pump flow rates.

- With the bubblers off and upper spargers operating, decreasing the steam ring air flow rate had minimal effect on the filter-loop pump flow rates whether or not the PJMs and lower spargers were on.

- With the bubblers off, and steam ring air, upper and lower spargers operating, turning the PJMs on or off had negligible impact on the filter-loop pump flow rates.

- With PJMs on, bubblers, upper spargers and steam ring air off, turning lower spargers on caused the filter-loop flow rate to drop, with the lower spargers turned off, the filter-loop flow rate increased without making pump setting adjustments (pump vibration and noise also decreased when lower spargers were turned off). The same result was seen whether three of the five lower spargers were turned on/off, or the remaining two lower spargers were turned on/off.

In an effort to quantify the air entrainment problem, the test data were analyzed to estimate the quantity of entrained air in the slurry. During Integrated Test A, the target flow rate for the filter-loop system, Q, was $109 \mathrm{gal} / \mathrm{min}$, which corresponds to $15-\mathrm{ft} / \mathrm{sec}$ in the filter tubes. Flowmeters were located on the suction line to Pump T42A and the discharge line to Pump T43A. From days zero to 13.6, while operating with a single filter unit, both flowmeters indicated that the target flow rate of $109 \mathrm{gal} / \mathrm{min}$ was achieved (see Figure 13.13). However, after 13.6 days, the readings on both flowmeters diverged significantly and continued to do so throughout the rest of the testing. The onset of the divergence corresponded to the time when the air entrainment first became apparent.

The divergence of the suction and discharge flow rates may be in part the result of a partial failure of the flowmeter in the discharge line, sensor FT-0623, on February 14, 2009 (test day 13), although the exact time of partial failure of the instrument is uncertain (NCR 42317.1). It is reasonable to expect, given that the suction and discharge flow rates were essentially equivalent for days zero to 13.6, that the flowmeter partial failure occurred after 13.6 days into the test. The failed flowmeter (FT-0635) was replaced prior to the start of Integrated Test B.

Air entrainment also contributes to the divergence of the flowmeters. Gas bubbles present in the slurry will expand and contract with local pressure changes. The sensor located on the suction side of Pump T42A, FT-0623, is typically operating under negative pressure conditions. 
Consequently, bubbles in this location will be larger than bubbles on the discharge side of Pump T43A operating at several atmospheres of pressure where the FT- 0635 sensor is located. This causes an increase in the entrained gas fraction relative to regions with a higher pressure. Note that the relatively high pressure at the outlet of the T43A pump drives gas into solution; this dissolved gas volume is not and cannot be measured by either the FT-0623 or FT-0635 flow sensors. The gas exsolves (comes out of solution) as the pressure decreases through the filter-loop. The effect of gas dissolution and exsolution on the calculation of the entrained gas fraction is negligible, as will be shown.

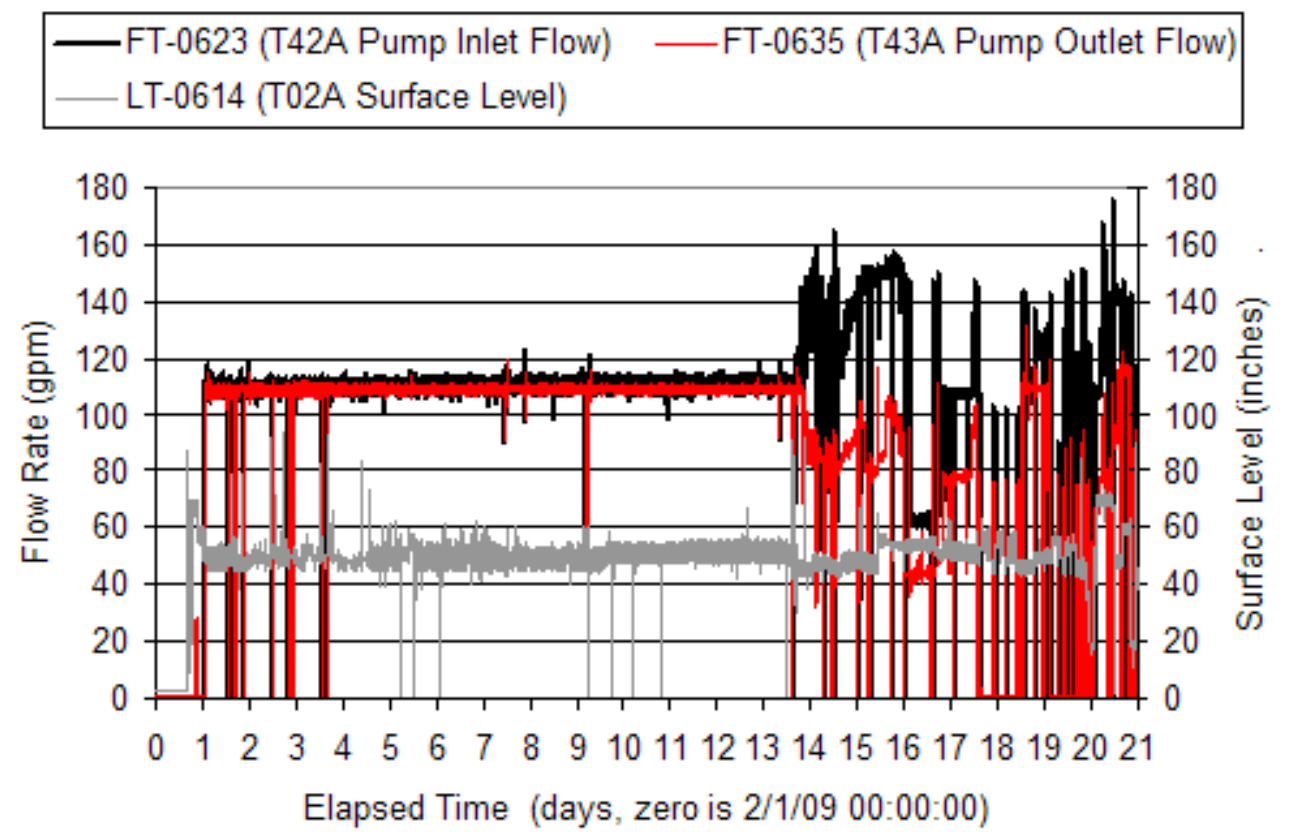

Figure 13.13. Filter-Loop Flow Rates for Integrated Test A

The fraction of entrained gas can readily be estimated if it is assumed that the gas flow in the pumping line is uniformly distributed in the slurry. The slurry mass flow rates on the suction and discharge sides of the pumps are necessarily equal, and the total mass flow rate is equal to the sum of the slurry and gas flow rates.

The flow rate at the suction and discharge of the pumps in-series is found from the flowmeter measurements at those locations.

$$
\begin{aligned}
& \mathrm{Q}_{\mathrm{S}}=\mathrm{FT}_{-} 0623 \\
& \mathrm{Q}_{\mathrm{d}}=\text { FT_0635 }
\end{aligned}
$$


Given the constant slurry mass flow rate ${ }^{(a)}$, the difference in the suction and discharge volumetric flow rates is accounted for by the difference in gas volumetric flow:

$$
Q_{s}-Q_{d}=Q_{g s}-Q_{g d}
$$

where $\mathrm{Q}_{\mathrm{gs}}$ and $\mathrm{Q}_{\mathrm{gd}}$ are the volumetric dry gas flow rates at the suction and discharge, respectively. These are flow rates of wet gas, i.e., they include some volume of water vapor. The total moles of dry gas (leaving out water vapor) are equal at suction and discharge, but some of the gas dissolves and enters the liquid phase; the dissolved gas is not measured by the volumetric flow sensors, but does affect the calculation. Assuming isothermal conditions and a dry gas phase that follows the ideal gas law, the conservation of moles of dry gas can be expressed by the equation

$$
\left[\frac{Q_{g s}}{R T}+\left(Q_{s}-Q_{g s}\right)(1-\phi) K_{H}\right]\left(P_{s}-p_{w}\right)=\left[\frac{Q_{g d}}{R T}+\left(Q_{d}-Q_{g d}\right)(1-\phi) K_{H}\right]\left(P_{d}-p_{w}\right)
$$

where:

$$
\begin{aligned}
& R=\text { the ideal gas constant, } 0.08206 \mathrm{~atm} \mathrm{~L} / \mathrm{mol} \mathrm{K} \\
& T=\text { temperature, } \mathrm{K} \\
& \phi \quad=\text { volume fraction of solid phase in the gas-free slurry } \\
& P_{s}=\text { pressure at suction }(\mathrm{PT}-0625), \text { atm } \\
& P_{d}=\text { pressure at discharge }(\mathrm{PT}-0739), \text { atm } \\
& K_{H}=\text { Henry's law constant for gas at temperature } T,(\mathrm{~mol} / \mathrm{L} \text { liquid) } / \text { atm } \\
& p_{w}=\text { partial pressure of water, atm (potentially significant at suction conditions). }
\end{aligned}
$$

Mahoney et al. (1999) Section 3.6 provides a more detailed discussion of the basis for calculating the phase distribution of slightly soluble gas species.

Equations (13.3) and (13.4) can be combined and solved for the volumetric flow rates of wet gas at the suction and discharge as

$$
\begin{gathered}
Q_{g s}=Q_{s}+\frac{\left(Q_{s} P_{s}-Q_{d} P_{d}\right)-\left(Q_{s}-Q_{d}\right) p_{w}}{\left(P_{d}-P_{s}\right)\left(1-(1-\phi) K_{H} R T\right)} \\
Q_{g d}=Q_{d}+\frac{\left(Q_{s} P_{s}-Q_{d} P_{d}\right)-\left(Q_{s}-Q_{d}\right) p_{w}}{\left(P_{d}-P_{s}\right)\left(1-(1-\phi) K_{H} R T\right)}
\end{gathered}
$$

If the water vapor pressure is negligible compared to the total pressure, and if the gas is insoluble $\left(K_{H}\right.$ $=0$ ), Equations (13.5) and (13.6) can be simplified to

(a) Measured by mag flowmeters that measure the velocity of ions in the pipe (and are relatively insensitive to the ion flux), so they effectively measure the velocity of the liquid, which is proportional to the volumetric flowrate, 


$$
\mathrm{Q}_{\mathrm{gs}}=\frac{\mathrm{Q}_{\mathrm{s}}-\mathrm{Q}_{\mathrm{d}}}{\left(1-\frac{\mathrm{P}_{\mathrm{s}}}{\mathrm{P}_{\mathrm{d}}}\right)}
$$

and

$$
\mathrm{Q}_{\mathrm{gd}}=\frac{\mathrm{Q}_{\mathrm{s}}-\mathrm{Q}_{\mathrm{d}}}{\left(\frac{\mathrm{P}_{\mathrm{d}}}{\mathrm{P}_{\mathrm{s}}}-1\right)}
$$

The object of simplifying the equations is to avoid the necessity of tracking liquid composition, temperature, and solids volume fraction in the slurry over time.

Neglecting gas solubility (setting $K_{H}$ to zero in Equations [13.5] and [13.6]) gives an underestimate of the second term in the equations, and therefore overestimates the wet gas flow rate. To simplify calculation of the gas-solubility effect, air is treated as a single gas. The Henry's Law constant for nitrogen can be used to represent that of air with reasonable accuracy. Although the $K_{H}$ for oxygen is about twice that of nitrogen, oxygen makes up only $21 \%$ of air; treating air as nitrogen therefore underestimates the average $K_{H}$ of air by only about $20 \%$. At $25^{\circ} \mathrm{C}$, the $K_{H}$ of nitrogen is $9.1 \times 10^{-5} \mathrm{~mol} \mathrm{~N}_{2} / \mathrm{L} \mathrm{liq} / \mathrm{atm} \mathrm{N}_{2}$ for the liquid in the feed simulant, $3.5 \times 10^{-5} \mathrm{~mol} \mathrm{~N}_{2} / \mathrm{L} \mathrm{liq} / \mathrm{atm} \mathrm{N}_{2}$ for the liquid in the post-caustic-leach slurry, and $6.5 \times 10^{-4} \mathrm{~mol} \mathrm{~N}_{2} / \mathrm{L} \mathrm{liq} / \mathrm{atm} \mathrm{N}_{2}$ for water, the liquid present at the end of wash operations. The $K_{H}$ values above were calculated using the known liquid compositions and the approach given in Mahoney et al. (1999) Section 3.6. Based on these values, the highest value of $K_{H} R T$ is less than 0.02 ; therefore gas solubility has a trivial effect on the wet gas flow calculated using Equations (13.5) and (13.6). Note that the values of $K_{H} R T$ would be lower at higher temperatures.

The fact that wet gas flow can be calculated with little error by neglecting gas solubility does not mean that the amount of gas forced into solution at the pump discharge is trivial. Water at $25^{\circ} \mathrm{C}$ contains $0.0069 \mathrm{~mol} \mathrm{~N}_{2} / \mathrm{L}$ liq when at equilibrium with nitrogen gas at $140 \mathrm{psig}$. If the pressure is reduced to one atm, the exsolved $\mathrm{N}_{2}$ is 0.15 -L gas per $\mathrm{L}$ water. Thus, for the most dilute solutions (end of wash) the gas dissolved at discharge pressure can produce a significant gas volume fraction further along in the filter-loop. However, the exsolved gas is a factor of 10 to 20 less for feed liquid or for feed plus caustic than it is for water, and so is in the range of $2-\mathrm{vol} \%$ or less until dilution begins during washing.

Neglecting water vapor pressure (setting $p_{w}$ to zero in Equations [13.5] and [13.6]) leads to an underestimate of the second term in each equation (which is a negative term), and therefore to an overestimate of the volumetric flow rate of entrained wet gas. At $25^{\circ} \mathrm{C}$, the water vapor pressure over the liquids being filtered in Integrated Test $A$ is in the range of $0.03 \mathrm{~atm}$ to $0.04 \mathrm{~atm}$. The effect of water vapor pressure alone was calculated for Integrated Test A assuming a water vapor pressure of $0.04 \mathrm{psi}$ and zero gas solubility. The maximum relative overestimation produced by omitting the water vapor term is $3 \%$ of the gas fraction for the suction gas fraction and $12 \%$ of the gas fraction for the discharge gas fraction. The maximum absolute overestimation was $2.3-\mathrm{vol} \%$ gas for the suction and $3.0-\mathrm{vol} \%$ gas for the discharge. These errors were considered acceptable, so water vapor pressure was neglected in the entrained gas calculations. Equations (13.7) and (13.8) were used. 
The entrained gas volumetric concentration in the suction line can be calculated using

$$
\alpha_{\mathrm{s}}=\frac{\mathrm{Q}_{\mathrm{gs}}}{\mathrm{Q}_{\mathrm{s}}}
$$

and similarly, the discharge entrained gas volumetric concentration is given by

$$
\alpha_{\mathrm{d}}=\frac{\mathrm{Q}_{\mathrm{gd}}}{\mathrm{Q}_{\mathrm{d}}}
$$

As noted above, the discharge side flow rate sensor FT-0635 partially failed at some point after 13.6 test days. Quantification of the potential entrained air via Equations (13.9) and (13.10) may therefore not be meaningful for Integrated Test A. However, a sample taken from the filter-loop at approximately 14.4 days was determined to have a gas fraction of $7.5 \%$ by volume at atmospheric conditions (Guzman-Leong et al. 2009). Thus, it is significant that the calculated entrained gas fraction before 13.6 days, when the suction and discharge flow rates were equivalent (2), indicated that sensor FT-0635 was still operating equivalently to sensor FT-0623.

The calculated fractions of entrained gas are shown in Figure 13.14. Major test periods are also indicated by the colored bars in the figure. The calculation predicts negligible entrained gas on the discharge side and on the order of 2 to $4 \%$ volume entrained gas on the suction side throughout the initial 13.6-day period of caustic leaching and concentration. The measured $7.5 \%$ by volume at atmospheric conditions in the 14.4-day sample is thus indicative that an increase of entrained gas occurred after 13.6 days. The entrained gas fractions at the suction and discharge lines during the period from 13.6 days to the end of Integrated Test A (encompassing caustic leached slurry wash, oxidative leaching, and oxidative-leached slurry wash), included for information only, are calculated to be on the order of $40 \%$ by volume on the suction side and $5 \%$ by volume on the discharge side. 


\begin{tabular}{|c|c|}
\hline$\diamond$ at T42A Suction & - at T43A discharge \\
\hline Leaching and Concentration & —Wash Caustic Leached Slurry \\
\hline Oxidative Leach & —Wash Oxidative Leached Slurry \\
\hline Concentration & \\
\hline
\end{tabular}

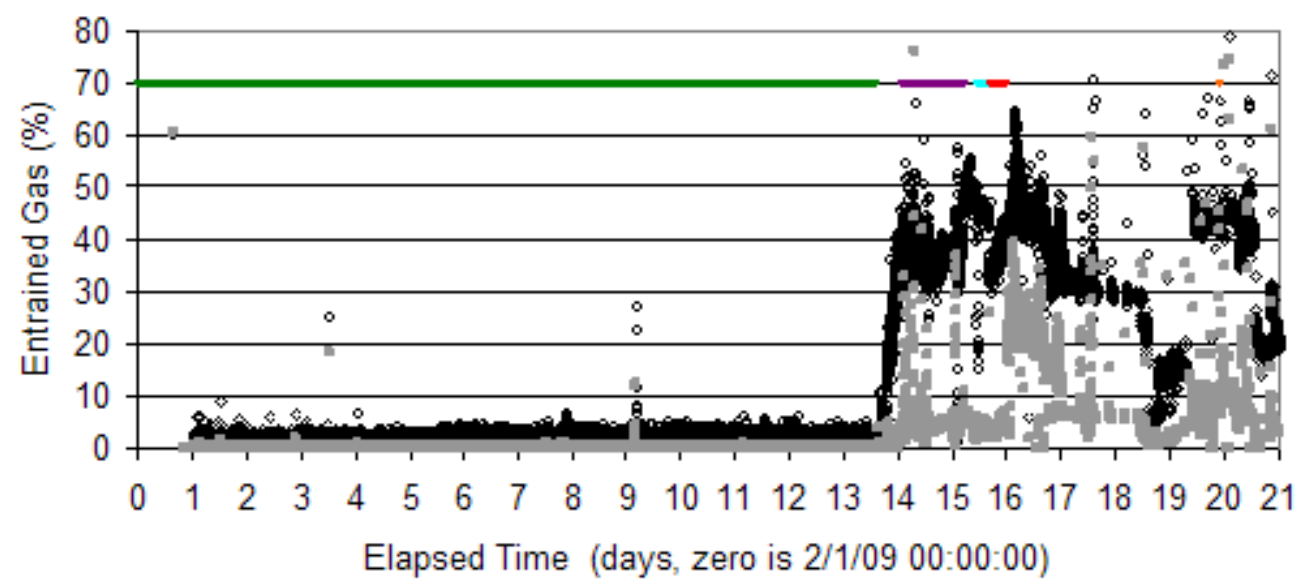

Figure 13.14. Entrained Gas Present in Filter-Loop During Integrated Test A. The calculated entrained gas fractions during the period from 13.6 days to the end of Integrated Test A are included for information only.

\subsubsection{Integrated Test B Data Observations and Estimate of Air Entrainment in the Filter-Loop}

The target flow rate for the filter-loop system was $109 \mathrm{gal} / \mathrm{min}$ during Integrated Test B. Flowmeters are located on the suction line to Pump T42A and the discharge line to Pump T43A. Both flowmeters indicate that the target flow rate of $109 \mathrm{gal} / \mathrm{min}$ is achieved (Figure 13.15) during much of the initial concentration before caustic leaching. As noted in Geeting et al. (2009), however, when the slurry level in Tank T02A was within several inches of the filter-loop return nozzle the targeted flow rate could not be maintained. This occurred near the end of the initial concentration steps (day 1 and day 3), the end of concentration of the leached slurry (days 5 through 7), and during post-caustic and oxidative-leach wash, oxidative leaching, and the final concentration steps (collectively days 7.5 to 9). The divergence in the flowmeters near the end of the test during the post-oxidative-leach wash suggests that the decreased flow rate may have been caused by entrained air. 


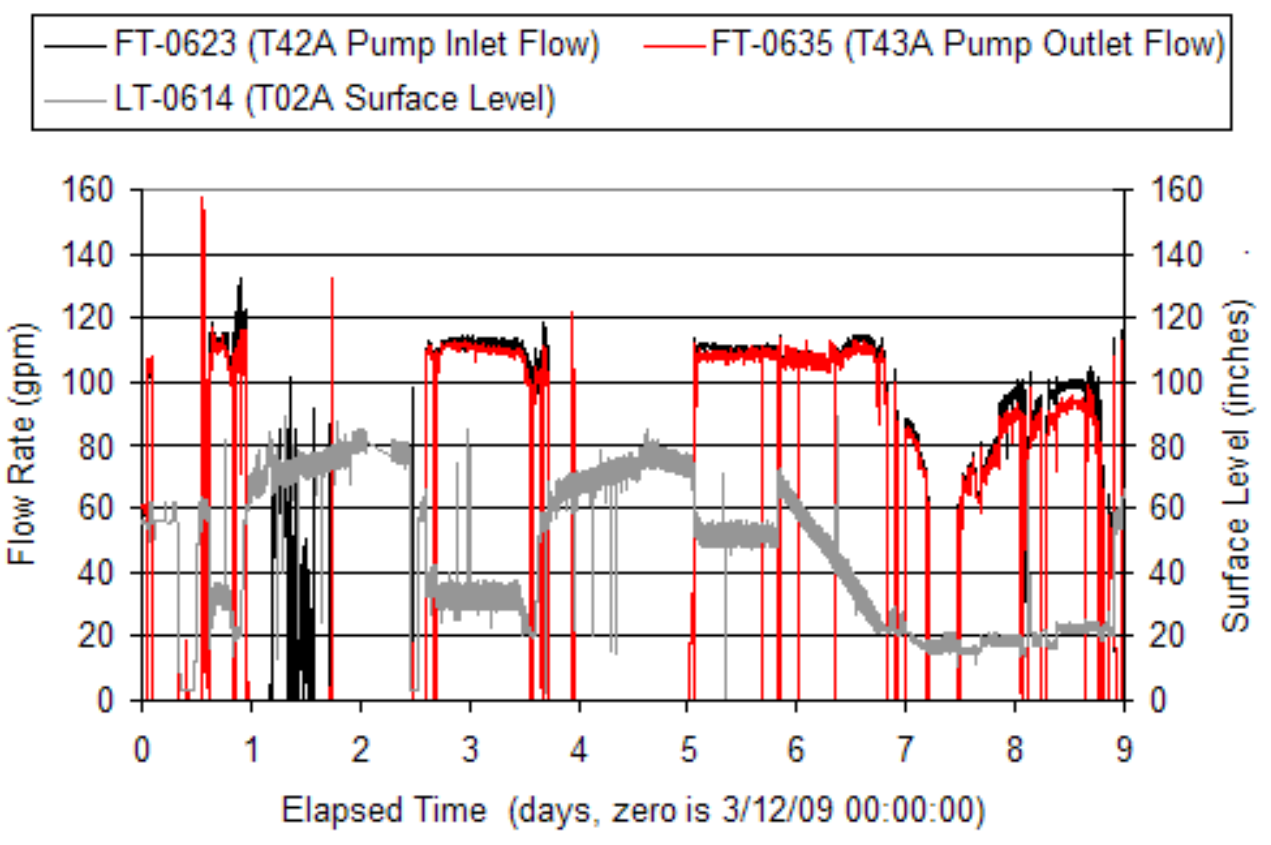

Figure 13.15. Filter-Loop Flow Rates During Integrated Test B

The fraction of entrained gas can be estimated as described in Section 13.6.1. The calculated fractions of entrained gas are shown together with the major test periods in Figure 13.16. An increase in the entrained gas can be seen near the end of the initial concentration steps (days one and three) and during the final steps (days seven through nine). The period of divergence of the flowmeters ${ }^{(a)}$, the post-oxidative-leach wash (near the end of day eight), shows a significant increase in the calculated entrained gas content in the slurry. The decreased flow rate ${ }^{(b)}$ during the final concentration of the leached slurry observed in Figure 13.15 does correspond to an increase in gas content (as compared to that of the post-oxidative-leach wash). The discharge gas concentration during the concentration of the leached slurry compares reasonably with that reported from the slurry sample of 2.6 volume percent.

(a) Filter-loop flow meter FT-623 was replaced between Integrated Test A and Integrated Test B.

(b) The flow was adjusted manually to limit air entrainment. 

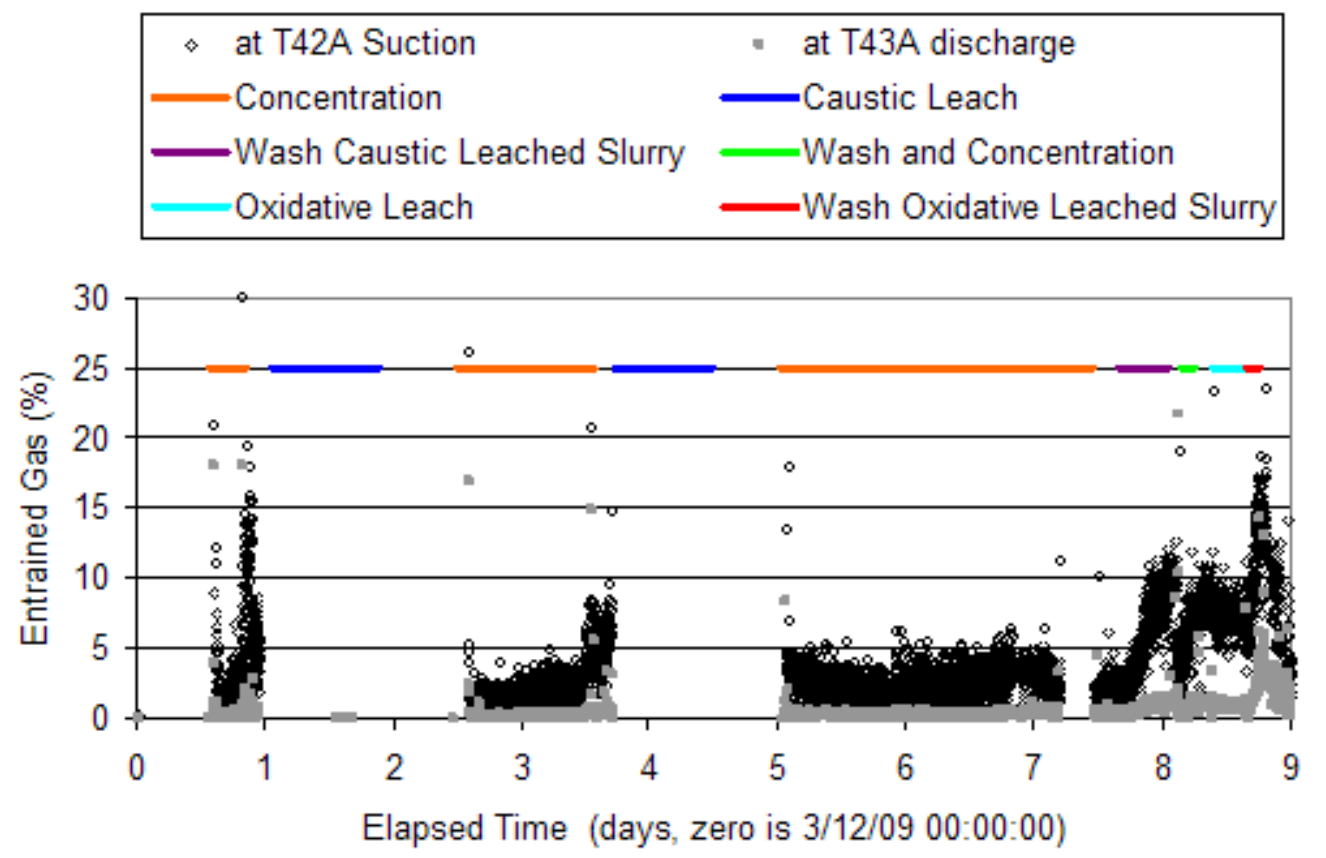

Figure 13.16. Entrained Gas Present in Filter-Loop During Integrated Test B

\subsubsection{Integrated Test D Data Observations and Estimate of Air Entrainment in the Filter-Loop}

The target flow rate for the filter-loop system was $109 \mathrm{gal} / \mathrm{min}$ during Integrated Test $\mathrm{D}$. Flowmeters were located on the suction line to Pump T42A and the discharge line to Pump T43A. As in Integrated Test D (Sevigny et al. 2009), the flow rate was maintained (Figure 13.17) near the target for much of the initial concentration steps (days one through five). Near the end of these steps, the flow rate could not be maintained. The flow rate target was also not met near the end of the post-caustic-leach wash step (day eight) or during the post-oxidative-leach wash (day nine). These time periods correspond with decreased fill levels in Tank T02A (Figure 13.13). The minor divergence in the flowmeters near the end of the test suggests that the decreased flow rate may have been caused by entrained air. 


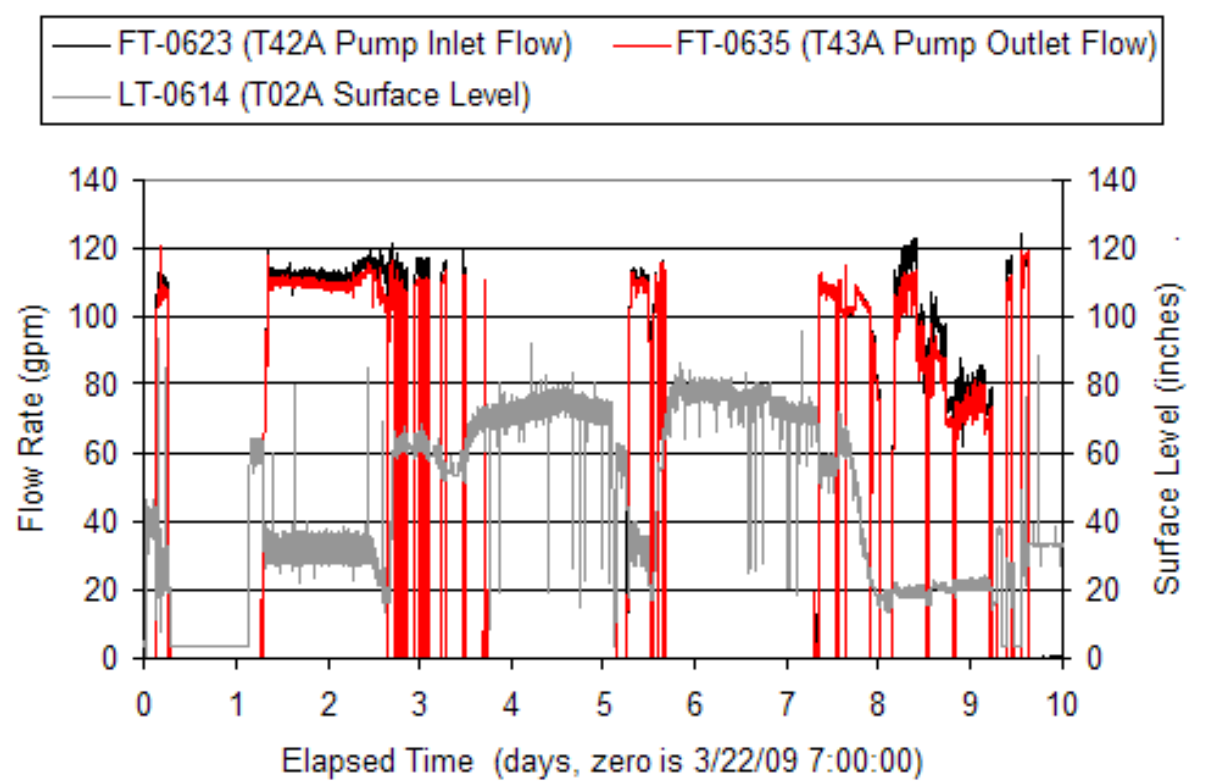

Figure 13.17. Filter-Loop Flow Rates During Integrated Test D

The fraction of entrained gas can be estimated as describe in Section 13.6.1. The calculated fractions of entrained gas are shown in Figure 13.18. The major test periods are also indicated. A greater than a factor of two increase in the calculated entrained gas content in the slurry is shown during the leached slurry washing and post-oxidative-leach wash days eight and nine.
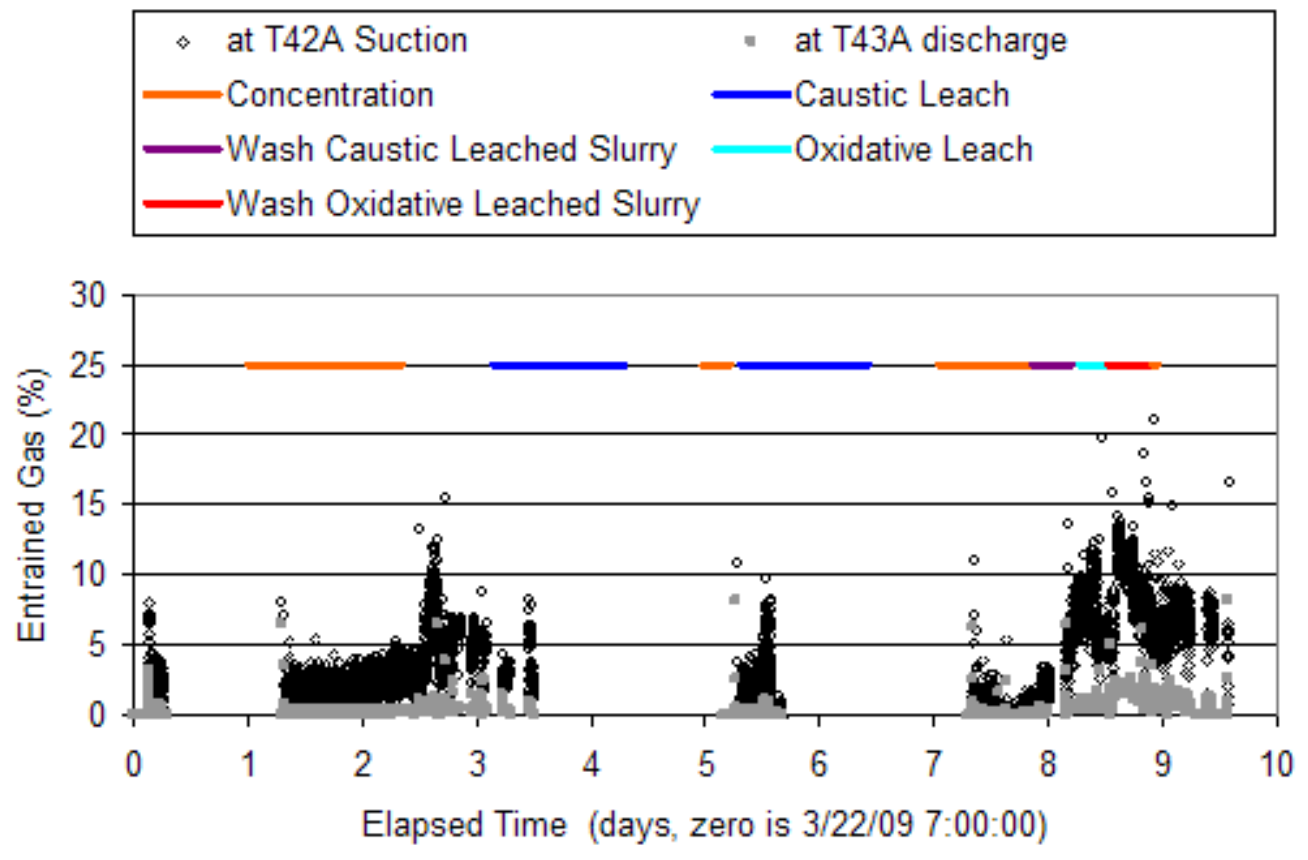

Figure 13.18. Entrained Gas Present in Filter-Loop During Integrated Test D 


\subsubsection{Pump Operations Without Air Entrainment}

The PEP filter-loop operated with two pumps in-series with Pump T42A feeding the suction inlet of Pump T43A. During periods of high air entrainment, such as during Integrated Test A (see Figure 13.14), the ability to control the flow rate using both the pumps in-series was challenging. When the air entrainment in the slurry was not a significant factor, the dual pumps in-series could be controlled. It should be noted that Pumps T42A and T43A are significantly larger in power ratings than the PEP 1/4.5 scaling factor. The higher horsepower ratings on the pumps were to allow flexibility in the possible future testing of vertical ultrafilters and higher filter-loop flow rates.

\subsubsection{Summary of Entrained Air Issue}

Based on the evaluations conducted during the testing, it was apparent that the single most important source of air entrainment was caused by the filter-loop return nozzle when the Tank T02A level was at or below this nozzle. While some air appeared to be present in the slurry under other conditions, air entrainment was most significant at low slurry levels. The presence of some entrained air at the higher slurry levels implies that other air sources in the tank (i.e., air spargers and steam ring air purge) were contributing to the entrained air in the system. At the lower vessel levels, the operation of the PJMs also played a role. Under normal operation of the PJMs, the vessel level rises and falls as the PJMs cycle. As the PJMs fill, the slurry level in the vessel falls, and if the level was low enough and the amplitude great enough, the filter-loop return nozzle was temporarily uncovered.

Once air was entrained into the slurry, it was very difficult to remove. It is hypothesized that larger air bubbles were extensively sheared while going through the pumps and broken up into a large number of much smaller bubbles. It was also thought that the compression/decompression cycle of the filter-loop could create microbubbles: some of the air present on the outlet of the second pump would dissolve into the liquid under the roughly 150 psia pressure at that point and then nucleate and form microbubbles on the surfaces of particles as the pressure was reduced to roughly 15 psia in Tank T02A. Previous work has shown that AFA increases gas retention and slows gas release (Stewart et al. 2006). Similar work indicates that the gas holdup is also a function of the slurry chemical and physical properties (Stewart et al. 2007).

A number of attempts were made to deaerate the slurry during Integrated Test A (for a more detailed description, see Guzman-Leong et al. 2009). Based on these investigations, the following actions are suggested for degassing:

- Operate spargers and PJMs with the filter-loop pumps off for one to two hours.

- Wait 30 minutes to allow air to leave the slurry.

- Turn PJMs and filter-loop pumps on for at least 30 minutes.

- Repeat PJM and pump operation until sufficient gas is removed to resume operation.

To allow the completion of the PEP tests, the following actions were implemented when the slurry level in the tank was near or below the level of the filter-loop return nozzle (22-in): 
- The flow rate through the filter-loop was reduced from the 109 GPM target. This minimized the amount of air entrained by the return nozzle jet. In some cases, the entrained air reduced the maximum achievable flow rate produced by the pumps.

- The air flow rate through the spargers was reduced or turned off.

- The air flow through the steam ring was turned off.

- The mode of PJM operation was modified to minimize the change in vessel level. One mode that was used was the "star mode" in which the center and one outer PJM were operating at any given time. This reduced the amplitude of the slurry level in the vessel. In some cases, the stroke length of the PJMs was reduced, in some cases to $\approx 20 \%$.

- The testing protocol was modified slightly to allow for operation at higher levels as much as possible. This was implemented during the initial solids-concentration steps.

It should be noted that while air entrainment was an issue in the PEP, it is not clear how this problem scales to the full-scale system. The air entrainment in the PEP involves complex three-phase flow, which was not considered during the scaling of the PEP.

\subsection{UFP Tank Temperature Profiles}

This section discusses the temperature distribution profiles within the test vessels. The objective of the temperature profile testing was to measure the temperature in various areas in the tank to ascertain temperature profiles near the wall, identify "hot spots" in the tank due to steam addition, and evaluate temperature variability within the vessel during caustic leaching. To accomplish these objectives, many resistance temperature detectors (RTDs) were installed in the vessels as described below.

\subsubsection{Temperature Sensors}

The scaled PEP vessel was provided originally with a complement of temperature measurement instruments (Ref. Drawing 007Z006A, TE-0619, and TE-0621) and were later supplemented with additional RTDs. The position of the RTDs is provided in Table 13.8.

Two different RTDs were used in the tanks. Sensors attached to the tank or PJM wall used Conax Buffalo Technologies RTD43 sensor element (Pt100, Class B, 3-wire $\pm 0.3^{\circ} \mathrm{C}$ tolerance) with a 0.125 -in. 304 stainless steel (SS) sheath (Part number RTD43-W-3-SS12-T3-120 in. or equivalent). These sensors are identified in Table 13.8, by identification numbers that begin with $\mathrm{N}$ (the nozzle $(\mathrm{N})$ port in which they were inserted). The vendor-stated response time constant, defined as the time required for the temperature sensor to respond to $63.2 \%$ of the total temperature change, is approximately 3.5 seconds. In determining the time constant, tests were performed in still water going through an instantaneous step change from $0^{\circ}$ to $100^{\circ} \mathrm{C}$.

Sensors attached to the stainless steel (SS) rod were originally provided as a thermowell from Rosemount (part number 1082R1A10N-E-1-D-C-03000-A-01118-F36). Each thermowell contained 10 RTDs (Pt100 class A, 4-wire, $\pm 0.15^{\circ} \mathrm{C}$ tolerance) with a 0.125 -in. $316 \mathrm{SST}$ sheath. The $10 \mathrm{RTDs}$ were mounted inside with a sealed SS pipe (thermowell). Vendor data indicated that the response time was longer than desired (many minutes versus seconds) and the SS pipe was removed, and the sensors were 
attached to an SST rod for support. These sensors are identified in Table 13.8, by identification numbers that begin with"TT." The new configuration resulted in much faster RTD response times. Illustration of the RTDs in the vessels are shown in section 4 and an example for Tank T02A is shown in Figure 13.19.

Table 13.8. RTD Locations

\begin{tabular}{|c|c|c|c|c|c|c|}
\hline Vessel & $\begin{array}{c}\text { Identification } \\
\text { Number }\end{array}$ & Nozzle & Radius (in.) & $\begin{array}{c}\text { Distance From Wall } \\
\text { (in.) }\end{array}$ & $\begin{array}{l}\text { Orientation } \\
\text { (degrees) }\end{array}$ & Elevation (in.) \\
\hline \multirow[t]{40}{*}{ Tank T01A } & TTA-0325 & 19 & 4.6 & 22.3 & 60 & 73.8 \\
\hline & TTB-0325 & 19 & 4.6 & 22.3 & 60 & 65.4 \\
\hline & TTD-0325 & 19 & 4.6 & 22.3 & 60 & 49.2 \\
\hline & TTE-0325 & 19 & 4.6 & 22.3 & 60 & 41.1 \\
\hline & TTF-0325 & 19 & 4.6 & 22.3 & 60 & 32.8 \\
\hline & TTG-0325 & 19 & 4.6 & 22.3 & 60 & 24.7 \\
\hline & TTH-0325 & 19 & 4.6 & 22.3 & 60 & 16.6 \\
\hline & TTJ-0325 & 19 & 4.6 & 22.3 & 60 & 8.4 \\
\hline & TTK-0325 & 19 & 4.6 & 22.3 & 60 & 0.7 \\
\hline & TTL-0325 & 19 & 4.6 & 22.3 & 60 & 57.6 \\
\hline & TTA-0327 & 20 & 24.2 & 2.8 & 105 & 73.3 \\
\hline & TTB-0327 & 20 & 24.2 & 2.8 & 105 & 65.1 \\
\hline & TTD-0327 & 20 & 24.2 & 2.8 & 105 & 48.8 \\
\hline & TTE-0327 & 20 & 24.2 & 2.8 & 105 & 40.6 \\
\hline & TTF-0327 & 20 & 24.2 & 2.8 & 105 & 32.4 \\
\hline & TTG-0327 & 20 & 24.2 & 2.8 & 105 & 24.4 \\
\hline & TTH-0327 & 20 & 24.2 & 2.8 & 105 & 16.0 \\
\hline & TTJ-0327 & 20 & 24.2 & 2.8 & 105 & 8.1 \\
\hline & TTK-0327 & 20 & 24.2 & 2.8 & 105 & 0.5 \\
\hline & TTL-0327 & 20 & 24.2 & 2.8 & 105 & 56.9 \\
\hline & N33-1 & 33 & 26.4 & 0.6 & 0 & 61.5 \\
\hline & N33-2 & 33 & 25.8 & 1.3 & 0 & 38.5 \\
\hline & N33-4 & 33 & 27 & 0.0 & 0 & 38.5 \\
\hline & N33-5 & 33 & 25.8 & 1.3 & 0 & 15.5 \\
\hline & N33-6 & 33 & 26.4 & 0.6 & 0 & 15.5 \\
\hline & N33-7 & 33 & 27 & 0.0 & 0 & 15.5 \\
\hline & N34-1 & 34 & 26.4 & 0.6 & 90 & 61.5 \\
\hline & N34-2 & 34 & 25.8 & 1.3 & 90 & 38.5 \\
\hline & N34-3 & 34 & 26.4 & 0.6 & 90 & 38.5 \\
\hline & N34-4 & 34 & 27 & 0.0 & 90 & 38.5 \\
\hline & N34-5 & 34 & 25.8 & 1.3 & 90 & 15.5 \\
\hline & N34-6 & 34 & 26.4 & 0.6 & 90 & 15.5 \\
\hline & N34-7 & 34 & 27 & 0.0 & 90 & 15.5 \\
\hline & N36-1 & 36 & 26.4 & 0.6 & 270 & 61.5 \\
\hline & N36-2 & 36 & 25.8 & 1.3 & 270 & 38.5 \\
\hline & N36-3 & 36 & 26.4 & 0.6 & 270 & 38.5 \\
\hline & N36-4 & 36 & 27 & 0.0 & 270 & 38.5 \\
\hline & N36-5 & 36 & 25.8 & 1.3 & 270 & 15.5 \\
\hline & N36-6 & 36 & 26.4 & 0.6 & 270 & 15.5 \\
\hline & N36-7 & 36 & 27 & 0.0 & 270 & 15.5 \\
\hline \multirow[t]{5}{*}{ Tank T02A } & TTA-0619 & 22 & 10.7 & 8.0 & 288 & 73.4 \\
\hline & ТTВ-0619 & 22 & 10.7 & 8.0 & 288 & 65.3 \\
\hline & TTD-0619 & 22 & 10.7 & 8.0 & 288 & 48.7 \\
\hline & TTE-0619 & 22 & 10.7 & 8.0 & 288 & 40.8 \\
\hline & TTF-0619 & 22 & 10.7 & 8.0 & 288 & 32.4 \\
\hline
\end{tabular}


Table 13.8. RTD Locations

\begin{tabular}{|c|c|c|c|c|c|c|}
\hline Vessel & $\begin{array}{c}\text { Identification } \\
\text { Number }\end{array}$ & Nozzle & Radius (in.) & $\begin{array}{l}\text { Distance From Wall } \\
\text { (in.) }\end{array}$ & $\begin{array}{c}\text { Orientation } \\
\text { (degrees) }\end{array}$ & Elevation (in.) \\
\hline & TTG-0619 & 22 & 10.7 & 8.0 & 288 & 24.3 \\
\hline & TTH-0619 & 22 & 10.7 & 8.0 & 288 & 16.0 \\
\hline & TTJ-0619 & 22 & 10.7 & 8.0 & 288 & 7.9 \\
\hline & TTK-0619 & 22 & 10.7 & 8.0 & 288 & 0.4 \\
\hline & TTL-0619 & 22 & 10.7 & 8.0 & 288 & 57.1 \\
\hline & TTA-0621 & 23 & 16.4 & 2.3 & 90 & 73.4 \\
\hline & TTB-0621 & 23 & 16.4 & 2.3 & 90 & 65.2 \\
\hline & TTD-0621 & 23 & 16.4 & 2.3 & 90 & 48.8 \\
\hline & TTE-0621 & 23 & 16.4 & 2.3 & 90 & 40.8 \\
\hline & TTF-0621 & 23 & 16.4 & 2.3 & 90 & 32.6 \\
\hline & TTG-0621 & 23 & 16.4 & 2.3 & 90 & 24.2 \\
\hline & TTH-0621 & 23 & 16.4 & 2.3 & 90 & 16.1 \\
\hline & TTJ-0621 & 23 & 16.4 & 2.3 & 90 & 7.8 \\
\hline & TTK-0621 & 23 & 16.4 & 2.3 & 90 & 0.4 \\
\hline & TTL-0621 & 23 & 16.4 & 2.3 & 90 & 57.0 \\
\hline & N39-1 & 39 & 17.4 & 1.3 & 64 & 12.0 \\
\hline & N39-2 & 39 & 18.1 & 0.6 & 64 & 12.0 \\
\hline & N39-3 & 39 & 18.7 & 0.0 & 64 & 12.0 \\
\hline & N39-4 & 39 & 17.4 & 1.3 & 64 & 45.0 \\
\hline & N39-5 & 39 & 18.1 & 0.6 & 64 & 45.0 \\
\hline & N39-6 & 39 & 18.7 & 0.0 & 64 & 45.0 \\
\hline & N39-7 & 39 & 18.1 & 0.6 & 64 & 79.0 \\
\hline & N41-1 & 41 & 17.4 & 1.3 & 170 & 12.0 \\
\hline & N41-2 & 41 & 18.1 & 0.6 & 170 & 12.0 \\
\hline & N41-3 & 41 & 18.7 & 0.0 & 170 & 12.0 \\
\hline & N41-4 & 41 & 17.4 & 1.3 & 170 & 45.0 \\
\hline & N41-5 & 41 & 18.1 & 0.6 & 170 & 45.0 \\
\hline & N41-6 & 41 & 18.7 & 0.0 & 170 & 45.0 \\
\hline & N41-7 & 41 & 18.1 & 0.6 & 170 & 79.0 \\
\hline & N42-1 & 42 & 17.4 & 1.3 & 280 & 12.0 \\
\hline & N42-2 & 42 & 18.1 & 0.6 & 280 & 12.0 \\
\hline & $\mathrm{N} 42-3$ & 42 & 18.7 & 0.0 & 280 & 12.0 \\
\hline & N42-4 & 42 & 17.4 & 1.3 & 280 & 45.0 \\
\hline & N42-5 & 42 & 18.1 & 0.6 & 280 & 45.0 \\
\hline & N42-6 & 42 & 18.7 & 0.0 & 280 & 45.0 \\
\hline & N42-7 & 42 & 18.1 & 0.6 & 280 & 79.0 \\
\hline & N52-1 & 52 & 10.4 & OPJ & 36 & 10.5 \\
\hline & N52-2 & 52 & 10.4 & OPJ & 36 & 10.5 \\
\hline & N52-3 & 52 & 10.4 & OPJ & 36 & 10.5 \\
\hline & N52-4 & 52 & 10.4 & OPJ & 36 & 43.5 \\
\hline & N52-5 & 52 & 10.4 & OPJ & 36 & 43.5 \\
\hline & N52-6 & 52 & 10.4 & OPJ & 36 & 43.5 \\
\hline & N52-7 & 52 & 10.4 & OPJ & 36 & 55.5 \\
\hline
\end{tabular}

OPJ - On pulse jet tube structure wall.

Note: For temperature element in the middle of the tank, distances from the tank wall are $+/-1$ inch 


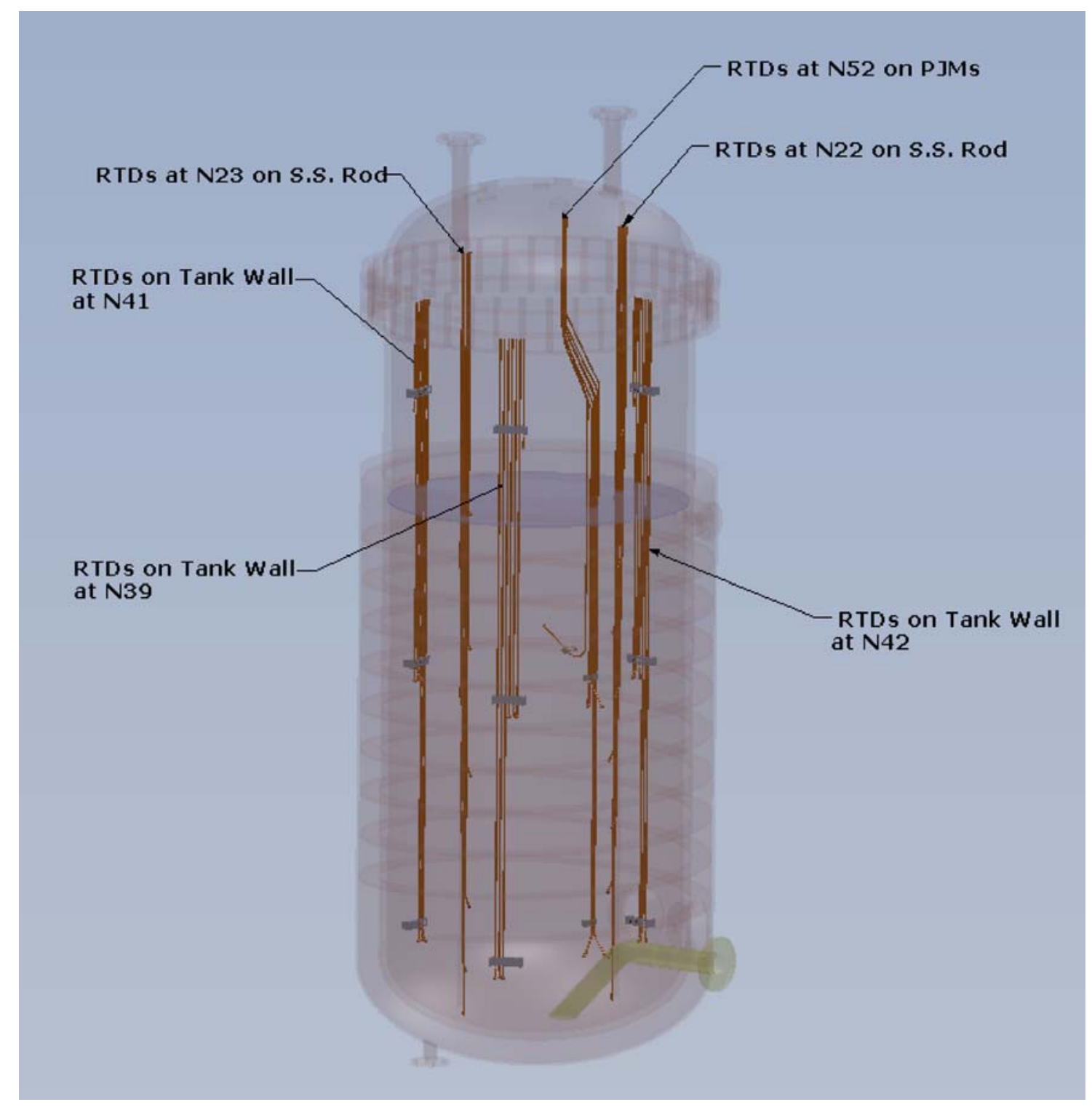

Figure 13.19. Illustration of Tank T02A RTD Locations.

\subsubsection{Data Analysis for Vessel Temperature Profiles}

The following analyses focus on the temperatures reported in the vessels during caustic leaching in Tank T01A during Integrated Test A and Tank T02A during Integrated Test B.

During caustic leaching treatment for Integrated Tests A and B, the temperature of the slurry is increased from approximately $25^{\circ} \mathrm{C}$ to $98^{\circ} \mathrm{C}$ and held at $98^{\circ} \mathrm{C}$ for 16 hours. Steam is added to the slurry through 48 or 40 holes in a steam ring in Tanks T01A/B and Tank T02A, respectively. During caustic leaching, mixing in Tank T01A is supplied by $8 \mathrm{PJMs}$ while mixing in T02A is supplied by air sparging and 6 PJMs. The maximum temperature during caustic leaching is to be kept below $100^{\circ} \mathrm{C}$ to minimize the risk of stress corrosion cracks forming in the vessels. 
Analyses of temperature data from Tank T01A, indicate no significant temperature gradients exist in the slurry at the vessel walls. The RTDs were placed at distances of $0,0.6$, and $\approx 1.3$ inches from the wall at different elevation and radial locations. Figure 13.20 provides the average temperature at each of the sensors, over three caustic-leach steam addition cycles, near the wall in Tank T01A. Comparison of temperature sensors from the same nozzle and elevation indicate there is a pattern of increasing temperature toward the tank wall. As heat should not enter through the wall, it is concluded that the temperature difference observed is within the error of the RTDs.

Figure 13.21 provides similar data for Tank T02A. Comparing temperature sensors from the same nozzle and elevation indicates that there is not a consistent thermal profile. For both tanks, the observed temperature variations are within $1^{\circ} \mathrm{C}$ and are on the same order of magnitude as the RTD calibration uncertainty. Thus, the mixing in the tanks was sufficient to prevent a measureable thermal gradient near the tank wall.

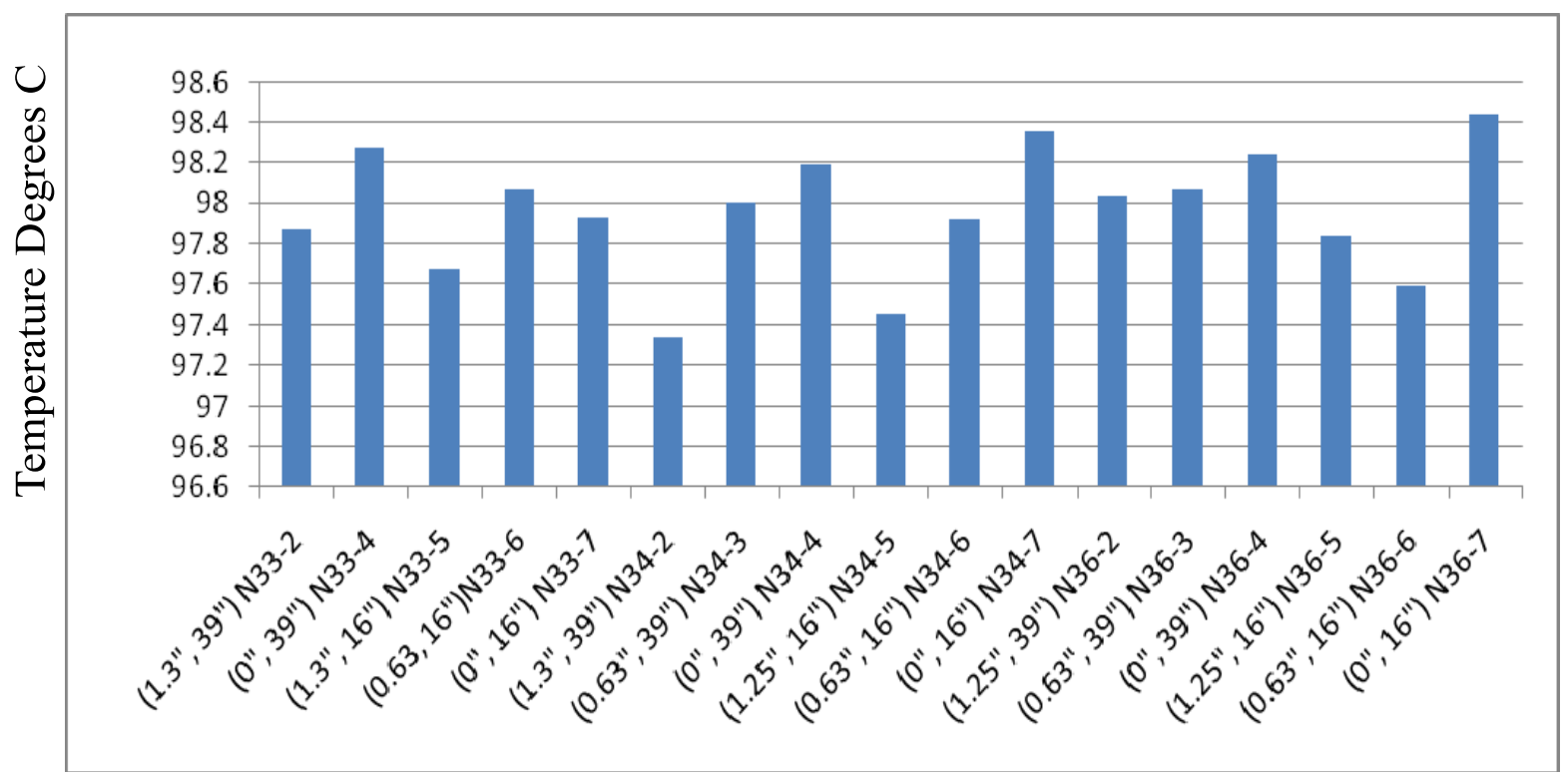

Sensor Number with Distance from Tank Wall and Tank Elevation in Inches

Figure 13.20. Tank T01A Temperature Near the Tank Wall at Various Locations. The numbers in labeling of the abscissa indicate distance from tank wall and elevation in the tank, respectively. 


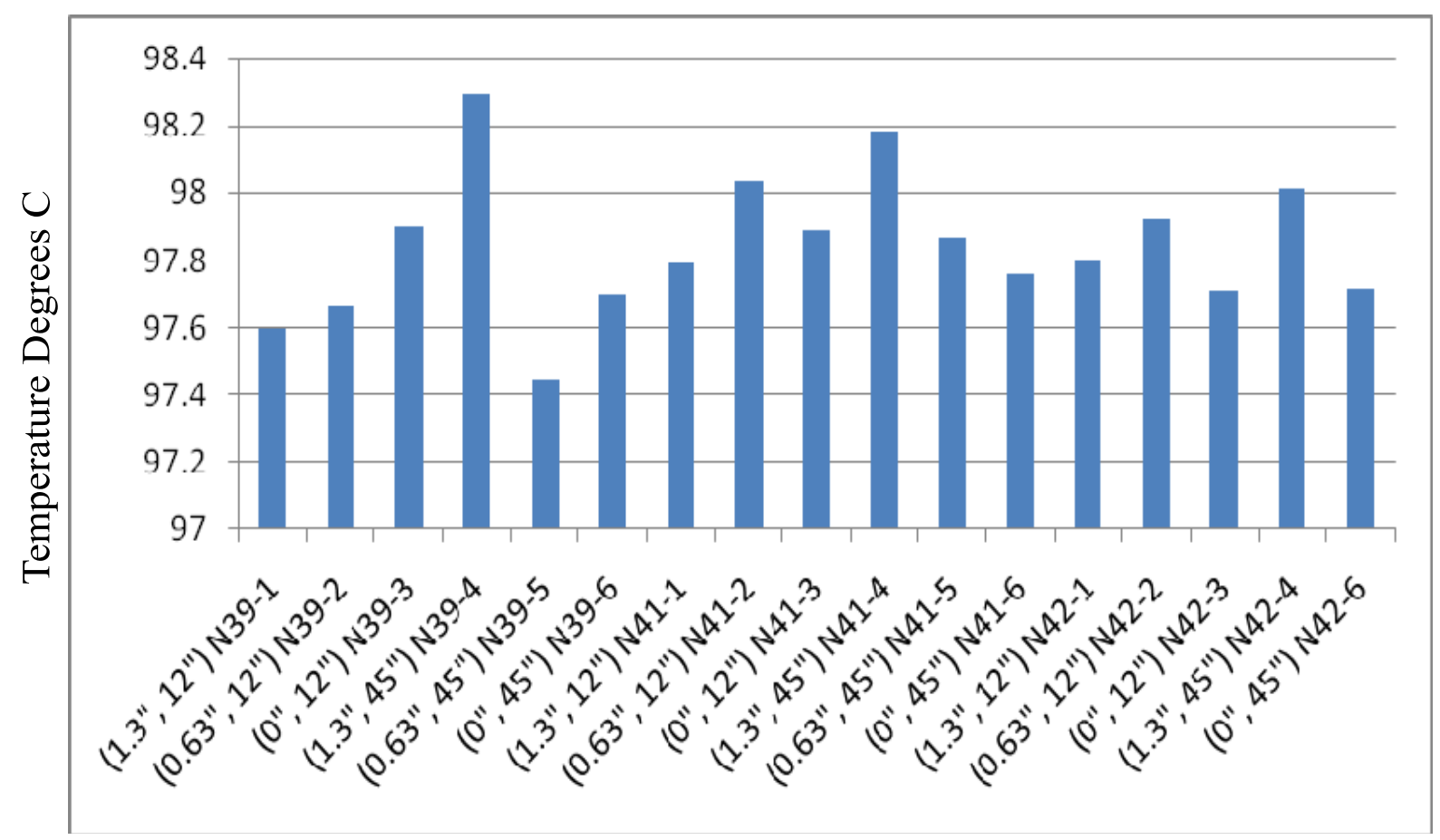

Sensor Number with Distance from Tank Wall and Tank Elevation in Inches

Figure 13.21. Tank T02A Temperature Near the Tank Wall at Various Locations. The numbers in labeling of the abscissa indicate distance from tank wall and elevation in the tank, respectively.

Figure 13.22 shows that the maximum temperature in Tank T01A was $99.7^{\circ} \mathrm{C}$, which is $<1^{\circ} \mathrm{C}$ higher than the average and $<2^{\circ} \mathrm{C}$ higher than the set point of $98^{\circ} \mathrm{C}$. The standard deviation of temperature within the tank varies between 0.4 and $1.9^{\circ} \mathrm{C}$. As expected, the standard deviation is higher when the steam is on. Figure 13.23 provides similar data for Tank T02A, with the maximum temperature $99.7^{\circ} \mathrm{C}$, which is $<2^{\circ} \mathrm{C}$ higher than the average and the set point. The standard deviation varies between 1.0 and $1.9^{\circ} \mathrm{C}$. Overall, there were no significant temperature differences between RTDs, and hot spots were not observed. 


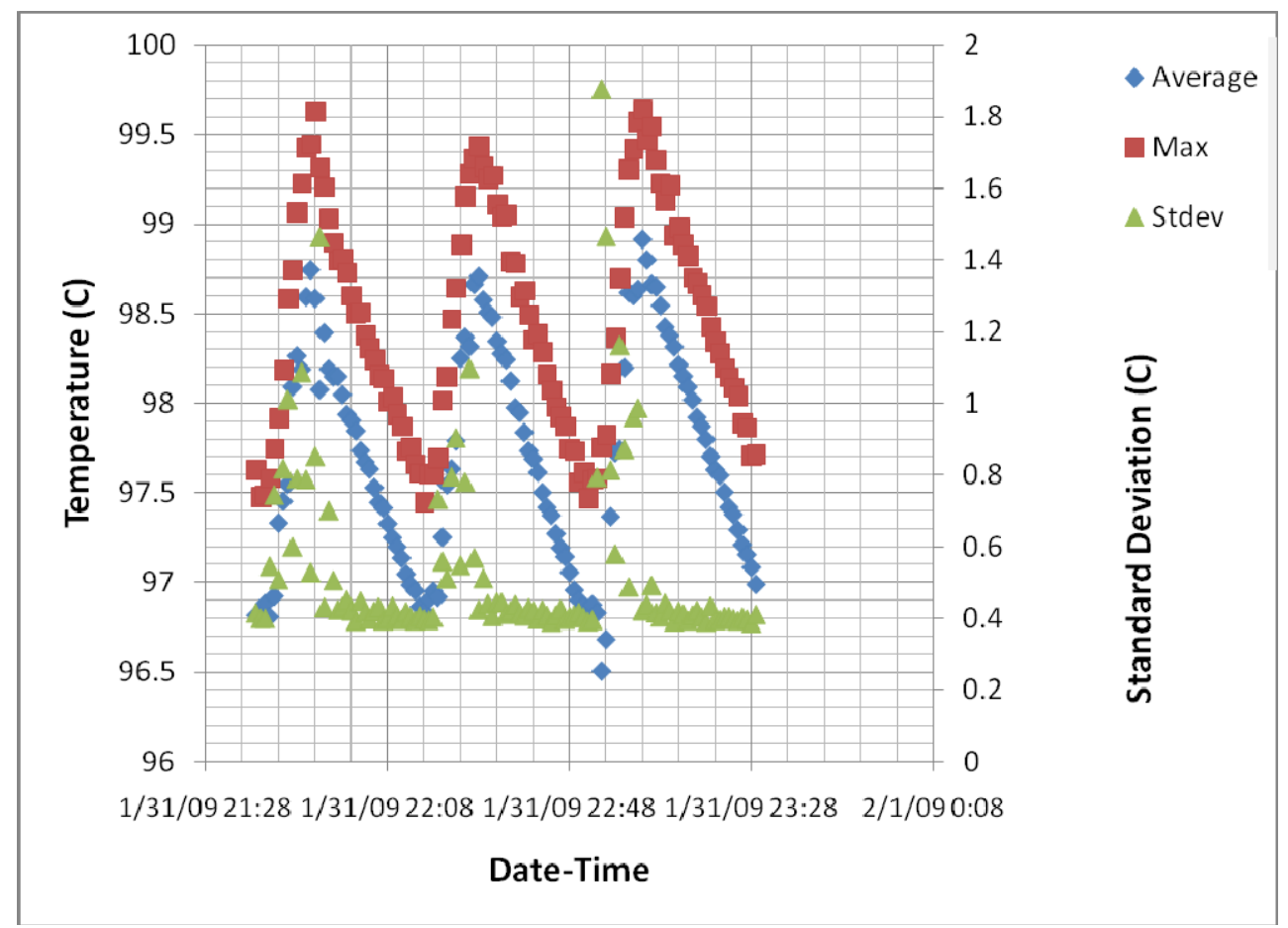

Figure 13.22. Tank T01A Average, Maximum, and Standard Deviation of the Tank T01A Sensors During Three Caustic-Leach Steam Addition Cycles for Integrated Test A, Batch 1

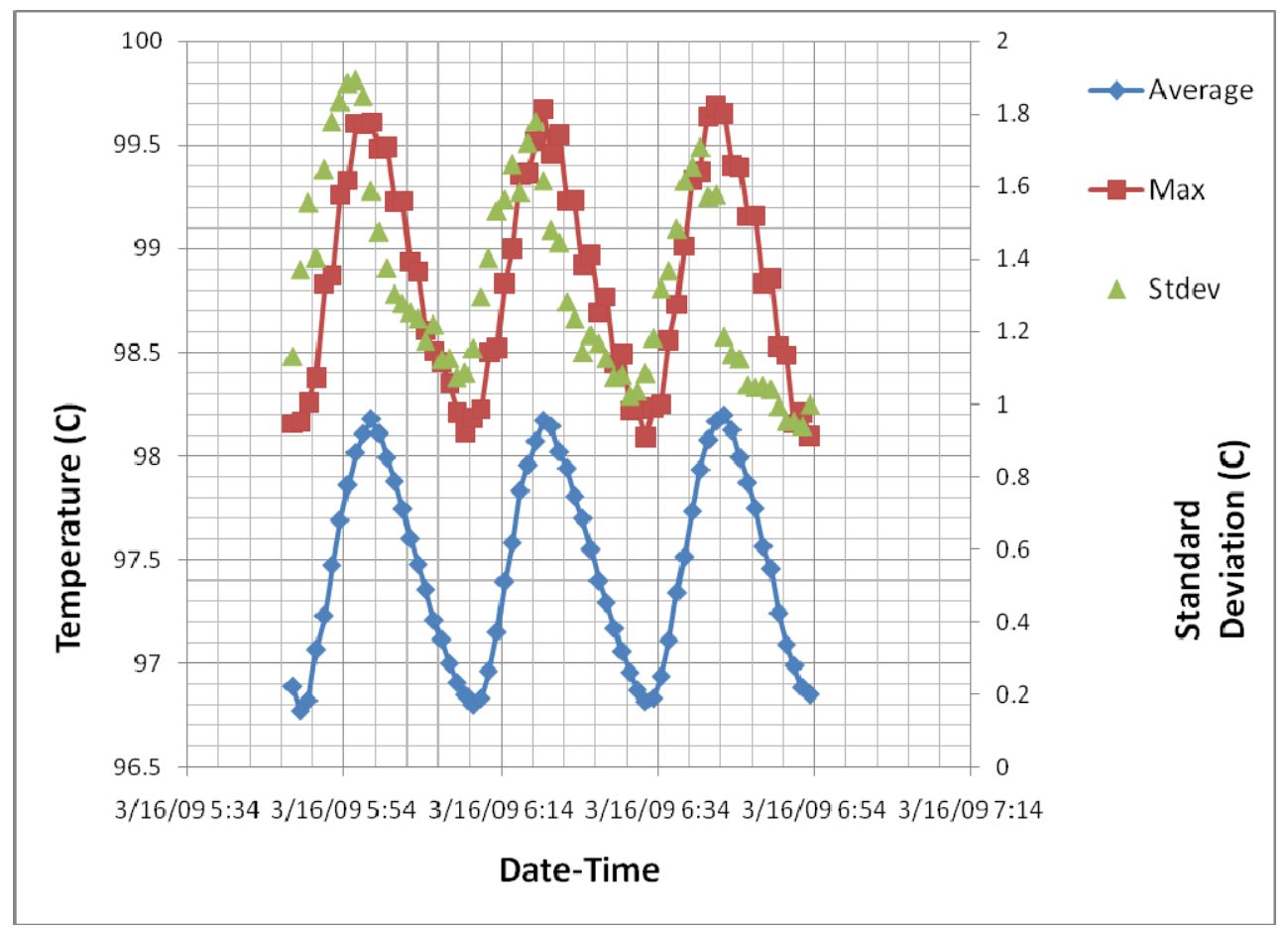

Figure 13.23. Tank T02A Average, Maximum, and Standard Deviation of All Tank T02A Sensors During Three Caustic-Leach Steam Addition Cycles for Integrated Test B, Batch 2 
During caustic leaching, 1-sec interval data was analysed to determine the impact of the PJMs on the tank temperatures. The timing of PJM operation was determined from the level changes in the tank. The PJMs did not have any effect on the temperatures except where the level of the slurry oscillated above and below the RTD position as shown in Figure 13.24 and Figure 13.25 for Tanks T01A and T02A, respectively. The data show that the RTDs responded during the cycle time and are a good check on the height of the slurry in the tank. No other RTDs showed any changes due to the PJMs. This was true for all of the other sets of RTDs in Tanks T02A and T01A.

In Figure 13.24, two groupings of RTDs provide readings approximately $1{ }^{\circ} \mathrm{C}$ apart. The lower temperature grouping includes three of four highest submerged RTDs (elevation: 49-in., 33-in., and 25-in.). TTE-0325 (elevation 41-in.) is in the upper grouping. It is concluded that the $1^{\circ} \mathrm{C}$ temperature difference observed is within the measurement uncertainty, as no consistent thermal profile is established.

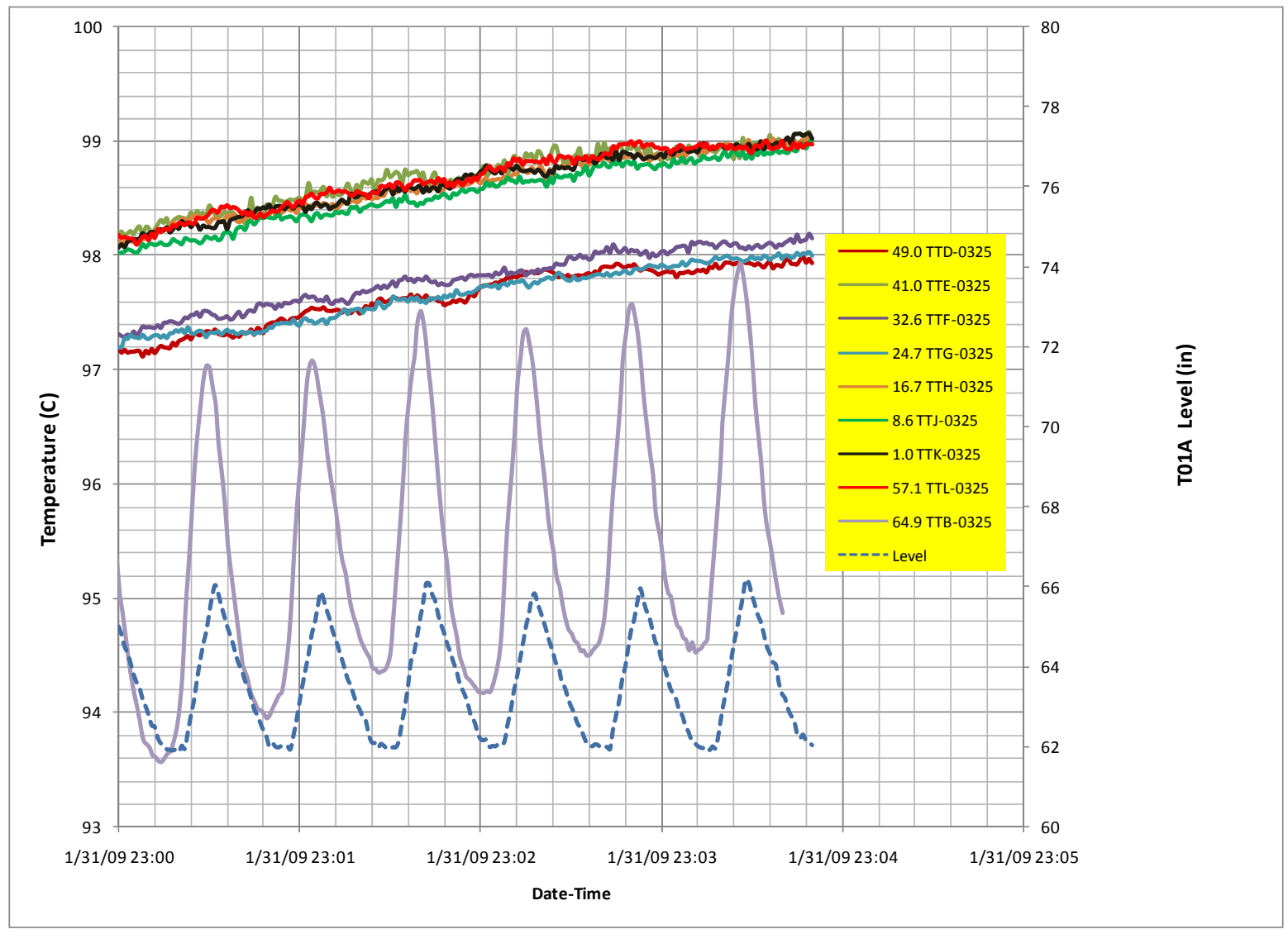

Figure 13.24. Effect of PJM Operation on Tank Temperature in Tank T01A 


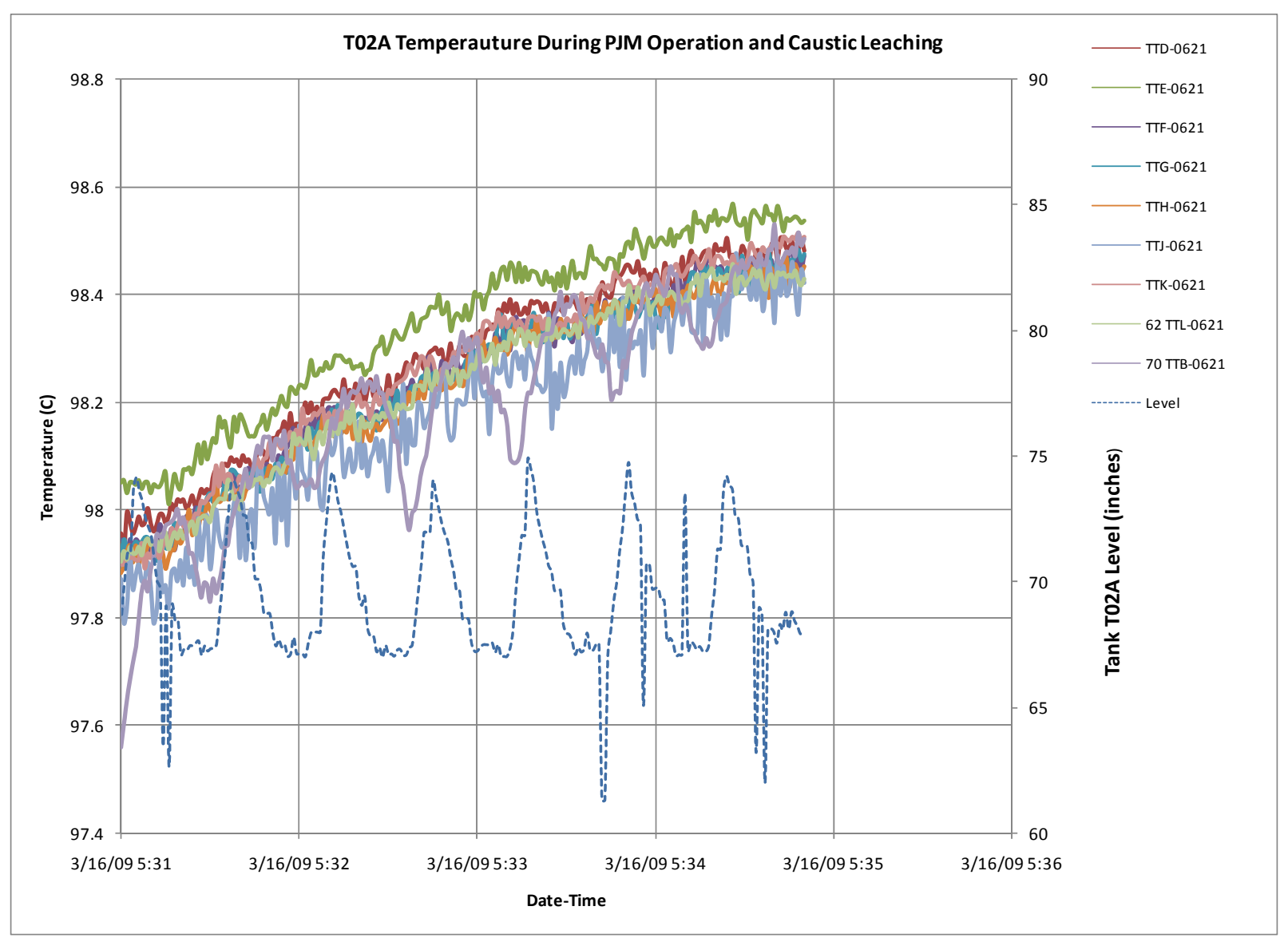

Figure 13.25. Effect of PJM Operation on Tank Temperature in Tank T02A 



\subsection{Summary and Conclusions}

This section summarizes the PEP Functional and Integrated Tests. This summary is primarily based on information presented in this document, but in some cases draws on other references. The first two sections address the two overall PEP objectives:

- Perform an integrated demonstration using prototypic equipment to confirm the operability and functionality of the ultrafiltration system components.

- Provide system effectiveness data to estimate WTP performance.

The third section presents some topics related to PEP operation that may be of interest for future PEP tests and/or provide information relevant to PTF operations.

\subsection{Demonstration of Process Operability, Controls, and Flowsheets}

This section presents information related to the first objective: perform an integrated demonstration using prototypic equipment to confirm the operability and functionality of the ultrafiltration system components. It is structured to provide a discussion of the key processes and issues.

\subsubsection{Cross-Flow Ultrafiltration}

All process ultrafiltration steps were successfully demonstrated, including initial solids concentration (Integrated Tests B and D only), post-caustic-leach solids reconcentration, post-caustic-leach wash, post-oxidative-leach wash and final solids concentration. Specific filter operations were also successfully demonstrated, including flow and transmembrane pressure (TMP) control with two pumps in-series, filter backpulsing, chemical filter cleaning, and the clearing of a plugged filter bundle. Because the PEP was not designed to perform filter-loop backflushing at the high prototypic flow rate, this particular operation was not demonstrated.

Generally, the flow and TMP controls were adequate, the backpulse control strategy worked well, and visual inspections of permeate samples indicated no significant solids breakthrough. Air entrainment in the slurry, particularly when slurry levels in Tank T02A were low, resulted in a loss of pumping efficiency and lower flow rates. The presence of entrained air and the reduced flow rate in the filter-loop generally appeared to have some effect on the filtration performance. Oscillating filtrate rates observed during the post-caustic-leach washing operations in Integrated Tests A and D may have been caused in part by entrained air blocking some of the filter pores. Filter-fouling and low axial velocity also contributed to a low permeate rate during the Integrated Test D post-oxidative-leach wash. Detailed accounts of ultrafiltration system behavior are given in the run reports (Josephson et al. 2009, Guzman-Leong et al. 2009, Geeting et al. 2009, Sevigny et al. 2009).

Periodic filter backpulsing was conducted during the post-caustic-leach solids concentration step of Integrated Tests $\mathrm{A}$ and $\mathrm{B}$. The results show that backpulsing yielded a significant but temporary increase in flux. A simple evaluation of the data suggests that backpulsing resulted in higher average fluxes during the post-caustic-leach concentration step in Integrated Test A but this increase was not observed in Integrated Test B. No notable differences in the flux recovery were observed with multiple backpulses performed in rapid succession or backpulses conducted at different overpressures. 
The PEP filters were chemically cleaned seven times with either oxalic or nitric acid. Oxalic acid worked well but does not represent the PTF baseline. The final filter cleaning was conducted according to the WTP-specified protocols and involved three successive contacts with 2-M nitric acid. Each contact consisted of circulating the acid with the filter-loop pumps for 1.5 hours at a target flow rate of 70 GPM. Each filter bundle was backpulsed at $0,0.5,1$, and 1.5 hours. Clean water flux increased from about $0.1-\mathrm{kg} / \mathrm{min}-\mathrm{ft}^{2}$ to approximately $0.2-$, then $0.8-$, and finally about $1.5-\mathrm{kg} / \mathrm{min}-\mathrm{ft}^{2}$ after the three nitric acid contacts. After the acid was neutralized, the final inhibited water (IW) permeate rate was approximately $0.8-\mathrm{kg} / \mathrm{min}-\mathrm{ft}^{2}$. The TMP was set at $40 \mathrm{psi}$. If $40 \mathrm{psi}$ could not be maintained, a lower TMP was acceptable.

\subsubsection{In-Line and Vessel Mixing}

Wash-water, 19-M caustic $(\mathrm{NaOH})$, and the permanganate reagent were added, as is prototypic of the $\mathrm{PTF}$, in-line during slurry transfers and filter-loop recirculation. After in-line addition of 19-M caustic samples collected from nine different locations within Tank T01A at the start of caustic leaching indicated no statistically significant difference in hydroxide concentration. Similarly, samples collected from Tank T02A indicated that the caustic added in-line during filter-loop recirculation was well mixed by the time the samples were collected 15 minutes after the caustic addition. In-line addition of a chemical tracer into the filter-loop after post-caustic-leach solids concentration (when the solids content and liquid viscosity were at nearly their highest values) indicated that the concentrations of tracer in the filter-loop and lower region of Tank T02A were essentially the same and within about $10 \%$ of their final, fully diluted value in 2 to 4 minutes.

The 19-M caustic added directly to Tanks T01A (during Functional testing) and T01B (during Integrated Test A) was observed to mix rapidly. In Tank T01A, the caustic was well mixed by the time the samples were collected 25 minutes after the caustic addition. In Tank T01B, in-line addition of $80 \%$ of the caustic required for leaching and $20 \%$ to the slurry surface of the filled tank had no measureable impact on the total fraction of aluminum leached (compared to $100 \%$ in-line caustic addition). Because the 19-M caustic is denser than the slurry $(\sim 1.5-\mathrm{vs} . \sim 1.26-\mathrm{g} / \mathrm{mL})$, a bulk addition of caustic to the slurry surface would likely sink to the bottom where it could be blended rapidly by the pulse jet mixers (PJMs).

A concern identified in the design of the UFP-VSL-00002A/B vessels was that fluid returning from the filter-loop would be channeled into the suction of the filter-loop pumps, thereby reducing the mixing impact of the jet and increasing the time required to blend the filter-loop contents throughout the tank. Chemical tracer tests were performed to evaluate this issue with a relatively high slurry level in Tank T02A ( 41- to 43-in.) and with a relatively low slurry level ( $\sim 15$-in.). In each test, a CsBr solution was injected into the suction of the filter-loop pumps, and samples were collected from the filter-loop and the lower region of Tank T02A periodically for 60 minutes. In all tests, the Cs concentrations at the two sample locations were essentially the same and within about $10 \%$ of the final, fully diluted value within 2 to 4 minutes. Between the 4-min and 60-min samples, a decrease in tracer concentration ranging from 8 to $10 \%$ was observed in each test. This decrease was within the limits of the analytical uncertainty, but the consistency of this decay suggests there was a region that mixed much more slowly. The same result was observed in both the high-slurry level and low-slurry level tests, so the slowly mixed region may simply be the dead volume of the filter-loop ( $\sim 9$ gal of piping is connected to the filter-loop without flow going directly through it). 
Two tests conducted in Tank T01A indicate that there was no statistically significant stratification due to settling of solids over a 36-hr period with PJM and steam ring air purge mixing of the as-received PEP simulant (a Newtonian slurry). Both tests were conducted with PJMs controlled to match the (mixing power)/volume ratio of the PTF. No effort has been made to extend these stratification results with PEP simulant to other slurries in the PTF. It should also be noted that the PEP simulant was not designed to challenge the solids suspension capability of the vessel mixing system.

Similar solids-settling tests were conducted in Tanks T01A and T02A while caustic leaching was conducted at $98^{\circ} \mathrm{C}$. In both tests, the slurry was Newtonian, and PJMs were controlled to match the (mixing power)/volume ratio of the PTF. Samples taken after 2 hours during the caustic-leach in Tank T01A indicated no significant stratification of solids. After 16 hours, samples from the inner-low and middle-low locations of Tank T01A had slightly higher UDS content, but no statistically significant difference in slurry densities. This indicates that there may have been a slight amount of stratification although it is reasonable to expect that if significant settling had been present that the sample from the outer-low location would also have a high UDS value but this was not the case. The 2-hr samples collected during the caustic-leach in Tank T02A also showed no stratification of solids. The outer radius 16-hr samples were found to have slightly lower UDS content, but no significant difference was observed in the slurry densities.

No problems inherent to air sparge mixing were encountered, and the PJM operation was reasonably stable. Changes in slurry density and vessel fill level resulted in modest changes in the PJM stroke length and drive velocity. Temperature changes over the range of about 20 to $98^{\circ} \mathrm{C}$ caused only minor changes in stroke length and average nozzle velocity. Gravity refill of the PJMs is proposed for PTF operation at elevated temperatures since vacuum refill at high temperatures may result in flashing and excessive evaporation of water. During the PEP testing, the PJMs were successfully operated with gravity refill when the vessel temperature was $>60^{\circ} \mathrm{C}$. An evaluation of a subset of PJM data for Tanks T01A/B indicates that the drive time was 12 seconds, the refill time was 21 seconds, the total required cycle time was 33 seconds which was 2 seconds less than the specified total cycle time of 25 seconds. A similar analysis for the PJMs in Tank T02A indicates the drive time was 7 seconds, the refill time was 18 seconds, the total required cycle time was 25 seconds which is 8 seconds shorter than the specified total cycle time of 33 seconds. An estimate of the refill and total cycle times for the PTF PJMs was made using the Bernoulli equation. The refill time for the PJMs in UFP-VSL-00001 is estimated to be 45 seconds, the total cycle time is 78 seconds which is 18 seconds shorter than the specified total cycle time of 96 seconds. The refill time for the PJMs in UFP-VSL-0002 is estimated to be 39 seconds, the total cycle time is 58 seconds which is 33 seconds shorter than the specified total cycle time of 91 seconds. For the PJMs, it should be noted that the instrumentation and control logic used to operate the PEP PJMs was not prototypic of the PTF PJMs.

\subsubsection{Temperature Control}

The heat-up and cooling performance of ultrafiltration process (UFP) vessels and heat exchangers was sufficient to conduct the PEP tests. After adding caustic, heating to the caustic-leach temperature was conducted with the PEP control system to match a projected temperature profile. The cooling curves were matched manually. It should be noted that the heat-transfer characteristics do not readily scale to the full-size equipment. The heat-up and cooling were only functionally prototypic, and the PEP performance in this area had little bearing on the PTF performance. 
Arrays of resistance temperature detectors (RTDs) installed in the UFP vessels indicated that the caustic-leach solutions were largely isothermal during caustic leaching except during process upsets. While some variability in the temperature was observed, there were no identifiable trends. The variability was relatively small so the temperature remained within the $\pm 2^{\circ} \mathrm{C}$ tolerance for caustic leaching. No hot spots that could be attributed to the addition of steam via the steam ring were observed. While areas of elevated temperature certainly existed close to the steam ring, none of the RTDs were close enough to detect this, even though the nearest RTDs were four to five inches from the steam ring holes. There were no hot spots detected at the vessel walls. While the PEP heat losses and thermal variability are not strictly prototypic, they are reasonably representative and probably a good indication of the WTP performance.

A few instances of deviation from the target caustic-leach temperatures were noted during testing The temperature profiles measured during caustic leaching at the prototypic temperature sensors in each vessel were compared to the targets and found to be good matches for most of the time. Significant divergences from the target (differences that were outside the specified tolerance of $\pm 2^{\circ} \mathrm{C}$ )) were most often the result of process disturbances caused by high-high level alarms from erratic level measurements. The high-high level alarm shut off steam injection and PJMs, causing a drop in temperature that was sometimes followed by a temperature spike if steam was turned on before PJMs were started (producing a local temperature increase owing to the lack of mixing). Additionally, restarting steam flow with PJMs on and transitioning from the temperature ramp up to a steady temperature hold sometimes resulted in a slight temperature overshoot, due to the tuning of the temperature controller.

\subsubsection{Make-Up and Wash-Water Batch Control}

The operation of the instruments for measuring bubbler levels was impacted by flow past the outlet of the bubbler tubes. These instruments function by measuring the pressure difference between tubes inserted to different depths in the slurry. The tubes are open-ended and are continuously purged with a small air stream. Fluid flowing past the ends of the tubes affects the pressure and distorts the level measurement. This was especially evident during the PJM drive phase in Tanks T01A/B and T02A, and when the filter-loop pumps were on in Tank T02A. The bubblers in Tanks T01A/B were not influenced by the recirculation pumps because of lower flow.

The bubbler level tubes were susceptible to plugging, which resulted in erroneous readings. Plugged bubblers were cleaned by blowing high-pressure air through the piping, and by water (steam condensate or IW) when high-pressure air was not effective. The cleaning was not always successful on the first attempt, and when the operation was restored, the duration of the functionality was variable.

Level control was used as the basis for adding make-up batches of wash-water and simulant batches for filtration and generally worked well. The bubbler plugging often required that the lasers be used for the level-control signal.

\subsubsection{Transfer Line Flushing}

PEP transfer lines were designed to be flushed like the PTF; however, neither the configurations (i.e., pipe lengths, bends, and tees) nor the volumes of the PEP transfer lines are prototypic of the PTF. (PEP line volumes are significantly larger than prototypic.) Because truly prototypic line flushes were not possible, and the amount of water introduced by line-flushing was determined to be small (relative to the 
slurry volumes of the receiver vessels), PEP testing did not include routine line flushes. No line-plugging issues were observed.

A test of the line-flushing capability indicated that one to two line volumes of IW are adequate to flush the Phase I simulant. This test involved flushing the neat simulant from the line between Tank HLP-VSL-T22 and Tank T01B. Due to the limited water flow rate, the line flush flow rate was about $70 \%$ of the scaled PTF flush-water flow rate.

During maintenance and final clean out of the PEP system, solids were mainly found to have accumulated in line drains and piping that was below and out of the main flow. It should be noted that the PEP design and/or operation of the low points and clean outs was not prototypic of the PTF. In general, significant solids accumulation was not observed and was not an issue during testing.

\subsubsection{Material Balances}

Material balances were performed for selected species based on sample analyses and process measurements. Table 14.1 lists the percentage of key components removed by ultrafiltration. The percentage removed is based on the amount removed in the liquid phase relative to the total amount entering (including process chemicals) the system. The listed removal of $100 \%$ of several species should not be understood to represent total removal of a species; trace amounts of these species remained in the concentrated product. Manganese is a special case since it is added to the process for oxidative leaching and is not very soluble. It accumulates in the final slurry, and this leads to the negative values listed in Table 14.1. The values shown are adjusted for nonprototypic steps, such as flushing the filter-loop to the waste receipt vessels or materials left in vessels because they were not needed to meet test objectives.

Table 14.1. Percent of Species Removed in the Liquid Phase During Integrated Tests A, B, and D

\begin{tabular}{lccc}
\hline \multicolumn{1}{c}{ Species } & $\begin{array}{c}\text { Integrated } \\
\text { Test A }\end{array}$ & $\begin{array}{c}\text { Integrated } \\
\text { Test B }\end{array}$ & $\begin{array}{c}\text { Integrated } \\
\text { Test D }\end{array}$ \\
\hline Aluminum & $69.5 \%$ & $65.3 \%$ & $56.1 \%$ \\
Sodium & $99.7 \%$ & $98.8 \%$ & $99.3 \%$ \\
Chromium & $90.1 \%$ & $95.6 \%$ & $97.4 \%$ \\
Manganese & $-5.4 \%$ & $-13.5 \%$ & $-14.5 \%$ \\
Oxalate & $97.6 \%$ & $99.0 \%$ & $99.4 \%$ \\
Sulfate & $97.6 \%$ & $100.0 \%$ & $100.0 \%$ \\
Phosphate & $99.8 \%$ & $100.0 \%$ & $99.9 \%$ \\
Free OH & $93.2 \%$ & $84.9 \%$ & $92.6 \%$ \\
Water & $95.2 \%$ & $94.4 \%$ & $94.3 \%$ \\
\hline
\end{tabular}

The antifoam additive, Dow Corning ${ }^{\circledR}$ Q2-3183A Antifoam, was tracked by analyzing the concentrations of polydimethylsiloxane (PDMS), polypropylene glycol (PPG) and silicon (Si) solids in samples taken at various points in each of the Integrated tests: 1) the simulant feed, 2) the start of post-caustic-leach wash, 3) the end of the post-caustic-leach wash, 4) before permanganate was added for the oxidative-leach, 5) the end of the oxidative-leach, and 6) after the post-oxidative-leach wash. Solid and liquid fractions were analyzed separately. The measurable components of AFA (PDMS [siloxane fraction], PPG [organic fraction], and $\mathrm{Si}$ ) partitioned to the solid phase in each test; by the end of the tests 
and liquid fractions were analyzed separately. The measurable components of AFA (PDMS [siloxane fraction], PPG [organic fraction], and $\mathrm{Si}$ ) partitioned to the solid phase in each test; by the end of the tests only around $15-25 \%$ of the AFA that was added during the tests remained in the final slurry. The balance of the AFA components were either removed during the filtration and washing steps, undetected by the analytical methods or degraded during processing. Only Integrated Test D had evidence of degradation caused by oxidative leaching, which was probably a result of excess permanganate. More quantitative conclusions were not possible due to inconsistencies in the analytical results.

\subsubsection{Air Entrainment in Tank T02A}

Air entrainment by the slurry in Tank T02A was observed in Integrated Tests A, B, and D. It was characterized by very small air bubbles, assumed to be attached to slurry particles, which formed a relatively stable three-phase emulsion. This caused both measureable level changes, a significant decrease in filter-loop pump efficiency and may have reduced filter flux. In Integrated Test A, the problem appears to have been initiated by a PJM overblow and may have been perpetuated by efforts to achieve higher than prototypic filter-loop flow rates (due to erroneous flowmeter readings). In Integrated Tests B and D, air entrainment was a problem, primarily when the slurry level in Tank T02A was at or below the filter-loop return nozzle. When the filter-loop return jet impinged on the slurry surface (instead of being submerged), air entrainment was markedly increased.

Tests indicated that 1) air from any of the lower air sparge tubes and the steam ring purge could be carried into the filter-loop pump suction and increase air entrainment, and 2) exposing the filter-loop return nozzle caused air to be entrained. These relatively large air bubbles were then sheared by the filter-loop pumps into smaller bubbles. It was also thought that the compression/decompression cycle of the filter-loop could create microbubbles: some of the air present on the outlet of the second pump would dissolve into the liquid under the roughly 150 psia pressure at that point and then nucleate and form microbubbles on the surfaces of particles as the pressure was reduced to roughly 15 psia in Tank T02A. Previous work has shown that AFA can increase gas retention and slows gas release (Stewart et al. 2006). Other work indicates that the gas holdup is also a function of the slurry chemical and physical properties (Stewart et al. 2007).

Once air was entrained, it was very difficult to remove. Attempts to remove the entrained air, primarily by shutting off the pumps and increasing air sparge mixing, were successful enough to allow completion of the tests. Methods to prevent air entrainment in the PEP tests at low vessel levels included reducing the filter-loop flow rate, temporarily reducing or eliminating the various sources of air, and modifying the testing protocol to operate the vessels at higher levels as much as possible.

\subsubsection{Summary of Precipitation Studies}

As discussed in Russell et al. (2009d), permeate samples were obtained during the post-caustic-leach dewatering and washing steps. These samples were examined for precipitation. Follow-on studies (which are not summarized here) may be found in Russell et al. (2009e).

The precipitates from the PEP post-caustic-leach wash permeate solutions from Integrated Test A were studied to develop an understanding of post-filtration precipitation. After individual permeate samples taken throughout the whole length of the washing process were allowed to sit at laboratory 
temperature for 10 days, needle-shaped and rod-shaped crystalline precipitates appeared in the first 38 of the 50 samples (that is, those from all but the last quarter of the washing process). Upon X-ray diffraction (XRD) analysis, the majority of the solids phase proved to be phosphate, oxalate, and hydrogen phosphate salts. No aluminum-bearing solids were detected. Crystals continued to form in the permeate samples over the next 2 months.

Precipitates in permeate samples taken at four different points during the post-caustic-leach wash in Integrated Test $\mathrm{D}$ were also studied. Examination with polarized light microscopy (PLM) showed that crystals were, again, mainly sodium phosphate and oxalate salts. The maximum length of these crystals after 2 weeks was between $100-\mu \mathrm{m}$ and $120-\mu \mathrm{m}$. Particle-size distributions (PSD) were obtained.

Precipitate studies were also conducted for 1) liquids produced by blending together washing permeate samples taken from the first third of the Integrated Test A wash process, 2) a mixture of this wash blend with permeate samples from post-caustic-leach solids concentration in Integrated Test A, and 3) leachate from post-caustic-leach solids concentration in Integrated Tests B and D. Needle-like crystals were formed in all mixtures. They appeared more rapidly (in less than 10 days) in the liquids that were entirely or partly composed of wash permeate than in the post-caustic-leach permeate, in which crystals did not appear until after at least 2 months.

\subsection{UFP Performance Model Verification}

This section addresses the objective: provide system effectiveness data to estimate WTP

performance. The four key unit operations discussed are cross-flow ultrafiltration, caustic leaching, solids washing, and oxidative leaching.

\subsubsection{Cross-Flow Ultrafiltration}

Tests were conducted to compare PEP and CUF filter performance at the two different cross-flow ultrafiltration regimes observed with waste. The regimes are distinguished by whether the primary resistance to permeation occurs in the filter media or in the filter cake. At low-solids concentrations, the resistance to permeation is primarily in the filter media, and permeation rates decline as the filter media are fouled by fine particles. At high-solids concentrations, the thickness of the cake of particles on the surface of the filter media increases, and, for slurries that form cakes having lower porosity than the filter media, the filter cake provides the primary resistance to permeation.

For the low-solids filter test, the scaling factor was defined as the ratio of the PEP filter flux to the CUF filter flux. For both scales, the filter flux was corrected to standard temperature $\left(25^{\circ} \mathrm{C}\right)$ and TMP (40 psid) before determining the ratio. The final filter scaling factors based on total PEP flux for low-solids tests \#1 and \#2 were both $1.1 \pm 0.1$. To provide a conservative estimate for process scaling, a scaling factor of 1.0 is recommended for scaling low-solids filtration operations. It should be noted that this low-solids operations scaling-factor estimate is subject to limitations associated with the test. These limitations include the following: 1) divergence of the filter flux from individual PEP filter bundles in which downstream filter bundles appear to foul more rapidly relative to the upstream filter bundles, 2) differences in the state of the PEP and CUF initial filter conditioning, and 3) insufficient time to achieve a filtration steady state (i.e., the duration of the tests was limited to 36 hours). 
For high-solids slurry filtration, the scaling factor analysis considered scaling in terms of the parameters characterizing filtration dewatering performance at concentrations approaching the limiting gel concentration. These parameters are 1) the dewatering mass transfer coefficient $(k)$, and 2) the slurry-limiting gel concentration $\left(C_{g}\right)$. Two separate scaling factors were defined - the first is the ratio of PEP $k$ to CUF $k$, and the second is the ratio of PEP $C_{g}$ to CUF $C_{g}$.

The analysis of PEP and CUF high-solids dewatering curves indicates scaling factors of $0.97 \pm 0.03$ and $0.96 \pm 0.05$ for both $k$ and $C_{g}$, respectively. These results indicate that the high-solids filtration performance of CUF and PEP are indistinguishable from one another. Based on the best information currently available, the scaling factor for high-solids dewatering operations appears to be one. That is, CUF appears to provide a reasonable indication of PEP filter flux performance during high-solids dewatering operations approaching the gel point.

\subsubsection{Caustic Leaching}

Parallel caustic-leach tests were conducted at the laboratory-scale and in the PEP to obtain data to develop scale-up factors. The scale-up factors are defined as the ratio of the kinetic rate constant for the dissolution of boehmite at the PEP scale to the kinetic rate constant determined at the laboratory-scale.

The rate constants and scale-up factors were calculated as the median of the population for the Integrated tests and for both laboratory-scale tests and are presented in Table 14.2. The uncertainties are expressed as the $95 \%$ confidence interval around the median values and were calculated with a Monte Carlo approach based on uncertainties derived from sample handling and analytical techniques. Much of the uncertainty comes from uncertainty in the initial-condition concentrations used as inputs to the kinetic model. Given the broad overlapping confidence intervals, the rate constants from the six PEP and laboratory-scale tests are not statistically distinguishable from each other at a $95 \%$ confidence level.

Table 14.2. Median Scale-Up Factors and Kinetic Rate Constants for PEP and Laboratory-Scale Tests (95\% confidence intervals in parentheses)

\begin{tabular}{l|c|c|}
\hline \multicolumn{1}{|c|}{ Test } & $\begin{array}{c}\text { Rate Constant } k \\
\left(\mathrm{hr}^{-1} *[\mathrm{~mol} \text { total OH} / \mathrm{L}]^{-1}\right)\end{array}$ & $\begin{array}{c}\text { Scale-Up } \\
\text { Factor, } k_{P E P} / k_{\text {lab }}\end{array}$ \\
\hline $\begin{array}{l}\text { PEP Integrated Test A Batch 1 (caustic-leach in } \\
\left.\text { Ultrafiltration Feed Preparation Vessel at } 98^{\circ} \mathrm{C}\right)\end{array}$ & $0.019(0.013-0.025)$ & --- \\
Combined Laboratory-Scale Test A results & $0.021(0.013-0.035)$ & $0.88(0.47-1.56)$ \\
\hline $\begin{array}{l}\text { PEP Integrated Test B Batch 2 (caustic-leach in } \\
\left.\text { Ultrafiltration Feed Vessel at 98 }{ }^{\circ} \mathrm{C}\right)\end{array}$ & $0.025(0.018-0.034)$ & --- \\
Combined Laboratory-Scale Test B results & $0.018(0.012-0.028)$ & $1.38(0.80-2.41)$ \\
\hline $\begin{array}{l}\text { PEP Integrated Test D Batch 2 (caustic-leach in } \\
\left.\text { Ultrafiltration Feed Vessel at } 85^{\circ} \mathrm{C}\right)\end{array}$ & $0.014(0.010-0.019)$ & --- \\
Combined Laboratory-Scale Test D results & $0.013(0.0078-0.019)$ & $1.10(0.64-2.02)$ \\
\hline
\end{tabular}

The results suggest that the conditions present during caustic-leach at $98^{\circ} \mathrm{C}$ in Tank T02A (Integrated Test B) might produce higher scale-up factors than the other tested conditions. The reasons for scale-up factors significantly less than or greater than one are not completely clear, but could include temperature and solids-concentration variation within the vessel. However, the Integrated Test B scale-up factors are 
within the $95 \%$ confidence intervals of the factors from other tests, and so are not conclusively different from them.

Using the caustic leaching results from Integrated Test A, the aluminum-leach performance in Tank T01A/Bwas compared for two methods of caustic addition. In one method (Batches 1, 3, and 5) all of the $\mathrm{NaOH}$ is added in-line as simulant was transferred to Tank T01A/B. In the other method (Batches $2,4$, and 6$), 80 \%$ of the caustic was added in-line, and $20 \%$ was added directly to the tank after the simulant transfer was complete. Based on a comparison of the rate constants between Batches 1 and 3 , and 2,4 , and 6 , the two methods of caustic addition produce results that are statistically the same. Batch 5 was not included in the analysis because of a high-temperature spike at the beginning of the constant-temperature leach.

In an attempt to estimate the amount of caustic added to the PEP in excess of that needed to keep aluminate in solution, gibbsite was added to PEP process permeate samples to measure the amount of gibbsite that could be dissolved. For each PEP Integrated Test, one sample of post-caustic-leach permeate and one of post-caustic-leach wash permeate were used in excess caustic testing — a total of six cases. As shown in Table 14.3, a significant amount of gibbsite was dissolved in five of the six cases. The exception was the wash permeate from Integrated Test B: no statistically significant amount of gibbsite dissolved, indicating that there was no significant excess caustic present at this point in the process.

Table 14.3. Final Dissolved Al Concentration Increase Resulting from Gibbsite Addition

\begin{tabular}{lcc}
\hline Solution & $\begin{array}{c}\text { Initial Dissolved } \\
\mathrm{Al}(\mathrm{M})\end{array}$ & $\begin{array}{c}\text { Percent Increase } \\
\text { in Dissolved Al }\end{array}$ \\
\hline Wash, Integrated Test A & 0.235 & 19 \\
Wash, Integrated Test B & 0.583 & 3 \\
Wash, Integrated Test D & 0.397 & 24 \\
Leachate, Integrated Test A & 0.418 & 58 \\
Leachate, Integrated Test B & 0.801 & 28 \\
Leachate, Integrated Test D & 0.668 & 96 \\
\hline
\end{tabular}

\subsubsection{Solids Washing}

Washing operations in PEP across all three Integrated Tests A, B, and D were conducted successfully as per the approved Test Instructions. Minor instrumentation problems occurred, and some of the process conditions specified in the run sheets were not met during the wash operations, such as filter-loop flow rate targets.

For Integrated Tests A, B, and D, five analytes were selected based on full solubility and monitored in the post-caustic-leach wash as successful indicators of washing efficiency: aluminum, sulfate, nitrate, nitrite, and free hydroxide. Other analytes, including sodium, oxalate, phosphate, and total dissolved solids (TDS), showed indications of slow dissolution and therefore were unsuitable for monitoring washing efficiency. 
For Integrated Tests A, B, and D, in the post-oxidative-leach wash, two analytes with full solubility and good concentration behavior were selected as suitable indicators of washing efficiency: chromium and oxalate. All other candidate analytes, including sodium, manganese, nitrate, and TDS, show deviations from ideal washing behavior attributable to the dead volume of the filter-loop $\mathrm{NaOH}$ in the wash solution, and/or analytical quantitation limits.

For Integrated Tests A, B, and D, an overall wash efficiency of $1.00 \pm 0.01$ was determined for the post-caustic-leach wash. Similarly, the overall wash efficiency for the post-oxidative-leach wash was determined to be $0.98 \pm 0.01$. These wash efficiencies were based on the weighted least squares fit of the full data set for each applicable analyte and are an average of several analytes traced during the washing steps in all of Integrated Tests A, B, and D.

The number of IW batches required to reach the target of $0.25-\mathrm{M}$ free hydroxide during the post-caustic-leach washing stage was 64 batches for Integrated Test A, 39 batches for Integrated Test B, and 43 batches for Integrated Test D. As part of an assessment of the WPT process control strategy, these are compared to the WTP projections to reach the target of $0.25-\mathrm{M}$ free hydroxide of 64 for Integrated Test A, 38 for Integrated Test B, and 45 for Integrated Test D. It is concluded that the WTP process control strategy for specifying the number of wash batches for post-caustic-leach washing is successful.

\subsubsection{Oxidative Leaching}

A comparison was made between the $\mathrm{Cr}$ leach factors found for PEP Integrated Tests $\mathrm{A}, \mathrm{B}$, and D and laboratory-scale testing using the same simulant and permanganate-to-Cr ratios of approximately 1 or greater.

The following observations were made:

- The actual permanganate-to-chromium ratios used in Integrated Tests A and B were all close to the targeted ratio of 1 . In Integrated Test $\mathrm{D}$, the method for estimating the amount of $\mathrm{Cr}$ remaining after caustic leaching overestimated the amount of $\mathrm{Cr}$ that would remain in the solids phase leading to permanganate-to-slurry-Cr initial ratios greater than 10 . The source of the discrepancy between $\mathrm{Cr}$ dissolution during the preliminary laboratory-scale caustic-leach as opposed to the results in PEP is unknown. Based on these results, the WTP process control strategy for accurately projecting the amount of permanganate required for oxidative leaching was not successful.

- A Cr mass balance for Integrated Test D indicated an excess of $47 \% \mathrm{Cr}$ in the solution at the end of the oxidative leaching step. It is proposed that the excess permanganate may have leached $\mathrm{Cr}$ from the PEP components.

- The kinetic behavior observed with respect to the $\mathrm{Cr}$ leach factors indicates that the rate of $\mathrm{Cr}$ oxidative dissolution is extremely fast for the Cr(III) form used in the simulant. For both the laboratory scale and PEP tests, the fraction of dissolved $\mathrm{Cr}$ reached its final value within a few minutes of permanganate contact time.

- Consistent with a rapid, exothermic reaction, an initial increase in slurry temperature was observed upon permanganate addition to the more concentrated $\mathrm{Cr}$ slurries used in Integrated Tests A and B. The superior temperature control in the PEP allowed for more rapid cooling 
(returning to the target temperature within 1 hour of leaching) than with the laboratory-scale testing (return to the initial temperature not observed after the conclusion [eight hours] of leaching). For Integrated Test D, no observable increase in temperature was observed. The much lower Cr-slurry concentration did not result in enough heat being generated to generate a noticeable increase in temperature.

- The cumulative fraction of $\mathrm{Cr}$ removed by leaching gives a leach factor of approximately 0.9 regardless of the test and regardless of test scale. This allows a key conclusion to be made--namely, that the scale-up factor from laboratory-scale oxidative leaching to PEP-scale testing is 1.

\subsection{PEP Operation}

This section contains various aspects of PEP operation that are not discussed elsewhere in this section. The in-line and in-tank sampling variability test was conducted during the Functional testing to determine the best locations for obtaining samples. The other topics may be of interest for future PEP tests or provide information relevant to WTP operations. These topics are covered in detail in the PEP run reports (Josephson et al. 2009, Guzman-Leong et al. 2009, Geeting et al. 2009, and Sevigny et al. 2009).

\subsubsection{In-Line and In-Tank Sampling Variability}

A comparison of wt $\%$ UDS measurements on samples obtained from the filter-loop in-line sampler to those obtained from the in-tank sampler in Tank T02A indicated that the variance of the in-line samples was approximately a factor of 5 times greater than the variance of the samples obtained from the in-tank sampler. Based on this observation, samples were obtained directly from Tank T02A whenever possible in preference to samples obtained in-line.

\subsubsection{PJM Plugging}

One of the PJMs in Tank T01A displayed unusual level behavior as indicated by the Drexelbrook level probe and was inoperative during most of Integrated Test B. The level in the PJM was observed to be unchanged even though the expected air pressure was applied to during the drive phase. An intentional overblow resolved the issue for approximately one hour. However, the level probe displayed the same behavior again and was disabled when additional overblows did not resolve the issue. Several causes of this problem were investigated including PJM plugging and instrument/equipment problems. The source of the problem could not be verified during testing since this would have required disrupting the chemical processes during the test. A post-test inspection verified that the air supply was functioning properly including the valves and the regulator. After rinsing and flushing, the level probes were also verified to work properly. The post-test inspection did not reveal any plug, but a plug may have been removed by flushing operations before the inspection. If a plug was present the most likely location was in the air supply line in the vicinity of a spacer used to hold the Drexelbrook level probe away from the wall of the neck. Because the Drexelbrook probes are nonprototypic and are not planned for the PTF, this problem would not be expected in the PTF. The PTF also has an air supply wash-down system designed to clean the PJM air supply lines that the PEP does not have. 


\subsubsection{PEP Instrumentation}

The PEP contained approximately 1500 instruments, including 400 Nuclear Quality Assurance (NQA)-1 qualified instruments to monitor the process and record test data. These instruments provided data on flow rates, vessel levels, pressures, temperatures, and filter-loop pump speed and power. The PEP instrumentation, by requirement, mimicked the actual system design although additional instrumentation was added to support the testing. The additional instrumentation was not prototypical of PTF, and is not necessary for actual plant operation. Detailed lists of the instrumentation are included in the run reports (Josephson et al. 2009, Guzman-Leong et al. 2009, Geeting et al. 2009, Sevigny et al. 2009). An overview of the observed benefits and challenges of some of the instrumentation is provided below. In general there were very few failures and many of these occurred during installation or were due to sensors that were not completely suitable for the application.

Several types of flowmeters were used for the simulant and process streams including coriolis mass flowmeters, swirl meters and mag flowmeters. The mag flowmeters on the intake and outlet of the filter-loop pumps were valuable in identifying the air entrainment issue by showing a large divergence in the flow measured by the two instruments. The presence of entrained gas was indicated by a much larger flow rate as measured at the pump intake where the entrained air bubbles expanded in the low pressure environment. One of the mag flowmeters failed due to a failed plastic liner. The cause of the failure of the mag flowmeter was indeterminate. Swirl meters did not work very well as they were susceptible to vibration which resulted in a significant increase in the variability of the measured flow including non-zero readings at no flow conditions. PEP also used Coriolis flowmeters for measuring permeate flow rate, process chemical addition flow rates and flow through the in-tank sampling lines. These are robust instruments that generally worked well. They do require calibration of the density, flow and temperature functions over the range of conditions in which they will be used. The density function failed on one of the flowmeters on the in-tank sampling loops.

Extensive pressure instrumentation on the filter-loop was used to monitor and control the filtration process and assisted in the identification of the air entrainment issue. The pressure instruments after the ultrafilters were used for controlling valve settings on the filter-loop to maintain backpressure in the filters. The pressure instruments were relatively trouble free with no recorded instances of in-process failures.

Temperature instrumentation in the tank was used to control the heat-up and cool-down phases of the caustic leaching process as well as maintain the process temperature at the target parameters during the other process steps. A single RTD was provided in each of the leaching vessels in a prototypic location. Originally this was supplied in a thermowell for insertion into the tank. The thermowell was removed prior to testing because the thermal mass and conductivity of the thermowell resulted in a slow response time (minutes) in detecting temperature changes. Placing the RTD directly in the slurry/simulant improved temperature change response times but could lead to shorter instrument life time due to the corrosive nature of the simulant. The single RTD failure was attributed to damage incurred during installation. There were no instances of RTD failure due to corrosion during the PEP tests. The RTDs placed in thermowells in the flow loop did not provide reliable temperature data because the thermowell was too short and did not extend into the flowing fluid. This resulted in a stagnant layer of slurry that formed in the pipe Tee that contained the thermowells and was particularly a problem with non-Newtonian slurries. In general the RTDs provide acceptable performance for the PEP monitoring and testing as long as they were properly installed and calibrated. 


\subsubsection{Vessel Level Measurement}

Measuring the level in the vessels and PJMs was an important aspect of the PEP testing that presented significant challenges. During portions of the testing (particularly Integrated Test A), there were no credible level instrument readings for level control in the vessels. Poor tank level data also caused a number of high vessel level alarms that resulted in the temporary shutdown of portions of the process. The importance of level measurement was recognized during the design of the PEP, and Drexelbrook level probes were installed in the pulse tubes. The level in the vessels was measured by the bubbler instruments, laser level instruments, and a Drexelbrook probe. All of these instruments had been successfully used in previous PJM testing programs.

The Drexelbrook level indicators provided reasonable level measurements in the PJMs except at elevated temperature during the caustic leaching steps. The failure of the level probes to work during the caustic leaching steps appeared to be correlated with an uptake of simulant into the air lines above the pulse tubes during the vacuum refill. It was hypothesized that the simulant tended to hang up in the air line and induce a false high-level reading in the instrument. All of the original Drexelbrook instruments were replaced during the Functional testing with Teflon coated probes for improved chemical compatibility. The active area of the probes was also limited to the region of the probe actually in the pulse tubes. The new instruments did not improve the level measurement performance in the PJMs. Drexelbrook level probes installed in Tanks T01A/B and T02A often provided acceptable level measurements but did experience periods where they did not provide reliable data. The level data from the Drexelbrook was also affected by foam.

The laser-level instruments generally provided usable data, but the readings were impacted by foam on top of the simulant, surface turbulence, aerosols in the head space of the vessel, and splattering of simulant on the lens of the instrument. The foam and the aerosols generated numerous spurious data. For the purpose of process control, this was mitigated by changes in the data processing software to filter out the spurious data. The aerosol concentration was reduced by opening a tank vent. The open vent also appeared to have an effect on the foam because the incoming air moved the foam layer away from the spot where the laser was reflecting off of the simulant. A laser vent plug was also removed, which allowed air to flow directly past the instrument lens. The splattering of simulant on the instrument lens necessitated periodic cleaning.

As previously mentioned in Section 14.1.4, the bubbler instruments were impacted by fluid flow (from the PJMs and filter-loop return nozzle) past the bubbler tubes as well as periodic plugging by the simulant. The plugging required periodic cleaning using high pressure air that was sometimes followed by water. Multiple cleaning attempts were sometimes required to unplug the bubblers. After a successful bubbler cleaning, the duration of the functionality was variable. The effect of plugging on the density measurements from the bubbler instruments was particularly noticeable with density readings often being physically unrealistic $(<1$ or $>1.5-\mathrm{g} / \mathrm{L})$. This is due in part because the distance between the two bubbler tubes was relatively small ( $\sim 6$-in.) so small pressure changes result in relatively large changes in density. Maximizing the distance between the two bubblers tubes would minimize this problem. Placement of the bubbler tubes to minimize the impact of fluid flow should be considered.

It should be noted that there are significant differences between the design and operation of the PEP bubblers and those planned for the PTF. The PTF bubblers incorporate a wide mouth outlet (2-in. vs 0.5-in. in the PEP) to minimize plugging. The PTF also has an automatic washing system to prevent the 
build-up of solids in the bubbler tubes. These differences are expected to mitigate the bubbler level issues experienced in the PEP.

The effect of entrained gas and foam on the bubbler level measurements deserves some additional comment. Foam should have no impact on the levels measured by the bubblers since it has a negligible impact on the hydrostatic pressure at the bubbler tubes. Assuming that the entrained gas is uniformly distributed throughout the slurry, the bubblers will account for the entrained gas and provide good level measurements. However, they do not account for the compression of the entrained gas due to the hydrostatic head of the slurry. In the PEP this was a small effect since the slurry depth was limited to a few feet. In the PTF the slurry depth will often be $>20$-ft so the hydrostatic head will be significant. This will result in a measured density at the bottom of the vessel that is greater than the density of the slurry near the surface. The will lead to a measured level that is less than the actual level.

While the level measurements during the PEP testing created operational difficulties there was little practical impact on the conduct of the test or the test results. In most cases, other instruments were used to monitor the process. For example, the volume of simulant and reagents was determined using flowmeters. The level instruments worked well for controlling when batches of wash-water and make-up batches of simulant were added during the test. Level measurements were used sparingly in the data analysis. Level data was used in condensate analyses (caustic leaching) and for a few estimates of final slurry mass and tank heels in mass balance calculations.

\subsubsection{Foaming in the PEP Vessels}

There is a concern that bubbles from the air sparge mixers and steam ring purge in the PTF ultrafiltration feed vessels, and the steam ring air purge in the ultrafiltration feed preparation vessels, will result in excessive foam on the waste surface. To mitigate the foam, the WTP plans to maintain an antifoam agent (AFA), Dow Corning ${ }^{\circledR}$ Q2-3183A, at a concentration of 350 ppm during most process steps. Because the oxidant to be used for oxidative leaching (permanganate) is known to attack and degrade components of the AFA, WTP plans to not attempt to maintain AFA at the $350 \mathrm{ppm}$ level during oxidative leaching, and to reduce air sparge mixer use to limit foaming. Thus, in addition to the general interest in foam formation, there is particular interest in whether foaming is worse during oxidative leaching.

Foam was observed during many of the PEP process steps. Based on level probe data presented in the PEP run reports and videos of the slurry surface in PEP vessels, the foam layer may have been as much as several inches thick. The impact of the foam on the conduct of the tests was to induce erratic level measurements. In several instances during the caustic leaching in Tank T02A, with the vessel fill level relatively high, the foam and erratic level measurements are thought to have contributed to high-high tank level alarms that temporarily interrupted the steam heating. During oxidative leaching, the level probe measurements did not show a significant change, indicating that the level of foaming was constant.

Prototypic PEP operation would require the Tank T02A steam ring air purge to be on whenever steam was not being used, and as indicated in Table 5.2, the lower air sparger mixer flow rates would need to be at their "idle" rate during oxidative leaching and whenever the filter-loop pumps were on and the slurry level was less than about $\approx 52$ inches. However, to minimize air entrainment during the integrated PEP testing, the air flow to both the Tank T02A steam ring and the lower air sparge mixers was typically 
turned off to reduce air entrainment in the filter-loop. Thus, the lack of significant foam during PEP testing may have at times been due to the lack of either sparge mixer or steam ring purge air. 



\subsection{References}

Baldwin DL, PP Schonewill, JJ Toth, JL Huckaby, PW Eslinger, BD Hanson, DE Kurath, and MJ Minette. 2009. EFRT M12 Issue Resolution: Solids Washing. WTP-RPT-187, PNNL-18499, Pacific Northwest National Laboratory, Richland, Washington.

Barnes HA and Quoc Dzuy Nguyen. 2001. "Rotating vane rheometry - a review." J. Non-Newtonian Fluid Mech, 98, 1-14.

Billing JM, RC Daniel, DE Kurath, and RA Peterson. 2009. Bench-Scale Filtration Testing in Support of the Pretreatment Engineering Platform (PEP). WTP-RPT-203, PNNL-18673, Pacific Northwest National Laboratory, Richland, Washington.

Bontha, JR, CW Stewart, DE Kurath, PA Meyer, ST Arm, CE Guzman-Leong, MS Fountain, M Friedrich, SA Hartley, LK Jagoda, CD Johnson, KS Koschik, DL Lessor, F Nigl, RL Russell, GL Smith, W Yantasee, and ST Yokuda. 2006. Technical Basis for Predicting Mixing and Flammable Gas Behavior in the Ultrafiltration Feed Process and High-level Waste Lag Storage Vessels with Non-Newtonian Slurries. WTP-RPT-132, PNWD-3676, Battelle, Pacific Northwest Division, Richland, Washington.

Daniel RC, JM Billing, ML Luna, KJ Cantrell, RA Peterson, ML Bonebrake, RW Shimskey, and LK Jagoda. 2009a. Characterization of Filtration Scale-Up Performance. WTP-RPT-168, PNNL-18117, Pacific Northwest National Laboratory, Richland, Washington.

Daniel RC, JM Billing, JR Bontha, CF Brown, PW Eslinger, BD Hanson, JL Huckaby, NK Karri, ML Kimura, DE Kurath, and MJ Minette. 2009b. EFRT M12 Issue Resolution: Comparison of Filter Performance at PEP and CUF Scale. WTP-RPT-185, PNNL-18498, Pacific Northwest National Laboratory, Richland, Washington.

Fiskum SK, JM Billing, EC Buck, RC Daniel, KE Draper, MK Edwards, ED Jenson, AE Kozelisky, PJ MacFarlan, RA Peterson, RW Shimskey, and LA Snow. 2009. Laboratory Demonstration of the Pretreatment Process with Caustic and Oxidative Leaching Using Actual Hanford Tank Waste. WTP-RPT-171, PNNL-18007, Pacific Northwest National Laboratory, Richland, Washington.

Geeting JGH, RT Hallen, LK Jagoda, AP Poloski, RD Scheele, and DR Weier. 2003. Filtration, Washing, and Caustic Leaching of Hanford Tank AZ-101 Sludge. WTP-RPT-043, PNWD-3206, Battelle, Pacific Northwest Division, Richland, Washington.

Geeting JGH, OP Bredt, CA Burns, EC Golovich, E Guzman-Leong, GB Josephson, DE Kurath, GJ Sevigny, and RL Aaberg. 2009. Pretreatment Engineering Platform (PEP) Integrated Test B Run Report-Caustic and Oxidative Leaching in UFP-VSL-T02A. WTP-RPT-192, PNNL-18723, Pacific Northwest National Laboratory, Richland, Washington.

Guzman-Leong CE, OP Bredt, CA Burns, RC Daniel, YF Su, JGH Geeting, EC Golovich, GB Josephson, DE Kurath, GJ Sevigny, DM Smith, PLJ Valdez, ST Yokuda, and JK Young. 2009. PEP Run Report for Integrated Test A; Caustic Leaching in UFP-VSL-T01A, Oxidative Leaching in UFP-VSL-T02A. WTP-RPT-191, PNNL-18755, Pacific Northwest National Laboratory, Richland, Washington. 
Hermia J. 1998. "Constant Pressure Blocking Filtration Laws - Application to Power-Law and Non-Newtonian Fluids.” Transactions of the Institution of Chemical Engineers, 59(1):183-187.

Josephson GB, JGH Geeting, OP Bredt, CA Burns, CE Guzman-Leong, DE Kurath, and GJ Sevigny. 2009. PEP Run Report for Simulant Shakedown/Functional Testing. WTP-RPT-190, PNNL-18823, Pacific Northwest National Laboratory, Richland, Washington.

Kuhn WL, ST Arm, JL Huckaby, DE Kurath, and SD Rassat. 2008. Technical Basis for Scaling Relationships for the Pretreatment Engineering Platform. WTP-RPT-160, PNNL-16948, Pacific Northwest National Laboratory, Richland, Washington.

Long GL and JD Winefordner. 1983. "Limit of Detection. A Closer Look at the IUPAC Definition." Analytical Chemistry, 55(7):712A-724A.

Mahoney LA, ZI Antoniak, JM Bates, and ME Dahl. 1999. Retained Gas Sampling Results for the Flammable Gas Program. PNNL-13000, Pacific Northwest National Laboratory, Richland, Washington.

Mahoney LA, SD Rassat, PW Eslinger, RL Aaberg, PM Aker, EC Golovich, BD Hanson, TS Hausmann, JL Huckaby, DE Kurath, MJ Minette, SK Sundaram, and ST Yokuda. 2009. EFRT M12 Issue Resolution: Caustic-Leach Rate Constants from PEP and Laboratory-Scale Tests. WTP-RPT-186, PNNL-18502, Pacific Northwest National Laboratory, Richland, Washington.

Misra C. 1970. "Solubility of aluminum trihydroxide (hydrargillite) in sodium hydroxide solutions." Chemistry and Industry, 19:619-623.

Panias D, P Asimidis, and I Paspaliaris. 2001. "Solubility of Boehmite in Concentrated Sodium Hydroxide Solutions: Model Development and Assessment." Hydrometallurgy, 59(1):15-29.

Rapko BM, JGH Geeting, SI Sinkov, and JD Vienna. 2004. Oxidative-Alkaline Leaching of Washed 241-SY-102 and 241-SX-101 Tank Sludges. WTP-RPT-117, PNWD-3512, Battelle, Pacific Northwest Division, Richland, Washington.

Rapko BM, GJ Lumetta, JR Deschane, and RA Peterson. 2007. Process Development for Permanganate Addition During Oxidative Leaching of Hanford Tank Sludge Simulants. WTP-RPT-164, PNNL-16794, Pacific Northwest National Laboratory, Richland Washington.

Rapko BM, CF Brown, PW Eslinger, MS Fountain, TS Hausmann, JL Huckaby, BD Hanson, DE Kurath, and MJ Minette. 2009. EFRT M12 Issue Resolution: Comparison of PEP and Bench-Scale Oxidative Leaching Results. WTP-RPT-188, PNNL-1850, Pacific Northwest National Laboratory, Richland, Washington.

Russell RL, RA Peterson, HD Smith, DE Rinehart, PM Aker, and EC Buck. 2009a. Development and Characterization of Boehmite Component Simulant. WTP-RPT-184, PNNL-18176, Pacific Northwest National Laboratory, Richland Washington.

Russell RL, HD Smith, DE Rinehart, and RA Peterson. 2009b. Development and Characterization of Gibbsite Component Simulant. WTP-RPT-176, PNNL-18013, Pacific Northwest National Laboratory, Richland Washington. 
Russell RL, JM Billing, RA Peterson, DE Rinehart, and HD Smith. 2009c. Development and Demonstration of Ultrafiltration Simulants. WTP-RPT-183, PNNL-18090, Pacific Northwest National Laboratory, Richland Washington.

Russell RL, RA Peterson, DE Rinehart, and WC Buchmiller. 2009d. PEP Support: Laboratory Scale Leaching and Permeate Stability Tests. WTP-RPT-200, PNNL-18597, Pacific Northwest National Laboratory, Richland Washington.

Russell RL, RA Peterson, DE Rinehart, and JV Crum. 2009e. Results of the Laboratory Precipitate Study from PEP Simulant. WTP-RPT-205, PNNL 18876, Pacific Northwest National Laboratory, Richland, Washington.

Sevigny GJ, OP Bredt, CA Burns, DE Kurath, JGH Geeting, EC Golovich, CE Guzman-Leong, and GB Josephson. 2009. PEP Integrated Test D Run Report--Caustic and Oxidative Leaching in UFP-VSL-T02A. WTP-RPT-193, PNNL-18741, Pacific Northwest National Laboratory, Richland, Washington.

Skoog DA, DM West. 1969. Fundamentals of Analytical Chemistry, $2^{\text {nd }}$ Ed. Holt, Rinehart and Winston, Inc., New York, New York.

Smith HD, RL Russell, and RA Peterson. 2009. Simulated Waste for Leaching and Filtration Studies--Development, Property Comparison,, and Preparation Procedure. WTP-RPT-201, PNNL-18701, Pacific Northwest National Laboratory, Richland, Washington.

Stewart CW, PA Meyer, MS Fountain, CE Guzman-Leong, SA Hartley-McBride, JL Huckaby, and BE Wells. 2006. Effect of Anti-Foam Agent on Gas Retention and Release Behavior in Simulated High-Level Waste. WTP-RPT-147, PNWD-3786, Battelle, Pacific Northwest Division, Richland, Washington.

Stewart CW, CE Guzman-Leong, ST Arm, MG Butcher, EC Golovich, LK Jagoda, WR Park, RW Slaugh, Y Su, CF Wend, LA Mahoney, JM Alzheimer, JA Bailey, SK Cooley, DE Hurley, CD Johnson, LD Reid, HD Smith, BE Wells, and ST Yokuda. 2007. Results of Large-Scale Testing on Effects of Anti-Foam Agent on Gas Retention and Release. WTP-RPT-156, PNNL-17170, Pacific Northwest National Laboratory, Richland, Washington.

U.S. Department of Energy-Richland Operations. 1998. Hanford Analytical Services Quality Assurance Requirements Documents (HASQARD). DOE-RL-96-68, Rev 2, Volumes 1 through 4, U.S. Department of Energy-Richland Operations, Richland, Washington.

DD Wagman, WH Evans, VB Parker, RH Schumm, I Halow, SM Bailey, KL Churney, and RL Nuttall. 1982. "The NBS Tables of Chemical Thermodynamic Properties." Journal of Physical and Chemical Reference Data. Volume 11, Supplement 2. 



\title{
Appendix A
}

\author{
Data Used in Caustic-Leach Factor \\ and Boehmite Dissolution Rate Constants
}





\section{Appendix A: Data Used in Caustic-Leach Factor and Boehmite Dissolution Rate Constants}

This appendix provides the primary analytical results used in caustic-leach and kinetics calculations. All concentrations and properties are stated at the dilution conditions actually existing in the sample. These values have not been subjected to any adjustment for the volume "normalization" that is discussed in Section 9.

This appendix contains only the concentrations and properties that were measured during the Pretreatment Engineering Platform (PEP) and laboratory-scale caustic-leach tests. ${ }^{\text {(a) }}$ In the PEP tests, the caustic-leach samples include those taken from the slurry before the $\mathrm{NaOH}$ reagent was added and those taken throughout the period starting after $\mathrm{NaOH}$ was added. The last ones taken were at the end of the constant-temperature digestion period. In the laboratory-scale tests, all the samples taken from the initial diluted condition $^{(\mathrm{b})}$ through the end of the constant-temperature leach are included. The post-cool-down slurry samples are also included. Of the slurry samples taken during the laboratory-scale tests, only the data for those that were not washed with $0.01-\mathrm{M} \mathrm{NaOH}$ before analysis are included.

Where only one sample was taken for a given point in the process, the entries in the tables are the measurements, and the \pm values are equal to half the laboratory uncertainty values (equivalent to a $95 \%$ confidence interval, or two standard deviations) that were supplied by the analytical organization for each concentration measurement. The laboratory uncertainty includes the "noise" of the analytical determination (which is related to the reporting limit) and uncertainty from instrumental techniques including aliquoting, standards, standardization, and subsampling.

The superscripts (2) or (3) on an entry indicate that duplicate or triplicate samples were taken. For these entries, the concentrations (or properties) in the table are the means of the set of samples, and the \pm values are the standard deviations of the means, calculated as follows:

$$
\sigma_{\text {mean }}=\frac{1}{N} \sqrt{\sum_{i=1}^{N} \sigma_{i}^{2}}
$$

where $\sigma_{i}$ is the standard deviation for the individual measurement denoted by $i$, based on the estimate of laboratory uncertainty provided by the analytical organization, $N$ is the number of measurements in the set, and $\sigma_{\text {mean }}$ is the standard deviation of the mean of the set.

The tables contain data only for the concentrations and properties that were used in caustic-leach data analysis. The only liquid and solid tracers that appear are the particular ones used in the calculations for each batch. These are not the same for all batches. As noted in Section 9, tracers were selected from those whose dilution trends generally matched the trend for the slurry aluminum concentration, although it was not always possible to pick a tracer that matched every point. More specific information about the tabulated data is given in the footnotes of each table.

(a) A complete reporting of the analytical results is provided in the PEP run reports.

(b) The "initial diluted" samples are those taken from the beaker after slurry from PEP was diluted in-beaker with DIW (for all but one of the tests) or with DIW plus $\mathrm{NaOH}$ reagent (for Test A-2). 
Table A.1. Sample Timing During Integrated Test A

\begin{tabular}{|c|c|c|c|c|c|c|}
\hline \multirow[b]{2}{*}{ Point in Process } & \multicolumn{6}{|c|}{ Sample Date and Time } \\
\hline & $\begin{array}{l}\text { Batch } 1 \text { in } \\
\text { Tank T01A }\end{array}$ & $\begin{array}{l}\text { Batch } 2 \text { in } \\
\text { Tank T01B }\end{array}$ & $\begin{array}{l}\text { Batch } 3 \text { in } \\
\text { Tank T01A }\end{array}$ & $\begin{array}{l}\text { Batch } 4 \text { in } \\
\text { Tank T01B }\end{array}$ & $\begin{array}{l}\text { Batch } 5 \text { in } \\
\text { Tank T01A }\end{array}$ & $\begin{array}{l}\text { Batch } 6 \text { in } \\
\text { Tank T01B }\end{array}$ \\
\hline Feed & $11 / 25 / 08$ & $11 / 25 / 08$ & $11 / 25 / 08$ & $11 / 25 / 08$ & $11 / 25 / 08$ & $11 / 25 / 08$ \\
\hline & $17: 38$ & $17: 38$ & $17: 38$ & $17: 38$ & $17: 38$ & $17: 38$ \\
\hline After $\mathrm{NaOH}$ & $1 / 31 / 09 \quad 13: 12$ & $1 / 31 / 09 \quad 18: 36$ & $2 / 2 / 09 \quad 20: 46$ & $2 / 4 / 09 \quad 16: 24$ & 2/7/09 $12: 16$ & 2/10/09 06:28 \\
\hline At $88^{\circ} \mathrm{C}$ & $1 / 31 / 09 \quad 18: 05$ & 2/1/09 02:39 & $2 / 3 / 09 \quad 01: 52$ & $2 / 4 / 09 \quad 21: 42$ & $2 / 7 / 09 \quad 16: 40$ & $2 / 10 / 09 \quad 11: 00$ \\
\hline $\begin{array}{l}98^{\circ} \mathrm{C} \text { reached at the } \\
\text { prototypic } \mathrm{TC}^{(\mathrm{a})}\end{array}$ & $1 / 31 / 09 \quad 19: 40$ & 2/1/09 03:25 & 2/3/09 $02: 44$ & $2 / 4 / 09 \quad 22: 39$ & 2/7/09 17:26 & $2 / 10 / 09 \quad 12: 06$ \\
\hline $\begin{array}{l}0 \mathrm{hr} \text { at } 98^{\circ} \mathrm{C} \\
\text { sample }\end{array}$ & $1 / 31 / 09 \quad 19: 44$ & $2 / 1 / 09 \quad 03: 25$ & 2/3/09 02:49 & $2 / 4 / 09 \quad 22: 43$ & 2/7/09 17:40 & 2/10/09 12:07 \\
\hline $1 \mathrm{hr}$ & $1 / 31 / 09 \quad 20: 40$ & $2 / 1 / 09 \quad 04: 22$ & 2/3/09 03:48 & $2 / 4 / 09 \quad 23: 39$ & 2/7/09 $18: 34$ & $2 / 10 / 09 \quad 13: 10$ \\
\hline $2 \mathrm{hr}$ & $1 / 31 / 09 \quad 21: 40$ & 2/1/09 05:21 & 2/3/09 $\quad 04: 47$ & $2 / 5 / 09 \quad 00: 37$ & $2 / 7 / 09 \quad 19: 32$ & $2 / 10 / 09 \quad 14: 10$ \\
\hline $4 \mathrm{hr}$ & $1 / 31 / 09 \quad 23: 40$ & 2/1/09 07:22 & 2/3/09 $06: 44$ & 2/5/09 $02: 27$ & 2/7/09 21:30 & $2 / 10 / 09 \quad 16: 08$ \\
\hline $8 \mathrm{hr}$ & 2/1/09 03:42 & $\mathrm{n} / \mathrm{m}$ & $2 / 3 / 09 \quad 10: 45$ & 2/5/09 $06: 40$ & 2/8/09 01:28 & 2/10/09 20:11 \\
\hline $10 \mathrm{hr}$ & $2 / 1 / 09 \quad 05: 41$ & $2 / 1 / 09 \quad 13: 27$ & $2 / 3 / 09 \quad 12: 50$ & 2/5/09 $08: 42$ & 2/8/09 03:26 & $2 / 10 / 09 \quad 22: 11$ \\
\hline $12 \mathrm{hr}$ & 2/1/09 07:47 & $2 / 1 / 09 \quad 15: 23$ & $2 / 3 / 09 \quad 14: 47$ & $2 / 5 / 09 \quad 10: 39$ & 2/8/09 $05: 28$ & 2/11/09 00:10 \\
\hline $14 \mathrm{hr}$ & 2/1/09 09:40 & $2 / 1 / 09 \quad 17: 21$ & $2 / 3 / 09 \quad 16: 44$ & $2 / 5 / 09 \quad 12: 40$ & 2/8/09 07:28 & 2/11/09 02:06 \\
\hline $16 \mathrm{hr}$ & 2/1/09 11:49 & $2 / 1 / 09 \quad 19: 22$ & 2/3/09 $18: 49$ & $2 / 5 / 09 \quad 14: 39$ & 2/8/09 $09: 37$ & 2/11/09 04:10 \\
\hline
\end{tabular}


Table A.2. Sample Timing During Laboratory-Scale Integrated Test A

\begin{tabular}{|c|c|c|}
\hline \multirow[b]{3}{*}{ Point in Process } & \multicolumn{2}{|c|}{ Sample Date and Time } \\
\hline & Laboratory-Scale & Laboratory-Scale \\
\hline & Test A-1 & Test A-2 \\
\hline Feed (PEP) & $11 / 25 / 08 \quad 17: 38$ & $11 / 25 / 08 \quad 17: 38$ \\
\hline After $\mathrm{NaOH}$ (PEP) & 1/31/09 13:12 & 1/31/09 13:12 \\
\hline Initial diluted & 2/9/09 08:27 & 2/9/09 08:28 \\
\hline At $88^{\circ} \mathrm{C}$ & 2/9/09 $12: 40$ & 2/9/09 $12: 42$ \\
\hline $0 \mathrm{hr}$ at $98^{\circ} \mathrm{C}$ & 2/9/09 13:43 & $2 / 9 / 09 \quad 13: 45$ \\
\hline $1 \mathrm{hr}$ & $2 / 9 / 09 \quad 14: 43$ & $2 / 9 / 09 \quad 14: 45$ \\
\hline $2 \mathrm{hr}$ & 2/9/09 $15: 43$ & $2 / 9 / 09 \quad 15: 45$ \\
\hline $4 \mathrm{hr}$ & $2 / 9 / 09 \quad 17: 43$ & $2 / 9 / 09 \quad 17: 45$ \\
\hline $8 \mathrm{hr}$ & 2/9/09 21:43 & 2/9/09 21:45 \\
\hline $10 \mathrm{hr}$ & 2/9/09 23:43 & 2/9/09 23:45 \\
\hline $12 \mathrm{hr}$ & $2 / 10 / 09 \quad 01: 43$ & $2 / 10 / 09 \quad 01: 45$ \\
\hline $14 \mathrm{hr}$ & 2/10/09 03:43 & $2 / 10 / 09 \quad 03: 45$ \\
\hline $16 \mathrm{hr}$ & 2/10/09 05:43 & 2/10/09 05:45 \\
\hline $18 \mathrm{hr}$ & $2 / 10 / 09 \quad 07: 43$ & $2 / 10 / 09 \quad 07: 45$ \\
\hline $20 \mathrm{hr}$ & 2/10/09 09:43 & 2/10/09 09:45 \\
\hline $22 \mathrm{hr}$ & $2 / 10 / 09 \quad 11: 43$ & $2 / 10 / 09 \quad 11: 45$ \\
\hline $24 \mathrm{hr}$ & $2 / 10 / 09 \quad 13: 43$ & $2 / 10 / 09 \quad 13: 45$ \\
\hline After cooling & $2 / 10 / 09 \quad 14: 35$ & $2 / 10 / 09 \quad 14: 39$ \\
\hline
\end{tabular}


Table A.3. Temperatures During Digestion Period For Integrated Test A and Related Laboratory Tests

\begin{tabular}{|c|c|c|c|c|c|c|}
\hline \multirow[b]{2}{*}{ Point in Process } & \multicolumn{6}{|c|}{ Temperature $\left({ }^{\circ} \mathrm{C}\right) \pm 1$ Standard Deviation } \\
\hline & $\begin{array}{l}\text { Batch } 1 \text { in } \\
\text { Tank T01A }\end{array}$ & $\begin{array}{l}\text { Batch } 2 \text { in } \\
\text { Tank T01B }\end{array}$ & $\begin{array}{l}\text { Batch } 3 \text { in } \\
\text { Tank T01A }\end{array}$ & $\begin{array}{l}\text { Batch } 4 \text { in } \\
\text { Tank T01B }\end{array}$ & $\begin{array}{l}\text { Batch } 5 \text { in } \\
\text { Tank T01A }\end{array}$ & $\begin{array}{l}\text { Batch } 6 \text { in } \\
\text { Tank T01B }\end{array}$ \\
\hline \multicolumn{7}{|c|}{ PEP test from start to end of digestion (submerged instruments) ${ }^{(\mathrm{a})}$} \\
\hline Prototypic RTD & $97.9 \pm 0.7$ & $97.6 \pm 1.2$ & $97.9 \pm 0.7$ & $97.8 \pm 0.9$ & $98.1 \pm 1.1$ & $97.8 \pm 0.9$ \\
\hline RTD trees & $97.6 \pm 0.8$ & $97.8 \pm 1.3$ & $97.6 \pm 0.8$ & $98.0 \pm 1.0$ & $97.8 \pm 1.4$ & $98.2 \pm 0.9$ \\
\hline $\begin{array}{l}\text { Resistance } \\
\text { temperature detectors } \\
\text { (RTDs) near vessel } \\
\text { walls }\end{array}$ & $97.7 \pm 0.7$ & none in vessel & $97.9 \pm 0.8$ & $\begin{array}{l}\text { none in } \\
\text { vessel }\end{array}$ & $98.2 \pm 1.4$ & none in vessel \\
\hline RTDs near PJMs & \multicolumn{6}{|c|}{ none in these vessels } \\
\hline $\begin{array}{l}\text { All submerged } \\
\text { temperature instruments }\end{array}$ & $97.6 \pm 0.8$ & $97.8 \pm 1.3$ & $97.8 \pm 0.8$ & $98.0 \pm 1.0$ & $98.1 \pm 1.4$ & $98.2 \pm 0.9$ \\
\hline $\begin{array}{l}\text { Laboratory-Scale Test } \\
\text { A-1 }{ }^{(\mathrm{b})}\end{array}$ & $98.0 \pm 0.2$ & $\mathrm{n} / \mathrm{a}$ & & & & \\
\hline $\begin{array}{l}\text { Laboratory-Scale Test } \\
\text { A- } 2^{\text {(b) }}\end{array}$ & $98.0 \pm 0.3$ & \multicolumn{5}{|l|}{$\mathrm{n} / \mathrm{a}$} \\
\hline \multicolumn{7}{|c|}{$\begin{array}{l}\text { (a) The standard deviations for PEP temperatures include temperature cycling and differences between sensors. Data were sampled once per minute } \\
\text { from all submerged sensors in the set. } \\
\text { (b) Laboratory-test temperatures are measured at a single point in the vessel. The values shown are an average } \pm 1 \text { standard deviation for the set of } \\
\text { temperatures measured at all sampling times during digestion. } \\
\text { " } \mathrm{n} / \mathrm{a} \text { " = not applicable (the laboratory tests did not use slurry from this vessel). }\end{array}$} \\
\hline
\end{tabular}


Table A.4. Slurry Density During Caustic-Leach Integrated Test A

Slurry Density $(\mathrm{g} / \mathrm{mL})^{(\mathrm{a})}$

\pm 1 Standard Deviation from Laboratory Analysis

Integrated Test $\mathrm{A}$, Integrated Test $\mathrm{A}$, Integrated Test $\mathrm{A}$, Integrated Test $\mathrm{A}$, Integrated Test $\mathrm{A}$, Integrated Test $\mathrm{A}$,

\begin{tabular}{|c|c|c|c|c|c|c|c|c|}
\hline $\begin{array}{l}\text { Point in } \\
\text { Process }\end{array}$ & $\begin{array}{c}\text { Batch } 1 \text { in Tank } \\
\text { T01A }\end{array}$ & $\begin{array}{c}\text { Batch } 2 \text { in Tank } \\
\text { T01B }\end{array}$ & $\begin{array}{c}\text { Batch } 3 \text { in Tank } \\
\text { T01A }\end{array}$ & $\begin{array}{c}\text { Batch } 4 \text { in Tank } \\
\text { T01B }\end{array}$ & $\begin{array}{c}\text { Batch } 5 \text { in Tank } \\
\text { T01A }\end{array}$ & $\begin{array}{c}\text { Batch } 6 \text { in Tank } \\
\text { T01B }\end{array}$ & $\begin{array}{c}\text { Laboratory-Scale } \\
\text { Test A-1 } 1^{(\mathrm{b}, \mathrm{c})}\end{array}$ & $\begin{array}{c}\text { Laboratory-Scale } \\
\text { Test } A-2^{(\mathrm{c})}\end{array}$ \\
\hline $\begin{array}{l}\text { Before } \\
\mathrm{NaOH}\end{array}$ & $1.278 \pm 0.006^{(\mathrm{d})}$ & $1.278 \pm 0.006^{(\mathrm{d})}$ & $1.278 \pm 0.006^{(\mathrm{d})}$ & $1.278 \pm 0.006^{(\mathrm{d})}$ & $1.278 \pm 0.006^{(\mathrm{d})}$ & $1.278 \pm 0.006^{(\mathrm{d})}$ & $\mathrm{n} / \mathrm{m}$ & $\mathrm{n} / \mathrm{m}$ \\
\hline $\begin{array}{l}\text { After } \\
\mathrm{NaOH}\end{array}$ & $1.362 \pm 0.006^{(\mathrm{d})}$ & $1.354 \pm 0.006^{(\mathrm{d})}$ & $1.356 \pm 0.006^{(\mathrm{d})}$ & $1.364 \pm 0.006^{(\mathrm{d})}$ & $1.357 \pm 0.006^{(\mathrm{d})}$ & $1.368 \pm 0.006^{(\mathrm{d})}$ & $\mathrm{n} / \mathrm{m}$ & $\mathrm{n} / \mathrm{m}$ \\
\hline $\begin{array}{l}\text { Initial } \\
\text { diluted }\end{array}$ & $\mathrm{n} / \mathrm{m}$ & $\mathrm{n} / \mathrm{m}$ & $\mathrm{n} / \mathrm{m}$ & $\mathrm{n} / \mathrm{m}$ & $\mathrm{n} / \mathrm{m}$ & $\mathrm{n} / \mathrm{m}$ & $\mathrm{n} / \mathrm{m}$ & $\mathrm{n} / \mathrm{m}$ \\
\hline At $88^{\circ} \mathrm{C}$ & $1.326 \pm 0.011$ & $1.332 \pm 0.011$ & $1.334 \pm 0.011$ & $1.347 \pm 0.011$ & $1.333 \pm 0.011$ & $1.336 \pm 0.010$ & $\mathrm{n} / \mathrm{m}$ & $\mathrm{n} / \mathrm{m}$ \\
\hline $0 \mathrm{hr}$ & $1.323 \pm 0.006^{(\mathrm{d})}$ & $1.323 \pm 0.011$ & $1.324 \pm 0.011$ & $1.334 \pm 0.011$ & $1.324 \pm 0.011$ & $1.343 \pm 0.010$ & $\mathrm{n} / \mathrm{m}$ & $\mathrm{n} / \mathrm{m}$ \\
\hline $1 \mathrm{hr}$ & $1.324 \pm 0.011$ & $1.323 \pm 0.011$ & $1.324 \pm 0.011$ & $1.340 \pm 0.011$ & $1.324 \pm 0.011$ & $1.336 \pm 0.010$ & $\mathrm{n} / \mathrm{m}$ & $\mathrm{n} / \mathrm{m}$ \\
\hline $2 \mathrm{hr}$ & $1.324 \pm 0.011$ & $1.320 \pm 0.011$ & $1.322 \pm 0.011$ & $1.334 \pm 0.011$ & $1.329 \pm 0.011$ & $1.336 \pm 0.010$ & $\mathrm{n} / \mathrm{m}$ & $\mathrm{n} / \mathrm{m}$ \\
\hline $4 \mathrm{hr}$ & $1.318 \pm 0.010$ & $1.319 \pm 0.011$ & $1.323 \pm 0.011$ & $1.325 \pm 0.011$ & $1.321 \pm 0.011$ & $1.334 \pm 0.010$ & $\mathrm{n} / \mathrm{m}$ & $\mathrm{n} / \mathrm{m}$ \\
\hline $8 \mathrm{hr}$ & $1.306 \pm 0.010$ & $\mathrm{n} / \mathrm{m}$ & $1.312 \pm 0.010$ & $1.327 \pm 0.011$ & $1.315 \pm 0.010$ & $1.326 \pm 0.010$ & $\mathrm{n} / \mathrm{m}$ & $\mathrm{n} / \mathrm{m}$ \\
\hline $10 \mathrm{hr}$ & $1.323 \pm 0.011$ & $1.306 \pm 0.010$ & $1.307 \pm 0.010$ & $1.323 \pm 0.011$ & $1.314 \pm 0.010$ & $1.318 \pm 0.010$ & $\mathrm{n} / \mathrm{m}$ & $\mathrm{n} / \mathrm{m}$ \\
\hline $12 \mathrm{hr}$ & $1.316 \pm 0.010$ & $1.310 \pm 0.010$ & $1.307 \pm 0.010$ & $1.315 \pm 0.010$ & $1.312 \pm 0.010$ & $1.319 \pm 0.010$ & $\mathrm{n} / \mathrm{m}$ & $\mathrm{n} / \mathrm{m}$ \\
\hline $14 \mathrm{hr}$ & $1.298 \pm 0.010$ & $1.308 \pm 0.010$ & $1.312 \pm 0.010$ & $1.317 \pm 0.010$ & $1.305 \pm 0.010$ & $1.319 \pm 0.010$ & $\mathrm{n} / \mathrm{m}$ & $\mathrm{n} / \mathrm{m}$ \\
\hline $16 \mathrm{hr}$ & $1.319 \pm 0.006^{(\mathrm{d})}$ & $1.305 \pm 0.006^{(\mathrm{d})}$ & $1.301 \pm 0.006^{(\mathrm{d})}$ & $1.310 \pm 0.006^{(\mathrm{d})}$ & $1.301 \pm 0.006^{(\mathrm{d})}$ & $1.319 \pm 0.006^{(\mathrm{d})}$ & $\mathrm{n} / \mathrm{m}$ & $\mathrm{n} / \mathrm{m}$ \\
\hline $18 \mathrm{hr}$ & $\mathrm{n} / \mathrm{m}$ & $\mathrm{n} / \mathrm{m}$ & $\mathrm{n} / \mathrm{m}$ & $\mathrm{n} / \mathrm{m}$ & $\mathrm{n} / \mathrm{m}$ & $\mathrm{n} / \mathrm{m}$ & $\mathrm{n} / \mathrm{m}$ & $\mathrm{n} / \mathrm{m}$ \\
\hline $20 \mathrm{hr}$ & $\mathrm{n} / \mathrm{m}$ & $\mathrm{n} / \mathrm{m}$ & $\mathrm{n} / \mathrm{m}$ & $\mathrm{n} / \mathrm{m}$ & $\mathrm{n} / \mathrm{m}$ & $\mathrm{n} / \mathrm{m}$ & $\mathrm{n} / \mathrm{m}$ & $\mathrm{n} / \mathrm{m}$ \\
\hline $22 \mathrm{hr}$ & $\mathrm{n} / \mathrm{m}$ & $\mathrm{n} / \mathrm{m}$ & $\mathrm{n} / \mathrm{m}$ & $\mathrm{n} / \mathrm{m}$ & $\mathrm{n} / \mathrm{m}$ & $\mathrm{n} / \mathrm{m}$ & $\mathrm{n} / \mathrm{m}$ & $\mathrm{n} / \mathrm{m}$ \\
\hline $24 \mathrm{hr}$ & $\mathrm{n} / \mathrm{m}$ & $\mathrm{n} / \mathrm{m}$ & $\mathrm{n} / \mathrm{m}$ & $\mathrm{n} / \mathrm{m}$ & $\mathrm{n} / \mathrm{m}$ & $\mathrm{n} / \mathrm{m}$ & $\mathrm{n} / \mathrm{m}$ & $\mathrm{n} / \mathrm{m}$ \\
\hline
\end{tabular}

(a) Slurry density was measured at ambient temperature by pycnometry at SwRI

(b) The sample used in these laboratory-scale tests was taken from the PEP after $\mathrm{NaOH}$ had been added.

(c) Note that water was added all at once at the beginning of laboratory-scale runs, but was added gradually throughout the PEP runs as injected steam.

(d) Triplicate samples were taken at this point. The concentration shown is the mean of the set.

"n $/ \mathrm{m} "=$ not measured 
Table A.5. Liquid Density During Caustic-Leach Integrated Test A

\begin{tabular}{|c|c|c|c|c|c|c|c|c|}
\hline \multirow[b]{2}{*}{$\begin{array}{l}\text { Point in } \\
\text { Process }\end{array}$} & \multicolumn{8}{|c|}{$\begin{array}{l}\text { Liquid Density }(\mathrm{g} / \mathrm{mL})^{(\mathrm{a})} \\
\text { rd Deviation from Laboratory }\end{array}$} \\
\hline & $\begin{array}{c}\text { Integrated Test } \\
\text { A, Batch } 1 \text { in } \\
\text { Tank T01A }\end{array}$ & $\begin{array}{c}\text { Integrated Test } \\
\text { A, Batch } 2 \text { in } \\
\text { Tank T01B }\end{array}$ & $\begin{array}{c}\text { Integrated Test } \\
\text { A, Batch } 3 \text { in } \\
\text { Tank T01A }\end{array}$ & $\begin{array}{c}\text { Integrated Test } \\
\text { A, Batch } 4 \text { in } \\
\text { Tank T01B }\end{array}$ & $\begin{array}{c}\text { Integrated Test } \\
\text { A, Batch } 5 \text { in } \\
\text { Tank T01A }\end{array}$ & $\begin{array}{c}\text { Integrated Test } \\
\text { A, Batch } 6 \text { in } \\
\text { Tank T01B }\end{array}$ & $\begin{array}{l}\text { Laboratory-Scale } \\
\text { Test A-1 }{ }^{\text {(b, c, d) }}\end{array}$ & $\begin{array}{l}\text { Laboratory-Scale } \\
\text { Test A-2 } 2^{(\mathrm{c}, \mathrm{d})}\end{array}$ \\
\hline $\begin{array}{l}\text { Before } \\
\mathrm{NaOH}\end{array}$ & $1.239 \pm 0.001^{(\mathrm{e})}$ & $1.239 \pm 0.001^{(\mathrm{e})}$ & $1.239 \pm 0.001^{(\mathrm{e})}$ & $1.239 \pm 0.001^{(\mathrm{e})}$ & $1.239 \pm 0.001^{(\mathrm{e})}$ & $1.239 \pm 0.001^{(\mathrm{e})}$ & $1.239 \pm 0.001^{(\mathrm{e})}$ & $1.239 \pm 0.001^{(\mathrm{e})}$ \\
\hline $\begin{array}{l}\text { After } \\
\mathrm{NaOH}\end{array}$ & $1.330 \pm 0.006^{(\mathrm{e})}$ & $1.326 \pm 0.006^{(\mathrm{e})}$ & $1.329 \pm 0.006^{(\mathrm{e})}$ & $1.341 \pm 0.006^{(\mathrm{e})}$ & $1.332 \pm 0.006^{(\mathrm{e})}$ & $1.338 \pm 0.006^{(\mathrm{e})}$ & $\mathrm{n} / \mathrm{m}$ & $\mathrm{n} / \mathrm{m}$ \\
\hline $\begin{array}{l}\text { Initial } \\
\text { diluted }\end{array}$ & $\mathrm{n} / \mathrm{m}$ & $\mathrm{n} / \mathrm{m}$ & $\mathrm{n} / \mathrm{m}$ & $\mathrm{n} / \mathrm{m}$ & $\mathrm{n} / \mathrm{m}$ & $\mathrm{n} / \mathrm{m}$ & $1.323 \pm 0.010$ & $1.305 \pm 0.010$ \\
\hline At $88^{\circ} \mathrm{C}$ & $1.312 \pm 0.010$ & $1.312 \pm 0.010$ & $1.315 \pm 0.010$ & $1.321 \pm 0.011$ & $1.317 \pm 0.010$ & $1.312 \pm 0.011$ & $1.332 \pm 0.010$ & $1.312 \pm 0.010$ \\
\hline $0 \mathrm{hr}$ & $1.308 \pm 0.006^{(\mathrm{e})}$ & $1.293 \pm 0.010$ & $1.307 \pm 0.006$ & $1.315 \pm 0.010$ & $1.307 \pm 0.010$ & $1.315 \pm 0.010$ & $1.321 \pm 0.010$ & $1.334 \pm 0.010$ \\
\hline $1 \mathrm{hr}$ & $1.308 \pm 0.010$ & $1.305 \pm 0.010$ & $1.304 \pm 0.010$ & $1.317 \pm 0.010$ & $1.310 \pm 0.010$ & $1.313 \pm 0.010$ & $1.336 \pm 0.010$ & $1.328 \pm 0.010$ \\
\hline $2 \mathrm{hr}$ & $1.308 \pm 0.010$ & $1.297 \pm 0.010$ & $1.304 \pm 0.010$ & $1.315 \pm 0.010$ & $1.310 \pm 0.010$ & $1.312 \pm 0.010$ & $1.330 \pm 0.010$ & $1.332 \pm 0.010$ \\
\hline $4 \mathrm{hr}$ & $1.305 \pm 0.010$ & $1.298 \pm 0.010$ & $1.295 \pm 0.010$ & $1.307 \pm 0.010$ & $1.307 \pm 0.010$ & $1.313 \pm 0.010$ & $1.332 \pm 0.010$ & $1.330 \pm 0.010$ \\
\hline $8 \mathrm{hr}$ & $1.296 \pm 0.010$ & $\mathrm{n} / \mathrm{m}$ & $1.297 \pm 0.010$ & $1.305 \pm 0.010$ & $1.302 \pm 0.010$ & $1.309 \pm 0.010$ & $1.343 \pm 0.010$ & $1.316 \pm 0.010$ \\
\hline $10 \mathrm{hr}$ & $1.291 \pm 0.010$ & $1.288 \pm 0.010$ & $1.294 \pm 0.010$ & $1.310 \pm 0.010$ & $1.305 \pm 0.010$ & $1.308 \pm 0.010$ & $1.334 \pm 0.010$ & $1.319 \pm 0.010$ \\
\hline $12 \mathrm{hr}$ & $1.286 \pm 0.010$ & $1.288 \pm 0.010$ & $1.296 \pm 0.010$ & $1.305 \pm 0.010$ & $1.301 \pm 0.010$ & $1.301 \pm 0.010$ & $1.341 \pm 0.010$ & $1.348 \pm 0.010$ \\
\hline $14 \mathrm{hr}$ & $1.291 \pm 0.010$ & $1.291 \pm 0.010$ & $1.294 \pm 0.010$ & $1.300 \pm 0.010$ & $1.301 \pm 0.010$ & $1.300 \pm 0.010$ & $1.343 \pm 0.010$ & $1.370 \pm 0.010$ \\
\hline $16 \mathrm{hr}$ & $1.288 \pm 0.006^{(\mathrm{e})}$ & $1.289 \pm 0.006^{(\mathrm{e})}$ & $1.288 \pm 0.006^{(\mathrm{e})}$ & $1.302 \pm 0.006^{(\mathrm{e})}$ & $1.294 \pm 0.006^{(\mathrm{e})}$ & $1.301 \pm 0.006^{(\mathrm{e})}$ & $1.341 \pm 0.010$ & $1.368 \pm 0.010$ \\
\hline $18 \mathrm{hr}$ & $\mathrm{n} / \mathrm{m}$ & $\mathrm{n} / \mathrm{m}$ & $\mathrm{n} / \mathrm{m}$ & $\mathrm{n} / \mathrm{m}$ & $\mathrm{n} / \mathrm{m}$ & $\mathrm{n} / \mathrm{m}$ & $1.350 \pm 0.010$ & $1.386 \pm 0.010$ \\
\hline $20 \mathrm{hr}$ & $\mathrm{n} / \mathrm{m}$ & $\mathrm{n} / \mathrm{m}$ & $\mathrm{n} / \mathrm{m}$ & $\mathrm{n} / \mathrm{m}$ & $\mathrm{n} / \mathrm{m}$ & $\mathrm{n} / \mathrm{m}$ & $1.345 \pm 0.010$ & $1.379 \pm 0.010$ \\
\hline $22 \mathrm{hr}$ & $\mathrm{n} / \mathrm{m}$ & $\mathrm{n} / \mathrm{m}$ & $\mathrm{n} / \mathrm{m}$ & $\mathrm{n} / \mathrm{m}$ & $\mathrm{n} / \mathrm{m}$ & $\mathrm{n} / \mathrm{m}$ & $1.343 \pm 0.010$ & $1.384 \pm 0.010$ \\
\hline $24 \mathrm{hr}$ & $\mathrm{n} / \mathrm{m}$ & $\mathrm{n} / \mathrm{m}$ & $\mathrm{n} / \mathrm{m}$ & $\mathrm{n} / \mathrm{m}$ & $\mathrm{n} / \mathrm{m}$ & $\mathrm{n} / \mathrm{m}$ & $1.363 \pm 0.010$ & $1.386 \pm 0.010$ \\
\hline $\begin{array}{l}\text { (a) Liquid } \\
\text { (b) The sa } \\
\text { (c) Note tl } \\
\text { (d) Liquid } \\
\text { using t } \\
\text { deviati } \\
\text { (e) Triplic } \\
\text { " } \mathrm{n} / \mathrm{m} \text { " = no }\end{array}$ & $\begin{array}{l}\text { nsity was measure } \\
\text { le used in these la } \\
\text { water was added a } \\
\text { asity values for th } \\
\text { correlations with } 1 \\
\text { were set equal to } \\
\text { samples were tak } \\
\text { easured }\end{array}$ & $\begin{array}{l}\text { ambient temperat } \\
\text { ory-scale tests w } \\
\text { once at the begin } \\
\text { oratory-scale test } \\
\text { atory-scale nitrat } \\
\text {-g/mL; this was } t \\
\text { this point. The c }\end{array}$ & $\begin{array}{l}\text { ky pycnometry at } \\
\text { ken from the PEP } \\
\text { of laboratory-sca } \\
\text { re estimated by co } \\
\text { a to estimate labo } \\
\text { pproximate value } \\
\text { entration shown is }\end{array}$ & $\begin{array}{l}\text { RI. } \\
\text { er NaOH had been } \\
\text { uns, but was adde } \\
\text { lating liquid densi } \\
\text { ry-scale liquid de } \\
\text { the densities meas } \\
\text { mean of the set. }\end{array}$ & $\begin{array}{l}\text { ded. } \\
\text { adually throughou } \\
\text { ata to nitrate conce } \\
\text { y. The nitrate conc } \\
\text { d from PEP sampl }\end{array}$ & $\begin{array}{l}\text { PEP runs as injec } \\
\text { ation for PEP sam } \\
\text { ration serves as a }\end{array}$ & $\begin{array}{l}\text { steam. } \\
\text { ogate for dissolved }\end{array}$ & $\begin{array}{l}\text { is added and then } \\
\text { lids. Standard }\end{array}$ \\
\hline
\end{tabular}


Table A.6. Weight Fraction UDS During Caustic-Leach Integrated Test A

\begin{tabular}{|c|c|c|c|c|c|c|c|c|}
\hline \multirow[b]{2}{*}{$\begin{array}{l}\text { Point in } \\
\text { Process }\end{array}$} & \multicolumn{8}{|c|}{$\begin{array}{l}\text { Slurry Solid-Phase Weight Fraction (wt } \% \text { undissolved solids) } \\
\pm 1 \text { Standard Deviation from Laboratory Analysis }\end{array}$} \\
\hline & $\begin{array}{c}\text { Integrated Test A, } \\
\text { Batch } 1 \text { in Tank } \\
\text { T01A }\end{array}$ & $\begin{array}{c}\text { Integrated Test A, } \\
\text { Batch } 2 \text { in Tank } \\
\text { T01B }\end{array}$ & $\begin{array}{c}\text { Integrated Test A, } \\
\text { Batch } 3 \text { in Tank } \\
\text { T01A }\end{array}$ & $\begin{array}{c}\text { Integrated Test A, } \\
\text { Batch } 4 \text { in Tank } \\
\text { T01B }\end{array}$ & $\begin{array}{c}\text { Integrated Test A, } \\
\text { Batch } 5 \text { in Tank } \\
\text { T01A }\end{array}$ & $\begin{array}{c}\text { Integrated Test A, } \\
\text { Batch } 6 \text { in Tank } \\
\text { T01B }\end{array}$ & $\begin{array}{l}\text { Laboratory-Scale } \\
\text { Test A-1 }{ }^{(b, c)}\end{array}$ & $\begin{array}{c}\text { Laboratory-Scale } \\
\text { Test A-2 }{ }^{\text {(c) }}\end{array}$ \\
\hline Before & & & & & & & & \\
\hline $\mathrm{NaOH}$ & $5.52 \% \pm 0.03 \%{ }^{(\mathrm{d})}$ & $5.52 \% \pm 0.03 \%{ }^{(\mathrm{d})}$ & $5.52 \% \pm 0.03 \%{ }^{(\mathrm{d})}$ & $5.52 \% \pm 0.03 \%{ }^{(\mathrm{d})}$ & $5.52 \% \pm 0.03 \%{ }^{(\mathrm{d})}$ & $5.52 \% \pm 0.03 \%{ }^{(\mathrm{d})}$ & $5.52 \% \pm 0.03 \%{ }^{(\mathrm{d})}$ & $5.52 \% \pm 0.03 \%{ }^{(\mathrm{d})}$ \\
\hline $\begin{array}{l}\text { After } \\
\mathrm{NaOH}\end{array}$ & $2.91 \% \pm 0.01 \%{ }^{(\mathrm{d})}$ & $2.87 \% \pm 0.01 \%{ }^{(\mathrm{d})}$ & $2.83 \% \pm 0.01 \%{ }^{(\mathrm{d})}$ & $2.48 \% \pm 0.01 \%{ }^{(\mathrm{d})}$ & $2.56 \% \pm 0.01 \%{ }^{(\mathrm{d})}$ & $2.65 \% \pm 0.01 \%{ }^{(\mathrm{d})}$ & $\mathrm{n} / \mathrm{m}$ & $\mathrm{n} / \mathrm{m}$ \\
\hline $\begin{array}{l}\text { Initial } \\
\text { diluted }\end{array}$ & $\mathrm{n} / \mathrm{m}$ & $\mathrm{n} / \mathrm{m}$ & $\mathrm{n} / \mathrm{m}$ & $\mathrm{n} / \mathrm{m}$ & $\mathrm{n} / \mathrm{m}$ & $\mathrm{n} / \mathrm{m}$ & $2.15 \% \pm 0.02 \%{ }^{(\mathrm{e})}$ & $1.89 \% \pm 0.02 \%{ }^{(\mathrm{e})}$ \\
\hline At $88^{\circ} \mathrm{C}$ & $2.35 \% \pm 0.02 \%$ & $2.50 \% \pm 0.03 \%$ & $2.78 \% \pm 0.02 \%$ & $2.18 \% \pm 0.02 \%$ & $2.06 \% \pm 0.02 \%$ & $2.16 \% \pm 0.02 \%$ & $\mathrm{n} / \mathrm{m}$ & $\mathrm{n} / \mathrm{m}$ \\
\hline $0 \mathrm{hr}$ & $2.38 \% \pm 0.01 \%{ }^{(2)}$ & $2.58 \% \pm 0.03 \%$ & $2.27 \% \pm 0.02 \%$ & $2.12 \% \pm 0.02 \%$ & $2.13 \% \pm 0.02 \%$ & $2.15 \% \pm 0.02 \%$ & $\mathrm{n} / \mathrm{m}$ & $\mathrm{n} / \mathrm{m}$ \\
\hline $1 \mathrm{hr}$ & $2.36 \% \pm 0.02 \%$ & $2.51 \% \pm 0.03 \%$ & $2.22 \% \pm 0.02 \%$ & $2.12 \% \pm 0.02 \%$ & $2.03 \% \pm 0.02 \%$ & $2.12 \% \pm 0.02 \%$ & $\mathrm{n} / \mathrm{m}$ & $\mathrm{n} / \mathrm{m}$ \\
\hline $2 \mathrm{hr}$ & $2.36 \% \pm 0.02 \%$ & $2.80 \% \pm 0.03 \%$ & $2.10 \% \pm 0.02 \%$ & $2.14 \% \pm 0.02 \%$ & $2.10 \% \pm 0.02 \%$ & $2.11 \% \pm 0.02 \%$ & $\mathrm{n} / \mathrm{m}$ & $\mathrm{n} / \mathrm{m}$ \\
\hline $4 \mathrm{hr}$ & $2.37 \% \pm 0.02 \%$ & $2.09 \% \pm 0.02 \%$ & $2.18 \% \pm 0.02 \%$ & $2.03 \% \pm 0.02 \%$ & $2.20 \% \pm 0.02 \%$ & $2.13 \% \pm 0.02 \%$ & $\mathrm{n} / \mathrm{m}$ & $\mathrm{n} / \mathrm{m}$ \\
\hline $8 \mathrm{hr}$ & $2.20 \% \pm 0.02 \%$ & $\mathrm{n} / \mathrm{m}$ & $2.10 \% \pm 0.02 \%$ & $1.88 \% \pm 0.02 \%$ & $1.95 \% \pm 0.02 \%$ & $1.88 \% \pm 0.02 \%$ & $\mathrm{n} / \mathrm{m}$ & $\mathrm{n} / \mathrm{m}$ \\
\hline $10 \mathrm{hr}$ & $2.15 \% \pm 0.02 \%$ & $2.21 \% \pm 0.02 \%$ & $2.12 \% \pm 0.02 \%$ & $1.95 \% \pm 0.02 \%$ & $1.96 \% \pm 0.02 \%$ & $1.83 \% \pm 0.02 \%$ & $\mathrm{n} / \mathrm{m}$ & $\mathrm{n} / \mathrm{m}$ \\
\hline $12 \mathrm{hr}$ & $2.18 \% \pm 0.02 \%$ & $2.09 \% \pm 0.02 \%$ & $1.87 \% \pm 0.02 \%$ & $1.92 \% \pm 0.02 \%$ & $1.84 \% \pm 0.02 \%$ & $1.85 \% \pm 0.02 \%$ & $\mathrm{n} / \mathrm{m}$ & $\mathrm{n} / \mathrm{m}$ \\
\hline $14 \mathrm{hr}$ & $2.17 \% \pm 0.02 \%$ & $2.21 \% \pm 0.02 \%$ & $1.89 \% \pm 0.02 \%$ & $1.88 \% \pm 0.02 \%$ & $1.85 \% \pm 0.02 \%$ & $1.82 \% \pm 0.02 \%$ & $\mathrm{n} / \mathrm{m}$ & $\mathrm{n} / \mathrm{m}$ \\
\hline $16 \mathrm{hr}$ & $2.05 \% \pm 0.01 \%{ }^{(\mathrm{d})}$ & $2.04 \% \pm 0.01 \%{ }^{(\mathrm{d})}$ & $1.80 \% \pm 0.01 \%{ }^{(\mathrm{d})}$ & $1.72 \% \pm 0.01 \%{ }^{(\mathrm{d})}$ & $1.73 \% \pm 0.01 \%{ }^{(\mathrm{d})}$ & $1.70 \% \pm 0.01 \%{ }^{(\mathrm{d})}$ & $\mathrm{n} / \mathrm{m}$ & $\mathrm{n} / \mathrm{m}$ \\
\hline $18 \mathrm{hr}$ & $\mathrm{n} / \mathrm{m}$ & $\mathrm{n} / \mathrm{m}$ & $\mathrm{n} / \mathrm{m}$ & $\mathrm{n} / \mathrm{m}$ & $\mathrm{n} / \mathrm{m}$ & $\mathrm{n} / \mathrm{m}$ & $\mathrm{n} / \mathrm{m}$ & $\mathrm{n} / \mathrm{m}$ \\
\hline $20 \mathrm{hr}$ & $\mathrm{n} / \mathrm{m}$ & $\mathrm{n} / \mathrm{m}$ & $\mathrm{n} / \mathrm{m}$ & $\mathrm{n} / \mathrm{m}$ & $\mathrm{n} / \mathrm{m}$ & $\mathrm{n} / \mathrm{m}$ & $\mathrm{n} / \mathrm{m}$ & $\mathrm{n} / \mathrm{m}$ \\
\hline $22 \mathrm{hr}$ & $\mathrm{n} / \mathrm{m}$ & $\mathrm{n} / \mathrm{m}$ & $\mathrm{n} / \mathrm{m}$ & $\mathrm{n} / \mathrm{m}$ & $\mathrm{n} / \mathrm{m}$ & $\mathrm{n} / \mathrm{m}$ & $\mathrm{n} / \mathrm{m}$ & $\mathrm{n} / \mathrm{m}$ \\
\hline $24 \mathrm{hr}$ & $\mathrm{n} / \mathrm{m}$ & $\mathrm{n} / \mathrm{m}$ & $\mathrm{n} / \mathrm{m}$ & $\mathrm{n} / \mathrm{m}$ & $\mathrm{n} / \mathrm{m}$ & $\mathrm{n} / \mathrm{m}$ & $1.59 \% \pm 0.03 \%{ }^{(\mathrm{f})}$ & $1.27 \% \pm 0.03 \%{ }^{(\mathrm{f})}$ \\
\hline $\begin{array}{l}\text { (a) The wt" } \\
\text { (b) The san } \\
\text { (c) Note thr } \\
\text { (d) Triplica } \\
\text { (e) Duplica } \\
\text { (f) The sam } \\
\text { " } \mathrm{n} / \mathrm{m} \text { " = not }\end{array}$ & $\begin{array}{l}\text { UDS was measured b } \\
\text { le used in these labor } \\
\text { water was added all } \\
\text { samples were taken } \\
\text { samples were taken } \\
\text { les were removed wh } \\
\text { easured }\end{array}$ & $\begin{array}{l}y \text { drying and weighin } \\
\text { atory-scale tests was } t \\
\text { t once at the beginnin } \\
\text { t this point. The cond } \\
\text { at this point. The cond } \\
\text { en the vessel slurry ha }\end{array}$ & $\begin{array}{l}\text { at SwRI. Wt\% UD } \\
\text { aken from the PEP af } \\
g \text { of laboratory-scale } \\
\text { entration shown is th } \\
\text { entration shown is th } \\
d \text { been cooled to a ter }\end{array}$ & $\begin{array}{l}\text { is mass undissolved } \\
\text { er } \mathrm{NaOH} \text { had been ad } \\
\text { uns, but was added gr } \\
\text { mean of the set. } \\
\text { mean of the set. } \\
\text { nperature of }<60^{\circ} \mathrm{C} \text { (a }\end{array}$ & $\begin{array}{l}\text { olids per mass as-san } \\
\text { led. } \\
\text { idually throughout th }\end{array}$ & $\begin{array}{l}\text { pled slurry. } \\
\text { PEP runs as injected }\end{array}$ & steam. & \\
\hline
\end{tabular}


Table A.7. Water in Liquid Phase During Caustic-Leach Integrated Test A

\begin{tabular}{|c|c|c|c|c|c|c|c|c|}
\hline \multirow[b]{2}{*}{$\begin{array}{l}\text { Point in } \\
\text { Process }\end{array}$} & \multicolumn{8}{|c|}{$\begin{array}{l}\text { Concentration of } \mathrm{H}_{2} \mathrm{O}(\mathrm{wt} \%) \text { in Liquid Phase }{ }^{(\mathrm{a})} \\
\pm 1 \text { Standard Deviation from Laboratory Analysis }\end{array}$} \\
\hline & $\begin{array}{c}\text { Integrated Test A, } \\
\text { Batch } 1 \text { in Tank } \\
\text { T01A }\end{array}$ & $\begin{array}{c}\text { Integrated Test A, } \\
\text { Batch } 2 \text { in Tank } \\
\text { T01B }\end{array}$ & $\begin{array}{c}\text { Integrated Test A, } \\
\text { Batch } 3 \text { in Tank } \\
\text { T01A }\end{array}$ & $\begin{array}{c}\text { Integrated Test A, } \\
\text { Batch } 4 \text { in Tank } \\
\text { T01B }\end{array}$ & $\begin{array}{c}\text { Integrated Test A, } \\
\text { Batch } 5 \text { in Tank } \\
\text { T01A }\end{array}$ & $\begin{array}{c}\text { Integrated Test A, } \\
\text { Batch } 6 \text { in Tank } \\
\text { T01B }\end{array}$ & $\begin{array}{c}\text { Laboratory-Scale } \\
\text { Test A-1 }{ }^{(b, c)}\end{array}$ & $\begin{array}{c}\text { Laboratory-Scale } \\
\text { Test A-2 }\end{array}$ \\
\hline $\begin{array}{l}\text { Before } \\
\mathrm{NaOH}\end{array}$ & $72.7 \% \pm 0.1 \%{ }^{(\mathrm{d})}$ & $72.7 \% \pm 0.1 \%{ }^{(\mathrm{d})}$ & $72.7 \% \pm 0.1 \%(\mathrm{~d})$ & $72.7 \% \pm 0.1 \%{ }^{(\mathrm{d})}$ & $72.7 \% \pm 0.1 \%{ }^{(\mathrm{d})}$ & $72.7 \% \pm 0.1 \%(\mathrm{~d})$ & $\mathrm{n} / \mathrm{m}$ & $\mathrm{n} / \mathrm{m}$ \\
\hline $\begin{array}{l}\text { After } \\
\mathrm{NaOH}\end{array}$ & $64.6 \% \pm 0.2 \%(\mathrm{~d})$ & $64.7 \% \pm 0.2 \% \%^{(\mathrm{d})}$ & $64.7 \% \pm 0.2 \%{ }^{(\mathrm{d})}$ & $63.6 \% \pm 0.2 \%{ }^{(\mathrm{d})}$ & $64.0 \% \pm 0.2 \%{ }^{(\mathrm{d})}$ & $63.8 \% \pm 0.2 \%{ }^{(\mathrm{d})}$ & $\mathrm{n} / \mathrm{m}$ & $\mathrm{n} / \mathrm{m}$ \\
\hline $\begin{array}{l}\text { Initial } \\
\text { diluted }\end{array}$ & $\mathrm{n} / \mathrm{m}$ & $\mathrm{n} / \mathrm{m}$ & $\mathrm{n} / \mathrm{m}$ & $\mathrm{n} / \mathrm{m}$ & $\mathrm{n} / \mathrm{m}$ & $\mathrm{n} / \mathrm{m}$ & $\mathrm{n} / \mathrm{m}$ & $\mathrm{n} / \mathrm{m}$ \\
\hline At $88^{\circ} \mathrm{C}$ & $66.4 \% \pm 0.3 \%$ & $66.9 \% \pm 0.3 \%$ & $67.1 \% \pm 0.3 \%$ & $65.3 \% \pm 0.3 \%$ & $66.1 \% \pm 0.3 \%$ & $65.4 \% \pm 0.3 \%$ & $\mathrm{n} / \mathrm{m}$ & $\mathrm{n} / \mathrm{m}$ \\
\hline $0 \mathrm{hr}$ & $67.1 \% \pm 0.2 \%{ }^{(\mathrm{d})}$ & $67.7 \% \pm 0.3 \%$ & $67.1 \% \pm 0.3 \%$ & $65.9 \% \pm 0.3 \%$ & $67.1 \% \pm 0.3 \%$ & $66.3 \% \pm 0.2 \%$ & $\mathrm{n} / \mathrm{m}$ & $\mathrm{n} / \mathrm{m}$ \\
\hline $1 \mathrm{hr}$ & $67.4 \% \pm 0.3 \%$ & $67.7 \% \pm 0.3 \%$ & $67.2 \% \pm 0.3 \%$ & $65.9 \% \pm 0.3 \%$ & $66.5 \% \pm 0.3 \%$ & $66.1 \% \pm 0.3 \%$ & $\mathrm{n} / \mathrm{m}$ & $\mathrm{n} / \mathrm{m}$ \\
\hline $2 \mathrm{hr}$ & $67.2 \% \pm 0.3 \%$ & $67.8 \% \pm 0.3 \%$ & $67.1 \% \pm 0.3 \%$ & $66.0 \% \pm 0.3 \%$ & $66.7 \% \pm 0.3 \%$ & $66.3 \% \pm 0.3 \%$ & $\mathrm{n} / \mathrm{m}$ & $\mathrm{n} / \mathrm{m}$ \\
\hline $4 \mathrm{hr}$ & $67.6 \% \pm 0.3 \%$ & $68.1 \% \pm 0.3 \%$ & $67.5 \% \pm 0.3 \%$ & $66.3 \% \pm 0.3 \%$ & $67.0 \% \pm 0.3 \%$ & $66.9 \% \pm 0.3 \%$ & $\mathrm{n} / \mathrm{m}$ & $\mathrm{n} / \mathrm{m}$ \\
\hline $8 \mathrm{hr}$ & $68.1 \% \pm 0.3 \%$ & $\mathrm{n} / \mathrm{m}$ & $67.8 \% \pm 0.3 \%$ & $66.6 \% \pm 0.3 \%$ & $67.3 \% \pm 0.3 \%$ & $66.9 \% \pm 0.3 \%$ & $\mathrm{n} / \mathrm{m}$ & $\mathrm{n} / \mathrm{m}$ \\
\hline $10 \mathrm{hr}$ & $68.2 \% \pm 0.3 \%$ & $68.8 \% \pm 0.3 \%$ & $68.3 \% \pm 0.3 \%$ & $67.0 \% \pm 0.3 \%$ & $67.9 \% \pm 0.3 \%$ & $67.0 \% \pm 0.3 \%$ & $\mathrm{n} / \mathrm{m}$ & $\mathrm{n} / \mathrm{m}$ \\
\hline $12 \mathrm{hr}$ & $68.7 \% \pm 0.3 \%$ & $68.8 \% \pm 0.3 \%$ & $68.4 \% \pm 0.3 \%$ & $67.5 \% \pm 0.3 \%$ & $68.2 \% \pm 0.3 \%$ & $67.5 \% \pm 0.3 \%$ & $\mathrm{n} / \mathrm{m}$ & $\mathrm{n} / \mathrm{m}$ \\
\hline $14 \mathrm{hr}$ & $68.9 \% \pm 0.3 \%$ & $69.0 \% \pm 0.3 \%$ & $68.7 \% \pm 0.3 \%$ & $67.5 \% \pm 0.3 \%$ & $68.4 \% \pm 0.3 \%$ & $67.6 \% \pm 0.3 \%$ & $\mathrm{n} / \mathrm{m}$ & $\mathrm{n} / \mathrm{m}$ \\
\hline $16 \mathrm{hr}$ & $69.2 \% \pm 0.2 \%{ }^{(\mathrm{d})}$ & $69.2 \% \pm 0.2 \%{ }^{(\mathrm{d})}$ & $68.9 \% \pm 0.1 \%{ }^{(\mathrm{d})}$ & $67.8 \% \pm 0.1 \%{ }^{(\mathrm{d})}$ & $68.6 \% \pm 0.1 \%{ }^{(\mathrm{d})}$ & $67.7 \% \pm 0.1 \%{ }^{(\mathrm{d})}$ & $\mathrm{n} / \mathrm{m}$ & $\mathrm{n} / \mathrm{m}$ \\
\hline $18 \mathrm{hr}$ & $\mathrm{n} / \mathrm{m}$ & $\mathrm{n} / \mathrm{m}$ & $\mathrm{n} / \mathrm{m}$ & $\mathrm{n} / \mathrm{m}$ & $\mathrm{n} / \mathrm{m}$ & $\mathrm{n} / \mathrm{m}$ & $\mathrm{n} / \mathrm{m}$ & $\mathrm{n} / \mathrm{m}$ \\
\hline $20 \mathrm{hr}$ & $\mathrm{n} / \mathrm{m}$ & $\mathrm{n} / \mathrm{m}$ & $\mathrm{n} / \mathrm{m}$ & $\mathrm{n} / \mathrm{m}$ & $\mathrm{n} / \mathrm{m}$ & $\mathrm{n} / \mathrm{m}$ & $\mathrm{n} / \mathrm{m}$ & $\mathrm{n} / \mathrm{m}$ \\
\hline $22 \mathrm{hr}$ & $\mathrm{n} / \mathrm{m}$ & $\mathrm{n} / \mathrm{m}$ & $\mathrm{n} / \mathrm{m}$ & $\mathrm{n} / \mathrm{m}$ & $\mathrm{n} / \mathrm{m}$ & $\mathrm{n} / \mathrm{m}$ & $\mathrm{n} / \mathrm{m}$ & $\mathrm{n} / \mathrm{m}$ \\
\hline $24 \mathrm{hr}$ & $\mathrm{n} / \mathrm{m}$ & $\mathrm{n} / \mathrm{m}$ & $\mathrm{n} / \mathrm{m}$ & $\mathrm{n} / \mathrm{m}$ & $\mathrm{n} / \mathrm{m}$ & $\mathrm{n} / \mathrm{m}$ & $\mathrm{n} / \mathrm{m}$ & $\mathrm{n} / \mathrm{m}$ \\
\hline $\begin{array}{l}\text { (a) } \mathrm{Wt} \% \\
\text { (b) The sc } \\
\text { (c) Note t } \\
\text { (d) Tripli } \\
\text { "n/m" } \mathrm{m} \text { " no }\end{array}$ & $\begin{array}{l}\text { ter is }(1-\mathrm{wt} \% \text { dissol } \\
\text { ple used in these labo } \\
\text { t water was added all } \\
\text { te samples were taken } \\
\text { neasured }\end{array}$ & $\begin{array}{l}\text { ed solids). Dissolve } \\
\text { atory-scale tests was } \\
\text { at once at the beginn } \\
\text { at this point. The co }\end{array}$ & $\begin{array}{l}\text { solids were measur } \\
\text { taken from the PEP } \\
\text { ag of laboratory-scal } \\
\text { centration shown is }\end{array}$ & $\begin{array}{l}\mathrm{d} \text { by drying and weigh } \\
\text { fter } \mathrm{NaOH} \text { had been a } \\
\text { runs, but was added } \\
\text { he mean of the set. }\end{array}$ & $\begin{array}{l}\text { ing supernatant liqui } \\
\text { lded. } \\
\text { radually throughout }\end{array}$ & $\begin{array}{l}\text { at SwRI. Wt\% wat } \\
\text { he PEP runs as inject }\end{array}$ & $\begin{array}{l}\text { is mass water/ma } \\
\text { steam. }\end{array}$ & \\
\hline
\end{tabular}


Table A.8. Molar Concentration of Free Hydroxide During Caustic-Leach Integrated Test A

\section{Concentration of Free Hydroxide (mole/L liquid) in Liquid Phase ${ }^{(a)}$}

\pm 1 Standard Deviation from Laboratory Analysis

\begin{tabular}{|c|c|c|c|c|c|c|c|c|}
\hline $\begin{array}{l}\text { Point in } \\
\text { Process }\end{array}$ & $\begin{array}{c}\text { Integrated Test A, } \\
\text { Batch } 1 \text { in Tank T01A }\end{array}$ & $\begin{array}{c}\text { Integrated Test A, } \\
\text { Batch } 2 \text { in Tank T01B }\end{array}$ & $\begin{array}{c}\text { Integrated Test A, } \\
\text { Batch } 3 \text { in Tank T01A }\end{array}$ & $\begin{array}{c}\text { Integrated Test A, } \\
\text { Batch } 4 \text { in Tank T01B }\end{array}$ & $\begin{array}{c}\text { Integrated Test A, } \\
\text { Batch } 5 \text { in Tank T01A }\end{array}$ & $\begin{array}{c}\text { Integrated Test A, } \\
\text { Batch } 6 \text { in Tank T01B }\end{array}$ & $\begin{array}{l}\text { Laboratory- } \\
\text { Scale } \\
\text { Test A-1 } \\
\text { (b,c) }\end{array}$ & $\begin{array}{l}\text { Laboratory- } \\
\text { Scale } \\
\text { Test A-2 } 2^{(\mathrm{c})}\end{array}$ \\
\hline $\begin{array}{l}\text { Before } \\
\mathrm{NaOH}\end{array}$ & $1.11 \pm 0.048^{(\mathrm{d})}$ & $1.11 \pm 0.048^{(\mathrm{d})}$ & $1.11 \pm 0.048^{(\mathrm{d})}$ & $1.11 \pm 0.048^{(\mathrm{d})}$ & $1.11 \pm 0.048^{(\mathrm{d})}$ & $1.11 \pm 0.048^{(\mathrm{d})}$ & $1.11 \pm 0.048^{(\mathrm{d})}$ & $1.11 \pm 0.048^{(\mathrm{d})}$ \\
\hline $\begin{array}{l}\text { After } \\
\mathrm{NaOH}\end{array}$ & $4.91 \pm 0.12^{(\mathrm{d})}$ & $5.17 \pm 0.22^{(\mathrm{d})}$ & $5.43 \pm 0.24^{(\mathrm{d})}$ & $5.85 \pm 0.25^{(\mathrm{d})}$ & $5.83 \pm 0.25^{(\mathrm{d})}$ & $5.68 \pm 0.10^{(\mathrm{e})}$ & $\mathrm{n} / \mathrm{m}$ & $\mathrm{n} / \mathrm{m}$ \\
\hline $\begin{array}{l}\text { Initial } \\
\text { diluted }\end{array}$ & $\mathrm{n} / \mathrm{m}$ & $\mathrm{n} / \mathrm{m}$ & $\mathrm{n} / \mathrm{m}$ & $\mathrm{n} / \mathrm{m}$ & $\mathrm{n} / \mathrm{m}$ & $\mathrm{n} / \mathrm{m}$ & $4.00 \pm 0.10$ & $3.86 \pm 0.10$ \\
\hline At $88^{\circ} \mathrm{C}$ & $\mathrm{n} / \mathrm{c}$ & $4.68 \pm 0.35$ & $4.86 \pm 0.36$ & $5.26 \pm 0.39$ & $5.24 \pm 0.39$ & $4.97 \pm 0.12$ & $4.04 \pm 0.10$ & $3.80 \pm 0.10$ \\
\hline $0 \mathrm{hr}$ & $4.33 \pm 0.11^{(\mathrm{d})}$ & $4.53 \pm 0.34$ & $4.75 \pm 0.36$ & $5.16 \pm 0.39$ & $5.08 \pm 0.38$ & $5.21 \pm 0.13$ & $4.03 \pm 0.10$ & $3.69 \pm 0.09$ \\
\hline $1 \mathrm{hr}$ & $\mathrm{n} / \mathrm{c}$ & $4.42 \pm 0.33$ & $4.68 \pm 0.35$ & $5.17 \pm 0.39$ & $5.11 \pm 0.38$ & $4.78 \pm 0.12$ & $3.96 \pm 0.10$ & $3.74 \pm 0.09$ \\
\hline $2 \mathrm{hr}$ & $\mathrm{n} / \mathrm{c}$ & $4.35 \pm 0.33$ & $4.66 \pm 0.35$ & $5.16 \pm 0.39$ & $5.01 \pm 0.38$ & $4.77 \pm 0.12$ & $3.92 \pm 0.10$ & $3.59 \pm 0.09$ \\
\hline $4 \mathrm{hr}$ & $\mathrm{n} / \mathrm{c}$ & $4.30 \pm 0.32$ & $4.60 \pm 0.34$ & $5.06 \pm 0.38$ & $5.03 \pm 0.38$ & $4.60 \pm 0.11$ & $3.83 \pm 0.10$ & $3.55 \pm 0.09$ \\
\hline $8 \mathrm{hr}$ & $4.18 \pm 0.10$ & $\mathrm{n} / \mathrm{m}$ & $4.52 \pm 0.34$ & $4.92 \pm 0.37$ & $4.88 \pm 0.37$ & $4.18 \pm 0.10$ & $3.95 \pm 0.10$ & $3.87 \pm 0.10$ \\
\hline $10 \mathrm{hr}$ & $\mathrm{n} / \mathrm{c}$ & $4.23 \pm 0.32$ & $4.45 \pm 0.33$ & $4.89 \pm 0.37$ & $4.80 \pm 0.36$ & $4.08 \pm 0.10$ & $3.91 \pm 0.10$ & $3.94 \pm 0.10$ \\
\hline $12 \mathrm{hr}$ & $\mathrm{n} / \mathrm{c}$ & $4.14 \pm 0.31$ & $4.39 \pm 0.33$ & $4.80 \pm 0.36$ & $\mathrm{n} / \mathrm{m}$ & $3.76 \pm 0.09$ & $4.11 \pm 0.10$ & $4.46 \pm 0.11$ \\
\hline $14 \mathrm{hr}$ & $\mathrm{n} / \mathrm{c}$ & $4.19 \pm 0.31$ & $4.29 \pm 0.32$ & $4.76 \pm 0.36$ & $\mathrm{n} / \mathrm{m}$ & $3.46 \pm 0.09$ & $3.99 \pm 0.10$ & $4.77 \pm 0.12$ \\
\hline $16 \mathrm{hr}$ & $3.88 \pm 0.097^{(\mathrm{d})}$ & $4.12 \pm 0.18^{(\mathrm{d})}$ & $4.32 \pm 0.19^{(\mathrm{d})}$ & $4.70 \pm 0.25^{(\mathrm{d})}$ & $4.52 \pm 0.20^{(\mathrm{d})}$ & $4.59 \pm 0.07^{(\mathrm{d})}$ & $3.96 \pm 0.10$ & $4.75 \pm 0.12$ \\
\hline $18 \mathrm{hr}$ & $\mathrm{n} / \mathrm{m}$ & $\mathrm{n} / \mathrm{m}$ & $\mathrm{n} / \mathrm{m}$ & $\mathrm{n} / \mathrm{m}$ & $\mathrm{n} / \mathrm{m}$ & $\mathrm{n} / \mathrm{m}$ & $4.01 \pm 0.10$ & $4.85 \pm 0.12$ \\
\hline $20 \mathrm{hr}$ & $\mathrm{n} / \mathrm{m}$ & $\mathrm{n} / \mathrm{m}$ & $\mathrm{n} / \mathrm{m}$ & $\mathrm{n} / \mathrm{m}$ & $\mathrm{n} / \mathrm{m}$ & $\mathrm{n} / \mathrm{m}$ & $4.26 \pm 0.11$ & $4.75 \pm 0.12$ \\
\hline $22 \mathrm{hr}$ & $\mathrm{n} / \mathrm{m}$ & $\mathrm{n} / \mathrm{m}$ & $\mathrm{n} / \mathrm{m}$ & $\mathrm{n} / \mathrm{m}$ & $\mathrm{n} / \mathrm{m}$ & $\mathrm{n} / \mathrm{m}$ & $4.09 \pm 0.10$ & $4.83 \pm 0.12$ \\
\hline $24 \mathrm{hr}$ & $\mathrm{n} / \mathrm{m}$ & $\mathrm{n} / \mathrm{m}$ & $\mathrm{n} / \mathrm{m}$ & $\mathrm{n} / \mathrm{m}$ & $\mathrm{n} / \mathrm{m}$ & $\mathrm{n} / \mathrm{m}$ & $3.96 \pm 0.10$ & $4.71 \pm 0.12$ \\
\hline
\end{tabular}

(a) For Batches 1, 6, and both laboratory-scale tests, all samples except those before $\mathrm{NaOH}$ was added had free hydroxide measured in molarity by titration at Analytical Support Operations (ASO) (PNNL). The results for the first inflection point were used to represent free hydroxide. The measurements before NaOH was added in Batches 1,6 , and both

laboratory-scale tests were measured in molarity by Raman spectroscopy. All the free-hydroxide measurements in Batches 2 through 5 were made by Raman spectroscopy.

(b) The sample used in these laboratory-scale tests was taken from the PEP after $\mathrm{NaOH}$ had been added.

(c) Note that water was added all at once at the beginning of laboratory-scale runs, but was added gradually throughout the PEP runs as injected steam.

(d) Triplicate samples were taken at this point. The concentration shown is the mean of the set.

(e) Duplicate samples were taken at this point. The concentration shown is the mean of the set.

"n/m" = not measured

" $\mathrm{n} / \mathrm{c} "=$ data that were measured only by Raman spectroscopy; for the sake of consistency, they are not included in this table because they were not used in data analysis.

The \pm values are equal to half the laboratory uncertainty values (equivalent to a $95 \%$ confidence interval, or two standard deviations) that were supplied by the analytical organization for each concentration measurement. For duplicate or triplicate sets, the \pm values are standard deviations of the means. 
Table A.9. Mass Concentration of Aluminum in Bulk Slurry During Caustic-Leach Integrated Test A

\begin{tabular}{|c|c|c|c|c|c|c|c|c|}
\hline \multirow[b]{2}{*}{$\begin{array}{l}\text { Point in } \\
\text { Process }\end{array}$} & \multicolumn{8}{|c|}{$\begin{array}{l}\text { Concentration of Aluminum }(\mu \mathrm{g} / \mathrm{g}) \text { in Bulk Slurry }{ }^{(\mathrm{a})} \\
\pm 1 \text { Standard Deviation from Laboratory Analysis }\end{array}$} \\
\hline & $\begin{array}{c}\text { Integrated Test A, } \\
\text { Batch } 1 \text { in Tank T01A }\end{array}$ & $\begin{array}{c}\text { Integrated Test A, } \\
\text { Batch } 2 \text { in Tank T01B }\end{array}$ & $\begin{array}{c}\text { Integrated Test A, } \\
\text { Batch } 3 \text { in Tank T01A }\end{array}$ & $\begin{array}{c}\text { Integrated Test A, } \\
\text { Batch } 4 \text { in Tank T01B }\end{array}$ & $\begin{array}{c}\text { Integrated Test A, } \\
\text { Batch } 5 \text { in Tank T01A }\end{array}$ & $\begin{array}{c}\text { Integrated Test A, } \\
\text { Batch } 6 \text { in Tank T01B }\end{array}$ & $\begin{array}{l}\text { Laboratory- } \\
\text { Scale } \\
\text { Test A-1 } \\
\text { (b,c,d) }\end{array}$ & $\begin{array}{l}\text { Laboratory- } \\
\text { Scale } \\
\text { Test A-2 }^{(\mathrm{c}, \mathrm{d})}\end{array}$ \\
\hline $\begin{array}{l}\text { Before } \\
\mathrm{NaOH}\end{array}$ & $20023 \pm 344^{(\mathrm{e})}$ & $20023 \pm 344^{(\mathrm{e})}$ & $20023 \pm 344^{(\mathrm{e})}$ & $20023 \pm 344^{(\mathrm{e})}$ & $20023 \pm 344^{(\mathrm{e})}$ & $20023 \pm 344^{(\mathrm{e})}$ & $20023 \pm 344^{(\mathrm{e})}$ & $20023 \pm 344^{(\mathrm{e})}$ \\
\hline $\begin{array}{l}\text { After } \\
\mathrm{NaOH}\end{array}$ & $14468 \pm 238^{(\mathrm{e})}$ & $\mathrm{n} / \mathrm{m}$ & $\mathrm{n} / \mathrm{m}$ & $\mathrm{n} / \mathrm{m}$ & $\mathrm{n} / \mathrm{m}$ & $13387 \pm 197^{(\mathrm{e})}$ & $\mathrm{n} / \mathrm{m}$ & $\mathrm{n} / \mathrm{m}$ \\
\hline $\begin{array}{l}\text { Initial } \\
\text { diluted }\end{array}$ & $\mathrm{n} / \mathrm{m}$ & $\mathrm{n} / \mathrm{m}$ & $\mathrm{n} / \mathrm{m}$ & $\mathrm{n} / \mathrm{m}$ & $\mathrm{n} / \mathrm{m}$ & $\mathrm{n} / \mathrm{m}$ & $9525 \pm 229^{(\mathrm{f})}$ & $9285 \pm 223^{(\mathrm{f})}$ \\
\hline At $88^{\circ} \mathrm{C}$ & $\mathrm{n} / \mathrm{m}$ & $\mathrm{n} / \mathrm{m}$ & $\mathrm{n} / \mathrm{m}$ & $\mathrm{n} / \mathrm{m}$ & $\mathrm{n} / \mathrm{m}$ & $\mathrm{n} / \mathrm{m}$ & $\mathrm{n} / \mathrm{m}$ & $\mathrm{n} / \mathrm{m}$ \\
\hline $0 \mathrm{hr}$ & $13842 \pm 195^{(\mathrm{e})}$ & $13768 \pm 314$ & $12293 \pm 278$ & $12644 \pm 286$ & $12516 \pm 284$ & $12239 \pm 276$ & $\mathrm{n} / \mathrm{m}$ & $\mathrm{n} / \mathrm{m}$ \\
\hline $1 \mathrm{hr}$ & $\mathrm{n} / \mathrm{m}$ & $\mathrm{n} / \mathrm{m}$ & $\mathrm{n} / \mathrm{m}$ & $\mathrm{n} / \mathrm{m}$ & $\mathrm{n} / \mathrm{m}$ & $\mathrm{n} / \mathrm{m}$ & $\mathrm{n} / \mathrm{m}$ & $\mathrm{n} / \mathrm{m}$ \\
\hline $2 \mathrm{hr}$ & $\mathrm{n} / \mathrm{m}$ & $\mathrm{n} / \mathrm{m}$ & $\mathrm{n} / \mathrm{m}$ & $\mathrm{n} / \mathrm{m}$ & $\mathrm{n} / \mathrm{m}$ & $\mathrm{n} / \mathrm{m}$ & $\mathrm{n} / \mathrm{m}$ & $\mathrm{n} / \mathrm{m}$ \\
\hline $4 \mathrm{hr}$ & $13051 \pm 314$ & $12668 \pm 285$ & $13120 \pm 297$ & $12368 \pm 279$ & $12260 \pm 276$ & $12038 \pm 271$ & $\mathrm{n} / \mathrm{m}$ & $\mathrm{n} / \mathrm{m}$ \\
\hline $8 \mathrm{hr}$ & $13215 \pm 312$ & $\mathrm{n} / \mathrm{m}$ & $12324 \pm 277$ & $12076 \pm 273$ & $12235 \pm 275$ & $11930 \pm 269$ & $\mathrm{n} / \mathrm{m}$ & $\mathrm{n} / \mathrm{m}$ \\
\hline $10 \mathrm{hr}$ & $\mathrm{n} / \mathrm{m}$ & $13508 \pm 304$ & $\mathrm{n} / \mathrm{m}$ & $\mathrm{n} / \mathrm{m}$ & $\mathrm{n} / \mathrm{m}$ & $\mathrm{n} / \mathrm{m}$ & $\mathrm{n} / \mathrm{m}$ & $\mathrm{n} / \mathrm{m}$ \\
\hline $12 \mathrm{hr}$ & $13010 \pm 305$ & $12801 \pm 289$ & $12097 \pm 273$ & $12130 \pm 275$ & $11920 \pm 270$ & $11696 \pm 267$ & $\mathrm{n} / \mathrm{m}$ & $\mathrm{n} / \mathrm{m}$ \\
\hline $14 \mathrm{hr}$ & $\mathrm{n} / \mathrm{m}$ & $\mathrm{n} / \mathrm{m}$ & $\mathrm{n} / \mathrm{m}$ & $\mathrm{n} / \mathrm{m}$ & $\mathrm{n} / \mathrm{m}$ & $\mathrm{n} / \mathrm{m}$ & $\mathrm{n} / \mathrm{m}$ & $\mathrm{n} / \mathrm{m}$ \\
\hline $16 \mathrm{hr}$ & $12751 \pm 173^{(\mathrm{e})}$ & $12927 \pm 170^{(\mathrm{e})}$ & $12018 \pm 158^{(\mathrm{e})}$ & $11778 \pm 156^{(\mathrm{e})}$ & $11311 \pm 151^{(\mathrm{e})}$ & $11633 \pm 155^{(\mathrm{e})}$ & $\mathrm{n} / \mathrm{m}$ & $\mathrm{n} / \mathrm{m}$ \\
\hline $18 \mathrm{hr}$ & $\mathrm{n} / \mathrm{m}$ & $\mathrm{n} / \mathrm{m}$ & $\mathrm{n} / \mathrm{m}$ & $\mathrm{n} / \mathrm{m}$ & $\mathrm{n} / \mathrm{m}$ & $\mathrm{n} / \mathrm{m}$ & $\mathrm{n} / \mathrm{m}$ & $\mathrm{n} / \mathrm{m}$ \\
\hline $20 \mathrm{hr}$ & $\mathrm{n} / \mathrm{m}$ & $\mathrm{n} / \mathrm{m}$ & $\mathrm{n} / \mathrm{m}$ & $\mathrm{n} / \mathrm{m}$ & $\mathrm{n} / \mathrm{m}$ & $\mathrm{n} / \mathrm{m}$ & $\mathrm{n} / \mathrm{m}$ & $\mathrm{n} / \mathrm{m}$ \\
\hline $22 \mathrm{hr}$ & $\mathrm{n} / \mathrm{m}$ & $\mathrm{n} / \mathrm{m}$ & $\mathrm{n} / \mathrm{m}$ & $\mathrm{n} / \mathrm{m}$ & $\mathrm{n} / \mathrm{m}$ & $\mathrm{n} / \mathrm{m}$ & $\mathrm{n} / \mathrm{m}$ & $\mathrm{n} / \mathrm{m}$ \\
\hline $24 \mathrm{hr}$ & $\mathrm{n} / \mathrm{m}$ & $\mathrm{n} / \mathrm{m}$ & $\mathrm{n} / \mathrm{m}$ & $\mathrm{n} / \mathrm{m}$ & $\mathrm{n} / \mathrm{m}$ & $\mathrm{n} / \mathrm{m}$ & $11600 \pm 394^{(\mathrm{g})}$ & $13000 \pm 441^{(\mathrm{g})}$ \\
\hline
\end{tabular}

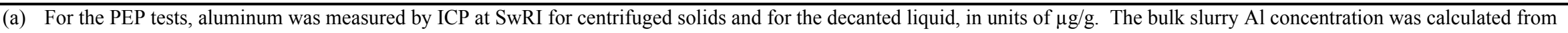
these measured concentrations and from the masses of centrifuged solids and liquid, which were weighed at PNNL.

(b) The sample used in these laboratory-scale tests was taken from the PEP after NaOH had been added.

(c) Note that water was added all at once at the beginning of laboratory-scale runs, but was added gradually throughout the PEP runs as injected steam.

(d) Uncertainties are estimated for initial diluted through 24-hour samples using similar data from Integrated Test A, Batch 1.

(e) Triplicate samples were taken at this point. The concentration shown is the mean of the set.

(f) Duplicate samples were taken at this point. The concentration shown is the mean of the set.

(g) The samples were removed when the vessel slurry had been cooled to a temperature of $<60^{\circ} \mathrm{C}$ (approximate cooling time was 40 minutes).

" $\mathrm{n} / \mathrm{m}$ " = not measured

The \pm values are standard deviations calculated by linearized error propagation methods. For duplicate or triplicate sets, the \pm values are standard deviations of the means. The method used to estimate the uncertainty of the centrifuged solids weight fraction depends on measurements for the triplicate data sets. The different number of triplicate data sets in PEP and laboratory-scale tests causes differences in centrifuged solids fraction uncertainty, and therefore in slurry concentration uncertainty, for the same sample, when determined from PEP test

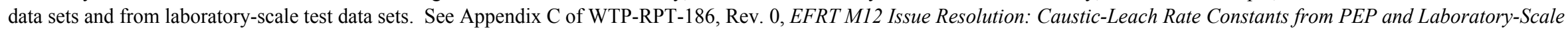
Tests for more information. 
Table A.10. Mass Concentration of Dissolved Aluminum During Caustic-Leach Integrated Test A

\begin{tabular}{|c|c|c|c|c|c|c|c|c|}
\hline \multirow[b]{2}{*}{$\begin{array}{l}\text { Point in } \\
\text { Process }\end{array}$} & \multicolumn{8}{|c|}{$\begin{array}{l}\text { Concentration of Aluminum }(\mu \mathrm{g} / \mathrm{g}) \text { in Liquid Phase }{ }^{(\mathrm{a})} \\
\pm 1 \text { Standard Deviation from Laboratory Analysis }\end{array}$} \\
\hline & $\begin{array}{c}\text { Integrated Test } \\
\text { A, Batch } 1 \text { in } \\
\text { Tank T01A }\end{array}$ & $\begin{array}{c}\text { Integrated Test } \\
\text { A, Batch } 2 \text { in } \\
\text { Tank T01B }\end{array}$ & $\begin{array}{c}\text { Integrated Test } \\
\mathrm{A}, \text { Batch } 3 \text { in } \\
\text { Tank T01A }\end{array}$ & $\begin{array}{c}\text { Integrated Test } \\
\text { A, Batch } 4 \text { in } \\
\text { Tank T01B }\end{array}$ & $\begin{array}{c}\text { Integrated Test } \\
\text { A, Batch } 5 \text { in } \\
\text { Tank T01A }\end{array}$ & $\begin{array}{c}\text { Integrated Test } \\
\text { A, Batch } 6 \text { in } \\
\text { Tank T01B }\end{array}$ & 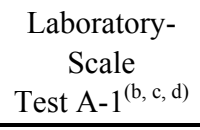 & $\begin{array}{c}\text { Laboratory- } \\
\text { Scale } \\
\text { Test A-2 } 2^{(\mathrm{c}, \mathrm{d})} \\
\end{array}$ \\
\hline $\begin{array}{l}\text { Before } \\
\mathrm{NaOH}\end{array}$ & $2977 \pm 52^{(\mathrm{e})}$ & $2977 \pm 52^{(\mathrm{e})}$ & $2977 \pm 52^{(\mathrm{e})}$ & $2977 \pm 52^{(\mathrm{e})}$ & $2977 \pm 52^{(\mathrm{e})}$ & $2977 \pm 52^{(\mathrm{e})}$ & $2977 \pm 52^{(\mathrm{e})}$ & $2977 \pm 52^{(\mathrm{e})}$ \\
\hline $\begin{array}{l}\text { After } \\
\mathrm{NaOH}\end{array}$ & $4713 \pm 82^{(\mathrm{e})}$ & $\mathrm{n} / \mathrm{c}$ & $\mathrm{n} / \mathrm{c}$ & $\mathrm{n} / \mathrm{c}$ & $\mathrm{n} / \mathrm{c}$ & $4450 \pm 78^{(\mathrm{e})}$ & $\mathrm{n} / \mathrm{m}$ & $\mathrm{n} / \mathrm{m}$ \\
\hline $\begin{array}{l}\text { Initial } \\
\text { diluted }\end{array}$ & $\mathrm{n} / \mathrm{m}$ & $\mathrm{n} / \mathrm{m}$ & $\mathrm{n} / \mathrm{m}$ & $\mathrm{n} / \mathrm{m}$ & $\mathrm{n} / \mathrm{m}$ & $\mathrm{n} / \mathrm{m}$ & $4610 \pm 139$ & $2000 \pm 60$ \\
\hline At $88^{\circ} \mathrm{C}$ & $6970 \pm 210$ & $\mathrm{n} / \mathrm{c}$ & $\mathrm{n} / \mathrm{c}$ & $\mathrm{n} / \mathrm{c}$ & $\mathrm{n} / \mathrm{c}$ & $6790 \pm 204$ & $6360 \pm 192$ & $6050 \pm 182$ \\
\hline $0 \mathrm{hr}$ & $7220 \pm 125^{(\mathrm{e})}$ & $7180 \pm 216$ & $6750 \pm 203$ & $6820 \pm 206$ & $6580 \pm 198$ & $6780 \pm 204$ & $6550 \pm 197$ & $6140 \pm 185$ \\
\hline $1 \mathrm{hr}$ & $6950 \pm 210$ & $\mathrm{n} / \mathrm{c}$ & $\mathrm{n} / \mathrm{c}$ & $\mathrm{n} / \mathrm{c}$ & $\mathrm{n} / \mathrm{c}$ & $6740 \pm 203$ & $6730 \pm 203$ & $6270 \pm 189$ \\
\hline $2 \mathrm{hr}$ & $7390 \pm 223$ & $\mathrm{n} / \mathrm{c}$ & $\mathrm{n} / \mathrm{c}$ & $\mathrm{n} / \mathrm{c}$ & $\mathrm{n} / \mathrm{c}$ & $6900 \pm 208$ & $6580 \pm 198$ & $6430 \pm 194$ \\
\hline $4 \mathrm{hr}$ & $7270 \pm 219$ & $7310 \pm 220$ & $7210 \pm 217$ & $7230 \pm 218$ & $7220 \pm 218$ & $7150 \pm 215$ & $7220 \pm 217$ & $5810 \pm 175$ \\
\hline $8 \mathrm{hr}$ & $8050 \pm 242$ & $\mathrm{n} / \mathrm{m}$ & $7600 \pm 229$ & $7740 \pm 233$ & $7530 \pm 227$ & $7660 \pm 230$ & $7790 \pm 235$ & $7210 \pm 217$ \\
\hline $10 \mathrm{hr}$ & $8000 \pm 241$ & $8420 \pm 253$ & $\mathrm{n} / \mathrm{c}$ & $\mathrm{n} / \mathrm{c}$ & $\mathrm{n} / \mathrm{c}$ & $7880 \pm 237$ & $7570 \pm 228$ & $7460 \pm 225$ \\
\hline $12 \mathrm{hr}$ & $8410 \pm 253$ & $8300 \pm 249$ & $7920 \pm 238$ & $8150 \pm 245$ & $7870 \pm 237$ & $8070 \pm 243$ & $8060 \pm 243$ & $8320 \pm 251$ \\
\hline $14 \mathrm{hr}$ & $8190 \pm 247$ & $\mathrm{n} / \mathrm{c}$ & $\mathrm{n} / \mathrm{c}$ & $\mathrm{n} / \mathrm{c}$ & $\mathrm{n} / \mathrm{m}$ & $8250 \pm 248$ & $8340 \pm 251$ & $9200 \pm 277$ \\
\hline $16 \mathrm{hr}$ & $8697 \pm 151^{(\mathrm{e})}$ & $8807 \pm 153^{(\mathrm{e})}$ & $8257 \pm 143^{(\mathrm{e})}$ & $8263 \pm 143^{(\mathrm{e})}$ & $8107 \pm 141^{(\mathrm{e})}$ & $8383 \pm 146^{(\mathrm{e})}$ & $8330 \pm 251$ & $9190 \pm 277$ \\
\hline $18 \mathrm{hr}$ & $\mathrm{n} / \mathrm{m}$ & $\mathrm{n} / \mathrm{m}$ & $\mathrm{n} / \mathrm{m}$ & $\mathrm{n} / \mathrm{m}$ & $\mathrm{n} / \mathrm{m}$ & $\mathrm{n} / \mathrm{m}$ & $8610 \pm 259$ & $9620 \pm 290$ \\
\hline $20 \mathrm{hr}$ & $\mathrm{n} / \mathrm{m}$ & $\mathrm{n} / \mathrm{m}$ & $\mathrm{n} / \mathrm{m}$ & $\mathrm{n} / \mathrm{m}$ & $\mathrm{n} / \mathrm{m}$ & $\mathrm{n} / \mathrm{m}$ & $8800 \pm 265$ & $9960 \pm 300$ \\
\hline $22 \mathrm{hr}$ & $\mathrm{n} / \mathrm{m}$ & $\mathrm{n} / \mathrm{m}$ & $\mathrm{n} / \mathrm{m}$ & $\mathrm{n} / \mathrm{m}$ & $\mathrm{n} / \mathrm{m}$ & $\mathrm{n} / \mathrm{m}$ & $8970 \pm 270$ & $10300 \pm 310$ \\
\hline $24 \mathrm{hr}$ & $\mathrm{n} / \mathrm{m}$ & $\mathrm{n} / \mathrm{m}$ & $\mathrm{n} / \mathrm{m}$ & $\mathrm{n} / \mathrm{m}$ & $\mathrm{n} / \mathrm{m}$ & $\mathrm{n} / \mathrm{m}$ & $9600 \pm 289$ & $10600 \pm 319$ \\
\hline
\end{tabular}

(a) Dissolved aluminum was measured in $\mathrm{g} / \mathrm{g}$ liquid by inductively coupled plasma (ICP) at Southwest Research Institute (SwRI).

(b) The sample used in these laboratory-scale tests was taken from the PEP after $\mathrm{NaOH}$ had been added.

(c) Note that water was added all at once at the beginning of laboratory-scale runs, but was added gradually throughout the PEP runs as injected steam.

(d) Uncertainties are estimated for initial diluted through 24-hour samples using similar data from Integrated Test A, Batch 1.

(e) Triplicate samples were taken at this point. The concentration shown is the mean of the set.

" $\mathrm{n} / \mathrm{c} "$ = data that were measured only by Raman spectroscopy; for the sake of consistency, they are not included in this table or in data analysis.

"n/m" = not measured

The \pm values are equal to half the laboratory uncertainty values (equivalent to a $95 \%$ confidence interval, or two standard deviations) that were supplied by the analytical organization for each concentration measurement. For duplicate or triplicate sets, the \pm values are standard deviations of the means. 
Table A.11. Mass Concentration of Tracer in Bulk Slurry During Caustic-Leach Integrated Test A

\begin{tabular}{|c|c|c|c|c|c|c|c|c|}
\hline \multirow[b]{2}{*}{ Point in Process } & \multicolumn{8}{|c|}{ Concentration of Tracer $(\mu \mathrm{g} / \mathrm{g})$ in Bulk Slurry ${ }^{(\mathrm{a})} \pm 1$ Standard Deviation from Laboratory Analysis } \\
\hline & $\begin{array}{c}\text { Integrated Test A, } \\
\text { Batch } 1 \text { in Tank } \\
\text { T01A } \\
\text { (Sr) }\end{array}$ & $\begin{array}{c}\text { Integrated Test A, } \\
\text { Batch } 2 \text { in Tank } \\
\text { T01B } \\
\text { (Sr) }\end{array}$ & $\begin{array}{c}\text { Integrated Test A, } \\
\text { Batch } 3 \text { in Tank } \\
\text { T01A } \\
\text { (Sr) }\end{array}$ & $\begin{array}{c}\text { Integrated Test A, } \\
\text { Batch } 4 \text { in Tank } \\
\text { T01B } \\
\text { (Sr) }\end{array}$ & $\begin{array}{c}\text { Integrated Test A, } \\
\text { Batch } 5 \text { in Tank } \\
\text { T01A } \\
(\mathrm{Fe})\end{array}$ & $\begin{array}{c}\text { Integrated Test A, } \\
\text { Batch } 6 \text { in Tank } \\
\text { T01B } \\
\text { (Sr) }\end{array}$ & $\begin{array}{l}\text { Laboratory-Scale } \\
\text { Test A-1 } \\
\text { (b, c, d, Sr) }\end{array}$ & $\begin{array}{l}\text { Laboratory-Scale } \\
\text { Test A-2 } \\
\text { (c, d, Sr) }\end{array}$ \\
\hline Before $\mathrm{NaOH}$ & $43.7 \pm 1.3^{(\mathrm{e})}$ & $43.7 \pm 1.3^{(\mathrm{e})}$ & $43.7 \pm 1.3^{(\mathrm{e})}$ & $43.7 \pm 1.3^{(\mathrm{e})}$ & $4734 \pm 94^{(\mathrm{e})}$ & $43.7 \pm 1.3^{(\mathrm{e})}$ & $43.7 \pm 1.3^{(\mathrm{e})}$ & $43.7 \pm 1.3^{(\mathrm{e})}$ \\
\hline After $\mathrm{NaOH}$ & $32.7 \pm 0.8^{(\mathrm{e})}$ & $32.9 \pm 0.7^{(\mathrm{e})}$ & $31.3 \pm 0.7^{(\mathrm{e})}$ & $29.6 \pm 0.6^{(\mathrm{e})}$ & $3242 \pm 65^{(\mathrm{e})}$ & $27.6 \pm 0.6^{(\mathrm{e})}$ & $\mathrm{n} / \mathrm{m}$ & $\mathrm{n} / \mathrm{m}$ \\
\hline Initial diluted & $\mathrm{n} / \mathrm{m}$ & $\mathrm{n} / \mathrm{m}$ & $\mathrm{n} / \mathrm{m}$ & $\mathrm{n} / \mathrm{m}$ & $\mathrm{n} / \mathrm{m}$ & $\mathrm{n} / \mathrm{m}$ & $26.2 \pm 0.7^{(\mathrm{f})}$ & $25.9 \pm 0.7^{(\mathrm{f})}$ \\
\hline At $88^{\circ} \mathrm{C}$ & $\mathrm{n} / \mathrm{m}$ & $\mathrm{n} / \mathrm{m}$ & $\mathrm{n} / \mathrm{m}$ & $\mathrm{n} / \mathrm{m}$ & $\mathrm{n} / \mathrm{m}$ & $\mathrm{n} / \mathrm{m}$ & $\mathrm{n} / \mathrm{m}$ & $\mathrm{n} / \mathrm{m}$ \\
\hline $0 \mathrm{hr}$ & $30.2 \pm 0.7^{(\mathrm{e})}$ & $29.5 \pm 1.0$ & $28.4 \pm 1.0$ & $27.0 \pm 0.9$ & $2980 \pm 101$ & $27.0 \pm 0.9$ & $\mathrm{n} / \mathrm{m}$ & $\mathrm{n} / \mathrm{m}$ \\
\hline $1 \mathrm{hr}$ & $\mathrm{n} / \mathrm{m}$ & $\mathrm{n} / \mathrm{m}$ & $\mathrm{n} / \mathrm{m}$ & $\mathrm{n} / \mathrm{m}$ & $\mathrm{n} / \mathrm{m}$ & $\mathrm{n} / \mathrm{m}$ & $\mathrm{n} / \mathrm{m}$ & $\mathrm{n} / \mathrm{m}$ \\
\hline $2 \mathrm{hr}$ & $\mathrm{n} / \mathrm{m}$ & $\mathrm{n} / \mathrm{m}$ & $\mathrm{n} / \mathrm{m}$ & $\mathrm{n} / \mathrm{m}$ & $\mathrm{n} / \mathrm{m}$ & $\mathrm{n} / \mathrm{m}$ & $\mathrm{n} / \mathrm{m}$ & $\mathrm{n} / \mathrm{m}$ \\
\hline $4 \mathrm{hr}$ & $30.1 \pm 1.2$ & $27.6 \pm 1.0$ & $32.2 \pm 1.2$ & $27.4 \pm 1.0$ & $2968 \pm 102$ & $25.8 \pm 0.9$ & $\mathrm{n} / \mathrm{m}$ & $\mathrm{n} / \mathrm{m}$ \\
\hline $8 \mathrm{hr}$ & $29.7 \pm 1.2$ & $\mathrm{n} / \mathrm{m}$ & $30.0 \pm 1.1$ & $23.6 \pm 0.9$ & $3187 \pm 109$ & $25.8 \pm 0.9$ & $\mathrm{n} / \mathrm{m}$ & $\mathrm{n} / \mathrm{m}$ \\
\hline $10 \mathrm{hr}$ & $\mathrm{n} / \mathrm{m}$ & $30.6 \pm 1.1$ & $\mathrm{n} / \mathrm{m}$ & $\mathrm{n} / \mathrm{m}$ & $\mathrm{n} / \mathrm{m}$ & $\mathrm{n} / \mathrm{m}$ & $\mathrm{n} / \mathrm{m}$ & $\mathrm{n} / \mathrm{m}$ \\
\hline $12 \mathrm{hr}$ & $29.3 \pm 1.2$ & $28.5 \pm 1.0$ & $26.3 \pm 1.0$ & $26.4 \pm 1.0$ & $3047 \pm 104$ & $25.0 \pm 0.9$ & $\mathrm{n} / \mathrm{m}$ & $\mathrm{n} / \mathrm{m}$ \\
\hline $14 \mathrm{hr}$ & $\mathrm{n} / \mathrm{m}$ & $\mathrm{n} / \mathrm{m}$ & $\mathrm{n} / \mathrm{m}$ & $\mathrm{n} / \mathrm{m}$ & $\mathrm{n} / \mathrm{m}$ & $\mathrm{n} / \mathrm{m}$ & $\mathrm{n} / \mathrm{m}$ & $\mathrm{n} / \mathrm{m}$ \\
\hline $16 \mathrm{hr}$ & $28.9 \pm 0.7^{(\mathrm{e})}$ & $28.9 \pm 0.6^{(\mathrm{e})}$ & $26.2 \pm 0.6^{(\mathrm{e})}$ & $26.8 \pm 0.6^{(\mathrm{e})}$ & $2836 \pm 56^{(\mathrm{e})}$ & $25.6 \pm 0.5^{(\mathrm{e})}$ & $\mathrm{n} / \mathrm{m}$ & $\mathrm{n} / \mathrm{m}$ \\
\hline $18 \mathrm{hr}$ & $\mathrm{n} / \mathrm{m}$ & $\mathrm{n} / \mathrm{m}$ & $\mathrm{n} / \mathrm{m}$ & $\mathrm{n} / \mathrm{m}$ & $\mathrm{n} / \mathrm{m}$ & $\mathrm{n} / \mathrm{m}$ & $\mathrm{n} / \mathrm{m}$ & $\mathrm{n} / \mathrm{m}$ \\
\hline $20 \mathrm{hr}$ & $\mathrm{n} / \mathrm{m}$ & $\mathrm{n} / \mathrm{m}$ & $\mathrm{n} / \mathrm{m}$ & $\mathrm{n} / \mathrm{m}$ & $\mathrm{n} / \mathrm{m}$ & $\mathrm{n} / \mathrm{m}$ & $\mathrm{n} / \mathrm{m}$ & $\mathrm{n} / \mathrm{m}$ \\
\hline $22 \mathrm{hr}$ & $\mathrm{n} / \mathrm{m}$ & $\mathrm{n} / \mathrm{m}$ & $\mathrm{n} / \mathrm{m}$ & $\mathrm{n} / \mathrm{m}$ & $\mathrm{n} / \mathrm{m}$ & $\mathrm{n} / \mathrm{m}$ & $\mathrm{n} / \mathrm{m}$ & $\mathrm{n} / \mathrm{m}$ \\
\hline $24 \mathrm{hr}$ & $\mathrm{n} / \mathrm{m}$ & $\mathrm{n} / \mathrm{m}$ & $\mathrm{n} / \mathrm{m}$ & $\mathrm{n} / \mathrm{m}$ & $\mathrm{n} / \mathrm{m}$ & $\mathrm{n} / \mathrm{m}$ & $27.9 \pm 1.1^{(\mathrm{g})}$ & $31.1 \pm 1.2^{(\mathrm{g})}$ \\
\hline
\end{tabular}

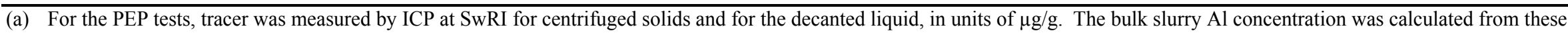
measured concentrations and from the masses of centrifuged solids and liquid, which were weighed at PNNL.

(b) The sample used in these laboratory-scale tests was taken from the PEP after $\mathrm{NaOH}$ had been added.

(c) Note that water was added all at once at the beginning of laboratory-scale runs, but was added gradually throughout the PEP runs as injected steam.

(d) Uncertainties are estimated for initial diluted through 24-hour samples using similar data from Integrated Test A, Batch 1.

(e) Triplicate samples were taken at this point. The concentration shown is the mean of the set.

(f) Duplicate samples were taken at this point. The concentration shown is the mean of the set.

(g) The samples were removed when the vessel slurry had been cooled to a temperature of $<60^{\circ} \mathrm{C}$ (approximate cooling time was 40 minutes).

(Sr) Solid tracer is strontium for this column.

(Fe) Solid tracer is iron for this column.

" $\mathrm{n} / \mathrm{m}$ " = not measured

The \pm values are standard deviations calculated by linearized error propagation methods. For duplicate or triplicate sets, the \pm values are standard deviations of the means. The method used to estimate the uncertainty of the centrifuged solids weight fraction depends on measurements for the triplicate data sets. The different number of triplicate data sets in PEP and laboratory-scale tests causes differences in centrifuged solids fraction uncertainty, and therefore in slurry concentration uncertainty, for the same sample, when determined from PEP test

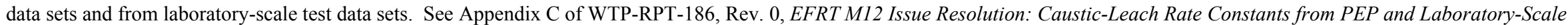
Tests for more information. 
Table A.12. Mass Concentration of Liquid Tracer During Caustic-Leach Integrated Test A

\begin{tabular}{|c|c|c|c|c|c|c|c|c|}
\hline \multirow[b]{2}{*}{ Point in Process } & \multicolumn{8}{|c|}{ Concentration of Tracer $(\mu \mathrm{g} / \mathrm{g})$ in Liquid Phase ${ }^{(\mathrm{a})} \pm 1$ Standard Deviation from Laboratory Analysis } \\
\hline & $\begin{array}{c}\text { Integrated Test } \mathrm{A}, \\
\text { Batch } 1 \text { in Tank } \\
\text { T01A }\left(\mathrm{NO}_{3}\right)\end{array}$ & $\begin{array}{l}\text { Integrated Test } \\
\text { A, Batch } 2 \text { in } \\
\text { Tank T01B } \\
\text { (Cl) }\end{array}$ & $\begin{array}{l}\text { Integrated Test } \\
\text { A, Batch } 3 \text { in } \\
\text { Tank T01A } \\
\text { (Cl) }\end{array}$ & $\begin{array}{l}\text { Integrated Test } \\
\text { A, Batch } 4 \text { in } \\
\text { Tank T01B } \\
\text { (Cl) }\end{array}$ & $\begin{array}{c}\text { Integrated Test A, } \\
\text { Batch } 5 \text { in Tank } \\
\text { T01A } \\
(\mathrm{Cl})\end{array}$ & $\begin{array}{l}\text { Integrated Test } \\
\text { A, Batch } 6 \text { in } \\
\text { Tank T01B } \\
(\mathrm{Cl})\end{array}$ & $\begin{array}{l}\text { Laboratory-Scale } \\
\text { Test A-1 } \\
\text { (b, c, d, Cl) }\end{array}$ & $\begin{array}{c}\text { Laboratory-Scale } \\
\text { Test A-2 } 2^{(\mathrm{c}, \mathrm{d}, \mathrm{Cl})}\end{array}$ \\
\hline Before $\mathrm{NaOH}$ & $79333 \pm 1380^{(\mathrm{e})}$ & $1137 \pm 20^{(\mathrm{e})}$ & $1137 \pm 20^{(\mathrm{e})}$ & $1137 \pm 20^{(\mathrm{e})}$ & $1137 \pm 20^{(\mathrm{e})}$ & $1137 \pm 20^{(\mathrm{e})}$ & $1137 \pm 20^{(\mathrm{e})}$ & $1137 \pm 20^{(\mathrm{e})}$ \\
\hline After $\mathrm{NaOH}$ & $56967 \pm 1016^{(\mathrm{e})}$ & $\mathrm{n} / \mathrm{c}$ & $\mathrm{n} / \mathrm{c}$ & $\mathrm{n} / \mathrm{c}$ & $\mathrm{n} / \mathrm{c}$ & $735 \pm 13^{(\mathrm{e})}$ & $\mathrm{n} / \mathrm{m}$ & $\mathrm{n} / \mathrm{m}$ \\
\hline Initial diluted & $\mathrm{n} / \mathrm{m}$ & $\mathrm{n} / \mathrm{m}$ & $\mathrm{n} / \mathrm{m}$ & $\mathrm{n} / \mathrm{m}$ & $\mathrm{n} / \mathrm{m}$ & $\mathrm{n} / \mathrm{m}$ & $736 \pm 22$ & $741 \pm 23^{(\mathrm{e})}$ \\
\hline At $88^{\circ} \mathrm{C}$ & $52700 \pm 1636$ & $\mathrm{n} / \mathrm{c}$ & $\mathrm{n} / \mathrm{c}$ & $\mathrm{n} / \mathrm{c}$ & $\mathrm{n} / \mathrm{c}$ & $694 \pm 21$ & $763 \pm 23$ & $758 \pm 23$ \\
\hline $0 \mathrm{hr}$ & $52650 \pm 1132^{(\mathrm{f})}$ & $732 \pm 23$ & $690 \pm 21$ & $705 \pm 21$ & $656 \pm 20$ & $672 \pm 21$ & $736 \pm 22$ & $789 \pm 24$ \\
\hline $1 \mathrm{hr}$ & $51100 \pm 1593$ & $\mathrm{n} / \mathrm{c}$ & $\mathrm{n} / \mathrm{c}$ & $\mathrm{n} / \mathrm{c}$ & $\mathrm{n} / \mathrm{c}$ & $675 \pm 21$ & $775 \pm 24$ & $756 \pm 23$ \\
\hline $2 \mathrm{hr}$ & $51600 \pm 1602$ & $\mathrm{n} / \mathrm{c}$ & $\mathrm{n} / \mathrm{c}$ & $\mathrm{n} / \mathrm{c}$ & $\mathrm{n} / \mathrm{c}$ & $670 \pm 21$ & $760 \pm 23$ & $778 \pm 24$ \\
\hline $4 \mathrm{hr}$ & $50900 \pm 1584$ & $707 \pm 22$ & $671 \pm 21$ & $650 \pm 20$ & $631 \pm 19$ & $663 \pm 20$ & $768 \pm 23$ & $775 \pm 24$ \\
\hline $8 \mathrm{hr}$ & $51000 \pm 1561$ & $\mathrm{n} / \mathrm{m}$ & $626 \pm 19$ & $664 \pm 20$ & $642 \pm 20$ & $649 \pm 20$ & $794 \pm 24$ & $778 \pm 24$ \\
\hline $10 \mathrm{hr}$ & $49400 \pm 1541$ & $709 \pm 22$ & $\mathrm{n} / \mathrm{c}$ & $\mathrm{n} / \mathrm{c}$ & $\mathrm{n} / \mathrm{c}$ & $652 \pm 20$ & $778 \pm 24$ & $779 \pm 24$ \\
\hline $12 \mathrm{hr}$ & $49400 \pm 1534$ & $693 \pm 21$ & $655 \pm 20$ & $617 \pm 20$ & $620 \pm 19$ & $639 \pm 20$ & $800 \pm 24$ & $863 \pm 26$ \\
\hline $14 \mathrm{hr}$ & $48200 \pm 1511$ & $\mathrm{n} / \mathrm{c}$ & $\mathrm{n} / \mathrm{c}$ & $\mathrm{n} / \mathrm{c}$ & $\mathrm{n} / \mathrm{c}$ & $634 \pm 20$ & $793 \pm 24$ & $932 \pm 28$ \\
\hline $16 \mathrm{hr}$ & $48533 \pm 866^{(\mathrm{e})}$ & $684 \pm 12^{(\mathrm{e})}$ & $645 \pm 11^{(\mathrm{e})}$ & $635 \pm 11^{(\mathrm{e})}$ & $622 \pm 11^{(\mathrm{e})}$ & $634 \pm 11^{(\mathrm{e})}$ & $793 \pm 24$ & $922 \pm 28$ \\
\hline $18 \mathrm{hr}$ & $\mathrm{n} / \mathrm{m}$ & $\mathrm{n} / \mathrm{m}$ & $\mathrm{n} / \mathrm{m}$ & $\mathrm{n} / \mathrm{m}$ & $\mathrm{n} / \mathrm{m}$ & $\mathrm{n} / \mathrm{m}$ & $817 \pm 25$ & $976 \pm 30$ \\
\hline $20 \mathrm{hr}$ & $\mathrm{n} / \mathrm{m}$ & $\mathrm{n} / \mathrm{m}$ & $\mathrm{n} / \mathrm{m}$ & $\mathrm{n} / \mathrm{m}$ & $\mathrm{n} / \mathrm{m}$ & $\mathrm{n} / \mathrm{m}$ & $805 \pm 25$ & $960 \pm 29$ \\
\hline $22 \mathrm{hr}$ & $\mathrm{n} / \mathrm{m}$ & $\mathrm{n} / \mathrm{m}$ & $\mathrm{n} / \mathrm{m}$ & $\mathrm{n} / \mathrm{m}$ & $\mathrm{n} / \mathrm{m}$ & $\mathrm{n} / \mathrm{m}$ & $797 \pm 24$ & $968 \pm 30$ \\
\hline $24 \mathrm{hr}$ & $\mathrm{n} / \mathrm{m}$ & $\mathrm{n} / \mathrm{m}$ & $\mathrm{n} / \mathrm{m}$ & $\mathrm{n} / \mathrm{m}$ & $\mathrm{n} / \mathrm{m}$ & $\mathrm{n} / \mathrm{m}$ & $854 \pm 26$ & $975 \pm 30$ \\
\hline
\end{tabular}

(a) Dissolved tracer was measured in $\mathrm{g} / \mathrm{g}$ liquid by inductively coupled plasma (ICP) at Southwest Research Institute (SwRI).

(b) The sample used in these laboratory-scale tests was taken from the PEP after $\mathrm{NaOH}$ had been added.

(c) Note that water was added all at once at the beginning of laboratory-scale runs, but was added gradually throughout the PEP runs as injected steam.

(d) Uncertainties are estimated for initial diluted through 24-hour samples using similar data from Integrated Test A, Batch 1.

(e) Triplicate samples were taken at this point. The concentration shown is the mean of the set.

(f) Duplicate samples were taken at this point. The concentration shown is the mean of the set.

$\left(\mathrm{NO}_{3}\right)$ Liquid tracer is nitrate for this column.

(Cl) Liquid tracer is chloride for this column.

" $\mathrm{n} / \mathrm{c} "$ = data that were measured only by Raman spectroscopy; for the sake of consistency, they are not included in this table or in data analysis

"n/m" = not measured

The \pm values are equal to half the laboratory uncertainty values (equivalent to a $95 \%$ confidence interval, or two standard deviations) that were supplied by the analytical organization for each concentration measurement. For duplicate or triplicate sets, the \pm values are standard deviations of the means. 
Table A.13. Sample Timing During PEP Integrated Test B

\begin{tabular}{|c|c|c|}
\hline \multirow[b]{2}{*}{ Point in Process } & \multicolumn{2}{|c|}{ Sample Date and Time } \\
\hline & Batch 1 in Tank T02A & Batch 2 in Tank T02A \\
\hline Feed & $2 / 2 / 09$ & $2 / 2 / 09$ \\
\hline Before $\mathrm{NaOH}$ & $3 / 12 / 09 \quad 20: 49$ & $3 / 15 / 09 \quad 14: 03$ \\
\hline After $\mathrm{NaOH}$ & $3 / 12 / 09 \quad 22: 51$ & $3 / 15 / 09 \quad 17: 12$ \\
\hline At $88^{\circ} \mathrm{C}$ & 3/13/09 03:07 & 3/15/09 19:03 \\
\hline $\begin{array}{l}98^{\circ} \mathrm{C} \text { reached at the } \\
\text { prototypic } \mathrm{TC}^{(\mathrm{a})}\end{array}$ & 3/13/09 03:56 & $3 / 15 / 09 \quad 19: 50$ \\
\hline $0 \mathrm{hr}$ at $98^{\circ} \mathrm{C}$, sample & 3/13/09 03:59 & $3 / 15 / 09 \quad 19: 55$ \\
\hline $1 \mathrm{hr}$ & 3/13/09 04:59 & $3 / 15 / 09 \quad 20: 52$ \\
\hline $2 \mathrm{hr}$ & 3/13/09 05:59 & $3 / 15 / 09 \quad 21: 51$ \\
\hline $4 \mathrm{hr}$ & 3/13/09 07:57 & $3 / 15 / 09 \quad 23: 50$ \\
\hline $8 \mathrm{hr}$ & $3 / 13 / 09 \quad 11: 58$ & 3/16/09 03:51 \\
\hline $10 \mathrm{hr}$ & $3 / 13 / 09 \quad 13: 58$ & 3/16/09 05:51 \\
\hline $12 \mathrm{hr}$ & $3 / 13 / 09 \quad 15: 58$ & 3/16/09 07:52 \\
\hline $14 \mathrm{hr}$ & $3 / 13 / 09 \quad 17: 58$ & 3/16/09 09:51 \\
\hline $16 \mathrm{hr}$ & $3 / 13 / 09 \quad 20: 54$ & $3 / 16 / 09 \quad 11: 52$ \\
\hline
\end{tabular}


Table A.14. Sample Timing During Laboratory-Scale Integrated Test B

\begin{tabular}{|c|c|c|}
\hline \multirow[b]{2}{*}{ Point in Process } & \multicolumn{2}{|c|}{ Sample Date and Time } \\
\hline & Laboratory-Scale Test B-1 & Laboratory-Scale Test B-2 \\
\hline Feed (PEP) & $2 / 2 / 09$ & $2 / 2 / 09$ \\
\hline Before $\mathrm{NaOH}$ (PEP) & $3 / 15 / 09 \quad 14: 03$ & $3 / 15 / 09 \quad 14: 03$ \\
\hline After $\mathrm{NaOH}$ (PEP) & $3 / 15 / 09 \quad 17: 12$ & $3 / 15 / 09 \quad 17: 12$ \\
\hline Initial diluted & 3/19/09 08:45 & 3/19/09 08:30 \\
\hline At $88^{\circ} \mathrm{C}$ & 3/19/09 11:33 & 3/19/09 11:38 \\
\hline $0 \mathrm{hr}$ at $98^{\circ} \mathrm{C}$ & $3 / 19 / 09 \quad 12: 30$ & $3 / 19 / 09 \quad 12: 35$ \\
\hline $1 \mathrm{hr}$ & 3/19/09 13:30 & $3 / 19 / 09 \quad 13: 35$ \\
\hline $2 \mathrm{hr}$ & $3 / 19 / 09 \quad 14: 30$ & $3 / 19 / 09 \quad 14: 35$ \\
\hline $4 \mathrm{hr}$ & $3 / 19 / 09 \quad 16: 30$ & $3 / 19 / 09 \quad 16: 35$ \\
\hline $8 \mathrm{hr}$ & $3 / 19 / 09 \quad 20: 30$ & $3 / 19 / 09 \quad 20: 37$ \\
\hline $10 \mathrm{hr}$ & $3 / 19 / 09 \quad 22: 30$ & $3 / 19 / 09 \quad 22: 35$ \\
\hline $12 \mathrm{hr}$ & $3 / 20 / 09 \quad 00: 30$ & $3 / 20 / 09 \quad 00: 35$ \\
\hline $14 \mathrm{hr}$ & $3 / 20 / 09 \quad 02: 30$ & $3 / 20 / 09 \quad 02: 35$ \\
\hline $16 \mathrm{hr}$ & $3 / 20 / 09 \quad 04: 30$ & 3/20/09 05:00 \\
\hline $18 \mathrm{hr}$ & 3/20/09 06:30 & $3 / 20 / 09 \quad 06: 50$ \\
\hline $20 \mathrm{hr}$ & 3/20/09 09:30 & $3 / 20 / 09 \quad 09: 35$ \\
\hline $22 \mathrm{hr}$ & $\mathrm{n} / \mathrm{m}$ & $\mathrm{n} / \mathrm{m}$ \\
\hline $24 \mathrm{hr}$ & $3 / 20 / 09 \quad 12: 30$ & $3 / 20 / 09 \quad 12: 35$ \\
\hline After cooling & $\mathrm{n} / \mathrm{m}$ & $\mathrm{n} / \mathrm{m}$ \\
\hline
\end{tabular}


Table A.15. Temperatures During Digestion Period For Integrated Test B and Related Laboratory Tests

\begin{tabular}{|c|c|c|}
\hline \multirow[b]{2}{*}{ Point in Process } & \multicolumn{2}{|c|}{$\begin{array}{c}\text { Temperature }\left({ }^{\circ} \mathrm{C}\right) \\
\pm 1 \text { Standard Deviation }\end{array}$} \\
\hline & Batch 1 in Tank T02A & Batch 2 in Tank T02A \\
\hline \multicolumn{3}{|c|}{$\begin{array}{l}\text { PEP test from start to end of digestion } \\
\text { (submerged instruments) }^{(a)}\end{array}$} \\
\hline Prototypic RTD & $97.2 \pm 2.0$ & $97.7 \pm 0.5$ \\
\hline RTD trees & $97.2 \pm 2.0$ & $97.7 \pm 0.5$ \\
\hline $\begin{array}{l}\text { Resistance temperature } \\
\text { detectors (RTDs) near } \\
\text { vessel walls }\end{array}$ & $97.3 \pm 2.1$ & $97.9 \pm 0.6$ \\
\hline RTDs near PJMs & $97.6 \pm 2.1$ & $98.1 \pm 0.8$ \\
\hline $\begin{array}{l}\text { All submerged } \\
\text { temperature instruments }\end{array}$ & $97.3 \pm 2.0$ & $97.8 \pm 0.6$ \\
\hline $\begin{array}{l}\text { Laboratory-Scale Test } \\
\text { B-1 }{ }^{(\text {b) }}\end{array}$ & $\mathrm{n} / \mathrm{a}$ & $98.0 \pm 0.1$ \\
\hline $\begin{array}{l}\text { Laboratory-Scale Test } \\
\text { B- } 2^{(\text {b) }}\end{array}$ & $\mathrm{n} / \mathrm{a}$ & $98.0 \pm 0.1$ \\
\hline \multicolumn{3}{|c|}{$\begin{array}{l}\text { (a) The standard deviations for PEP temperatures include temperature cycling and differences } \\
\text { between sensors. Data were sampled once per minute from all submerged sensors in the set. } \\
\text { (b) Laboratory-test temperatures are measured at a single point in the vessel. The values shown are } \\
\text { an average } \pm 1 \text { standard deviation for the set of temperatures measured at all sampling times } \\
\text { during digestion. } \\
\text { "n/a" = not applicable (the laboratory tests did not use slurry from this vessel) }\end{array}$} \\
\hline
\end{tabular}


Table A.16. Slurry Density During Caustic-Leach Integrated Test B

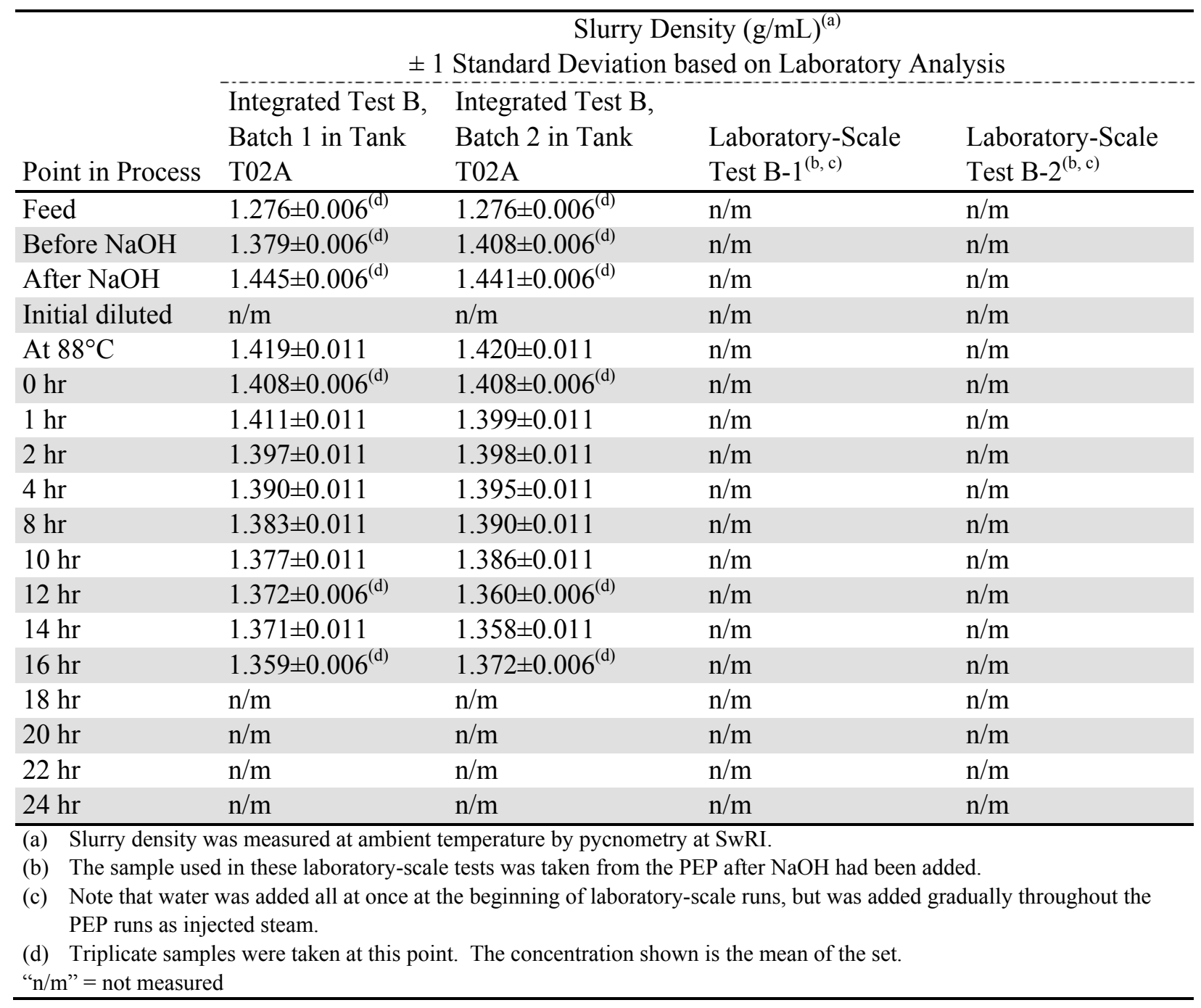


Table A.17. Liquid Density During Caustic-Leach Integrated Test B

\begin{tabular}{|c|c|c|c|c|}
\hline \multirow[b]{2}{*}{ Point in Process } & \multicolumn{4}{|c|}{$\begin{array}{c}\text { Liquid Density }(\mathrm{g} / \mathrm{mL})^{(\mathrm{a})} \\
1 \text { Standard Deviation based on Laboratory Ar }\end{array}$} \\
\hline & $\begin{array}{l}\text { Integrated Test B, } \\
\text { Batch } 1 \text { in Tank } \\
\text { T02A }\end{array}$ & $\begin{array}{l}\text { Integrated Test B, } \\
\text { Batch } 2 \text { in Tank } \\
\text { T02A }\end{array}$ & $\begin{array}{l}\text { Laboratory-Scale } \\
\text { Test B-1 } 1^{(\mathrm{b}, \mathrm{c}, \mathrm{d})}\end{array}$ & $\begin{array}{l}\text { Laboratory-Scale } \\
\text { Test B-2 }{ }^{(b, c, d)}\end{array}$ \\
\hline Feed & $1.233 \pm 0.005^{(\mathrm{e})}$ & $1.233 \pm 0.005^{(\mathrm{e})}$ & $1.233 \pm 0.005^{(\mathrm{e})}$ & $1.233 \pm 0.005^{(\mathrm{e})}$ \\
\hline Before $\mathrm{NaOH}$ & $1.234 \pm 0.005^{(\mathrm{e})}$ & $1.235 \pm 0.005^{(\mathrm{e})}$ & $1.235 \pm 0.005^{(\mathrm{e})}$ & $1.233 \pm 0.005^{(\mathrm{e})}$ \\
\hline After $\mathrm{NaOH}$ & $1.382 \pm 0.006^{(\mathrm{e})}$ & $1.377 \pm 0.006^{(\mathrm{e})}$ & $\mathrm{n} / \mathrm{m}$ & $\mathrm{n} / \mathrm{m}$ \\
\hline Initial diluted & $\mathrm{n} / \mathrm{m}$ & $\mathrm{n} / \mathrm{m}$ & $1.351 \pm 0.010$ & $1.348 \pm 0.010$ \\
\hline At $88^{\circ} \mathrm{C}$ & $1.366 \pm 0.011$ & $1.367 \pm 0.011$ & $1.351 \pm 0.010$ & $1.351 \pm 0.010$ \\
\hline $0 \mathrm{hr}$ & $1.347 \pm 0.006^{(\mathrm{e})}$ & $1.355 \pm 0.006^{(\mathrm{e})}$ & $1.354 \pm 0.010$ & $1.357 \pm 0.010$ \\
\hline $1 \mathrm{hr}$ & $1.358 \pm 0.011$ & $1.354 \pm 0.011$ & $1.357 \pm 0.010$ & $1.354 \pm 0.010$ \\
\hline $2 \mathrm{hr}$ & $1.349 \pm 0.011$ & $1.346 \pm 0.011$ & $1.354 \pm 0.010$ & $1.353 \pm 0.010$ \\
\hline $4 \mathrm{hr}$ & $1.351 \pm 0.011$ & $1.345 \pm 0.011$ & $1.356 \pm 0.010$ & $1.370 \pm 0.010$ \\
\hline $8 \mathrm{hr}$ & $1.350 \pm 0.011$ & $1.339 \pm 0.011$ & $1.355 \pm 0.010$ & $1.367 \pm 0.010$ \\
\hline $10 \mathrm{hr}$ & $1.343 \pm 0.011$ & $1.339 \pm 0.011$ & $1.359 \pm 0.010$ & $1.359 \pm 0.010$ \\
\hline $12 \mathrm{hr}$ & $1.337 \pm 0.006^{(\mathrm{e})}$ & $1.338 \pm 0.006^{(\mathrm{e})}$ & $1.359 \pm 0.010$ & $1.357 \pm 0.010$ \\
\hline $14 \mathrm{hr}$ & $1.324 \pm 0.011$ & $1.338 \pm 0.010$ & $1.356 \pm 0.010$ & $1.356 \pm 0.010$ \\
\hline $16 \mathrm{hr}$ & $1.318 \pm 0.006^{(\mathrm{e})}$ & $1.330 \pm 0.006^{(\mathrm{e})}$ & $1.361 \pm 0.010$ & $1.359 \pm 0.010$ \\
\hline $18 \mathrm{hr}$ & $\mathrm{n} / \mathrm{m}$ & $\mathrm{n} / \mathrm{m}$ & $1.361 \pm 0.010$ & $1.359 \pm 0.010$ \\
\hline $20 \mathrm{hr}$ & $\mathrm{n} / \mathrm{m}$ & $\mathrm{n} / \mathrm{m}$ & $1.364 \pm 0.010$ & $1.362 \pm 0.010$ \\
\hline $22 \mathrm{hr}$ & $\mathrm{n} / \mathrm{m}$ & $\mathrm{n} / \mathrm{m}$ & $\mathrm{n} / \mathrm{m}$ & $\mathrm{n} / \mathrm{m}$ \\
\hline $24 \mathrm{hr}$ & $\mathrm{n} / \mathrm{m}$ & $\mathrm{n} / \mathrm{m}$ & $1.363 \pm 0.010$ & $1.362 \pm 0.010$ \\
\hline \multicolumn{5}{|c|}{ (a) Liquid density was measured at ambient temperature by pycnometry at SwRI. } \\
\hline \multicolumn{5}{|c|}{ (b) The sample used in these laboratory-scale tests was taken from the PEP after $\mathrm{NaOH}$ had been } \\
\hline \multicolumn{5}{|l|}{ (c) Note that water } \\
\hline \multicolumn{5}{|c|}{. } \\
\hline $\begin{array}{l}\text { (e) Triplicate samp } \\
\text { "n } / \mathrm{m} "=\text { not measure }\end{array}$ & were taken at this point & The concentration shown & the mean of the set. & \\
\hline
\end{tabular}


Table A.18. Weight Fraction UDS During Caustic-Leach Integrated Test B

\begin{tabular}{|c|c|c|c|c|}
\hline \multirow[b]{2}{*}{ Point in Process } & \multicolumn{4}{|c|}{$\begin{array}{c}\text { Slurry Solid-Phase Weight Fraction (wt\% undissolved solids) } \\
\pm 1 \text { Standard Deviation from Laboratory Analysis }\end{array}$} \\
\hline & $\begin{array}{l}\text { Integrated Test B, } \\
\text { Batch } 1 \text { in Tank } \\
\text { T02A }\end{array}$ & $\begin{array}{l}\text { Integrated Test B, } \\
\text { Batch } 2 \text { in Tank } \\
\text { T02A }\end{array}$ & $\begin{array}{l}\text { Laboratory-Scale } \\
\text { Test B-1 } 1^{(\mathrm{b}, \mathrm{c})}\end{array}$ & $\begin{array}{l}\text { Laboratory-Scale } \\
\text { Test B-2 } 2^{(\mathrm{b}, \mathrm{c})}\end{array}$ \\
\hline Feed & $5.20 \% \pm 0.03 \%{ }^{(\mathrm{d})}$ & $5.20 \% \pm 0.03 \%{ }^{(\mathrm{d})}$ & $5.20 \% \pm 0.03 \%{ }^{(\mathrm{d})}$ & $5.20 \% \pm 0.03 \%{ }^{(\mathrm{d})}$ \\
\hline Before $\mathrm{NaOH}$ & $20.3 \% \pm 0.1 \%{ }^{(\mathrm{d})}$ & $21.8 \% \pm 0.1 \%{ }^{(\mathrm{d})}$ & $21.8 \% \pm 0.1 \%{ }^{(\mathrm{d})}$ & $21.8 \% \pm 0.1 \%{ }^{(\mathrm{d})}$ \\
\hline After $\mathrm{NaOH}$ & $6.93 \% \pm 0.03 \%{ }^{(\mathrm{d})}$ & $8.37 \% \pm 0.04 \%{ }^{(\mathrm{d})}$ & $\mathrm{n} / \mathrm{m}$ & $\mathrm{n} / \mathrm{m}$ \\
\hline Initial diluted & $\mathrm{n} / \mathrm{m}$ & $\mathrm{n} / \mathrm{m}$ & $5.74 \% \pm 0.06 \%$ & $5.67 \% \pm 0.06 \%$ \\
\hline At $88^{\circ} \mathrm{C}$ & $6.44 \% \pm 0.05 \%$ & $7.37 \% \pm 0.06 \%$ & $\mathrm{n} / \mathrm{m}$ & $\mathrm{n} / \mathrm{m}$ \\
\hline $0 \mathrm{hr}$ & $5.60 \% \pm 0.03 \%{ }^{(3)}$ & $6.68 \% \pm 0.03 \%{ }^{(\mathrm{d})}$ & $\mathrm{n} / \mathrm{m}$ & $\mathrm{n} / \mathrm{m}$ \\
\hline $1 \mathrm{hr}$ & $5.69 \% \pm 0.05 \%$ & $6.77 \% \pm 0.06 \%$ & $\mathrm{n} / \mathrm{m}$ & $\mathrm{n} / \mathrm{m}$ \\
\hline $2 \mathrm{hr}$ & $5.52 \% \pm 0.05 \%$ & $6.41 \% \pm 0.05 \%$ & $\mathrm{n} / \mathrm{m}$ & $\mathrm{n} / \mathrm{m}$ \\
\hline $4 \mathrm{hr}$ & $5.31 \% \pm 0.05 \%$ & $6.34 \% \pm 0.05 \%$ & $\mathrm{n} / \mathrm{m}$ & $\mathrm{n} / \mathrm{m}$ \\
\hline $8 \mathrm{hr}$ & $5.12 \% \pm 0.04 \%$ & $5.93 \% \pm 0.05 \%$ & $\mathrm{n} / \mathrm{m}$ & $\mathrm{n} / \mathrm{m}$ \\
\hline $10 \mathrm{hr}$ & $5.07 \% \pm 0.04 \%$ & $5.74 \% \pm 0.05 \%$ & $\mathrm{n} / \mathrm{m}$ & $\mathrm{n} / \mathrm{m}$ \\
\hline $12 \mathrm{hr}$ & $4.84 \% \pm 0.02 \%{ }^{(\mathrm{d})}$ & $5.75 \% \pm 0.03 \%{ }^{(\mathrm{d})}$ & $\mathrm{n} / \mathrm{m}$ & $\mathrm{n} / \mathrm{m}$ \\
\hline $14 \mathrm{hr}$ & $4.13 \% \pm 0.04 \%$ & $5.65 \% \pm 0.05 \%$ & $\mathrm{n} / \mathrm{m}$ & $\mathrm{n} / \mathrm{m}$ \\
\hline $16 \mathrm{hr}$ & $4.50 \% \pm 0.02 \%{ }^{(\mathrm{d})}$ & $5.64 \% \pm 0.03 \%{ }^{(\mathrm{d})}$ & $\mathrm{n} / \mathrm{m}$ & $\mathrm{n} / \mathrm{m}$ \\
\hline $18 \mathrm{hr}$ & $\mathrm{n} / \mathrm{m}$ & $\mathrm{n} / \mathrm{m}$ & $\mathrm{n} / \mathrm{m}$ & $\mathrm{n} / \mathrm{m}$ \\
\hline $20 \mathrm{hr}$ & $\mathrm{n} / \mathrm{m}$ & $\mathrm{n} / \mathrm{m}$ & $\mathrm{n} / \mathrm{m}$ & $\mathrm{n} / \mathrm{m}$ \\
\hline $22 \mathrm{hr}$ & $\mathrm{n} / \mathrm{m}$ & $\mathrm{n} / \mathrm{m}$ & $\mathrm{n} / \mathrm{m}$ & $\mathrm{n} / \mathrm{m}$ \\
\hline $24 \mathrm{hr}$ & $\mathrm{n} / \mathrm{m}$ & $\mathrm{n} / \mathrm{m}$ & $5.01 \% \pm 0.06 \%^{(\mathrm{e})}$ & $4.80 \% \pm 0.06 \%{ }^{(\mathrm{e})}$ \\
\hline \multicolumn{5}{|c|}{$\begin{array}{l}\text { (a) The wt } \% \text { UDS was measured by drying and weighing at SwRI. Wt } \% \text { UDS is mass undissolved solid per mass as-sampled } \\
\text { slurry. }\end{array}$} \\
\hline \multicolumn{5}{|c|}{ (b) The sample used in these laboratory-scale tests was taken from the PEP after $\mathrm{NaOH}$ had been added. } \\
\hline \multicolumn{5}{|c|}{$\begin{array}{l}\text { Note that water was added all at once at th } \\
\text { PEP runs as injected steam. }\end{array}$} \\
\hline \multicolumn{5}{|c|}{ (d) Triplicate samples were taken at this point. The concentration shown is the mean of the set. } \\
\hline \multicolumn{5}{|c|}{$\begin{array}{l}\text { (e) The samples were removed when the vessel slurry had been cooled to a temperature of }<60^{\circ} \mathrm{C} \text { (approximate cooling time } \\
\text { unknown). }\end{array}$} \\
\hline
\end{tabular}


Table A.19. Water in Liquid Phase During Caustic-Leach Integrated Test B

\begin{tabular}{|c|c|c|c|c|}
\hline \multirow[b]{2}{*}{ Point in Process } & \multicolumn{4}{|c|}{$\begin{array}{l}\text { Concentration of } \mathrm{H}_{2} \mathrm{O}(\mathrm{wt} \%) \text { in Liquid Phase }{ }^{(\mathrm{a})} \\
\pm 1 \text { Standard Deviation from Laboratory Analysis }\end{array}$} \\
\hline & $\begin{array}{l}\text { Integrated Test B, } \\
\text { Batch } 1 \text { in Tank } \\
\text { T02A }\end{array}$ & $\begin{array}{l}\text { Integrated Test B, } \\
\text { Batch } 2 \text { in Tank } \\
\text { T02A }\end{array}$ & $\begin{array}{l}\text { Laboratory-Scale } \\
\text { Test B-1 }{ }^{(\mathrm{b}, \mathrm{c})}\end{array}$ & $\begin{array}{l}\text { Laboratory-Scale } \\
\text { Test B-2 }\end{array}$ \\
\hline Feed & $73.4 \% \pm 0.1 \%{ }^{(\mathrm{d})}$ & $73.4 \% \pm 0.1 \%{ }^{(\mathrm{d})}$ & $\mathrm{n} / \mathrm{m}$ & $\mathrm{n} / \mathrm{m}$ \\
\hline Before $\mathrm{NaOH}$ & $73.6 \% \pm 0.1 \%{ }^{(\mathrm{d})}$ & $73.0 \% \pm 0.1 \%{ }^{(\mathrm{d})}$ & $\mathrm{n} / \mathrm{m}$ & $\mathrm{n} / \mathrm{m}$ \\
\hline After $\mathrm{NaOH}$ & $59.2 \% \pm 0.2 \%{ }^{(\mathrm{d})}$ & $60.0 \% \pm 0.2 \%{ }^{(\mathrm{d})}$ & $\mathrm{n} / \mathrm{m}$ & $\mathrm{n} / \mathrm{m}$ \\
\hline Initial diluted & $\mathrm{n} / \mathrm{m}$ & $\mathrm{n} / \mathrm{m}$ & $\mathrm{n} / \mathrm{m}$ & $\mathrm{n} / \mathrm{m}$ \\
\hline At $88^{\circ} \mathrm{C}$ & $61.0 \% \pm 0.3 \%$ & $61.8 \% \pm 0.3 \%$ & $\mathrm{n} / \mathrm{m}$ & $\mathrm{n} / \mathrm{m}$ \\
\hline $0 \mathrm{hr}$ & $62.0 \% \pm 0.2 \%{ }^{(\mathrm{d})}$ & $62.3 \% \pm 0.2 \%{ }^{(\mathrm{d})}$ & $\mathrm{n} / \mathrm{m}$ & $\mathrm{n} / \mathrm{m}$ \\
\hline $1 \mathrm{hr}$ & $61.7 \% \pm 0.3 \%$ & $62.8 \% \pm 0.3 \%$ & $\mathrm{n} / \mathrm{m}$ & $\mathrm{n} / \mathrm{m}$ \\
\hline $2 \mathrm{hr}$ & $62.3 \% \pm 0.3 \%$ & $63.1 \% \pm 0.3 \%$ & $\mathrm{n} / \mathrm{m}$ & $\mathrm{n} / \mathrm{m}$ \\
\hline $4 \mathrm{hr}$ & $62.9 \% \pm 0.3 \%$ & $63.4 \% \pm 0.3 \%$ & $\mathrm{n} / \mathrm{m}$ & $\mathrm{n} / \mathrm{m}$ \\
\hline $8 \mathrm{hr}$ & $63.8 \% \pm 0.3 \%$ & $63.9 \% \pm 0.3 \%$ & $\mathrm{n} / \mathrm{m}$ & $\mathrm{n} / \mathrm{m}$ \\
\hline $10 \mathrm{hr}$ & $64.2 \% \pm 0.3 \%$ & $64.0 \% \pm 0.3 \%$ & $\mathrm{n} / \mathrm{m}$ & $\mathrm{n} / \mathrm{m}$ \\
\hline $12 \mathrm{hr}$ & $64.5 \% \pm 0.2 \%{ }^{(\mathrm{d})}$ & $64.5 \% \pm 0.2 \%{ }^{(\mathrm{d})}$ & $\mathrm{n} / \mathrm{m}$ & $\mathrm{n} / \mathrm{m}$ \\
\hline $14 \mathrm{hr}$ & $65.0 \% \pm 0.3 \%$ & $64.8 \% \pm 0.3 \%$ & $\mathrm{n} / \mathrm{m}$ & $\mathrm{n} / \mathrm{m}$ \\
\hline $16 \mathrm{hr}$ & $65.5 \% \pm 0.2 \%{ }^{(\mathrm{d})}$ & $65.1 \% \pm 0.2 \%{ }^{(\mathrm{d})}$ & $\mathrm{n} / \mathrm{m}$ & $\mathrm{n} / \mathrm{m}$ \\
\hline $18 \mathrm{hr}$ & $\mathrm{n} / \mathrm{m}$ & $\mathrm{n} / \mathrm{m}$ & $\mathrm{n} / \mathrm{m}$ & $\mathrm{n} / \mathrm{m}$ \\
\hline $20 \mathrm{hr}$ & $\mathrm{n} / \mathrm{m}$ & $\mathrm{n} / \mathrm{m}$ & $\mathrm{n} / \mathrm{m}$ & $\mathrm{n} / \mathrm{m}$ \\
\hline $22 \mathrm{hr}$ & $\mathrm{n} / \mathrm{m}$ & $\mathrm{n} / \mathrm{m}$ & $\mathrm{n} / \mathrm{m}$ & $\mathrm{n} / \mathrm{m}$ \\
\hline $24 \mathrm{hr}$ & $\mathrm{n} / \mathrm{m}$ & $\mathrm{n} / \mathrm{m}$ & $\mathrm{n} / \mathrm{m}$ & $\mathrm{n} / \mathrm{m}$ \\
\hline $\begin{array}{l}\text { (a) } \mathrm{Wt} \% \text { water is (1 } \\
\mathrm{SwRI} . \mathrm{Wt} \% \text { wo } \\
\text { (b) The sample use } \\
\text { (c) Note that water } \\
\text { PEP runs as inj } \\
\text { (d) Triplicate samp } \\
\text { " } \mathrm{n} / \mathrm{m} \text { " = not measure }\end{array}$ & $\begin{array}{l}\mathrm{wt} \% \text { dissolved solids). } \\
\mathrm{r} \text { is mass water/mass lic } \\
\mathrm{n} \text { these laboratory-scale } \\
\text { as added all at once at th } \\
\text { ed steam. } \\
\text { were taken at this point }\end{array}$ & $\begin{array}{l}\text { Dissolved solids were mea } \\
\text { id. } \\
\text { ests was taken from the PI } \\
\text { beginning of laboratory-s } \\
\text { The concentration shown }\end{array}$ & $\begin{array}{l}\text { afted by drying and weig } \\
\text { a le runs, but wad been added } \\
\text { the mean of the set. }\end{array}$ & $\begin{array}{l}\text { d. } \\
\text { dually throughout the }\end{array}$ \\
\hline
\end{tabular}


Table A.20. Molar Concentration of Free Hydroxide During Caustic-Leach Integrated Test B

\begin{tabular}{|c|c|c|c|c|}
\hline \multirow[b]{2}{*}{ Point in Process } & \multicolumn{4}{|c|}{$\begin{array}{c}\text { Concentration of Free Hydroxide (mole/L liquid) in Liquid Phase }{ }^{(\mathrm{a})} \\
\pm 1 \text { Standard Deviation from Laboratory Analysis }\end{array}$} \\
\hline & $\begin{array}{l}\text { Integrated Test B, } \\
\text { Batch } 1 \text { in Tank } \\
\text { T02A }\end{array}$ & $\begin{array}{l}\text { Integrated Test B, } \\
\text { Batch } 2 \text { in Tank } \\
\text { T02A }\end{array}$ & $\begin{array}{l}\text { Laboratory-Scale } \\
\text { Test B-1 }{ }^{(\mathrm{b}, \mathrm{c})}\end{array}$ & $\begin{array}{l}\text { Laboratory-Scale } \\
\text { Test B-2 }\end{array}$ \\
\hline Feed & $0.92 \pm 0.02^{(\mathrm{d})}$ & $0.92 \pm 0.01^{(\mathrm{d})}$ & $0.92 \pm 0.01^{(\mathrm{d})}$ & $0.92 \pm 0.01^{(\mathrm{d})}$ \\
\hline Before $\mathrm{NaOH}$ & $1.01 \pm 0.01^{(\mathrm{d})}$ & $1.19 \pm 0.02^{(\mathrm{d})}$ & $1.19 \pm 0.02^{(\mathrm{d})}$ & $1.19 \pm 0.02^{(\mathrm{d})}$ \\
\hline After $\mathrm{NaOH}$ & $7.69 \pm 0.11^{(\mathrm{d})}$ & $7.15 \pm 0.10^{(\mathrm{d})}$ & $\mathrm{n} / \mathrm{m}$ & $\mathrm{n} / \mathrm{m}$ \\
\hline Initial diluted & $\mathrm{n} / \mathrm{m}$ & $\mathrm{n} / \mathrm{m}$ & $\mathrm{n} / \mathrm{m}$ & $\mathrm{n} / \mathrm{m}$ \\
\hline At $88^{\circ} \mathrm{C}$ & $7.00 \pm 0.18$ & $6.30 \pm 0.16$ & $\mathrm{n} / \mathrm{m}$ & $\mathrm{n} / \mathrm{m}$ \\
\hline $0 \mathrm{hr}$ & $6.56 \pm 0.09^{(\mathrm{d})}$ & $6.35 \pm 0.09^{(\mathrm{d})}$ & $5.82 \pm 0.15$ & $5.37 \pm 0.13$ \\
\hline $1 \mathrm{hr}$ & $6.76 \pm 0.17$ & $6.33 \pm 0.16$ & $5.67 \pm 0.14$ & $5.44 \pm 0.14$ \\
\hline $2 \mathrm{hr}$ & $6.51 \pm 0.16$ & $6.19 \pm 0.15$ & $5.65 \pm 0.14$ & $5.44 \pm 0.14$ \\
\hline $4 \mathrm{hr}$ & $6.34 \pm 0.16$ & $5.97 \pm 0.15$ & $5.40 \pm 0.13$ & $5.45 \pm 0.14$ \\
\hline $8 \mathrm{hr}$ & $6.05 \pm 0.15$ & $5.71 \pm 0.14$ & $5.56 \pm 0.14$ & $5.74 \pm 0.14$ \\
\hline $10 \mathrm{hr}$ & $5.78 \pm 0.14$ & $5.62 \pm 0.14$ & $5.56 \pm 0.14$ & $5.53 \pm 0.14$ \\
\hline $12 \mathrm{hr}$ & $5.79 \pm 0.08^{(\mathrm{d})}$ & $5.46 \pm 0.08^{(\mathrm{d})}$ & $5.31 \pm 0.13$ & $5.54 \pm 0.14$ \\
\hline $14 \mathrm{hr}$ & $5.52 \pm 0.14$ & $5.36 \pm 0.13$ & $5.64 \pm 0.14$ & $5.37 \pm 0.13$ \\
\hline $16 \mathrm{hr}$ & $5.40 \pm 0.08^{(\mathrm{d})}$ & $5.25 \pm 0.08^{(\mathrm{d})}$ & $5.74 \pm 0.14$ & $5.60 \pm 0.14$ \\
\hline $18 \mathrm{hr}$ & $\mathrm{n} / \mathrm{m}$ & $\mathrm{n} / \mathrm{m}$ & $5.55 \pm 0.14$ & $5.64 \pm 0.14$ \\
\hline $20 \mathrm{hr}$ & $\mathrm{n} / \mathrm{m}$ & $\mathrm{n} / \mathrm{m}$ & $4.72 \pm 0.12$ & $5.56 \pm 0.14$ \\
\hline $22 \mathrm{hr}$ & $\mathrm{n} / \mathrm{m}$ & $\mathrm{n} / \mathrm{m}$ & $\mathrm{n} / \mathrm{m}$ & $\mathrm{n} / \mathrm{m}$ \\
\hline $24 \mathrm{hr}$ & $\mathrm{n} / \mathrm{m}$ & $\mathrm{n} / \mathrm{m}$ & $5.56 \pm 0.14$ & $5.39 \pm 0.13$ \\
\hline \multicolumn{5}{|c|}{$\begin{array}{l}\text { (a) Free hydroxide was measured in molarity by titration at Analytical Support Operations (ASO) (PNNL). The results for } \\
\text { the first inflection point were used to represent free hydroxide. }\end{array}$} \\
\hline \multirow{2}{*}{\multicolumn{5}{|c|}{$\begin{array}{l}\text { (b) The sample used in these laboratory-scale tests was taken from the } \mathrm{PEP} \text { after } \mathrm{NaOH} \text { had been added. } \\
\text { (c) Note that water was added all at once at the beginning of laboratory-scale runs, but was added gradually throughout the } \\
\text { PEP runs as injected steam. }\end{array}$}} \\
\hline & & & & \\
\hline \multirow{2}{*}{\multicolumn{5}{|c|}{$\begin{array}{l}\text { (d) Triplicate samples were taken at this point. The concentration shown is the mean of the set. } \\
\text { " } \mathrm{n} / \mathrm{m} "=\text { not measured }\end{array}$}} \\
\hline & & & & \\
\hline \multicolumn{5}{|c|}{$\begin{array}{l}\text { The } \pm \text { values are equal to half the laboratory uncertainty values (equivalent to a } 95 \% \text { confidence interval, or two standard } \\
\text { deviations) that were supplied by the analytical organization for each concentration measurement. In the cases where } \\
\text { triplicate samples were taken, the concentrations are means of the set, and the } \pm \text { values are standard deviations of the means. }\end{array}$} \\
\hline
\end{tabular}


Table A.21. Mass Concentration of Aluminum in Bulk Slurry During Caustic-Leach Integrated Test B

\begin{tabular}{|c|c|c|c|c|}
\hline \multirow[b]{2}{*}{ Point in Process } & \multicolumn{4}{|c|}{$\begin{array}{c}\text { Concentration of Aluminum }(\mu \mathrm{g} / \mathrm{g}) \text { in Bulk Slurry } \\
\pm 1 \text { Standard Deviation from Laboratory Analysis }\end{array}$} \\
\hline & $\begin{array}{l}\text { Integrated Test B, } \\
\text { Batch } 1 \text { in Tank } \\
\text { T02A }\end{array}$ & $\begin{array}{l}\text { Integrated Test B, } \\
\text { Batch } 2 \text { in Tank } \\
\text { T02A }\end{array}$ & $\begin{array}{l}\text { Laboratory-Scale } \\
\text { Test B-1 }{ }^{(\mathrm{b}, \mathrm{c}, \mathrm{d})}\end{array}$ & $\begin{array}{l}\text { Laboratory-Scale } \\
\text { Test B-2 }{ }^{(\mathrm{b}, \mathrm{c}, \mathrm{d})}\end{array}$ \\
\hline Feed & $18794 \pm 378$ & $18794 \pm 378$ & $18794 \pm 378$ & $18794 \pm 378$ \\
\hline Before $\mathrm{NaOH}$ & $57833 \pm 1091$ & $63323 \pm 1428$ & $63323 \pm 1244$ & $63323 \pm 1244$ \\
\hline After $\mathrm{NaOH}$ & $29696 \pm 417$ & $35727 \pm 564$ & $\mathrm{n} / \mathrm{m}$ & $\mathrm{n} / \mathrm{m}$ \\
\hline Initial diluted & $\mathrm{n} / \mathrm{m}$ & $\mathrm{n} / \mathrm{m}$ & $26800 \pm 904$ & $25700 \pm 867$ \\
\hline At $88^{\circ} \mathrm{C}$ & $\mathrm{n} / \mathrm{m}$ & $33809 \pm 892$ & $\mathrm{n} / \mathrm{m}$ & $\mathrm{n} / \mathrm{m}$ \\
\hline $0 \mathrm{hr}$ & $28867 \pm 404$ & $32398 \pm 486$ & $\mathrm{n} / \mathrm{m}$ & $\mathrm{n} / \mathrm{m}$ \\
\hline $1 \mathrm{hr}$ & $\mathrm{n} / \mathrm{m}$ & $32436 \pm 840$ & $\mathrm{n} / \mathrm{m}$ & $\mathrm{n} / \mathrm{m}$ \\
\hline $2 \mathrm{hr}$ & $\mathrm{n} / \mathrm{m}$ & $32105 \pm 820$ & $\mathrm{n} / \mathrm{m}$ & $\mathrm{n} / \mathrm{m}$ \\
\hline $4 \mathrm{hr}$ & $26770 \pm 621$ & $32374 \pm 815$ & $\mathrm{n} / \mathrm{m}$ & $\mathrm{n} / \mathrm{m}$ \\
\hline $8 \mathrm{hr}$ & $26005 \pm 592$ & $32536 \pm 800$ & $\mathrm{n} / \mathrm{m}$ & $\mathrm{n} / \mathrm{m}$ \\
\hline $10 \mathrm{hr}$ & $\mathrm{n} / \mathrm{m}$ & $31008 \pm 745$ & $\mathrm{n} / \mathrm{m}$ & $\mathrm{n} / \mathrm{m}$ \\
\hline $12 \mathrm{hr}$ & $25558 \pm 332$ & $31009 \pm 433$ & $\mathrm{n} / \mathrm{m}$ & $\mathrm{n} / \mathrm{m}$ \\
\hline $14 \mathrm{hr}$ & $\mathrm{n} / \mathrm{m}$ & $31099 \pm 741$ & $\mathrm{n} / \mathrm{m}$ & $\mathrm{n} / \mathrm{m}$ \\
\hline $16 \mathrm{hr}$ & $24758 \pm 321$ & $30924 \pm 423$ & $\mathrm{n} / \mathrm{m}$ & $\mathrm{n} / \mathrm{m}$ \\
\hline $18 \mathrm{hr}$ & $\mathrm{n} / \mathrm{m}$ & $\mathrm{n} / \mathrm{m}$ & $\mathrm{n} / \mathrm{m}$ & $\mathrm{n} / \mathrm{m}$ \\
\hline $20 \mathrm{hr}$ & $\mathrm{n} / \mathrm{m}$ & $\mathrm{n} / \mathrm{m}$ & $\mathrm{n} / \mathrm{m}$ & $\mathrm{n} / \mathrm{m}$ \\
\hline $22 \mathrm{hr}$ & $\mathrm{n} / \mathrm{m}$ & $\mathrm{n} / \mathrm{m}$ & $\mathrm{n} / \mathrm{m}$ & $\mathrm{n} / \mathrm{m}$ \\
\hline $24 \mathrm{hr}$ & $\mathrm{n} / \mathrm{m}$ & $\mathrm{n} / \mathrm{m}$ & $28300 \pm 955^{(\mathrm{e})}$ & $28700 \pm 968^{(\mathrm{e})}$ \\
\hline
\end{tabular}

(a) For the PEP tests, aluminum was measured by ICP at SwRI for centrifuged solids and for the decanted liquid, in units of $\mu \mathrm{g} / \mathrm{g}$. The bulk slurry Al concentration was calculated from these measured concentrations and from the masses of centrifuged solids and liquid, which were weighed at PNNL.

(b) The sample used in these laboratory-scale tests was taken from the PEP after $\mathrm{NaOH}$ had been added.

(c) Note that water was added all at once at the beginning of laboratory-scale runs, but was added gradually throughout the PEP runs as injected steam.

(d) Uncertainties are estimated for initial diluted through 24-hour samples using similar data from Integrated Test B, Batch 2.

(e) The samples were removed when the vessel slurry had been cooled to a temperature of $<60^{\circ} \mathrm{C}$ (approximate cooling time unknown).

" $\mathrm{n} / \mathrm{m}$ " = not measured

The \pm values are standard deviations calculated by linearized error propagation methods. The method used to estimate the uncertainty of the centrifuged solids weight fraction depends on measurements for the triplicate data sets. The different number of triplicate data sets in PEP and laboratory-scale tests causes differences in centrifuged solids fraction uncertainty, and therefore in slurry concentration uncertainty, for the same sample, when determined from PEP test data sets and from laboratory-scale test data sets. See Appendix C of WTP-RPT-186, Rev. 0, EFRT M12 Issue Resolution: Caustic-Leach Rate Constants from PEP and Laboratory-Scale Tests for more information. 
Table A.22. Mass Concentration of Dissolved Aluminum During Caustic-Leach Integrated Test B

\begin{tabular}{|c|c|c|c|c|}
\hline \multirow[b]{2}{*}{ Point in Process } & \multicolumn{4}{|c|}{$\begin{array}{l}\text { Concentration of Aluminum }(\mu \mathrm{g} / \mathrm{g}) \text { in Liquid Phase }{ }^{(\mathrm{a})} \\
\pm 1 \text { Standard Deviation from Laboratory Analysis }\end{array}$} \\
\hline & $\begin{array}{l}\text { Integrated Test B, } \\
\text { Batch } 1 \text { in Tank } \\
\text { T02A }\end{array}$ & $\begin{array}{l}\text { Integrated Test B, } \\
\text { Batch } 2 \text { in Tank } \\
\text { T02A }\end{array}$ & $\begin{array}{l}\text { Laboratory-Scale } \\
\text { Test B-1 } 1^{(\mathrm{b}, \mathrm{c}, \mathrm{d})}\end{array}$ & $\begin{array}{l}\text { Laboratory-Scale } \\
\text { Test B-2 } 2^{(\mathrm{b}, \mathrm{c}, \mathrm{d})}\end{array}$ \\
\hline Feed & $3163 \pm 55^{(\mathrm{e})}$ & $3163 \pm 55^{(\mathrm{e})}$ & $3163 \pm 55^{(\mathrm{e})}$ & $3163 \pm 55^{(\mathrm{e})}$ \\
\hline Before $\mathrm{NaOH}$ & $3317 \pm 58^{(\mathrm{e})}$ & $3687 \pm 64^{(\mathrm{e})}$ & $3687 \pm 64^{(\mathrm{e})}$ & $3687 \pm 64^{(\mathrm{e})}$ \\
\hline After $\mathrm{NaOH}$ & $13733 \pm 238^{(\mathrm{e})}$ & $16400 \pm 284^{(\mathrm{e})}$ & $\mathrm{n} / \mathrm{m}$ & $\mathrm{n} / \mathrm{m}$ \\
\hline Initial diluted & $\mathrm{n} / \mathrm{m}$ & $\mathrm{n} / \mathrm{m}$ & $12400 \pm 372$ & $12200 \pm 366$ \\
\hline At $88^{\circ} \mathrm{C}$ & $13100 \pm 394$ & $16700 \pm 500$ & $12300 \pm 369$ & $12600 \pm 378$ \\
\hline $0 \mathrm{hr}$ & $12600 \pm 219^{(\mathrm{e})}$ & $16500 \pm 286^{(\mathrm{e})}$ & $13000 \pm 390$ & $12200 \pm 366$ \\
\hline $1 \mathrm{hr}$ & $12800 \pm 385$ & $16600 \pm 498$ & $13700 \pm 411$ & $13300 \pm 399$ \\
\hline $2 \mathrm{hr}$ & $13200 \pm 397$ & $17000 \pm 510$ & $13600 \pm 408$ & $13400 \pm 402$ \\
\hline $4 \mathrm{hr}$ & $13900 \pm 418$ & $17800 \pm 535$ & $14500 \pm 435$ & $14500 \pm 435$ \\
\hline $8 \mathrm{hr}$ & $14700 \pm 442$ & $19000 \pm 570$ & $15800 \pm 474$ & $16300 \pm 489$ \\
\hline $10 \mathrm{hr}$ & $15500 \pm 466$ & $19400 \pm 580$ & $16100 \pm 483$ & $16100 \pm 483$ \\
\hline $12 \mathrm{hr}$ & $15867 \pm 275^{(\mathrm{e})}$ & $19067 \pm 330^{(\mathrm{e})}$ & $16900 \pm 507$ & $16800 \pm 504$ \\
\hline $14 \mathrm{hr}$ & $16000 \pm 481$ & $20200 \pm 605$ & $17200 \pm 516$ & $17300 \pm 519$ \\
\hline $16 \mathrm{hr}$ & $16500 \pm 286^{(\mathrm{e})}$ & $20433 \pm 353^{(\mathrm{e})}$ & $17700 \pm 531$ & $18200 \pm 546$ \\
\hline $18 \mathrm{hr}$ & $\mathrm{n} / \mathrm{m}$ & $\mathrm{n} / \mathrm{m}$ & $18200 \pm 546$ & $19000 \pm 570$ \\
\hline $20 \mathrm{hr}$ & $\mathrm{n} / \mathrm{m}$ & $\mathrm{n} / \mathrm{m}$ & $18900 \pm 567$ & $19300 \pm 579$ \\
\hline $22 \mathrm{hr}$ & $\mathrm{n} / \mathrm{m}$ & $\mathrm{n} / \mathrm{m}$ & $\mathrm{n} / \mathrm{m}$ & $\mathrm{n} / \mathrm{m}$ \\
\hline $24 \mathrm{hr}$ & $\mathrm{n} / \mathrm{m}$ & $\mathrm{n} / \mathrm{m}$ & $19800 \pm 594$ & $19800 \pm 594$ \\
\hline $\begin{array}{l}\text { (a) Dissolved alum } \\
\text { (SwRI). } \\
\text { (b) The sample use } \\
\text { (c) Note that water } \\
\text { PEP runs as inj } \\
\text { (d) Uncertainties ar } \\
\text { (e) Triplicate samp } \\
\text { " } \mathrm{n} / \mathrm{m} \text { " = not measur } \\
\mathrm{The} \pm \text { values are equ } \\
\text { deviations) that wer } \\
\text { triplicate samples w } \\
\text { means. }\end{array}$ & $\begin{array}{l}\mathrm{n} \text { was measured in } \mu \mathrm{g} / \mathrm{g} \\
\text { these laboratory-scale } \\
\text { added all at once at the } \\
\mathrm{d} \text { steam. } \\
\text { timated for initial dilut } \\
\text { were taken at this point. } \\
\text { o half the laboratory un } \\
\text { pplied by the analytical } \\
\text { taken, the concentration }\end{array}$ & $\begin{array}{l}\text { lid by inductively coupl } \\
\text { was taken from the PEI } \\
\text { ginning of laboratory-sc } \\
\text { rough 24-hour samples } \\
\text { e concentration shown } \mathrm{I} \\
\text { inty values (equivalent } \\
\text { nization for each conce } \\
\text { the means of the set, a }\end{array}$ & $\begin{array}{l}\text { plasma (ICP) at South } \\
\text { after } \mathrm{NaOH} \text { had been ad } \\
\text { runs, but was added gr } \\
\text { ing similar data from Ir } \\
\text { the mean of the set. } \\
\text { a } 95 \% \text { confidence inter } \\
\text { ration measurement. In } \\
\text { the } \pm \text { values are standa }\end{array}$ & $\begin{array}{l}\text { est Research Institute } \\
\text { ed. } \\
\text { dually throughout the } \\
\text { egrated Test B, Batch } 2 \text {. } \\
\text { al, or two standard } \\
\text { he cases where } \\
\text { deviations of the }\end{array}$ \\
\hline
\end{tabular}


Table A.23. Mass Concentration of Tracers in Bulk Slurry During Caustic-Leach Integrated Test B

\begin{tabular}{|c|c|c|c|c|}
\hline \multirow[b]{2}{*}{ Point in Process } & \multicolumn{4}{|c|}{$\begin{array}{l}\text { Concentration of Tracer }(\mu \mathrm{g} / \mathrm{g}) \text { in Bulk Slurry } \\
\pm 1 \text { Standard Deviation from Laboratory Analysis }\end{array}$} \\
\hline & $\begin{array}{l}\text { Integrated Test B, } \\
\text { Batch } 1 \text { in Tank } \\
\text { T02 } \mathrm{A}^{(\mathrm{Fe})}\end{array}$ & 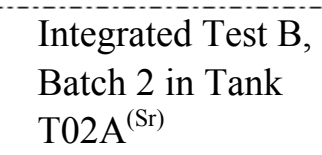 & $\begin{array}{l}\text { Laboratory-Scale } \\
\text { Test B-1 }{ }^{(\mathrm{b}, \mathrm{c}, \mathrm{d}, \mathrm{Sr})}\end{array}$ & $\begin{array}{l}\text { Laboratory-Scale } \\
\text { Test B-2 } 2^{(\mathrm{b}, \mathrm{c}, \mathrm{d}, \mathrm{Sr})}\end{array}$ \\
\hline Feed & $4943 \pm 98^{(\mathrm{e})}$ & $44.1 \pm 1.1^{(\mathrm{e})}$ & $44.1 \pm 1.1^{(\mathrm{e})}$ & $44.1 \pm 1.1^{(\mathrm{e})}$ \\
\hline Before $\mathrm{NaOH}$ & $19910 \pm 389^{(\mathrm{e})}$ & $181.3 \pm 4.3^{(\mathrm{e})}$ & $181 \pm 4^{(\mathrm{e})}$ & $181 \pm 4^{(\mathrm{e})}$ \\
\hline After $\mathrm{NaOH}$ & $9690 \pm 189^{(\mathrm{e})}$ & $98.6 \pm 2.3^{(\mathrm{e})}$ & $\mathrm{n} / \mathrm{m}$ & $\mathrm{n} / \mathrm{m}$ \\
\hline Initial diluted & $\mathrm{n} / \mathrm{m}$ & $\mathrm{n} / \mathrm{m}$ & $80.6 \pm 2.8$ & $79.6 \pm 2.7$ \\
\hline At $88^{\circ} \mathrm{C}$ & $\mathrm{n} / \mathrm{a}$ & $93.0 \pm 3.8$ & $\mathrm{n} / \mathrm{m}$ & $\mathrm{n} / \mathrm{m}$ \\
\hline $0 \mathrm{hr}$ & $8745 \pm 171^{(\mathrm{e})}$ & $89.8 \pm 2.1^{(\mathrm{e})}$ & $\mathrm{n} / \mathrm{m}$ & $\mathrm{n} / \mathrm{m}$ \\
\hline $1 \mathrm{hr}$ & $\mathrm{n} / \mathrm{a}$ & $92.4 \pm 3.8$ & $\mathrm{n} / \mathrm{m}$ & $\mathrm{n} / \mathrm{m}$ \\
\hline $2 \mathrm{hr}$ & $\mathrm{n} / \mathrm{a}$ & $89.6 \pm 3.7$ & $\mathrm{n} / \mathrm{m}$ & $\mathrm{n} / \mathrm{m}$ \\
\hline $4 \mathrm{hr}$ & $8737 \pm 295$ & $86.8 \pm 3.6$ & $\mathrm{n} / \mathrm{m}$ & $\mathrm{n} / \mathrm{m}$ \\
\hline $8 \mathrm{hr}$ & $8532 \pm 288$ & $85.7 \pm 3.5$ & $\mathrm{n} / \mathrm{m}$ & $\mathrm{n} / \mathrm{m}$ \\
\hline $10 \mathrm{hr}$ & $\mathrm{n} / \mathrm{a}$ & $86.0 \pm 3.5$ & $\mathrm{n} / \mathrm{m}$ & $\mathrm{n} / \mathrm{m}$ \\
\hline $12 \mathrm{hr}$ & $8232 \pm 160^{(\mathrm{e})}$ & $84.2 \pm 2.0^{(\mathrm{e})}$ & $\mathrm{n} / \mathrm{m}$ & $\mathrm{n} / \mathrm{m}$ \\
\hline $14 \mathrm{hr}$ & $\mathrm{n} / \mathrm{a}$ & $84.7 \pm 3.5$ & $\mathrm{n} / \mathrm{m}$ & $\mathrm{n} / \mathrm{m}$ \\
\hline $16 \mathrm{hr}$ & $7897 \pm 154^{(\mathrm{e})}$ & $80.7 \pm 1.9^{(\mathrm{e})}$ & $\mathrm{n} / \mathrm{m}$ & $\mathrm{n} / \mathrm{m}$ \\
\hline $18 \mathrm{hr}$ & $\mathrm{n} / \mathrm{m}$ & $\mathrm{n} / \mathrm{m}$ & $\mathrm{n} / \mathrm{m}$ & $\mathrm{n} / \mathrm{m}$ \\
\hline $20 \mathrm{hr}$ & $\mathrm{n} / \mathrm{m}$ & $\mathrm{n} / \mathrm{m}$ & $\mathrm{n} / \mathrm{m}$ & $\mathrm{n} / \mathrm{m}$ \\
\hline $22 \mathrm{hr}$ & $\mathrm{n} / \mathrm{m}$ & $\mathrm{n} / \mathrm{m}$ & $\mathrm{n} / \mathrm{m}$ & $\mathrm{n} / \mathrm{m}$ \\
\hline $24 \mathrm{hr}$ & $\mathrm{n} / \mathrm{m}$ & $\mathrm{n} / \mathrm{m}$ & $87.2 \pm 3.0^{(\mathrm{f})}$ & $86.6 \pm 3.0^{(f)}$ \\
\hline \multicolumn{5}{|c|}{$\begin{array}{l}\text { (a) For the PEP tests, tracer was measured by ICP at SwRI for centrifuged solids and for the decanted liquid, in units of } \mu \mathrm{g} / \mathrm{g} \text {. } \\
\text { The bulk slurry Al concentration was calculated from these measured concentrations and from the masses of centrifuged } \\
\text { solids and liquid, which were weighed at PNNL. }\end{array}$} \\
\hline \multicolumn{5}{|c|}{ (b) The sample used in these laboratory-scale tests was taken from the PEP after $\mathrm{NaOH}$ had been added. } \\
\hline \multicolumn{5}{|c|}{ (c) Note that water was added all at once at the beginning of laboratory-scale runs, but was addec } \\
\hline \multirow{2}{*}{\multicolumn{5}{|c|}{$\begin{array}{l}\text { (d) Uncertainties are estimated for initial diluted through 24-hour samp } \\
\text { (e) Triplicate samples were taken at this point. The concentration shor }\end{array}$}} \\
\hline & & & & \\
\hline $\begin{array}{l}\text { (f) The samples we } \\
\text { unknown). } \\
\text { (Fe) Solid tracer is ir } \\
\text { (Sr) Solid tracer is st } \\
\text { " } \mathrm{n} / \mathrm{m} \text { " = not measure }\end{array}$ & $\begin{array}{l}\text { n removed when the ves } \\
\text { ontium for this column. }\end{array}$ & l slurry had been cooled $t$ & temperature of $<60^{\circ} \mathrm{C}$ & roximate cooling time \\
\hline
\end{tabular}


Table A.25. Sample Timing During PEP Integrated Test D

\begin{tabular}{|c|c|c|}
\hline \multirow[b]{2}{*}{ Point in Process } & \multicolumn{2}{|c|}{ Sample Date and Time } \\
\hline & $\begin{array}{l}\text { Batch } 1 \text { in Tank } \\
\text { T02A }\end{array}$ & $\begin{array}{l}\text { Batch } 2 \text { in Tank } \\
\text { T02A }\end{array}$ \\
\hline Feed & $3 / 17 / 09$ & $3 / 17 / 09$ \\
\hline Before $\mathrm{NaOH}$ & $3 / 24 / 09 \quad 15: 15$ & $3 / 27 / 09 \quad 12: 46$ \\
\hline After $\mathrm{NaOH}$ & $3 / 25 / 09 \quad 12: 10$ & $3 / 27 / 09 \quad 16: 00$ \\
\hline At $75^{\circ} \mathrm{C}$ & $3 / 25 / 09 \quad 13: 12$ & $3 / 27 / 09 \quad 16: 43$ \\
\hline $\begin{array}{l}85^{\circ} \mathrm{C} \text { reached at the } \\
\text { prototypic } \mathrm{TC}^{(\mathrm{a})}\end{array}$ & $3 / 25 / 09 \quad 13: 54$ & 3/27/09 17:19 \\
\hline $0 \mathrm{hr}$ at $85^{\circ} \mathrm{C}$, sample & $3 / 25 / 09 \quad 14: 00$ & $3 / 27 / 09 \quad 17: 27$ \\
\hline $1 \mathrm{hr}$ & $3 / 25 / 09 \quad 15: 05$ & $3 / 27 / 09 \quad 18: 24$ \\
\hline $2 \mathrm{hr}$ & $3 / 25 / 09 \quad 16: 06$ & $3 / 27 / 09 \quad 19: 22$ \\
\hline $4 \mathrm{hr}$ & $3 / 25 / 09 \quad 17: 58$ & $3 / 27 / 09 \quad 21: 21$ \\
\hline $8 \mathrm{hr}$ & $3 / 25 / 09 \quad 22: 01$ & $3 / 28 / 09 \quad 01: 21$ \\
\hline $10 \mathrm{hr}$ & 3/26/09 00:02 & $3 / 28 / 09 \quad 03: 21$ \\
\hline $12 \mathrm{hr}$ & 3/26/09 02:01 & $3 / 28 / 09 \quad 05: 21$ \\
\hline $14 \mathrm{hr}$ & 3/26/09 04:01 & $3 / 28 / 09 \quad 07: 21$ \\
\hline $16 \mathrm{hr}$ & $3 / 26 / 09 \quad 06: 02$ & 3/28/09 09:21 \\
\hline $18 \mathrm{hr}$ & 3/26/09 08:00 & $3 / 28 / 09 \quad 11: 20$ \\
\hline $20 \mathrm{hr}$ & $3 / 26 / 09 \quad 10: 01$ & $3 / 28 / 09 \quad 13: 21$ \\
\hline $22 \mathrm{hr}$ & $3 / 26 / 09 \quad 11: 57$ & $3 / 28 / 09 \quad 15: 22$ \\
\hline $24 \mathrm{hr}$ & $3 / 26 / 09 \quad 14: 01$ & $3 / 28 / 09 \quad 17: 22$ \\
\hline
\end{tabular}


Table A.26. Sample Timing During Laboratory-Scale Integrated Test D

\begin{tabular}{|c|c|c|}
\hline \multirow[b]{2}{*}{ Point in Process } & \multicolumn{2}{|c|}{ Sample Date and Time } \\
\hline & $\begin{array}{l}\text { Laboratory- } \\
\text { Scale Test D-1 }\end{array}$ & $\begin{array}{l}\text { Laboratory- } \\
\text { Scale Test D-2 }\end{array}$ \\
\hline Feed (PEP) & $3 / 17 / 09$ & $3 / 17 / 09$ \\
\hline Before $\mathrm{NaOH}$ (PEP) & $3 / 27 / 09 \quad 12: 46$ & $3 / 27 / 09 \quad 12: 46$ \\
\hline After $\mathrm{NaOH}$ (PEP) & $3 / 27 / 09 \quad 16: 00$ & $3 / 27 / 09 \quad 16: 00$ \\
\hline Initial diluted & $4 / 8 / 09 \quad 08: 25$ & 4/8/09 08:25 \\
\hline At $75^{\circ} \mathrm{C}$ & 4/8/09 09:28 & 4/8/09 09:28 \\
\hline $0 \mathrm{hr}$ at $85^{\circ} \mathrm{C}$ & 4/8/09 11:00 & 4/8/09 11:00 \\
\hline $1 \mathrm{hr}$ & 4/8/09 12:00 & 4/8/09 12:00 \\
\hline $2 \mathrm{hr}$ & 4/8/09 13:00 & 4/8/09 13:00 \\
\hline $4 \mathrm{hr}$ & 4/8/09 15:00 & 4/8/09 15:00 \\
\hline $8 \mathrm{hr}$ & 4/8/09 19:00 & 4/8/09 19:00 \\
\hline $10 \mathrm{hr}$ & 4/8/09 21:00 & 4/8/09 21:00 \\
\hline $12 \mathrm{hr}$ & 4/8/09 23:00 & 4/8/09 23:00 \\
\hline $14 \mathrm{hr}$ & 4/9/09 01:00 & 4/9/09 01:00 \\
\hline $16 \mathrm{hr}$ & 4/9/09 03:00 & 4/9/09 03:00 \\
\hline $18 \mathrm{hr}$ & 4/9/09 05:00 & 4/9/09 05:00 \\
\hline $20 \mathrm{hr}$ & 4/9/09 07:00 & 4/9/09 07:00 \\
\hline $22 \mathrm{hr}$ & $\mathrm{n} / \mathrm{m}$ & $\mathrm{n} / \mathrm{m}$ \\
\hline $24 \mathrm{hr}$ & 4/9/09 11:00 & 4/9/09 11:00 \\
\hline After cooling & 4/9/09 $14: 30$ & 4/9/09 $14: 30$ \\
\hline
\end{tabular}


Table A.27. Temperatures During Digestion Period For Integrated Test D and Related Laboratory Tests

\begin{tabular}{|c|c|c|}
\hline \multirow[b]{2}{*}{ Point in Process } & \multicolumn{2}{|c|}{$\begin{array}{c}\text { Temperature }\left({ }^{\circ} \mathrm{C}\right) \\
\pm 1 \text { Standard Deviation }\end{array}$} \\
\hline & $\begin{array}{l}\text { Batch } 1 \text { in Tank } \\
\text { T02A }\end{array}$ & $\begin{array}{l}\text { Batch } 2 \text { in Tank } \\
\text { T02A }\end{array}$ \\
\hline \multicolumn{3}{|c|}{$\begin{array}{l}\text { PEP test from start to end of digestion } \\
\text { (submerged instruments) }\end{array}$} \\
\hline Prototypic RTD & $84.3 \pm 2.3$ & $84.7 \pm 0.9$ \\
\hline RTD trees & $84.3 \pm 2.3$ & $84.7 \pm 1.0$ \\
\hline $\begin{array}{l}\text { Resistance temperature } \\
\text { detectors (RTDs) near vessel } \\
\text { walls }\end{array}$ & $84.4 \pm 2.3$ & $84.8 \pm 1.0$ \\
\hline RTDs near PJMs & $84.6 \pm 2.4$ & $85.0 \pm 1.0$ \\
\hline $\begin{array}{l}\text { All submerged temperature } \\
\text { instruments }\end{array}$ & $84.4 \pm 2.3$ & $84.8 \pm 1.0$ \\
\hline Laboratory-Scale Test D-1 ${ }^{(\mathrm{b})}$ & $\mathrm{n} / \mathrm{a}$ & $85.0 \pm 0.1$ \\
\hline Laboratory-Scale Test D-2 ${ }^{(b)}$ & $\mathrm{n} / \mathrm{a}$ & $85.0 \pm 0.1$ \\
\hline \multicolumn{3}{|c|}{$\begin{array}{l}\text { (a) The standard deviations for PEP temperatures include temperature cycling and } \\
\text { differences between sensors. Data were sampled once per minute from all } \\
\text { submerged sensors in the set. }\end{array}$} \\
\hline
\end{tabular}


Table A.28. Slurry Density During Caustic-Leach Integrated Test D

\begin{tabular}{|c|c|c|c|c|}
\hline \multirow[b]{2}{*}{ Point in Process } & \multicolumn{4}{|c|}{$\begin{array}{c}\text { Slurry Density }(\mathrm{g} / \mathrm{mL})^{(\mathrm{a})} \\
\text { 1 Standard Deviation Based on Laboratory A }\end{array}$} \\
\hline & $\begin{array}{l}\text { Integrated Test D, } \\
\text { Batch } 1 \text { in Tank } \\
\text { T02A }\end{array}$ & $\begin{array}{l}\text { Integrated Test D, } \\
\text { Batch } 2 \text { in Tank } \\
\text { T02A }\end{array}$ & $\begin{array}{l}\text { Laboratory-Scale } \\
\text { Test D-1 }{ }^{(\mathrm{b}, \mathrm{c})}\end{array}$ & $\begin{array}{l}\text { Laboratory-Scale } \\
\text { Test D-2 } 2^{(\mathrm{b}, \mathrm{c})}\end{array}$ \\
\hline Feed & $1.276 \pm 0.006^{(\mathrm{d})}$ & $1.276 \pm 0.006^{(\mathrm{d})}$ & $1.276 \pm 0.006^{(\mathrm{d})}$ & $1.276 \pm 0.006^{(\mathrm{d})}$ \\
\hline Before $\mathrm{NaOH}$ & $1.419 \pm 0.006^{(\mathrm{d})}$ & $1.428 \pm 0.006^{(\mathrm{d})}$ & $1.428 \pm 0.006^{(\mathrm{d})}$ & $1.428 \pm 0.006^{(\mathrm{d})}$ \\
\hline After $\mathrm{NaOH}$ & $1.468 \pm 0.012$ & $1.489 \pm 0.012$ & $\mathrm{n} / \mathrm{m}$ & $\mathrm{n} / \mathrm{m}$ \\
\hline Initial diluted & $\mathrm{n} / \mathrm{m}$ & $\mathrm{n} / \mathrm{m}$ & $1.424 \pm 0.013$ & $1.425 \pm 0.013$ \\
\hline At $75^{\circ} \mathrm{C}$ & $1.450 \pm 0.012$ & $1.474 \pm 0.012$ & $\mathrm{n} / \mathrm{m}$ & $\mathrm{n} / \mathrm{m}$ \\
\hline $0 \mathrm{hr}$ & $1.439 \pm 0.006^{(\mathrm{d})}$ & $1.462 \pm 0.007^{(\mathrm{d})}$ & $\mathrm{n} / \mathrm{m}$ & $\mathrm{n} / \mathrm{m}$ \\
\hline $1 \mathrm{hr}$ & $1.436 \pm 0.011$ & $1.452 \pm 0.012$ & $\mathrm{n} / \mathrm{m}$ & $\mathrm{n} / \mathrm{m}$ \\
\hline $2 \mathrm{hr}$ & $1.435 \pm 0.011$ & $1.427 \pm 0.011$ & $\mathrm{n} / \mathrm{m}$ & $\mathrm{n} / \mathrm{m}$ \\
\hline $4 \mathrm{hr}$ & $1.434 \pm 0.011$ & $1.421 \pm 0.011$ & $\mathrm{n} / \mathrm{m}$ & $\mathrm{n} / \mathrm{m}$ \\
\hline $8 \mathrm{hr}$ & $1.428 \pm 0.011$ & $1.441 \pm 0.011$ & $\mathrm{n} / \mathrm{m}$ & $\mathrm{n} / \mathrm{m}$ \\
\hline $10 \mathrm{hr}$ & $1.422 \pm 0.011$ & $1.433 \pm 0.011$ & $\mathrm{n} / \mathrm{m}$ & $\mathrm{n} / \mathrm{m}$ \\
\hline $12 \mathrm{hr}$ & $1.405 \pm 0.011$ & $1.432 \pm 0.011$ & $\mathrm{n} / \mathrm{m}$ & $\mathrm{n} / \mathrm{m}$ \\
\hline $14 \mathrm{hr}$ & $1.402 \pm 0.011$ & $1.425 \pm 0.011$ & $\mathrm{n} / \mathrm{m}$ & $\mathrm{n} / \mathrm{m}$ \\
\hline $16 \mathrm{hr}$ & $1.398 \pm 0.011$ & $1.421 \pm 0.011$ & $\mathrm{n} / \mathrm{m}$ & $\mathrm{n} / \mathrm{m}$ \\
\hline $18 \mathrm{hr}$ & $1.406 \pm 0.011$ & $1.415 \pm 0.011$ & $\mathrm{n} / \mathrm{m}$ & $\mathrm{n} / \mathrm{m}$ \\
\hline $20 \mathrm{hr}$ & $1.400 \pm 0.011$ & $1.415 \pm 0.011$ & $\mathrm{n} / \mathrm{m}$ & $\mathrm{n} / \mathrm{m}$ \\
\hline $22 \mathrm{hr}$ & $1.404 \pm 0.011$ & $1.407 \pm 0.008$ & $\mathrm{n} / \mathrm{m}$ & $\mathrm{n} / \mathrm{m}$ \\
\hline $24 \mathrm{hr}$ & $1.394 \pm 0.006^{(\mathrm{d})}$ & $1.399 \pm 0.010^{(\mathrm{d})}$ & $1.408 \pm 0.013^{(\mathrm{e})}$ & $1.442 \pm 0.013^{(\mathrm{e})}$ \\
\hline \multicolumn{5}{|c|}{$\begin{array}{l}\text { (a) Slurry density was measured at ambient temperature by pycnometry at SwRI. } \\
\text { (b) The sample used in these laboratory-scale tests was taken from the PEP after } \mathrm{NaOH} \text { had been added. } \\
\text { (c) Note that water was added all at once at the beginning of laboratory-scale runs, but was added gradually throughout the } \\
\text { PEP runs as injected steam. } \\
\text { (d) Triplicate samples were taken at this point. The concentration shown is the mean of the set. } \\
\text { (e) The samples were removed when the vessel slurry had been cooled to a temperature of }<60^{\circ} \mathrm{C} \text { (approximate cooling time } \\
\text { was } 3.5 \text { hours). } \\
\text { " } \mathrm{n} / \mathrm{m} \text { " = not measured }\end{array}$} \\
\hline
\end{tabular}


Table A.29. Liquid Density During Caustic-Leach Integrated Test D

\begin{tabular}{|c|c|c|c|c|}
\hline \multirow[b]{2}{*}{ Point in Process } & \multicolumn{4}{|c|}{$\begin{array}{c}\text { Liquid Density }(\mathrm{g} / \mathrm{mL})^{(\mathrm{a})} \\
\pm 1 \text { Standard Deviation Based on Laboratory Analysis }\end{array}$} \\
\hline & $\begin{array}{l}\text { Integrated Test D, } \\
\text { Batch } 1 \text { in Tank } \\
\text { T02A }\end{array}$ & $\begin{array}{l}\text { Integrated Test D, } \\
\text { Batch } 2 \text { in Tank } \\
\text { T02A }\end{array}$ & $\begin{array}{l}\text { Laboratory-Scale } \\
\text { Test D-1 }{ }^{(\mathrm{b}, \mathrm{c})}\end{array}$ & $\begin{array}{l}\text { Laboratory-Scale } \\
\text { Test D-2 } 2^{(b, c)}\end{array}$ \\
\hline Feed & $1.236 \pm 0.005^{(\mathrm{d})}$ & $1.236 \pm 0.005^{(\mathrm{d})}$ & $1.236 \pm 0.005^{(\mathrm{d})}$ & $1.236 \pm 0.005^{(\mathrm{d})}$ \\
\hline Before $\mathrm{NaOH}$ & $1.201 \pm 0.008^{(\mathrm{d})}$ & $1.238 \pm 0.006^{(\mathrm{d})}$ & $1.238 \pm 0.010^{(\mathrm{d})}$ & $1.238 \pm 0.010^{(\mathrm{d})}$ \\
\hline After $\mathrm{NaOH}$ & $1.383 \pm 0.011$ & $1.418 \pm 0.011$ & $\mathrm{n} / \mathrm{m}$ & $\mathrm{n} / \mathrm{m}$ \\
\hline Initial diluted & $\mathrm{n} / \mathrm{m}$ & $\mathrm{n} / \mathrm{m}$ & $1.360 \pm 0.010$ & $1.368 \pm 0.010$ \\
\hline At $75^{\circ} \mathrm{C}$ & $1.391 \pm 0.011$ & $1.403 \pm 0.011$ & $1.375 \pm 0.010$ & $1.371 \pm 0.010$ \\
\hline $0 \mathrm{hr}$ & $1.372 \pm 0.006^{(\mathrm{d})}$ & $1.392 \pm 0.006^{(\mathrm{d})}$ & $1.368 \pm 0.010$ & $1.366 \pm 0.010$ \\
\hline $1 \mathrm{hr}$ & $1.377 \pm 0.011$ & $1.392 \pm 0.011$ & $1.370 \pm 0.010$ & $1.370 \pm 0.010$ \\
\hline $2 \mathrm{hr}$ & $1.377 \pm 0.011$ & $1.378 \pm 0.011$ & $1.368 \pm 0.010$ & $1.369 \pm 0.010$ \\
\hline $4 \mathrm{hr}$ & $1.378 \pm 0.011$ & $1.377 \pm 0.011$ & $1.373 \pm 0.010$ & $1.372 \pm 0.010$ \\
\hline $8 \mathrm{hr}$ & $1.373 \pm 0.011$ & $1.379 \pm 0.011$ & $1.384 \pm 0.010$ & $1.370 \pm 0.010$ \\
\hline $10 \mathrm{hr}$ & $1.360 \pm 0.011$ & $1.379 \pm 0.011$ & $1.379 \pm 0.010$ & $1.376 \pm 0.010$ \\
\hline $12 \mathrm{hr}$ & $1.366 \pm 0.011$ & $1.380 \pm 0.011$ & $1.378 \pm 0.010$ & $1.379 \pm 0.010$ \\
\hline $14 \mathrm{hr}$ & $1.364 \pm 0.011$ & $1.373 \pm 0.011$ & $1.376 \pm 0.010$ & $1.382 \pm 0.010$ \\
\hline $16 \mathrm{hr}$ & $1.362 \pm 0.011$ & $1.376 \pm 0.011$ & $1.384 \pm 0.010$ & $1.376 \pm 0.010$ \\
\hline $18 \mathrm{hr}$ & $1.355 \pm 0.011$ & $1.371 \pm 0.011$ & $1.385 \pm 0.010$ & $1.378 \pm 0.010$ \\
\hline $20 \mathrm{hr}$ & $1.349 \pm 0.011$ & $1.365 \pm 0.011$ & $1.391 \pm 0.010$ & $1.381 \pm 0.010$ \\
\hline $22 \mathrm{hr}$ & $1.359 \pm 0.011$ & $1.365 \pm 0.011$ & $\mathrm{n} / \mathrm{m}$ & $\mathrm{n} / \mathrm{m}$ \\
\hline $24 \mathrm{hr}$ & $1.356 \pm 0.006^{(\mathrm{d})}$ & $1.365 \pm 0.006^{(\mathrm{d})}$ & $1.388 \pm 0.010$ & $1.383 \pm 0.010$ \\
\hline $\begin{array}{l}\text { (a) Liquid density } \\
\text { (b) The sample use } \\
\text { (c) Note that water } \\
\text { PEP runs as inj } \\
\text { (d) Triplicate samp } \\
\text { "n/m" = not measure }\end{array}$ & $\begin{array}{l}\text { is measured at ambient to } \\
\text { in these laboratory-scale } \\
\text { as added all at once at th } \\
\text { ted steam. } \\
\text { s were taken at this point }\end{array}$ & $\begin{array}{l}\text { perature by pycnometry } \\
\text { sts was taken from the P } \\
\text { beginning of laboratory-s } \\
\text { The concentration shown }\end{array}$ & $\begin{array}{l}\text { SwRI. } \\
\text { after } \mathrm{NaOH} \text { had been } \\
\text { ale runs, but was added } \\
\text { s the mean of the set. }\end{array}$ & $\begin{array}{l}\text { d. } \\
\text { lually throughout the }\end{array}$ \\
\hline
\end{tabular}


Table A.31. Water in Liquid Phase During Caustic-Leach Integrated Test D

\begin{tabular}{|c|c|c|c|c|}
\hline \multirow[b]{2}{*}{ Point in Process } & \multicolumn{4}{|c|}{$\begin{array}{l}\text { Concentration of } \mathrm{H}_{2} \mathrm{O}(\mathrm{wt} \%) \text { in Liquid Phase }{ }^{(\mathrm{a})} \\
\pm 1 \text { Standard Deviation from Laboratory Analysis }\end{array}$} \\
\hline & $\begin{array}{l}\text { Integrated Test D, } \\
\text { Batch } 1 \text { in Tank } \\
\text { T02A }\end{array}$ & $\begin{array}{l}\text { Integrated Test D, } \\
\text { Batch } 2 \text { in Tank } \\
\text { T02A }\end{array}$ & $\begin{array}{l}\text { Laboratory-Scale } \\
\text { Test D-1 }{ }^{(\mathrm{b}, \mathrm{c})}\end{array}$ & $\begin{array}{l}\text { Laboratory-Scale } \\
\text { Test D-2 }{ }^{(\mathrm{b}, \mathrm{c})}\end{array}$ \\
\hline Feed & $73.1 \% \pm 0.1 \%{ }^{(\mathrm{d})}$ & $73.1 \% \pm 0.1 \%^{(\mathrm{d})}$ & $\mathrm{n} / \mathrm{m}$ & $\mathrm{n} / \mathrm{m}$ \\
\hline Before $\mathrm{NaOH}$ & $73.2 \% \pm 0.1 \%{ }^{(\mathrm{d})}$ & $73.1 \% \pm 0.2 \%{ }^{(\mathrm{d})}$ & $\mathrm{n} / \mathrm{m}$ & $\mathrm{n} / \mathrm{m}$ \\
\hline After $\mathrm{NaOH}$ & $57.8 \% \pm 0.3 \%$ & $55.7 \% \pm 0.4 \%$ & $\mathrm{n} / \mathrm{m}$ & $\mathrm{n} / \mathrm{m}$ \\
\hline Initial diluted & $\mathrm{n} / \mathrm{m}$ & $\mathrm{n} / \mathrm{m}$ & $\mathrm{n} / \mathrm{m}$ & $\mathrm{n} / \mathrm{m}$ \\
\hline At $75^{\circ} \mathrm{C}$ & $58.7 \% \pm 0.3 \%$ & $56.9 \% \pm 0.3 \%$ & $\mathrm{n} / \mathrm{m}$ & $\mathrm{n} / \mathrm{m}$ \\
\hline $0 \mathrm{hr}$ & $59.8 \% \pm 0.2 \%{ }^{(\mathrm{d})}$ & $58.1 \% \pm 0.2 \%{ }^{(\mathrm{d})}$ & $\mathrm{n} / \mathrm{m}$ & $\mathrm{n} / \mathrm{m}$ \\
\hline $1 \mathrm{hr}$ & $60.2 \% \pm 0.3 \%$ & $58.6 \% \pm 0.3 \%$ & $\mathrm{n} / \mathrm{m}$ & $\mathrm{n} / \mathrm{m}$ \\
\hline $2 \mathrm{hr}$ & $60.6 \% \pm 0.4 \%$ & $58.8 \% \pm 0.3 \%$ & $\mathrm{n} / \mathrm{m}$ & $\mathrm{n} / \mathrm{m}$ \\
\hline $4 \mathrm{hr}$ & $60.7 \% \pm 0.3 \%$ & $58.6 \% \pm 0.3 \%$ & $\mathrm{n} / \mathrm{m}$ & $\mathrm{n} / \mathrm{m}$ \\
\hline $8 \mathrm{hr}$ & $61.1 \% \pm 0.3 \%$ & $59.8 \% \pm 0.3 \%$ & $\mathrm{n} / \mathrm{m}$ & $\mathrm{n} / \mathrm{m}$ \\
\hline $10 \mathrm{hr}$ & $61.5 \% \pm 0.3 \%$ & $60.1 \% \pm 0.3 \%$ & $\mathrm{n} / \mathrm{m}$ & $\mathrm{n} / \mathrm{m}$ \\
\hline $12 \mathrm{hr}$ & $61.4 \% \pm 0.3 \%$ & $60.4 \% \pm 0.3 \%$ & $\mathrm{n} / \mathrm{m}$ & $\mathrm{n} / \mathrm{m}$ \\
\hline $14 \mathrm{hr}$ & $61.5 \% \pm 0.3 \%$ & $60.6 \% \pm 0.3 \%$ & $\mathrm{n} / \mathrm{m}$ & $\mathrm{n} / \mathrm{m}$ \\
\hline $16 \mathrm{hr}$ & $62.2 \% \pm 0.3 \%$ & $60.7 \% \pm 0.3 \%$ & $\mathrm{n} / \mathrm{m}$ & $\mathrm{n} / \mathrm{m}$ \\
\hline $18 \mathrm{hr}$ & $62.1 \% \pm 0.3 \%$ & $61.2 \% \pm 0.3 \%$ & $\mathrm{n} / \mathrm{m}$ & $\mathrm{n} / \mathrm{m}$ \\
\hline $20 \mathrm{hr}$ & $62.2 \% \pm 0.3 \%$ & $61.2 \% \pm 0.3 \%$ & $\mathrm{n} / \mathrm{m}$ & $\mathrm{n} / \mathrm{m}$ \\
\hline $22 \mathrm{hr}$ & $62.6 \% \pm 0.3 \%$ & $61.5 \% \pm 0.3 \%$ & $\mathrm{n} / \mathrm{m}$ & $\mathrm{n} / \mathrm{m}$ \\
\hline $24 \mathrm{hr}$ & $62.9 \% \pm 0.2 \%{ }^{(\mathrm{d})}$ & $61.7 \% \pm 0.2 \%{ }^{(\mathrm{d})}$ & $\mathrm{n} / \mathrm{m}$ & $\mathrm{n} / \mathrm{m}$ \\
\hline $\begin{array}{l}\text { (a) } \mathrm{Wt} \% \text { water is ( } \\
\mathrm{SwRI} . \mathrm{Wt} \% \mathrm{w} \\
\text { (b) The sample use } \\
\text { (c) Note that water } \\
\text { PEP runs as inj } \\
\text { (d) Triplicate samp } \\
\text { " } \mathrm{n} / \mathrm{m} \text { " = not measure }\end{array}$ & $\begin{array}{l}-\mathrm{wt} \% \text { dissolved solids). } \\
\text { er is mass water/mass li } \\
\text { in these laboratory-scale } \\
\text { vas added all at once at th } \\
\text { ted steam. } \\
\text { es were taken at this poin }\end{array}$ & $\begin{array}{l}\text { issolved solids were mea } \\
\text { id. } \\
\text { bts was taken from the P } \\
\text { beginning of laboratory-s } \\
\text { The concentration shown }\end{array}$ & $\begin{array}{l}\text { ared by drying and weig } \\
\text { after } \mathrm{NaOH} \text { had been } \\
\text { ale runs, but was added } \\
\text { s the mean of the set. }\end{array}$ & $\begin{array}{l}\text { g supernatant liquid at } \\
\text { dually throughout the } \\
\end{array}$ \\
\hline
\end{tabular}


Table A.32. Molar Concentration of Free Hydroxide During Caustic-Leach Integrated Test D

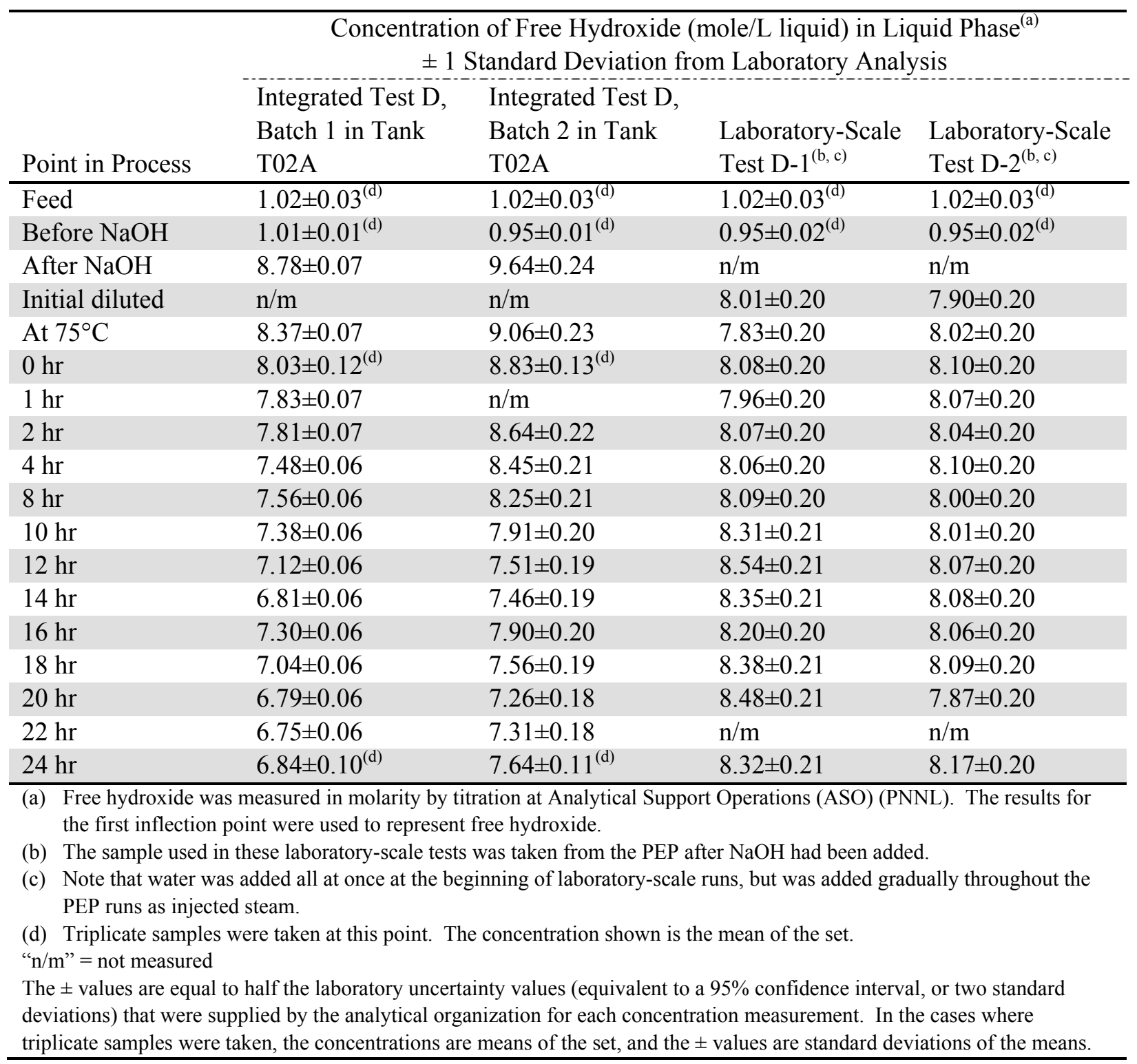


Table A.33. Mass Concentration of Aluminum in Bulk Slurry During Caustic-Leach Integrated Test D

\begin{tabular}{|c|c|c|c|c|}
\hline \multirow[b]{2}{*}{ Point in Process } & \multicolumn{4}{|c|}{$\begin{array}{c}\text { Concentration of Aluminum }(\mu \mathrm{g} / \mathrm{g}) \text { in Bulk Slurry } \\
\pm 1 \text { Standard Deviation from Laboratory Analysis }\end{array}$} \\
\hline & $\begin{array}{l}\text { Integrated Test D, } \\
\text { Batch } 1 \text { in Tank } \\
\text { T02A }\end{array}$ & $\begin{array}{l}\text { Integrated Test D, } \\
\text { Batch } 2 \text { in Tank } \\
\text { T02A }\end{array}$ & $\begin{array}{l}\text { Laboratory-Scale } \\
\text { Test D-1 }{ }^{(\mathrm{b}, \mathrm{c}, \mathrm{d})}\end{array}$ & $\begin{array}{l}\text { Laboratory-Scale } \\
\text { Test D-2 } 2^{(b, c, d)}\end{array}$ \\
\hline Feed & $18372 \pm 308^{(\mathrm{e})}$ & $18372 \pm 308^{(\mathrm{e})}$ & $18372 \pm 308^{(\mathrm{e})}$ & $18372 \pm 308^{(\mathrm{e})}$ \\
\hline Before $\mathrm{NaOH}$ & $68101 \pm 1295^{(\mathrm{e})}$ & $70719 \pm 1349^{(\mathrm{e})}$ & $70719 \pm 1349^{(\mathrm{e})}$ & $70719 \pm 1349^{(\mathrm{e})}$ \\
\hline After $\mathrm{NaOH}$ & $31913 \pm 788$ & $30289 \pm 781$ & $\mathrm{n} / \mathrm{m}$ & $\mathrm{n} / \mathrm{m}$ \\
\hline Initial diluted & $\mathrm{n} / \mathrm{m}$ & $\mathrm{n} / \mathrm{m}$ & $22100 \pm 746$ & $22100 \pm 746$ \\
\hline At $75^{\circ} \mathrm{C}$ & $\mathrm{n} / \mathrm{m}$ & $\mathrm{n} / \mathrm{m}$ & $\mathrm{n} / \mathrm{m}$ & $\mathrm{n} / \mathrm{m}$ \\
\hline $0 \mathrm{hr}$ & $29599 \pm 428^{(\mathrm{e})}$ & $30816 \pm 444^{(\mathrm{e})}$ & $\mathrm{n} / \mathrm{m}$ & $\mathrm{n} / \mathrm{m}$ \\
\hline $1 \mathrm{hr}$ & $\mathrm{n} / \mathrm{m}$ & $\mathrm{n} / \mathrm{m}$ & $\mathrm{n} / \mathrm{m}$ & $\mathrm{n} / \mathrm{m}$ \\
\hline $2 \mathrm{hr}$ & $\mathrm{n} / \mathrm{m}$ & $\mathrm{n} / \mathrm{m}$ & $\mathrm{n} / \mathrm{m}$ & $\mathrm{n} / \mathrm{m}$ \\
\hline $4 \mathrm{hr}$ & $29025 \pm 711$ & $30888 \pm 755$ & $\mathrm{n} / \mathrm{m}$ & $\mathrm{n} / \mathrm{m}$ \\
\hline $8 \mathrm{hr}$ & $29064 \pm 701$ & $29001 \pm 705$ & $\mathrm{n} / \mathrm{m}$ & $\mathrm{n} / \mathrm{m}$ \\
\hline $10 \mathrm{hr}$ & $\mathrm{n} / \mathrm{m}$ & $\mathrm{n} / \mathrm{m}$ & $\mathrm{n} / \mathrm{m}$ & $\mathrm{n} / \mathrm{m}$ \\
\hline $12 \mathrm{hr}$ & $27947 \pm 658$ & $29083 \pm 696$ & $\mathrm{n} / \mathrm{m}$ & $\mathrm{n} / \mathrm{m}$ \\
\hline $14 \mathrm{hr}$ & $\mathrm{n} / \mathrm{m}$ & $\mathrm{n} / \mathrm{m}$ & $\mathrm{n} / \mathrm{m}$ & $\mathrm{n} / \mathrm{m}$ \\
\hline $16 \mathrm{hr}$ & $27057 \pm 635$ & $28356 \pm 668$ & $\mathrm{n} / \mathrm{m}$ & $\mathrm{n} / \mathrm{m}$ \\
\hline $18 \mathrm{hr}$ & $\mathrm{n} / \mathrm{m}$ & $\mathrm{n} / \mathrm{m}$ & $\mathrm{n} / \mathrm{m}$ & $\mathrm{n} / \mathrm{m}$ \\
\hline $20 \mathrm{hr}$ & $\mathrm{n} / \mathrm{m}$ & $\mathrm{n} / \mathrm{m}$ & $\mathrm{n} / \mathrm{m}$ & $\mathrm{n} / \mathrm{m}$ \\
\hline $22 \mathrm{hr}$ & $\mathrm{n} / \mathrm{m}$ & $\mathrm{n} / \mathrm{m}$ & $\mathrm{n} / \mathrm{m}$ & $\mathrm{n} / \mathrm{m}$ \\
\hline $24 \mathrm{hr}$ & $26505 \pm 352^{(\mathrm{e})}$ & $27398 \pm 365^{(\mathrm{e})}$ & $25200 \pm 850^{(\mathrm{f})}$ & $24500 \pm 827^{(\mathrm{f})}$ \\
\hline
\end{tabular}

(a) For the PEP tests, aluminum was measured by ICP at SwRI for centrifuged solids and for the decanted liquid, in units of $\mu \mathrm{g} / \mathrm{g}$. The bulk slurry Al concentration was calculated from these measured concentrations and from the masses of centrifuged solids and liquid, which were weighed at PNNL.

(b) The sample used in these laboratory-scale tests was taken from the PEP after $\mathrm{NaOH}$ had been added.

(c) Note that water was added all at once at the beginning of laboratory-scale runs, but was added gradually throughout the PEP runs as injected steam.

(d) Uncertainties are estimated for initial diluted through 24-hour samples using similar data from Integrated Test D, Batch 1.

(e) Triplicate samples were taken at this point. The concentration shown is the mean of the set.

(f) The samples were removed when the vessel slurry had been cooled to a temperature of $<60^{\circ} \mathrm{C}$ (approximate cooling time was 3.5 hours).

"n/m" = not measured

The concentrations in the bulk slurry are calculated from the liquid concentrations, the concentrations measured in centrifuged solids, and the mass fraction of the slurry that was centrifuged solids. The \pm values are standard deviations calculated by linearized error propagation methods. The method used to estimate the uncertainty of the centrifuged solids weight fraction depends on measurements for the triplicate data sets. The different number of triplicate data sets in PEP and laboratory-scale tests causes differences in centrifuged solids fraction uncertainty, and therefore in slurry concentration uncertainty, for the same sample, when determined from PEP test data sets and from laboratory-scale test data sets. See Appendix C of WTP-RPT-186, Rev. 0, EFRT M12 Issue Resolution: Caustic-Leach Rate Constants from PEP and Laboratory-Scale Tests for more information. 
Table A.34. Mass Concentration of Dissolved Aluminum During Caustic-Leach Integrated Test D

\begin{tabular}{|c|c|c|c|c|}
\hline \multirow[b]{2}{*}{ Point in Process } & \multicolumn{4}{|c|}{$\begin{array}{c}\text { Concentration of Aluminum }(\mu \mathrm{g} / \mathrm{g}) \text { in Liquid Phase }{ }^{(\mathrm{a})} \\
\pm 1 \text { Standard Deviation from Laboratory Analysis }\end{array}$} \\
\hline & $\begin{array}{l}\text { Integrated Test D, } \\
\text { Batch } 1 \text { in Tank } \\
\text { T02A }\end{array}$ & $\begin{array}{l}\text { Integrated Test D, } \\
\text { Batch } 2 \text { in Tank } \\
\text { T02A }\end{array}$ & $\begin{array}{l}\text { Laboratory-Scale } \\
\text { Test D- } 1^{(\mathrm{b}, \mathrm{c}, \mathrm{d})}\end{array}$ & $\begin{array}{l}\text { Laboratory-Scale } \\
\text { Test D- } 2^{(\mathrm{b}, \mathrm{c}, \mathrm{d})}\end{array}$ \\
\hline Feed & $3230 \pm 56^{(\mathrm{e})}$ & $3230 \pm 56^{(\mathrm{e})}$ & $3230 \pm 56^{(\mathrm{e})}$ & $3230 \pm 56^{(\mathrm{e})}$ \\
\hline Before $\mathrm{NaOH}$ & $2957 \pm 52^{(\mathrm{e})}$ & $3230 \pm 57^{(\mathrm{e})}$ & $3230 \pm 57^{(\mathrm{e})}$ & $3230 \pm 57^{(\mathrm{e})}$ \\
\hline After $\mathrm{NaOH}$ & $13800 \pm 415$ & $12400 \pm 373$ & $\mathrm{n} / \mathrm{m}$ & $\mathrm{n} / \mathrm{m}$ \\
\hline Initial diluted & $\mathrm{n} / \mathrm{m}$ & $\mathrm{n} / \mathrm{m}$ & $9340 \pm 281$ & $10400 \pm 312$ \\
\hline At $75^{\circ} \mathrm{C}$ & $12500 \pm 376$ & $12900 \pm 388$ & $10400 \pm 312$ & $10700 \pm 321$ \\
\hline $0 \mathrm{hr}$ & $11933 \pm 207^{(\mathrm{e})}$ & $13367 \pm 232^{(\mathrm{e})}$ & $10200 \pm 306$ & $10500 \pm 315$ \\
\hline $1 \mathrm{hr}$ & $12300 \pm 370$ & $13600 \pm 409$ & $10600 \pm 318$ & $10900 \pm 327$ \\
\hline $2 \mathrm{hr}$ & $12500 \pm 376$ & $13600 \pm 409$ & $10700 \pm 321$ & $10900 \pm 327$ \\
\hline $4 \mathrm{hr}$ & $12600 \pm 379$ & $14100 \pm 424$ & $11500 \pm 345$ & $11500 \pm 345$ \\
\hline $8 \mathrm{hr}$ & $13100 \pm 394$ & $13300 \pm 400$ & $12500 \pm 375$ & $11700 \pm 351$ \\
\hline $10 \mathrm{hr}$ & $13300 \pm 400$ & $13600 \pm 409$ & $12700 \pm 381$ & $12500 \pm 375$ \\
\hline $12 \mathrm{hr}$ & $13800 \pm 415$ & $13800 \pm 414$ & $13000 \pm 391$ & $13400 \pm 403$ \\
\hline $14 \mathrm{hr}$ & $12500 \pm 376$ & $13900 \pm 418$ & $13600 \pm 409$ & $13700 \pm 412$ \\
\hline $16 \mathrm{hr}$ & $13200 \pm 396$ & $14000 \pm 420$ & $13900 \pm 418$ & $14000 \pm 421$ \\
\hline $18 \mathrm{hr}$ & $13500 \pm 406$ & $14300 \pm 430$ & $14400 \pm 433$ & $14600 \pm 439$ \\
\hline $20 \mathrm{hr}$ & $13800 \pm 415$ & $14200 \pm 427$ & $14200 \pm 427$ & $14300 \pm 430$ \\
\hline $22 \mathrm{hr}$ & $13900 \pm 418$ & $14300 \pm 430$ & $\mathrm{n} / \mathrm{m}$ & $\mathrm{n} / \mathrm{m}$ \\
\hline $24 \mathrm{hr}$ & $14067 \pm 244^{(\mathrm{e})}$ & $14433 \pm 250^{(\mathrm{e})}$ & $14900 \pm 448$ & $15000 \pm 451$ \\
\hline $\begin{array}{l}\text { (a) Dissolved alum } \\
\text { (SwRI). } \\
\text { (b) The sample use } \\
\text { (c) Note that water } \\
\text { runs as injected } \\
\text { (d) Uncertainties ar } \\
\text { (e) Triplicate samp } \\
\text { " } \mathrm{n} / \mathrm{m} \text { " = not measure } \\
\text { The } \pm \text { values are equ } \\
\text { deviations) that were } \\
\text { samples were taken, }\end{array}$ & $\begin{array}{l}\mathrm{m} \text { was measured in } \mu \mathrm{g} / \mathrm{g} \\
\text { these laboratory-scale to } \\
\mathrm{s} \text { added all at once at the } \\
\text { am. } \\
\text { stimated for initial dilute } \\
\text { were taken at this point. } \\
\text { o half the laboratory unc } \\
\text { pplied by the analytical } \\
\text { concentrations are mean }\end{array}$ & $\begin{array}{l}\text { uid by inductively coupl } \\
\text { was taken from the PEI } \\
\text { ginning of laboratory-sc } \\
\text { hrough } 24 \text {-hour samples } \\
\text { e concentration shown } \\
\text { ainty values (equivalent } \\
\text { anization for each conce } \\
\text { f the set, and the } \pm \text { value }\end{array}$ & $\begin{array}{l}\text { plasma (ICP) at Southr } \\
\text { fter } \mathrm{NaOH} \text { had been add } \\
\text { runs, but was added gre } \\
\text { ing similar data from In } \\
\text { he mean of the set. } \\
\text { a } 95 \% \text { confidence inter } \\
\text { ation measurement. In } \\
\text { re standard deviations }\end{array}$ & $\begin{array}{l}\text { lly throughout the PEP } \\
\text { ated Test D, Batch } 1 . \\
\text { or two standard } \\
\text { cases where triplicate } \\
\text { e means. }\end{array}$ \\
\hline
\end{tabular}


Table A.35. Mass Concentration of Tracers in Bulk Slurry During Caustic-Leach Integrated Test D

\begin{tabular}{|c|c|c|c|c|}
\hline \multirow[b]{2}{*}{ Point in Process } & \multicolumn{4}{|c|}{$\begin{array}{c}\text { Concentration of Tracer }(\mu \mathrm{g} / \mathrm{g}) \text { in Bulk Slurry }{ }^{(\mathrm{a})} \\
\pm 1 \text { Standard Deviation from Laboratory Analysis }\end{array}$} \\
\hline & $\begin{array}{l}\text { Integrated Test D, } \\
\text { Batch } 1 \text { in Tank } \\
\text { T02A }^{(\mathrm{Sr})}\end{array}$ & $\begin{array}{l}\text { Integrated Test D, } \\
\text { Batch } 2 \text { in Tank } \\
\mathrm{T}_{02} \mathrm{~A}^{(\mathrm{Fe})}\end{array}$ & $\begin{array}{l}\text { Laboratory-Scale } \\
\text { Test D-1 }{ }^{\text {(b, c, d. Fe })}\end{array}$ & $\begin{array}{l}\text { Laboratory-Scale } \\
\text { Test D-2 }\end{array}$ \\
\hline Feed & $41.5 \pm 0.8^{(\mathrm{e})}$ & $4032 \pm 84^{(\mathrm{e})}$ & $4032 \pm 84^{(\mathrm{e})}$ & $4032 \pm 84^{(\mathrm{e})}$ \\
\hline Before $\mathrm{NaOH}$ & $210 \pm 4^{(\mathrm{e})}$ & $22589 \pm 441^{(\mathrm{e})}$ & $22589 \pm 441^{(\mathrm{e})}$ & $22589 \pm 441^{(\mathrm{e})}$ \\
\hline After $\mathrm{NaOH}$ & $90.6 \pm 3.1$ & $8864 \pm 299$ & $\mathrm{n} / \mathrm{m}$ & $\mathrm{n} / \mathrm{m}$ \\
\hline Initial diluted & $\mathrm{n} / \mathrm{m}$ & $\mathrm{n} / \mathrm{m}$ & $7670 \pm 259$ & $7730 \pm 261$ \\
\hline At $75^{\circ} \mathrm{C}$ & $\mathrm{n} / \mathrm{m}$ & $\mathrm{n} / \mathrm{m}$ & $\mathrm{n} / \mathrm{m}$ & $\mathrm{n} / \mathrm{m}$ \\
\hline $0 \mathrm{hr}$ & $85.5 \pm 1.7^{(\mathrm{e})}$ & $8920 \pm 174^{(\mathrm{e})}$ & $\mathrm{n} / \mathrm{m}$ & $\mathrm{n} / \mathrm{m}$ \\
\hline $1 \mathrm{hr}$ & $\mathrm{n} / \mathrm{m}$ & $\mathrm{n} / \mathrm{m}$ & $\mathrm{n} / \mathrm{m}$ & $\mathrm{n} / \mathrm{m}$ \\
\hline $2 \mathrm{hr}$ & $\mathrm{n} / \mathrm{m}$ & $\mathrm{n} / \mathrm{m}$ & $\mathrm{n} / \mathrm{m}$ & $\mathrm{n} / \mathrm{m}$ \\
\hline $4 \mathrm{hr}$ & $84.8 \pm 2.9$ & $9077 \pm 306$ & $\mathrm{n} / \mathrm{m}$ & $\mathrm{n} / \mathrm{m}$ \\
\hline $8 \mathrm{hr}$ & $82.9 \pm 2.8$ & $8425 \pm 285$ & $\mathrm{n} / \mathrm{m}$ & $\mathrm{n} / \mathrm{m}$ \\
\hline $10 \mathrm{hr}$ & $\mathrm{n} / \mathrm{m}$ & $\mathrm{n} / \mathrm{m}$ & $\mathrm{n} / \mathrm{m}$ & $\mathrm{n} / \mathrm{m}$ \\
\hline $12 \mathrm{hr}$ & $80.0 \pm 2.7$ & $8691 \pm 294$ & $\mathrm{n} / \mathrm{m}$ & $\mathrm{n} / \mathrm{m}$ \\
\hline $14 \mathrm{hr}$ & $\mathrm{n} / \mathrm{m}$ & $\mathrm{n} / \mathrm{m}$ & $\mathrm{n} / \mathrm{m}$ & $\mathrm{n} / \mathrm{m}$ \\
\hline $16 \mathrm{hr}$ & $78.1 \pm 2.7$ & $8245 \pm 278$ & $\mathrm{n} / \mathrm{m}$ & $\mathrm{n} / \mathrm{m}$ \\
\hline $18 \mathrm{hr}$ & $\mathrm{n} / \mathrm{m}$ & $\mathrm{n} / \mathrm{m}$ & $\mathrm{n} / \mathrm{m}$ & $\mathrm{n} / \mathrm{m}$ \\
\hline $20 \mathrm{hr}$ & $\mathrm{n} / \mathrm{m}$ & $\mathrm{n} / \mathrm{m}$ & $\mathrm{n} / \mathrm{m}$ & $\mathrm{n} / \mathrm{m}$ \\
\hline $22 \mathrm{hr}$ & $\mathrm{n} / \mathrm{m}$ & $\mathrm{n} / \mathrm{m}$ & $\mathrm{n} / \mathrm{m}$ & $\mathrm{n} / \mathrm{m}$ \\
\hline $24 \mathrm{hr}$ & $75.4 \pm 1.5^{(\mathrm{e})}$ & $8190 \pm 160^{(\mathrm{e})}$ & $8160 \pm 275^{(f)}$ & $8010 \pm 270^{(\mathrm{f})}$ \\
\hline \multicolumn{5}{|c|}{$\begin{array}{l}\text { (a) For the PEP tests, tracer was measured by ICP at SwRI for centrifuged solids and for the decanted liquid, in units of } \mu \mathrm{g} / \mathrm{g} \text {. } \\
\text { The bulk slurry Al concentration was calculated from these measured concentrations and from the masses of centrifuged } \\
\text { solids and liquid, which were weighed at PNNL. }\end{array}$} \\
\hline \multicolumn{5}{|c|}{ (b) The sample used in these laboratory-scale tests was taken from the PEP after $\mathrm{NaOH}$ had been added. } \\
\hline \multicolumn{5}{|c|}{$\begin{array}{l}\text { (c) Note that water was added all at once at the beginning of laboratory-scale runs, but was added gradually throughout the } \\
\text { PEP runs as injected steam. }\end{array}$} \\
\hline \multicolumn{5}{|c|}{ (d) Uncertainties are estimated for initial diluted through 24-hour samples using similar data from Integrated Test D, Batch 1.} \\
\hline \\
\hline \\
\hline \multicolumn{5}{|c|}{ (Sr) Solid tracer is strontium for this column. } \\
\hline \multicolumn{5}{|c|}{ (Fe) Solid tracer is iron for this column. } \\
\hline \multicolumn{5}{|c|}{ "n/m" = not measured } \\
\hline \multicolumn{5}{|c|}{$\begin{array}{l}\text { The } \pm \text { values are standard deviations calculated by linearized error propagation methods. For duplicate or triplicate sets, the } \pm \\
\text { values are standard deviations of the means. The method used to estimate the uncertainty of the centrifuged solids weight } \\
\text { fraction depends on measurements for the triplicate data sets. The different number of triplicate data sets in PEP and } \\
\text { laboratory-scale tests causes differences in centrifuged solids fraction uncertainty, and therefore in slurry concentration } \\
\text { uncertainty, for the same sample, when determined from PEP test data sets and from laboratory-scale test data sets. See } \\
\text { Appendix C of WTP-RPT-186, Rev. 0, EFRT M12 Issue Resolution: Caustic-Leach Rate Constants from PEP and Laboratory- } \\
\text { Scale Tests for more information. }\end{array}$} \\
\hline
\end{tabular}


Table A.36. Mass Concentration of Liquid Tracer During Caustic-Leach Integrated Test D

\begin{tabular}{|c|c|c|c|c|}
\hline \multirow[b]{2}{*}{ Point in Process } & \multicolumn{4}{|c|}{$\begin{array}{c}\text { Concentration of Liquid Tracer }(\mu \mathrm{g} / \mathrm{g}) \text { in Liquid Phase }{ }^{(\mathrm{a})} \\
\pm 1 \text { Standard Deviation from Laboratory Analysis }\end{array}$} \\
\hline & $\begin{array}{l}\text { Integrated Test D, } \\
\text { Batch } 1 \text { in Tank } \\
\mathrm{T}_{0} 2 \mathrm{~A}^{(\mathrm{Cl})}\end{array}$ & $\begin{array}{l}\text { Integrated Test D, } \\
\text { Batch } 2 \text { in Tank } \\
\mathrm{T}_{02} \mathrm{~A}^{(\mathrm{Cl})}\end{array}$ & $\begin{array}{l}\text { Laboratory-Scale } \\
\text { Test D- } 1^{(\mathrm{b}, \mathrm{c}, \mathrm{d}, \mathrm{NO} 3)}\end{array}$ & $\begin{array}{l}\text { Laboratory-Scale } \\
\text { Test D-2 } 2^{(\mathrm{b}, \mathrm{c}, \mathrm{d}, \mathrm{NO})}\end{array}$ \\
\hline Feed & $1023 \pm 18^{(\mathrm{e})}$ & $1023 \pm 18^{(\mathrm{e})}$ & $75633 \pm 1332^{(\mathrm{e})}$ & $75633 \pm 1332^{(\mathrm{e})}$ \\
\hline Before $\mathrm{NaOH}$ & $1013 \pm 18^{(\mathrm{e})}$ & $1067 \pm 19^{(\mathrm{e})}$ & $82800 \pm 1438^{(\mathrm{e})}$ & $82800 \pm 1438^{(\mathrm{e})}$ \\
\hline After $\mathrm{NaOH}$ & $434 \pm 14$ & $366 \pm 12$ & $\mathrm{n} / \mathrm{m}$ & $\mathrm{n} / \mathrm{m}$ \\
\hline Initial diluted & $\mathrm{n} / \mathrm{m}$ & $\mathrm{n} / \mathrm{m}$ & $26030 \pm 788$ & $27269 \pm 825$ \\
\hline At $75^{\circ} \mathrm{C}$ & $422 \pm 13$ & $364 \pm 12$ & $28376 \pm 859$ & $27756 \pm 840$ \\
\hline $0 \mathrm{hr}$ & $403 \pm 7^{(\mathrm{e})}$ & $374 \pm 7^{(\mathrm{e})}$ & $27314 \pm 827$ & $26915 \pm 815$ \\
\hline $1 \mathrm{hr}$ & $403 \pm 13$ & $374 \pm 12$ & $27579 \pm 835$ & $27624 \pm 836$ \\
\hline $2 \mathrm{hr}$ & $394 \pm 13$ & $369 \pm 12$ & $27314 \pm 827$ & $27491 \pm 832$ \\
\hline $4 \mathrm{hr}$ & $403 \pm 13$ & $367 \pm 12$ & $28066 \pm 849$ & $27889 \pm 844$ \\
\hline $8 \mathrm{hr}$ & $391 \pm 13$ & $351 \pm 11$ & $29881 \pm 904$ & $27668 \pm 837$ \\
\hline $10 \mathrm{hr}$ & $389 \pm 12$ & $328 \pm 11$ & $29129 \pm 882$ & $28598 \pm 866$ \\
\hline $12 \mathrm{hr}$ & $381 \pm 12$ & $333 \pm 11$ & $28996 \pm 878$ & $29107 \pm 881$ \\
\hline $14 \mathrm{hr}$ & $372 \pm 12$ & $327 \pm 11$ & $28642 \pm 867$ & $29616 \pm 896$ \\
\hline $16 \mathrm{hr}$ & $376 \pm 12$ & $315 \pm 11$ & $29926 \pm 906$ & $28686 \pm 868$ \\
\hline $18 \mathrm{hr}$ & $363 \pm 12$ & $322 \pm 11$ & $30147 \pm 912$ & $28996 \pm 878$ \\
\hline $20 \mathrm{hr}$ & $358 \pm 12$ & $308 \pm 10$ & $31077 \pm 941$ & $29527 \pm 894$ \\
\hline $22 \mathrm{hr}$ & $363 \pm 12$ & $307 \pm 10$ & $\mathrm{n} / \mathrm{m}$ & $\mathrm{n} / \mathrm{m}$ \\
\hline $24 \mathrm{hr}$ & $358 \pm 7^{(\mathrm{e})}$ & $310 \pm 6^{(\mathrm{e})}$ & $30634 \pm 927$ & $29837 \pm 903$ \\
\hline \multicolumn{5}{|c|}{$\begin{array}{l}\text { (d) Uncertainties are estimated for initial diluted through 24-hour samples using similar data from Integrated Test D, Batch } 1 . \\
\text { (e) Triplicate samples were taken at this point. The concentration shown is the mean of the set. } \\
\left(\mathrm{NO}_{3}\right) \text { Liquid tracer is nitrate for this column. } \\
(\mathrm{Cl}) \text { Liquid tracer is chloride for this column. } \\
\text { "n/m" = not measured }\end{array}$} \\
\hline
\end{tabular}



Appendix B

\section{Filtration Appendix}





\section{Appendix B: Filtration Appendix}

This appendix provides supplementary information to Section 8 of this report. It provides the equations underlying the mass balance for dewatering and washing filtration operations. It also provides the equations for estimating filter backpulse effectiveness. Finally, it presents a detailed description and analysis of backpulsing effectiveness for backpulse events Integrated Test A and Integrated Test B.

\section{B.1 Analysis of Solids Dewatering/Concentration Operations}

Dewatering operations affect a change in the slurry UDS concentration by removing permeate from the slurry. Because the filtration regime (either membrane- or cake-resistance controlled) and filter flux are strongly dependent on the solids concentration, knowledge of UDS throughout the dewatering process is crucial to understanding the dewatering behavior. Even though the permeate production rate was continuously monitored and recorded (typically at a frequency of $1 \mathrm{~Hz}$ ), only a limited number of analytical samples were taken during dewater operations. As a result, the concentration at which the dewatering curve may be assessed is restricted to the limited number of unique UDS concentrations measured. To overcome this limitation, a mass balance of the circulating slurry volume is typically performed to fill in the "gaps" between measured UDS concentrations.

During PEP dewatering operations, slurry concentration may be accompanied by transfer of dilute slurry from either Tank T01A or T01B and return of permeate to the filter-loop when the filters are backpulsed. Because the rate of permeate production and slurry transfer are measured using calibrated sensors, it is possible, given the known starting mass and concentration of circulating slurry and the concentration of transferred slurry, to estimate the UDS as a function of time. The volume of permeate returned during backpulse events can be determined by evaluating the change in pulse-pot permeate level. However, the level sensors in the pulse-pots were not calibrated and, may be used for indication only. While this impacts the ability to provide qualified material balances for the filter-loop, estimates of the slurry concentration as a function of time can be provided and verified (or fit) against analytical measurements of slurry UDS concentration. For the evaluations of slurry dewatering curves provided herein, values for the 1) initial slurry UDS concentration, 2) initial Tank T02A slurry mass, and 3) transfer slurry UDS concentration were selected to fit available analytical data.

For filtration mass balances in PEP, the concentration of the circulating slurry, defined as that contained in the slurry reservoir (i.e., mixing tank) and filter-loop, is assessed at several equally spaced time intervals $(\Delta t)$. At a given time step, $n$, the slurry UDS concentration $x(n)$ can be determined using

$$
x(n)=\frac{m_{U D S}(n)}{m_{T}(n)}
$$

where $m_{U D S}(n)$ is the mass of undissolved solids, $m_{T}(n)$ is the total mass of circulating of slurry, and $n$ is the time interval.

Filtration is assumed to retain all slurry solids and proceed with no dissolution of slurry solids. Then, the mass of undissolved solids can be evaluated as a function of time as 


$$
m_{U D S}(n)=m_{U D S}(n-1)+x_{s} \rho_{s}\left[F_{A}(n)+F_{B}(n)\right] \cdot \Delta t
$$

where $F_{A}(n)$ and $F_{B}(n)$ is the volumetric rate of slurry transfer from Tank T01A and T01B, respectively, $\rho_{s}$ is the density of the transfer slurry, and $x_{s}$ is the UDS concentration of transferred slurry. $F_{A}(n)$ and $F_{B}(n)$ are both zero when batch transfers of slurry to Tank T02A are not occurring.

The mass of UDS can be expressed in terms of the initial slurry UDS concentration, $x_{o}$, and the initial slurry circulating mass, $m_{T, o}$, through

$$
m_{U D S}(n)=x_{o} m_{T, o}+\Delta t \cdot x_{s} \rho_{s} \cdot \sum_{j=1}^{n}\left[F_{A}(j)+F_{B}(j)\right]
$$

The mass of circulating slurry at time interval $n$ is given by

$$
m_{T}(n)=m_{T}(n-1)+B(n)-G(n) \cdot \Delta t
$$

Here, $G(n)$ is the mass flow rate of permeate measured by the PEP Coriolis permeate flowmeter and $B(n)$ is the mass of permeate returned via backpulsing (and is zero when not backpulsing). The circulating slurry mass may also be expressed in terms of the original slurry mass using

$$
m_{T}(n)=m_{T, o}+\sum_{j=1}^{n} B(j)-\Delta t \cdot \sum_{j=1}^{n} G(j)
$$

Thus, the slurry UDS concentration at time interval $n$ may be expressed in terms of the previous permeate mass flow rates

$$
x(n)=\frac{x_{o} m_{T, o}+\Delta t \cdot x_{s} \rho_{s} \cdot \sum_{j=1}^{n}\left[F_{A}(j)+F_{B}(j)\right]}{m_{T, o}+\sum_{j=1}^{n} B(j)-\Delta t \cdot \sum_{j=1}^{n} G(j)}
$$

\section{B.2 Analysis of Slurry Washing Operations}

Washing operations reduce the concentration of slurry DS through batch transfers of inhibited water (IW) to Tank T02A and subsequent removal of the diluted solution via filtration. Tank T02A level is maintained by matching the volume of water added to the volume of permeate removed. The drop in supernate dissolved solids concentration typically yields a corresponding increase in filter permeate rates as a result of a drop in permeate viscosity (although other mechanisms may also affect flux). To allow calculation of filter flux in GPM/ $\mathrm{ft}^{2}$ as a function of the test time, the permeate density must also be determined with test time. To do this, the permeate DS is estimated using a mass balance similar to that used to estimate UDS. As with slurry concentration operations, measurement of permeate DS is limited to the number of analytical samples taken during testing. These limited DS measurements can be supplemented by performing a material balance on the permeate DS. 
A material balance for washing operations can be accomplished using the known rate of permeate production and inhibited water addition along with estimates for initial slurry mass and dissolved solids content. Analysis of dewatering operations is complicated by both dissolved and undissolved solids solubility limits. To simplify the current analysis, the following assumptions are made:

- dissolved solids do not precipitate during washing operations

- undissolved solids do not dissolve upon addition of IW

- mixing of IW with the circulating slurry mass is instantaneous

- inhibited water contributes a negligible amount of dissolved solids to the circulating mass.

These assumptions simplify the circulating slurry mass balance, but impact the ability of the mass balance to provide accurate stand-alone estimates of the dissolved solids as a function of time during washing operations. This deficiency is overcome by selecting an initial circulating slurry mass and concentration (i.e., those at the start of washing operations) so that DS predictions made through mass balance match the results of DS analytical samples for the washing operation under consideration. With reasonable selection of initial slurry mass and concentration, the simplified material balance allows estimation of the DS concentration throughout the washing process.

At a given time step $n$, the DS concentration $y(n)$ can be determined using

$$
y(n)=\frac{m_{D S}(n)}{m_{L}(n)}
$$

where $m_{D S}(n)$ is the mass of dissolved solids in the supernate, $m_{L}(n)$ is the mass of supernate associated with the circulating slurry, and $n$ is the time interval.

Given the assumptions outlined above, the mass of dissolved solids can be evaluated as a function of time as

$$
m_{D S}(n)=m_{D S}(n-1)-y_{D S}(n-1) \cdot G(n-1) \cdot \Delta t
$$

Here, the second term of Equation B.8 accounts for the loss of dissolved solids mass through filter permeate. It should also be noted that the form of the equation employs a forward predict of the step $n$ using information from the previous step $(n-1)$. The mass of DS can be expressed in terms of the initial slurry DS concentration, $\mathrm{y}_{\mathrm{o}}$, and the initial slurry circulating mass, $\mathrm{m}_{\mathrm{T}, \mathrm{o}}$, through

$$
m_{D S}(n)=\left(1-x_{o}\right) y_{o} m_{T, o}-\Delta t \cdot \sum_{j=1}^{n-1} y_{D S}(j) \cdot G(j)
$$

The mass of supernate associated with the circulating slurry at time interval $n$ is given by

$$
m_{L}(n)=m_{L}(n-1)+\left[F_{I W}(n-1)-G(n-1)\right] \cdot \Delta t
$$


Here, $G(n-1)$ is the mass flow rate of permeate and $F_{I W}(n-1)$ is the flow of IW into Tank T02A (both at time step $n$-1). The supernate mass associated with the circulating slurry may also be expressed in terms of the original slurry mass using

$$
m_{L}(n)=\left(1-x_{o}\right) m_{T, o}+\Delta t \cdot \sum_{j=1}^{n-1}\left[F_{I W}(j)-G(j)\right]
$$

Thus, the DS concentration at time interval $n$ may be expressed in terms of the previous permeate mass flow rates

$$
y(n)=\frac{\left(1-x_{o}\right) y_{o} m_{T, o}-\Delta t \cdot \sum_{j=1}^{n-1} y_{D S}(j) \cdot G(j)}{\left(1-x_{o}\right) m_{T, o}+\Delta t \cdot \sum_{j=1}^{n-1}\left[F_{I W}(j)-G(j)\right]}
$$

\section{B.3 Evaluation of Backpulsing Effectiveness}

The goal of backpulsing is to increase the rate of permeate production by disrupting or removing surface (typically solids cake) and depth-fouling that limits permeate flow. Backpulsing temporarily increases the filter rate at the cost of the mass of permeate forced back through the filters and the mass of permeate that could have been produced had filtration not been stopped to allow backpulsing. In addition to the loss of permeate produced, backpulsing may yield an increased potential for irreversible depth-fouling, lowering the filter flux achieved at for long duration filtration operations. For Integrated Tests A and B, backpulsing was applied (when needed) during post-caustic-leach concentration activities in an attempt to reduce the time required to complete the dewatering operations.

For backpulsing to be beneficial, the net permeate filtered in the backpulsed system must be greater than the permeate produced had there been no backpulsing. Backpulsing was implemented on an as-needed basis in Integrated Tests A and B. No parallel control filtration studies where the slurry was treated without backpulsing (either on other PEP filter bundles or as a complete separate test). Because filter flux is strongly dependent on filter and backpulse history and because of the unusual fouling dynamics observed in the low-solids conditioning tests (see Daniel et al. 2009b), a point of reference for non-backpulsed permeate production masses to which the backpulsed operations can be compared cannot be defined for the current studies. Consequently, it is not possible to evaluate the overall impact of backpulsing on the average rate of filtration.

For the current report, a rough assessment of individual backpulsing effectiveness shall be made from the limited test data available. These assessments compare the actual mass of permeate filtered during the interval between two adjacent backpulses to an estimate of the maximum mass of permeate that could have been produced had the first backpulse not taken place.

To facilitate evaluation of backpulsing effectiveness, consider the period of filtration that occurs between two backpulses, backpulse 1 and backpulse 2, at times $t_{1}$ and $t_{2}$, respectively (where $t_{2}>t_{1}$ ). Here, $t_{1}$ and $t_{2}$ correspond to the time permeate production is stopped to perform the backpulse. Times $t_{1}$ and $t_{2}$ have associated values of permeate production rate, $R_{i}$, total mass of permeate filtered, $M_{i}$, and 
mass of permeate returned during backpulse operations, $B_{i}$. For these three quantities, $i$ corresponds to the time subscript ( 1 or 2 ). Given these values, the actual mass of permeate produced between backpulses 1 and $2, m_{a c t}{ }^{(12)}$, is

$$
m_{a c t}^{(12)}=\left(M_{2}-M_{1}\right)-B_{1}
$$

An estimate of the best possible permeate production mass without backpulsing, $m_{\text {best }}{ }^{(12)}$, is determined from

$$
m_{\text {best }}^{(12)}=R_{1} \cdot \Delta t^{(12)}
$$

where $\Delta t^{(12)}$ is the interval of time between the two backpulses given by

$$
\Delta t^{(12)}=t_{2}-t_{1}
$$

Calculation of $m_{\text {best }}{ }^{(12)}$ assumes no loss of flux as a result of cake formation/maturation and/or depth-fouling; therefore, this quantity provides an upper bound for the mass of permeate that could be produced had backpulsing not been conducted.

Given these parameters, the effectiveness of backpulsing can be evaluated as a percent change in mass filtered as a result of backpulse 1 . That is, the local (individual) effectiveness of backpulsing over time interval $\Delta t^{(12)}$, defined as $E^{(12)}$, is

$$
E^{(12)}=\left(\frac{m_{a c t}^{(12)}-m_{\text {best }}^{(12)}}{m_{\text {best }}^{(12)}}\right) \cdot 100 \%
$$

Under this analysis:

- $E^{(12)}>0$ indicates backpulsing was beneficial and increased the permeate production mass over the time interval examined.

- $E^{(12)} \sim 0$ indicates backpulsing yielded no improvement in permeate production mass over the time interval examined.

- $E^{(12)}<0$ indicates backpulsing was harmful and reduced the permeate production mass over the time interval examined.

For the current evaluation of backpulsing effectiveness, the benefits of backpulsing depend both on the flux recovery and on the time allowed before the next backpulse (i.e., backpulse 2). Because estimates of best possible permeate production mass used a single production rate value, $m_{\text {best }}{ }^{(12)}$ will not be impacted by declines in permeate production rate. In contrast, $m_{a c t}{ }^{(12)}$ is based on actual permeate production rates that are impacted by filter transience. This means that $E^{(12)}$ may underestimate actual performance for large $\Delta t^{(12)}$. 


\section{B.4 Analysis of Integrated Test A Backpulsing}

During Integrated Test A post-caustic-leach concentration operations, a series of backpulses were performed in an attempt to reduce the required filtration time and investigate backpulsing effectiveness. These backpulses were conducted over a period starting on February 5 and ending on February 14, 2009. For the current analysis and discussion, these backpulses are presented as 38 separate backpulse events performed on UFP-FILT-T01A. Each event was typically comprised of a single backpulse (an example is shown in Figure B.1); however, select events included multiple backpulses performed within a few minutes of each other. In addition, the programmable logic controller (PLC) controller errors sometimes caused a double backpulse (see Figure B.2).

The sequence of events for each backpulse was typically as follows:

1. Permeate collection was stopped.

2. The pulse-pot was drained to the target pulse level (typically around 10 inches).

3. The pulse-pot was charged to the target overpressure, defined as the difference between pulse-pot pressure and filter inlet pressure.

4. The fast-acting valve between the pulse-pot and filter was opened, allowing the high pressure in the pulse-pot to pressurize the filter shell and force a small amount of the liquid in the filter shell backward through the filter elements.

5. When the pressure inside the pulse-pot was reduced to the target deadband pressure, the fast-acting valve was closed.

6. The permeate valve was opened and permeate production resumed.

Backpulses typically used an overpressure target of 40 psid, but overpressures from $\sim 20$ psid to $\sim 60$ psid were tested. A summary of backpulse operations conducted during Integrated Test A is provided in Table B.1. There were seven instances where apparent PLC errors caused double pulses. Because the volume of liquid actually backpulsed through the filters is determined by the pulse-pot headspace volume and pressure drop in the pulse-pot (i.e., the drop from the overpressure to the deadband pressure), less liquid in the pulse-pot when it is pressurized results in a correspondingly greater volume of liquid pushed backward through the filter elements. Thus the second backpulse of a PLC-error double pulse is longer and results in a larger volume of liquid pushed backward through the filter elements than the first backpulse.

Table B. 2 presents a summary of permeate production before and after each backpulse. For all cases, backpulsing provided a significant $(\sim 100 \%)$, but temporary, increase in permeate production rate. Figure B. 1 and Figure B. 2 show examples of the permeate production recovery and a portion of the subsequent rapid decline. There is a general decline in the maximum permeate production rate recovered by backpulsing throughout the dewatering process. This observation is consistent with the general declines in filter flux in Figure 8.6 and Figure 8.7 (see Section 8). This could indicate irreversible filter-fouling, but may also be associated with increased slurry UDS (and the speed at which the cake is capable of reforming at higher slurry concentrations. In addition, comparison of the flux recovery for backpulse events with multiple planned pulses (\#3, \#5, and \#8) indicate that for the backpulse conditions tested, repeat pulses do not provide significant (greater than 10\%) increases in recovered permeate rate 
over the first pulse. That is, a single backpulse appears to be sufficient to clear the filter surface of all reversible cake formation for the range of backpulse TMPs achieved (roughly 20 psid to 60 psid).

Finally, Table B.3 presents estimations of individual backpulse effectiveness for Integrated Test A. With only a few exceptions, the backpulsing schedule as employed for Integrated Test A appears to have effectively increased the local filter flux, as the effectiveness (or percent increase in filtrate produced by each backpulse) is generally around $10 \%$ or greater.

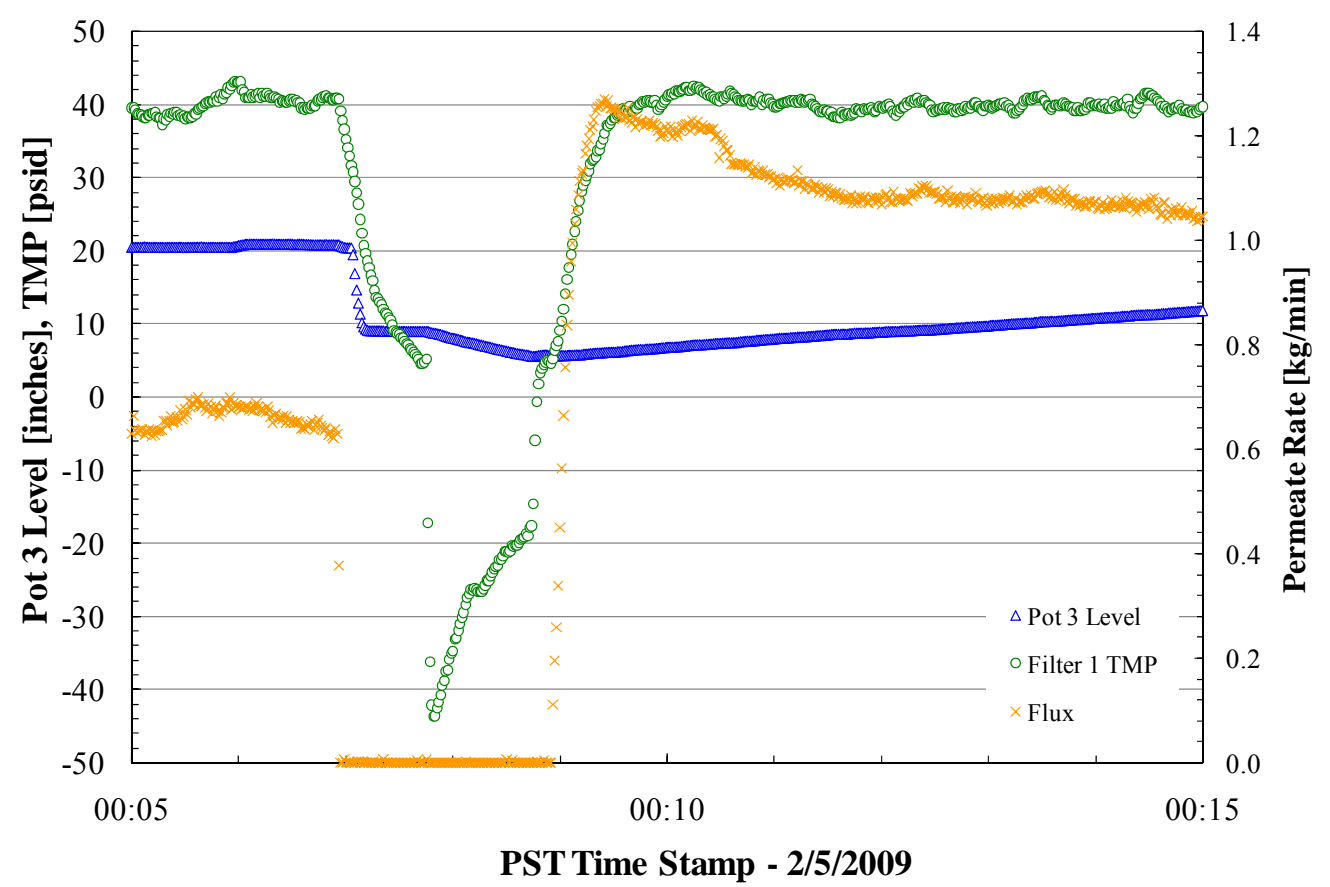

Figure B.1. Backpulse Event During Post-Caustic Leaching Operations Showing a Single Pulse (for information only) 


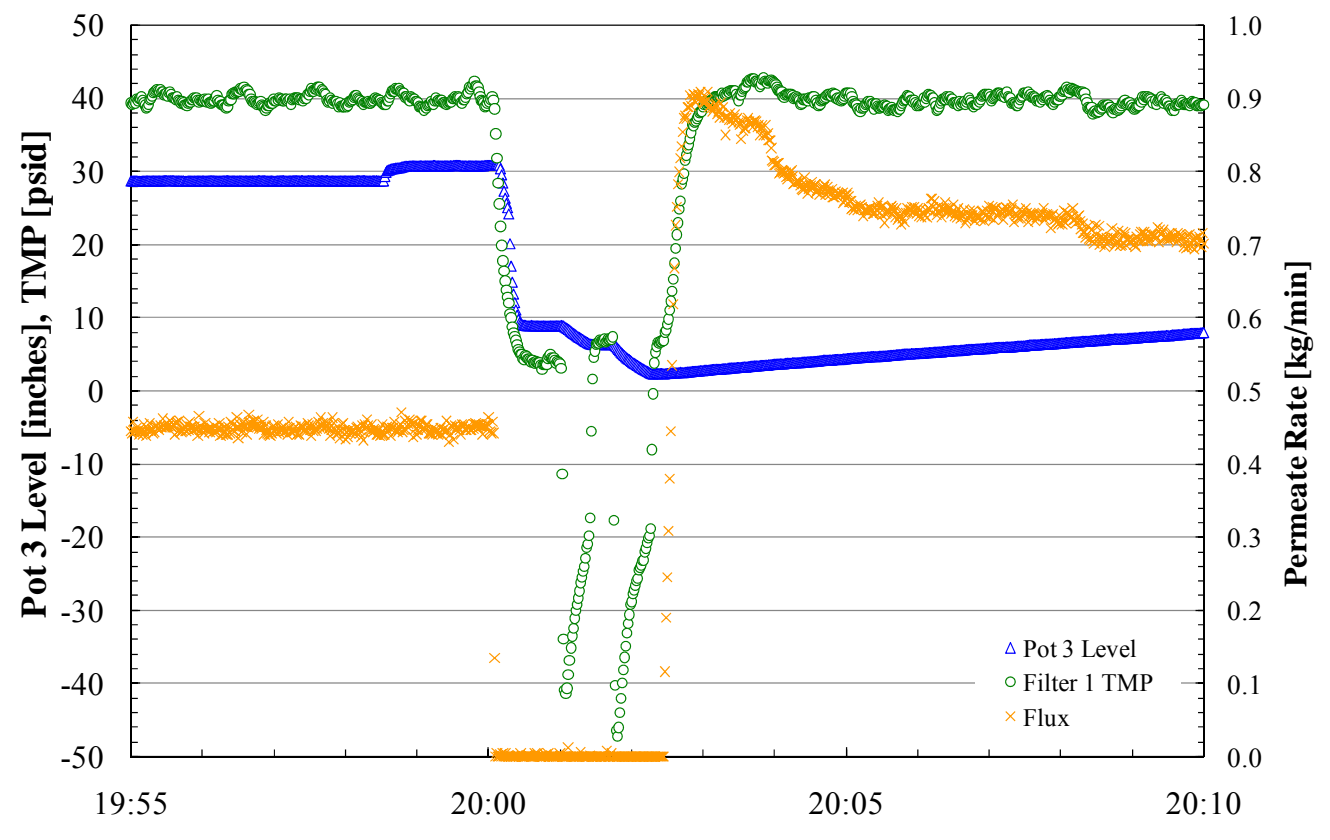

Time Stamp - 2/12/2009

Figure B.2. Backpulse Event During Post-Caustic Leaching Operations Showing a Double Pulse (for information only)

\section{B.5 Analysis of Integrated Test B Backpulsing}

During Integrated Test B post-caustic-leach concentration operations, four backpulses were performed on an as-needed basis to reduce the required filtration time. These four backpulses were conducted from March 18 to March 19, 2009. Unlike backpulsing in Integrated Test A, the backpulse event in Integrated Test B was comprised of a single backpulse without any double pulse errors.

Backpulsing was performed using an overpressure of 40 psid and a target pulse-pot level of 10 inches. Table B. 4 presents a summary of backpulse operations conducted and conditions achieved during post-caustic-leach concentration activities in Integrated Test B. Pulse volumes fell between 0.45 gal and 0.81 gal and never brought the pulse-pots to a near-empty configuration (in contrast to backpulsing in Integrated Test A).

Table B.5 presents a summary of permeate production before and after each backpulse. These results (in conjunction with those in Section 8.4.3) confirm that backpulsing always yielded a significant but transient flux recovery. Finally, Table B.6 presents estimations of individual backpulse effectiveness. The results indicate that for Integrated Test B post-caustic-leach operations, backpulsing did not appear to significantly improve flux. 
Table B.1. Summary of Backpulse TMPs, Durations, and Volumes for Backpulsing Conducted During Post-Caustic-Leach Concentration in Integrated Test A

\begin{tabular}{|c|c|c|c|c|c|c|c|c|}
\hline Event & Pulse & Type & $\begin{array}{c}\text { PST Time } \\
\text { (mm-dd hh:mm) }\end{array}$ & $\begin{array}{c}\text { Pulse-Pot } \\
\text { Level }^{(a)} \\
\text { (inches) }\end{array}$ & $\begin{array}{c}\text { Final Pot } \\
\text { Level }^{(a)} \\
\text { (inches) }\end{array}$ & $\begin{array}{l}\text { TMP } \\
\text { (psid) }\end{array}$ & $\begin{array}{l}\text { Duration } \\
\text { (s) }\end{array}$ & $\begin{array}{l}\text { Volume }^{(\mathrm{a})} \\
\quad(\mathrm{gal})\end{array}$ \\
\hline 1 & -- & Single & 02-05 00:06 & 9.06 & 5.60 & 44 & 78 & 0.85 \\
\hline 2 & -- & Single & $02-05 \quad 15: 44$ & 8.89 & 5.93 & 44 & 68 & 0.73 \\
\hline \multirow{2}{*}{3} & 1 & Single & $02-05 \quad 21: 45$ & 8.90 & 6.31 & 44 & 57 & 0.64 \\
\hline & 2 & Double & $02-05$ 21:54 & 8.58 & 0.39 & 47 & 140 & 2.0 \\
\hline 4 & -- & Single & $02-06 \quad 02: 59$ & 8.98 & 7.98 & 28 & 39 & 0.24 \\
\hline \multirow{2}{*}{5} & 1 & Single & $02-06 \quad 10: 44$ & 8.68 & 7.74 & 27 & 35 & 0.23 \\
\hline & 2 & Single & 02-06 10:49 & 8.53 & 7.17 & 28 & 40 & 0.33 \\
\hline 6 & - & Single & $02-06 \quad 17: 24$ & 8.98 & 6.31 & 57 & 41 & 0.66 \\
\hline 7 & -- & Single & 02-07 00:09 & 8.97 & 6.29 & 58 & 38 & 0.66 \\
\hline \multirow{5}{*}{8} & 1 & Single & 02-07 07:02 & 8.72 & 5.93 & 56 & 37 & 0.69 \\
\hline & 2 & Single & 02-07 07:32 & 8.52 & 5.51 & 56 & 37 & 0.74 \\
\hline & 3 & Double & 02-07 07:40 & 8.50 & 0.67 & 60 & 78 & 1.9 \\
\hline & 4 & Single & 02-07 07:55 & 8.57 & 5.45 & 56 & 37 & 0.77 \\
\hline & 5 & Single & 02-07 08:04 & 8.57 & 5.48 & 55 & 37 & 0.76 \\
\hline 9 & -- & Single & $02-0714: 04$ & 8.96 & 6.67 & 54 & 34 & 0.56 \\
\hline 10 & -- & Single & 02-07 18:32 & 8.98 & 6.67 & 64 & 34 & 0.57 \\
\hline 11 & -- & Single & 02-07 21:59 & 8.96 & 2.68 & 66 & 59 & 1.5 \\
\hline 12 & -- & Single & 02-08 00:59 & 8.99 & 6.30 & 39 & 43 & 0.66 \\
\hline 13 & -- & Single & 02-08 03:59 & 8.98 & 6.35 & 42 & 41 & 0.65 \\
\hline 14 & -- & Double & 02-08 06:59 & 8.97 & 1.70 & 45 & 93 & 1.8 \\
\hline 15 & -- & Single & 02-08 10:05 & 8.97 & 6.14 & 42 & 42 & 0.70 \\
\hline 16 & -- & Single & 02-08 20:04 & 8.90 & 4.96 & 45 & 57 & 0.97 \\
\hline 17 & -- & Single & 02-09 02:00 & 8.98 & 6.36 & 43 & 45 & 0.64 \\
\hline 18 & -- & Double & 02-09 08:06 & 8.98 & 2.31 & 45 & 98 & 1.6 \\
\hline 19 & -- & Single & 02-09 14:06 & 8.96 & 6.43 & 42 & 43 & 0.62 \\
\hline 20 & -- & Single & 02-09 20:01 & 8.96 & 6.20 & 41 & 59 & 0.68 \\
\hline 21 & -- & Single & 02-10 02:04 & 8.72 & 5.78 & 44 & 51 & 0.72 \\
\hline 22 & -- & Single & 02-10 08:00 & 8.77 & 5.95 & 44 & 45 & 0.69 \\
\hline 23 & -- & Single & 02-10 14:01 & 8.91 & 6.33 & 43 & 43 & 0.63 \\
\hline 24 & -- & Single & 02-10 20:04 & 8.99 & 6.55 & 42 & 42 & 0.60 \\
\hline 25 & -- & Single & 02-11 02:01 & 8.91 & 6.15 & 43 & 45 & 0.68 \\
\hline 26 & -- & Double & 02-11 07:58 & 8.97 & 2.33 & 45 & 93 & 1.6 \\
\hline 27 & -- & Single & 02-11 13:57 & 8.96 & 6.47 & 43 & 42 & 0.61 \\
\hline 28 & -- & Single & 02-11 20:00 & 8.97 & 6.51 & 41 & 43 & 0.61 \\
\hline 29 & -- & Single & 02-12 02:00 & 8.97 & 6.42 & 41 & 43 & 0.63 \\
\hline 30 & -- & Double & 02-12 07:59 & 8.96 & 2.88 & 44 & 90 & 1.5 \\
\hline 31 & -- & Single & 02-12 14:01 & 8.85 & 6.01 & 41 & 45 & 0.70 \\
\hline 32 & -- & Double & 02-12 19:59 & 8.95 & 2.42 & 44 & 94 & 1.6 \\
\hline 33 & -- & Single & 02-13 01:59 & 8.97 & 6.21 & 44 & 44 & 0.68 \\
\hline 34 & -- & Single & 02-13 07:58 & 8.90 & 6.51 & 41 & 42 & 0.59 \\
\hline 35 & -- & Single & 02-13 14:00 & 8.91 & 6.30 & 41 & 44 & 0.64 \\
\hline 36 & -- & Single & 02-13 19:59 & 8.97 & 6.52 & 44 & 42 & 0.60 \\
\hline 37 & -- & Single & 02-14 02:04 & 8.90 & 6.48 & 43 & 44 & 0.59 \\
\hline 38 & -- & Single & $02-1408: 23$ & 8.97 & 6.49 & 43 & 42 & 0.61 \\
\hline
\end{tabular}

(a) Backpulse levels/volumes are based on uncalibrated pulse-pot level sensors and are provided "for information only." 
Table B.2. Comparison of Filter Rate Before and After Each Backpulse in Integrated Test A

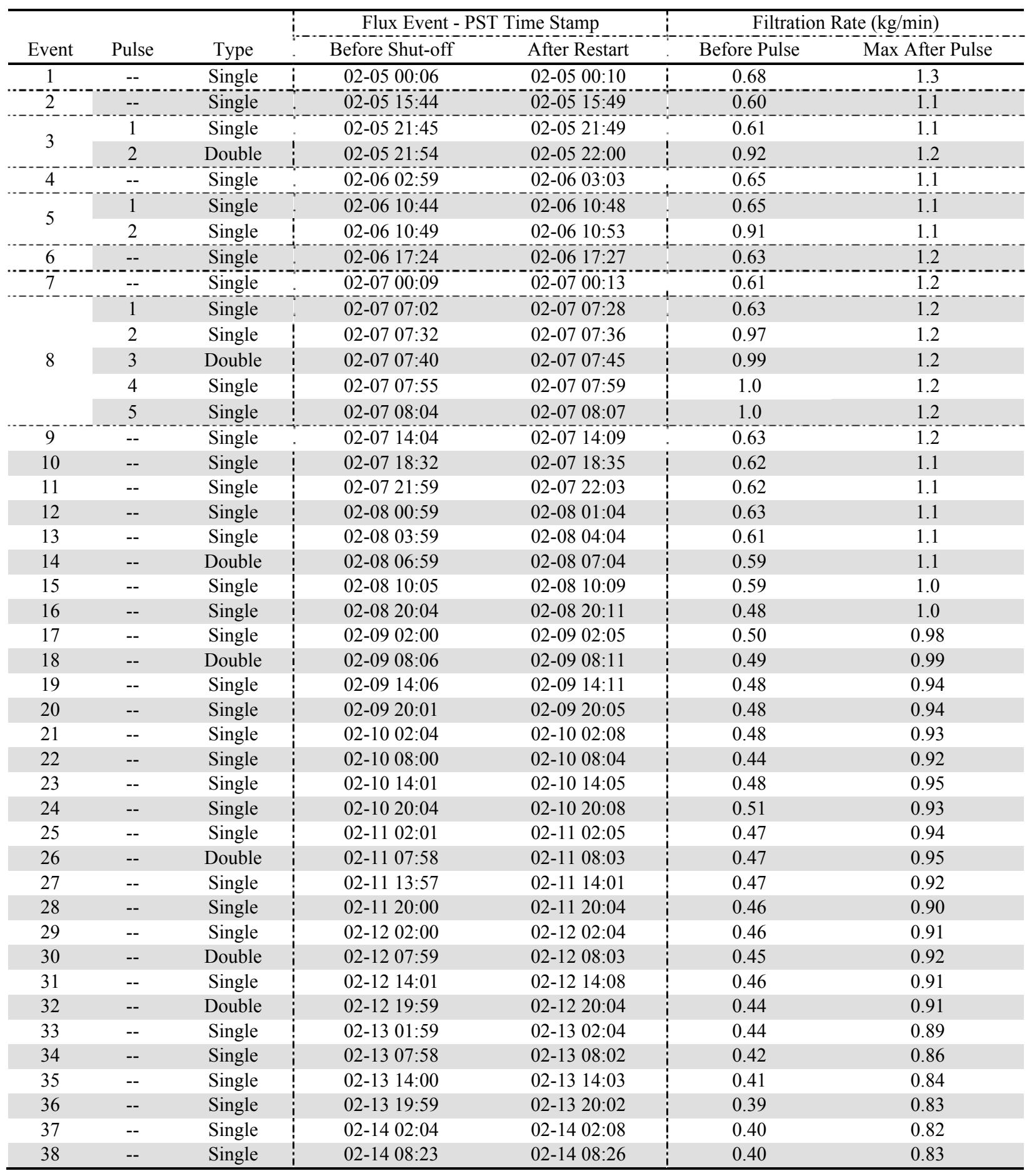


Table B.3. Local Backpulse Effectiveness in Integrated Test A

\begin{tabular}{|c|c|c|c|c|c|}
\hline \multirow[b]{2}{*}{ Event } & \multirow{2}{*}{$\begin{array}{l}\text { Pulse PST Time } \\
\text { (mm-dd hh:mm) }\end{array}$} & \multirow{2}{*}{$\begin{array}{c}\text { Interval }^{(a)} \\
\text { (min) }\end{array}$} & \multicolumn{2}{|c|}{ Mass Filtered (kg) } & \multirow{2}{*}{$\begin{array}{c}\text { Effectiveness }^{(\mathrm{d})} \\
(\%)\end{array}$} \\
\hline & & & Best $^{(b)}$ & Actual ${ }^{(c)}$ & \\
\hline 1 & 02-05 00:06 & -- & -- & -- & -- \\
\hline 2 & 02-05 15:44 & 940 & 640 & 640 & 0 \\
\hline 3 & 02-05 21:45 & 360 & 220 & 250 & 14 \\
\hline 4 & 02-06 02:59 & 310 & 190 & 220 & 12 \\
\hline 5 & 02-06 10:44 & 470 & 300 & 300 & 0 \\
\hline 6 & 02-06 17:24 & 400 & 260 & 280 & 9 \\
\hline 7 & 02-07 00:09 & 410 & 250 & 290 & 12 \\
\hline 8 & 02-07 07:02 & 410 & 250 & 290 & 16 \\
\hline 9 & 02-07 14:04 & 420 & 260 & 280 & 6 \\
\hline 10 & 02-07 18:32 & 270 & 170 & 190 & 12 \\
\hline 11 & 02-07 21:59 & 210 & 130 & 140 & 13 \\
\hline 12 & 02-08 00:59 & 180 & 110 & 120 & 9 \\
\hline 13 & 02-08 03:59 & 180 & 110 & 120 & 7 \\
\hline 14 & 02-08 06:59 & 180 & 110 & 120 & 9 \\
\hline 15 & 02-08 10:05 & 190 & 110 & 120 & 7 \\
\hline 16 & 02-08 20:04 & 600 & 350 & 350 & 0 \\
\hline 17 & 02-09 02:00 & 360 & 170 & 200 & 18 \\
\hline 18 & 02-09 08:06 & 370 & 180 & 200 & 12 \\
\hline 19 & 02-09 14:06 & 360 & 180 & 200 & 11 \\
\hline 20 & 02-09 20:01 & 350 & 170 & 190 & 13 \\
\hline 21 & 02-10 02:04 & 360 & 170 & 190 & 10 \\
\hline 22 & 02-10 08:00 & 360 & 170 & 180 & 6 \\
\hline 23 & 02-10 14:01 & 360 & 160 & 190 & 18 \\
\hline 24 & 02-10 20:04 & 360 & 180 & 200 & 15 \\
\hline 25 & 02-11 02:01 & 360 & 180 & 190 & 6 \\
\hline 26 & 02-11 07:58 & 360 & 170 & 190 & 14 \\
\hline 27 & 02-11 13:57 & 360 & 170 & 190 & 11 \\
\hline 28 & $02-1120: 00$ & 360 & 170 & 190 & 12 \\
\hline 29 & 02-12 02:00 & 360 & 170 & 190 & 13 \\
\hline 30 & 02-12 07:59 & 360 & 170 & 190 & 12 \\
\hline 31 & 02-12 14:01 & 360 & 160 & 180 & 11 \\
\hline 32 & 02-12 19:59 & 360 & 160 & 180 & 10 \\
\hline 33 & 02-13 01:59 & 360 & 160 & 180 & 11 \\
\hline 34 & 02-13 07:58 & 360 & 160 & 170 & 11 \\
\hline 35 & 02-13 14:00 & 360 & 150 & 170 & 12 \\
\hline 36 & 02-13 19:59 & 360 & 150 & 160 & 11 \\
\hline 37 & 02-14 02:04 & 360 & 140 & 160 & 14 \\
\hline 38 & 02-14 08:23 & 380 & 150 & 170 & 10 \\
\hline \multicolumn{6}{|c|}{ (a) See Eq. B.15 } \\
\hline \multicolumn{6}{|c|}{ (b) See Eq. B.14 } \\
\hline \multicolumn{6}{|c|}{ (c) See Eq. B.13 } \\
\hline (d) $\mathrm{Se}$ & Eq. B.16 & & & & \\
\hline
\end{tabular}


Table B.4. Summary of Backpulse TMPs, Durations, and Volumes for Backpulsing Conducted During Post-Caustic-Leach Concentration in Integrated Test B

\begin{tabular}{|c|c|c|c|c|c|c|c|c|}
\hline Event & Pulse & Type & 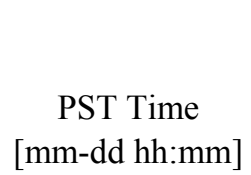 & $\begin{array}{c}\text { Pulse- } \\
\text { Pot } \\
\text { Level } \\
\text { [inches] }\end{array}$ & $\begin{array}{c}\text { Final Pot } \\
\text { Level } \\
\text { [inches] }\end{array}$ & $\begin{array}{l}\text { TMP } \\
\text { [psid] }\end{array}$ & $\begin{array}{c}\text { Duration } \\
{[\mathrm{s}]}\end{array}$ & $\begin{array}{l}\text { Volume }^{(\mathrm{a})} \\
\text { [gal] }\end{array}$ \\
\hline 1 & -- & Single & $03-18$ 06:28 & 9.19 & 7.13 & 40 & 44 & 0.51 \\
\hline 2 & -- & Single & 03-18 12:41 & 8.89 & 7.05 & 40 & 38 & 0.45 \\
\hline 3 & -- & Single & 03-18 18:36 & 8.62 & 6.69 & 38 & 37 & 0.47 \\
\hline 4 & -- & Single & 03-19 00:36 & 8.98 & 5.66 & 39 & 49 & 0.81 \\
\hline
\end{tabular}

(a) Backpulse volumes are based on uncalibrated pulse-pot level sensors and are provided "for information only."

Table B.5. Comparison of Filter Rate Before and After Each Backpulse in Integrated Test B

\begin{tabular}{ccc|cc|cc}
\hline & & & \multicolumn{2}{|c}{ Flux Event - PST Time Stamp } & \multicolumn{2}{c}{ Filtration Rate [kg/min] } \\
Event & Pulse & Type & Before Shut-off & After Restart & Before Pulse & Max After Pulse \\
\hline 1 & -- & Single & $03-1806: 28$ & $03-1806: 31$ & 0.61 & 1.8 \\
2 & -- & Single & $03-1812: 41$ & $03-1812: 44$ & 0.55 & 1.7 \\
3 & -- & Single & $03-1818: 36$ & $03-1818: 47$ & 0.39 & 1.6 \\
4 & -- & Single & $03-1900: 36$ & $03-1900: 39$ & 0.34 & 1.7 \\
\hline
\end{tabular}

Table B.6. Local Backpulse Effectiveness in Integrated Test B

\begin{tabular}{ccc:cc|c}
\hline Event & $\begin{array}{c}\text { Pulse PST Time } \\
{[\mathrm{mm}-\mathrm{dd} \text { hh:mm }]}\end{array}$ & $\begin{array}{c}\text { Interval }^{(\mathrm{a})} \\
{[\mathrm{min}]}\end{array}$ & $\begin{array}{c}\text { Mass Filtered }[\mathrm{kg}] \\
\text { Best }^{\left(\mathrm{b}^{\mathrm{b}}\right.}\end{array}$ & Actual $^{(\mathrm{c})}$ & $\begin{array}{c}\text { Effectiveness }^{(\mathrm{d})} \\
{[\%]}\end{array}$ \\
\hline 1 & $03-1806: 28$ & -- & -- & -- & - \\
2 & $03-1812: 41$ & 370 & 230 & 230 & 0 \\
3 & $03-1818: 36$ & 360 & 200 & 210 & 6 \\
4 & $03-1900: 36$ & 360 & 140 & 84 & -40 \\
\hline
\end{tabular}
(a) See Eq. B.15
(b) See Eq. B.14
(c) See Eq. B.13
(d) See Eq. B.16 
Appendix C

Solids Washing 



\section{Appendix C: Solids Washing}

The three tables C.1, C.2, and C.3 provide supplemental data supporting Section 10, Solids Washing. These contain analyte concentration data, at each sampled wash step, for Integrated Test D, for post-caustic-leach wash, and for post-oxidative-leach wash. Included are $\mathrm{C}_{\mathrm{n}}$, the analyte concentration, in molarity, at each sampled wash step and $\mathrm{C}_{\mathrm{n}} / \mathrm{C}_{\mathrm{o}}$, the ratio of wash step concentration to initial concentration, used to evaluate concentration behavior.

Table C.1. Concentration Data for Soluble Analytes Measured During the Integrated Test D Post-Caustic-Leach Wash. The last row labeled "RL" is the reporting limit ${ }^{(a)}$ for each analyte.

\begin{tabular}{|c|c|c|c|c|c|c|c|c|c|c|}
\hline \multirow{2}{*}{$\begin{array}{l}\text { Wash } \\
\text { Step }\end{array}$} & \multicolumn{2}{|c|}{ Nitrate } & \multicolumn{2}{|c|}{ Nitrite } & \multicolumn{2}{|c|}{ Sulfate } & \multicolumn{2}{|c|}{ Aluminum } & \multicolumn{2}{|c|}{ Free $\mathrm{OH}$} \\
\hline & $\mathrm{C}_{\mathrm{n}}^{(\mathrm{b})}(\mathrm{M})^{(\mathrm{c})}$ & $\mathrm{C}_{\mathrm{n}} / \mathrm{C}_{\mathrm{o}}(\mathrm{d})$ & $\mathrm{C}_{\mathrm{n}}(\mathrm{M})$ & $\mathrm{C}_{\mathrm{n}} / \mathrm{C}_{\mathrm{o}}$ & $\mathrm{C}_{\mathrm{n}}(\mathrm{M})$ & $\mathrm{C}_{\mathrm{n}} / \mathrm{C}_{\mathrm{o}}$ & $\mathrm{C}_{\mathrm{n}}(\mathrm{M})$ & $\mathrm{C}_{\mathrm{n}} / \mathrm{C}_{\mathrm{o}}$ & $\mathrm{C}_{\mathrm{n}}(\mathrm{M})$ & $\mathrm{C}_{\mathrm{n}} / \mathrm{C}_{\mathrm{o}}$ \\
\hline 0 & 0.640 & 1.000 & 0.203 & 1.000 & 0.069 & 1.000 & 0.746 & 1.000 & 7.350 & 1.000 \\
\hline 3 & 0.496 & 0.775 & 0.159 & 0.781 & 0.088 & 1.283 & -- & -- & 5.600 & 0.762 \\
\hline 6 & 0.380 & 0.594 & 0.123 & 0.605 & 0.068 & 0.995 & 0.429 & 0.575 & 4.350 & 0.592 \\
\hline 8 & 0.326 & 0.510 & 0.106 & 0.522 & 0.059 & 0.863 & -- & -- & 3.710 & 0.505 \\
\hline 11 & 0.310 & 0.485 & 0.088 & 0.432 & 0.046 & 0.668 & 0.287 & 0.384 & 2.920 & 0.397 \\
\hline 13 & 0.234 & 0.365 & 0.075 & 0.371 & 0.040 & 0.583 & -- & -- & 2.510 & 0.341 \\
\hline 16 & 0.179 & 0.279 & 0.057 & 0.279 & 0.030 & 0.444 & 0.194 & 0.260 & 1.920 & 0.261 \\
\hline 19 & 0.141 & 0.221 & 0.044 & 0.219 & 0.024 & 0.357 & -- & -- & 1.580 & 0.215 \\
\hline 22 & 0.107 & 0.167 & 0.034 & 0.166 & 0.019 & 0.273 & 0.120 & 0.161 & 1.220 & 0.166 \\
\hline 24 & 0.092 & 0.143 & 0.029 & 0.143 & 0.016 & 0.238 & -- & -- & 1.040 & 0.141 \\
\hline 27 & 0.067 & 0.105 & 0.022 & 0.107 & 0.012 & 0.176 & 0.082 & 0.110 & 0.790 & 0.107 \\
\hline 29 & 0.059 & 0.092 & 0.019 & 0.094 & 0.011 & 0.156 & -- & -- & 0.650 & 0.088 \\
\hline 32 & 0.043 & 0.068 & 0.014 & 0.071 & 0.008 & 0.118 & 0.057 & 0.076 & 0.560 & 0.076 \\
\hline 35 & 0.035 & 0.055 & 0.012 & 0.058 & 0.007 & 0.096 & -- & -- & 0.460 & 0.063 \\
\hline 37 & 0.028 & 0.044 & 0.010 & 0.048 & 0.005 & 0.078 & 0.041 & 0.054 & 0.360 & 0.049 \\
\hline 40 & 0.025 & 0.039 & 0.009 & 0.042 & 0.005 & 0.068 & -- & -- & 0.360 & 0.049 \\
\hline 43 & 0.017 & 0.026 & 0.006 & 0.030 & 0.003 & 0.045 & 0.027 & 0.037 & 0.230 & 0.031 \\
\hline 45 & 0.016 & 0.025 & 0.006 & 0.028 & 0.003 & 0.043 & -- & -- & 0.220 & 0.030 \\
\hline 48 & 0.012 & 0.018 & 0.004 & 0.021 & 0.002 & 0.032 & 0.020 & 0.027 & 0.170 & 0.023 \\
\hline 50 & 0.011 & 0.017 & 0.004 & 0.020 & 0.002 & 0.030 & -- & -- & 0.160 & 0.022 \\
\hline 53 & 0.009 & 0.013 & 0.003 & 0.016 & 0.001 & 0.022 & 0.015 & 0.020 & 0.120 & 0.016 \\
\hline RL & 0.001 & -- & 0.001 & -- & 0.0002 & -- & 0.0001 & -- & 0.100 & -- \\
\hline
\end{tabular}

(a) The reporting limit (RL) as defined by SwRI is an achievable concentration they determine on a daily basis. The criterion they use is that the RL must be greater than or equal to the calculated minimum detection limit (MDL)/instrument detection limit (IDL). They do not apply a specific factor to MDL/IDLs for determining the RL since these can change every time a new MDL/IDL study is performed. For techniques that use a calibration curve (total organic carbon [TOC] and ion chromatography $[\mathrm{IC}])$, the RL is equal to the lowest calibration standard.

(b) $\mathrm{Cn}=$ molar concentration of a species at the current wash step.

(c) $\mathrm{M}=$ molarity.

(d) $\mathrm{Cn} / \mathrm{Co}=$ Ratio of wash step concentration to initial concentration, used to evaluate concentration behavior. 
Table C.2. Concentration Data for Partially Soluble Analytes Measured During the Integrated Test D Post-Caustic-Leach Wash. TDS and Sodium were not measured for the steps where there are blank entries. The value given in the last row labeled "RL" is the reporting limit for each analyte.

\begin{tabular}{|c|c|c|c|c|c|c|c|c|}
\hline \multirow{2}{*}{ Wash Step } & \multicolumn{2}{|c|}{ Sodium } & \multicolumn{2}{|c|}{ Phosphate } & \multicolumn{2}{|c|}{ Oxalate } & \multicolumn{2}{|c|}{ Total Dissolved Solids } \\
\hline & $\mathrm{C}_{\mathrm{n}}(\mathrm{M})$ & $\mathrm{C}_{\mathrm{n}} / \mathrm{C}_{\mathrm{o}}$ & $\mathrm{C}_{\mathrm{n}}(\mathrm{M})$ & $\mathrm{C}_{\mathrm{n}} / \mathrm{C}_{\mathrm{o}}$ & $\mathrm{C}_{\mathrm{n}}(\mathrm{M})$ & $\mathrm{C}_{\mathrm{n}} / \mathrm{C}_{\mathrm{o}}$ & $\mathrm{C}_{\mathrm{n}}(\mathrm{kg} / \mathrm{L})$ & $\mathrm{C}_{\mathrm{n}} / \mathrm{C}_{\mathrm{o}}$ \\
\hline 0 & 9.393 & 1.000 & 0.025 & 1.000 & 0.001 & 1.000 & 0.513 & 1.000 \\
\hline 3 & -- & -- & 0.021 & 0.829 & 0.001 & 1.099 & -- & -- \\
\hline 6 & 5.615 & 0.598 & 0.027 & 1.043 & 0.004 & 3.034 & 0.327 & 0.637 \\
\hline 8 & -- & -- & 0.026 & 1.028 & 0.006 & 4.846 & -- & -- \\
\hline 11 & 3.790 & 0.404 & 0.021 & 0.825 & 0.011 & 9.120 & 0.224 & 0.437 \\
\hline 13 & -- & -- & 0.018 & 0.719 & 0.014 & 11.890 & -- & -- \\
\hline 16 & 2.536 & 0.270 & 0.014 & 0.543 & 0.021 & 18.199 & 0.154 & 0.300 \\
\hline 19 & -- & -- & 0.011 & 0.425 & 0.029 & 24.600 & -- & -- \\
\hline 22 & 1.609 & 0.171 & 0.008 & 0.329 & 0.042 & 35.527 & 0.100 & 0.196 \\
\hline 24 & -- & -- & 0.007 & 0.283 & 0.049 & 41.991 & -- & -- \\
\hline 27 & 1.134 & 0.121 & 0.005 & 0.201 & 0.065 & 55.458 & 0.074 & 0.144 \\
\hline 29 & -- & -- & 0.005 & 0.181 & 0.076 & 64.424 & -- & -- \\
\hline 32 & 0.865 & 0.092 & 0.003 & 0.134 & 0.096 & 81.331 & 0.056 & 0.110 \\
\hline 35 & -- & -- & 0.003 & 0.109 & 0.117 & 99.078 & -- & -- \\
\hline 37 & 0.700 & 0.075 & 0.002 & 0.089 & 0.131 & 111.658 & 0.050 & 0.097 \\
\hline 40 & -- & -- & 0.002 & 0.078 & 0.141 & 120.227 & -- & -- \\
\hline 43 & 0.625 & 0.066 & 0.001 & 0.056 & 0.176 & 149.619 & 0.043 & 0.083 \\
\hline 45 & -- & -- & 0.001 & 0.050 & 0.169 & 143.416 & -- & -- \\
\hline 48 & 0.413 & 0.044 & 0.001 & 0.040 & 0.121 & 102.553 & 0.033 & 0.063 \\
\hline 50 & -- & -- & 0.001 & 0.034 & 0.119 & 101.314 & -- & -- \\
\hline 53 & 0.300 & 0.032 & 0.001 & 0.027 & 0.080 & 68.226 & 0.022 & 0.043 \\
\hline RL & 0.001 & -- & 0.0006 & -- & 0.001 & -- & N/A & -- \\
\hline
\end{tabular}


Table C.2. Concentration Data for Selected Analytes Measured During the Integrated Test D Post-Oxidative-Leach Wash. TDS was not measured for the steps where there are blank entries in the table. The value given in the last row labeled "RL" is the reporting limit for each analyte.

\begin{tabular}{|c|c|c|c|c|c|c|c|c|c|c|}
\hline \multirow{2}{*}{$\begin{array}{l}\text { Wash } \\
\text { Step }\end{array}$} & \multicolumn{2}{|c|}{ Nitrate } & \multicolumn{2}{|c|}{ Chromium } & \multicolumn{2}{|c|}{ Sodium } & \multicolumn{2}{|c|}{ Oxalate } & \multicolumn{2}{|c|}{ Total Dissolved Solids } \\
\hline & $\mathrm{C}_{\mathrm{n}}(\mathrm{M})$ & $\mathrm{C}_{\mathrm{n}} / \mathrm{C}_{\mathrm{o}}$ & $\mathrm{C}_{\mathrm{n}}(\mathrm{M})$ & $\mathrm{C}_{\mathrm{n}} / \mathrm{C}_{\mathrm{o}}$ & $\mathrm{C}_{\mathrm{n}}(\mathrm{M})$ & $\mathrm{C}_{\mathrm{n}} / \mathrm{C}_{\mathrm{o}}$ & $\mathrm{C}_{\mathrm{n}}(\mathrm{M})$ & $\mathrm{C}_{\mathrm{n}} / \mathrm{C}_{\mathrm{o}}$ & $\mathrm{C}_{\mathrm{n}}(\mathrm{kg} / \mathrm{L})$ & $\mathrm{C}_{\mathrm{n}} / \mathrm{C}_{\mathrm{o}}$ \\
\hline 0 & 0.014 & 1.000 & 0.004 & 1.000 & 0.405 & 1.000 & 0.092 & 1.000 & 0.028 & 1.000 \\
\hline 3 & 0.011 & 0.814 & 0.003 & 0.795 & 0.339 & 0.838 & 0.071 & 0.767 & 0.023 & 0.828 \\
\hline 6 & 0.011 & 0.762 & 0.003 & 0.726 & 0.315 & 0.779 & 0.063 & 0.688 & -- & -- \\
\hline 9 & 0.008 & 0.549 & 0.002 & 0.504 & 0.220 & 0.544 & 0.044 & 0.481 & 0.017 & 0.609 \\
\hline 12 & 0.007 & 0.500 & 0.002 & 0.450 & 0.202 & 0.499 & 0.040 & 0.437 & -- & -- \\
\hline 15 & 0.005 & 0.395 & 0.001 & 0.339 & 0.154 & 0.382 & 0.030 & 0.324 & 0.012 & 0.436 \\
\hline 18 & 0.005 & 0.353 & 0.001 & 0.297 & 0.139 & 0.343 & 0.026 & 0.280 & -- & -- \\
\hline 21 & 0.004 & 0.271 & 0.001 & 0.208 & 0.101 & 0.249 & 0.018 & 0.194 & -- & -- \\
\hline 24 & 0.003 & 0.243 & 0.001 & 0.175 & 0.088 & 0.218 & 0.015 & 0.162 & -- & -- \\
\hline 27 & 0.003 & 0.213 & 0.001 & 0.149 & 0.076 & 0.188 & 0.012 & 0.132 & 0.006 & 0.224 \\
\hline 30 & 0.003 & 0.203 & 0.001 & 0.125 & 0.067 & 0.166 & 0.010 & 0.112 & -- & -- \\
\hline 33 & 0.003 & 0.196 & 0.0005 & 0.116 & 0.064 & 0.157 & 0.010 & 0.105 & 0.004 & 0.151 \\
\hline 36 & 0.002 & 0.166 & 0.0004 & 0.090 & 0.053 & 0.131 & 0.007 & 0.077 & -- & -- \\
\hline 39 & 0.002 & 0.154 & 0.0003 & 0.065 & 0.043 & 0.105 & 0.005 & 0.058 & 0.003 & 0.101 \\
\hline 42 & 0.002 & 0.141 & 0.0002 & 0.050 & 0.037 & 0.092 & 0.004 & 0.045 & -- & -- \\
\hline 44 & 0.002 & 0.135 & 0.0002 & 0.047 & 0.035 & 0.088 & 0.004 & 0.041 & 0.003 & 0.102 \\
\hline 45 & 0.002 & 0.148 & 0.0002 & 0.047 & 0.035 & 0.087 & 0.004 & 0.039 & 0.002 & 0.080 \\
\hline RL & 0.001 & -- & 0.000005 & -- & 0.001 & -- & 0.0002 & -- & N/A & -- \\
\hline
\end{tabular}



Appendix D

Isometric Of Tank T02A 



\section{Appendix D: Isometric Of Tank T02A}

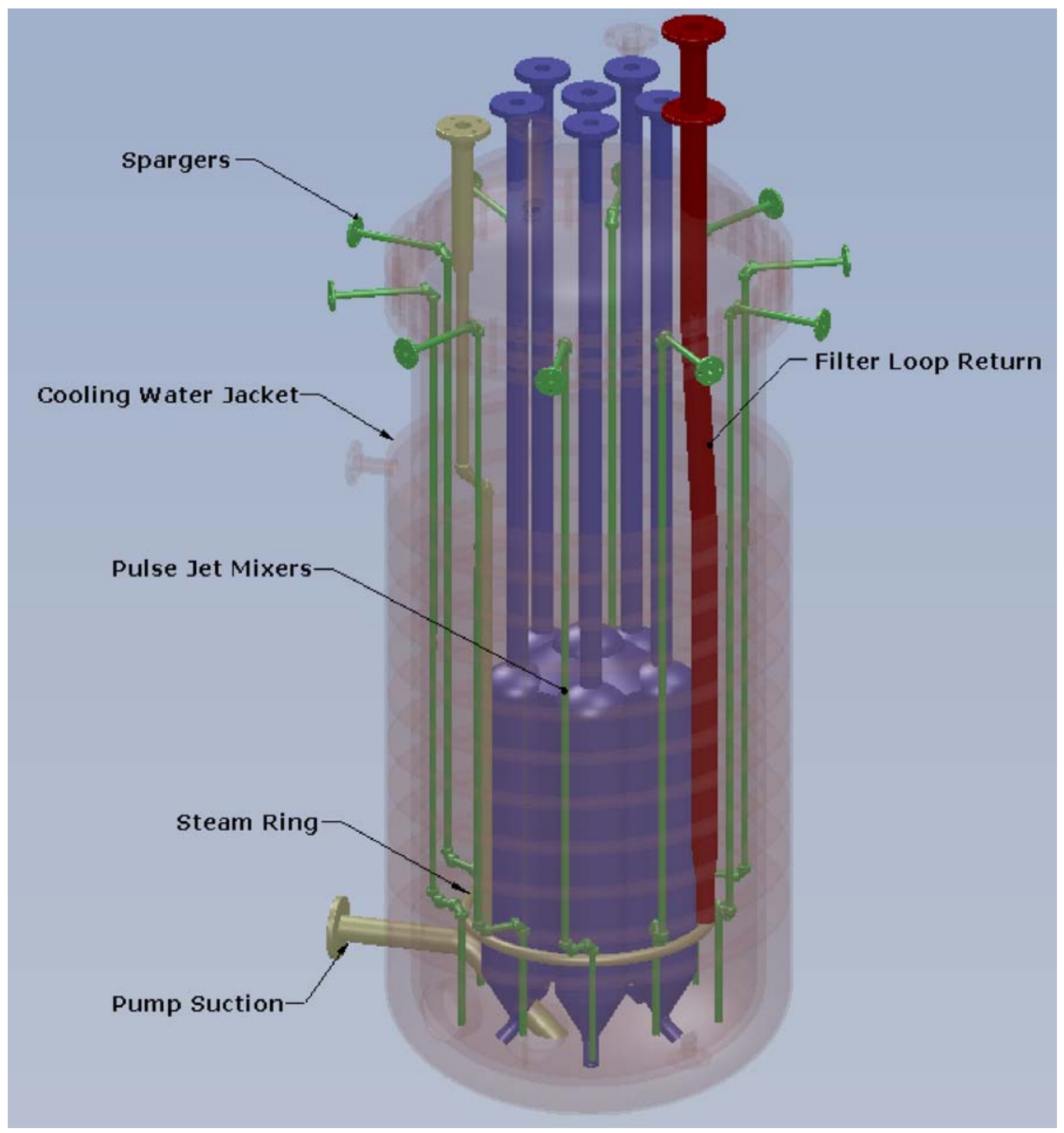

Figure D.1. Isometric of Tank T02A with Lower Spargers (not to scale) 

Appendix E

Analytical Techniques, Sample Handling and Naming 



\section{Appendix E: Analytical Techniques, Sample Handling and Naming}

\section{E.1 Analytical Methods}

The types of sample analysis techniques used are described below. The applicable preparative and analytical quality control for common analytical methods such as inductively coupled plasma-atomic emission spectroscopy (ICP-AES), inductively couple plasma-mass spectrometry (ICP-MS), ion chromatography (IC) and free $\mathrm{OH}$ are specified in HASQARD Rev 2, Section 6 (DOE/RL-96-68). The quality control for methods not in HASQARD, such as particle-size distribution or X-ray diffraction, is based on common practices within the discipline. Typically for methods not in HASQARD, the quality control is described in the technical procedure.

\section{E.1.1 Chemical Analysis}

This section describes the analytical methods used to determine the chemical composition of the Pretreatment Engineering Platform (PEP) simulant samples collected during testing.

\section{E.1.1.1 Preparation for ICP or ICP-MS}

Solution samples were diluted with hydrochloric acid prior to analysis. For the dilutions, a representative sample aliquot of approximately 2 grams was combined with 5-mL of 50\% hydrochloric acid and then diluted to a final volume of 50-mL with deionized water (DIW).

Two preparative techniques were used for solids. The first was lithium metaborate/tetraborate fusion, referred to as prep method " $80 / 20$ Fusion." Aluminum, barium, cerium, chromium, iron, lanthanum, manganese, neodymium, silicon, and strontium were reported from the fusion. The second preparative method used concentrated nitric, perchloric, hydrofluoric, and hydrochloric acids in an open vessel and was referred to as the "Teflon" prep method. If residue remained from the "Teflon" method, then the residue was separated, dried, and fused using the lithium metaborate/tetraborate fusion technique. Both the "Teflon" and residue preparations were analyzed. The remaining metals were reported from either the "Teflon" digestion only or the combination of the two. If an analyte was detected in both the Teflon digestate and the residue fusions, then the reported result was the sum of the results obtained from the two preparations. These results were identified as "combined" on Sample Analysis Data Sheets while analytes reported from only the fusion were identified as "80/20 Fusion," and analytes reported solely from the acid digestions were identified as "Teflon" on the Sample Analysis Data Sheets. The preparative quality control (QC) samples included a sample duplicate, preparation blank, solid laboratory control samples (LCSs) consisting of obsidian rock and basalt rock, and an aqueous LCS and a matrix spike (MS) for "Teflon." The results are reported on an "as received" or wet weight basis. The percent solids were determined at $105^{\circ} \mathrm{C}$ and reported on the Sample Analysis Data Sheets for all solids.

\section{E.1.1.2 Metals Analysis by ICP-AES}

All metals were determined by inductively coupled plasma-atomic emission spectroscopy (ICP-AES) using Southwest Research Institute (SwRI) procedure TAP01-0406-130 with the exception of cerium, 
cesium, lanthanum, and neodymium. The preparative QC samples (duplicate, PB, LCS, MS) were processed along with analytical workstation QC (initial and continuing calibration verifications, initial and continuing blanks, interference check samples, and post-digestion spikes).

\section{E.1.1.3 Metals Analysis by ICP-MS}

Cerium, cesium, lanthanum, and neodymium were determined by ICP-MS in accordance with SwRI procedure TAP01-0406-046. The preparative QC samples (duplicate, PB, LCS, MS) were processed along with analytical workstation QC (initial and continuing calibration verifications, initial and continuing blanks, interference check samples, and post-digestion spikes).

\section{E.1.1.4 Anions (IC)}

Decanted supernatant and rinsants were analyzed by ion chromatography (IC) for chloride, nitrate, nitrite, phosphate, sulfate, and oxalate at SwRI in accordance with procedure SwRI TAP01-0406-042. Approximately 0.25 -g of the sample was diluted to $50-\mathrm{mL}$ using DIW. Since the dilution was performed by weight, the sample results were reported on a weight basis. The standard reporting by the laboratory is nitrate as N, nitrite as N, and phosphate as P. Shortly after PEP testing began, Pacific Northwest National Laboratory (PNNL) requested that results be reported as nitrate, nitrite, and phosphate and not as nitrogen or phosphorus. The IC analytical report narrative identifies conversion factors used to report as anions. QC samples generated at the analytical workstation included a sample replicate determination, preparation blank, LCS, and matrix spike MS.

\section{E.1.1.5 Total Inorganic Carbon/Total Organic Carbon}

The samples were analyzed for total carbon (TC) using a Dohrman DC-80 Carbon Analyzer in accordance with procedure SwRI TAP01-0406-001. The liquids were directly injected, and the slurry was analyzed using the soil/sludge sampler. Another aliquot of the sample was acidified with sulfuric acid and sparged to remove inorganic carbon and then analyzed for TOC. The TIC was calculated from the difference in the TC and TOC results. All samples were analyzed in duplicate, and average results were reported when the relative percent differences (RPDs) were less than $20 \%$. If the RPD was greater than $20 \%$, then the sample was analyzed twice more, and the average of the quadruplicate analysis was reported. The liquids were corrected for density, and all sample results were reported on a weight basis. QC samples were generated at the analytical workstation and included a sample replicate determination, preparation blank, LCS, and MS.

\section{E.1.1.6 Hydroxide}

The free-hydroxide concentration was determined by PNNL's Analytical Support Operations (ASO) by potentiometric titration with standardized $\mathrm{HCl}$ according to procedure RPG-CMC-228, Determination of Hydroxyl (OH-) and Alkalinity of Aqueous Solutions, Leachates, and Supernates and Operation of Brinkman 636 Auto-Titrator. The free hydroxide was defined as the first inflection point on the titration curve. QC samples were generated at the analytical workstation and included a sample replicate determination, preparation blank, and continuing calibration verification $(\mathrm{CCV})$. 


\section{E.1.1.7 Raman}

Raman was used to quantify aluminate, carbonate, chromate, hydroxide, nitrate, nitrite, oxalate, phosphate, and sulfate following procedure RPG-CMC-240. The method uses a Raman RS2000 echelle spectrograph (Inphotonics Inc.) located in the Radiochemical Processing Laboratory (RPL) at PNNL. If precipitate formed in the solution samples submitted for Raman before the analysis, then the samples were centrifuged, and aliquots of the liquid were pipetted and analyzed. Two sets of Raman results were reported for Shakedown, Integrated Test A, and some of the Integrated Test B samples. The first set of results was generated using calibrations that were periodically adjusted to optimize the performance of QC check samples. The second set of results was recalculated based on the original calibration parameters. The generation of these two sets of results and the discovery of the calibration adjustments are documented as RPP-WTP CAR, number 42708.1. Only Raman results from the recalculation are provided. As a result of using the original calibration parameters, an occasional QC sample falls outside of established performance limits. QC samples were generated at the analytical workstation and included a sample replicate determination, preparation blank, blank spike, and MS.

\section{E.1.1.8 Preparation for Gel Permeation Chromatography (AFA Components)}

Duplicate samples were collected to support this analysis. Both samples were centrifuged and phase separated at Process Development Laboratory-West (PDL-W) before shipping. Once at the Dow Corning analytical laboratory, one of the two liquid fractions was mixed with toluene while the other was mixed with tetrahydrofuran (THF). Both were shaken for an hour and allowed to settle overnight. The upper organic layer was removed and allowed to concentrate. The toluene extract was dried at room temperature to completeness and brought to $3.0-\mathrm{mL}$ with toluene. The THF extracts were concentrated to approximately $2-\mathrm{mL}$ at room temperature and then placed in an $80^{\circ} \mathrm{C}$ oven to dry to completeness and brought up to $3.0-\mathrm{mL}$ with THF. The solids fraction corresponding to the liquid fraction extracted by toluene was extracted with $10-\mathrm{mL}$ of toluene while the solids fraction corresponding to the liquid fraction extracted by THF was extracted with $10.0-\mathrm{mL}$ of THF. In both cases, the solvent was added directly into the receipt vessel, and the initial sample and solvent were shaken for 2 hours. All solutions were filtered through $0.45-\mu \mathrm{m}$ PTFE syringe filters. Calibration verification was performed before sample analysis and after every 15 samples.

\section{E.1.1.9 Gel Permeation Chromatography (AFA Components)}

The toluene extract allowed polydimethylsiloxane (PDMS) to be analyzed by gel permeation chromatography (GPC) while the THF extract allowed polypropylene glycol (PPG) to be analyzed by GPC. The toluene extract was analyzed by a Water 717 autosampler and a Waters 2410 differential refractometer. Two columns, a PLgel 5- $\mu \mathrm{m}$ guard column and a PLgel 5- $\mu \mathrm{m}$ Mixed-C column, were used for separation, and an HPLC-grade toluene at a flow of $1.0-\mathrm{mL} /$ minute was used as the eluent. Both the columns and detector were heated to $45^{\circ} \mathrm{C}$. The THF extract was analyzed with a Waters 2695 Separation Module equipped with a vacuum degasser and a Waters 2410 differential refractometer. Two columns, a PLgel 5- $\mu \mathrm{m}$ guard column and a PLgel 5- $\mu \mathrm{m}$ Mixed-C column, were used for separation, and a certified grade THF at a flow of $1.0-\mathrm{mL} /$ minute was used as the eluent. Both the columns and detector were heated to $35^{\circ} \mathrm{C}$. The quantity of PDMS and PPG was used to determine the amount of AFA, Q2-3183A Antifoam, in the samples. Since the AFA is a proprietary composition belonging to Dow 
Corning, they performed the analytical work. Calibration verification was performed before sample analysis and after every 15 samples.

\section{E.1.2 Physical Properties}

This section describes the methods used to determine the physical properties of the PEP simulant samples, the crystal form and habit of the solids, density, wt $\%$ undissolved solids (UDS), rheology, particle-size attributes, and heat capacity. A more detailed outline of the methods used in this section is given, where applicable, in the appropriate Test Data Package supplied with the sample results for each characterization.

\section{E.1.2.1 Percent UDS and Density}

Weight percent UDS, wt $\%$ dissolved solids, bulk slurry density, and supernatant density were determined following Bechtel procedure 24590-WTP-GPG-RTD-001, Rev 0. Some Bechtel 24590-WTP-GPG-RTD-001, Rev 0 steps were not performed because the results generated from these steps were not needed, or steps were slightly modified to reduce analysis time. These modifications were not believed to impact the final results.

Slurry sample UDS analysis was performed with the following modifications:

- Steps 4, 6, and 7 were omitted because the settling data were not required.

- Steps 8 and 9. The cones were centrifuged at $\sim 1000$ gravities for 1 hour. The volume of the total sample and the volume of centrifuged solids on the physical properties data sheet were recorded. After this, the WTP procedures required that the supernatant be decanted into a pre-weighed graduated cylinder to obtain the supernatant mass and volume. Rather than use a graduated cylinder, the volume of supernatant was calculated as the difference between the volume of the total sample and the volume of centrifuged solids.

- Step 11 requires decanting the centrifuged supernatant liquid to a pre-weighed graduated cylinder. Because of the high concentration of $\mathrm{NaOH}$ in some of the samples, some of the liquid was left in the cylinder. Rather than decant, the centrifuged supernatant liquid was pipetted to a pre-weighed glass Petri dish or vial, and the mass of the supernatant liquid was recorded.

- Step 12 was omitted because air-drying was not necessary.

- Separated slurry samples UDS analysis was performed with the following modifications:

- Step 8 requires centrifuging at $\sim 1000$ gravities for 1 hour. Samples were centrifuged at $\sim 4500$ gravities for either 10 minutes or 1 hour. The centrifuge time is documented on the sample handling benchsheets in Test Data Package TDP-WTP-349.

- Wet solids (designated as "B") and decanted supernatants (designated as "D") were sent to SwRI along with empty vials and separated sample weights. These weights are also documented on the sample handing benchsheets in Test Data Package TDP-WTP-349.

- The wet solids were transferred to a tared container using DIW to completely remove the solids. The solids and DIW rinses were then oven dried to constant weight. 
- The total weight of the supernatant was calculated from the sample-handling benchsheets. Since it was not feasible for the entire volume of supernatant to be oven dried, approximately 5-mL was transferred to a Petri dish for drying.

- Density was determined on the supernatant liquid using a 5-mL volumetric flask.

Two sets of UDS reports were issued for Shakedown, Integrated Test A, Integrated Test B, and some of the Integrated Test D samples. The uncertainty associated with the first set of UDS results was used for a Taylor series expansion. This first estimate of uncertainty provided reasonable results until the quantity of total dissolved solids approached the detection limit of the method. The quantity of dissolved solids was used to calculate the UDS so the uncertainty for the UDS would increase as the quantity of total dissolved solids decreased. The estimate of uncertainty provided in the revised reports was calculated more rigorously. Only UDS reports with the more rigorous uncertainty calculation were used in data analysis.

\section{E.1.2.2 Density}

Three pre-weighed 5-mL Class A volumetric flasks were filled to the specified line with the sample and reweighed. The density was calculated as the mass of the sample divided by the certified volume of the volumetric flask.

\section{E.1.2.3 Rheology Measurements}

Rheological testing was conducted on the solids in contact with the supernatant generated as part of the homogenization process. Testing was conducted according to RPL-COLLIOD-02, Measurement of Physical and Rheological Properties of Solutions, Slurries and Sludges. For the current study, two regions of tank waste flow behavior are considered: 1) incipient motion in settled tank waste solids (shear strength), and 2) non-elastic flow of tank waste slurries and supernates (flow curve).

\section{Shear-Strength Testing}

For tank waste slurries, a finite stress must be applied before the material will begin to flow. The stress required to transition the material from elastic deformation to viscous flow is referred to as the shear strength, and its origin can be attributed to static and kinetic friction between individual particles and/or aggregates, the strength of the matrix supporting the coarse fraction (i.e., the interstitial fluid), and sludge cohesion arising from interparticle adhesive forces such as van der Waals forces.

The shear strength was measured using the vane method. For the vane technique, the stress required to begin motion is determined by slowly rotating a vane immersed in the test sample's settled solids while continuously monitoring the resisting torque as a function of time. A material's static shear strength is then associated with the maximum torque measured during the transition from initial to steady-state vane rotation.

The maximum torque required for incipient motion is dependent on vane geometry. To account for vane-geometry effects, the shear strength is expressed in terms of the uniform and isotropic stress acting over the surface area of the cylinder of rotation swept out by the vane. The shear strength is related to the maximal torque during incipient motion according to Equation 5.1 (Barnes and Dzuy 2001): 


$$
\tau_{S S}=\frac{M_{\max }}{4 \pi R^{3}\left(\frac{H}{2 R}+\frac{1}{3}\right)}
$$

Here, $\tau_{s s}$ is the shear strength $\left(\mathrm{N} / \mathrm{m}^{2}\right), M_{\max }$ is the maximum torque $(\mathrm{N} \cdot \mathrm{m})$, and $R$ and $H$ are the radius and height of the cylinder of rotation swept out by the vane $(\mathrm{m})$. Because the shear band observed upon slow rotation of the vane does not extend appreciably beyond the vane paddles, $R$ and $H$ are taken to be the dimensions of the vane itself.

The proximity of the vane to the sample container inner surfaces as well as the free surface of the settled solids can impact shear-strength results. As such, certain geometric constraints must be satisfied for the test to be considered independent of container geometry. These constraints are outlined in Table E.1.

Table E.1. Vane Immersion Depth and Container Geometry Constraints for Shear-Strength Tests Using the Vane Technique

\begin{tabular}{lll}
\hline Constraint & Criterion & For 8 $\times 16-\mathrm{mm}(\mathrm{R} \times \mathrm{H})$ Vane \\
\hline Vane height to radius & $\mathrm{H}<7 \mathrm{R}$ & $\mathrm{H}<56-\mathrm{mm}$ (Satisfied) \\
Container radius to vane radius & $\mathrm{R}_{\text {cont }}>2 \mathrm{R}$ & $\mathrm{R}_{\text {cont }}>16-\mathrm{mm}$ \\
Immersion depth to vane height & $\mathrm{h}>\mathrm{H}$ & $\mathrm{h}>16-\mathrm{mm}$ \\
$\begin{array}{l}\text { Separation between bottom of vane } \\
\text { and container floor }\left(\mathrm{h}_{\text {floor }}\right)\end{array}$ & $\mathrm{h}_{\text {floor }}>0.5 \mathrm{H}$ & $\mathrm{h}_{\text {floor }}>8-\mathrm{mm}$ \\
\hline $\mathrm{R}=$ radius & & \\
$\mathrm{H}=$ height & & \\
\hline
\end{tabular}

\section{Flow-Curve Testing}

The non-elastic flow of tank waste slurries and supernates is characterized with rotational viscometry. The typical result of such testing is a set of flow-curve data, which shows the stress response of a material to a range of applied rates-of-deformation. Specifically, flow-curve testing allows characterization of a material's shear stress, $\tau$, which is the response as a function of applied shear rate, $\dot{\gamma}$. Once measured, the flow-curve data can be interpreted with several constitutive equations for the viscous stress/rate-of-strain relationship. Such analysis allows the flow behavior over a broad range of conditions to be described with just a few rheological descriptors, such as viscosity, yield stress, consistency, and flow index.

A concentric cylinder rotational viscometer operated in controlled-rate mode was used for flow-curve testing of tank waste slurries and supernates. Rotational viscometers operate by placing a given volume of test sample into a measurement cup of known geometry. A cylindrical rotor attached to a torque sensor is then lowered into the sample until the slurry is even with, but does not cover, the top of the rotor. A single-point determination of a fluid's flow properties is made by spinning a rotor at a known rotational speed, $\Omega$, and measuring the resisting torque, $M$, acting on the rotor. The torque acting on the rotor can be directly related to the shear stress at the rotor using the equation, 


$$
\tau=\frac{M}{2 \pi H R_{I}^{2}}
$$

The shear stress has units of force per area $\left(\mathrm{N} / \mathrm{m}^{2}\right)$. The rotational rate is related to the shear rate. However, calculating the fluid shear rate at the rotor is complicated by the fact that shear rate depends on both the measurement-system geometry and the fluid rheological properties. For the simplest fluids (i.e., Newtonian fluids), the shear rate of the fluid at the rotor can be calculated given the geometry of the cup rotor shear by using the equation,

$$
\dot{\gamma}=\left(\frac{2 R_{O}^{2}}{R_{O}^{2}-R_{I}^{2}}\right) \Omega
$$

Here, the shear rate has units of inverse seconds $\left(\mathrm{s}^{-1}\right)$. Calculating the shear rate for materials showing more complex shear-stress versus shear-rate behavior (i.e., non-Newtonian fluids) requires estimates of yield stress and a degree of shear-thinning or shear-thickening. As the goal of rheological testing is to determine and quantify such behavior, these values are typically not known. This requirement can be circumvented by using a cup-and-rotor system with a small gap $(\sim 1-\mathrm{mm})$ for fluid shear. For fluid flow in small-gap cup and rotor systems, shear-rate effects introduced by fluid properties are minimized such that Equation E.3 provides an accurate determination of shear rate for non-Newtonian materials.

The resistance of a fluid to flow is often described in terms of the fluid's apparent viscosity, $\eta_{\text {app}}$, which is defined as the ratio of the shear stress to the shear rate:

$$
\eta_{a p p}=\frac{\tau}{\dot{\gamma}}
$$

For Newtonian fluids, the apparent viscosity is independent of the shear rate. For non-Newtonian fluids, the apparent viscosity will vary as a function of the shear rate. The unit of apparent viscosity is $\mathrm{Pa} \cdot \mathrm{s}$, although it is typically reported in the unit of centipoise (cP; where $1 \mathrm{cP}=1-\mathrm{mPa} \cdot \mathrm{s})$.

Flow-curve data are usually combined plots of $\tau$ and $\eta_{a p p}$ as a function of $\dot{\gamma}$. As stated above, flow-curve data can be interpreted with several constitutive equations (i.e., flow curves), allowing characterization of those data with just a few rheological descriptors. The behavior of tank waste sludges, slurries, and supernates can be described by four common flow-curve equations:

- Newtonian: Newtonian fluids flow as a result of any applied stress and show constant viscosity over all shear conditions. The flow curve for Newtonian fluids is

$$
\tau=\eta \dot{\gamma}
$$

where $\eta$ is the Newtonian viscosity. 
- Ostwald (Power Law): Power-law fluids flow as a result of any applied stress and have viscosities that either increase or decrease with increasing shear rate. They are described by,

$$
\tau=m \dot{\gamma}^{n}
$$

where $m$ is the power-law consistency index, and $n$ is the power-law index. Power-law fluids with $n<1$ are referred to as pseudoplastic (shear-thinning), whereas power-law fluids with $n>1$ are referred to as dilatant (shear-thickening).

- Bingham Plastic: Bingham plastics are fluids that show finite yield points. A finite stress (i.e., the yield stress), must be exceeded before these types of materials flow. Once flow is initiated, the stress response of the material is Newtonian over the rest of the shear-rate range. Bingham plastics are described by

$$
\tau=\tau_{O}^{B}+k_{B} \dot{\gamma}
$$

where $\tau_{O}^{B}$ is the Bingham yield index, and $k_{B}$ is the Bingham consistency index.

- Casson: Fluids that behave in accordance with a Casson model show a finite yield followed by pseudoplastic behavior. They are described by,

$$
(\tau)^{0.5}=\left(\tau_{o}^{C}\right)^{0.5}+\left(k_{C} \dot{\gamma}\right)^{0.5}
$$

where $\tau_{o}^{C}$ is the Casson yield index, and $k_{C}$ is the Casson consistency index. Although more limited in the types of flow behavior that it can describe relative to the Herschel-Bulkley equation, the Casson model is popular because it is capable of accurately describing many shear-thinning fluids and because units on the parameters are more physically meaningful (e.g., the consistency is in $\mathrm{Pa} \cdot \mathrm{s}$ versus $\mathrm{Pa} \cdot \mathrm{s}^{\mathrm{n}}$ for the Herschel-Bulkley model).

Power-law fluids, Bingham plastics, and Casson fluids are referred to as non-Newtonian fluids. Generally, liquids without internal and/or interconnected structures (such as tank waste supernatants) are Newtonian. Sludges and slurries are typically non-Newtonian, but their exact behavior depends on the concentration of solids and suspending phase chemistry. Sufficiently dilute slurries may show Newtonian behavior.

\section{$\underline{\text { Rheology Instrumentation }}$}

Rheological characterization was accomplished using an Anton Parr Rheometer (MCR 301) for shear-rate measurements, and shear strength was performed on a Rotovisco RV20 Measuring System M equipped with an M5 measuring head and RC20 controller sold by HAAKE Mess-Technik GmbH u Co. (now the Thermo Electron Corporation). The M5 measuring head is a "Searle" type viscometer capable of producing rotational speeds up to $500 \mathrm{rpm}$ and measuring torques up to $0.049 \mathrm{~N} \cdot \mathrm{m}$. The minimum rotational speed and torque resolution achievable by this measuring head are $0.05 \mathrm{rpm}$ and $0.49-\mathrm{mN} \cdot \mathrm{m}$, respectively. 
Calibration and analysis were performed according to TPR-WTP-PEP-049.

Specific measurement tools, such as cup-and-rotor assemblies and shear vanes, are attached to measure selected rheological properties. Shear-strength measurements employ an 8-mm $\times 16-\mathrm{mm}(\mathrm{R} \times \mathrm{H})$ shear vane tool. Flow-curve measurements employed an MV1 stainless steel measuring cup and rotor. The dimensions of the MV1 and vane measuring systems are listed in Table E.2.

Table E.2. Vane and Cup and Rotor Measuring System Dimensions

\begin{tabular}{lcccc}
\hline Measuring System & $\begin{array}{c}\text { Vane/Rotor Radius } \\
(\mathrm{mm})\end{array}$ & $\begin{array}{c}\text { Vane/Rotor Height } \\
(\mathrm{mm})\end{array}$ & $\begin{array}{c}\text { Container Radius } \\
(\mathrm{mm})\end{array}$ & $\begin{array}{c}\text { Gap Width } \\
(\mathrm{mm})\end{array}$ \\
\hline Vane tool & 8 & 16 & $>16^{(\mathrm{a})}$ & $>8^{(\mathrm{a})}$ \\
MV1 & 20.04 & 60 & 21 & 0.96 \\
\hline (a) Vane tests must satisfy the requirements outlined in Table E.1. & &
\end{tabular}

The temperature is controlled with a combination of the standard measuring system temperature jacket and a temperature-controlled recirculator. The jacket temperature is monitored using a Type-K thermocouple calibrated over $0^{\circ}$ to $100^{\circ} \mathrm{C}$ and connected to a calibrated multichannel temperature display. The temperature control is employed only for flow-curve measurements. Shear-strength measurements are carried out at ambient cell temperature.

The rheometer was controlled, and data were acquired with a remote computer connection using the RheoWin Pro Job Manager Software, Version 2.96. During measurement, the software automatically collects and converts rotor torque readings into shear stresses based on E.1 (for vane testing) or E.2 (for flow-curve testing). Likewise, the software also automatically converts the rotational rate readings into shear rates based on E.3.

\section{$\underline{\text { Rheology Materials and Methods }}$}

No sample treatment was performed before analysis with the exception of the mechanical agitation required to mix and sub-sample selected sample containers.

\section{Shear-Strength Testing}

Before testing, the simulant slurries that were provided for shear-strength testing were mixed thoroughly and subsequently allowed to settle for at least 48 to $72 \mathrm{~h}$. When possible, the shear strength was measured by immersing the $16-\times 16-\mathrm{mm}$ vane tool to a depth of $15-\mathrm{mm}$ into the settled solids. The vane was slowly rotated at $0.3 \mathrm{rpm}$ for 180 seconds. For the entire duration of rotation, the time, rotational rate, and vane torque were continuously monitored and recorded. At the end of the measurement, shear stress versus time data were parsed, and the maximum measured shear stress (i.e., the material's shear strength) was determined.

\section{Flow-Curve Testing}

Each flow curve was measured over an 11-min period and split into three intervals. Over the first 5 minutes, the shear rate was smoothly increased from zero to $1000 \mathrm{~s}^{-1}$. For the next minute, the shear 
rate was held constant at $1000 \mathrm{~s}^{-1}$. For the final 5 minutes, the shear rate was smoothly reduced back to zero. During this time, the resisting torque and rotational rate were continuously monitored and recorded.

\section{E.1.2.4 Particle-Size Distribution}

Particle sizes were characterized according to procedure RPL-COLLOID-01, Rev. 1, Particle Size Analysis Using Malvern MS2000. This procedure uses a Mastersizer 2000 (Malvern Instruments, Inc., Southborough, MA 01772 USA) with a Hydro S wet dispersion accessory. Malvern lists the Mastersizer particle-size measurement range as nominally $0.02-$ to $2000-\mu \mathrm{m}$. The actual particle-size distribution (PSD) measurement range is dependent on the accessory used as well as the properties of the solids being analyzed. The Malvern 2000 uses laser diffraction technology to define PSD.

The Hydro S wet-dispersion accessory consisted of a 150-mL dispersion unit coupled with a sample flow cell with a continuous variable and independent pump and stirrer and ultrasound. The flow, stirring rate, and sonication can be controlled and altered during measurement. PSD measurements can be made before, during, and after sonication, allowing the influence of each on the sample PSD to be determined. The primary measurement functions of the Malvern analyzer were controlled with Mastersizer 2000 software (Malvern Instruments, Ltd. Copyright 1998-2002). The properties applied to the test samples are summarized in Table E.3.

The PSD measurements were conducted in either DIW or in a $0.01-\mathrm{M} \mathrm{NaOH}$ dispersion solution matrix, depending on the sample being analyzed. The sample dispersion was added drop-wise to the dispersion unit (while the pump and stirrer were active) until an obscuration in the range of 10 to $20 \%$ was reached.

The size distributions of particles were measured under varying flow conditions before and after sonication. For each condition, multiple measurements of PSD were taken. The analyzer software then generated an average of these measurements. Both the individual measurement and average were saved to the analyzer data file.

Table E.3. Properties Applied to Group 8 Test Materials

\begin{tabular}{ll}
\hline \multicolumn{2}{c}{ Property } \\
\hline Material Selected for & Ferric Oxide \\
Optical Properties & Hydroxide \\
Refractive index (RI) & 2.94 \\
Absorption & 0 \\
Analysis mode & General purpose \\
Sensitivity & Normal \\
Suspending phase & Water/0.01-M NaOH \\
\hline
\end{tabular}

\section{E.1.2.5 X-Ray Diffraction}

The sample mounts for XRD examination were prepared by first cleaning the solids. This procedure included centrifuging the solids into a pellet and decanting the solute. Fresh washing solution was added to the pellet, and it was resuspended. The pellets in solution were vortexed to reconstitute them into the 
solution, and the centrifuging procedure was repeated three times. Following the final centrifuging and decant, the remaining pellet was left to dry in a $105^{\circ} \mathrm{C}$ oven overnight. The pellet was then pulverized to a powder with a tungsten carbide milling chamber for 1 minute in the Angstrom shaker mill, mixed with an internal standard (rutile, $\mathrm{TiO}_{2}$, or alumina, $\mathrm{Al}_{2} \mathrm{O}_{3}$ ), milled for another 2 minutes to make sure that the two powders were a homogenous mixture, and then mounted into an off-axis, zero background, quartz sample holder. The XRD examination was conducted according to procedure APEL-PAD-V, Operation of Scintag Pad-V X-Ray Diffractometer. The XRD instrument used for these samples was the PNNL Scintag PAD V XRD (property number WD33356), located in Laboratory 102 in the APEL building. The data range for the sample was $5^{\circ}$ to $80^{\circ} 2 \theta$, with a step size of $0.02^{\circ} 2 \theta$ and count time of 2.0 seconds per step. Copper K $\alpha$ X-rays were used. The X-ray tube operating conditions were $45 \mathrm{kV}$ and 40-mA. Phase identification was done by use of the JADE search match routines (Version 6.0, Materials Data, Inc.) with comparison to the International Centre for Diffraction Data (ICDD) database PDF-2, release 1999, which includes the Inorganic Crystal Structure Database (ICSD) maintained by Fachinformationszentrum (FIZ), Karlsruhe, Germany. The chemistry provided for Group 7, in order of decreasing concentration, was $\mathrm{Fe}, \mathrm{Na}, \mathrm{U}, \mathrm{P}, \mathrm{Ca}, \mathrm{Al}, \mathrm{Si}, \mathrm{Bi}, \mathrm{Sr}$, and $\mathrm{Mg}$. Phase identifications were first done without chemistry restrictions. Searches were restricted to the PDF and ICSD inorganic sections.

The pattern was also examined using RIQAS (release 4.0.0.26, 6/10/2002, Materials Data Inc.) rietveld analysis software. The phases identified above were input into the analysis along with a polynomial background and an amorphous hump at $\sim 35^{\circ} 2 \theta$.

\section{E.1.2.6 Scanning Electron Microscopy}

Within the same sample processing as above for the XRD sample preparation, the final step just before the supernatant was decanted, the specimen was vortexed, and a small volume of slurry was drawn up using a pipette, and it was placed on an aluminum stub. The slurry was placed in an oven at $105^{\circ} \mathrm{C}$ to dry overnight. The sample was then coated with gold-palladium using a Polaron Range plasma sputter coater and analyzed with a JEOL SEM (property number WD30596) according to APEL-102-SEM, Scanning Electron Microscope Examination. Selected sample areas were evaluated by X-ray energy dispersive spectroscopy (EDS) for qualitative elemental composition.

\section{E.1.2.7 Heat Capacity}

Approximately eight samples at key process steps were collected and analyzed for heat capacity during Integrated Tests A and B. Three nominal 30-mg sub-samples were taken from each of these samples as they were vigorously stirred using a pipette with an enlarged tip to confirm that the slurry samples were representative. Each slurry sample was analyzed in triplicate, recognizing that obtaining a 30-mg representative sample is challenging.

A Perkin-Elmer DSC7 differential scanning calorimeter (DSC) was used to determine the heat capacity of each sub-sample at temperatures between $20^{\circ} \mathrm{C}$ and $95^{\circ} \mathrm{C}$. The DSC7 was temperature- and enthalpy-calibrated using a gallium standard (NIST SRM 2234) (m.p. 29.8 ${ }^{\circ} \mathrm{C}$ ) and/or an indium standard (NIST SRM 2232) (m.p. $156.6^{\circ} \mathrm{C}$ ).

The method used for heat-capacity measurement was provided in the DSC7 operating manual. In this method, the heat capacity of the empty sample pan was measured to provide the "baseline"; the sample 
pan was a gold "volatile" sample pan designed to contain volatile samples such as the water in these PEP slurries. The heat capacity of a reference or standard material such as sapphire or high-purity water was then determined; the purity of these water standards was determined by measuring their electrical conductivity. Finally, the heat capacity of the sample was determined. The measured heat capacity of the sample was adjusted to remove the contribution of the empty pan. The reported heat capacity was further adjusted by applying a measured response factor for the high-purity water.

Optimally, the heat-capacity measurement approach would include analyzing a standard or reference material in the same container in which the sample was analyzed; however, because the analysis of these slurry samples required a hermetic seal, which cannot be broken and resealed, an equivalent gold volatile sample pan was used for the water. In addition, we characterized a sapphire standard to demonstrate instrument performance; the heat capacity of sapphire $\left(0.8 \mathrm{~J} / \mathrm{g}{ }^{\circ} \mathrm{C}\right)$ is significantly lower than that of the PEP slurries $(\sim 3.5 \mathrm{~J} / \mathrm{g})$ and does not provide an adequate calibration adjustment.

\section{E.2 Sample Handling}

\section{E.2.1 Introduction}

The sample-handling scope included preparation activities before sample collection and after sample collection processing within PDL-W. Pre-sampling preparation included activities such as sample container selection based on sample size and sample naming. The sample naming consisted of creating names for originally collected samples, aliquots of phase-separated supernate, and wet solids, some of which went for analysis while other went to archive. Post sample collection might have included phase separation, supernate density measurement at PDL-W, and even though not discussed here, packaging, shipping, and transferring samples under chains of custody. The Pretreatment Engineering Platform Sample Handling Procedure, TPR-WTP-PEP-058, contains working details of all these activities. This section will discuss in detail the naming convention, non-leaching phase separation, leaching phase separation, PDL-W supernatant density, and $\mathrm{wt} \%$ UDS performed at PNNL.

In total, four tests as described in the Pretreatment Engineering Platform (PEP) Testing (Phase I) Test Plan ${ }^{(a)}$ were conducted at the PEP over 5 months. These tests generated approximately 3300 samples, of which roughly 1400 were stored as archive samples. A significant number of the original intact samples and processed aliquots were analyzed for chemical composition, such as metals, anions, and hydroxide, or physical properties, such as UDS, density, and particle size. The Test Instruction for each test contained a sample collection and analysis table that summarized sampling events and the analysis to be performed on the collected samples. In each run report (Josephson et al. 2009, Guzman-Leong et al. 2009, Geeting et al. 2009, Sevigny et al. 2009), there is a list of every sample collected and the associated disposition. The organization responsible for the analysis is given in Table E.4.

(a) Josephson GB, OP Bredt, JK Young, and DE Kurath. 2009. Test Plan for Pretreatment Engineering Platform (PEP) Testing (Phase I). TP-RPP-WTP-506, Rev 0.4, Pacific Northwest National Laboratory, Richland, Washington. 
Table E.4. Organization Responsible for Analysis

\begin{tabular}{|c|c|}
\hline $\begin{array}{l}\text { Analysis } \\
\end{array}$ & Organization \\
\hline Inductively coupled plasma (ICP) & \multirow{5}{*}{ Southwest Research Institute } \\
\hline Ion chromatography (IC) & \\
\hline $\begin{array}{l}\text { Total inorganic carbon and total organic carbon } \\
\text { (TIC/TOC) }\end{array}$ & \\
\hline Weight percent UDS ${ }^{(a)}$ & \\
\hline Density & \\
\hline Heat capacity & \multirow{9}{*}{ Pacific Northwest National Laboratory } \\
\hline Shear strength & \\
\hline Shear stress vs. shear rate & \\
\hline Particle-size distribution & \\
\hline X-ray diffraction & \\
\hline Scanning electron microscope & \\
\hline Raman & \\
\hline Free hydroxide & \\
\hline Weight percent UDS ${ }^{(b)}$ & \\
\hline Gel permeation chromatography (GPC) & DOW Corning \\
\hline
\end{tabular}

This section provides a description of the:

- sample naming convention

- $\quad$ sample processing during PEP testing

- analytes of interest

- analytical methods.

\section{E.2.2 Sample Naming Convention}

Every sample was given a unique sample name. The sample names were a composite of either six or seven separate descriptors. The descriptors are defined in Table E.5 and the acronyms for each descriptor are defined in Table E.6. The spacings between descriptors were separated by either an underscore symbol ( $\_$) or a space ( ). Sample naming examples are provided after Table E.6. 
Table E.5. Sample Naming Nomenclature Definitions

\begin{tabular}{|c|c|c|}
\hline Descriptor & Identification & Explanation \\
\hline Descriptor 1 & Test Name & $\begin{array}{l}\text { Refers to the Shakedown Test, Functional Test, Integrated } \\
\text { Test A, Integrated Test B, or Integrated Test D. }\end{array}$ \\
\hline Descriptor 2 & Location & $\begin{array}{l}\text { Identifies the location that the sample is being collected from } \\
\text { based on Table E.3. For example, a sample collected from a } \\
\text { tank will include the acronym of the tank followed by the } \\
\text { location within the tank. }\end{array}$ \\
\hline Descriptor 3 & Test Process Step & $\begin{array}{l}\text { Refers to the process step as identified in the sample collection } \\
\text { and analysis table in the governing Test Instruction. The test } \\
\text { process step includes an identifier for processes that are } \\
\text { repeated during testing. }\end{array}$ \\
\hline Descriptor 4 & Sequential Number & $\begin{array}{l}\text { Unique number identifier that increments by } 1 \text { each time a } \\
\text { sample is collected. All sub-samples and separated samples } \\
\text { generated from the original sample had the same unique } \\
\text { number identifier. }\end{array}$ \\
\hline Descriptor 5 & Sample Routing & $\begin{array}{l}\text { Refers to the sample destination, type of analysis, storage, or } \\
\text { archive. }\end{array}$ \\
\hline Descriptor 6 & Store code & Final destination code. \\
\hline Descriptor 7 & $\begin{array}{l}\text { Separated-sample } \\
\text { identifier }\end{array}$ & $\begin{array}{l}\text { Refers to the type of sub-sample; e.g., decantate, solids, rinse } \\
\text { solution, etc. For a separated-sample, a descriptor of the } \\
\text { matrix was added after the sample routing identifier. }\end{array}$ \\
\hline
\end{tabular}

Table E.6. Sample Naming Acronyms

\begin{tabular}{ll}
\hline Acronym & Definition \\
\hline Test Name (1 character) Descriptor 1 & \\
\hline S & Shakedown testing \\
F & Functional testing \\
A & First Integrated Test to be performed \\
B & Second Integrated Test to be performed \\
C & Third Integrated Test to be performed \\
D & Fourth Integrated Test to be performed
\end{tabular}

Location (maximum of 5 characters) Descriptor 2

Vessels Name (3 characters)

$\begin{array}{ll}\text { T22 } & \text { HLP-VSL-T22 } \\ \text { FRP } & \text { FRP-VSL-T01 } \\ \text { FEP } & \text { FEP-VSL-T01 } \\ 01 \mathrm{~A} & \text { UFP-VSL-T01A } \\ 01 \mathrm{~B} & \text { UFP-VSL-T01B } \\ 02 \mathrm{~A} & \text { UFP-VSL-T02A } \\ \text { T27 } & \text { HLP-VSL-T27A }\end{array}$




\begin{tabular}{|c|c|}
\hline Acronym & Definition \\
\hline $62 \mathrm{~A}$ & UFP-VSL-T62A \\
\hline 62B & UFP-VSL-T62B \\
\hline \multicolumn{2}{|l|}{ Vessel Sampling Location (2 characters) } \\
\hline $\mathrm{IH}$ & Inner High \\
\hline IM & Inner Middle \\
\hline IL & Inner Low \\
\hline MH & Middle High \\
\hline MM & Middle Middle \\
\hline ML & Middle Low \\
\hline $\mathrm{OH}$ & Outer High \\
\hline OM & Outer Middle \\
\hline OL & Outer Low \\
\hline RL & Recirculation Line \\
\hline GT & Grab sample at top of a tank \\
\hline GM & Grab sample at middle of a tank \\
\hline GB & Grab sample at bottom of a tank \\
\hline \multicolumn{2}{|l|}{ In-Line/Transfer Sampling Locations (5 characters) } \\
\hline $\mathrm{T} 221 \mathrm{~A}$ & In-line transfer from HT22 to UT01A \\
\hline 01A2A & In-line transfer from UT01A to UT02A \\
\hline 01B2A & In-line transfer from UT01B to UT02A \\
\hline T221B & In-line transfer from HT22 to UT01B \\
\hline 000FL & Filter-loop in-line sample \\
\hline 00PF1 & Permeate filter number 1 \\
\hline 00PF2 & Permeate filter number 2 \\
\hline 00PF3 & Permeate filter number 3 \\
\hline 00PF4 & Permeate filter number 4 \\
\hline 00PF5 & Permeate filter number 5 \\
\hline 00C01 & Downstream of CS-PMP-T01 \\
\hline 00C02 & Downstream of CS-PMP-T02 \\
\hline $00 \mathrm{C} 03$ & Downstream of CS-PMP-T03 \\
\hline \multicolumn{2}{|c|}{ Test Process Step (3 characters ${ }^{(a)}$ plus 2 repetitive process characters ${ }^{(b)}$ ) Descriptor 3} \\
\hline (a) 001 through 032 (initial 3 characters) & As described in the guiding document such as \\
\hline $\begin{array}{l}\text { (b) A two-character field to identify any repetitive } \\
\text { process. }\end{array}$ & $\begin{array}{l}\text { Appendix A or B in TP-RPP-WTP-506 or the } \\
\text { governing Test Instruction. }\end{array}$ \\
\hline \multicolumn{2}{|l|}{ Repetitive Process (2 characters) } \\
\hline $\mathrm{XX}$ & No repeating process \\
\hline bT & $10^{\circ} \mathrm{C}$ below set-point temperature \\
\hline 00 & Time when set-point temperature reached (in hours) \\
\hline 01 through 16 & $\begin{array}{l}\text { Time after set-point temperature is reached (in } \\
\text { hours) or cycle number, depending on the process } \\
\text { step. }\end{array}$ \\
\hline
\end{tabular}




\begin{tabular}{ll}
\hline Acronym & Definition \\
\hline
\end{tabular}

Sequence Number (4 characters) Descriptor 4

0001 through 9999

Sequential number incremented by 1 for replicate samples

Sample Routing (3 characters) Descriptor 5

\begin{tabular}{|c|c|}
\hline $\mathrm{ARC}$ & Archive \\
\hline UDS & Undissolved Solids \\
\hline XSP & XRD, SEM, and/or PSD \\
\hline AFA & Anti-foaming agent analysis \\
\hline SOX & Solid oxalate analysis \\
\hline HTC & Heat capacity \\
\hline DEN & Density \\
\hline ICP & $\begin{array}{l}\text { Inductively coupled plasma atomic emission } \\
\text { spectrometry (ICP-AES) analysis }\end{array}$ \\
\hline RAM & Raman analysis \\
\hline RHE & Rheology (shear strength/shear stress) \\
\hline TDS & Total dissolved solids \\
\hline CUF & Crossflow ultrafilter (CUF)/parallel testing \\
\hline TFI & $\begin{array}{l}\text { Total inorganic carbon analysis (TIC)/ Free } \\
\text { hydroxide analysis (FOH)/ Ion chromatography (IC) } \\
\text { analysis }\end{array}$ \\
\hline ALK & Total alkalinity \\
\hline ADT & Acidity titration \\
\hline OST & Oxidation state titration \\
\hline OTR & Other \\
\hline SUP & Supernate, used when no Raman required \\
\hline \multicolumn{2}{|c|}{ Separated-samples ( 1 character) Descriptor 6} \\
\hline 0 & RTL-520 Store \\
\hline 1 & RTL-520 Archive \\
\hline 2 & SwRI \\
\hline 3 & RPL \\
\hline 4 & APEL \\
\hline 5 & Dow Corning \\
\hline 6 & Other \\
\hline \multicolumn{2}{|c|}{ Separated-samples ( 1 character) Descriptor 7} \\
\hline $\mathrm{D}$ & Decanted supernatant (decantate) \\
\hline B & Bulk solids not rinsed \\
\hline $\mathrm{R}$ & Rinsate composite \\
\hline $\mathrm{S}$ & Rinsed solids \\
\hline $\mathrm{P}$ & Process, samples that were filtered/processed \\
\hline $\mathrm{F}$ & Filtrate \\
\hline
\end{tabular}


The sample names are constructed in the following manner:

\section{Descriptor1_Descriptor2_Descriptor3a_Descriptor3b_Descriptor4_Descriptor5_Descriptor6_ Descriptor7}

The following description is an example of sample naming for samples collected from HLP-VSL-T22 during Functional testing.

- The sample name for the first Functional Test grab slurry sample collected from the top of HLP-VSL-T22 during process Step 1 that was to be archived would have been:

F_T22GT_001_XX_0001_ARC_1.

- For the same sample location and type described above, analyzed for PSD on a bulk solid that was not rinsed and analyzed by ICP on the decantate, the original sample vial would have been labeled:

F_T22GM_001_XX_0009_XSP_4_B for the solid.

- Since the solid phase always stayed in the original sample vial, and the liquid was decanted off into a new vial, then the new vial would have been labeled:

F_T22GM_001_XX_0009_DEN_0_D for the decantate.

- The decantate from the above sample container could have been sub-sampled for ICP and Raman; the ICP container would have been labeled as follows:

F_T22GM_001_XX_0009_ICP_2_D.

- The Raman container would have been labeled as follows:

F_T22GM_001_XX_0009_RAM_3_D.

\section{E.2.3 Sample Processing}

The samples were collected in pre-labeled sample containers that were prepared and staged within PDL-W based upon the Sample Collection and Analysis table in the governing Test Instruction. The required analysis determined the sample volume and sample collection container. Sample handling flow diagrams are given in Figures E.1 through E.3 at the end of this section. Figure E.1 described samples collected and processed in PDL-W. The letters "D," "B," "R," and "S," which are shown in the figures, were included in the sample names for phase-separated processed samples. The letter " $D$ " was included in the decanted supernatant sample names. The letter " $\mathrm{B}$ " was included in the wet centrifuged solid sample names. The letter " $R$ " was included in the sample name of the combined rinse solution. The letter "S" was included in the sample names of the wet rinsed centrifuged solids. These figures represent two basic sample processing methods. One approach was used during non-leaching test steps, and another was used during leaching.

\section{E.2.4 Non-Leaching Samples}

Non-leaching samples were not always processed immediately after collection. Because sample collection could occur at anytime during testing and testing was being performed 24 hours per day, non-leached samples collected after 0600 were typically processed and prepared for shipment by 0600 the morning following sample collection. Non-leach samples used for the analyses listed below were shipped 
as collected in the container size specified and with the exception of the archive samples, tare and full sample weights were not required.

- weight percent UDS (50-mL)

- density $(50-\mathrm{mL})$

- heat Capacity $(50-\mathrm{mL})$

- $\quad$ shear strength $(2 \times 1-\mathrm{L})$

- $\quad$ shear stress vs. shear rate on original intact slurry $(100-\mathrm{mL})$

- $\quad$ shear stress vs. shear rate on supernatant $(100-\mathrm{mL})$

- total organic carbon on the slurry $(50-\mathrm{mL})$

- inductively coupled plasma - Silicon $(50-\mathrm{mL})$

- $\operatorname{archive}(50-\mathrm{mL})$.

During a sampling event, if an intact slurry sample was collected for density analysis, and another intact slurry sample was collected for wt\% UDS, then density measurements were performed on the supernatant in addition to the intact slurry submitted for density analysis. These density measurements were higher accuracy then density measurements obtained following the $\mathrm{wt} \%$ UDS method described in Bechtel procedure 24590-WTP-GPG-RTD-001 Rev 0. ${ }^{\left({ }^{a}\right)}$

A single 50-mL sample was centrifuged and the supernatant decanted to allow multiple laboratories to perform several analyses simultaneously on the supernatant. To perform this phase separation, the original sample was centrifuged at $\sim 4500 \mathrm{G}$ with a swinging bucket rotor in PDL-W. The centrifuging time was initially set for 10 minutes. This centrifuging time was sufficient to cause phase separation during Shakedown, Integrated Test A, and oxidative leaching. However, during some of the Integrated Test B and Integrated Test D process steps, phase separation was not achieved after 10 minutes, so the samples were centrifuged for an hour. The actual centrifuging time is recorded on the sample bench sheets. After centrifuging, the supernatant was decanted and submitted for some or all the analyses listed below:

- ICP

- $\quad$ total dissolved solids

- density

- IC

- $\mathrm{TOC}$

- Raman

- free hydroxide

- density.

(a) Smith GL and K Prindiville. 2002. Guidelines for Performing Chemical, Physical, and Rheological Properties Measurements. 24590-WTP-GPG-RTD-001, Rev 0, Bechtel National, Inc., Richland, Washington. 
Not all of these analyses were necessarily performed on every decanted supernatant. The specific analysis was identified in the Sample Collection and Analysis table in the governing Test Instruction. Density was determined on the decanted supernatant at PDL-W for all samples being analyzed by Raman spectroscopy before the samples were transported for analysis. In addition, at times, density was determined by SwRI before ICP analysis. The wet centrifuged solids from this same container were either submitted for ICP analysis, if it was required, or stored in the original sample collection container as excess. A tare weight (before filling) and gross weight (after filling) of the sample container were documented on sample benchsheets.

For DOW Corning to quantify the AFA compounds by GPC in the solid and supernatant fractions of the slurry, two $50-\mathrm{mL}$ slurry samples were collected and centrifuged at 4500 -g for 10 minutes, and the supernatant was decanted into two additional properly labeled $50-\mathrm{mL}$ containers before shipping. Weighing empty and filled containers was not required.

For SwRI to quantify silicon by ICP in the AFA, a 50-ml slurry sample was collected and shipped as collected during non-leaching process steps. Once at SwRI, the slurry was centrifuged at $2200-\mathrm{g}$ for an hour, the supernatant was separated from the wet centrifuged solids and then each phase was analyzed separately. During leaching, the phase separation occurred in PDL-W following the standard practice of centrifuging at $\sim 4500 \mathrm{G}$ for 10 minutes.

A single 50-mL container was filled for PSD, XRD, and SEM. Initially, these samples were centrifuged. The supernatant was decanted and stored while the wet solids were submitted for analysis. Intact slurry samples were submitted after Shakedown and Integrated Test A and initial Integrated Test B simulant characterization. If a phase-separated sample was submitted, then descriptor 7 was included in the sample name. If descriptor 7 was not in the name, then an intact sample was submitted for analysis. Weighing empty and filled containers was not required.

For parallel CUF and laboratory-scale testing, varying amounts of either permeate or slurry samples were collected. A tare weight (before filling) and gross weight (after filling) of the sample container was recorded on the sample container. These samples were delivered to APEL by the next business day after sample collection.

\section{E.2.5 Leaching Samples}

The core critical analyses for leached samples were wt\% UDS, slurry density, ICP, IC, Raman, and free-hydroxide analyses. Two 50-mL samples were collected for the UDS and density analyses. Another 50-mL sample was collected for the remaining core analyses.

- During caustic leaching, the original samples were immediately placed in a thermostatically controlled water bath at $20^{\circ} \pm 2^{\circ} \mathrm{C}$ to decrease the sample temperature to $25 \pm 5^{\circ} \mathrm{C}$ after collection. Once the desired temperature was reached, which typically took less than 10 minutes for $50-\mathrm{mL}$ containers, the samples were allowed to sit for 24 hours in PDL-W. The density sample was shipped as collected. The two other samples to be used for analysis were centrifuged following the sample process described for non-leached samples.

- During oxidative leaching, sample processing began immediately after sample collection. The oxidative-leach density sample was shipped as collected while the other two samples were phase-separated immediately after collection by centrifuging and decanting the supernatant as 
described above for non-leached samples. To allow for consistency in comparing analytical results, the samples for ICP analysis collected immediately before adding $\mathrm{NaMnO}_{4}$ were phase-separated immediately after collection. The oxidative-leached centrifuged solids from samples collected immediately before adding $\mathrm{NaMnO}_{4}$ and at the end of oxidative leaching for analysis were weighed and rinsed three times with $0.01-\mathrm{M} \mathrm{NaOH}$ solution. The actual quantity of rinse is recorded on sample benchsheets. The wet solids were vortexed three times to suspend and rinse the solids after each addition of $\mathrm{NaOH}$ solution. The rinsate was collected and weighed. The density of the rinsate was measured at PDL-W, and then it was split into sub-samples for ICP and Raman analysis.

During leaching, additional 50-mL samples were collected for archiving. Caustic-leached archived samples were also cooled and phase-separated as described above before storage. The oxidative-leached archived samples were also immediately phase-separated after collection as described above. The centrifuged oxidative-leached solids that went to storage were not rinsed.

\section{E.2.6 Undissolved Solids}

The sample processing for weight percent undissolved solids (wt $\%$ UDS) is given in Figure E.3. The $\mathrm{wt} \%$ UDS was measured at PNNL only when results were needed the same day the sample was collected. A halogen moisture analyzer (HG63, Mettler Toledo) was used to determine the wt\% UDS under procedure TPR-RPP-WTP-648, Operation of the Mettler Moisture Analyzer. If wt $\%$ UDS results for multiple samples were required, then a modified version of wt\% UDS using an oven as described in Guidelines for Performing Chemical, Physical, and Rheological Properties Measurements (24590-WTP-GPG-RTD-001 Rev. 0) was used as described in Section E.1.2.1.

\section{E.2.6.1 Supernatant Density}

Density measurements were performed at PDL-W on samples that were analyzed by Raman. Density was measured in accordance with TPR-WTP-PEP-054, Determination of Density using Pycnometer or Graduated Cylinder. All other density values were analyzed and reported by SwRI as described in Section E.1.2.1 and E.1.2.2.

\section{E.3 Uncertainties for Analytical Methods}

This section provides a brief description of the basis for uncertainty assigned to chemical analysis results. The uncertainty estimates are also used as inputs to the Monte Carlo methods used in the data analysis.

\section{E.3.1 IC, ICP, ICP-MS, TOC and UDS Methods}

The estimation of the uncertainties associated with the instrumental methods performed by SwRI is based on "Type A" and "Type B" factors. The uncertainty of the "Type A" factor is based on the noise of the analytical determination which is founded on a series of observations. The uncertainty for the "Type A" factor is estimated as $1 / 2$ of the minimum Reporting Limit (RL). The minimum reporting limit takes into account all dilutions and preparation factors for instrumental methods such as IC, ICP, ICP-MS 
and TIC. The percent uncertainty of Type B factors was evaluated based on scientific judgment and experience by SwRI ${ }^{(a)}$ using all pertinent information available, which may have included:

- previous measurement data,

- experience with the analytical method, instruments, and sample matrix

- manufacturer's specifications for calibration standards, analytical balances and volumetric devices

- $\quad$ precision and accuracy of reference samples.

For IC, ICP, ICP-MS and TOC methods, the uncertainties were calculated using the following equation:

$$
\text { Uncertatnty }=\sqrt{(F C x w \%)^{2}+(R E x 50 \%)^{2}}
$$

where:

$$
\begin{aligned}
& \mathrm{FC}=\text { Final concentration } \\
& \mathrm{u} \%=\text { Sum of percent uncertainties for Type B factors } \\
& \mathrm{RL}=\text { Reporting limit (Type A factor). }
\end{aligned}
$$

Based on this equation, the impact of Type A factors on the analytical uncertainty is low when the measured concentration is more than 10 times the reporting limit; as a result the relative uncertainty is roughly constant for concentrations in this high range.

Table E.6. Type B Factors for SwRI

\begin{tabular}{|c|c|c|}
\hline \multirow{2}{*}{ Type B Factors } & \multicolumn{2}{|c|}{$\begin{array}{c}\text { Percent Uncertainties for } \\
\text { Instrumental }\end{array}$} \\
\cline { 2 - 3 } & Liquids & Solid/Slurry \\
\hline Aliquoting & $0.25 \%$ & $0.25 \%$ \\
Standards & $0.50 \%$ & $0.50 \%$ \\
Standardization & $5.00 \%$ & $5.00 \%$ \\
Sub-sampling & $0.25 \%$ & $1.00 \%$ \\
\hline Sum & $6.00 \%$ & $6.75 \%$ \\
\hline \multicolumn{3}{|c}{} \\
\hline \multicolumn{3}{|c}{ Percent } \\
\hline Methods & Uncertainties & \\
\hline ICP \& ICP-MS solid, & $6.75 \%$ \\
ICP \& ICP-MS solution, & $6.00 \%$ \\
IC + oxalate on solution, & $6.00 \%$ \\
TIC on solution, & $6.00 \%$ \\
\hline TOC on solid, & $6.75 \%$ \\
\hline
\end{tabular}

(a) SwRI has conducted analysis on similar simulants and slurries prior to the PEP plant analytical campaign. 
The estimated uncertainties for the UDS analysis performed by SwRI were based on the propagation of uncertainties through the following equation:

$$
U D S=\left(1-\frac{1-\frac{M_{D C S}}{M_{C S}}}{1-\frac{M_{D C L}}{M_{V L}}}\right) \frac{M_{C S}}{M_{B}}=\left(\frac{M_{V L} M_{D C S}-M_{C S} M_{D C L}}{M_{V L}-M_{D C L}}\right) \frac{1}{M_{B}}
$$

Where:

$$
\begin{aligned}
& M_{C S}=\text { mass of centrifuged solids in sample }(\mathrm{g}) \\
& M_{D C S}=\text { mass of centrifuged solids after drying }(\mathrm{g}) \\
& M_{V L}=\text { mass of supernatant liquid decanted from sample after centrifugation }(\mathrm{g}) \\
& M_{D C L}=\text { mass of decanted supernatant liquid after drying }(\mathrm{g}) \\
& M_{B}=\text { mass of bulk slurry in sample }(\mathrm{g})
\end{aligned}
$$

The uncertainties of mass measurements were propagated to give the uncertainty of the UDS by the standard methods discussed in Skoog and West (1969, p. 52-58).

All balances in the SwRI Inorganics department are calibrated using NIST-traceable weights and certified by the Institute Calibration Laboratory (SwRI Cal Lab) on an annual basis, in accordance with the manufacturer's specified criteria. Prior to use on each working day, the analytical balance calibrations are verified using three NIST traceable check weights that bracket the expected range of use. Control limits for the weight are $\pm 0.01 \%$ or $\sim$ two times the uncertainty of the balance.

\section{E.3.2 Free $\mathrm{OH}$ and Raman Methods}

The reliability of the methods of $\mathrm{OH}$ titration and Raman spectroscopy is dependent upon the complexity and make-up of the sample. For example, for $\mathrm{OH}$ samples containing only acid or hydroxyl components, the accuracy and precision of $\mathrm{OH}$ titration in determining free $\mathrm{OH}$ are $< \pm 5 \%$. Borates, phosphates, silicates, or any hydrolysable ions that may be present can interfere and degrade the precision and accuracy of the determination. Based on scientific judgment and experience the uncertainty of these methods was estimated using all pertinent information available, which may have included:

- $\quad$ previous measurement data

- experience with the analytical method, instruments, and sample matrix

- manufacturer's specifications for calibration standards, analytical balances and volumetric devices

- precision and accuracy of reference samples.

The method uncertainty assigned to free $\mathrm{OH}$ determined by titration within the calibration range was $\pm 5 \%$. The uncertainty for free $\mathrm{OH}$ and other analytes quantified by Raman within the calibration range was $\pm 15 \%$. 


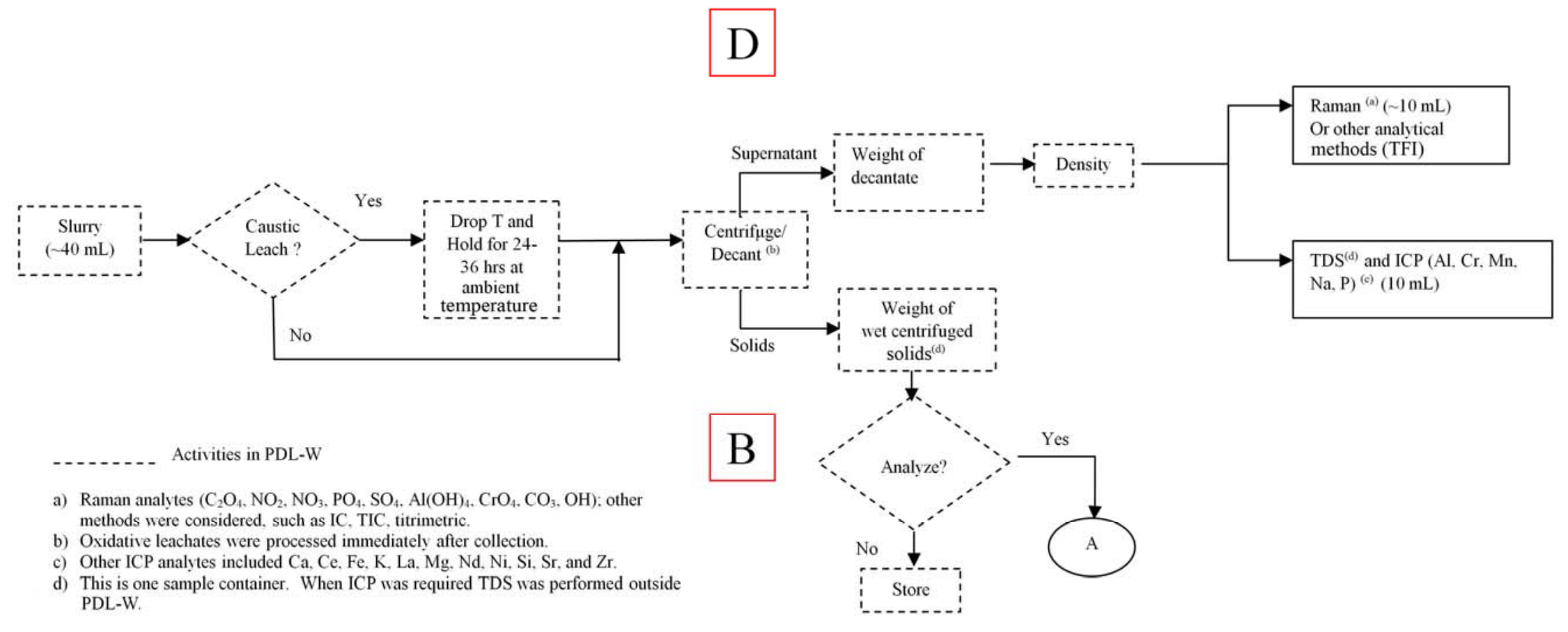

Figure E.1. Sample Processing for Decantate Handling 


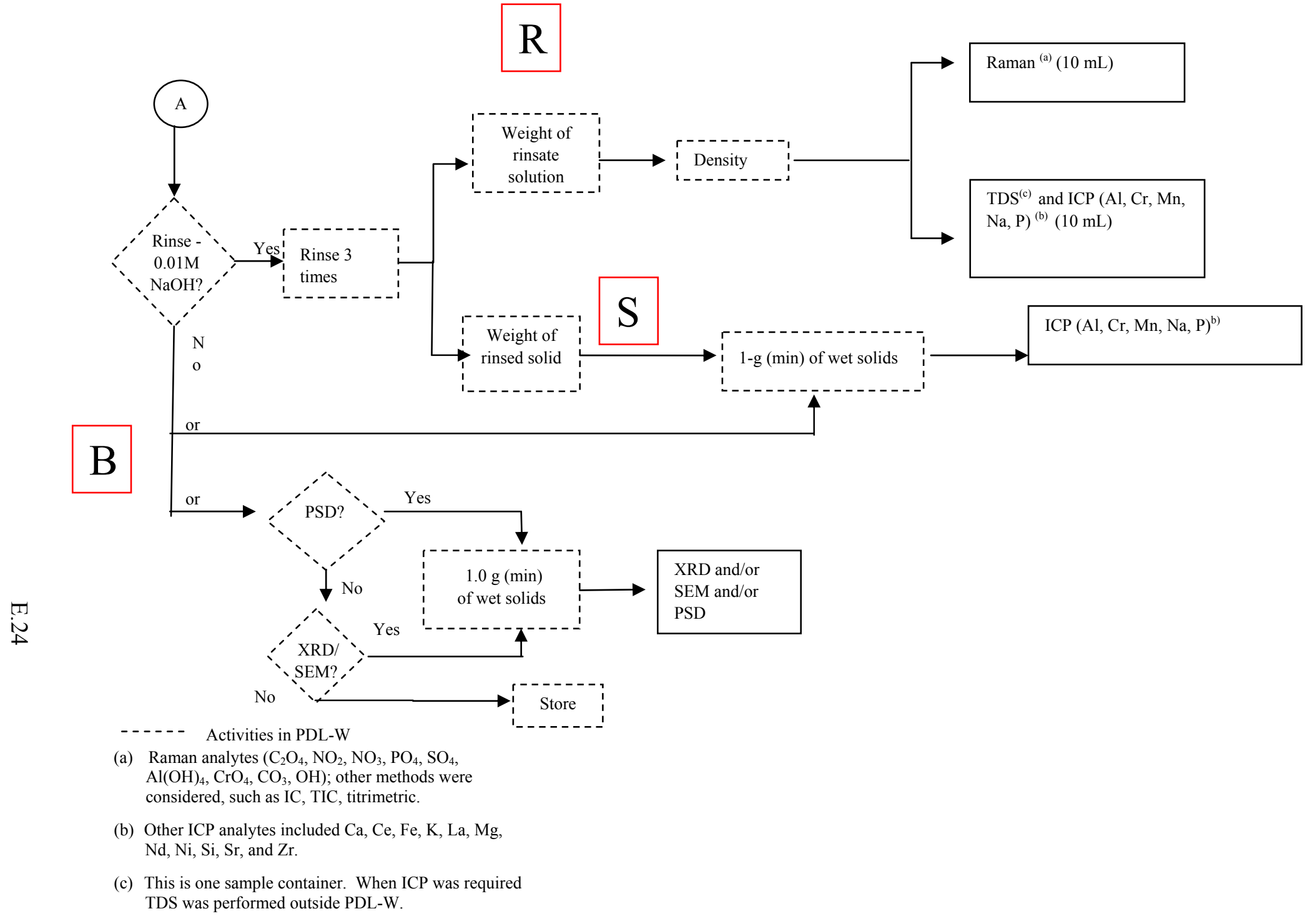

Figure E.2. Sample Processing for Solids 


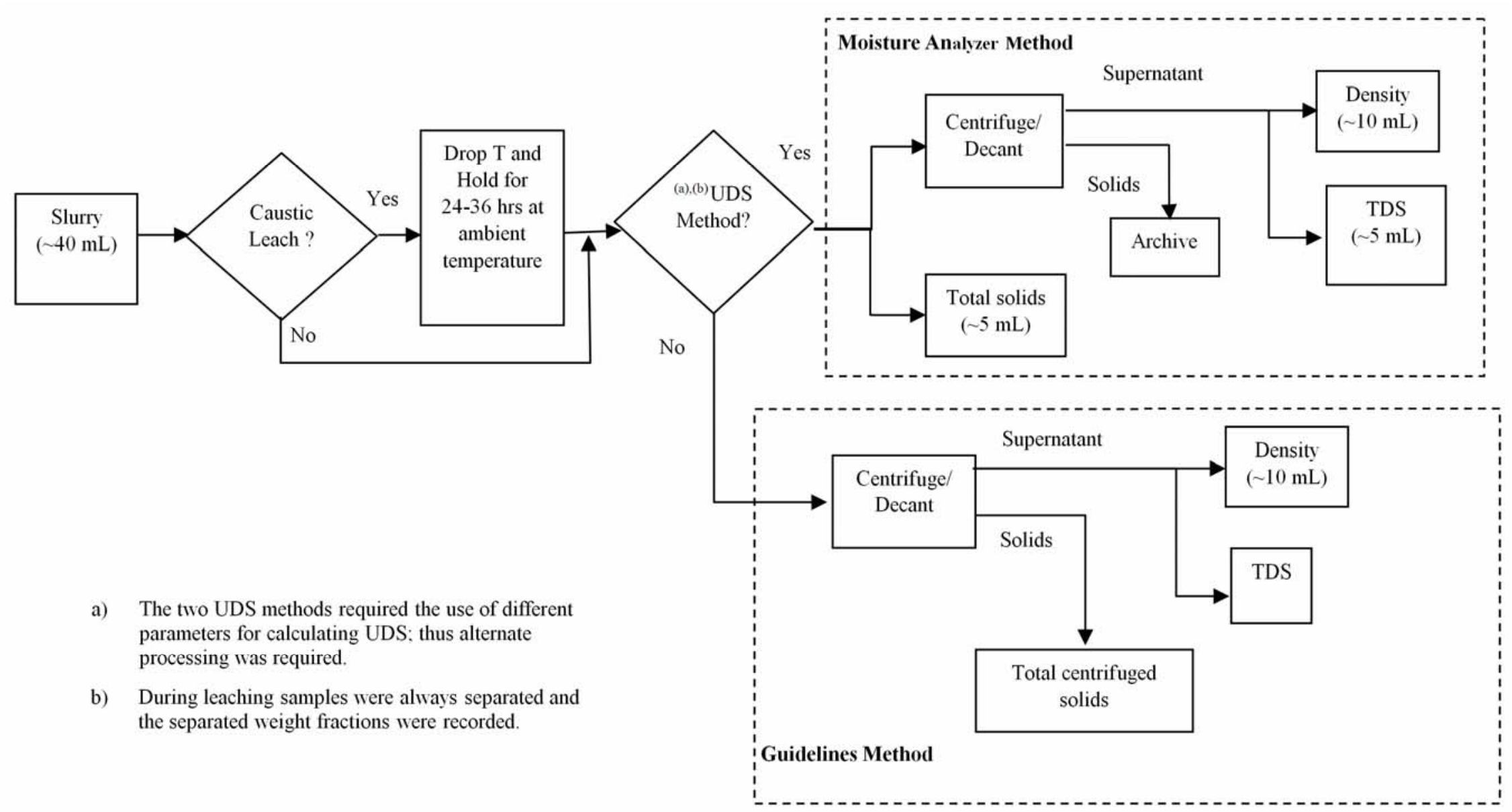

Figure E.3. Sample Processing for UDS 



\section{Distribution}

No. of

Copies

OFFSITE
No. of

Copies

ONSITE

$1 \quad$ Pacific Northwest National Laboratory

(authors will be notified electronically)

B.D. Hanson

P7-27

J.L. Huckaby

$\mathrm{H} 4-02$

D.E. Kurath

K3-52

L.A. Mahoney

K7-15

M.J. Minette

$\mathrm{P} 7-25$

Information Release (pdf)

Project File

K3-52

2 Bechtel National Inc.

WTP R\&T Docs (1)

H4-02

SM Barnes
$\mathrm{H} 4-02$ 


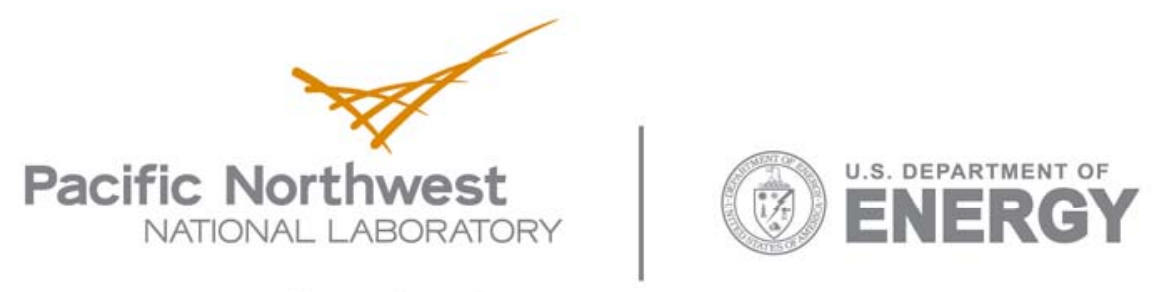

902 Battelle Boulevard

P.O. Box 999

Richland, WA 99352

1-888-375-PNNL (7665)

www.pnl.gov 